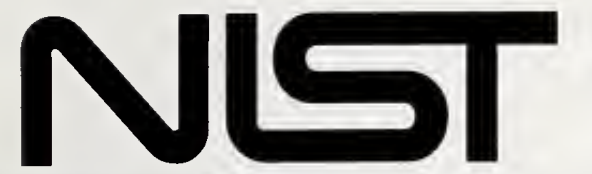

United States Department of Commerce Technology Administration

National Institute of Standards and Technology

ALIT05 प42984 ial Publication 901 PUBLICATIONS

(ICSSC TR18)

\title{
The January 17, 1995 Hyogoken-Nanbu (Kobe) Earthquake
}

Performance of Structures, Lifelines, and Fire Protection Systems
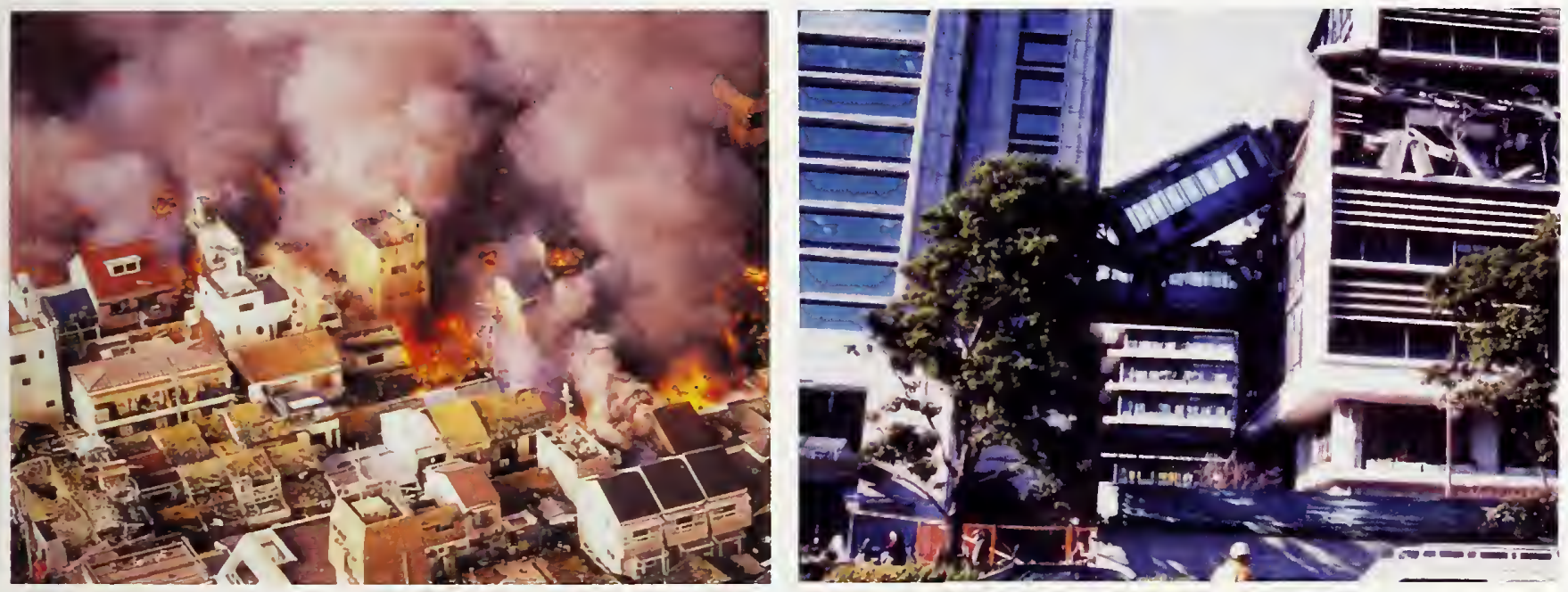

$Q C$
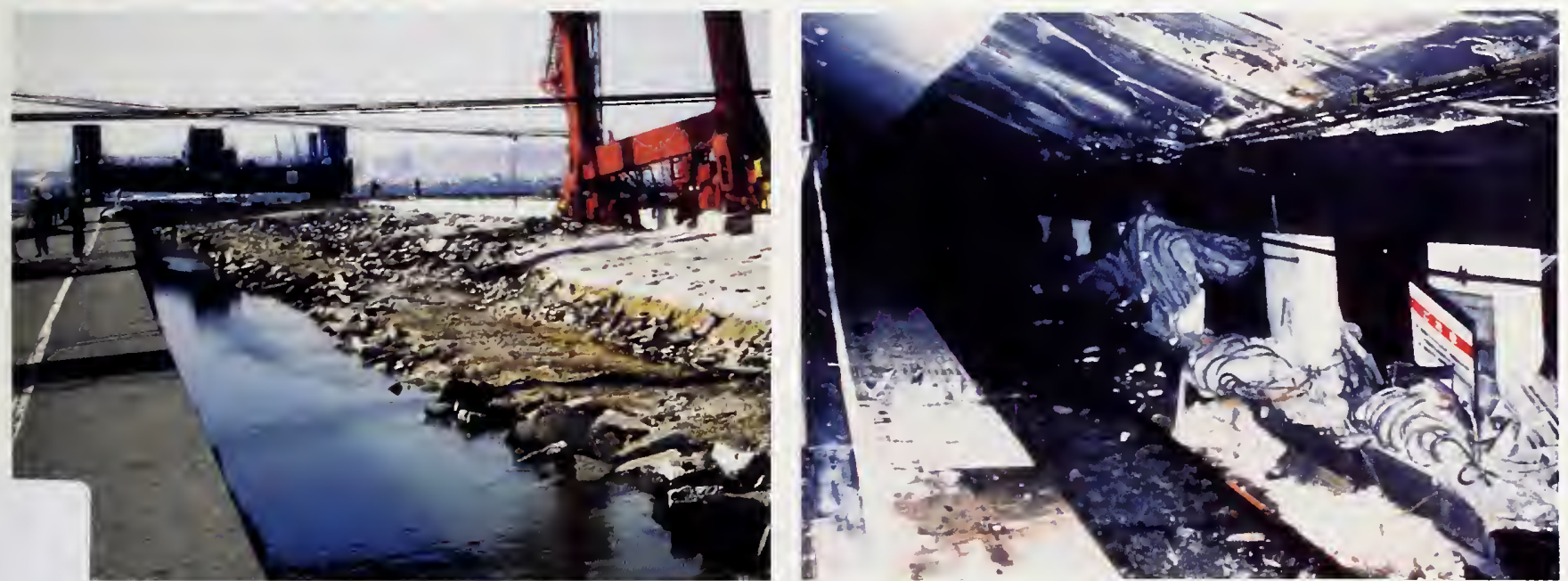


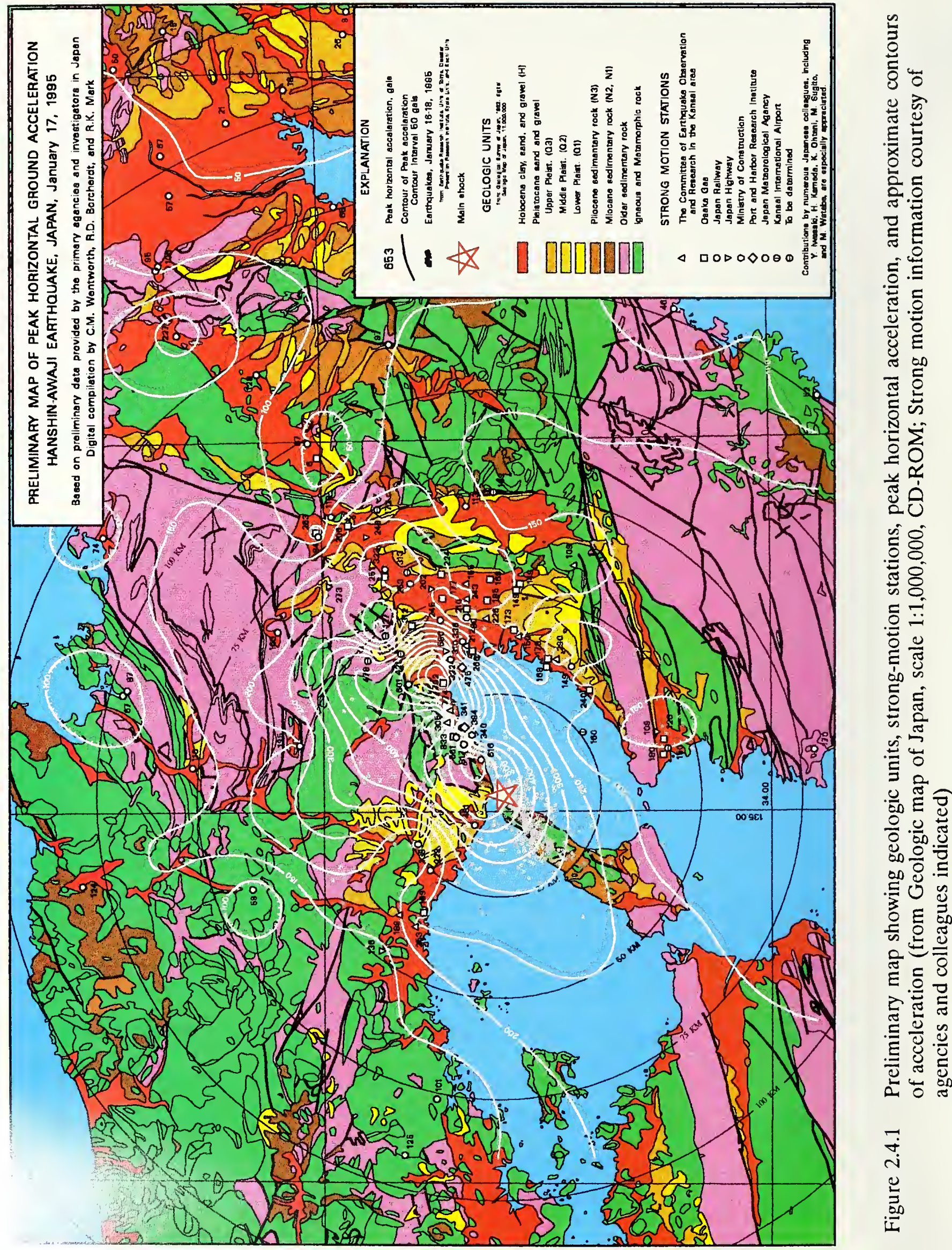




\section{The January 17, 1995 Hyogoken-Nanbu (Kobe) Earthquake}

\section{Performance of Structures, Lifelines, and Fire Protection Systems}

Riley Chung, Team Leader and Editor

Donald Ballantyne

Edward Comeau

Thomas Holzer

Daniel Madrzykowski

Anshel Schiff

William Stone

James Wilcoski

Building and Fire Research Laboratory

National Institute of Standards and Technology

Gaithersburg, MD 20899-0001

July 1996

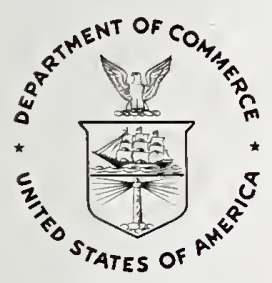

U.S. Department of Commerce

Michael Kantor, Secretary

Technology Administration

Mary L. Good, Under Secretary for Technology

National Institute of Standards and Technology

Arati Prabhakar, Director
Ian Bucker

John Hayes

E. V. Leyendecker

Thomas O'Rourke

M. P. Singh

Michael Whitney

\section{California Department of}

Transportation

Federal Highway Administration

National Center for Earthquake

Engineering Research

National Fire Protection Association

National Science Foundation

U.S. Army Construction Engineering

Research Laboratory

U.S. Geological Survey 
National Institute of Standards and Technology

Special Publication 901

Natl. Inst. Stand. Technol.

Spec. Publ. 901

544 pages (July 1996)

CODEN: NSPUE2

\section{U.S. Government Printing Office}

Washington: 1996

For sale by the Superintendent of Documents U.S. Government Printing Office Washington, DC 20402 
The January 17, 1995 Hyogoken-Nanbu earthquake of magnitude 7.2 in JMA scale $\left(M_{w}=6.9\right)$, which struck Kobe, Japan and its surrounding area was the most severe earthquake to affect that region this century. The earthquake resulted in more than 6,000 deaths and over 30,000 injuries. Fires following the earthquake incinerated the equivalent of 70 U.S. city blocks. They together destroyed over 150,000 buildings and left about 300,000 people homeless. The economic loss as a result of this earthquake is estimated to reach $\$ 200$ billion.

An investigation was conducted under the auspices of the Panel on Wind and Seismic Effects of the U.S.-Japan Program in Natural Resources to observe, document, and summarize important lessons from this earthquake that can be used to mitigate the potentially tragic impact of future earthquakes on modern urbanized communities. An 18-member team was in Japan from February 12 to February 18,1995 to study seismology, geology, and geotechnical effects; as well as the performance of buildings, lifelines, and fire safety systems.

This document summarizes the information collected during as well as following this investigation. Key findings of the investigation include needs for research and for improvements in practices to achieve earthquake loss reduction in the United States.

Key words: airports, bridges, buildings, building technology, engineering seismology, electric power, fires, gas, geology, geotechnology, harbor, highway, lateral spread, lifeline, liquefaction, railroad, rapid transit, reinforced concrete, sewage, steel, telecommunication, wastewater, water, wood frame construction 


\section{ACKNOWLEDGMENTS}

The authors wish to thank the following individuals for their extraordinary support during the investigation team's visit to Kobe. Many of them also have provided valuable information through followup correspondences that helped prepare this report.

Public Works Research Institute, Ministry of Construction, Japan

Dr. Hiroshi Sato

Dr. Yasuyuki Koga

Mr. Tomonobu Nakaoka

Mr. Takaaki Kusakabe

Mr. Yoshio Ninomiya

Mr. Shuji Tanaka

Dr. Koichi Yokoyama

Building Research Institute, Ministry of Construction, Japan

Dr. Shinsuke Nakata

Dr. Isao Nishiyama

National Research Institute for Earth Science and Disaster Prevention, STA

Mr. Keiichi Ohtani

Geographical Survey Institute, Ministry of Construction

Mr. Masaharu Tsuzawa

Kobe Waterworks Bureau, City of Kobe

Mr. Makoto Matsushita

Kobe University

Prof. Shiro Takada

Nippon Telegraph and Telephone Corporation

Mr. Kenichi Honda

Mr. Yasui Kuribayashi

Mr. K. Yamagami

Kansai Electric Company

Mr. K. Yasuda

Osaka Gas Company

Mr. Nobuhiro Kanatsuji

Mr. Chiaki (Jack) Gomi

Mr. Shimizu

Ms. Noriko Fukunaga 
Hanshin Expressway Public Corporation

Mr. Motohiko Nishibayashi

Japan Highway Public Corporation

Dr. Yuzuru Ito

Ministry of Construction, Naniwa National Highway Construction Bureau

Mr. Toshai Kato

Kobe Rapid Transit Railway Co., Ltd.

Mr. Toshi Aki Syo

Mr. Hiroshi Kishimoto

American Consulate General in Osaka

Mr. Robert G. Rapson

The authors also wish to thank Mr. LeVal Lund, and Dr. Bijan Mohraz and Ms. Ann Bieniawski of the Building and Fire Research Laboratory, National Institute of Standards and Technology, for their review of the manuscript; as well as the support that they have been receiving from Drs. Richard Wright and Jack Snell, Director and Deputy Director, respectively, of the Building and Fire Research Laboratory. Other individuals who have helped contribute the work of this investigation are specifically recognized in the acknowledgments in separate chapters. 


\section{CHAPTER CONTRIBUTORS}

Chapter 1

Chapter 2

Chapter 3

Chapter 4

Chapter 5

Chapter 6

Chapter 7
INTRODUCTION

Riley Chung

SEISMOLOGY, GEOLOGY, AND GEOTECHNICAL ISSUES Roger Borcherdt

Thomas Holzer

PERFORMANCE OF BUILDINGS

John Hayes

H. S. Lew

E. V. Leyendecker

Jack Moehle

M. P. Singh

William Stone

PERFORMANCE OF TRANSPORTATION SYSTEMS

Ian Buckle

James Cooper

Thomas Holzer

Thomas O'Rourke

Anshel Schiff

Li-Hong Sheng

Andrew Taylor

Michael Whitney

James Wilcoski

PERFORMANCE OF LIFELINE SYSTEMS

Donald Ballantyne

Riley Chung

Thomas O'Rourke

Anshel Schiff

POST EARTHQUAKE FIRES

Daniel Madrzykowski

Edward Comeau

OBSERVATIONS, CONCLUSIONS, AND RECOMMENDATIONS

FOR RESEARCH

Riley Chung 


\section{TABLE OF CONTENTS}

\section{EXECUTIVE SUMMARY}

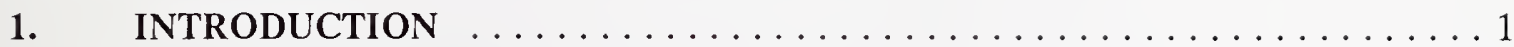

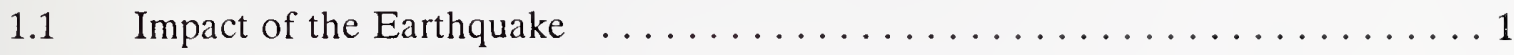

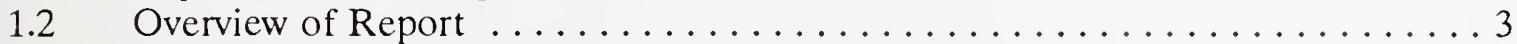

2. SEISMOLOGY, GEOLOGY, AND GEOTECHNICAL ISSUES $\ldots \ldots \ldots \ldots 5$

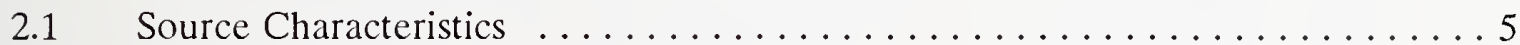

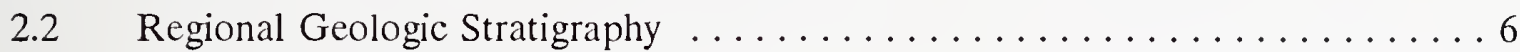

2.3 Geotechnical Overview - Kobe City Area . . . . . . . . . . . . . . 7

2.4 Strong Ground Shaking $\ldots \ldots \ldots \ldots \ldots \ldots \ldots \ldots \ldots \ldots \ldots \ldots \ldots \ldots \ldots \ldots$

2.4.1 Strong Motion Recordings $\ldots \ldots \ldots \ldots \ldots \ldots \ldots \ldots \ldots$

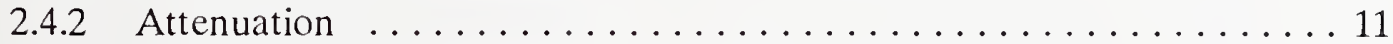

2.4.3 Amplification Effects of Soft-Soil Deposits ............... 12

2.5 Ground Failure . . . . . . . . . . . . . . . . . . . . 14

2.6 Engineering Seismology and Geotechnical Lessons for the United States . . . . 15

2.7 Research Needs for Engineering Seismology and Geotechnical Engineering . . 16

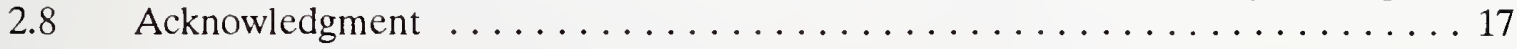

2.9 References .................................. 17

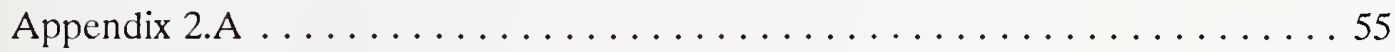

3. PERFORMANCE OF BUILDINGS $\ldots \ldots \ldots \ldots \ldots \ldots \ldots \ldots \ldots \ldots \ldots$

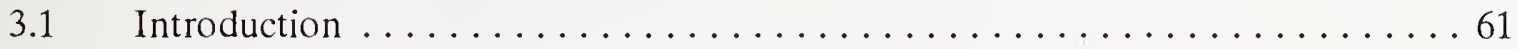

3.2 Development of Japanese Building Construction ...............66 62

3.2.1 Development of Japanese Building Seismic Requirements . . . . . . 62

3.2.2 Types of Construction in Japan ..................... 63

3.2.2.1 Wood Frame Construction for Traditional Houses ........6 63

3.2.2.2 Reinforced Concrete Bearing Wall Construction ......... 64

3.2.2.3 Reinforced Concrete Frame and Frame-Wall Construction . . . 64

3.2.2.4 Steel-Reinforced Concrete (SRC) Construction .........6 65

3.2.2.5 Steel Construction .....................66 66

3.2.3 Lateral Force and Design Requirements ...............66 66

3.2.3.1 The Building Standard Law from 1950 through $1980 \ldots \ldots 67$

3.2.3.2 The Building Standard Law of $1981 \ldots \ldots \ldots \ldots \ldots \ldots 67$

3.3 Performance of Traditional .Wood Houses .................. 79

3.4 Reinforced Concrete and Steel-Reinforced Concrete Buildings . . . . . . . 87

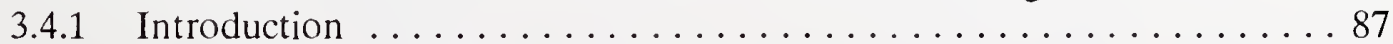

3.4.2 Description of Damage $\ldots \ldots \ldots \ldots \ldots \ldots \ldots \ldots \ldots$

3.4.2.1 Damaged Reinforced Concrete Shear Walls .......... 88

3.4.2.2 Damage to Reinforced Concrete Frame Members ........ 8 89

3.4.2.3 "Soft" First-Story Collapses . . . . . . . . . . . . . . . . 89

3.4.2.4 Mid-height Story Collapses in RC and SRC Mid-rise

Buildings .......................... 90

3.4.2.5 Other Observations $\ldots \ldots \ldots \ldots \ldots \ldots \ldots \ldots \ldots \ldots \ldots$ 
3.5 Performance of Steel Buildings $\ldots \ldots \ldots \ldots \ldots \ldots \ldots \ldots \ldots \ldots \ldots \ldots \ldots \ldots$

3.5.1 Introduction .............................. 111

3.5.2 Description of Damage $\ldots \ldots \ldots \ldots \ldots \ldots \ldots \ldots \ldots \ldots \ldots \ldots \ldots \ldots$

3.5.2.1 Weld Fractures in Light Gage Steel Frames . . . . . . . . 113

3.5.2.2 Diagonal Brace Fractures $\ldots \ldots \ldots \ldots \ldots \ldots \ldots \ldots \ldots$

3.5.2.3 Buckling of Columns ................... 114

3.5.2.4 Weld Fractures in Low-rise Buildings .............. 114

3.5.2.5 Moment Frame Behavior: Mid-rise Buildings . . . . . . . 114

3.5.2.6 Anchor Bolt Failure . . . . . . . . . . . . . . . . . 115

3.5.2.7 Behavior of High-rise Buildings $\ldots \ldots \ldots \ldots \ldots \ldots \ldots .116$

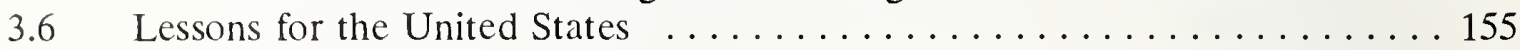

3.7 Research Needs . . . . . . . . . . . . . . . . . . . 157

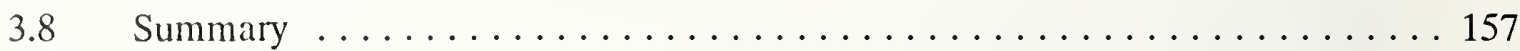

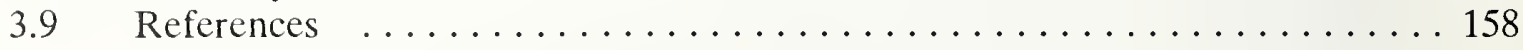

4. PERFORMANCE OF TRANSPORTATION SYSTEMS $\ldots \ldots \ldots \ldots \ldots 163$

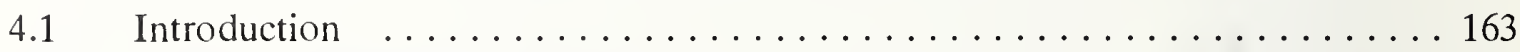

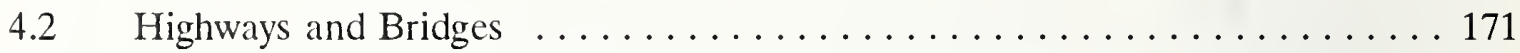

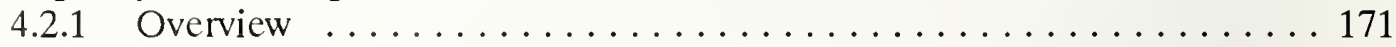

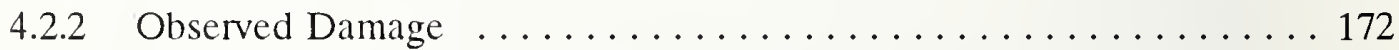

4.2.2.1 Damage to Superstructures Due to Bearing Failure ...... 174

4.2.2.2 Damage to Concrete Substructures . . . . . . . . . . 177

4.2.2.3 Damage to Steel Substructures ............... 183

4.2.2.4 Damage to Structures Due to Special Conditions _... . . 186

4.2.2.5 Performance of Other Highway Bridge Structures ....... 188

4.2.3 Lessons for the United States $\ldots \ldots \ldots \ldots \ldots \ldots \ldots \ldots \ldots \ldots$

4.2.4 Research Needs and Opportunities . . . . . . . . . . . . . . 190

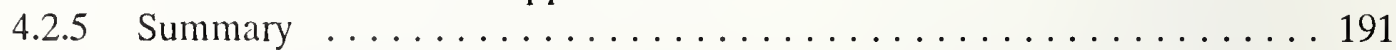

4.2.6 References ............................. 192

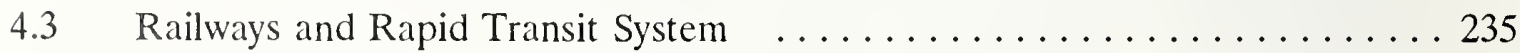

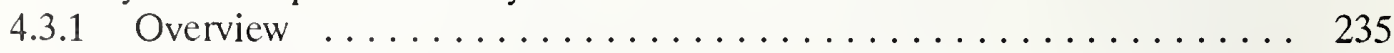

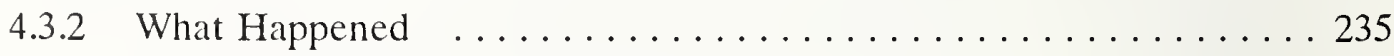

4.3.2.1 Shinkansen - Western JR ................ 235

4.3.2.2 JR Main Line - Western JR . . . . . . . . . . 237

4.3.2.3 Hanshin Dentetsu ..................... 237

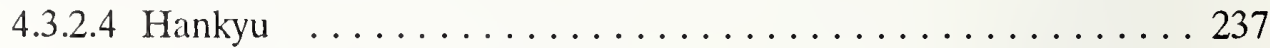

4.3.2.5 Kobe New Tram System _................ 237

4.3.2.6 Underground Rapid Transit Systems . . . . . . . . . . 238

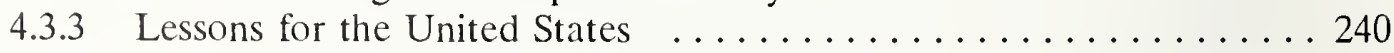

4.3.4 Research Needs ............................ 242

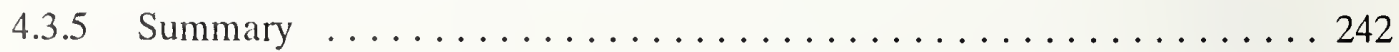

4.3.6 References ............................. 242

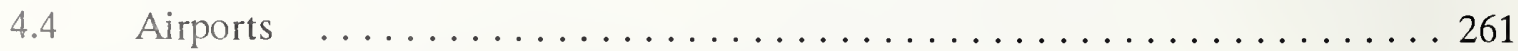

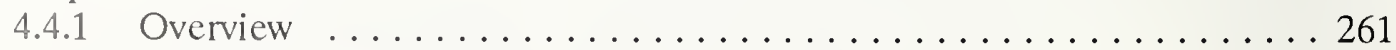

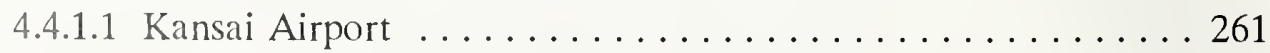

4.4.1.2 Osaka Airport ........................ 264

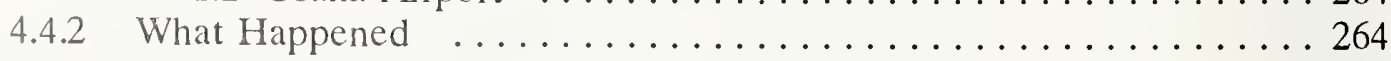

4.4.2.1 Kansai Airport ......................... 264

4.4.2.2 Osaka Airport ....................... 265 
6. POST EARTHQUAKE FIRES

6.1 Introduction $\ldots \ldots \ldots \ldots \ldots \ldots \ldots \ldots \ldots \ldots \ldots \ldots \ldots \ldots \ldots$

6.2 Fire Events Following the Earthquake ................... 497

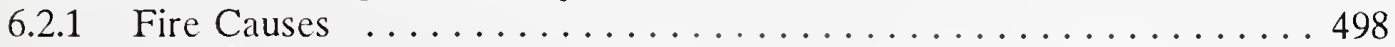

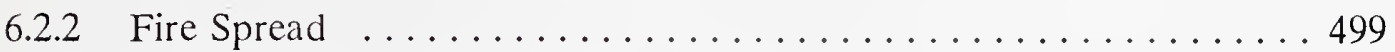

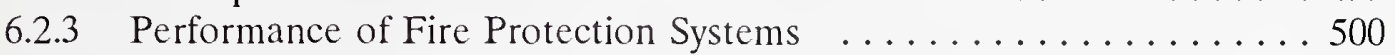

6.2 .3 .1 Active Systems . . . . . . . . . . . . . . . . . . 501

6.2 .3 .2 Passive Systems ....................... 501

6.2 .4 Fire Service ............................. 502

6.2 .5 Resident Self-help ......................... 504

6.3 Lessons for the United States . . . . . . . . . . . . . . . . . . 504

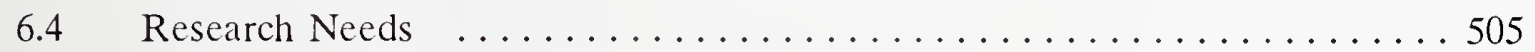

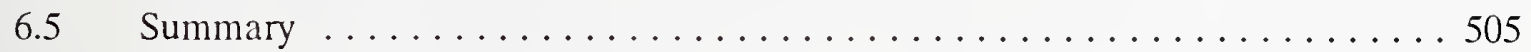

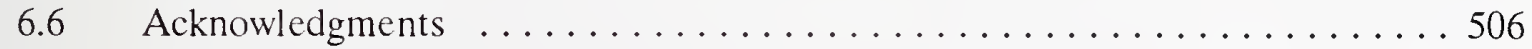

6.7 References ........................... 506

7. OBSERVATIONS, CONCLUSIONS, AND RECOMMENDATIONS FOR

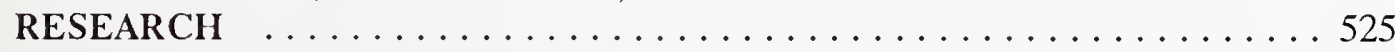

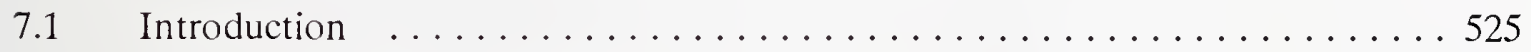

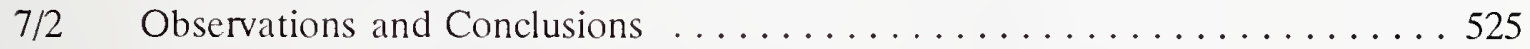

7.2.1 Seismology, Geology, and Geotechnology .............. 525

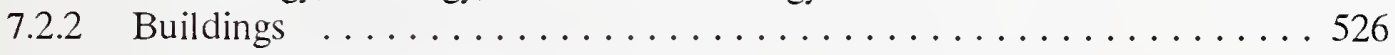

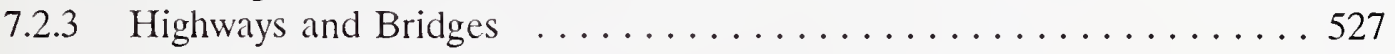

7.2 .4 Railways and Rapid Transit System .................. 528

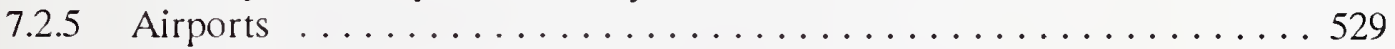

7.2 .6 Ports and Harbors ... . . . . . . . . . . . . . . . . . . . . 529

7.2.7 Water and Wastewater Systems ... . . . . . . . . . . . . . . . . 529

7.2 .8 Gas Delivery System ... . . . . . . . . . . . . . . . 530

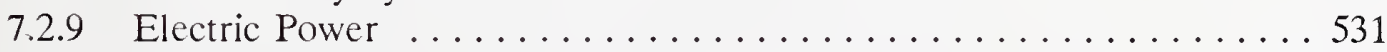

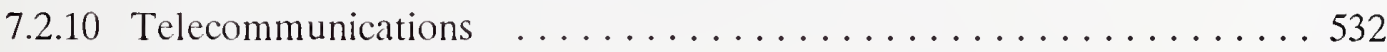

7.2 .11 Hospitals . . . . . . . . . . . . . . . . . . . 532

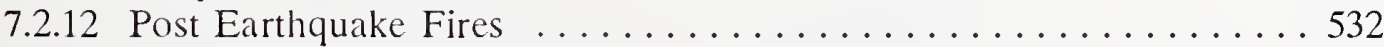

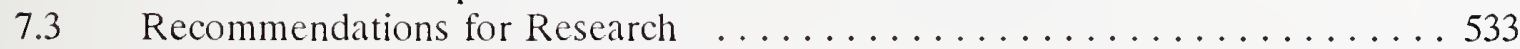

7.3.1 Seismology, Geology, and Geotechnology $\ldots \ldots \ldots \ldots \ldots \ldots 33$

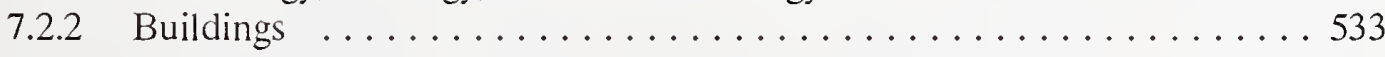

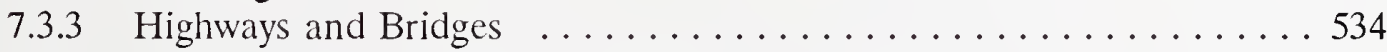

7.3.4 Railways and Rapid Transit System ................. 535

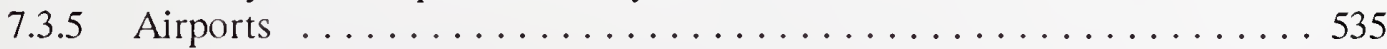

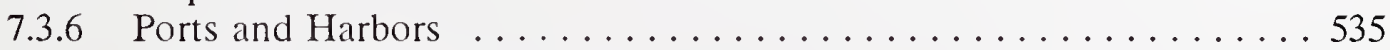

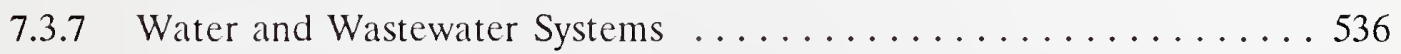

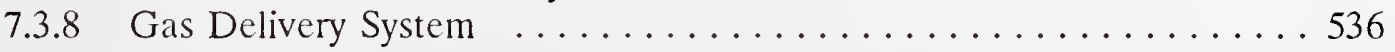

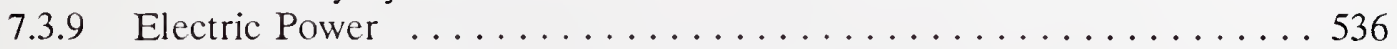

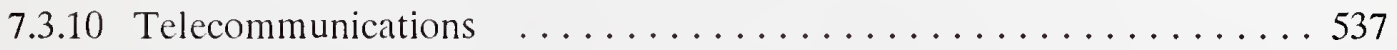

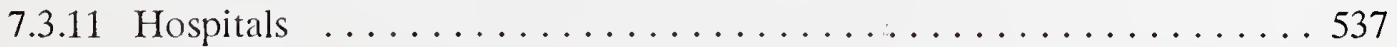

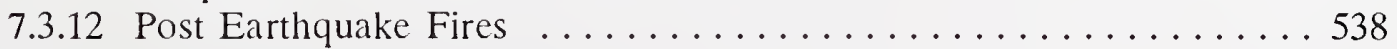

APPENDIX Seismic Intensity Scale, Japan Meteorological Agency vs Modified Mercalli Intensity Scale 
$5.4 \quad$ Electric Power . . . . . . . . . . . . . . . . . . . . . . . 387

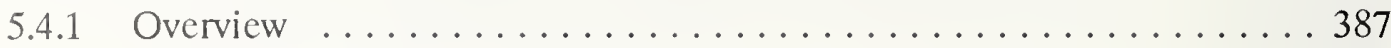

5.4.1.1 Kansai Electric Company .................. 387

5.4.1.2 System Description ................. 387

5.4.1.3 Differences in Equipment, Facilities, and Practices between Kobe and the United States ........... 387

5.4.1.4 Seismic Design Criteria .................... 389

5.4.2 What Happened ........................... 390

5.4.2.1 Seismic Environment at Power Facilities . . . . . . . . 390

5.4.2.2 Restoration of Service . . . . . . . . . . . . . . 390

5.4 .2 .3 Overview of Damage ................... 391

5.4.2.4 Itami Control Center and Substation . . . . . . . . . . 392

5.4.2.5 Shin-Kobe Substation ................. 396

5.4.2.6 Fukiai Control Center and Substation _........... 396

5.4.2.7 Performance of Generating Facilities ........... 397

5.4.2.8 Performance of High Voltage Transmission Lines . . . . . . 397

5.4.2.9 Performance of the Distribution System _... . . . . . . 398

5.4.3 Implications of Observations to the United States . . . . . . . . 398

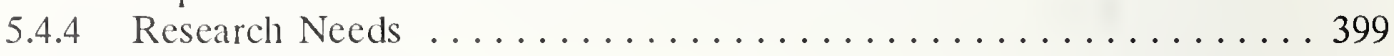

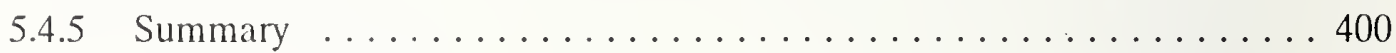

5.4.6 Acknowledgments ....................... 400

5.4 .7 References ............................ 400

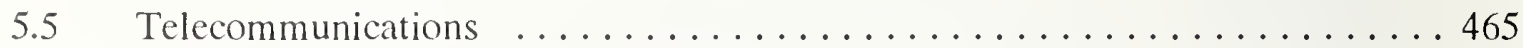

5.5.1 Nippon Telegraph and Telephone (NTT) Corporation ........ 465

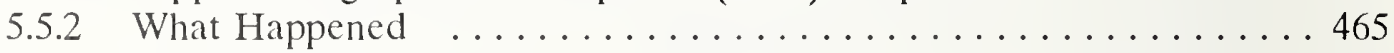

5.5.2.1 Central Offices ...................... 465

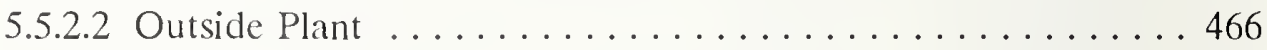

5.5.2.3 Network Operations . . . . . . . . . . . . . . . 467

5.5.2.4 Restoration ....................... 468

5.5.2.5 Special Post-Earthquake Services _........... 468

5.5.3 Lessons for the United States $\ldots \ldots \ldots \ldots \ldots \ldots \ldots \ldots \ldots . . \ldots 68$

5.5 .4 Research Needs ... . . . . . . . . . . . . . . . . . . . . . . . 468

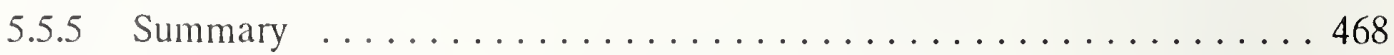

5.5 .6 Acknowledgments . . . . . . . . . . . . . . . . . 469

5.5 .7 References ............................... 469

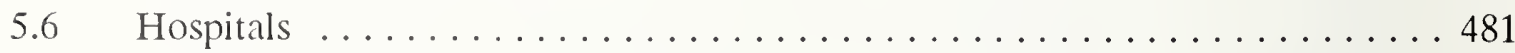

5.6 .1 Overview ............................ 481

5.6.1.1 Scope of Investigations $\ldots \ldots \ldots \ldots \ldots \ldots \ldots \ldots \ldots 48$

5.6.1.2 Kobe Medical College of the University of Kobe . . . . . . 481

5.6 .2 What Happened ........................ 481

5.6.2.1 Kobe Medical College of the University of Kobe . . . . . . 481

5.6.2.2 Hyogo Medical Center . . . . . . . . . . . . . . . . . . 484

5.6.3 Lessons for the United States . . . . . . . . . . . . . . . 484

5.6 .4 Research Needs ... . . . . . . . . . . . . . . . . . . . . . . . . 484

5.6 .5 Summary ............................. 485

5.6 .6 Acknowledgment ........................ 485 
4.4.3 Lessons for the United States . . . . . . . . . . . . . . . . . . . 266

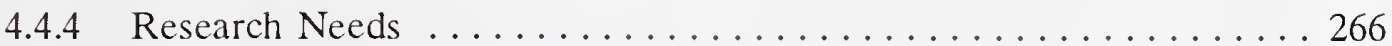

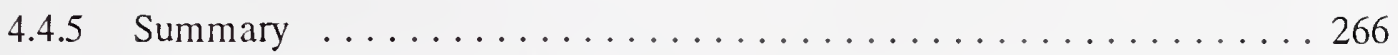

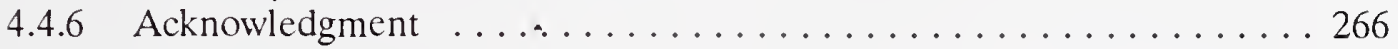

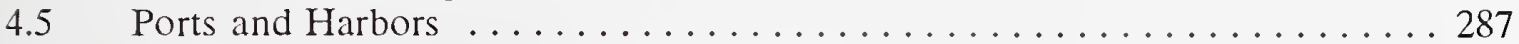

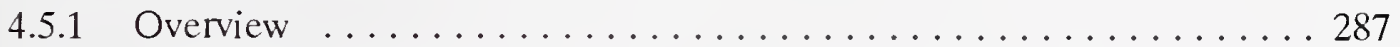

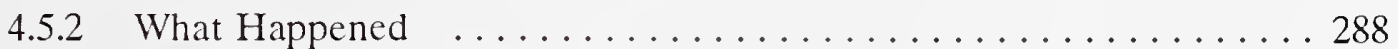

4.5.3 Lessons for the United States . . . . . . . . . . . . . . . . . 289

4.5 .4 Research Needs ............................ 290

4.5 .5 Summary .............................. 290

4.5.6 References ............................... 290

5. PERFORMANCE OF LIFELINE SYSTEMS . . . . . . . . . . . . . . . . . . 299

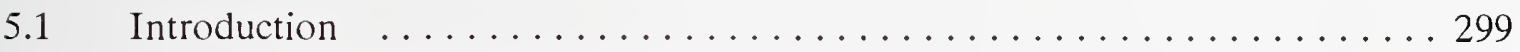

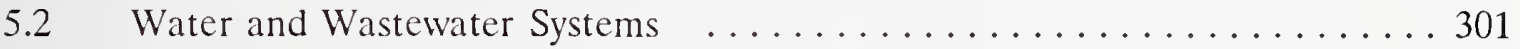

5.2 .1 Overview of Water System . . . . . . . . . . . . . . . . . 301

5.2.1.1 System General Overview ................ 301

5.2 .1 .2 Supplies . .......................... 302

5.2.1.3 Water Treatment Plants .................... 302

5.2.1.4 Distribution ....................... 302

5.2.1.5 Distribution Reservoir and Pump Stations . . . . . . . . 303

5.2.1.6 Control System .............. . . . . . . . . . 304

5.2.1.7 Earthquake Monitoring and Control . . . . . . . . . 304

5.2.2 What Happened to the Water System .............. 305

5.2.2.1 Conditions Following the Earthquake .......... 305

5.2.2.2 Damage to Water Facilities . . . . . . . . . . . 306

5.2.3 Wastewater System Overview and Damage .............. 308

5.2.3.1 System and Damage Overview ................ 309

5.2.3.2 Higashinada Wastewater Treatment Plant .......... 309

5.2.4 Lessons for United States and Research Needs . . . . . . . . . . 311

5.2.4.1 Overwhelming Conditions $\ldots \ldots \ldots \ldots \ldots \ldots \ldots \ldots \ldots \ldots$

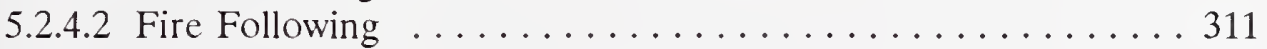

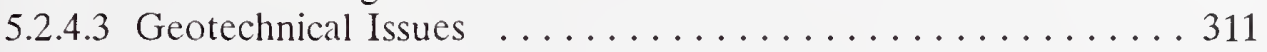

5.2 .4 .4 Design . . . . . . . . . . . . . . . . . 312

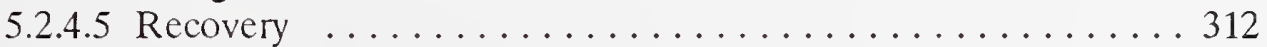

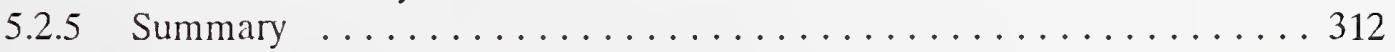

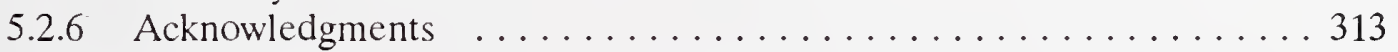

$5.3 \quad$ Gas Delivery System . . . . . . . . . . . . . . . . . . . 375

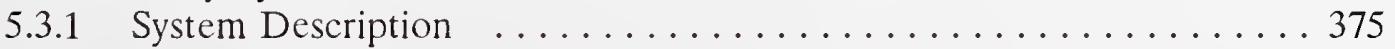

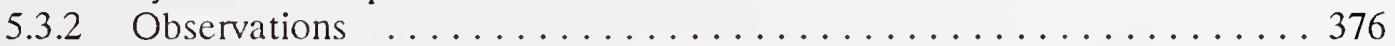

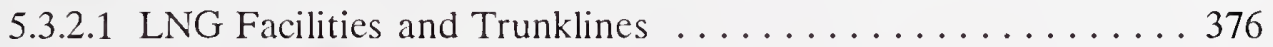

5.3.2.2 Medium Pressure Lines . . . . . . . . . . . . 376

5.3.2.3 Low Pressure Distribution System ... . . . . . . . . 377

5.3.2.4 Seismic Monitoring and Control System . . . . . . . . 377

5.3.2.5 Repair and Restoration .................. 378

5.3.2.6 Intelligent Meters . . . . . . . . . . . . . . . 378

5.3 .3 Lessons for the United States . . . . . . . . . . . . . . . 379

5.3 .4 Research Needs . . . . . . . . . . . . . . . . . . . 380

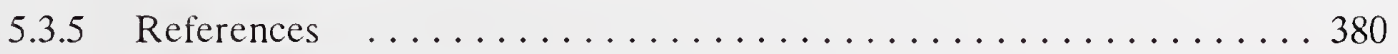




\section{EXECUTIVE SUMMARY}

\section{INTRODUCTION}

The January 17, 1995 earthquake of magnitude 7.2 in the Japan

Meteorological Agency scale or $\mathrm{M}_{\mathrm{w}}=$ 6.9 , which struck the northwest, north, and northeast shorelines of Osaka Bay of Japan, was the most devastating earthquake to affect the region this century. The earthquake resulted in the worst natural disaster since the 1923 Great Kanto earthquake devastated Tokyo and Yokohama.

The earthquake resulted in more than 6000 fatalities and over 30000 injuries. Fire following the earthquake incinerated the equivalent of 70 U.S. city blocks. They together destroyed over 150000 buildings and left about 300000 people homeless. The economic loss of this earthquake is estimated to reach $\$ 200$ billion, the costliest earthquake in the world thus far, and its impact has been felt worldwide.

Kobe and its surrounding area is about $50 \mathrm{~km}$ long east-west and about $1.5 \mathrm{~km}$ to $6 \mathrm{~km}$ wide north-south with Rokko Mountain to its north, peaking at about $1000 \mathrm{~m}$, and Osaka Bay to its south. This narrow piece of coastal plain is heavily urbanized and industrialized. It is a modern urban setting with a population of about 15 million (about $15 \%$ of the total Japan population). Kobe port is the third largest port in the world and handles about $20 \%$ of Japan's total trade. Most of the port consists of three man-made islands: Port Island, Rokko Island, and Maya Terminal. The region is served by a number of modern transportation systems, such as the bullet trains, railways, expressways and elevated highways, new tram systems, ferries, and rapid transit systems. It is also served by modern utility systems for water, wastewater, electrical power, gas, and telecommunications.

The earthquake brought the region's livelihood to a standstill. Houses and buildings were destroyed and surface transportation systems paralyzed. Emergency response and searclı and rescue operations had to be carried out under extremely difficult conditions. Water line breaks cut off water and depleted supplies for fire fighting. The loss of electricity and telephone communication put majority of residences in the region into total darkness.

The weeks and months after the earthquake brought out further problems for the local authorities, transportation agencies, and utility companies. Traffic jams became a normal part of daily routine, for a while walking was the best way to get from point "A" to point "B". The authorities tried to restore public transportation systems as soon as possible. Removing the debris from 
fallen houses and buildings and damaged highway bridges became a monumental problem. Schooling had to be suspended temporarily because many of the school buildings had to be used as shelters.

Meanwhile, crews from utilities worked around the clock to repair broken water lines, sewage lines, downed power and telephone poles, and leaking gas lines. Because of the lack of pre-earthquake planning, often these activities had to be carried out haphazardly. In fact, it is believed that early restoration in electricity to some part of the Kobe City was responsible for the ignition of additional fires after the initial burst of fires immediately following the earthquake.

Reclaimed lands along the shoreline of Kobe City settled significantly during the earthquake. Liquefaction and lateral spreading were the two prominent factors contributing to the damage from this earthquake in areas of reclaimed ground. Restoration of the port facilities is estimated to take 2 years to complete. Meanwhile, goods have to be transported to other neighboring ports and harbors and then through surface transportation to reach factories in Kobe. This could turn out to cause a permanent loss of business; it remains to be seen how much of the original' share of business the Kobe Port can recapture once it is again open for traffic.
The earthquake brought out some of the best qualities of human beings, as evidenced by the outpouring of support and assistance from other communities. Water trucks brought in drinking water througlı mutual aid arrangement. Tens of thousands of utility and construction workers from all over Japan participated in the restoration of lifelines.

Unfortunately, the earthquake also highlighted the helpless expressions on the faces of search and rescue workers; something that has been witnessed in every recent natural disaster.

This earthquake provided an unprecedented opportunity to learn many valuable lessons that can help prepare us to reduce the devastating effects of future earthquakes. Many of U.S. cities have a geographic setting similar to the City of Kobe, i.e., a narrow strip of coastal land, soft soils along the shore, and congested urban buildup and transportation systems. These cities include Seattle and Tacoma, Washington; Long Beach, San Diego, and San Francisco, California; as well as New York City; Boston; Charleston, South Carolina; and Memphis, Tennessee; all located in the eastern and central regions of the United States. The nature of devastation of Kobe by this earthquake is perhaps most relevant to the cities in the eastern and central regions of the United States. This is because the difference between the maximum credible earthquake and the design earthquake is clearly very large for the Kobe region of Japan; a situation that also exists in the eastern and central parts of the United States. 
These parts of the United States may be even more vulnerable to earthquake damage since the urban areas in eastern and central United States are much older than the region where this earthquake hit (Kobe was rebuilt after World War II). Most of the U.S. buildings have been constructed without the benefit of modern seismic design, likewise the lifeline systems. The Kobe earthquake should serve as a wakeup to the communities in those U.S. regions to begin a concerted effort to reduce the impact from future disasters.

The investigation of the Kobe area described in this report was carried out under the auspices of the U.S.-Japan Cooperative Program on Natural Resources (UJNR) Panel on Winds and Seismic Effects. The panel's U.S. effort is led by NIST and its counterpart in Japan is the Ministry of Construction's Public Works Research Institute (PWRI).

To every member of the investigation team, the visit to Kobe and the area devastated by the January 1995 earthquake will be a lifelong experience. It was through this visit that we came to appreciate the awesome power of nature, that we came to have direct understanding of which mitigation measures worked and which did not, that we also came to feel for those families whose lives were dramatically altered as the result of the earthquake. The visit also provided us with another reminder of our responsibilities to help our society better prepare for future earthquakes.

\section{SEISMOLOGY, GEOLOGY, AND GEOTECHNICAL ISSUES}

\section{The Hyogoken-Nanbu (Kobe)} earthquake of January 17, 1995 occurred in an area of complex faulting located near Awaji Island and the Hanshin area of Japan. This area, which includes the urban centers of Kobe City, is located about $250 \mathrm{~km}$ from the Nankai trough, which forms the boundary between the Philippine Sea and Eurasian plates.

Coseismic crustal rupture associated with the earthquake initiated on the Nojima fault located on Awaji island. The rupture extended to the ground surface along a $9 \mathrm{~km}$ segment of the fault on Awaji Island. Maximum surface displacements of $1.7 \mathrm{~m}$ right-lateral, horizontal and $1.0 \mathrm{~m}$ vertical were observed. Aftershocks during the first 10 days suggest the seismic rupture surface was between $35 \mathrm{~km}$ and $50 \mathrm{~km}$ long. The shallowest seismicity occurred beneath Awaji Island and downtown Kobe City.

Most of Kobe City is built on a narrow $2 \mathrm{~km}$ - to $3 \mathrm{~km}$-wide coastal plain confined between Rokko Mountains and the Osaka Bay. Soils of the coastal plain divide into two major groups from a geotechnical perspective, natural soils and man-made landfills. Much of the recent growth of Kobe, however, has been on sandy landfills that were dumped into Osaka Bay.

The floor of Osaka Bay offshore of Kobe is blanketed by a compressible marine clay that existed before the 
modern landfills were emplaced. The clay is up to $20 \mathrm{~m}$ thick in the Kobe offshore area but it thins to about $2 \mathrm{~m}$ near the natural shoreline. The water content of the soft clay ranges from $70 \%$ to $100 \%$ and the compression index ranges from 0.2 to 0.6 . Its shear wave velocity is about $180 \mathrm{~m} / \mathrm{s}$.

Following emplacements of landfills, settlements of about $4 \mathrm{~m}$ have been measured on top of the upper clay surface. Settlements are expected to continue for many years. This has prompted the use of pile supported foundations for all heavy structures built on the fill.

The first reclamation efforts filled 529 ha along the Kobe City shoreline from 1953 to 1970. Following these reclamation efforts, Port and Rokko Island were created. Reclamation of Port Island started first and was done in two phases. The first phase, which filled 436 ha, was from 1966 to 1980 . The second phase started in 1986, and increased the size of the island by 390 ha. Rokko Island, which is 580 ha, was reclaimed from 1973 to 1992 .

The strong motion data from this earthquake provides an exceptional set of near source measurements of strong shaking. Measurements at 10 sites indicate peak ground shaking was near or exceeded $0.5 \mathrm{~g}$ and reached levels exceeding $0.8 \mathrm{~g}$ at two locations.

\footnotetext{
Records also show that on the average the peak vertical accelerations were about $62 \%$ or $2 / 3$ of the corresponding
}

horizontal values. Peak vertical accelerations that exceeded the peak horizontal values are most evident for sites near or on Port Island. These larger vertical accelerations are consistent with larger amplification factors observed for vertical motion above the liquefied layer on the Port Island array.

When artificial fills were subjected to the strong shaking of the earthquake, they liquefied and expelled large quantities of both sand and water. More than $17 \mathrm{~km}^{2}$ of land area was covered by vented materials. Splash marks on walls and other structures indicated that water fountains typically reached $0.5 \mathrm{~m}$ and reached heights of almost $2 \mathrm{~m}$ in a few locations.

\section{BUILDINGS AND HOUSES}

The most serious damage was concentrated within a narrow band about $0.5 \mathrm{~km}$ to $1 \mathrm{~km}$ either side of the fault lines. This extended about $30 \mathrm{~km}$, from the northern tip of Awaji island, through the central part of Kobe, toward Nishinomiya City near Osaka. Within this band many old wooden houses, over 30 years old, were interspersed among commercial structures. Many of these houses totally or partially collapsed burying their occupants.

The walls of single family dwellings provided little lateral load resisting capacity, and could not support the heavy clay tile roof load during severe ground shaking. Likewise, 2- and 3-story dwelling structures with commercial 
operations in the first story had few interior walls to resist lateral loads, thereby sustaining partial or total collapse.

Major revisions to the seismic design requirements took place in 1971 and 1981. Ductility was introduced in the seismic design for the first time in 1981. Many reinforced concrete buildings constructed prior to 1981 sustained severe damage. Many buildings sustained damage to the first story. Shear failure of first-story columns and collapse of soft first stories were most common. A prominent mode of failure of reinforced concrete multi-story buildings was a partial or a total collapse of an entire story at an upper level. Many buildings that failed in this mode were of steel-encased reinforced concrete (SRC).

Similar to reinforced concrete buildings, steel buildings constructed 20 to 30 years ago sustained severe damage whereas buildings designed and constructed according to the 1981 Building Standard suffered little. Welding failures at member connections contributed to many of the building failures. Light steel frame structures suffered member failures, particularly diagonal bracing members, with reduction in cross section due to corrosion. Brittle fractures of heavy steel columns with flange thickness of $50 \mathrm{~mm}$ occurred in a post-1981 multistory complex in Ashiya city.

\section{TRANSPORTATION SYSTEMS}

Two important features of the Kobe area had a major impact on the seismic damage suffered by transportation systems in the Hyogoken-Nanbu earthquake: the coastal topography and the surface soil conditions along the Osaka Bay.

Many transportation routes are located adjacent to or on top of one another. Rail lines are also routed closely together, with three separate rail systems occupying the same right-of-way in some locations. The tunnels of the municipal subway system run beneatlı major urban streets in Kobe. Cut-and-cover subway stations collapsed during the earthquake, causing surface subsidence.

Unfortunately this corridor lay directly above the ruptured fault zone of the earthquake, so all major transportation routes in Kobe were severely damaged by the earthquake.

Out of necessity newer transportation routes have been constructed on artificial fill in and around Kobe. For example, the Wangan, or "Bay Shore" route of the Hanshin Expressway system rings the entire bay from Kansai International Airport on the south to Kobe on the north.

\section{Highways and Bridges}

The region is served by a complex network of freeways and highways built since the early 1960's. Damage to highway bridges was both widespread and catastrophic. Typical damage 
included shear and flexural failures in nonductile concrete columns, flexural and buckling failures in steel columns, unseated girders due to bearing failures, and gross foundation movements due to liquefaction. In addition, pounding between spans occurred. Some special structures also suffered atypical damage such as the excessive rotation of a skew bridge on pin-ended columns and the loss of seismic energy dissipators in a cable-stayed bridge due to the failure of a wind shoe.

Most of this distress was confined to older structures, built more than 30 years ago before the introduction of modern seismic codes. The poor performance of these older bridges and elevated expressways confirms previous lessons learned in California and elsewhere, about the pressing need to retrofit the existing inventory of deficient bridges.

Some new bridges also suffered serious damage which implies a need to re-evaluate the design loads and procedures in the current design specifications.

The closure of three major expressways in the Hanshin region has had a major societal and economic impact on the region. The estimated total repair cost for one highway authority alone, the Hanshin Expressway Public Corporation, is $\$ 4.6$ billion. Furthermore, it does not include the loss of toll revenue while the network is inoperative (estimated at $\$ 2$ million per day) nor does it include the indirect losses which are expected to exceed the repair costs by the time the system is fully operational.

\section{Railways and Rapid Transit System}

There are four electric rail service lines between Kobe and Osaka. Two of the rail lines are operated by Western Japan Rail and the other two are owned by private companies, Hanshin and Hankyu. Most of the rail lines that run through this corridor are on elevated embankments and on elevated structures. There are two guideway systems in Kobe, the Port Liner from Sannomiya to Port Island and the Rokko Liner from Sumiyoshi to Rokko Island.

There are five other railways and transit systems in Kobe including the Kobe Kosotku, Kobe Dentetsu, Kosoku Kobe, Sanyo Dentetsu, and the Kobe Subway.

The Kobe Rapid Transit Railway, or Kobe Kosotku, is owned and operated by the Kobe Rapid Transit Railway Company, Ltd. The system was constructed between 1962 and 1968. Underground sections were built by means of cut-and-cover techniques. Running tunnels are reinforced concrete box structures with center column support.

The Kobe Municipal Subway, or Metro, is operated by the City of Kobe and is composed of $22.7 \mathrm{~km}$ of elevated, surface, and underground railway.

All four railways between Kobe and Osaka and two guideway systems in Kobe were seriously damaged. It is 
obvious that the number of casualties would have been much higher if the earthquake had occurred during the day time or rush hour.

The inability to resist the applied lateral load for the elevated structures which collapsed can be attributed to a lack of confining steel within the critical reinforced concrete column and joint regions. The unexpected higher ground accelerations over a wide area caused damage to miles of elevated structures. Insufficient seat length caused the Rokko Liner to lose one span. Modern steel columns performed well with minor local buckling.

\section{Airports}

The Kansai area is served by three airports: Kansai International Airport, Osaka International Airport, and Yao Airport. The Terminal Radar Approach Control (TRACON), which is located at Kansai Airport, controls airplanes in the area before each is turned over to the respective control towers. Kansai Airport was opened for service on September 1, 1994, and primarily serves international flights. Osaka Airport primarily serves domestic flights and a few international flights. Neither of these airports allows general aviation, which is served by Yao Airport. The Kansai airport is built on a 511 ha island of reclaimed land in Osaka Bay. It is located $27 \mathrm{~km}$ southeast of the epicenter.

Kansai control tower was well constructed with an innovative method of leveling the tower should it be subjected to differential settlement. This tower also had columns in the interior of the cab to support the roof and resist lateral motion of the cab, thus protecting the windows. The columns appeared to cause little visual interference. The cooling system for the emergency generator was provided with a large local water supply. The tower sustained no damage from the low level ground motion in this earthquake. The peak ground acceleration measured on the runways was less than $0.2 \mathrm{~g}$ and at the building foundations less than $0.1 \mathrm{~g}$.

Both administration building and control tower at the Osaka Airport sustained minor damage. Damage included a crack in a window in the cab of the tower, minor damage to shear walls in the administration building and temporary loss of use of the elevators.

\section{Ports and Harbors}

Kobe has been one of the world's most expensive ports to construct. Two major man made islands, Port and Rokko Islands, cost about $\$ 2$ billion to create. The port contains 152 berths with an aggregate wharf length of $27 \mathrm{~km}$. The Port operates 400 dockside gantry cranes and derricks to load and unload cargo.

Most of the quay walls forming the wharfs are sand-filled caisson structures, although a few consist of cellular steel sheet piles. The foundation for each caisson was prepared by excavating the natural silt layer on the sea floor and replacing it with sand fill. A gravel pad 
was placed on the fill and then the $10 \mathrm{~m}$-tall concrete caisson was lowered into place and filled with local sandy material. The waterside crane rail rests on the caisson. Most of the gantry cranes have rail spans of $30.5 \mathrm{~m}$, but a few of the older cranes at Port Island and Maya Wharf have rail spans of 16 $\mathrm{m}$. The $30.5 \mathrm{~m}$-rail girders are supported either by a concrete slab placed on engineered fill or a concrete pile supported wall and the 16-m-rail girders rest on a concrete pile supported wall. The crane rails were not structurally connected to each other.

Liquefaction during the 1995 HyogokenNanbu earthquake disabled the port of Kobe. Permanent ground deformation caused failure of quay walls and differential displacements of crane rails causing crane operations to stop. Lateral spreading was restricted to the margins of the port facilities, usually extending less than $100 \mathrm{~m}$ from quay walls. Vertical settlements of $30 \mathrm{~cm}$ to $50 \mathrm{~cm}$ were widespread inland, but did not do great damage because of their uniform character.

\section{LIFELINES}

Lifelines are vulnerable to natural and man-made hazards such as earthquake, extreme wind, flood, accident, and terrorism. Proper performance of lifelines is important to assure public safety, vitality of economic activity, and quality of life. However, lifelines and their importance to our way of life generally are not recognized until their failure causes deaths and destruction, impedes emergency response following a major disaster, hinders post-disaster recovery, or paralysis to a community. Disruption of regional lifeline systems as the result of a major natural disaster, such as this earthquake in Kobe, can have a profound effect on the entire nation because of the economic interdependence of lifeline systems and the functions they support.

\section{Water and Wastewater Systems}

The City of Kobe water system serves 608844 households including 1.5 million people. The system was started in 1900 , as the 7th modern water system in Japan. The Water Department began actively using computers in 1987 , inputting water pipe drawings and boring $\log$ data for 4000 borings in 1988.

Water is pumped to the water purification plants and runs by gravity to the west at an elevation starting at $90 \mathrm{~m}$ above sea level through Kobe's tunnel system. The tunnel system operates in the open channel flow or low pressure regime. The first tunnel, $1.8-\mathrm{m}$ diameter and built in the 1930's, is constructed in rock with an unreinforced concrete lining. The second tunnel, $2.5-\mathrm{m}$ diameter, was built in the 1950's and is lined with reinforced concrete. Water used at an elevation above $90 \mathrm{~m}$ (apparently 15\% of the demand) is pumped from the tunnel system.

The Kobe water system is designed to provide both water for drinking and fire protection. There is no dedicated water system for fire suppression, although one 
was under consideration in 1993.

There are a number of cisterns located throughout the City for use for fire suppression. The urban area is laid out on a $400 \mathrm{~m}$ by $400 \mathrm{~m}$ grid. Three quadrants of the grid each has a fire hydrant, and the fourth quadrant has a cistern. There is one special radio system for communication between the water and fire departments during emergency response situation.

Kobe Water has an earthquake monitoring and control system in place to isolate water from the system and to maintain it in selected reservoirs for drinking following an earthquake. The system is also designed to maintain water for fire suppression. There is no capability, however, to isolate major lines crossing vulnerable areas, such as lines to the reclaimed land areas.

There are dual reservoirs at each of the 21 sites, one has an isolation valve to be controlled following an earthquake and the other does not. This concept allows shutdown of one reservoir while maintaining service should an inadvertent shutdown signal be received.

The earthquake left one million households without water following the event, with only $70 \%$ restoration in 3 weeks. Water for fire suppression was substantially exhausted after 6 hours.

The two large diameter transmission lines carrying water from the Yodogawa River to the water purification plants failed in ten locations. There were no tank failures reported for the 239 tanks located at 119 sites. There was some connecting piping failure at one tank.

- However, it should be noted that these tanks were in the hills surrounding the city and in areas of relatively low ground motion.

Nearly $90 \%$ of Kobe's water distribution system was made of either welded steel or ductile iron pipe, both thouglit to be resistant to earthquakes. This unusually high percentage of earthquake resistant pipe resulted from an aggressive pipeline replacement program initiated in the mid-1960's. Even with this in place, an estimated 1800 pipeline failures occurred in distribution piping. It is speculated that much of this damage is associated with joint separation from liquefactioninduced lateral spread.

Kobe has eight wastewater treatment plants, three of which were damaged by the earthquake. There are 23 pump stations; 20 were damaged or inoperable from power loss, building damage, or caisson damage. Most were operable when power was restored.

Collection system pipe is $70 \%$ concrete, $20 \%$ PVC, and 10\% VCP. Kobe uses Fiber Reinforced Plastic for large diameter pipe and PVC for smaller cliameter pipe in liquefaction areas.

The Higashinada Wastewater Treatment Plant provides one-third of Kobe's treatment capacity. Liquefaction or lateral spreading failures resulting in movement of a retaining wall $2 \mathrm{~m}$ to $3 \mathrm{~m}$ towards a waterway dropping the entire 
site an average of $1 \mathrm{~m}$. The result was devastating. A $2 \mathrm{~m} \mathrm{x} 2 \mathrm{~m}$ effluent channel separated in four places. The control and filter buildings moved, and equipment and piping settled as the soil moved away from under them. The plant was placed into temporary operation using an open channel as the sedimentation basin.

\section{Gas Delivery System}

The Osaka Gas Company provides gas to more than 5.6 million metered customers, accounting for $30 \%$ of the total gas sales volume in Japan. Major trunk lines, pipelines, and distribution mains total $49430 \mathrm{~km}$. The Osaka Gas system is comparable in size to the gas delivery network operated by the Southern California Gas Company, which is the largest U.S. gas supplier with approximately 4.6 million metered customers and nearly $74000 \mathrm{~km}$ of transmission, distribution supply, and distribution pipelines. Liquefied natural gas (LNG) accounts for about 94\% of the Osaka Gas system feedstock. Most of the supply is imported.

Three LNG terminals provide the primary sources for distribution. Gas is conveyed regionally through a system of major trunk lines, which operate at internal pressures of $4 \mathrm{MPa}$.

Transportation of gas also is accomplished tlirouglı wliat is termed a "medium pressure" system of A lines, at internal pressures of $0.3 \mathrm{MPa}$ to 1.0 $\mathrm{MPa}$, and $\mathrm{B}$ lines at internal pressures of $0.1 \mathrm{MPa}$ to $0.3 \mathrm{MPa}$.
The Osaka Gas system is divided into what company personnel call "super blocks." The eight super blocks of the network are large areas which can be isolated through telemeter control by closing valves activated by compressed carbon dioxide. Closing valves with carbon dioxide allows for control independent of electric power supply. The system can be subdivided further into about 55 "middle blocks," eacli of which may provide service to hundreds of thousands of customers. The middle blocks must be isolated by means of manually operated valves. The low pressure pipeline system within the middle blocks can be subdivided again into sectors, eacli provides service to between 3000 and 4000 customers.

There was no significant damage reported at the Senboku and Himeji LNG terminals, and at the gas distribution stations.

Osaka Gas personnel reported that there was a total of 35 and 61 repairs to medium pressure A and B lines, respectively. No major damage was reported in these lines. Medium pressure steel pipelines were subjected to large permanent ground deformation at several locations, but no leakage was observed.

The low pressure distribution system which operates at internal pressures equivalent to $150 \mathrm{~mm}$ to $210 \mathrm{~mm}$ of water column, or about $1.8 \mathrm{kPa}$ sustained the greatest eartliquake damage. There were $43895 \mathrm{~km}$ of low pressure lines at the time of the 
earthquake. In Kobe and adjacent communities, the low pressure system is composed predominantly of steel pipe with threaded steel couplings, or screw joints. A small portion of the low pressure system, approximately $5 \%$, is composed of polyethylene mains and services. Some steel piping with restrained mechanical joints and polyethylene linings was deployed in areas of artificial fill as a seismic countermeasure.

There was no observed failure in the bodies of steel pipe segments, and only 36 locations of ruptured cast iron pipe walls. There was a total of 5190 repairs to distribution mains and branches within city streets, compared with 10161 damaged service lines and 11108 locations of damage at piping attached to buildings. There were no repairs in polyethylene piping.

The Osaka Gas Company operates a system of seismic sensors throughout its service area to provide rapid feedback about the likelihood of earthquake damage to pipelines and associated facilities. Thirty four sensors had been installed at the time of the earthquake. The company plans had been implemented to install an additional 30 sensors by the end of March 1995.

About $74 \%$ of customers were equipped with intelligent meters according to Osaka Gas personnel. The meter is equipped with a seismic sensor triggered by acceleration exceeding $0.2 \mathrm{~g}$, a pressure sensor, and a flow rate transducer. A microcomputer monitors the incoming signals and shuts off flow, if required. A lithium battery is used as a power supply. Gas company personnel

- report that the intelligent meters appear to have functioned as intended.

\section{Electric Power}

Established in 1951, the Kansai Electric Power Company is one of the nine major investor-owned electric utilities in Japan. The company serves four major cities: Osaka with 2.5 million, Kyoto with 1.39 million, Kobe with 1.47 million, and Nara with 0.35 million people. In the earthquake impacted area the transmission and sub-transmission voltages are $500 \mathrm{kV}, 275 \mathrm{kV}, 154 \mathrm{kV}$, and $77 \mathrm{kV}$. The $500 \mathrm{kV}$ system lies primarily to the north, northeast, and east of the earthquake impacted area. These lines carry power from major nuclear generating stations on the Japan Sea, and large pumped storage facilities. There are eight fossil-fuel generating facilities on Osaka Bay east of the epicenter. The primary distribution voltage is $6.6 \mathrm{kV}$, although there are some $22 \mathrm{kV}$ and $33 \mathrm{kV}$ distribution lines.

Aerial lines and towers are used for most high voltage lines, although there are more $275 \mathrm{kV}$ cables in urban areas than is typical for $230 \mathrm{kV}$ in California. Distribution is primarily aerial on concrete poles, with cables in steel conduit in central business areas like Kobe.

The overall performance of power systems, as measured by the extent and duration of disruption, was very good. 
Service was restored to most customers who could use power about one day after the earthquake. This earthquake indicated that if sites are subject to liquefaction, it is important that flexible bus be used with liberal, but manageable slack. Transformer anchorage frequently failed. There was relatively little damage to high voltage substations as compared to what was observed in the Loma Prieta and Northridge earthquakes. The subsidence of substation sites appears to have contributed to the failure of bushings connected to vertical conductor drops, as little slack is typically provided. There was uniformly high quality use of good design and installation details in station batteries.

Most disruption of power was associated with the damage to the distribution system. Spun, thin-wall concrete poles were severely damaged by ground vibrations, subsidence in liquefied soils, and secondary damage when hit by falling houses. There was extensive damage to conduit in downtown Kobe due to ground deformation associated with liquefaction, but cable in the conduit was generally undamaged.

\section{Telecommunications}

The telephone communication system is dominated by Nippon Telegraph and Telephone Corp. (NTT), although independent companies are now providing long-distance services.

Welded steel conduit is exclusively used in Japan as current measures for improving the earthquake resistance of conduit joints. This is in contrast to the United States, where plastic conduit is used. Central offices are connected by optical fiber, copper cable and microwave trunks. Tunnels are used to carry communication trunk lines. NTT has two types of tunnels: bored or shielded tunnels make up $60 \%$ of the tunnel system, and cut and cover tunnels make up the other $40 \%$. In addition, there are joint utility tunnels built by the government that have separate sections for communication, power, and gas lines that are paid for by a utility tax. These tunnels are costly, but are encouraged by the government because they reduce the impact of surface transportation caused by the installation of tunnels or repair of buried lines.

There was relatively little service-disrupting damage to central offices. Emergency power was disrupted due to the loss of water at central offices, which caused the loss of service to 285000 lines. There was extensive damage to outside plant. A massive restoration effort was required to restore service and the restoration of conduit and other facilities continues, two months after the earthquake. Total cost of damage from the earthquake is estimated by NTT at $\$ 3$ billion.

\section{Hospitals}

The investigations of hospitals focused on the impact of lifeline disruption on hospital operations. The Kobe Medical College of the University of Kobe was visited. A limited amount of 
information about the Hyogo Medical Center was also obtained through a brief interview.

The quality of lifeline facilities and their installation, from an earthquake engineering perspective, was very high as compared to U.S. installations. Few U.S. hospitals would have a large emergency water supply as existed at Kobe Medical College. The loss of water had a large impact on hospital operations. The loss of water disabled one generator at the hospital and caused the loss of all emergency power at another medical facility. The dependence on gas for food preparation was disruptive to hospital operations.

\section{$\underline{\text { FIRES }}$}

The earthquake resulted in 148 fires in the Kobe city area, between January 17 and 20. Approximately $660000 \mathrm{~m}^{2}$, occupied by more than 6900 buildings, were damaged by fire. Due to the large number of simultaneous fires, disrupted water supplies and blocked roads, fire fighting efforts were largely ineffective. The fire spread was limited primarily by wide roads, open spaces, noncombustible walls, fire resistive building construction and favorable weather conditions.

The earthquake demonstrated the potential for significant fire damage following an earthquake even though favorable weather conditions kept fire intensities relatively low and helped to limit fire spread. New fire ignitions and spread continued for days after the earthquake as a result of electric power restoration and the need for open fires by earthquake survivors.

\section{OBSERVATIONS AND CONCLUSIONS}

Some key observations and conclusions are summarized below.

\section{Seismology, Geology, and Geotechnical Issues}

The earthquake reemphasized that moderate to large earthquakes directly beneath densely urbanized areas can cause catastrophic loss of life and property.

Proximity to the earthquake crustal-rupture zone Strong-motion recordings show that peak acceleration values attenuated from values greater than $0.8 \mathrm{~g}$ near the source zone to values less than $0.25 \mathrm{~g}$ at some sites at distances near $20 \mathrm{~km}$ on firm soils. This rapid attenuation of strong shaking appears to have been an important factor influencing the confinement of damage primarily to the Awaji Island, Kobe City and Nishnomiya areas.

Amplification effects of soft-soil deposits The amplification effects of Holocene soil deposits appear to have contributed to increased peak amplitudes and duration of strong shaking at many sites. The increased levels of shaking contributed to direct structural failures and liquefaction induced ground failures.

Liquefaction susceptibilities of reclaimed land and soft soil deposits From the 
geotechnical viewpoint, the liquefaction of about $17 \mathrm{~km}^{2}$ of land underlain by artificial fill highlights the seismic hazard of loose sandy soils. The experience during the 1995 earthquake reaffirmed the proclivity of areas built on these fills for large permanent ground deformations when they are strongly shaken. Many artificial fills in coastal and river areas of the United States are similar to the loose sandy fills in Kobe, which performed so poorly. Much artificial land has been created in the United States by dredging or dumping sand into open water without compaction. These older fill areas in ports and harbors, both in seismically active areas and areas of low seismicity, are vulnerable to earthquakes. As the 1995 earthquake demonstrated, this vulnerability can extract a steep price when these areas are strongly shaken.

\section{Buildings}

The earthquake offers an excellent opportunity to reflect on several general issues.

Poor performance of traditional wood frame houses The majority of the casualties in this earthquake were caused by the collapse of old Shinkabe and Ohkabe houses made of wood. They were built primarily to support gravity loads. Many severely damaged houses had heavy ceramic roof tiles set on soil as bedding, which contributed a great deal to their collapse.
Damages to older reinforced concrete buildings Many older reinforced concrete ( $\mathrm{RC}$ ) moment frame buildings experienced full or partial floor collapses. The damaged low to mid-rise $\mathrm{RC}$ buildings that were observed could easily have been U.S. buildings that were constructed in the 1950's and 1960's, particularly in zones of low to moderate seismicity. The large amount of damage that occurred in Kobe points out the high vulnerability of these older, poorly detailed structures. These older and less ductile RC structures will require significant rehabilitation to be made less vulnerable.

Good performance in new $R C$ buildings No evidence of collapse in any of the newer (post-1981) engineered RC structures was evident. The 1981 Japanese code improvements is quite similar to the intent of current U.S. building codes that focus on life safety, or collapse prevention, in the one-time severe seismic event. This earthquake is a vindication of the current code philosophies in both countries and the technical changes that have occurred in those codes as a result of the RC research since the early 1970's in both the United States and Japan.

Performance-based design philosophy A somewhat more subtle issue regarding new construction is whether there should be standards that provide better building envelope integrity than the basic one-event life safety standard that we have today. The event should fuel further clebate about weighing initial construction costs against potential 
future earthquake losses.

Avoiding stiffness or mass irregularities Many older building collapses could be at least partially attributed to the presence of "soft-stories" as weak links.

Performance of steel frame structures Although there was extensive damage in many of these structures, particularly low to mid-rise apartments and offices, few collapsed and egress means were maintained. The extensive base metal and weld failures observed at the AHST complex in Ashiya City echo problems first observed in steel structures in the United States following the January 17, 1994 Northridge earthquake.

\section{Highways and Bridges}

Lessons for bridge design in central and eastern United States The predominant type of bridge in Japan is the steel girder superstructure supported by bearings on concrete columns and foundations. This class of bridge is also found throughout the central and eastern United States. Bridges in California tend to be concrete box girders with monolithic bents and integral abutments especially in shorter bridges. The performance of Japanese bridges is thus of particular relevance to states east of the central and eastern United States.

The difference between the maximum credible earthquake and the design earthquake is clearly very large for this region of Japan, which is a situation that also exists in the eastern and central United States.
The closure of arterial highways and bridges affects emergency relief and business recovery and can have a major economic impact on a region and its ability to survive such a disaster. Capacity design procedures, ductile details and generous seat widths are necessary to prevent catastrophic collapse during large earthquakes. Critically important structures must be designed to a higher level of performance than that provided by current specifications, if full service is to be maintained after a large earthquake. Lateral spreading due to liquefaction can lead to span collapse even in modern structures with massive foundations (caissons) and well-engineered fills.

\section{Railways and Rapid Transit System}

\section{Damage to elevated structure sections} Rail services suffered more damage along the elevated structure sections than along the elevated embankment sections. Most damage to the elevated structures occurred at columns either at the bottom of superstructures or at a joint region. The damage was similar to unretrofitted column damage observed in past California earthquakes.

Better performance of Port and Rokko Liners The Port Liner and the Rokko Liner were built with modern codes. But they did suffer localized failures.

Need for systematic retrofit techniques for $R C$ structures With the vast amount of elevated old RC structures in need of repair and retrofit, systematic and cost effective retrofit techniques is needed. 
Collapse at the Daikai Station The failure of the Daikai Station is the first instance of catastrophic earthquake damage to a modern cut-and-cover subway station. Shear distortion and vertical accelerations apparently led to collapse of the center reinforced concrete columns at the Daikai Station. The lack of significant confining steel at failed reinforced concrete columns suggests that attention to confinement and ductility can play an important role in strengthening underground structures against earthquake effects.

\section{Airports}

Good performance of airport facilities at Kansai Airport The braced frame structural system in the recently completed Kansai control tower appears to have an effective seismic design, but it has not yet been put to a severe test. The leveling system provided in the basement of this building is an innovative approach to provide for the possible uneven ground settlement that may be caused by liquefaction or consolidation. The use of interior columns to support the roof of the cab in the Kansai control tower did not appear to be a significant visual impediment. Its use in the United States should be explored to reduce earthquake window damage frequently observed in this country.

Ports and Harbors

Severity of damage Loose sandy fills have been widely used in both the United States and worldwide to reclaim ground for port development and expansion. The earthquake illustrates once again the potential for these fills to liquefy and generate large permanent ground displacements when shaken by earthquakes. It further illustrates the ability of such liquefaction to totally disable a port.

Ground improvement of loose sandy fills The localization of lateral spreading around the margin of the Port and Rokko Islands suggests that the hazard of permanent horizontal ground deformation can be substantially reduced by improving only the outer margins of these loose fills. Modern pile-supported structures on Port and Rokko Islands performed well.

Consideration of multi-style of design By repeatedly using the same type of quay wall designs that were vulnerable to lateral spreading, operation of the entire port was left vulnerable to this hazard.

\section{Water and Wastewater Systems}

\section{Overwhelming Conditions Utility}

decision makers need to be thinking in terms of consequences similar to the Kobe event. For example, what happens when you have no records because all utility buildings are destroyed or become inaccessible? What happens if the plan is to dispatch crew to isolate critical pipelines to save water or shut off natural gas, but the fastest way to get there is by walking?

Water Supply for Fire Fighting The use of monitoring and control systems should 
be considered to enable the timely control of a water system following an earthquake to increase the probability of delivering water to suppress fires. Water purveyors and fire departments should use permanent ground deformation mapping to identify areas where pipelines will likely fail so that plans can be made to isolate damaged areas and/or use alternate water supplies.

Geotechnical Issues In Kobe, geotechnical failures governed the poor performance of the water system.

Landslides, consolidation, and liquefaction or lateral spread stopped the flow of water from the source; damaged two major and one small water treatment plants; and tore the distribution system apart.

Recovery The three Kobe Water Department buildings storing records were destroyed or damaged to limit access. The probability of this occurring is very low. In the United States, we should make sure that our resources are distributed so that the loss of any one facility will not substantially impact our ability to respond to an earthquake.

\section{Gas Delivery System}

Coordination in restoration process In Kobe, it appears that there was no prearranged coordination between gas and electric company personnel to restore electric service in concert with shutting off and venting gas in areas severely damaged by the earthquake. It appears that early restoration of electric power in some areas of Kobe with leaking gas may have contributed to additional fires.

Emergency plans should be developed and specific, formal communication procedures should be established between gas, electric power, water supply, and fire department personnel.

Gas service restoration can be a timeconsuming process Restoration of gas service can be difficult and timeconsuming and is especially critical in winter, as it was in Kobe. It may be advantageous to provide for remote control and other rapid means, such as through microzonation, for isolation of smaller, more manageable areas of the gas system. Hazard mapping and scenario earthquake planning can be especially valuable to identify and isolate troublesome areas.

\section{Electric Power}

Poor performance of high voltage bushings Leaks and porcelain failures of transformers and circuit breaker bushings has contributed to the poor seismic performance of high voltage substation equipment in the United States and Japan.

Flexible couplings for transformer radiators The use of flexible couplings in piping connections of the transformer radiator to the transformer body may reduce problems with leaks observed in the United States.

Better performance of instrumentation transformers The performance of instrumentation transformers in Japan 
appears to be better than in the United

States. Some units acted as lower restraints to suspended wave traps, and still performed better than those in the United States.

Need for adequate slack At potentially liquefiable sites, the need for adequate slack was demonstrated. Slack needs to be provided in vertical drops at sites that are vulnerable to subsidence.

Performance of concrete poles The use of concrete poles appear to increase the vulnerability of the aerial distribution system. In the 1992 Cape Mendocino earthquake over 600 wooden poles were about to be replaced because they were weakened due to dry rot, and none of these failed.

\section{Telecommunications}

Performance of microwave towers A striking feature about communications towers in Japan is their mass construction considering large wind loads associated with typhoons, compared to those constructed in the United States. The damage to Japanese towers suggests that those in the United States are vulnerable, particularly where central offices are built on poor soil.

Effect of loss of water The loss of water to communication facilities and its effect on emergency power further substantiates this vulnerability of U.S. facilities.

\section{Hospitals}

Need for emergency water supply The loss of water supply at Kobe Medical College indicates that hospitals need to establish an emergency water use policy and normal water use in hospitals is well beyond what one could expect in resupply after a major earthquake.

\section{Post Earthquake Fires}

Effectiveness of passive fire protection Passive fire protection systems need to be designed on a city wide basis. A network of wide roadways would serve as fire breaks and provide ample egress and emergency access. Consideration must be given to buildings which border the egress routes and its components such as bridges. The buildings should be designed to withstand earthquake forces and should be built of noncombustible materials.

Effectiveness in using wire glass exterior windows Wired glass exterior windows appeared to be effective in reducing the fire spread. These windows with small gauge wire are common in Japan but are rare in the United States.

Alternative water delivery systems Alternative water delivery systems need to be developed and utilized. One such system might consist of caches of high volume, diesel powered (or other independent power supply), portable pumps located near natural sources of water around the city. 
Fire fighting with aircraft Fire fighting with aircraft dropping water or Class A foam should be examined. Although aircraft dropped water cannot attack interior fires it may be effective on fires in rubblized buildings. Fire fighting from the air may be a method of overcoming the problem of accessing the fires due to blocked roads.

Information regarding preparation for post earthquake fires Information necessary for residents to prepare for postearthquake fires needs to be further developed and disseminated to the public.

\section{RECOMMENDATIONS FOR RESEARCH}

Research needs in each of the technical areas are identified as follows:

Seismology, Geology, and Geotechnology

Availability of strong-motion data set in soft-soil deposits The large set of recordings on Holocene soil deposits provides a unique set of in-situ measurements of the response of softsoil deposits at high input ground motion levels. These data provide a potentially important data set for research on: (a) the location and nature of the crustal-rupture process, (b) development of an improved understanding of the response of softsoil deposits at high input ground motion levels, and (c) improved estimates of the response of soft-soil deposits for purposes of code revisions and site-specific design analyses.

The extensive lateral spreading around - the margins of the artificial fills placed in Osaka Bay provides an opportunity to clarify the mechanism of horizontal ground displacements associated with soil liquefaction. The widespread damage to engineered works should permit documentation of details of deformation fields associated with lateral spreading. This understanding should improve the design of countermeasures to minimize the impact of liquefaction on engineered works. Areas of ground improvement need to be documented. Evaluation of the performance of these areas should increase confidence in our ability to reduce the hazard from liquefaction of sandy soils.

\section{Buildings}

Improvement of performance of existing $R C$ buildings The most urgent research need for RC buildings is the extensive research on seismic vulnerability assessment, rehabilitation, and retrofit for older, non-ductile RC moment frame and shear wall buildings. Rehabilitation techniques need to be cost-effective and nonintrusive for building owners and users. Research into less traditional techniques for rehabilitation, such as supplemental energy dissipation and the use of newer structural composites, should be conducted.

Steel frame structures The behavior of heavy steel frame highrise structures under strong low cycle lateral loading should be examined. Given the wealtl 
of data concerning the design

procedures, weldment details, and material specifications for the AHST complex in Ashiya City, research should be conducted into the behavior of builtup steel column sections and truss weldments under very low cycle fatigue. This would augment research programs already underway in the United States following the Northridge earthquake.

Highways and Bridges

Study of bridges with strong-motion records Conduct correlation studies on those bridges with strong motion records to calibrate theoretical models against actual behavior. Valuable insight into the performance of these two important types of bridges would be derived from such studies.

Case studies of steel bearings and earthquake couplers Develop a detailed database on the performance of steel bearings and earthquake couplers (restrainers) followed by case studies on selected bridges in which these devices failed. Results from such a study would help determine the need for a review of current U.S. design criteria for connection forces and restrainers.

Study of superstructure-foundation interaction Analyze structural response due to large foundation movements during liquefaction and lateral spreading and the development of optimum mitigation measures to minimize structural impacts.
Performance of retrofitted bridges

Perform case studies on those bridges that had been retrofitted before the earthquake to determine the effectiveness of the retrofit measures.

Development of performance-based design approach Develop multiple-level performance criteria which define expected damage and serviceability states for various earthquake scenarios and the corresponding design strategies/structural options necessary to satisfy these criteria.

Study of bridges with steel substructures The relatively large number of damaged steel substructures provides an opportunity to calibrate proposed new methods for the seismic design of steel bridge columns. In particular, their capacity for ductile actions and the identification of their limit states should be investigated with the objective of refining the R-factors in the U.S. bridge codes for these components.

\section{Railways and Rapid Transit System}

Ductility study between $R C$, Steel, and $S R C$ columns Because of the low redundancy of single column structures, the structural layout and substructure performance becomes more important for those structures than for structures with multiple column bents. Research is needed to compare the ductility between reinforced concrete, steel and steel reinforced concrete composite columns. A damage index should be developed to assess the repairability of columns after an earthquake. Force levels 
encountered at collapse sites should be compared to current U.S. design forces to validate current designs.

Study of transient shear distortion The severity of racking in underground structures resulting from strong motion with high amplitude and relatively long periods needs to be understood better, and the combined effects of racking and high vertical accelerations needs additional clarification.

Study of differential lateral movements Site response needs to be investigated in terms of differential lateral movements which occur during earthquake loading at sites with thick deposits of soft to medium clay and loose sand. The effects of depth and soil liquefaction on soil shear distortion and structural racking also need further research.

\section{Airports}

Development of methods for improving the performance of control towers The Kansai Airport control tower incorporated columns in their design that did not appear to significantly adversely effect the functionality of the tower. Practical methods are needed to upgrade these towers in a way that will not interfere with the function of the towers.

\section{Ports and Harbors}

Better design and construction of quay walls The extensive damage to the quay walls that disabled the port operations indicates that the failure mechanism of these structures needs to be understood. The localization of lateral spreading near the quay walls suggests that only

- portions of the fill need to be improved. The development of such guidelines would facilitate remedial efforts at other ports with similar exposure.

Study of ground deformation due to liquefaction The large vertical settlements observed in sandy fill during the earthquake also provide an excellent opportunity to develop a case history of ground deformation associated with liquefaction.

\section{Water and Wastewater Systems}

Study of water treatment plant design In general, water treatment plants and service reservoirs performed well. We should study Japanese design approaches for these facilities. Their tank designs are somewhat different from those used in the United States and apparently had no damage when subject to high peak ground acceleration.

Study of the performance of S-joint pipe Pipelines were heavily damaged, except that preliminary information on performance of the ductile iron $S$ joint pipe indicates that it had no or few failures. If it is confirmed, we should introduce it to the United States. If it did not perform well, we should find out why, and improve U.S. pipe design based on those findings. 
Gas Delivery System

Study of interaction among lifelines Of special importance is the relationship between gas system disruption as a potential source of flammable substances and the damage to and restoration of electric power as a potential source of ignition. There is a need to evaluate and optimize the use of water and fire protection relative to gas and electric system vulnerabilities and operational characteristics.

Performance of intelligent gas meter The performance of the intelligent gas meter should be investigated to provide a more complete database with respect to the earthquake operation and effectiveness of seismic gas sliutoff valves.

\section{Electric Power}

Study of the performance of transformers and circuit breaker bushings The performance of transformers and circuit breaker bushings in the United States and Japan is just the opposite of each other. That is, in Japan circuit breaker bushings failed due to slipping and transformer bushings did not. Study should be conducted to find out wliether there is a difference in design and installation procedures in the two countries.

\section{Study of failure mechanism of bolted} transformers Several bolted transformers moved, even though they appeared to have substantial anchorage. While new transformers are typically welded to embedments in the United States, bolts are often used for retrofit. The design and actual loads on the equipment that failed and the cause of the anchorage failures should be evaluated.

Study of the performance of instrumentation transformers It would be interesting to explore the reasons for the relatively good performance of instrumentation transformers in Japan as compared to those in the United States. While these components appear to be larger in Japan, they also appear to be supported on more rigid structures. The differences in design and installation should be explored.

Study of substation performance with respect to strong-motion records It would be very beneficial to review the performance of equipment at these sites using the response spectra for the site and more detailed information that derived from site conditions.

\section{Telecommunications}

Study of the performance of outside plant There is a need to get a better understanding of practices used for outside plant in Japan and to review in detail their earthquake performance. The collection and analysis of this data on outside plant damage can provide insight into the outside plant in the United States, particularly in the Midwest where liquefaction is expected to be a serious problem. 


\section{Hospitals}

Review to establish guidelines for minimum levels of service for each lifeline There is a need to review lifeline needs at critical facilities, such as hospitals, and establish guidelines for minimum levels of service for each lifeline. Alternative facilities and equipment that can mitigate the effect of the loss of lifeline service should be evaluated and guidance provided to facility designers.

\section{Post Earthquake Fires}

Passive fire protection systems There is a need to examine current construction requirements for fire resistive buildings, especially the protection of openings such as windows and doorways. Special efforts should be taken toward materials or systems which could be retrofit to existing structures. The concepts of fire resistive egress corridors for cities should continue to be investigated.
Alternative water supplies and delivery systems Wildland fire agencies utilize a wide variety of methods to move water to the fire location. Their methods should be examined for applicability to an urban conflagration.

Predictions of post-earthquake fire losses Case studies of the fire propagation and the fire suppression activities from this earthquake could provide a basis for further post earthquake fire model development. 



\section{CHAPTER 1}

\section{INTRODUCTION}

\subsection{Impact of the Earthquake}

The January 17, 1995 earthquake of magnitude 7.2 in JMA scale (Japan Meteorological Agency) or $\mathrm{M}_{\mathrm{w}}=6.9$, which struck the northwest, north, and northeast shorelines of Osaka Bay near Kobe, Japan, was the most severe local earthquake to affect the region this century. The earthquake resulted in the worst natural disaster since the 1923 Great Kanto earthquake devastated Tokyo and Yokohama. Several names have been used to refer to this earthquake, including the Hygoken-Nanbu earthquake, the Great Hanshin earthquake, the Hanshin-Awaji earthquake, or simply the Kobe earthquake. This report uses the "Hyogoken-Nanbu (Kobe) earthquake" which is the official name now being used in Japan. It also highlights Kobe, which was devastated by the earthquake.

The earthquake resulted in more than 6000 fatalities and over 30000 injuries. Nearly 150 fires following the earthquake incinerated the equivalent of 70 U.S. city blocks. Together they destroyed over 150,000 buildings and left about 300000 people homeless. The total loss, including direct and indirect and economic losses, of this earthquake is estimated to reach $\$ 200$ billion, making it the costliest earthquake in the world thus far, and its impact has been felt worldwide.

Kobe and its surrounding area is about 50 $\mathrm{km}$ long east-west and about $1.5 \mathrm{~km}$ to $6 \mathrm{~km}$ wide north-south with Rokko Mountain to its north, peaking at about $1000 \mathrm{~m}$ above sea level, and Osaka Bay to its south. This narrow piece of coastal plain is heavily urbanized and industrialized. It is a modern urban setting with a population of about 15 million (about $15 \%$ of the total Japan population). It is the third largest port in the world and handles about $20 \%$ of Japan's total trade. Most of the port consists of three man-made islands: Port Island, Rokko Island, and Maya Terminal. The region is served by a number of modern transportation systems, such as the bullet trains, railways, expressways and elevated highways, new tram systems, ferries, and rapid transit systems. It is also served by modern utility systems for water, wastewater, electrical power, gas and telecommunications.

The earthquake brought the region's livelihood to a standstill. Houses and buildings were destroyed and surface transportation systems paralyzed.

Emergency response and search and rescue operations had to be carried out under extremely difficult conditions. Water line breaks cut off water for fire fighting. The loss of electricity and telephone communication put majority of residences in the region into total darkness.

The weeks and months after the earthquake brought out further problems for the local authorities, transportation agencies, and utility companies. Traffic jams became a normal part of the daily routine and for a while walking was the best way to get from point "A" to point "B". The authorities tried to bring public transportation systems back to functioning as soon as possible; however, removing the debris from fallen houses and buildings and damaged highway bridges 
became a monumental problem. Schooling had to be suspended temporarily because many of the school buildings had to be used as shelters.

Utility crews worked around the clock to repair broken water and sewage lines, down power and telephone poles, and leaking gas lines. Because of the lack of pre-earthquake planning, often these activities had to be carried out haphazardly. In fact, it is believed that early restoration in electricity to some parts of Kobe City was responsible for the ignition of additional fires after the initial burst of fires immediately following the earthquake.

Reclaimed lands along the shoreline of Kobe City settled significantly during the earthquake. Liquefaction and lateral spreading were the two most prominent factors contributing to the damage from this earthquake in areas of reclaimed ground. Restoration of the port facilities is estimated to take a couple of years to complete. Kobe was a hub port. Some of hub business went to Hong Kong and Seoul, Korea.

Meanwhile, goods have to be transported to other neighboring ports and harbors and then through surface transportation to reach factories in Kobe. This could turn out to be a permanent loss of business; it remains to be seen how much of its original share of business the Kobe Port can recapture once it is again open for traffic.

The earthquake also brought out some of the best qualities in human beings, as evidenced by the outpouring of support and assistance from other communities. Water trucks brought in drinking water through mutual aid arrangements. Tens of thousands of utility and construction workers from all over Japan participated in the restoration of lifelines. Unfortunately, the earthquake also highlighted the helpless expressions on the faces of search and rescue workers; something that has been witnessed in every recent natural disaster.

This earthquake was the first earthquake in recent history that occurred directly underneath a modern urban city and resulted in unprecedented damage and economic loss. Nevertheless, it provided an unprecedented opportunity to learn many valuable lessons that can help prepare us to reduce the devastating effect from future earthquakes.

Exactly one year previous to this earthquake, the Northridge earthquake occurred in Southern California with a similar magnitude $\left(M_{w}=6.8\right)$. The epicenter of the Northridge earthquake was about $30 \mathrm{~km}$ northwest of downtown Los Angeles. The occurrence of these two earthquakes in a span of one year offered a unique chance to compare and contrast the impact of an earthquake on the built environment developed by two different countries, half a globe apart. Many of our cities have a geographic setting which is similar to the City of Kobe, i.e., narrow strip of coastal land, soft soils along the shore, and congested urban buildup and transportation systems. These cities include Seattle and Tacoma, Washington; San Francisco Bay, Long Beach, San Diego, California; along the west coast; as well as New York City; Boston, Massachusetts; Charleston, South Carolina; and Memphis, Tennessee; all located in the eastern and central regions of the United States. The nature of devastation on Kobe by this earthquake is perhaps even more relevant to the cities in the eastern and central United States. This is because the difference between the maximum credible earthquake and the design earthquake is very large for the Kobe region of Japan; a situation that is also considered to exist in the eastern and central 
parts of the United States. Bridges in these parts are more like those in Japan than those in Califorynia, therefore the performance of Japanese bridges is of particular relevance.

Adding to the vulnerability of these regions is the fact that urban areas in eastern and central United States are much older than the region where the earthquake hit (Kobe was rebuilt after World War II). Most of the buildings and lifeline systems were constructed without the benefit of modern seismic design. The Kobe earthquake can serve as wakeup call to the communities in these U.S. regions to begin a concerted effort to prepare their communities to reduce the impact from future disasters.

\subsection{Overview of Report}

After the earthquake, the National Institute of Standards and Technology's Building and Fire Research Laboratory (BFRL) dispatched an advance team of three BFRL members, followed by a larger team of 18 members made up of individuals from a number of federal agencies and others affiliated with national earthquake engineering research centers. The teams were to observe, document, and summarize important lessons from this earthquake. These lessons can be utilized to mitigate the potential tragic impact of future earthquakes on urbanized communities around the world, especially urban centers in seismic-prone areas of the United States.

This investigation was carried out under the auspices of the U.S.-Japan Cooperative Program on Natural Resources (UJNR) Panel on Winds and Seismic Effects. The panel's U.S. effort is led by NIST and its counterpart in Japan is the Ministry of Construction's Public Works Research Institute (PWRI). It was the extraordinary efforts of the colleagues at PWRI and its sister agencies in Japan that made the team's investigation trip a success.

The 18-member team was in Japan from February 12 to February 18 . The investigation was carried out by dividing the Team into five groups, each focusing on one or two special technical areas. These groups were:

- Seismology/Geology

- Buildings

- Transportation

- Lifeline/Geotechnology

- Fire

Team members and their assignments are given below:

- Seismology/Geology

Roger Borcherdt, Thomas Holzer

- Buildings

William Stone, John Hayes,

H.S. Lew, E.V. Leyendecker,

Jack Moehle, M.P. Singh,

James Wilcoski

- Transportation Systems

James Cooper, Ian Buckle,

Michael Whitney, Li-Hong Sheng,

Andrew Taylor

- Lifelines/Geotechnical

Riley Chung, Donald Ballantyne, Thomas Holzer, Thomas O'Rourke, Anshel Schiff

\section{- Fires}

Daniel Madrzykowski, Edward Comeau

The team was briefed by staff of the hosting agencies upon their arrival. They then launched a three-day intensive field investigation, working together with their Japanese colleagues. 
To every team member, the visit to Kobe and the area devastated by the January 1995 earthquake will be a lifelong experience. It was through this visit that we came to appreciate the awesome power of nature, that we came to have direct understanding of what mitigation measures worked and what did not, that we also came to feel for those families whose lives were dramatically altered as the result of the earthquake. The visit also provided us with another reminder of our responsibilities to help our society better prepare for future earthquake events.

The report is divided into seven chapters. Chapter 2 addresses issues related to seismology, geology, and geotechnology. Chapter 3 assesses the performance of various types of buildings, old and new. Chapter 4 takes a close look of the performance of different types of transportation systems. Chapter 5 examines the impact on the community by the disruption of utility systems; water and wastewater, gas, electric power, and telecommunications. It also reviews the performance of hospitals in Kobe. Chapter 6 studies the operation of fire suppression following the earthquake. And finally, Chapter 7 summarizes the lessons and conclusions learned from the investigation and lists research that the earthquake community should undertake in order to learn from this earthquake to reduce future losses. 


\section{CHAPTER 2}

\section{SEISMOLOGY, GEOLOGY, AND GEOTECHNICAL ISSUES}

\subsection{Source Characteristics}

The Hyogoken-Nanbu (Kobe) earthquake of January 17, 1995 (5:46:52 JST) occurred in an area of complex faulting located near Awaji Island and the Hanshin area of Japan (34.607 N, $135.043 \mathrm{E}$, depth $14.3 \mathrm{~km}$; Japan Meteorological Agency, JMA). The area which is near the urban centers of Kobe City and Osaka is located about $250 \mathrm{~km}$ from the Nankai trough, which forms the boundary between the Philippine Sea and Eurasian plates (Figure 2.1.1). The earthquake of magnitude 7.2 (JMA) is the most severe earthquake to affect the region this century. The largest previous earthquake near Kobe City was a magnitude 6.1 which occurred in 1916 on or near the same fault. Other large but distant earthquakes occurred in 1944 and 1946 along the plate boundary (Figure 2.1.1). Numerous faults known to be active in the Quaternary extend throughout the affected region (Figure 2.1.2). However, prior to January 17,1995 the area was characterized by relatively low seismicity compared with areas near the plate boundaries (Figure 2.1.1). This 1995 earthquake having occurred at considerable distance from the plate margin, can be considered an intraplate event.

Coseismic crustal rupture associated with the earthquake initiated on the Nojima fault located on Awaji island. The rupture extended to the ground surface along a $9 \mathrm{~km}$ segment of the fault on Awaji Island.

Maximum surface displacements of $1.7 \mathrm{~m}$ right-lateral, horizontal and $1.0 \mathrm{~m}$ vertical were observed [T. Masaharu, personal communication, 1995]. No surface rupture associated with the fault system had been confirmed in Kobe City.

Aftershocks during the first 10 days suggest a rupture surface extending between $35 \mathrm{~km}$ and $50 \mathrm{~km}$. Comparison of the seismicity pattern with mapped surface faults suggests that the rupture zone extends about $46 \mathrm{~km}$ from about $19 \mathrm{~km}$ southwest of the epicenter to about $27 \mathrm{~km}$ northwest of the epicenter. The aftershock locations suggest the rupture zone slightly increases in average depth to the northeast. The shallowest seismicity occurred beneath Awaji Island and downtown Kobe City.

Source rupture characteristics inferred from teleseismic and regional data by Kikuchi [1] suggest three subevents (Figure 2.1.3, Table 2.1.1). The subevents are inferred to have moment magnitudes of $6.8,6.3$, and 6.4 and predominantly strike-slip source mechanisms. Relative locations of the subevents (Figure 2.1.3) suggest the third subevent is located beneath Kobe City near the region of shallow seismicity apparent in the aftershock distribution. The source mechanism inferred by Kikuchi suggests that rupture for the first subevent was bilateral, then the rupture proceeded unilaterally with the two subsequent events in a northeasterly direction beneath Kobe City. Duration of total rupture is about 11 seconds with average depth inferred at $8 \mathrm{~km}$. Hypocentral depth or depth of rupture initiation is $\mathbf{1 4 . 3}$ $\mathrm{km}$.

Comparison of source characteristics for the Loma Prieta $\left(M_{s} 7.1, M_{w} 6.9\right)$ and Northridge $\left(M_{s} 6.8, M_{w} 6.7\right)$ earthquakes suggests the Hyogoken-Nanbu earthquake $\left(M_{s} 7.2, M_{w} 6.9\right)$ is about the same 
magnitude, but slightly longer rupture duration (11 seconds as opposed to 6 to 8 or 9 seconds for the other events). The rupture mechanism is predominantly strike slip or horizontal for the Hyogoken-Nanbu

\section{The rupture mechanism for the} Hyogoken-Nanbu Earthquake is predominantly strike-slip or horizontal compared to relatively larger vertical motion associated with reverse and thrust faulting for the Loma Prieta and Northridge Earthquake.

earthquake compared to relatively larger vertical components of motion associated with reverse and thrust faulting for the Loma Prieta and Northridge earthquakes. The average depth of rupture and hypocentral depth for the Hyogoken-Nanbu earthquake are less than those for Loma Prieta and Northridge earthquakes. Rupture for the Hyogoken-Nanbu earthquake reached the surface on Awaji Island and may have come within $4 \mathrm{~km}$ of the surface beneath Kobe City. Rupture was inferred not to extend closer than $6 \mathrm{~km}$ to $8 \mathrm{~km}$ of the surface for the Loma Prieta and Northridge events.

\subsection{Regional Geologic Stratigraphy}

Southwestern Japan is geologically divided into the "Inner Zone" and "Outer Zone" by the east-west trending Median Tectonic Line, a major structural and lithologic geologic boundary. Kobe lies in the Inner Zone about $60 \mathrm{~km}$ north of the line. The geology and geologic history of the Kobe region have been described by Huzita and Kasama [6, 7, 8] and Huzita and Maeda [9].

Basement rocks of the Inner Zone chiefly consist of Paleozoic and Mesozoic sediments. In the Kobe region, these sediments are intruded by large bodies of Late Cretaceous granite and granodiorite. These intrusive rocks compose the mountain massif north of Kobe. They consist of the Nunobiki Granodiorite, a medium-grained hornblende-biotite granodiorite, and the Rokko Granite, a coarse to fine-grained biotite granite with pinkish feldspar.

Downwarping within the Inner Zone during the Cenozoic created sedimentary basins bounded by the basement rocks. Kobe sits on the northwestern margin of one of these basins, the Osaka Basin (Figure 2.4.1). This area has subsided at a high rate throughout the Plio-Pleistocene and consequently has accumulated a thick sequence of nonmarine and marine sediment. The Osaka Basin is superimposed on an older large depressional area within the Inner Zone that contains sediment of the Miocene Kobe Group. Formations within this group sporadically cover the uplifted mountainous areas and presumably are the basal part of the sediments filling the Osaka Basin. Members of the Kobe Group range from lacustrine to pyroclastic deposits.

The Quaternary Osaka Group sediments and the overlying alluvium, and the geologic units filling the Osaka basin, are of particular engineering significance in the Kobe area because they underlie most of the urban and industrial development. These sediments are exposed along the foot of the Rokko Mountains and thicken abruptly toward the subsurface of Osaka Bay. They are more than $600 \mathrm{~m}$ thick. The Osaka Group is divided into three subgroups, Lower, Middle, and Upper. These subgroups 
unconformably overlap each other. The Lower Subgroup is of Pliocene age and contains primarily lacustrine facies. The Middle Subgroup is of early to middle Pleistocene age, and contains alternating marine and nonmarine sediment. It unconformably overlies the Lower Subgroup. The Upper Subgroup also locally unconformably overlies the Middle Subgroup. It contains 50-m-thick gravel beds intercalated with marine clay beds. The Upper Subgroup, which is middle Pleistocene in age, is believed to have been deposited during marine transgressions that buried an erosional surface incised into the Middle Subgroup.

The Osaka Group is overlain by up to approximately $80 \mathrm{~m}$ of Late Pleistocene and Holocene alluvium that was deposited in two cycles of deltaic sedimentation. The alluvium in the eastern part of the Osaka Basin beneath the Osaka Plain consists of two coarse-grained layers separated by a marine clay which reaches a thickness of $10 \mathrm{~m}$. The clay bed was deposited during the Holocene global rise in sea level that ended about 6000 years ago, which is known in Japan as the Jomon Transgression. The underlying coarse-grained material is believed to have been deposited following the last major regression before the Jomon Transgression.

Much of the coast in the Kobe and Osaka regions was reclaimed from Osaka Bay by filling. Significant land reclamation occurred in the Osaka region before 1868 and has continued to the present. Land reclamation along the Kobe shoreline occurred later, primarily after 1953. Landfill in the Kobe region is from quarries in the weathered Rokko Granite and the Kobe and Osaka Groups.

\subsection{Geotechnical Overview - Kobe City Area}

Most of Kobe City is built on a narrow 2-km to $3-\mathrm{km}$-wide coastal plain. The landward, or northern, margin of the coastal plain is the Rokko Mountains, and the shoreward margin is Osaka Bay. Soils of the coastal plain divide into two major groups from a geotechnical perspective, natural soils and man-made landfills. The natural soils range from clays to gravels. A lot of the recent growth of Kobe, however, has been on sandy landfills that were dumped into Osaka Bay. In the Kobe area, the predominant rock of the mountain is granite. The granite is intensely sheared and deeply weathered.

Figure 2.3.1 is a generalized soils map of the Kobe area. The inner part of the Kobe coastal plain is underlain by an approximately 2-km-wide zone of soils that were deposited by the streams that discharge from the Rokko Mountains. Near the modern stream channels, soils tend to be coarser grained, frequently containing beds of stream gravels. These stream channel deposits range from $10 \mathrm{~m}$ to $20 \mathrm{~m}$ in thickness. Interchannel areas are underlain by both sandy and clayey deposits. On their southern margin, these alluvial deposits are truncated by a prehistoric shoreline that roughly parallels the modern shoreline. This shoreline is marked by a 4 -m-high erosional scarp. The erosional scarp was cut at the end of the Jomon marine transgression into Osaka Bay. Bayward of this old shoreline is an approximately $1-\mathrm{km}$-wide flat plain that is underlain by alternating littoral sands and lagoonal clays. These sands and clays, which are only a few meters thick, represent postJomon deposition and progradation of the coastal plain.

The floor of Osaka Bay offshore of Kobe is blanketed by a compressible marine clay that 
was deposited during the Jomon

transgression. The clay is up to $20 \mathrm{~m}$ thick in the Kobe offshore area, but thins to about $2 \mathrm{~m}$ near the natural shoreline that existed before the modern landfills were emplaced. The base of the marine clay layer slopes gently bayward (Fig 2.3.1). The water content of the soft clay ranges from $70 \%$ to $100 \%$ and the compression index ranges from 0.2 to 0.6 . Its shear wave velocity is about $180 \mathrm{~m} / \mathrm{s}$. The soft clay is underlain by a complex interbedded gravel, sand, and clay sequence. This sequence was deposited during the low stand of sea level before the Jomon transgression as indicated by multiple layers of peat that have been dated by radiocarbon. They are correlative with the sediments of the inner coastal plain. The thickness of this sequence ranges from $20 \mathrm{~m}$ to $40 \mathrm{~m}$ in the Kobe Harbor area. Field blow counts are highly variable in this sequence, ranging from 10 to 50 . Another marine clay, presumably representing a preJomon sea transgression, underlies the sand and clay sequence. It is about $20 \mathrm{~m}$ thick. Although its water content is slightly lower than the upper marine clay, $40 \%$ to $55 \%$, field measurements of the vertical distribution of consolidation contributing to land-surface settlements on Port Island indicate that approximately 40 percent of the total settlement was caused by compression of the lower clay layer. Figure 2.3.2 shows a representative boring $\log$ from the harbor area.

The compressibility of the marine clays has created two problems for reclamation and construction. Following emplacements of landfills, settlements of about $4 \mathrm{~m}$ have been measured on top of the upper clay surface. Because of the low permeability of the clay layers, settlements are expected to continue for many years. This has prompted the use of pile supported foundations for all heavy structures built on the fill.
The fill used to reclaim ground was obtained from outcrops of the Kobe and Osaka Groups and weathered granite in the adjacent Rokko Mountains. Fill was excavated from several large scrapping areas east and west of Kobe. The first reclamation efforts filled 529 ha along the Kobe City shoreline from 1953 to 1970 . Following these reclamation efforts, Port and Rokko Island were created. Reclamation of Port Island started first and was done in two phases. The first phase, which filled 436 ha, was from 1966 to 1980 . The second phase started in 1986, and increased the size of the island by 390 ha. Rokko Island, which is 580 ha, was reclaimed from 1973 to 1992.

Construction of Port Island is described by Nakakita and Watanabe [12]. Sand fill was dumped in standing water that had an average water depth of $12 \mathrm{~m}$. Filling continued to an elevation of about $4 \mathrm{~m}$ above water level. The upper and lower parts of the fill were placed using different techniques. The lower part of the fill was dumped into standing water from a trapbase barge with no compaction effort to within $2 \mathrm{~m}$ of high water level. It was created in $2 \mathrm{~m}$ to $4 \mathrm{~m}$ thick layers. The upper part of the fill was emplaced by scooping from barges that were moored to the quay wall, transporting to the interior of the island by a movable conveyor, and spreading with modest compaction by rolling. No significant effort was made during reclamation to compact the sandy fill to increase its liquefaction resistance. Preearthquake field blow counts typically ranged from 5 to 10 .

Most of the multistory buildings on Port Island were built on piles to reduce postconstruction settlement. For some of the single-story buildings, slab foundations were used and the fill was improved by vibrocompaction. This technique increased field 
blow counts from an average of about 10 to 22 [8].

\subsection{Strong Ground Shaking}

The Hyogoken-Nanbu earthquake generated an outstanding set of strong motion data.

The data were recorded on stations installed and maintained by a variety of private, government, and university affiliated agencies. Data assimilation and distribution is provided by each agency with coordination provided for several of the agencies and organizations by The National Research Institute for Earth Science and Disaster Prevention of the Science and Technology Agency. All of the data and results reported here have been derived from information supplied by the various agencies and the "Prompt Report on Strong Motion Accelerograms No. 46." A conscious effort has been made to report the results accurately with appropriate credit to the agencies, which made this outstanding data set possible. Any omissions or inaccuracies are not intentional, but some are sure to exist due to language translation difficulties. This compilation is intended to provide an overview of this excellent data set with the understanding that additional and more accurate information should be incorporated to improve the result as it becomes available.

\subsubsection{Strong Motion Recordings}

Locations for the strong-motion stations, superimposed upon the 1:1000000 scale geologic map are shown in Figure 2.4.1. The geologic map was derived digitally from the published map for Japan in digital format on CD-ROM. Coordinates for the stations are given in Table 2.4.1. Coordinates for some stations were provided by the agencies and for others, inferred from projected map images. The locations inferred from map images are considered least accurate and should be updated, when additional information becomes available. Projection of available maps is expected to have introduced location errors in general less than $100 \mathrm{~m}$; however, other sources of error may have contributed to larger uncertainties for some sites.

Station identification and various measures of distance and peak amplitude data are tabulated (Table 2.4.1). Measurements exceeding full scale at two stations are indicated. Measurements reported by the Committee on Earthquake Research and Observation in the Kansai region were detected with velocity transducers. Peak accelerations reported by the Railway Technical Research Institute [10] and Osaka Gas represent the maximum value of the vectorial sum of the two perpendicular horizontal components. Other agencies report the maximum value of the three orthogonal components, while others report the maximum value of only the horizontal components. An effort has been made to tabulate peak horizontal values (PGA in Table 2.4.1) as reported by the individual agencies. It is not possible at this writing to resolve all of the differences in reported values; rather, resolution of these differences as additional information becomes available is needed to reduce uncertainty.

Conclusions derived from these data should account for variations due to differences in reported values, differences in the types of instrumentation, and possible uncertainties in station locations.

The strong-motion data from the HyogokenNanbu earthquake provides an exceptional set of near source measurements of strong shaking. The mapped locations of the stations indicate that 20 measurements are within $20 \mathrm{~km}$ of the surface projection of the 
inferred rupture surface. Twelve of the stations are within about $10 \mathrm{~km}$. About $60 \%$ of these three-component measurements are located on relatively soft soil deposits of Holocene age. Measurements at 10 sites indicate peak ground shaking was near or exceeded $0.5 \mathrm{~g}$ and reached levels exceeding $0.8 \mathrm{~g}$ at two sites. The measurements represent the first extensive set of nearsource measurements on soft soils. As such, they provide an important data base for inferring strong shaking on soft soils near the source of future strike-slip earthquakes.

The strong motion data from this earthquake provides an exceptional set of near source measurements of strong shaking. Measurements at 10 sites indicate peak ground shaking was near or exceed $0.5 \mathrm{~g}$ and reached levels exceeding $0.8 \mathrm{~g}$ at two locations.

Record sections showing the north-south, east-west, and vertical components of motion as recorded at stations located at increasing distance from the fault are shown in Figure 2.4.2. These recordings, shown with the same amplitude scale, indicate a well-defined velocity pulse near 1 second period. They suggest that the peak amplitude of ground velocity decreases rapidly within the first few kilometers of the projected surface rupture, with the duration of shaking extended from about 11-15 seconds for a site on Pleistocene deposits (KC-KBU) near the source to more than 60 seconds at several sites on Holocene soil deposits (see e.g. sites KC-FKS, KC-YAE, $\mathrm{KC}-\mathrm{SAS})$.
Acceleration, velocity and displacement time histories as derived by Nakamura [13] for four locations are reproduced in Figures 2.4.3a through $2.4 .3 \mathrm{~d}$. These analyzed versions illustrate effects of source rupture, wave propagation and local geology on the resultant motions. Corresponding response spectra are provided by Nakamura [13].

The acceleration time histories recorded at the Kobe Ocean Meteorological Station JMKBM) are shown in Figure 2.4.3a. The peak acceleration amplitude of $818 \mathrm{gal}$ on the north-south component is one of three recording sites near the source region for which motions exceeded $0.8 \mathrm{~g}$. The measurements at the JM-KBM site were obtained using accelerometers and 16 bit digital recorders (K. Ohtani, personal communication, 1995). These recordings were obtained on a concrete pier inside a single story concrete building. The building is located atop a hill with a steeply dipping slope near the building. The station is located near the boundary of Holocene and Pleistocene deposits. Inspection of the site revealed a collapsed brick wall outside the instrument structure, but relatively minor amounts of damage to structures located at the base of the hill. Detailed studies to infer the role of topographic amplification at this site are needed.

Response spectra were provided by the Building Research Institute for several significant earthquake recordings (Figure 2.4.4 a, b, c). They show that the JM-KBM spectra are greater than the other spectra in the period band 0.8 seconds to 2.0 seconds. Comparison of the spectra with those used for tall building design in Japan (Figure 2.4.4c) shows that the JM-KBM spectra exceed the design spectra in the period band 0.25 seconds to 2.0 seconds by about a factor of 2 at periods near 1 second. 
Measurements obtained from a threecomponent vertical borehole array of sensors located on Port Island at a distance of about $4 \mathrm{~km}$ from the projected surface rupture are of special importance. They provide

measurements of shaking at the ground surface and at depths of $12 \mathrm{~m}, 27 \mathrm{~m}$, and $79 \mathrm{~m}$. With liquefaction occurring at this site, these measurements provide an exceptionally important data set for inferring the in-situ response characteristics of soils at ground-motion levels sufficient to induce failure. Receipt of the digital recordings will permit a thorough investigation of this important set of recordings by many investigators. Some preliminary observations follow.

Ground motion measurements obtained on the vertical array located on Port Island are shown in Figure 2.4.5. This figure also gives the simplified geologic $\log$ and velocity profiles for the site. The site is underlain by about $13 \mathrm{~m}$ of fill, which in turn is underlain by at least two thick layers of clay and several layers of interbedded sands and clays. Depth of bedrock at the site is thought to exceed $100 \mathrm{~m}$.

Peak acceleration, velocity and displacement values inferred at the various depths (Figures 2.4.6a, b, c) reveal several effects of the soil deposits on resultant ground motions. Horizontal motions at the surface above the liquefied layer show a marked reduction in high-frequencies, but a significant amplification of low frequency motion. The peak horizontal accelerations increase slightly as they propagate upward toward the bottom of the liquefied layer, but are reduced by factors of 1.7 and 1.9 in the north-south and east-west directions respectively, upon reaching the surface. Peak horizontal velocities atop the liquefied layer are comparable to those at the bottom of the layer, which are larger than those at depth by factors of 1.7 and 1.3. Peak displacement values inferred at the surface are about 1.5 and 1.9 times larger than corresponding values measured at a depth of $79 \mathrm{~m}$.

Each measure of vertical motion (acceleration, velocity and displacement) is larger at the surface than at depth. The vertical motions probably are predominantly dilatational energy. The various measures of vertical motion are amplified by the liquefied layer by factors of 1.0 for acceleration, 1.9 for velocity, and 1.6 for displacement.

The shear-wave velocity profile shows that the velocity of the near-surface fill, clay, and interbedded sands and clays within the first $30 \mathrm{~m}$ of the surface range between $170 \mathrm{~m} / \mathrm{s}$, $210 \mathrm{~m} / \mathrm{s}$ and $245 \mathrm{~m} / \mathrm{s}$, resulting in an average shear velocity to a $30 \mathrm{~m}$ depth of $196 \mathrm{~m} / \mathrm{s}$. These velocities clearly illustrate that the upper shear-wave velocity limit of $183 \mathrm{~m} / \mathrm{s}$ as it has currently evolved for consideration in the proposed NEHRP and UBC site definitions should be reinstated at a minimum of $200 \mathrm{~m} / \mathrm{s}$ as initially proposed [1]. Otherwise, soft-soil sites with interlayered sands and clays with a high failure potential, such as this site, will be inappropriately classified.

The excellent set of recordings obtained on the Hagashi-Kobi Cable stayed bridge are provided in Appendix 2.A.

\subsubsection{Attenuation}

Peak horizontal accelerations as reported for the Hyogoken-Nanbu earthquake (Table 2.4.1) are plotted versus the closest distance to seismogenic rupture approximated to be at a depth of about $4 \mathrm{~km}$ beneath Kobe City (Figure 2.4.7). Peak horizontal accelerations from the Northridge earthquake with a 
minimum depth to seismogenic rupture of $6 \mathrm{~km}$ are superimposed. Also superimposed are attenuation curves developed by Boore et al. [5] and Campbell and Borzognia [4].

\section{Velocity measurements from Port} Island vertical array illustrate that the upper shear wave velocity limit of $183 \mathrm{~m} / \mathrm{s}$, as it has currently evolved for consideration in the proposed NEHRP and UBC site definitions should be reinstated at a minimum of $200 \mathrm{~m} / \mathrm{s}$ as initially proposed.

The peak values for the Hyogoken-Nanbu earthquake tend to be less than those for the Northridge earthquake for sites within $4 \mathrm{~km}$ to $20 \mathrm{~km}$ of the seismogenic source, but greater at distances exceeding about $30 \mathrm{~km}$. These differences in amplitude are roughly consistent with differences in source mechanism and types of geologic site conditions. The source mechanism for the Northridge earthquake is predominantly vertical movement on a reverse fault. Such source mechanisms typically generate higher peak accelerations near the source than comparable sized strike-slip mechanisms. The geologic conditions beneath a majority of the recording sites for the HyogokenNanbu earthquake are soft-soil (Holocene) deposits with higher amplification capabilities for ground motions near one second pcriod than the stiff Pleistocene deposits beneath many of the recording sites for the Northridge earthquake. Consequently, the high frequency motions near the source might be expected to be larger for the Northridge earthquake, but the longer period motions at some distance from the source might be expected to be larger for the Hyogoken-Nanbu earthquake.

The peak acceleration values plotted as lincar function of distance (Figure 2.4.8) emphasize the rapid decrease in peak acceleration values with distance. The recent attenuation curves derived by Boore, et al.[5] when extrapolated to soft soils using an average shear-wave velocity of $200 \mathrm{~m} / \mathrm{s}$ fit the data quite well. Peak values observed at sites in a \pm 22.5 degree window centered along strike with apex at the epicenter are superimposed on those observed in a \pm 67.5 degree window centered at the epicenter perpendicular to strike. Similar trends in each data set suggest that a significant directivity effect is not apparent in these two samples of peak acceleration values. However, a similar comparison of peak velocity values reflecting the mid-period characteristics of the ground motion might be expected to yield a different result.

Comparison of the peak vertical acceleration recorded at each of the sites with the peak horizontal (Figure 2.4.9) shows that on the average the peak vertical accelerations are about $62 \%$ or $2 / 3$ of the corresponding horizontal values. Peak vertical accclerations that exceed the peak horizontal values are most evident for sites near or on Port Island (MC-PRI, MC-PIA). These larger vertical accelcrations are consistent with larger amplification factors observed for vertical motion above the liquefied layer on Port Island array.

\subsubsection{Amplification Effects of Soft-Soil Deposits}

The geologic classification of the sites shown in Table 2.4.1 provides a basis for a preliminary evaluation of the effect of local site conditions on recorded peak accelerations. The geologic classification 
was inferred from superposition of the strong-motion station location coordinates on the 1:1,000,000 scale geologic map of Japan. The resultant classification is dependent on both the accuracy of the station coordinates and the published map scale. Consequently, the geologic classification for sites inferred from map projections and associated results must be regarded as preliminary.

Observations from this earthquake suggest that amplification factors currently being suggested for the NEHRP and UBC code provisions should be modified so as to reduce the influence of nonlinearity on site factors for which the potential for ground failure is low.

Site-specific amplification factors were computed for each site by normalizing the peak values by corresponding peak values observed at the nearest station on rock or firm alluvium at seismogenic-rupture distances (SR-Dis, Table 2.4.1) of about $4 \mathrm{~km}, 25 \mathrm{~km}, 50 \mathrm{~km}$ and $75 \mathrm{~km}$ in 45 degree azimuthal windows centered along strike of the fault with apex at the epicenter. The amplification factors also are normalized by the reciprocal ratio of the seismogenicrupture distances for each site. Sites for normalization were chosen from those for which coordinates had been provided by owner agencies. If chosen normalization sites were not on rock [SC-Ib, 2], then corresponding average amplification factors were used to adjust resultant amplifications to rock.
The mean and standard deviation for amplification factors inferred for Holocene sites in the azimuthal window of 45 degrees centered along strike are 1.8 and 1.5,

respectively. Corresponding values inferred for the azimuthal window of \pm 67.5 degrees perpendicular to strike are 1.7 and 1.5. The Holocene sites are thought to be categorized as soft-soil sites as defined by Borcherdt [2] (classified as $S C-I V$ ) or as D sites as initially proposed for the NEHRP code revisions.

The preliminary 1.8 value is slightly smaller than the 2.0 value for $S C$ - $I V$ sites as initially inferred from the Loma Prieta strongmotion for input ground motion levels near $0.1 \mathrm{~g}[3]$.

As a preliminary attempt to quantify the response characteristics of the Holocene deposits at high input ground motion levels near the source, amplification ratios were computed with respect to the Shin-Kobe site (JR-SNK) for which a peak acceleration of $0.57 \mathrm{~g}$ was recorded at a distance of about $4.1 \mathrm{~km}$ from the seismogenic source. The geologic map and site coordinates imply that the site is underlain by geologic unit QP3 (gravels, sands, and clays of Late Pleistocene age). The amplification ratios, normalized by the reciprocal ratio of the seismogenicrupture distance, are plotted for sites along strike at distances less than $22 \mathrm{~km}$ (Figure 2.4.10). The mean and standard deviation for the amplification factors are 2.0 and 1.1, respectively. The linear trend fit to the data do not show a tendency to decrease with increasing peak acceleration level.

Liquefaction induced ground failure is known to have reduced the amplification at only the Port Island vertical array station. These preliminary observations suggest that the amplification factors for these Holocene sites do not decrease with increasing peak amplitude. Confirmation of this important result with further analyses would suggest that amplification factors currently being 
suggested for the NEHRP and UBC code revisions should be modified so as to reduce the influence of nonlinearity on site factors at sites for which the potential for ground failure is low.

\subsection{Ground Failure}

The 1995 Hyogoken-Nanbu earthquake caused extensive liquefaction of the artificial fills that had been placed in Osaka Bay near Kobe. As was noted in Section 2.3, most of these fills consist of sands that were dumped into standing water and left uncompacted. Consequently, when they were subjected to the strong shaking of the earthquake, they liquefied and expelled large quantities of both sand and water (Figure 2.5.1). More than $17 \mathrm{~km}^{2}$ of land area was covered by vented materials (Figure 2.5.2). Splash marks on walls and other structures indicated that water fountains typically reached $0.5 \mathrm{~m}$ and reached heights of almost $2 \mathrm{~m}$ in a few locations.

The severity of ground shaking on the artificial fill was recorded at two locations, one without any reported liquefaction and one with liquefaction. A recording of ground shaking on reclaimed ground in Kobe north of Port Island is shown in Figure 2.5.3. The station is free field. It is located at the Port of Kobe Construction Office near the shoreline that existed before land reclamation. No evidence of liquefaction was reported at this station. The peak horizontal acceleration is 502 gals $(0.51 \mathrm{~g})$. Figure 2.4.5 illustrates that liquefaction reduced the strength of shaking at the land surface on Port Island. The Port Island station is 1860 m south of the Construction Office station where sand and water vented to the surface. The peak horizontal acceleration at the land surface was only 341 gals $(0.35 \mathrm{~g}$ ) at the Port Island site despite a peak acceleration of 565 gals $(0.58 \mathrm{~g})$ at the base of the sandy fill.

Post-liquefaction consolidation and expulsion of particulate matter caused regionally extensive settlements. Settlements ranged from $30 \mathrm{~cm}$ to $50 \mathrm{~cm}$ throughout the area underlain by artificial fill, and locally exceeded $100 \mathrm{~cm}$. Settlements were easy to detect because many of the structures built on reclaimed ground are supported by piles or columns that extend through the zone that liquefied. Figure 2.5.4 shows differential settlements between columns of the Harbor Expressway, and Figure 2.5.5 shows settlements between columns of a covered parking structure. At many locations, the former position of the ground surface was obvious on the walls of pile-supported structures.

Lateral spreading was common along the perimeters of the artificial fill and usually involved failure of quay walls (See Section 4.5). Maximum permanent horizontal ground deformation from lateral spreading was about $2 \mathrm{~m}$. Ground deformation from lateral spreading diminished rapidly in severity inland from the quay walls, although ground cracks extended as much as $100 \mathrm{~m}$ inland from some walls.

Despite the rugged terrain of the Rokko Mountains, only a few landslides were reported. Unpublished reconnaissance maps provided by the Geographical Survey of Japan, although of limited areal coverage of the mountain front near Kobe, showed only 12 landslides. Most of these slope failures were inland from Nishinomiya. The largest and most damaging slope failure was next to the Nikawa-Yurino Filtration Plant (Figure 2.5.2). The failure killed 34 people. Embankment failures were also noted along streams in the coastal plain. 
Another significant ground failure occurred above the underground Daikai railroad station in Nagata-ku in Kobe City (Figure 2.5.2). The station is operated by the Kobe Express Railroad Company as part of the Japanese National Railroad. The station and adjacent running tunnels were constructed by the cut-and-cover method. The reinforced concrete columns in the station, which supported the roof of the station and $4.8 \mathrm{~m}$ to $5.2 \mathrm{~m}$ of overlying soil, buckled and caused $1800 \mathrm{~m}^{2}$ of land to settle in an approximately $100 \mathrm{~m}$ long elongate depression. Maximum settlement was $2.5 \mathrm{~m}$. Collapse was localized above the $17 \mathrm{~m}$ wide underground station and did not extend into the narrower $9 \mathrm{~m}$ wide running tunnels on either end of the station.

\subsection{Engineering Seismology and Geotechnical Lessons for the United $\underline{\text { States. }}$}

The Hyogoken-Nanbu earthquake has reemphasized that moderate to large earthquakes directly beneath densely urbanized areas can cause catastrophic loss of life and property.

Important factors contributing to these losses from an earth science perspective are:

(a) proximity to the earthquake crustalrupture zone A large number of vulnerable structures experienced especially strong levels of ground shaking in a zone thought to be directly above a portion of the crustalrupture area. Strong-motion recordings show that peak acceleration values attenuated from values greater than $0.8 \mathrm{~g}$ near the source zone to values less than $0.25 \mathrm{~g}$ at some sites at distances near $20 \mathrm{~km}$ on firm soils. This rapid attenuation of strong shaking appears to have been an important factor influencing the confinement of damage primarily to the Awaji Island,
Kobe City and Nishnomiya areas.

(b) amplification effects of soft-soil deposits The amplification effects of Holocene soil deposits appear to have contributed to increased peak amplitudes and duration of strong shaking at many sites. The increased levels of shaking contributed to direct structural failures and liquefaction induced ground failures. The amplification effects of the Holocene soil deposits are consistent with those inferred empirically from the Loma Prieta earthquake. With the exception of those sites experiencing liquefaction, the amplification effects appear to be greater than those currently predicted by numerical models for levels of input ground motion near $0.3 \mathrm{~g}$ to $0.5 \mathrm{~g}$.

(c) liquefaction susceptibilities of reclaimed land and soft soil deposits Where clean, water-saturated, granular layers exist near the surface, shaking-induced or ground failure associated with liquefaction was a significant contributor to damage experienced by port and harbor facilities.

Refinements in U.S. building codes that should be considered for evaluation in order to better account for these factors are:

(a) incorporation of "near-source factors" to account for high levels of shaking at sites near the crustal-rupture zone,

(b) increase the amplification factors for site class $S C-I V(\mathrm{D}, \mathrm{E})$ at high input ground motion levels according to empirical results derived from strong-motion recordings of the Hyogoken-Nanbu earthquake, and

(c) increase the upper shear-wave velocity limit for site class $S C-I V$ from $183 \mathrm{~m} / \mathrm{s}$ to at least $200 \mathrm{~m} / \mathrm{s}$ in order that soft-soil sites with a high liquefaction susceptibility are not misclassified. 
From the geotechnical viewpoint, the liquefaction of about $17 \mathrm{~km}^{2}$

of land underlain by artificial fill highlights the seismic hazard of loose sandy soils. The experience during the 1995 earthquake reaffirmed the proclivity of areas built on these fills for large permanent ground deformations when they are strongly shaken. Large differential horizontal displacements were observed around quay walls where lateral spreading occurred. Regional and localized differential vertical displacements also were observed throughout the area of artificial fill. The Kobe Port and other engineering works such as wastewater treatment facilities were crippled by these deformations.

Many artificial fills in coastal and river areas of the United States are similar to the loose sandy fills in Kobe, which performed so poorly. Much artificial land has been created in the United States by dredging or dumping sand into open water without compaction. Until three to four decades ago, the seismic hazard of soils placed by these techniques was not widely recognized. Consequently, many older fill areas in ports and harbors, both in seismically active areas and areas of low seismicity, are vulnerable to earthquakes. As the 1995 earthquake demonstrated, this vulnerability can extract a steep price when these areas are strongly shaken.

\subsection{Research Needs for Engineering Seismology and Geotechnical Engineering}

The Hyogoken-Nanbu earthquake has provided an especially important set of strong-motion data for purposes of earthquake engineering. The large set of recordings on Holocene soil deposits within $5 \mathrm{~km}$ to $20 \mathrm{~km}$ of the crustal rupture zone are unprecedented. They provide a unique set of in-situ measurements of the response of soft-soil deposits at high input ground motion levels. These data provide a potentially important data set for developing improved site factors for site-specific designs as well as revised building codes.

Important engineering-seismology issues for further research are: (a) the location and nature of the crustal-rupture process as it can be inferred from augmentations to the seismological and strong-motion data sets, (b) compilation, analyses, and distribution of the strong-motion recordings obtained by all contributing agencies, (c) compilation of detailed seismic and geotechnical logs at as many of the strong-motion stations as resources permit, (d) thorough analyses of surface and borehole strong motion recordings to develop an improved understanding of the response of soft-soil deposits at high input ground motion levels, and (e) interpret improved estimates of the response of soft-soil deposits for purposes of code revisions and site-specific design analyses.

The extensive lateral spreading around the margins of the artificial fills placed in Osaka Bay provides an opportunity to clarify the mechanism of horizontal ground displacements associated with soil liquefaction. The widespread damage to engineered works should permit documentation of details of deformation fields associated with lateral spreading. This understanding should improve the design of countermeasures to minimize the impact of liquefaction on engineered works. The large and readily documentable settlements of the land surface provide an excellent opportunity to check and improve techniques to predict magnitudes of postliquefaction consolidation. By determining engineering properties of soils at sites where 
settlements were well documented, the empirical data base can be substantially augmented. Finally, areas of ground improvement need to be documented. Evaluation of the performance of these areas should increase confidence in our ability to reduce the hazard from liquefaction of sandy soils. To date, field experience with the dynamic response of improved ground is limited to relatively low levels of seismic shaking.

\subsection{Acknowledgments}

The authors are especially appreciative of the information and data provided by numerous agencies and colleagues on which this report is based. In particular, data and information provided by colleagues of The Public Works Research Institute; The National Research Institute for Earth Science and Disaster Prevention, Science and Technology Agency; The Disaster Prevention Research Institute, Kyoto University; the Earthquake Research Institute, University of Tokyo; Department of Civil Engineering, Gifu University; the Port and Harbor Research Institute; the Architectural Institute of Japan; The Committee on Earthquake Observation and Research in the Kansai Area; Osaka Gas; Japan Railway; Japan Highways; Japan Meteorological Agency; Building Research Institute; Geological Survey of Japan and others are appreciated. A special note of thanks is expressed to Y. Iwasaki, H. Kameda, Y. Koga, Y. Ninomiya, K. Ohtani, M. Sugito, M. Watabe, and numerous other colleagues for information and personal contributions. The efforts of $\mathrm{C}$. Wentworth in compiling the geologic map were essential for the preparation of Figure 2.4.1 and subsequent geologic classifications of the strong-motion stations. Manuscript reviews by W. Joyner and D. Boore are appreciated.
Translations of Japanese text to English by Yoko Takauchi and Yoshiko Suzu were helpful.

\subsection{References}

1. Borcherdt, R.D., 1994a, Simplified site classes and empirical amplification factors for sitedependent code provisions, Proceedings NCEER, SEAOC, BSSC workshop on site response during earthquakes and seismic code provisions, University of Southern California, Los Angeles, California, November 18 - 20, 1992.

2. Borcherdt, R.D., 1994b, Estimates of site-dependent response spectra for design (Methodology and Justification), Earthquake Spectra, 10, p. 617-653.

3. Borcherdt, R.D., and Glassmoyer, G., On the characteristics of local geology and their influence on ground motions generated by the Loma Prieta earthquake in the San Francisco Bay region, California: Bulletin of the Seismological Society of America, 82, p. 603-641, 1992.

4. Campbell, K. W. and Bosorgnia, Y., Near-source attenuation of peak acceleration from worldwide accele rograms recorded from 1957 to 1993, Proc. Fifth U.S. National Conference on Earthquake Engineering, Chicago Illinois, 1994.

5. Boore, D.M., Joyner, W.B., and Fumal, T., Estimates of response spectra and peak accelerations from western North American earthquakes; an interim report part 2 
(with insert), U. S. Geological Survey Open File Report 94-127, 39 pp., 1994.

6. Huzita, K., and Kasama, T., Geology of the Osaka-Seihokubu District, Scale 1:50,000: Geological Survey of Japan, 1982.

7. Huzita, K., and Kasama, T., Geology of the Kobe District, Scale 1:50,000: Geological Survey of Japan, 1983.

8. Huzita, K., and Maeda, Y., Geology of the Suma District, Scale 1;50,000: Geological Survey of Japan, 1984.

9. Huzita, K., and Maeda, Y., Geology of the Osaka-Seinambu District, Scale 1;50,000: Geological Survey of Japan, 1985.

10. Maximum accelerations observed by JR, JR Earthquake Information No. $23 a$, Internet.
11. Kikuchi, M., The Mechanism of the Hyogoken-Nanbu earthquake of January 17,1995, in YCU (Yokohama City University) Seismology Report No. 38, 1995.

12. Nakakita, U., and Watanabe, Y., Soil stabilization by preloading in Kobe Port Island, in Proceedings of the 9th International Conference on Soil Mechanics and Foundation Engineering, Tokyo, Case History Volume, p. 611-622, 1977.

13. Nakamura, Y., Waveform and its analysis of the 1995 HyogokenNanbu earthquake, JR Earthquake Information No. 23c, 46 pp., 1995. 
Table 2.1.1

Source parameters inferred for the Hyogoken-Nanbu earthquake (Kikuchi,1995)

\section{Subevent}

$\begin{array}{lllll}\underline{\text { Parameter }} & \underline{1} & \underline{2} & \underline{3} & \underline{\text { Total }} \\ \mathrm{M}_{\mathrm{w}} & 6.8 & 6.3 & 6.4 & 6.9 \\ \text { Area }\left(\mathrm{km}^{2}\right) & 24 \times 12 & 9 \times 5 & 12 \times 6 & 40 \times 10 \\ \text { Slip (m) } & 2.1 & 2.5 & 2.7 & 2.1 \\ \text { Stress Drop (MPa) } & 9.3 & 13 & 24 & 10-20 \\ \mathrm{M}_{\text {o (newton-m) }} & & & & 2.5 \times 10^{19}\end{array}$


A preliminary list of strong motion stations for the Hyogoken-Nanbu earthquake

\begin{tabular}{|c|c|c|c|c|c|c|c|c|c|c|c|c|c|c|c|}
\hline Station Name & $\begin{array}{l}\text { Sta } \\
\text { Code }\end{array}$ & Ged. & $\begin{array}{l}\text { Site } \\
\text { Clas }\end{array}$ & $\begin{array}{l}\text { N. Lat. } \\
\text { (deg) }\end{array}$ & $\begin{array}{c}\text { E. Long. } \\
\text { (deg) }\end{array}$ & $\begin{array}{l}\text { Azm } \\
\text { (deg) }\end{array}$ & $\begin{array}{l}\text { E-dist } \\
(\mathrm{km})\end{array}$ & $\begin{array}{l}\text { H-dist } \\
(\mathrm{km})\end{array}$ & $\begin{array}{l}\text { urf-Dis } \\
(\mathrm{km})\end{array}$ & $\begin{array}{c}\text { SR-Dis } \\
(\mathrm{km})\end{array}$ & $\begin{array}{l}\text { PGA } \\
\text { (gal) }\end{array}$ & $\begin{array}{l}\text { Sta } \\
\text { Azm }\end{array}$ & $\begin{array}{c}\mathrm{H1} \\
\text { (gal) }\end{array}$ & $\begin{array}{c}\mathrm{H} 2 \\
\text { (gal) }\end{array}$ & $\begin{array}{c}\text { UD } \\
\text { (gal) }\end{array}$ \\
\hline ukiai & OG-FUI & Qp-Q3 & III & 34.710 & 135.202 & 52 & 18.5 & 23.4 & 0.4 & 4.0 & 833 & & & & \\
\hline hin-Kobe & JR-SNK & Qp-Q3 & III & 34.704 & 135.200 & 53 & 18.0 & 22.9 & 0.8 & 4.1 & 561 & NS & -530 & -267 & -344 \\
\hline obe Marine & $J M-K B M$ & Qh & IV & 34.688 & 135.180 & 54 & 15.4 & 21.0 & 0.9 & 1.1 & 817 & NS & 817 & 617 & 332 \\
\hline Kobe University & KC-KBU & Qp-Q3 & III & 34.725 & 135.240 & 54 & 22.3 & 26.4 & 1.0 & 4.2 & 305 & NS & 270 & 305 & 447 \\
\hline Takatori & JR-TKT & Qh & IV & 34.649 & 135.139 & 62 & 9.9 & 17.4 & 1.7 & 4.3 & 616 & NS & 635 & 553 & 175 \\
\hline PHRI & PH-KOB & Qh & IV & 34.697 & 135.225 & 59 & 19.4 & 24.1 & 2.7 & 4.8 & 394 & NS & 394 & 169 & 275 \\
\hline Port 1 & MC-PRI & Qh & IV & 34.691 & 135.226 & 61 & 19.1 & 23.9 & 3.3 & 5.2 & 341 & NS & 341 & 284 & 557 \\
\hline yama & KC-KOB & Qh & IV & 34.718 & 135.273 & 60 & 24.4 & 28.2 & 3.8 & 5.5 & $775 ?$ & NS & 421? & $775 ?$ & $379 ?$ \\
\hline Array & MC-PIA & Qh & IV & 34.669 & 135.206 & 65 & 16.4 & 21.8 & 4.0 & 5.6 & 340 & NS & 340 & 282 & 567 \\
\hline ishit & OG-NSM & Qh & IV & 34.732 & 135.346 & 63 & 31.0 & 34.1 & 7.5 & 8.5 & 792 & & & & \\
\hline Takar & JR-TKD & Qh & IV & 34.809 & 135.344 & 51 & 35.5 & 38.2 & 8.5 & 9.3 & 601 & NS & 595 & 530 & 377 \\
\hline ishi & JR-NSA & Qh & IV & 34.664 & 134.964 & 311 & 9.7 & 17.2 & 10.1 & 10.8 & 481 & NS & 481 & -389 & 338 \\
\hline$i 1$ & KC-AMG & Qh & IV & 34.718 & 135.408 & 70 & 35.6 & 38.3 & 13.4 & 14.0 & $>321$ & NS & 271 & 322 & 328 \\
\hline ki & PH-AMG & Qh & IV & 34.689 & 135.388 & 74 & 32.9 & 35.8 & & & 475 & NS & 475 & 320 & 312 \\
\hline 2 & MC-AMG & Qh & IV & 34.715 & 135.410 & 70 & 35.7 & 38.4 & & & 310 & $T R$ & 310 & 274 & 336 \\
\hline ma & & Qh & IV & 34.724 & 135.432 & 70 & 37.9 & 40.4 & & & 580 & NS & & & \\
\hline & TD-OKI & Qh & IV & 34.826 & 135.426 & 55 & 42.6 & 44.9 & & & 421 & & & & \\
\hline al & OG-r & Oh & IV & 34.666 & 135.432 & 80 & 36.2 & 38.9 & & & 266 & & & & \\
\hline & k & Qh & IV & 34.681 & 135 & 78 & 37.8 & 40.3 & & & 212 & NS & 180 & 212 & 195 \\
\hline odo & & th & IV & & 135 & 77 & 39.0 & 41.5 & & & 336 & $T R$ & 150 & 200 & 300 \\
\hline & $T$ & sed & 1 & & 13 & 46 & 46.7 & 48.7 & & & 478 & & & & \\
\hline Toy & $\mathrm{K}$ & $Q p-C$ & IIII & & & 6 & 46.3 & 48.4 & & & & NS & & & \\
\hline Senri & & $T$ & 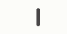 & & 13 & 6 & 47.1 & $4 !$ & & & 312 & & & & \\
\hline$n$ & $T$ & & I & 0 & 13 & 5 & 3.5 & 5 & & & 127 & & & & \\
\hline 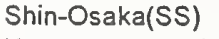 & Ji & $c$ & IV & 37 & 1 & 72 & 5.6 & $t$ & & & 245 & NS & -218 & -217 & 56 \\
\hline i & 0 & Qh & IV & 34.791 & 134 & 330 & 23.8 & 27.7 & & & 39 & $T R$ & 136 & 139 & 114 \\
\hline Osa & $\mathrm{JM}$ & Qp-Q3 & III & 34.678 & 135 & 80 & 44.5 & 46.7 & 7 & & 80 & NS & 80 & 66 & -65 \\
\hline$p$ & KA-KIA & Qh & IV & 421 & 135. & 143 & 25.8 & 29.5 & 2 & & 160 & & & & 247 \\
\hline lako & $J R-K$ & Qh & IV & 34.764 & 134.843 & 314 & 25.3 & 29.0 & & .0 & 229 & NS & 165 & 262 & 98 \\
\hline & $\mathrm{KC}-\mathrm{ABN}$ & Qp-Q3 & III & 34.636 & 135. & 86 & 43.7 & 45.9 & & 9 & 226 & NS & 217 & 226 & 136 \\
\hline & & Qh & IV & 34.678 & 135 & 80 & 46.5 & 48.6 & 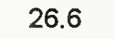 & 6.9 & 210 & NS & 210 & 123 & 159 \\
\hline & & Qh & IV & 34.732 & 135 & 74 & 50.5 & 52.4 & & 3.1 & 177 & & & & \\
\hline & & Qh & IV & 564 & 135 & 97 & 39.3 & 41.7 & & 3.7 & 150 & NS & 150 & 125 & 100 \\
\hline & & Qh & IV & & 135 & $g$ & 40.8 & 43.2 & & .0 & 173 & & & & \\
\hline Euiii & & Qh & IV & & 13 & 111 & 33.6 & 36.5 & & .2 & 168 & & & & \\
\hline & & Qh & IV & & 13 & 8 & 9.0 & 51.0 & & & 243 & NS & & & \\
\hline ka & & Qh & IV & 55 & 13 & 72 & 53.5 & 55.3 & & & 202 & & & & \\
\hline & & Qh & IV & & & 110 & 35.6 & 38.4 & & & 178 & & & & \\
\hline & & Qh & IV & & & 8 & 48.1 & 50.1 & & .9 & 185 & & & & \\
\hline lira & & Qh & IV & & & 67 & 56.6 & 58.3 & & .9 & 253 & TR & 144 & 253 & 57 \\
\hline Tac & & Qp-Q3 & III & & 13 & 113 & 36.3 & 39.0 & & 2.2 & 290 & NS & 290 & 190 & 137 \\
\hline & & Qh & IV & & & 81 & 52.7 & 54.5 & & 2.6 & 155 & NS & 155 & 145 & 127 \\
\hline & $c$ & QP-Q3 & III & & & 131 & 34.0 & 36.9 & & 3.4 & 240 & & & & \\
\hline & JR-SMG & sed & 1 & & 135 & 14 & 51.2 & 53.0 & 33.5 & 3.7 & 195 & NS & 139 & -177 & 39 \\
\hline & JR-HGK & Qp-Q3 & III & 34.445 & 135.388 & 120 & 36.3 & 39.0 & 33.7 & 3.9 & 149 & NS & -110 & -144 & 49 \\
\hline & OG-SHR & Qh & IV & 34.779 & 134.729 & 304 & 34.5 & 37.3 & 3.7 & 4.0 & 189 & & & & 189 \\
\hline & S-SHJ & Qh & IV & & 135. & 7 & 56.3 & 58.0 & & 1.0 & 224 & & & & \\
\hline$a$ & TD-HKC & Qh & IV & & & 6 & 59.5 & 61.1 & & 4.8 & 313 & & & & \\
\hline & OG.HSM & Qh & IV & & & 6 & 60.9 & 62.5 & 34.8 & 35.1 & 251 & & & & \\
\hline$\therefore$ & & Qh & IV & & & 88 & 53.2 & 55.0 & 35.6 & 35.9 & 169 & & & & \\
\hline Eujiic & OG-FJ3 & Qp-Q3 & III & & & 95 & 50.6 & 52.5 & 36.5 & 36.7 & 149 & & & & \\
\hline tsuki(S & JR-SNT & Qh & IV & 34.859 & 135.654 & 63 & 62.5 & 64.0 & 36.6 & 36.8 & 323 & NS & & & \\
\hline & OG-MTS & Qh & IV & 34.241 & 135.150 & 167 & 41.8 & 44.2 & 36.7 & 36.9 & 180 & & & & \\
\hline & KC-SHM & Qh & IV & 34.799 & 134.691 & 304 & 38.7 & 41.2 & 37.7 & 37.9 & 253 & & & & \\
\hline & OG-FU1 & Qp-Q3 & III & 34.558 & 135.611 & 96 & 52.3 & 54.1 & 38.4 & 38.6 & 149 & & & & \\
\hline $6-$ & TD-KKO & 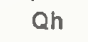 & IV & 34.231 & 135.167 & 165 & 43.3 & 45.6 & 38.6 & 38.8 & 150 & & & & \\
\hline
\end{tabular}


Table 2.4.1 (continued)

A preliminary list of strong motion stations for the Hyogoken-Nanbu earthquake

\begin{tabular}{|c|c|c|c|c|c|c|c|c|c|c|c|c|c|c|c|}
\hline Himeji & KC-HIM & volc & 1 & 34.835 & 134.723 & 311 & 38.8 & 41.3 & 38.9 & 39.1 & 189 & & & & \\
\hline Nakanoshima & JG-NKS & Qh & IV & 34.240 & 135.191 & 162 & 43.0 & 45.3 & 39.3 & 39.5 & 126 & & & & \\
\hline Wakayama $\mathrm{Br}$ & JH-WKY & Qn & IV & 4.254 & 135.211 & 159 & 42.2 & 44.5 & 39.3 & 39.5 & 109 & & & & \\
\hline lame & JH-OMK & Qp-Q2 & III & 4.983 & 35.609 & 51 & 66.5 & 67.9 & 39.4 & 39.6 & 273 & & & & \\
\hline Sonobo & JR-SNB & Qh & IV & 100 & 35.487 & 37 & 68.2 & 69.6 & 42.4 & 42.6 & 163 & NS & -102 & 163 & -47 \\
\hline eiji Bypass & $J H-K J B$ & Qh & IV & 34.898 & 135.741 & 63 & 71.5 & 72.8 & 45.4 & 45.6 & 249 & & & & \\
\hline Tatsuno & JH-TSN & volc & 1 & 34.871 & 134.626 & 308 & 48.2 & 50.2 & 47.7 & 47.9 & 136 & & & & \\
\hline Fushimi & OG-FUS & Qh & IV & 34.941 & 135.772 & 61 & 76.2 & 77.4 & 49.8 & 49.9 & 206 & & & & \\
\hline Chihaya & $\mathrm{KC}-\mathrm{CHY}$ & ig/meta & 1 & 34.439 & 135.659 & 108 & 59.4 & 61.1 & 50.4 & 50.6 & 109 & NS & 91 & 109 & 74 \\
\hline Nijo & JR-NNO & Qh & IV & 007 & 35.744 & 55 & 77.9 & 79.1 & 51.0 & 51.1 & 84 & NS & & & \\
\hline Nara & JR-NRA & Qh & IV & 4.677 & 135.821 & 84 & 71.6 & 72.9 & 51.1 & 51.2 & 113 & NS & 112 & 104 & -36 \\
\hline Amagase Dam & TO-AMD & Qp-Q1 & III & 34.875 & 135.815 & 67 & 76.6 & 77.8 & 51.2 & 51.3 & 172 & & & & \\
\hline Kyoto & OG-KYO & Qh & IV & 35.012 & 135.755 & 55 & 79.1 & 80.2 & 52.1 & 52.3 & 67 & & & & \\
\hline Higashiyama & JR-HGY & sed & 1 & 34.978 & 135.797 & 59 & 80.3 & 81.4 & 53.6 & 53.8 & 113 & NS & & & \\
\hline Shirakaw & TD-SKD & $\mathrm{mN} 1 / 2$ & ॥ & 34.615 & 135.858 & 90 & 74.6 & 75.9 & 56.1 & 56.2 & 169 & & & & \\
\hline Fukuchiy & JR-FHY & Qh & IV & 93 & 21 & 5 & 76.7 & 77.8 & 60.7 & 60.8 & 110 & NS & 72 & 107 & 21 \\
\hline Ikuno & JR-IKN & vole & I & 35.160 & 134.792 & 339 & 65.7 & 67.1 & 62.1 & 62.2 & 59 & NS & -36 & 53 & 20 \\
\hline In & JR-IN & volc & 1 & 34.750 & 134.227 & 282 & 76.3 & 77.6 & 66.9 & 67.0 & 101 & NS & -36 & 53 & 20 \\
\hline Kusatsu & OG-KUS & Qh & IV & 35.008 & 135.956 & 62 & 94.5 & 95.5 & 68.2 & 68.3 & 6 & & & & \\
\hline Gobo & JR-GBO & sed & 1 & 33.904 & 135 & 172 & 78.9 & 80.1 & 69.9 & 70.0 & 170 & NS & -111 & 132 & 26 \\
\hline Ritto & JR-RTO & Qh & IV & 35.028 & 135.996 & 62 & 98.8 & 99.7 & 72.4 & 72.5 & 67 & NS & & & \\
\hline Nishi-Maiduro & JR-NSM & sed & 1 & 35.438 & 135.333 & 16 & 96.1 & 97.0 & 75.4 & 75.5 & 87 & NS & -60 & 79 & -20 \\
\hline Maizura & JM-MAZ & $\mathrm{lg} / \mathrm{meta}$ & 1 & 35.448 & 135.320 & 15 & 96.9 & 97.8 & 76.4 & 76.5 & 67 & NS & -67 & -52 & -40 \\
\hline Himeji & JR-HMJ & volc & 1 & 34.821 & 134.075 & 285 & 91.7 & 92.7 & 82.9 & 83.0 & 125 & NS & 82 & 125 & 48 \\
\hline Tsuge & JR-TSG & Tp-N3 & III & 34.843 & 136.259 & 77 & 114.2 & 114.9 & 90.6 & 90.7 & 97 & NS & 77 & -67 & 33 \\
\hline Obama & JR-OBM & Qh & IV & 35.488 & 135.749 & 33 & 117.2 & 117.9 & 91.7 & 91.8 & 74 & NS & 70 & -57 & -24 \\
\hline Gokasou & JR-GOK & volc & 1 & 35.139 & 136.184 & 61 & 119.7 & 120.4 & 93.1 & 93.2 & 128 & NS & -125 & 119 & -44 \\
\hline Toyooka & JR-TYK & $\mathrm{mN} 1 / 2$ & II & 41 & 134 & 348 & 106.2 & 107.0 & 96.7 & 96.8 & 124 & NS & 103 & -90 & -27 \\
\hline Shin-Malb & JR-SNM & Qn & IV & 16 & 136 & 56 & 138.5 & 139.1 & 111.6 & 111.6 & 227 & NS & 217 & 135 & -25 \\
\hline Kji-Nagash & $J R-K N G$ & sed & 1 & 05 & 136 & 111 & 127.2 & 127.9 & 16.0 & 16.1 & 46 & NS & & & \\
\hline Matsuzaka & JR-MTZ & Qh & IV & 34.573 & 136 & 92 & 136.9 & 137.5 & 117.7 & 117.8 & 49 & NS & & & \\
\hline Kumancshi & JR-KUM & vole & 1 & 33.889 & 136.105 & 130 & 126.1 & 126.8 & 123.5 & 123.6 & 52 & NS & & & \\
\hline Yokkaichi & $J R-Y K C$ & Qh & IV & 34.960 & 136.633 & 75 & 150.4 & 150.9 & 126.2 & 126.2 & 65 & NS & & & \\
\hline Sekigahara & JR-SKH & Qh & IV & 35.360 & 136.472 & 58 & 154.8 & 155.2 & 127.9 & 128.0 & 95 & NS & & & \\
\hline Shin-Sekig & JR-SNS & Qh & IV & 35.354 & 136.483 & 58 & 155.3 & 155.7 & 128.4 & 28.5 & 106 & NS & 106 & 72 & -29 \\
\hline Hashima & JR-HSM & Qh & IV & 35.326 & 136.675 & 62 & 168.8 & 169.2 & 142.3 & 142.4 & 57 & NS & 57 & -31 & 10 \\
\hline Kisogawa & JR-KS & Qh & IV & 35.343 & 136.783 & 63 & 178.4 & 178.8 & 152.0 & 152.1 & 67 & NS & & & \\
\hline Biwajima( & JR-BWJ & Qh & IV & 95 & 67 & 69 & 178.7 & 179.1 & 153.1 & 53.2 & 21 & NS & -21 & 18 & -7 \\
\hline Odaka(SS & JR-ODK & Tp-N3 & III & 66 & 136 & 74 & .6 & 182.0 & 157.0 & 57.1 & 18 & NS & -17 & -14 & -7 \\
\hline Anjo(SS) & JR-ANJ & Qp-Q3 & III & 34.929 & 137.099 & 80 & 191.2 & 191.5 & 167.8 & 167.8 & 26 & NS & -22 & -19 & -7 \\
\hline Okazaki & JR-OKZ & $Q p-Q 3$ & III & 34.920 & 137.160 & 80 & 196.5 & 196.8 & 173.2 & 173.3 & 9 & NS & & & \\
\hline Mino-Ota & JR-MNO & Qh & IV & 35.443 & 137.022 & 63 & 202.8 & 203.0 & 176.3 & 176.4 & 50 & NS & & & \\
\hline Tajimi & JR-TJM & $\mathrm{mN} 1 / 2$ & $\|$ & 35.330 & 137.122 & 68 & 205.8 & 206.0 & 179.9 & 180.0 & 15 & NS & & & \\
\hline Toyohashi & JR-TYH & & & 34.760 & 137.385 & 86 & 214.8 & 215.0 & 193.1 & 193.1 & 12 & NS & & & \\
\hline Gero & JR-GRO & & & 35.802 & 137.242 & 57 & 239.9 & 240.1 & 213.0 & 213.0 & 10 & NS & & & \\
\hline Nakatsugawa & JR-NKT & & & 95 & 05 & 67 & 2 & .0 & 18.9 & 218.9 & 14 & NS & & & \\
\hline Nagiso & JR-NGS & & & & 137 & 66 & 258.3 & .3 & 232.1 & 232.1 & 19 & NS & & & \\
\hline Takayama & JR-TKY & & & 36.138 & 137.254 & 50 & 263.0 & 263.0 & 235.9 & 236.0 & 7 & NS & & & \\
\hline Shin-Iwata(SS) & JR-SHI & & & 34.723 & 137.901 & 88 & 261.7 & 261.8 & 240.3 & 240.3 & 14 & NS & 10 & 13 & -4 \\
\hline Hiraoka & JR-HRK & & & 35.271 & 137.857 & 75 & 266.9 & 267.0 & 242.2 & 242.2 & 8 & NS & & & \\
\hline Ida & $J R-I D A$ & & & 35.517 & 137.825 & 69 & 272.7 & 272.7 & 246.9 & 246.9 & 18 & NS & & & \\
\hline \multicolumn{8}{|c|}{$\begin{array}{l}\text { KC - Kansai Committee for Earthquake Observation and Research } \\
O G \text { - Osaka Gas } \\
\text { JR - Japan Railway } \\
\text { JH - Japan Highway } \\
\text { MC - Ministry of Construction }\end{array}$} & \multicolumn{8}{|c|}{$\begin{array}{l}\text { PH - Port and Harbor Research Institute } \\
\text { JM - Japan Meterological Agency } \\
\text { KA - Kansai International Airport } \\
\text { TD - To be Determined }\end{array}$} \\
\hline
\end{tabular}




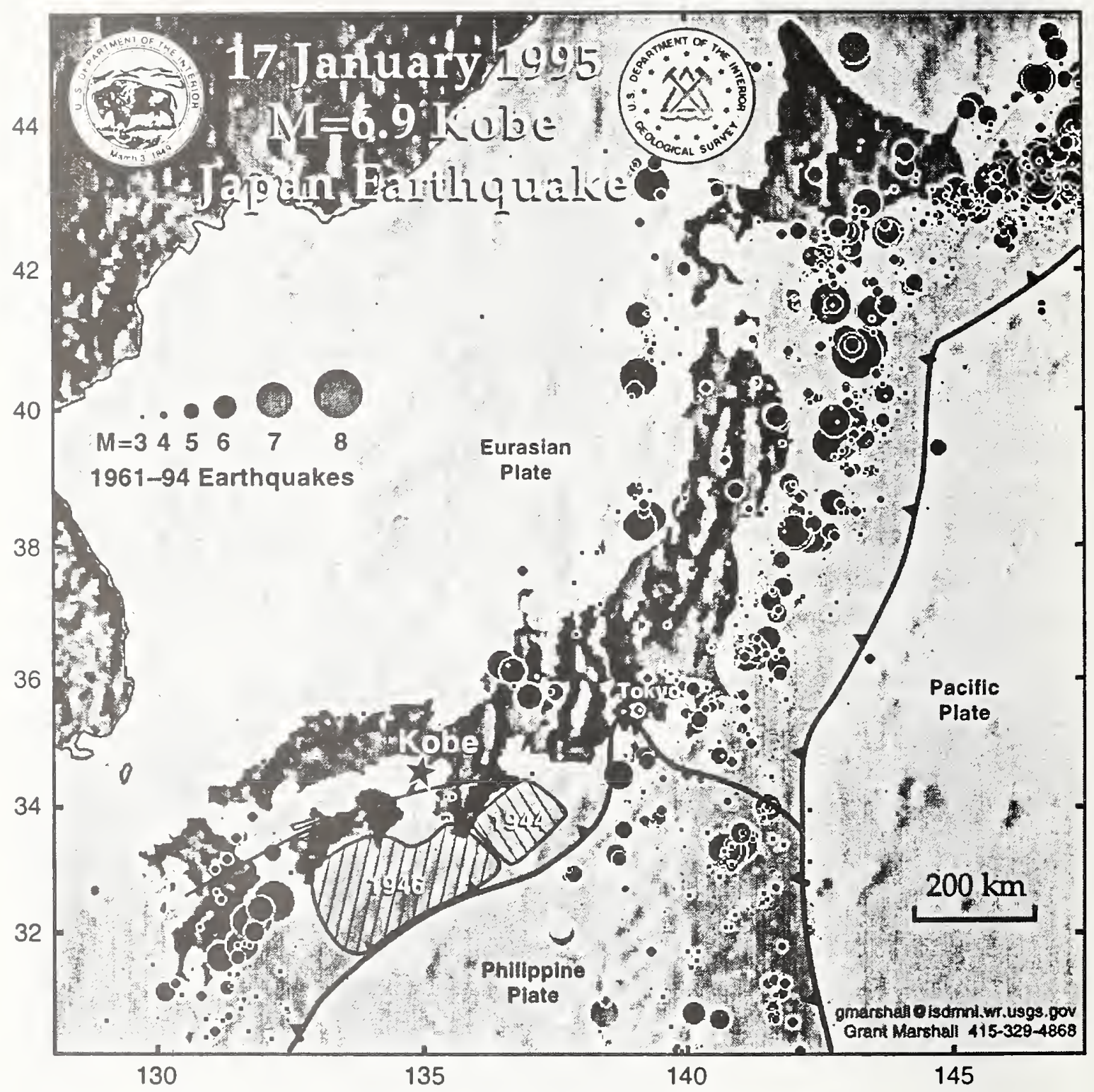

Figure 2.1.1 Map showing seismicity for Japan for time period 1961-1994, plate margins and approximate rupture zones for the large 1944 and 1946 earthquakes (compiled by G. Marshall). 
1/16 00:00 - 1/18 18:00

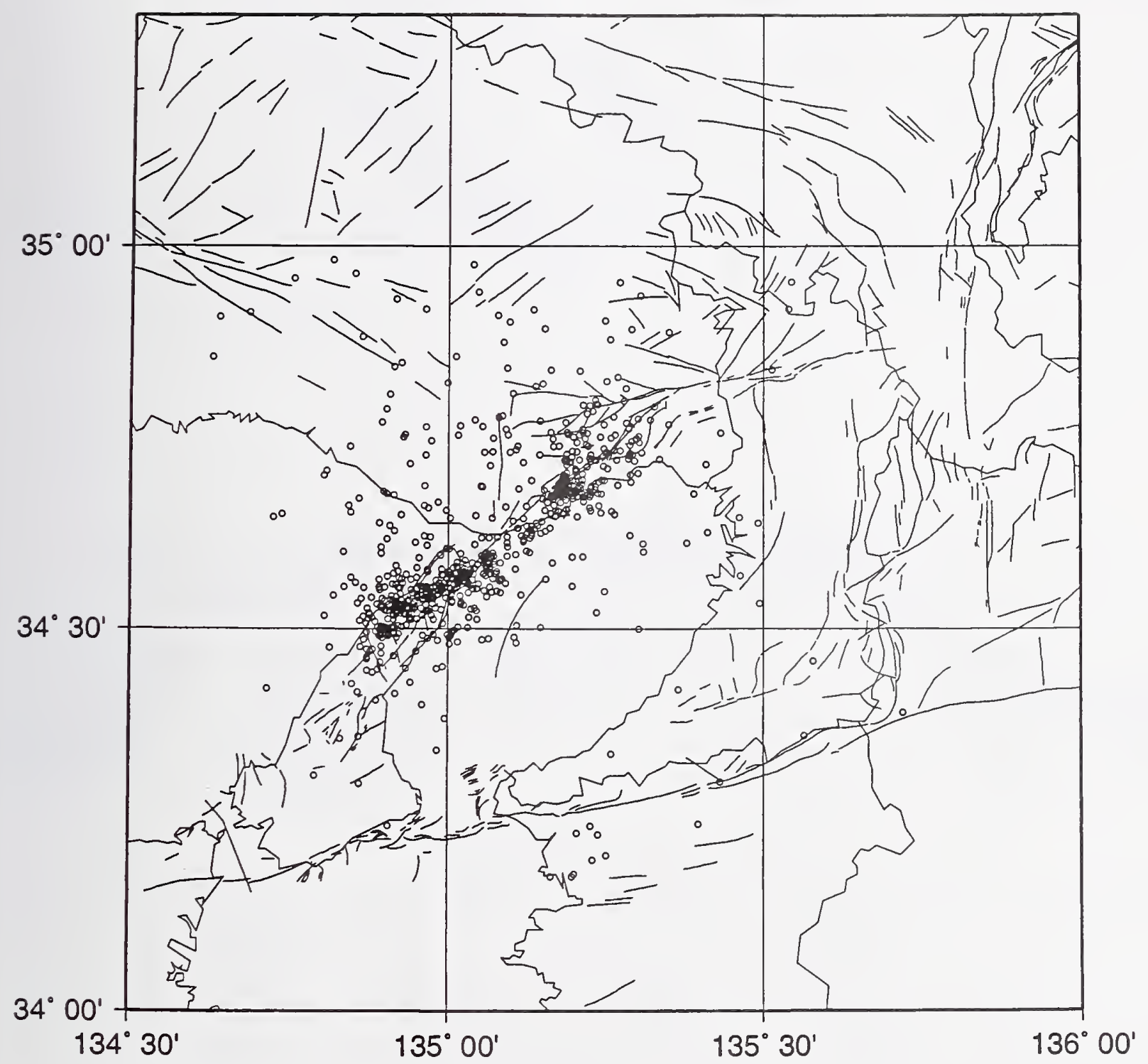

Figure 2.1.2 Map showing Quaternary faults and seismicity for a two day time period including the occurrence time of the Hyogoken-Nanbu earthquake (from Earthquake Research Institute, University of Tokyo via ftp, Observation Networks of Disaster Prevention Research Institute, Kyoto University, and Faculty of Science, Kochi University). 


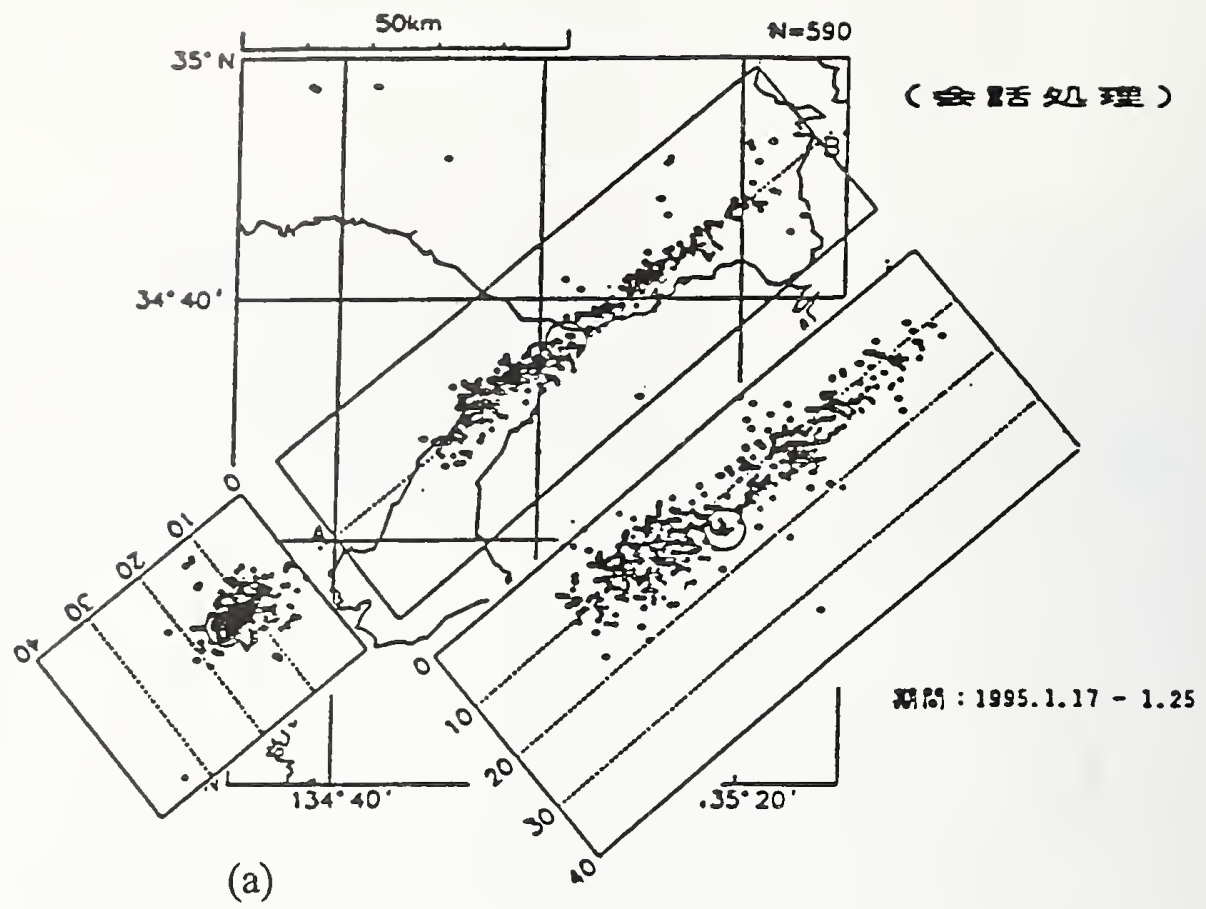

\section{Subevent Distribution}

Source Time Functions
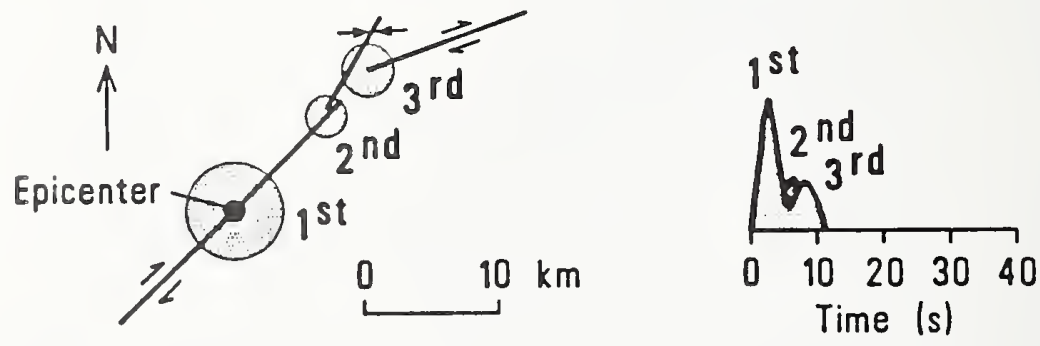

\section{Focal Mechanisms}

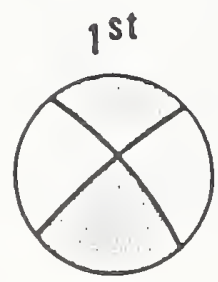

$$
2^{\text {nd }}
$$

$3^{\text {rd }}$

8

(b)
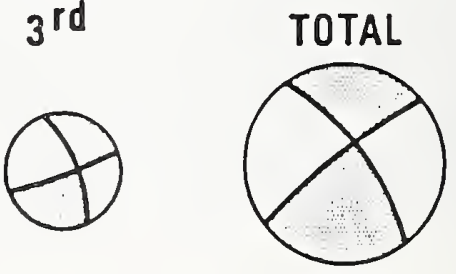

Figure 2.1.3 (a) Map showing aftershock distribution in plan and cross section views (from Disaster Prevention Research Institute, Kyoto University) and (b) source mechanism for inferred subevents (from Kikuchi, 1995). 


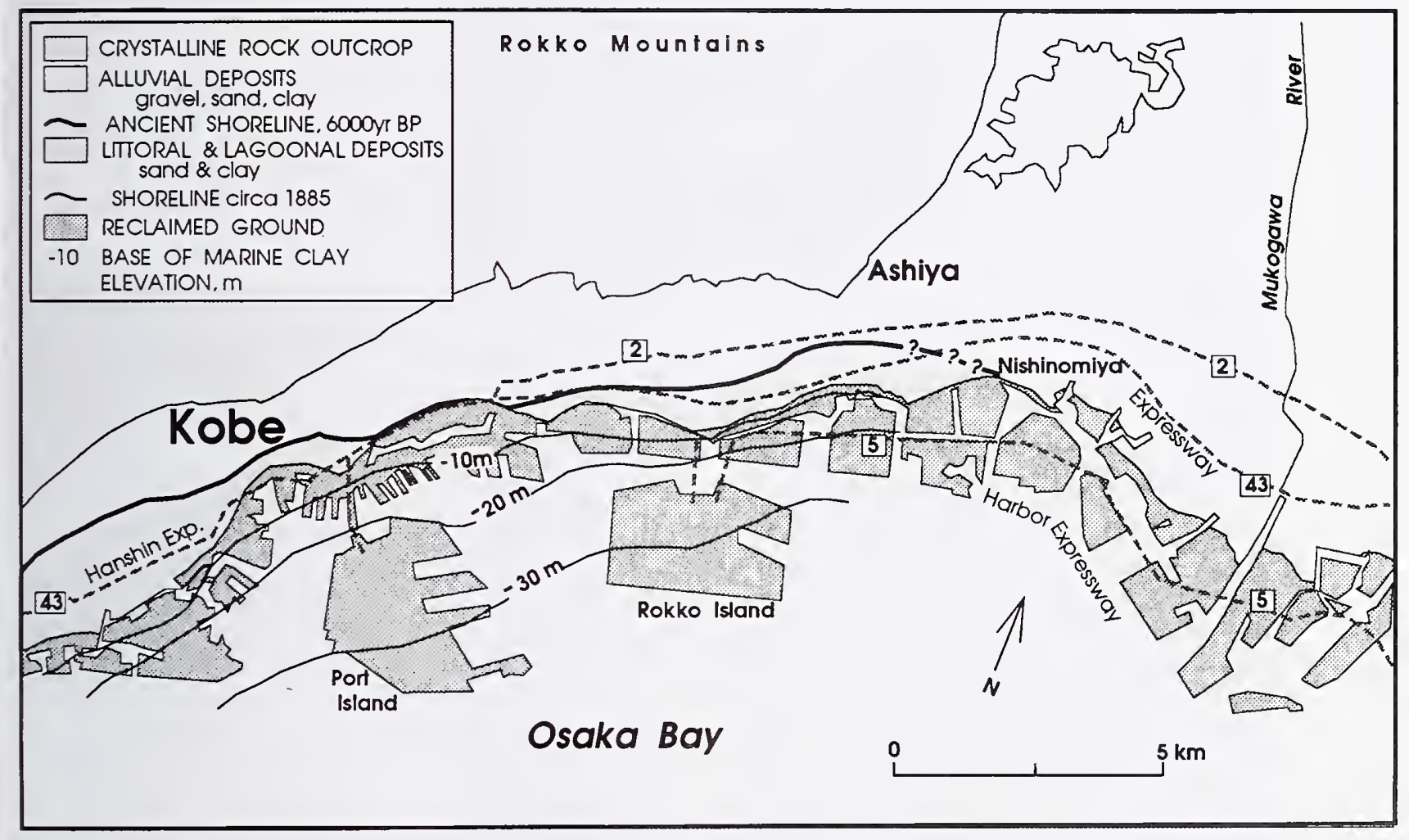

Figure 2.3.1 Soils map of Kobe City area (generalized from Huzita and Kasama, 1983). 


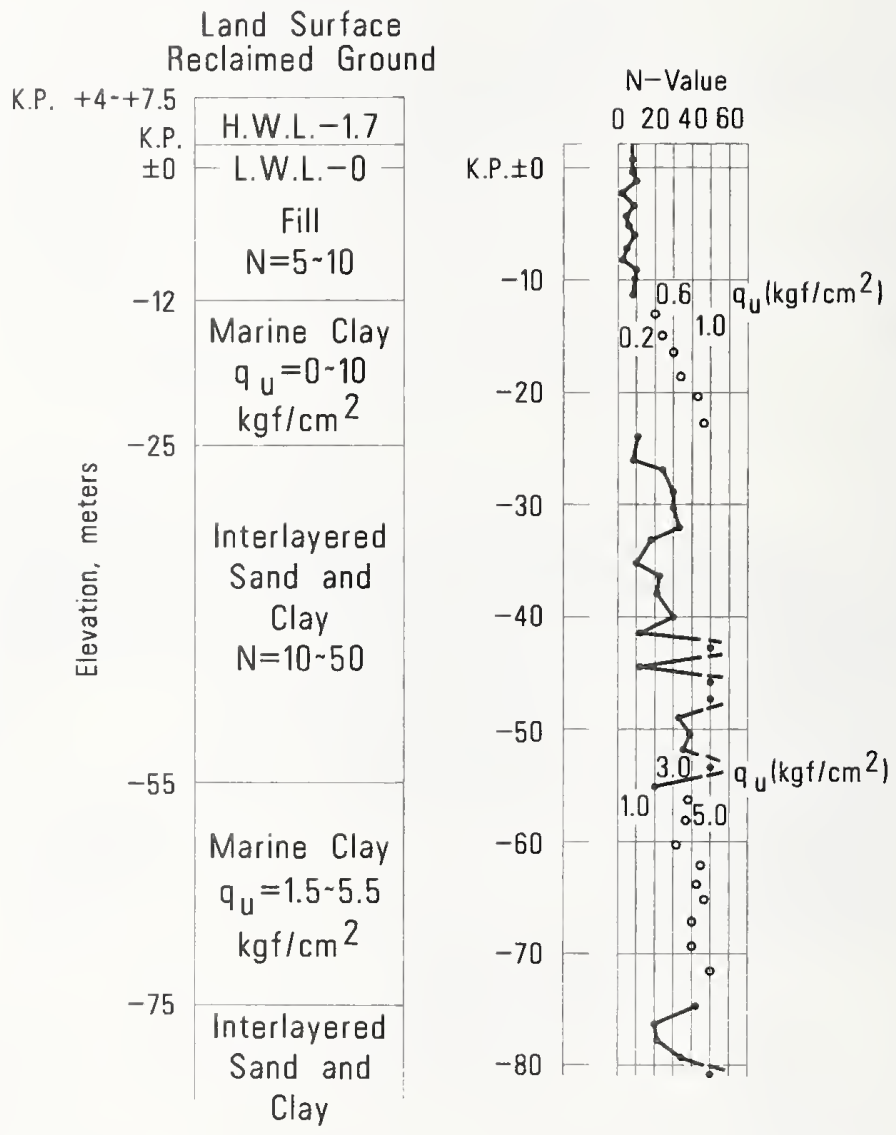

Figure 2.3.2 Representative soil boring from Port Island showing fill overlying natural soils (Nakakita and Watanabe, 1977. 


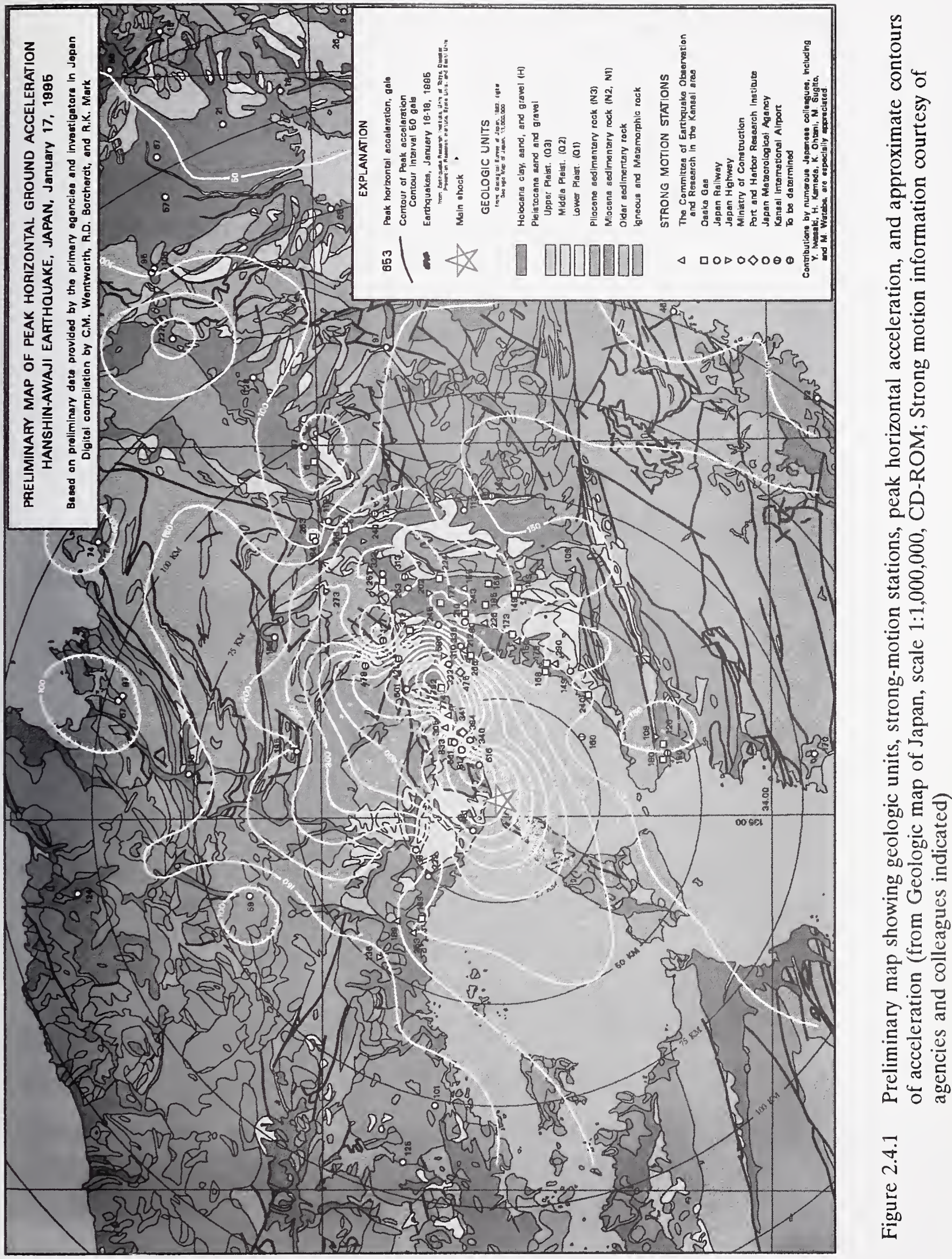




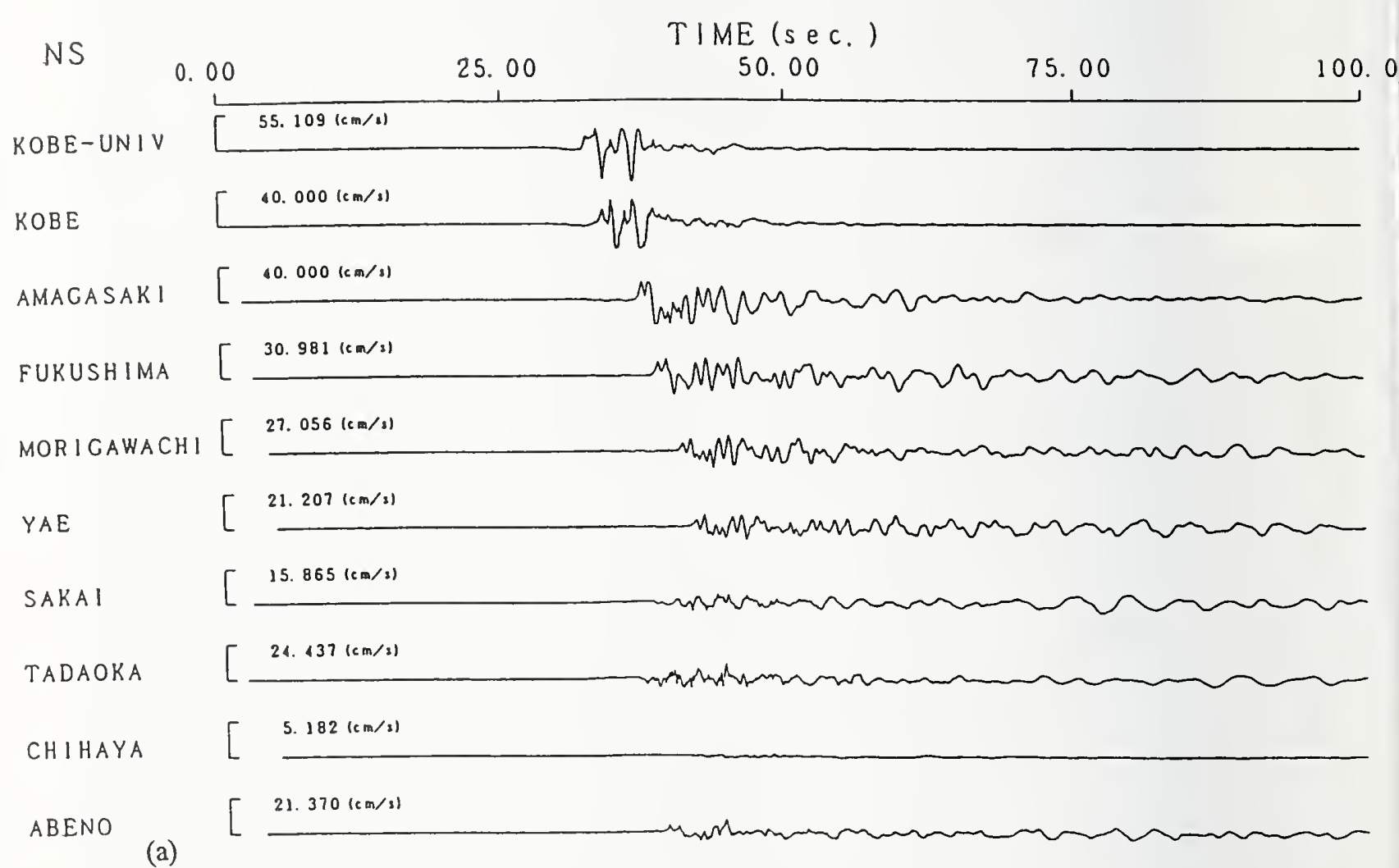

Figure 2.4.2 (a) Record section showing ground velocity in the NS (a) direction (from The Committee on Earthquake Observation and Research in the Kansai Area, CEORKA). 


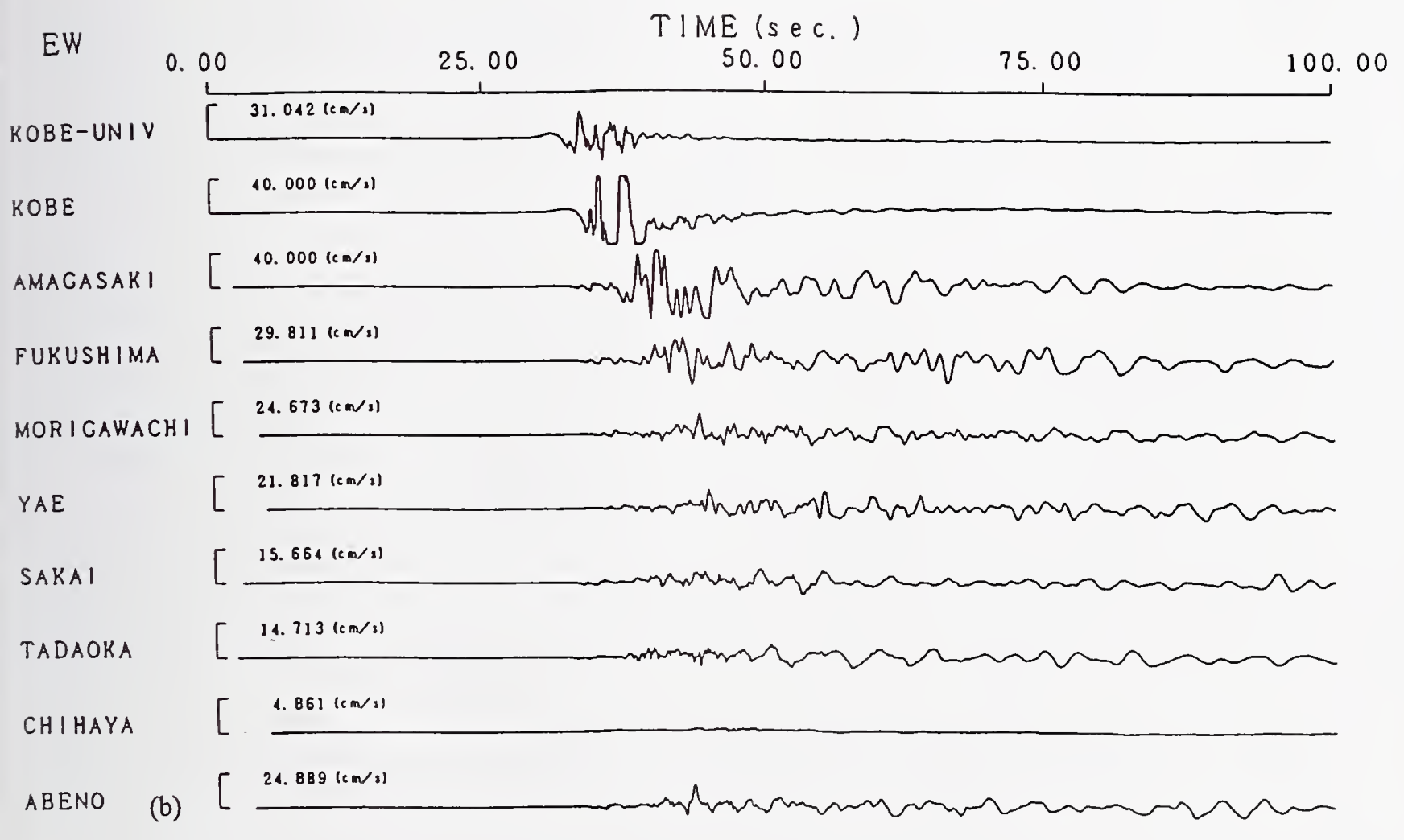

Figure 2.4.2 (b) Record section showing ground velocity in the EW (b) direction (from The Committee on Earthquake Observation and Research in the Kansai Area, CEORKA). 


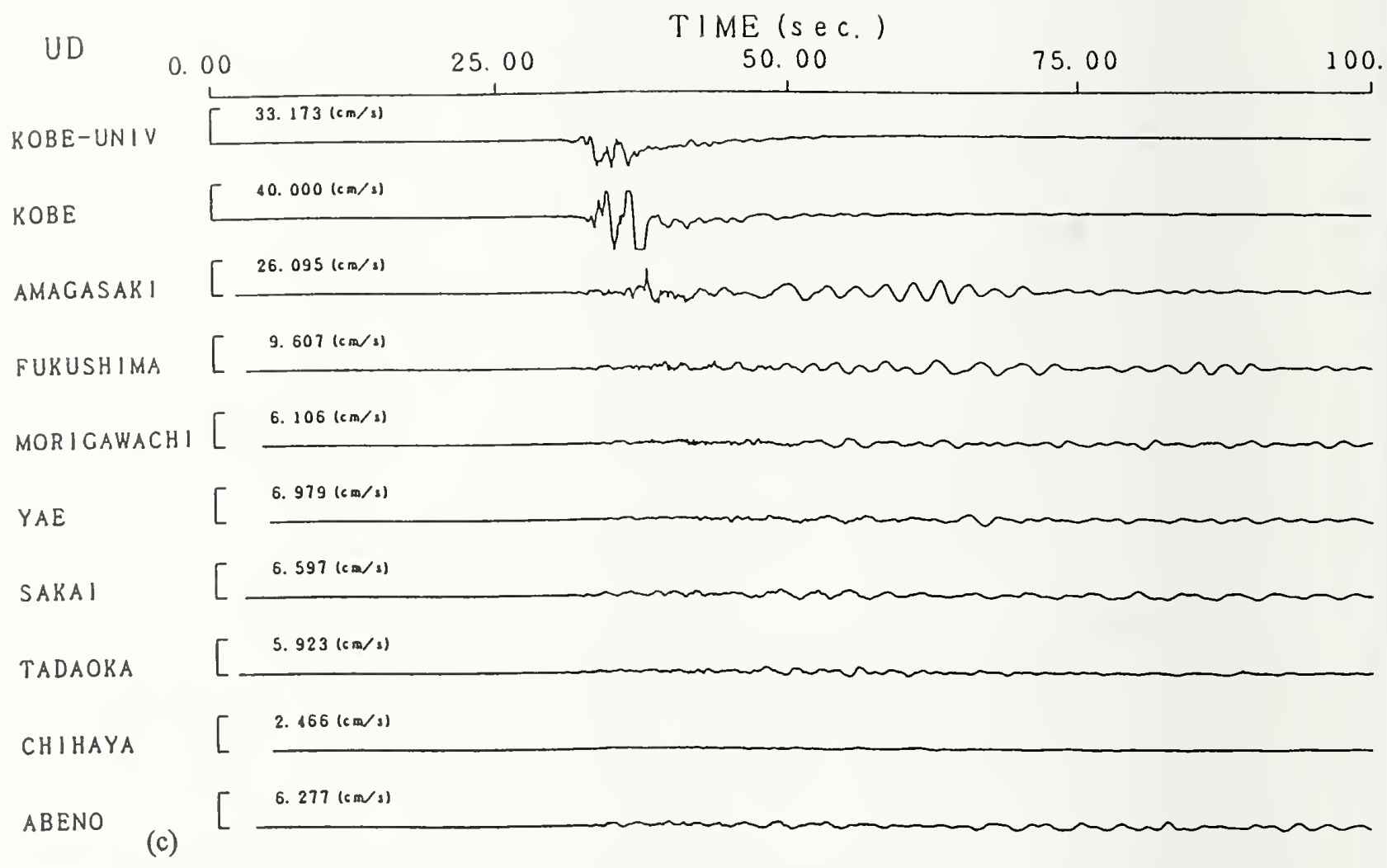

Figure 2.4.2 (c) Record section showing ground velocity in the UD (c) direction (from The Committee on Earthquake Observation and Research in the Kansai Area, CEORKA). 
$9501.1705 .4634 .36135 .00 \quad 20.07 .219 .2 \mathrm{KOBE}(J M A)$

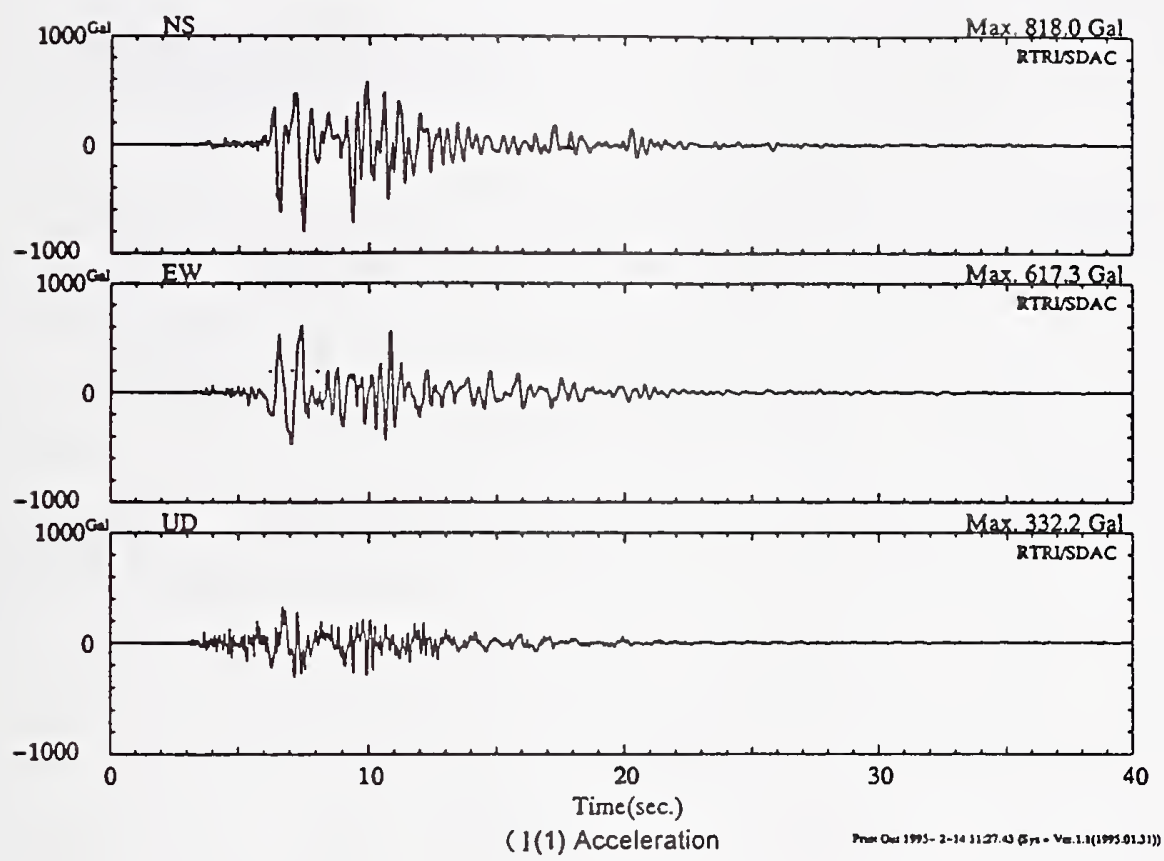

$9501.1705 .4634 .36135 .0020 .07 .219 .2 \mathrm{KOBE}(\mathrm{JMA})$

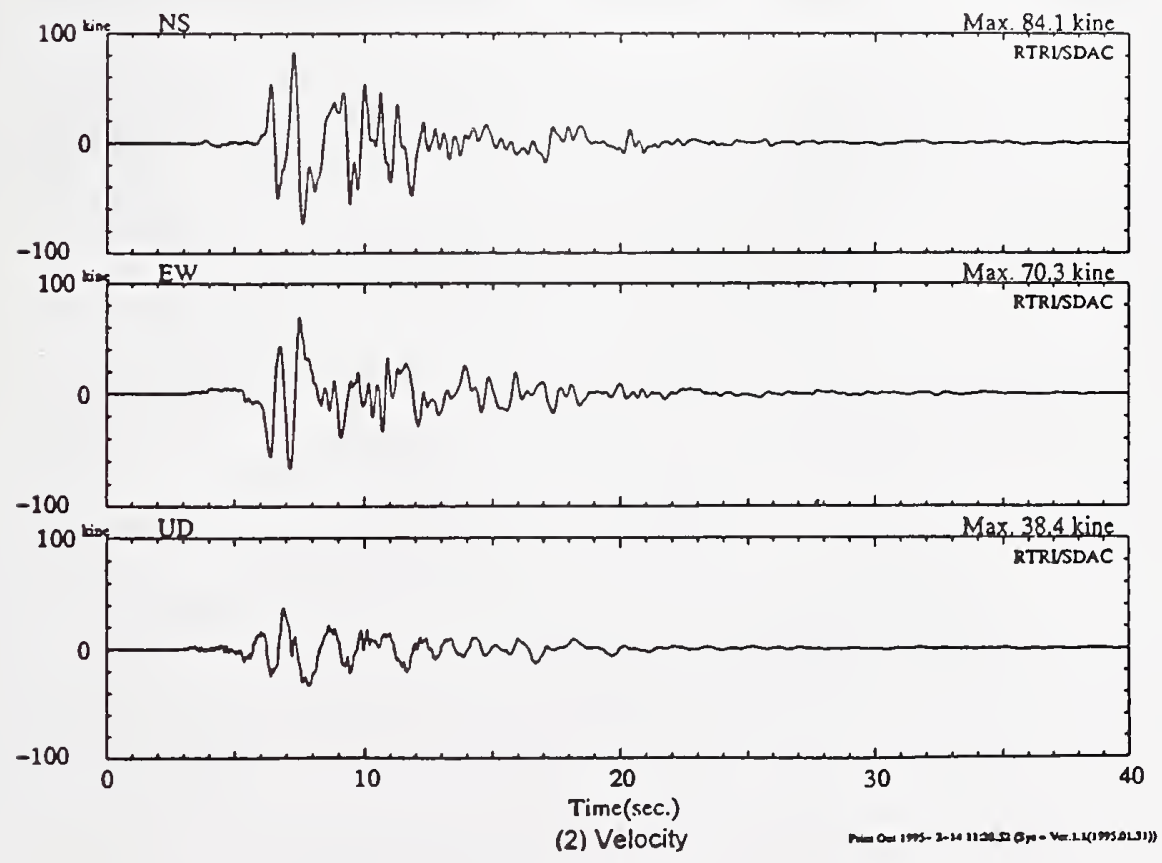

Figure 2.4.3 (a) Three-component (1) acceleration, (2) velocity, (3) displacement, and (4) displacement loci inferred by Nakamura (1995) from strong-motion recordings at site (a), Kobe Marine (JM-KBM). 


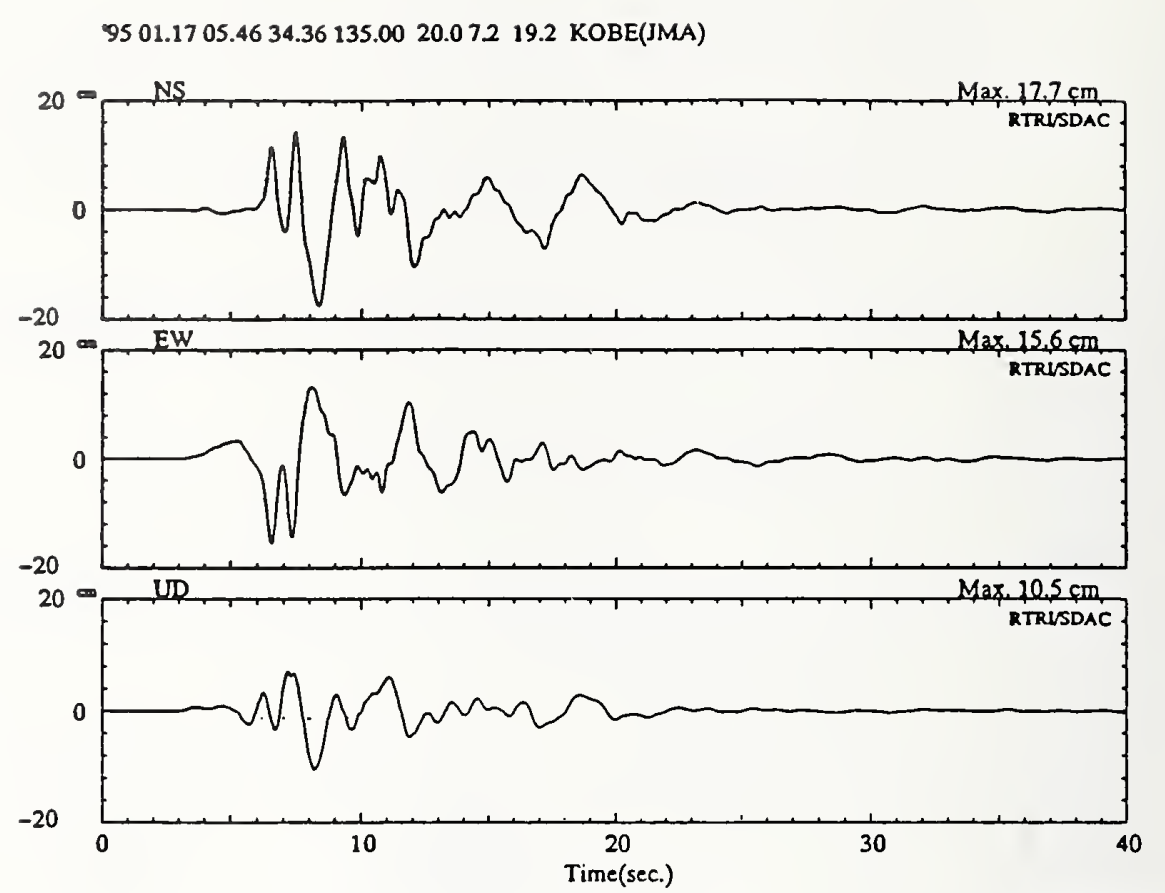

(3) Displacement
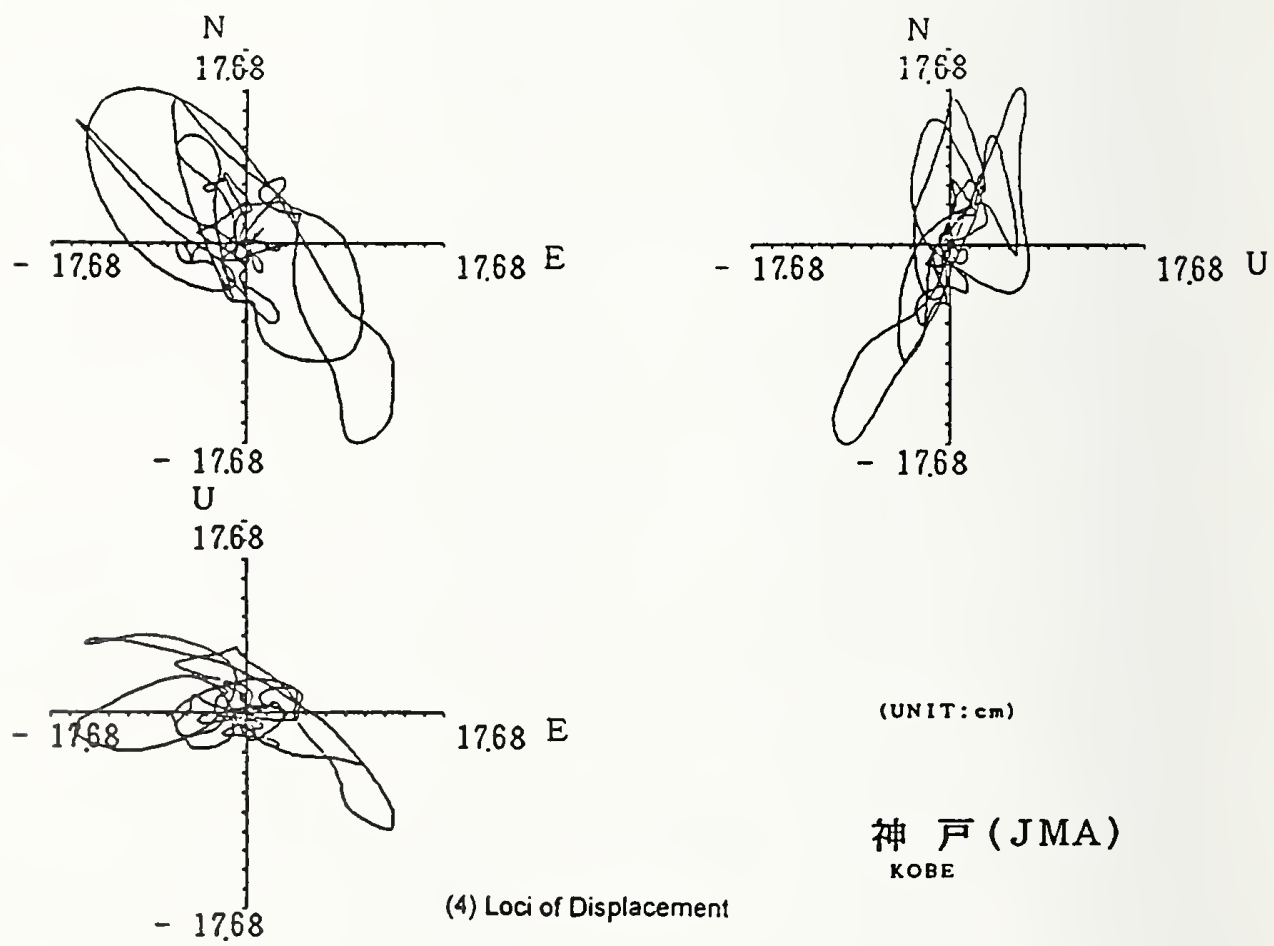

Figure 2.4.3 (a) Three-component (1) acceleration, (2) velocity, (3) displacement, and (4) displacement loci inferred by Nakamura (1995) from strong-motion recordings at site (a), Kobe Marine (JM-KBM). (Continued) 


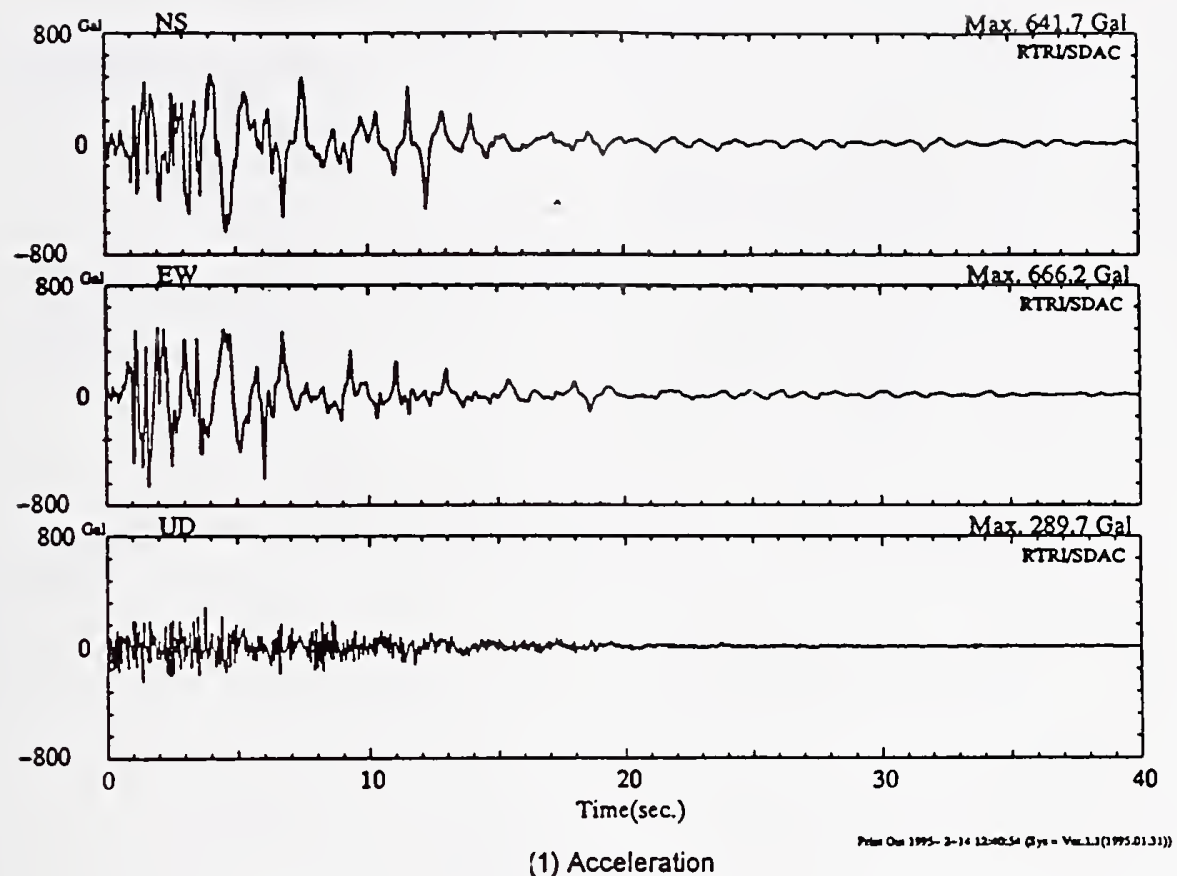

9501.1705 .4634 .36135 .0020 .07 .213 .8 TAKATORI

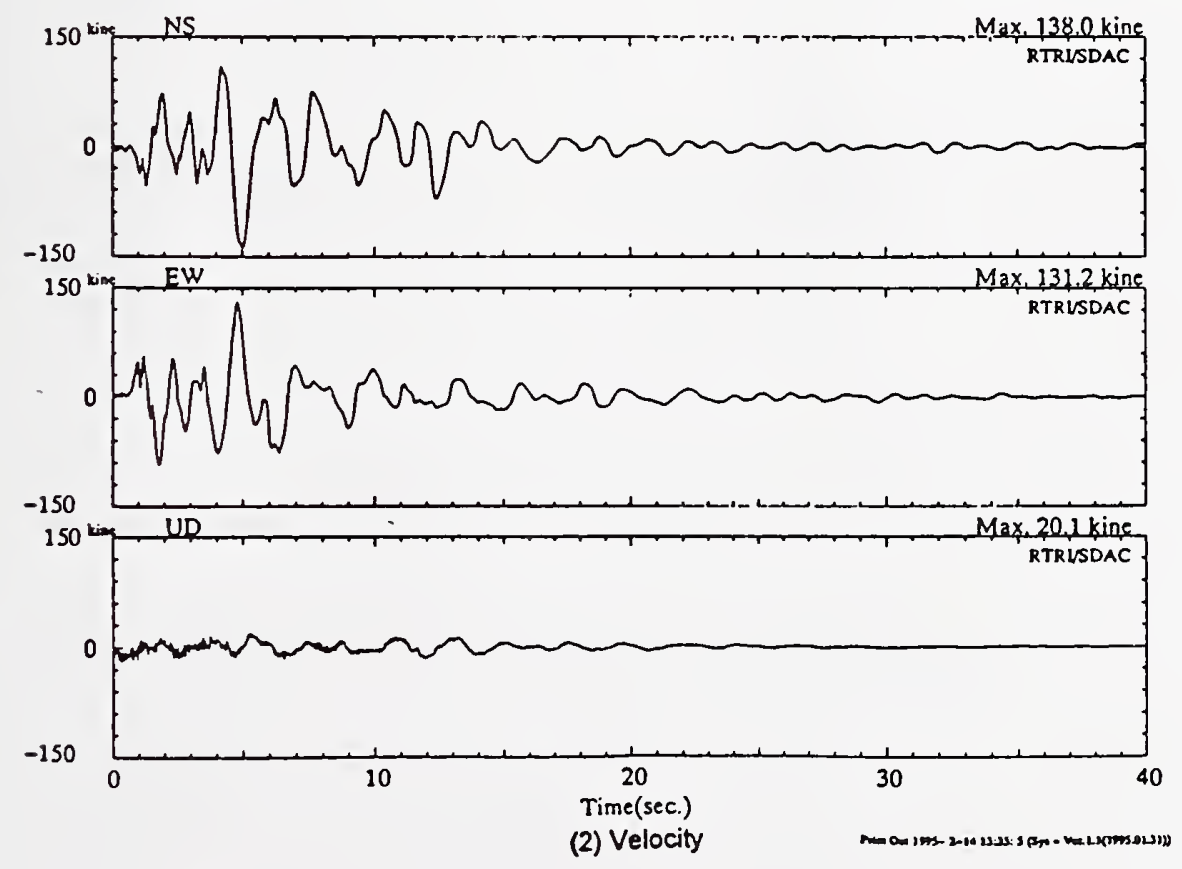

Figure 2.4.3 (b) Three-component (1) acceleration, (2) velocity, (3) displacement, and (4) displacement loci inferred by Nakamura (1995) from strong-motion recordings at site (b), Takatori (JR-TKT). 

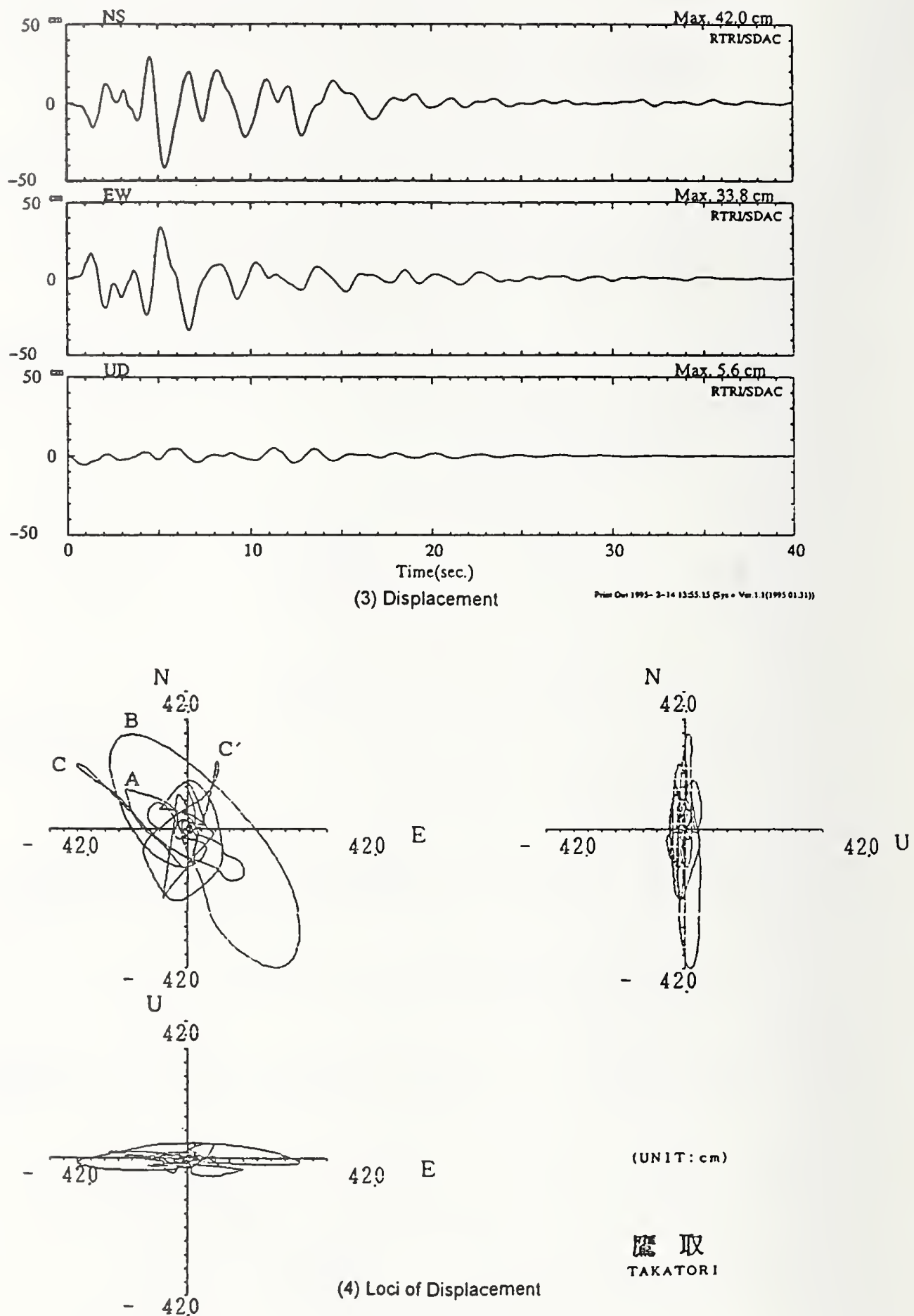

Figure 2.4.3 (b) Three-component (1) acceleration, (2) velocity, (3) displacement, and (4) displacement loci inferred by Nakamura (1995) from strong-motion recordings at site (b), Takatori (JR-TKT). (Continued) 
9501.1705 .4634 .36135 .0020 .07 .239 .2 TAKARAZUKA

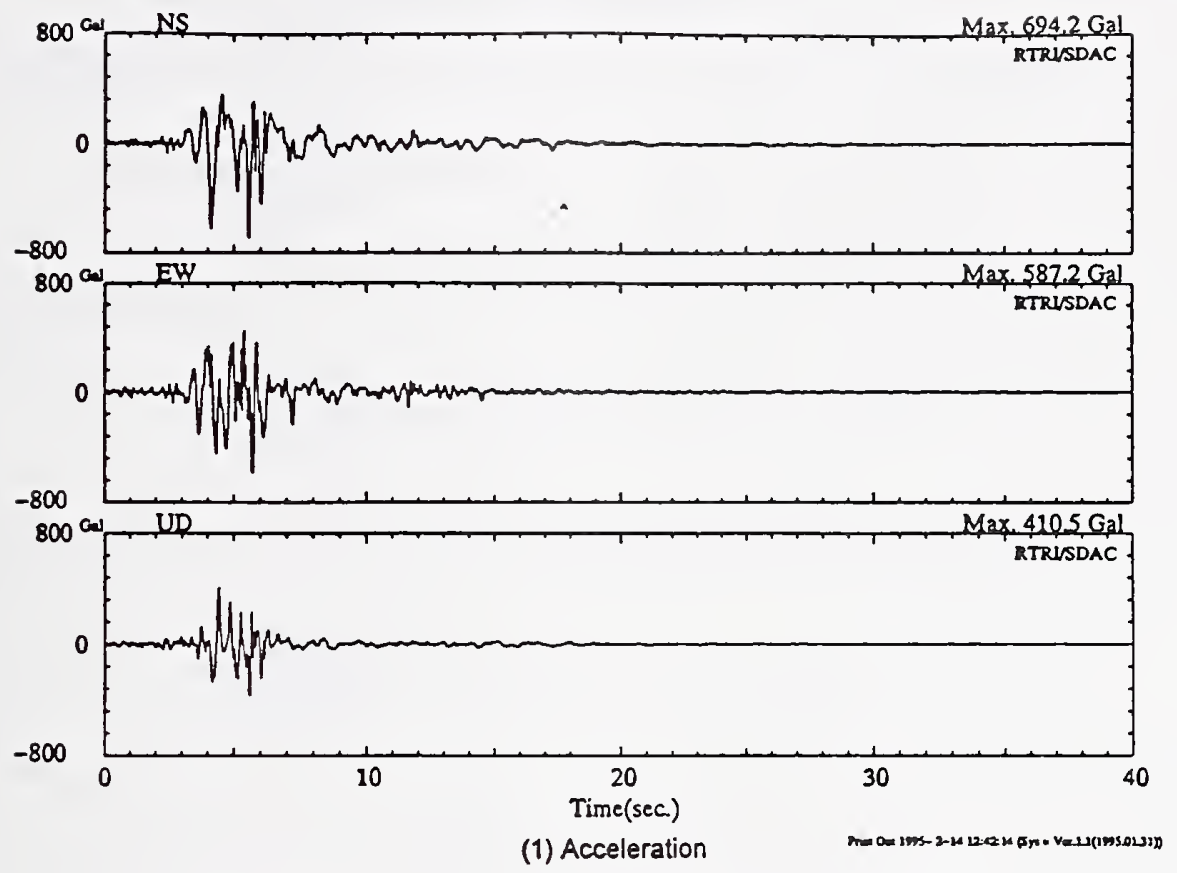

9501.1705 .4634 .36135 .0020 .07 .239 .2 TAKARAZUKA

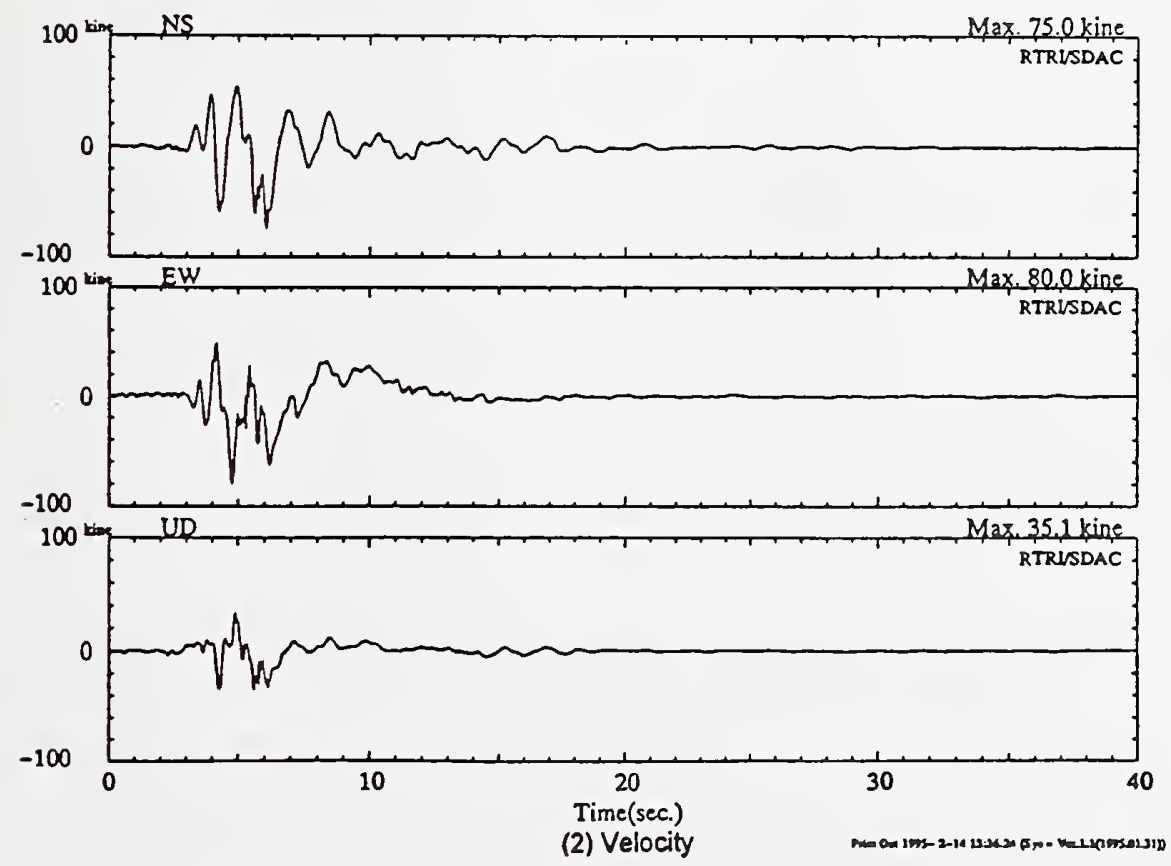

Figure 2.4.3 (c) Three-component (1) acceleration, (2) velocity, (3) displacement, and (4) displacement loci inferred by Nakamura (1995) from strong-motion recordings at site (c), Takarazuka (JR-TKD). 


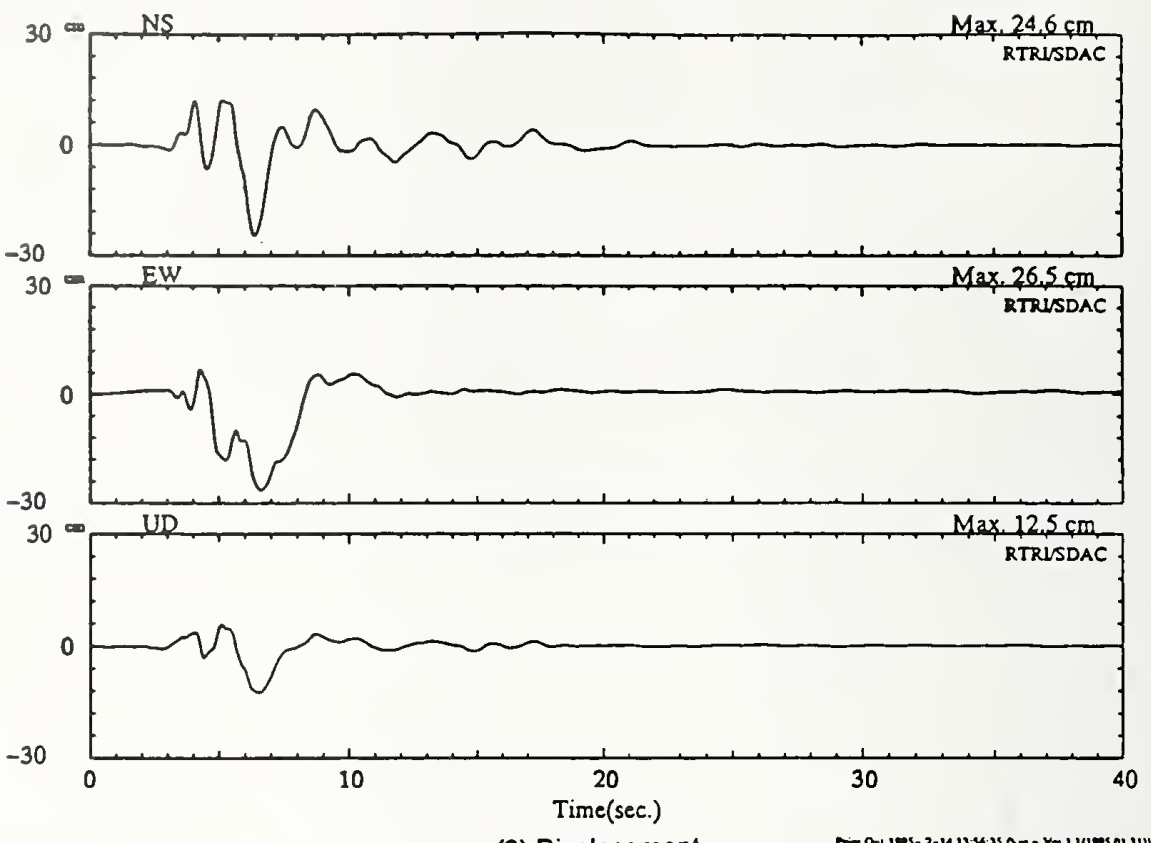

(3) Displacement
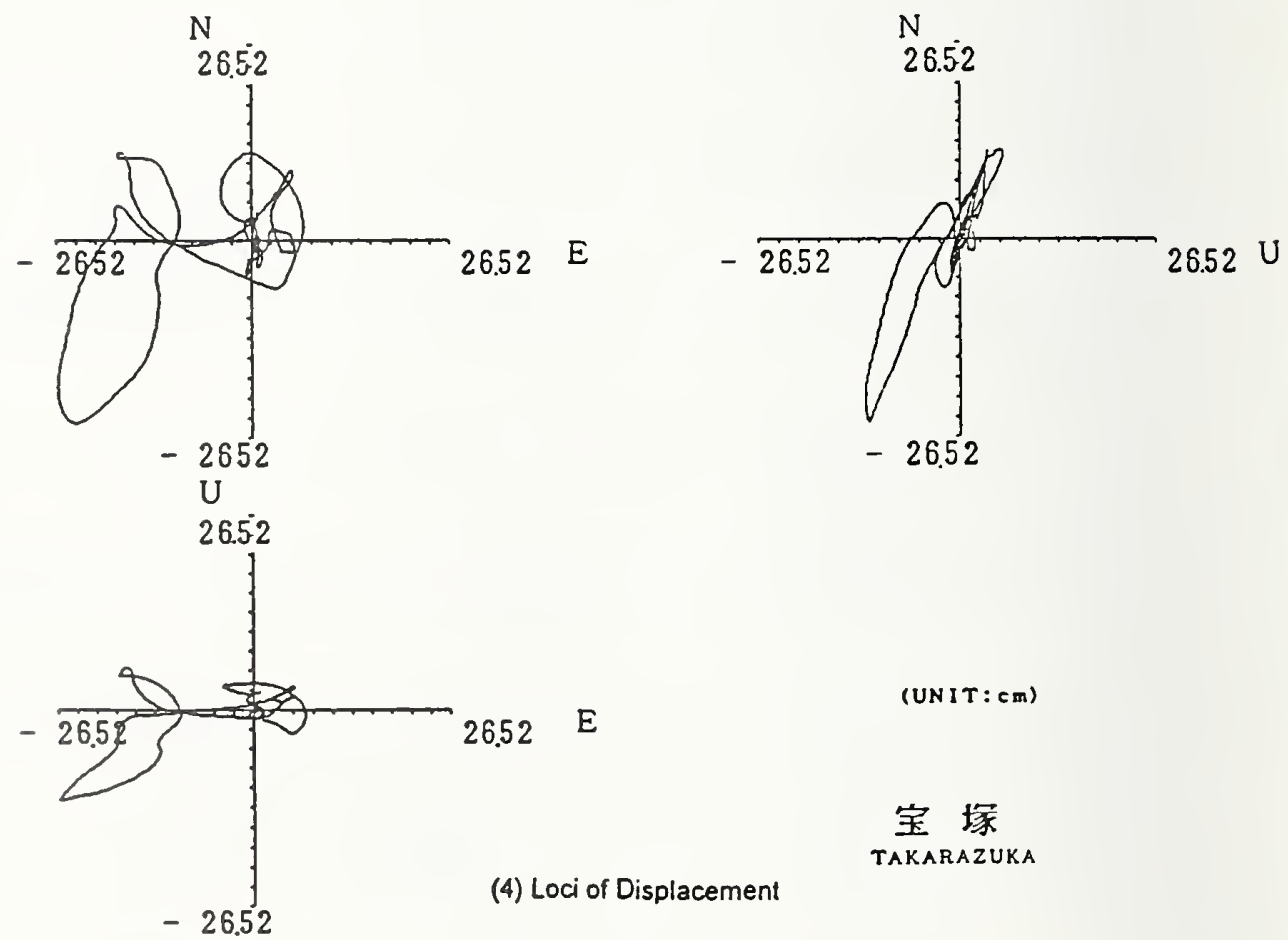

26.52

E

(UNIT: $\mathrm{cm}$ )

宝 塚

TAKARAZUKA

(4) Loci of Displacement

Figure 2.4.3 (c) Three-component (1) acceleration, (2) velocity, (3) displacement, and (4) displacement loci inferred by Nakamura (1995) from strong-motion recordings at site (c), Takarazuka (JR-TKD). (Continued) 
$9501.1705 .4634 .36135 .0020 .07 .2 \quad 8.0$ NISHI-AKASHI

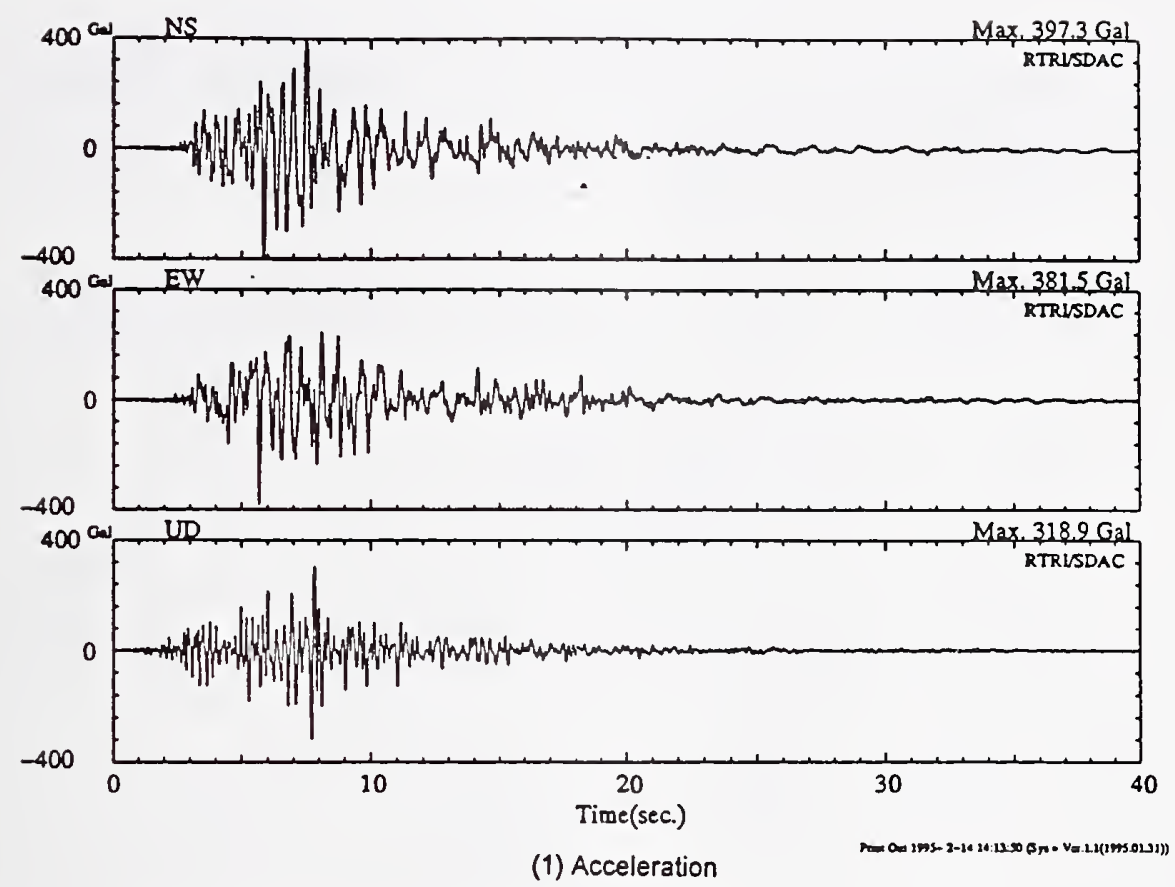

$9501.1705 .4634 .36135 .0020 .07 .2 \quad 8.0 \mathrm{NISHI}-\mathrm{AKASHI}$

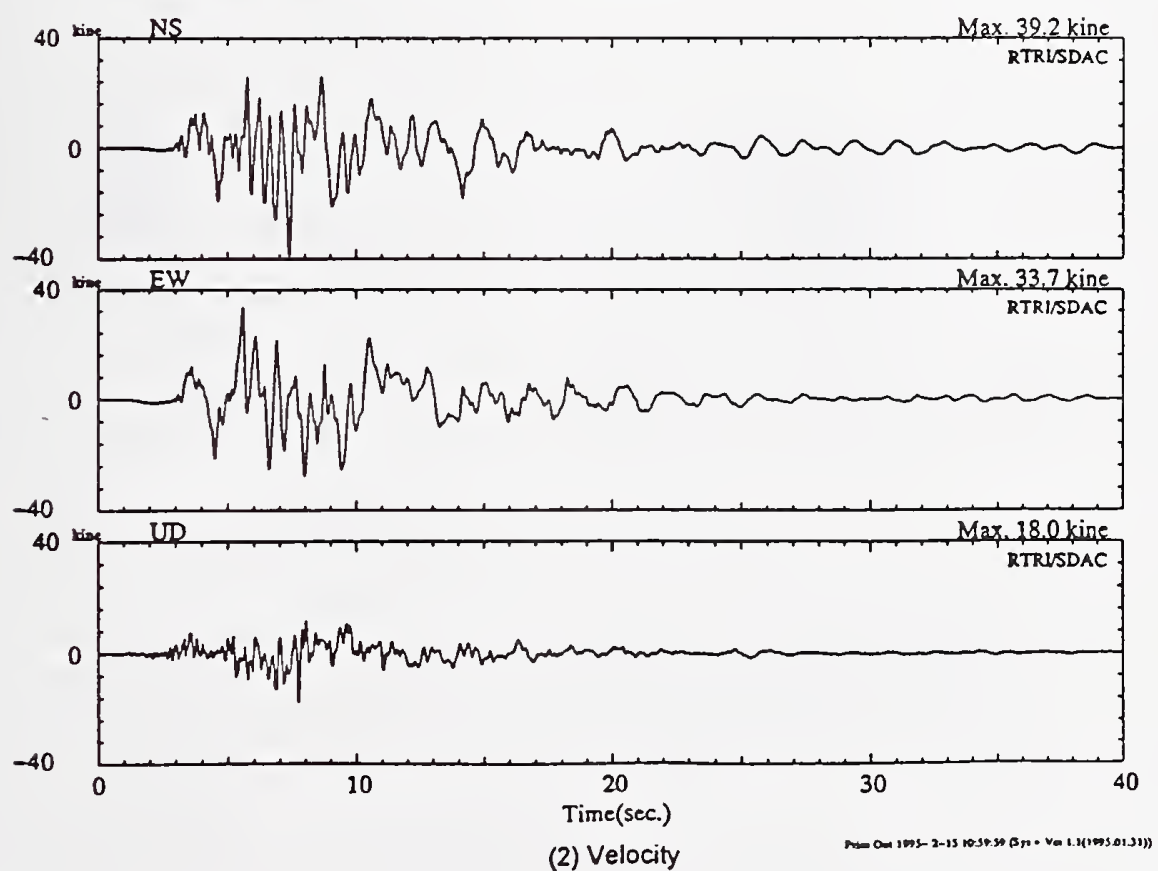

(2) Velocity

Figure 2.4.3 (d) Three-component (1) acceleration, (2) velocity, (3) displacement, and (4) displacement loci inferred by Nakamura (1995) from strong-motion recordings at site (d), Nishi-Akashi (JR-NSA). 


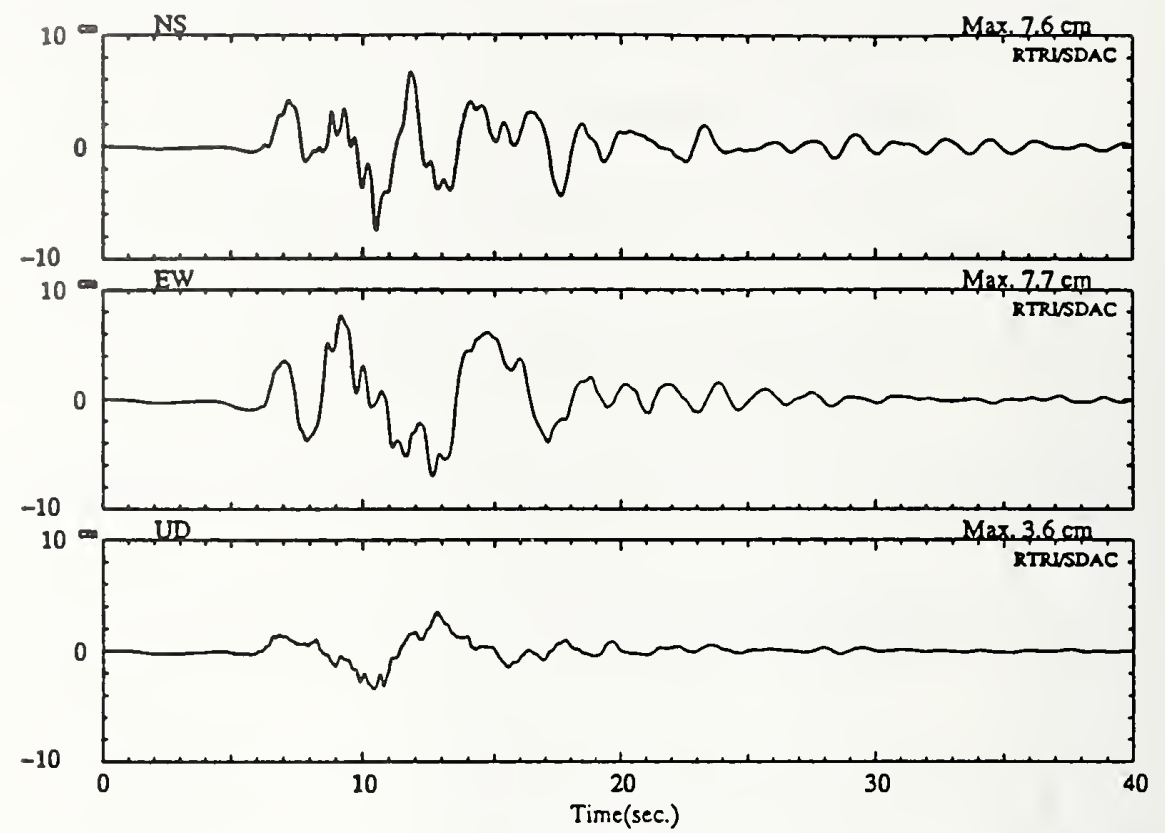

(3) Displacement
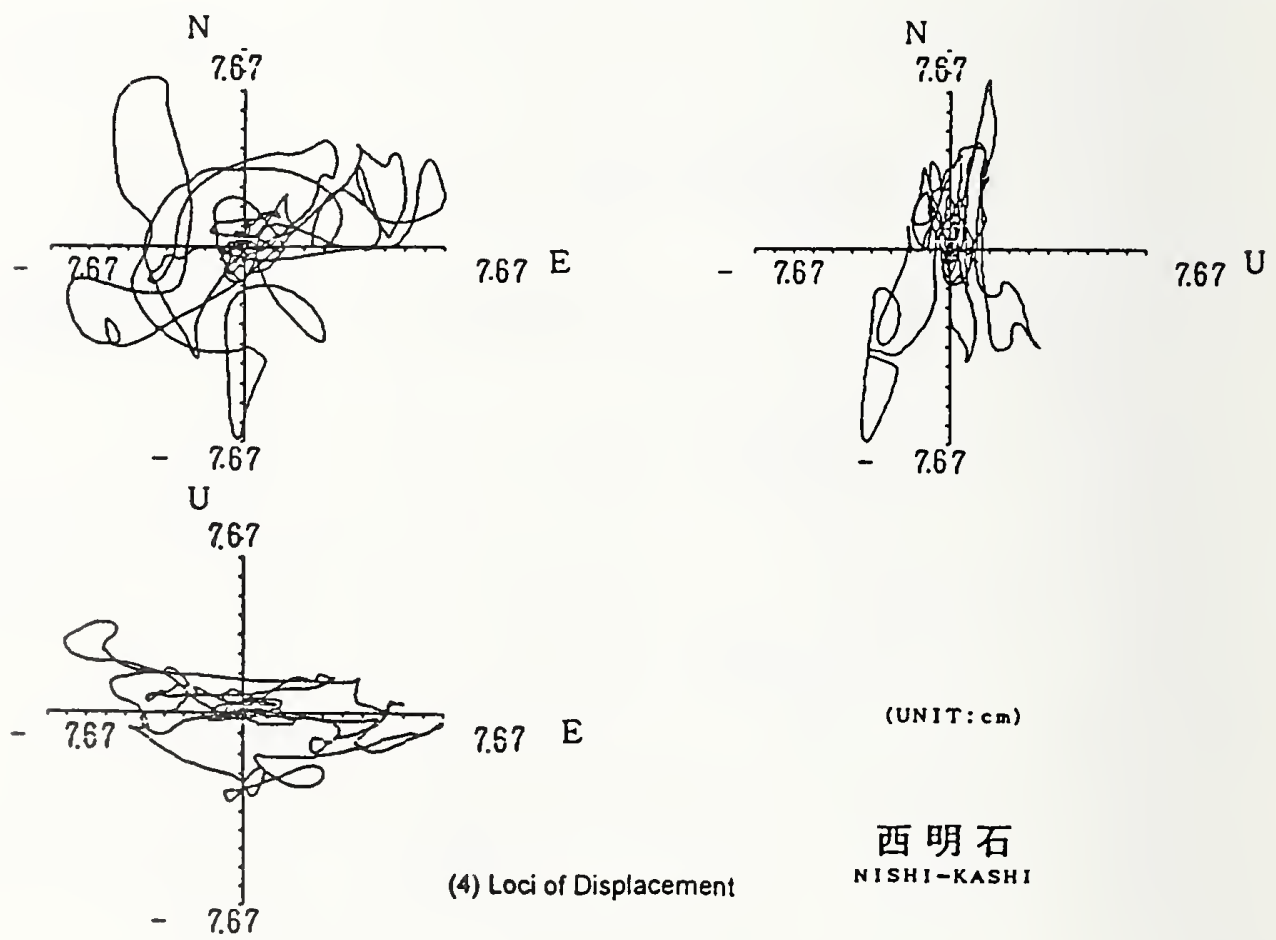

(UNIT: $c m$ )

西明石

NISHI-KASHI

Figure 2.4.3 (d) Three-component (1) acceleration, (2) velocity, (3) displacement, and (4) displacement loci inferred by Nakamura (1995) from strong-motion recordings at site (d), Nishi-Akashi (JR-NSA). (Continued) 
Response Spectra for Recent Devastating Earthquakes
(Pseudo Response Spectrum with 5\% Damping)

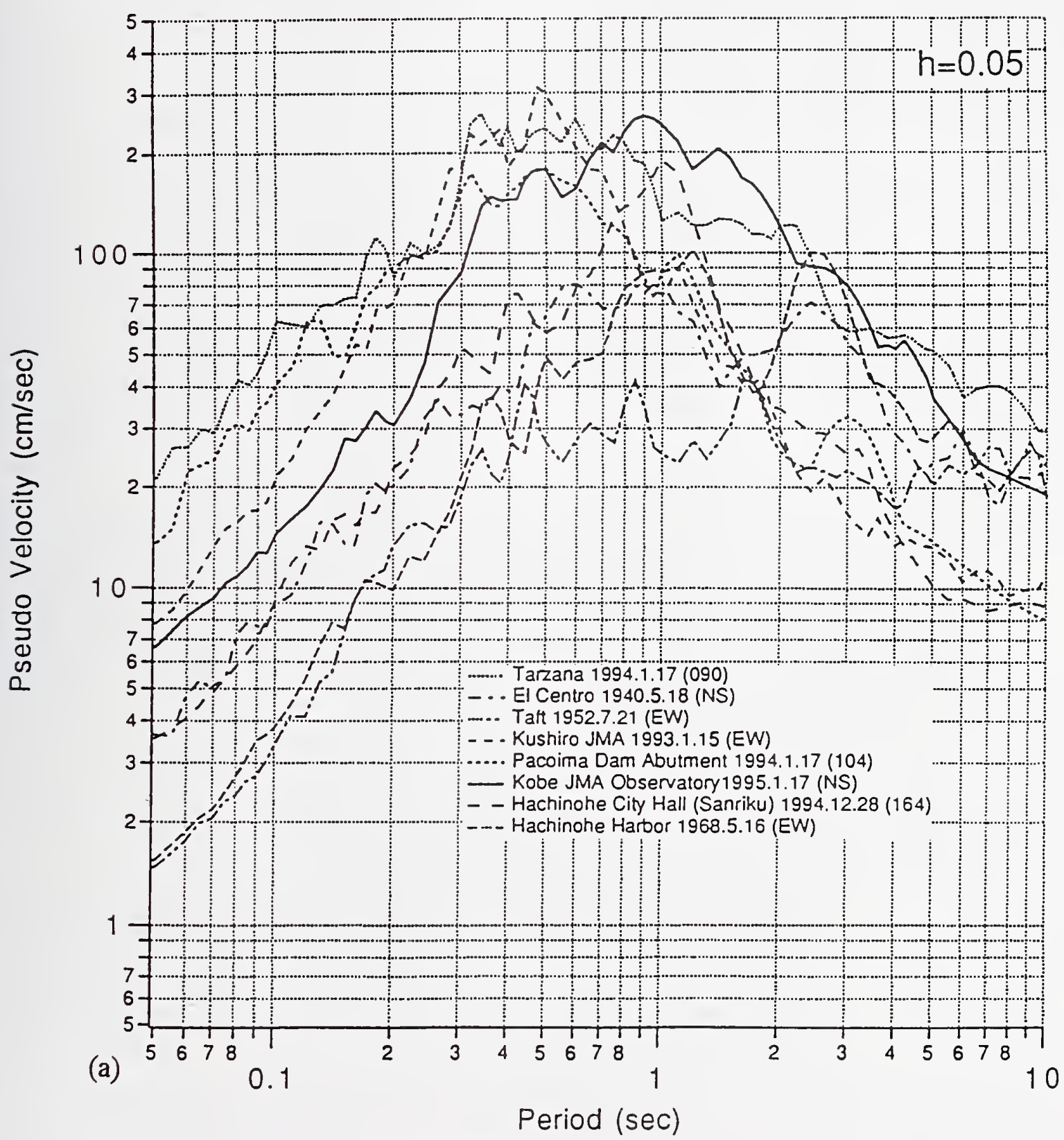

Figure 2.4.4 (a) Pseudo Velocity Response Spectra for recent devastating earthquakes for the horizontal components (a). (from Building Research Institute, courtesy M. Watabe). 


\section{Response Spectra for Recent Devastating Earthquakes (Pseudo Velocity Spectrum with 5\% damping)}

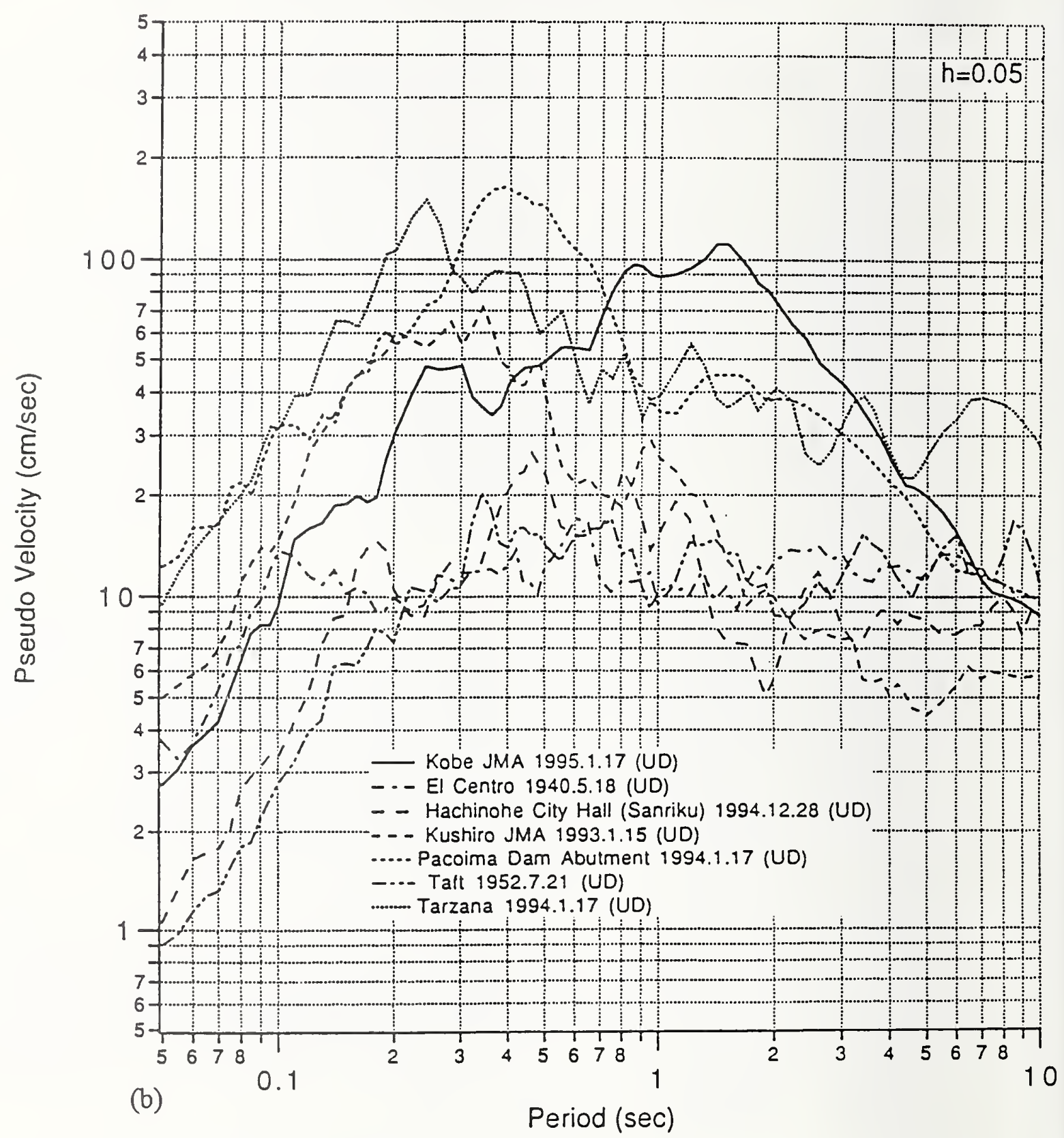

Figure 2.4.4 (b) Pseudo Velocity Response Spectra for recent devastating earthquakes for the UD component (b). (from Building Research Institute, courtesy M. Watabe). 
Kobe JMA Record 1995.1.17

vs Design Spectra for Tall Buildings in Japan

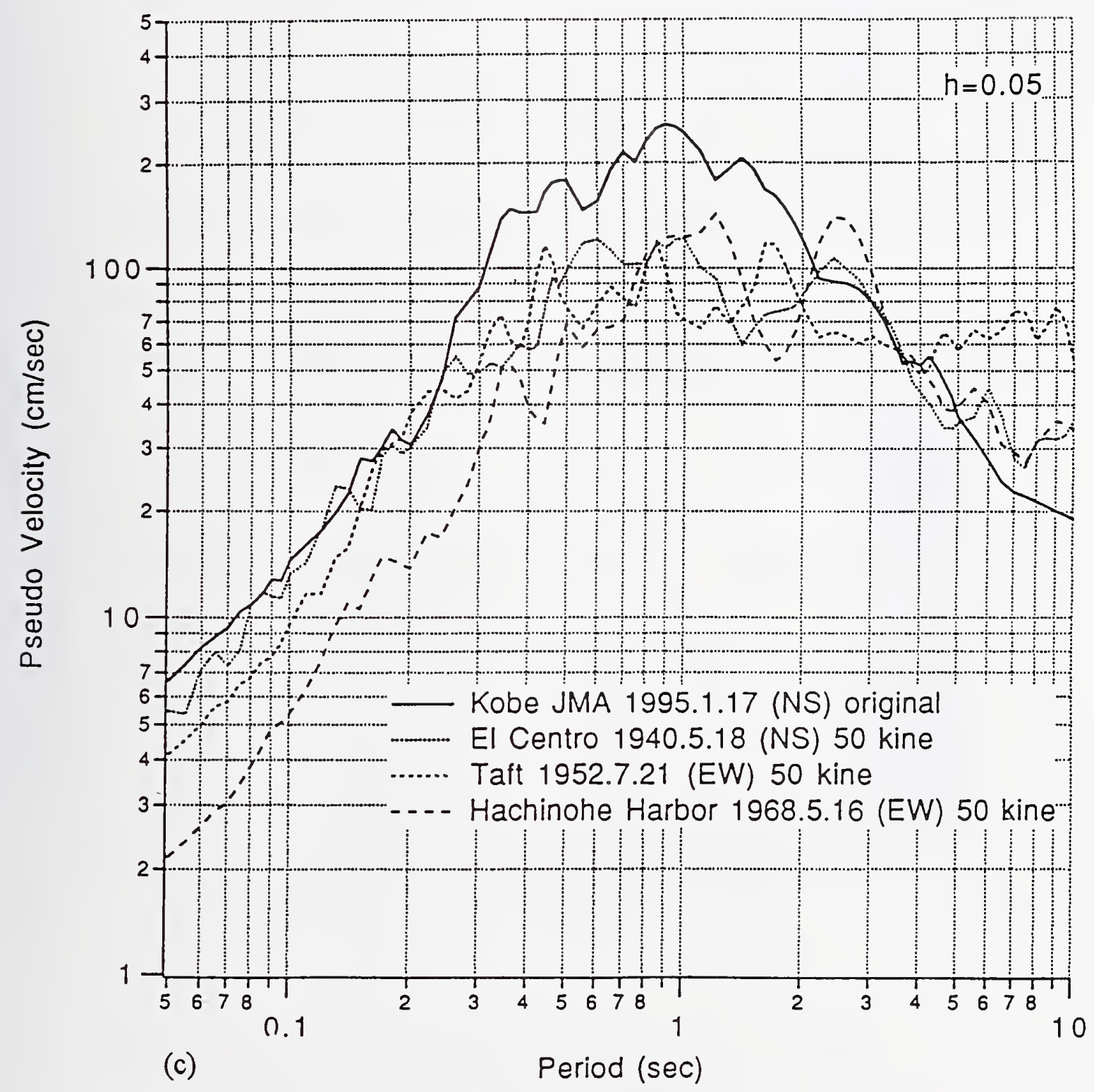

Figure 2.4.4 (c) Pseudo Velocity Response Spectra for recent devastating earthquakes for design spectral for tall buildings (c). (from Building Research Institute, courtesy M. Watabe). 

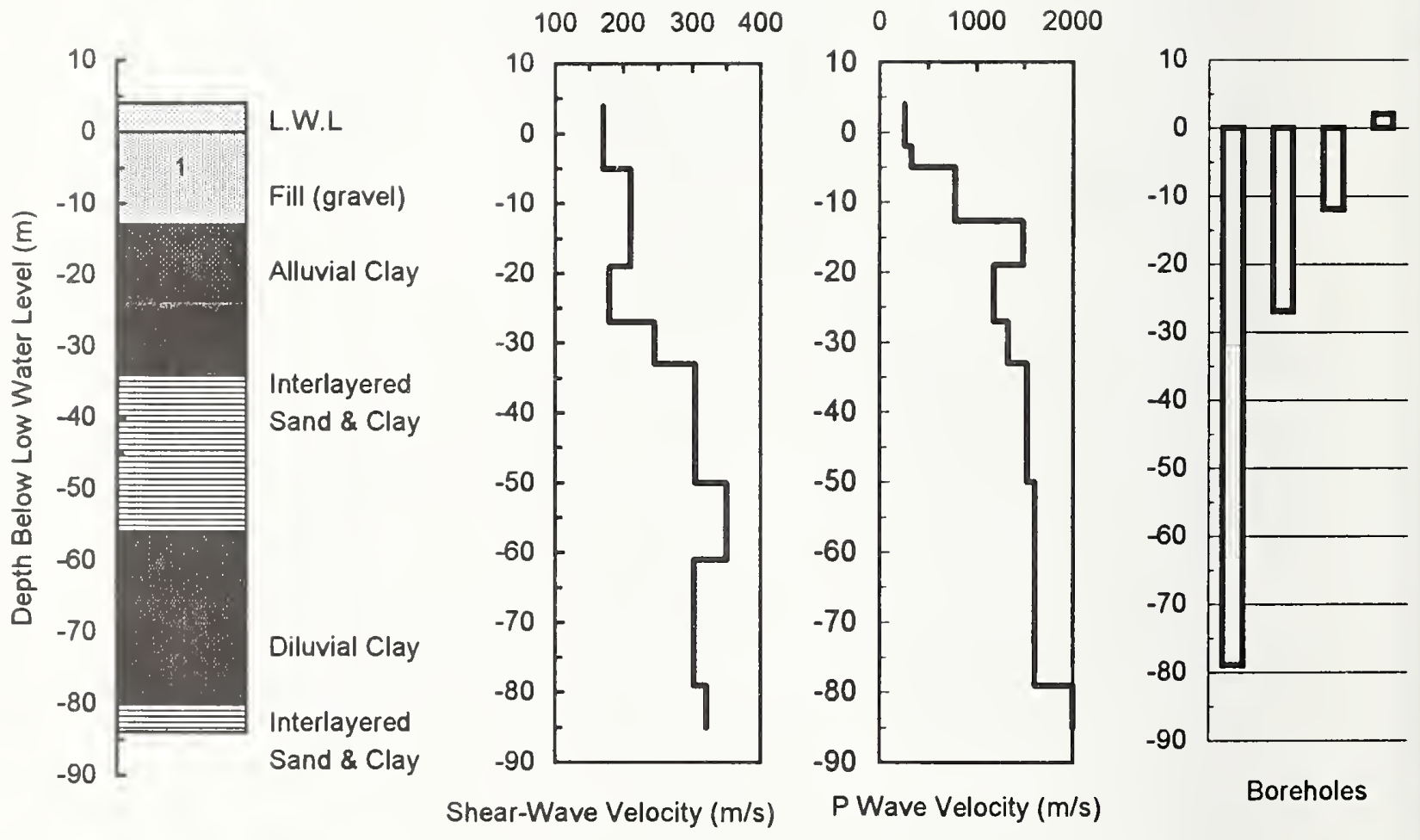

Figure 2.4.5 Geologic and seismic logs for the Port Island vertical array site (modified from logs provided by The Committee on Earthquake Observation and Research in the Kansai Area, CEORKA, courtesy Y. Iwasaki). 


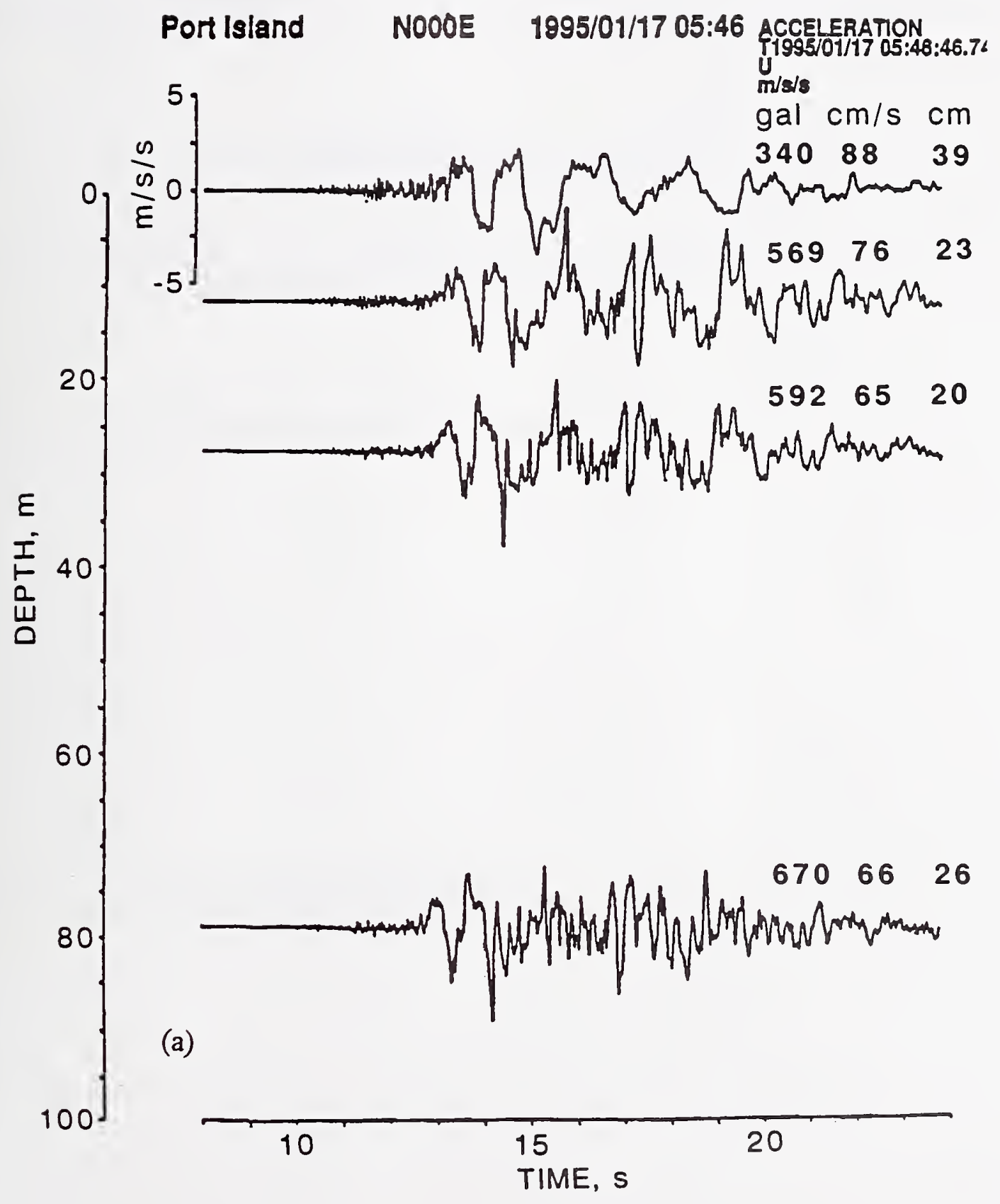

Figure 2.4.6 (a) Strong motion recordings obtained on the Port Island vertical array at the surface and at approximate depths of 12,27, and $79 \mathrm{~m}$ for the NS (a) component (from The Committee on Earthquake Observation and Research in the Kansai Area, CEORKA, courtesy Y. Iwasaki). 


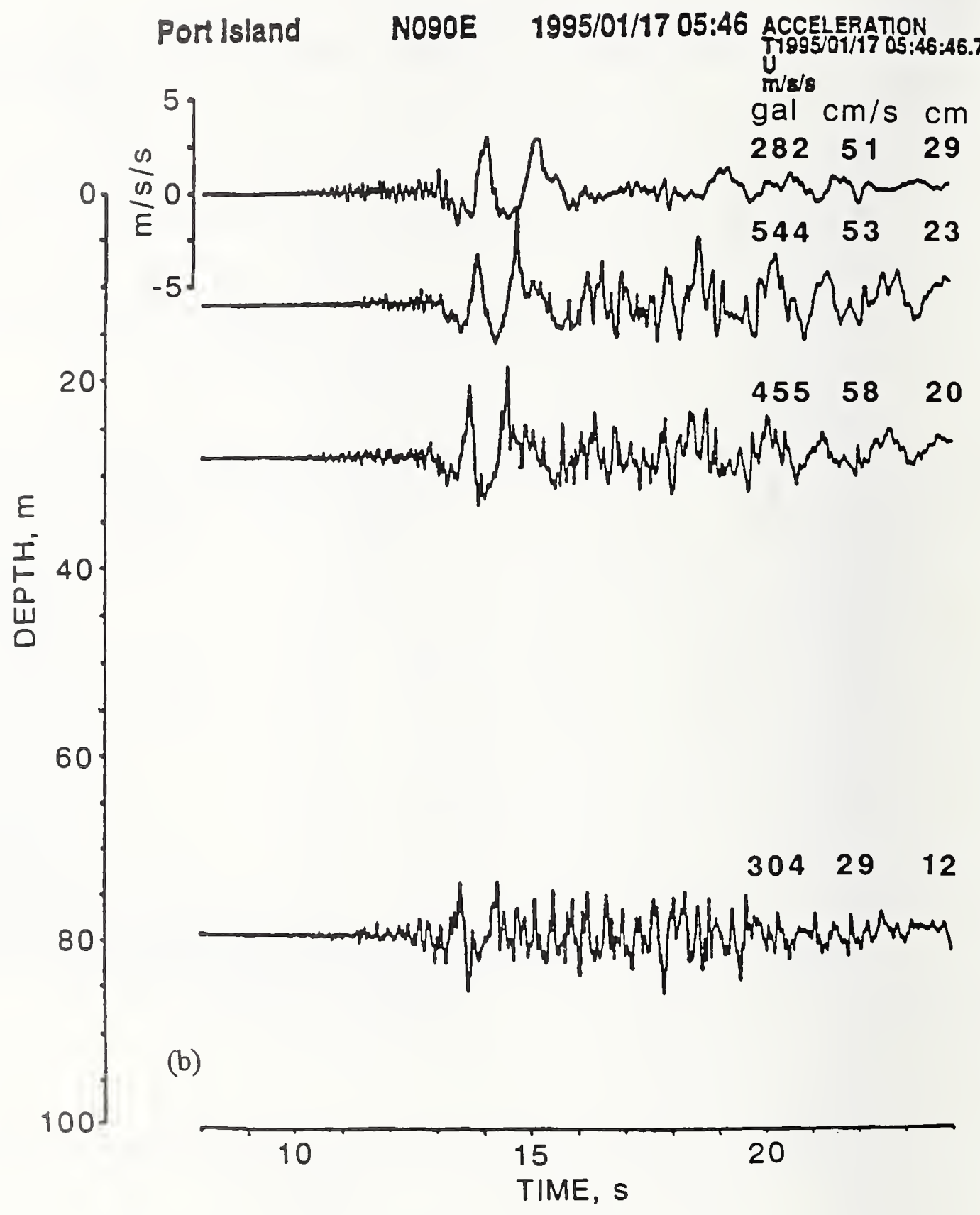

Figure 2.4.6 (b) Strong motion recordings obtained on the Port Island vertical array at the surface and at approximate depths of 12, 27, and $79 \mathrm{~m}$ for the EW (b) component (from The Committee on Earthquake Observation and Research in the Kansai Area, CEORKA, courtesy Y. Iwasaki). 


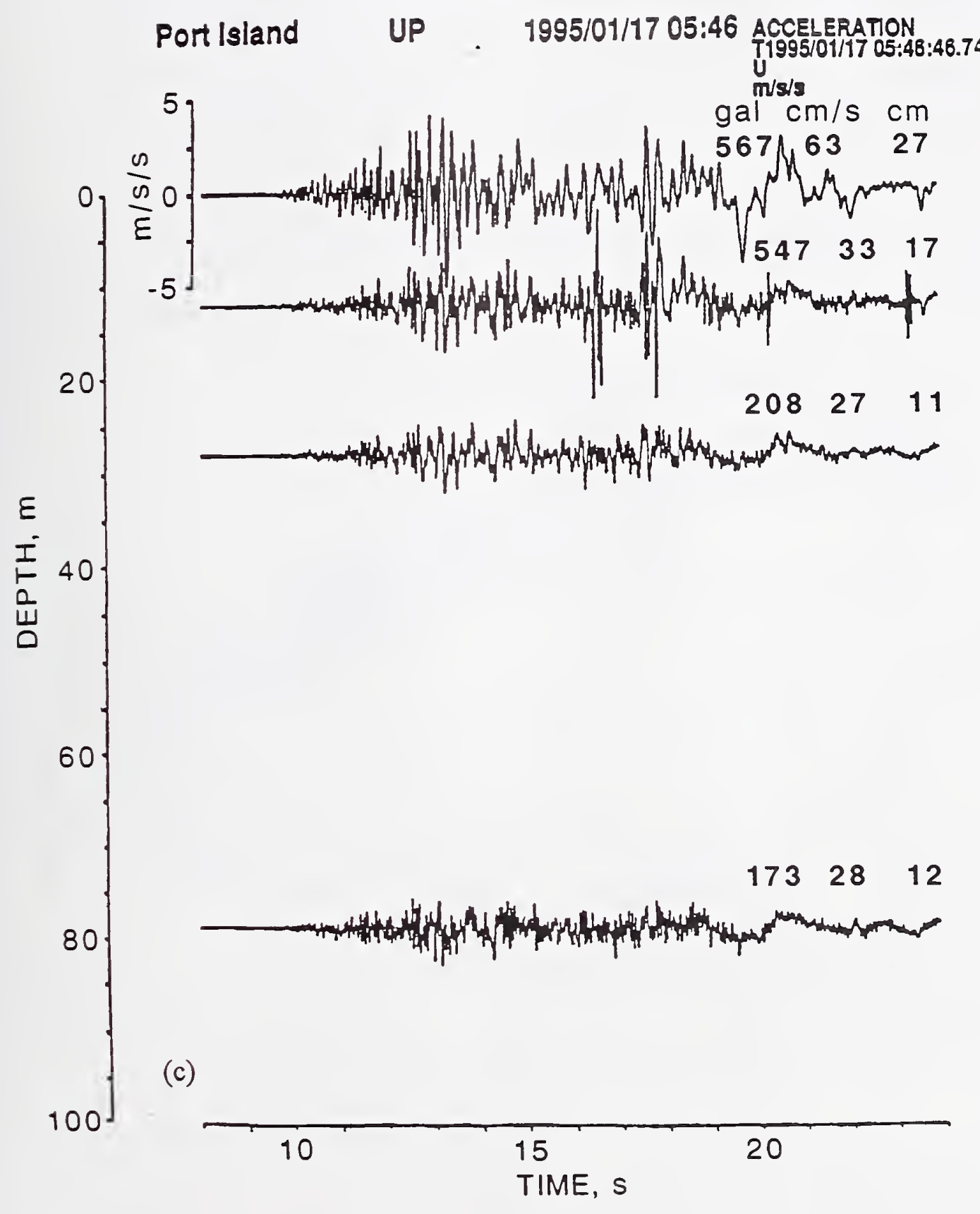

Figure 2.4.6 (c) Strong motion recordings obtained on the Port Island vertical array at the surface and at approximate depths of 12, 27, and $79 \mathrm{~m}$ for the UD (c) component (from The Committee on Earthquake Observation and Research in the Kansai Area, CEORKA, courtesy Y. Iwasaki). 


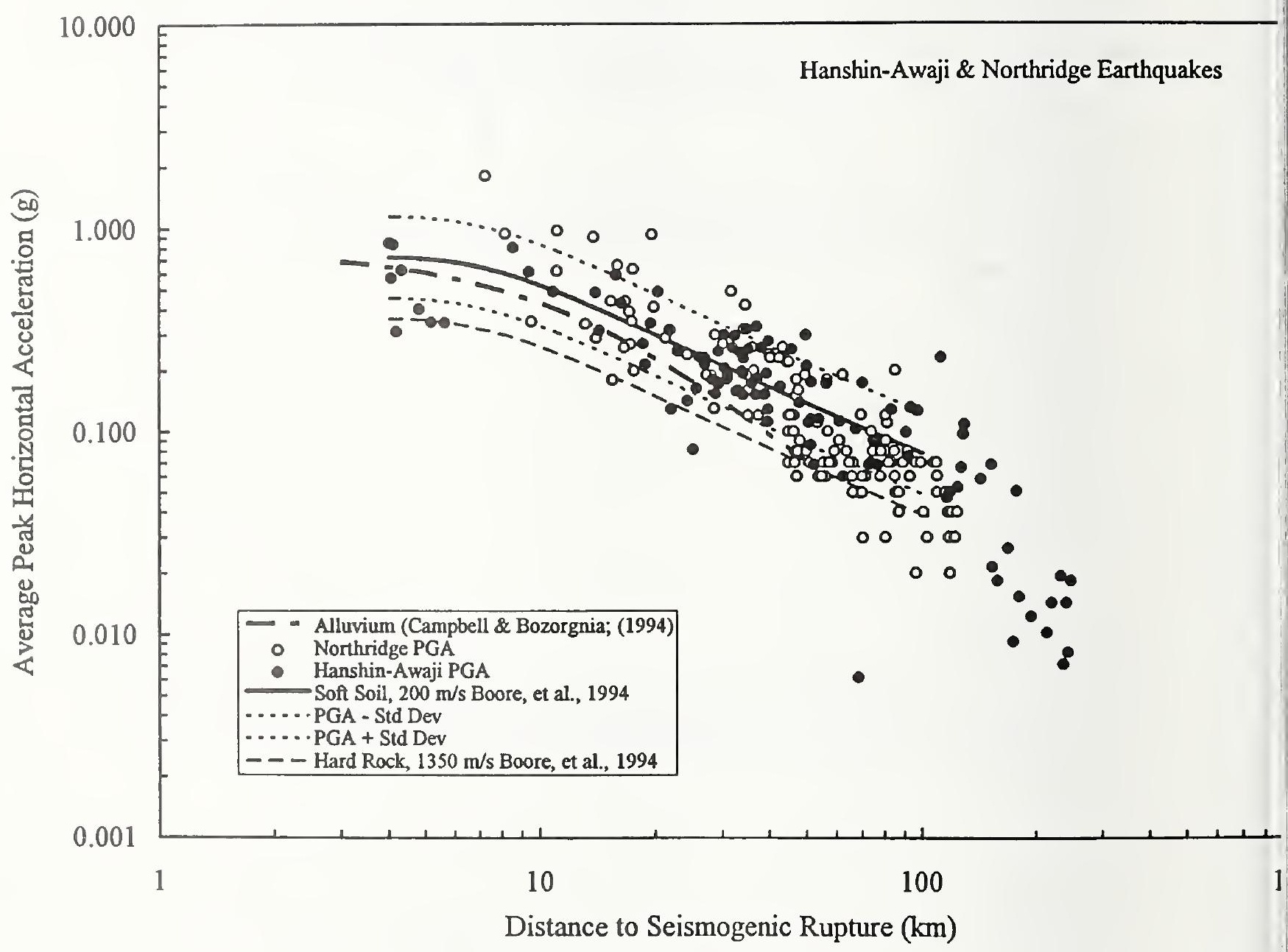

Figure 2.4.7 Preliminary compilation of peak horizontal acceleration as a function of closest distance to seismogenic rupture for the Northridge and Hyogoken-Nanbu earthquakes (attenuation curves courtesy of K. Campbell for evaluation of Northridge data). 


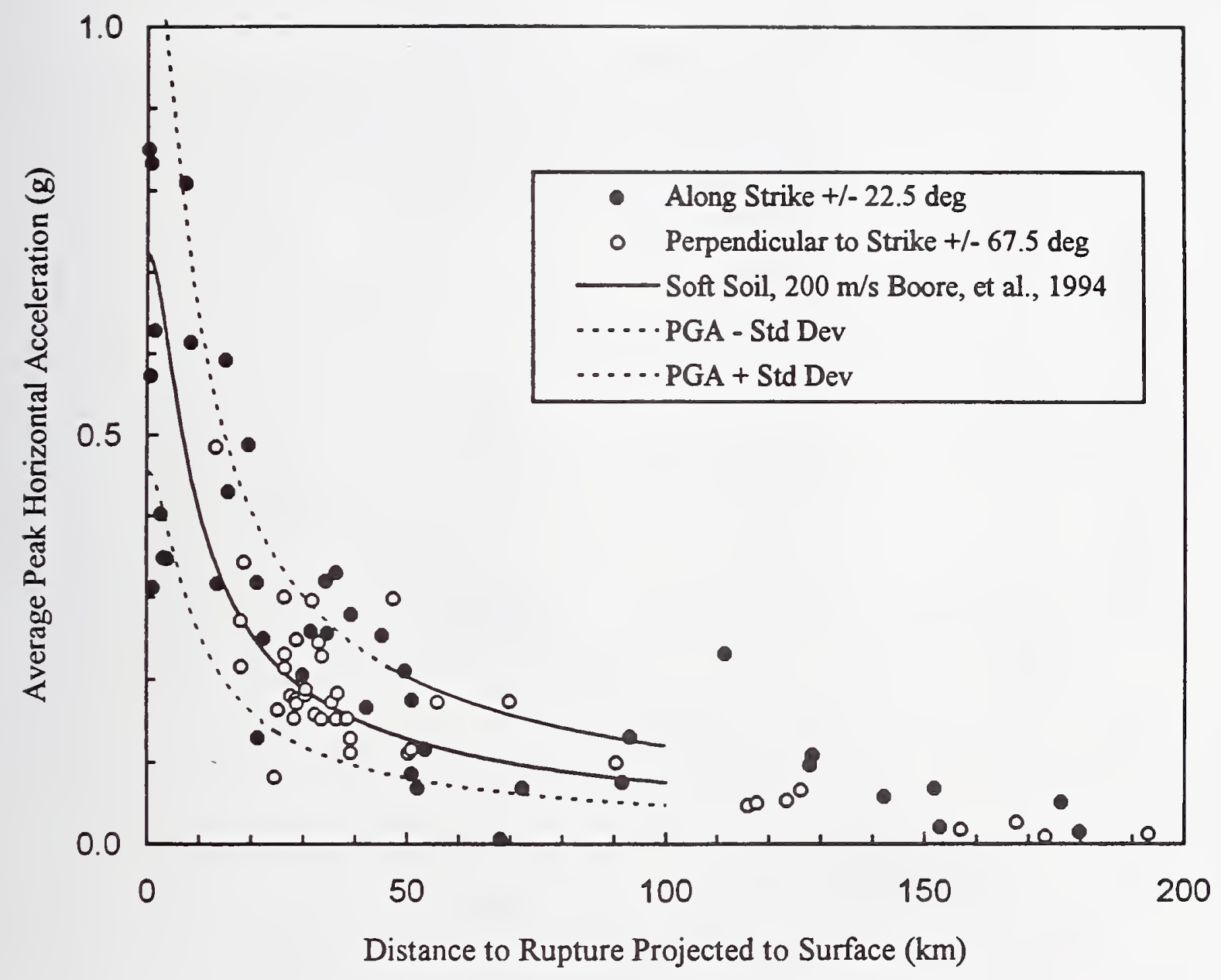

Figure 2.4.8 Preliminary compilation of peak horizontal acceleration compiled along strike $( \pm$ 22.5 degree) and perpendicular to strike (+ 67.5 degrees). 


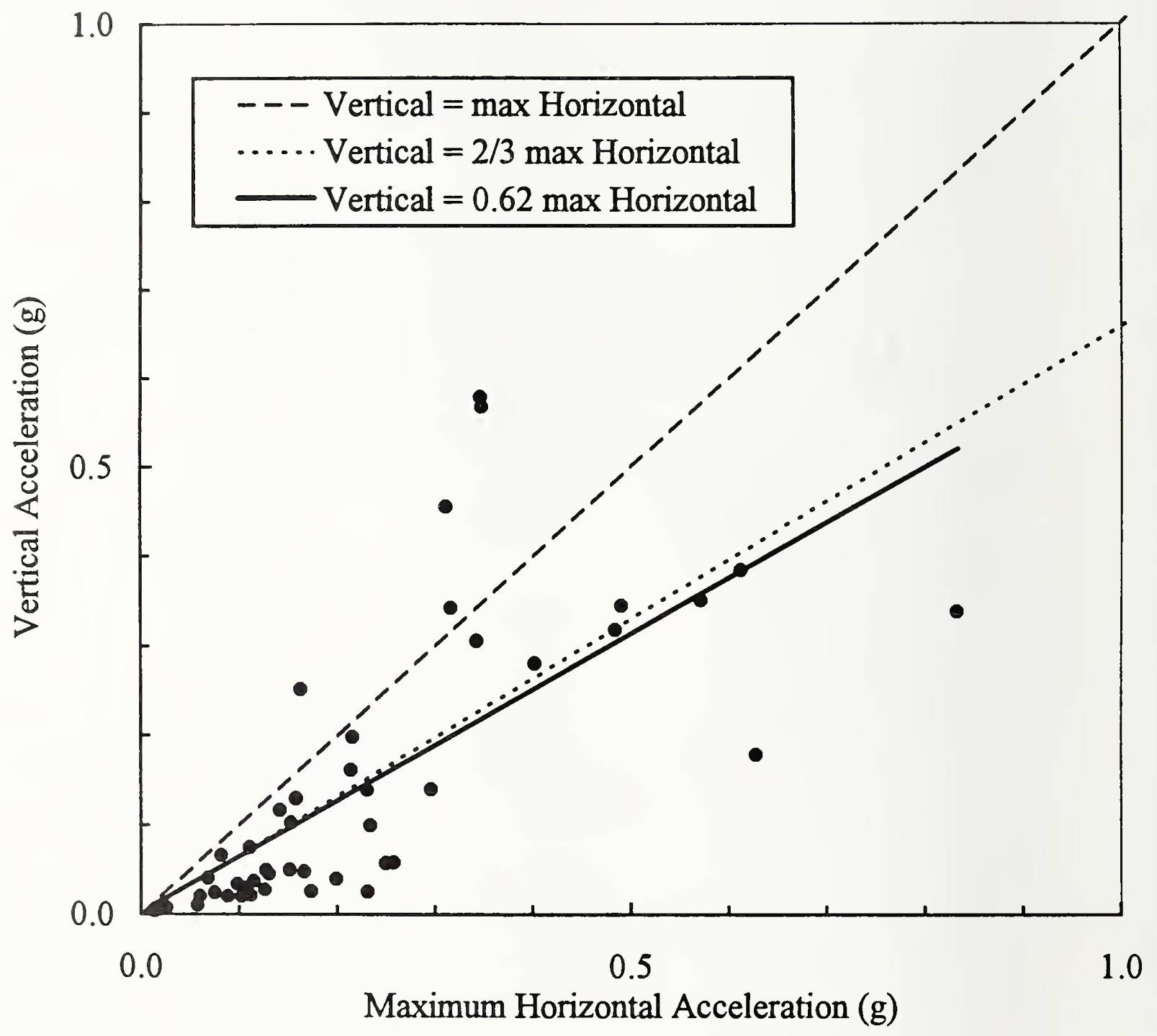

Figure 2.4.9 Preliminary compilation of peak vertical and peak horizontal acceleration. 


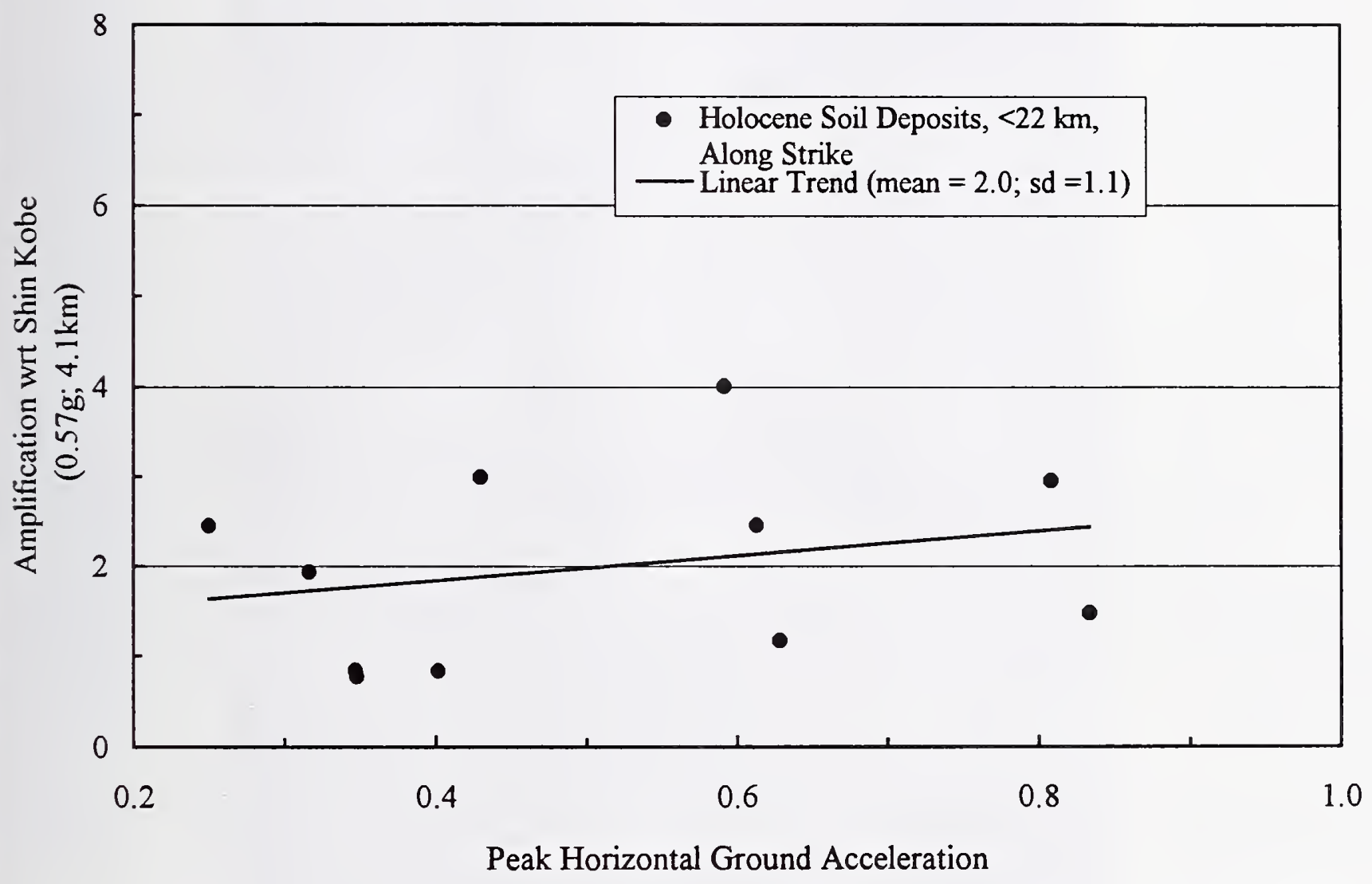

Figure 2.4.10 Amplification of peak horizontal acceleration with respect to corresponding value at Shin-Kobe station $(0.57 \mathrm{~g})$ as normalized by the reciprocal ratio of respective distances to seismogenic rupture for sites within a $+/-22.5$ degree azimuthal window of fault strike $\left(51^{\circ}\right)$. 


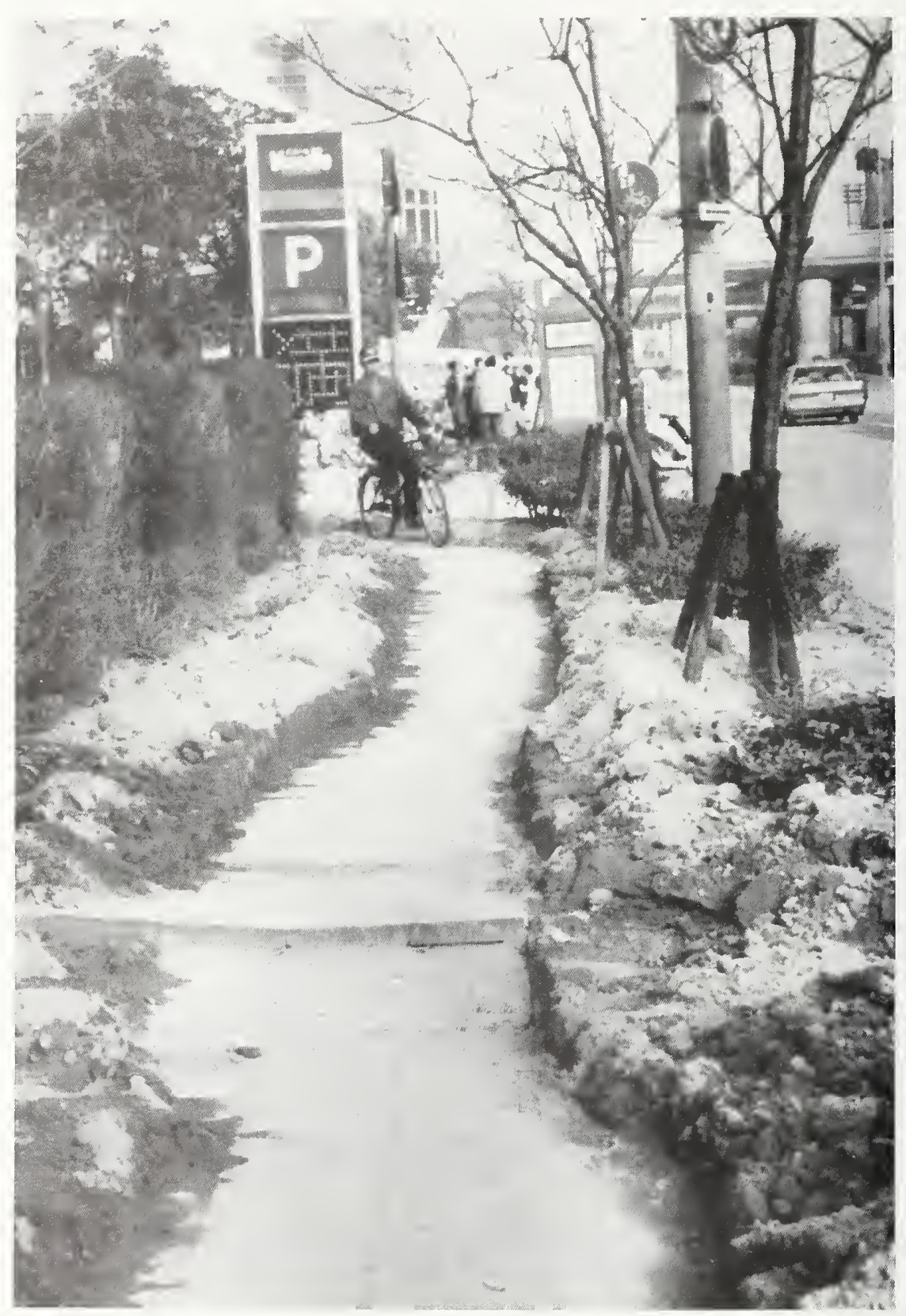

Figure 2.5.1 Path cleared through soil vented by liquefaction that covered sidewalk on Port Island (Photograph by Carol S. Prentice, USGS). 


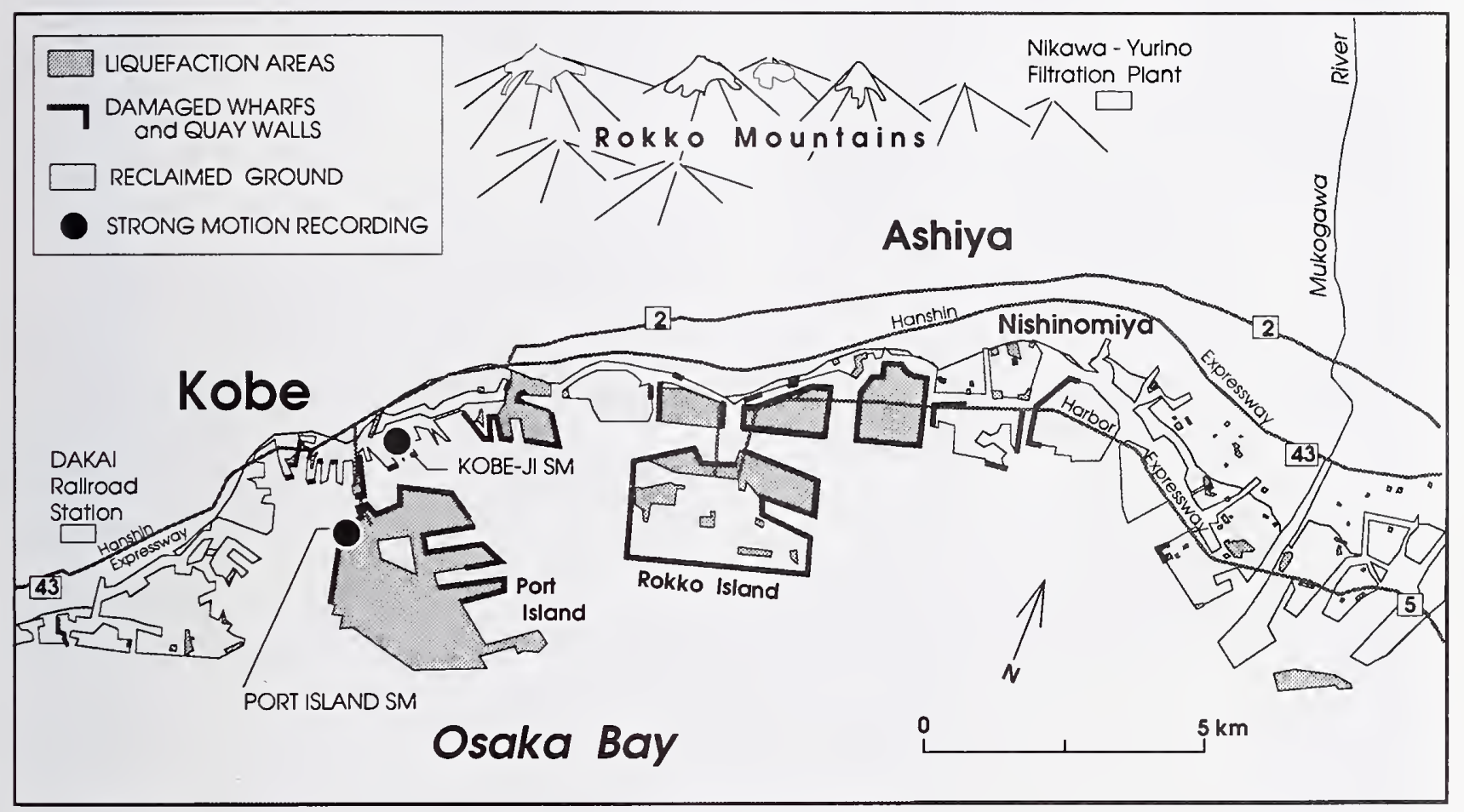

Figure 2.5.2 Generalized areas where liquefaction vented material at the land surface. Areas are inferred primarily from aerial photographs and unpublished maps by the Geographical Survey of Japan. 


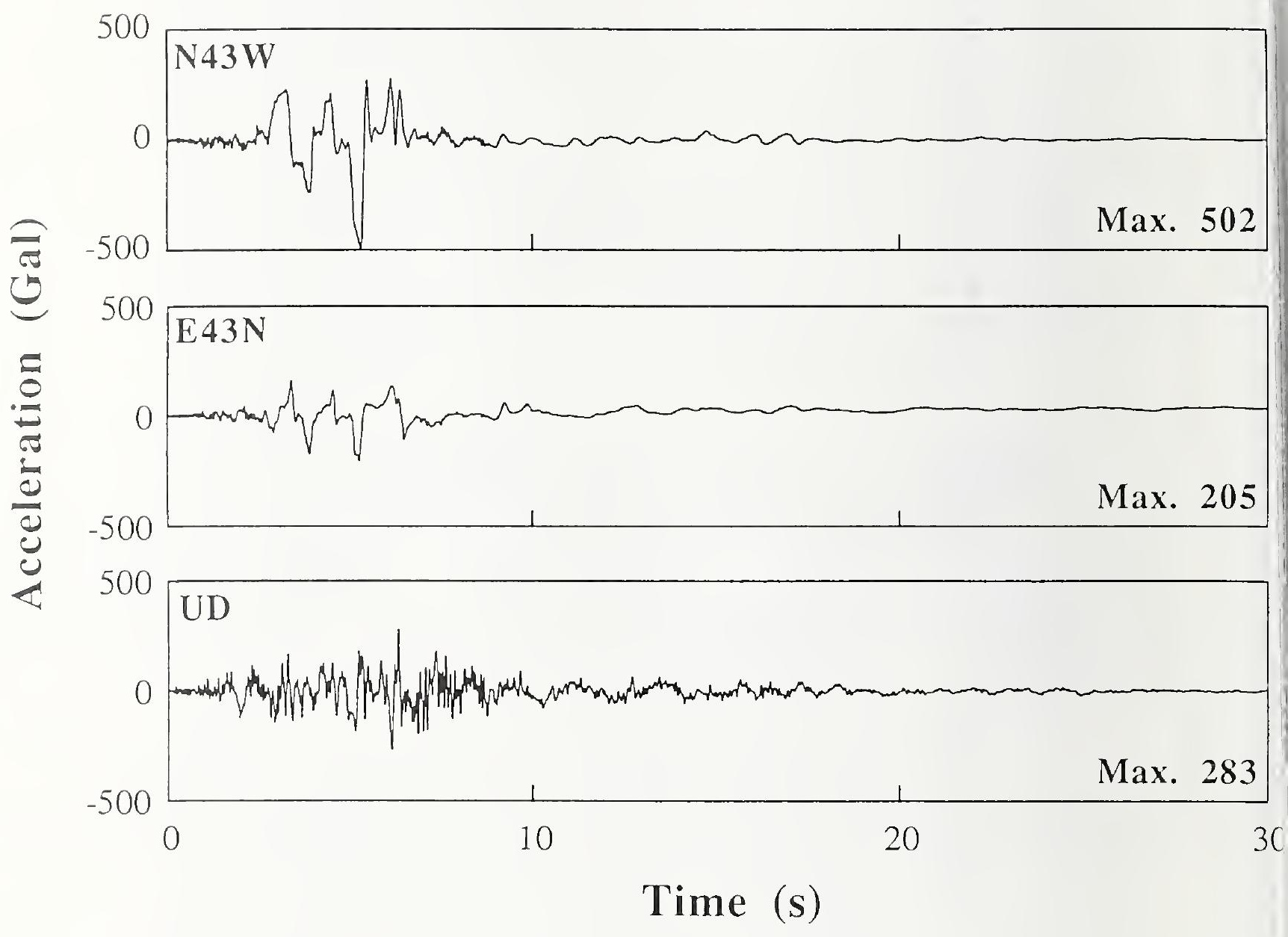

Figure 2.5.3 Kobe-Awaji strong ground motion record at Port of Kobe Construction Office from January 17, 1995, Hyogoken-Nanbu earthquake (source: Port and Harbor Research Institute). 


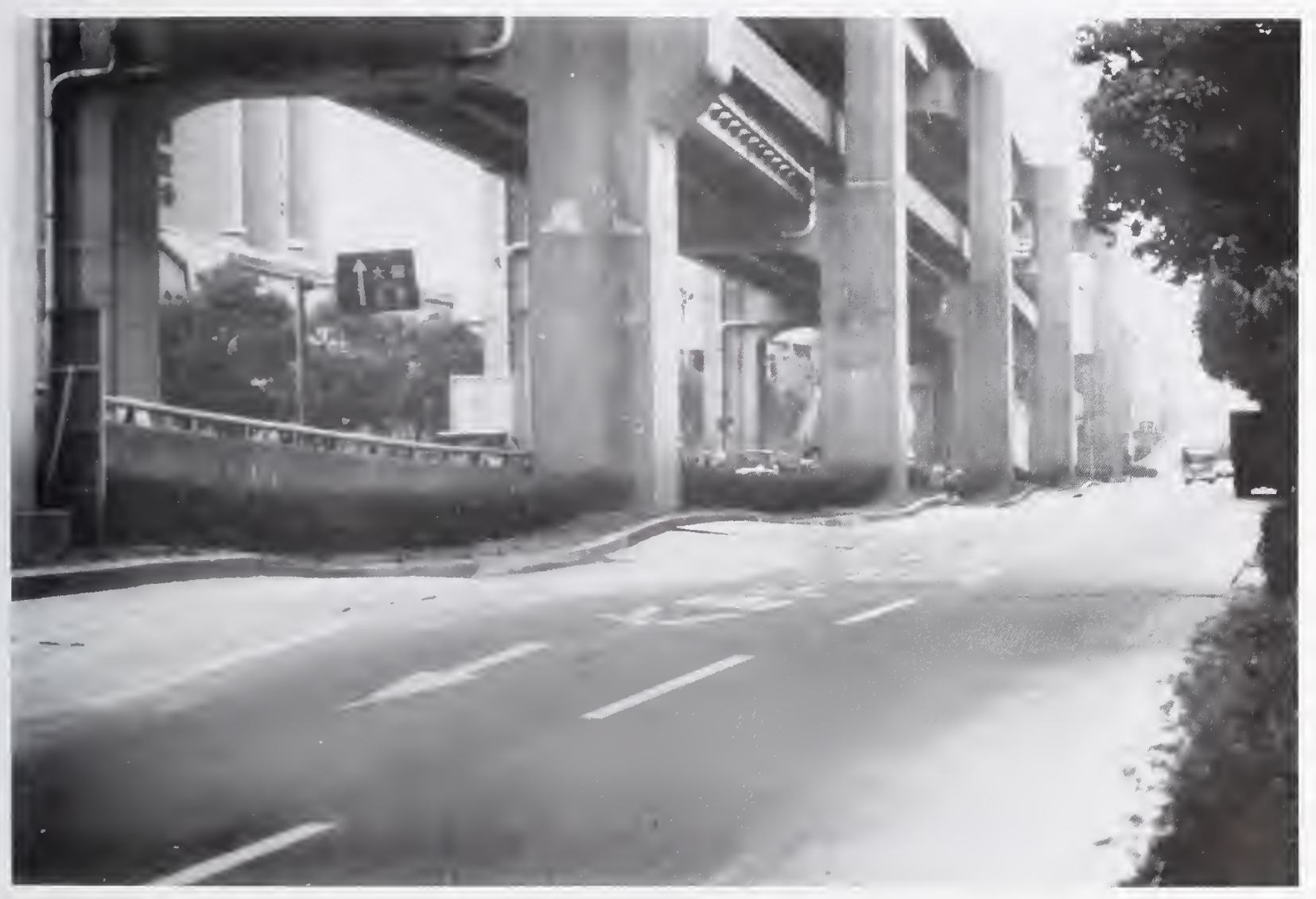

Figure 2.5.4 Differential ground settlement in artificial fill along the Harbor Freeway. Postliquefaction consolidation cause ground to settle between bridge columns. Columns extend through the liquefied zone. (Photograph by Carol S. Prentice, USGS). 


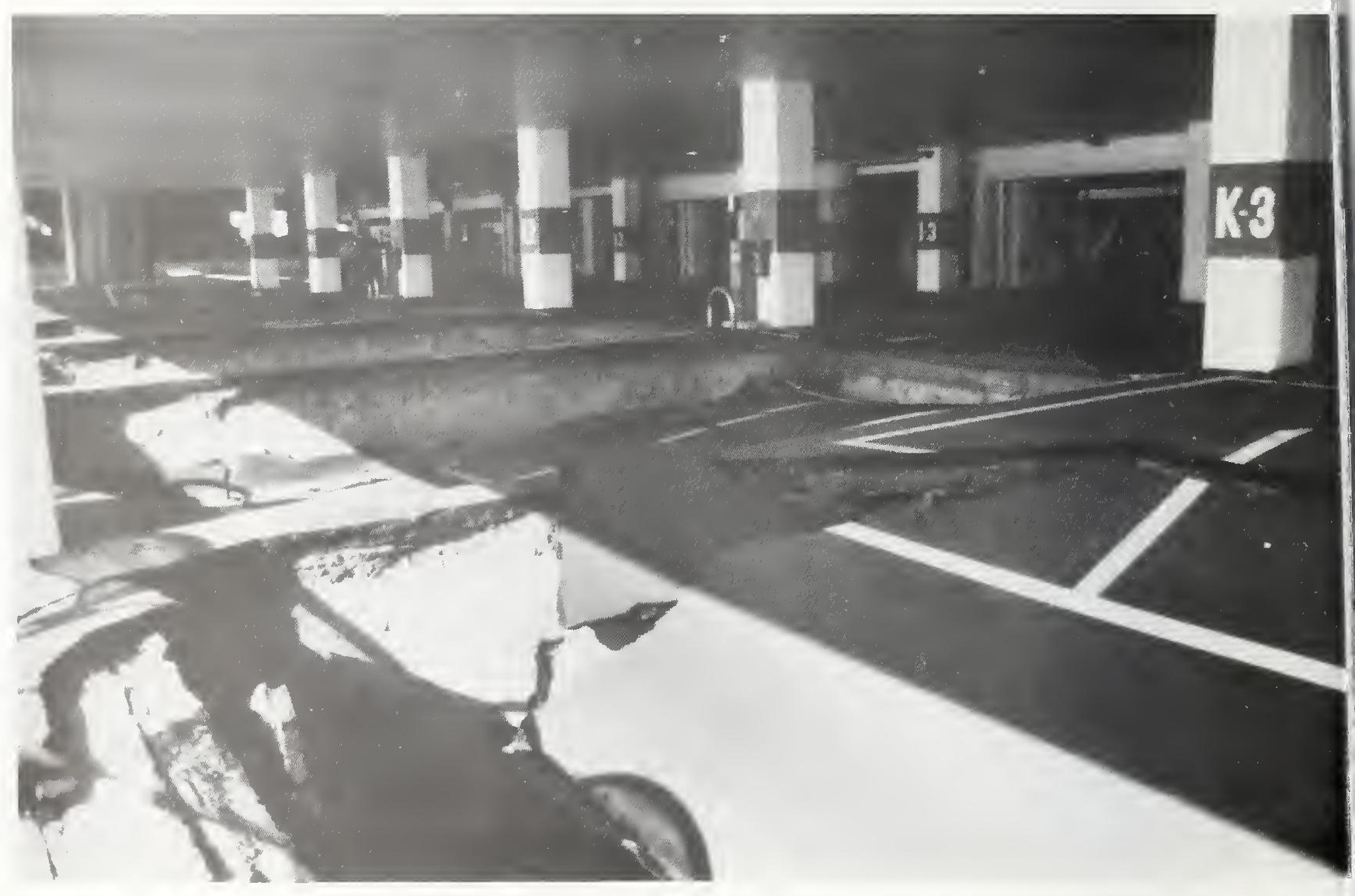

Figure 2.5.5 Differential settlement of about $1 \mathrm{~m}$ between columns of parking structure on reclaimed ground near the bridge to Port Island. 
Appendix 2.A

This appendix provides copies of strong motion recordings obtained on the Higashi-Kobe bridge. These recordings were provided to I. Buckle and J. Cooper by officials of the Hanshin Expressway Public Corporation, Japan. 


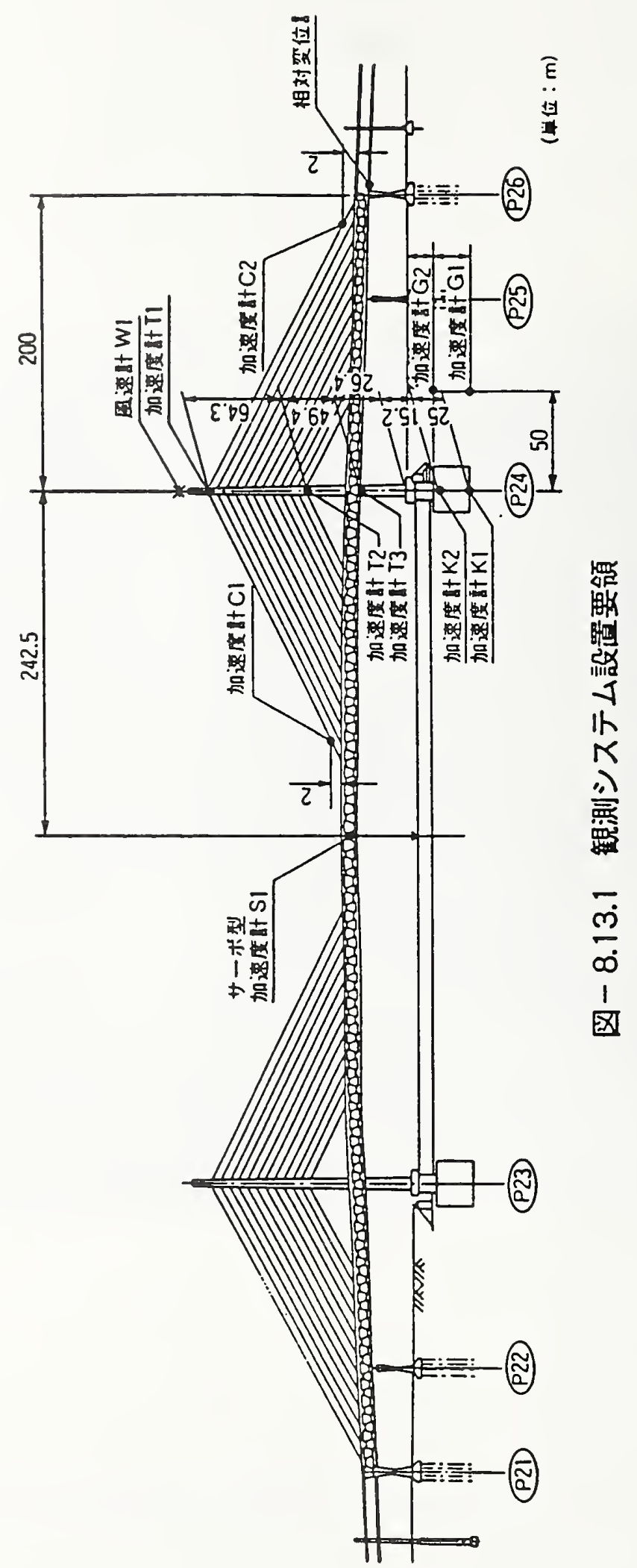




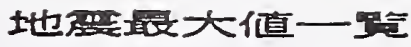

\begin{tabular}{|c|c|c|c|}
\hline \multirow{3}{*}{$\begin{array}{l}\text { 集録 } \\
\text { チャ执 }\end{array}$} & \multicolumn{2}{|c|}{ 起 助 時 間 } & 平成 7 年 1 月 17 日 05 時 46 分 \\
\hline & \multicolumn{2}{|c|}{ 正碈 地 } & 兵軲県南部 \\
\hline & \multicolumn{2}{|c|}{ 度度階 } & VI \\
\hline $\mathrm{CH}-1$ & \multirow{2}{*}{ G 1} & $\mathrm{x}$ & $304.5 \mathrm{gal}$ \\
\hline $\mathrm{CH}-2$ & & $\mathrm{Y}$ & $442.9 \mathrm{gal}$ \\
\hline $\mathrm{CH}-3$ & \multirow{3}{*}{ G 2} & $\mathrm{X}$ & $281.2 \mathrm{gal}$ \\
\hline CR- 4 & & $Y$ & $327.3 \mathrm{gal}$ \\
\hline CH -5 & & $\mathrm{Z}$ & $395.6 \mathrm{gal}$ \\
\hline CH- 6 & \multirow{3}{*}{$\mathrm{K} 1$} & $\mathrm{x}$ & $2.8 \mathrm{gal}$ \\
\hline $\mathrm{CH}-7$ & & $Y$ & $3.2 \mathrm{gal}$ \\
\hline CH- 8 & & $Z$ & $354.7 \mathrm{gal}$ \\
\hline CH- 9 & \multirow{2}{*}{ K 2} & $\mathrm{x}$ & $333.9 \mathrm{gal}$ \\
\hline CH-10 & & $Y$ & $389.2 \mathrm{gal}$ \\
\hline $\mathrm{CH}-11$ & \multirow{2}{*}{ T 1} & $x$ & \multirow{2}{*}{$\frac{1000.0 \mathrm{gal} \text { 以上 }}{1000.0 \mathrm{gal} \text { 以上 }}$} \\
\hline $\mathrm{CH}-12$ & & $Y$ & \\
\hline $\mathrm{CH}-13$ & \multirow{2}{*}{ T 2} & $\mathrm{X}$ & $384.6 \mathrm{gal}$ \\
\hline $\mathrm{CH}-14$ & & $Y$ & $964.8 \mathrm{gal}$ \\
\hline CH -15 & \multirow{3}{*}{ T 3} & $\mathrm{x}$ & $595.3 \mathrm{gal}$ \\
\hline $\mathrm{CH}-16$ & & $Y$ & $821.8 \mathrm{gal}$ \\
\hline $\mathrm{CH}-17$ & & $Z$ & $804.4 \mathrm{gal}$ \\
\hline $\mathrm{CH}-18$ & & & \\
\hline CHA -19 & W 1 & & $\mathrm{a} / \mathrm{s}$ \\
\hline $\mathrm{CH}-20$ & & & $\mathrm{~m} / \mathrm{s}$ \\
\hline $\mathrm{CH}-21$ & $D$ & & $190.8 \mathrm{dm}$ \\
\hline $\mathrm{CH}-22$ & & $x$ & gal \\
\hline $\mathrm{CH}-23$ & S 1 & $Y$ & gal \\
\hline $\mathrm{CH}-24$ & & $z$ & gal \\
\hline $\mathrm{CH}-25$ & C. 1 & & $\mathrm{gal}$ \\
\hline $\mathrm{CH}-26$ & 41 & & $\mathrm{gal}$ \\
\hline $\mathrm{CH}-27$ & $c ?$ & & gal \\
\hline $\mathrm{CH}-28$ & 22 & & gal \\
\hline $\mathrm{CH}-29$ & W & & $\mathrm{m} / \mathrm{m}$ \\
\hline $\mathrm{CH}-30$ & $w 1$ & & $\mathrm{~m} / \mathrm{m}$ \\
\hline $\mathrm{CH}-31$ & 末伎田 & & 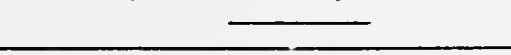 \\
\hline $\mathrm{Cl}-32$ & 条使为 & & $\longrightarrow$ \\
\hline
\end{tabular}




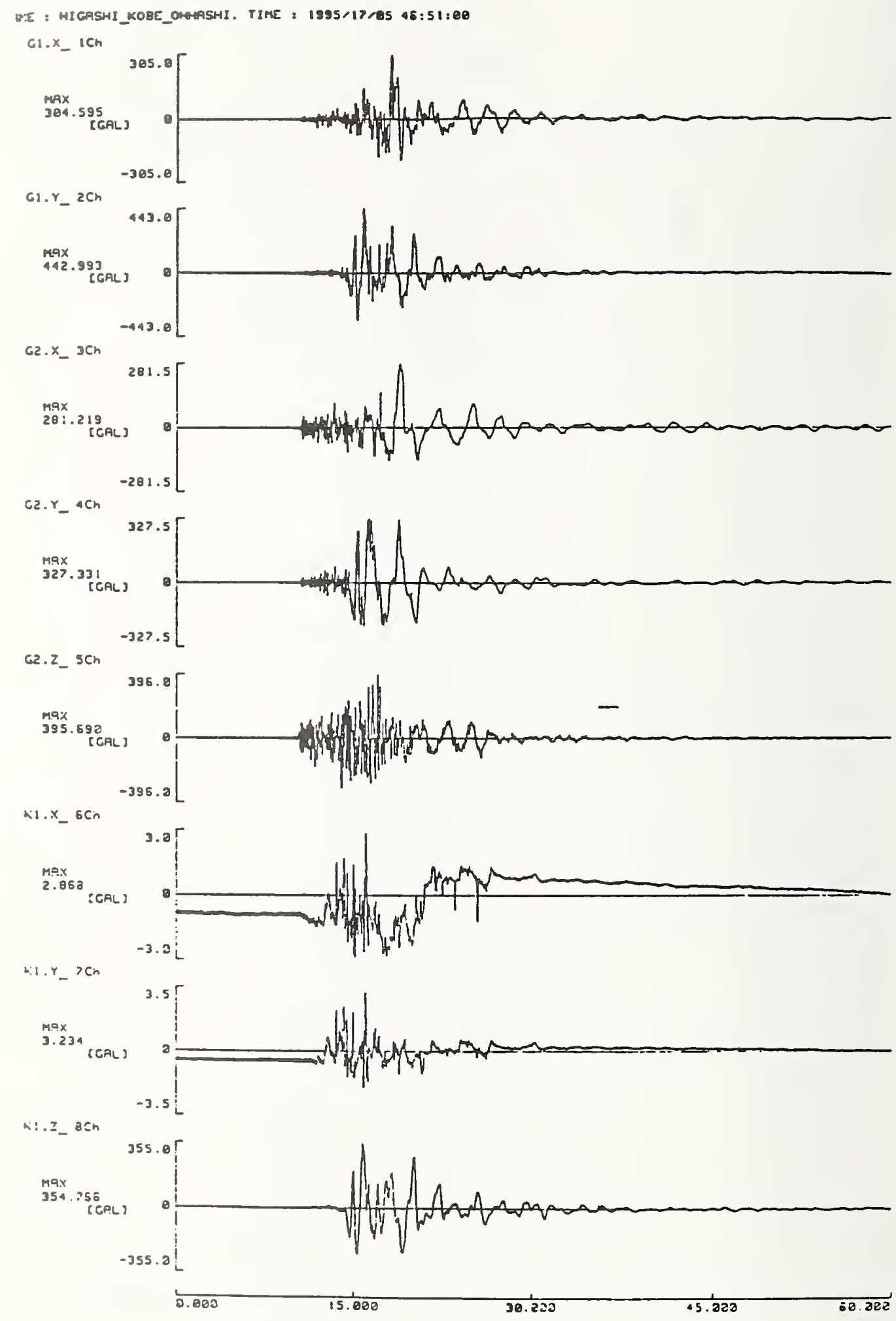

58 
:AME : HICASHI_NOBE_OHASHI. TIME : 1995/17/25 46:5i:02 $\mathrm{Kz} \cdot \mathrm{x}_{-} \mathrm{gCh}$
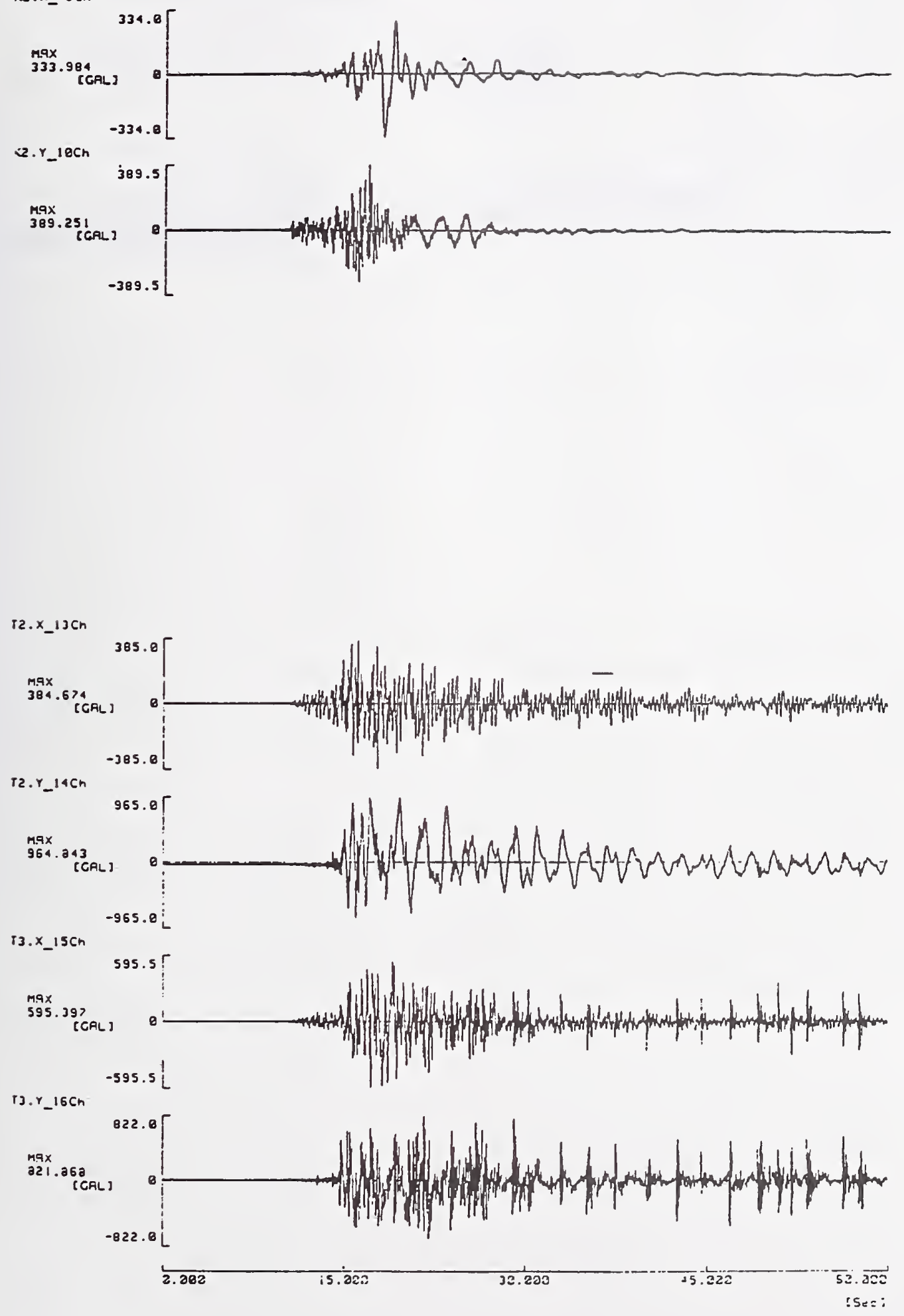

59 


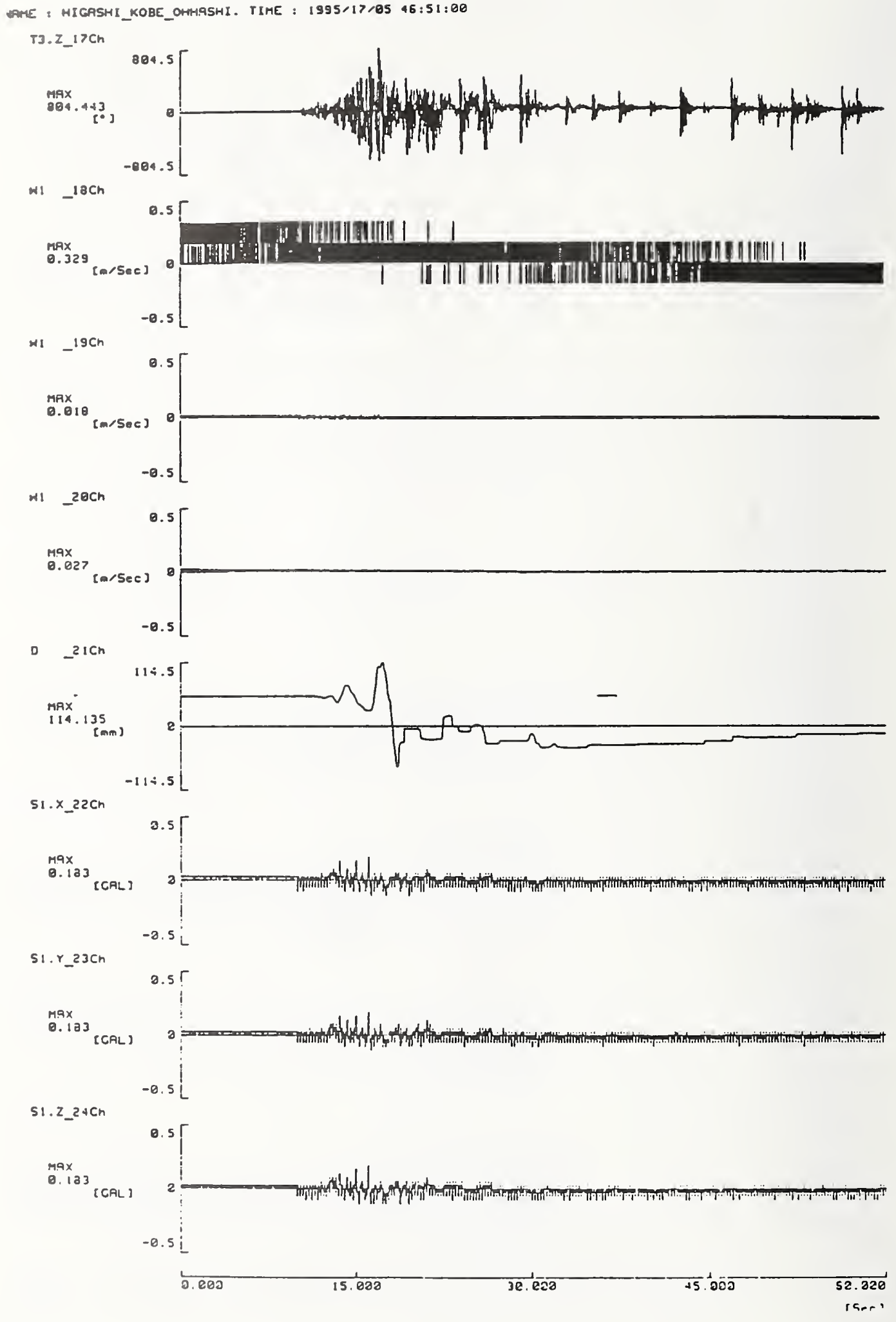




\section{CHAPTER 3}

\section{PERFORMANCE OF BUILDINGS}

\subsection{Introduction}

The magnitude 7.2 (JMA) earthquake occurred at 5:46 a.m. when most people were still in their homes. As described in Chapter 2, severe ground shaking along with surface ruptures occurred in densely built urban areas resulting in the partial or total collapse of many structures. The most serious damage was concentrated within a narrow band about $0.5 \mathrm{~km}$ to $1 \mathrm{~km}$ either side of the fault lines. This extended about $30 \mathrm{~km}$, from the northern tip of Awaji island, through the central part of Kobe (the Sannomiya area), toward Nishinomiya City near Osaka (Figure 3.1.1). Within this band many old wooden houses, over 40 years old, were interspersed among commercial structures. Many of these houses totally or partially collapsed burying their occupants. Over 5,500 people were crushed to death by the collapse of their houses.

Both reinforced concrete (RC) and hybrid steel-reinforced concrete (SRC) structures built prior to the 1971 building code revision sustained severe damage. Many of these structures experienced a complete collapse of an entire story at the mid-height of the building. Japanese engineers stated that this type of collapse most likely occurred at a story where stiffness discontinuity was present, particularly in SRC buildings in which columns changed from a composite section to a reinforced concrete section. In recent past U.S. earthquakes, however, it was more common to observe collapse or severe damage of a "soft" first story. Detailed investigation of damaged RC and SRC buildings is needed to reveal the causes of collapse of the buildings at their mid-height.

Most steel buildings which experienced some form of distress were 20 to 30 years old. Observations showed many welded connection failures. In some cases, beams which were directly fillet welded to columns pulled away from the column face. Tubular columns of multi-story buildings fractured near the base without signs of inelastic deformation. Slender buildings that experienced a significant amount of lateral swing exhibited anchor bolt failures at the column base. In general, many non-ductile failures were observed.

The walls of single family dwellings provided little lateral load resisting capacity, and could not support the heavy roof load during severe ground shaking. Likewise, 2- and 3-story dwelling structures with cornmercial operations in the "soft" first story had little interior walls to resist lateral loads, thereby sustaining partial or total collapse.

This chapter provides documentation of damages observed by U.S. investigators during two reconnaissance visits (January 23 to 26 and February 13 to 18,1995 ).

Probable causes of failure are discussed where possible. To better understand the performance of buildings, the evolution of Japanese seismic building code requirements is presented. 


\subsection{Development of Japanese Building Construction}

\subsubsection{Development of Japanese Building Seismic Requirements}

The modern era of Japanese building construction was ushered in with the Meiji Restoration in 1868. At this time Japan was eager to embrace foreign culture and sciences, including adoption of some foreign building construction practices. The AIJ (Architectural Institute of Japan) was founded in 1886, and by 1888 the first city planning legislation was in place. Formation of the Earthquake Investigation Committee following the 1891 Nobi earthquake was an early step toward developing modern earthquake resistant construction technology in Japan [8] (Table 3.2.1).

Observations on building performance in earthquakes during this period strongly influenced development of modern earthquake engineering construction [Otsuki; 1956]. Masonry construction, introduced in the British form to reduce fire hazards associated with traditional wood construction, suffered many collapses in 1891 and 1894 earthquakes, slowing development of this construction form. Following the 1923 Great Kanto earthquake, engineers noted that steel frames withstood earthquake loads but could not stand up to the subsequent fires, contributing to development of SRC (Steel-Reinforced Concrete) construction in which reinforced concrete encloses structural steel sections. In the same earthquake, observations of poor performance of reinforced concrete construction without hooks at ends of reinforcement led to abandonment of this practice. Generally good performance of wall buildings in this same earthquake contributed to the development of this construction form.
In 1915, Riki Sano introduced the concept of the seismic coefficient, which defines a lateral force for seismic design as the product of a coefficient and the structure weight. The 1923 Great Kanto earthquake led to the addition of an article in the Urban Building Law which required the seismic design of all buildings for a seismic coefficient of 0.1 . This law, which applied to certain urban districts, was a landmark in seismic code development worldwide.

During World War II, because of a shortage of construction materials, allowable stresses were relaxed. In 1943, the Urban Building Law was suspended entirely, except for some fire restrictions. Bombing during World War II took a grim toll on many Japanese cities, and Kobe was not spared significant losses. As a consequence, the majority of medium and high-rise building construction in Kobe dates from after this war.

Following World War II the Urban Building Law was restored briefly, but was replaced when the 1950 Constitution of Japan stipulated the Building Standard Law. This law applied to building construction throughout Japan, as opposed to limited districts. Under this law, the seismic coefficient was increased from 0.1 to 0.2 . The net effect on proportioning materials was minimal, as there was a simultaneous increase in allowable stresses for materials. The increase in design lateral forces represented a significant change in overturning moment requirements. This effect was especially notable in the postwar building boom when many buildings were proportioned to be more slender than prewar buildings [12].

Later changes of significance included the abolishment in 1963 of the height limit of $30 \mathrm{~m}$. At the same time, the ministry of construction recommended that buildings 
over six stories in height should be constructed of hybrid steel-reinforced concrete (SRC) [10]. A very significant change in the reinforced concrete (RC) code to require closer spacing of column transverse reinforcement was imposed in 1971 in response to heavy damage to RC buildings in the 1968 Tokachi earthquake [4].

In the period 1972-1977 the Ministry of Construction directed a project for development of a new seismic design method, resulting in a proposal in 1977 [8].

The 1978 Miyagiken-Oki earthquake, causing serious damage in Sendai City and demonstrating the effects of a strong earthquake on an urban area, accelerated the adoption of the proposal in 1981. The new Building Standard Law included a seismic coefficient that varied with structural vibration period, and introduced a two level design procedure. The first level design, which is similar to the design method used in earlier codes, is intended as a strength check for frequent, moderate events. The second level design, which had not been included in previous codes, is intended as a check for strength and ductility for a maximum expected event. This same code was in effect at the time of the HyogokenNanbu earthquake.

\subsubsection{Types of Construction in Japan}

Figure 3.2.1 [4] shows types of construction common in Japan and the number of stories commonly used for each type. Not shown is masonry building construction, which is relatively uncommon in Japan. As shown, wood frame construction is the predominant form of traditional house construction, commonly being one or two stories in height. Reinforced concrete bearing wall construction is the most common form for apartment house construction; typical heights are from three to five stories, although it may be used up to eight stories. Reinforced concrete frame structures, with or without shear walls, are used for a variety of structures, with common heights up to seven stories but with recent examples up to 50 stories. SRC construction is common for a wide range of construction, and is most common for structures above six stories in height. Steel structures may be used over the height range and are the predominant form for modern high-rise buildings.

Each of these construction forms and materials has its own development history. In many cases, the history is unique to Japan. Some key aspects of each are described below. The discussion emphasizes aspects that were predominant in the period from the end of World War II to the present, and therefore had most significance for construction in Kobe.

\subsubsection{Wood Frame Construction for Traditional Houses}

Traditional wood-frame construction for houses was relatively unchanged from the beginning of this century until the 1970's. Two forms were in widespread use, the older being Shinkabe and the more recent being Ohkabe. More recently, prefabricated timber houses have become more common [6].

Shinkabe construction uses a post-and-beam framing, with lateral resistance being provided by a mud-filled lattice of bamboo in the walls. The need for additional bracing was recognized by the Architectural Institute of Japan (AIJ), although the specification merely recommended that such bracing, having dimension not less than half the column dimension, be placed wherever it would not impair the external appearance of the dwelling [1]. In Ohkabe construction 
the bamboo is replaced with a narrow-plank lathe, preferably placed on both sides of the wall, nailed to the posts, and covered with stucco. Diagonal bracing was also recommended. Connections between posts and beams are often by wood joiners rather than nailing or connectors. Roofs commonly are of relatively heavy tile, set in a relatively thick mud mortar.

\subsubsection{Reinforced Concrete Bearing Wall Construction}

Observations of building performance following the 1923 Great Kanto earthquake revealed the value of constructing low-rise buildings relying on reinforced concrete bearing walls.

As described by the AIJ [1], the emphasis in design of bearing wall construction is on proper layout and proportioning of the structural system, as opposed to structural calculations. Minimum wall thicknesses were required to range from $120 \mathrm{~mm}$ or $\mathrm{h} / 25$ ( $h=$ wall height) for one-story construction to $180 \mathrm{~mm}$ or $\mathrm{h} / 22$ for four-story construction. The required ratio of wall length (parallel each principal direction) to floor area was $15 \mathrm{~cm} / \mathrm{m}^{2}$ for the first story in four-story construction, and $12 \mathrm{~cm} / \mathrm{m}^{2}$ for all other floors. Web reinforcement ratios of $0.15 \%, 0.20 \%$, and $0.25 \%$ were required for the top story, the second-from-top story, and all other stories, respectively.

Studies of building damage following the 1968 Tokachi-oki earthquake demonstrate that bearing wall construction provides good protection against severe damage [4] (Figure 3.2.2). The curves plotted in this figure correspond to limits defined in the current (1981) Building Standard Law. Regularly configured wall buildings whose parameters fall within the limits are exempt from the check for ultimate lateral load carrying capacity of that Law.

\subsubsection{Reinforced Concrete Frame and Frame-Wall Construction}

Reinforced concrete frame construction in Japan is commonly taken to include both pure frame construction and combined frame-wall construction. Although both types are prevalent, experience in performance of $\mathrm{RC}$ frames has led to recommendations to combine frames and walls [1]. Wall construction may include solid walls framed by beams and columns, or walled frames that consist of deep girders and wide columns.

Concrete may include normal weight aggregate concrete or lightweight aggregate concrete [1]; apparently in the 1960's the lower mass associated with lightweight aggregates led to some applications in seismic zones similar to what occurred in the U.S. at the same time. According to the AIJ Structural Standards of the time, the minimum strength was not less than $135 \mathrm{~kg} / \mathrm{cm}^{2}$ for normal weight aggregate concrete or $120 \mathrm{~kg} / \mathrm{cm}^{2}$ for lightweight aggregate concrete. In the Osaka-Kobe area, builders began to use crushed stone for aggregate around 1970, and exclusively since 1975. In the transition period, both crushed stone and river gravel were used [3].

Plain reinforcement were used in Japan prior to 1960. Starting around 1960 , builders in the Osaka-Kobe region began to use deformed longitudinal reinforcement bars, and this became compulsory after 1970 . Deformed transverse reinforcement was used 6 years to 7 years after the introduction of deformed longitudinal reinforcement [3]. Five grades of reinforcement were used then, with minimum yield stresses of 24 $\mathrm{kg} / \mathrm{mm}^{2}, 30 \mathrm{~kg} / \mathrm{mm}^{2}, 35 \mathrm{~kg} / \mathrm{mm}^{2}, 40 \mathrm{k} / \mathrm{mm}^{2}$, and $50 \mathrm{~kg} / \mathrm{mm}^{2}[1]$. 
Pre-1971 construction details include haunched beams with maximum transverse reinforcement spacing not to exceed $30 \mathrm{~cm}$ and $2 / 3 D$ or $3 / 4 D(D=$ overall depth of beam). Columns were required to have hoops with maximum spacing not exceeding $30 \mathrm{~cm}$, minimum column depth, and 15 times the diameter of the main reinforcement. Walls were required to have minimum thickness of $12 \mathrm{~cm}$, and two layers of reinforcement were required where wall thickness exceeded $20 \mathrm{~cm}$. Maximum spacing of wall reinforcement was $30 \mathrm{~cm}$. Maximum allowable shear stress was oneeighth of the concrete compressive strength [1]. Common practice had been to hook the ends of all reinforcement, although Otsuki [12] reports a trend away from hooks. In the 1960's, hooks were only required for plain bars, except deformed bars required hooks in high stress areas and in stirrups and hoops [1]. Reinforcement splices could be either by lapping or welding. In recent decades, rebar splices are almost always done by gas pressure welding [3]. In this process, bars are aligned, butted together, and fused by a combination of heat and pressure applied by mechanical devices, causing bars to flare out at the splice.

In 1971, following damage to RC construction in the 1968 Tokachi-oki earthquake, there was a partial revision of the Building Standard Law and a large scale revision of the AIJ Standards incorporating ultimate strength design in shear of reinforced concrete [4]. Perhaps the most notable change in $\mathrm{RC}$ construction was the requirement that maximum spacing of hoops in columns be reduced to $15 \mathrm{~cm}$, except in column end regions the maximum spacing was further reduced to $10 \mathrm{~cm}$.

\subsubsection{Steel-Reinforced Concrete (SRC) Construction}

Steel-reinforced concrete construction in Japan grew out of observations of performance during the 1923 Great Kanto earthquake [11]. Bare steel frame construction, while highly resistant to earthquake forces, was less resistant to fire. In steel frames encased in bricks, the bricks failed, exposing the steel. Steel frames with concrete casing, or with walls, performed well. This led to an ascendance of SRC construction using steel encased in reinforced concrete.

The original form of SRC construction, known as the full web form, used steel "I" or " $\mathrm{H}$ " sections. Later, in the interest of maximizing section modulus and minimizing rolled section consumption, built-up sections with a smaller quantity of steel sections became more common.

Some examples of SRC construction details from the 1950's and 1960's are in Figure 3.2.3. The need for continuity of the steel framing members at joints was well established, and was provided using welded or riveted plates. Splice plates were commonly riveted or welded (Figure 3.2.3a). Butt welds were considered unsuitable for field work at the building site [AIJ; 1970]. Two types of connections were common at the foundation level: non-embedment type, where a steel base plate was anchored using anchor bolts, and embedment type, where the steel extends into the $\mathrm{RC}$ foundation with special detailing (Figure 3.2.3b). In 1963 , when the $30 \mathrm{~m}$ height limit was eliminated, the Ministry of Construction recommended use of SRC for buildings over six stories in height. While it is unclear whether this recommendation led to a practice where SRC was used for the first seven stories, with either RC or steel used 
for the remaining stories, it was reported that many buildings over seven floors had $\mathrm{RC}$ in upper floors supported by SRC in the lower seven stories [3].

The 1958 AIJ Standard for Structural Calculation of SRC Structures was the first standard for SRC in Japan. Until that time, many different types of SRC were built [10]. Subsequent revisions were published in 1963, 1975, and 1987. The current standard approach is to calculate allowable loads as the sum of the allowable loads for the steel and the concrete sections, with the $\mathrm{RC}$ part designed according to the RC standard, and the steel part designed according to the steel standard except local buckling is ignored. Because of observed superior behavior of full web construction in the laboratory, the 1975 revision to SRC building code recommended full steel webs [3]. The 1987 revision recommended use of the embedment type steel base [3]. It also showed how to evaluate lateral load resisting capacity as required by the 1981 law [9].

\subsubsection{Steel Construction}

The applications of steel in building construction grew rapidly in the years after World War II. According to Chiba [5], early steel products were light gauge steel. The next developments took place around 1961 when rolling mills began to produce standard column and beam sections. Developments in welding technology enabled production of box sections by welding starting in 1969. Square hollow steel sections began to be produced around 1977. Allowable stresses for design of buildings in the 1950's to 1990's were similar to those of the AISC (American Institute of Steel Construction) Specification during the same time period. With the introduction of higher strength steels by the mid-1960's, a wide range of steels was available for building construction. Allowable stresses were related to a nominal stress limit $\mathrm{F}$, defined as the lesser of the nominal yield stress and $70 \%$ of the nominal ultimate stress [2]. A wide range of structural details was used over the period of interest. Figure 3.2.4 shows a variety of connection details from the 1960's [1]. In the 1970's and 1980's, steel box sections became increasingly popular. These were produced directly for use as columns starting in 1977, or could be constructed by welding together light gauge steel sections, rolled parallel flange channel sections, or thick steel plates; some examples are in Figure 3.2.5 [5]. It was typical to shop weld the connections at the beamcolumn joint and to use rivets or bolts in the field away from the joint.

\subsection{Lateral Force and Design Requirements}

In 1915 Sano introduced the seismic coefficient concept, which offered an earthquake resistant design approach in which the structure was designed for a lateral force equal to the product of a coefficient and the weight. No specific value was assigned to the seismic coefficient, and the procedure was not part of law, until after the 1923 Great Kanto earthquake. In 1924 the Urban Building Law added an article to require a seismic coefficient of 0.1 . The height limit of $33 \mathrm{~m}(100 \mathrm{ft})$ remained unchanged from earlier times. This law governed construction in major cities until 1943, when it was suspended during wartime. The law was reinstated in 1948, and replaced by the Building Standard Law in 1950 [12]. This law, and the 1981 revision, governed lateral force requirements for the majority of the Kobe region buildings that were in place during the 1995 Hyogoken-Nanbu earthquake. Some aspects of these two laws are detailed in the following paragraphs. 


\subsubsection{The Building Standard Law from} 1950 through 1980

The basic seismic coefficient during this period was set at 0.2 , or double the value that had been used since 1924. As described by Otsuki [12], the doubling of the seismic coefficient caused problems in design related to overturning, and this was the subject of great debate among engineers. The outcome was not a decrease in the overturning moment, but instead an increase in the seismic coefficient for portions of the building over $16 \mathrm{~m}$ above ground. The Building Standard law was modified in 1955 to include reductions to account for the seismicity of the region and the subsoil at the site.

According to the code [1], the design horizontal seismic coefficient $K$ for the superstructure must be at least equal to the quantity $K=K_{o} \alpha \beta$, where the product $\alpha \beta$. must not be less than $0.5, K_{o}$ is 0.2 for the first 16 meters above the foundation and is increased by 0.01 for each additional 4 meters (Figure 3.2.6), $\alpha=$ a modification factor for ground condition and type of construction, and $\beta=$ modification factor for seismicity of the region (1.0 for the Kobe region). Values of $\alpha$ are in Table 3.2.2, with simplified descriptions of relevant conditions.

\subsubsection{The Building Standard Law of 1981}

In the period 1972 to 1977 the Ministry of

Construction conducted a project aimed at establishing a new seismic design method. The method was released in 1977, and generally accepted by 1978 [7]. The 1978 Miyagiken-Oki earthquake provided momentum for implementation of this proposal, which was enforced in June 1981 as part of the Building Standard Law [4].

The design method features a two-level procedure. The first phase design follows the traditional allowable stress design approach, with steel allowable stress equal to the yield stress and concrete allowable stress equal to two-thirds the specified compressive strength. The second phase design is a direct and explicit evaluation of strength and

ductility, and may be regarded as a check of whether these are sufficient for severe ground motions [4]. A flow chart of the design process is in Figure 3.2.7. Timber structures, and low-rise structures satisfying rigidity, eccentricity, and detailing limitations need not be checked using the second phase design. Other structures, including all structures of height between $31 \mathrm{~m}$ and $60 \mathrm{~m}$, must be checked by both phases. Structures over $60 \mathrm{~m}$ in height are subject to special approval. Details of this innovative design procedure are summarized by Aoyama [4]. 
Table 3.2.1

Some Events in the History of Japanese Seismic Code Development

\begin{tabular}{|c|c|c|}
\hline Date & Event & Code Change \\
\hline 1868 & $\begin{array}{l}\text { Meiji Restoration - Japan sets course of } \\
\text { modernization }\end{array}$ & \\
\hline 1886 & AIJ founded & \\
\hline 1888 & & First city planning legislation in Japan \\
\hline 1891 & $\begin{array}{l}\text { Nobi earthquake (M7.9) causes extensive } \\
\text { damage }\end{array}$ & \\
\hline 1892 & Earthquake Investigation Committee founded & \\
\hline 1894 & Earthquake shakes Tokyo and causes damage & \\
\hline 1906 & San Francisco earthquake (M8.3) & \\
\hline 1915 & $\begin{array}{l}\text { Riki Sano proposes concept of seismic } \\
\text { coefficient }\end{array}$ & \\
\hline 1919 & & $\begin{array}{l}\text { City Planning Law and Urban Building Law } \\
\text { enacted for six major cities. First structural } \\
\text { standards. }\end{array}$ \\
\hline 1923 & Great Kanto earthquake (M7.9) and fire & \\
\hline 1924 & & $\begin{array}{l}\text { Urban Building Law adds article to require } \\
\text { seismic coefficient of } 0.1 \text {. Height limit of } 100 \\
\mathrm{ft} \text { unchanged. }\end{array}$ \\
\hline 1925 & $\begin{array}{l}\text { Earthquake Investigation Committee } \\
\text { rechartered as the Earthquake Research } \\
\text { Institute }\end{array}$ & \\
\hline 1933 & $\begin{array}{l}\text { Muto proposes D-value method to calculate } \\
\text { stresses under horizontal forces }\end{array}$ & \\
\hline 1937 & $\begin{array}{l}\text { Japan-China War puts Japan under war } \\
\text { condition }\end{array}$ & \\
\hline 1943 & & $\begin{array}{l}\text { Urban Building Law suspended except for } \\
\text { some fire restrictions. Relaxation of } \\
\text { allowable stresses due to wartime shortage of } \\
\text { construction materials. Dual allowable } \\
\text { stresses introduced }\end{array}$ \\
\hline 1948 & & Urban Building Law restored. \\
\hline 1950 & Constitution of Japan & $\begin{array}{l}\text { Building Seismic Law replaces Urban } \\
\text { Building Law. Seismic coefficient increased } \\
\text { to } 0.2 \text {, allowable stresses under temporary } \\
\text { loads set at twice the allowable stress under } \\
\text { permanent loads }\end{array}$ \\
\hline 1958 & & First standard for SRC \\
\hline 1963 & & $\begin{array}{l}\text { Height limit of } 100 \mathrm{ft} \text { abolished. Ministry of } \\
\text { Construction recommends use of SRC for } \\
\text { buildings over } 6 \text { stories in height. }\end{array}$ \\
\hline 1964 & Niigata earthquake (M7.5) & \\
\hline
\end{tabular}


Table 3.2.1

(Continued)

Some Events in the History of Japanese Seismic Code Development

\begin{tabular}{|l|l|l|}
\hline 1968 & $\begin{array}{l}\text { Tokachi earthquake (M7.9) causes heavy } \\
\text { damage to RC buildings. First high-rise } \\
\text { building in Japan }\end{array}$ & \\
\hline 1970 & & Steel code revised \\
\hline 1971 & San Fernando earthquake (M6.4) & $\begin{array}{l}\text { Concrete code revised to require closer } \\
\text { spacing of transverse reinforcement }\end{array}$ \\
\hline $\begin{array}{l}1972- \\
77\end{array}$ & $\begin{array}{l}\text { Ministry of Construction project for } \\
\text { development of new seismic design method, } \\
\text { resulting in 1977 proposal }\end{array}$ & \\
\hline 1978 & Miyagiken-Oki earthquake (M7.5) & $\begin{array}{l}\text { Building Standard Law changed. Main } \\
\text { features include seismic coefficient that varies } \\
\text { with period and two-level design }\end{array}$ \\
\hline 1981 & & \multicolumn{2}{|l}{} \\
\hline
\end{tabular}

Table 3.2.2

Values of $\alpha$

\begin{tabular}{|l|c|c|c|}
\hline Soil & Wood & Steel & RC and SRC \\
\hline Rock, hard sandy gravel & 0.6 & 0.6 & 0.8 \\
\hline $\begin{array}{l}\text { Sandy gravel, sandy hard clay, } \\
\text { loam, classified as diluvial }\end{array}$ & 0.8 & 0.8 & 0.9 \\
\hline Alluvium & 1.0 & 1.0 & 1.0 \\
\hline Bad or soft ground & 1.5 & 1.0 & 1.0 \\
\hline
\end{tabular}




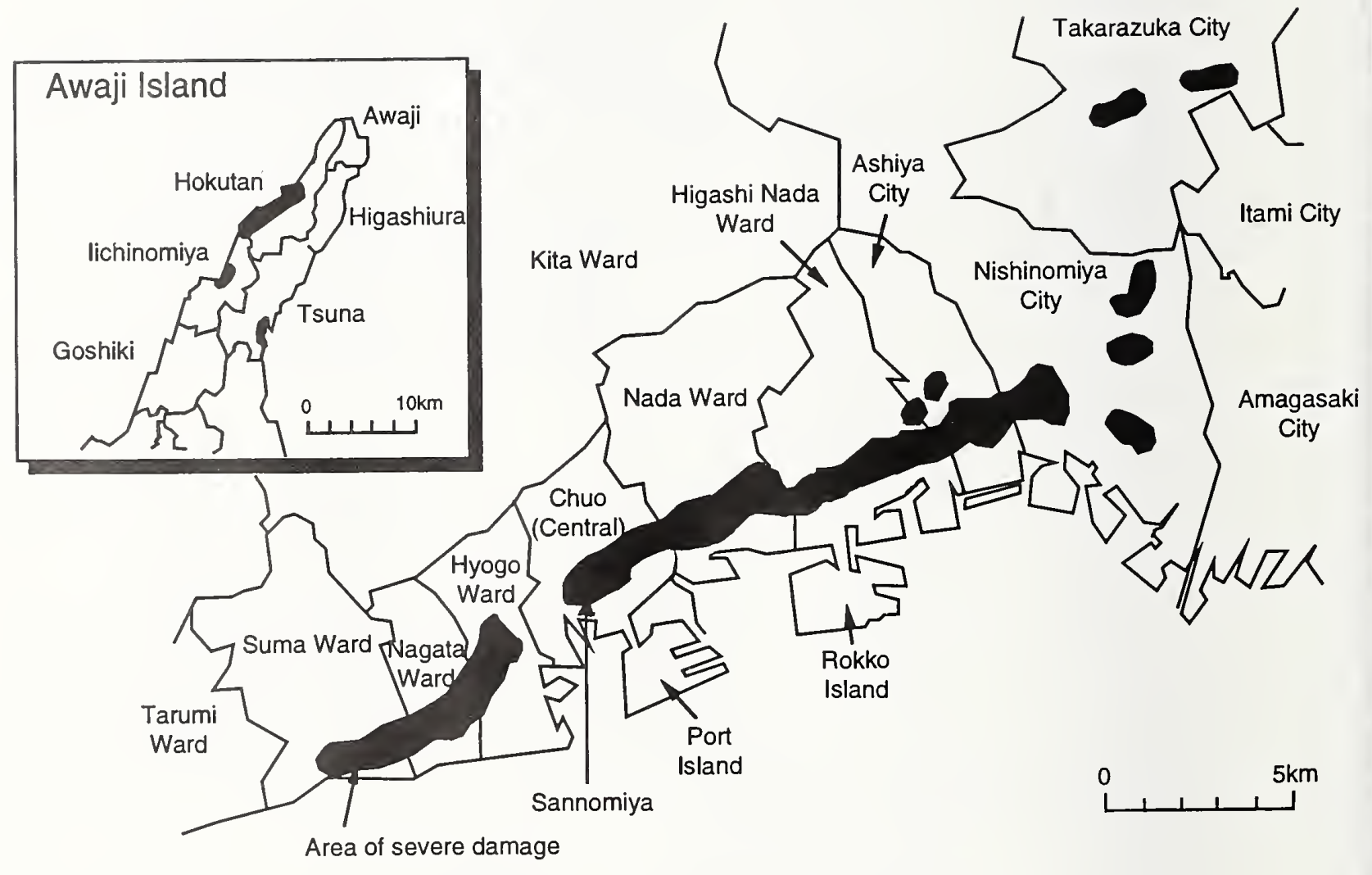

Figure 3.1.1 Kobe City and the Hanshin Area. 


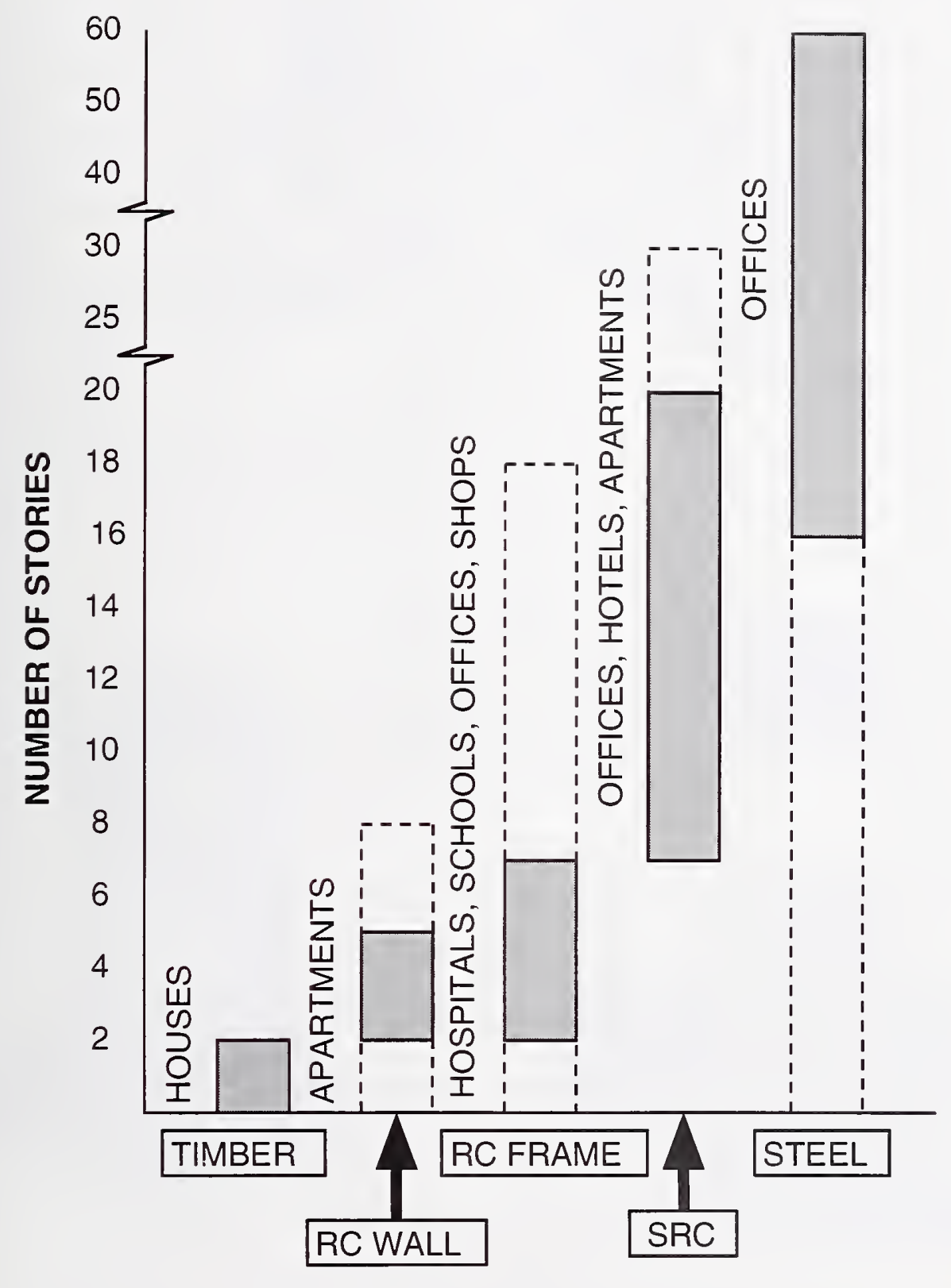

Figure 3.2.1 Types of construction in Japan \{Aoyama, 1993). 


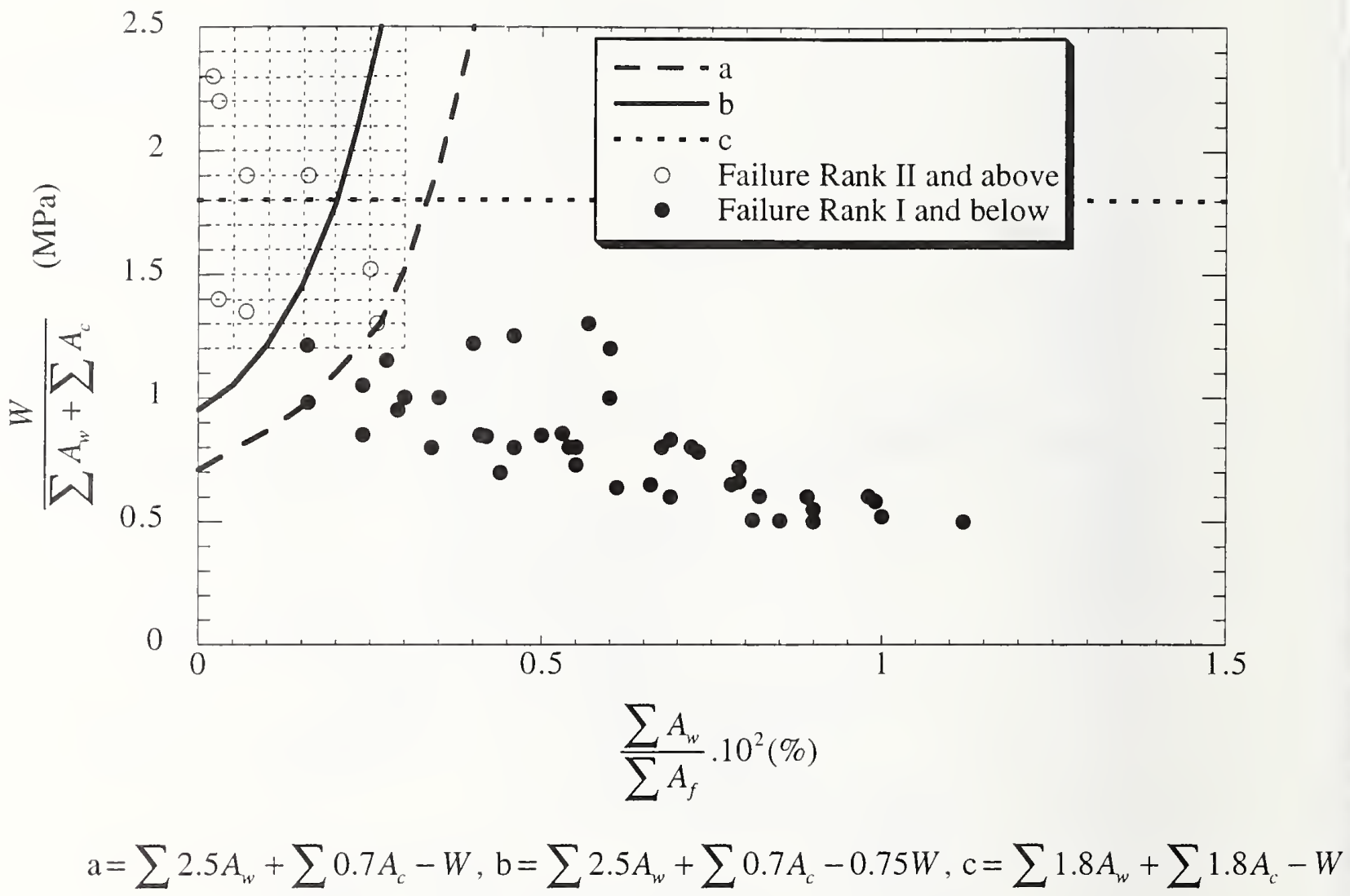

Figure 3.2.2 Wall area index and average shear stress in walls and columns, following results from Shiba (Aoyama, 1993). 

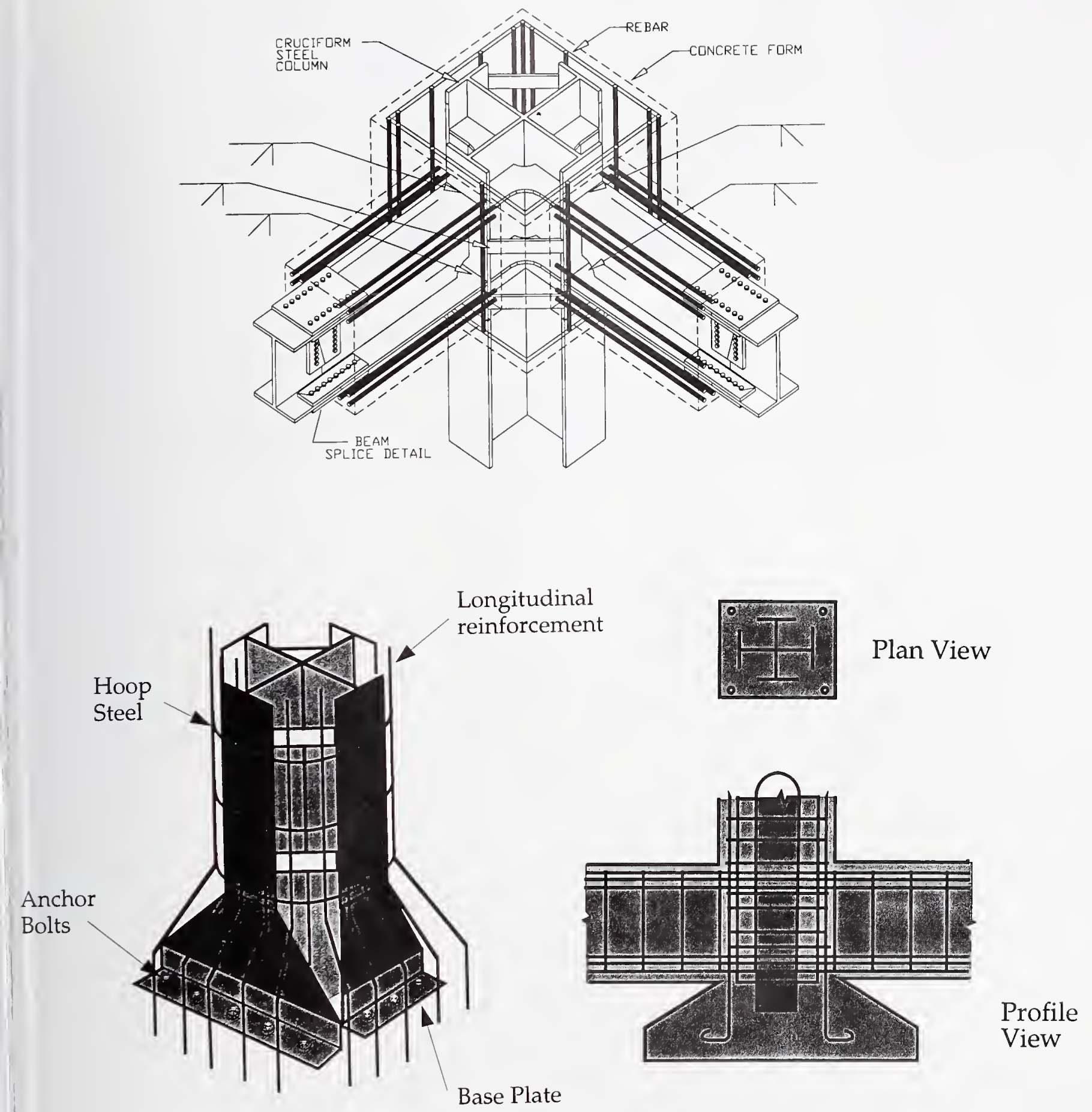

Figure 3.2.3 Examples of SRC construction. 
(a) Diaphragm Type
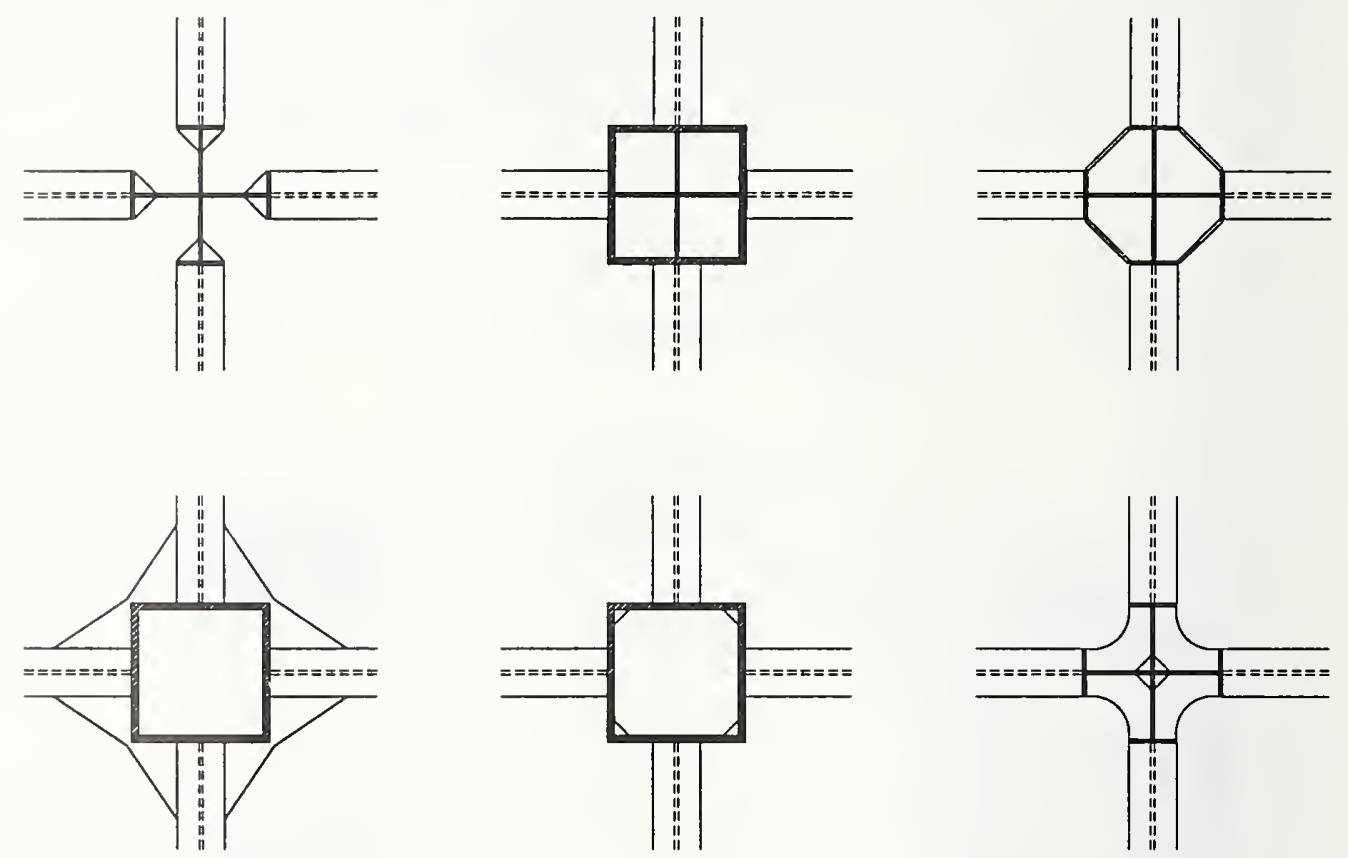

(b) Vertical Stiffener Type

(c) Flat Rib Type

Figure 3.2.4 Some steel beam-column joint details (AIJ, 1970). 

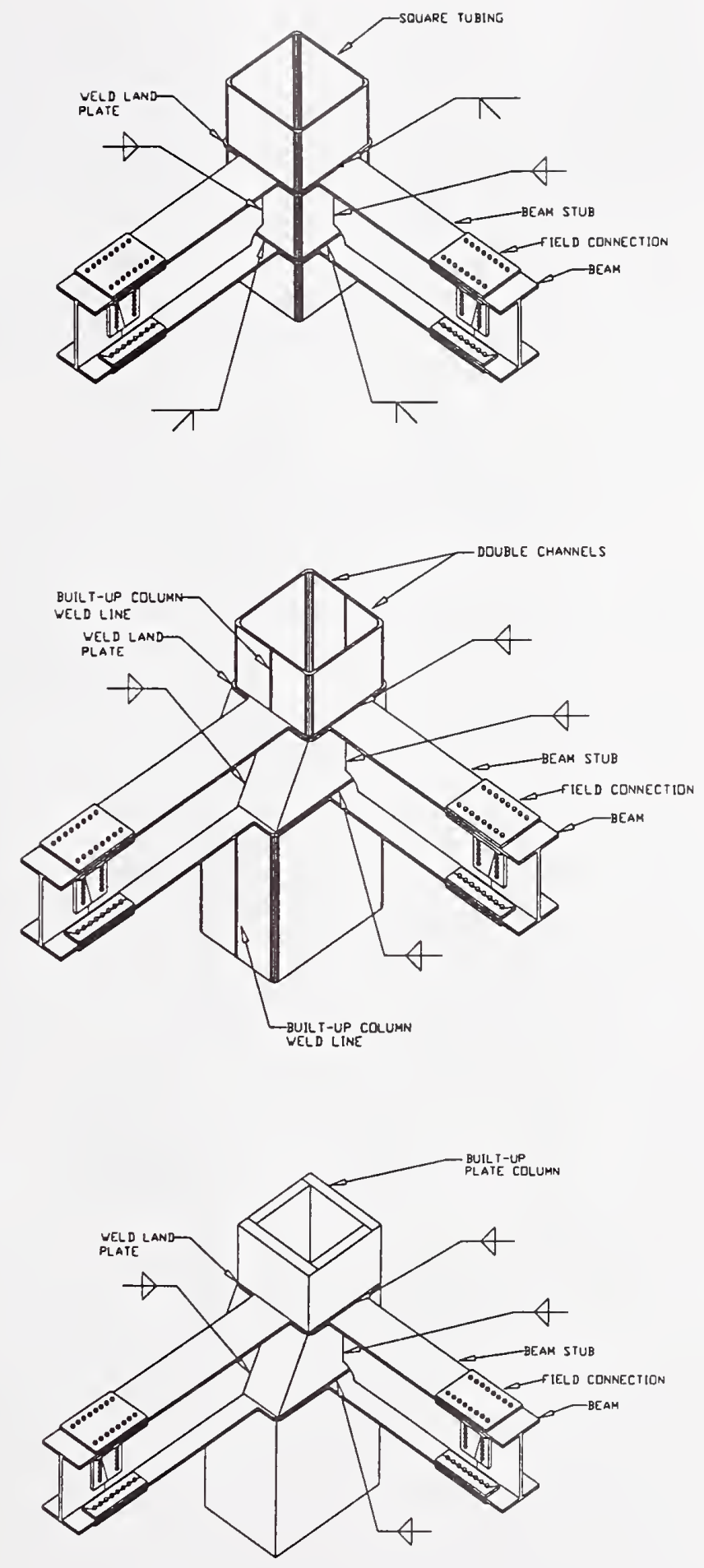

Figure 3.2.5 Some steel beam-column joint details with box columns (Chiba, 1989). 


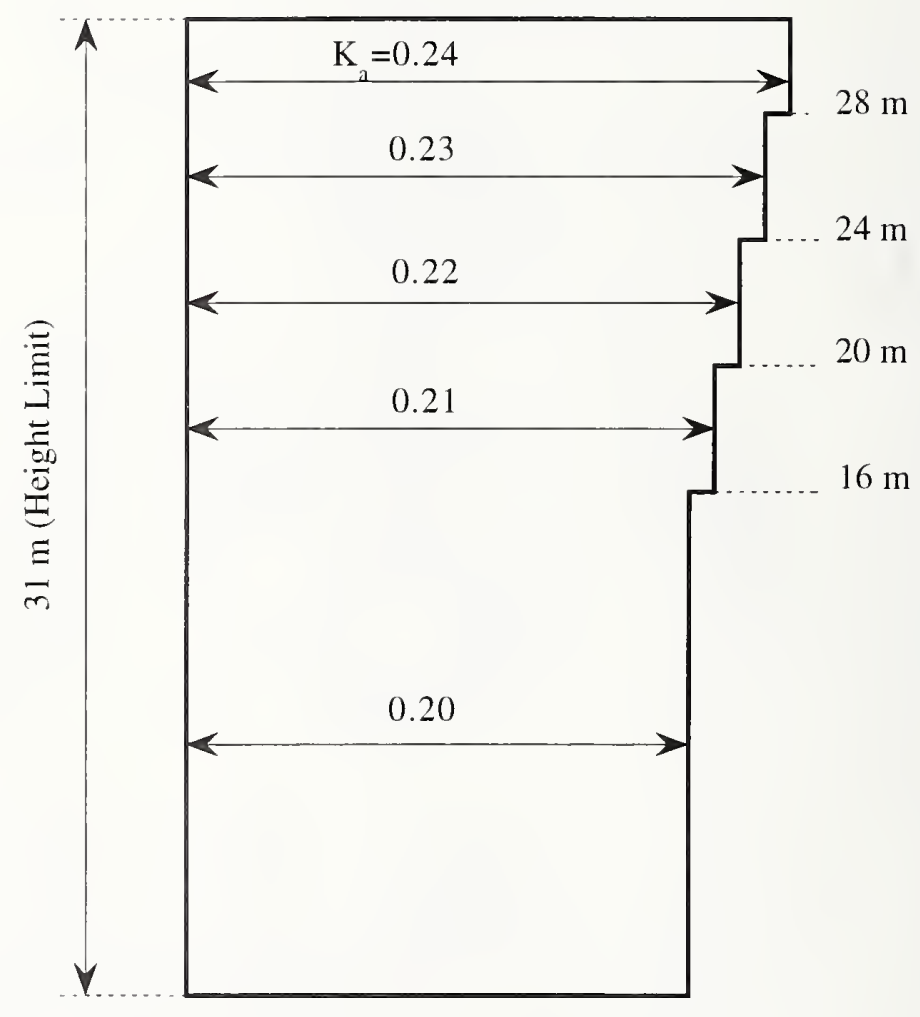

Figure 3.2.6 Lateral seismic coefficient from the Building Standard Law in the 1950's (Otsuki, 1956). 

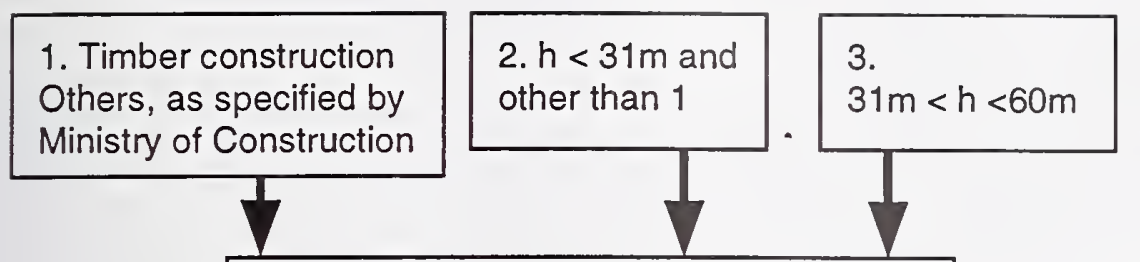

4.
$h>60 m$

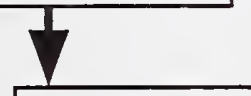

5. Conventional structural design including first phase design for earthquakes

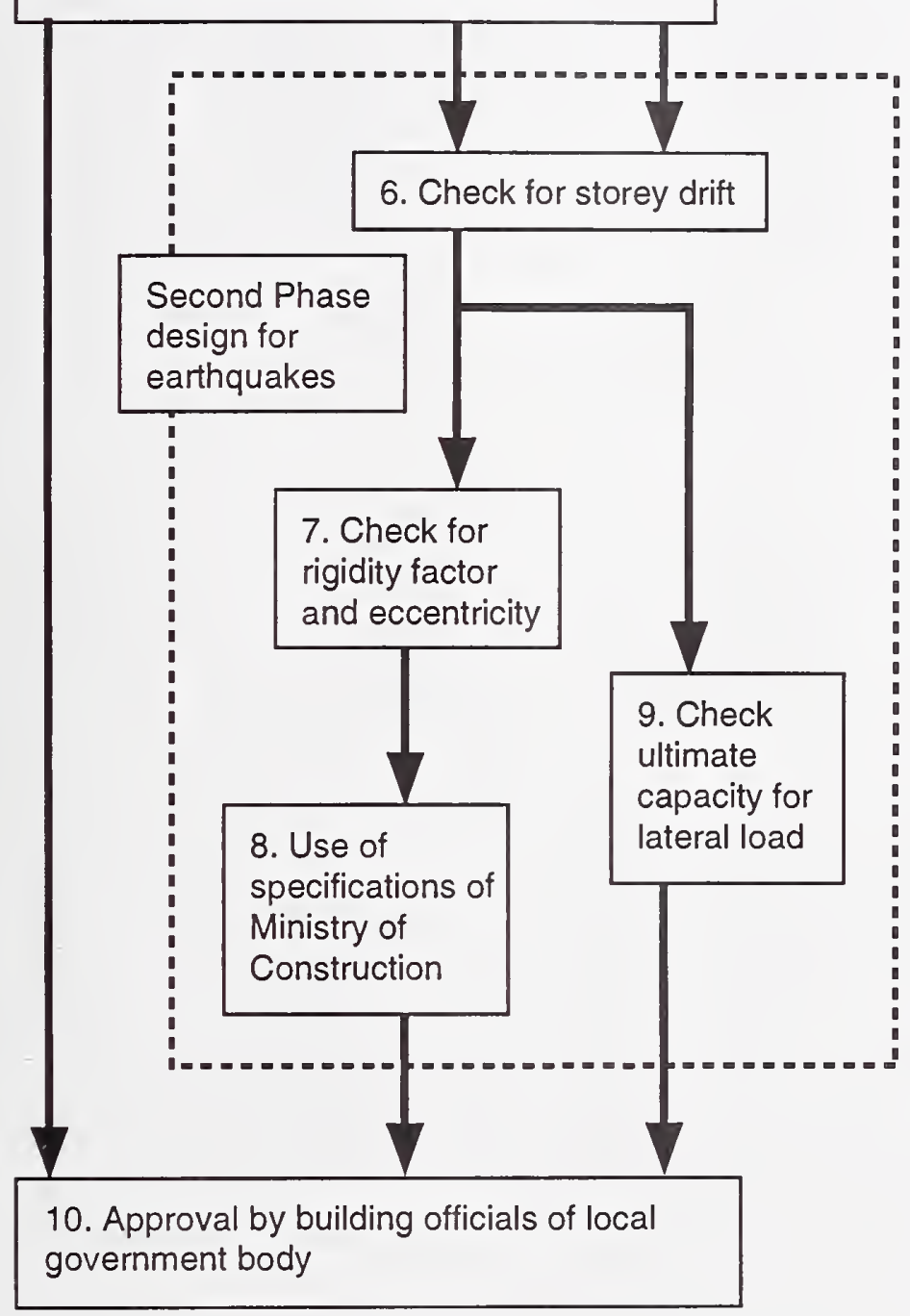

11. Special approval required

Figure 3.2.7 Flow chart for seismic design according to the 1981 Building Standard Law (Aoyama, 1993). 


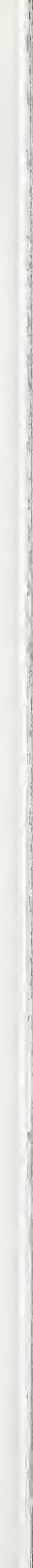




\subsection{Performance of Traditional Wood}

$\underline{\text { Houses }}$

The majority of the casualties reported in this earthquake were primarily due to the collapse of old Shinkabe and Ohkabe houses made of wood. Most of the damaged houses were of non-engineered type construction, primarily built to support the gravity loads. As described in Section 3.2.1, prior to World War II, the code of practice called the Urban Building Law was used to regulate building construction primarily in the six largest cities, including the city of Kobe. This older code apparently lacked detailed guidelines about seismic resistant structural construction; such details became available only in the later codes. During wartime and several years after the war, even the existing building construction "law was not enforced due to wartime conditions" [13]. The Ministry of Construction initiated the revision of the defunct Urban District Building Law in 1949. The revised version was finally adopted as the Building Standards Law in 1950. It appears that heavily damaged wood houses in this earthquake were constructed in the post-war period, but before the Building Standards Law became applicable. Due to postwar scarcity of adequate building material and immediate need to rebuild, the residential units were perhaps made with substandard materials and construction practices, and perhaps without any code regulations.

The number of collapsed houses constituted about 10 percent of the houses in the Kobe area. It was reported [3] that nearly 55000 houses collapsed and over 35000 houses were partially destroyed. These included both Shinkabe and Ohkabe houses. Typical damaged houses are shown in Figures 3.3.1 and 3.3.2.
In general, more Shinkabe houses sustained complete collapse. The Shinkabe construction employed walls of bamboo thatch tied with rope and packed with mud. The outside facade consisted of stucco or some light coverings with no structural resistance. Figure 3.3.3 shows a damaged two-story Shinkabe construction and Figure 3.3.4 shows a completely collapsed Shinkabe house. In Ohkabe construction, the columns were joined by thin wooden slats $(80 \mathrm{~mm} \mathrm{x}$ $20 \mathrm{~mm}$ ) placed horizontally (see Figure 3.3.5). Some parts of the Ohkabe houses were also reinforced by light wooden cross braces, and they performed better than the unbraced parts (see Figure 3.3.6). There were no indications of plywood or particleboard shearwalls being used in these constructions, as is a common practice in the United States. Only a few wood houses had some type of diagonal bracings, and a majority of the wood houses had essentially no significant lateral load carrying capacity to withstand earthquake loads.

Many severely damaged houses had heavy ceramic roof tiles set on soil as bedding (see Figure 3.3.7). It is believed that heavy tiled roofs were preferred not only for the aesthetic and architectural reasons, but also because they could not be easily dislodged by gusty winds in a typhoon. The heavy roofs of these houses have contributed a great deal to their collapse. On the other hand, some of the older houses which used less elaborate and less expensive synthetic roofing made of light material performed well in this earthquake.

The Building Standards Law of 1950 went through a series of major revisions in the 1960 's primarily to respond to the growing demand for and planned construction of high-rise buildings. In 1960, code provisions for bearing walls were introduced and a minimum wall ratio of the wall area to the 
floor area was established. The 1971-code provided regulations for the "frame wall construction method", also called the "two-by-four construction method" (because it used $2 \times 4$ lumber in the construction). It has been reported [3] that such two-by-four construction and the residential houses which followed the 1971 and later code regulations performed rather well in this earthquake. Figure 3.3.8 shows a frame house under construction using $2 \times 4$ 's which survived the earthquake. 


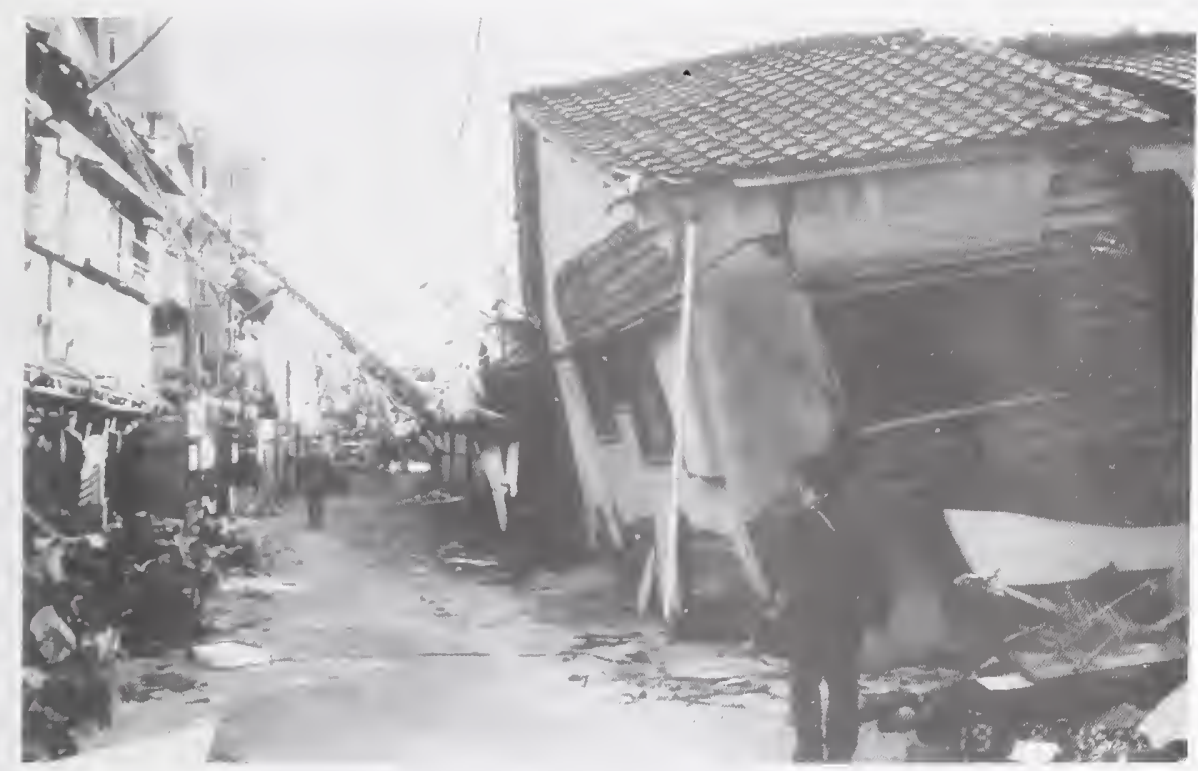

Figure 3.3.1 A collapsed Ohkabe construction-type house.

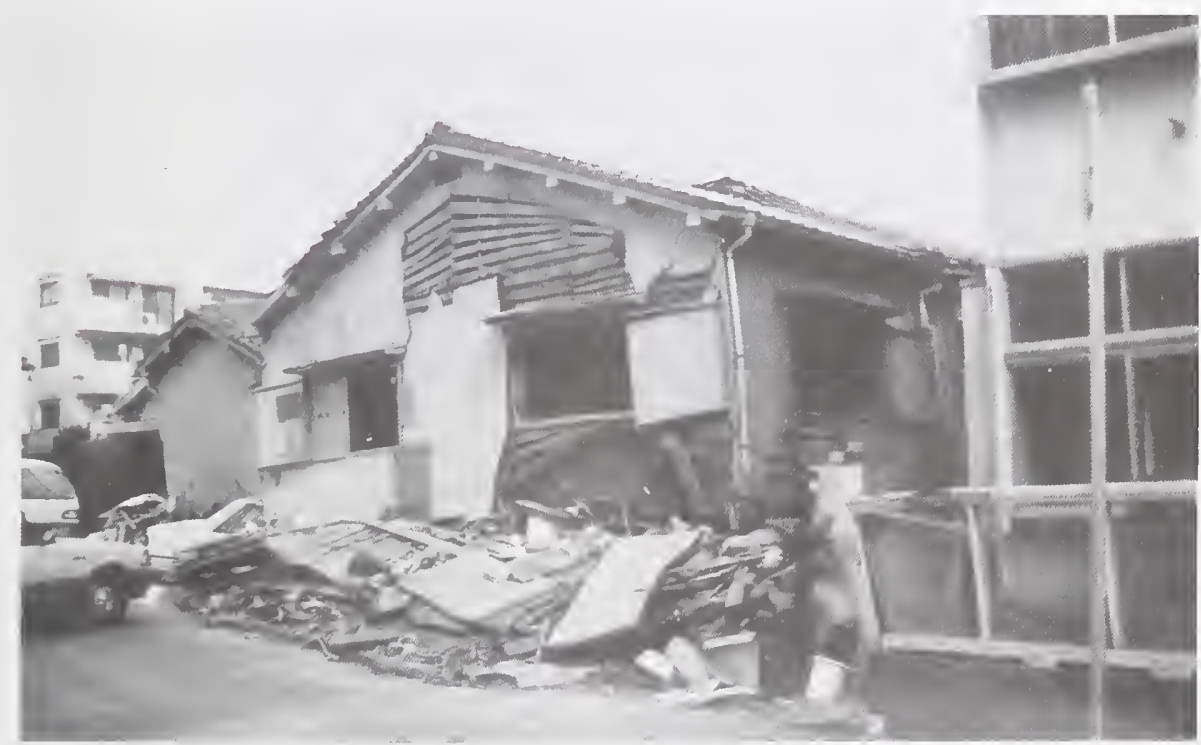

Figure 3.3.2 Same as Figure 3.3.1. 


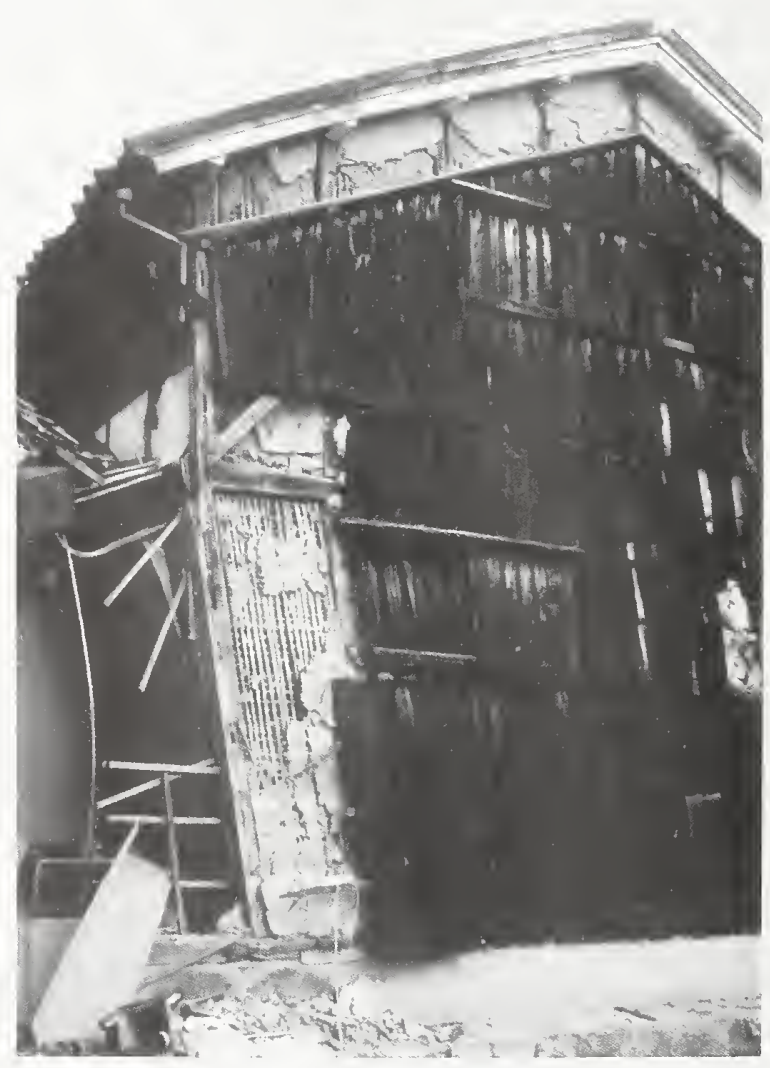

Figure 3.3.3 A damaged two-story Sake factory with Shinkabe construction. 


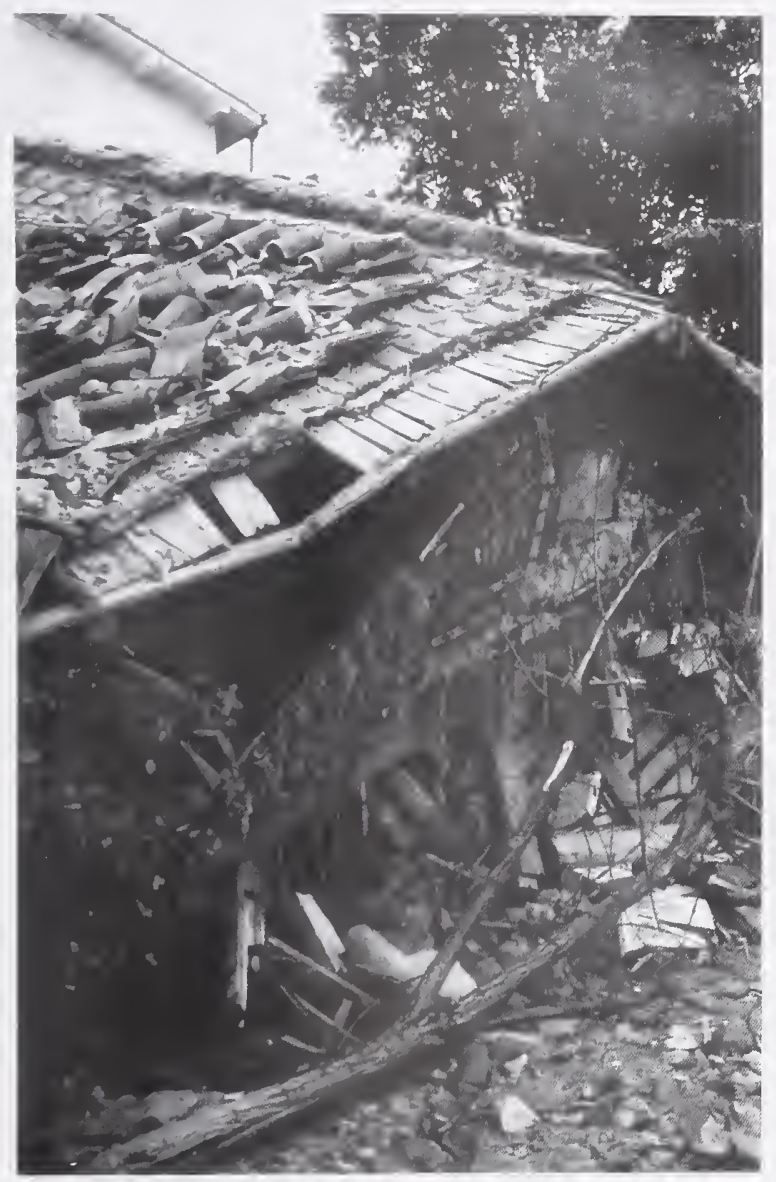

Figure 3.3.4 A completed collapsed Shinkabe construction-type house. 


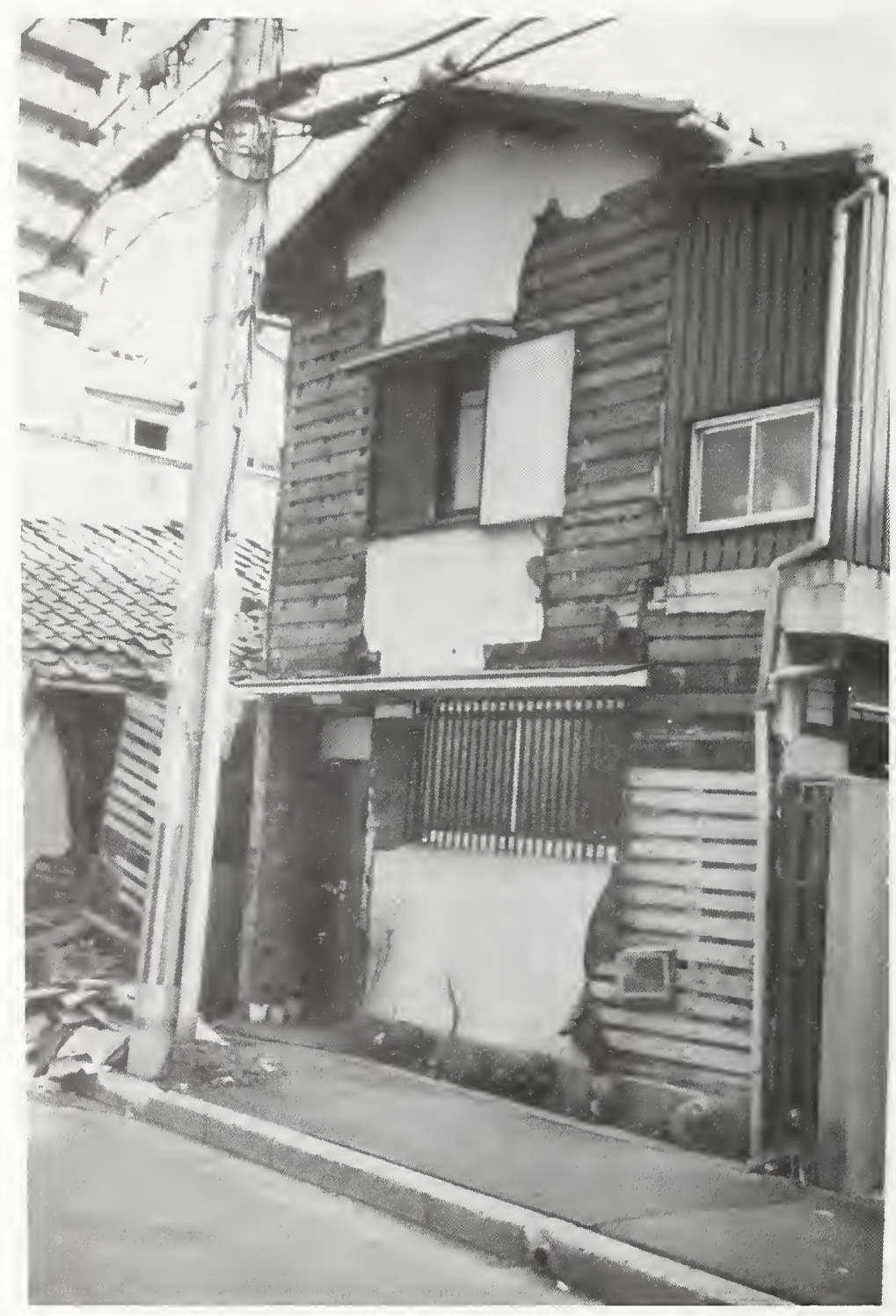

Figure 3.3.5 An Ohkabe house with only architectural design. Note a shadow of diagonal bracing on the left side of second story. 


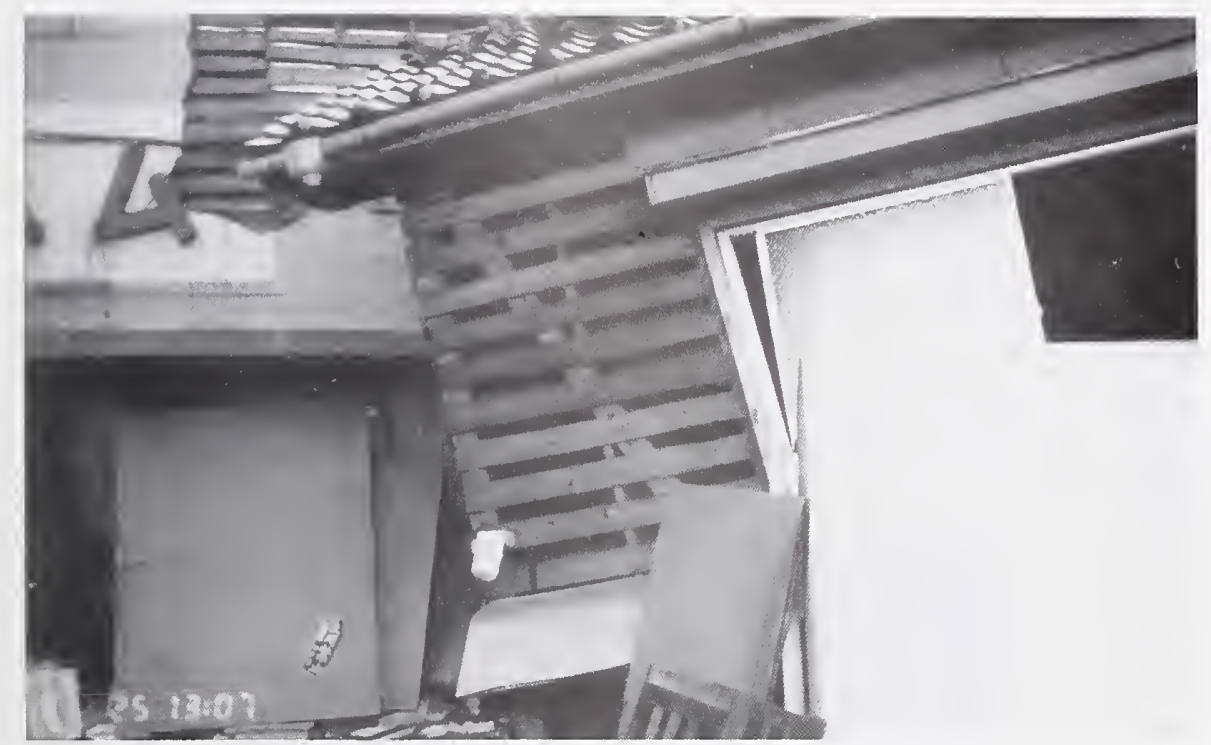

Figure 3.3.6 Intact upper story (braced) of a collapsed unit - Ohkabe construction.

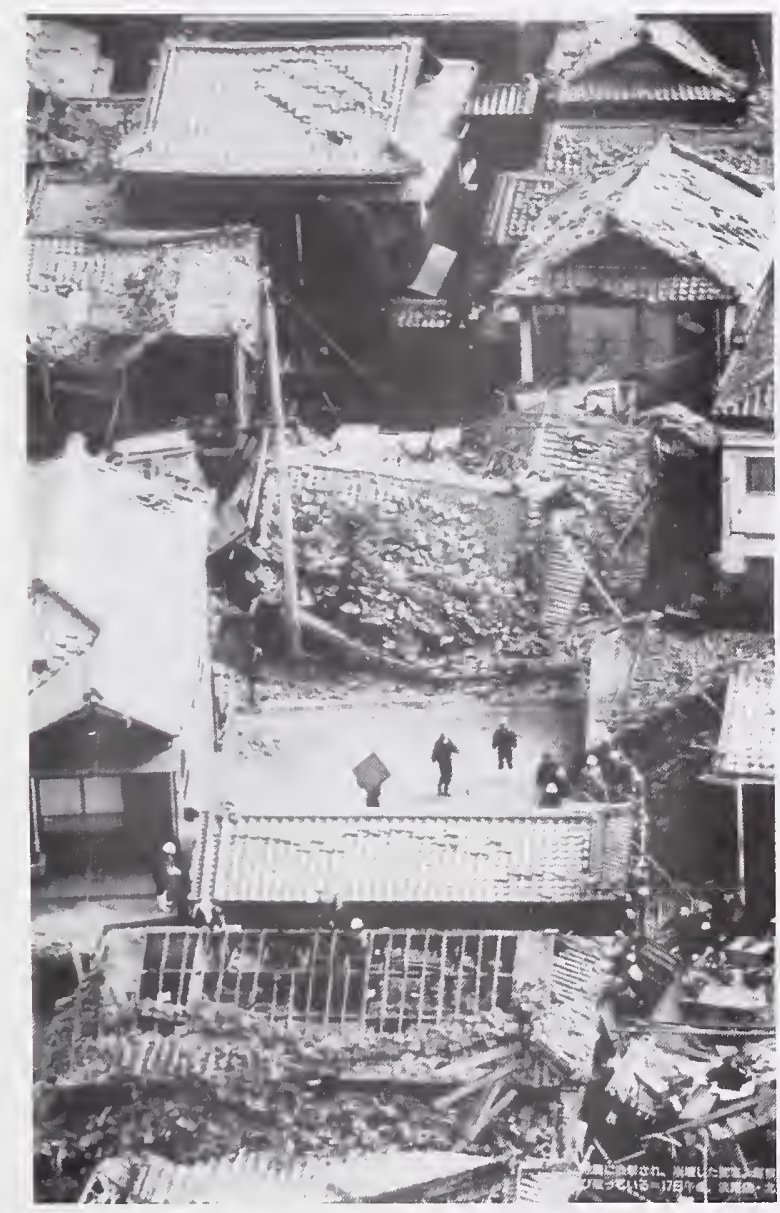

Figure 3.3.7 Collapse of some heavy tiled roof houses - Shinkabe construction. 


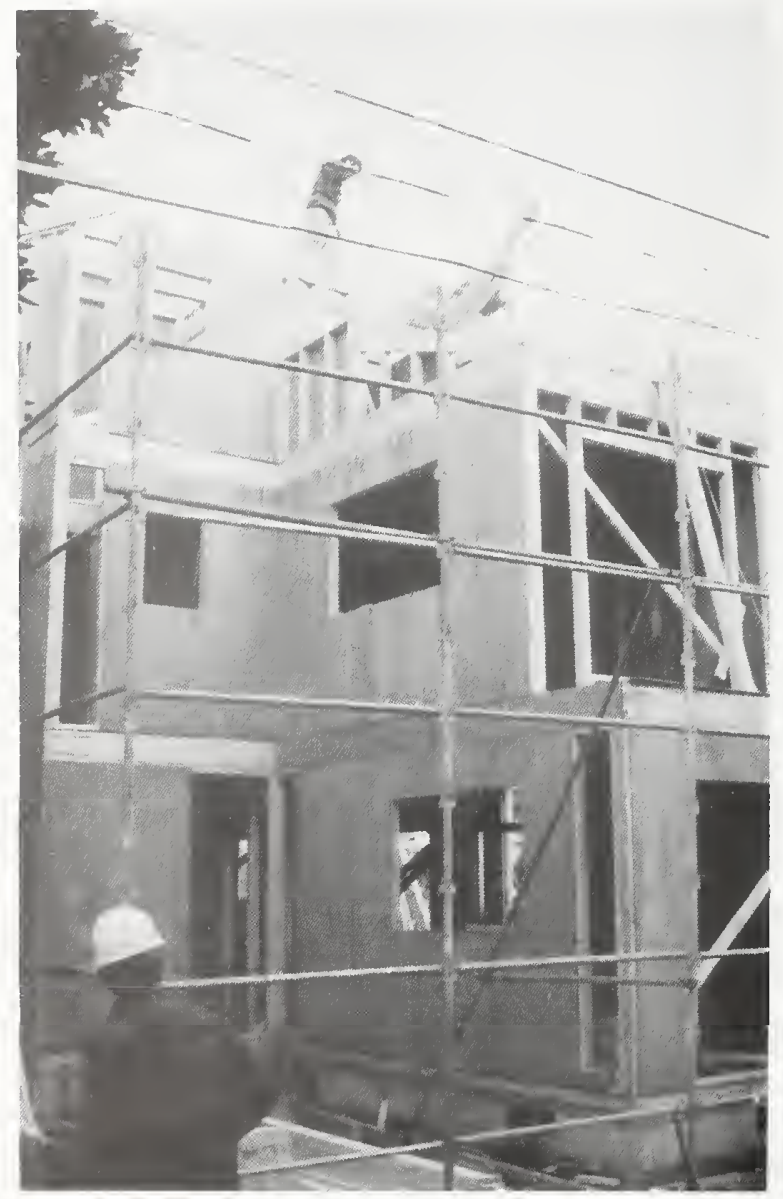

Figure 3.3.8 A new "two-by-four" construction replacing a destroyed residential unit. 


\subsection{Reinforced Concrete and Steel- Reinforced Concrete Buildings}

\subsubsection{Introduction}

Reinforced concrete (RC) and steelreinforced concrete (SRC) structures are most common for medium- and high-rise buildings in this region. SRC involves structural framing elements encased in RC. It is difficult to discern whether a building is $\mathrm{RC}$ or SRC type based on visual observation. However, based on Japanese common design practice, it is reasonable to assume that offices, hotels and apartments are SRC type if they are 7 stories and higher [4]. Both RC wall- and frame- structures range from 2 to 7 stories (see Figure 3.2.1).

Reinforced concrete buildings constructed prior to 1981 when the concept of ductility was introduced sustained severe damage. A prominent mode of failure of $R C$ multi-story buildings was the partial or total collapse of an entire story at an upper level. Many of these failed buildings were of steel-encased $R C$. (SRC) buildings.

In the central part of Kobe where a large number of buildings sustained damage, $\mathrm{RC}$ and SRC buildings comprised about 60 percent of about 2680 engineered buildings [3]. The Kyoto University survey showed the following damage distribution for $\mathrm{RC}$ and SRC buildings in the central part of Kobe:

$\begin{array}{ll}\text { Developed collapse: } & 5 \% \\ \text { mechanisms } & \\ \text { Severe damage: } & 8 \% \\ \text { Moderate damage: } & 11 \% \\ \text { Minor damage: } & 21 \% \\ \text { Slight damage: } & 55 \%\end{array}$

The distribution of severe damaged and collapsed RC frame structures in the central part (Chuo ward) of Kobe city is shown in Figure 3.4.1. In this figure the block numbers represent 20 damage survey zones in the central part that was used by the Kyoto University investigation team. Blocks 10 and 11 include the area near Sannomiya station and the city hall. These two blocks include the Kobe business district which had many mid- and high-rise commercial buildings, and consequently suffered a large number of damage.

The Kyoto University survey revealed that damage patterns closely paralleled the improvements of the seismic provisions in Japanese building code over time. It showed the following percentages of buildings that suffered severe damage or collapse:

Constructed before 1970: Over $55 \%$ Constructed from 1971 to 1975: $\quad 30 \%$ Constructed between 1976 \& 1980: $10 \%$ Constructed after 1980: None

These percentage figures clearly indicate the positive impact of improved building code provisions on the performance of buildings. The Kyoto University survey also noted that no $\mathrm{RC}$ building that primarily relied on shear walls for lateral load resistance collapsed. This trend of decreased damage of buildings with newer construction date and the general lack of collapse or damage to shear wall buildings were also noted by the survey team. 
Types of damage observed ranged from shear failure of columns to total collapse of an entire floor. As observed in other earthquakes, many buildings sustained damage to the first story. Particularly, many structures which were built prior to the 1971 revision of the Building Standard Law sustained severe damage to first-story columns. In most cases, shear failure of these columns resulted from the lack of column transverse reinforcement. As pointed out in section 3.2.1, closer spacing of column transverse reinforcement was introduced first in the 1971 revision.

An uncommon mode of failure observed in this earthquake is a total collapse of an entire story at a mid level of a building. One of the most likely causes of this type of failure is abrupt changes in the lateral stiffness at that story. Failure of splice of longitudinal reinforcement by "gas-pressure welding" also caused column failure of several buildings. Some buildings suffered significant damage due to shear failure of walls and short wall-columns or piers.

\subsubsection{Description of Damage}

Typical damage to reinforced concrete and steel- reinforced concrete buildings are described in the following.

\subsubsection{Damaged Reinforced Concrete (RC) Shear Walls}

Shear walls were used commonly in large mid-rise engineered buildings as major lateral load resisting elements, as well as in low-rise buildings. While no shear wall-related collapses were noted in larger engineered structures, numerous smaller structures with shear walls suffered collapses.
Figure 3.4.2 shows the east end of the second story of the seven-story Kobe Central Post Office. The structure had a dual shear wall and SRC moment frame system. Large diagonal tension cracks can be seen in the shear wall, and a thin masonry veneer can be seen to have fallen off. The height of the first and second story are about $5 \mathrm{~m}$ and $4 \mathrm{~m}$, respectively. Loss of concrete cover on some ground-level columns revealed smooth longitudinal reinforcement and wide column tie spacing; the building is estimated to be approximately 30 to 35 years old.

Figure 3.4 .3 shows a multistory office building in the western section of Chuo ward of Kobe. The building has suffered diagonal tension cracks in lower four stories, with the severity of damage increasing toward the ground level, paralleling increasing story shear. Figures 3.4.2 and 3.4.3 illustrate the typical damage seen in engineered shear walls; no collapses were seen, even in apparently older structures.

Figure 3.4.4 shows damage to window levels in a five story apartment building in the Nishinomiya area, which is several kilometers NE of the downtown Kobe area. The reduced cross-sectional areas in the window regions have suffered diagonal tension cracks, due to "short column" effects caused by the partial height infill walls.

Figure 3.4 .5 shows a complete shear wall failure in a low-rise apartment building in the Nishinomiya area. The failed wall was very lightly reinforced. This was an apparent "soft-story" failure, as the ground floor was a parking area (a situation that was very common). The entire story collapsed. The two sections of the failed wall, seen in the left side of the figure, were laterally separated by almost a meter. 


\subsubsection{Damage to Reinforced Concrete Frame Members}

The many RC structures that combined both "soft" first story and poor column details suffered severe damage throughout the Kobe area. Figure 3.4.6 shows a first story column in a low-rise storefront structure. The column racked excessively to cause loss of concrete integrity at its base. When the concrete integrity was lost, the longitudinal reinforcement buckled locally. Note the widely spaced ties and smooth longitudinal reinforcement. In Figure 3.4.7, a structure very similar to that in Figure 3.4.6, the smooth bars with widely spaced ties have buckled at the mid-height of the column.

As column detailing techniques were improved for newer (post-1971) structures, damage in newer structures was less severe. Figures 3.4.8 and 3.4.9 show columns with much more closely spaced hoops, and with deformed reinforcement. Figure 3.4 .8 shows a column that suffered complete deterioration of the core, but the reinforcement integrity was generally maintained, preventing collapse. Figure 3.4.9 shows a column with only minor damage, scabbing of the cover. This column was in a building that was located in the vicinity of the Sannomiya station where ground motions were intense.

Figure 3.4.10 illustrates classic "short column" failures through shearing of columns that have been stiffened over partial heights by infill walls. This structure was the Otaki Building in downtown Kobe. It was a nine-story RC structure with a penthouse on top. This cracking pattern extended over the entire building height, though its severity decreased with height. Figures 3.4.11 and 3.4.12 also illustrate classic short column damage. These are views of the ground floor in the Fukae
Mitsuku Housing Project, in the

Nishinomiya area. This 9-story SRC building has partial height infill walls which stiffened the first-story columns that led to shear failure. A close view of Figure 3.4.12 shows that a wide flange section is placed at the column centerline. With the severe amount of damage that is shown, it is likely that this building would have completely collapsed had it not been SRC.

An unusual problem was seen in downtown Kobe. Figure 3.4.13 shows a collapsed six-story RC building. It was located between two other buildings that appeared to be damaged only cosmetically. It is likely that pounding, caused by $\mathrm{N}$-S motions, contributed to the collapse, but note the relative size of the columns with respect to the girders. It appears that, with the almost universal failure of the columns, that a "strong girder-weak column" system existed.

\subsubsection{3 "Soft" First-Story Collapses}

A significant number of RC structures with collapsed first stories was observed. It is common Japanese practice to use first story and basement areas of both office and apartment buildings as parking areas or other open spaces (e.g., for street level shops). This frequently leads to flexible first stories that predominately or solely resist lateral loads by the first story columns. The upper stories are stiffened by the presence of walls. The stiffer upper portions of such structures will tend to translate and/or twist on the softer first story columns, leading to severe column damage or full story collapse. This problem has repeatedly arisen in past earthquakes around the world. In the Kobe area, this was exacerbated by the deficient detailing practices for RC members built during the pre-1971 era. First story columns that had collapsed typically showed small and widely spaced ties. Ties were often 
completely broken or otherwise displaced. Column longitudinal reinforcement suffered varying degrees of distress in such instances. In some minimum damage cases, the concrete cover had spalled off the longitudinal bars. Damage in other instances ranged from loss of all cover, complete shattering of the column core concrete over significant lengths of columns, and to complete buckling of the longitudinal reinforcement. Another significant poor practice was seen in a large number of RC buildings. The longitudinal column reinforcement was undeformed, or smooth. In many of these instances, reinforcement that was stubbed up from the column footings into the first floor columns was deformed, while the column reinforcement was not. This practice was discontinued in the 1960's. The use of smooth bars reduces bond strength, weakening all aspects of reinforcement performance. Complete buckling of the longitudinal reinforcement bars in such columns was quite common.

Figures 3.4.14, 3.4.15, and 3.4.16 illustrate the typical collapses that occurred in RC buildings due to soft first story. These collapses were generally confined to smaller commercial or apartment buildings that were five stories or less. The buildings shown in Figures 3.4.14 and 3.28 are apartment buildings location in Chuo ward of Kobe, while the building in Figure 3.4.15 shows a commercial building in downtown Kobe.

\subsubsection{Mid-height Story Collapses in $\mathrm{RC}$ and SRC Mid-rise Buildings}

A substantial number of RC and SRC frame buildings suffered partial or full story collapses at upper floor levels. In several cases, the collapses probably resulted from plan and stiffness irregularities; this phenomenon has been observed in almost every major earthquake. Figure 3.4.17 shows the Miyagi Hospital in the Ashiya area, which suffered a second floor collapse. The ground floor of this building was populated by shear walls, making it stiffer than the second floor framing. Immediately above the second floor, the plan size reduced considerably with a setback. The second floor was thus stiffer than the next floor up but not as strong as the ground floor. In Figure 3.4.18, the fourth floor of a ten story apartment building in the Ashiya area has collapsed. The fourth floor was the first setback floor above the larger plan of the lower three floors. In Figure 3.4.19, a five-story commercial building in downtown Kobe has suffered an almost complete collapse of its second story. The ground floor was a parking garage. It appeared that the ground floor was considerably stiffer than the second floor because of large columns and shear walls there. Since the building is in a street corner location, it is possible that its walls away from the street have fewer penetrations than the street walls, resulting in an uneven stiffness distribution, which could induce torsion in the structure. Figure 3.4 .20 shows a 10 -story SRC building, in which the third floor has collapsed. In Figures 3.4.21 and 3.4.22, an eight story (with offset penthouse) building in downtown Kobe has suffered an almost complete collapse of its seventh floor level. The offset penthouse may have contributed torsional effects in this structure. In Figure 3.4 .23 , in a building in downtown Kobe, the setback penthouse structure's shear wall has failed, and the penthouse is leaning noticeably.

A significant number of $\mathrm{RC}$ and SRC frame mid-rise buildings suffered partial or complete collapses of a single story at upper floor levels, where no obvious plan changes or eccentricities could be seen. This failure mode was particularly prevalent in downtown Kobe. Because the failures had 
occurred well above the ground level, thus prohibiting close examination of damage mechanisms. For example, Figure 3.4.24 shows the 8 -story old city hall building which experienced a total collapse of the sixth story. This SRC structure was completed in 1957. As can be seen in this figure, the building was not readily accessible. However, it was stated by the city engineer that encased structural steel section in concrete columns extended to the fifth story.

As described previously, Japan has the unique SRC construction, which when used properly, may enhance ductility. However, the Japanese host engineers indicated that it was typical in earlier times to discontinue the embedded structural steel elements above certain story levels, resulting in stiffness or strength discontinuities that could contribute to structural failures. If the framing system extending above the cutoff level for the embedded steel were made of $\mathrm{RC}$, initial stiffness of the upper level may have been essentially the same as that below, while strength was lower. If the framing system extending above the cutoff level for the embedded steel were structural steel only, the stiffness properties would change. Both techniques, using steel alone and using $\mathrm{RC}$ alone, above the cutoff level, have been used, although RC is apparently the more prevalent system.

Another potential contributing factor in the observed upper story collapses may have been the uniform lateral load distribution used in earlier Japanese seismic design. Post-1981 practice involves using lateral load distributions that more closely resemble the modal responses of a building structure to ground motions. A uniform lateral load distribution would tend to result in upper story members that are under-designed for the story shears and moments that are actually present, while lower story members would be less likely to be overstressed. It seems plausible that both the load distribution and SRC embedment cutoff would contribute to upper floor collapses.

One building that suffered an upper story collapse was the West Kobe Citizens Hospital. The hospital was an interlinked multi-building complex. The middle building was a 7-story structure, and a significant length of the north end of its fifth story suffered an almost complete collapse. Figure 3.4.25 shows a view of the NE corner of the collapsed area, while figure 3.4 .26 shows its NW corner. The north end of the structure collapsed completely, while the south end, away from the pounding zone that it had with the northernmost building was relatively intact. The south end of the collapsed building was bordered by what appeared to be a three story addition on its southwest corner, which may have provided a stiffening effect on the level below the collapsed story. While pounding with the adjacent building to the north is apparent, it is unclear that the pounding alone caused the severe collapse mechanism, and no major structural irregularities are noticeable. The floors above and below the collapsed floor are relatively undamaged. The failed columns in the collapsed floor appear to be pure RC.

\subsubsection{Other Observations}

There were several buildings which wee completely overturned due to large sway motion. One such building is a 9-story SRC building located on Flower Road, north of the Snnomiya station. This box-shaped building had two bays in the east-west direction and five bays in the north-south direction. Three sides of the building had shear walls and the side facing the main street (east side) was consisted of moment resisting frames. Immediately following the 
earthquake, the building was leaning

considerably toward east (Figure 3.4.27). In the evening of the same day, January 17, the building collapsed onto the six-lane street severing traffic flow (Figure 3.4.28).

According to a report by Takenaka

Corporation, torsional motion of the building caused the first story columns on the east side to fail in shear, thereby causing the building to lean toward east. Both the west side shear wall and SRC column connections failed in tension. The cause of the collapse is not clear. It is possible that aftershocks triggered the collapse. 


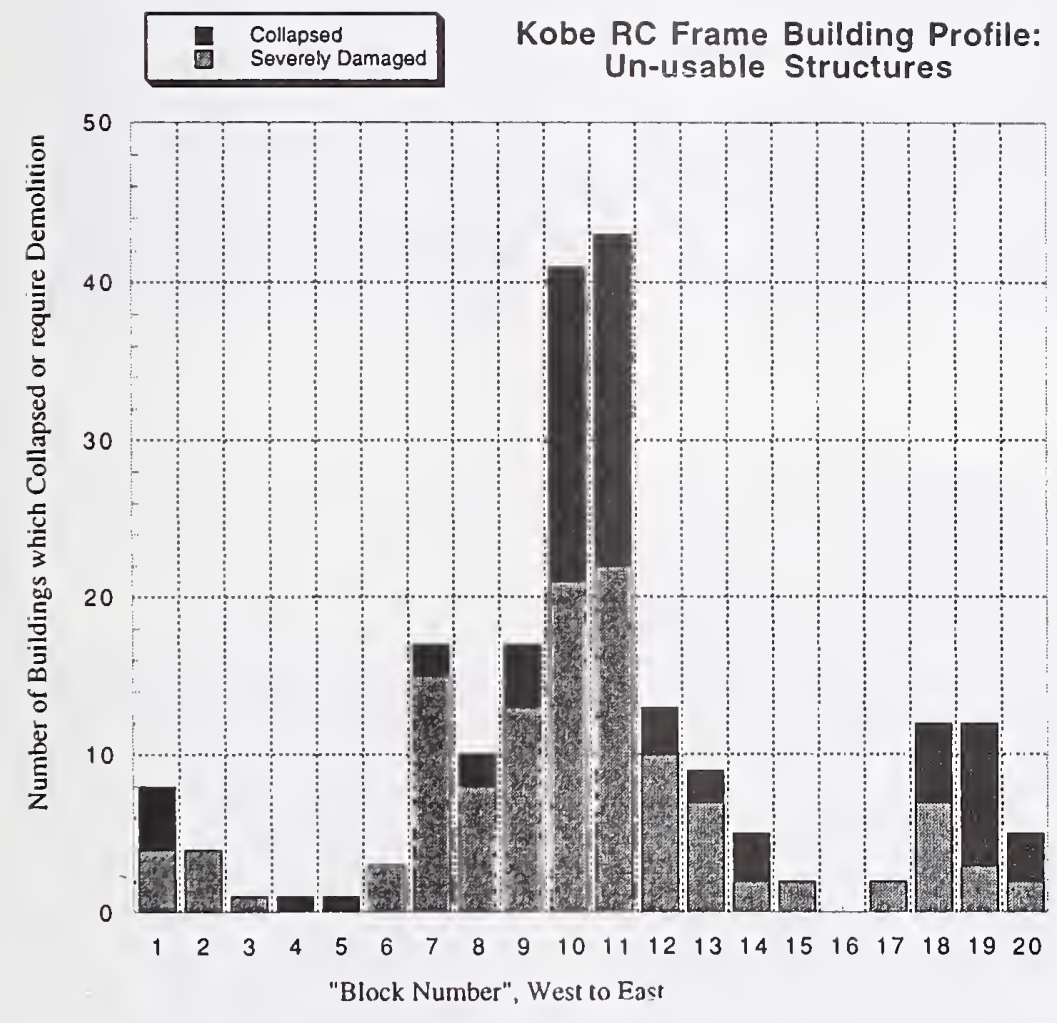

Figure 3.4.1 Collapsed and severely damaged RC frame structures in Kobe. 


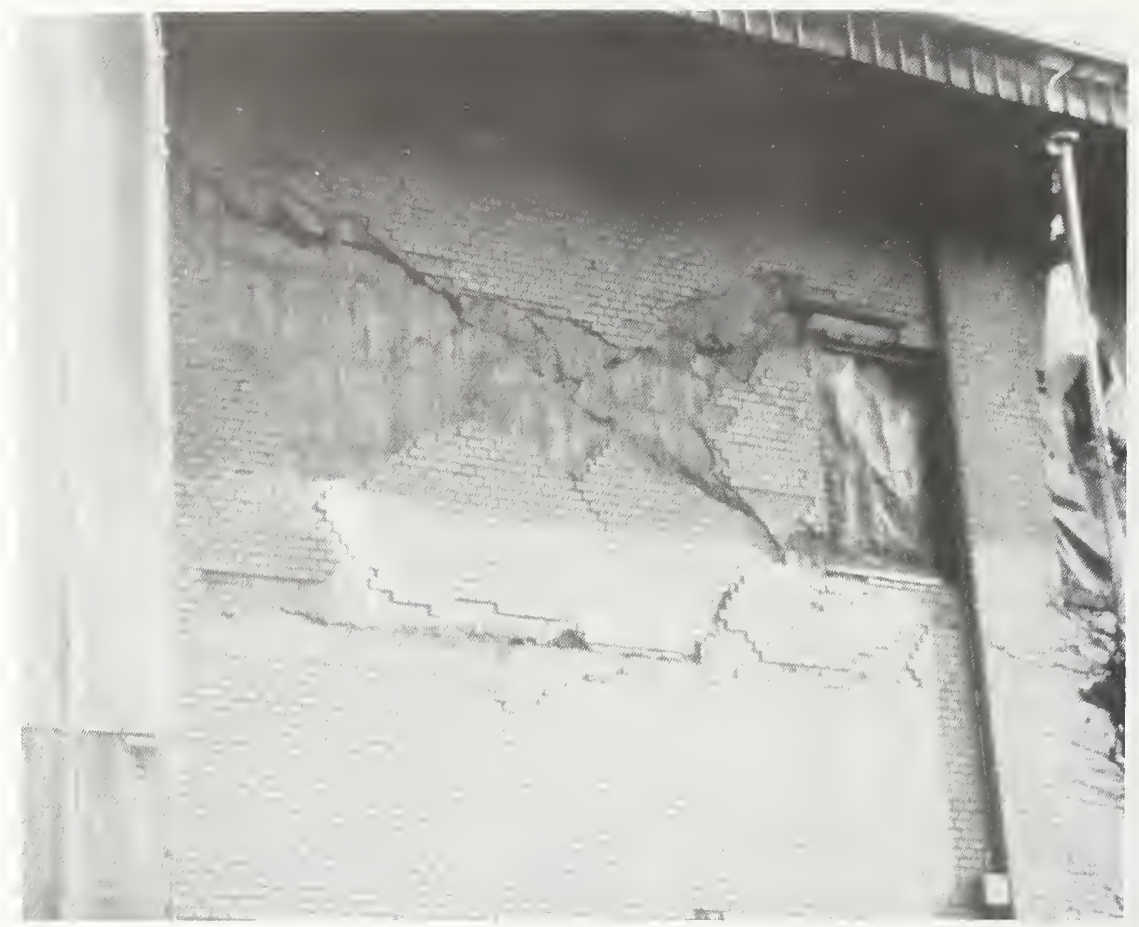

Figure 3.4.2 Damage to shear walls - Kobe Central Post Office.

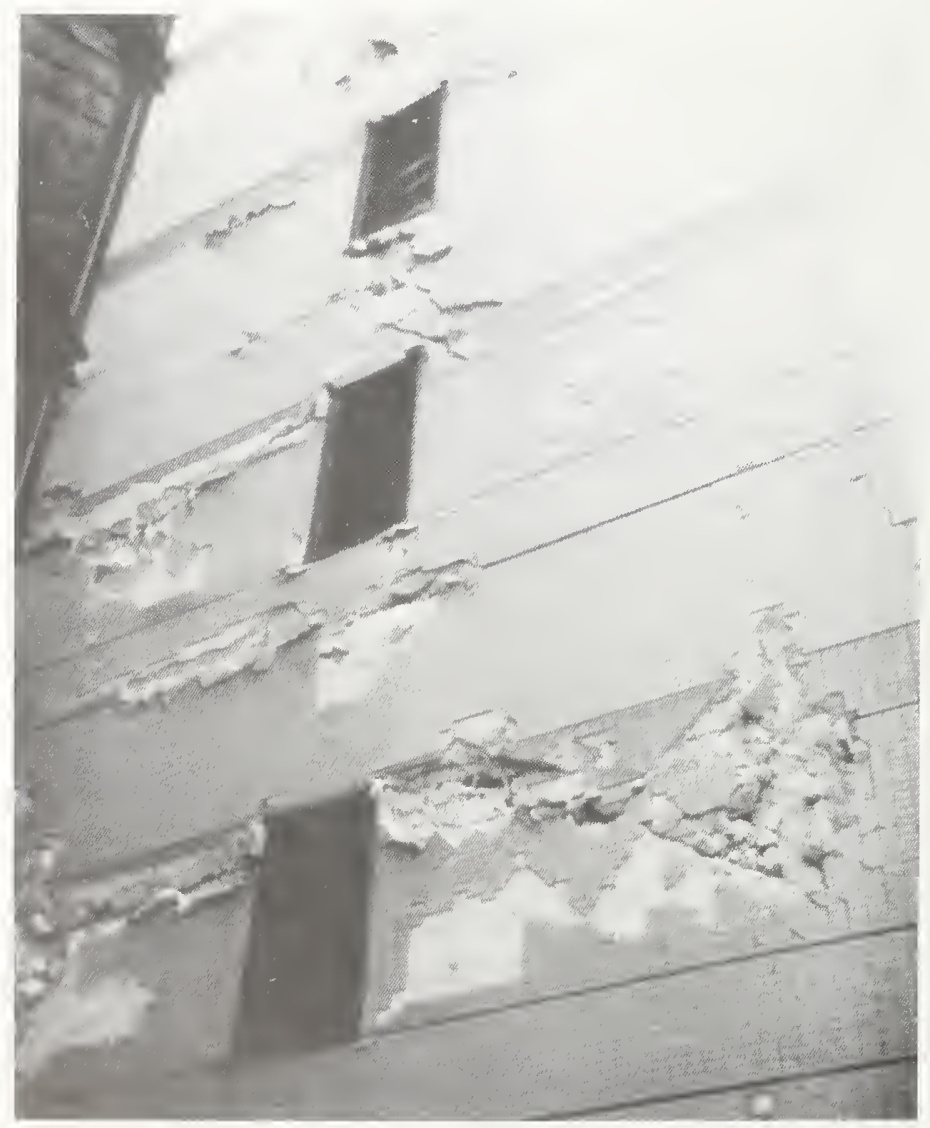

Figure 3.4.3 Damage to shear walls - office building in downtown Kobe. 


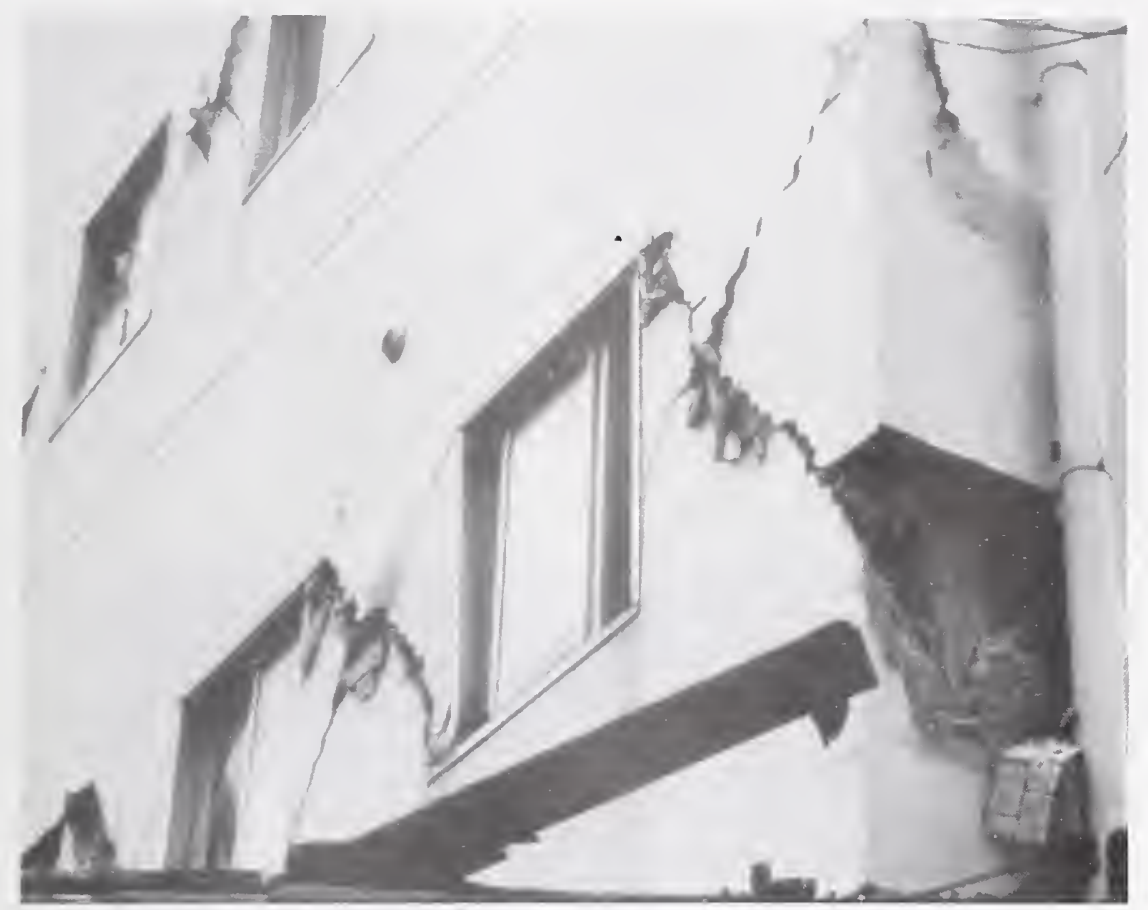

Figure 3.4.4 Diagonal tension cracks - apartment building in Nishinomiya area.

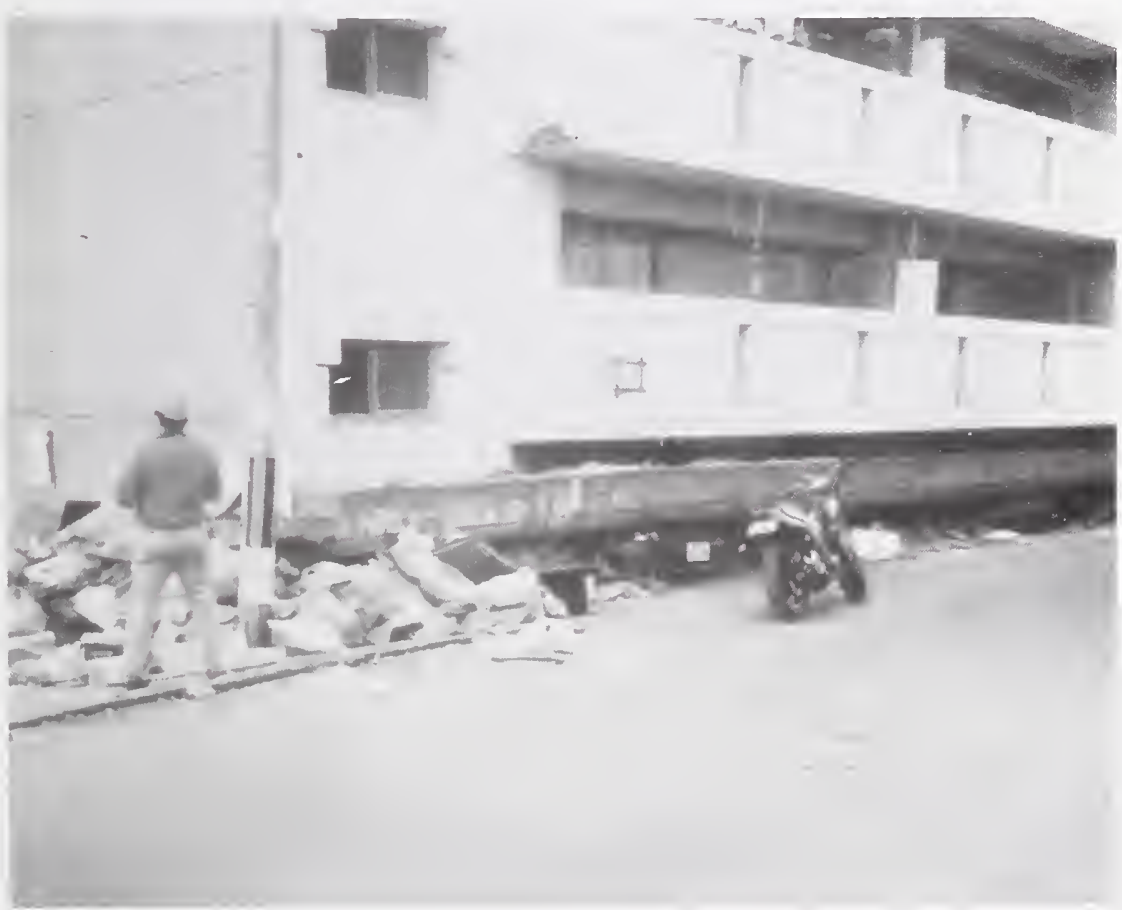

Figure 3.4.5 Failed ground floor shear wall - apartment building. 


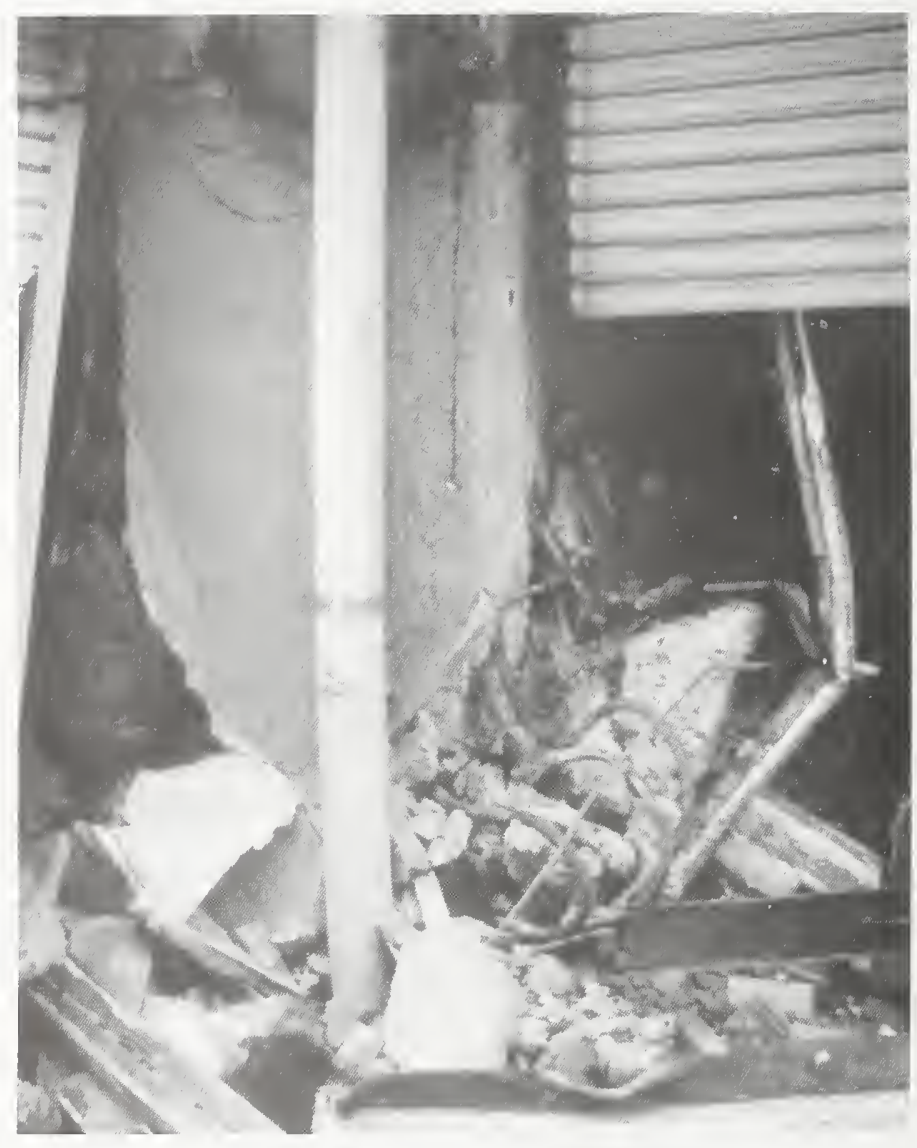

Figure 3.4.6 Failure of older column - local bar buckling. 


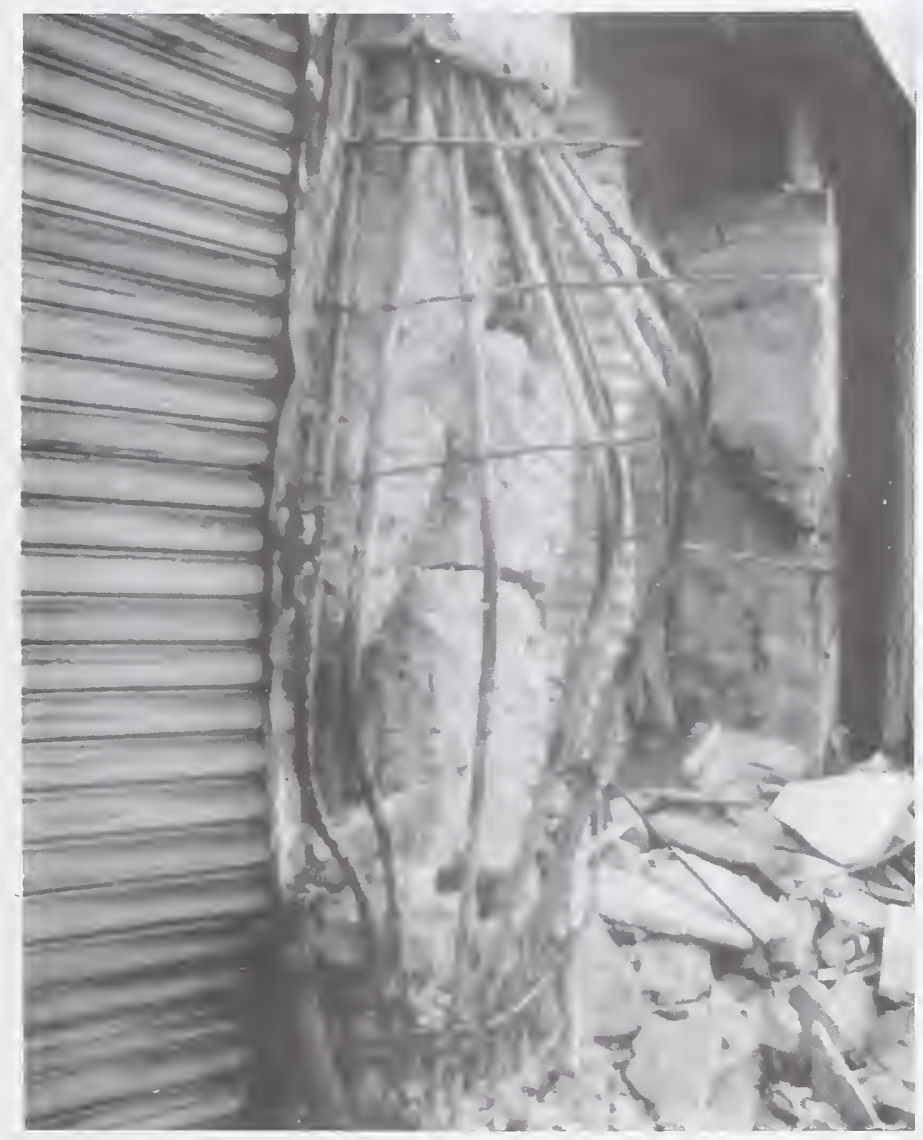

Figure 3.4.7 Failure of older column - general bar buckling. 


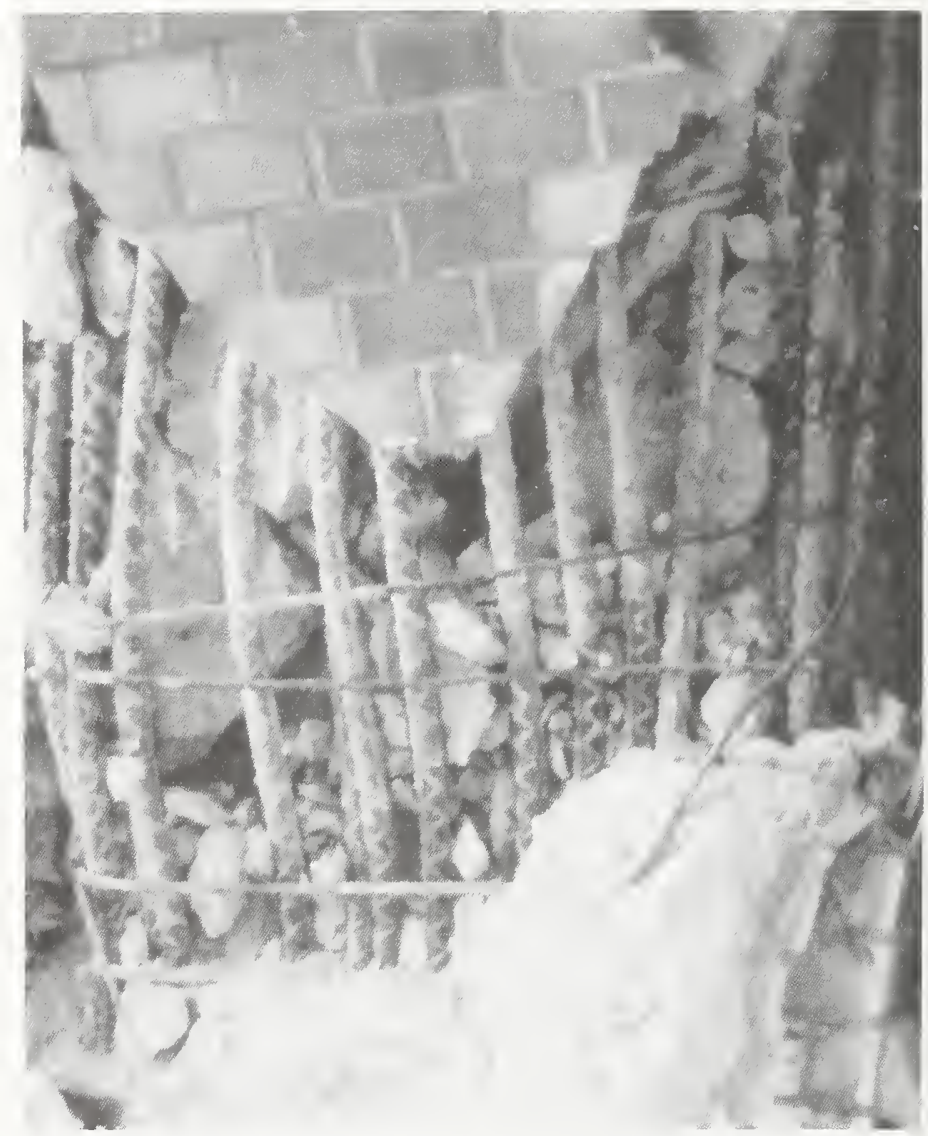

Figure 3.4.8 Failed column in commercial structure. 


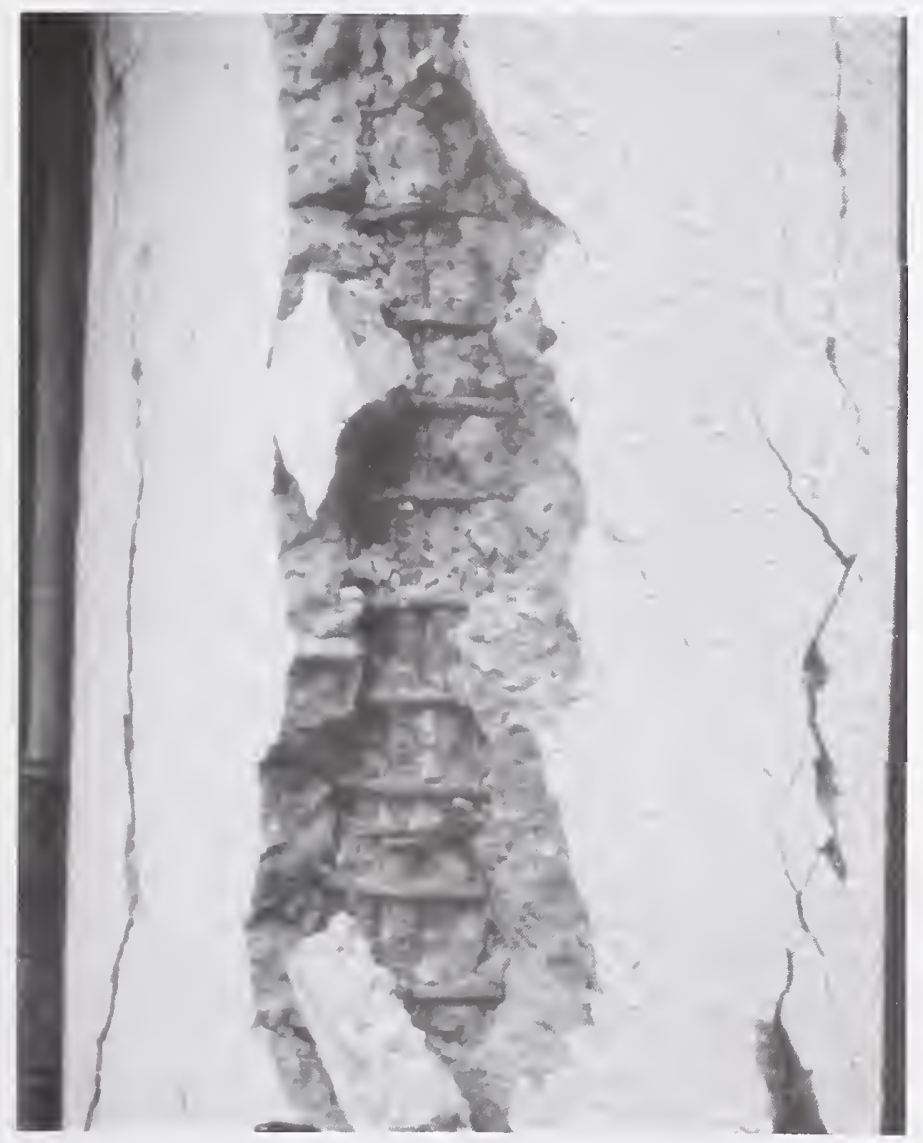

Figure 3.4.9 Damaged column in commercial structure. 

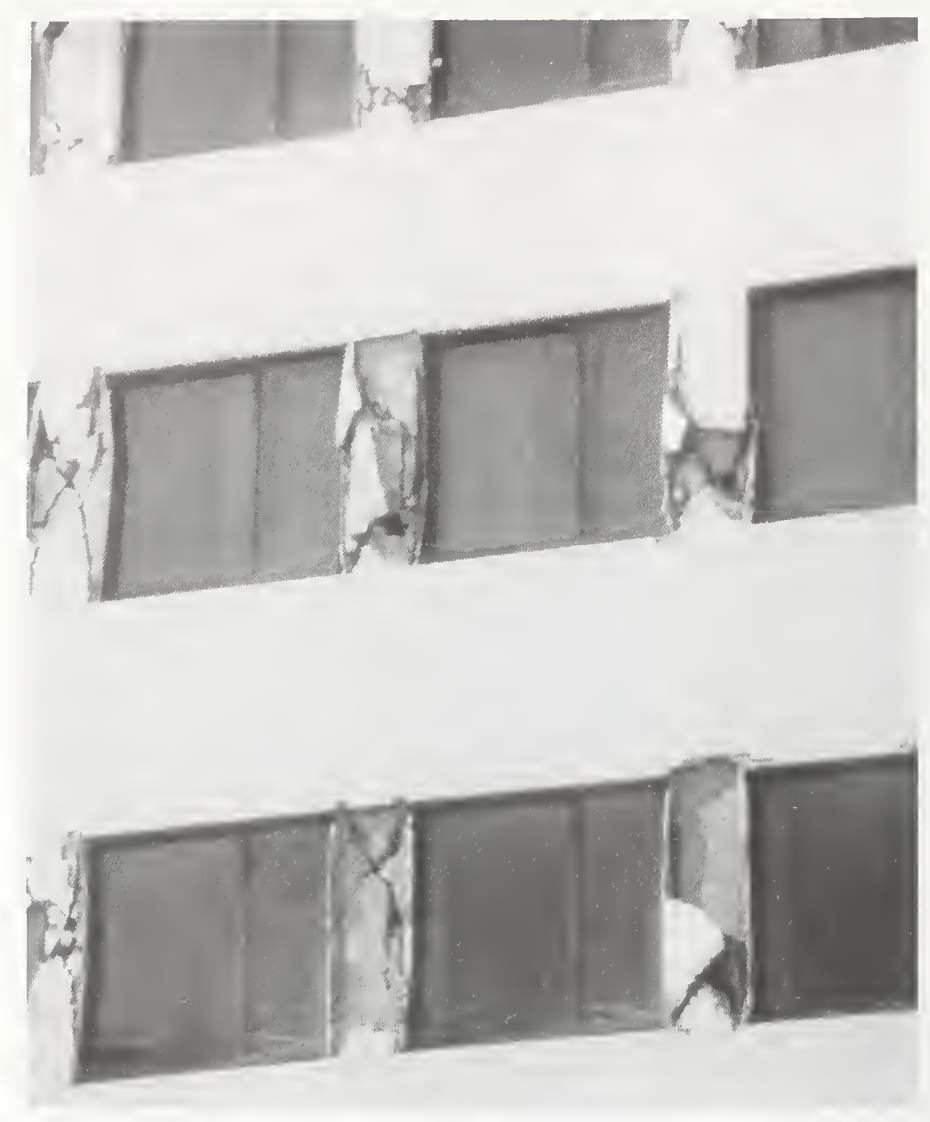

Figure 3.4.10 Short column effects - Otaki Building.

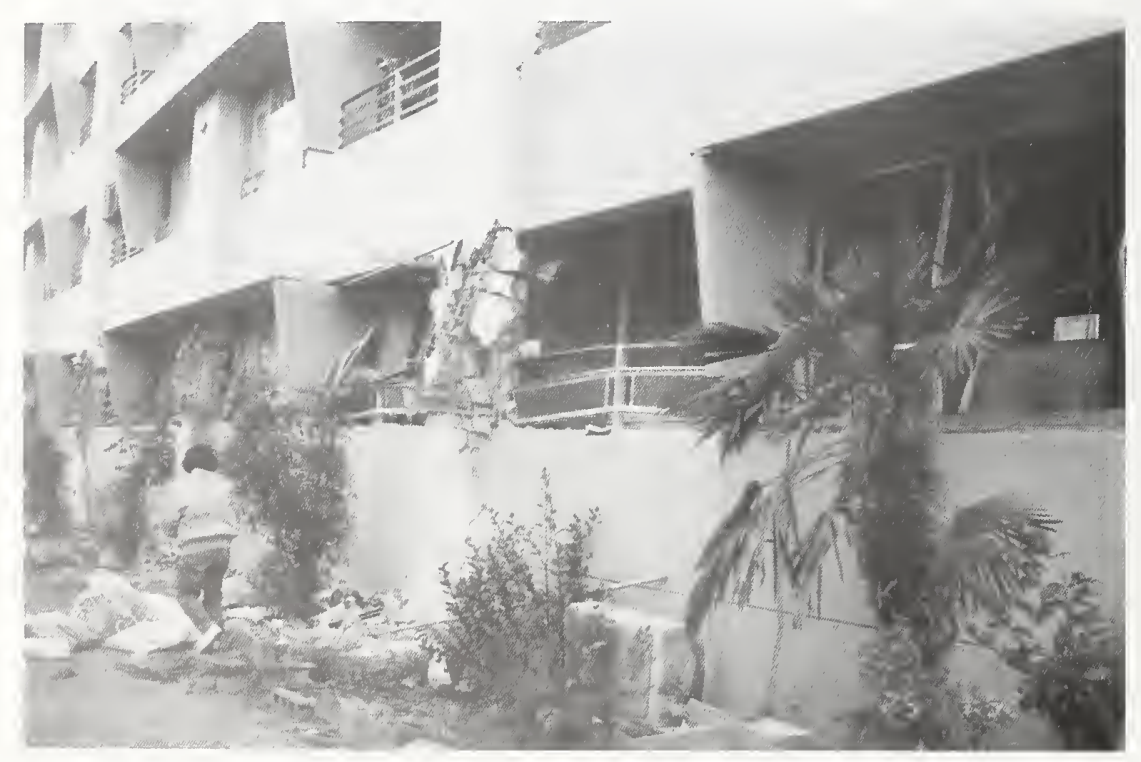

Figure 3.4.11 Short column effects - Fukae Mitsuku Housing Project. 


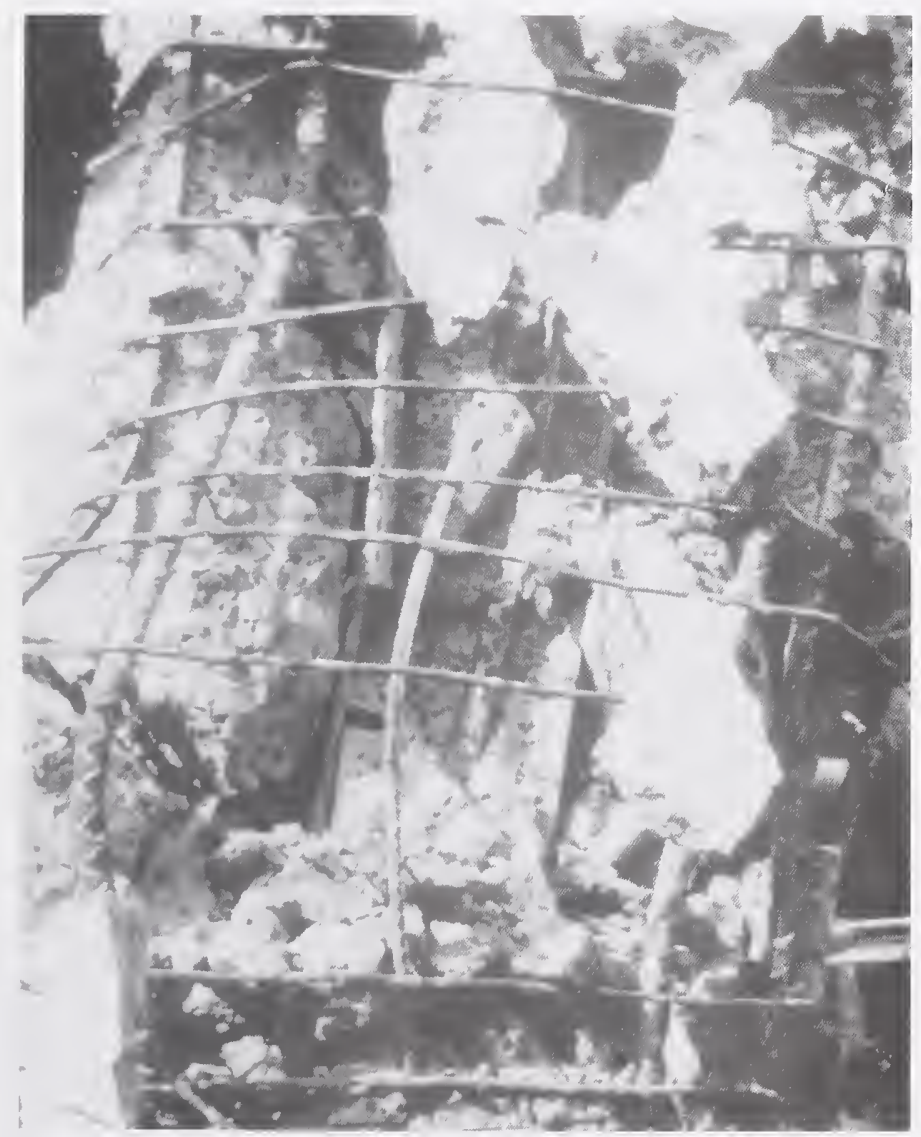

Figure 3.4.12 SRC column - Fukae Mitsuku Housing Project. 


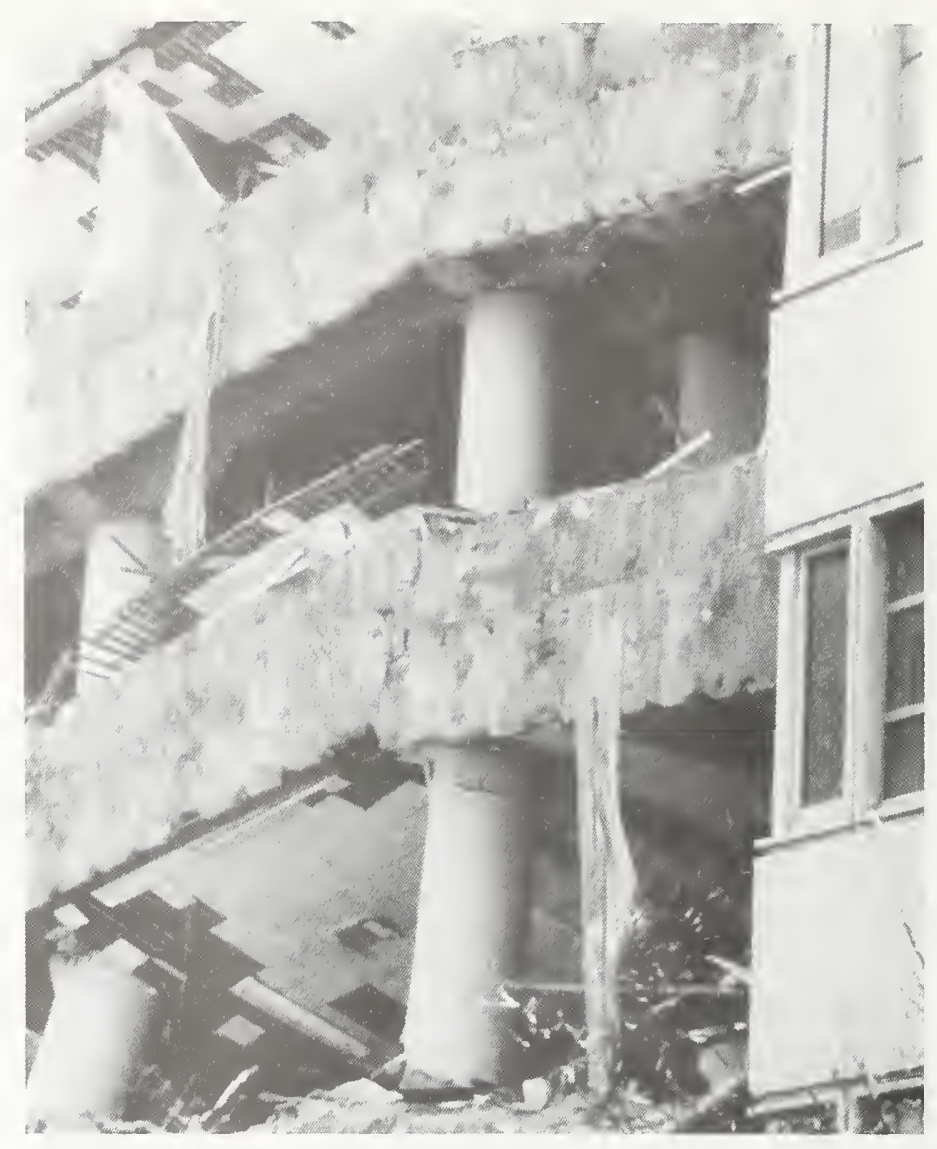

Figure 3.4.13 Strong beam-weak column failure.

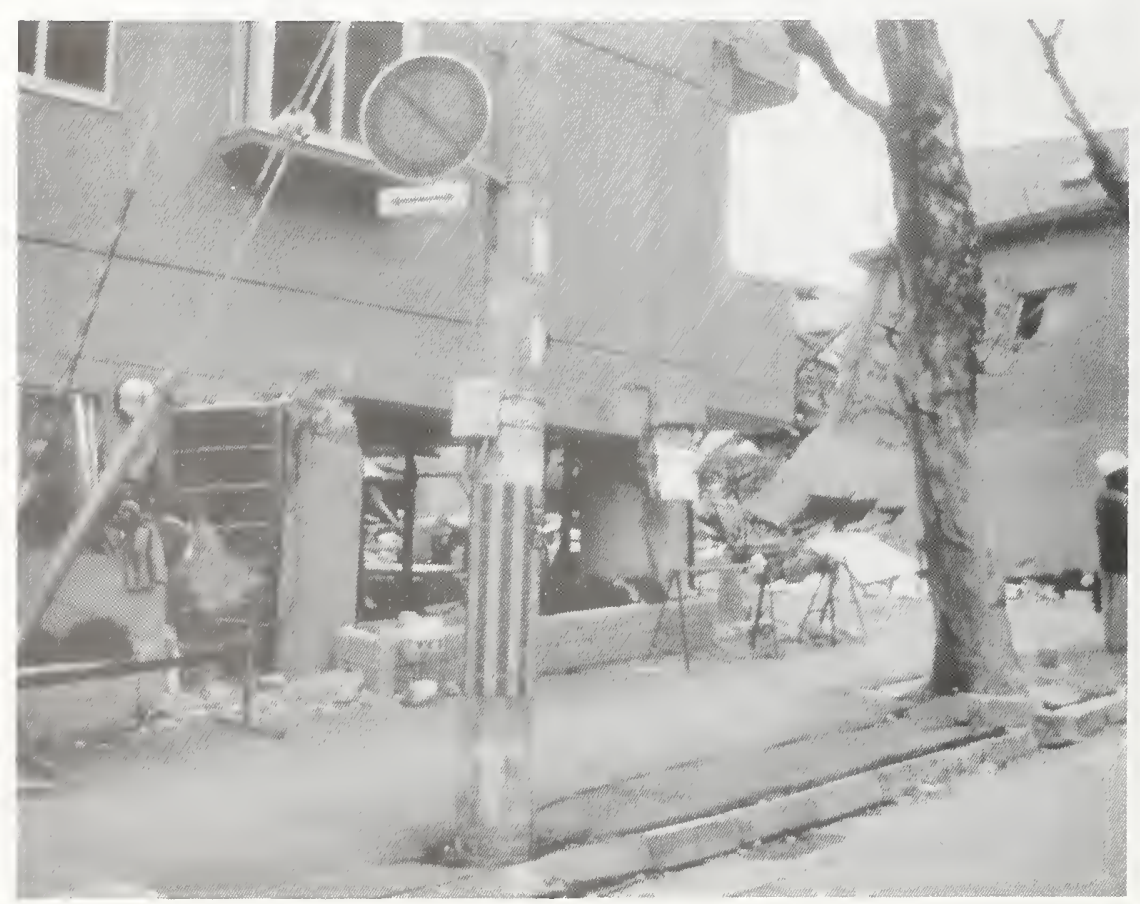

Figure 3.4.14 Collapsed first story near JR Line. 


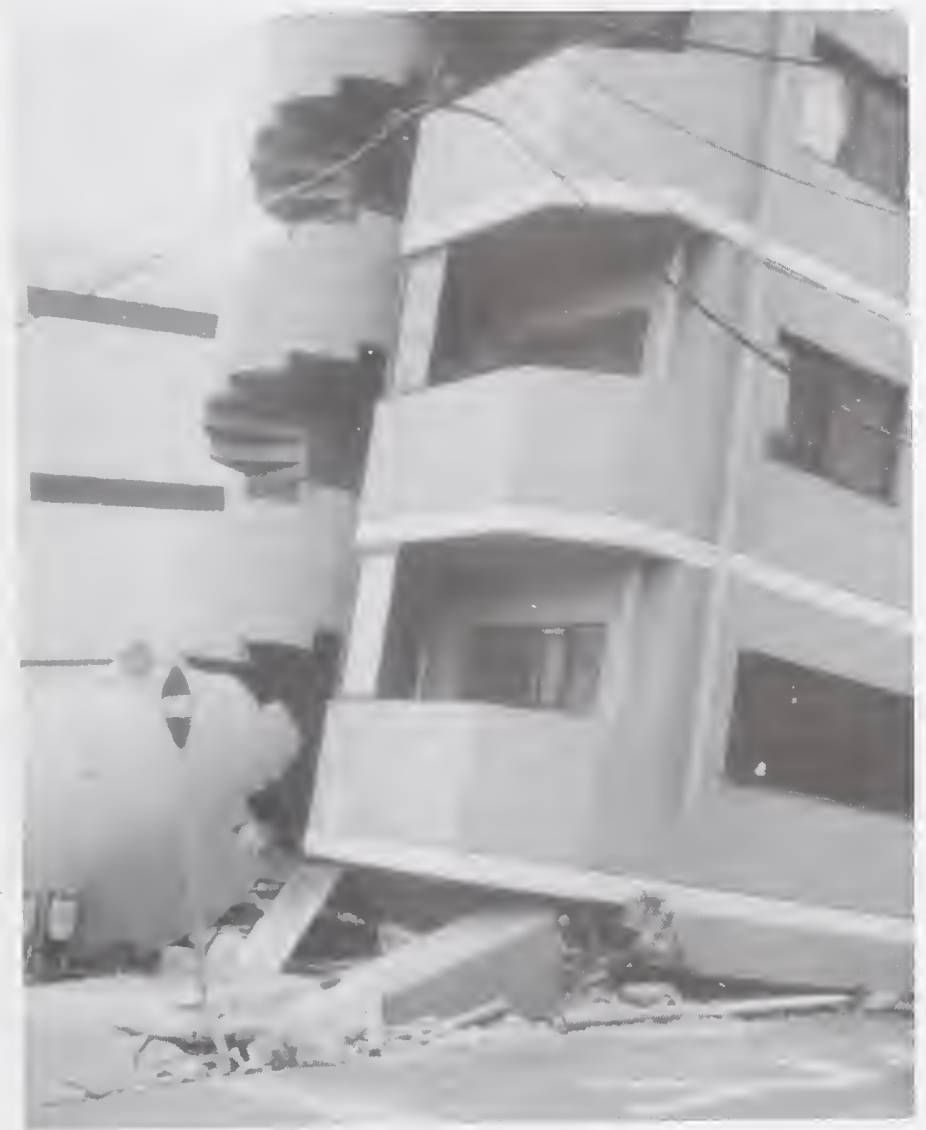

Figure 3.4.15 Collapsed first story. 


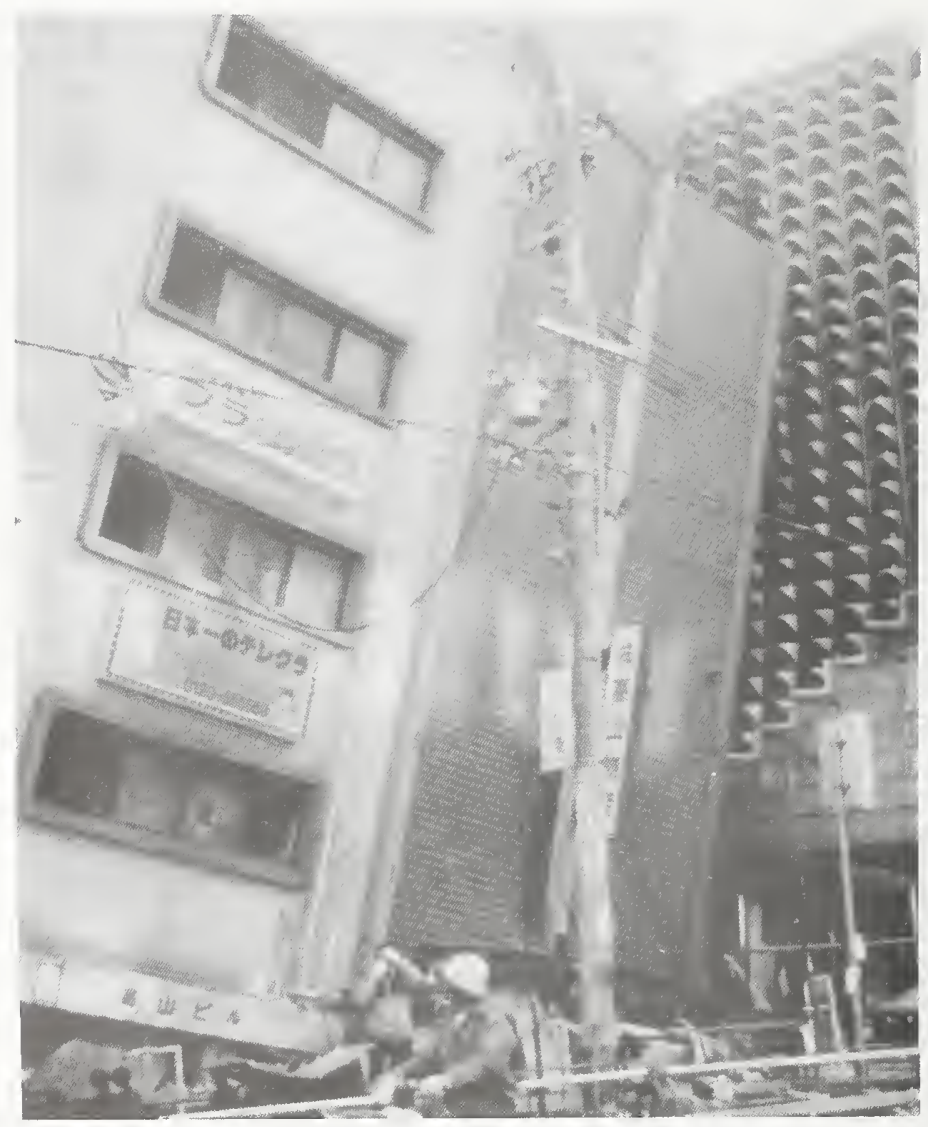

Figure 3.4.16 Collapsed first story - downtown Kobe. 


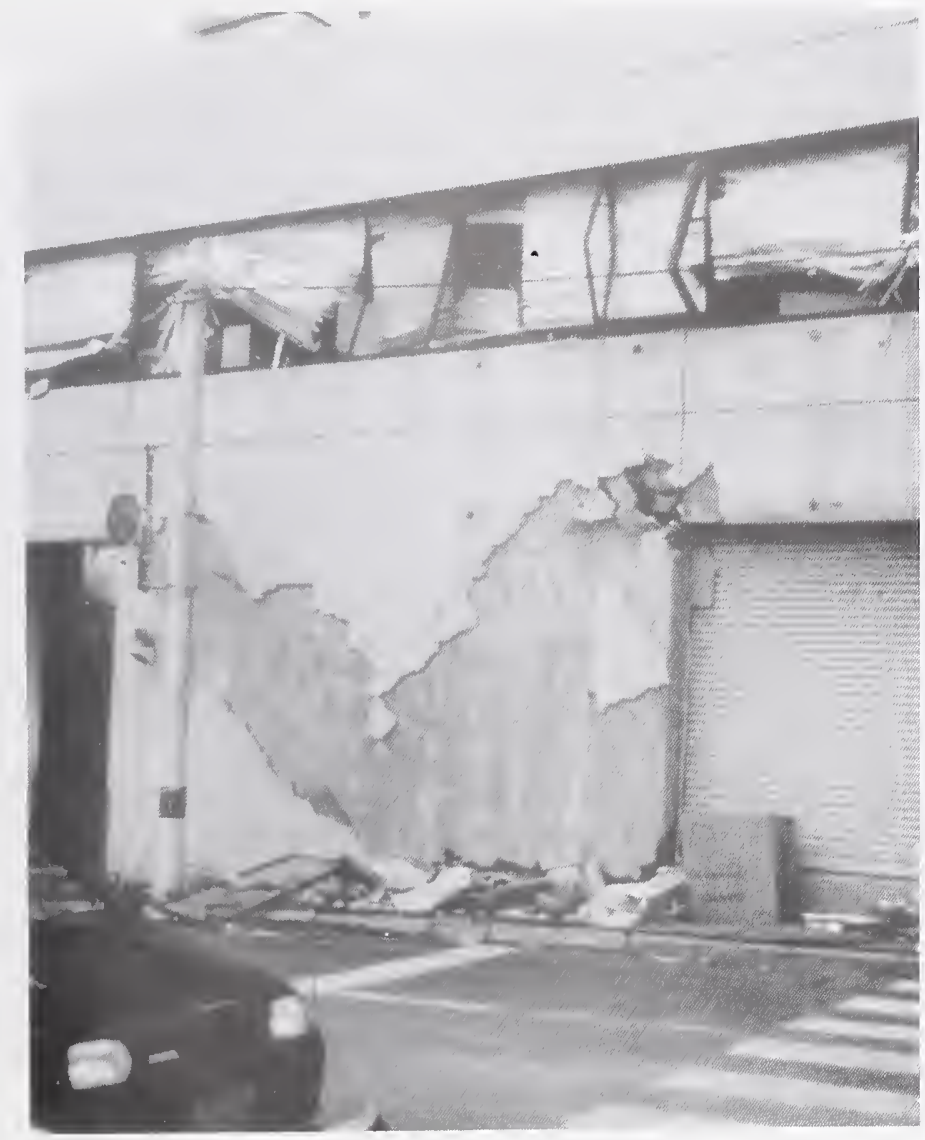

Figure 3.4.17 Second story collapse - Miyagi Hospital.

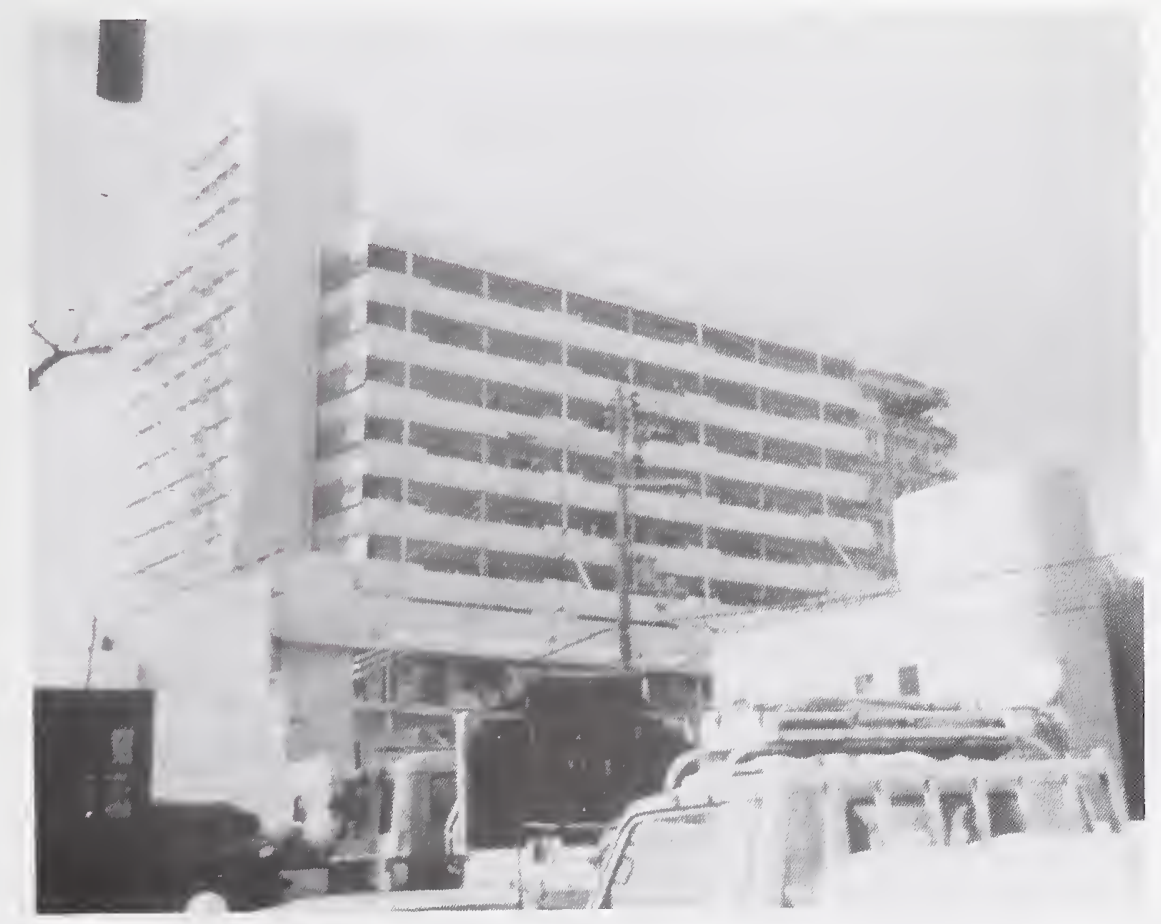

Figure 3.4.18 Fourth story collapse in apartment building. 


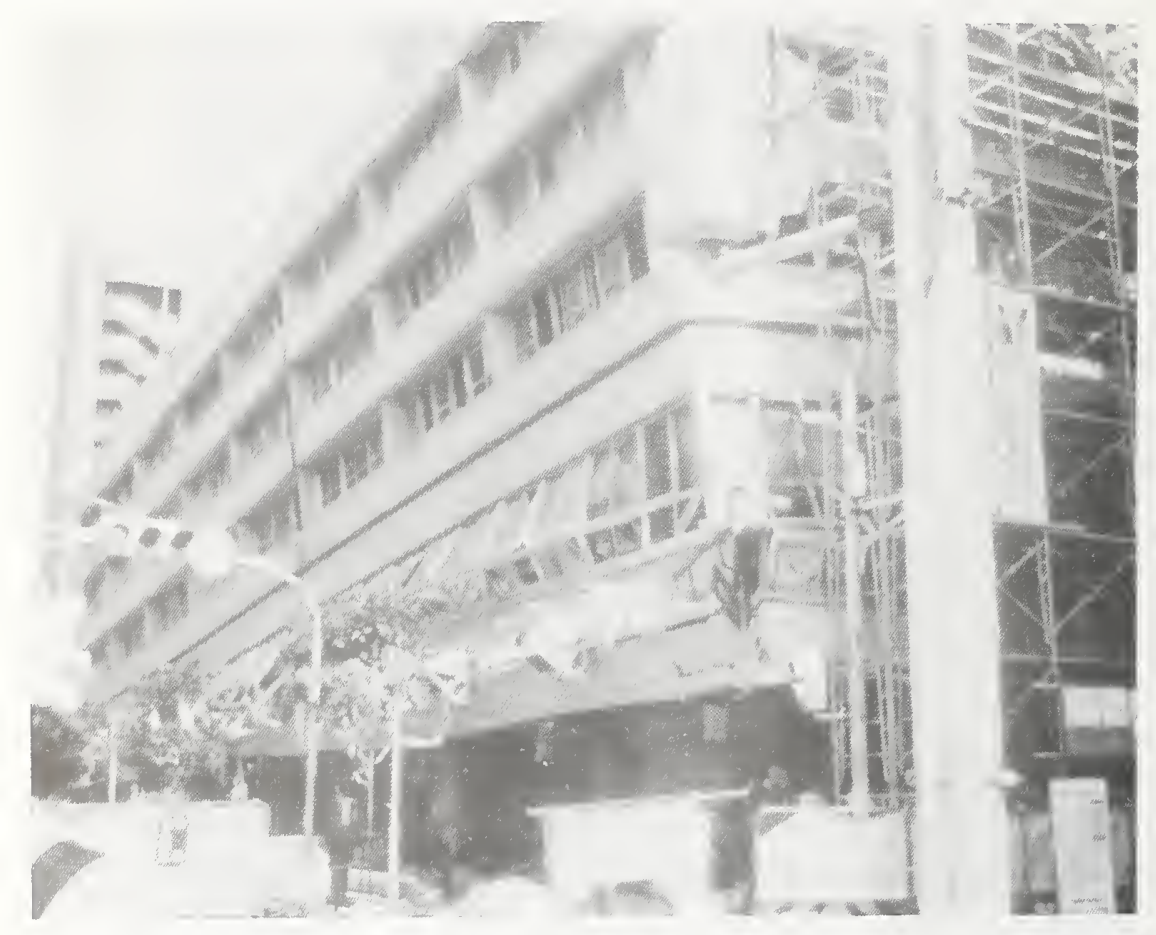

Figure 3.4.19 Second story collapse - Downtown Kobe.

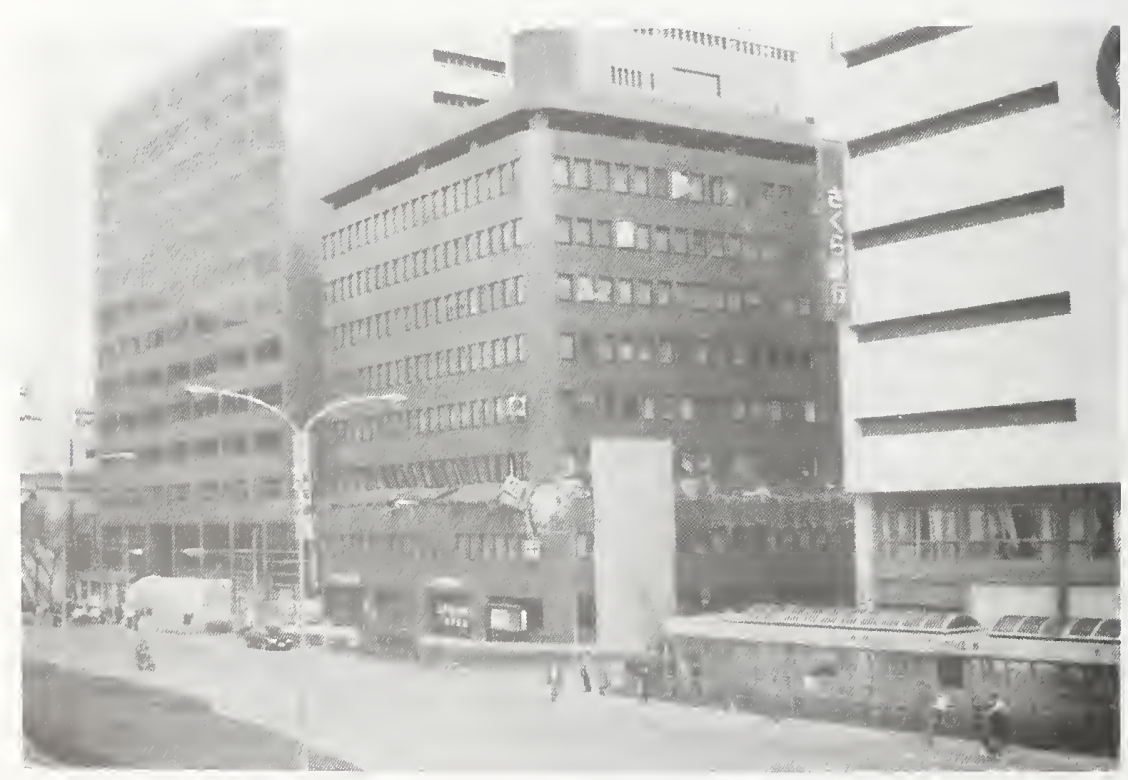

Figure 3.4.20 Third story collapse - Downtown Kobe. 


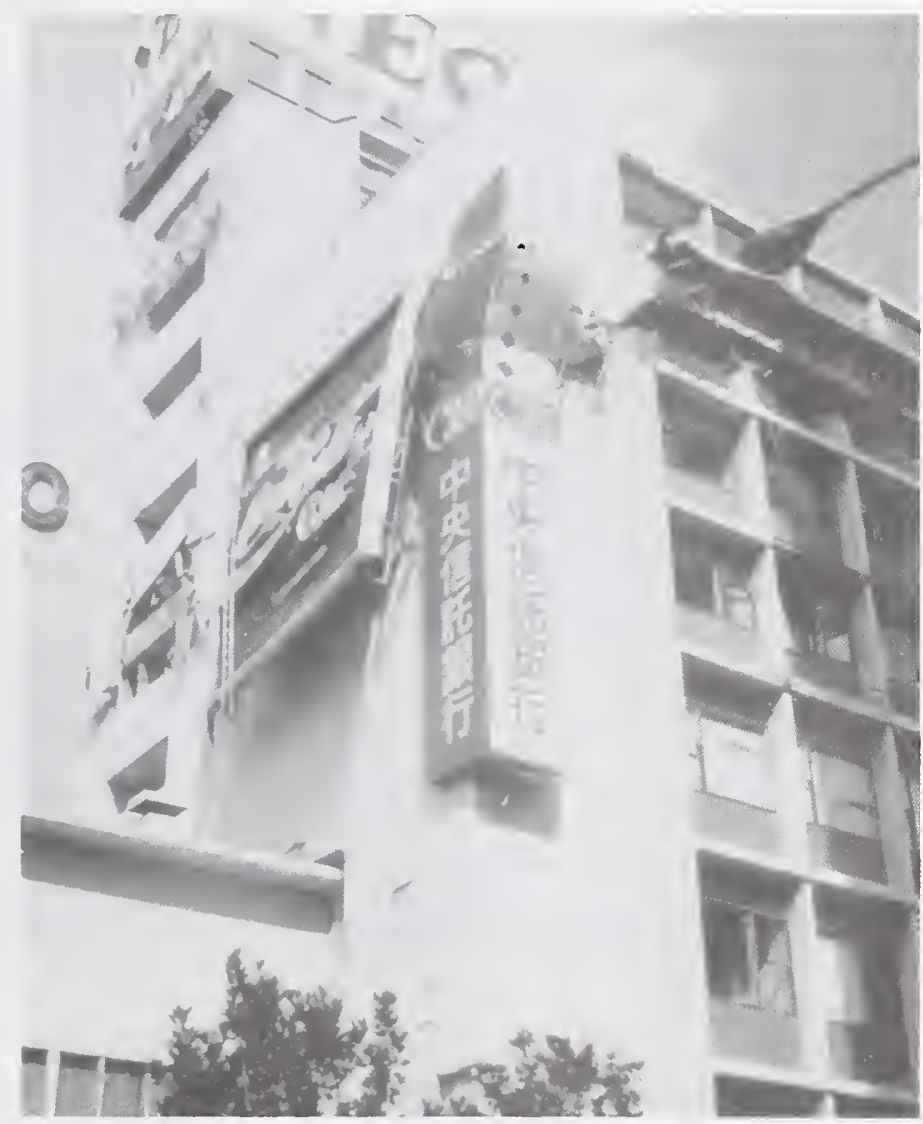

Figure 3.4.21 Upper story collapse - Downtown Kobe.

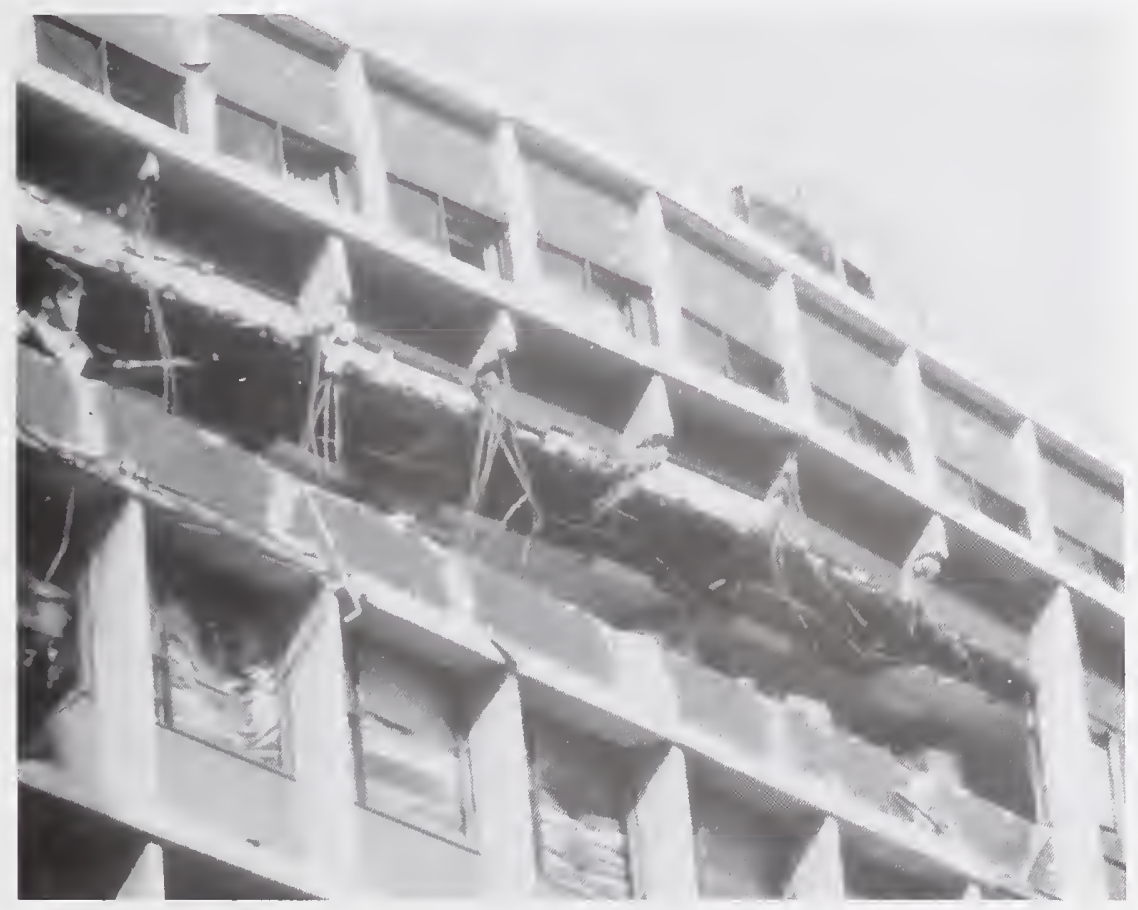

Figure 3.4.22 Upper story collapse - Downtown Kobe. 


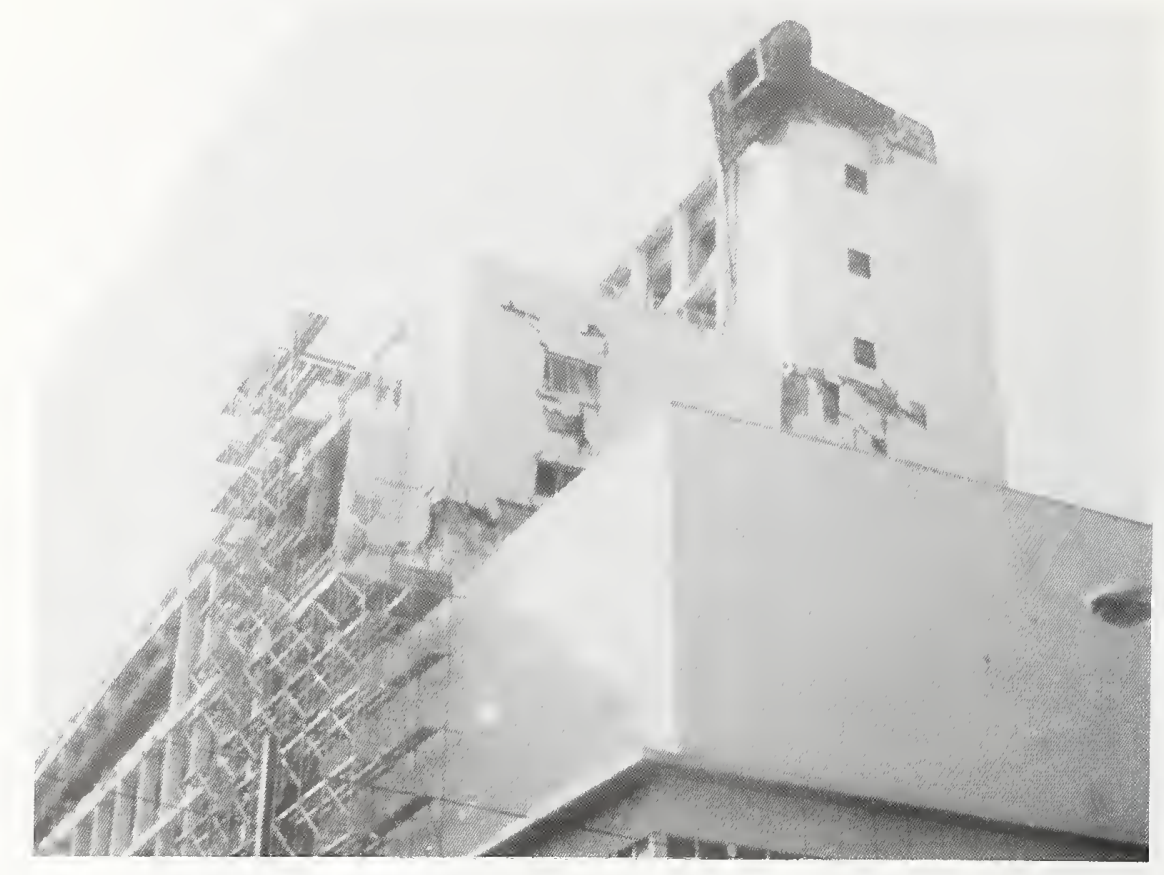

Figure 3.4.23 Collapsed penthouse structure.

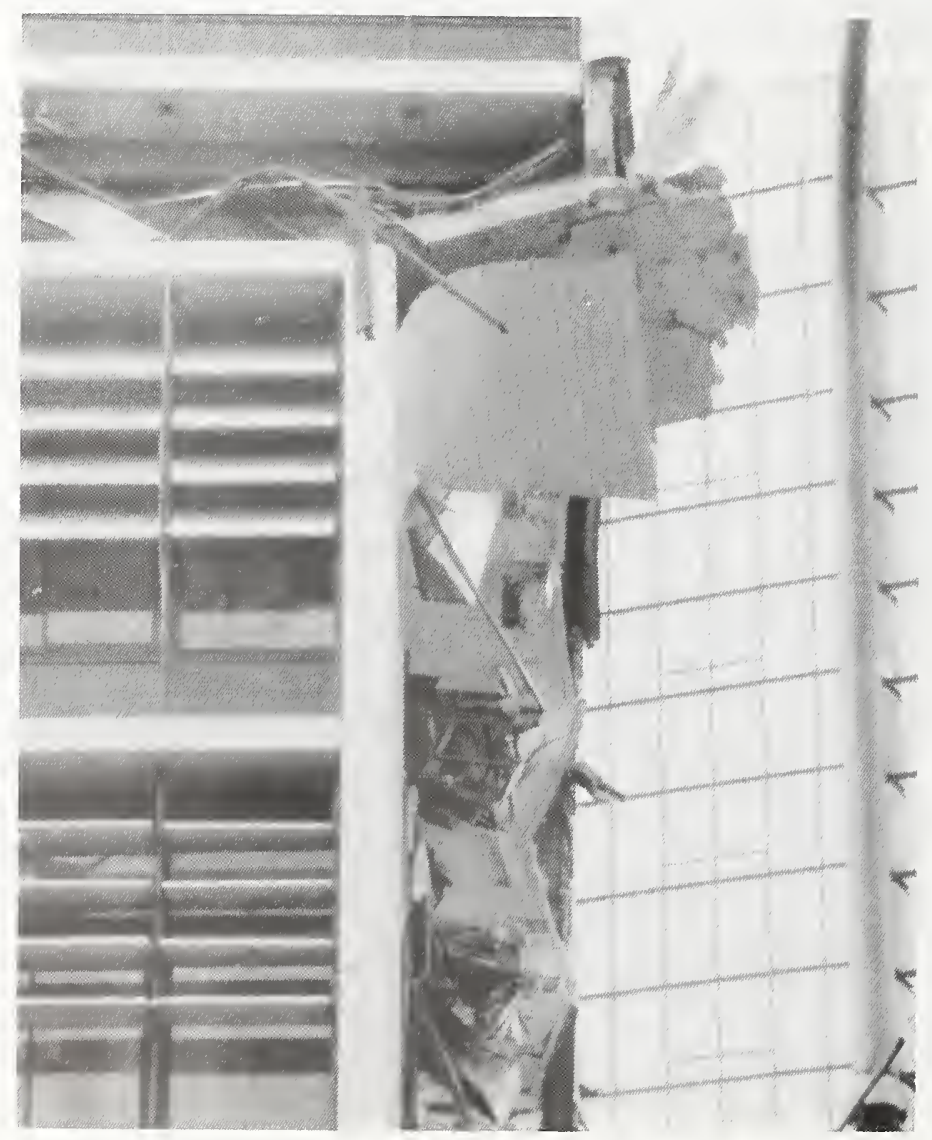

Figure 3.4.24 Collapsed upper story, north end - Kobe City Hall Annex. 


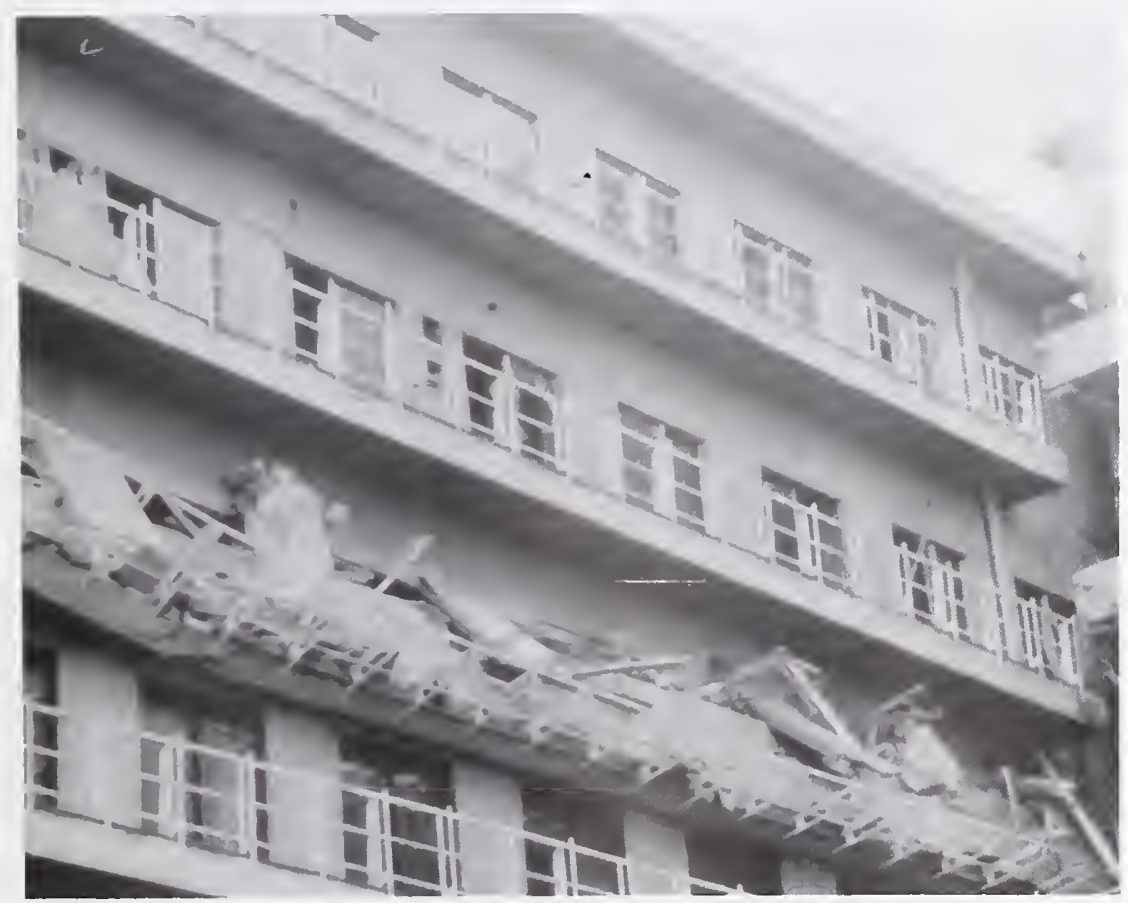

Figure 3.4.25 Collapsed upper story, northeast corner - West Kobe Citizens' Hospital.

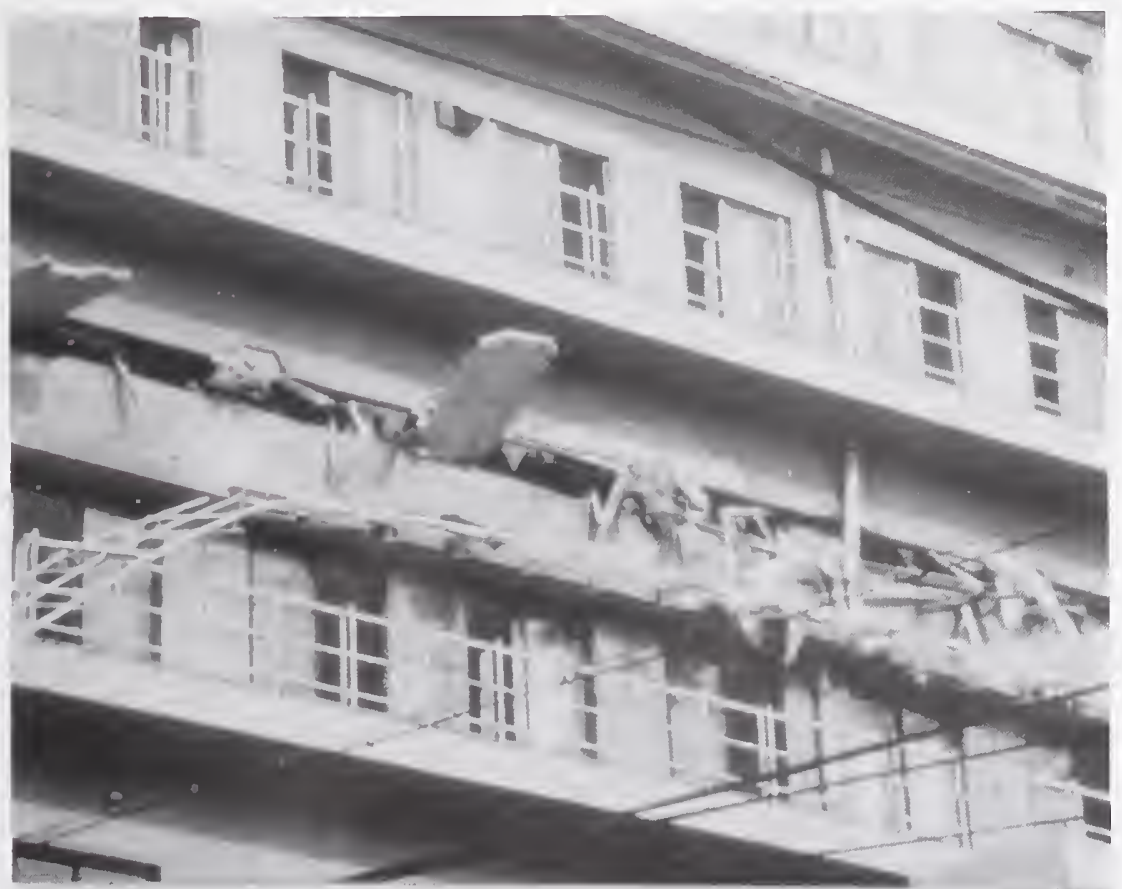

Figure 3.4.26 Collapsed upper story, northwest corner - West Kobe Citizens' Hospital. 


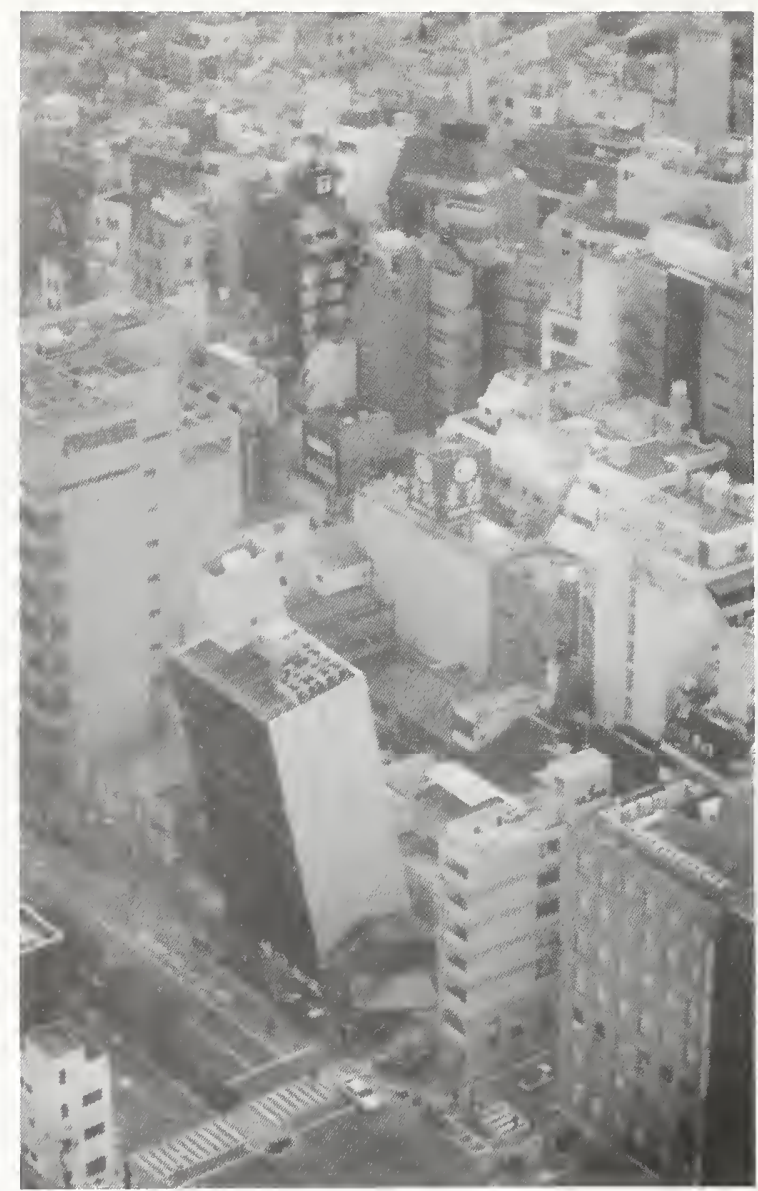

Figure 3.4.27 A leaning 9-story SRC building on Flower Road prior to total collapse.

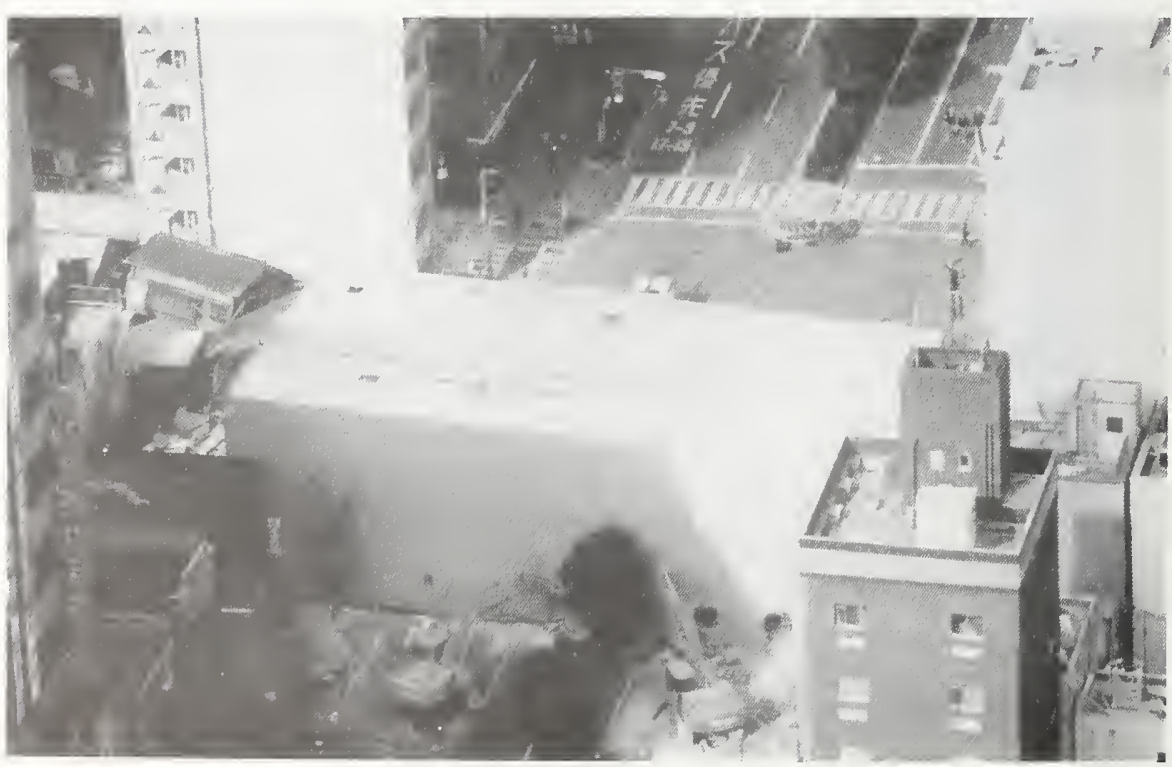

Figure 3.4.28 Totally collapsed building shown in Figure 3.4.27. 


\subsection{Performance of Steel Buildings}

\subsubsection{Introduction}

As was described in the introduction and in Section 3.2, Kobe is a rather unique situation from an engineering viewpoint in that it was essentially re-built from scratch following World War II. Code development for steel structures essentially followed that for reinforced concrete with regards to design loads. When the new two-phase design procedures were introduced in 1981 (see Figure 3.2.7) the procedures to be followed for steel frame construction were identical to those for reinforced concrete with two important exceptions:

(a) The present code permits the construction of a particular class of steel frame structures without meeting the second phase code design requirements, provided that:

1) It is not more than three stories tall, including a basement.

2) Not more than $13 \mathrm{~m}$ in total height and not more than $9 \mathrm{~m}$ at the elevation of the eaves.

3) The horizontal distance between major vertical structural supports is not more than $6 \mathrm{~m}$.

4) The total floor area is not more than $500 \mathrm{~m}^{2}$.

5) The design seismic shear force in the first phase design is calculated with the standard shear coefficient taken not less than 0.3 .

6) All end connections and joints of lateral (diagonal) braces which carry horizontal earthquake forces must not fracture when the bracing member is yielding. (b) For steel frame structures not exceeding $31 \mathrm{~m}$ in height and which do not meet the criteria described in (a) above, the following criteria apply:

1) If the building includes stories (except the basement) that are braced to carry horizontal forces (as opposed to moment resisting welded and/or bolted frames), the force in the members of each of those stories due to the design seismic force must be increased by the factor $\mathrm{B}$ as follows:

When $\beta$ is $\leq 5 / 7 \quad \mathrm{~B}=1+0.7 \beta$

For $\beta \geq 5 / 7 \mathrm{~B}=1.5$,

where $\beta$ is the ratio of horizontal force carried by the braces to the entire story shear in the story being considered.

2) It must be shown, when necessary, that columns, girders, and their connections, do not lose their loadcarrying capacity rapidly due to local buckling or fracture.

Three major types of steel buildings were noted in the Hanshin area: 1) braced frames in one lateral direction, 2) braced frames in both lateral directions, and 3) moment resisting frames without lateral braces. A damage survey carried out by the Steel Committee of Kinki Branch of the Architectural Institute of Japan [3] reported that, among 988 buildings which they investigated, 134 buildings had bracings in one direction, 34 buildings had bracings in two directions, 432 buildings had moment frames, and 388 contained unidentified framing systems. However, it is believed that moment frames comprised of about 70 
percent of the buildings of the unknown

framing system category. With this

assumption, it can be conclude that over

$70 \%$ of steel buildings investigated contained moment frames.

Similar to $R C$ buildings, steel

buildings constructed 20 to 30 years

ago sustained severe damage,

whereas buildings designed and

constructed according the 1981

Building Standard suffered little.

With the relaxed design procedures permitted under (a.1) above, prefabricated steel moment frame buildings are common in the Hanshin area and elsewhere in Japan.

Typically these frame involve shop fabricated columns in 3-story segments shipped to a construction site with integral beam stubs projecting about $0.5 \mathrm{~m}$. In this way, no field welding is required and the frames are rapidly assembled on site by connecting beam segments to the stubs by means of high strength bolts. An example of one such new construction is shown in Figures 3.5.1 and 3.5.2. As shown in these figure, the columns are usually made of cold-formed square tubular sections. The beam stubs are welded to the through diaphragms as shown in Figure 3.5.3. In some cases, wide-flange sections are also used for columns. Usually, the floor framing is comprised of cast-inplace concrete. External facades are commonly prefabricated autoclaved lightweight concrete (ALC) panels, approximately $0.5 \mathrm{~m}$ wide and $3 \mathrm{~m}$ high, or one story height. The ALC panels are attached to welded clip angles on the steel frame. Because the attachment hardware is not intended for structural resistance to seismic load, and because the panels are less ductile than the supporting steel frames, there is an inherent displacement incompatibility in this type of design under seismic loading. The response of this type of construction during the earthquake is discussed in further detail below.

For steel structures the minimum requirements, in theory, result in assurance of increased strength and ductile behavior of braces, and ductile behavior of frames when the frames carry some portion of the lateral loads. Clcarly the intent of the code in the case of braced frames is to have the cross section of the main brace yield before any weld or bolt failures in the attachment to the main vertical load bearing frame to occur. Many dramatic partial collapses in the Hanshin area were a result of failure of the as-built structures to meet this performance criteria.

For buildings grcater than $60 \mathrm{~m}$ in height, elastic and inelastic dynamic response analyses are required on a case-by-case basis. In these analyses, the input ground motion with maximum acceleration of $0.2 \mathrm{~g}$ to $0.3 \mathrm{~g}$ for elastic response and $0.3 \mathrm{~g}$ to $0.5 \mathrm{~g}$ for inelastic response. During this carthquake, no building greater than 10 stories collapsed. However, some sustained severe damage.

Figure 3.5.4 shows the distribution of damage of 988 steel buildings surveyed by the AIJ Kinki Branch [3]. The figure reveals that 3- and 4-story buildings sustained most damage. Figure 3.5.5 shows the distribution of collapsed steel buildings throughout Kobe. In this figure, the block numbers represents zones where the damage survey s were conducted in the central part of Kobe as described in section 3.4.1. Figure 3.5.5 shows clearly that most collapses occurred in Chuo ward of Kobe city where commercial buildings are concentrated. Comparison of 
Figure 3.4.1, the damage distribution of concrete buildings, and Figure 3.5.5, the same for steel buildings, indicate that the number of collapsed and severely damaged buildings of steel and of concrete are about the same.

\subsubsection{Description of Damage}

A variety of failures were observed in steel frame structures. These included:

a) complete joint failures in low rise, older buildings with severely corroded light gage sections and/or cold formed steel; b) fracture of diagonal braces; c) buckling of first floor columns; d) weld fractures at beam-column joints in medium-height prefabricated moment frames; and e) fractures in virgin column material and in beam joint welds in high rise structures. In addition there were some column base failures and anchor bolt pullouts in slender buildings and large permanent story drifts in the upper parts of buildings. Detailed examples with discussion of each of these follow below.

\subsubsection{Weld Fractures in Light Gage Steel Frames}

A large number of failures occurred in low rise steel frame structures constructed using light gage or cold formed steel. These wcre popular forms of construction in the 1960's when there were shortages of steel for general construction in Japan. In almost all cases, these were older (pre-1971) buildings with less than three stories and typically exhibiting significant corrosion and rusting (See Figures 3.5.6 and 3.5.7). The degree of corrosion in these older steel structures was surprising, despite evidence that the steel had originally been shop painted (usually red or orange) and was covered by various layers of cladding. This corrosion may possibly be related to Kobe's location as a port city on the south coast, where typhoons may drivc airborne salt water mist inland.

\subsubsection{Diagonal Brace Fractures}

Braced frame structures are very common in the Hanshin area although they seem to be less prevalent in more recently constructed buildings which tend to be prefabricated moment frame designs. The braced frame structures which failed were generally either garage buildings or low- to mid-rise office buildings. The low-rise buildings (Figure 3.5.8) often had masonry block infilled walls (Figure 3.5.9). Even with the added rigidity of the infill walls there were failures in the braces. Although the present (post-1981) code provides specific languagc concerning the designs of welds and bolted connections to insure first yielding of the braces, there were many such failures in the welds.

Those braced frame structures which did not have infilled walls were more flexible. Onc of the more striking failures in downtown Kobe was a seven-story braced frame system (Figure 3.5.10) with autoclaved lightwcight concrete panels for cladding (Figure 3.5.11). This building had a very narrow platform with one bay in the cast-west direction and two bays in the north-south dircction. However, the building drifted severely toward north (stiffer direction) duc to fracture of numerous braces (each approximately $6 \mathrm{~mm} \times 75 \mathrm{~mm}$ in cross section) at bolted connections to gusset plates which are welded to the columns. In the upper floors, it can be seen that the braces in tension, which attcmpted to prevent displacement of the building toward the north, fracturcd through the bolt hole. The building remained standing only due to the presence of bolted shear connections for the beams, which managed to resist some lateral load. 
Figures 3.5.12 and 3.5.13 are of a rather unique braced frame failure in Higashi Nada ward. This was originally a two story Ohkabe type traditional dwelling, as evidenced by the exposed slat timber wall construction beneath the stucco in Figure 3.5.12. At some time a third story was added. To do this, an exterior steel braced frame was used. During the earthquake the cross braces (18 $\mathrm{mm}$ round bars) failed. These were attached to the steel frames apparently by means of field welded clip angles (Figure 3.5.14). The clip angle welds failed and the third floor shifted westward by approximately $300 \mathrm{~mm}$.

\subsubsection{Buckling of Columns}

Column buckling in steel structures was a relatively rare event, with the notable exception of some unusual failures in transportation infrastructure. An example of column buckling in an 8-story building was a parking garage in downtown Kobe (Figure 3.5.15). This structure (NO.2 South Parking Building) is comprised of tubular columns (16 mm wall thickness) and wide-flange beams with diagonal braces. The first two floors of the northeast corner of the structure has a large unobstructed open space for the gas station. It was the northeast steel column that buckled (Figure

3.5.16). An unusual architecture (large eccentric open space on the first floor) contributed to the excessive loads experienced by column.

\subsubsection{Weld Fractures in Low-rise Buildings}

Next to reinforced concrete, shop fabricated steel moment frame construction seems to be a close second in terms of the number of buildings in the Kobe area. The main advantages are the speed of erection in the field, since the columns are shop fabricated in 3-story units with $0.5 \mathrm{~m}$ long beam stubs.
These eliminate the requirement for field welding. Furthermore, special provisions in the 1981 code ease the design process for buildings less than $31 \mathrm{~m}$ (10 stories) and particularly for buildings of three or fewer stories.

In many instances, evidence of damage to steel structures was somewhat difficult to recognize, since steel members are hidden by more layers of exterior cladding. The most common cladding is autoclaved lightweight concrete (ALC) panels. These $0.5 \mathrm{~m} \mathrm{x} 3 \mathrm{~m} \mathrm{x}$ a $75 \mathrm{~mm}$ thick panels are attached to the steel frame by means of welded clip angles.

One example of moment frame structures which did suffer severe damage was a sevenstory Nari Hiro Building in downtown Kobe (Figure 3.5.17). Figure 3.5.18 shows a closeup view of the southwest column, second story junction showing lateral buckling of the first story column. This, however, was a result of more dramatic weld failures on the east face of the building.

Figures 3.5.19 show details of a beam stubto-column connection failure on the east face of the same building. Figures 3.5.20 and 3.5.21 show first floor column to second story column joint fillet weld failure.

A 3-story steel frame building (Tanigawa Building) on Flower road in downtown Kobe also suffered beam-to-column connection failures (Figures 3.5.22 and 3.5.23). It is clearly seen that weld joint failure caused $\mathrm{H}$ shaped girders to fall.

\subsubsection{Moment Frame Behavior: Mid-rise Buildings}

Figures 3.5.24 through 3.5.34 show behavior of mid-rise steel moment prefabricated frames that are representative of this class of structure in the earthquake. In no case was 
the structural integrity of the building threatened. The steel frame, in all but a very few instances, did not yield. However, there is an apparent stiffness incompatibility between the precast exterior cladding and the ductile moment frame which led to widespread damage to the cladding. This damage was concentrated mostly at the corners between adjacent panels and in some cases the racking motion that induced the damage caused one or more panels to shear free of their attachment clips.

Figure 3.5.24 shows the west face of the Liberty apartment complex located in Higashi Nada ward. This eight story steel moment frame was typical of the performance of mid-rise steel structures designed according to post-1981 procedures. The columns were comprised of approximately $300 \mathrm{~mm}$ steel tube. The south face of the building had an artificial brick veneer on the extended patios from each floor and the remaining sides were faced with architectural autoclaved lightweight concrete paneling.

Figure 3.5.25 is a closeup view of west face steel moment frame of the Liberty apartments. The shop welded frame shows no damage but autoclaved lightweight concrete cladding suffered brittle failures along panel edges. Figures 3.5.26 and 3.5.27 show details of the east face of this same building. In this case one beam-column joint showed flaked paint indicative of local yielding.

The seven story Silver Heights hotel, also in Higashi Nada ward and located approximately $500 \mathrm{~m}$ east of the Liberty apartment complex, was similar in both design and behavior. Figures 3.5.28 and 3.5.29 show details of cladding damage.
The nine story Pacific Power Corporation building in downtown Kobe was yet another example of a tubular steel column frame which exhibited cladding failures. At first glance (Figures 3.5.30 and 3.5.31) this appeared to have suffered a significant failure of a reinforced concrete frame in the first story. Closer inspection (Figure 3.5.32) revealed that this was only the failure of elaborate corner cladding and that the 300 mm tubular steel column hidden inside was undamaged.

A much older example of steel moment frame behavior is shown in Figures 3.5.33 and 3.5.34. This apartment building had four bays in the east west direction and three bays in the north-south direction. The frame shows significant rusting and extensive cladding damage but was not considered to be in danger of collapse. It had two open garage entryway on the southwest corner and an open accessway on the first floor at the northwest corner. Neither of these apparently affected the performance of the structure. However the cosmetic artificial brick veneer and the precast window panels served as stress concentrators and, bccause of their brittle nature, were severely damaged.

\subsubsection{Anchor Bolt Failure}

Because of extremely high land costs, many of the newer Japanese structures are sited on very narrow lots; such buildings are often tall and narrow. Most of these structures seemed to be relatively undamaged in the earthquake, but a few sustained damage to anchor bolts for column base. One such building in downtown Kobe is shown in Figures 3.5.35, the SAGA building. This building is located adjacent to the overturned SRC building described in Section 3.4.2. It is a seven story building, one-bay wide and three-bay deep, sited on a 
narrow corner lot. The north side of the building suffered large uplift forces; the anchor bolts for the northwest corner column were stretched, with plastic deformation estimated at over $10 \mathrm{~cm}$ (see Figure 3.5.36). The building suffered minor damage to the exterior ALC panels and concrete footing.

\subsubsection{Behavior of High-rise Buildings}

The tallest building in downtown Kobe is the new 30-story city hall (Figure 3.5.37). This frame building appeared to have sustained no damage to the exterior. There were minor cosmetic damage to the interior finishing. It is not clear as to the structural framing system, whether moment resisting frame or braced frame. There was a damage to the sky bridge structure connecting the new and old city hall (Fig 3.5.38). The fifth-story collapse of the old city hall is described in Section 3.4.2.
Unexpected large column fractures were seen at the "Ashiya Hama Seaside Town" apartment complex (Fig. 3.5.39). There are 14-, 19-, 24-, and 29-story buildings. The main load carrying system is comprised of a truss-like frames madc of heavy steel sections (Fig. 3.5.40). The exterior columns are welded square tubular sections and the interior columns are $\mathrm{H}$ sections. These columns are supported on concrete piles some of which are $35 \mathrm{~m}$ long. The dimensions of some of the exterior tubular columns are $500 \mathrm{~mm} \times 500 \mathrm{~mm} \times 50 \mathrm{~mm}$ thick. The diagonal braces are either $\mathrm{H}$ sections or circular tubular sections. The prefabricated concrete dwelling units are attached to the main structural members. Most damage occurred in 19-story and 24story buildings. Many columns sustained complete fracture through the entire cross section without any sign of inelastic deformation. Figure 3.5.41 shows a complete fracture through a column section and extended into the bracing member. Figures 3.5.42 and 3.5.43 show repaired columns. In Figure 3.5.43, the fracture is not only repaired with full-penetration weld but also added stiffeners. 


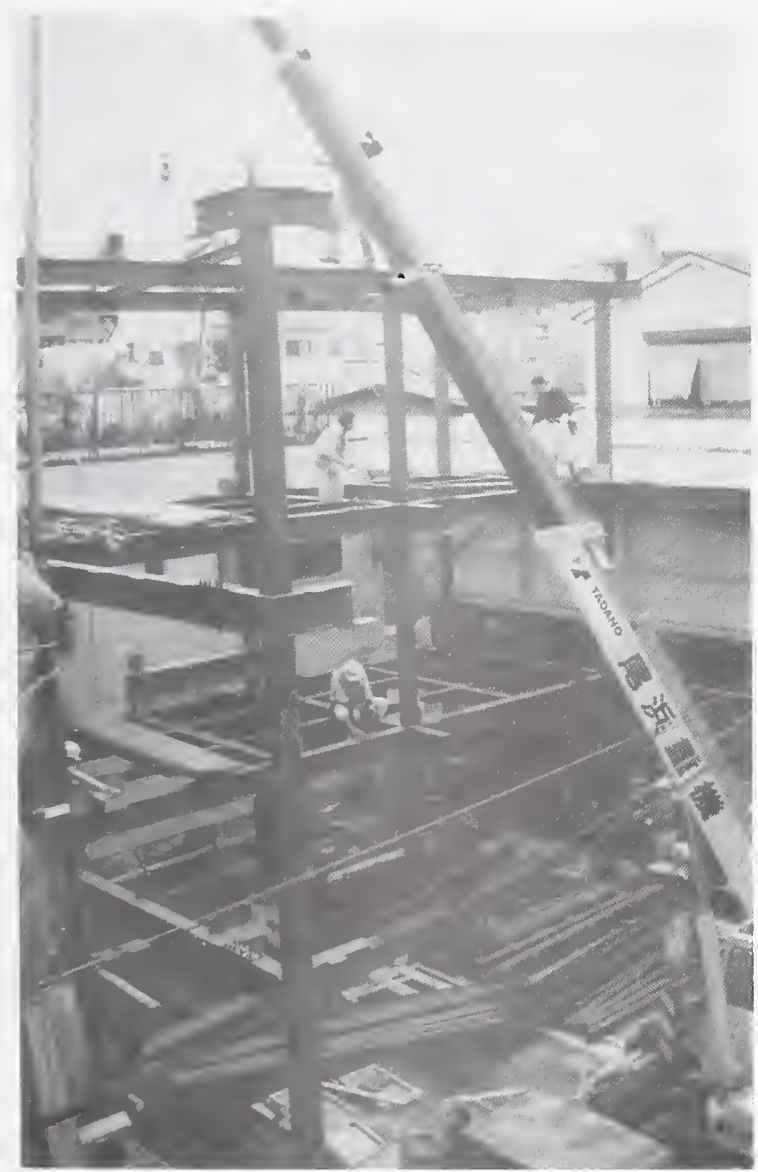

Figure 3.5.1 Typical modern 3 story new steel frame building being erected near Hanshin Expressway \#3 east of Kobe. Columns are pre-fabricated so that no field welding is required.

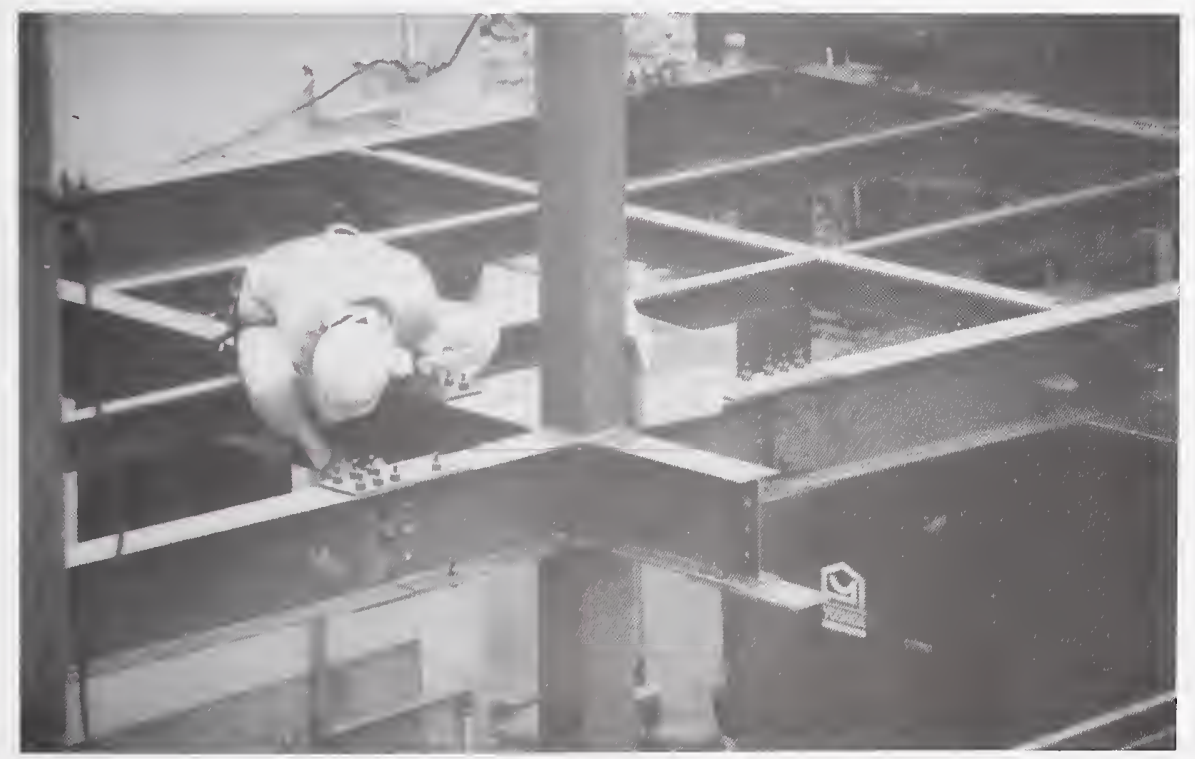

Figure 3.5.2 Field joint assembly of prefabricated steel frame structure east of Kobe using all high strength bolted connections. Beam stubs, approximately $0.5 \mathrm{~m}$ in length, are shop-welded for quality control improvement. 


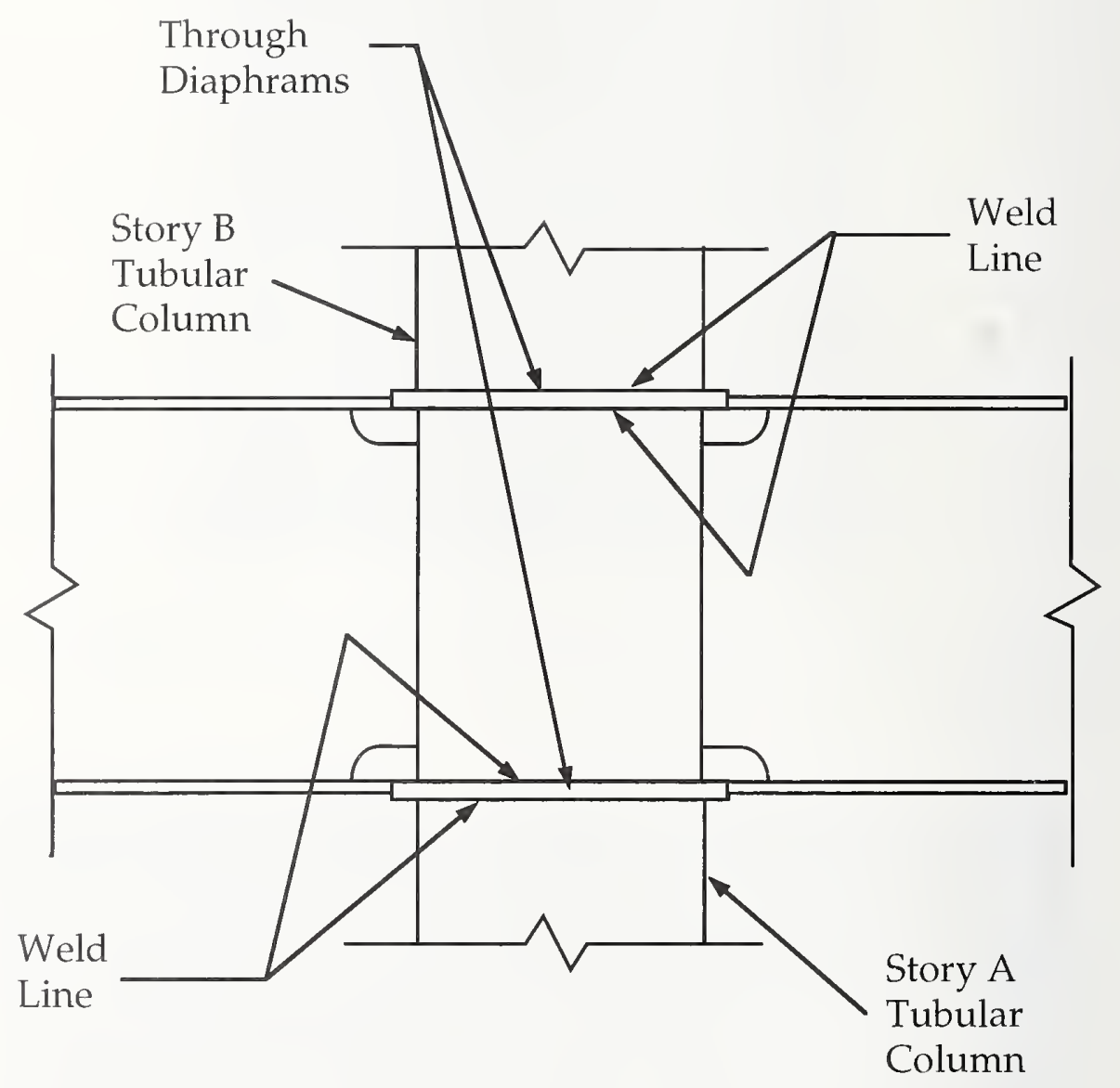

Figure 3.5.3 Beam-column construction detail. 
Kobe Building Damage Statistics as a Function of Building Height

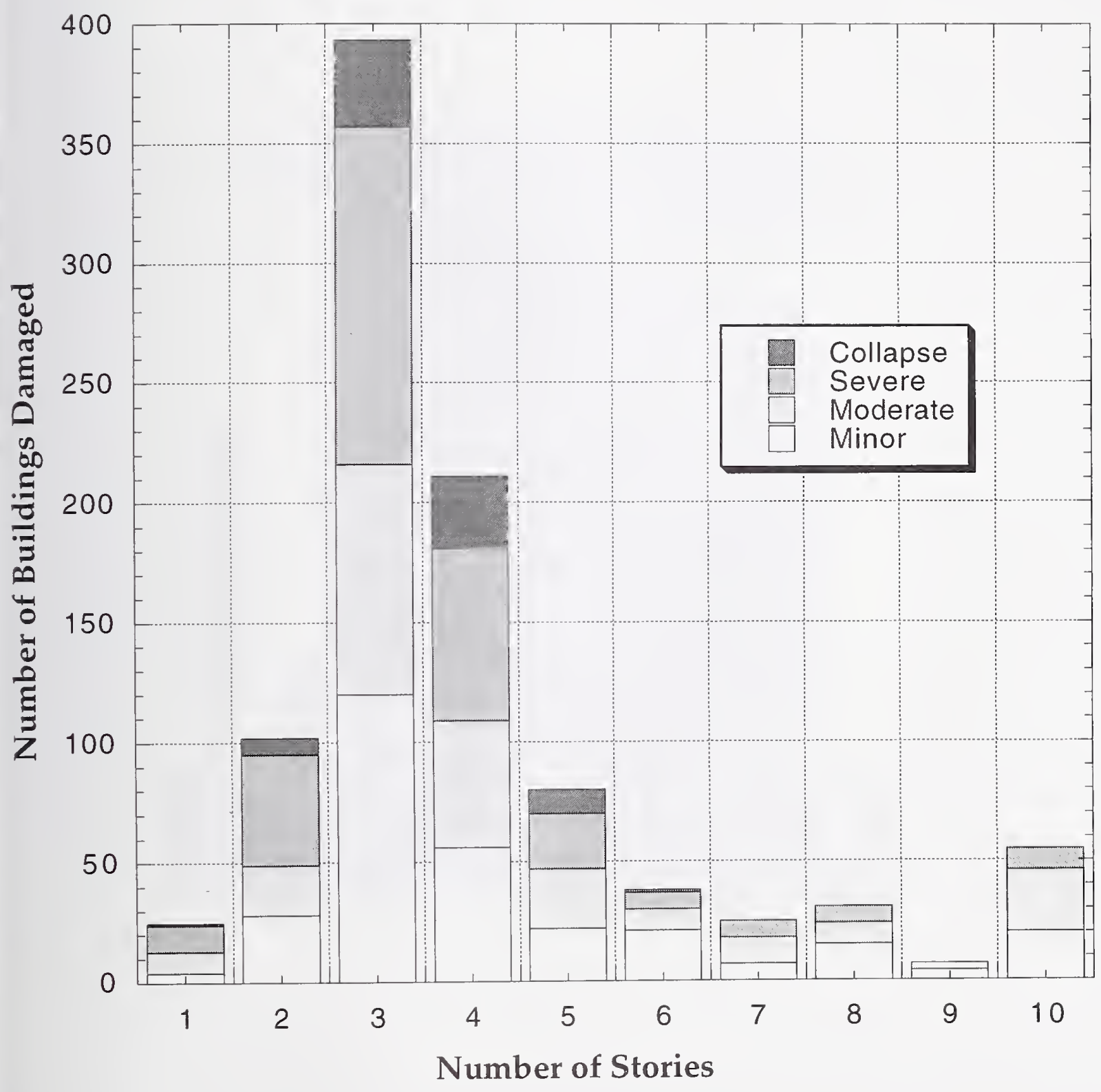

Figure 3.5.4 Damage distribution of steel buildings. 


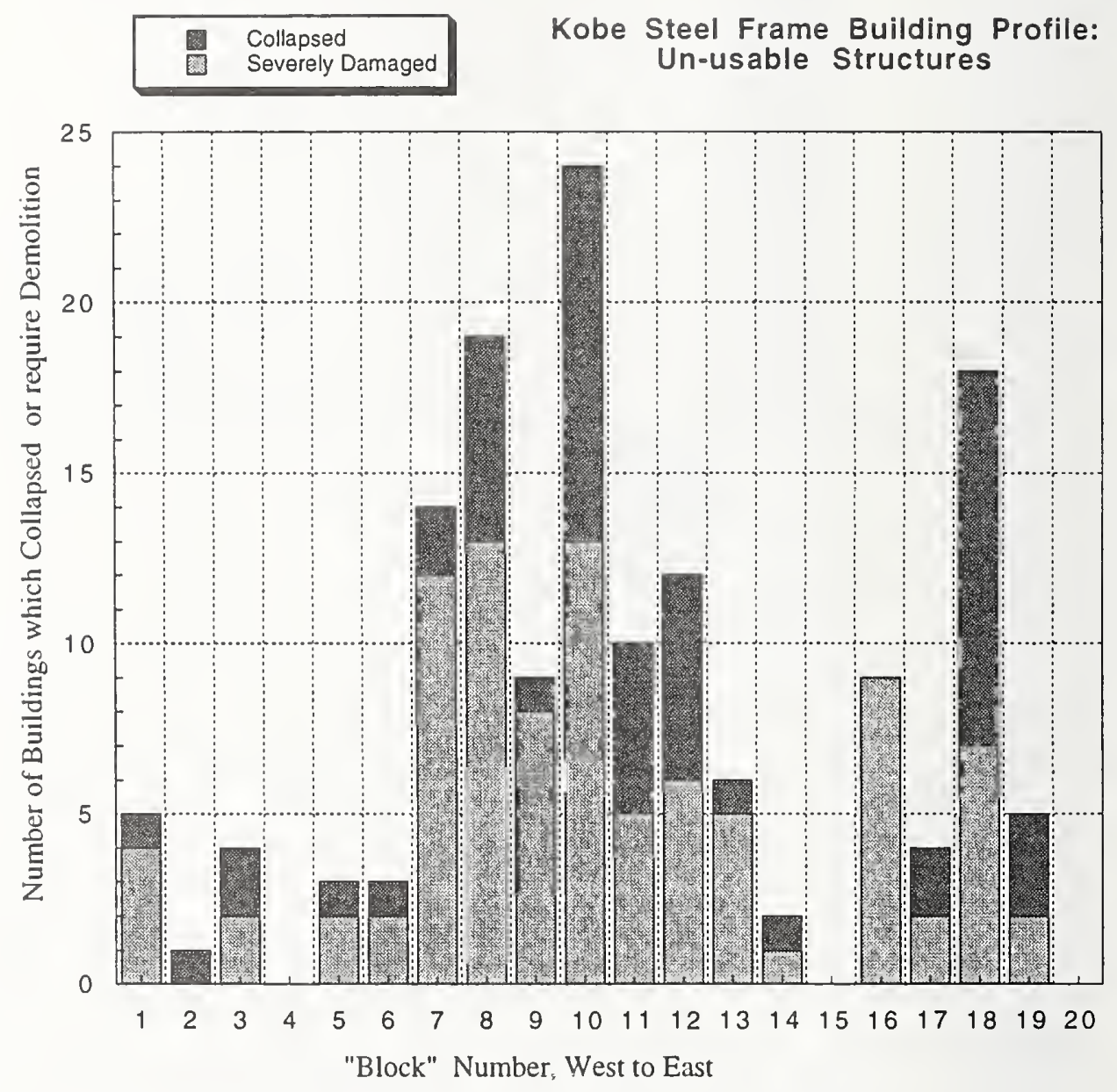

Figure 3.5.5 Kobe Damage Survey: Collapsed and severely damaged steel frame structures. 


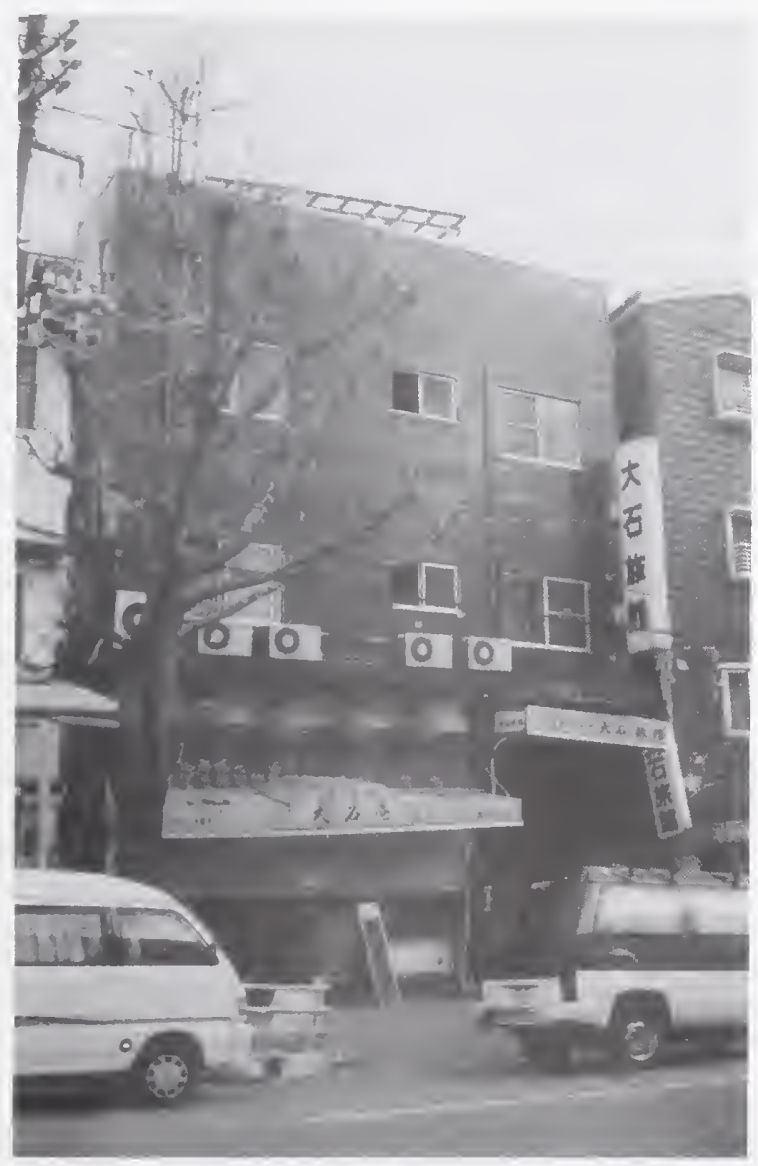

Figure 3.5.6 Three-story brick-faced light gage steel apartment. Has roll up door. Closeups (Fig 3.5.7) show that there is a great deal of rust at the connections at the second floor which connect 8 inch light gage wide flange columns. Rust clearly was at fault in the failure, not the steel frame itself... this is a common type of failure that seems peculiar to this form of light gage steel frame construction... perhaps it is the salt atmosphere of a port city that leads to such extensive corrosion. 


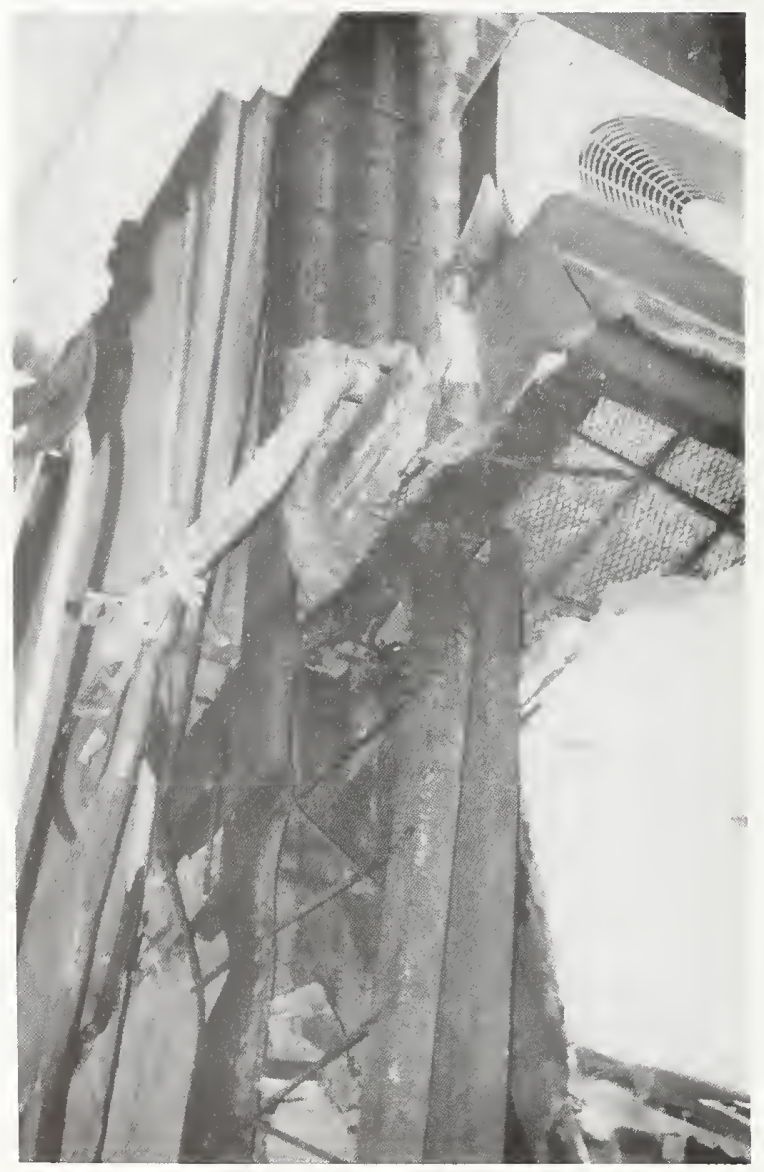

Figure 3.5.7 See caption for Figure 3.5.6: a closeup showing the rusted joint. 


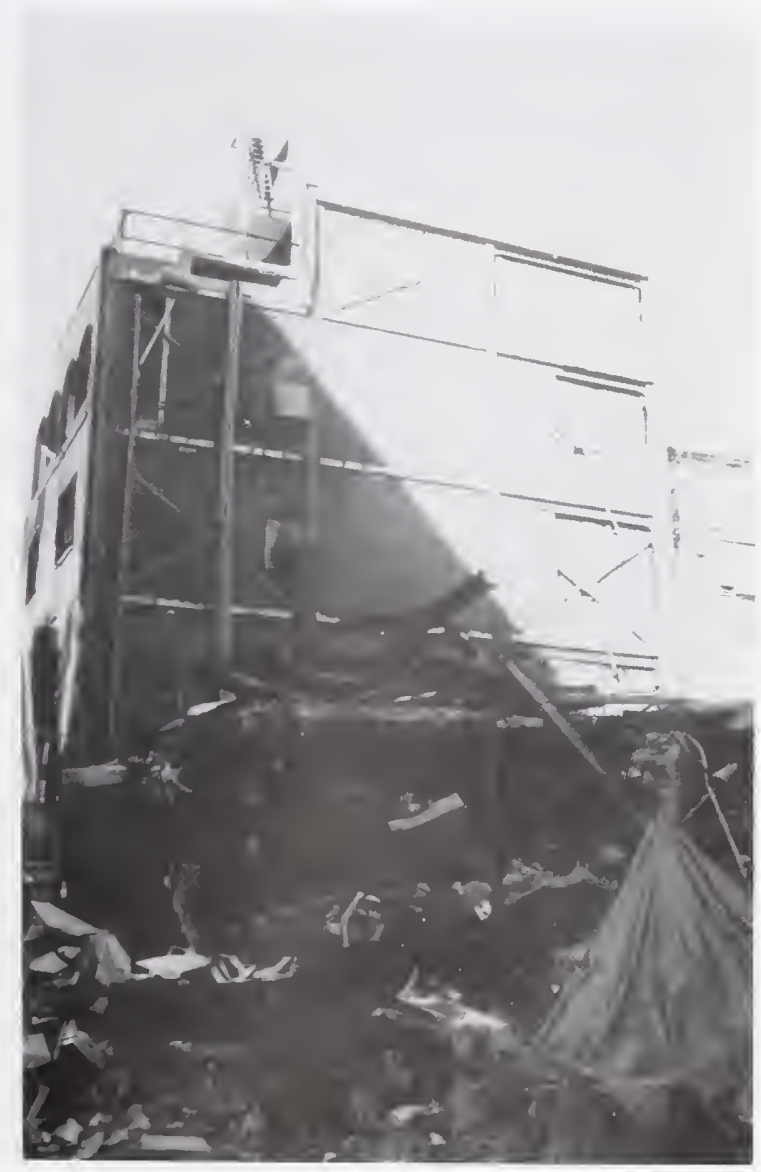

Figure 3.5.8 Braced steel frame, 5-story, in downtown Chuoku (Kobe). Masonry infill walls appear to have saved this structure while a neighboring structure did not fare as well. 


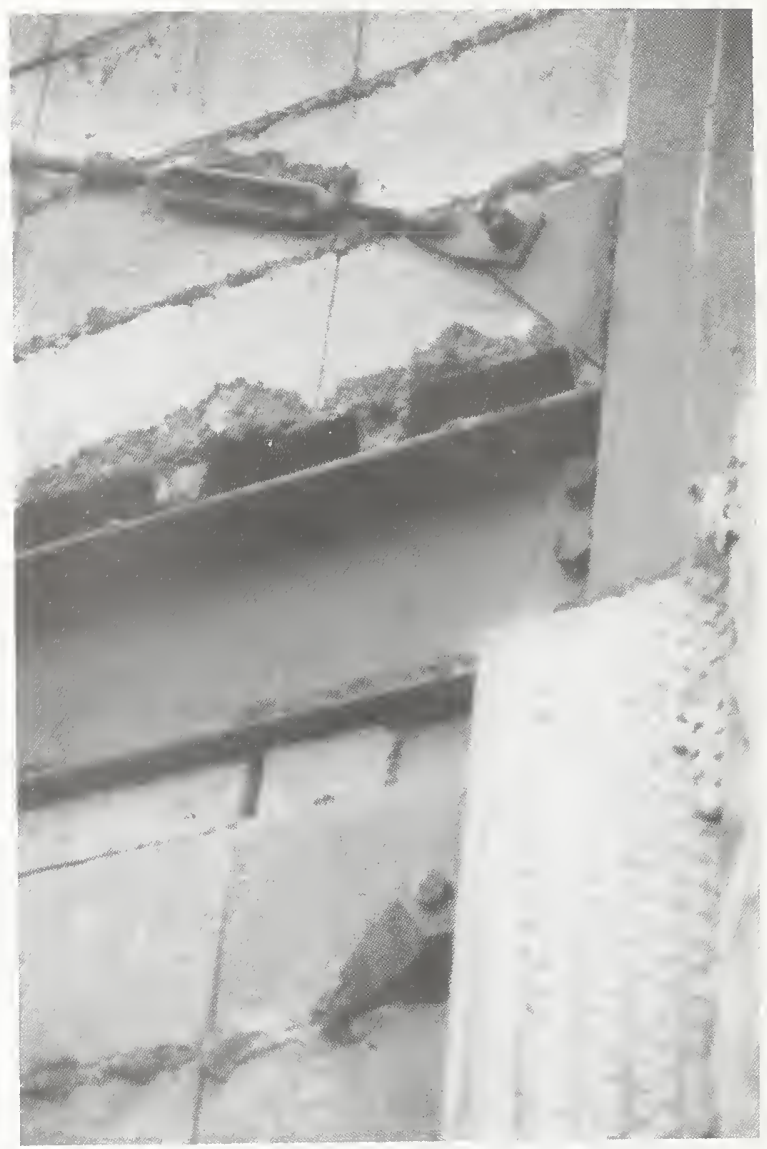

Figure 3.5.9 Many braced frame structures had failures of the diagonal braces at the welded connections. This photo shows a weld fracture between the turnbuckle rod and the gusset plate. 


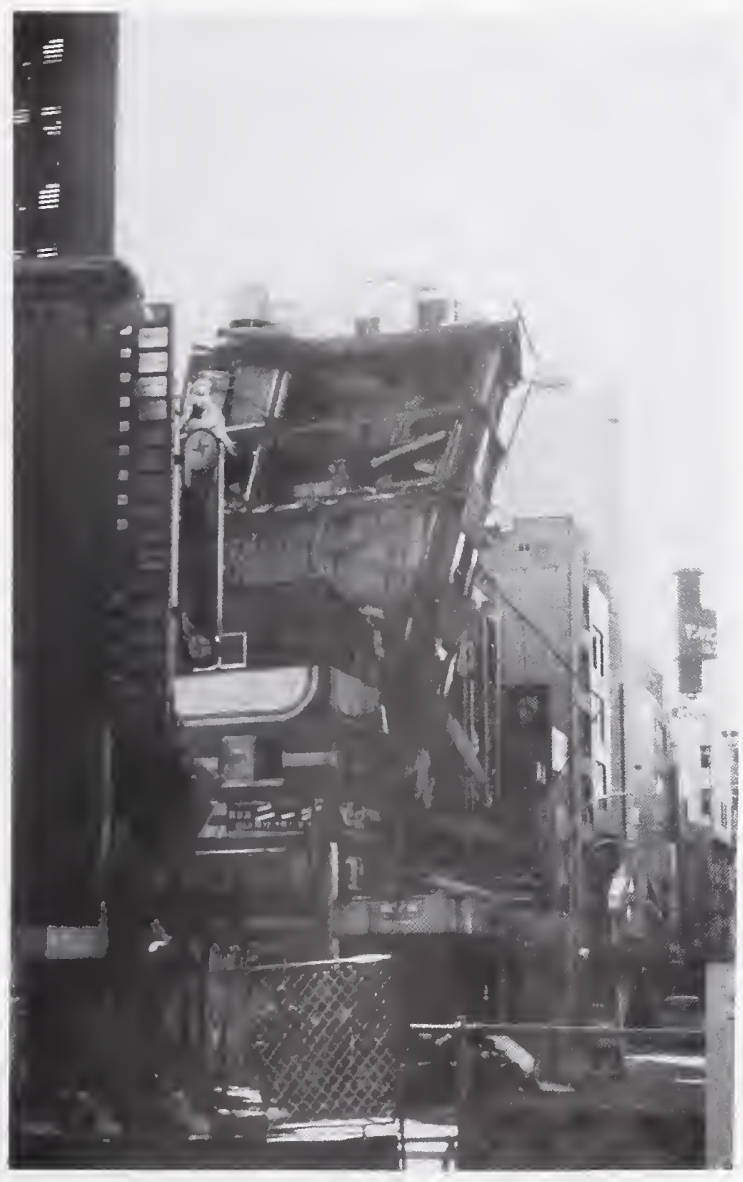

Figure 3.5.10 Partial failure of a 7-story steel braced frame structure. Braces failed in tension at the bolted connections. Significant rust is evident in most closeups (see next four slides) around the vicinity of these bolt holes which may have permitted widespread fracture of the brace plates (approximately $6 \mathrm{~mm} \times 75 \mathrm{~mm}$ plate). 


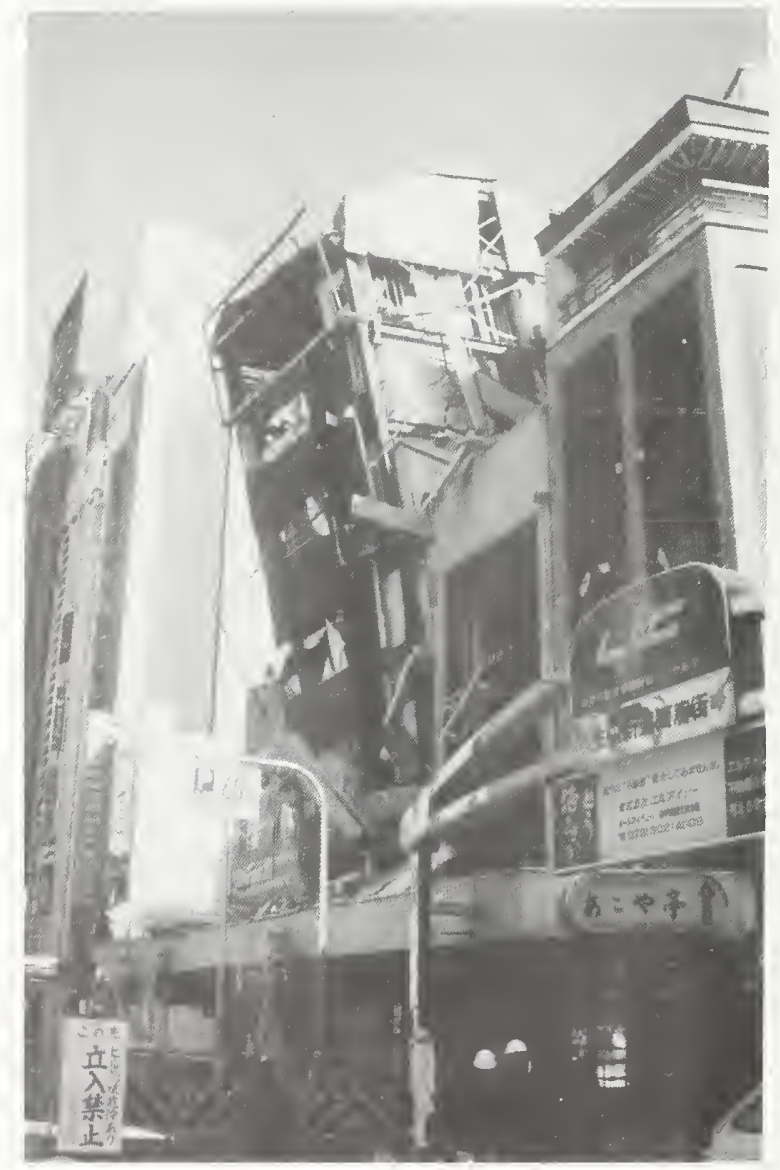

Figure 3.5.11 West side of the building shown in Figure 3.5.10. 


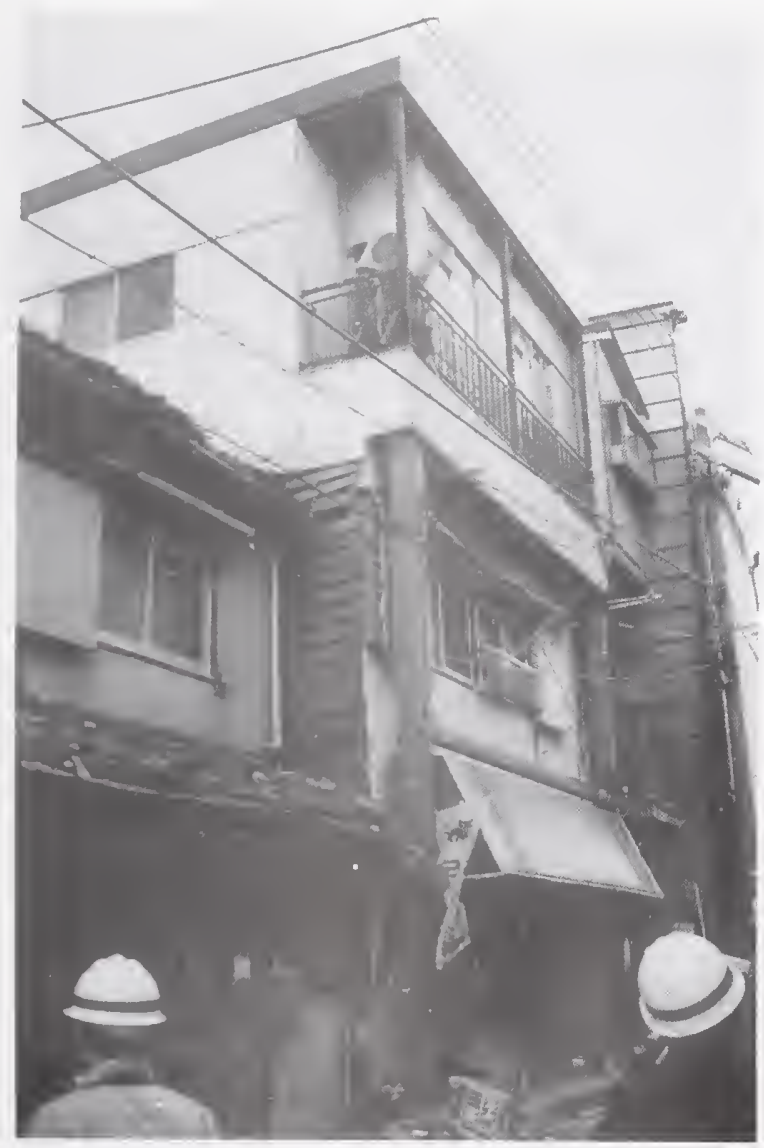

Figure 3.5.12 Two-story traditional Ohkabe construction house with a third story add-on supported by a steel braced frame near the Mikage metro station, Nada ku. 


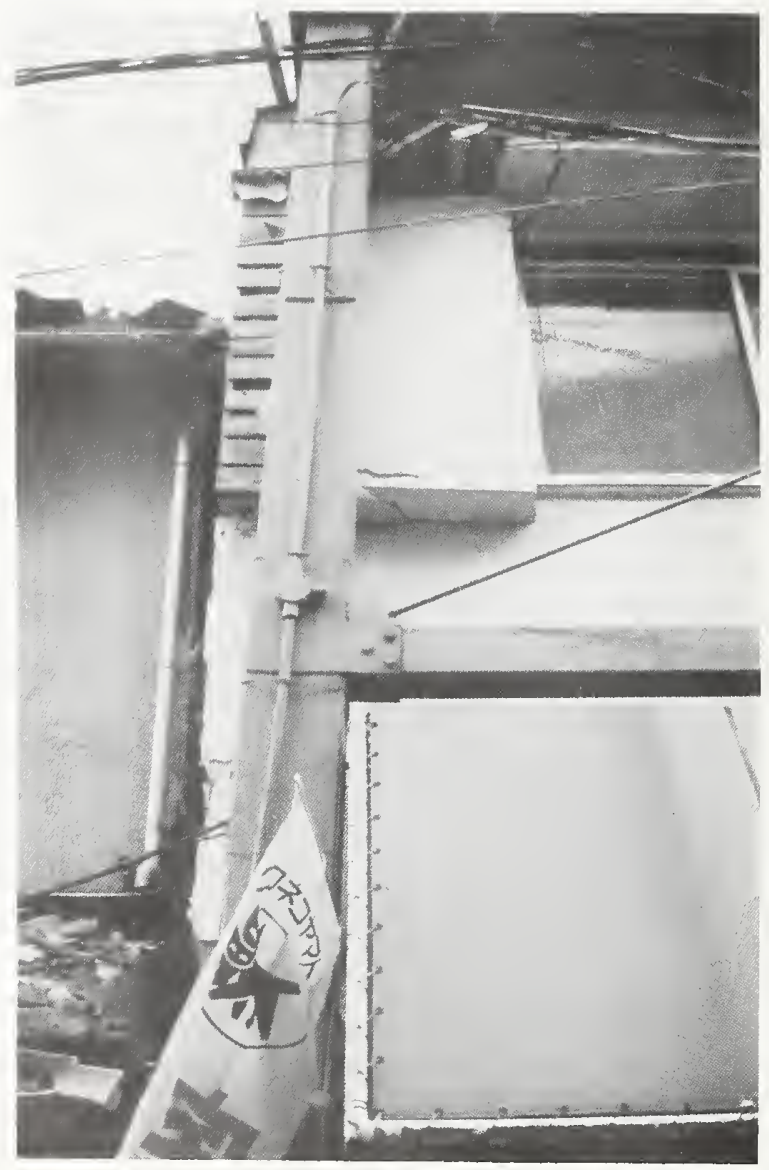

Figure 3.5.13 Detail showing drift in the building shown in Fig. 3.4.16 when diagonal braces failed. 


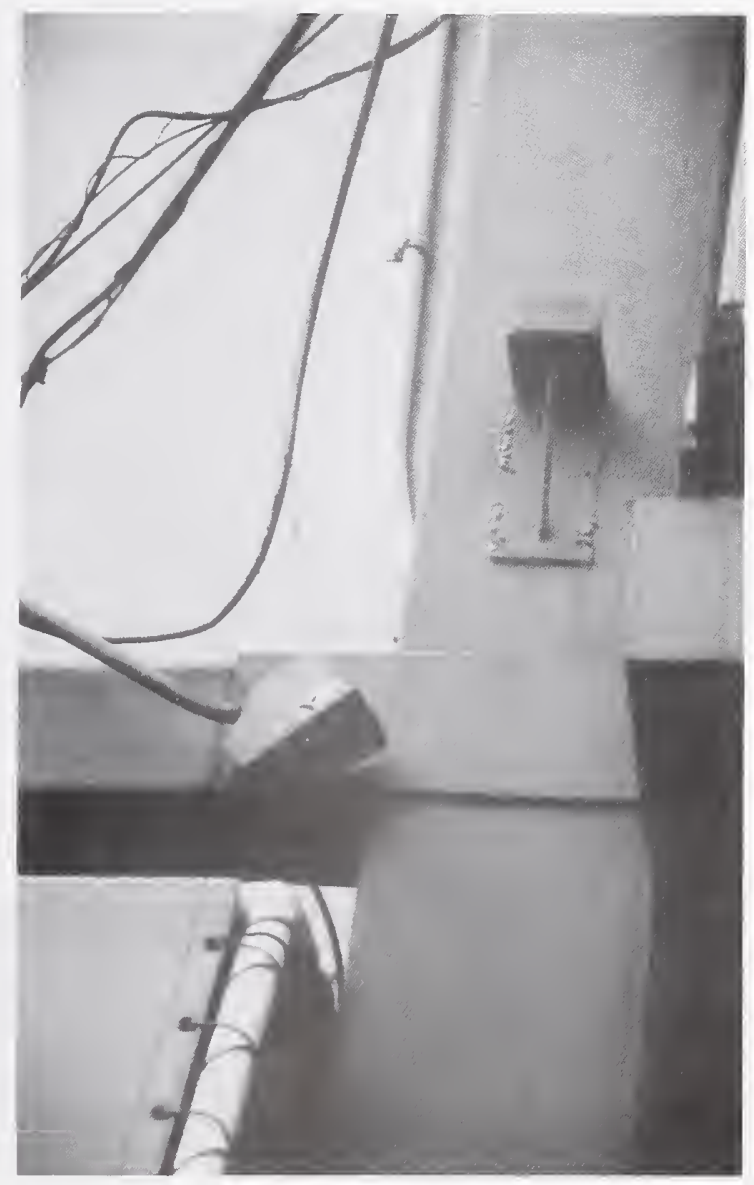

Figure 3.5.14 Detail of brace failure: angle plate weld to the steel frame failed (not the tension diagonal rod). 


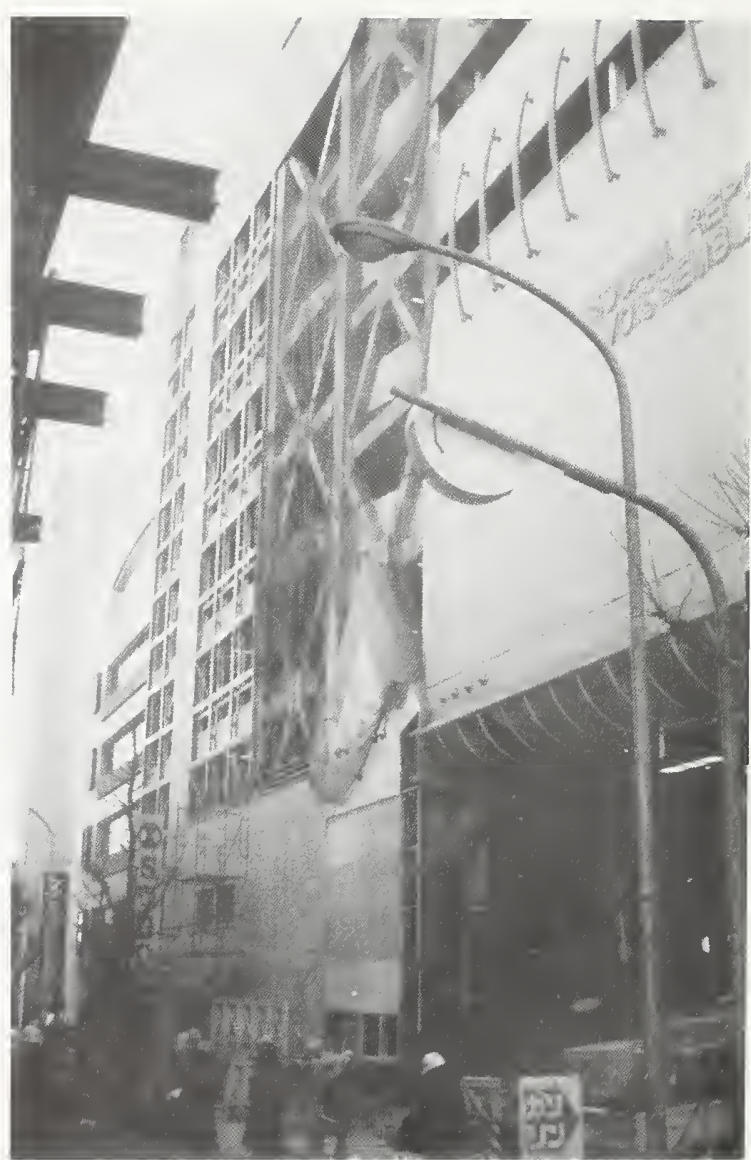

Figure 3.5.15 Northeast corner of a Mitsubishi/Sogo garage/gas station located just one block east of Kobe City Hall. Main steel tubular column at the northeast edge of the first floor opening buckled. 


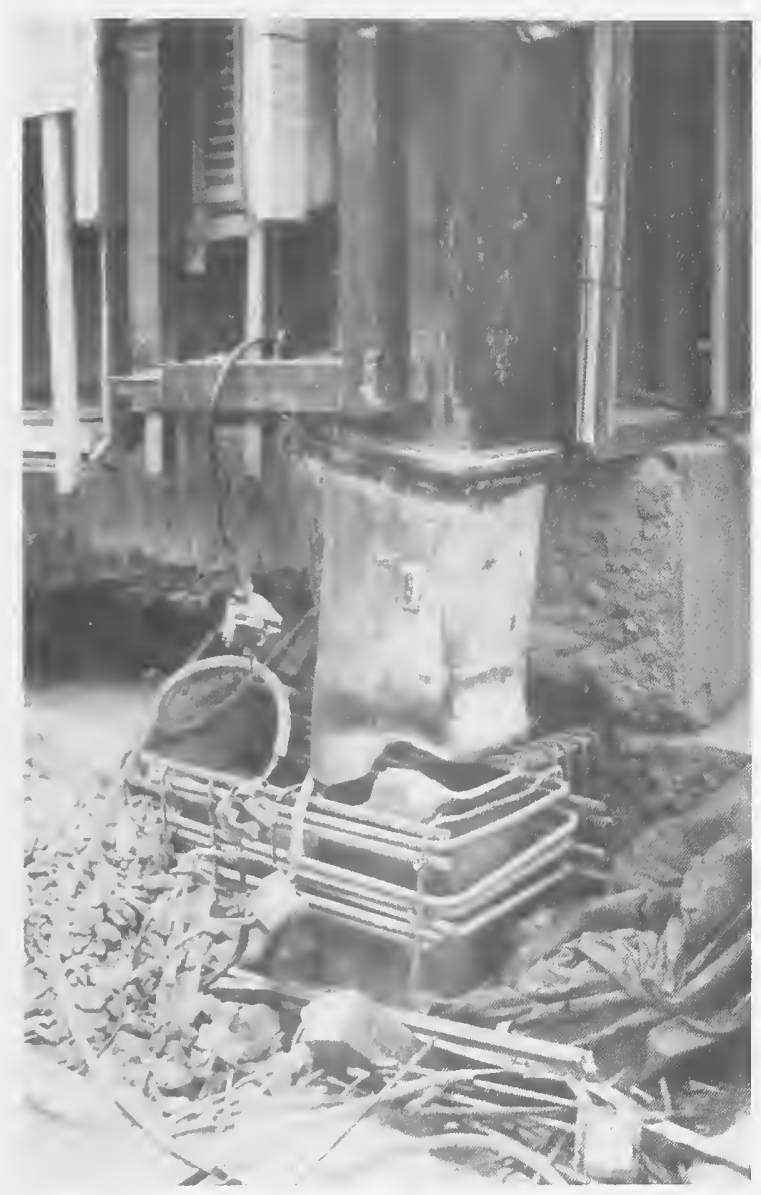

Figure 3.5.16 Closeup of the buckled tubular column in Figure 3.5.15. 


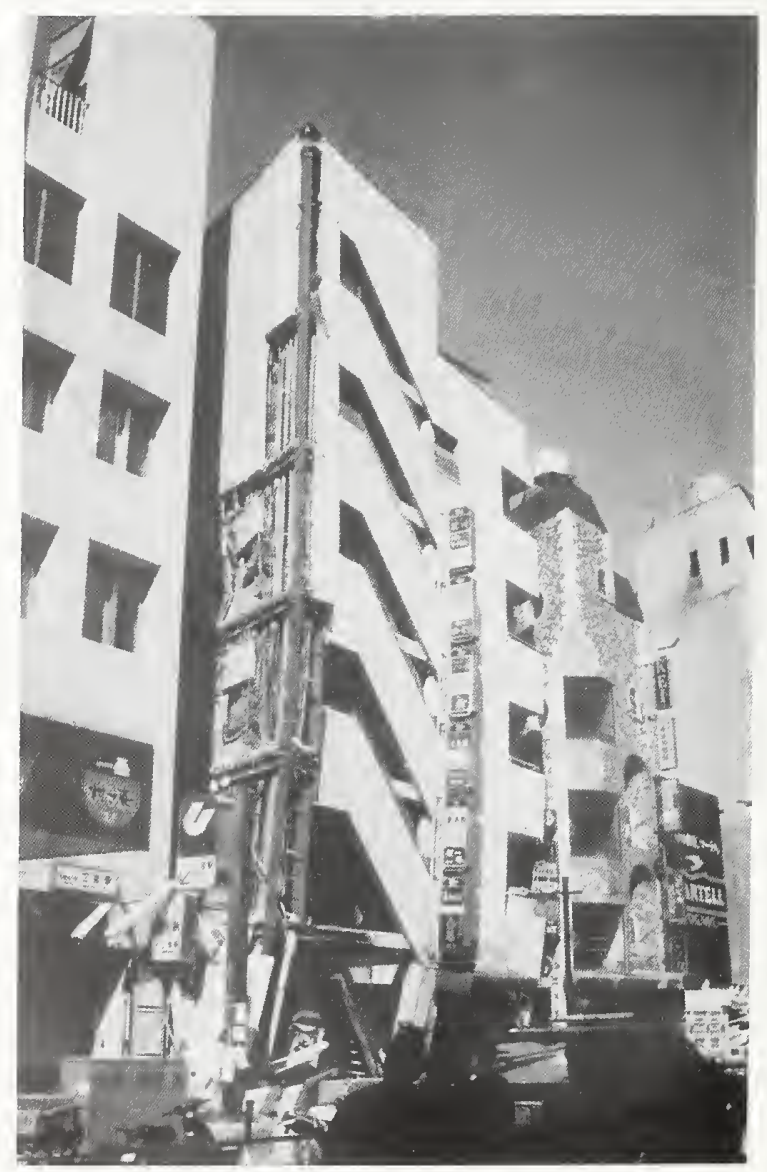

Figure 3.5.17 "Nairo Hiro" Building, a seven-story steel moment frame structure in downtown Kobe. 


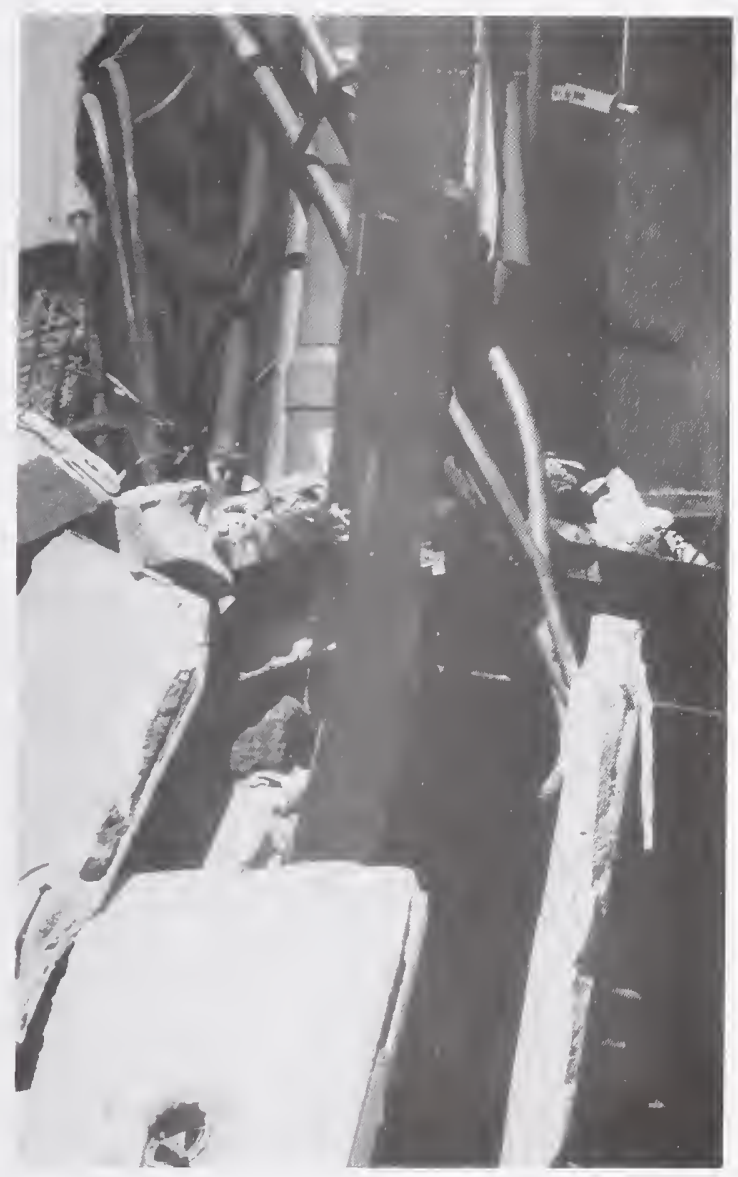

Figure 3.5.18 Closeup photo of the southwest column, second story junction in the Nairo Hiro building showing lateral buckling of the column. 


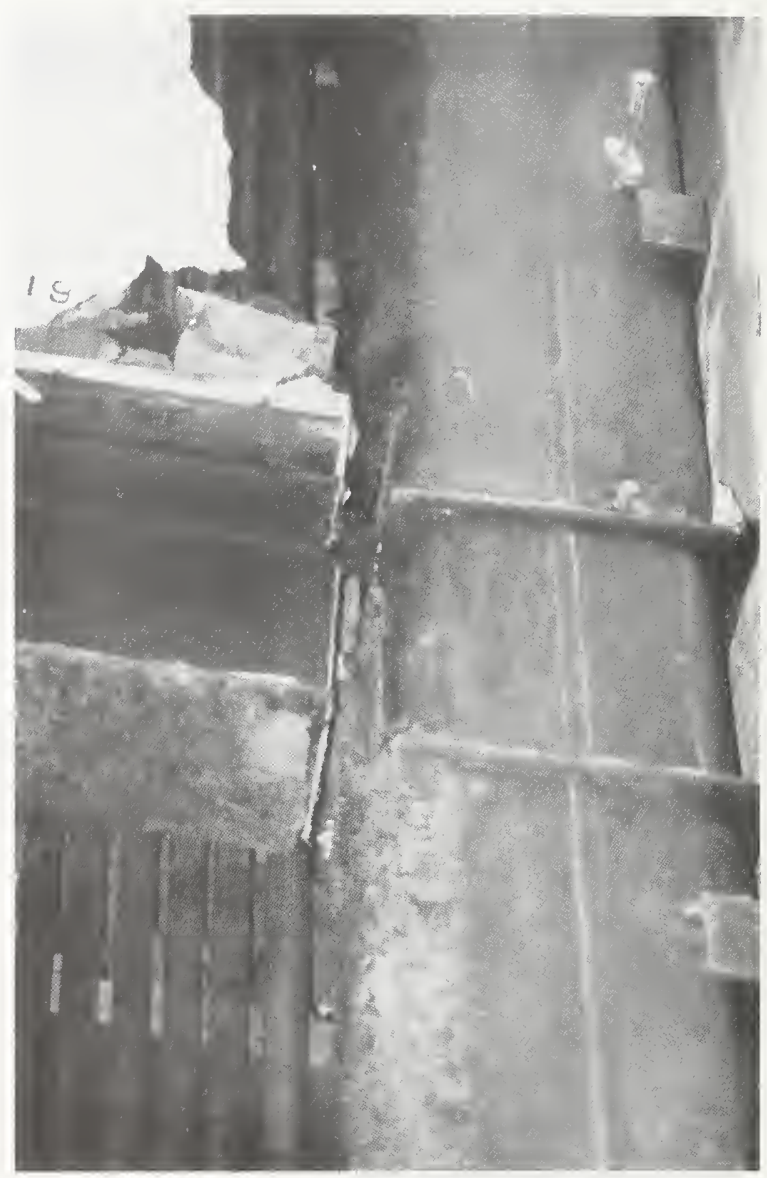

Figure 3.5.19 Beam Stub-to-Column weld failure on the east face of the Nairo Hiro building. 


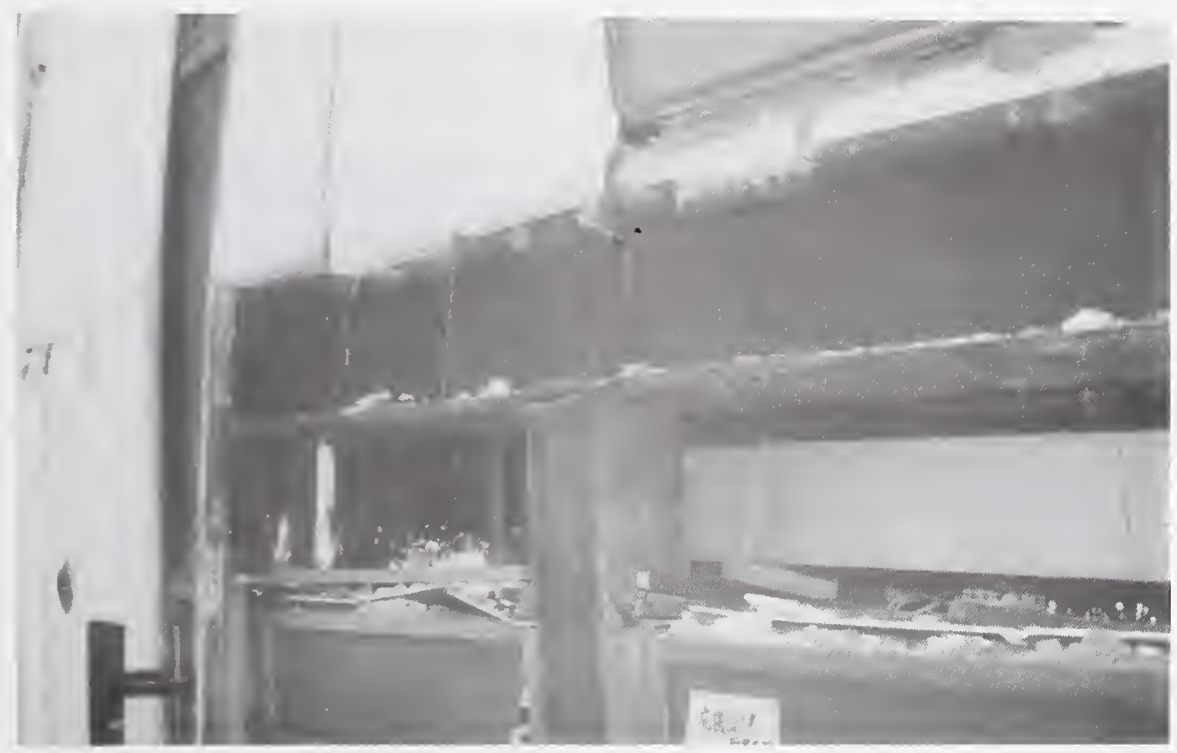

Figure 3.5.20 First floor column to second story column joint fillet weld failure on the east side of the Nairo Hiro Building, downtown Kobe.

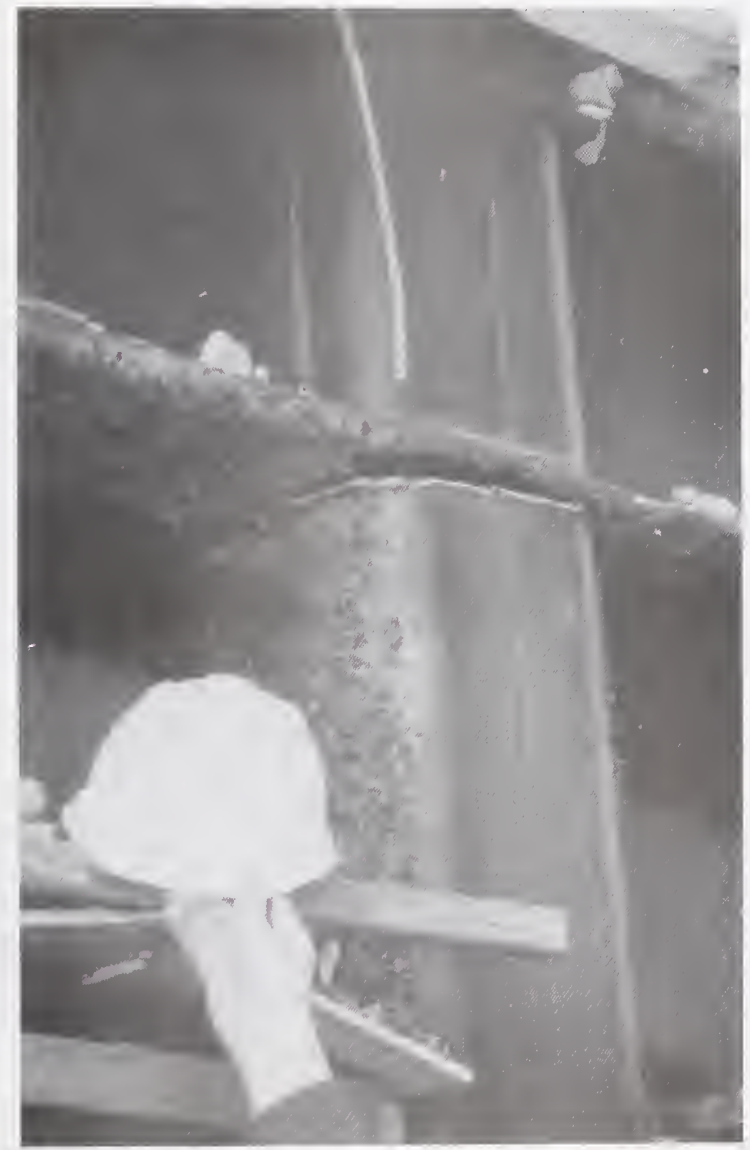

Figure 3.5.21 Closeup photo of column fillet weld failure in the Nairo Hiro building . 


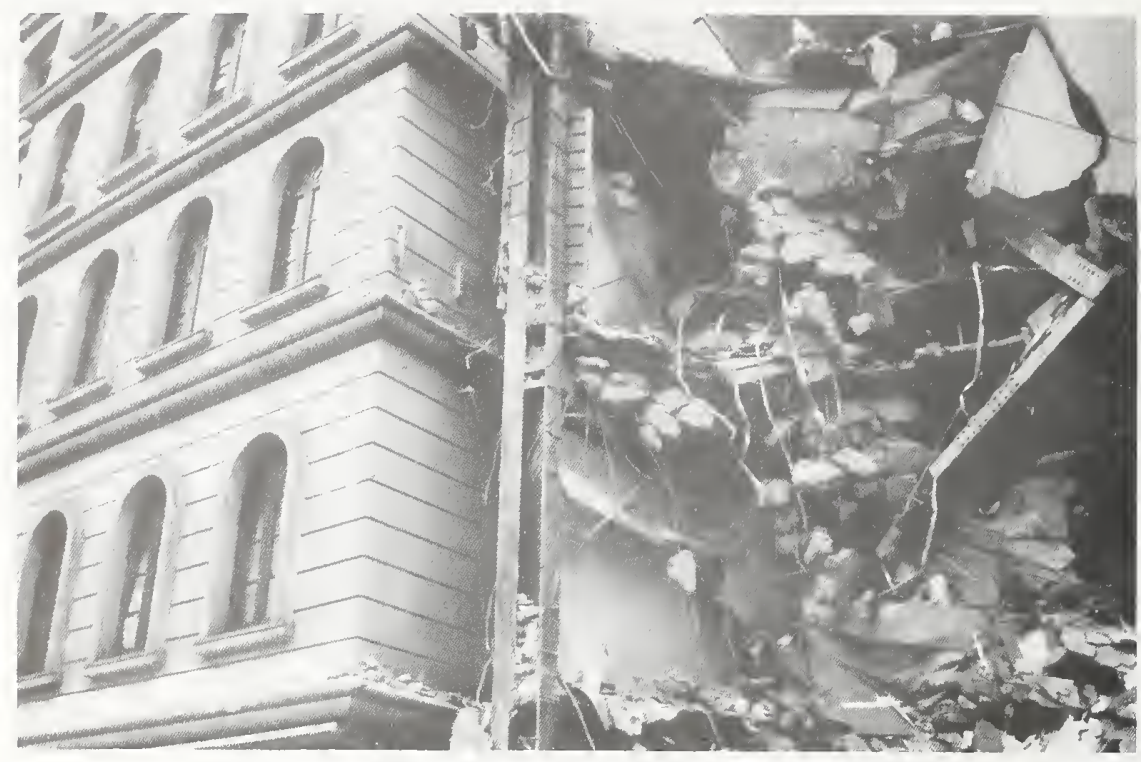

Figure 3.5.22 Collapse of the 3-story Tanigawa building on Flower Road in Kobe. This two-way steel frame was constructed of $\mathrm{H}$-shape beams welded to columns.

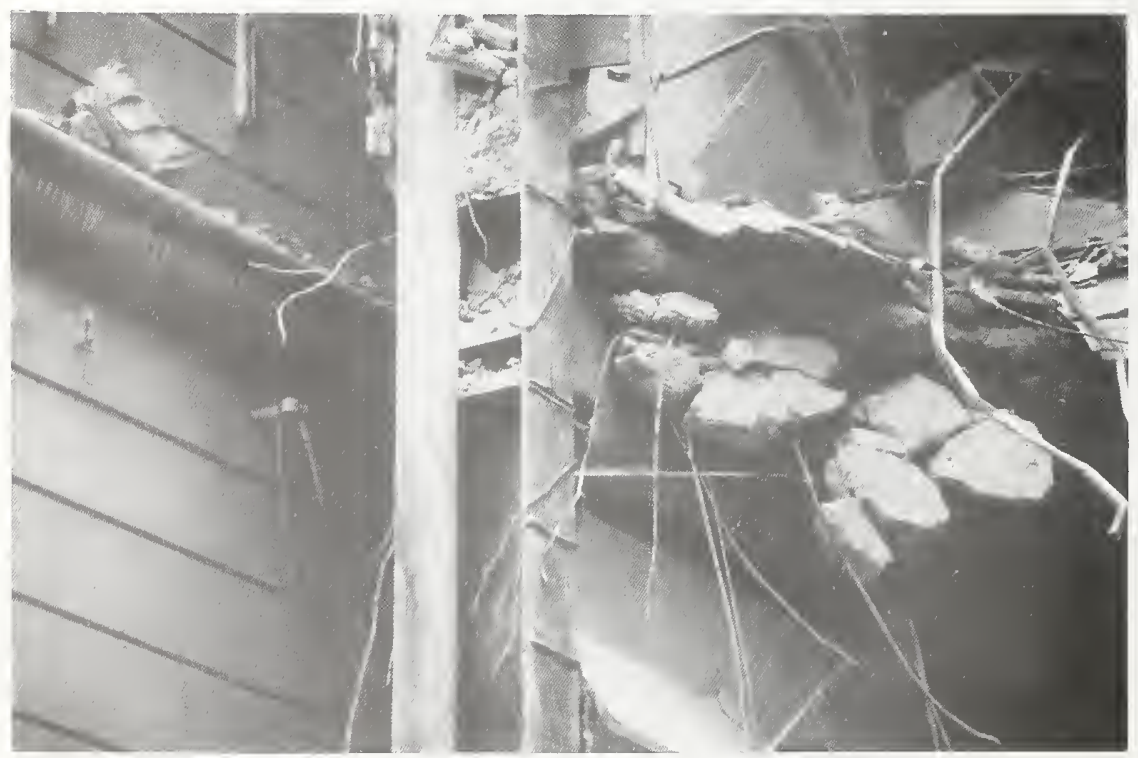

Figure 3.5.23 Close up of welded beam-column connection of Tanigawa building. 


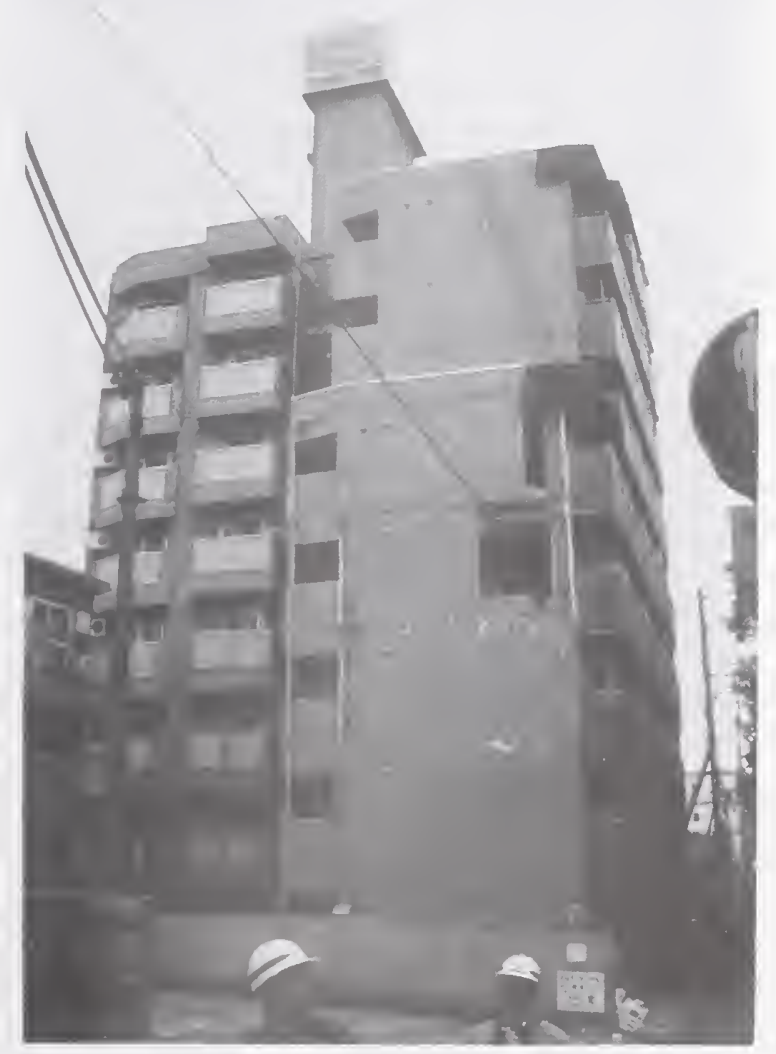

Figure 3.5.24 West face of the Liberty apartment complex in Higashi Nada-ku. This eight-story steel moment frame was typical of the performance of mid-rise steel structures designed according to post-1981 procedures. 


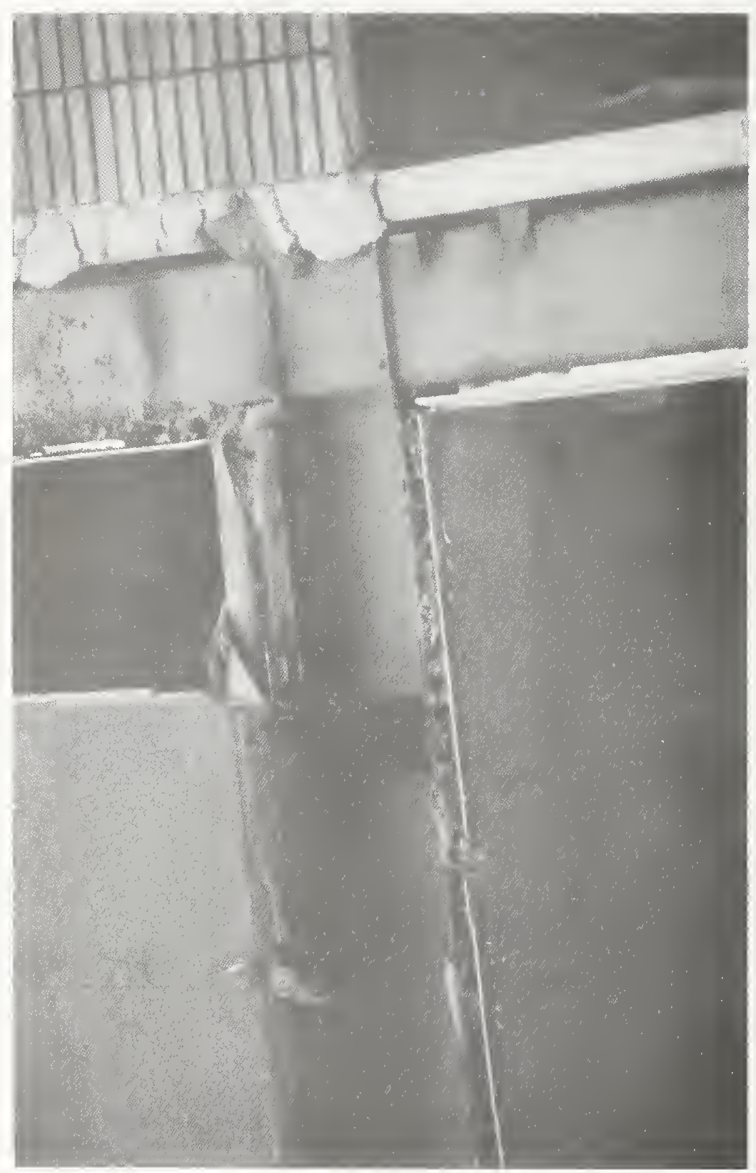

Figure 3.5.25 Closeup photo of west face steel moment frame of the Liberty apartments. Shop welded frame shows no damage but autoclaved lightweight concrete cladding suffered brittle failures along panel edges. 


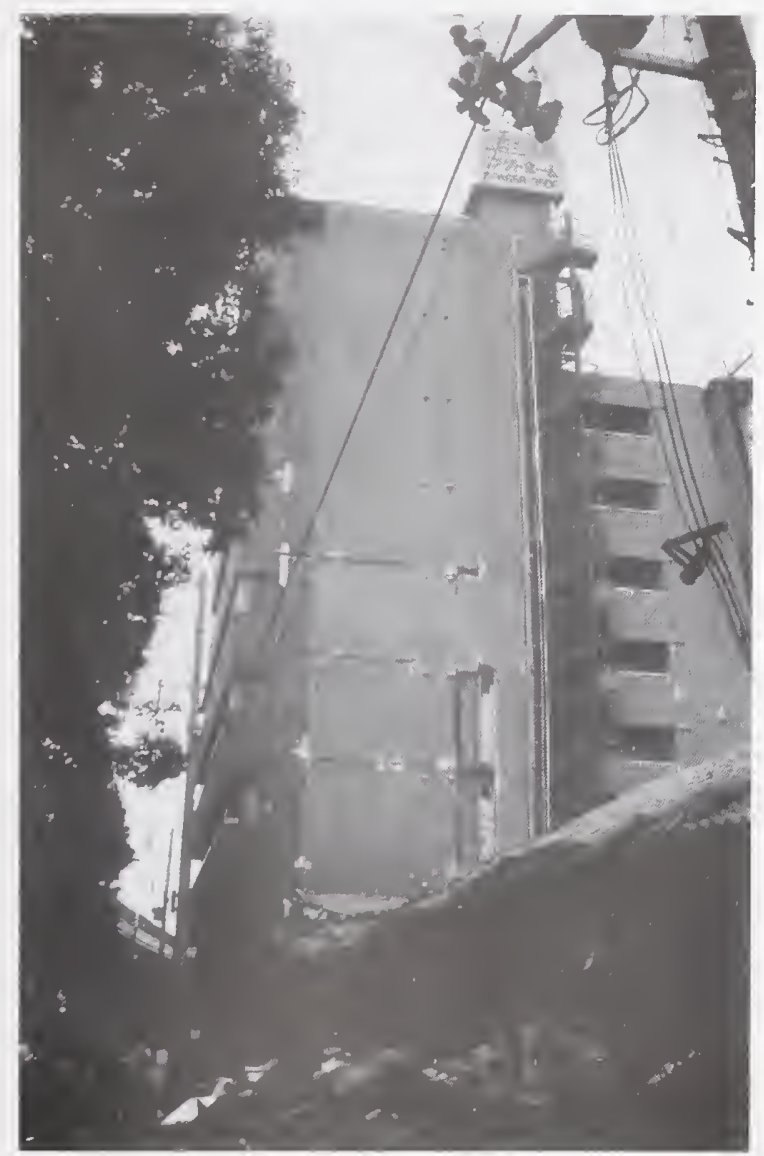

Figure 3.5.26 East face of the Liberty apartments. 


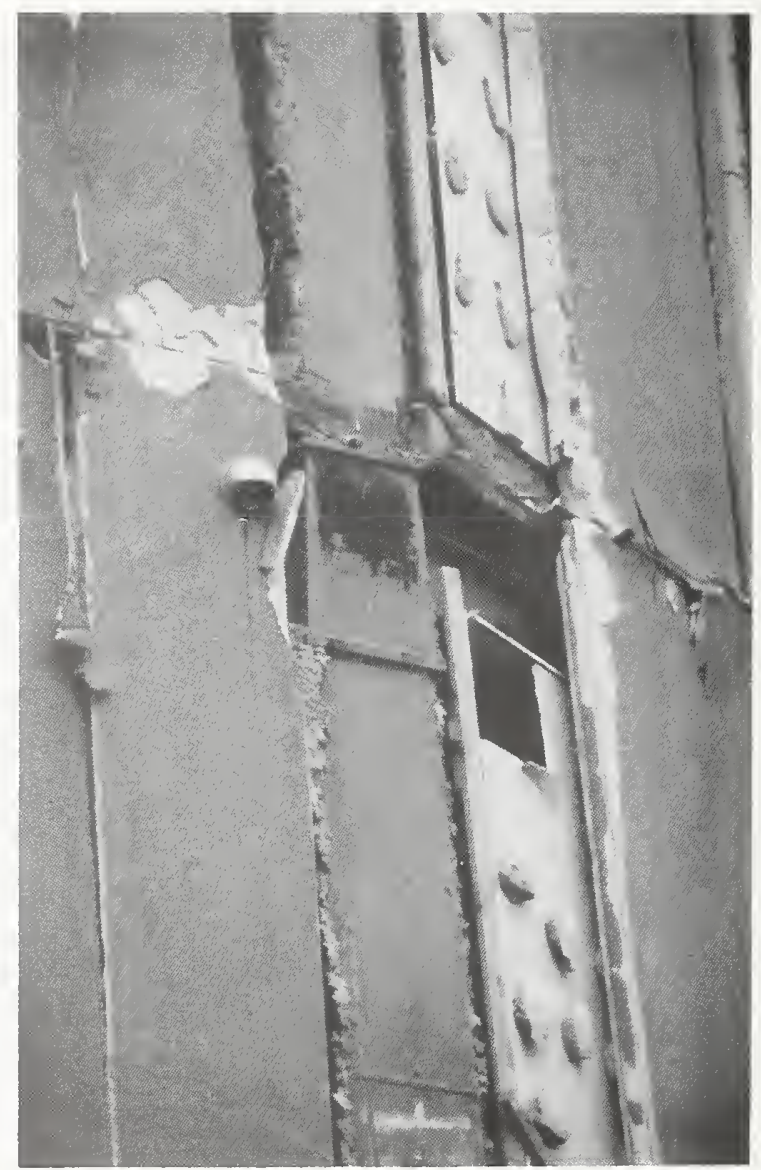

Figure 3.5.27 Closeup photo showing locally yielded third floor column joint in the Liberty apartment complex. 


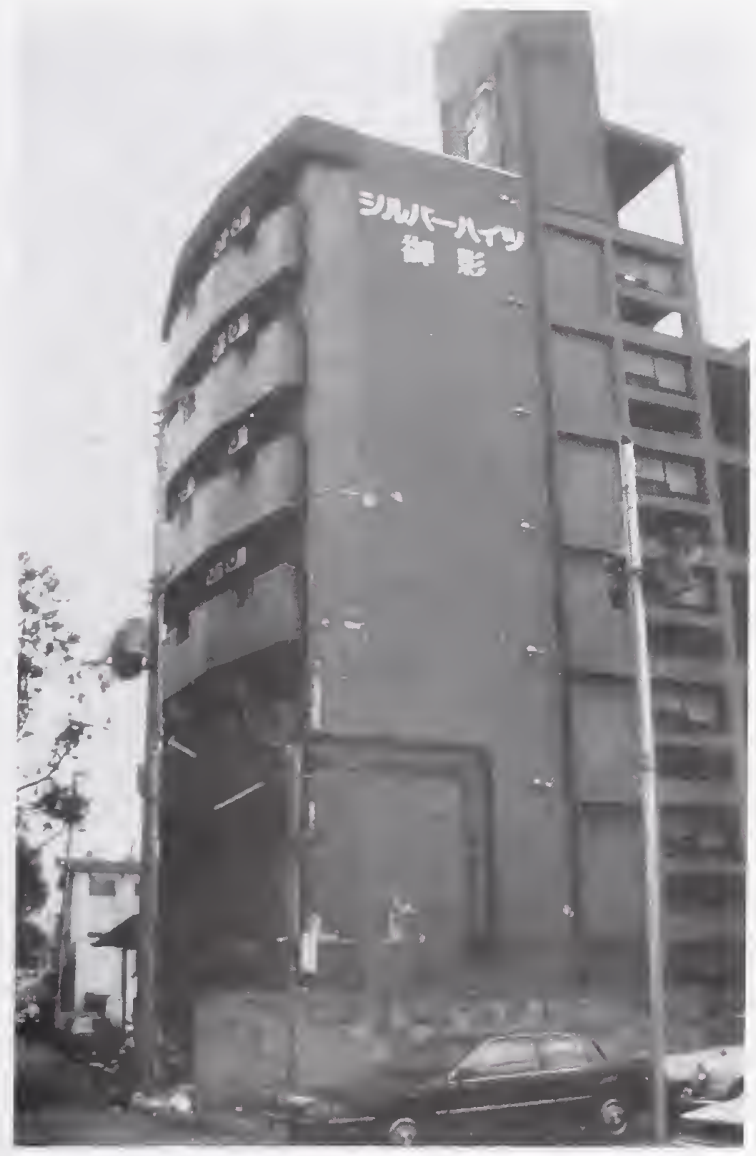

Figure 3.5.28 Seven-story Silver Heights Hotel in Higashi Nada-ku. This was another steel moment frame mid-rise building with cracking in the precast lightweight cladding. 


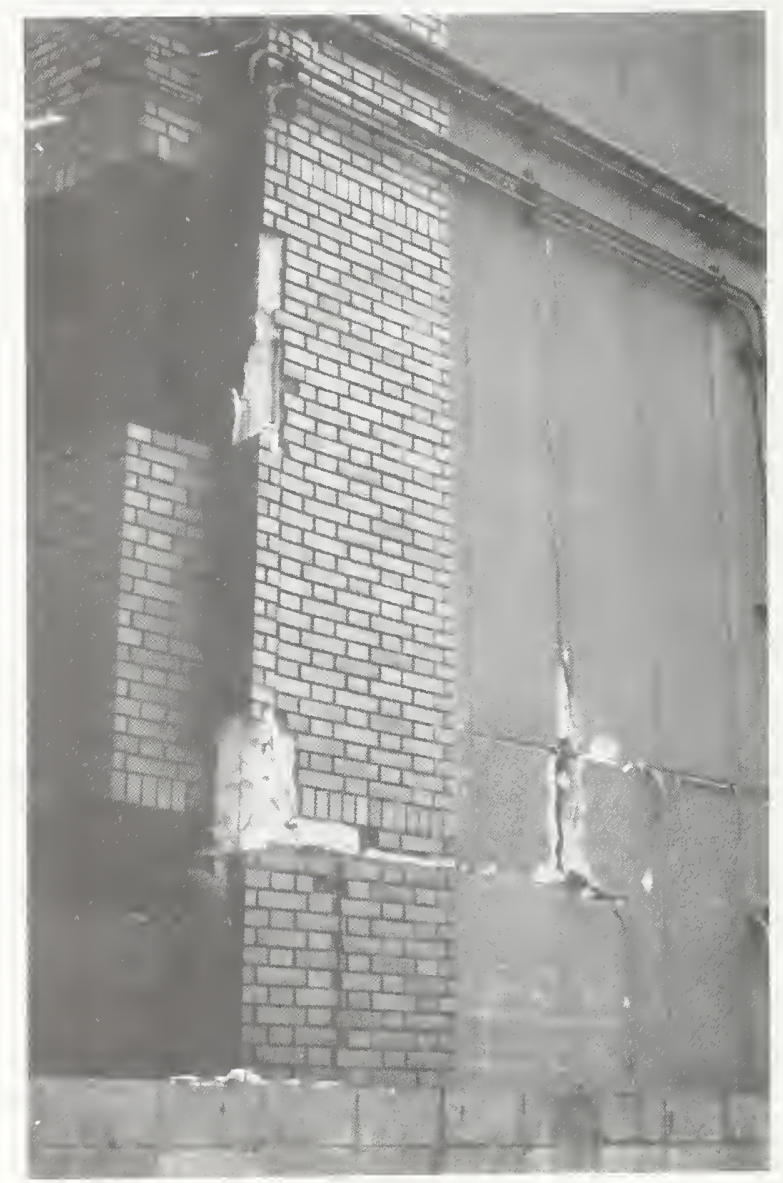

Figure 3.5.29 Closeup of cladding cracking at the Silver Heights Hotel. 


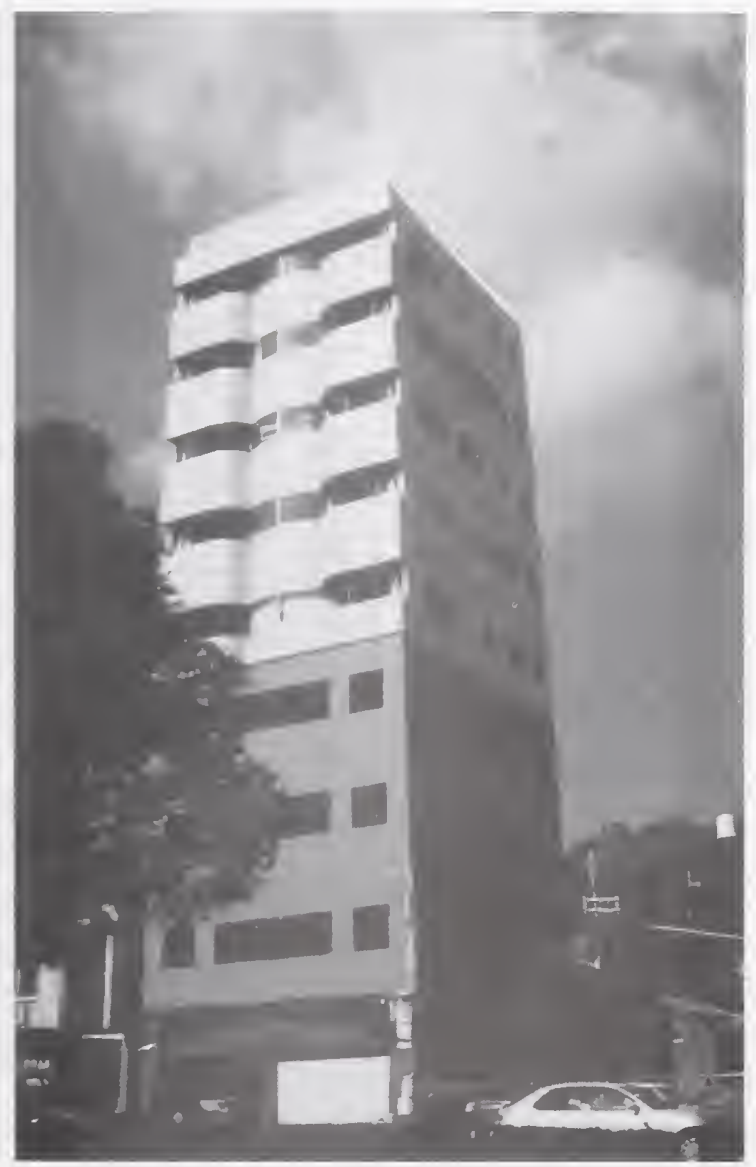

Figure 3.5.30 Nine-story Pacific Power Corporation building in Kobe. 


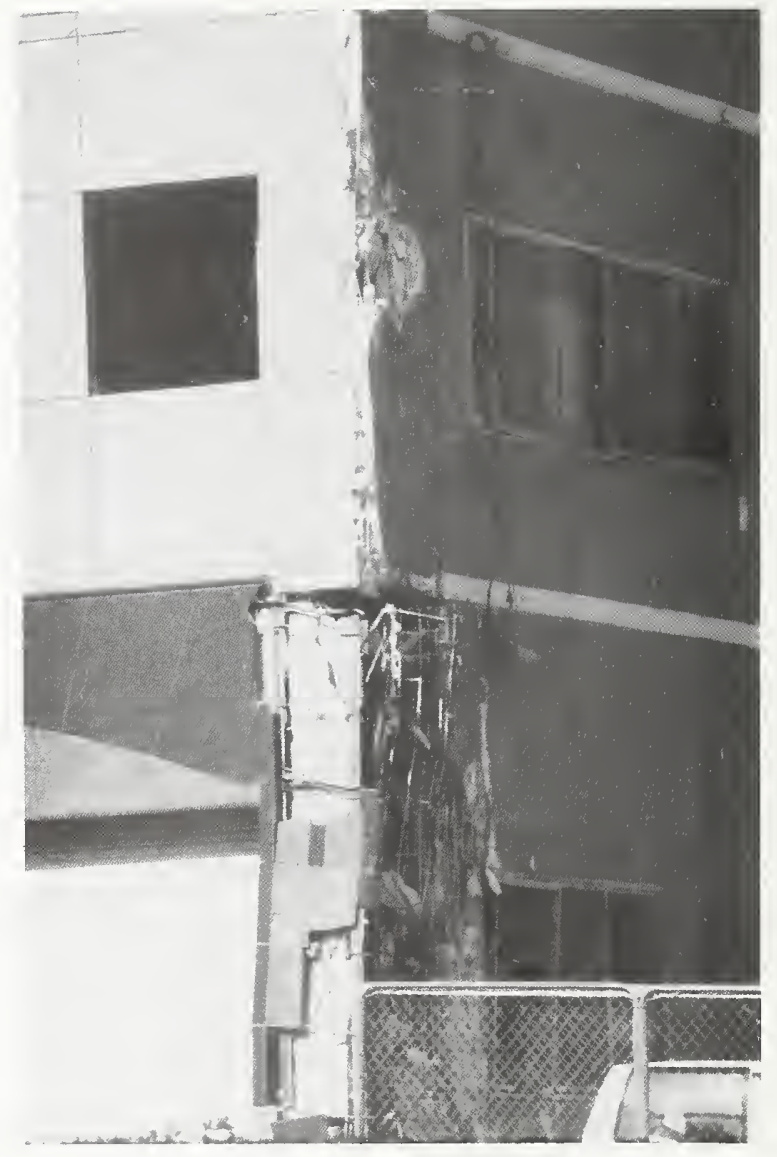

Figure 3.5.31 Detail of southeast corner of Pacific Power Corporation building. 


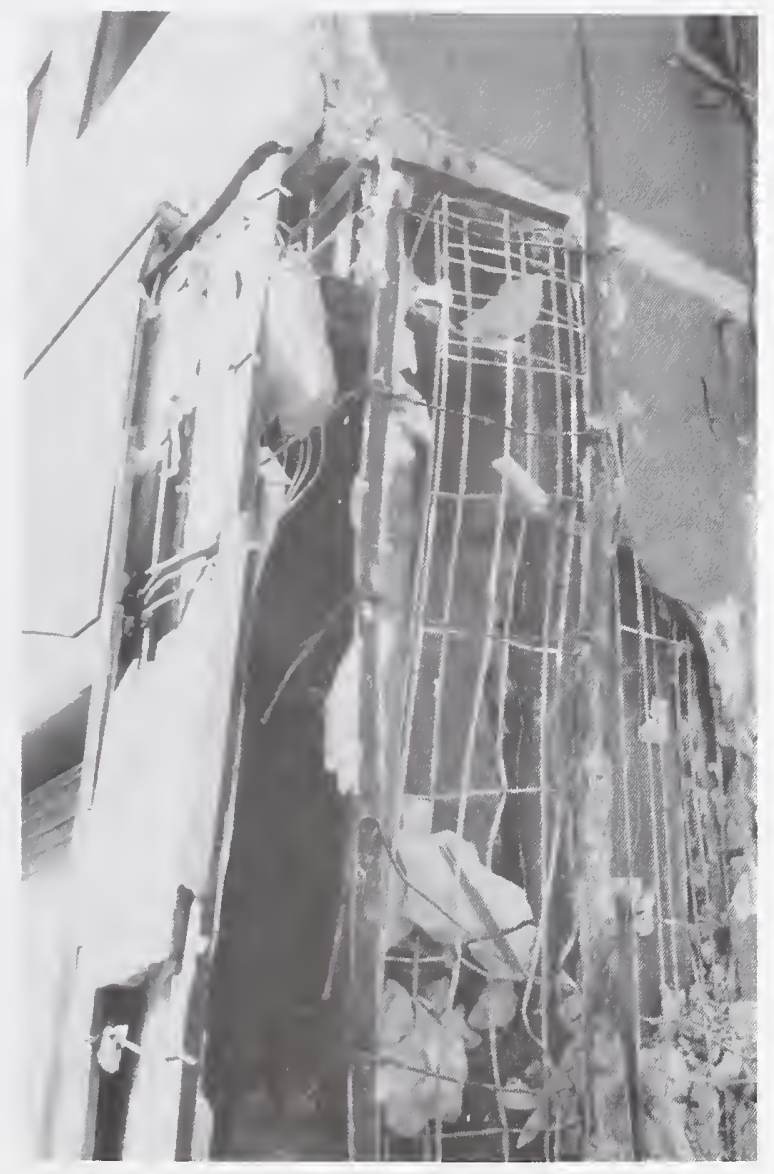

Figure 3.5.32 Closeup photo revealing steel moment frame beneath failed cladding of the Pacific Power Corporation building. 


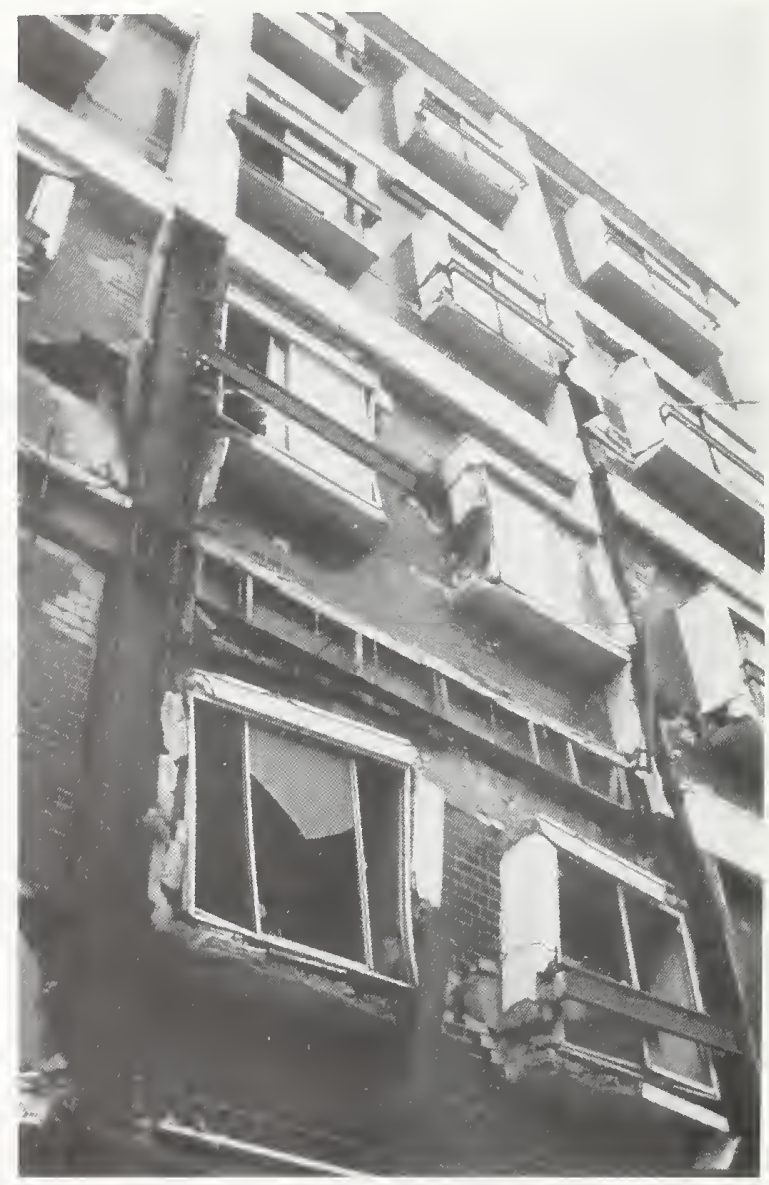

Figure 3.5.33 Older 5-story steel moment frame building showing extensive cladding damage to brittle cladding in Nada-ku near the Mikage metro station. 


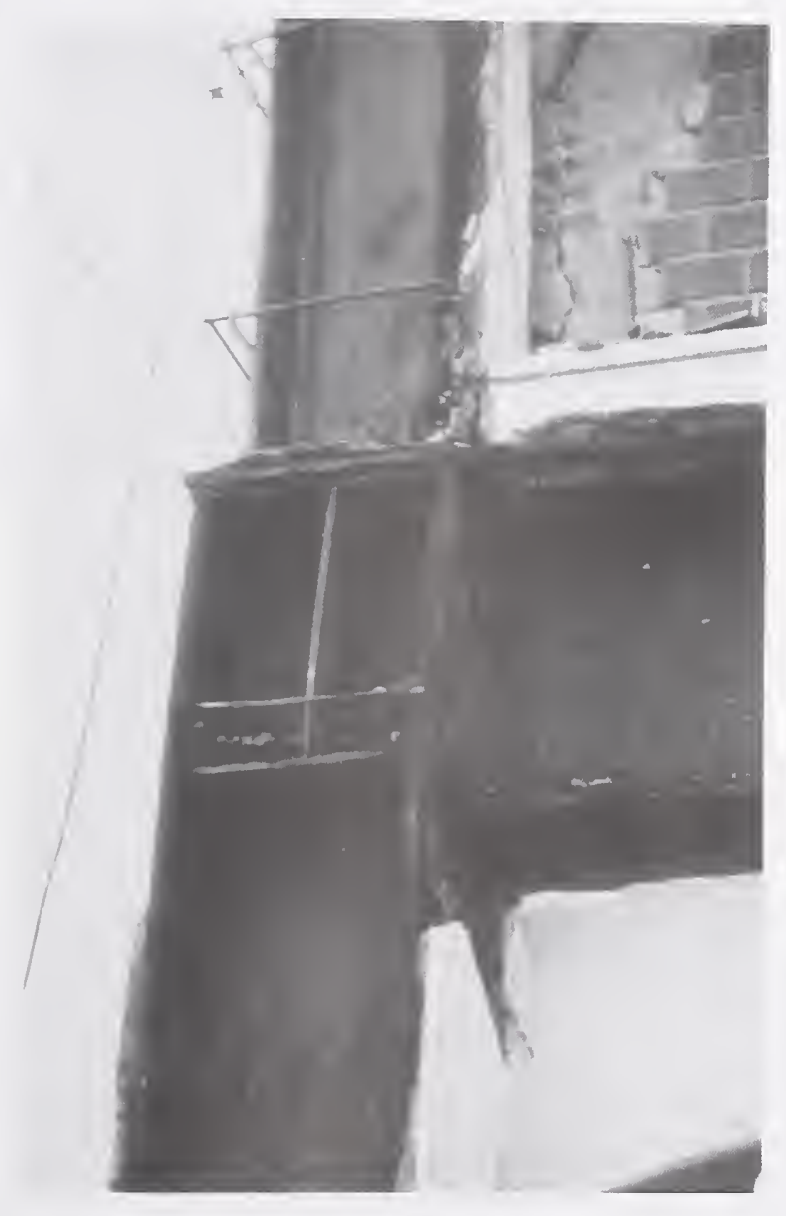

Figure 3.5.34 Closeup of rusted, older steel moment frame. 


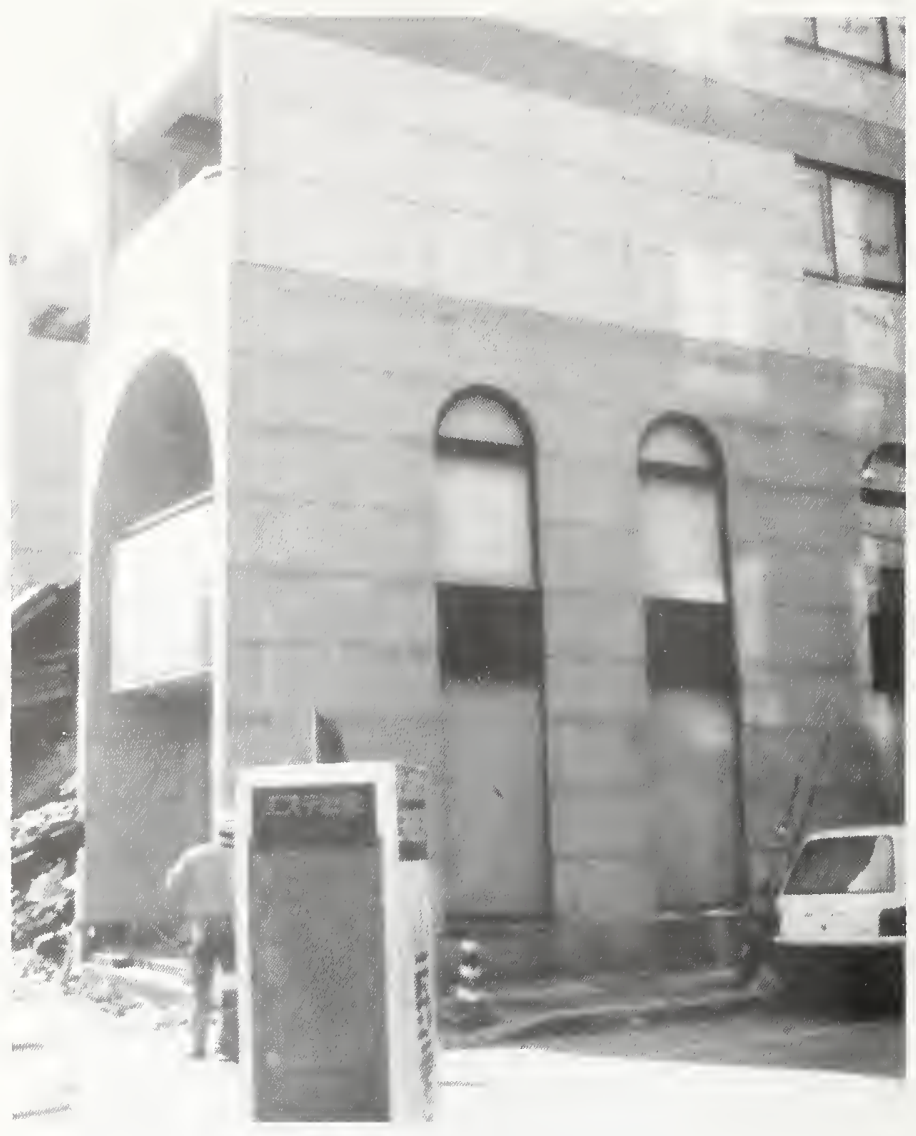

Figure 3.5.35 Seven-story steel frame SAGA Building - Flower Road in Kobe.

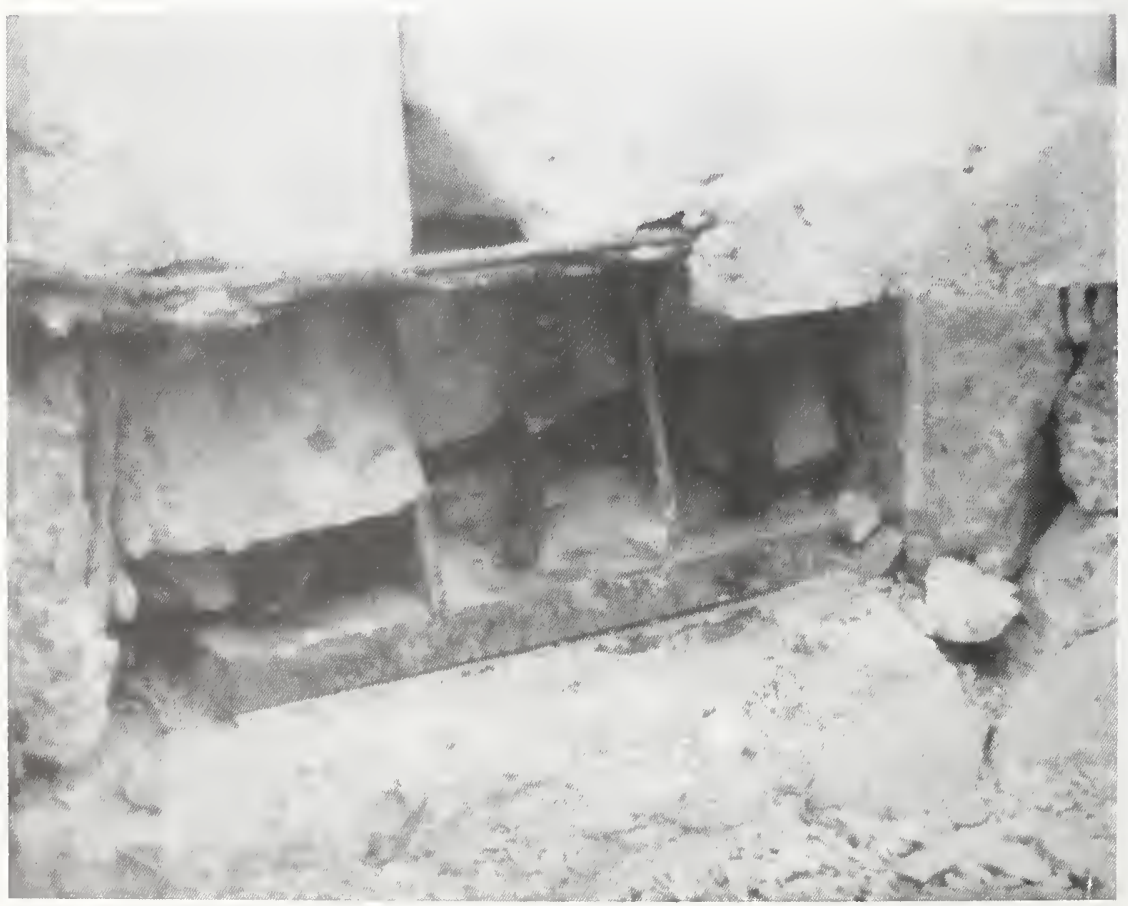

Figure 3.5.36 SAGA Building, anchor bolt was pulled out about $10 \mathrm{~cm}$. 


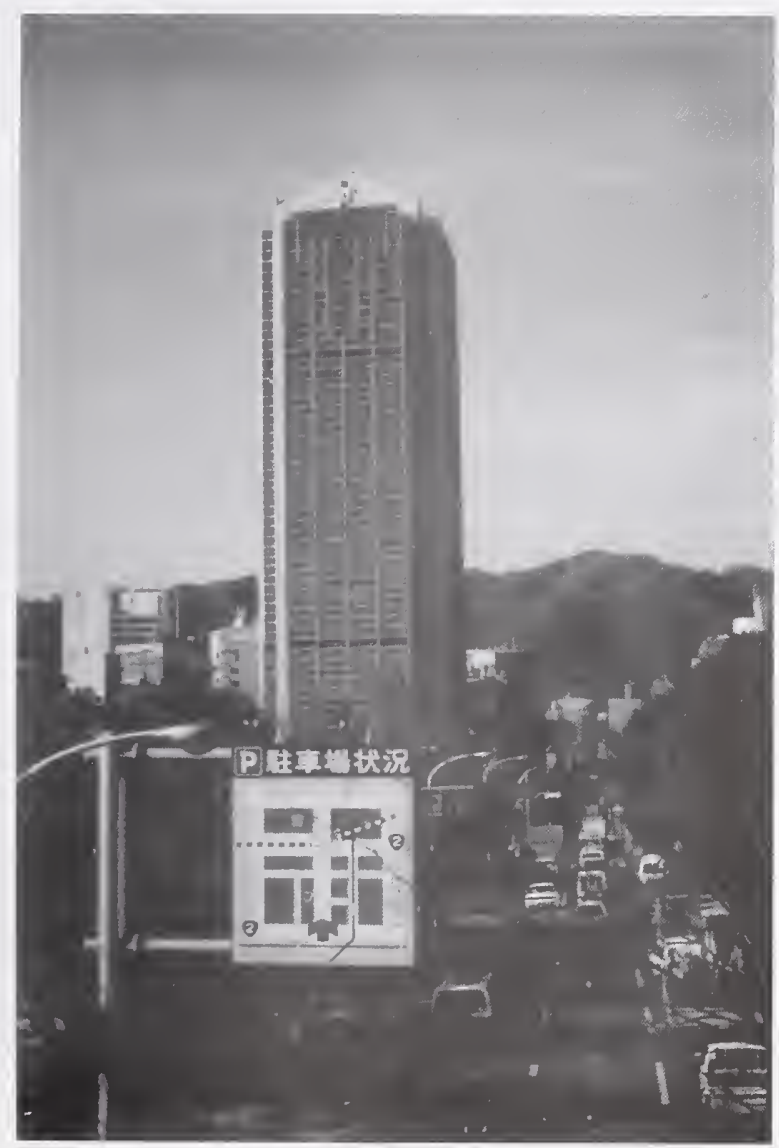

Figure 3.5.37 New Kobe City Office building. A 30-story steel frame structure without reported damage. The adjacent old Kobe City Office building sustained severe damage. 


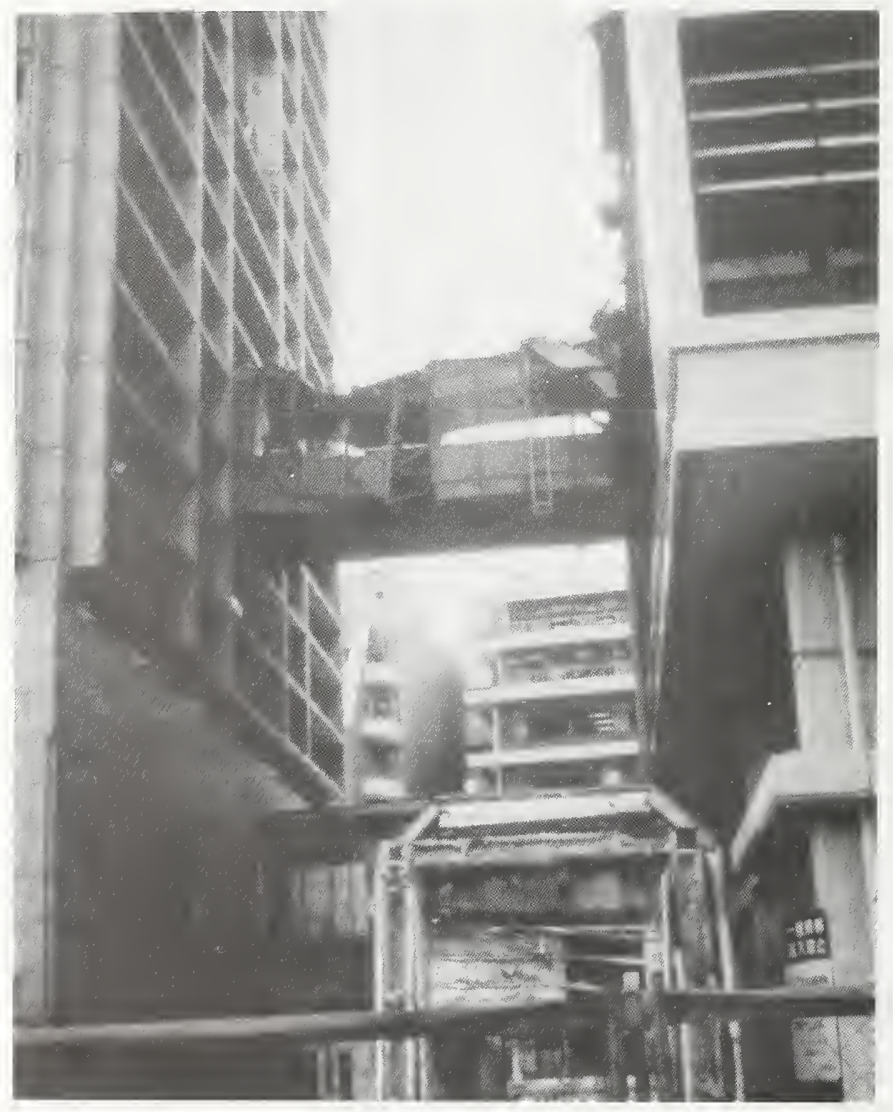

Figure 3.5.38 Sky bridge structure connecting the old and new City Hall buildings. 


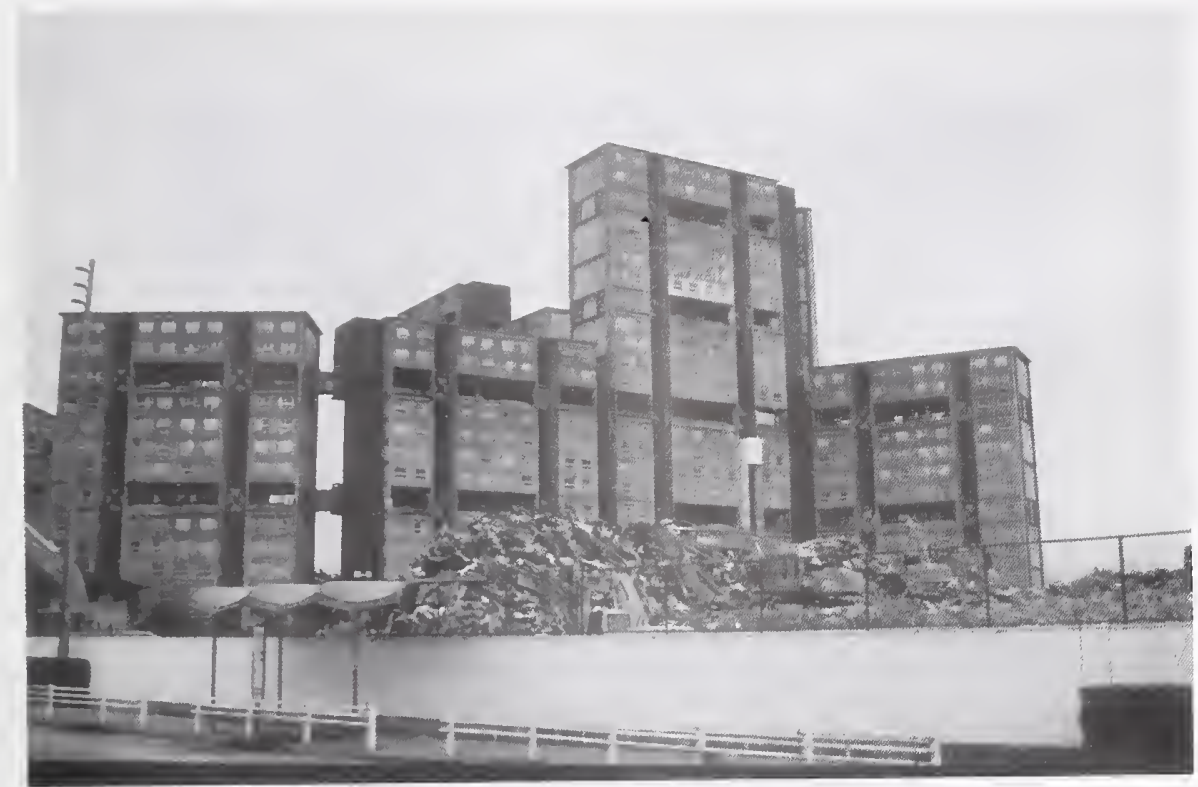

Figure 3.5.39 "Ashiya Hama Seaside Town" apartment complex.

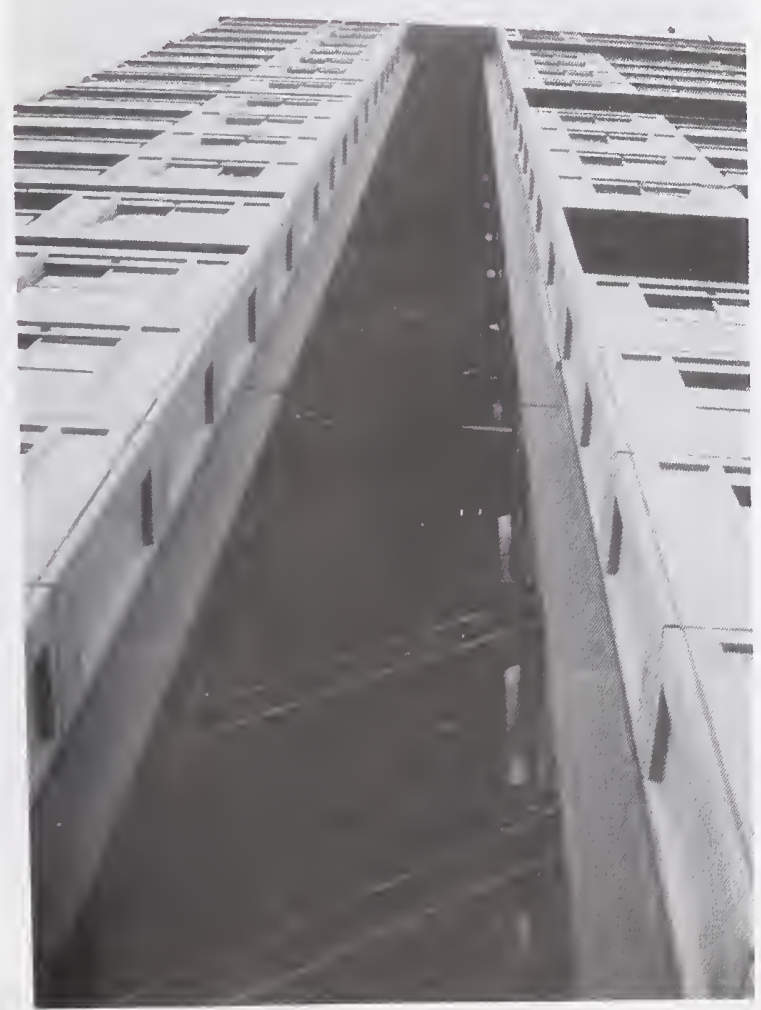

Figure 3.5.40 Load-carrying system: truss-like frames made of heavy steel sections. 


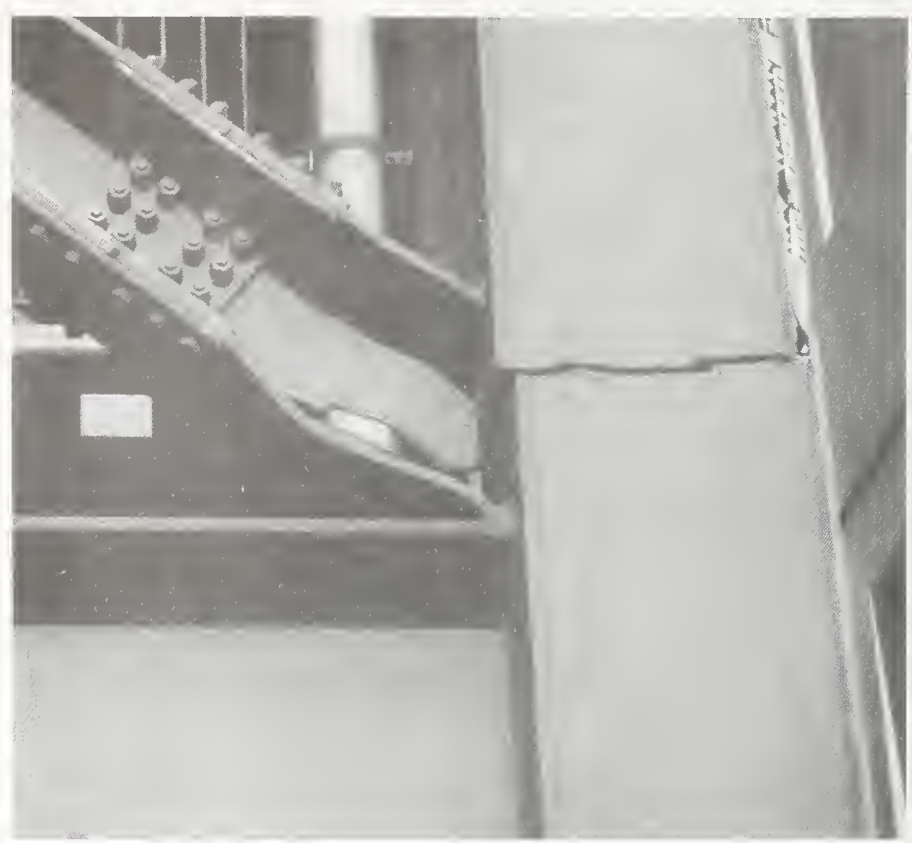

Figure 3.5.41 Complete fracture through a steel column section.

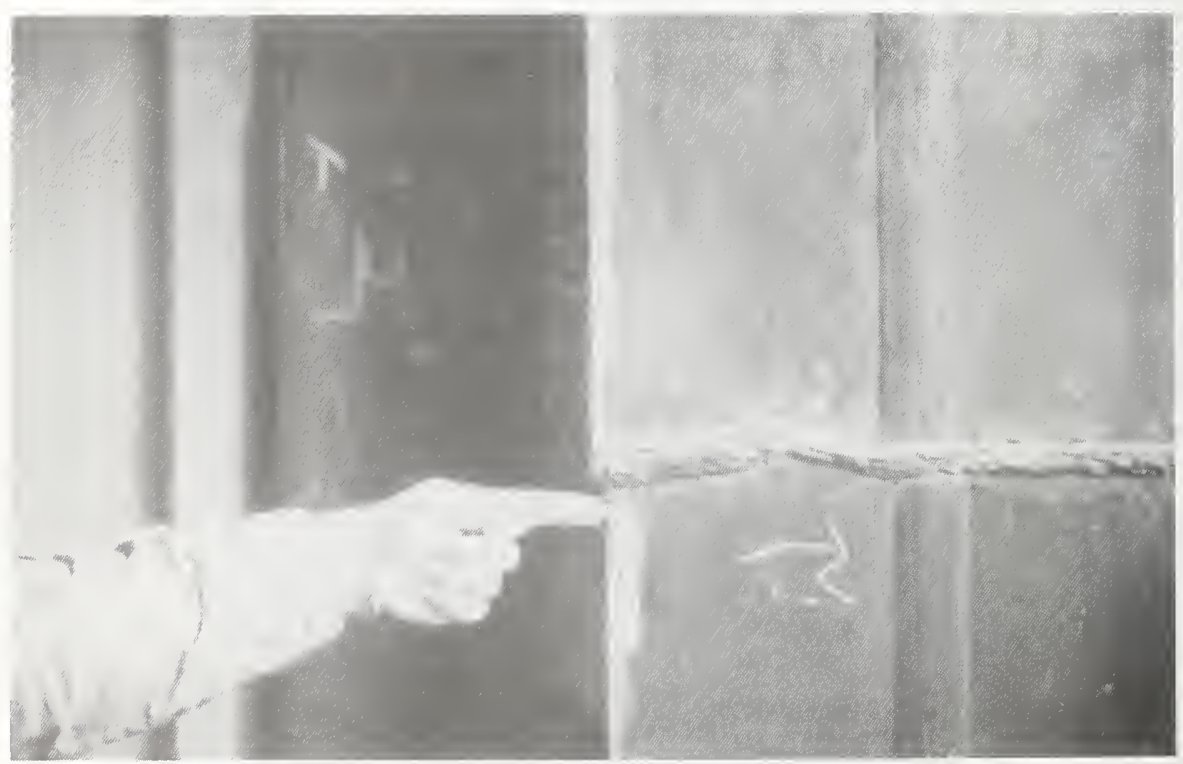

Figure 3.5.42 A repaired column immediately after the earthquake (Portland Cement Association). 


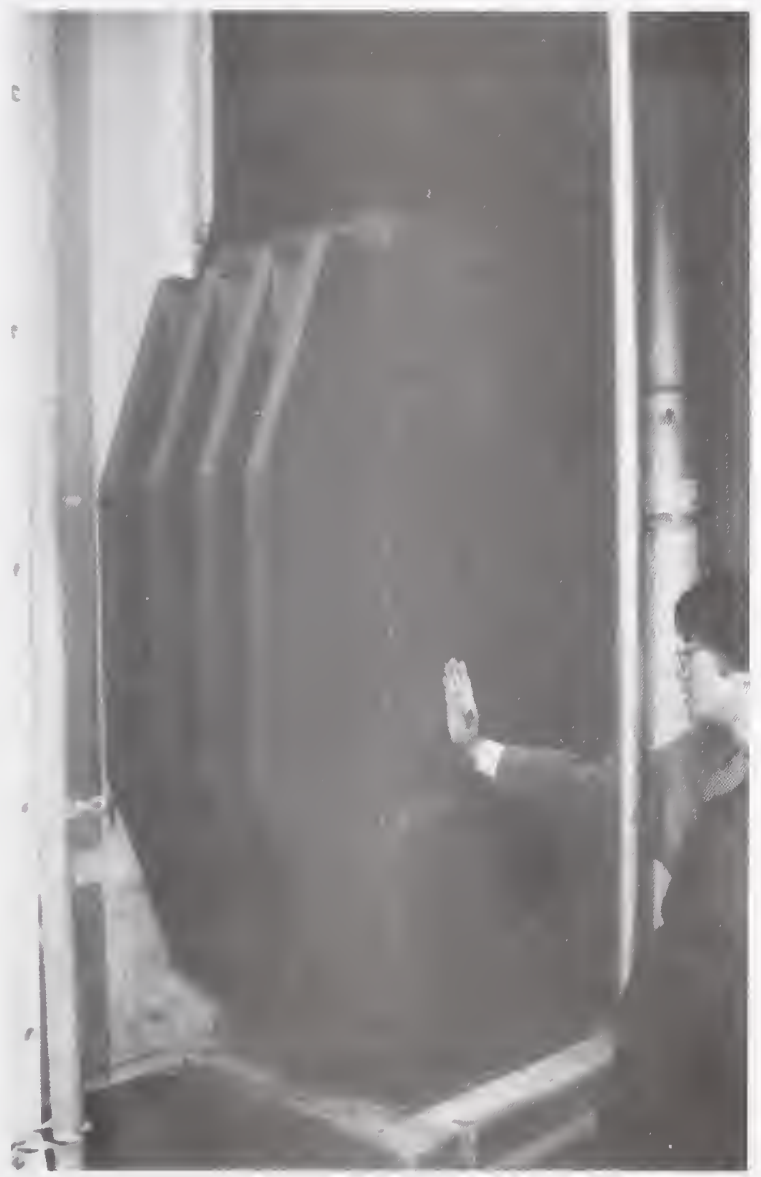

Figure 3.5.43 A column repaired not only with full-penetration weld, but also with stiffeners added. 



\subsection{Lessons for the United States}

With the exception of the unique SRC construction type, the construction and detailing practices of Japanese buildings have generally evolved in a manner that closely parallels U.S. practice. Code improvements, while not identical, have occurred at the same general pace in both countries. This is not surprising, as many of the more prominent Japanese researchers and practicing engineers have studied in the United States, and there has been an open interchange of ideas in the seismic area for many years. Engineers in the two countries have good rapport, and cooperation is quite good. The Hyogo Ken Nanbu earthquake, therefore, offers an excellent opportunity to reflect on several general issues.

First, and foremost, is the serious damage that older RC moment frame buildings suffered; many buildings experienced full or partial floor collapses. Both the cost of damage to the built environment and life safety are at issue. And, this event, with a magnitude of 7.2, was not the proverbial "big one," though strong ground motions clearly existed in the Kobe area. With the exception of the above-noted smooth longitudinal column reinforcement, the damaged low to mid-rise $\mathrm{RC}$ buildings that were observed could easily have been U.S. buildings that were constructed in the 1950's and 1960's. The $300 \mathrm{~mm}$ column hoop spacing is quite similar to U.S. practice of that era, particularly in zones of low to moderate seismicity. The large amount of damage that occurred in Kobe points out the high vulnerability of these older, poorly detailed, structures. This problem is not only one of concern for the zones of higher seismicity in the Western United States, but it is also one of concern for the lower seismicity zones in the Central and Eastern United States, where detailing practices in many cases have not kept pace with Western U.S. practice. These older and less ductile $\mathrm{RC}$ structures will require significant rehabilitation to be made less vulnerable. - Such a rehabilitation effort will no doubt be expensive; building owners and the general public should be apprised of the risks and costs, so that they might make informed decisions concerning rehabilitation, replacement, or status quo.

While damage to older $\mathrm{RC}$ buildings was severe, no evidence of collapse in any of the newer (post-1981) engineered RC structures was evident. The 1981 Japanese code improvements that added the sccond phase of seismic design that addresses ultimate capacity is quite similar to the intent of current-era U.S. building codes that focus on life safety, or the prevention of collapse, in the one-time severe seismic event. In this light, the Hyogoken-Nanbu earthquake is a vindication of the current code philosophies in both countries and the technical changes that have occurred in those codes as a result of the $\mathrm{RC}$ research that has occurred since the early 1970's in both the United States and Japan. The research investment seems to have generally paid for itself many times over.

A somewhat more subtle issue regarding new construction is one that arose after the 1994 Northridge, CA, earthquake, which was similar in magnitude to this most recent event. That is, should there be standards that provide better building envelope integrity than the basic one-event life safety standard that we have today? Because of time limitations, the survey team was unable to enter numerous newer buildings to observe what more subtle types of damage might have occurred on the interior elements of newer buildings. It was clear from the external envelope surveys that racking had caused many windows in newer 
structures to crack or pop out of their frames. Also, facade cracking and other minor damages were present. These less severe damages represent costs to the building owners, and in many circumstances can also pose life safety dangers from falling debris (since this event and the one in Northridge both occurred in the early morning hours, commercial districts were not yet active). Once more detailed damage estimates are available, the HyogokenNanbu event should fuel further debate in both the United States and Japan about weighing initial construction costs against potential future earthquake losses.

One general philosophical issue that is also tied to the poor performance of the older $\mathrm{RC}$ structures is the need for special standards for hospital and other facilities that are essential to post-earthquake disaster response. At least two Kobe-area hospitals suffered catastrophic floor collapses. While the State of California has commendably implemented special earthquake safety requirements for hospitals, not all U.S. jurisdictions have done so. This event should reinforce the need for such special measures.

While it seems that every major earthquake illustrates these problems, thus perhaps making the observation redundant, the Hyogoken-Nanbu event again pointed out the need for avoiding the use of "soft" stories and stiffness or mass irregularities either in plan or elevation. Many of the older building collapses could be at least partially attributed to the presence of such weak links. Particularly in the densely built downtown areas, the need to eliminate pounding of adjacent buildings was also evident; separation is the obvious solution, but, when it is not provided, the interactions of adjoining buildings must be considered.
From what the survey team members observed, the Kobe area had no significant pre-earthquake seismic rehabilitation initiatives. Likewise, there apparently were no newer energy dissipation technologies, such as base isolation or supplemental damping, used in any of the Kobe buildings.

The poor performance of steel frame structures was generally prevalent to low- to mid-rise structures constructed with light structural members. Types of welded connections that failed are not common in the United States. However, as many welded connection failures we have seen in the Northridge earthquake, we should not over look at types of welded connection failures occurred in Kobe. The use of precast autoclaved lightweight cladding for light steel frame structures is not common practice in the United States. It does, however, indicate that extensive monetary damage can be inflicted on a structure in the form of cladding failures. In this respect it will generally be the purview of the building owners to decide whether such loss, following a major design-level earthquake, is tolerable. If not, then displacement compatibility studies will need to be undertaken to insure that large racking motions, which can be tolerated by the ductile steel frames, are limited to that which is tolerable by the more brittle cladding.

A final note concerning steel structures are the questions raised by the extensive base metal and weld failures observed at the Ashiya Hama Seaside Town (AHST) complex in Ashiya City. A number of thick column sections and diagonal bracing members sustained brittle failures. These failures echo problems first observed in steel structures in the United States following the Northridge earthquake. 


\subsection{Research Needs}

Paralleling the "lessons learned," the largest overall research need for $\mathrm{RC}$ buildings seems to be the need for extensive research on seismic vulnerability assessment, rehabilitation, and retrofit for older, non-ductile $\mathrm{RC}$ moment frame and shear wall buildings in the three to ten story range. These buildings are numerous both in Japan and the United States, so they represent a substantial area of risk and potential damage cost. More accurate models of existing non-ductile structures are needed, necessitating research on older member and system capacities. Most U. S. research has focused on developing more ductile members and elements for new construction. Rehabilitation techniques need to be cost-effective and non-intrusive for building owners and users. Continued focus on improving the deformation capacities of columns, girders, and joints in moment frames is needed. Beyond this, continued research into less traditional techniques for rehabilitation, such as supplemental energy dissipation and the use of newer structural composites, should be conducted, both to provide architectural flexibility and to reduce costs to affordable levels.

Two areas of unique potential study involve the contrasts in Japanese and U.S. philosophies. First, as was described above, current Japanese design techniques result in stiffer but less ductile RC structures than in the United States. A study of these two differing approaches would seem to be appropriate. Second, the distinctive Japanese practice of SRC construction should be studied. Disregarding the apparent problems that existed with discontinuities in these systems, it is important to examine whether the use of such composite construction does enhance ductility in RC beyond that provided by current U.S. RC detailing techniques, and if so, to determine its cost-effectiveness with respect to current detailing techniques.

A final area of needed research relates to the behavior of heavy steel frame, high-rise structures under strong low cycle lateral loading. Given the wealth of data concerning the design procedures, weldment details, and material spccifications for the Ashiya Hama Seaside Town complex in Ashiya City, research should be conducted into the behavior of built-up steel column sections and truss weldments under very low cycle fatigue -- one cycle to yield followed by an immediate reverse cycle to yield in the opposite direction. This would augment research programs already underway in the United States following the Northridge earthquake.

\subsection{Summary}

The 7.2 magnitude Hyogoken-Nanbu (Kobe) earthquake claimed more lives than any other recent earthquakes in Japan. Eighty nine percent of over 6000 casualties resulted from collapsed residential buildings. Many of these buildings were over 40 years old and had little lateral load resisting capacity. The walls of single family dwellings provided little lateral load resisting capacity, and could not support the heavy roof load during severe ground shaking. Two- and threestory dwelling structures with commercial operations in the first story had little interior walls to resist lateral loads, thereby sustaining partial or total collapse.

As presented in Section 3.2, major revisions to the seismic design requirements took place in 1971 and 1981. For the first time, the ductility was introduced in the seismic design in 1981. As a result, many reinforced concrete buildings constructed prior to 1981 sustained severe damage. Many buildings 
sustained damage to the first story. Shear failure of first-story columns and collapse of soft first stories were most common. A prominent mode of failure of reinforce concrete multi-story buildings was a partial or a total collapse of an entire story at an upper level. Many buildings failed in this mode were of steel-encased reinforced concrete (SRC) buildings. The distribution of collapsed and damaged concrete buildings from Kobe to Ashiya city is shown in Figure 3.8.1. It is seen that most damage occurred in the central part of Kobe where commercial structures are concentrated.

Similar to reinforced concrete buildings, steel buildings constructed 20 years to 30 years ago sustained severe damage which buildings designed and constructed according to the 1981 Building Standard suffered little. Welding failures at member connections contributed to many of the failures. Light steel frame structures suffered member failures, particularly diagonal bracing members, reduction in cross section due to corrosion. Brittle fractures of heavy steel columns with flange thickness of 50 $\mathrm{mm}$ occurred in a multi-story complex in Ashiya city. This is the first known case of brittle fracture of multi-story building columns during earthquakes. The distribution of steel building damages throughout the Kobe area is shown in Figure 3.8.2. The shape of distribution of steel building damage is similar to the one for the concrete buildings. Furthermore, the severity of damage of concrete and steel buildings are about the same.

The degree of damage of reinforced concrete and steel buildings with respect to the year of construction are shown in Figure 3.8.3. These two plots are constructed based on damage observations of about 100 buildings in the central district of Kobe. It is seen that both reinforced concrete and steel buildings constructed prior to 1971 suffered severe damage beyond repair or collapse, while the buildings constructed after 1981 sustained no severe damage or collapse. This clearly attests that upgrading of building codes is a most important factor in improving the performance of buildings during earthquakes.

\subsection{References}

1. Design Essentials in Earthquake Resistant Buildings, (English translation of 1966 publication in Japanese), Architectural Institute of Japan, Tokyo, 295 pp., 1970.

2. Design Standard for Steel Structures, English translation of the 1970 Japanese publication, Architectural Institute of Japan, Tokyo, 113 pp., 1979.

3. Preliminary Reconnaissance Report of the 1995 Hyogoken-Nanbu Earthquake, English Edition, Architectural Institute of Japan, Tokyo, 1995.

4. Aoyama, H., "Outline of Earthquake Provisions in the Recently Revised Japanese Building Code," Japan International Cooperation Agency, Tsukuba International Center, Japan, 34 pp., 1993.

5. Chiba, N., "Building in Steel in Japan," Proceedings, from the International Symposium entitled "Building in Steel the Way Ahead," British Constructional Steelwork Association, London, 1989.

6. The Hyogo-Ken Nanbu Earthquake, January 17, 1995, Preliminary Reconnaissance Report, Earthquake Engineering Research Institute, 1995. 
7. Ishiyama, Y., "Aseismic Design Method and its History in Japan," summary of oral presentation, Proceedings of the 3rd U.S. -Japan Workshop on the Improvement of Building Structural Design and Construction Practices, ATC-15-2, Applied Technology Council, Redwood City, California, pp. 8, 1989.

8. Ishiyama, Y., and Y. Ohashi, "History of Structural Regulations in Japanese Building Codes and Outline of WindResistant and Seismic Regulations," Wind and Seismic Effects, Ed. N. Raufaste, NIST SP 776, NIST, Gaithersburg, Maryland, pp. 335-347, January 1990.

9. Morino, S., I. Nishiyama, and N. Sakaguchi, "Hybrid Structures in Japan Research and Practice," SSRC annual meeting, Lehigh University, 1994.
10. Naka, T., M. Wakabayashi, and J. Murata, "Steel-Reinforced Concrete Construction," IABSE preliminary report, Amsterdam, May, 1972.

11. Naka, T., M. Wakabayashi, S. Takada, "Quake Resisting Design of Composite Structures in Japan," Proceedings of the Second World Conference on Earthquake Engineering, V. 3, Tokyo, pp. 1811-1826, 1960.

12. Otsuki, Y., "Development of Earthquake Resisting Building Construction in Japan," Proceedings of the First World Conference on Earthquake Engineering, Berkeley, California, pp.16.1-16.17, 1956.

13. Mizukoshi, Y., "The New Illustrated Building Code," Shin-Nihon Hoki-Shuppan Co., Ltd., Tokyo, Japan, 1978 


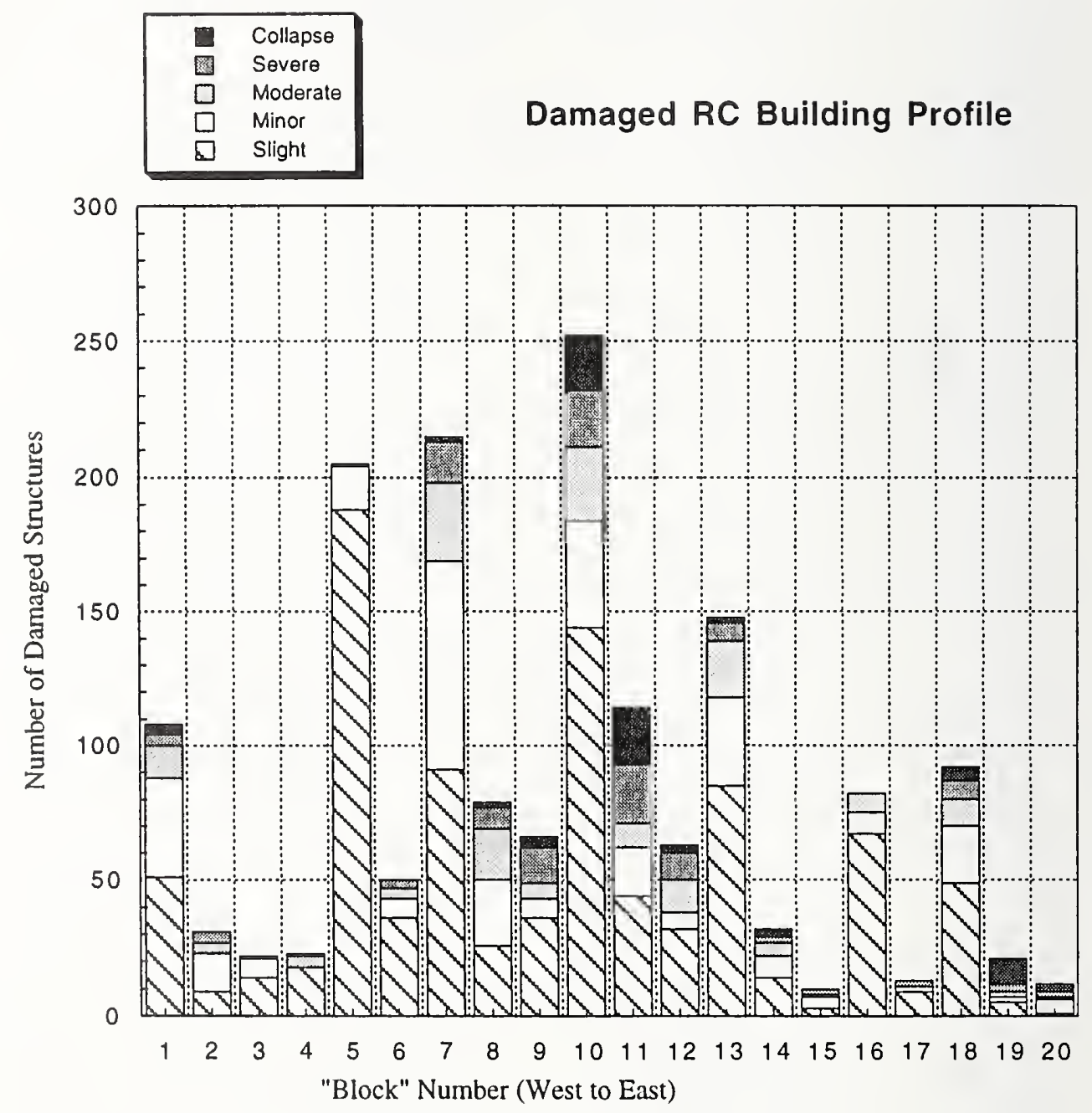

Figure 3.8.1 Kobe Damage Survey: All damaged RC frame structures. 


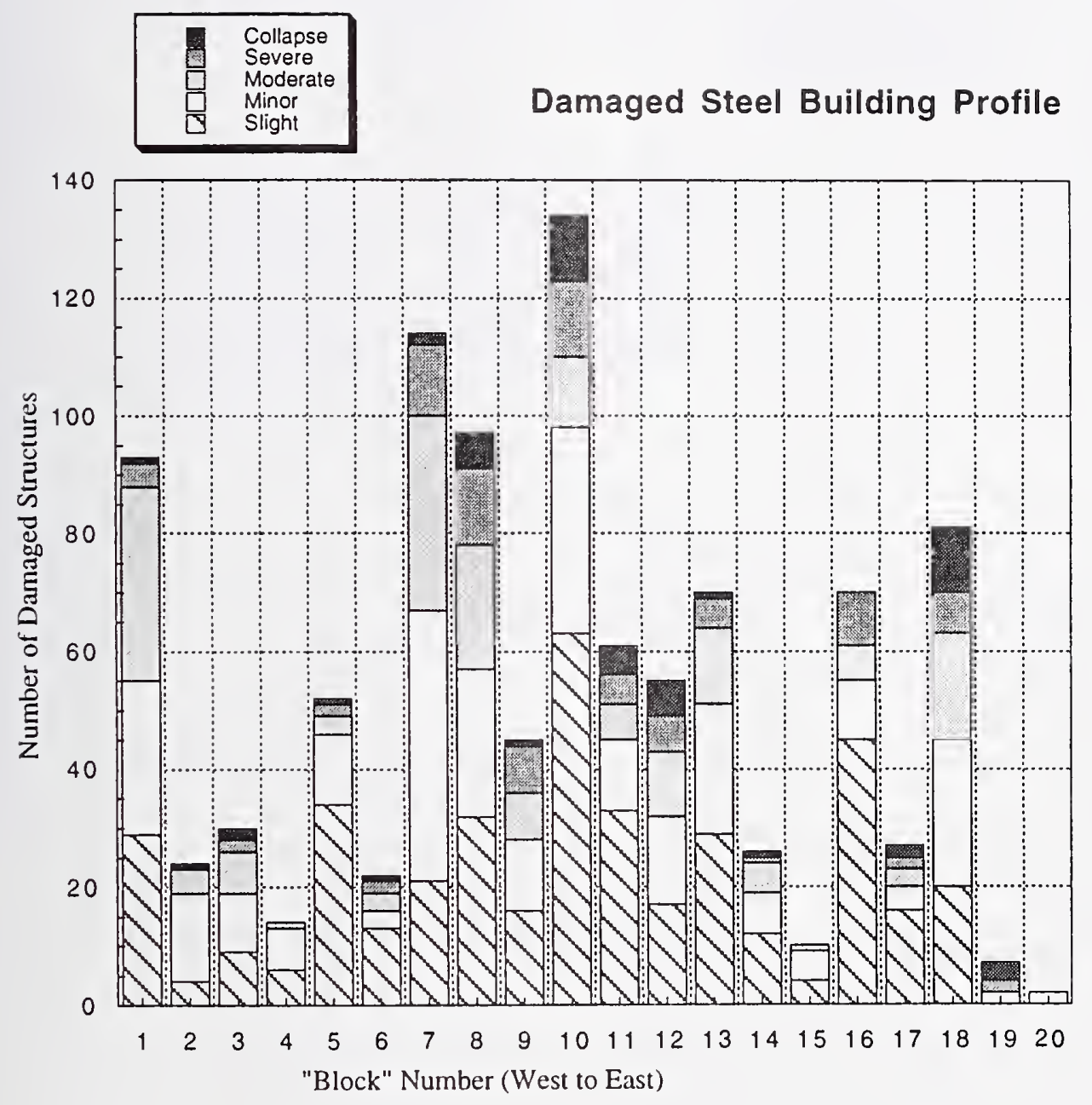

Figure 3.8.2 Kobe Damage Survey: All damaged Steel frame structures. 


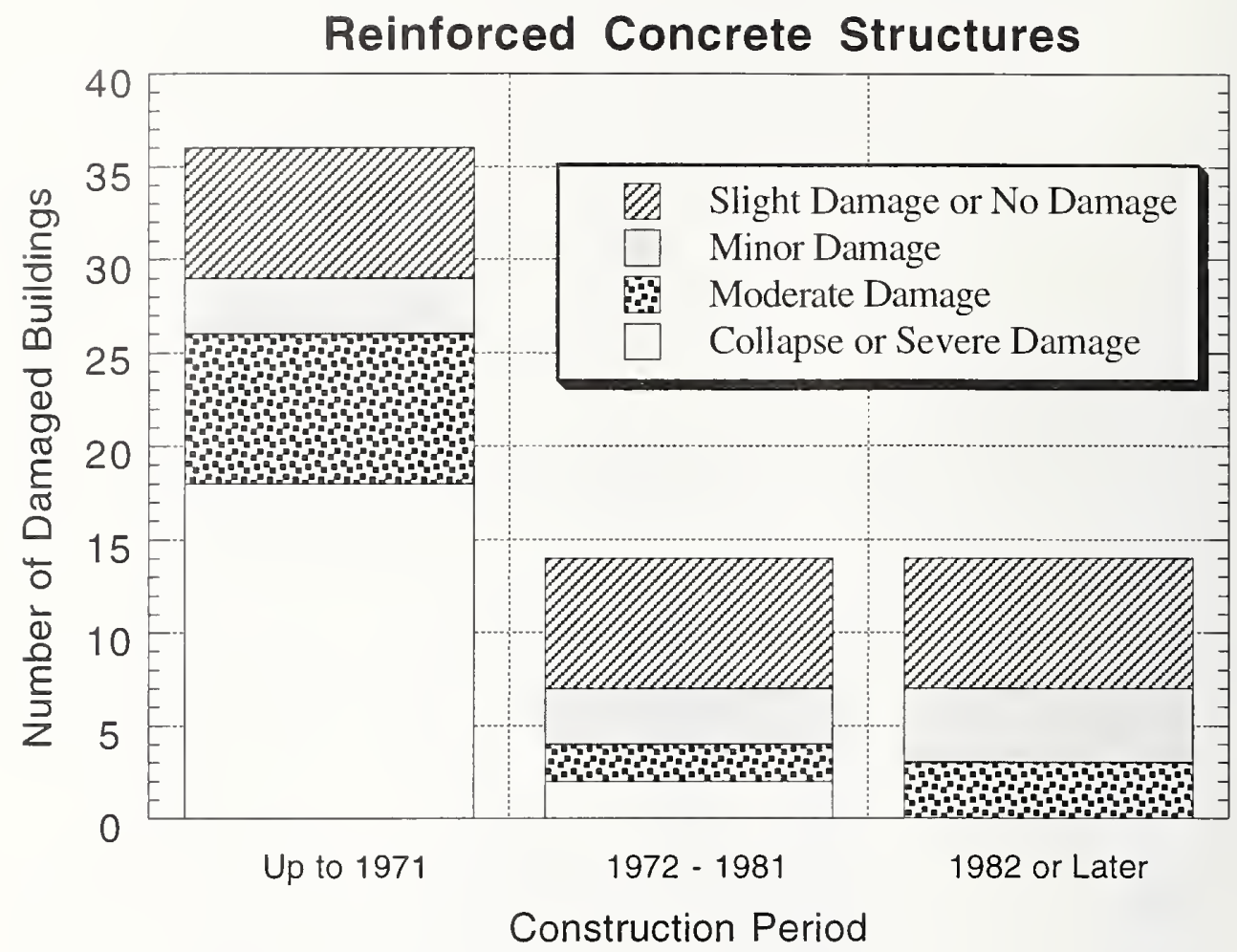

Steel Structures

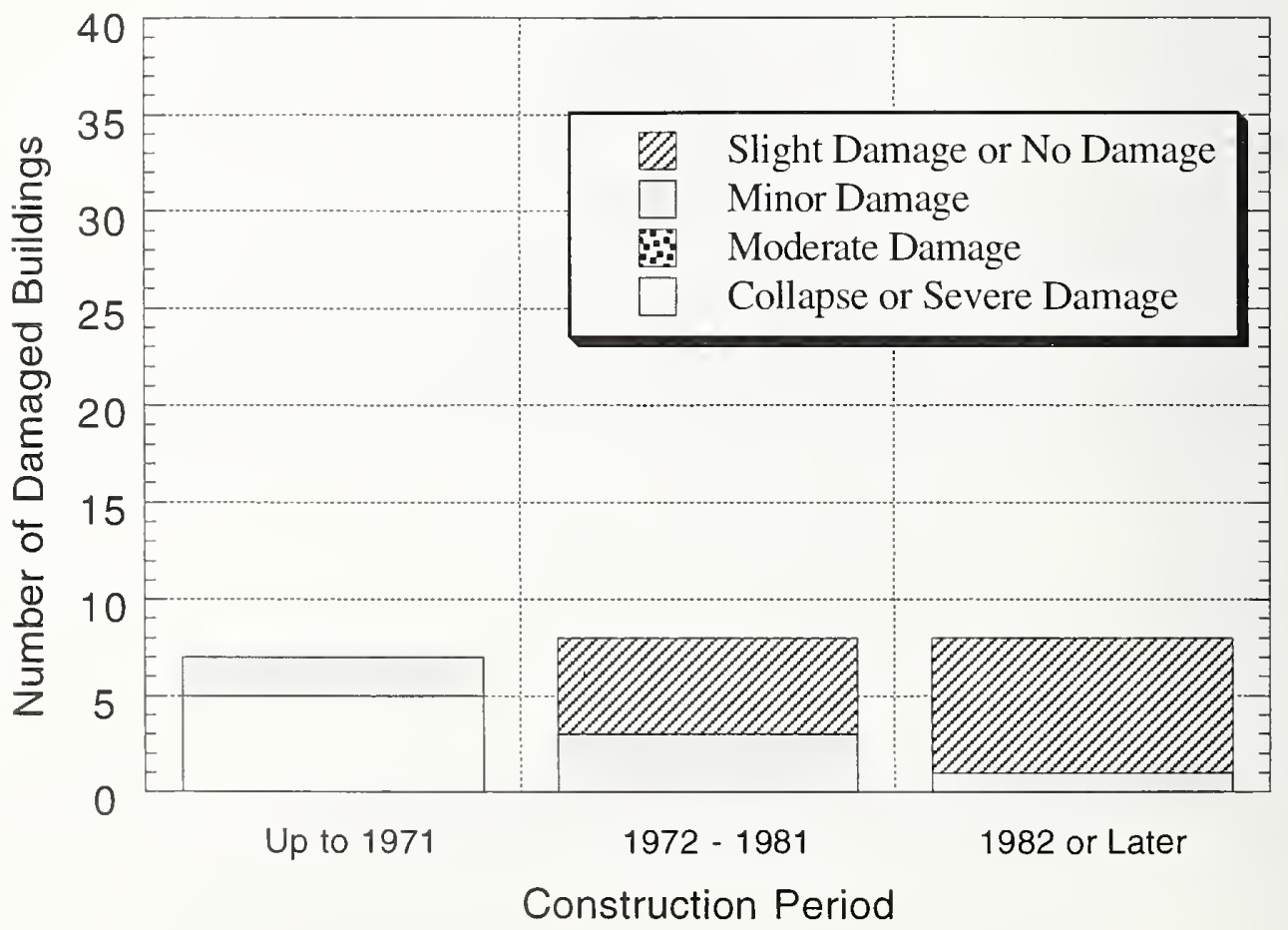

Figure 3.8.3 Damage level of RC and Steel structures with respect to the year of construction. 


\section{CHAPTER 4}

\section{PERFORMANCE OF TRANSPORTATION SYSTEMS}

\subsection{Introduction}

The Hyogoken-Nanbu earthquake caused damage to transportation facilities throughout the Kansai region, severely hampering rescue and recovery operations and crippling the flow of commerce. Observations on the performance of selected highway, rail, airport and port facilities are given in this chapter.

The elevated expressways and rail systems in the region were completely severed, creating extreme hardship to the public. Although rail service is being rapidly restored, it will be several years before the highway and rail systems are fully operational. Predominant types of observed bridge damage included massive shear and flexural failure of reinforced concrete columns and piers, local buckling of steel columns, numerous failures of both moveable and fixed bearing supports, and probable failure of foundations from lateral spreading of the ground and liquefaction.

The new Kansai International Airport performed well, with no reported structural damage to the air traffic control tower, while the older Osaka airport experienced cracking of a runway. The Osaka air traffic control tower experienced cracked shear walls, cracked glass, and had an inoperative elevator following the earthquake.

Permanent ground deformation and liquefaction disabled facilities at the Port of Kobe, the world's third largest port. Lateral spreading around the cargo loading areas of the port resulted in severe damage to most of the dockside gantry cranes, thus closing the port facility. Complete restoration is estimated by Japanese engineers to take about three years.

\section{The earthquake caused severe damage to transportation facilities throughout the Kansai region, severely hampering rescue and recovery operations and crippling the flow of commerce.}

There are two important features of the Kobe area which had a major impact on the seismic damage suffered by transportation systems in the Hyogoken-Nanbu earthquake. The first is the coastal topography of the Kobe area; the second is the surface soil conditions along the margins of Osaka Bay.

The general layout of Kobe is shown in Figure 4.1.1. Kobe is squeezed into a narrow strip of land, bounded by mountains on the north and Osaka Bay on the south. The city is aligned roughly in an east-west direction, and all surface transportation routes are located within a band only three kilometers wide in some areas. The Shinkansen, or "Bullet Train" line, also runs near Kobe, through an east-west tunnel in the mountains just north of the city. The transportation routes shown in Figure 4.1.1 not only serve Kobe, but they are also the primary links between the eastern and western parts of Japan's main island, Honshu. 
Because land and space is at a premium in Koloc, many transportation routes are located adjacent to or on top of one another. For example, over a distance of about $30 \mathrm{~km}$, National Route 43 and the Kobe Line of the Hanshin Expressway (also known as Route 3), occupy the same alignment: Route 43 runs along the surface, and the Kobe Line runs along a viaduct above. In locations where the elevated Kobe Line collapsed or was severely damaged during the Iyogoken-Nanbu carthquake, both the surface Route 43 and the elevated Kobe Line were impassable. Rail lines are also routed closely together, with three separate rail systems occupying the same right-of-way in some locations. The tunnels of the municipal subway system run bencath major urban strects in Kobe. Cut and cover subway stations collapsed during the carthquake, causing surface subsidenec of over $1 \mathrm{~m}$ in some locations.

Bridges in the central and eastern United States are more like those in Japan than those in California. The performance of Japanese bridges is therefore of particular relevance to states east of the Sierra Nevada mountains.

Thus, because the local topography dictates that all major transportation routes pass through a narrow corridor, the routes are crowded together. Unfortunately this corridor lay directly above the ruptured fault zone of the carthquake, so all major transportation routes in Kobe were severely damaged by the carthquake. This crippled not only the transportation infrastructure in Kobe, but also the main cast-west transportation corridor on the island of
Honshu.

The second characteristic which strongly intlueneed the seismic performanee of transportation structures in Kobe was the presence of poor ground conditions, especially along the bay shore. Historically, the land area of Kohe has been extended by filling the bay. Over the years the shoreline of Osaka Bay has been reshaped with numcrous port and inclustrial facilities constructed on reclaimed land. Figure 4.1.2 shows the extent of artificial fill in Osaka Bay. Some areas along the shoreline were filled over two centuries ago. The largest recent reclamation projects include Port Island (No. 10 on the map), Rokko Island (No. 12), and Kansai International Airport (No. 50).

Many artificial fill cleposits, especially older "non-enginecred" fill, are prone to licpucfaction and lateral spreading during carthquakes. However, out of necessity transportation routes have been constructed on artificial fill in and around Kobe. Figure 4.1.2 shows that several major highways are constructed on reclaimed land. For example, the Wangan, of "Bay Shore" route of the Hanshin Expressway system rings the entire bay from Kansai International Airport on the south to Kobe on the north. (The portion of the Bay Shore route shown in Figure 4.1.2 to the west of Rokko Island is planned, but has not yet been constructed). Several bridges on the Bay Shore route to the east of Rokko Island were damaged during the Hyogoken-Nanbu earthepuake.

Figure 4.1.3 shows the soil protile around the perimeter of the bay, along the alignment of the Bay Shore route. The rectangular blocks at the top of the soil strata indicate filled areas. The fill depth along the Bay Shore route is up to $15 \mathrm{~m}$. The figure also shows that the natural soil 
stratum underlying the fill layer is alluvial clay, $10 \mathrm{~m}$ to $15 \mathrm{~m}$ thick in the Kobe area. Soft clay layers such as this tend to filter earthquake ground motions, concentrating the energy of the earthquake at certain frequencies.

The difference between the maximum credible earthquake and the design earthquake, is clearly very large for this region of Japan - a situation that also exists in the United States.

To illustrate in more detail the typical bay side soil conditions near Kobe, a soil boring $\log$ from the site of the Nishinomiya Ko bridge, located on the Bay Shore Route to the east of Rokko Island, is shown in Figure 4.1.4. The eastern approach span of this bridge collapsed during the earthquake. A major cause of the collapse was probably liquefaction of the $10 \mathrm{~m}$ to $15 \mathrm{~m}$ of granular artificial fill soil at the site. When the fill on both banks of the river channel liquefied each bank moved towards the center of the channel. This lateral movement caused the two end piers of the main span to move towards one another, pushing the approach span off its support.

Poor soil conditions in Kobe are not limited to the immediate shore line of the bay. In Figure 4.1.5, two soil profiles along lines perpendicular to the shoreline are plotted. Profile (a) is in the Suma Ward at the west end of Kobe, and profile (b) in Higashinada Ward at the east end of Kobe. The profiles show that soil conditions are highly variable in the area, and that deep clay deposits can occur in areas away from the shore line. Thus, transportation structures throughout Kobe are founded on a variety of soil conditions, ranging from soft clays to competent granular materials, sometimes underlain by soft clay strata. 


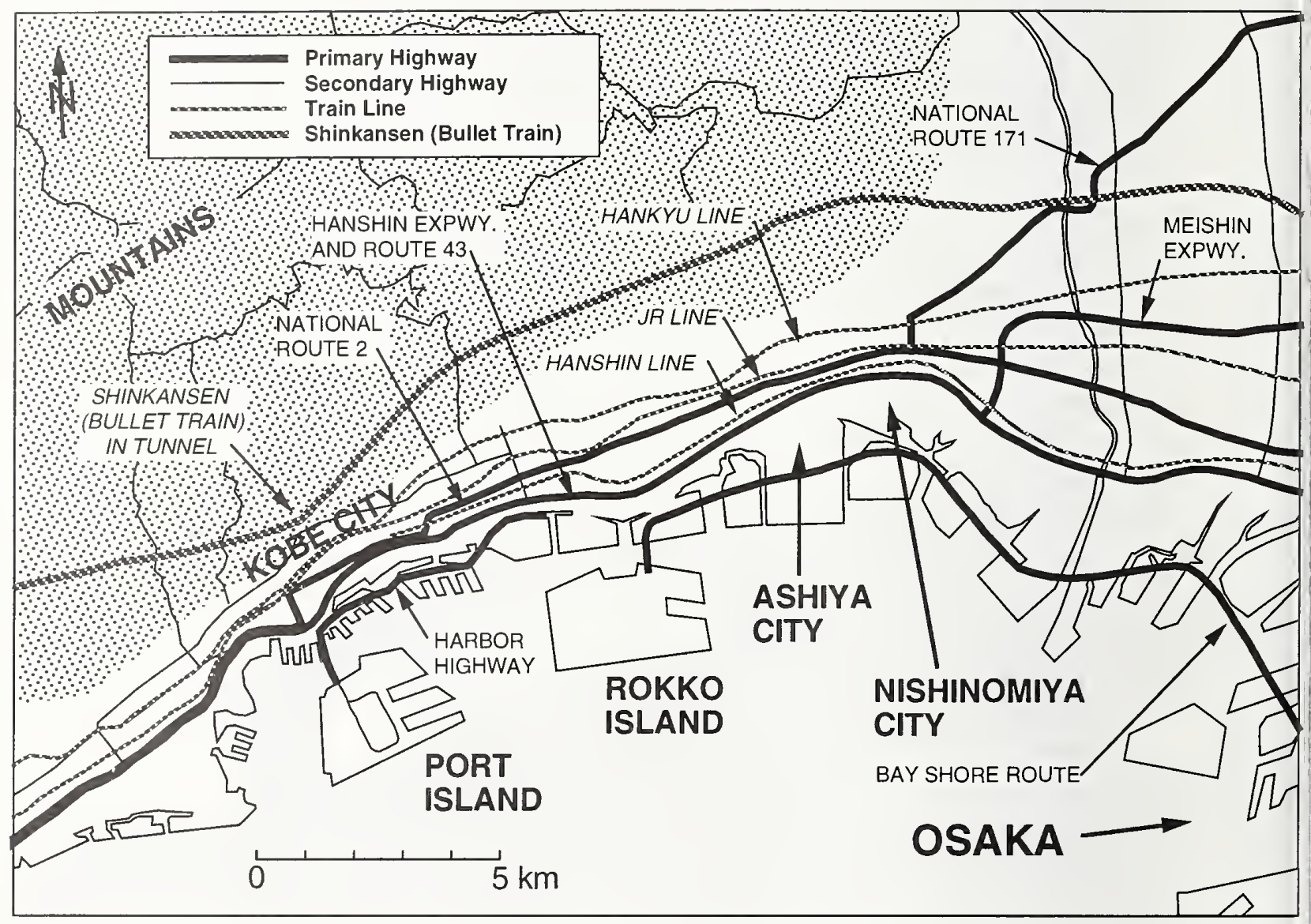

Figure 4.1.1 Major transportation routes through Kobe. 


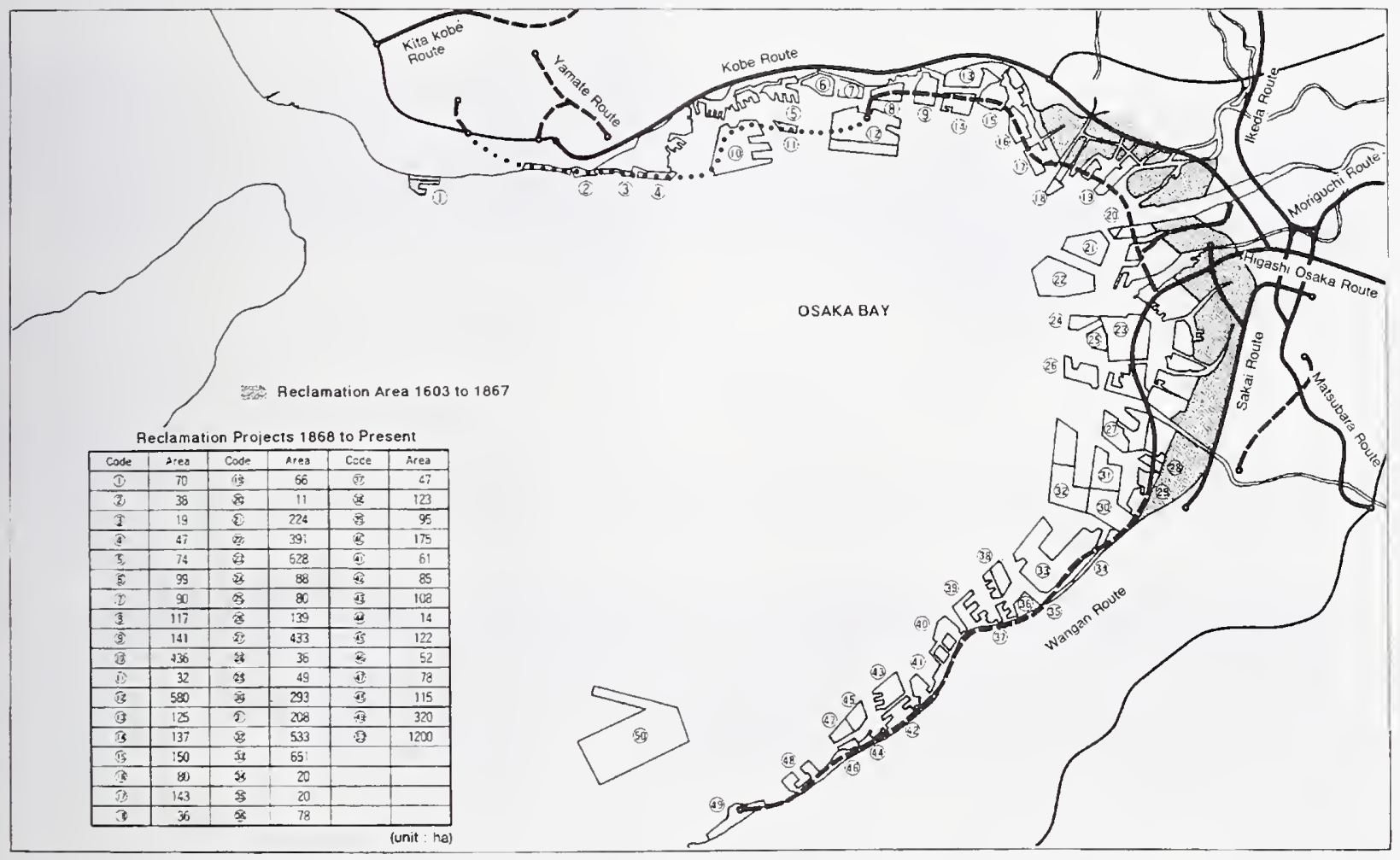

Figure 4.1.2 Artificial fill projects in Osaka Bay. Reproduced from HEPC (1990). 


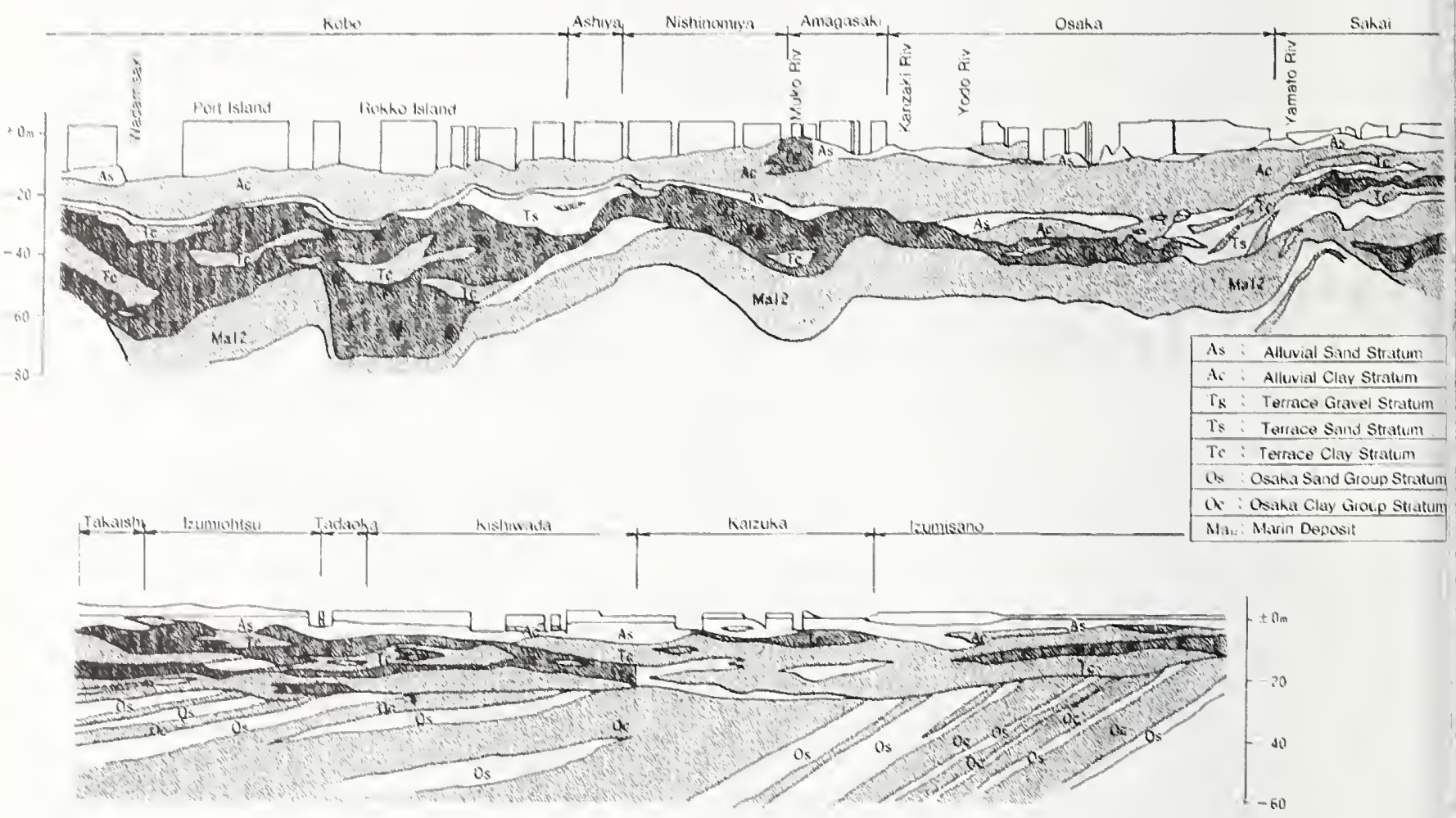

Figure 4.1.3 Soil profile around the perimeter of Osaka Bay, along the alignment of the Bay Shore Routc. Roproduced from HEPC (1990). 


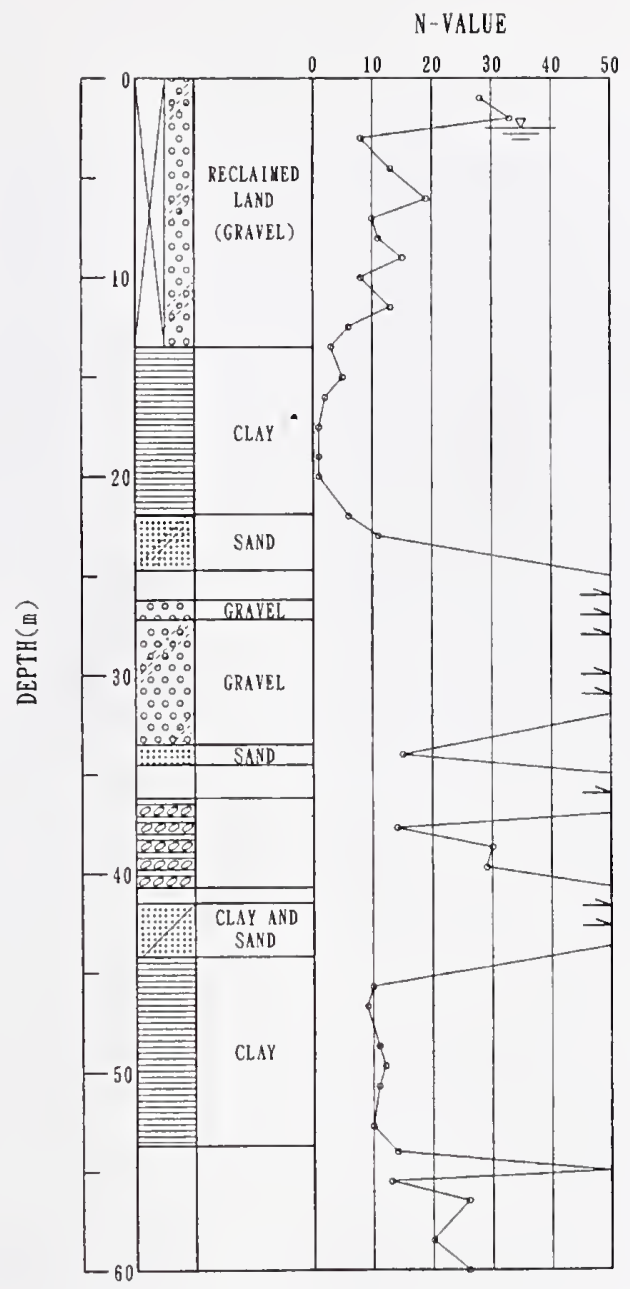

Figure 4.1.4 Soil boring $\log$ at the Nishinomiya Ko bridge, near Nishinomiya Port (Courtesy of the Public Works Research Institute, Ministry of Construction Tsukuba Science City, Japan).

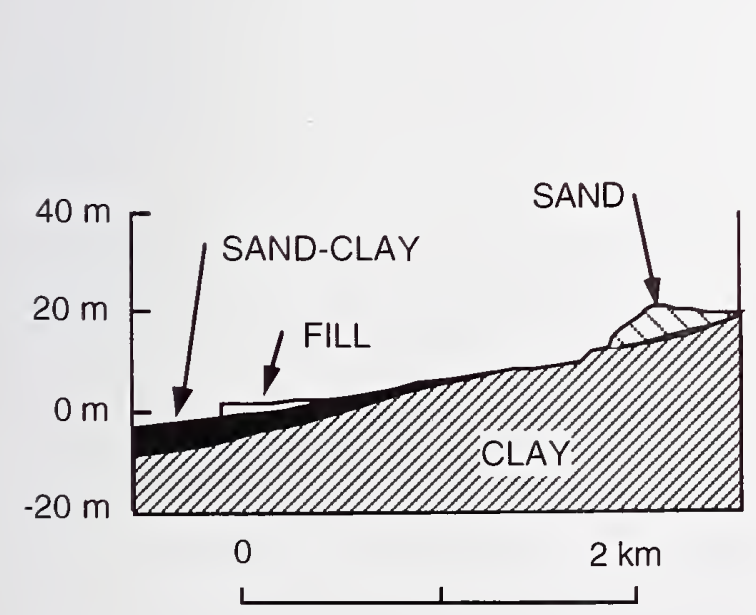

(a)

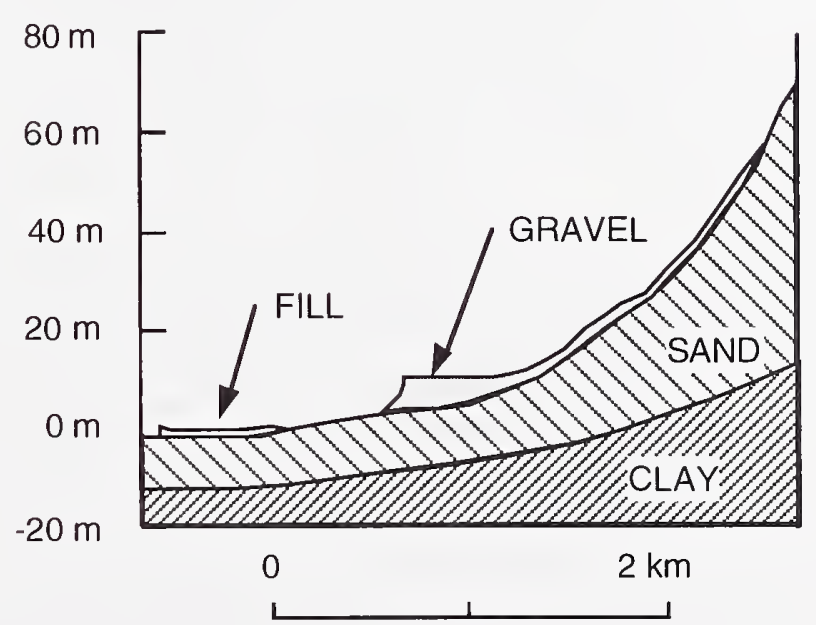

(b)

Figure 4.1.5 Soil profiles along lines perpendicular to the shoreline of Osaka bay. (a) at Suma Ward, at the west end of Kobe; (b) at Higashinada Ward, (b) at the east of Kobe. (Courtesy of the Public Works Research Institute, Ministry of Construction, Tsukuba Science City, Japan). 


\subsection{Highway and Bridges}

\subsubsection{Overview}

The Hanshin region comprises parts of the Hyogo, Kyoto and Osaka Prefectures to the north and east of Osaka Bay. The population of 12.5 million people living and working in the region is served by a complex network of freeways and highways built since the early 1960's. These major transportation routes generally run parallel to the shoreline of Osaka Bay with major links to the east to Nara, to the northeast to Kyoto, and to the west to Himeji. As the mountains behind Kobe approach the Bay shoreline, the east-west routes are forced into a narrow corridor which is barely $3 \mathrm{~km}$ wide in some parts and which must be shared with three major rail lines. Soil conditions vary throughout the region but most of the highway structures are founded on sand-gravel terraces (alluvial deposits) which overlie gravel-sand-mud deposits at depths of less than $10 \mathrm{~m}$. Liquefiable soils are present along the shoreline and in most ports and channels. As a consequence piled foundations are used extensively and caisson foundations are common for those large bridges that are in port areas or cross shipping channels.

Responsibility for the design, construction and maintenance of these highway routes is divided between the Ministry of Construction and two Public Expressway Corporations. Highways under the jurisdiction of the Ministry of Construction are free for public use whereas those owned by an Expressway Corporation are toll roads and road user fees are collected. These latter Corporations are independent but are nevertheless subject to government control and regulation.
The Ministry of Construction (MOC), through the Naniwa National Highway Work Office, has oversight for the National Highways (NH) in the region. These include Routes R-2 and R-43 which join Osaka with Kobe, as well as several other trunk roads such as Routes R-428 (Kobe to Chugoku Expressway), and R-171 (Nishinomiya to Kyoto and Route R-1). These arterial highways are generally surface routes but with some notable elevated sections. These include the Route 2 Hamate Bypass on the Kobe waterfront, the Port Island Connector and the $6.6 \mathrm{~km}$-long, Airport Access Highway to the new Kansai International Airport in Osaka Bay.

One of the two Expressway Corporations noted above is the Japan Highway Public Corporation (JHPC) which is responsible for at least three major freeways (expressways) in the region. These are the Meishin Expressway (the first such expressway in Japan built in the early 1960s) and the Chugoku and Kinki Expressways. The Meishin runs in a northeasterly direction from Osaka Bay (at Nishinomiya) to Kyoto. Both the Chugoku and Kinki Expressways start from Suita City, just to the north of Osaka City, and run west and south respectively.

The second Expressway Corporation noted earlier, is the Hanshin Expressway Public Corporation (HEPC). It is one of the largest such Corporations in Japan and is, today, responsible for approximately $200 \mathrm{~km}$ of freeway-standard highway throughout the Hanshin region. Opened in 1964 with an initial length of $2.3 \mathrm{~km}$ in Osaka, it has grown in both size and capacity during the intervening 30 years. Almost a million vehicles per day used the system in 1994 with the highest traffic counts (131500 per day) being recorded on the four lane, loop expressway in the center of Osaka City. For 
the fiscal year 1993, the average income from tolls was $¥ 340$ million per day (approximately $\$ 3.4$ million). More than $90 \%$ of the system is elevated, supported on about 8500 spans. Of these, $83 \%$ are steel and $17 \%$ are concrete spans [1]. Most substructures are single column concrete bents but single and multi-column steel bents are also used to a significant degree.

Major routes under the jurisdiction of the HEPC are Route 3 (Osaka - Kobe Route) and Routes 4 and 5 (Wangan Route). The Kobe Route was constructed from Nishinomiya to Kobe from 1965 to 1970. The link to Osaka was from 1981 to 1985. The Wangan (Bayshore) Route, which links Kansai Airport in the south (Route 4) to Rokko Island in the east (Route 5), was completed in 1994 although parts of Route 4 had been completed as early as 1990. Both routes were major technical accomplishments at the time of their construction. Average peak weekday traffic volumes in 1994 were 63000 and 18500 for Routes 3 and 5 respectively.

Route 3 is elevated over its entire length and runs above NH 43 from Osaka to Kobe. It is generally supported on single column bents, except at interchanges where ramps and adjoining structures demand additional width and the use of multi-column bents. At the time of its construction it was highly regarded for both its engineering achievement and its aesthetic appeal.

The Wangan Route is also elevated over much of its length but its most remarkable feature is the number of world-class, long span bridges included in its construction. Some of the more notable bridges include: (1) the Minato Gerber truss bridge $(510 \mathrm{~m}$ center span, the third longest truss span in the world); (2) three cable-stayed bridges including the Higashi-Kobe bridge $(485 \mathrm{~m}$ center span, the eighth longest cable-stayed span in the world); (3) two Nielsen-Lohse tied-arches including the Nishinomiya-ko bridge (252 m span); and (4) two Lohse tied-arches including the Rokko Island bridge (217 m span).

The HEPC has an active maintenance program and currently spends about $¥ 30$ billion per year (approximately $\$ 300$ million) in this area [1]. It also has an ongoing seismic retrofit program and has for many years used earthquake couplers to restrain the free ends of simply supported girders. The Corporation has recently begun to investigate the use of steel jackets for improving the performance of concrete columns and has installed some trial jackets on single column bents at the west end of Route 3.

Seismic design criteria for new structures meet or exceed those required by the Japan Road Association [2,3]. Furthermore the HEPC has been proactive in the use of energy dissipators in bridges and, as early as 1981, completed the Yoshino-Tamagawa Viaduct on Route 3 in Osaka, using viscous shearing dampers. More recently, the HEPC has constructed two menshin (base isolated) bridges on Route 4 (the Wangan Route near the new Kansai Airport). These are the 4-span, Matsunohama bridge (1994) and the 6-span, Izumisano bridge (1994); both use lead-rubber bearing (LRB) isolators. The Matsunohama bridge is instrumented for strong ground shaking with 9 accelerometers and a 23-channel data acquisition system.

\subsubsection{Observed Damage}

A large number of bridges were damaged in this earthquake and one estimate of the affected number is on the order of $60 \%$ of the total inventory. An exact number is 
difficult to count because of the use of long elevated sections that are tens of kilometers in length and the line where one bridge (or segment) ends and another begins is difficult to determine. Furthermore, several structures at the same interchange may be identified, in some damage reports, as one "bridge." Accepting these limitations, the number of highway "bridges" that sustained major damage (including collapsed spans) is of the order of 27. Many more suffered moderate-to-minor damage such as pounding, spalling of cover concrete and settlement of approach fills.

The 27 structures that were severely damaged by this earthquake, are listed by route number in Table 4.2.1 and by name in Table 4.2.2. Figure 4.2.1 shows the location of 16 of these structures. These sites were visited by the UJNR team from February 13 to $17,1995$.

It is seen in Table 4.2.1 that the HEPC suffered the largest loss, most probably because it has the largest inventory of elevated structures of any agency in the Hanshin region. The HEPC estimate for the direct cost of this damage is $¥ 460$ billion (approximately $\$ 4.6$ billion). Average traffic counts fell from 920000 to 500000 vehicles per day leading to a loss in toll revenue of $¥ 200$ million per day. According to the Hyogo Prefectural Police, 16 persons died in vehicles on the Hanshin Expressway and 280 vehicles were abandoned. The number of piers sustaining moderate-to-large scale damage on Route 3 has been estimated to be 637. Corresponding numbers for spans and bearings are 552 and 679 respectively. If all categories of damage are included, the HEPC estimates that the number of damaged spans on Route 3 is in excess of 1300 [4].
Of the two routes, R-3 and R-5, Route 3 is older by about 30 years and this probably accounts for the higher damage rate compared to that on the newer Route 5. Approximately 700 columns on Route 3 will be temporarily repaired and about 50 spans will be replaced before it is opened to traffic. Eventually, about 200 of these 700 columns will be replaced and the remainder will be strengthened to meet new seismic design criteria. By contrast, Route 5 performed considerably better despite poorer soils and difficult foundation conditions. The most likely reason is the improvement in the seismic codes during the intervening 30 years and the fact that a major revision was completed to the design specification in 1990 [2,3]. This revision was in effect during the design of some, but not all, of the structures on this route.

\section{The most likely reason that Route 5 performed much better than Route 3 is the improvement in the seismic codes during the intervening 30 years} and the fact that a major revision was completed to the design specification in 1990.

Typical damage sustained by these structures includes shear and flexural failures in nonductile concrete columns, flexural and buckling failures in steel columns, steel support bearing failures under lateral load, and foundation failures due to liquefaction. In addition there was pounding between spans, failure of several earthquake couplers and settlement of many approach fills. Not so typical was the failure of a skewed bridge on pin-ended columns and the fracture of a set of holding down bolts in a wind shoe of 
a cable-stayed bridge, which then led to failure of the seismic energy dissipators and other hardware at this location. This performance is described in the following sections.

\subsubsection{Damage to Superstructures Due to Bearing Failures}

Many bridge bearings were damaged during this earthquake and in general these failures can be grouped into three categories:

(a) primary bearing failures which caused member distress elsewhere in the bridge and, in extreme cases, triggered collapse.

(b) secondary bearing failures which were the result of structural failures elsewhere in the bridge and caused by the redistribution of load for which the bearings were not designed and which led, in extreme cases, to collapse; and

(c) fuse-like bearing failures of either the primary or secondary kind that relieved the supporting substructures of load, protecting them from major damage and preventing collapse.

Four examples of Type (a) damage, i.e., examples of bearing failures which appear to have been the primary reason for bridge damage and/or collapse, are given below. They are the Nishinomiya-ko, Rokko Island, Mukogawa and Hamate Bypass bridges. Other sections in this report note secondary failures (Type(b)) and Section 4.2.2.3 presents an example of Type (c) behavior.

The Nishinomiya-ko bridge $(8)^{*}$ carries Route 5 over one of the shipping entrances to the port of Nishinomiya (Figure 4.2.2a). It is one of the longest Nielsen-Lohse Arch bridges in the world with a main span of 252 $\mathrm{m}$ and a rise of $42 \mathrm{~m}$. Constructed in 1993, this all-steel tied-arch weighs approximately 8000 tonnes and is supported on 4 bearings:
2 fixed bearings at the west end (Pier 110) and 2 expansion bearings at the east end (Pier 111). Both Pier 110 and 111 are steel towers that are approximately $25 \mathrm{~m}$ high from top of foundation to bearing level. Each foundation is a concrete caisson extending to depth of about $23 \mathrm{~m}$ below ground level. Soils include reclaimed gravels on alternating layers of saturated clays, sands and gravels. N-values range from 2 to 20 over the first $20 \mathrm{~m}$.

At the east end, the first two approach spans (Piers 111 - 112 and Piers 112 - 113) are simply supported steel girders on steel piers and are $54 \mathrm{~m}$ and $62 \mathrm{~m}$ long respectively. The next three spans (Piers 113 to 116) are a continuous steel box girder of total length $183.5 \mathrm{~m}$; they are also supported on steel piers that are about $23 \mathrm{~m}$ high. Support conditions for these piers are given in Table 4.2.3. Earthquake couplers are provided in the longitudinal direction at all movement joints. In general these are a pair of $25 \mathrm{~mm}$ steel plates that have either one or two slotted holes to accommodate up to +300 $\mathrm{mm}$ before engagement. Plate sizes vary but are on the order of $950 \mathrm{~mm} \times 250 \mathrm{~mm}$.

Damage sustained during the earthquake included failure of one of the fixed bearings under the arch span at Pier 110 and collapse of the first span on the eastern approach (Figure 4.2.2b). This simply supported span fell from its support at Pier 111 but retained its seating on Pier 112. Ground movements measured after the event showed permanent offsets in the position of several piers probably due to lateral spreading of the soils during liquefaction. Secondary damage

\footnotetext{
"Numbers in parenthesis refer to bridge sites shown in Figure 4.2.1
} 
included anchorage failure in one of the cables between the arch rib and tie beam; failure of all of the restrainers at Pier 111; and failure of the bearings, couplers and expansion joints at Pier 112 and Pier 113 (Figure 4.2.3). It seems likely that the collapse began with the failure of one of the fixed bearings at the western end of the arch span (i.e., at Pier 110). These bearings have a gravity load rating of 4500 tonnes each.

Their lateral load capacity is 2800 tonnes in the longitudinal direction and 1400 tonnes in the transverse direction. Since the weight of the span is in excess of 8000 tonnes, the longitudinal capacity of the pair of fixed bearings is about $70 \%$ of the weight. Given the high ground accelerations in the area, and the probable uneven distribution of load between the pair of bearings, it is quite possible that the capacity of one of the pair was exceeded, leading to its failure. If this occurred during a half cycle of loading towards the west, then substantial longitudinal loads would have been transferred to the opposite end of the arch tearing the restrainers out of the webs of the girders in the approach span (Figure 4.2.4). At the same time the fixed bearings at this pier (Pier 111) would have been heavily overloaded and failure would follow immediately. In subsequent cycles the reversed motion of the arch and the lateral movement of Pier 111 towards the center of the channel led to the unseating of the approach span and its collapse from Pier 111.

The Rokko Island bridge (11) at the west end of Route 5, was completed in 1992 and gives access to Rokko Island in Osaka Bay. This single span, steel, tied-arch spans $217 \mathrm{~m}$ and rises $36 \mathrm{~m}$ above its springings (Figure 4.2.5). It varies in width from $16.25 \mathrm{~m}$ at the south end (Rokko Island) to $26.5 \mathrm{~m}$ at the north end (Ashiya City) to accommodate on ramps to the expressway. It follows that the ribs of the arch, although vertical, are not parallel to each other. They are held in this position by transverse floor beams at the deck level and by crossbracing members in the plane of the rib. The arch is supported at each end on two multi-column steel bents which are about $26 \mathrm{~m}$ high. All major structural members (archribs, tie beams and bent columns) are boxed, single cell, steel members fabricated from $50 \mathrm{~mm}$ plate and stiffened internally.

The arch weighs 6450 tonnes and is supported on four steel bearings, two at each end of the span. The fixed bearings are at the northern end (the wide cnd); the expansion bearings are at the southern end. Reaction loads are greater at the fixcd end because of its greater width. Rotation is permitted but translation prevented (both transversely and longitudinally) at all bearings except at the south end where the expansion bearings permit longitudinal movements to occur. These expansion bearings use nested rollers to accommodate movement in this direction and guide rails to prevent movement normal to the span. The guide rails are expected to transfer wind and seismic loads that are normal to the span of the arch. Normal practice is to design these restraints to resist a seismic load equal to 1.5 times the product of the scismic coefficient and the dead load reaction.

During the earthquake the guide rails at the expansion bearings failcd under transverse loading, allowing the south end of the truss to displace laterally a distance of about $3 \mathrm{~m}$ to the east across the bent cap (Figure 4.2.6). The arch came to rest with the east rib overhanging the end of the cap beam and as a consequence twisted the superstructure about its longitudinal axis (Figure 4.2.7). The racking of the superstructure caused buckling in the crossbracing in the plane of the ribs 
particularly in those panels just to the south of the midspan cross-member (Figure 4.2.8).

When constructed 3 years ago, this bridge was prefabricated in a shipyard to the west of Akashi-Kaikyo (Akashi Strait), transported by barge to the site and lifted into place by six floating cranes. Repair is also expected to involve floating cranes and the lifting of the south end off of the damaged bearings, followed by realignment on the supporting bent. Replacement of the buckled crossbracing and the damaged expansion joints will then be possible.

The Mukogawa bridge (13) on the Meishin Expressway, is a dual carriageway, six-span steel girder structure on concrete, single-column bents (Figure 4.2.9). Built in 1963, each carriageway is an independent structure and comprises three, $2 \mathrm{~m}$ deep plate girders with concrete deck slab and diagonal crossbracing in the plane of the lower flange. Two 3-span continuous segments make up the six spans. The length of each span is $46.5 \mathrm{~m}$ and is skewed to the support line by about $30^{\circ}$. The total length of the bridge is slightly over $280 \mathrm{~m}$ with an overall carriageway width of about $10 \mathrm{~m}$. All substructures are single, circular, concrete columns with hammerhcad cap beams. Each column is tapered to a depth of about $7 \mathrm{~m}$, at which point it is founded on a single large-diameter shaft that extends a further $24 \mathrm{~m}$ to stable gravel beds and stiff clays. The abutments are also founded on large-diameter shafts. The columns for Piers 1 and 5 are almost completely buried leaving only the hammerheads above ground level. All girders are supported on steel pin-type bearings, with and without sliding plates to provide for expansion as necessaly. Where sliding plates are installed beneath the pin assembly, guide bars are also provided to prevent lateral movement and restrain uplift (Figure 4.2.10). The location of the fixcd and cxpansion bearings are given in Table 4.2.4.

Longitudinal earthquake couplers were installed in the bridge between 1985 and 1990 as a retrofit measure to address inadequate seat widths in the longitudinal direction. These steel plate restraincrs are located at the abutments and connect the web of each girder directly to the adjacent back wall of the abutment. They are intended to be effective in the longitudinal direction only (the unrestrained expansion direction) and offer no restraint transversely; the bearing guide bars are expected to resist loads in this direction.

During the earthquake, the bearings at the west abutment (A1) failed in transverse loading due to a combination of anchorage pull-out and guide bar distortion.

Transverse loads were then transferred to the earthquake couplers which also failed, since they were now loaded in an unintended direction. Several were stripped from the abutment back wall while at the same time bending the webs of the deck girders about their weak vertical axis and imposing severe plastic distortion in these sections (Figure 4.2.11).

The loss of restraint at the abutment led to a redistribution of load to the intermediate piers and the overload of Piers 1 and 3 . It was obscrved that Pier 1 was almost completely buried over its full height and this may have been the reason it received a disproportionally high share of the seismic load after the abutment released its load. Once excavated, both columns at this location showed flexural distress in the upper third of their height, which, because of the taper, is the section of least strength in flexure and shear (Figure 4.2.12). These nonductile columns have inadequate transverse steel for confinement and shear 
reinforcement to satisfy current performance criteria. Some damage is therefore to be expected during strong ground shaking. In this earthquake, there appeared to be no residual misalignment in the columns and thus repair (to the columns) should be a straightforward exercise.

The Hamate Bypass (16) is a two level elevated viaduct carrying Route 2 along the Kobe waterfront. Longer spans are continuous steel box girders supported on steel bents constructed from single cell, internally stiffened, box sections. These dual-column bents support the upper and lower decks at about $22 \mathrm{~m}$ and $10 \mathrm{~m}$ above the ground respectively. Overall widths at the carriageway levels are about $15 \mathrm{~m}$ except where ramps and emergency stopping shoulders are accommodated. Column cross sections are about $2.8 \mathrm{~m} \times 2.2 \mathrm{~m}$. All girders are supported by either fixed or expansion steel bearings at these bents. Transverse restraint is provided by the bearings at all locations. Several sections of this elevated structure were damaged during the earthquake and the section from Pier 34 to Pier 38 suffered bearing damage with large lateral offsets at Pier 36 (Figure 4.2.13). This four span section is comprised of two, 2-span, continuous box girders of approximately equal length. All bearings at all five bents under the upper deck appear to have failed. The lack of transverse restraint then led to rotation of the upper level girders about a vertical axis. Both segments appear to have rotated clockwise about their respective end supports at Piers 34 and 38. This then imposed a large lateral displacement (estimated to be of the order of $3 \mathrm{~m}$ to $4 \mathrm{~m}$ ) at the opposite end of each segment (i.e. at Pier 36). Since these displacements are of opposite sign, the relative displacement, parallel to the expansion joint, at this pier is of the order of $6 \mathrm{~m}$ to $8 \mathrm{~m}$. A generous cap width in the transverse direction prevented collapse and limited the damage to the bearings, expansion joints and appurtenances (guardrails, drain pipes and the like). It is possible that this is an example of Type (c) bearing behavior, where failure of the transverse restraints at Piers 34 through 38 has relieved these piers of seismic load, protecting them from major damage.

\subsubsection{Damage to Concrete Substructures}

Although several hundred concrete piers were damaged in this earthquake, almost all were designed and constructed in the 1960's and early 1970's without the benefit of modern codes and recent developments in seismology and ductile design. Typical damage involved shear failures in shorter, under-reinforced columns. Flexural failures were also evident in taller columns that lacked adequate confining steel or terminated vertical steel in areas of high moment. Splice failures in this reinforcement were also common especially those splices that had been butt welded in regions of high moment.

\section{Almost all the several hundred concrete piers damaged in this earthquake were designed and constructed in the 1960's and early 1970's without the benefit of modern codes and recent development in ductile design.}

This section presents examples of these failures by summarizing the damage sustained to two sections of the Hanshin Expressway Route 3 (Higashi-Nada Viaduct and Pier 240), the Takarazuka Viaduct on 
the Chugoku Expressway, and the Moribe

Viaduct on the Meishin Expressway.

Reference is also made to the damage sustained by the Kobe-Oohashi distribution structure and the Route 3 structures at Minatogawa and Takatori (Pier 688).

Constructed in 1969, the Higashi-Nada Viaduct (3), also known as the Hirata-Fukae Viaduct, is an 18 span segment of the Hanshin Expressway on Route 3. It is the only segment of this Route which has both a concrete superstructure and concrete substructures. The superstructure is a series of $35 \mathrm{~m}$ prestressed concrete spans with a total length of $635 \mathrm{~m}$ (13 spans are $35 \mathrm{~m}$ long and 5 spans are $36 \mathrm{~m}$ long). Each span consists of two $6.5 \mathrm{~m}$ cantilevers that are monolithic with the columns, one at each end of the span, and a $22 \mathrm{~m}$ drop-in girder a form of construction that was popular in Europe in the 1960's and given the name "piltz" construction from the German word for "mushroom." The overall width of the superstructure is $20.25 \mathrm{~m}$ with an effective carriageway width of $15.5 \mathrm{~m}$.

The substructures are single column bents that are $3.3 \mathrm{~m}$ in diameter and vary in height from about $10.5 \mathrm{~m}$ to $12.5 \mathrm{~m}$, measured from the top of the piled footings to the underside of the cap beam. Vertical reinforcement at the bottom of a typical column comprises $180 \mathrm{~mm} \times 35 \mathrm{~mm}$ diameter bars arranged in 3 equal concentric layers. The inner layer is terminated at $3.5 \mathrm{~m}$ above the footing; the remaining two layers extend over the full height of the column and into the cap beam. Transverse steel comprises three circular hoops of $16 \mathrm{~mm}$ bars (one around each layer of vertical steel) at a vertical spacing of $300 \mathrm{~mm}$ in the central third of the column height and 200 $\mathrm{mm}$ in the end zones.
All foundations are piled footings that vary in size from $10.5 \mathrm{~m} \mathrm{x} 9.5 \mathrm{~m}$ to $13.8 \mathrm{~m} \mathrm{x} 11.5$ $\mathrm{m}$ with a minimum thickness of $2 \mathrm{~m}$. The number of $1 \mathrm{~m}$ diameter concrete piles supporting each footing varies from 16 to 20 , with lengths from $11 \mathrm{~m}$ to $15.5 \mathrm{~m}$.

All 17 single-column bents of this viaduct, from Piers 126 to 142, collapsed on their side during the earthquake (Figures 4.2.14 4.2.16). The failure mode appears to have been a flexural failure at the base of each column under strong transverse loading. The termination of one-third of the column vertical steel at one-third of the column height meant that this steel was largely ineffective in the potential plastic hinge zone and the section lacked the capacity (and probably the confining steel) to develop a stable plastic hinge. Collapse was due to uncontrolled (irreversible) inelastic rotation at the base of each column.

It is estimated that about 700 columns along Route 3 were damaged to some extent and of these 700 columns, about 200 will need replacement. Typical of this damage is the section from Piers 238 to 241 of Route 3 near Uozaki (4). This 3-span segment is a continuous, steel, twin-spine superstructure supported on single column bents and piled footings (Figure 4.2.17). Each spine is a $3 \mathrm{~m}$ deep single-cell box girder with spans of $55 \mathrm{~m}, 87 \mathrm{~m}$ and $55 \mathrm{~m}$. All piers have hammerhead cap beams that measure $16.2 \mathrm{~m}$ in overall length. Their width is constant at $3 \mathrm{~m}$, but their depth varies from $1.5 \mathrm{~m}$ at the free end to $3.3 \mathrm{~m}$ over the column. Two pairs of steel bearings support the two box girders over each cap beam. These restrain lateral movement and uplift while permitting rotation and longitudinal movement at all locations except at Pier 240 where the bearings are also fixed against longitudinal expansion (See Table 4.2.5). Principal dimensions for the columns, 
footings and piles are also given in Table 4.2.5.

During the earthquake, Pier 240 failed catastrophically in longitudinal shear despite the fact that it was clearly designed to resist large lateral loads (Figures 4.2.18 and 4.2.19). As the only fixed pier in this 3-span segment, all longitudinal load was attracted to this pier and it is clear from the relative sizes of the four substructures supporting this segment (Table 4.2.5) that this was anticipated by the designers. Nevertheless inadequate transverse steel was provided in this pier to allow ductile flexural hinging to occur before the onset of a brittle failure in shear. Once this column split along a diagonal line from upper right corner to lower left (when looking north at the pier) the column shortened in height and vertical support for the box girder was lost. The girder then sagged over Pier 240 and attempted to rotate about Pier 239. Since it was held down at Pier 238 by a bearing of type S0-36 (Table 4.2.5), large compressive forces were generated in the lower flanges of the box girders in the end span from Pier 238 to Pier 239. These forces exceeded the elastic limit and compressive buckling occurred in the lower flanges and webs of these girders (Figure 4.2.20). Pier 241 also sustained structural damage but not as severe or as catastrophic as its neighbor, Pier 240. The difference in support fixity between these two piers is probably the reason for this difference in damage level.

The Takarazuka Viaduct (15) is located on the Chugoku Expressway about $30 \mathrm{~km}$ northeast of Kobe (Figure 4.2.21).

Constructed in 1970, it is a 10 span viaduct of total length $172 \mathrm{~m}$. Two carriageways are carried on two independent substructures. Each superstructure is a continuous hollow concrete slab and is supported on concrete multi-column bents. Steel bearings connect the superstructure to the free-standing columns; there is no cap beam below the bearings. The superstructure is comprised of two 5-span segments from the west abutment to Pier 5 and from Pier 5 to Pier 10. A separate elevated structure extends east from Pier 10. All spans are $17.2 \mathrm{~m}$ in length; support fixity is given in Table 4.2.6.

Each multi-column bent consists of three rectangular columns, all founded on piled footings. Piers 2 and 3 are approximately $4.5 \mathrm{~m}$ high from top of footing to top of column, and Piers 7 and 8 are about $9 \mathrm{~m}$ high over the same distance. The footings under the fixed piers (Piers 2, 3, 7 and 8) are supported on 23 piles of uncertain diameter and length. Those under the expansion piers are supported on either six or eight piles depending on location. Individual columns are about $2.4 \mathrm{~m} \times 1.2 \mathrm{~m}$ in size and oriented so that the strong direction is transverse to the span. They are typically reinforced with 36 vertical bars that are $35 \mathrm{~mm}$ in diameter. Footings for the fixed and expansion piers are approximately $9.5 \mathrm{~m} \times 11.5 \mathrm{~m}$ and $4.25 \mathrm{~m} \times 10.5 \mathrm{~m}$ respectively.

Damage sustained during the earthquake implies strong ground shaking in the longitudinal direction. Piers 2 and 3 failed catastrophically in longitudinal shear under both carriageways (Figure 4.2.22). Major distress to all six columns under the eastbound carriageway shortened the overall height of these two piers and allowed this superstructure to sag $300 \mathrm{~mm}$ at Pier 2 and $450 \mathrm{~mm}$ at Pier 3. Residual longitudinal displacements of $300 \mathrm{~mm}$ and $160 \mathrm{~mm}$ at Piers 2 and 3 respectively were also observed - both in the same easterly direction. Similar distress was observed for the westbound carriageway. Since these piers are the fixed piers for this segment of the bridge, they experienced high longitudinal 
loads. Judging by the size of the substructures at these locations, this effect was clearly anticipated by the designers. However insufficient transverse steel was provided to force ductile flexural hinging to occur before the onset of a brittle failure in shear. This is a similar situation to that described above for Pier 240 on the Route 3 Expressway. In this case, however, the situation was aggravated by the relatively short height of Piers 2 and 3 which increases the shear demand in proportion to the reduction in height.

By contrast, Piers 7 and 8 were relatively free from damage. These are the fixed piers for the second segment and it is reasonable to expect them to have been subjected to the same ground motion as those in the previous segment. Light flexural cracking was observed at the bottom of almost all the columns in these piers but the cracking was not severe and did not appear to affect the gravity load capacity in any way. As noted above, these columns are twice the height of Piers 2 and 3 and the extra height, for the same transverse reinforcement, favors a flexural mode of failure.

Piers 6 and 9 in this segment were significantly damaged and this is a surprise in view of the expansion bearings carried by these piers. Flexural cracks were observed at the base of several columns in these piers and Pier 9 appeared to be leaning in a westerly direction, which is the opposite direction to the residual shear displacements in Piers 2 and 3. It seems likely that the expansion bearings were not free in the longitudinal direction as assumed and some longitudinal shear was transferred to these piers.

It seems that the two segments are responding as if they were two very different structures. The columns in the first segment have an average height of about $5 \mathrm{~m}$; those in the second segment average about $9 \mathrm{~m}$. This difference in height leads to an almost six-fold difference in lateral stiffness, which in turn means that the fundamental period of the second segment is about 2.5 times that of the first segment. This difference in period means that the seismic response of the two segments will be unrelated and quite possibly out-of-phase. Pounding between the two segments at Pier 5 is quite possible, but needs to be confirmed.

The Moribe Viaduct (12) on the Meishin Expressway was completed in 1964 and is located between the Nishinomiya interchange and the Amagaski interchange. It carries east- and west-bound traffic on two independent but parallel concrete bridges that are supported on concrete pier walls. The viaduct consists of a series of 5-span segments; each segment is $85 \mathrm{~m}$ long and comprises a continuous hollow concrete slab superstructure supported on six piers. All piers are approximately $5 \mathrm{~m}$ long and $7 \mathrm{~m}$ high and are supported on piled footings. Pier widths vary according to the fixity at the superstructure level. A single footing is used to support the two piers at each support under the parallel structures. Footings that support fixed piers are about $6 \mathrm{~m}$ wide and $18 \mathrm{~m}$ long and are founded on a double row of piles of unknown depth. Footings under expansion piers are about $3 \mathrm{~m}$ wide and use a single row of piles.

Five segments of this viaduct were damaged in this earthquake. The most common cause of distress was shear failures in those wall piers that were fixed in the longitudinal direction. Typical of this behavior is the performance of the segment from Pier 26 to Pier 31 . Of the six piers supporting this section, two have fixed bearings and four have expansion bearings as shown in Table 4.2.7. All bearings permit rotation by using 
rubber pads. At the fixed connections, restraint is provided by extending the vertical reinforcing steel near the neutral axis of the pier across the joint at $45^{\circ}$ and anchoring it in the superstructure.

In this segment, Pier 30 of the eastbound bridge and Pier 29 of the westbound bridge failed catastrophically in shear (Figures 4.2.23 and 4.2.24). Both are fixed piers and reinforced with 2 layers of $32 \mathrm{~mm}$ diameter bar in the longitudinal direction. Transverse steel is $16 \mathrm{~mm}$ bar at $250 \mathrm{~mm}$ spacing and placed between the two layers of vertical steel. The width of each pier is about 850 $\mathrm{mm}$. The collapse of Pier 30 reduced the height of the pier and allowed the superstructure to sag about $600 \mathrm{~mm}$; Pier 29 was not as severely affected.

Of interest is the fact that Pier 30 of the westbound bridge and Pier 29 of the eastbound bridge did not suffer the same distress. Both are also fixed piers and detailed in like manner to those piers that did fail at these locations. This might be explained if it is assumed that both fixed piers under the same bridge sustained the same, or almost the same, elastic shears but one had a slightly lower shear capacity than the other and failed first (in a brittle manner). This sudden reduction in stiffness would then have lengthened the natural period of the segment and perhaps unloaded the second pier to a safe level for the remainder of the earthquake. Close examination of the westbound Pier $30 \mathrm{did}$ show fine diagonal hairline cracks which indicate that this pier was indeed heavily loaded and perhaps on the brink of a massive shear failure when it was saved by the rupture of the adjacent pier (the westbound Pier 29).

The Kobe-ohashi (17) near Port Island is a dual level connector between the Harbor
Highway, the Route 2 Bypass at Kobe, and Route 3 of the Hanshin Expressway (Figure 4.2.25). The steel superstructure is comprised of a series of simple plate girders and 2- and 3-span continuous box girders.

The substructures are concrete and steel, multi-column, framed bents that support both the upper and lower carriageways. These bents differ from pier to pier but in general they are two-column bents of increasing height from south (Pier 23) to north (Pier 26). However, Pier 23 has three columns at the lower level and a steel cap beam at the upper level which is not monolithic with the concrete columns. Instead, this cap beam, which is also the diaphragm for the box girder that is supported at this level, is connected to the two columns of the bent by fixed bearings.

Support fixity for this section of the connector is summarized in Table 4.2.8. Spans are approximately $25 \mathrm{~m}$ in length.

During the earthquake, Piers 23 to 26 were damaged to varying degrees. Flexural hinges formed in the columns of all four piers due to longitudinal loading and bending about the weak axis (the transverse axis) of each bent (Figure 4.2.26). These hinges were well-developed in the shorter bents (Piers 23 and 24) and less well-developed in the taller frames (Piers 25 and 26). For example, the longitudinal reinforcement was buckled on both faces of the hinge zones and some welded splices failed in the inner steel layers in Pier 23 but only cover concrete was lost in Pier 26. Hinge locations also varied from the mid-height of the lower level columns in Pier 23 to just below the lower cap beam in Pier 26. These variations in the extent and location of the hinging may be due to the difference in column heights and the consequential variations in the amount and detailing of the longitudinal reinforcement. It is also expected that the shorter columns attracted a larger share of the base shear 
than the taller columns because of their greater stiffness while in the elastic range.

In addition to the column hinging, other damage sustained by this structure included several connection failures and pounding against adjacent ramp structures and buildings. In particular, the connection between the steel cap beam at the upper level of Pier 23 appears to have failed at one of the columns allowing the girder to slide on that column and develop a permanent offset of about $150 \mathrm{~mm}$. The resulting asymmetric load on the bent may have been sufficient to cause the diagonal cracking that was observed in both the lower cap beam and adjacent column of this bent.

The Minatogawa interchange (6) comprises four, highly curved ramp structures that provide access to Route 3 of the Hanshin Expressway between Piers 605 and 611. Each ramp is either a 3- or 4-span structure comprising steel girders on single column concrete bents with large hammerhead cap beams. The $90^{\circ}$ curvature in each ramp is largely provided by a 2-span curved continuous box girder which is fixed at its center pier but free to expand tangentially at both ends. The span(s) that makes up the remaining length of each ramp is a simply supported span. Since the Expressway is an east-west route, these ramps connect to a north-south highway and the four ramps can be identified by the compass quadrant, i.e., NE, SE, SW and NW. Two of the four footings for both the NE and $\mathrm{SE}$ ramps are piled footings whereas all of the bents for the NW and SW ramps are on spread footings. Further, both the NE and SE structures are 4-span ramps whereas the NW and SW ramps are 3-span ramps. These and other details are summarized in Table 4.2.9. Table 4.2.9 shows that although the NE and SE ramps are superficially similar to the NW and SW ramps, they are in fact different in a number of important details. In general the structures are longer, the columns are taller and the foundations are softer in the eastern half of the interchange compared to the western half.

During the earthquake, the northern-most span of the NE ramp and the southern-most span of the SE ramp collapsed due to loss of support at the expansion ends of these two ramps (Figures 4.2.27 - 4.2.29). No span collapsed in either the NW or SW structure. The most probable explanation for this behavior is the greater flexibility of the eastern ramps and thus the greater displacement demands on the available seat width.

In addition to the unseating of these two spans, the central piers under each of the curved, 2-span segments suffered damage to varying degrees. These are the fixed piers for these continuous segments and are required to resist the lateral load from about $80 \mathrm{~m}$ of tributary superstructure weight. In the shorter columns the failure was principally by shear whereas in the taller columns, shear and flexural distress were both evident. Of interest in these columns was the flexural cracking directly under the hammerheads where the bending moments are expected to be small (Figure 4.2.30). The distress at these locations implies that the superstructure provided significant rotational restraint to these columns which is not unreasonable in view of the high curvature, the high flexural and torsional stiffness of the box girders, and the fixity of the bearings above this pier. Presumably there was similar distress to the columns just above the footings but these were below ground and could not be easily inspected.

At the west end of Route 3, the Hanshin Expressway crosses the JR Sanyo Line on a pair of 3-span continuous steel box girders 
(Figure 4.2.31). This segment is supported on Piers 687 to 690 near the JR Takatori railyard (7). These piers are single column bents with hammerheads, except for Pier 688 which is a 2-column bent with a haunched cap beam. The bridge has a mild left-hand curve with a radius of $291 \mathrm{~m}$. Two pairs of steel bearings support the two box girders over each cap beam and hammerhead. These restrain radial movement and uplift while permitting rotation and tangential movement at all locations except Pier 688 where the bearings are also fixed against tangential expansion - see Table 4.2.10. Principal dimensions for the columns, footings and piles are also given in Table 4.2.10.

As noted above, Pier 688 is the fixed pier for this segment of Route 3 and it has clearly been designed for this purpose. Substantial additional strength has been given to this pier, especially when compared to adjacent substructures - see Table 4.2.10. However, during the earthquake both columns in this bent failed catastrophically in shear in the span-wise direction (Figure 4.2.32). It seems likely that the additional stiffness, which was included with the additional strength, attracted unexpectedly high loads to the bent and the shear capacity was quickly exceeded. The fact that the cap beam was only $2.5 \mathrm{~m}$ wide and therefore narrower than the column, meant that not all of the vertical steel was well confined by the cap beam. During the failure, much of the vertical steel on the north face of the cap pulled out of the cap, further contributing to severity of the failure. It appears that the gross shear deformation in the vertical direction shortened the height of the bent by about a meter. The

superstructure came to rest on the overhead electric supply lines for the JR Line causing closure, not only of the Expressivay, but also of the rail line.

\subsubsection{Damage to Steel Substructures}

Steel substructures for bridges are used quite frequently in Japan, in contrast to US practice. Although not as common as concrete columns, circular and boxed steel columns are found throughout Japan and their performance during this earthquake is of particular interest. Damage was sustained by both older and newer construction and included flexural hinging with local buckling and, in one case, section rupture.

This section presents examples of these failures by summarizing the damage sustained by two sections of the Hanshin Expressway Route 3 (Piers 55 to 58 near Tateishi and Piers 581 to 586 near Meiji) and the Route 2 Bypass at Hamate (Piers 41 to 49). Buckling of the cross-bracing in the Rokko Island tied arch and local buckling in the end piers and approach spans of the Higashi-Kobe cable-stayed bridge are described in Sections 4.2.2.1 and 4.2.2.4 respectively.

The 2-span section of Route 3 from Pier 54 to Pier 56 near Tateishi (2) varies in width to accommodate on-and off-ramps that join the elevated expressway here at Tateishi. Of the three bents supporting these two spans, two are steel box columns and one is reinforced concrete. All spans are simply supported steel girders with spans of $70 \mathrm{~m}$ and $45 \mathrm{~m}$ from Piers $54-55$ and from Piers 55 - 56 respectively. The average clear height of these columns is about $8 \mathrm{~m}$ measured from the top of the footing to the bottom of the hammerhead cap beam. Foundations are piled footings. Principal dimensions for the columns, footings and piles are summarized in Table 4.2.11.

The excessive width and unusual shape of Pier 55 is the result of subsequent widening to accommodate the later addition of new 
access ramps. Originally $20 \mathrm{~m}$ long, the steel cap beam was doubled in length to 44 $\mathrm{m}$ for this purpose. At the same time, concrete columns were added to support the free ends of the beam. Both the beam and central column are constructed from internally stiffened single cell box sections. For the beam, the plate thicknesses are 28 $\mathrm{mm}$ for the upper and lower flanges and 24 $\mathrm{mm}$ for the webs. For the column, the plate thicknesses are $19 \mathrm{~mm}$. Both the beam and column were pre-fabricated in sections using shop welds and assembled on site using bolted splices. High strength, $20 \mathrm{~mm}$ diameter bolts were generally used for these connections.

During the earthquake, the steel box column at Pier 55 split open along the welds that run the full height of the four corners of the box, allowing the column to collapse in compression, while the concrete outrigger columns remained upright (Figures 4.2.33 and 4.2.34). Without the support of the central column, the extended cap beam failed in flexure on both sides of the main girder as it attempted to span between the two external columns. The articulation in the superstructure allowed this gross deformation to occur without the superstructure being unseated. Other steel box columns in adjacent piers also showed evidence of incipient failures in the corner welds.

In the Meiji district (5), to the west of central Kobe, Route 3 separates into two independent east- and west-bound structures (Figure 4.2.35). These structures are supported on single steel columns that are in turn supported on hollow concrete shafts. The largest of these circular columns (Piers 583 and 584) have diameters of $2.2 \mathrm{~m}$ and clear heights, from foundation to under side of hanmerhead, of about $14 \mathrm{~m}$. The foundation shafts under these columns are 4 $\mathrm{m}$ in diameter and about $23 \mathrm{~m}$ deep. The superstructure is also steel and includes a series of simply supported plate girder spans ( $35 \mathrm{~m}$ to $50 \mathrm{~m}$ long) and a 3 -span continuous box girder segment with spans of $55 \mathrm{~m}, 78 \mathrm{~m}$ and $55 \mathrm{~m}$ respectively. The total length of the 8-span section from Pier 580 to Pier 588, which includes all of the single steel column bents, is approximately $415 \mathrm{~m}$. Principal dimensions for these columns and their foundations on the westbound structure are given in Table 4.2.12.

During the earthquake many of the columns in the westbound structure were damaged but the extent of this damage varied according to location. All columns appeared to have been heavily loaded in the transverse direction and in the cases of Piers 584 and 585 , the columns suffered permanent transverse displacements. In many columns plastic hinges began to form somewhere in the central one third of the column height, rather than at the base. Changes in the plate thickness with column height, probably accounts for these higher locations.

However, fully developed hinges did not occur due to local buckling, tensile ruptures and section buckling caused possibly by column out-of-roundness.

Pier 584 is one of the two largest piers in this section but it failed by section rupture within a potential plastic hinge zone at about mid-height (Figure 4.2.36). The hinge began to form immediately above a change in plate thickncss but the associated weld probably initiated the crack which propagated around the circumference of the column during the reversed loading imposed by the earthquake. The column was completely fractured at this level and it came to rest with a permanent lean to the north of about $10^{\circ}$ (Figure 4.2.37). Pier 585 also sustained permanent displacement but in this case the column did not rupture. Instead a plastic hinge began 
to develop about $2 \mathrm{~m}$ above the ground line but the section buckled, possibly due to section out-of-roundness, which prevented the full moment capacity from being reached. This column also tilted to the north by rotating about the failed plastic hinge.

As noted in Table 4.2.12, Pier 586 is almost two-thirds of the height of Piers 584 and 585. Despite its smaller diameter, this shorter height implies that it is about $25 \%$ stiffer than the adjacent piers. It therefore attracted a higher share of the lateral loads during the earthquake and it should have performed in a similar manner to Piers 584 and 585. In fact, the pier showed no visible signs of distress and the reason for this behavior appears to be the failed connection at the top of the pier (Figures 4.2.35 and 4.2.38). Inspection of the bearings at Pier 586 showed that the transverse restraint provided by these bearings had failed in lateral shear and the girder displaced across the pier cap a distance of about one meter. The release of load due to this bearing failure is another example of fuse-like behavior in superstructure-to-substructure connections. The consequential reduction in column shear almost certainly protected the column from the distress suffered by its neighbors. (The bearings on Piers 585 and 584 did not fail in transverse shear).

As noted in Section 4.2.2.1 the Hamate Bypass (16) is a two level elevated viaduct carrying Route 2 along the Kobe waterfront. Longer spans are continuous steel box girders supported on multi-column steel bents constructed from single cell, internally stiffened, box sections. In all piers the upper level roadway is supported by two columns from the lower level cap beam. This lower cap is then supported from the ground, in some cases by two columns, as in Pier 41, and in other cases by a single column (tennis racket-style) as in Pier 49.

In Pier 41, the upper and lower decks are supported at about $22 \mathrm{~m}$ and $10 \mathrm{~m}$ above the ground respectively. The overall width of the pier at the carriageway levels is about $15 \mathrm{~m}$. Column cross sections are $2.2 \mathrm{~m} \times 2.8$ $\mathrm{m}$. This is a fixed pier for the superstructure and it appears that during the earthquake the longitudinal forces attracted to the pier were sufficient to cause one-half cycle of inelastic flexure about $3 \mathrm{~m}$ up from the base (Figure 4.2.39). On the compression face, local buckling occurred between the stiffened panels of both columns whereas on the tension side horizontal striations in the paint were consistent with significant post-yield tensile strain. However no obvious offset or misalignment was observed in the pier and it was assumed to have returned to its original position. More detailed surveys may show, however, that some residual deformation was sustained.

As noted above, Pier 49 has a single column supporting the first level of traffic from which a two column bent extends upwards to support the second level. This single column is $3.2 \mathrm{~m}$ in diameter and is supported on a piled concrete footing that measures $10 \mathrm{~m}$ by $12.6 \mathrm{~m}$. The clear height of this column, from top of footing to bottom of the first cap beam, is $12.1 \mathrm{~m}$. The steel box sections that comprise the members of the upper level bent are generally $1.5 \mathrm{~m} \times 1.6 \mathrm{~m}$ in size. Attention has been drawn by others to the distinctive shape of this bent and its striking similarity to a tennis racket that is standing upright.

This pier is another fixed point for both levels of the superstructure and during the earthquake, sufficient lateral load was attracted to this bent to trigger section buckling (Figure 4.2.40). Section out-of-roundness and high gravity loads were 
pre-existing conditions that, when combined with the seismic overturning moment, precipitated a uniform buckling failure across the whole section at the mid-height of the column.

Factors which tend to confirm a failure in compression rather than one in flexure or shear include the location (unusually high for a flexural hinge), the uniform deformation around the circumference and the absence of residual translation over the height of the column. Furthermore, an access ladder runs the full height of this column and is attached to it at about $1.5 \mathrm{~m}$ intervals. It was also deformed into a bulge (by bending about its weak axis) but exhibited no horizontal offset between the upper and lower sections that might be indicative of permanent flexural or shear deformation in the column.

The shape of the buckle in the column may be compared to an elephant's foot failure, which occur in large diameter storage tanks during earthquakes. In this case, however, the buckle is half way up the leg of the pier and the damage to Pier 49 might therefore be likened to an elephant's knee failure in the handle of a tennis racket.

\subsubsection{Damage to Structures Due to Special Conditions (Liquefaction, Skew, Protective Systems)}

In addition to the damage already discussed, which was due to bearing and column failures, there was also damage due to other special conditions. These include foundation failure, adverse effects of skewed geometry, and failure of special connections associated with protective systems.

This section presents examples of these failures by summarizing the damage sustained by the Shukugawa bridge on the
Hanshin Expressway Route 5, the Kawaraginishi bridge on the Meishin Expressway and the Higashi-Kobe bridge, also on Route 5.

The Shukugawa bridge (9) is a 3-span continuous box girder bridge carrying Route 5 across the Shukugawa (Figure 4.2.41). It also supports a toll plaza at the west end (Pier 134) and is therefore about twice the width here than at the east end (Pier 131). The girder is supported on concrete multi-column bents and piled footings. Expansion bearings are provided at Piers 131 and 134 and fixed bearings located over Piers 132 and 133.

During the earthquake liquefaction was widespread in the general area of the bridge and lateral spreading was evident at many locations. Both banks of the Shukugawa were subject to large soil deformations and moved towards the center of the river (Figure 4.2.42). Piers 131 and 134 were displaced with the soil and in the process dislodged the bearings under the main girders as well as the approach spans. At Pier 134, the movement was of the order of one meter to the east, while at Pier 131, the movement was less (about $0.5 \mathrm{~m}$ ) to the west.

In addition to bearing damage, the expansion joints were also dislodged and twisted out of alignment by large vertical (up to $600 \mathrm{~mm}$ ) and horizontal offsets imposed by the piers (Figure 4.2.43).

At Pier 134, the one meter movement of the pier almost caused the collapse of the approach span due to insufficient seat width at the cap. The remaining overlap between girder and seat, was of the order of $100 \mathrm{~mm}$ or less but collapse was apparently prevented by the earthquake couplers (Figure 4.2.44). Preliminary results from excavations behind the footing under Pier 
134 , indicate that some piles failed during the lateral spreading and that replacements will be necessary around the perimeter of an expanded footing.

The 3-span Kawaraginishi Bridge (14) comprises two independent structures that carry east and westbound traffic on the Meishin Expressway (Figure 4.2.45). Both structures have continuous, reinforced concrete hollow slab superstructures supported on wall piers at each end (Piers 24 and 27) and by two multi-column bents (Piers 25 and 26). Two special features are of interest with this bridge. The first is that the bridge is skewed $35^{\circ}$ to the line of the support and fixed at the east end only (Pier 27); all other bearings permit longitudinal movements. The second feature is that each intermediate bent comprises three pin-ended columns and therefore has no lateral stiffness or resistance to lateral load.

During the earthquake, the transverse restraint at the west end (Pier 24) of the eastbound bridge failed and in the absence of any restraint from the intermediate piers, the superstructure was free to rotate about the fixed end (Pier 27) in a clockwise direction. Once support was lost at Pier 24, collapse of one or more spans and the associated intermediate bent (Pier 25) followed almost immediately. In addition, the high shear forces and twisting moments placed on Pier 27, as the superstructure rotated, exceeded the capacity of this wall and it failed in shear (Figure 4.2.46).

Since the westbound bridge shares the same features, it is surprising that it did not also collapse. It is of course possible that the eastbound bridge prevented the westbound structure from losing support at Pier 24 moments before the eastbound bridge lost its own support. It follows that an earthquake with a longer duration might have caused the collapse of both bridges.

The Higashi-Kobe bridge (10) is a 3 -span cable-stayed bridge with a total length of $885 \mathrm{~m}$ (Figure 4.2.47). The main girder - weighs 14100 tonnes and is totally supported by 48 cables arranged in a harp pattern from the two towers. It is restrained against transverse wind and seismic loads by six wind shoes, one at each tower and one at each of the two piers in both end spans. These shoes are only effective in the transverse direction and offer no restraint to the girder against longitudinal loads. A pair of viscous, vane-type dampers are therefore provided at both ends of the main girder to control longitudinal seismic loads. These dampers permit up to $900 \mathrm{~mm}$ of longitudinal movement, and each can develop a peak force of 108 tonnes at a velocity of $750 \mathrm{~mm} / \mathrm{sec}$. In addition, a pair of vertical eye-bars is provided to counteract the uplift in the main girder due to an imbalance in dead load.

During the earthquake the anchor bolts for the wind shoe at the west end of the main girder failed and the transverse restraint for the girder at this end was lost (Figure 4.2.48). The redistribution of load to the dampers and eye-bars (for which they were not designed) triggered failure in these devices also, and the end of the girder, which was now free of all restraint, rose upwards about one meter (Figures 4.2.49 and 4.2.50). Records from strong motion instruments in the east tower show that the input ground accelerations in the transverse direction were about $0.4 \mathrm{~g}$. These records also show considerable amplification with the increasing height of the tower to $0.8 \mathrm{~g}$ at deck level and to greater than $1 \mathrm{~g}$ at the top of the tower. These are very high in-structure accelerations and significantly larger than those assumed in design (the $2 \%$ damped, design spectrum has a peak value 
of $0.4 \mathrm{~g}$ from $0.6 \mathrm{~s}$ to $2.0 \mathrm{~s}$ ).

It is therefore not surprising that the structure suffered some distress, including not only the failure of the protective systems, but also local buckling in the box steel bents that support the western end of the main girder and the adjacent approach spans.

The above observation, regarding the design accelerations for the Higashi-Kobe bridge, also applies to the other structures described earlier. The design seismic coefficient for the Hanshin region is 0.3 and the minimum connection forces are 1.5 times the product of this coefficient and the tributary weight. These values were clearly exceeded during this earthquake and most probably by very wide margins.

\subsubsection{Performance of Other Highway Bridge Structures}

When completed in 1997, the Akashi-Kaikyo suspension bridge will have the world's longest span at $1990 \mathrm{~m}$. This bridge is currently under construction between the main island of Honshu and Awaji island immediately to the west and south of Kobe. The epicenter for the earthquake was directly under the bridge and the causative fault passes obliquely between the two towers. The right lateral movement on this strike-slip fault was on the order of a meter which has lengthened the distance between the towers by about $0.8 \mathrm{~m}$ and created a lateral offset of about $0.6 \mathrm{~m}$. At the time of the earthquake, the towers had been completed and the main cables were in place. Erection of the suspenders and the stiffening trusses had not begun. No significant structural damage to the bridge has been reported but detailed inspection and redesign of the stiffening trusses to accommodate the new geometry is expected to add a 10 -month delay to the completion of the structure.

Many bridge spans had been seismically retrofitted with couplers before the earthquake and at least two structures on Route 4 are menshin-designed bridges fitted with seismic isolators. As noted above, some earthquake couplers failed during the earthquake, but in many other instances they performed well and are believed to have prevented further collapses of simply supported spans. Furthermore, those few concrete columns that had been retrofitted with steel jackets at the west end of Route 3 , also appeared to have performed well during ground motion that caused shear failures in adjacent (unretrofitted) columns. There was likewise good performance of the two menshin bridges. No damage was sustained in either one but at $45 \mathrm{~km}$ from the epicenter, the input motion was less than $0.15 \mathrm{~g}$ and the performance of adjacent conventional bridges was also damage-free. Nevertheless, the records obtained from the Matsunohama bridge confirm the expected performance of a menshin-designed bridge during low-to-moderate ground motion i.e., slight amplification in the isolated (span-wise) direction and strong amplification in the fixed (transverse) direction.

\subsubsection{Lessons for the United States}

To bridge engineers and owners in the central and eastern United States, this particular earthquake is perhaps of greater significance than recent earthquakes in California (e.g., Loma Prieta, 1989 and Northridge, 1994). One reason for this opinion is that the predominant type of bridge in Japan is the steel girder superstructure (simple and/or continuous spans) supported by bearings on concrete columns and foundations. This class of 
bridge is also found throughout the central and eastern United States, whereas bridges in California tend to be concrete box girders with monolithic bents and integral abutments, especially in shorter bridges. It follows that bridges in the central and eastern Umoted States are more like those in Japan than those in California and the performance of Japanese bridges is thus of particular relevance to states east of the Sierra Nevada mountains "Snowy Range."

A second reason is that an earthquake of this size was considered to be a rare event for this part of Japan. Although bridges in this region are designed for seismic loads, the design coefficients are considerably lower than those recorded during this earthquake. The possibility of an earthquake larger than the design earthquake was considered to be unlikely and only nominal attention had been given to the problem, and then only for structures designed since 1990. This difference, between the maximum credible earthquake and the design earthquake, is clearly very large for this region of Japan - a situation that is also considered to exist in the United States, but to a greater degree in the eastern and central states than in the west.

It follows that the eastern and central US may have more to learn from this earthquake than from those in California. Some of these lessons are as follows:

(a) Large earthquakes can be very destructive in terms of lives lost, injuries sustained, business losses, reconstruction costs and societal disruption. The closure of arterial highways and bridges affects emergency relief and business recovery and can have a major economic impact on a region and its ability to survive such a disaster. (b) Large damaging earthquakes can occur in areas that are considered to have, on average, only a moderate exposure to seismic hazards.

(c) Capacity design procedures, ductile details and generous seat widths are necessary to prevent catastrophic collapse during large earthquakes.

(d) Minimum connection forces need to be enforced for all seismic zones unless such connections can be shown to be fully protected by acceptable yielding of the substructures. Redundancy in connection detailing is particularly important for essential structures. Alternative load paths are necessary if the primary load path fails due to unforeseen circumstances.

(e) Critically important structures must be designed to a higher level of performance than that provided by current specifications, if full service is to be maintained after a large earthquake. Multi-level performance criteria and corresponding design strategies are necessary for important bridges.

(f) Retrofit measures reduce damage but inappropriate use and/or installation can defeat their purpose and perhaps even trigger collapse. This observation is made with particular reference to couplers (restrainers).

(g) Lateral spreading due to liquefaction can lead to span collapse even in modern structures with massive foundations (caissons) and well-engineered fills.

(h) Premature failure of some bearings appear to have reduced the seismic loads in their supporting substructures by uncoupling the superstructure from its supports. This fuse-like action may have saved a 
number of spans from collapse and columns from failure in shear and flexure.

(i) Accelerations in isolated superstructures are less than in conventional structures.

(j) Skewed bridges are susceptible to in-plane rotation leading to large displacements at their supports and possible unseating of girders in the acute corners.

\subsubsection{Research Needs and Opportunities}

A number of research needs and opportunities have arisen as a consequence of this earthquake. These include the following:

(a) Conduct correlation studies on those bridges with strong motion records to calibrate theoretical models against actual behavior. As far as can be determined at this time, records are available for two bridges. They are the Higashi-Kobe cable-stayed bridge (with seismic energy dissipators) and the base-isolated Matsunohama bridge. Valuable insight into the performance of these two important types of bridges would be derived from such studies.

(b) Develop a detailed database on the performance of steel bearings and earthquake couplers (restrainers) followed by case studies on selected bridges in which these devices failed. Results from such a study would help determine the need for a review of current U.S. design criteria for connection forces and restrainers.

(c) Analyze structural response due to large foundation movements during liquefaction and lateral spreading. Develop optimum mitigation measures to minimize structural impacts of such movements. Case studies could include the Nishinomiya-ko and Shukugawa bridges.

(d) Perform case studies on those bridges that were retrofitted before the earthquake to determine the effectiveness of the retrofit measures. Known retrofit measures for which performance could be evaluated include earthquake couplers, steel jackets and viscous dampers.

(e) Develop multiple-level performance criteria which define expected damage and serviceability states for various earthquake scenarios and the corresponding design

strategies/structural options necessary to satisfy these criteria. Involvement of social scientists (planners, economists and experts in public policy) should be encouraged. Cooperative U.S.-Japan exchanges on this issue would also be beneficial.

(f) Study failure mechanisms in large concrete columns under combined axial and shear loads. Concrete columns in single or multi-column bents in Japanese bridges have very large cross sections and fall outside the range of U.S. test data. Although it is unlikely that U.S. practice will adopt similar sized members for short- and medium-span bridges in the near future, columns of this size and with these reinforcement ratios are encountered in some long span structures. Correlation of assessment methods and limit states with field data from this earthquake could give valuable insight into the lateral load capacity of large concrete members. It is noted that such field data are rare and this opportunity is 
probably unique.

(g) Perform case studies on bridges with steel substructures. The relatively large number of damaged steel substructures provides an opportunity to calibrate proposed new methods for the seismic design of steel bridge columns. In particular, their capacity for ductile actions and the identification of their limit states should be investigated with the objective of refining the $\mathrm{R}$-factors in U.S. bridge codes for these components.

The poor performance of these older bridges and elevated expressways confirms previous lessons in California and elsewhere, about the pressing need to retrofit the existing deficient bridges.

\subsubsection{Summary}

Damage to highway bridges was both widespread and catastrophic. Typical damage included shear and flexural failures in nonductile concrete columns, flexural and buckling failures in steel columns, unseated girders due to bearing failures, and gross foundation movements due to liquefaction. In addition, pounding between spans occurred. Some special structures also suffered atypical damage such as the excessive rotation of a skew bridge on pin-ended columns and the loss of seismic energy dissipators in a cable-stayed bridge due to the failure of a wind shoe.

Most of this distress was confined to older structures, built more than 30 years ago before the introduction of modern seismic codes. The poor performance of these older bridges and elevated expressways confirms previous lessons learned in California and elsewhere, about the pressing need to retrofit the existing inventory of deficient bridges.

However, some new bridges also suffered serious damage which implies a need to re-evaluate the design loads and procedures in the current design specifications. As noted above, the peak ground accelerations due to this "rare" earthquake were considerably higher than the seismic coefficients used in design. This is an example of a low-probability but high-consequence event causing serious distress to modern construction. From an owner's viewpoint, these circumstances might be best addressed through multiple-level performance criteria. In the United States, dual-level criteria have only recently been developed, and then only for critically important, long-span structures and a privately-owned transportation corridor. They should perhaps be extended to a wider range of bridge types and in doing so clearly state the expected performance under both small and large, rare and frequent earthquakes and identify design strategies that will satisfy these criteria.

The closure of three major expressways in the Hanshin region has had a major socictal and economic impact on the region. The estimated total repair cost for one highway authority alone, the Hanshin Expressway Public Corporation, is $\$ 4.6$ billion. Even though this is only about $2.5 \%$ of the total direct costs for the earthquake (estimated at $\$ 200$ billion), it is still a significant sum. Furthermore, it does not include the loss of toll revenue while the network is inoperative (estimated at $\$ 2$ million per day) nor does it include the indirect losses which are 
expected to exceed the repair costs by the time the system is fully operational. The simultaneous closure of the other transportation routes in the region, principally the rail lines, further aggravated the situation and paralyzed the region as emergency access and relief teams were forced to use surface streets. The interdependency of these lifelines, especially when collocated in narrow corridors, deserves further study.

\subsubsection{References}

1. Hanshin Expressway Public Corporation, "Techno Gallery: Structures and Technologies of the Hanshin Expressway," 88 pp., 1994.
2. Japan Road Association, "Design Specifications of Road Bridges; Part V: Seismic Design," February 1990.

3. Iwasaki,T., Kawashima, K. and Hasegawa, K., "New Seismic Design Specifications of Highway Bridges in Japan," Proc. 22nd Joint Meeting U.S.-Japan Panel on Wind nd Seismic Effects, UJNR, Gaithersburg, MD, May, 1990.

4. Hanshin Expressway Public Corporation, "Report on Damage to the Hanshin Expressways by the Great Hanshin Earthquake and its Restoration," Osaka, 1995. 
Table 4.2.1

Location of Bridges with Major Damage

Route No./

Owner/Agency

Number of Bridges (Major Damage)

Expressway

$\begin{array}{rlrr}2 & \text { (NH) } & \text { MOC } & 3 \\ 3 & \text { (Hanshin) } & \text { HEPC } & 11 \\ 5 & \text { (Hanshin) } & \text { HEPC } & 4 \\ 43 & \text { (NH) } & \text { MOC } & 1 \\ 171 & \text { (NH) } & \text { MOC } & 2 \\ & \text { Meishin } & \text { JHPC } & 4 \\ & \text { Chugoku } & \text { JHPC } & 2\end{array}$

Notes: MOC Ministry of Construction

HEPC Hanshin Expressway Public Corporation

JHPC Japan Highway Public Corporation

$\mathrm{NH}$ National Highway 
Table 4.2.2

List of Highway Bridges with Major Damage

HIGHWAY (ROUTE)

Hanshin (3)

Hanshin (5)

Meishin

Chugoku

National Highway

(NH 2)

Hamate Bypass ${ }^{(1)}$

Kobe-Port Island Ohashi ${ }^{(1)}$

Shioya Overpass

National Highway

(NH 43) Iwaya Overpass

National Highway

(NH 171) Mondo Overpass

Ikeda Overpass
TYPE

steel girders/concrete columns steel box girders/steel columns steel box girders/steel columns concrete girders/concrete columns steel box girders/concrete columns steel box girders/concrete columns steel girders/concrete columns concrete and steel girders/concrete cols. steel girders/steel and concrete columns steel girders/concrete columns steel box girders/concrete columns

Nielsen-Lohse tied arch/steel columns steel box girders/concrete multicol. bent cable stayed deck/steel columns Lohse tied arch/steel columns

concrete box girders/concrete pier walls steel girders/concrete columns concrete box girders/pin-ended concrete multi-column bent

concrete box girder/concrete multicolumn bent

steel box girders/steel columns steel box girders/concrete dual level 2column bent

concrete girders/concrete columns

concrete girders/concrete columns

Notes: $\quad$ 1. Sites visited by UJNR Reconnaissance Team Feb. 12-17, 1995

2. Includes Higashi-Nada Viaduct

3. Includes Meiji District Ramps 
Table 4.2.3

Support Fixity Conditions for the Nishinomiya-ko Bridge

Pier No. $\quad 110$

Arch Span

$\begin{array}{llll}111 & 112 & 113 & 11\end{array}$

$115 \quad 116$

Fixity

E-F

E-F E-E

F-E

F

F

E-E

Notes E: Expansion bearing (rotation and longitudinal movement permitted)

F: Fixed bearing (rotation only permitted)

Table 4.2.4

Support Fixity Conditions for the Mukogawa Bridge

Pier

A1

P1

P2

P3

P4

P5

A2

Fixity

$\mathrm{E}$

$\mathrm{E}$

F

$\mathrm{E}-\mathrm{E}$

F

E

$\mathrm{E}$

Notes A1,A2: west and east abutments

P1-P5: intermediate piers

E: Expansion bearing (rotation and longitudinal movement permitted)

F: Fixed bearing (rotation permitted) 
Table 4.2.5

Substructure Details for Piers 238 - 241, Route 3 near Uozaki

Pier

P241

P240

P239

P238

$\begin{array}{lllll}\text { Bearing Fixity } & \text { E-E } & \text { F } & \text { E } & \text { E-F } \\ \text { Bearing Type } & \text { S0-36 } & \text { S0-37 } & \text { S0-38 } & \text { S0-36 } \\ \text { Column Size } & 3.3 \mathrm{~m} \text { dia. } & 3.6 \times 3.3 \mathrm{~m} & 3.3 \mathrm{~m} \mathrm{sq} . & 3.3 \mathrm{~m} \text { dia. } \\ \text { Footing Size } & 11 \times 11 \times 2.5 \mathrm{~m} & 15.5 \times 12 \times 2.5 \mathrm{~m} & 12 \times 12 \times 2.5 \mathrm{~m} & 10 \times 10 \times 2.5 \mathrm{~m} \\ \text { Pile Size (LxD) } & 14 \times 1 \mathrm{~m} \text { dia } & 15 \times 1 \mathrm{~m} \text { dia } & 18.5 \times 1 \mathrm{~m} \text { dia } & 14 \times 1 \mathrm{~m} \text { dia } \\ \text { No. of Piles } & 17 & 28 & 25 & 16\end{array}$

Notes $E$ :

Expansion bearing (rotation and longitudinal movement permitted) F: $\quad$ Fixed bearing (rotation only permitted)

S0-36: $\quad$ Pin and roller bearing with uplift restraint

S0-37: $\quad$ Pin bearing

S0-38: $\quad$ Pin and roller bearing without uplift restraint

Table 4.2.6

Support Fixity Conditions for the Takarazuka Viaduct

$\begin{array}{llllllllllll}\text { Pier } & \text { A1 } & \text { P1 } & \text { P2 } & \text { P3 } & \text { P4 } & \text { P5 } & \text { P6 } & \text { P7 } & \text { P8 } & \text { P9 } & \text { P10 }\end{array}$

$\begin{array}{llllllllllll}\text { Fixity } & \text { E } & \text { E } & \text { F } & \text { F } & \text { E } & \text { E-E } & \text { E } & \text { F } & \text { F } & \text { E } & \text { E-E }\end{array}$

Notes E: Expansion bearing (rotation and longitudinal movement permitted)

F: Fixed bearing (rotation only permitted) 
Table 4.2 .7

Support Fixity Conditions for Piers 26 to 31, Moribe Viaduct

Pier 26

27

28

29

30

31

Fixity E-E

E

$\mathrm{E}$

$\mathrm{F}$

F

E-E

Notes E: Expansion bearing (rotation and longitudinal movement permitted) F: Fixed bearing (rotation only permitted)

Table 4.2.8

Support Fixity Conditions for Piers 23 to 26, Kobe-ohashi

Pier

23

24

25

26

Fixity

$\mathrm{F}$

E-F

E-F

E-E

Notes E: Expansion bearing (rotation and longitudinal movement permitted) F: Fixed bearing (rotation only permitted) 
Table 4.2.9

Structure Data for the Minatogawa Ramps, Route 3

\begin{tabular}{lllll} 
Ramp & NE & SE & SW & NW \\
\hline & & & & \\
Number of spans & 4 & 4 & 3 & 3 \\
Length of curved spans $^{1}$ & $42.4 / 44.0 \mathrm{~m}$ & $40.0 / 42.5 \mathrm{~m}$ & $30.1 / 29.2 \mathrm{~m}$ & $39.3 / 40.4 \mathrm{~m}$ \\
Column size $^{1}$ & $2.5 \times 3.75 \mathrm{~m}$ & $2.5 \times 3.75 \mathrm{~m}$ & $2.5 \mathrm{~m}$ dia. & $2.5 \mathrm{~m}$ dia. \\
& oval & oval & circular & circular \\
Clear Column height $^{1,2}$ & $6.1 \mathrm{~m}$ & $8.4 \mathrm{~m}$ & $5.7 \mathrm{~m}$ & $2.6 \mathrm{~m}$ \\
Footing size $^{1}$ & $8 \times 9.5 \mathrm{~m}$ & $8 \times 9.5 \mathrm{~m}$ & $8 \times 10 \mathrm{~m}$ & $8 \times 10 \mathrm{~m}$ \\
Number of piled footings $^{\text {Pile data }}{ }^{1}$ & 2 & 2 & 0 & 0 \\
& $12,1 \mathrm{~m}$ dia. & $12,1 \mathrm{~m}$ dia & N.A. & N.A.
\end{tabular}

Notes 1. Substructure data is given for central pier under curved 2-span segment.

2. Clear height is distance between top of footing and bottom of hammerhead.

3. Estimated.

Table 4.2.10

Substructure Details for Piers 687 - 690, Route 3 near Takatori

$\begin{array}{lllll}\text { Pier } & \text { P690 } & \text { P689 } & \text { P688 } & \text { P687 }\end{array}$

$\begin{array}{lllll}\text { Bearing Fixity } & \text { E-E } & \text { E } & \text { F } & \text { E-F } \\ \text { Column Size } & 3.2 \mathrm{~m} \text { dia. } & 3.6 \mathrm{~m} \text { dia. } & 2 . \times 3.5 \mathrm{~m} \text { dia. } & 3.2 \mathrm{~m} \text { dia. } \\ \text { Clear Column Ht } & 5.3 \mathrm{~m} & 4.0 \mathrm{~m} & 6.1 \mathrm{~m} & 7.4 \mathrm{~m} \\ \text { Footing Size } & 8 \times 9.5 \times 2.5 \mathrm{~m} & 9.5 \times 12 \times 3.0 \mathrm{~m} & 12.5 \times 17 \times 3.0 \mathrm{~m} & 9.5 \times 10 \times 2.5 \mathrm{~m} \\ \text { Pile Size (LxD) } & 21 \times 1 \mathrm{~m} \text { dia. } & 22.6 \times 1 \mathrm{~m} \text { dia. } & 22.6 \times 1 \mathrm{~m} \text { dia. } & 12.1 \times 1 \mathrm{~m} \text { dia. } \\ \text { No. of Piles } & 11 & 18 & 28 & 10\end{array}$

Notes E: Expansion bearing (rotation and longitudinal movement permitted) F: Fixed bearing (rotation only permitted) 
Table 4.2.11

Substructure Details for Piers 54 - 56, Route 3 near Tateishi

Pier

\begin{tabular}{|c|c|c|c|}
\hline Bearing Fixity ${ }^{1}$ & E-F & E-F & E-F \\
\hline Column Type & steel box & steel box ${ }^{2}$ & concrete \\
\hline Column Size & $3.0 \times 3.3 \mathrm{~m}$ & $2.8 \times 3.0 \mathrm{~m}^{2}$ & $3.5 \mathrm{~m}$ dia. \\
\hline Clear Column $\mathrm{Ht}^{3}$ & $6.96 \mathrm{~m}$ & $8.23 \mathrm{~m}$ & $9.07 \mathrm{~m}$ \\
\hline Cap Beam Length & $30.8 \mathrm{~m}$ & $44.3 \mathrm{~m}$ & $19.5 \mathrm{~m}$ \\
\hline Footing Size & $12 \times 12 \times 3.5 \mathrm{~m}$ & $12 \times 12 \times 3.5 \mathrm{~m}^{2}$ & $10 \times 12 \times 2.7 \mathrm{~m}$ \\
\hline Pile Size $(\mathrm{LxD})$ & $12.5 \times 1 \mathrm{~m}$ dia. & $11 \times 1 \mathrm{~m} \mathrm{dia.}{ }^{2}$ & $16 \times 1 \mathrm{~m}$ dia. \\
\hline No. of Piles & 23 & 212 & 17 \\
\hline
\end{tabular}

Notes 1. E: Expansion bearing (rotation and longitudinal movement permitted) F: Fixed bearing (rotation only permitted)

2. Pier 55 has 2 additional concrete columns that support each end of the cap beam; these columns are $1.2 \times 2.7 \mathrm{~m}$ in plan by $9.2 \mathrm{~m}$ high; footing sizes are $6.5 \times 13 \times 2.5 \mathrm{~m}$ and supported by nine $11 \times 1 \mathrm{~m}$ dia. piles.

3. Clear height is distance between top of the footing and bottom of cap beam. 
Table 4.2.12

Substructure Details for Piers 581 - 586, Westbound Route 3, Meiji

\begin{tabular}{lllllll} 
Pier & 586 & 585 & 584 & 583 & 582 & 581 \\
\hline & & & & & & \\
Bearing Fixity & F & E-F & E-E & F-E & F-E & F-E \\
Column Size (dia) & $1.8 \mathrm{~m}$ & $1.8 \mathrm{~m}$ & $2.2 \mathrm{~m}$ & $2.2 \mathrm{~m}$ & $1.8 \mathrm{~m}$ & $1.8 \mathrm{~m}$ \\
Clear Column Ht. & $10.3 \mathrm{~m}$ & $12.4 \mathrm{~m}$ & $14.1 \mathrm{~m}$ & $14.1 \mathrm{~m}$ & $13.4 \mathrm{~m}$ & $12.4 \mathrm{~m}$ \\
Shaft Size (dia) & $3.5 \mathrm{~m}$ & $3.5 \mathrm{~m}$ & $4.0 \mathrm{~m}$ & $4.0 \mathrm{~m}$ & $3.5 \mathrm{~m}$ & $3.5 \mathrm{~m}$ \\
Shaft Depth & $24.6 \mathrm{~m}$ & $23.8 \mathrm{~m}$ & $23.2 \mathrm{~m}$ & $23.4 \mathrm{~m}$ & $16.2 \mathrm{~m}$ & $17.4 \mathrm{~m}$
\end{tabular}

Notes E: Expansion bearing (rotation and longitudinal movement permitted) F: Fixed bearing (rotation only permitted) 


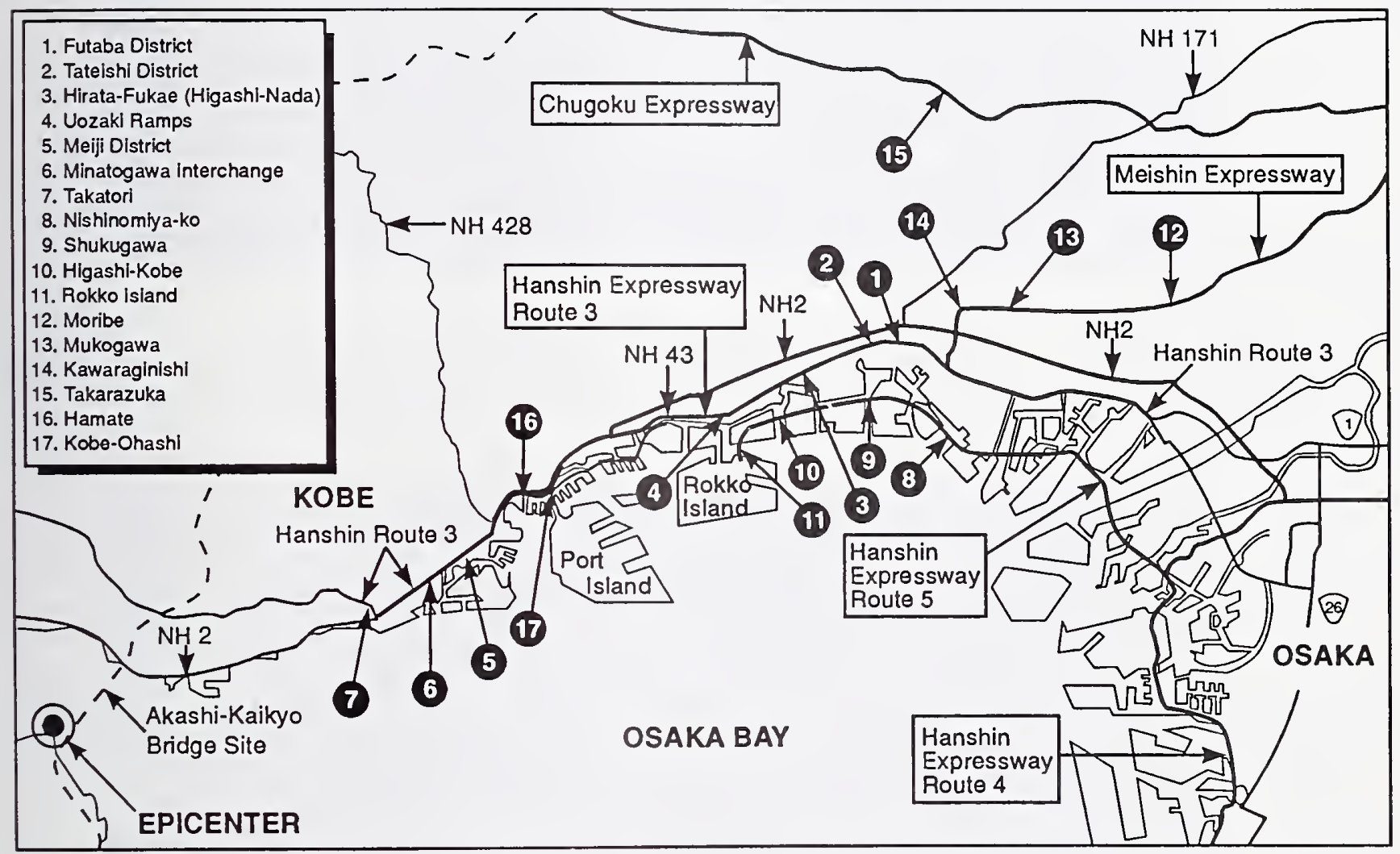

Figure 4.2.1

Bridge sites visited by the UJNR Reconnaissance Team, February 1217, 1995. 


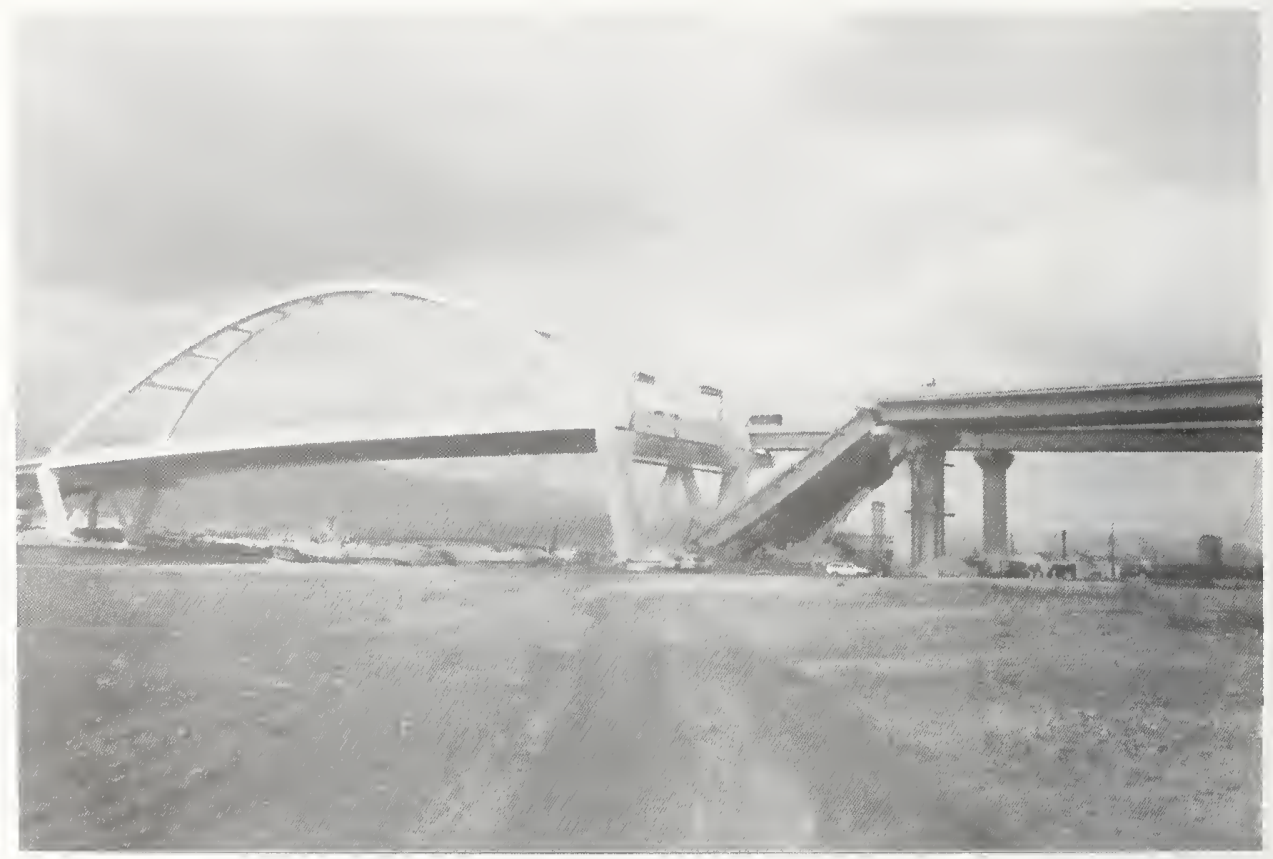

Figure 4.2.2a General view of Nishinomiya-ko Bridge, Route 5.

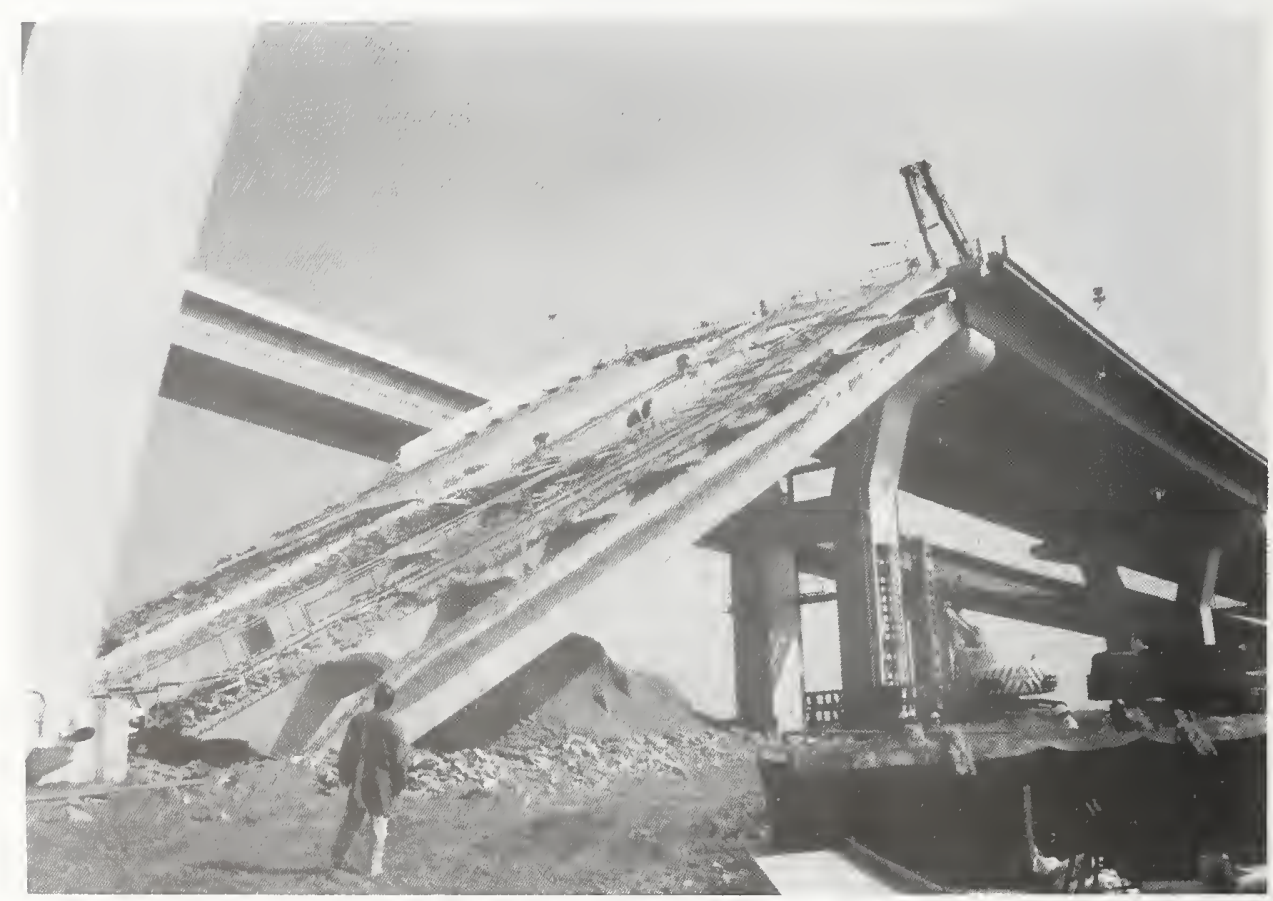

Figure 4.2.2b

Collapsed approach span between Piers 111 and 112, Nishinomiya-ko Bridge. 
Figure 4.2 .3

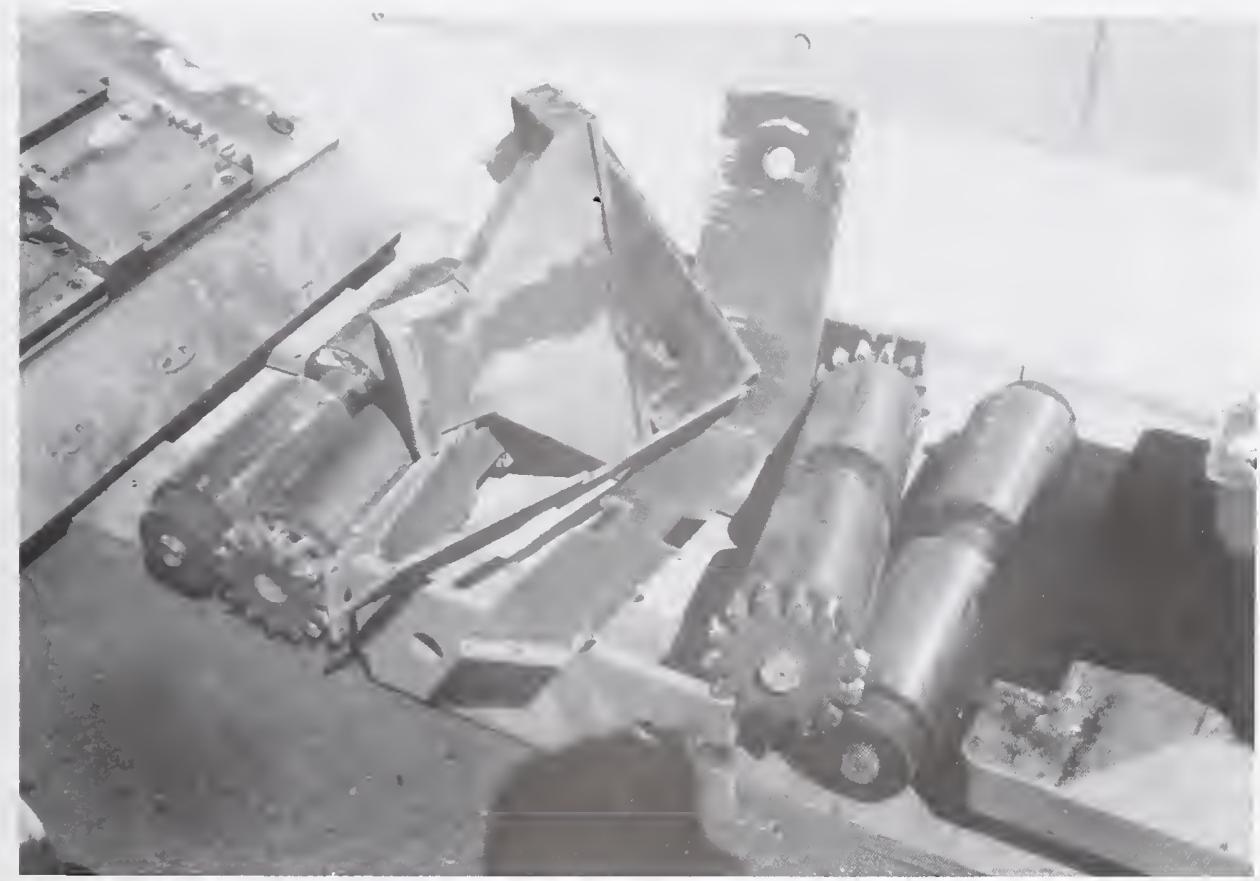

Damaged expansion bearings from under approach spans, Nishinomiya-ko Bridge, showing nested rollers and guide rails.

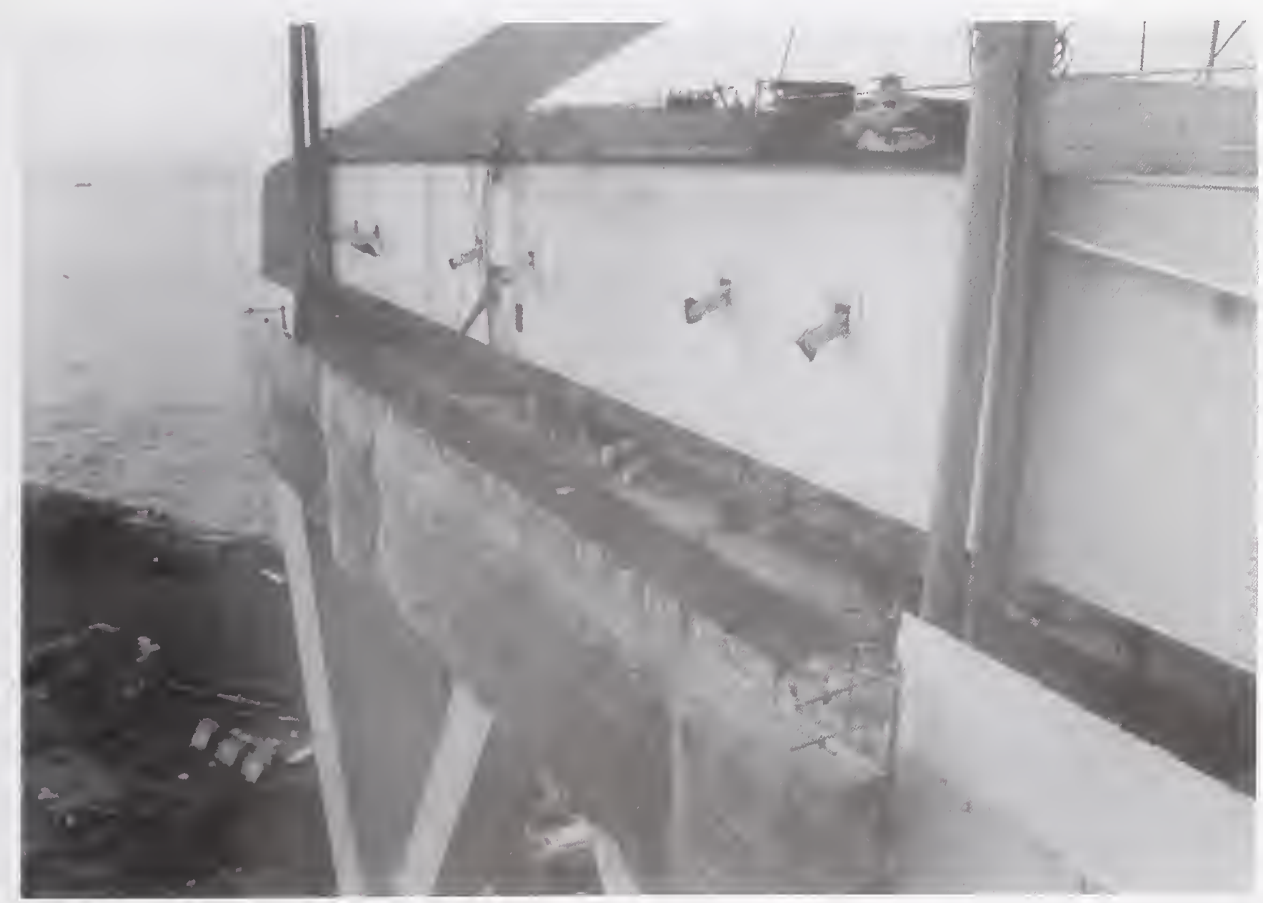

Figure 4.2 .4

Cap beam of Pier 111, Nishinomiya-ko Bridge, showing cross-girder of arch and failed restrainers. 


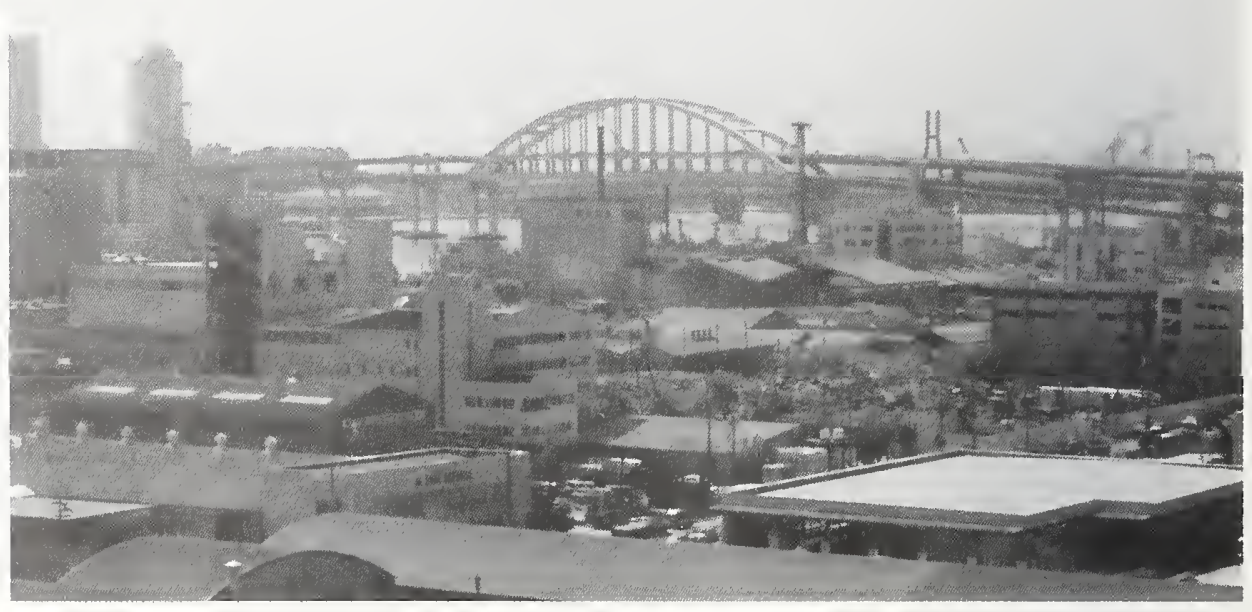

Figure 4.2.5 General view of Rokko Island Bridge, Route 5.

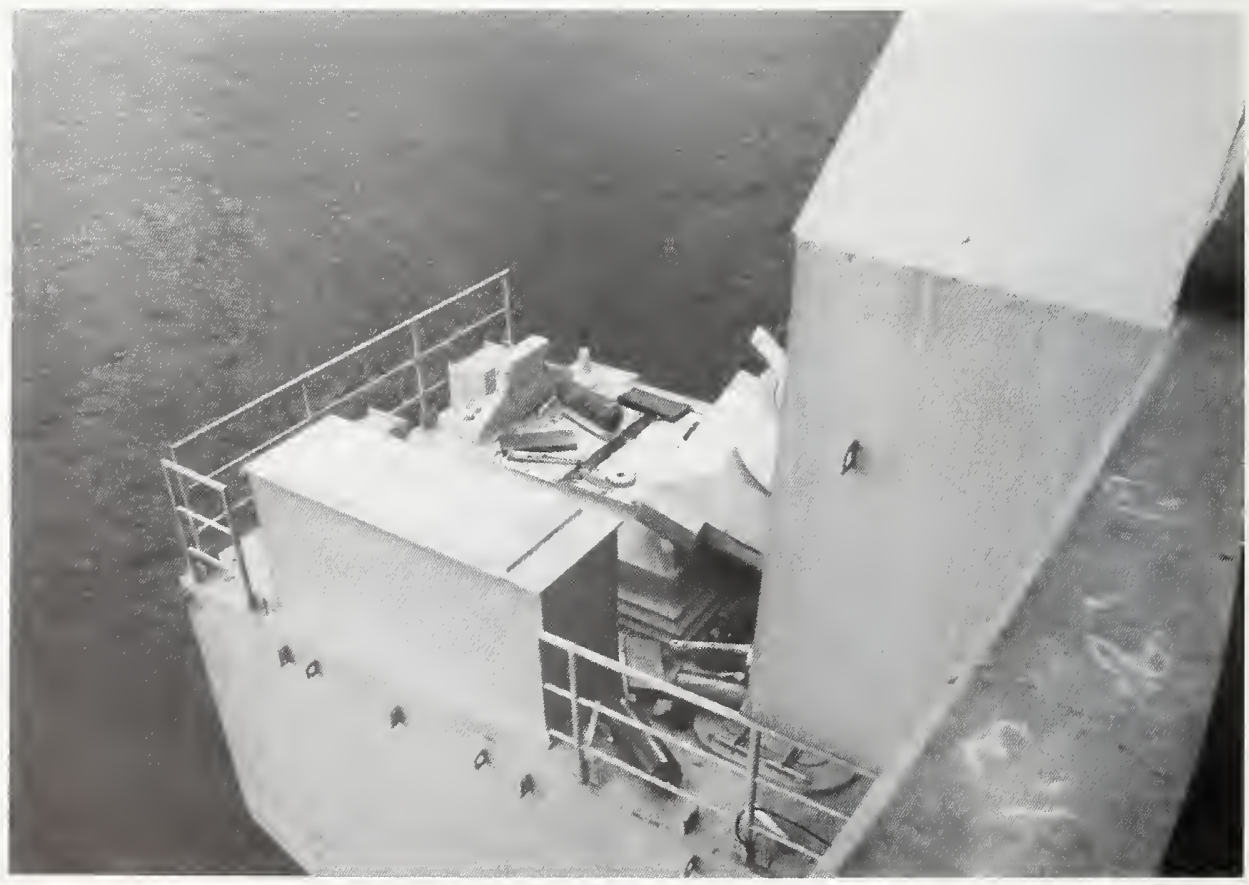

Figure 4.2.6 Damaged expansion bearing and lateral offset of west face of South Pier, Rokko Island Bridge. 


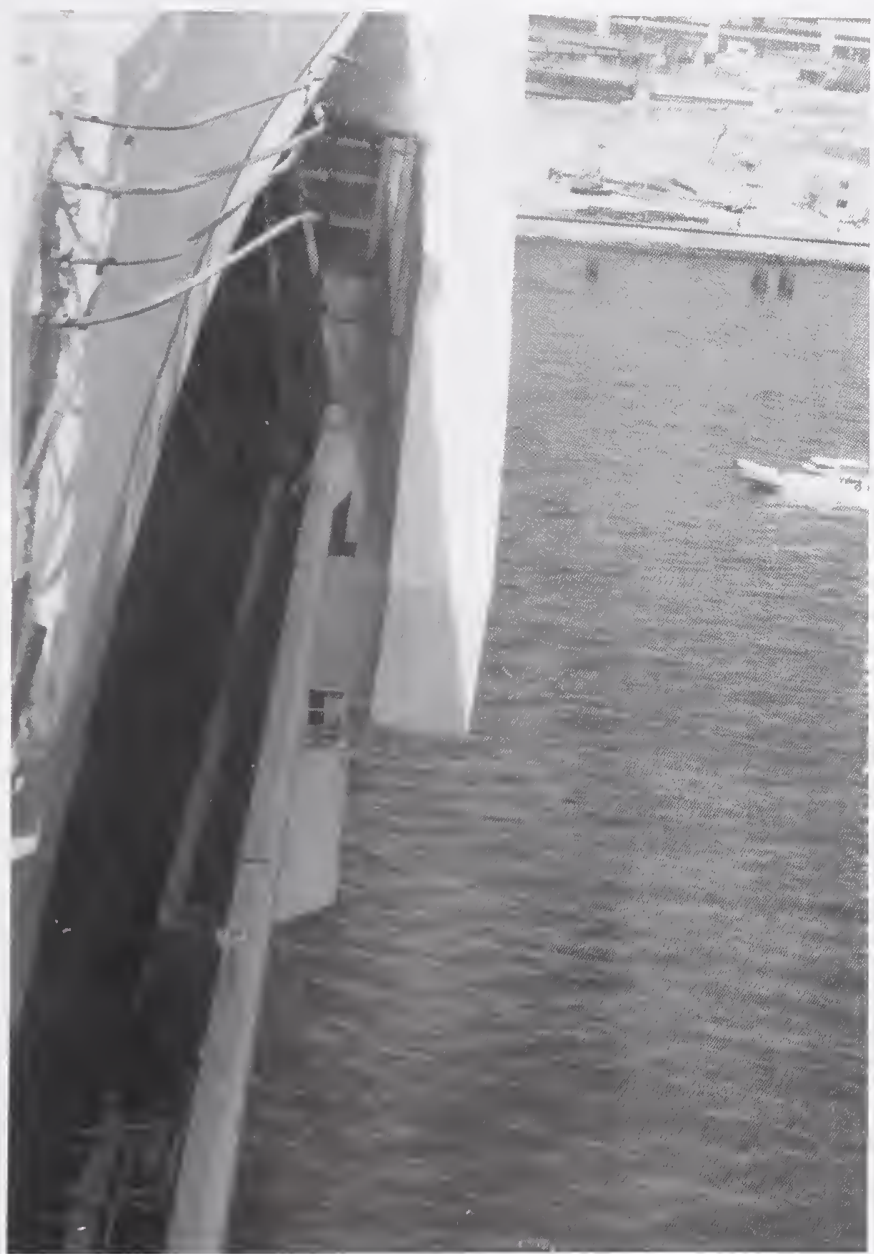

Figure 4.2.7 Lateral offset at east face of South Pier, Rokko Island Bridge. 


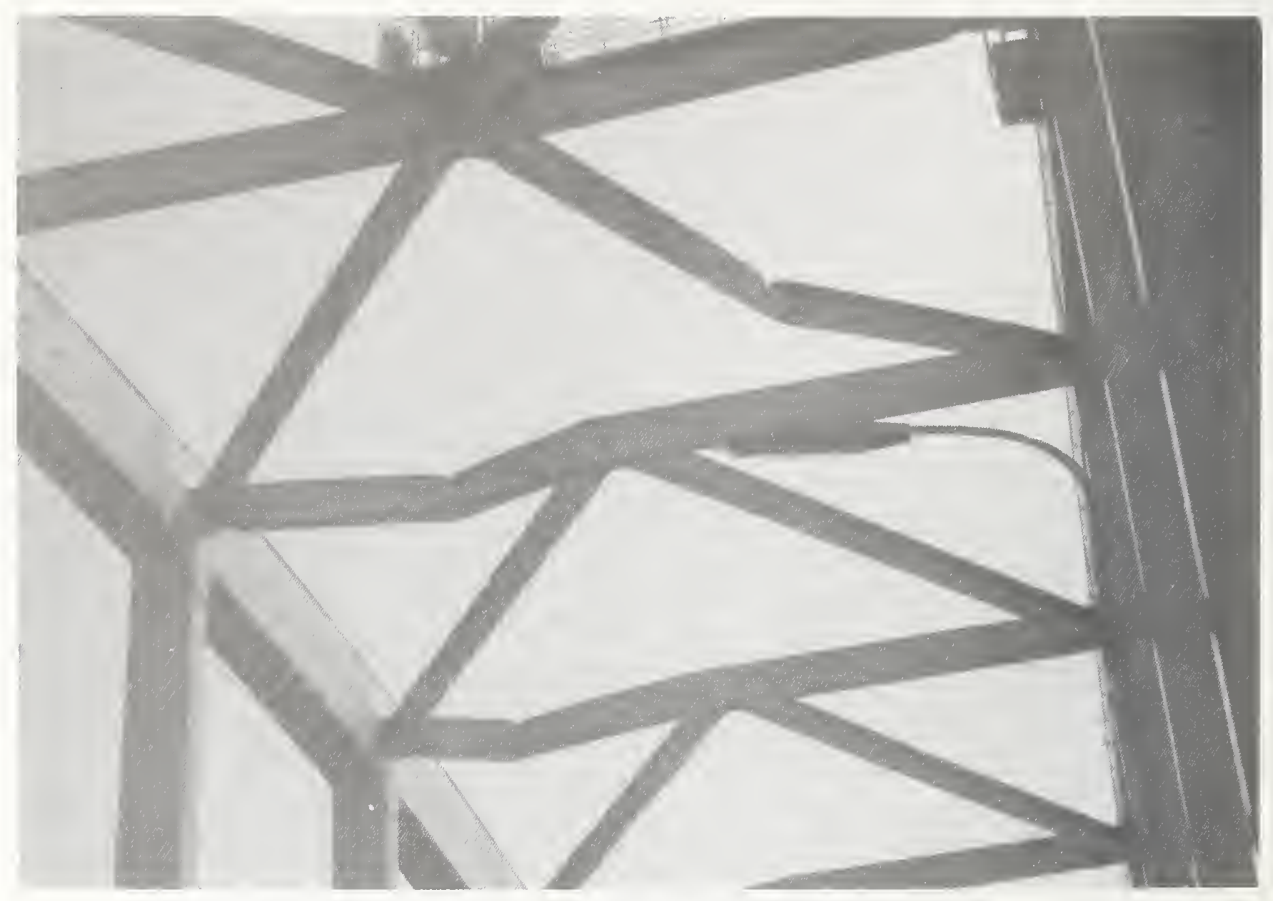

Figure 4.2.8 Buckled cross-members in Upper Chord, Rokko Island Bridge.

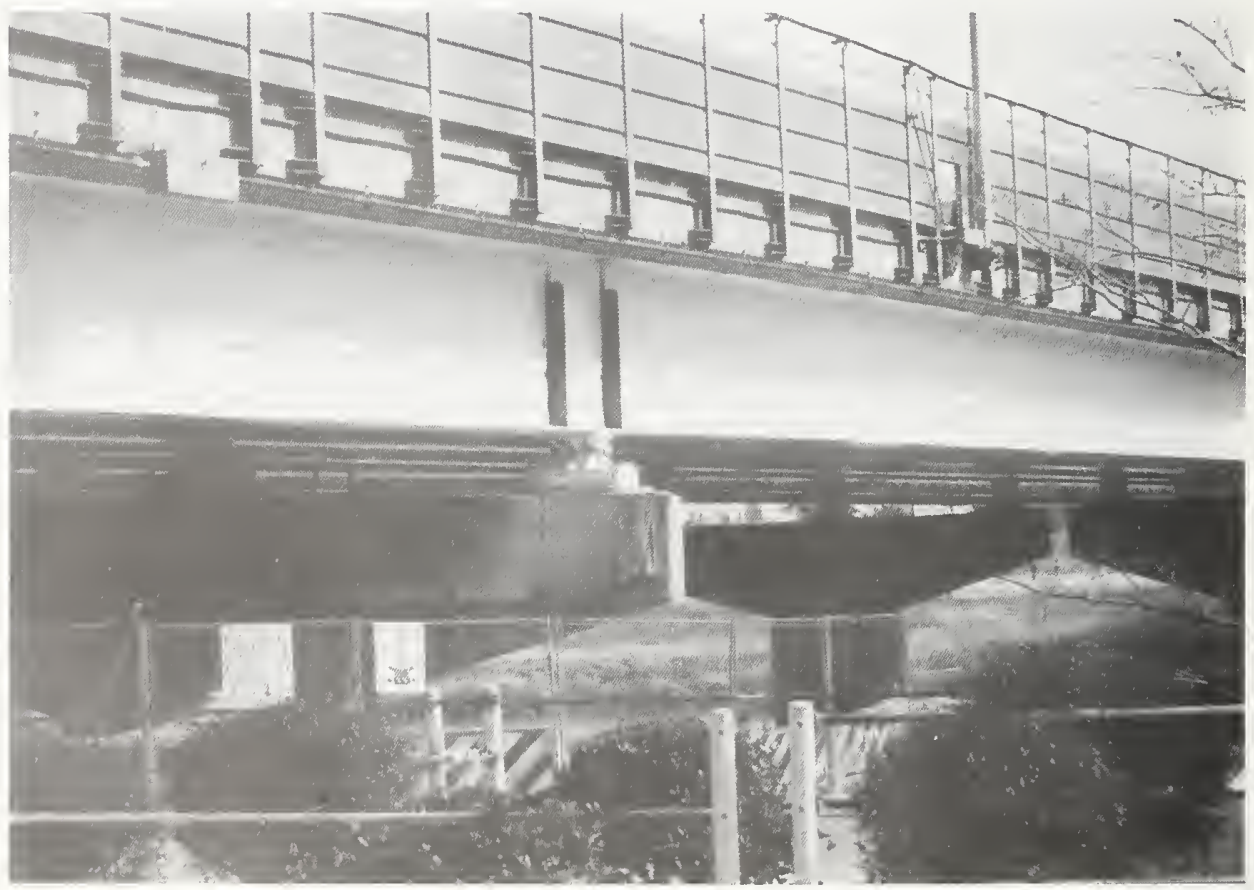

Figure 4.2.9

General view of Mukogawa Bridge, Meishin Expressway. 


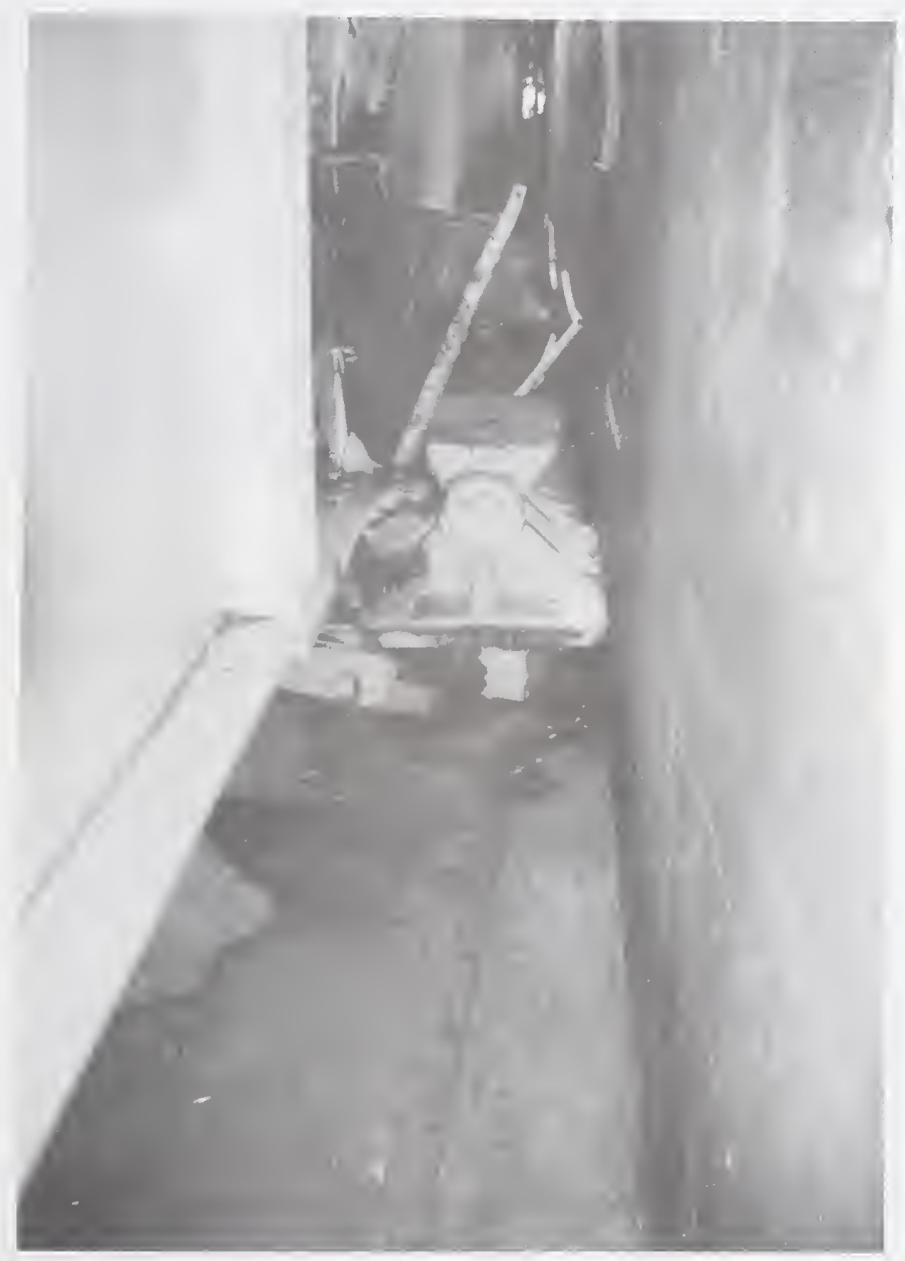

Figure 4.2.10

Bearing and restrainer damage at abutment A1, Mukogawa Bridge, showing distorted guide rails and uncoupled restrainer from abutment backwall. 


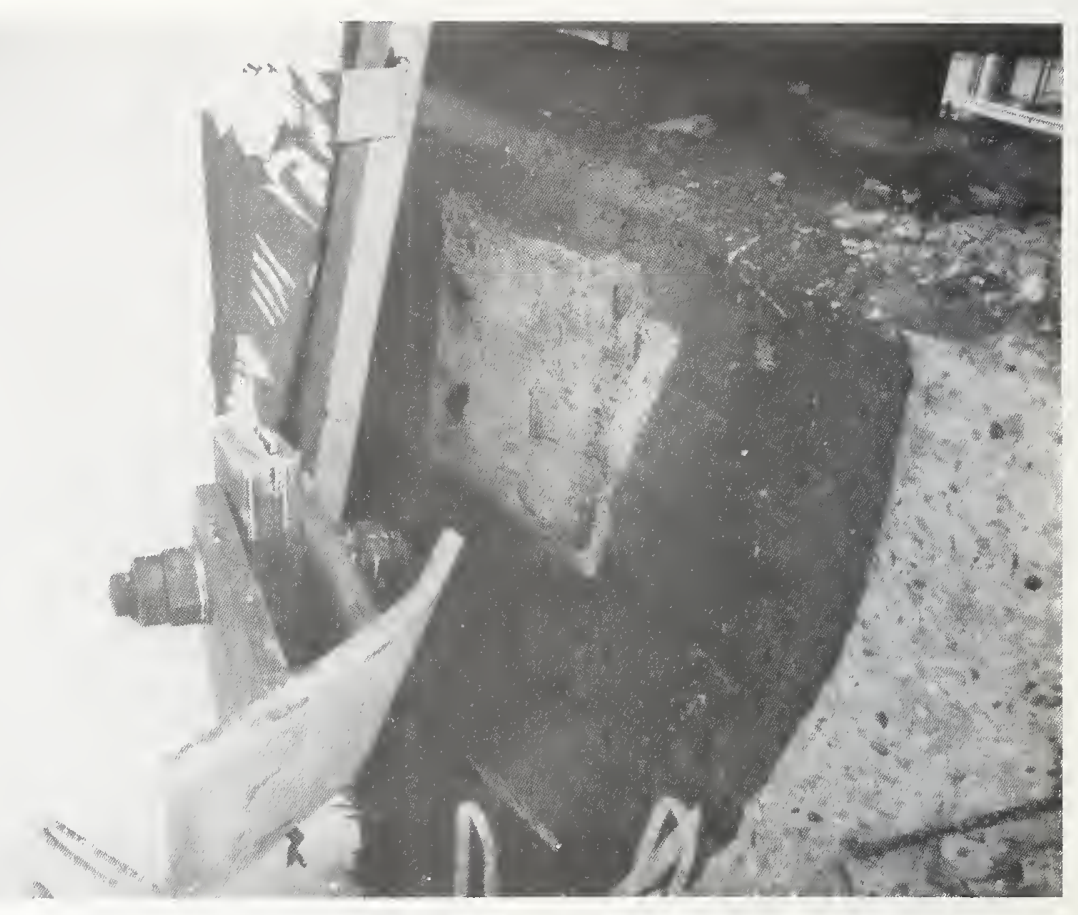

Figure 4.2.11

Damaged restrainer at Abutment A1, Mukogawa Bridge, showing failure of anchor bolts and distortion of web of main girder.

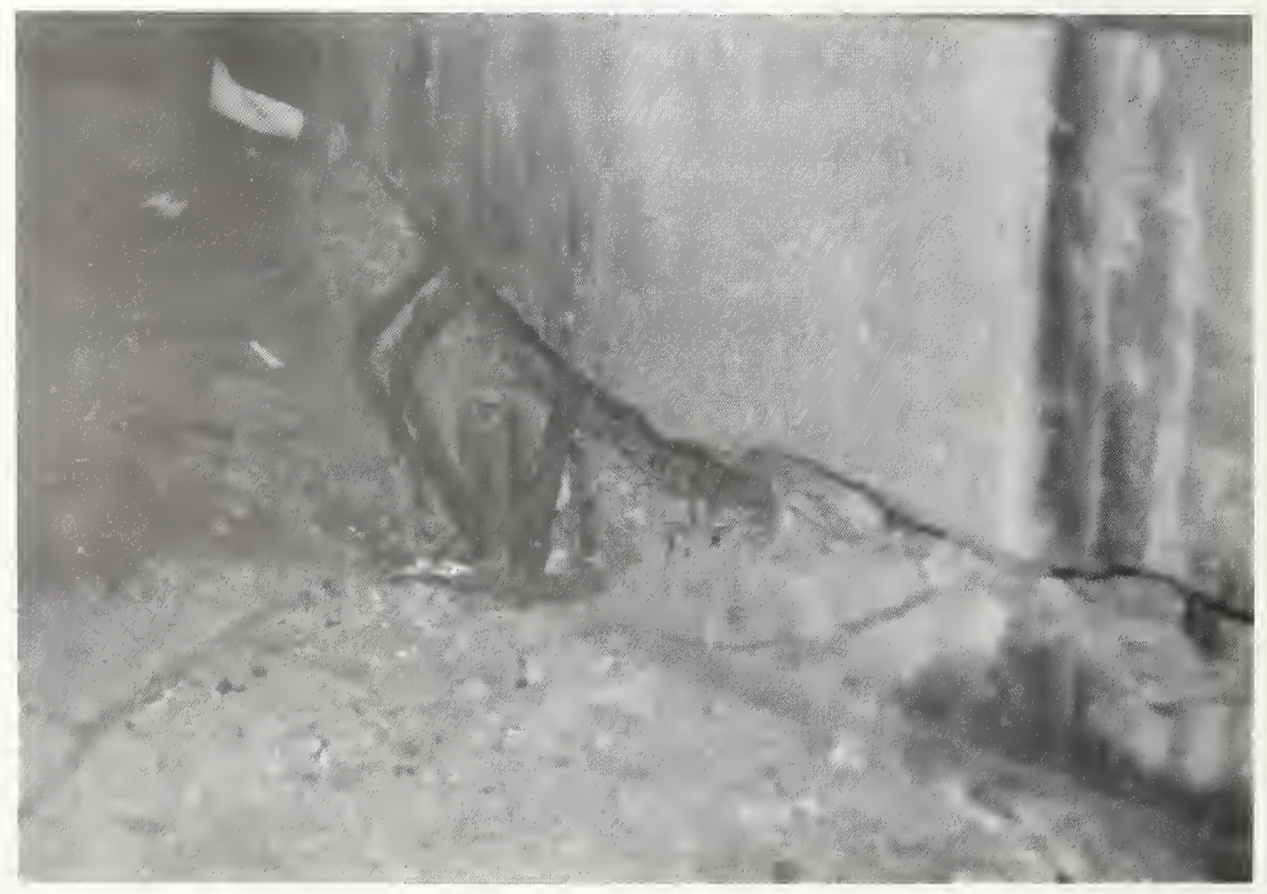

Figure 4.2.12

Failure at top of buried column, Pier P1, Mukogawa Bridge. 


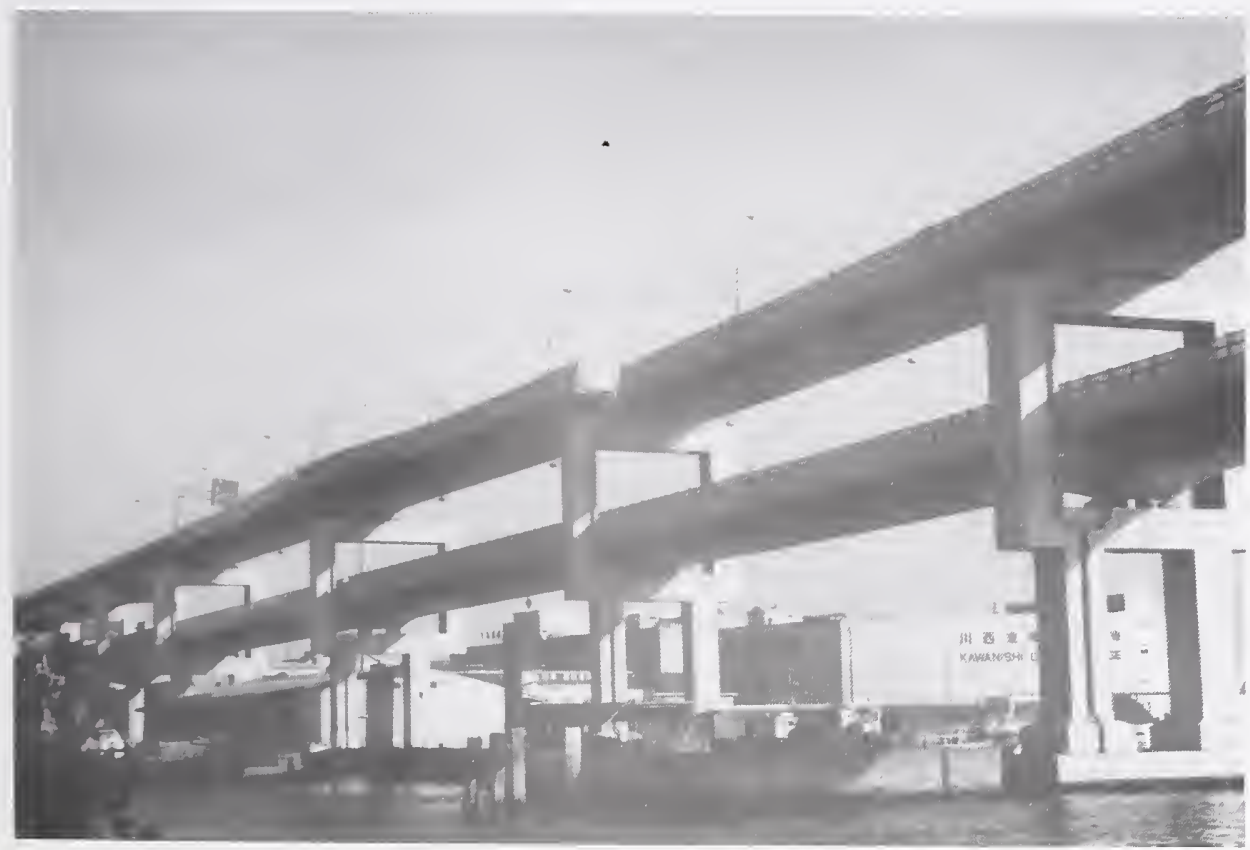

Figure 4.2.13

Lateral offset at Pier 36 in upper level of Hamate By-Pass due to bearing failures at Piers 34 through 38.

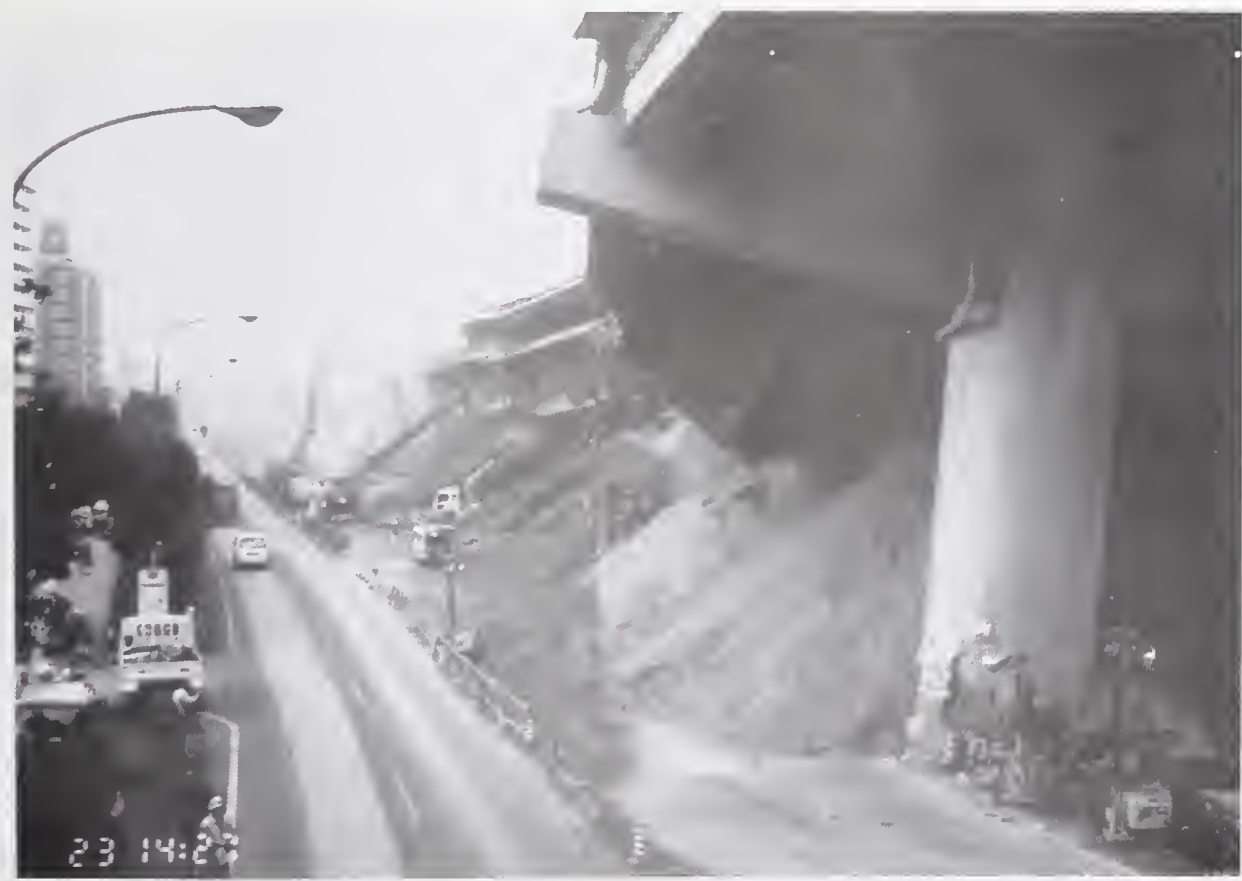

Figure 4.2.14

View of the collapsed Higashi-Nada Viaduct looking west from Pier 125. 


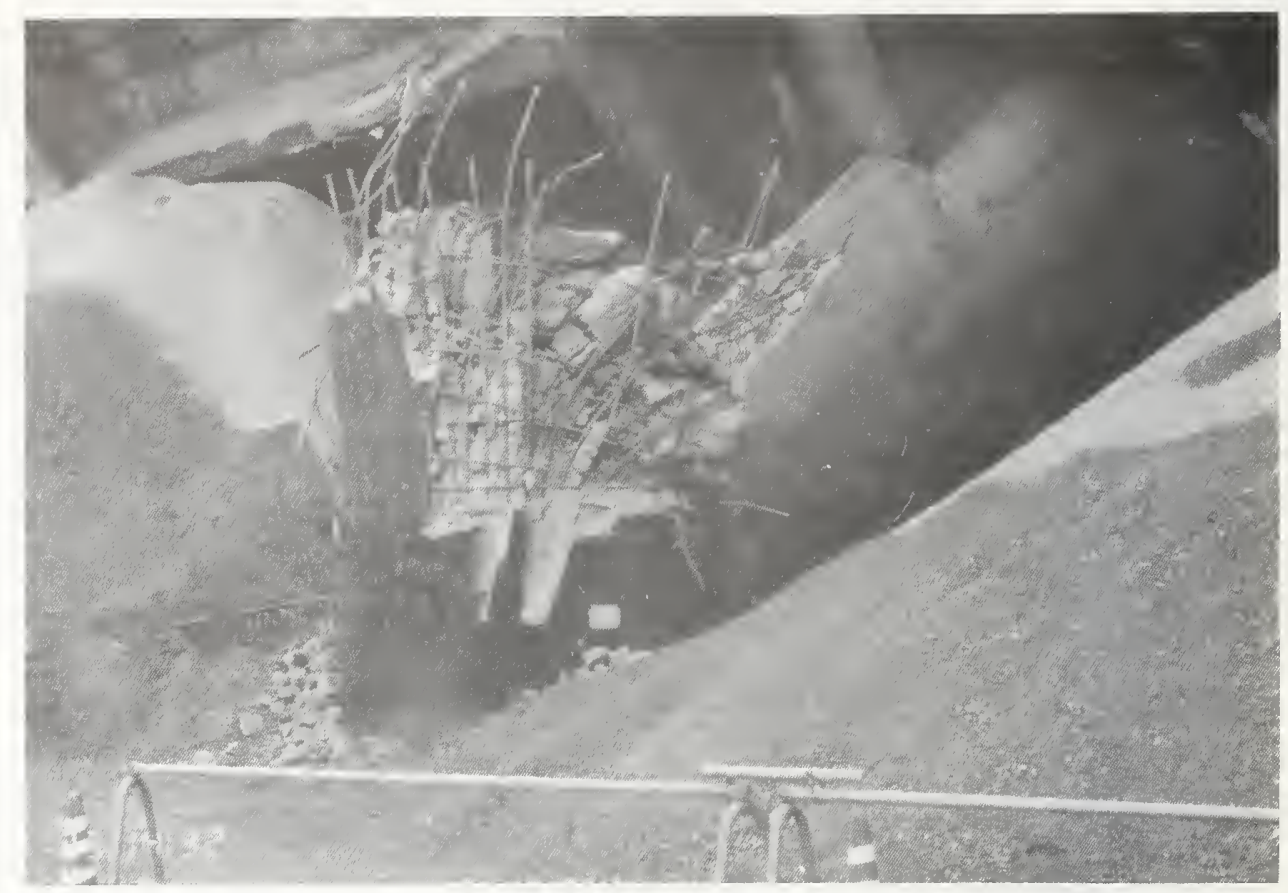

Figure 4.2.15 Higashi-Nada Viaduct, Pier 126.

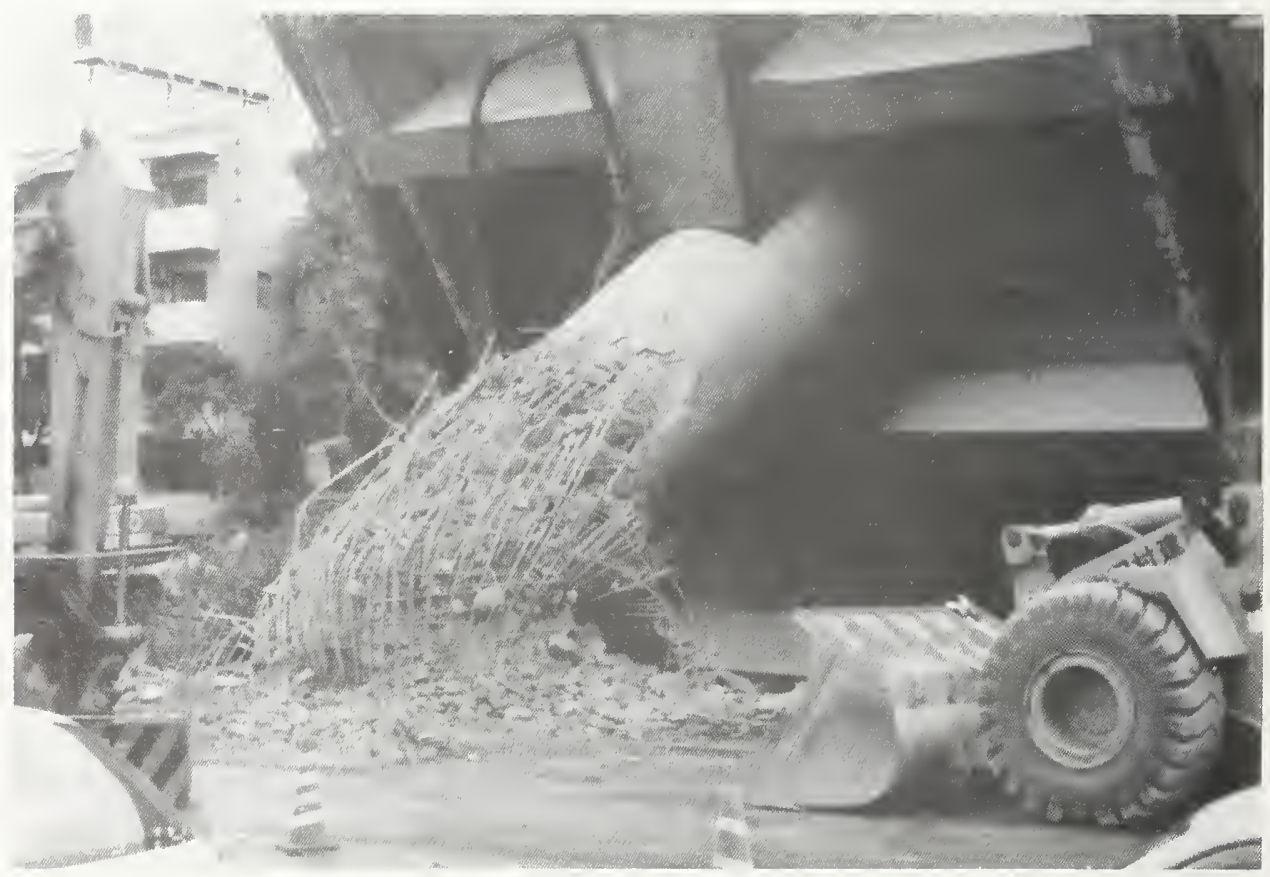

Figure 4.2.16

Higashi-Nada Viaduct, Pier 134. 


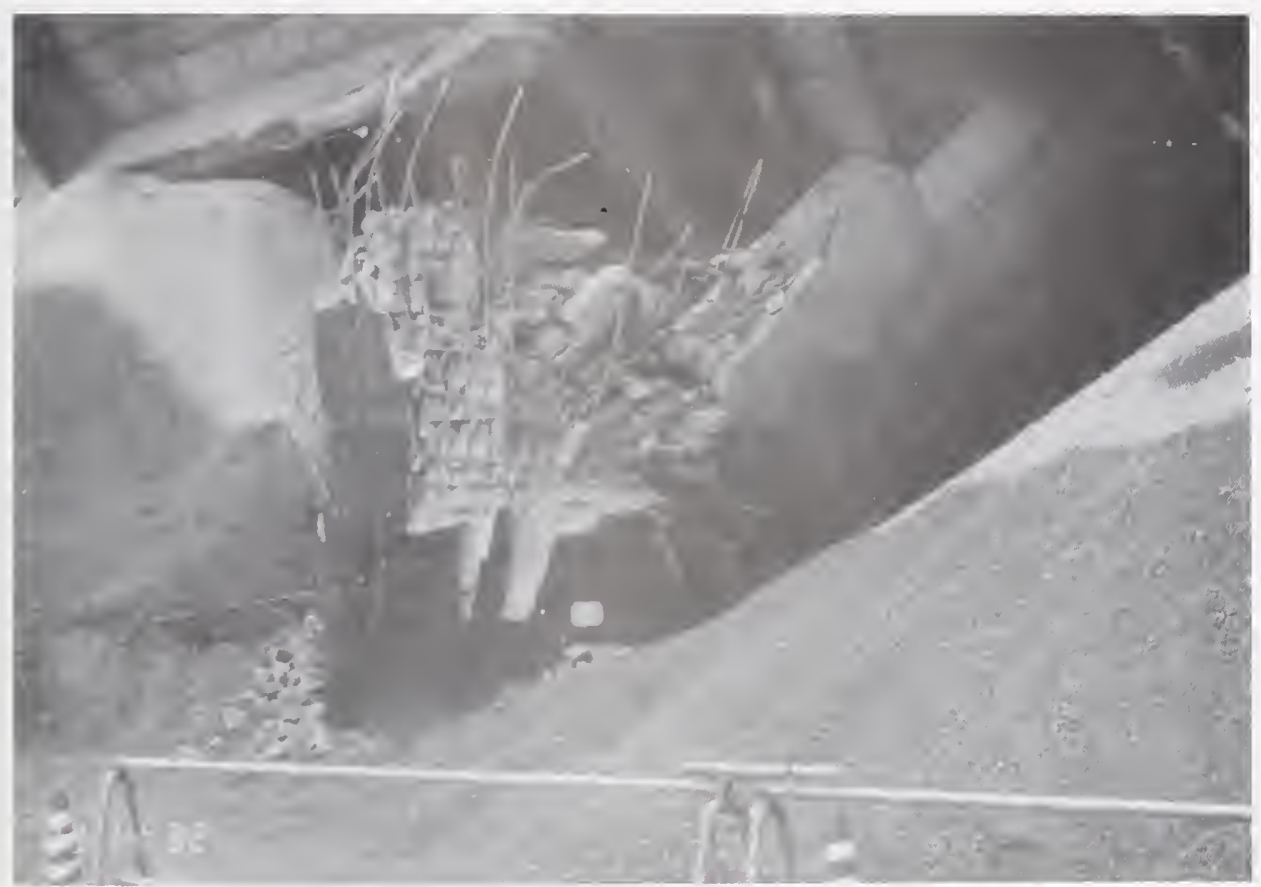

Figure 4.2.17 General view of Hashin Expressway (Route 5) near Uozaki showing collapse of section over Pier 240 in middle distance.

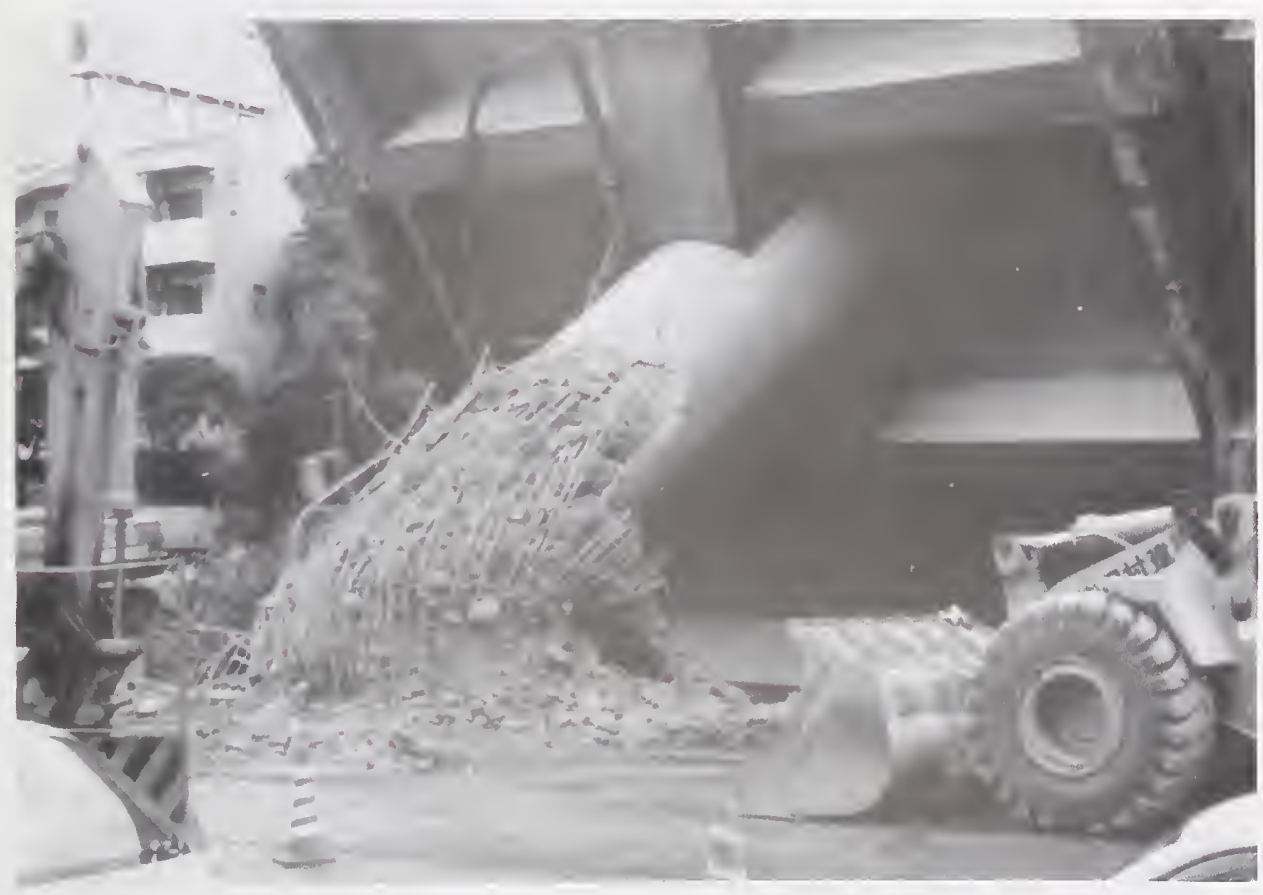

Figure 4.2.18

Pier 240 of Hanshin Expressway showing temporary repair to this single column bent. 


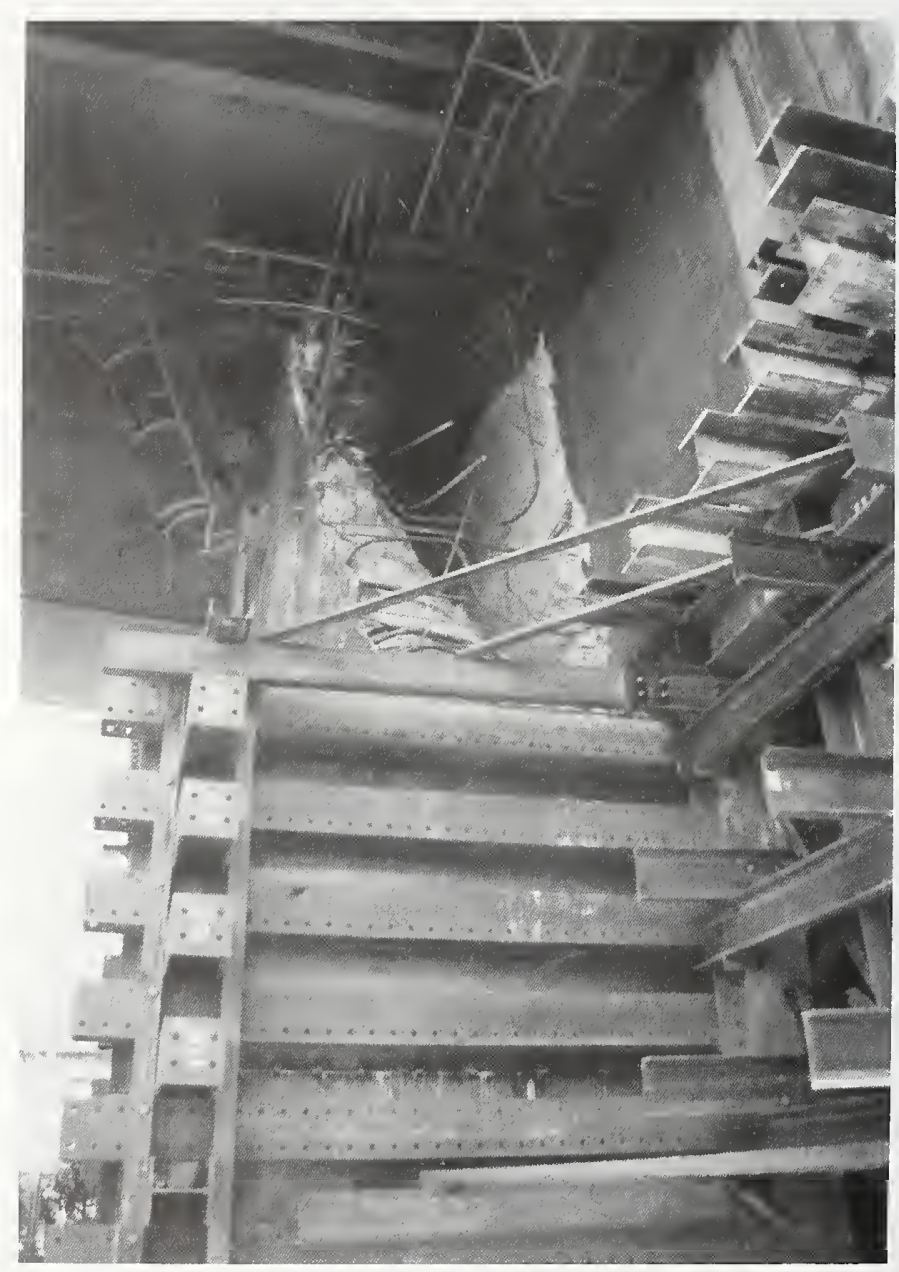

Figure 4.2.19

Shear failure in Pier 240 of Hanshin Expressway showing temporary repair to column to prevent total collapse. 


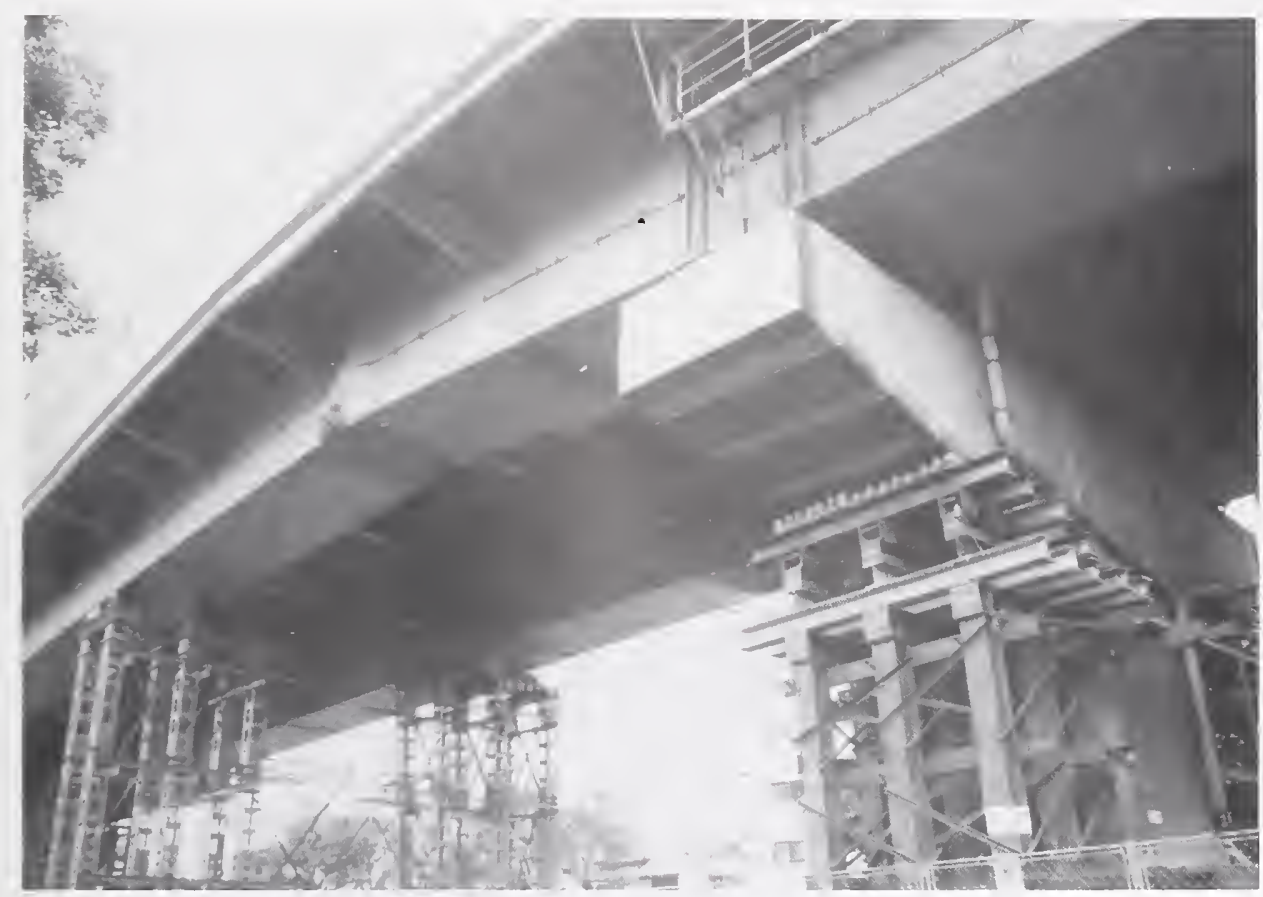

Figure 4.2.20

Compressive failure in lower flange of steel box girder between Piers 238 and 239 of Hanshin Expressway.

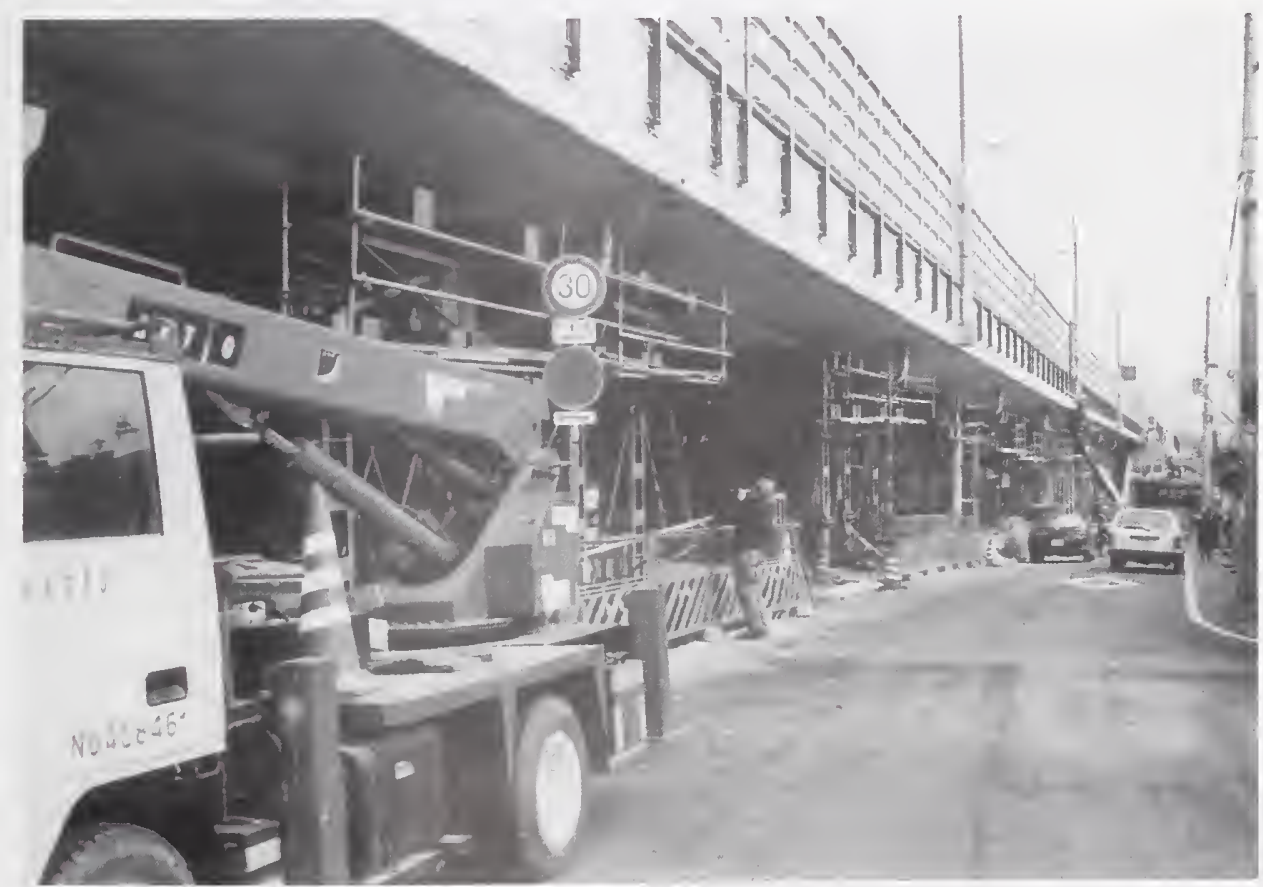

Figure 4.2.21 General view of Takarazuka Viaduct, Chugoku Expressway. 


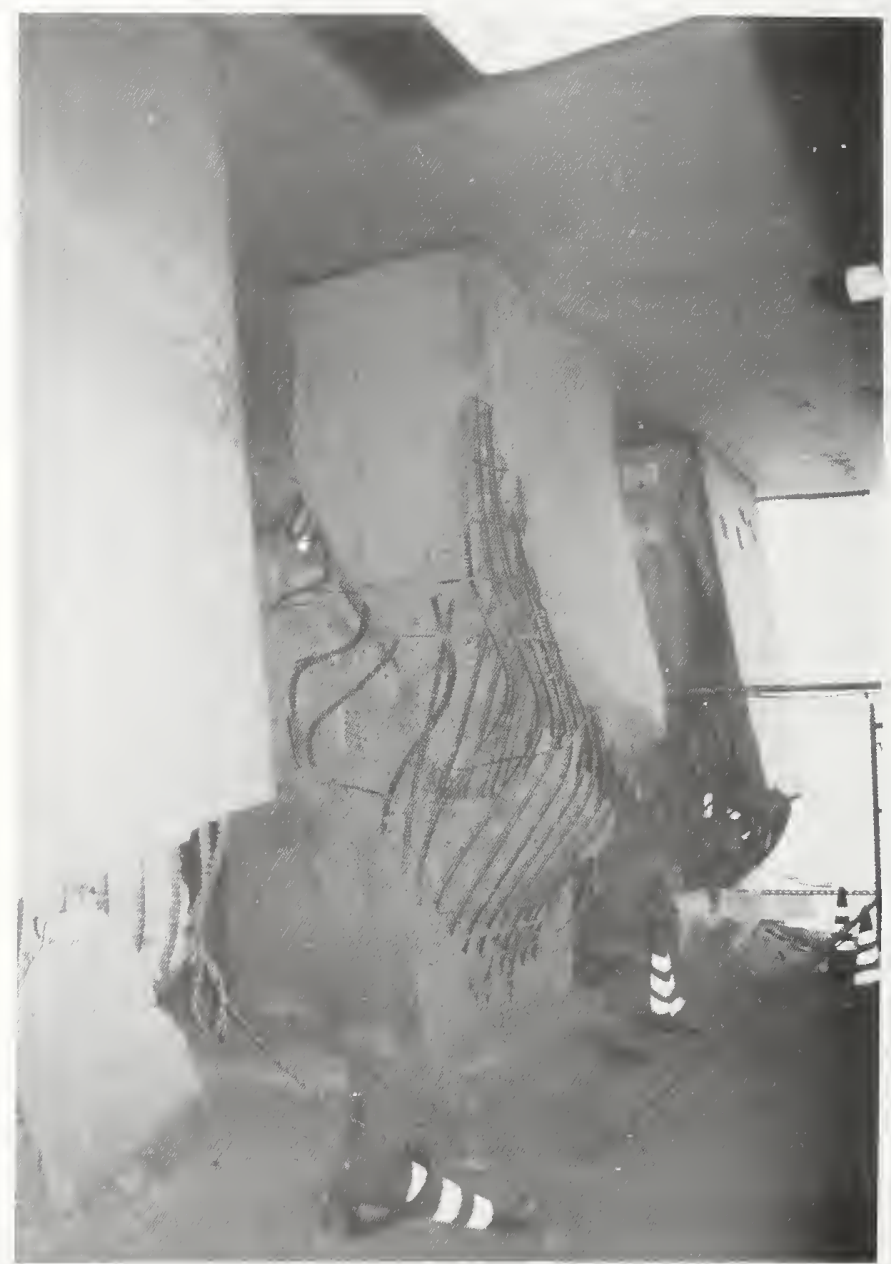

Figure 4.2.22 Shear failures in 3-column bent at Pier 3, Takarazuka Viaduct. 


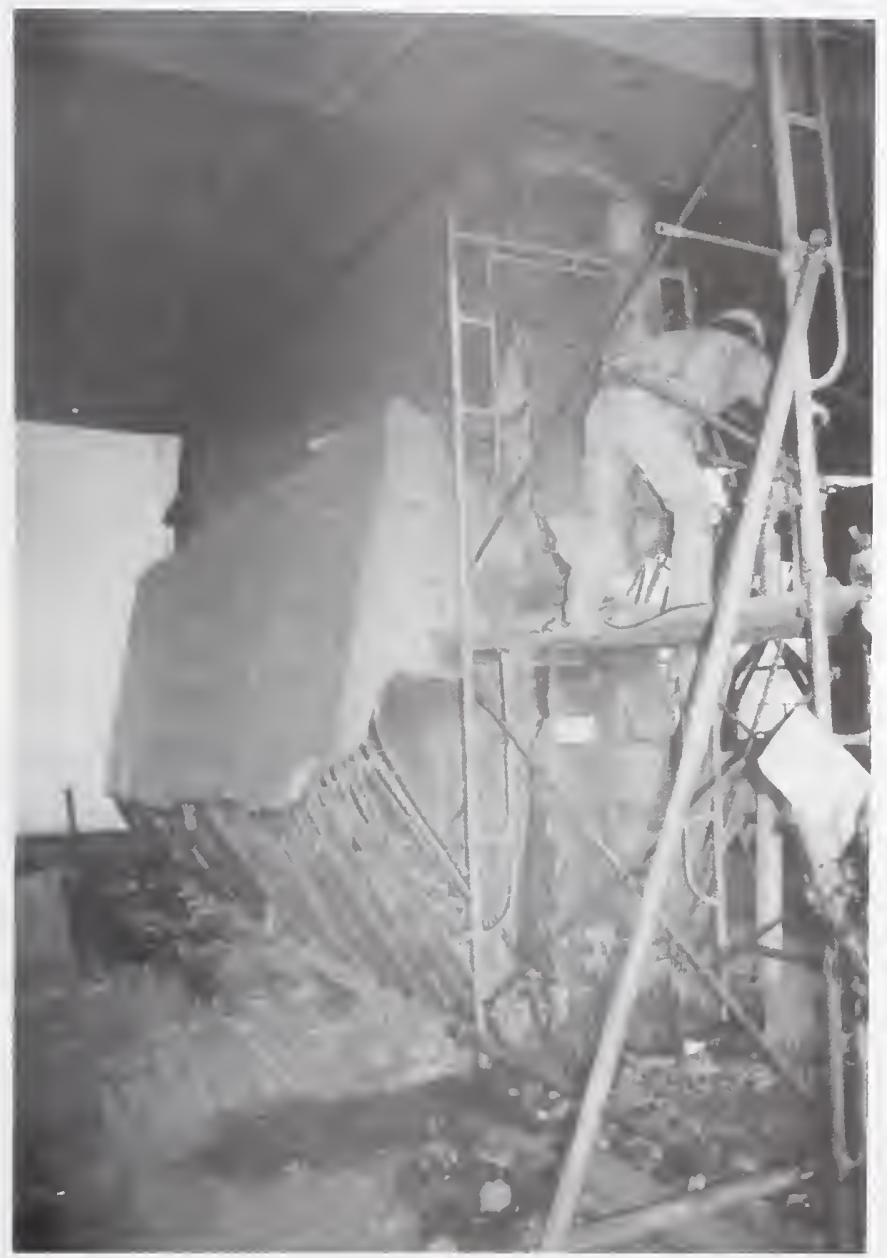

Figure 4.2.23 Shear failure in wall pier (west face), Moribe Viaduct. 


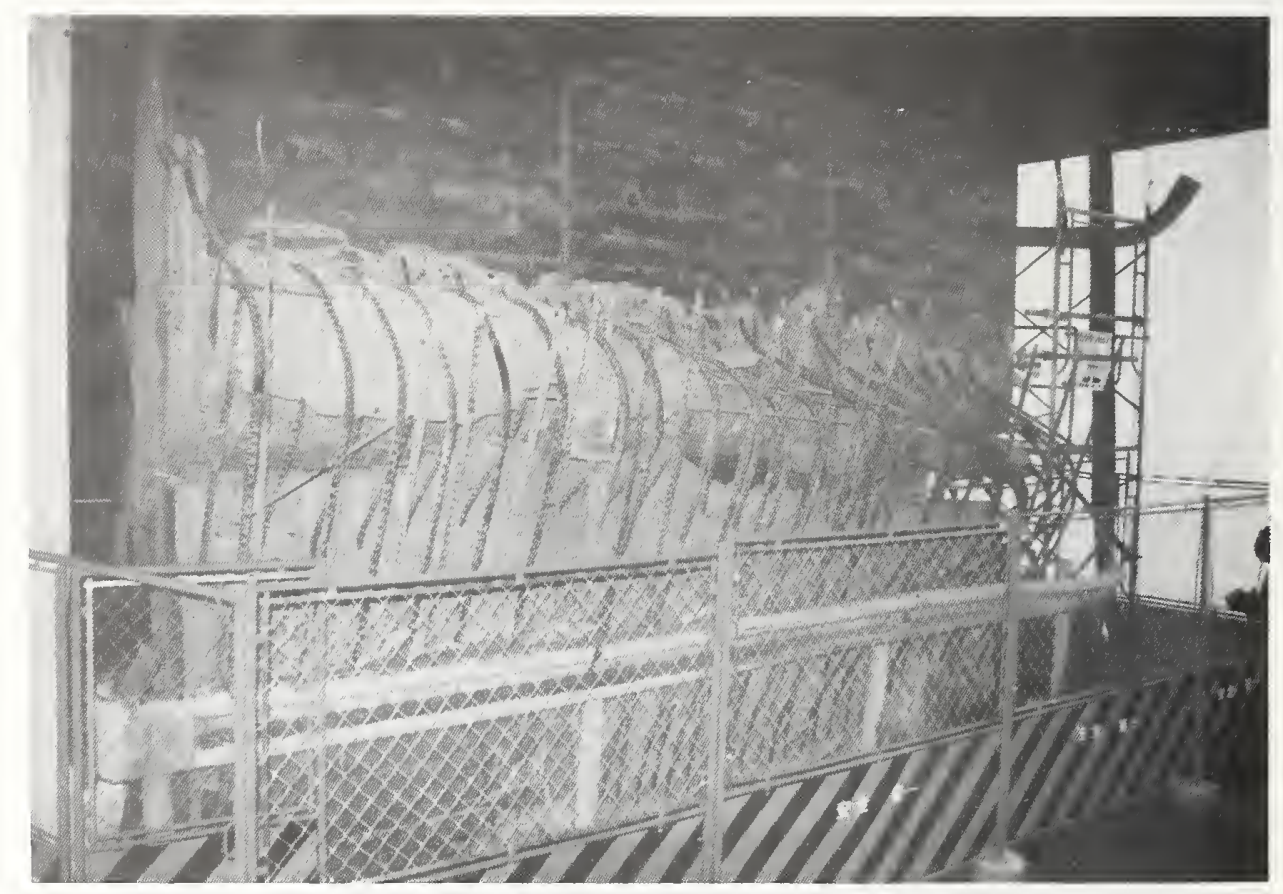

Figure 4.2.24 Shear failure in wall pier (east face), Moribe Viaduct.

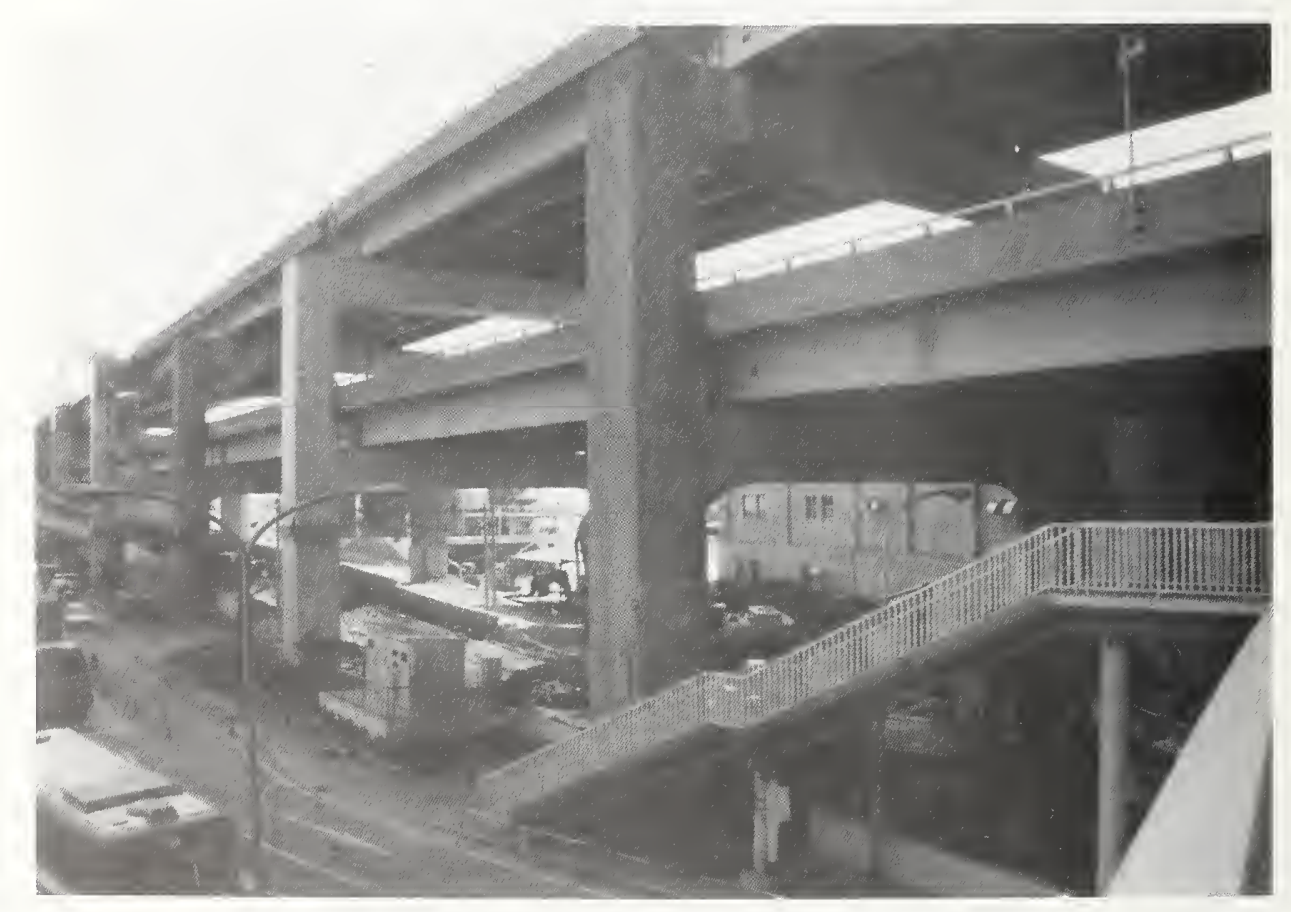

Figure 4.2.25

General view of Kobe-Ohashi Connector near Port Island showing formation of flexural hinges in lower level columns. 


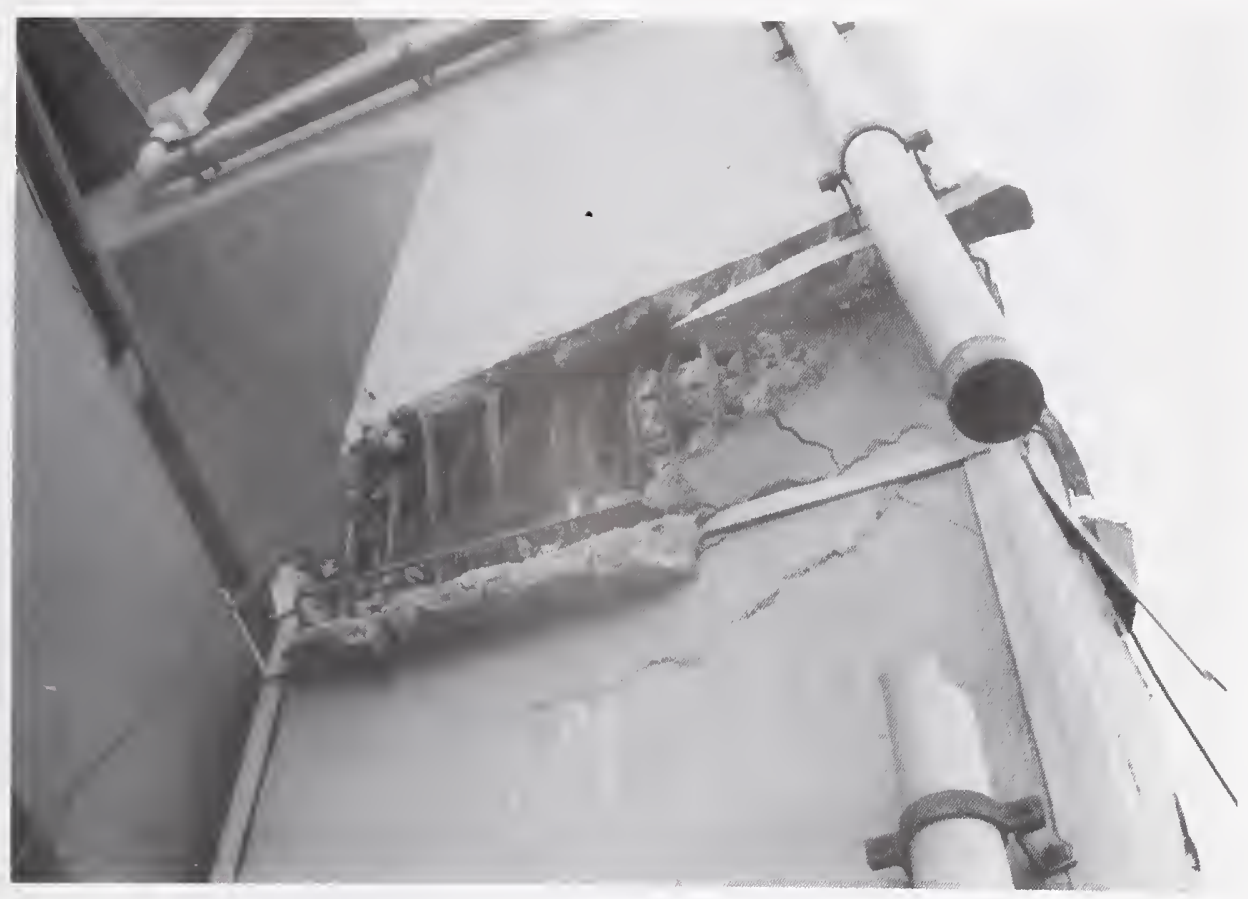

Figure 4.2.26

Hinge formation in east column of Pier 23, Kobe-Ohashi.

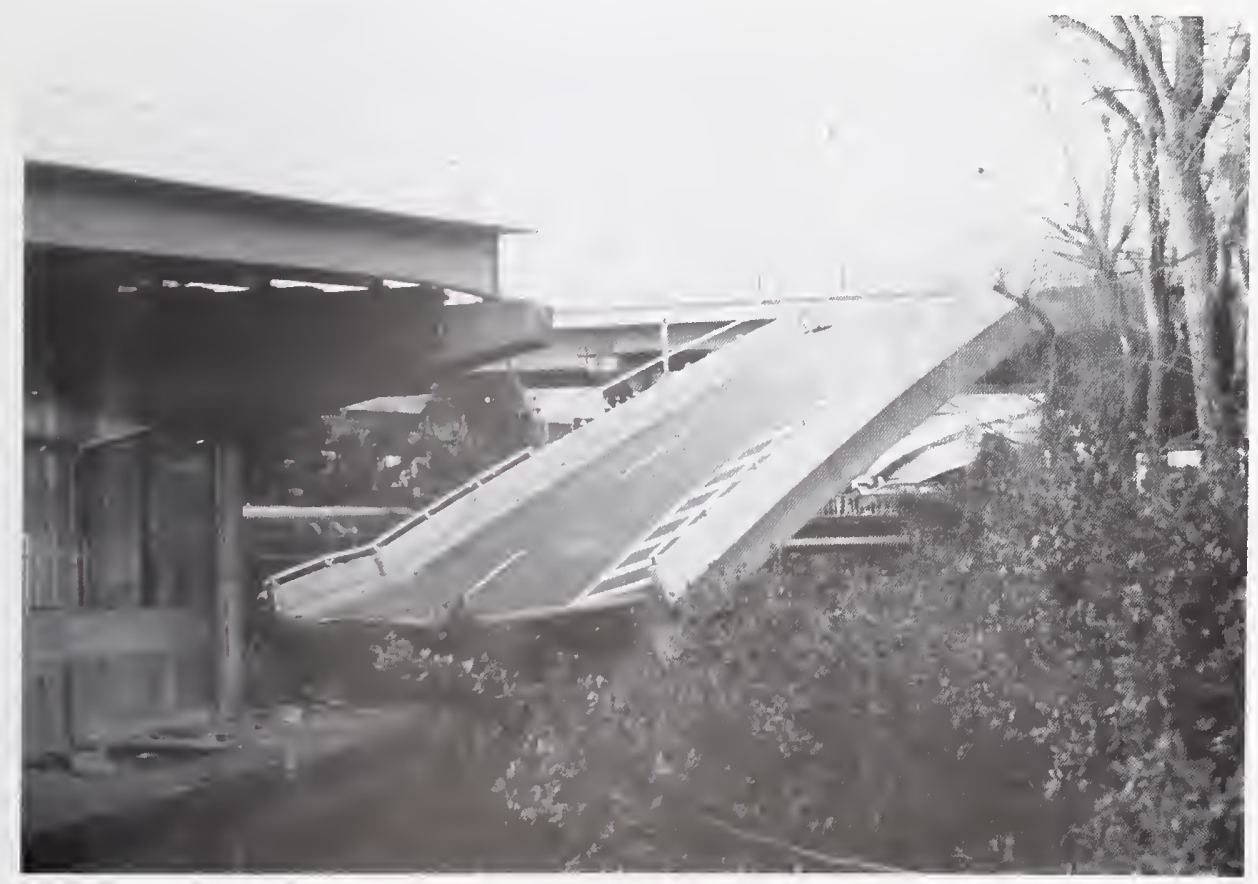

Figure 4.2.27

Collapse of Southeast Ramp at the Minatogawa Interchange. 


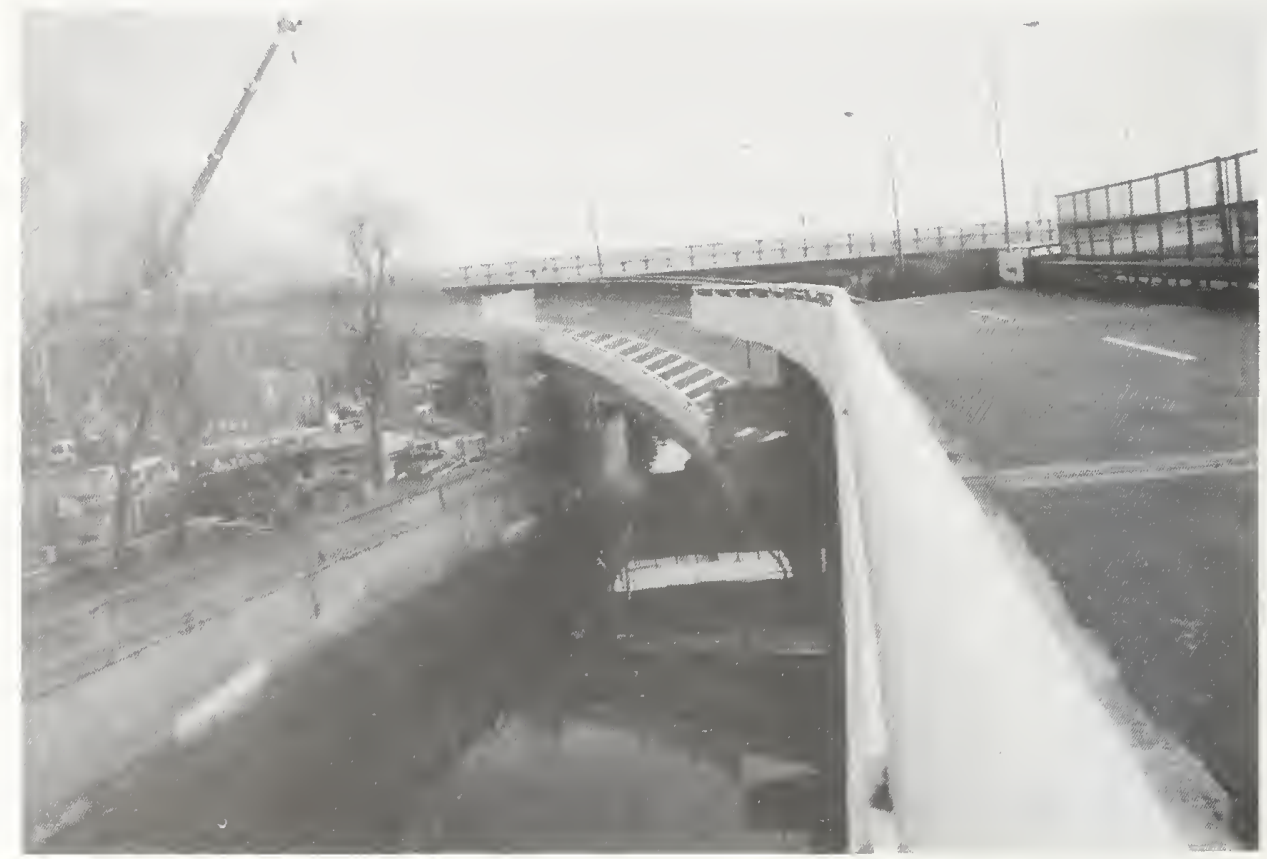

Figure 4.2.28

Collapse of Northeast Ramp at the Minatogawa Interchange.

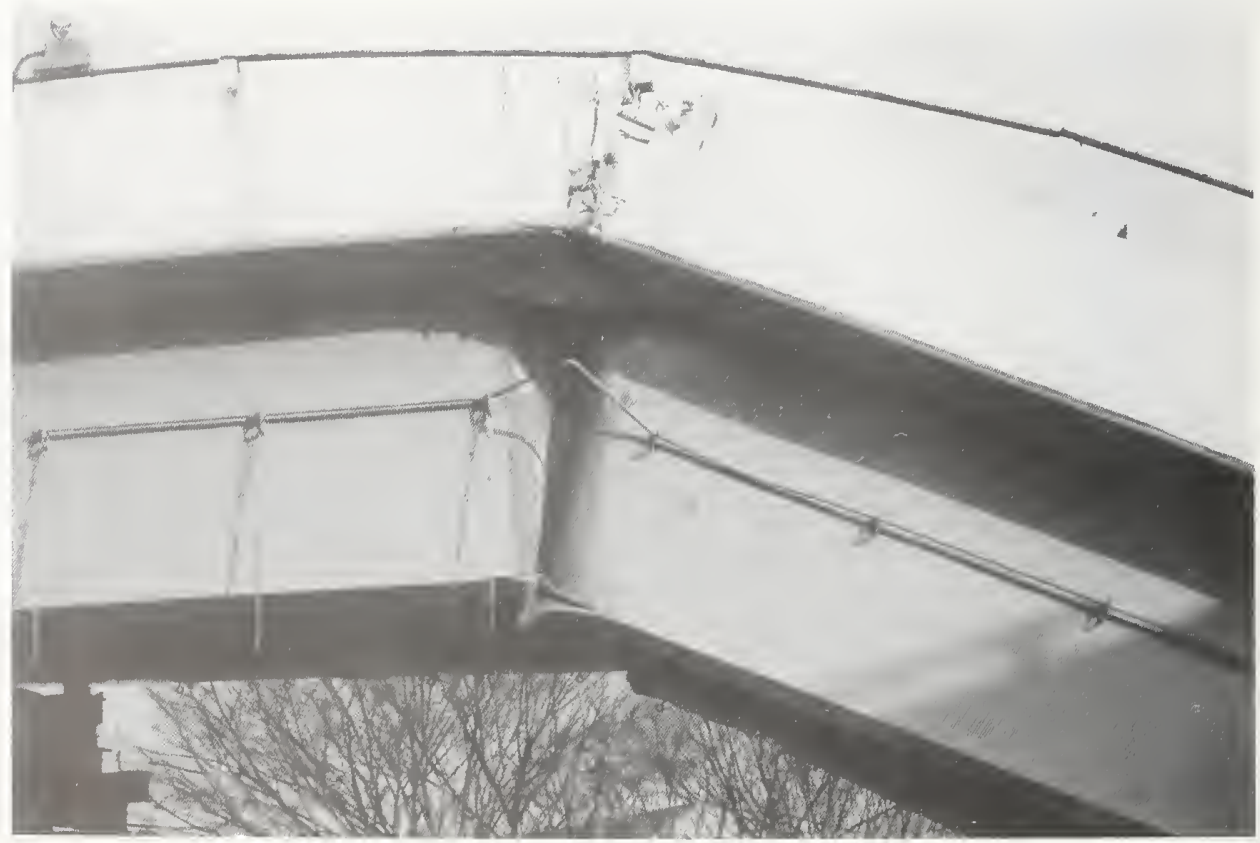

Figure 4.2.29

Girder web failure due to unseating of the Southeast Ramp at Minatogawa Interchange. 


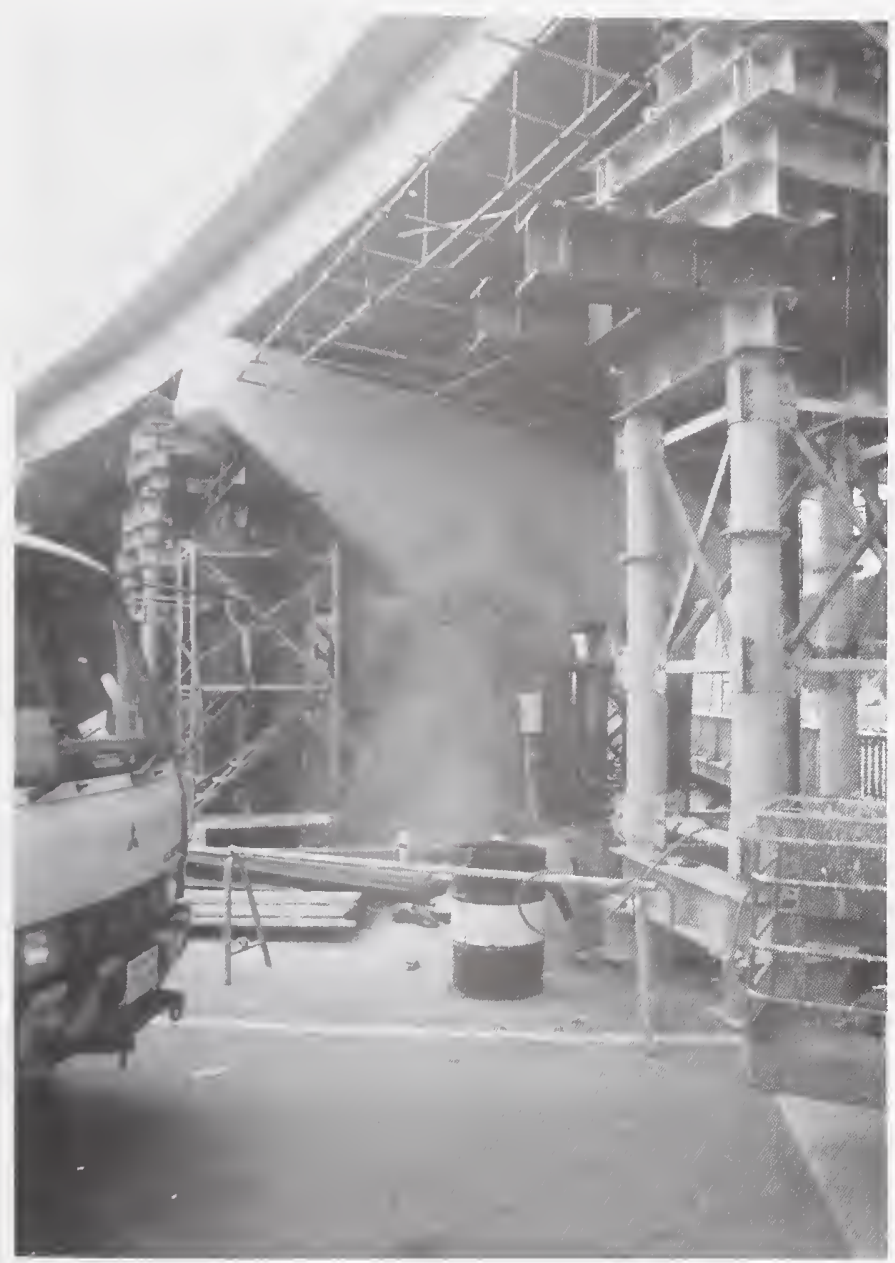

Figure 4.2.30

Column failure in Southwest Ramp at Minatogawa Interchange. 


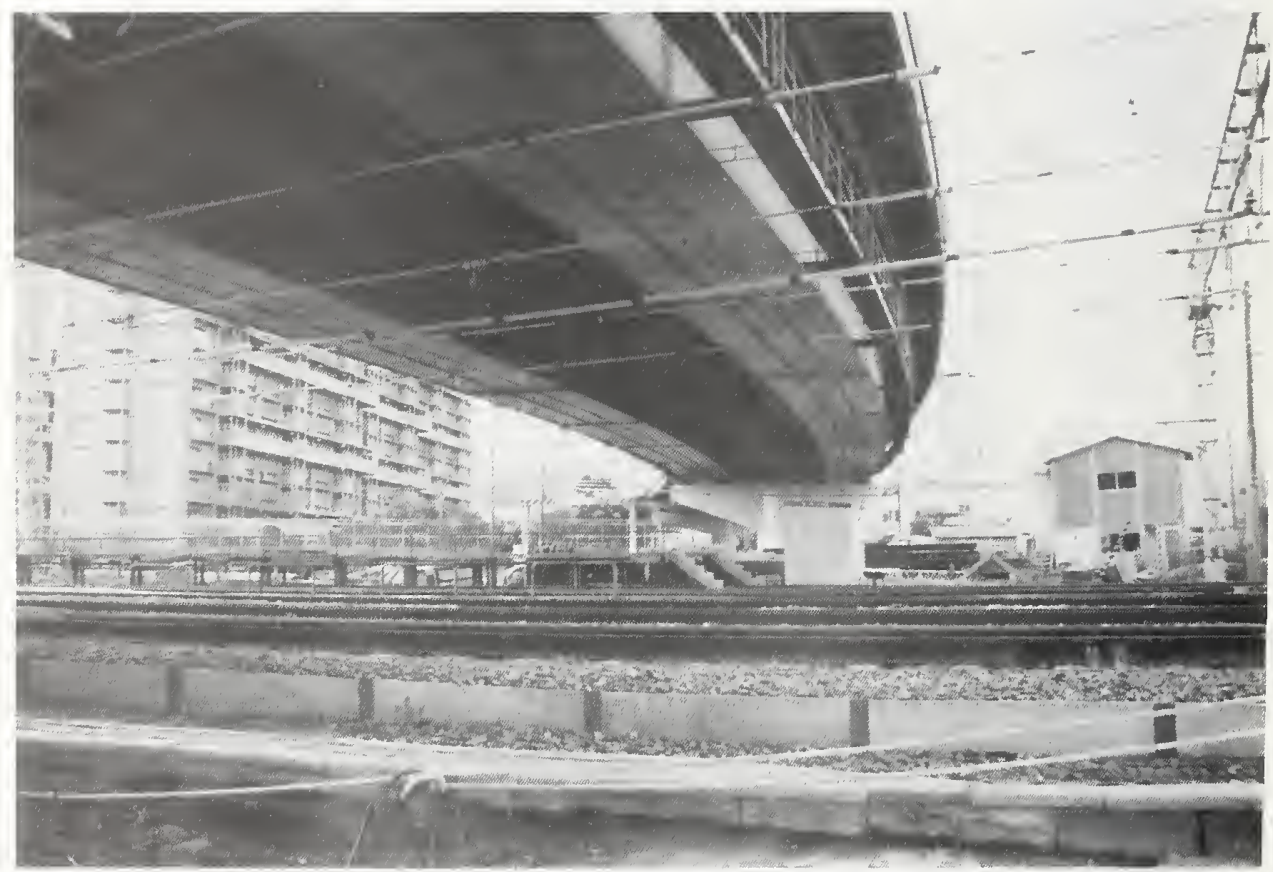

Figure 4.2.31

General view of Route 3 crossing JR Sanyo Line near Takatori. 


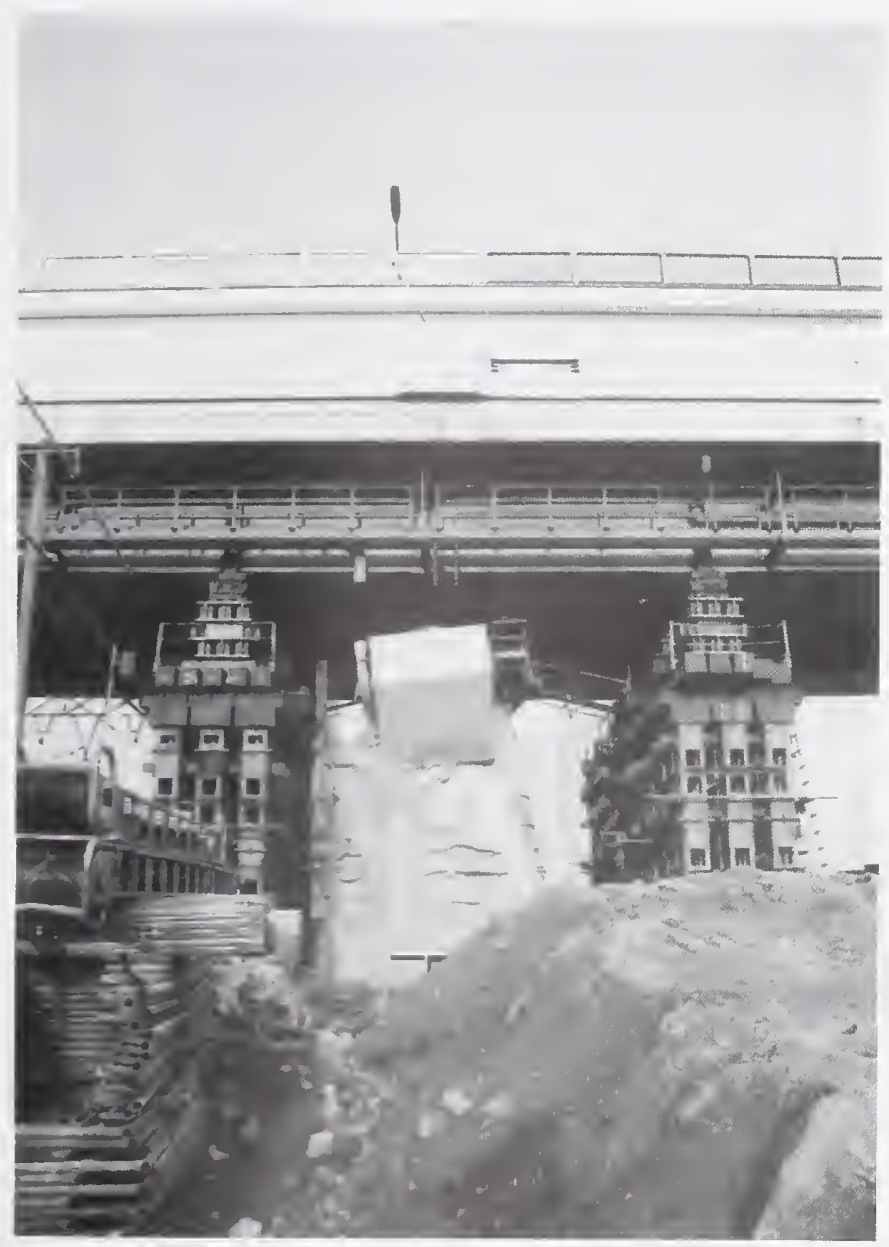

Figure 4.2 .32

Side view of shear failure in Pier 688 of Route 3 near JR Sanyo Line. 


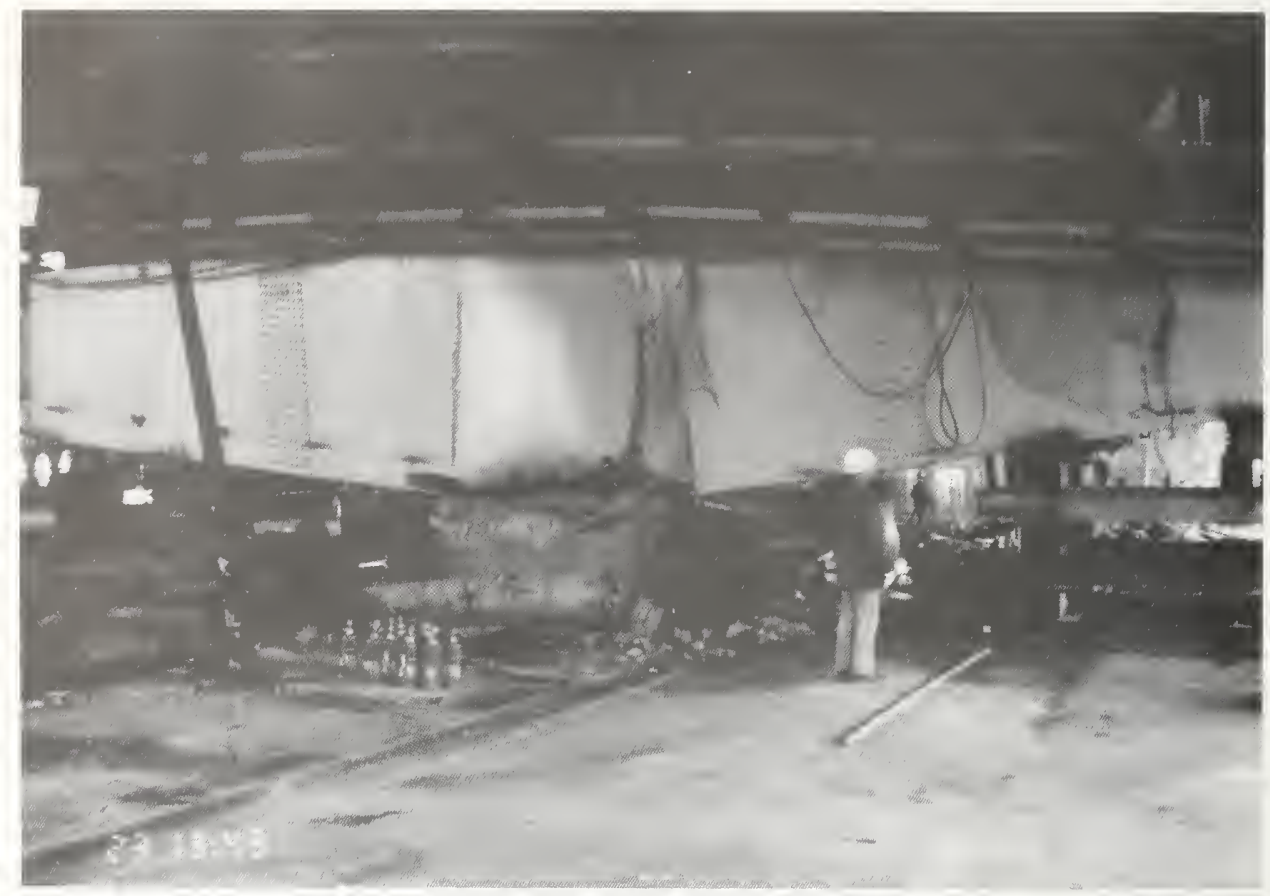

Figure 4.2.33

Pier 55, Route 3 near Tateishi.

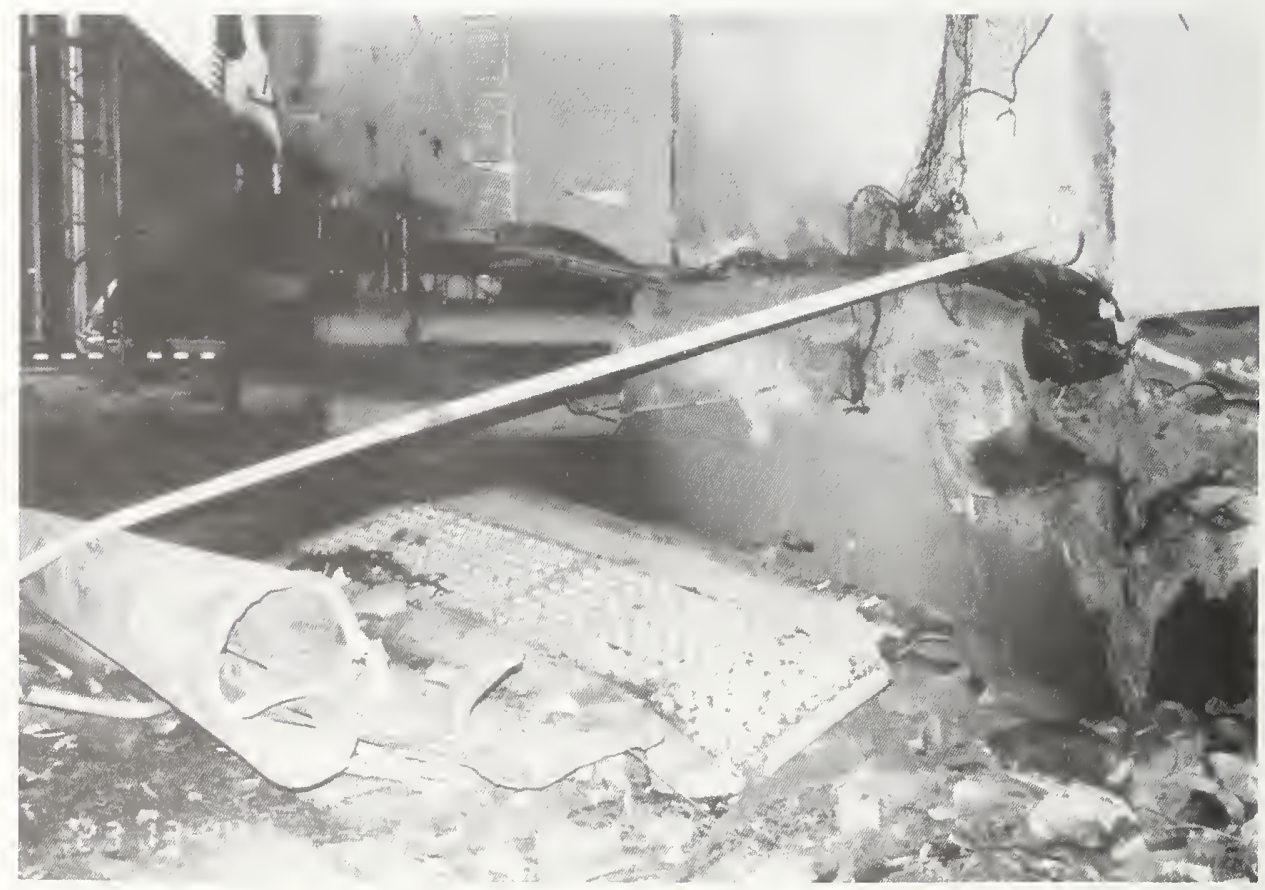

Figure 4.2 .34

Pier 55, Route 3 near Tateishi showing buckled steel plate on ground. 
Figure 4.2.35 General view of westbound elevated section of Route 3 near Meiji looking from Pier 586 towards Pier 585. 


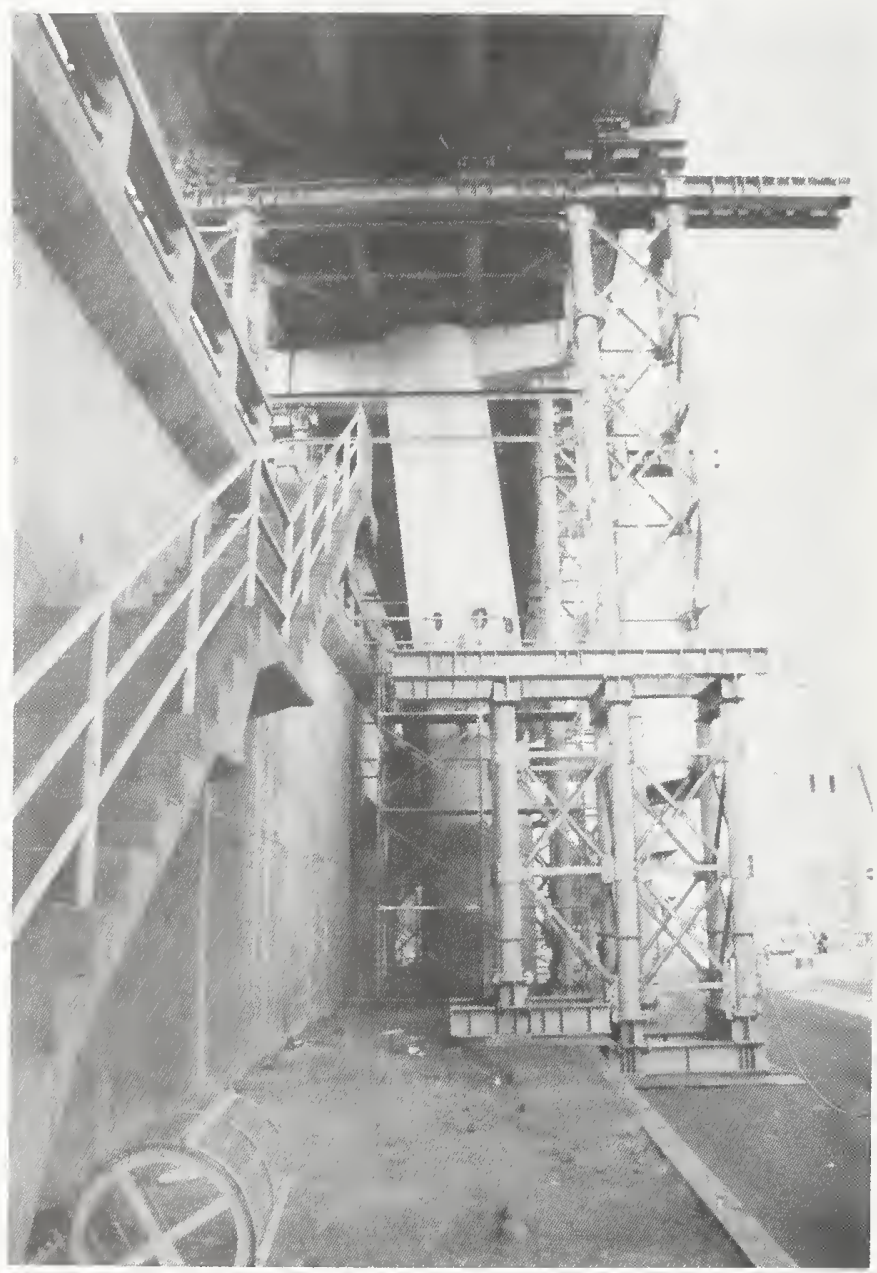

Figure 4.2.36

Pier 584 of westbound Route 3 near Meiji. 


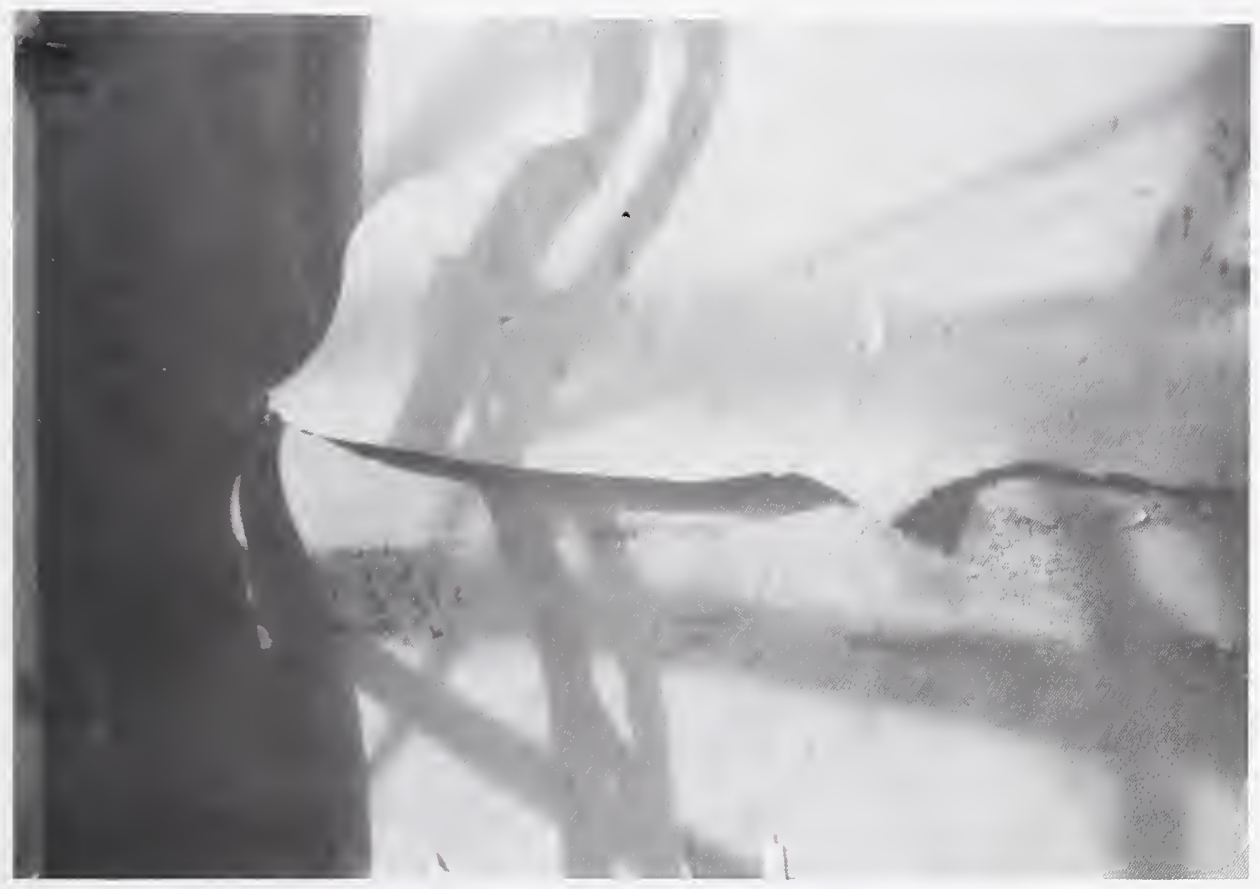

Figure 4.2.37 Fracture at mid-height of Pier 584 of westbound Route 3.

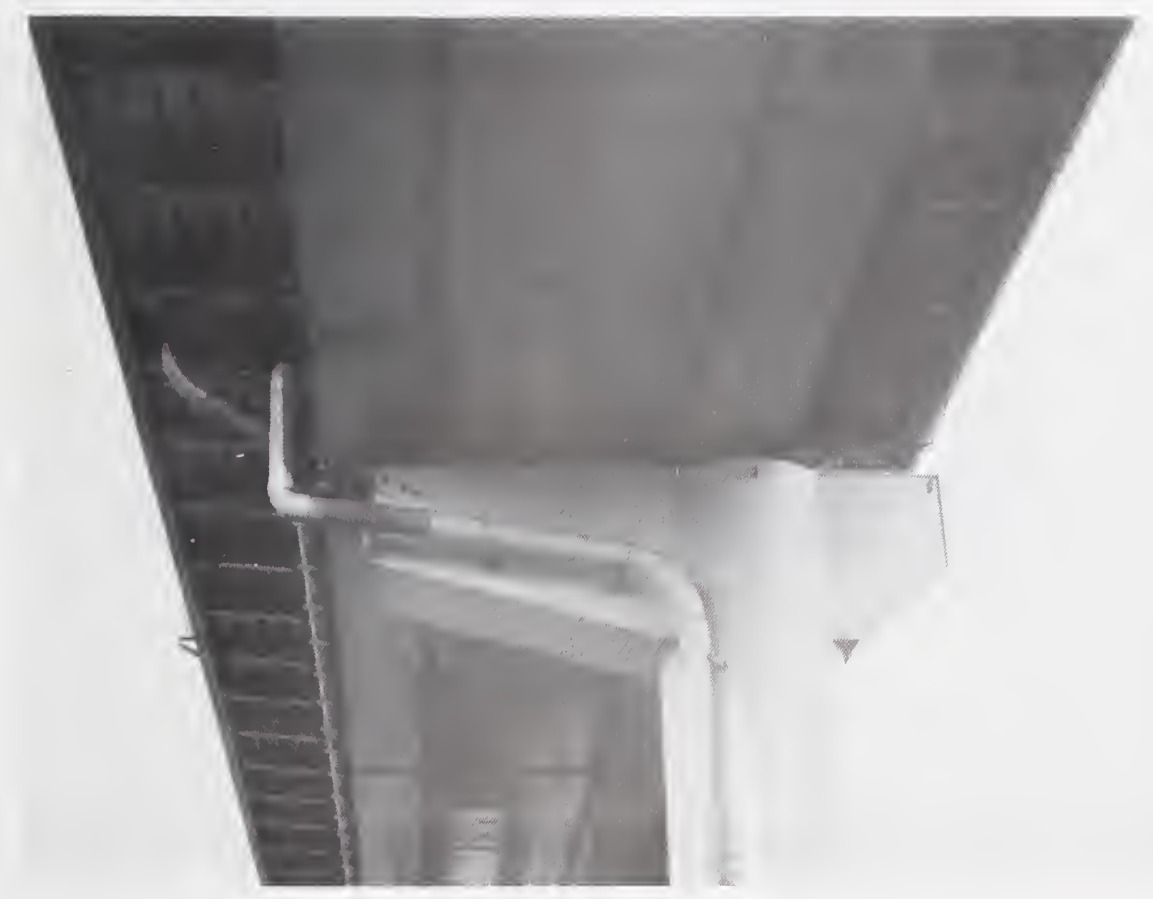

Figure 4.2.38 Failed bearings and lateral offset at top of Pier 586 of westbound Route 3. 


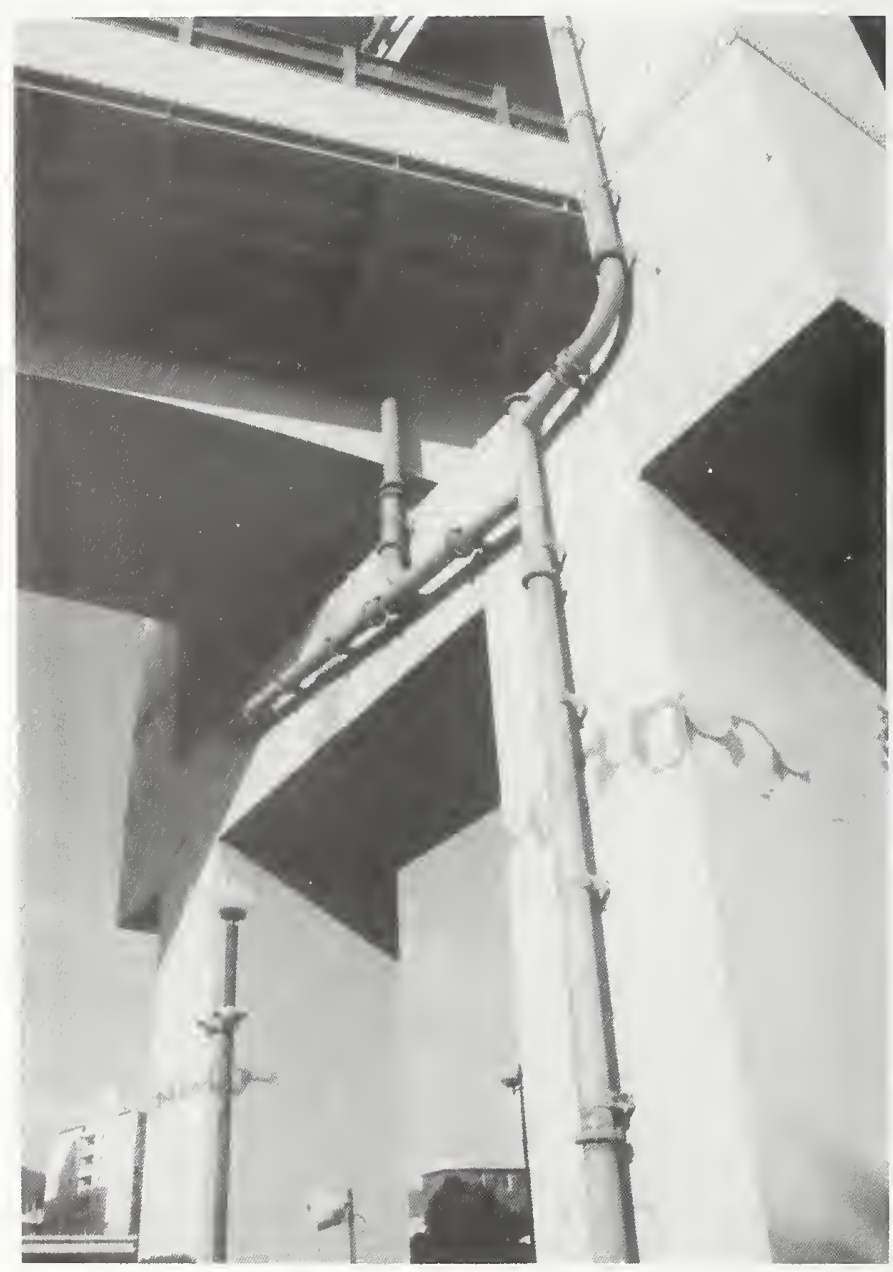

Figure 4.2.39 Local buckling in steel box columns at Pier 41 of the Hamate By-Pass Viaduct. 


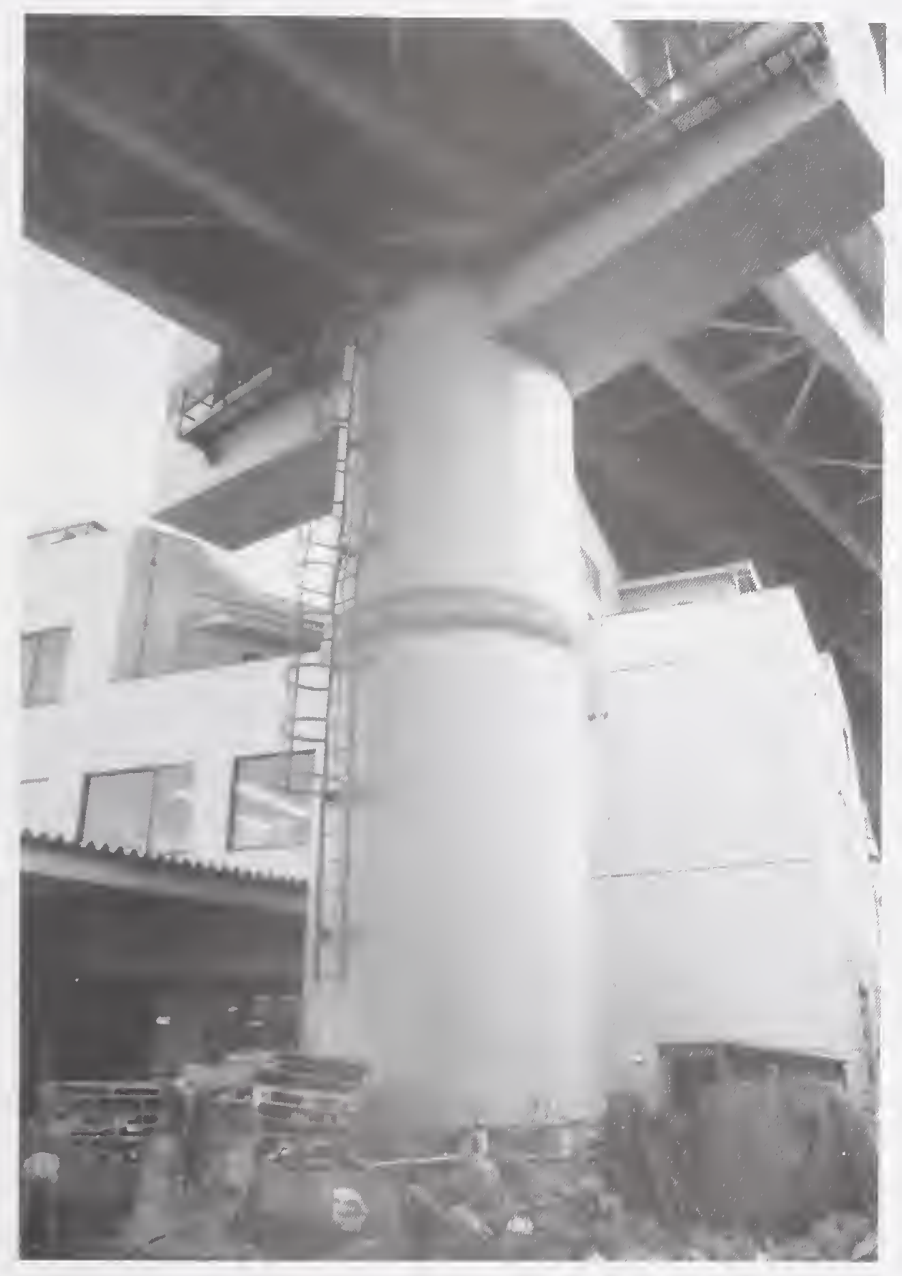

Figure 4.2.40 Buckling in steel columns at Pier 49 of the Hamate By-Pass Viaduct. 


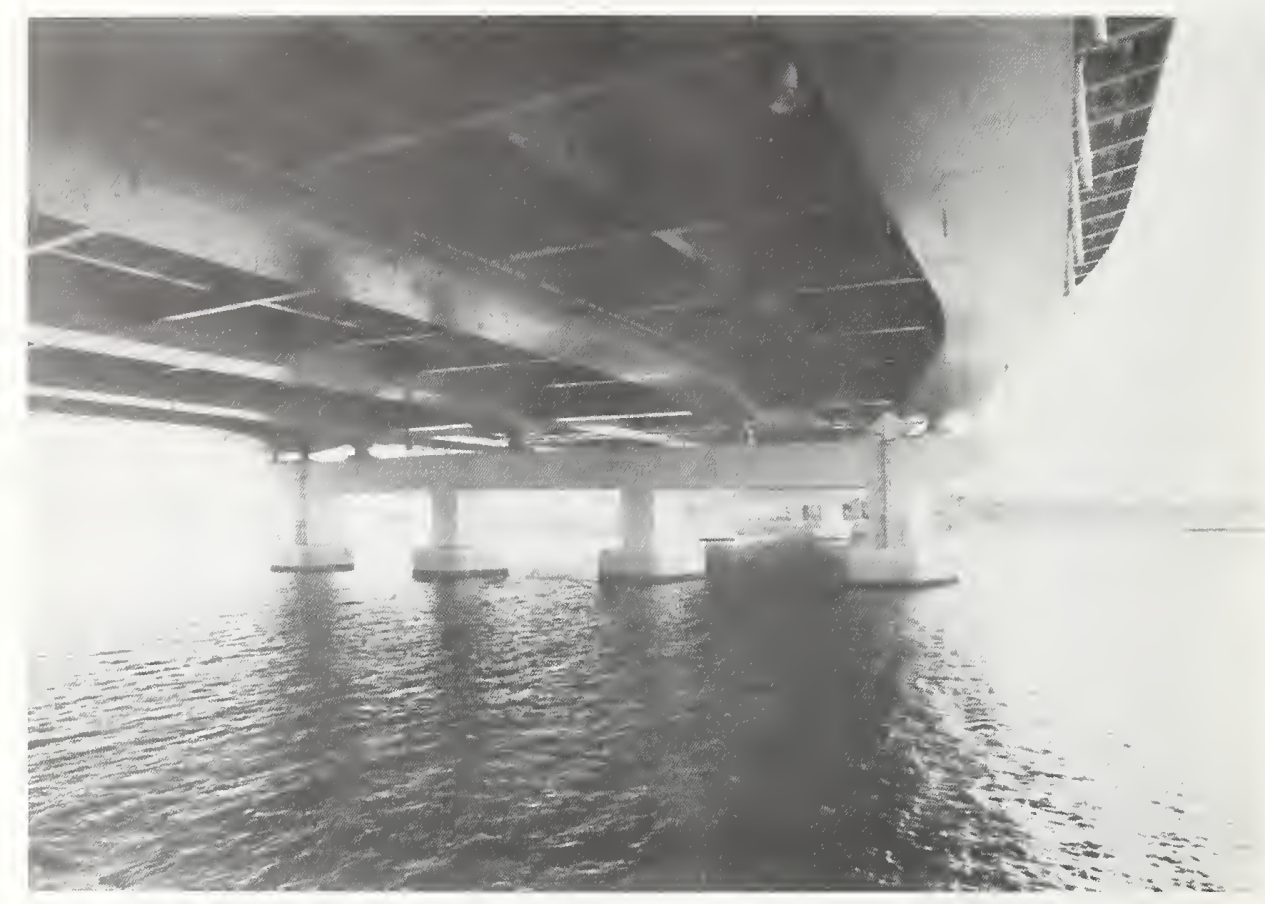

Figure 4.2.41 General view of the Shukugawa Bridge on Route 5.

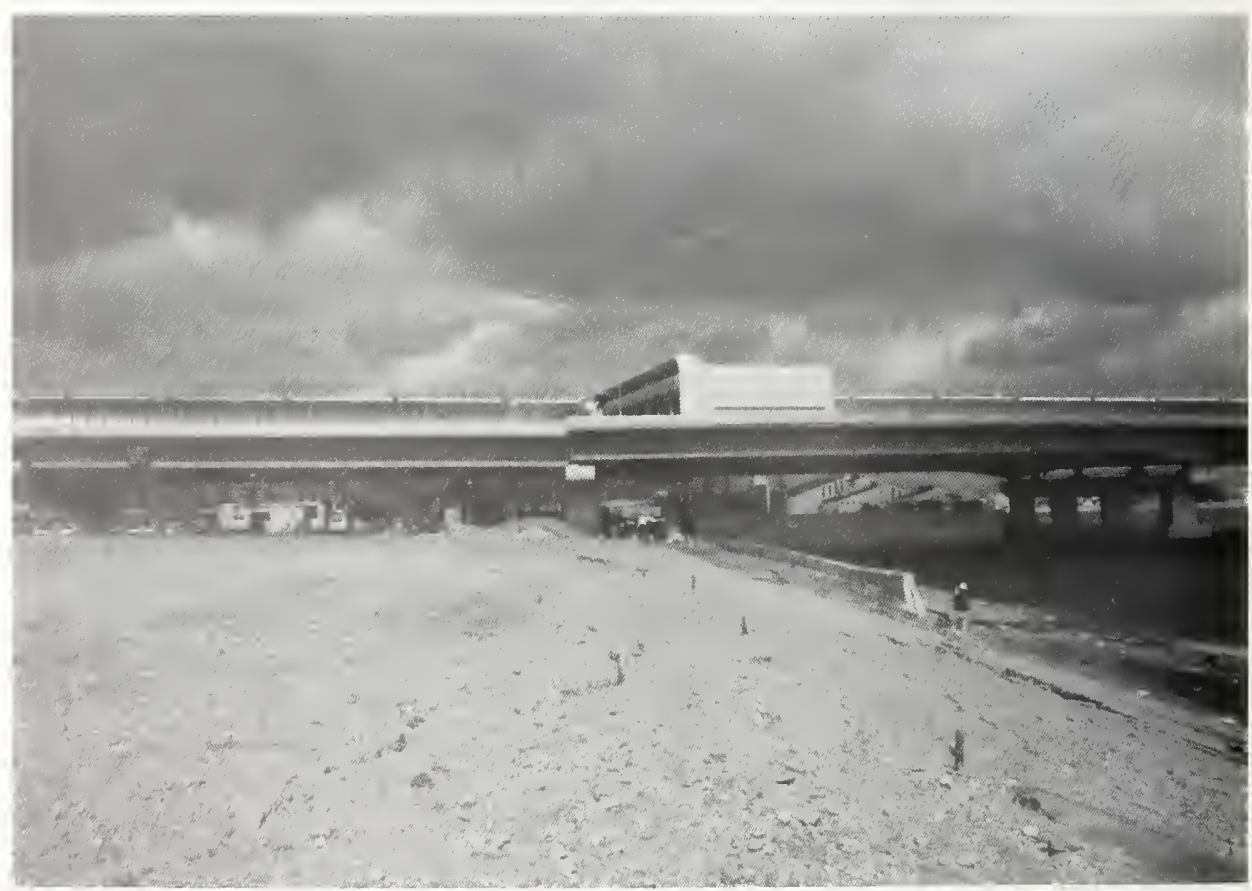

Figure 4.2.42

Distant view of the Shukugawa Bridge showing lateral deformation of the foundation soils and spreading to the right (to the center of the channel). 


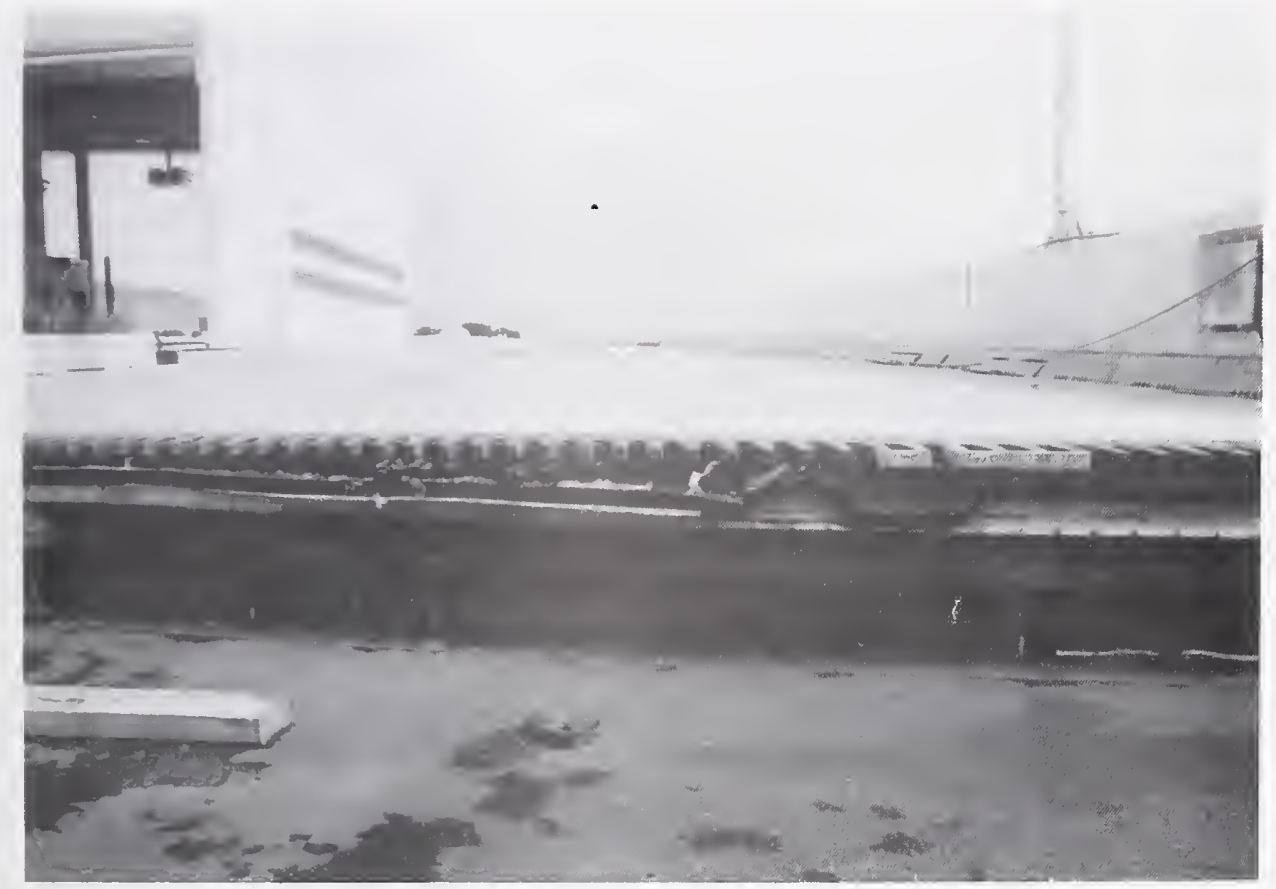

Figure 4.2 .43

Vertical offset in the expansion joints above Pier 134 of the Shukugawa Bridge due to bearing failure on the best cap below.

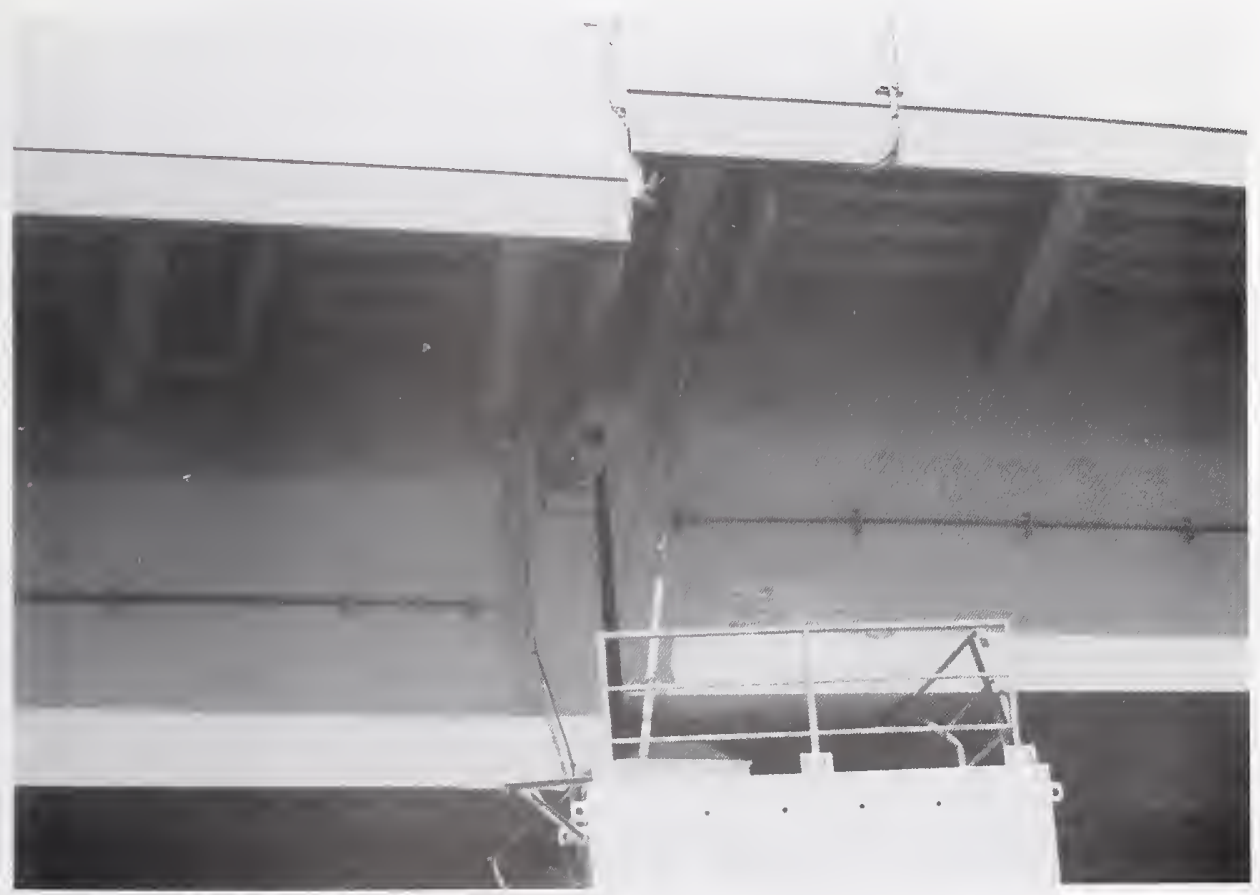

Figure 4.2.44

Approach span at edge of seat at Pier 134 of Shukugawa Bridge due to lateral movement of the pier by about $1 \mathrm{~m}$ towards the center of the channel. 


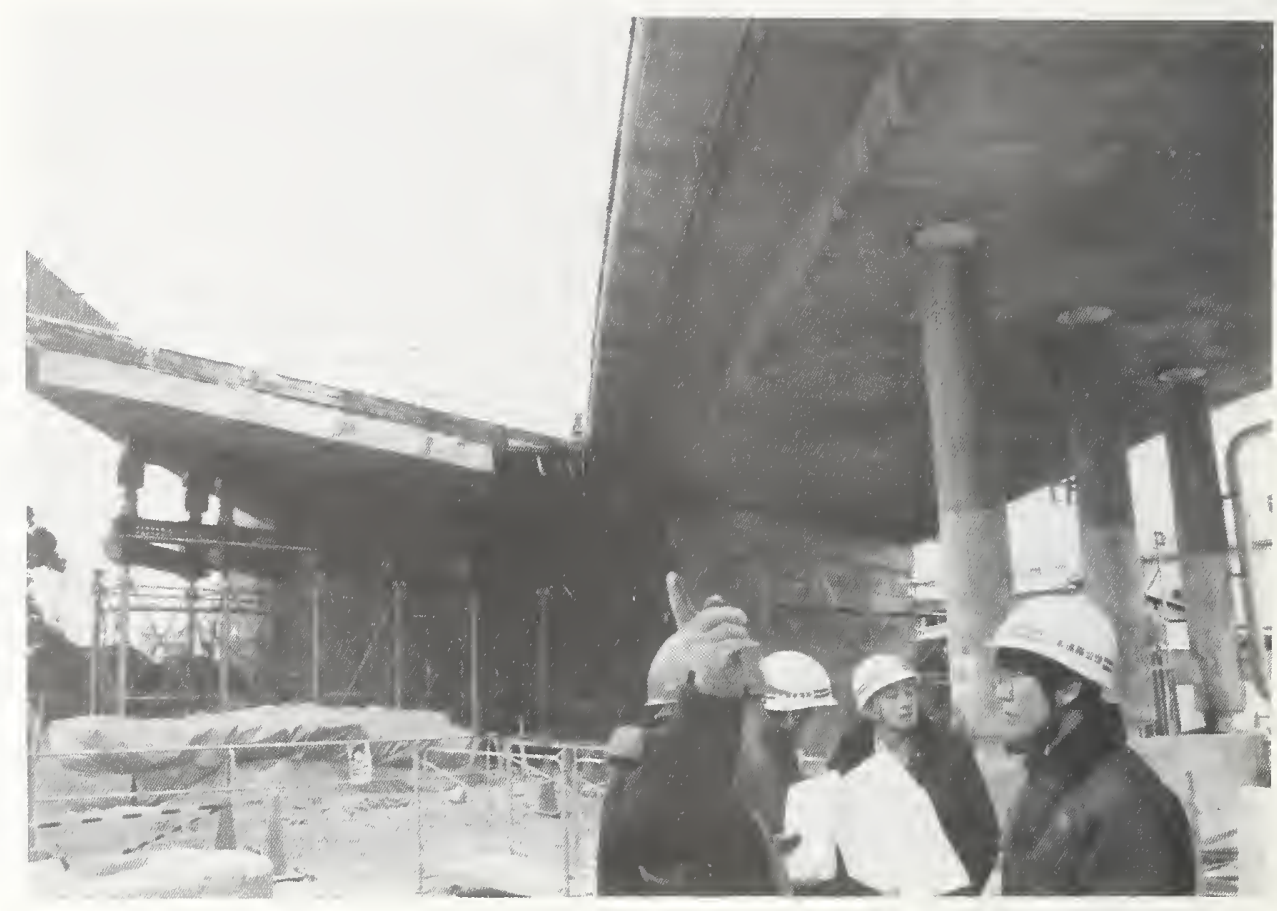

Figure 4.2.45

General view of Kawaraginishi Bridge after removal of collapsed eastbound bridge showing skew and pin-ended columns under westbound bridge.

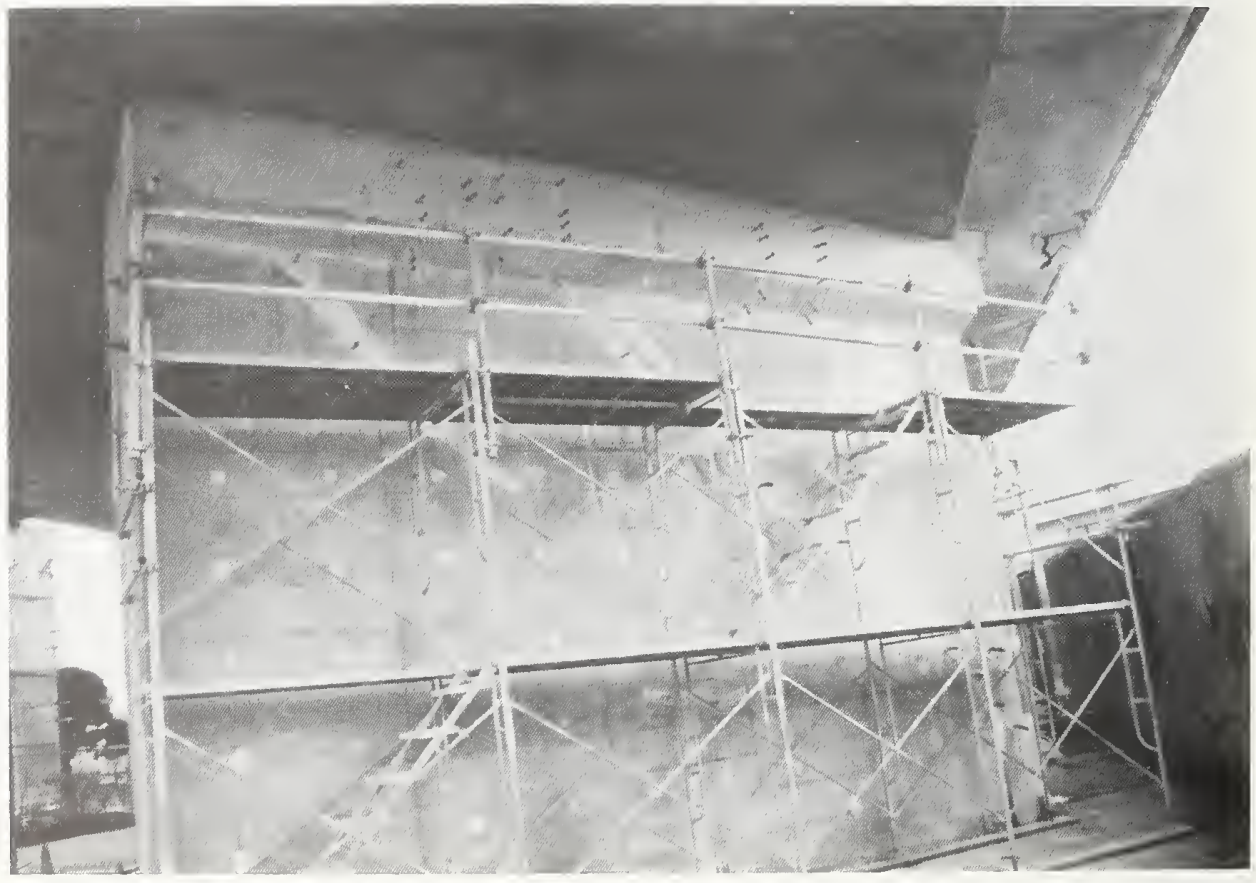

Figure 4.2.46

Pier 27 of the westbound Kawaraginishi Bridge showing shear cracking and repair by injection grouting. 


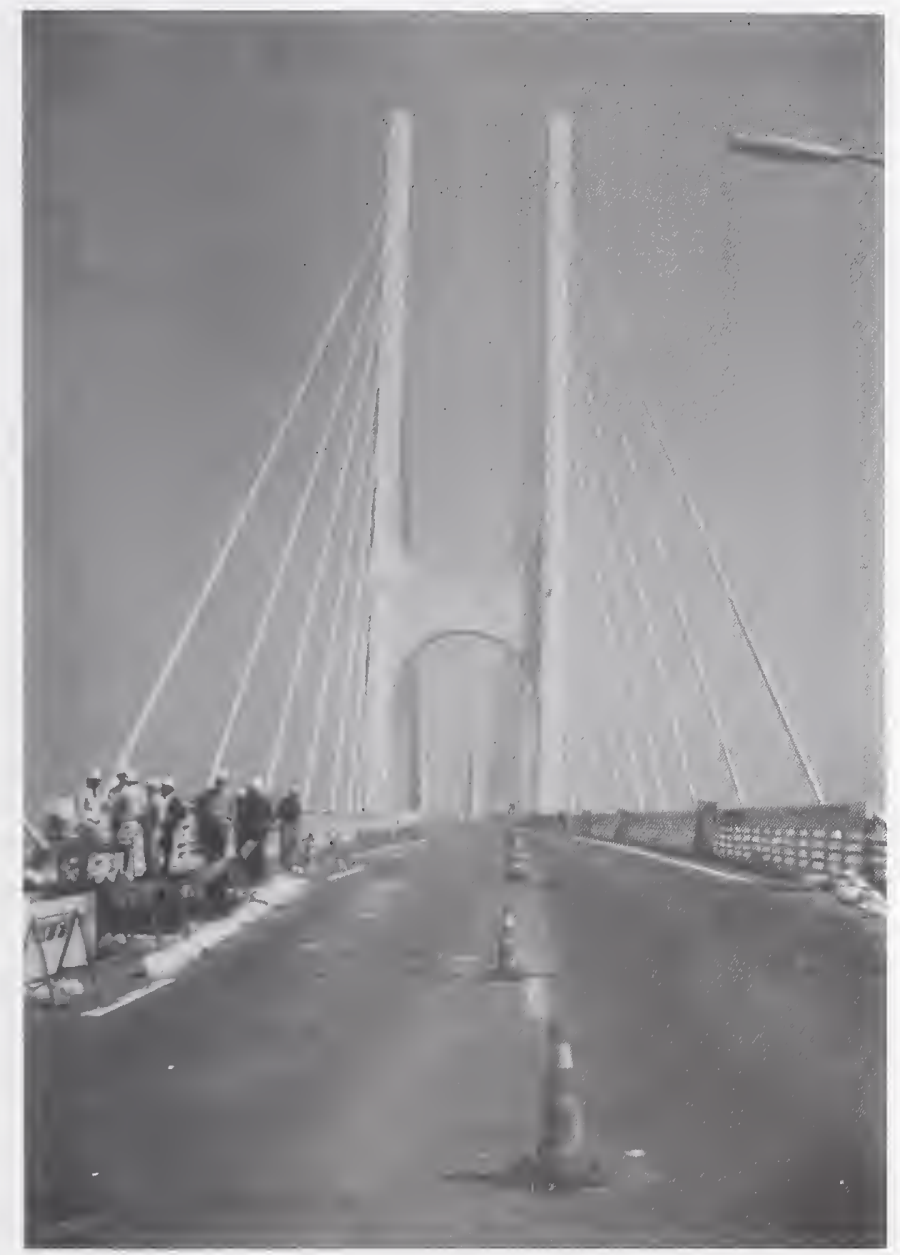

Figure 4.2.47 General view of the Higashi-Kobe Bridge on Route 5. 


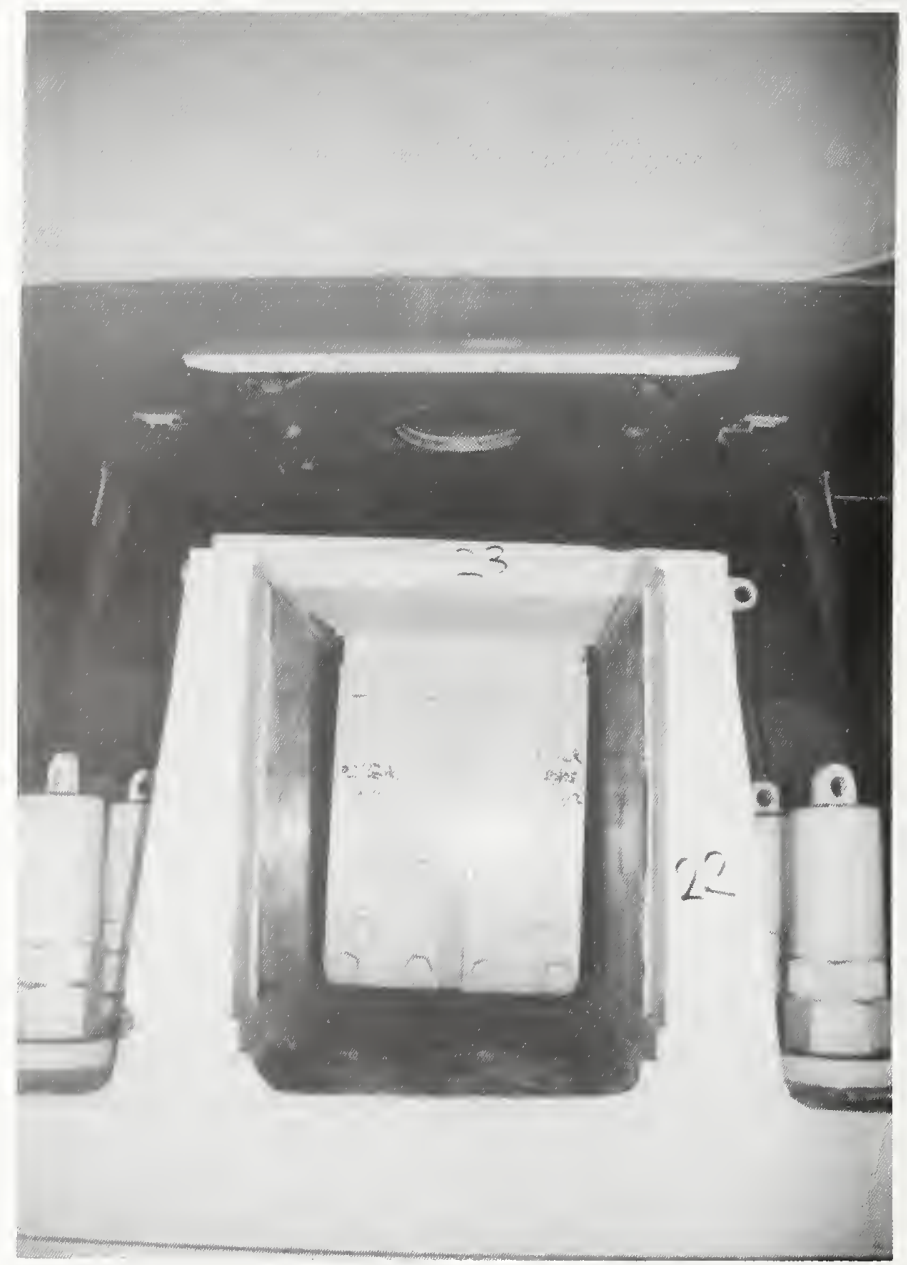

Figure 4.2.48

Failed wind shoe at Pier 187 of the Higashi-Kobe Bridge. 


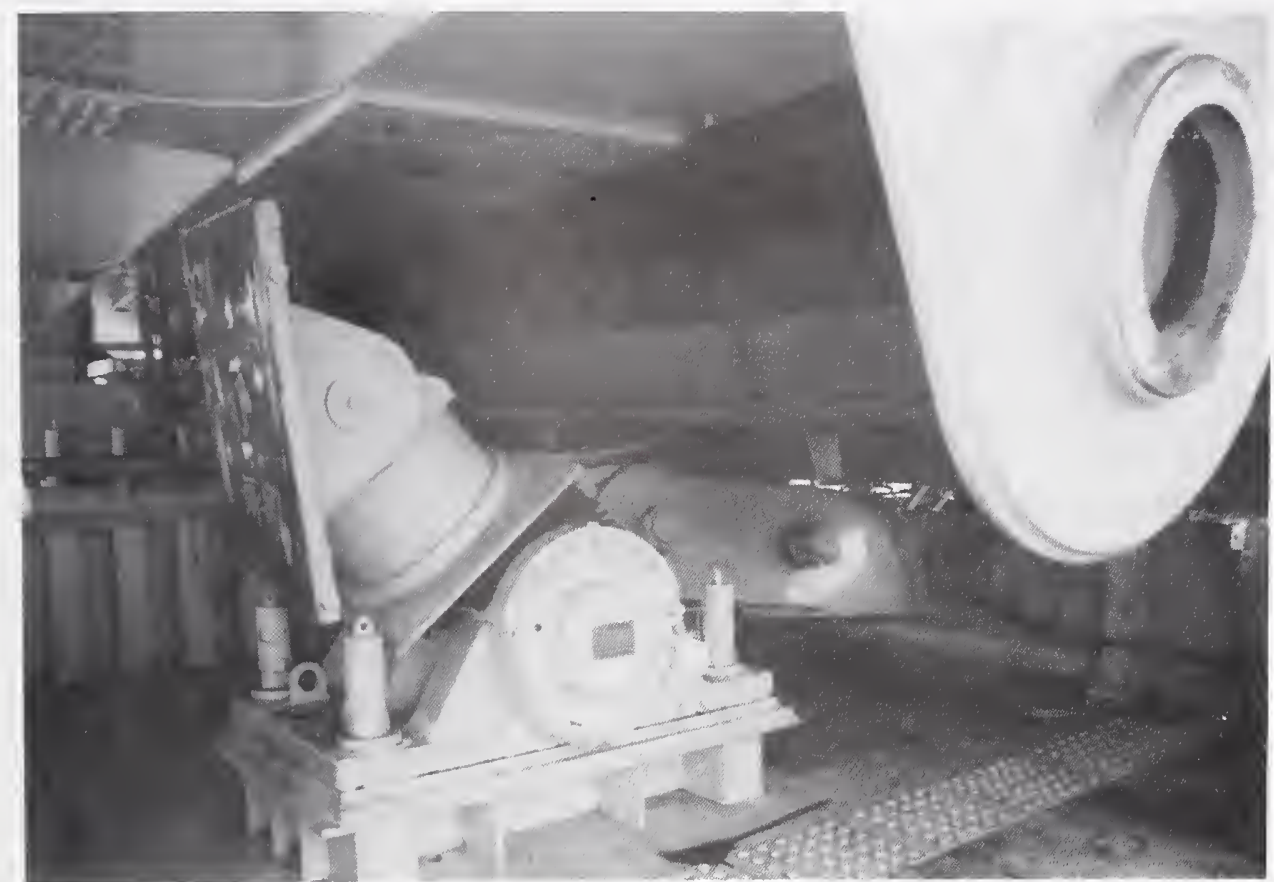

Figure 4.2.49

Failed connection of Vane-type energy dissipator and (at upper right) part of failed dead load tie-down at Pier 187 of the Higashi-Kobe Bridge.

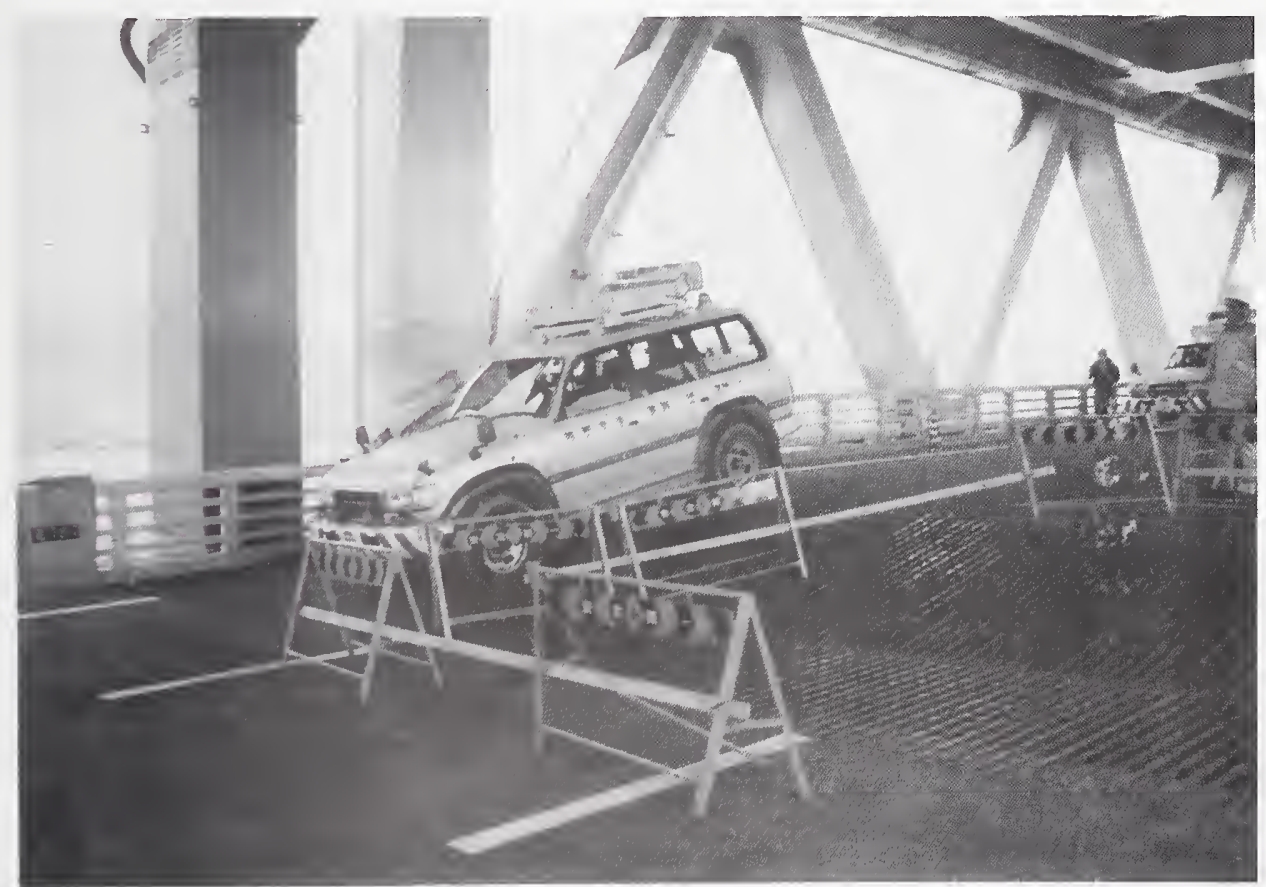

Figure 4.2.50

Uplift at the west end (Pier 187) of the main girder of the HigashiKobe Bridge due to failure of the dead load tie-down. 



\subsection{Railways and Rapid Transit System}

\subsubsection{Overview}

There are four electric rail service lines between Kobe and Osaka (Figure 4.3.1). Two of the rail lines are operated by Western Japan Rail and the other two are owned by private companies, Hanshin and Hankyu. Most of the rail lines that run through this corridor are on elevated embankments and on elevated structures. Additionally, there are two guideway systems in Kobe, the Port Liner from Sannomiya to Port Island and the Rokko Liner from Sumiyoshi to Rokko Island. The guideway systems, New Tram Systems, consist of computerized, automated trains with four to six medium cars. The Port Liner, constructed between 1977 and 1980 with a total length of $6.4 \mathrm{~km}$ and nine stations, was the first such transportation system built in Japan. It began operation in February, 1981. The Rokko Liner was constructed in 1990 with a total length of $4.5 \mathrm{~km}$ and six stations. These trains are the primary people movers between the islands and the Kobe area.

There are five other railways and transit systems in Kobe including the Kobe Kosotku, Kobe Dentetsu, Kosoku Kobe, Sanyo Dentetsu, and the Kobe Subway.

The Kobe Rapid Transit Railway, or Kobe Kosotku, is owned and operated by the Kobe Rapid Transit Railway Company, Ltd. As shown in Figure 4.3.2, the Kobe Rapid Transit Railway (KRTR) provides a rail system which interconnects the Hankyu and Hansin Railways in the east with the Sanyo Electric Railway in the west and the Kobe Electric Railway in the north. The KRTR is owned jointly by the City of Kobe, the four railway companies whose lines it interconnects, and local business investors.
A schematic of the KRTR is provided in Figure 4.3.3. The east-west routes are 7.2 $\mathrm{km}$ long in total, and the north-south line is $0.4 \mathrm{~km}$ long. About $6.6 \mathrm{~km}$ of the system are underground, with the remaining - sections at grade or carried by elevated structures. The system was constructed between 1962 and 1968. Underground sections were built by means of cut-and-cover techniques. Running tunnels are reinforced concrete box structures with center column support, generally having about $4.5 \mathrm{~m}$ to $6 \mathrm{~m}$ of cover between street surface and top of box. With the exception of the Shin Kaichi Station, the stations are reinforced concrete box structures with center column support. The Shin Kaichi Station is a steel frame structure with Vierendeel trusses and a mezzanine level. Depth of cover at the stations is approximately $4 \mathrm{~m}$ to $5 \mathrm{~m}$.

The Kobe Municipal Subway, or Metro, is operated by the City of Kobe and is composed of $22.7 \mathrm{~km}$ of elevated, surface, and underground railway. Underground construction between Shin Nagata and Sannomiya Stations was performed by cut-and-cover techniques prior to 1977. Soil shield tunneling and rock tunneling were used for portions of the system northwest of the Shin Nagata Station. Cut-and-cover sections of the Metro are similar to those of the KRTR. Both stations and running tunnels are reinforced concrete box structures with center columns separating inbound and outbound tracks. Depth of cover from street surface to top of box is typically $4.5 \mathrm{~m}$ to $7.0 \mathrm{~m}$.

\subsubsection{What happened}

\subsubsection{Shinkansen - Western JR}

The Shinkansen line was built during the 1960s and 1970s. The word "Shinkansen" in 
Japanese means "the new main line." It is a major line in addition to the original Japanese National Rail (JNR) main line in this area. The Tokaido Line, which runs from Tokyo to Shin-Osaka, has been in service since 1964. The Sanyo Line, from Shin-Osaka to Hakata, was in operation in 1972 from Shin-Osaka to Okayama and was extended to Hakata in 1975. The train can reach speeds up to $210 \mathrm{~km} / \mathrm{h}$ and up to 275 $\mathrm{km} / \mathrm{h}$ for later models. The rails are continuously welded and mounted on a concrete bed so there is no sway or clickety-clack noise.

Although damage to the reinforced concrete structures was extensive, the major cause of collapsed structures was the non-ductile detailing of the steel reinforcement. Structures designed by current specifications performed well with minor damage.

The earthquake damage to the Shinkansen was extensive. The Tokaido Line and The Sanyo Line were both damaged. The Sanyo Line had several locations with collapsed structures.

Tokaido Line It has been reported that seven locations along the line have column damage. Superstructures at two locations near the Shin-Osaka station have deck offset. This line was put back in service in a relatively short amount of time.

Sanyo Line In Kobe, the Shinkansen runs through a tunnel under Rokko Sanchi. Although damage along the tunnel is minor, no detailed information is available. It has been reported that nine locations between Shin-Osaka and Shin-Kobe had collapsed structures including damaged columns at thirteen locations. Superstructures at six locations had deck offsets. One platform at Shin-Kobe station was offset. One elevated structure collapsed between Shin-Kobe and Nishi-Akashi. The superstructure at five locations had deck offsets. From Nishi-Akashi to Himeji one elevated structure collapsed, the columns were damaged at 36 locations and decks were laterally offset at eight places. Strong motion records along the Shinkansen show that the highest peak ground acceleration was $0.65 \mathrm{~g}$ and the maximum ground displacement was $42 \mathrm{~cm}$ at the Takatori station. A 5\% damping response spectrum over $2.0 \mathrm{~g}$ is observed at this location (Figure 4.3.4).

At Itami, several elevated structural frames collapsed in a series. The typical elevated structure has two columns per bent with a total of four concrete bents per frame. Cantilever spans are located at both ends. Typical column size is $80 \mathrm{~cm} \mathrm{x} 80 \mathrm{~cm}$ with \#9 (D28) longitudinal rebars and \#2 (D5 @ $30 \mathrm{~cm}$ ) shear reinforcement in the middle and \#2@15 cm at the top and bottom. Link beams were used in the taller structure frames. The multi-column frames were severely damaged at the top portion of the columns and the whole superstructure deck settled without damage (Figure 4.3.5 and 4.3.6). At the time of the investigation, workers were removing concrete and cutting rebars. The superstructure was jacked up to its original elevation. Columns are being repaired between the existing deck and foundation. It is interesting to see that the cold joint below the top of the deck beam is very smooth which raises the question "did this type of joint ever initiate a plastic moment in the column?" 


\subsubsection{JR Main Line - Western JR}

On the JR main Line, the Tokaido Line runs from Tokyo to Kobe and the Sanyo Line from Kobe to Hakata.

Tokaido Line The Tokaido Line between Osaka and Kobe is sited mostly on an elevated embankment. The elevated structure collapsed from the Sumiyoshi station all the way to the elevated embankment near Nada $1.25 \mathrm{~km}$ to the west. The Rokkomichi station along this stretch also collapsed. Retaining walls used at an elevated embankment section between Nada and Rokkomichi station tilted outward. Soil anchorages are now being installed to stabilize the embankment. Near the Sumiyoshi station, workers are installing steel jackets around damaged columns. The jackets have the same shape as the original columns with a thickness of $10 \mathrm{~mm}$. Two U-shaped jackets (Figure 4.3.7) are welded together for the full column height. Welded joints are staggered (Figure 4.3.8) on different faces. Damage at this segment of the JR line is concentrated on the top of the columns, right below the construction joints. Less damaged columns show the formation of a shear crack at this region.

Sanyo Line Damage along the Sanyo line was less than the Tokaido line. It has been reported that one elevated structure collapsed, a retaining wall tilted and rail stations damaged. Detailed information is not available.

\subsubsection{Hanshin Dentetsu}

Kobe Line At Higashi-Nada, an elevated railroad yard collapsed (Figure 4.3.9). Columns failed in the top region. A small amount of shear reinforcement was used in these columns. The nearby elevated rail structures also collapsed from a similar cause. Space under the railroad is used by either businesses or residences (Figure 4.3.10). Retaining walls near the Mikage station overturned. Elevated structures from Iwaya to Mikage were mostly collapsed and damaged.

\subsubsection{Hankyu}

Kobe line It has been reported that the elevated structures between Nishinomiya and Shykugawa collapsed. The Shykugawa station also collapsed and the Sannomiya station was damaged.

Itami Line The Shin-Itami station collapsed (Figure 4.3.11). The elevated station was at the end of the Itami Line. Railroad tracks gradually rose through a segment of elevated embankment and a series of elevated structures and ended at this station. The collapse may have been caused by a whipping action.

Takarazuga Line It has been reported that two overpasses were damaged.

\subsubsection{Kobe New Tram System}

Rokko Liner The train station at Sumiyoshi was seriously damaged when its superstructure collapsed. Columns on the east side of this station tilted to the north and one segment of deck was offset. Foundations along the Sumiyoshigawa moved and several steel columns showed signs of local buckling. It has been reported that one long span at Rokko Island lost its support and collapsed.

Port Liner Five of the nine stations along the line suffered various degrees of damage. One concrete column near the Sannomiya station was seriously sheared and dropped approximately $120 \mathrm{~cm}$. The superstructures lost their bearings. Restrainers located at 
the east side of the steel box girder tore off the web of the girder. Pier 35 tilted to the north (Figure 4.3.12) and the southern span dropped off and the superstructure yielded near the bent cap. Piers 56 to 59 tilted to the west (Figure 4.3.13) which may have been caused by liquefaction in this area. The first span at the south end of the Kobe bridge offset approximately $15 \mathrm{~cm}$ to $20 \mathrm{~cm}$. Although the whole Port Island settled approximately $0.5 \mathrm{~m}$ to $1 \mathrm{~m}$, no columns supporting the train had suffered any damage in this area.

\subsubsection{Underground Rapid Transit Systems}

As shown in Figure 4.3.2, damage was sustained at the Daikai and Nagata Stations of the KRTR and at the Sannomiya, Kamisawa, and Shin Nagata Stations of the Metro. Damage to the Metro was less severe than that to the KRTR, and was primarily in the form of cracked and deformed reinforced concrete center columns. Metro transit service was restored one month after the earthquake, although the Sannomiya Station remained closed because of damage to the center columns. The KRTR, where more severe damage occurred, is not expected to resume service for over a year.

Figure 4.3.3 shows the locations of damage in the KRTR. Although the most serious damage in the system was the collapse of the Daikai Station, significant distress and failure were in evidence at other locations. There was structural damage in five reinforced concrete columns at the eastern end of the Nagata Station. Between the Daikai and Nagata Stations, 210 reinforced concrete columns were cracked and deformed in the running tunnel. Minor to moderate cracking of reinforced concrete columns and panel walls was observed in an underground shopping mall adjacent to the KRTR near Shin Kaichi Station. Figures 4.3.14 and 4.3.15 show typical damage within the shopping mall. There was severe damage of the elevated rail structure near Sannomiya Station.

The failure of the Daikai Station is highly significant because it is the first instance of catastrophic earthquake damage to a modern tunnel for reasons other than fault displacement and instability near the portal.

Soil conditions adjacent to the Daikai Station and connecting running tunnels are shown by means of boring records (Figure 4.3.16) obtained by the Kobe Rapid Transit Railway Company, Ltd. at the eastern and western ends of the station. The soil profile consists of relatively loose silty sand to a depth of about $3 \mathrm{~m}$ to $4 \mathrm{~m}$, with the water table at $3 \mathrm{~m}$ depth. Fines in the silty sand layer generally exceeds $20 \%$ by weight. Because the silty and clayey sands and sands and organic silty clay have relatively high percentages of fines with considerable plasticity, they are not considered to be susceptible to liquefaction. Uncorrected standard penetration test (SPT or blow counts) values are plotted for each boring. The locally high values are associated with the presence of gravel, and thus do not provide a reliable representation of in-situ density.

Using the criteria for liquefaction susceptibility set forth by Seed, et al., [4] and assuming a peak acceleration of $0.7 \mathrm{~g}$ to $0.8 \mathrm{~g}$, the silty sand and sand between $3.5 \mathrm{~m}$ and $6 \mathrm{~m}$ deep appear to be susceptible to 
liquefaction. The cyclic stress ratios and corrected blow counts for sands $4.5 \mathrm{~m}$ to 6.0 $m$ deep plot very close to the empirical threshold for liquefaction proposed by Seed, et al., and thus may be marginal regarding their tendency to liquefy.

The cut-and-cover construction for Daikai station involved a braced excavation supported by steel sheetpiles. The sheetpiles were left in place, and the concrete walls of the station were cast-in-place. A gap, approximately $300-\mathrm{mm}$ wide, was left between the reinforced concrete walls and sheetpiles. Because the narrow separation did not allow for compaction, sandy fill was mainly loose-dumped between the station walls and existing sheetpiles.

Figure 4.3.17 presents plans and profile views of the collapsed Daikai Station. Cross-sections at select locations along the station and running tunnel are shown in Figure 4.3.18.

The station and running tunnel are reinforced concrete box structures with $4.8 \mathrm{~m}$ to $5.2 \mathrm{~m}$ of soil cover. The eastern end of the station contains a second structural level which apparently provided sufficient strength and stiffness to restrict roof collapse to the single level box structure. The collapsed box structure was approximately $100 \mathrm{~m}$ long, $7.2 \mathrm{~m}$ high, and $17.0 \mathrm{~m}$ wide. The central reinforced concrete columns of the station failed, apparently by a combination of shear and vertical loading. There was only nominal confining steel $(9 \mathrm{~mm}$ diameter on $180 \mathrm{~mm}$ spacing) for the $20 \mathrm{~mm}$ diameter

longitudinal rebar on $140 \mathrm{~mm}$ centers in the concrete. Collapse of the columns caused subsidence at the street surface of a maximum $2.5 \mathrm{~m}$, with substantial settlement over an area of $20 \mathrm{~m}$ by $100 \mathrm{~m}$. Apart from the structural collapse-induced movement, there was no clear evidence of permanent ground deformation at the site induced by other causes, such as liquefaction.

Figures 4.3 .19 and 4.3.20 show the interior - portions of the collapsed station.

Compressive failure of the columns in Figure 4.3 .19 occurred in the form of bird caging of longitudinal steel and shear rupture of concrete. It appears that compressive failure occurred at the mid-height of the columns. Figure 4.3.21 shows subsidence at the street surface over the station. Many pipelines and conduits in the street failed, although some were able to survive the large deformation. An NTT fiber optic cable, for example, continued to provide a suitable signal despite the substantial deformation imposed on it. A medium pressure A-line operated by Osaka Gas (see Section 5.3 for Gas System Description) was deformed severely by the differential settlement, but did not leak at this location.

Because of severe distortion in the station walls, roof, and columns related to the roof collapse, clear evidence of structural response at incipient failure could not be found at the station. Nevertheless, observations provided by Professor M. Hamada of Waseda University in the running tunnel between Daikai and Nagata Stations provide clues about the seismic response of the reinforced box at the onset of structural failure. These observations are shear deformation of the box, with flexural failure of the reinforced concrete wall at a construction joint connecting the wall and base slab, bending failure where the center columns connect with the base slab, and cracks at the street surface roughly parallel to and directly over the running tunnel walls.

Deformation consistent with observations is illustrated at an exaggerated scale in Figure 


\subsubsection{Shear deformation of the box} structure is the result of transient shear deformation in the soil. This type of deformation leads to the formation of plastic hinges where columns and walls connect with the roof and base slab. Hinge formation and associated eccentric loading, in combination with increased loads from vertical accelerations and geometric distortion appear to have caused compressive failure of the columns at Daikai Station. The greater width of the station relative to the running tunncl would have contributed to higher vertical forces at the station center columns. Moreover, loose sandy fill that was placed originally between the station walls and sheetpiles used for temporary excavation support would have been subject to liquefaction and softening during dynamic loading, thereby reducing the shear stiffness and lateral support from adjacent soil.

The deformed shape of the running tunnel is consistent with assumptions about earthquake-induced deformation which are part of current design practices. For example, design criteria for the Southern California Rapid transit District (SCRTD) Metro Rail Project [2] call for the evaluation of structural racking by assuming that shear deformation in reinforced concrete boxes is equal to shear deformation in the surrounding soil as determined by one-dimensional wave propagation analyses using equivalent linear soil models. If certain joints are strained into the plastic range, the structure is checked and redesigned to assure that no plastic hinge combination capable of leading to a collapse mechanism can be formed. Using the design distortions, the effect of seismic racking has been to increase the rcinforcing steel at some joints by $5 \%$ to $10 \%$ of that rcquired for static loads. In addition, vertical loads for maximum earthquake conditions are taken as $40 \%$ larger than gravity loads under static conditions to account for vertical accelerations.

Seismic design for underground rapid transit structures was introduced in the United States during the planning and construction of the Bay Area Rapid Transit (BART) system during the 1960s. The design practices for BART were based on an assumed equivalence of soil and structural shear deformation and the introduction of additional reinforcing steel to prevent plastic hinge formation under the design transient shear deformation [1]. Construction of the KRTC and BART occurred during the same time. It is not clear, however, what assumptions and structural modifications, if any, were incorporated in the design of the KRTR to accommodate seismic shear distortion and vertical loading.

The KRTR followed design procedures which were derived from those of the Japan Railway and Tokyo Metropolitan Subway Corporation. In the KRTR design, dynamic earth pressures were considered, using the Mononobe Okabe analysis which has been discussed extensively in the technical literature $[4,6]$. A horizontal seismic coefficient of 0.1 to 0.15 was taken into consideration, but vertical acceleration was not accounted for. When hydrostatic pressures are included in the analysis, the increase in total lateral pressure associated with horizontal seismic coefficients of 0.1 to 0.15 is small, typically less than $5 \%$ to $10 \%$ of the lateral forces under static loads.

\subsubsection{Lessons for United States}

Rail services suffered more damage along the elevated structure sections than along the elevated embankment sections. Most damage to the elevated structures occurred at columns either at the bottom of 
superstructures or at a joint region. Although shear reinforcement spacing at both ends of the column were reduced by about one-half, the old non-ductile details were vulnerable to high ductility demands. The damage was similar to unretrofitted column damage observed in past California earthquakes.

Both the Port Liner and the Rokko Liner were built with modern codes. Columns along the Port Liner are mostly reinforced concrete whereas columns along the Rokko Liner were built with steel. It is difficult to conclude which type of substructure performed better without detailed structural information. In general, steel columns suffered minor yielding and local buckling while concrete columns either yielded or failed in shear.

Although damage to the reinforced concrete structures was extensive, the major cause of collapsed structures was the non-ductile detailing of the steel reinforcement.

Structures designed by current specifications performed well with minor damage.

Current retrofit methods can be used for beams, columns and joints, but with the vast amount of elevated structures in need of repair and retrofit, a systematic retrofit technique is needed.

The failure of the Daikai Station is highly significant because it is the first instance of catastrophic earthquake damage to a modern cut-and-cover subway station. The failure appears to have resulted from earthquake-induced transverse shear distortion in combination with loads enhanced by vertical accelerations. Shear distortion promotes plastic hinge formation which, in combination with enhanced vertical loads, can result in a collapse mechanism. Shear distortion and vertical accelerations apparently led to collapse of the center reinforced concrete columns at the Daikai Station. There was evidence of hingc formation and associated shear distortion in the running tunnel of the KRTR bctween Daikai and Nagata Stations. Elsewhere in an underground shopping mall near Shin Kaichi Station and at stations of the Kobe Municipal Subway, cracking and deformation of center columns provided evidence of high vertical loads and shcar distortion in the cut-and-cover structures.

Current design practices, which account for transient shear deformation and vertical accelerations, are consistent with the failure mechanisms inferred from observations of damaged sections of the Kobe underground rapid transit systems. Failure of the central columns at Daikai Station emphasize the importance of designing to prevent plastic hinge formation leading to a collapse mechanism. The lack of significant confining steel at failed reinforced concrete columns suggests that attention to confinement and ductility can play an important role in strengthening underground structures against earthquake cffects.

Attention also needs to be focused on the density and stiffness of backfill adjacent to structures built by cut-and-cover methods.

For design purpose, large shear distortion have been considered primarily in deep deposits of soft clay, where significant amplification of bedrock ground motion can occur. Because a rapid transit box structure tends to be relatively rigid with respect to adjacent soft clay, the shear deformation sustained by the embedded structure is considerably less than that of the surrounding ground [5]. Strong motion records from the Kobe and Northridgc earthquakes, however, show that large transient shear distortions can be generated in relatively dense and stiff soils at locations 
close to fault rupture. Because an underground box structure may not be relatively rigid in a stiff soil, large shear distortions may be conveyed to the embedded structure under conditions of near source ground motion. This condition should be considered for underground structure located close to a seismic source.

\subsubsection{Research Needs}

Because of the low redundancy of single column structures, the structural layout and substructure performance becomes more important for those structures than for structures with multiple column bents. Research is needed to compare the ductility between reinforced concrete, steel and steel reinforced concrete composite columns. A damage index should be developed to assess the repairability of columns after an earthquake. Force levels encountered at collapse sites should be compared to current U.S. design forces to validate current designs.

It would be advantageous to investigate the levels of transient shear distortion which can occur in soil profiles near a seismic source, particularly when strong motion is characterized by relatively long pulses of substantial acceleration, leading to high velocities and displacements. The severity of racking in underground structures resulting from strong motion with high amplitude and relatively long periods needs to be understood better, and the combined effects of racking and high vertical accelerations needs additional clarification. Site response needs to be investigated in terms of differential lateral movements which occur during earthquake loading at sites with thick deposits of soft to medium clay and loose sand. The effects of depth and soil liquefaction on soil shear distortion and structural racking also need further research.

\subsubsection{Summary}

All four railways between Kobe and Osaka and two guideway systems in Kobe were seriously damaged. Although the death toll caused by elevated structure collapses is not available, it is believed the number would have been much higher if the earthquake had occurred during the day time or rush hour.

The inability to resist the applied lateral load for the elevated structures which collapsed can be attributed to a lack of confining steel within the critical column and joint regions. The unexpected higher ground accelerations over a wide area caused damage to miles of elevated structures. Insufficient seat length caused the Rokko Liner to lose one span. Modern steel columns performed well with minor local buckling.

\subsubsection{References}

1. Kuesel, T.R., "Earthquake Design Criteria for Subways," Journal of the Structural Division, ASCE, Vol. ST6, June 1969, pp. 1213-1231.

2. Merritt, J.L., J.E. Monsees, and A.J. Hendron, "Seismic Design of Underground Structures," Proceedings, Rapid Excavation and Tunneling Conference, C.D. Mann and M.N. Kelly, Eds., AIMMPE, New York, NY, pp. 104-131, June 1985.

3. Seed, H.B. and R.V. Whitman, "Design of Earth Retaining Structures for Dynamic Loads," Proceedings, Lateral Stresses and Earth Retaining Structures Specialty Conference, ASCE, New York, NY, pp. 103-147, June 1970. 
4. Seed, H.B., Tokimatsu, M. Harder, and R.M. Chung, "Influence of SPT Procedures in Soil Liquefaction Resistance Evaluations," Journal of Geotechnical Engineering, Vol. 111, No. 12, pp. 1425-1445, 1985.

5. Wang, Jaw-Nan (Joe), "Seismic Design of Tunnels: A Simple Stateof-the-Art Design Approach." 1991 William Barclay Parsons Fellowship, Monograph 7, Parsons Brinckerhoff, Inc., New York, NY, June 1993.
6. Whitman, R.V., "Seismic Design and Behavior of Gravity Walls," Design and Performance of Earth Retaining Structures, Geotechnical Special Publication No. 25, P.C. Lambe and L.A. Hansen, Eds., ASCE, New York, NY, pp. 817-842, June 1970. 


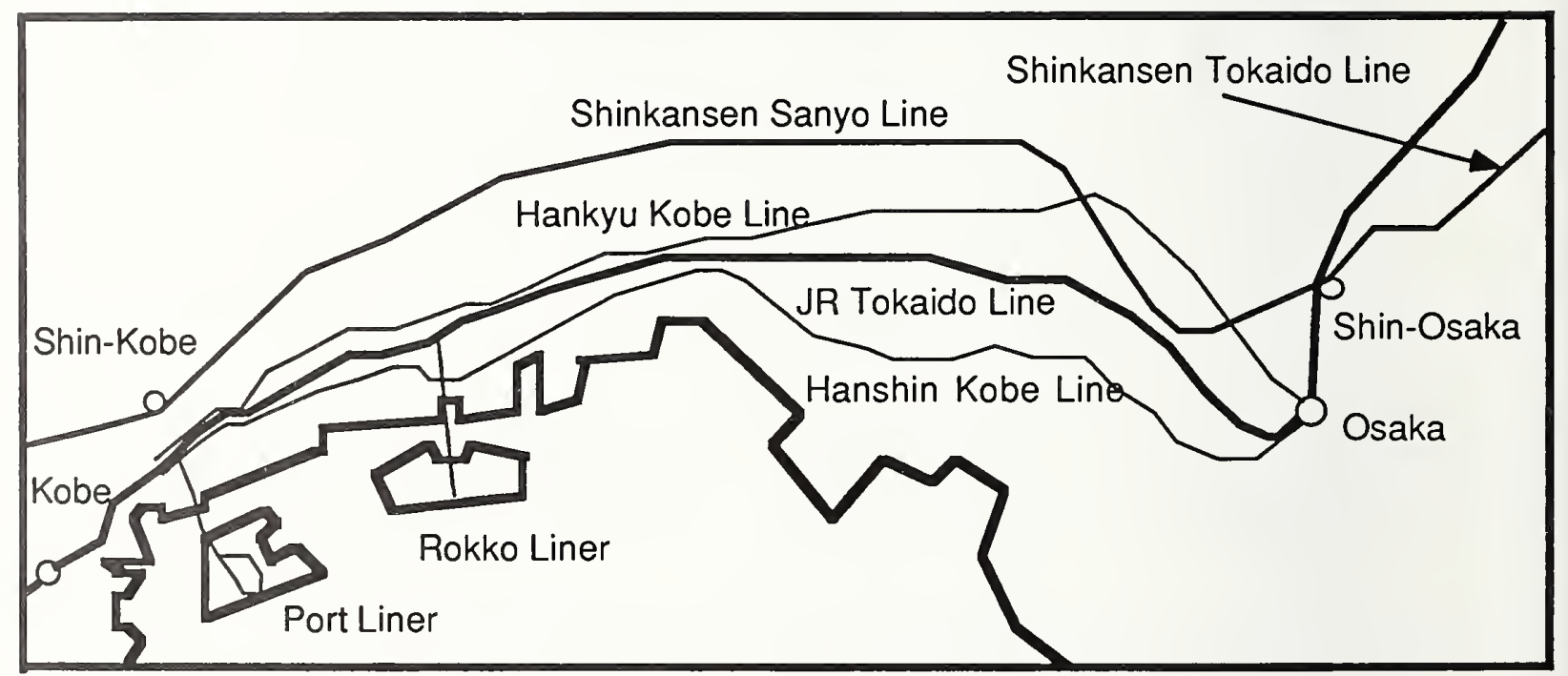

Figure 4.3.1 Rail lines connecting Kobe and Osaka. 


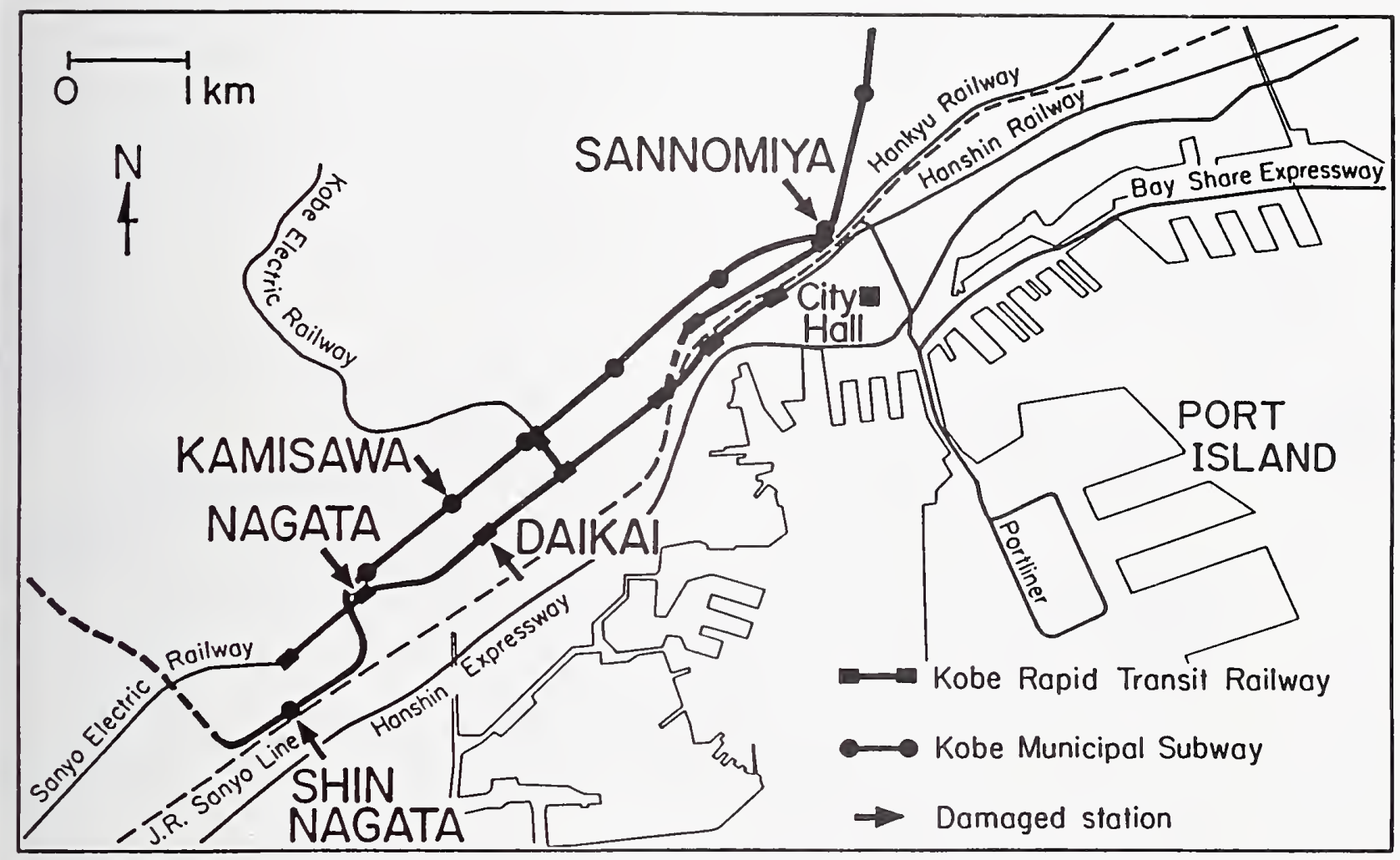

Figure 4.3.2 Map of Kobe Underground Rapid Transit Systems showing locations of earthquake damaged stations. 


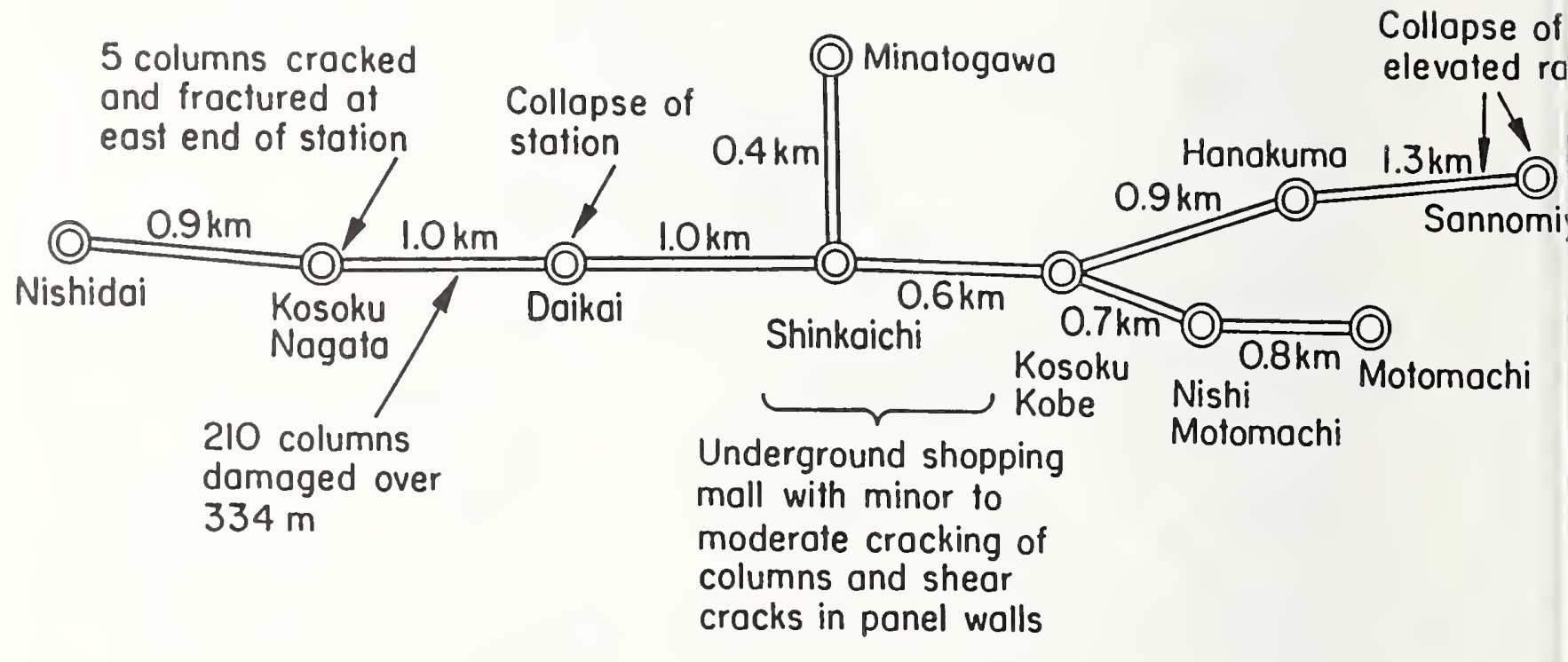

Figure 4.3.3 Schematic of the Kobe Rapid Transit Railway showing locations of earthquake damage. 

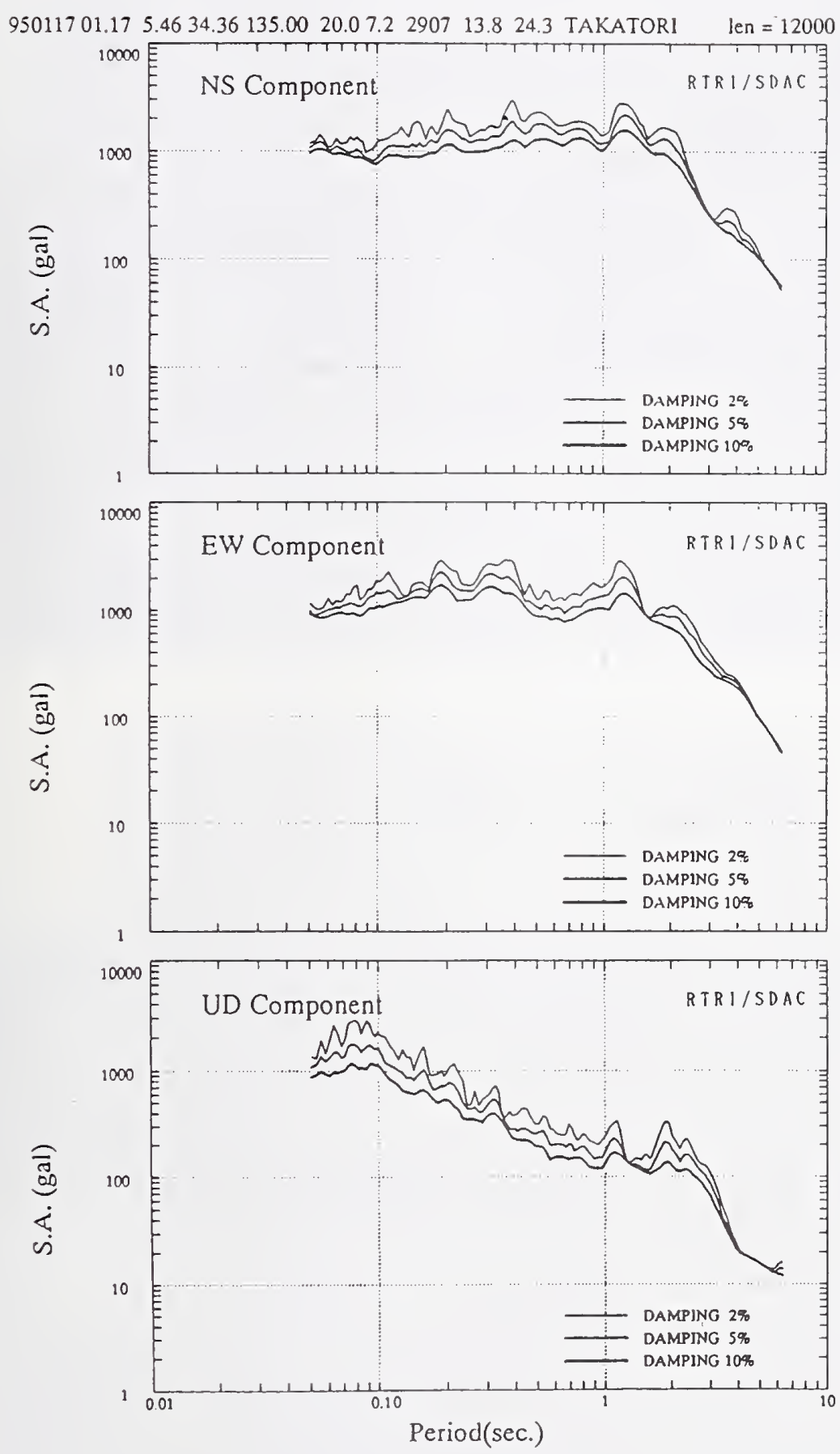

Figure 4.3.4 Takatori Station response spectrum. 


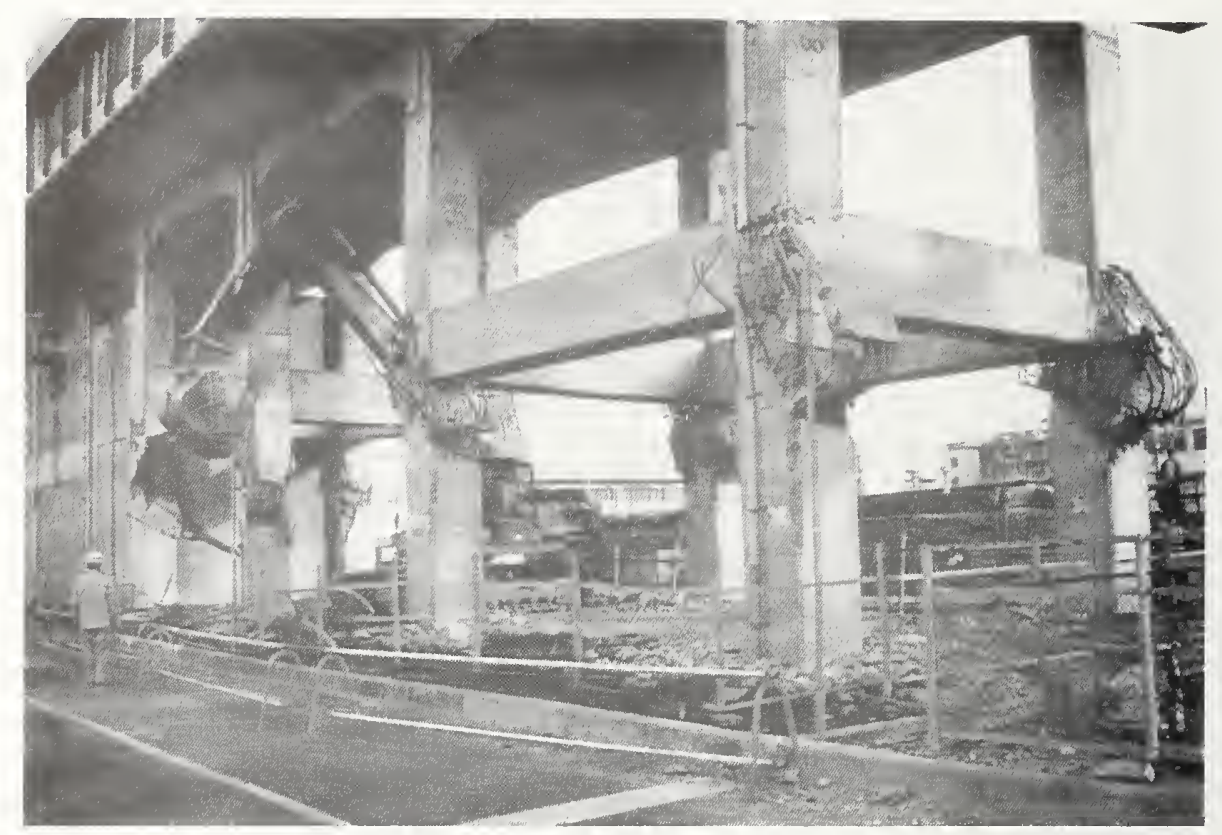

Figure 4.3.5 Damaged concrete frame - Shinkansen.

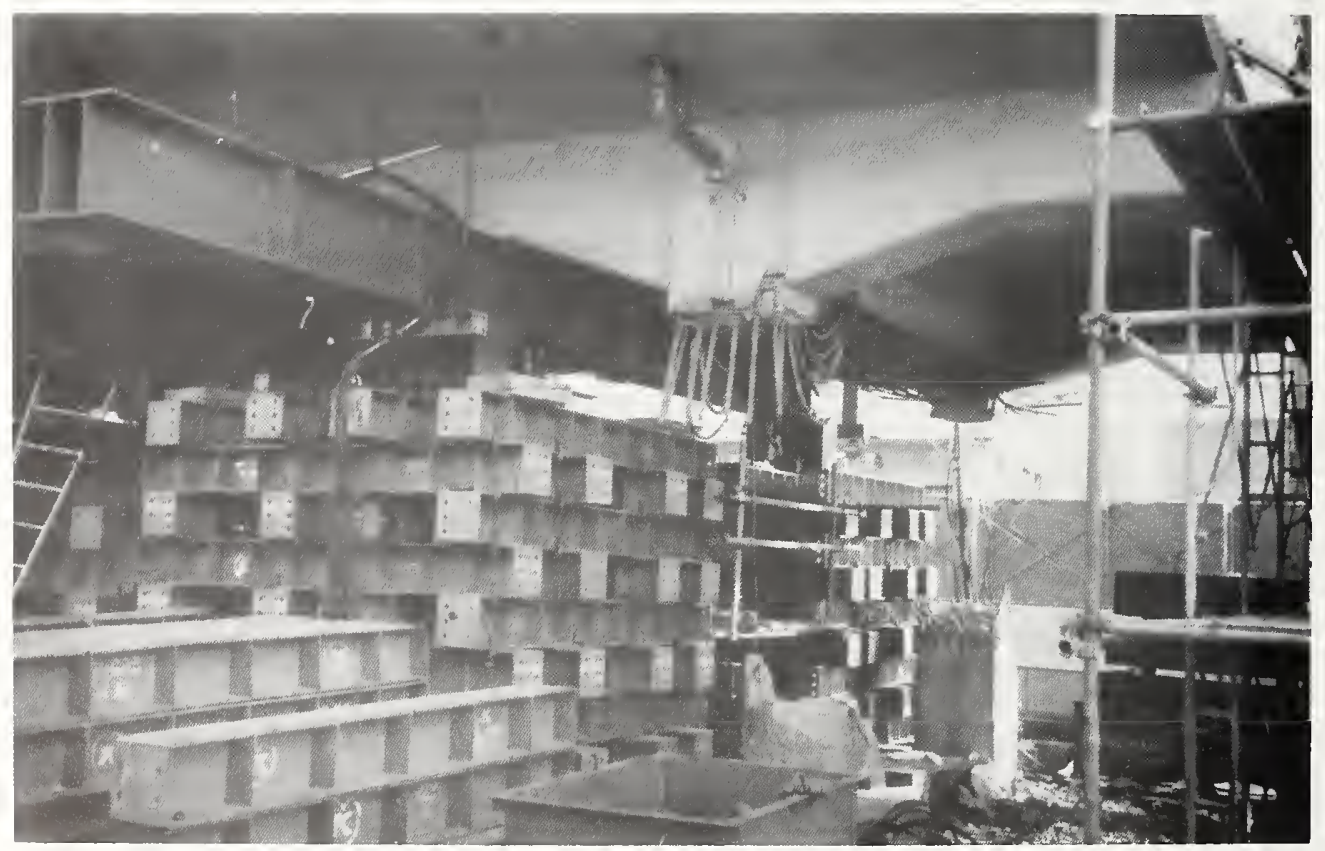

Figure 4.3.6 Column repair - Shinkansen. 


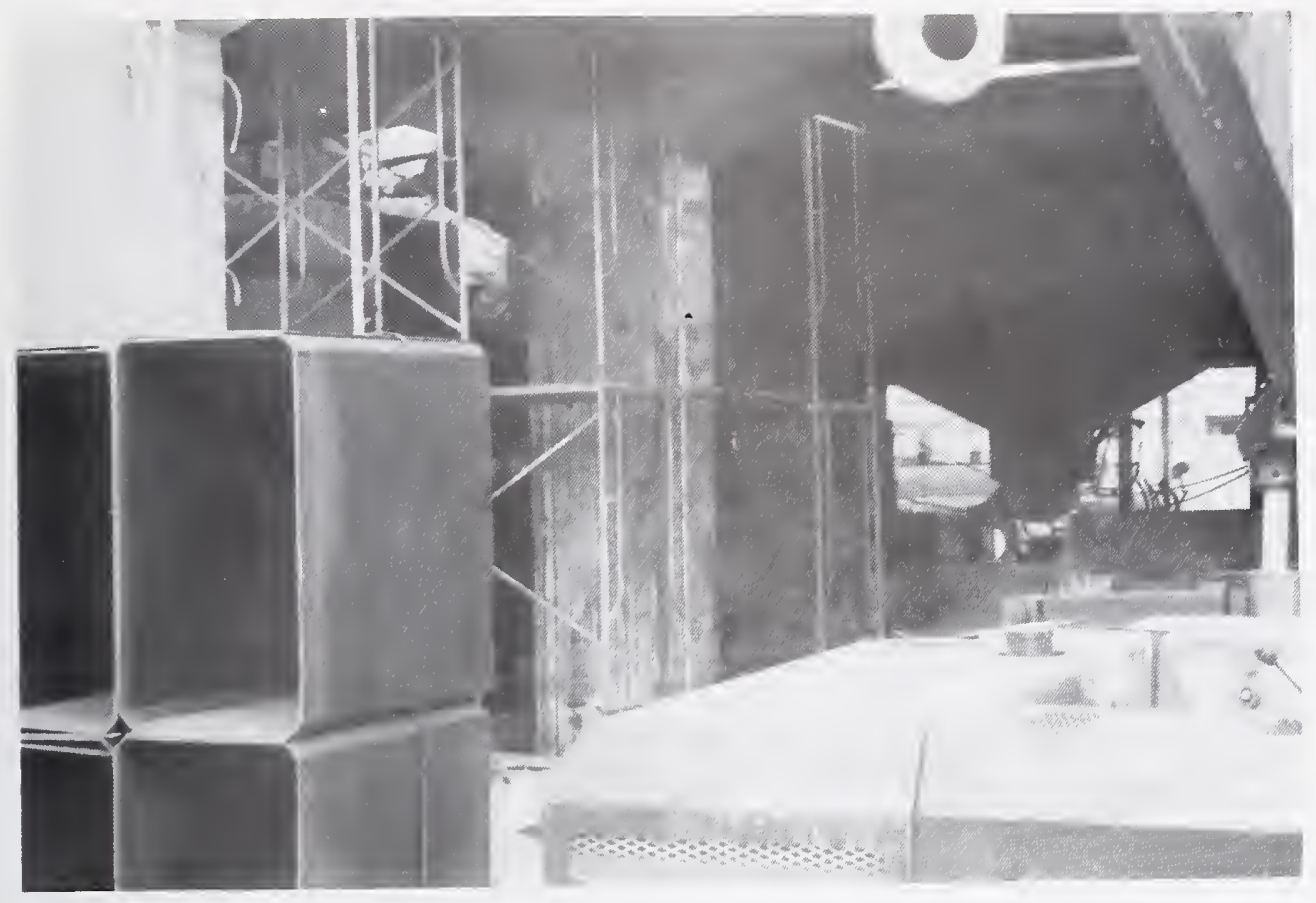

Figure 4.3.7 Column jacketing repair - JR Main Line.

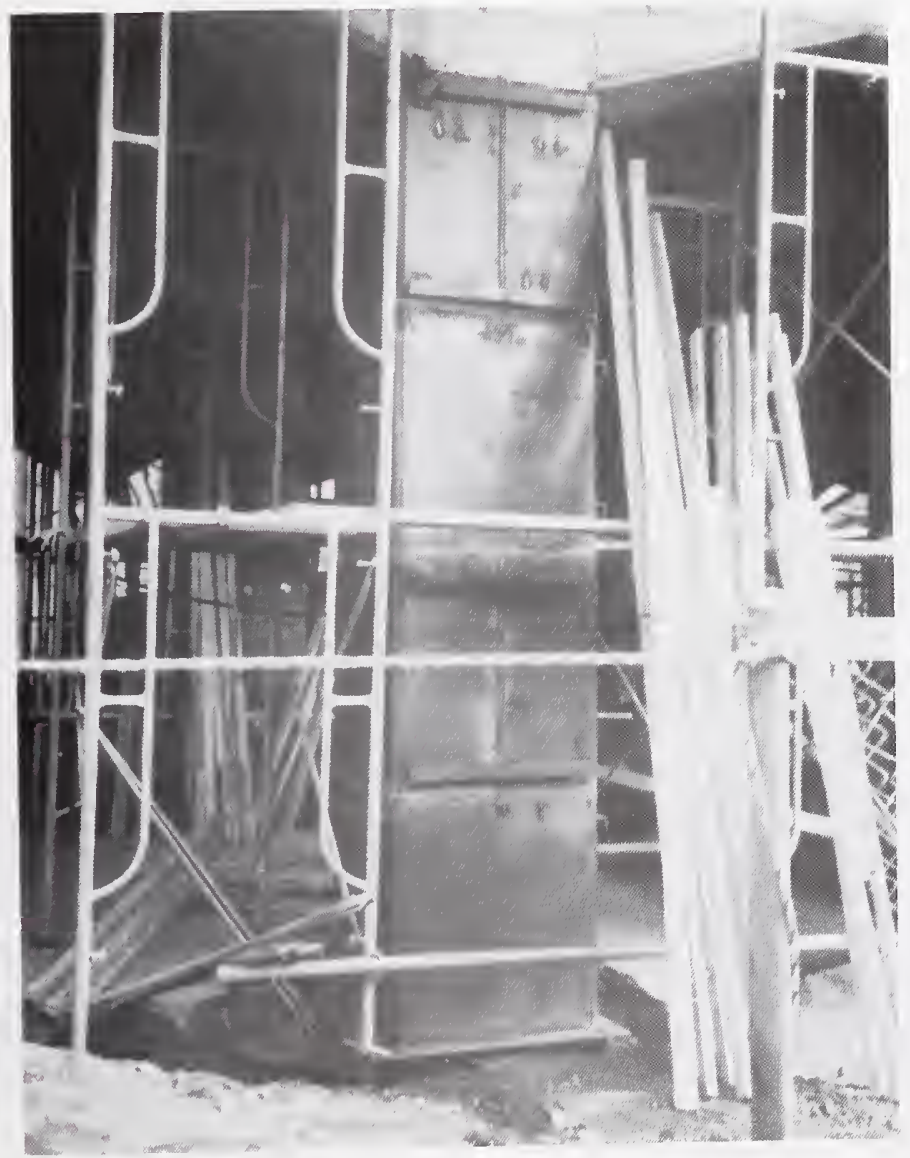

Figure 4.3.8 Jacketed column - JR Main Line. 


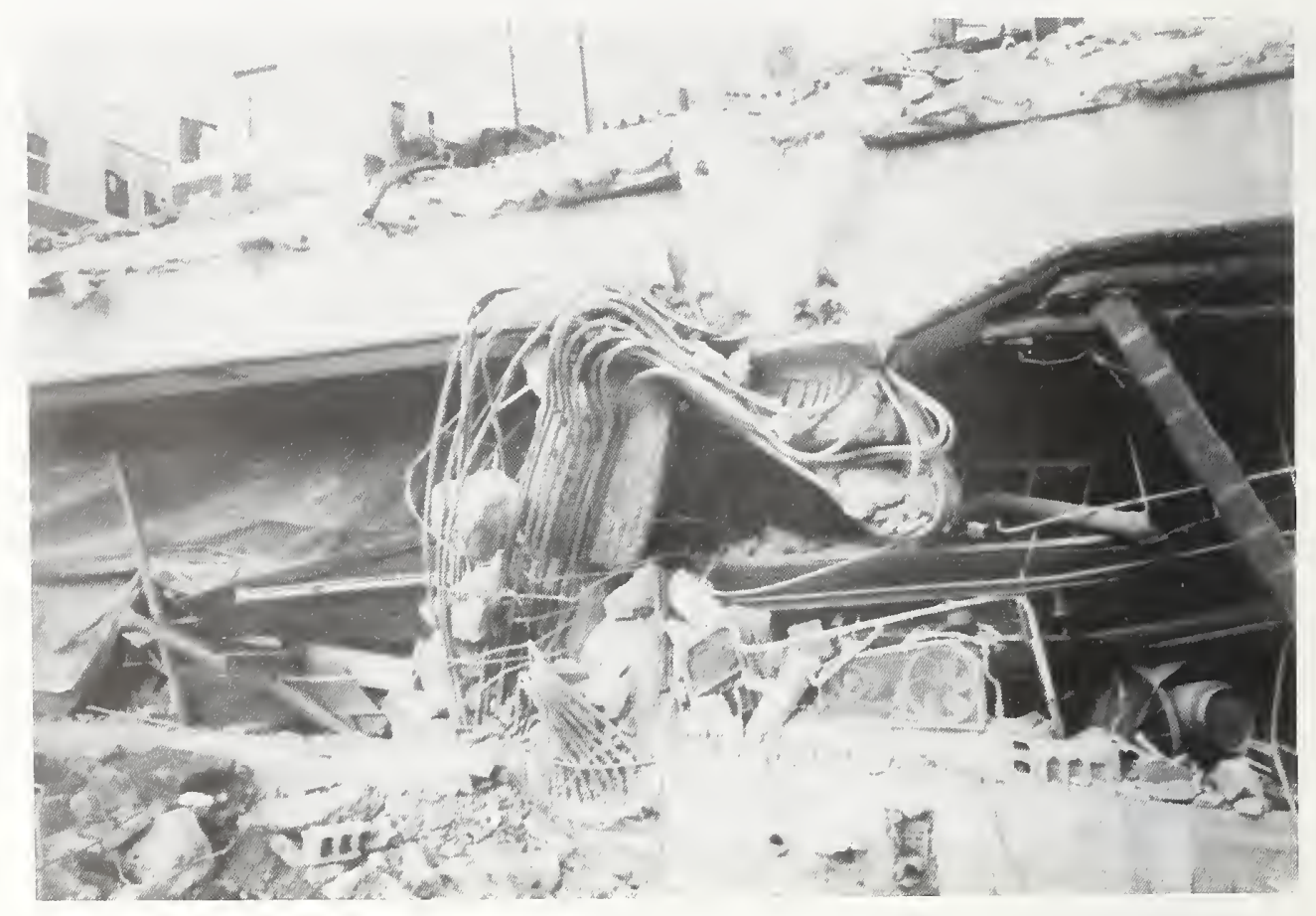

Figure 4.3.9 Failed column at Higashi - Nada - elevated rail yard.

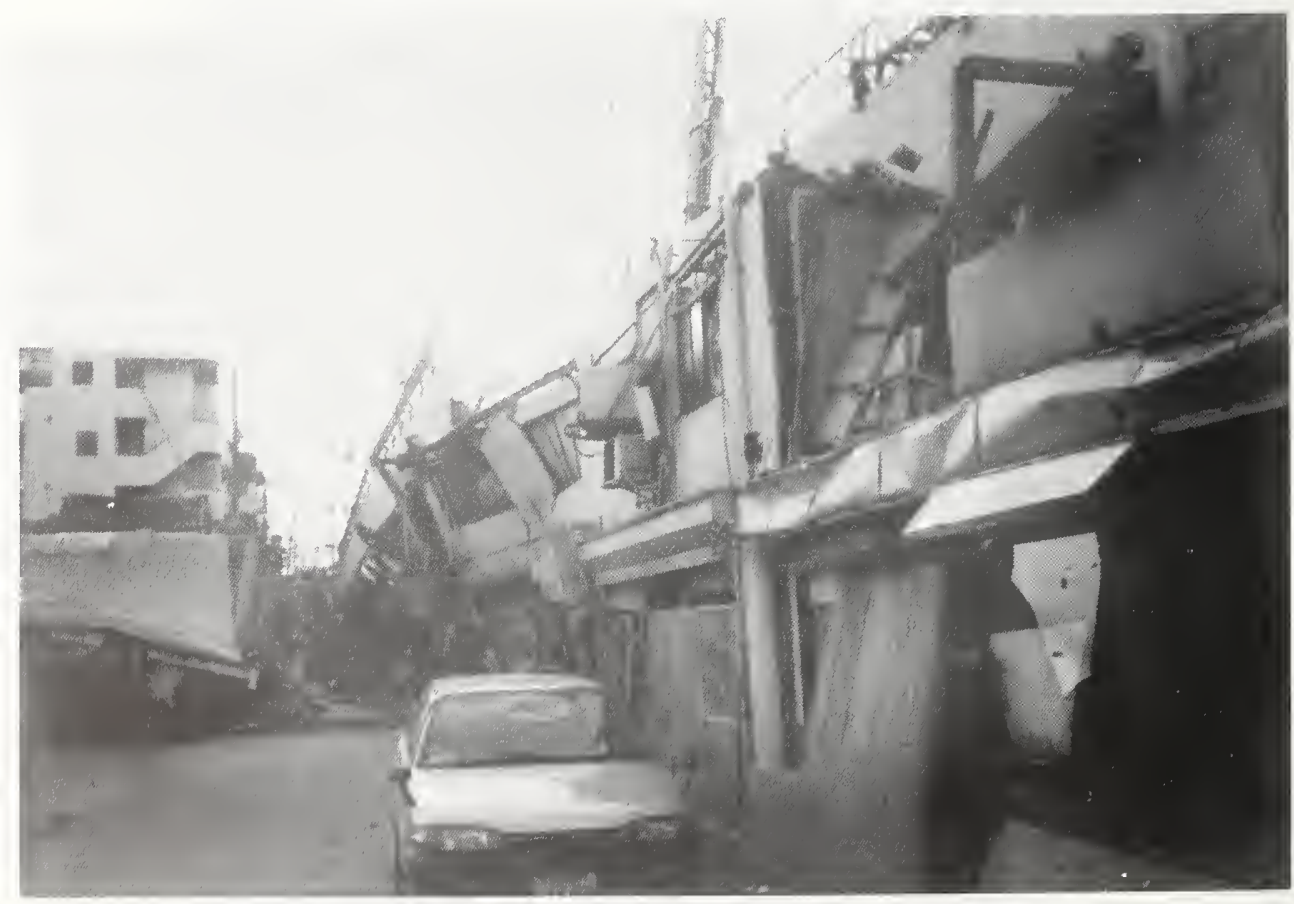

Figure 4.3.10 Collapsed rail yard at Higashi - Nada. 


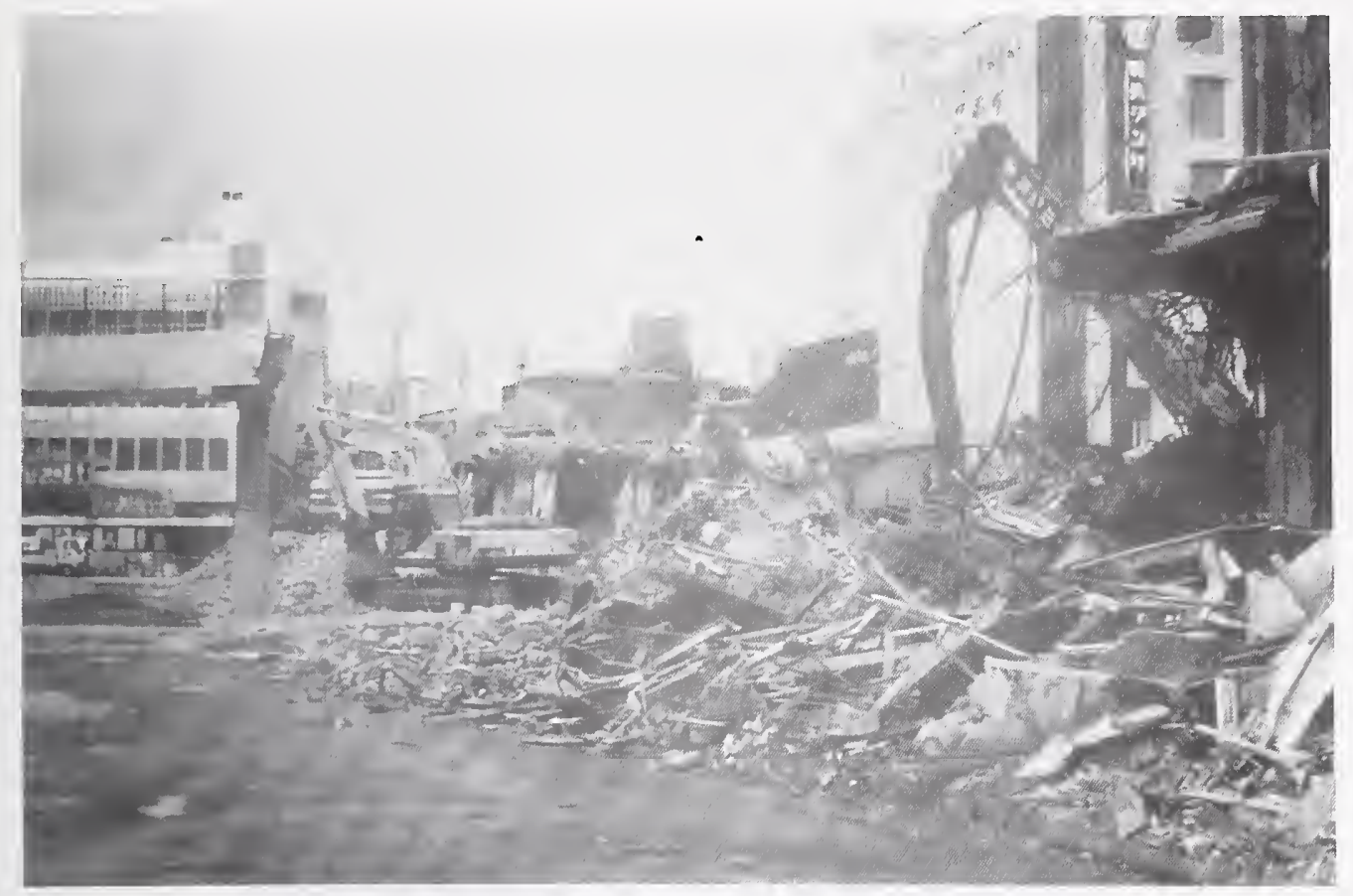

Figure 4.3.11 Collapsed Shin - Itami Station.

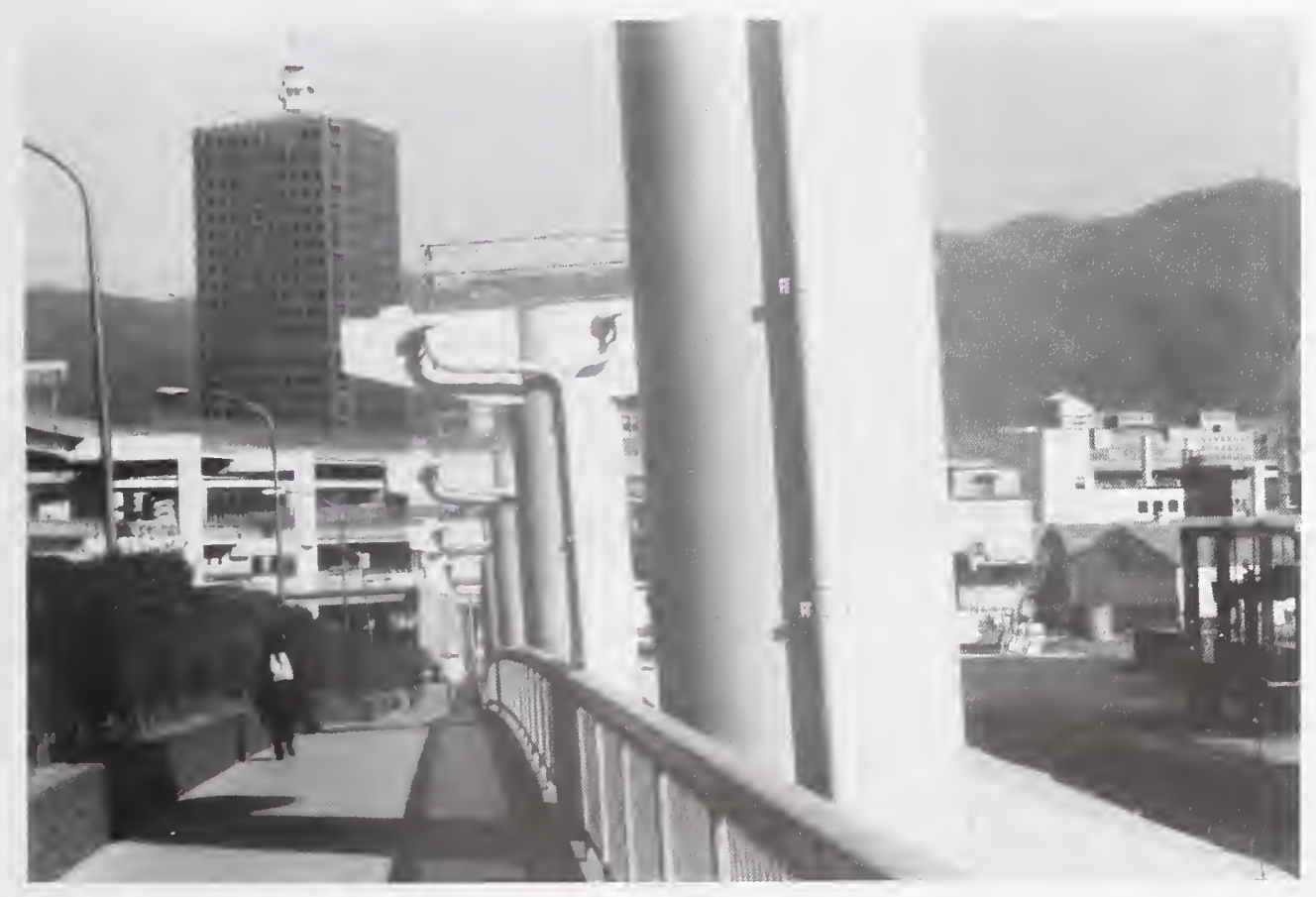

Figure 4.3.12 Tilted pier - Port Liner. 


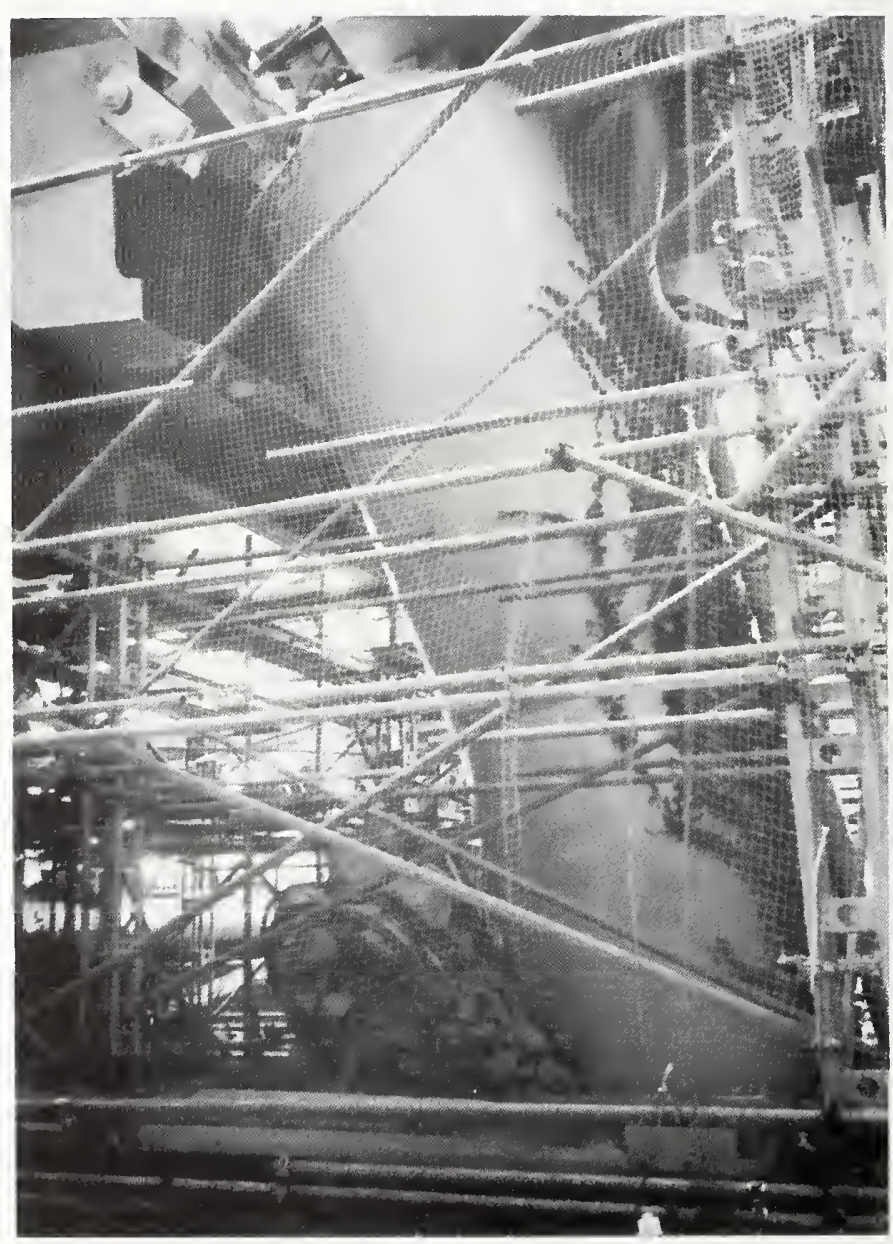

Figure 4.3.13 Tilted pier - Port Liner. 


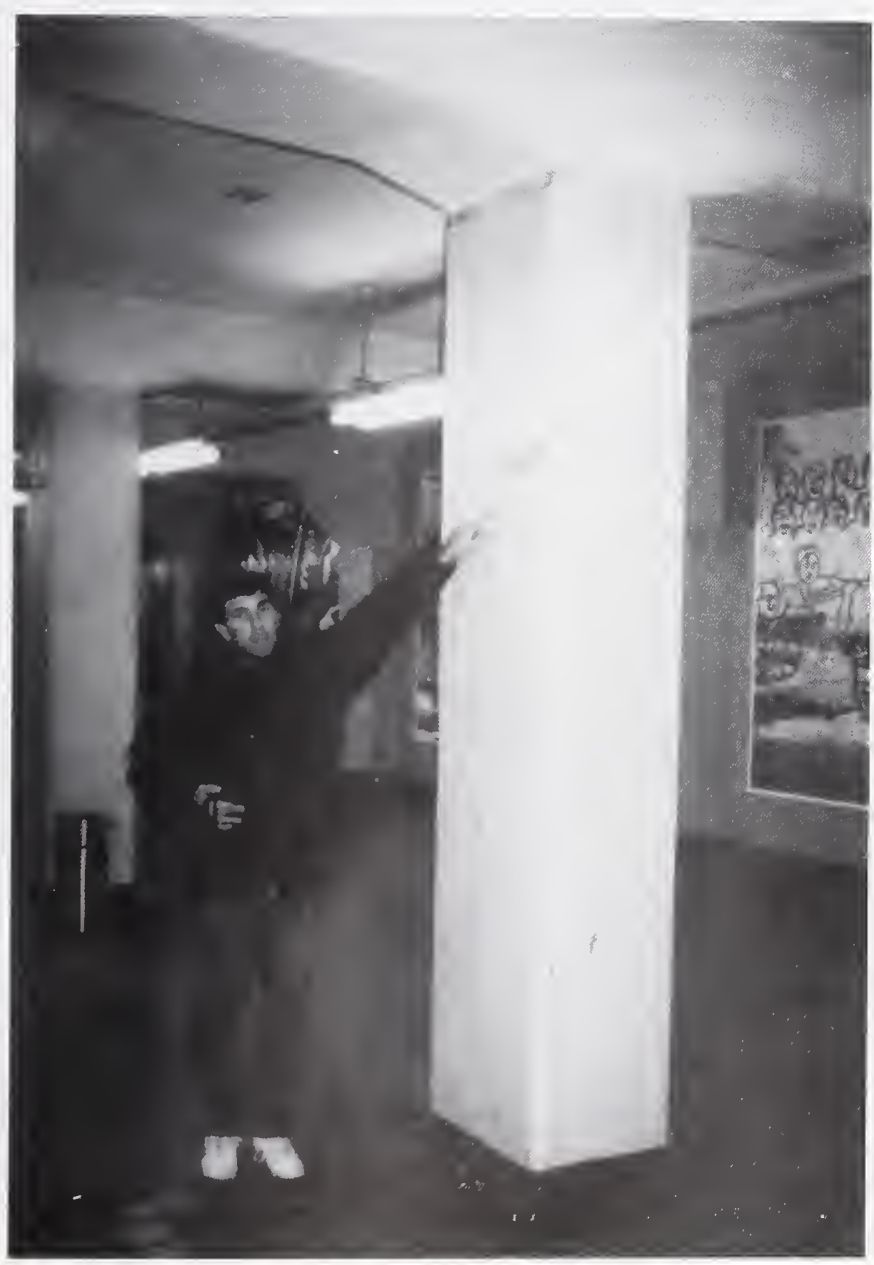

Figure 4.3.14 Cracked reinforced concrete column at underground shopping mall near Shin Kaichi Station. 


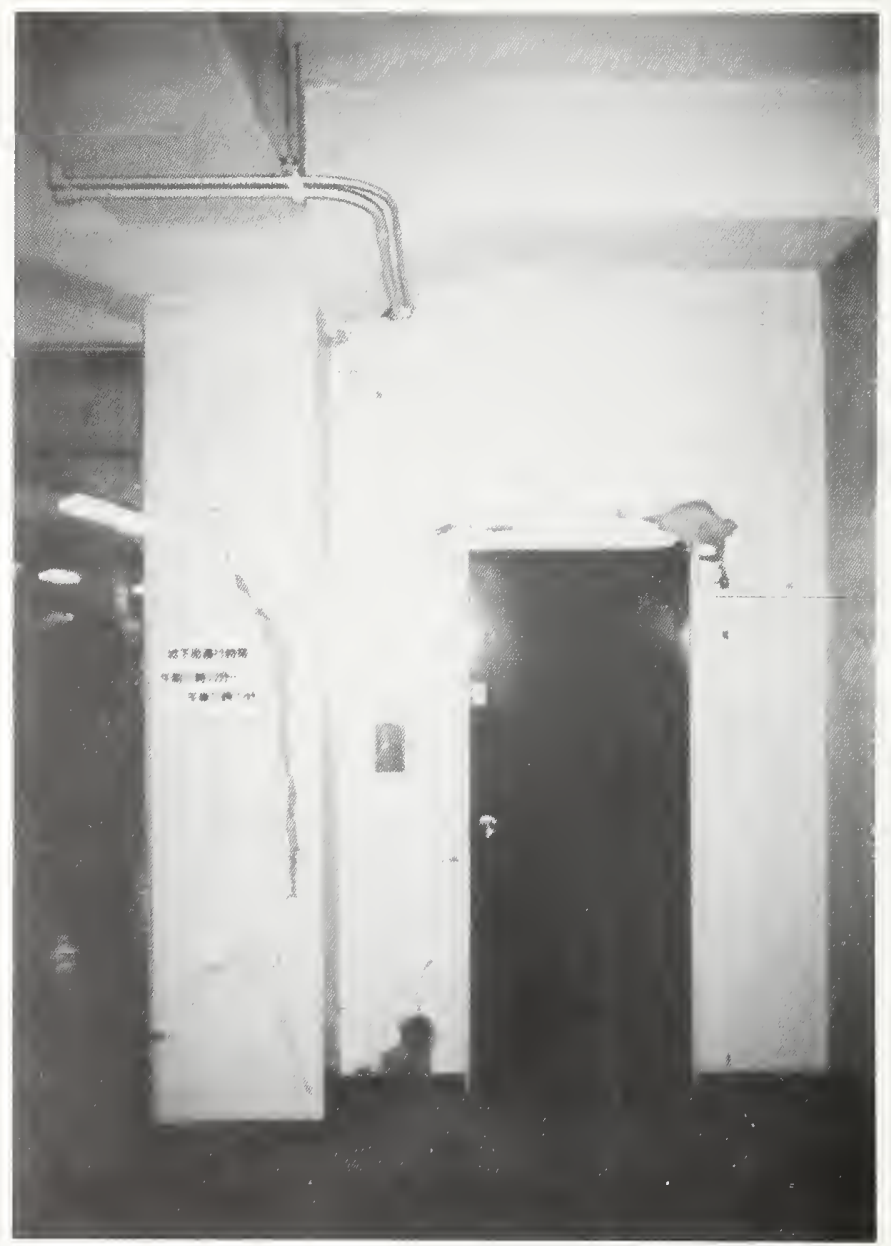

Figure 4.3.15 Cracked reinforced concrete column and concrete panel wall at underground shopping mall near Shin Kaichi Station. 

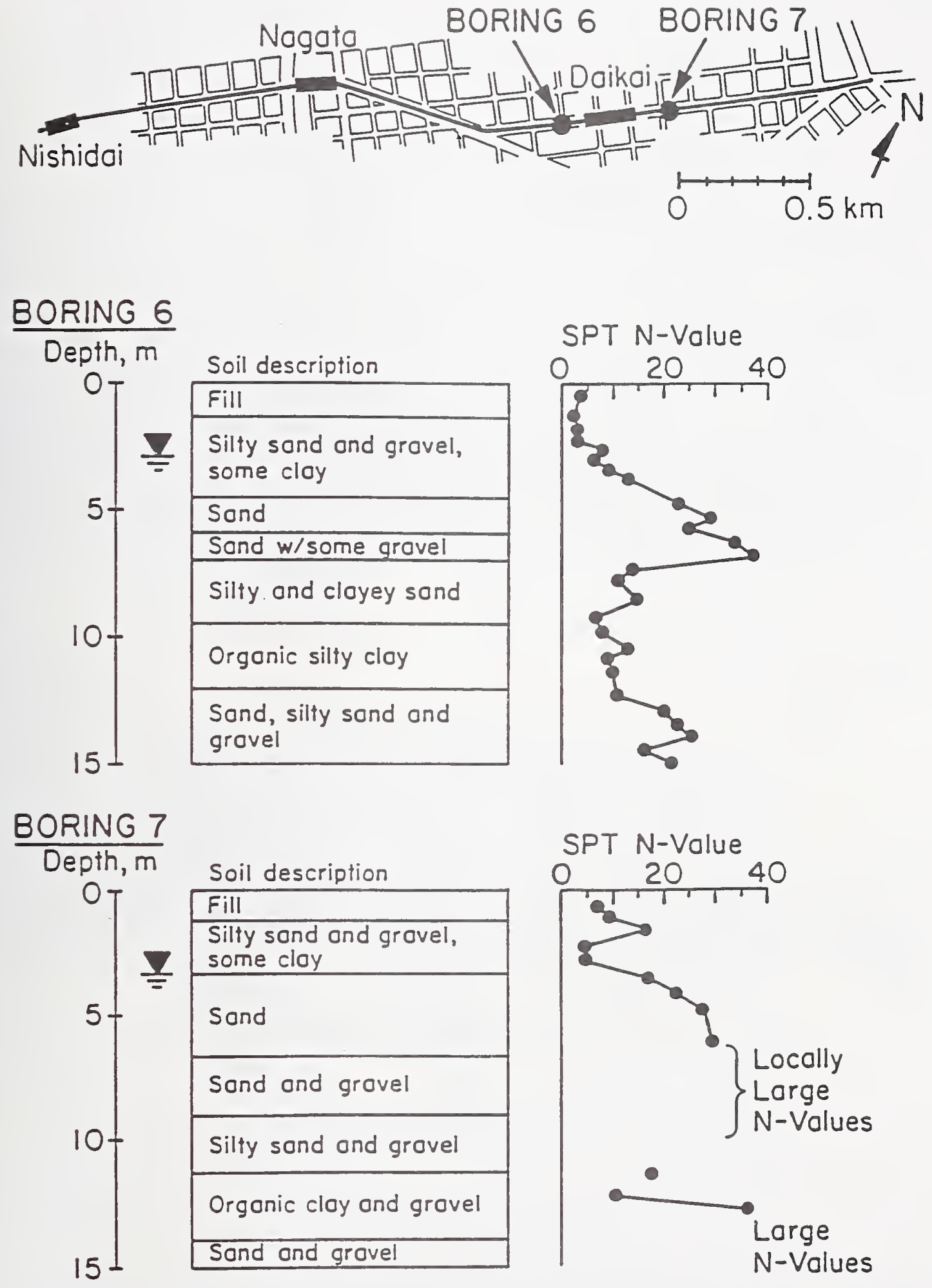

Figure 4.3.16 Soil boring records near Daikai Station. 


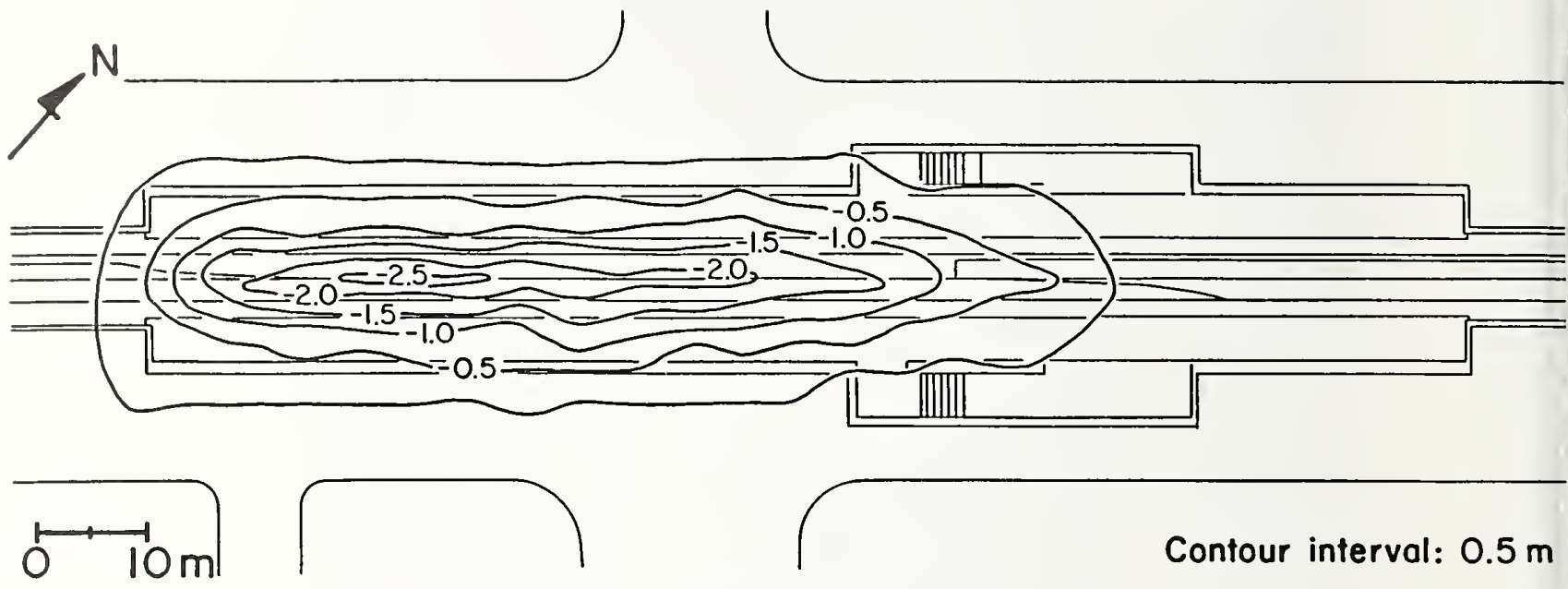

Plan View

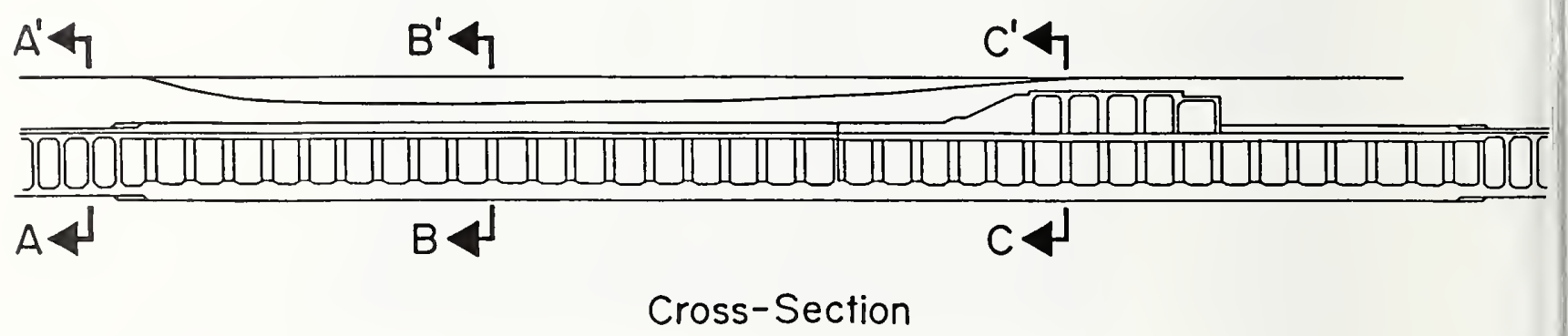

Figure 4.3.17 Plan and profile views of Daikai Station collapse. 


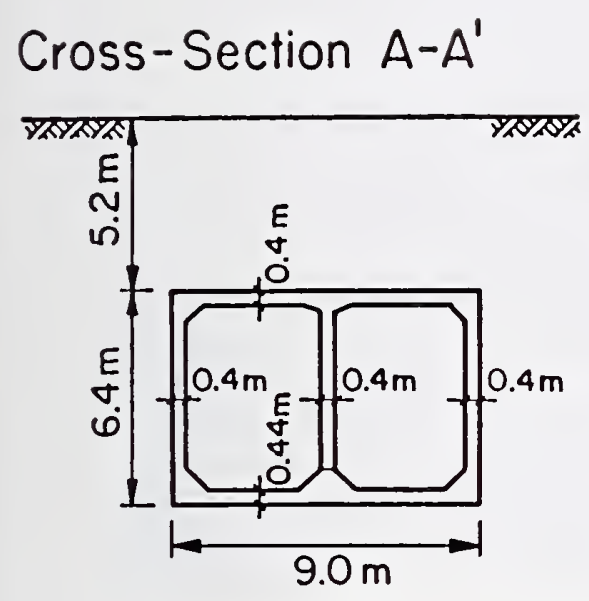

Cross-Section $A-A^{\prime}$
$B-B^{\prime}$

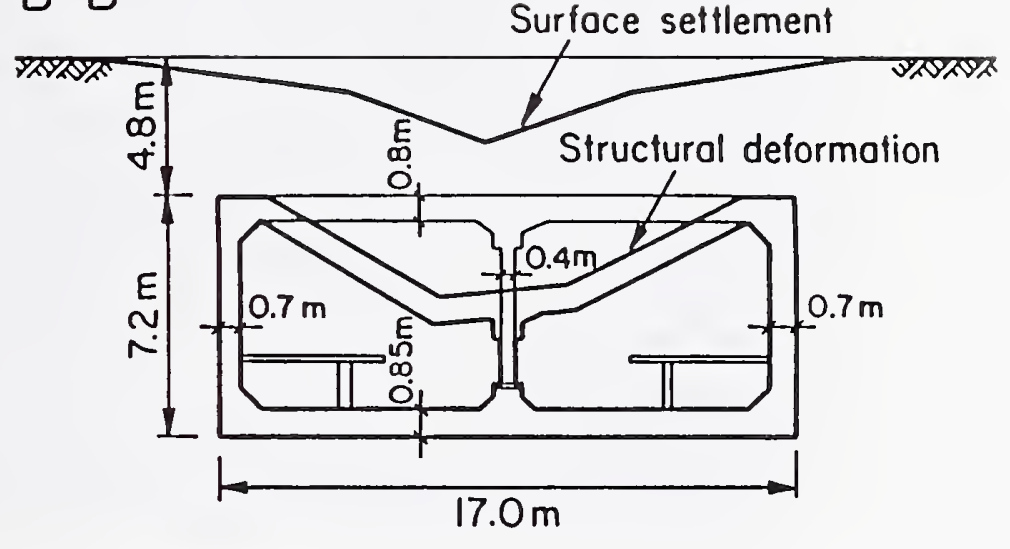

Cross-Section B-B'

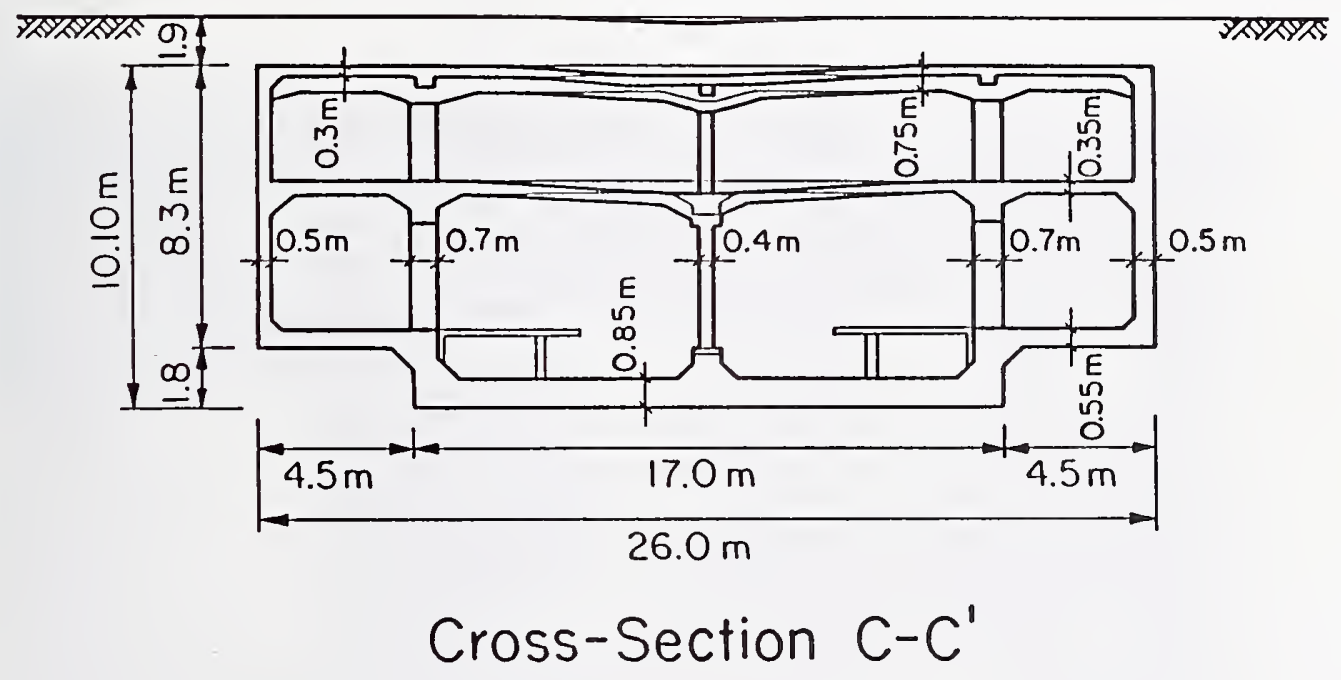

Figure 4.3.18 Cross-sections of reinforced concrete station and running tunnel structures at Daikai Station. 


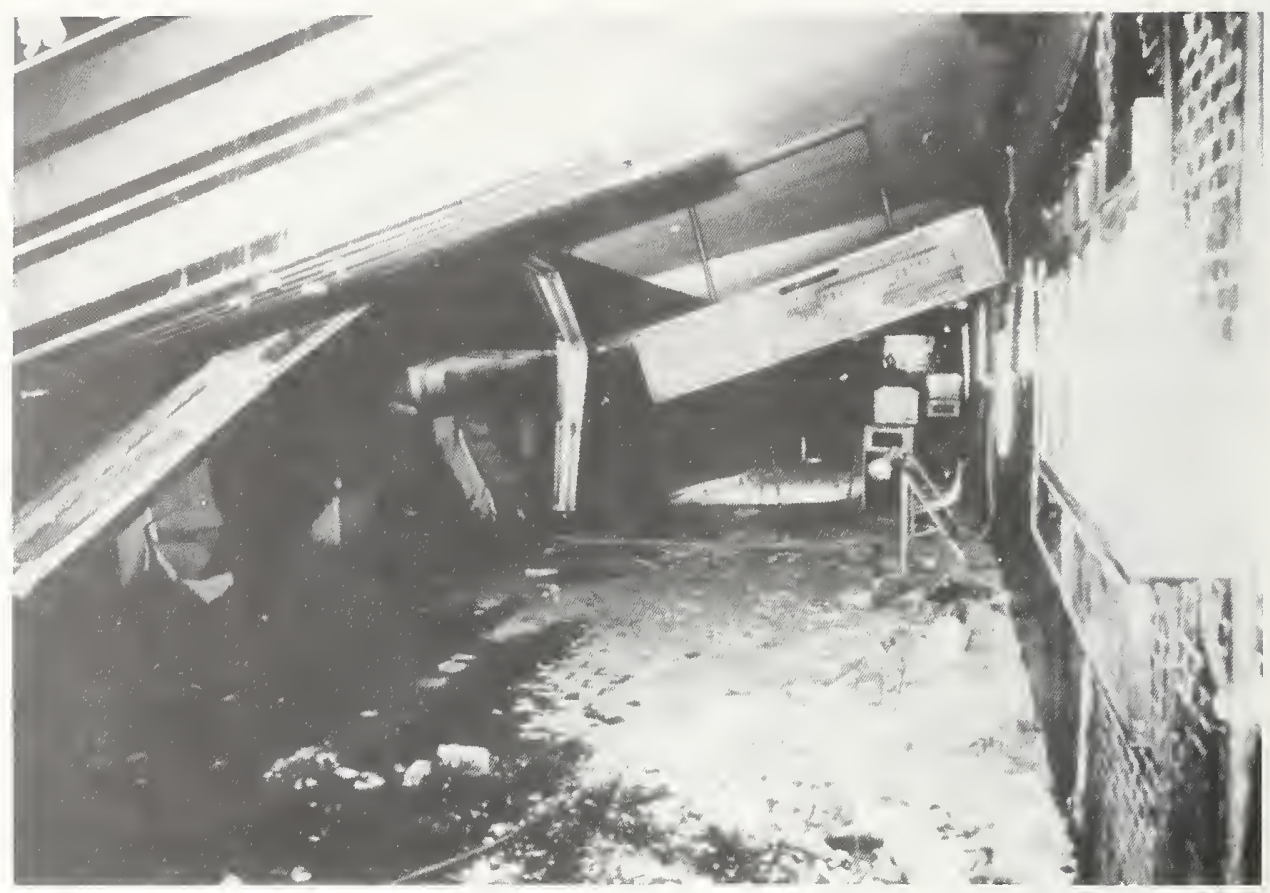

Figure 4.3.19 Roof collapse viewed from the station platform at Daikai Station.

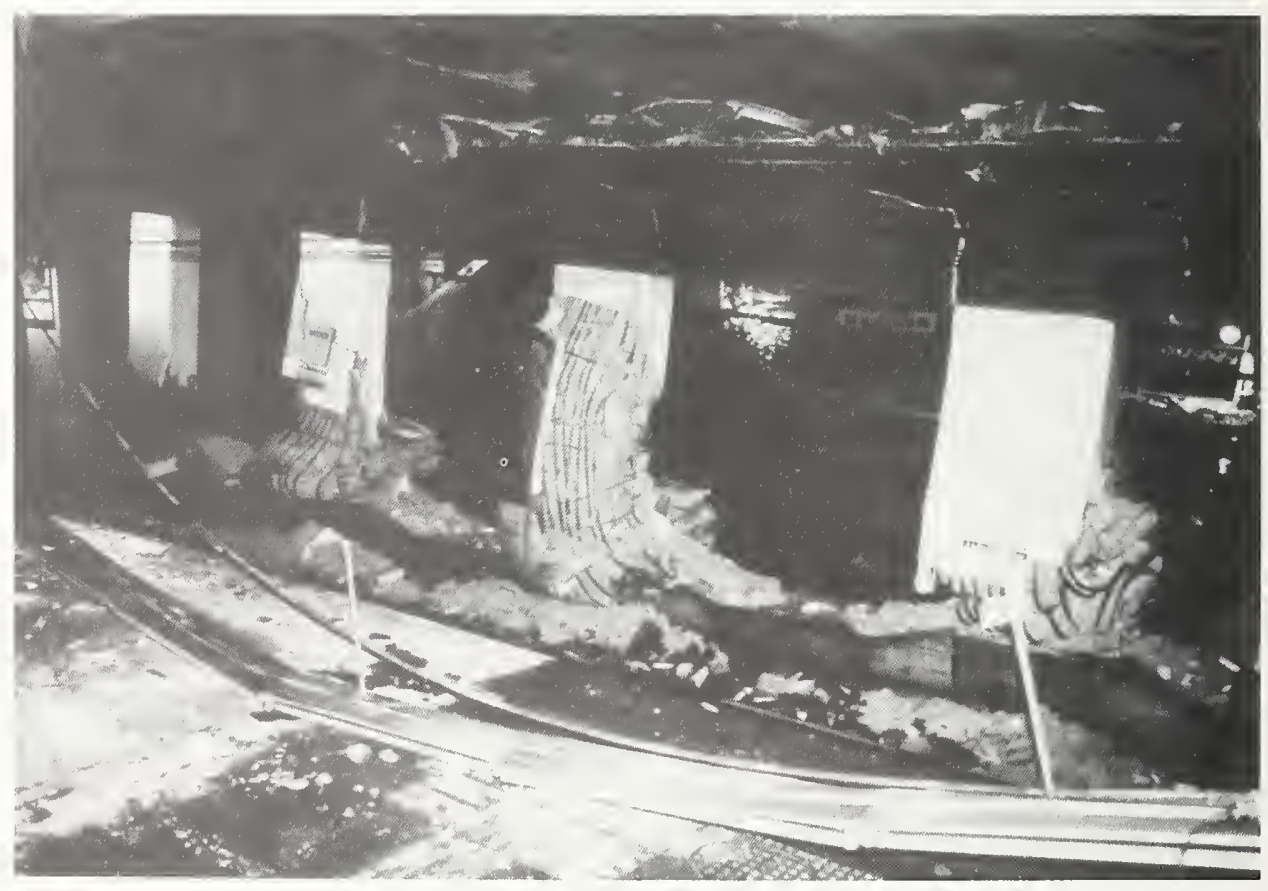

Figure 4.3.20 Compressive failure of center columns at Daikai Station. 


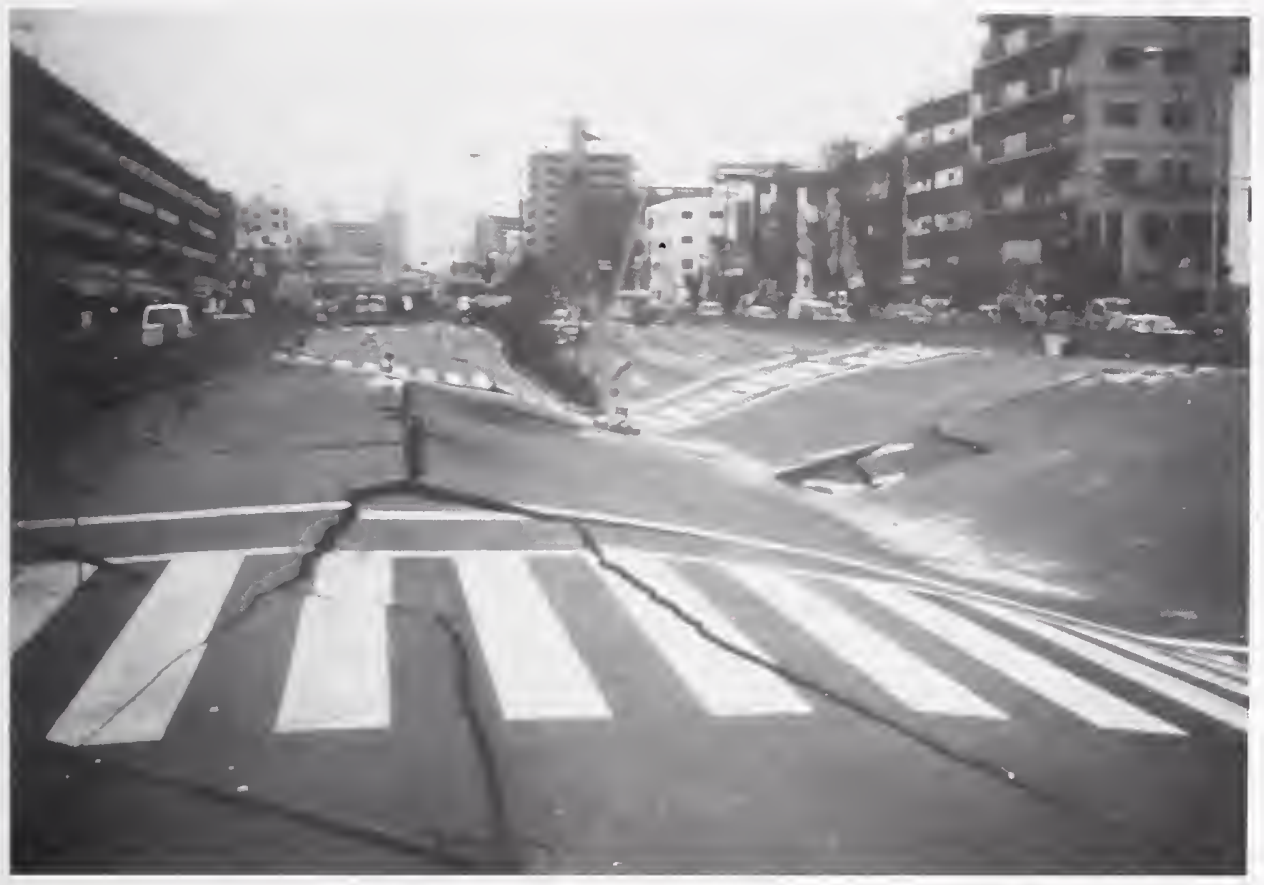

Figure 4.3.21 Subsidence of street surface over the collapsed Daikai Station.
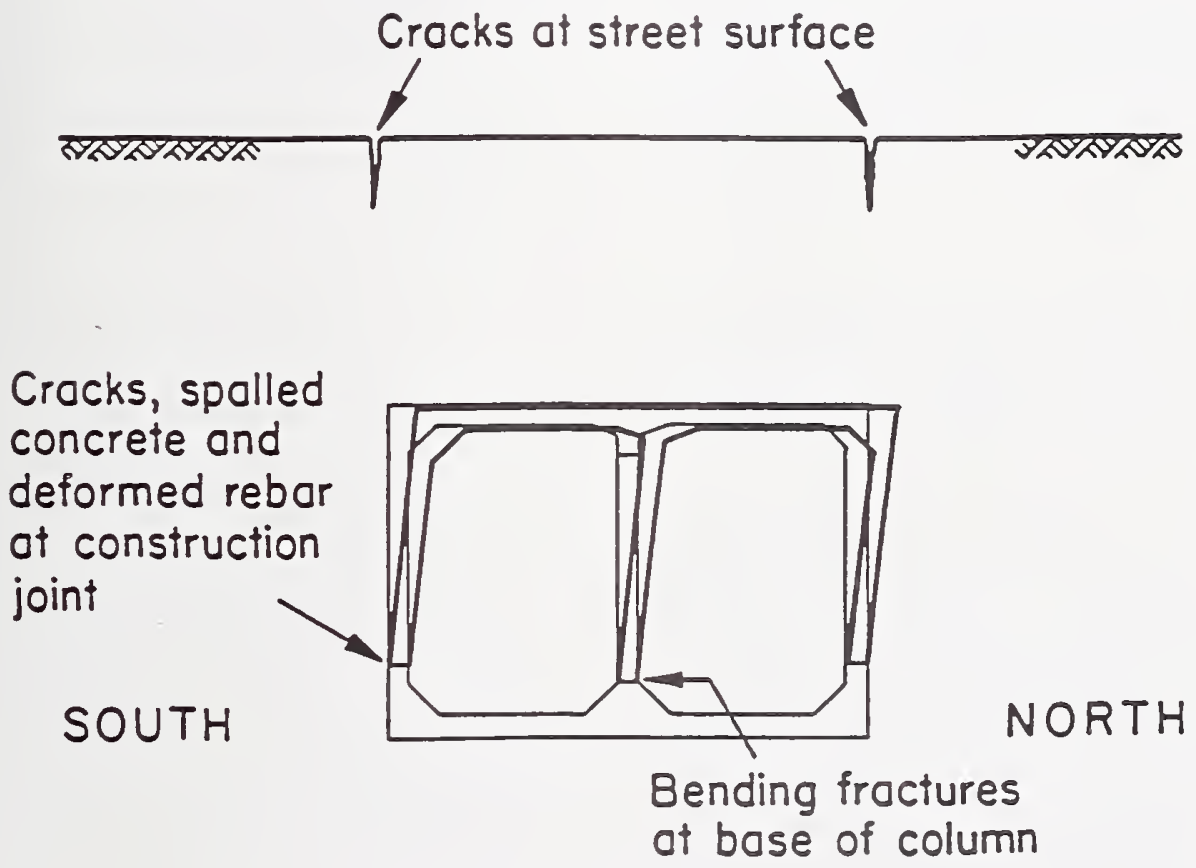

Figure 4.3.22 Earthquake deformation of running tunnel at an exaggerated scale as inferred from reconnaissance observations. 



\subsection{Airports}

\subsubsection{Overview}

The Kansai area is served by three airports: Kansai International Airport (Kansai Airport), Osaka International Airport (Osaka Airport), and Yao Airport. The Terminal Radar Approach Control (TRACON), which is located at Kansai Airport, controls airplanes in the area before each is turned over to the respective control towers. Kansai Airport was opened for service on September 1, 1994, and primarily serves international flights, although emergency services, such as police and rescue and news media, have access. Prior to the opening of the Kansai Airport, Osaka Airport served as the area's domestic and international airport. Osaka Airport now primarily serves domestic flights and a few international flights. Neither of these airports allows general aviation, which is served by Yao Airport. The control towers and some support facilities at Kansai and Osaka Airports were inspected.

\subsubsection{Kansai Airport}

The Kansai airport is built on a 511-hectare island of reclaimed land in Osaka Bay. The bay at the site was about $18 \mathrm{~m}$ deep and it took about 5 years to complete the island. It is $28 \mathrm{~km}$ southeast, and across the bay from downtown Kobe and $38 \mathrm{~km}$ southwest of downtown Osaka. It is located $27 \mathrm{~km}$ southeast of the epicenter. The island has subsided about 2 $m$ since it was completed and currently has about $5 \mathrm{~m}$ freeboard. Recently, subsidence has slowed and it is anticipated that the island will subside another $1.5 \mathrm{~m}$ in the next 50 years. There is a single runway about $3200 \mathrm{~m}$ long. Several tanks store $100000 \mathrm{kl}$ (kilo liter) of jet fuel. At a typical use of about $3500 \mathrm{kl} /$ day, there is about a month's supply of fuel. The airport is connected by a bridge to the mainland that carries auto and train traffic. It is also served by ferry companies from Kobe and four other cities. There is a pier for off-loading jet fuel.

- Expansion is planned in about 10 years to 15 years and another 700 ha of land will be reclaimed and two additional runways and a second terminal will be added. Figures 4.4.1 and 4.4.2 show overview of the airport from the control tower looking east and west, respectively. Figure 4.4 .3 shows a schematic diagram of the airport, access bridge and the location of strong-motion instruments discussed latter.

At the Kansai Airport Control Tower, it was noted that at one time, Japan used the sarne control console system that is currently used in the U.S., but Japan is now in the second generation of equipment that replaced the original U.S. equipment.

It was noted that in the winter there are normally strong winds. It was fortunate that at the time of earthquake there was no wind.

Air Traffic Control Tower The Air Traffic Control Tower (ATCT) at Kansai is a 19 story steel-tubing braced frame. The frame is comprised of four exterior pipe-columns outside the building envelope and four pipe-columns inside the building envelope. The exterior and interior columns are tied to each other at each floor level by a horizontal truss, Figure 4.4.4. The lateral force resisting system is provided by vertical cross bracing between each of the interior columns (Figure 4.4.5). An interior column, 
which is about $75 \mathrm{~cm}$ in diameter, can be seen in Figure 4.4.5. Beam/column connections were made by shop welding short beam sections to the columns in the shop and bolting the connecting beam to the beam stub in the field. Figure 4.4.6 shows such a detail in the penthouse above the cab. Based on a brief review of control tower drawings, the tower and the adjacent administrative building appears to have a stiff foundation mat. The drawings did not show any piles. The tower is connected to the administration building by two catwalks, on the fifth and seventh floors (Figure 4.4.4). The control tower contained an active control system to reduce wind induced vibration.

The vibration control system consists of two systems located on opposite sides of the control tower on an upper floor. Each system has a mass consisting of metal blocks filling a $1.2 \mathrm{~m}$ by $1.2 \mathrm{~m}$ by $.3 \mathrm{~m}$ box. The mass is suspended on an arm that has a universal joint at its top, which is supported by a box shaped frame. The frame is connected to the floor. There are two actuators, which lie in a horizontal plane, connected to the arm. The angle between the actuators is 90 degrees (Figure 4.4.7). Rubber snubbers are connected to the frame to limit the motion of the suspended mass. The strategy for the operation of the vibration control system is not known.

As noted above, Kansai Airport is built on reclaimed land which has experienced significant subsidence prior to airport construction, so that ground settlement is a serious concern. If settlement occurs the building can be leveled by using two hydraulic rams at each of the eight columns located on the foundation slab (Figure 4.4.8). The columns are held against the action of the hydraulic rams by about twelve $10-\mathrm{cm}$ studs. The shear capacity of the columns is not known, but there are two shear keys on each side of the tower (Figure 4.4.9). These shear keys are detailed to carry lateral load parallel to the foundation wall, including torsion of the building, but no vertical axial load (Figure 4.4.10). The lower end of each ram is supported by the foundation pad and the upper end is connected to a stiff diaphragm, consisting of the deep beams shown in Figure 4.4.11. The shear keys are configured so that they stay engaged when the rams are used to relevel the structure. It is not known if the leveling mechanism is used to compensate for differential settlement of the tower to prevent leaning, or if it is also used to maintain the level between the structure and the surrounding ground. This may be needed to prevent damage to utility lines that enter the building.

The terminal building columns are also supported so that they can be adjusted for settlement at the site. Unlike the control tower columns, the terminal building columns do not have permanently installed hydraulic cylinders to adjust column length. Instead, there is a position that can accommodate a portable hydraulic cylinder that can be used to raise the column. Anchor bolts would have to be loosened and shims inserted to reposition the column. This control tower cab is constructed differently than those found in the United States, in that the cab roof is supported by four columns in the interior of the cab (Figure 4.4.12). The column cross-section decreases in the cab, just above the floor and below the ceiling. In the United States the cab roof is supported only by the window mullions, in order to allow a 360 degree view from anywhere in the cab with the only obstruction being the narrow mullions. In the United States the failure of control tower windows, which is generally attributed to the flexibility of the cab roof 
relative to its floor, is relatively common. The columns at Kansai should provide the cab with much larger lateral stiffness.

The cab is octagonal in plan, with four wide sides and four more narrow sides. The windows are supported with twenty structural tubing mullions, with three larger members $(20 \mathrm{~cm} \times 10 \mathrm{~cm})$ along the interior of the wide window face and two smaller members $(15 \mathrm{~cm} \times 7.5 \mathrm{~cm})$ at the corners of the narrow sides. The window panes inserted in slots in the mullions with an engagement of about $2.5 \mathrm{~cm}$ on the sides and about $3.5 \mathrm{~cm}$ at top and bottom. An outside view of the cab is shown in Figure 4.4.13.

Operationally the control towers are different from the United States. Communication control consoles and monitoring oscilloscopes form controller positions around the periphery of the cab, as is done in the United States. However, near the center of the control tower is a master monitor for a supervisor (Figures 4.4.14 and 4.4.15). These appear to be used when there is more traftic than was the case during the visit. It is interesting to note that the monitors in Japan were much smaller than those used in the United States and are incorporated into the control console. In the United States they are often suspended from the ceiling. The computers that control the displays were not visited, as they were located in another building. It was noted that at one time, Japan used the same system that is currently used in the United States, but Japan is now in the second generation of equipment that replaced the original U.S. equipment.

Support Facilities A small room above the control tower cab contained communication transmission equipment, heat exchanger and cable trays. The communication equipment was well anchored. The cable trays used for communication lines resemble those used by the power industry for control cables in the United States, in that sections are bolted together (Figure 4.4.16). Cable trays were - typically supported by trapezes suspended by threaded rod. At some locations they were restrained by friction clips (Figure 4.4.17).

A heat exchanger on the roof was well anchored, as was most equipment observed (Figure 4.4.18).

A battery plant provided an uninterruptable power supply. Battery support structures observed in Japan tended to be short and close to the ground, well braced, and provided with rubber spacers between the batteries and their restraints and between cells (Figure 4.4.19). Because of the high operating voltage, very long battery strings were used.

A large diesel-generator that supplied emergency power was supported on vibration mounts typical of those seen at other Japanese facilities (Figure 4.4.20). Utilities connected to the diesel-generator were provided with flexible connections to accommodate the motion of the vibration isolation system. Large diameter pipes, such as those used for cooling water had flexible couplings (Figure 4.4.21). The diesel engine used compressed air for starting, typical of larger engines. The compressor and air storage tanks were well anchored.

The cooling system for the diesel used a small cooling tower adjacent to the building. The cooling tower was supported on a large concrete water storage tank that measured about $6 \mathrm{~m}$ by $15 \mathrm{~m}$ by $2 \mathrm{~m}$ (Figure 4.4.22), so that emergency power could continue to operate for a long time even if the external water supply was disrupted. 


\subsubsection{Osaka Airport}

Osaka Airport is located $28 \mathrm{~km}$ east-northeast of Kobe Japan Railroad

Station and $12 \mathrm{~km}$ north-northwest of downtown Osaka. It is located about $43 \mathrm{~km}$ east-northeast of the epicenter. The control tower was the only part of the airport that was visited.

The leveling system provided in the basement of the Kansai Airport Control Tower appears to be an innovative approach to provide for the possible uneven ground settlement that may be caused by liquefaction or consolidation.

The control tower at the Osaka Airport was constructed in 1969. It is on the top of an eight story reinforced concrete administration building. The concrete frame includes shear walls in the short direction. The cab is octagonal in plan and the roof and windows are supported by 16 window mullions. Equipment was generally well anchored, although there were some heat exchangers on the roof that were supported on unsecured concrete blocks (Figure 4.4.23), or had anchorage of questionable strength.

The window size is $2 \mathrm{~m}$ wide and $2.25 \mathrm{~m}$ high. They are rectangular except for the corner panes. What appeared to be double paned glass was secured in the mullions by inserting its sides about $2 \mathrm{~cm}$, the bottom about $2.5 \mathrm{~cm}$ and top about $2 \mathrm{~cm}$, but it is difficult to make these estimates accurately.
The emergency power was located in a separate building that was closed on the weekend, and the communications facility was off the airport site and was not visited.

\subsubsection{What Happened}

\subsubsection{Kansai Airport}

An array of 19 strong-motion instruments recorded the earthquake at Kansai Airport facilities [1]. Figure 4.4.3 gives a schematic layout of airport facilities, and a section view of the access bridge. It also indicates the location of four instruments on runways with letters W, C, S1 and S2. The location of instruments on the access bridge are also indicated. Figure 4.4.24 indicates the location of strong motion instruments in the main terminal building - 10 instruments at the first, forth and roof levels, 1 instrument at the Automated Guideway Transit System Control Center, 1 down-hole instrument, 2 instruments on the access bridge, and 1 instrument at the ground surface in the railway station. Table 4.4.1 lists the peak acceleration, in gals, recorded by each instrument. Figure 4.4 .25 shows the largest horizontal component recorded at location $\mathrm{W}$ on one of the runways. The duration of strong shaking is about 12 seconds and with most of the peaks below 110 gal. Thus, the ground motion at the site, even though it was recorded on land fill, was very low. The records give no indication of liquefaction. An air traffic controller in the Kansai tower at the time of the earthquake said it "shook like a snake," however, it was dark at the time of the earthquake and from the control tower, the deformation of the tower could not be observed. It is assumed that this refers to vibration rather than mode shape.

No damage was reported to the tower or its contents. The connections of the cross walks that span the control tower and the 
administrative building, which are locations of potential damage due to interaction between the buildings, were inspected for signs of damage from within the crosswalk, and none was observed. The area around column footings that support roadways was carefully inspected for signs of differential settlement and none was found. The only indication of damage was to a walkway in front of the main terminal building between the roadway and building foundation.

Repairs were being made, but there appeared to be a strip about $3 \mathrm{~m}$ wide running the length of the terminal that subsided about $7 \mathrm{~cm}$ (Figure 4.4.26). This was the only observed settlement and the strip, which lies between the terminal foundation and roadway, may have not been adequately compacted. It was reported that there was no subsidence or lateral spreading around the boundaries of the island. Small cracks across the runway were observed, primarily at construction joints, about every $100 \mathrm{~m}$ that were attributed to the earthquake.

Impact on Operations At the time of the earthquake, there was a flight on approach. The captain was told to hold until runways could be checked, and then cleared for landing. There are normally about 240 operations per day. Note that a landing and departure are two operations. At the time of the earthquake a maximum of 23 operations per hour were possible, but this was about to increase to 26 per hour. As a result of the earthquake, there was a drop in tourist traffic, but since east-west road and rail links were blocked at Kobe, there was an increase in domestic flights to and from western Japan. These flights were routed through Kansai because of the difficulty in getting to Osaka Airport and to reduce its load, as most relief traffic went to Osaka. As a result, there was little net change in traffic at Kansai Airport. The small cracks observed in the runway had no effect on operation.

\subsubsection{Osaka Airport}

- The ground motion at the airport is not known, but an air traffic controller on duty at the time of the earthquake indicated that the shaking was very severe, that it was difficult to stand, that things fell off of desks, and that it seemed to last one or two minutes. Damage in the area and at the nearby power substation indicates that the shaking at the site was severe. Numerous diagonal shear cracks were found in shear walls in the stair well and above windows. The largest crack was about $6 \mathrm{~mm}$ wide and located at the floor level just above the roof of the main building that adjoins the control tower. Other cracks were about $3 \mathrm{~mm}$ wide or less and decreased in size with the height at higher floor levels. The abrupt change in lateral stiffness at the floor above the roof of the main building and the reduction of shear loads with elevation explains the observations. The stairwell shear walls may have attracted large lateral loads because of relatively high stiffness in the short direction of the building. Figure 4.4.27 shows an example of this damage.

As noted above, this tower, like those in the United States, has its roof supported by the mullions. One window had a crack emanating from a lower corner that continued to lengthen as the days passed.

Both elevators serving the control tower were damaged and out of service following the earthquake. One elevator was restored to service in just one day, the other was out for 4 or 5 days.

The earthquake caused a crack perpendicular to and through the runway at the airport, but it did not disrupt operations. 
Impact on Operations Osaka Airport is a restricted airport, that is, there is no general aviation; however, police, fire, rescue, and press use of helicopters is allowed.

Normally there are about 20 Visual Flight Rule (VRF) operations per day. But after the earthquake, the Japan Self Defense Force and the U.S. forces had helicopters and there were about 300 operations a day. These operations were used to deliver emergency supplies and to move emergency personnel in and out of the earthquake affected region.

\subsubsection{Lessons for United States}

The braced frame structural system in the Kansai control tower appears to have an effective seismic design, but it has not yet been put to a severe test. The leveling system provided in the basement of this building appears to be an innovative approach to provide for the possible uneven ground settlement that may be caused by liquefaction or consolidation. The use of interior columns to support the roof of the cab in the Kansai control tower did not appear to be a significant visual impediment and should reduce earthquake window damage frequently observed in the United States. Future construction in the United States should consider this design feature in structures that might be subjected to seismic loads.

\subsubsection{Research Needs}

The earthquake performance of control tower windows in the United States has been poor and similar performance was observed at Osaka Airport. The loss of these windows can be very disruptive to operations; therefore improved performance is desirable. The Kansai Airport control tower had columns incorporated into its design that did not appear to adversely affect the functionality of the tower. Practical methods are needed to upgrade control towers in a way that will not interfere with their function.

\subsubsection{Summary}

Two members of the reconnaissance team inspected the control towers at the Kansai and Osaka Airports. They found the Kansai tower to be well constructed with an innovative method of leveling the tower should it be subjected to differential settlement. This tower also had columns in the interior of the cab to support the roof and resist lateral motion of the cab, thus protecting the windows. The columns appeared to cause little visual interference. The cooling system for the emergency generator was provided with a large local water supply. This tower sustained no damage from the low level ground motion in this earthquake.

Both administration building and control tower at the Osaka Airport sustained some damage. Damage included a crack in a window in the cab of the tower, minor damage to shear walls in the administration building and temporary loss of use of the elevators.

\subsubsection{Acknowledgment}

Strong-Motion data was provided by Stu Werner, Dames and Moore, San Francisco, 1995. 
Table 4.4.1

Peak Accelerations Recorded at Kansai Airport

( $>$ indicates input exceeds instrument range)

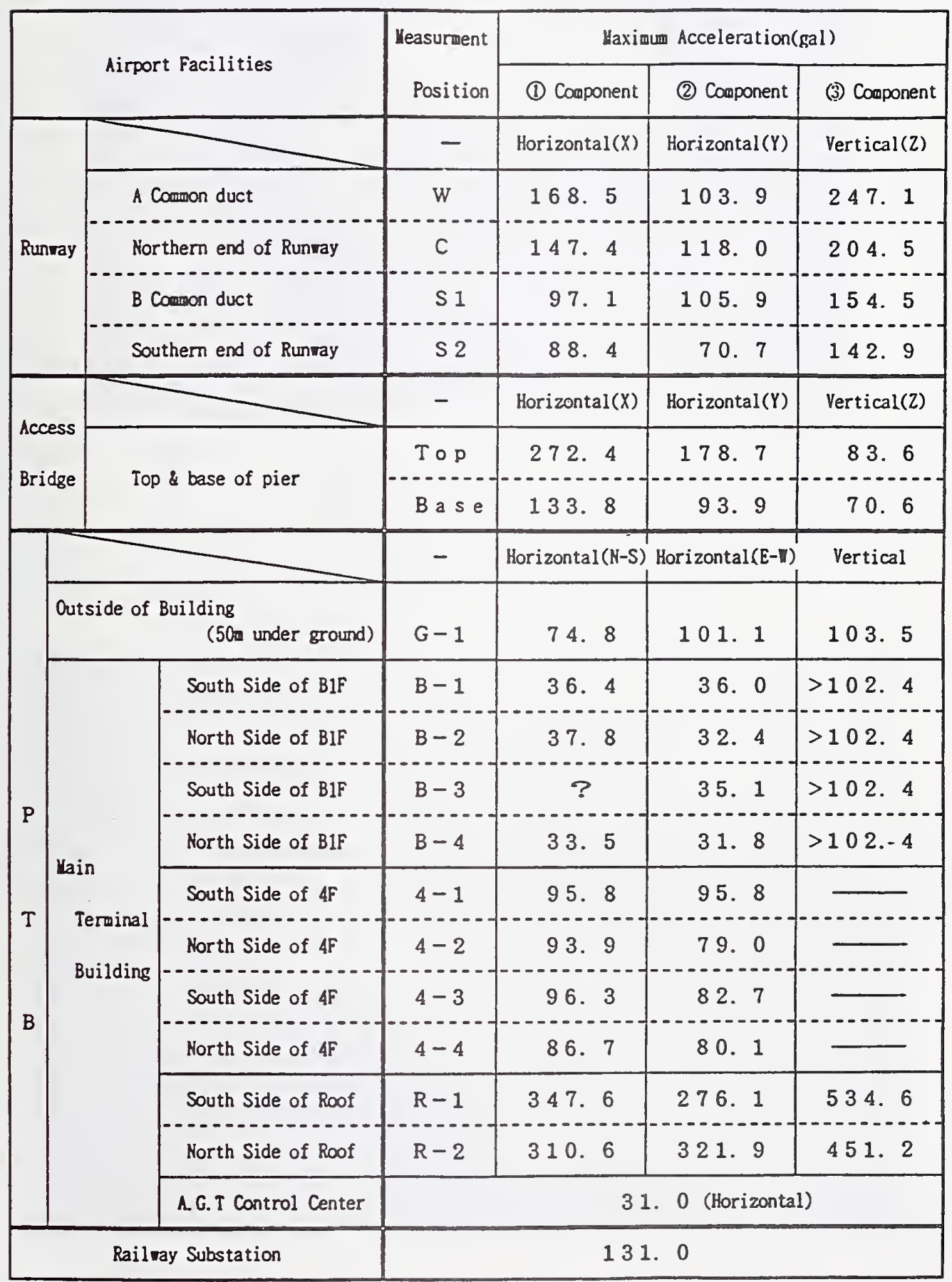




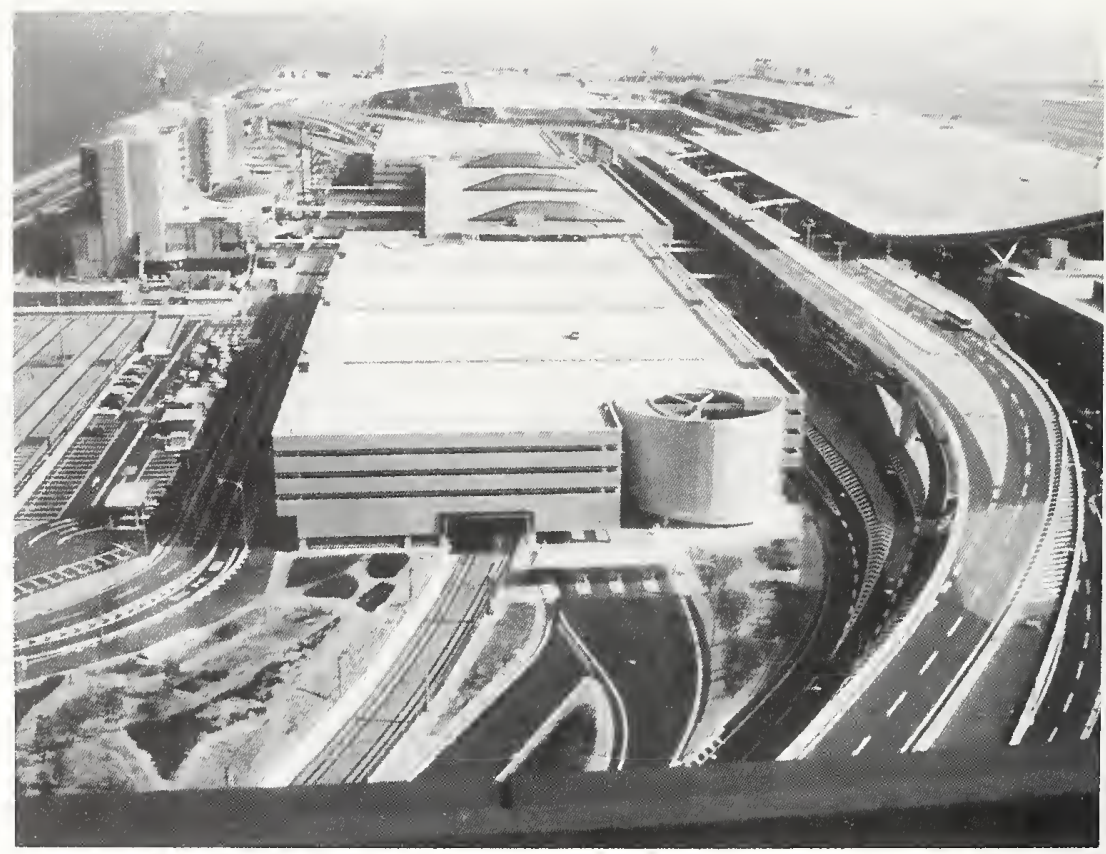

Figure 4.4.1 Overview of airport looking east from control tower.

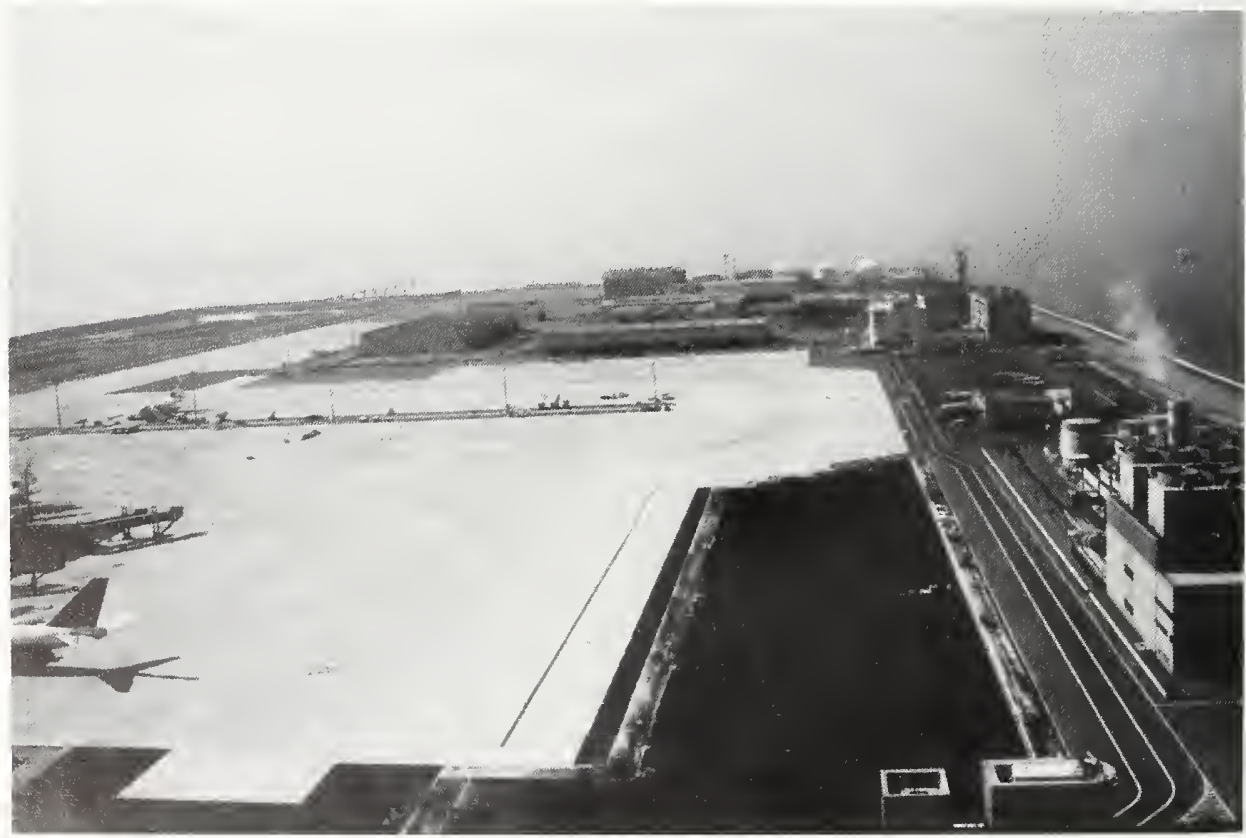

Figure 4.4.2 Overview of airport looking west from control tower. 


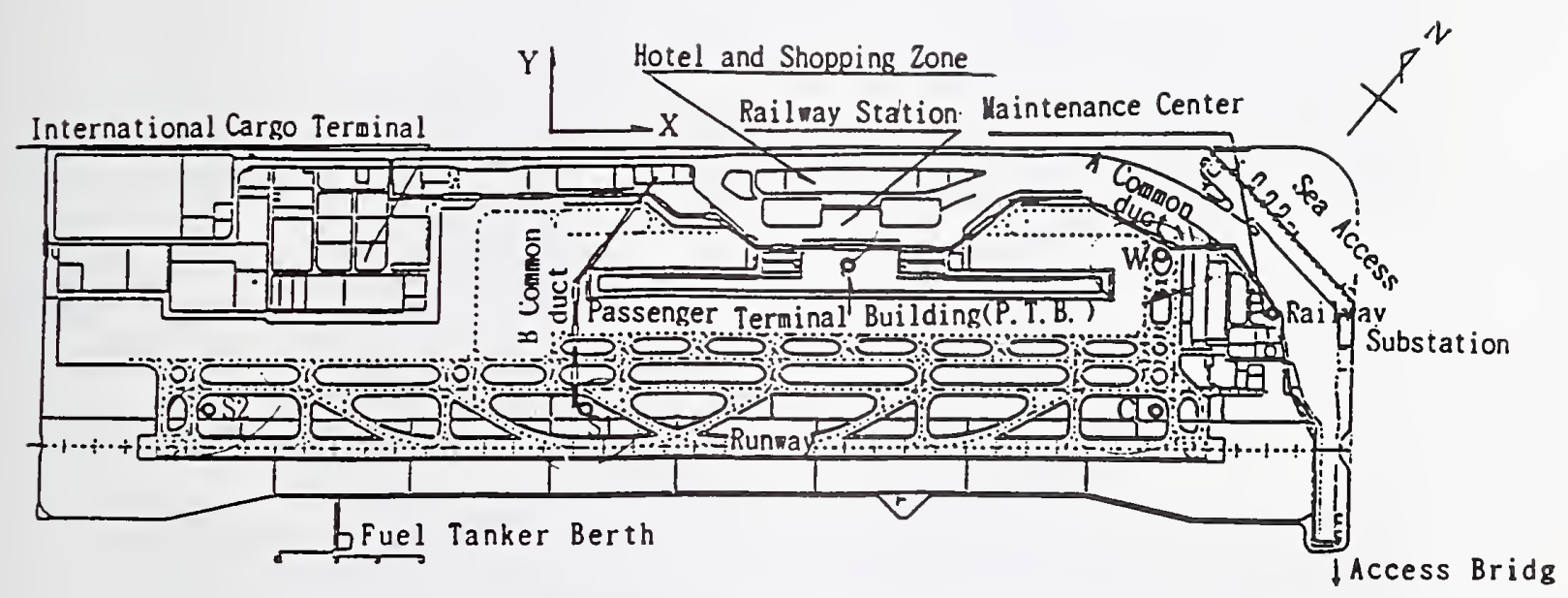

Schematic Diagram of Kansai Airport (Instrument Locations: SW, C, S1, S2)

Airport Island

Mainland

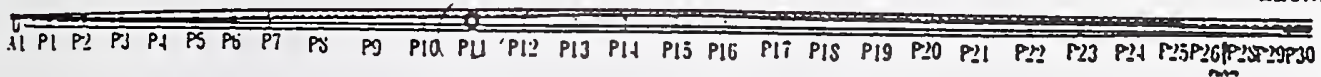

Profile of Kansai Access Bridge

Figure 4.4.3 Schematic diagram of airport, access bridge and strong-motion instrument locations. 


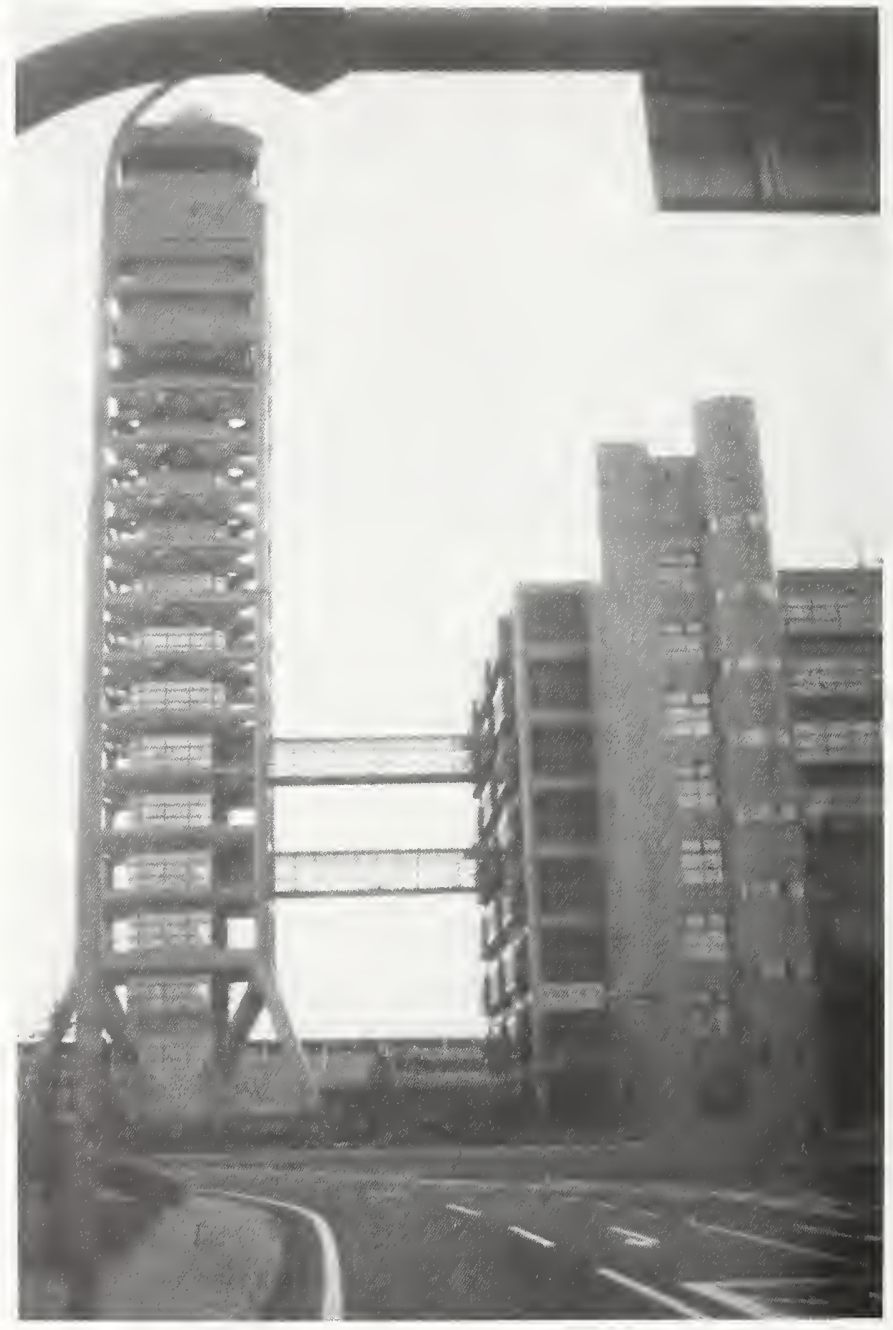

Figure 4.4.4 Kansai Airport Air Traffic Control Tower. 


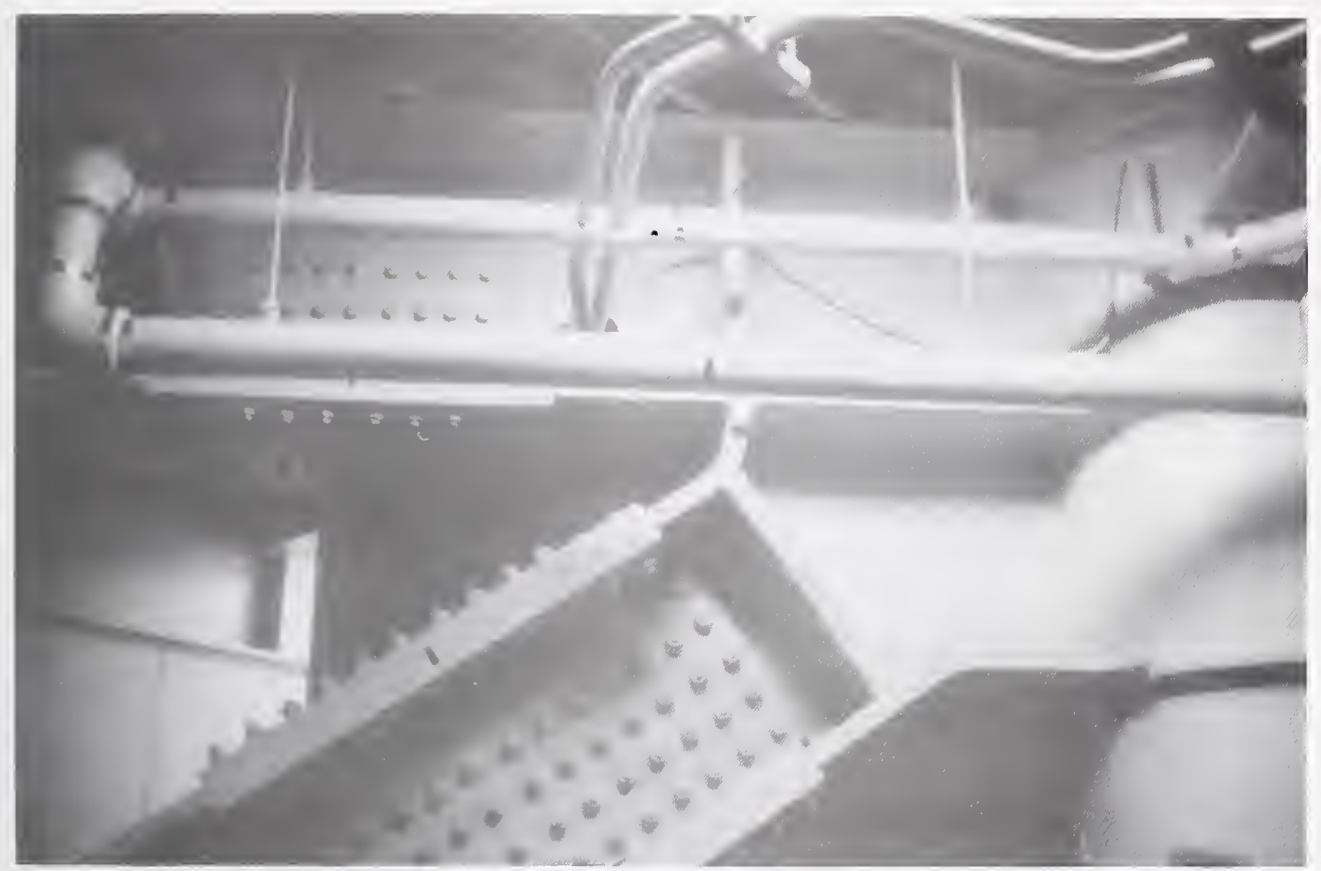

Figure 4.4.5 Connection between an interior pipe column and a vertical truss in the shaft of the tower.

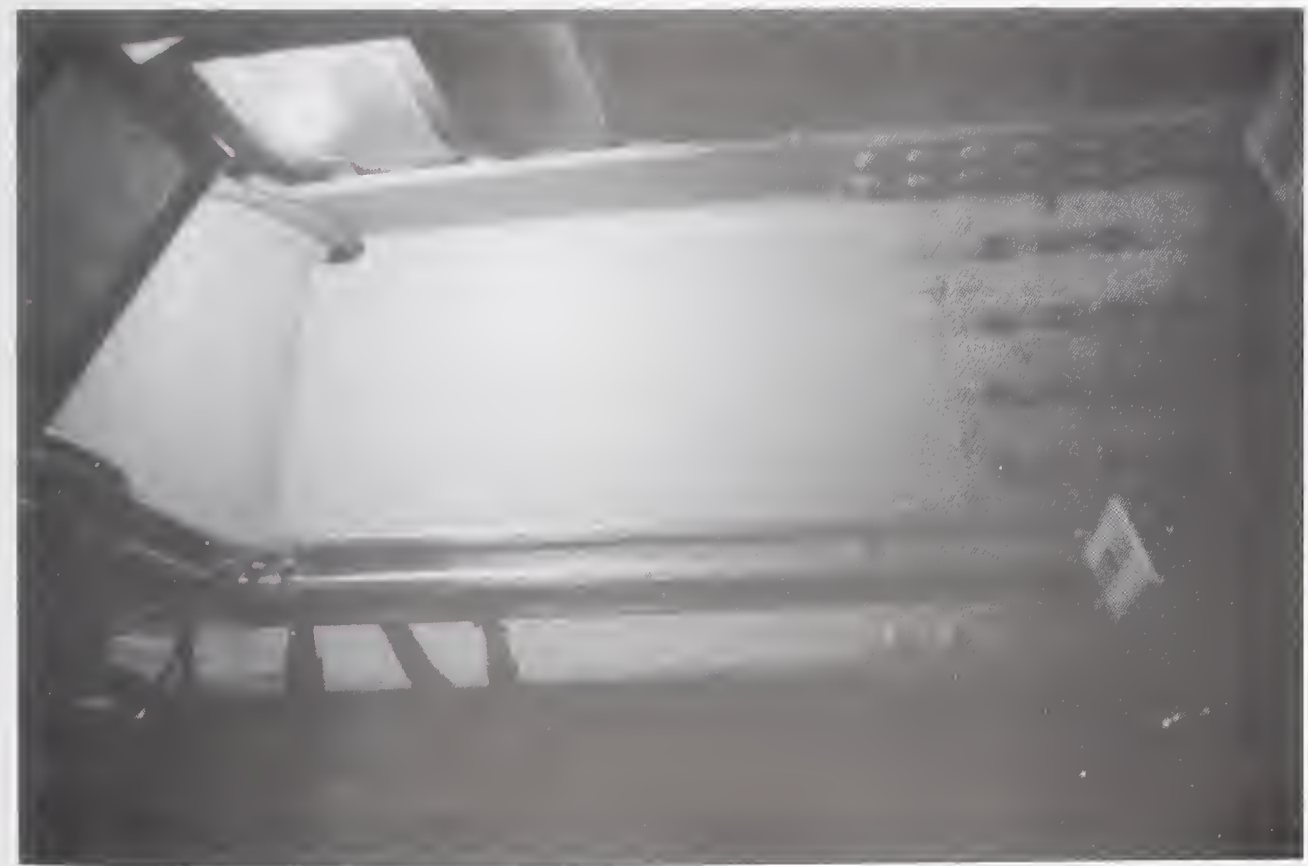

Figure 4.4.6 Beam/column connection in the penthouse above the cab. 

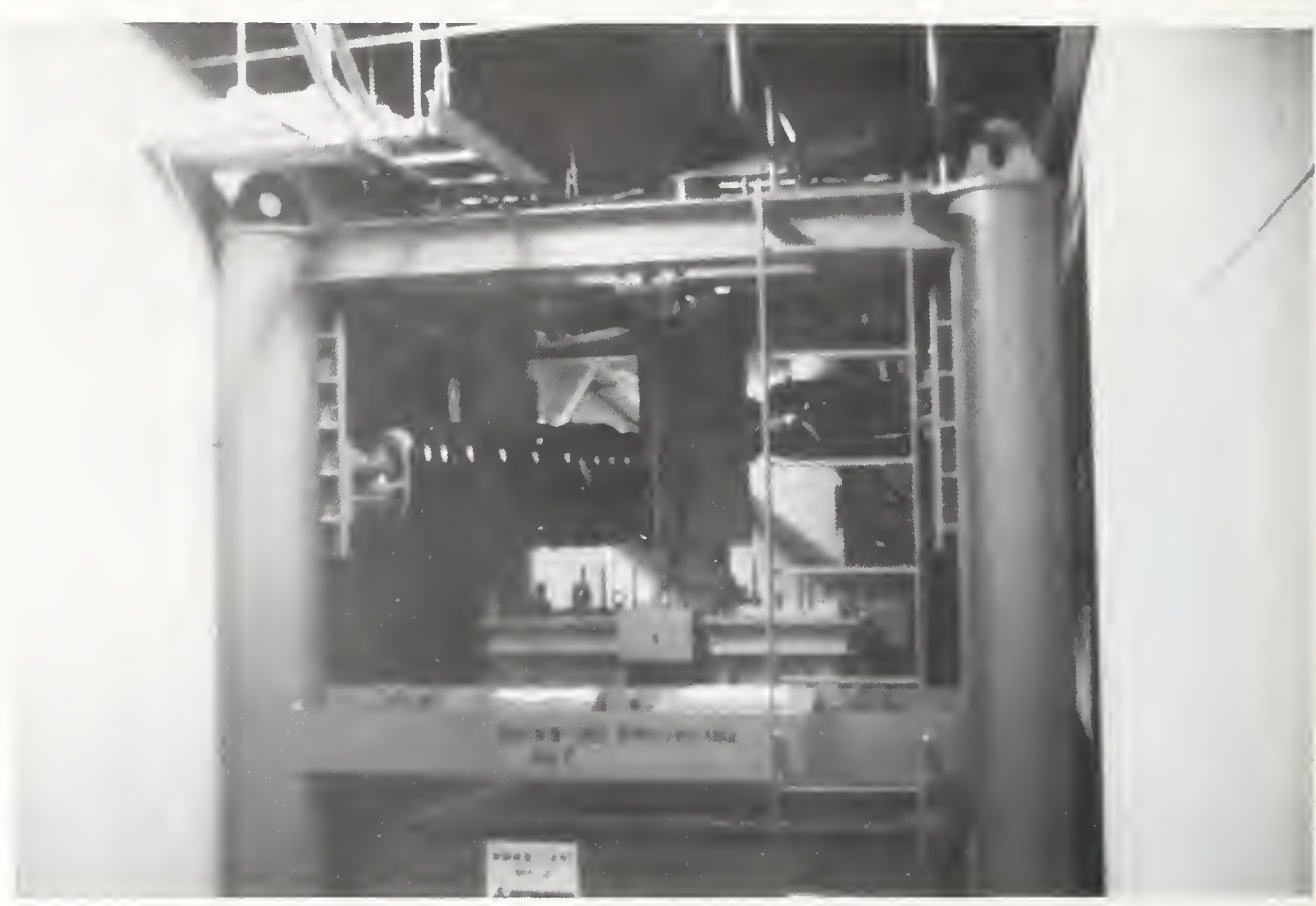

Figure 4.4.7 Active control system to reduce wind induced vibration.

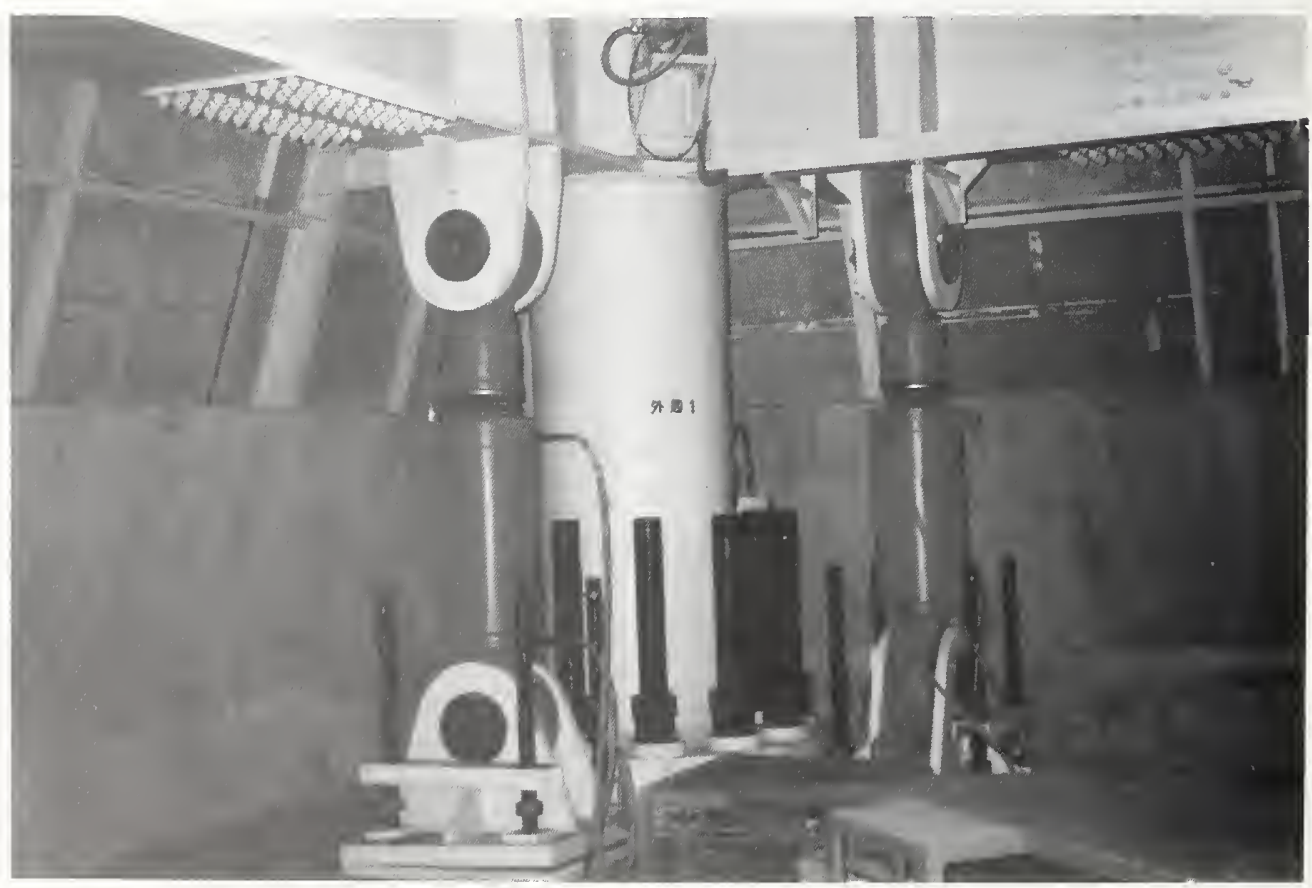

Figure 4.4.8 Hydraulic rams on either side of a column. 


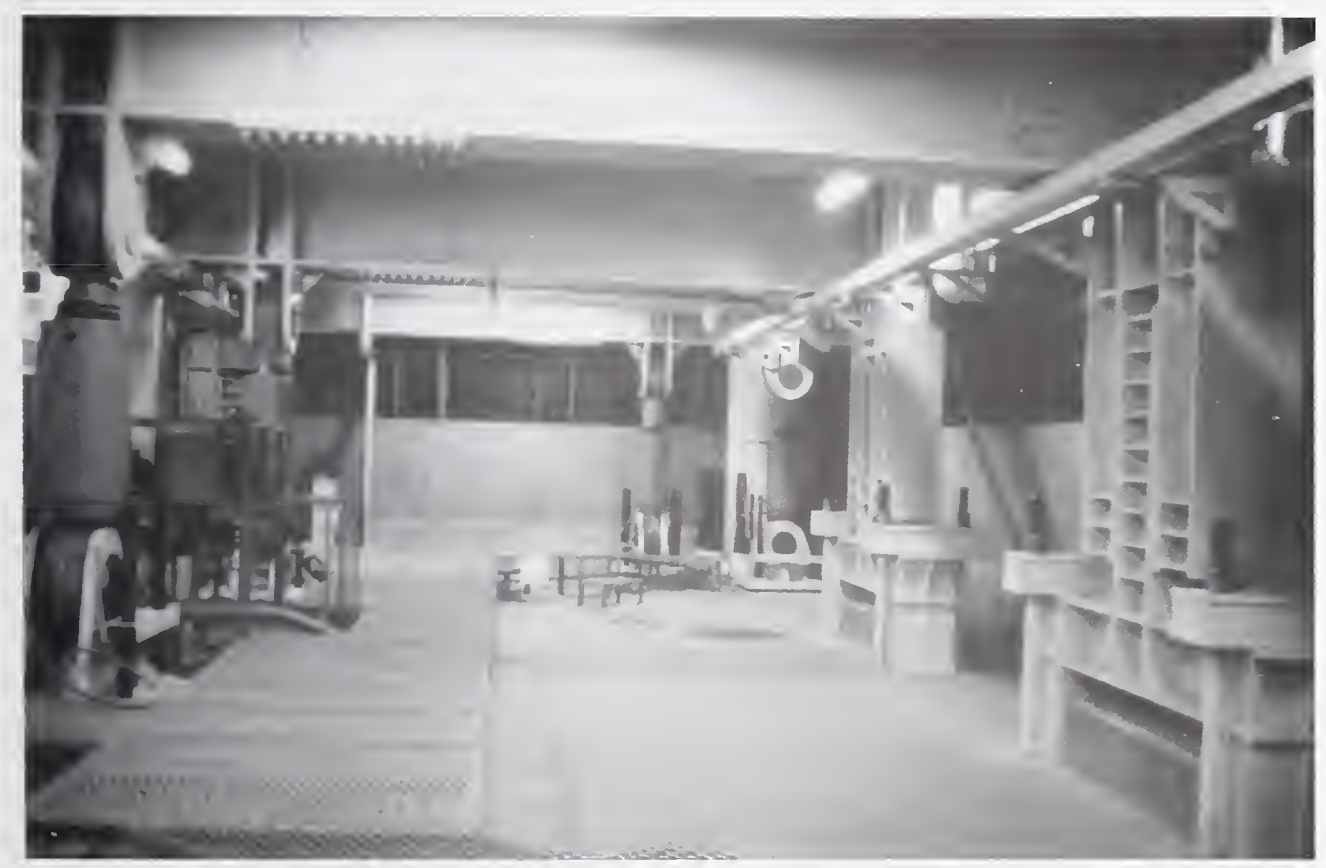

Figure 4.4.9 Basement of the tower showing system for leveling the building and shear keys. 


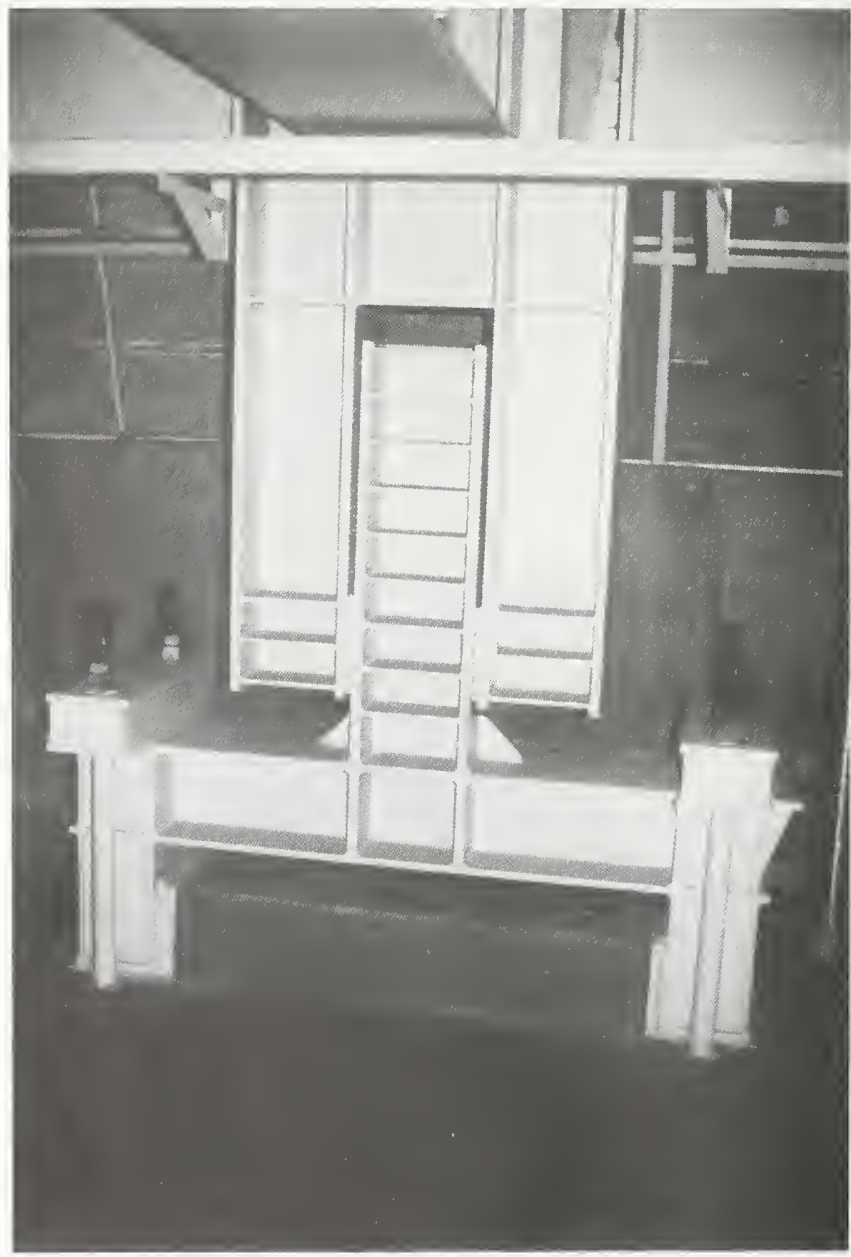

Figure 4.4.10 One of two shear keys parallel to each side of the control tower. 


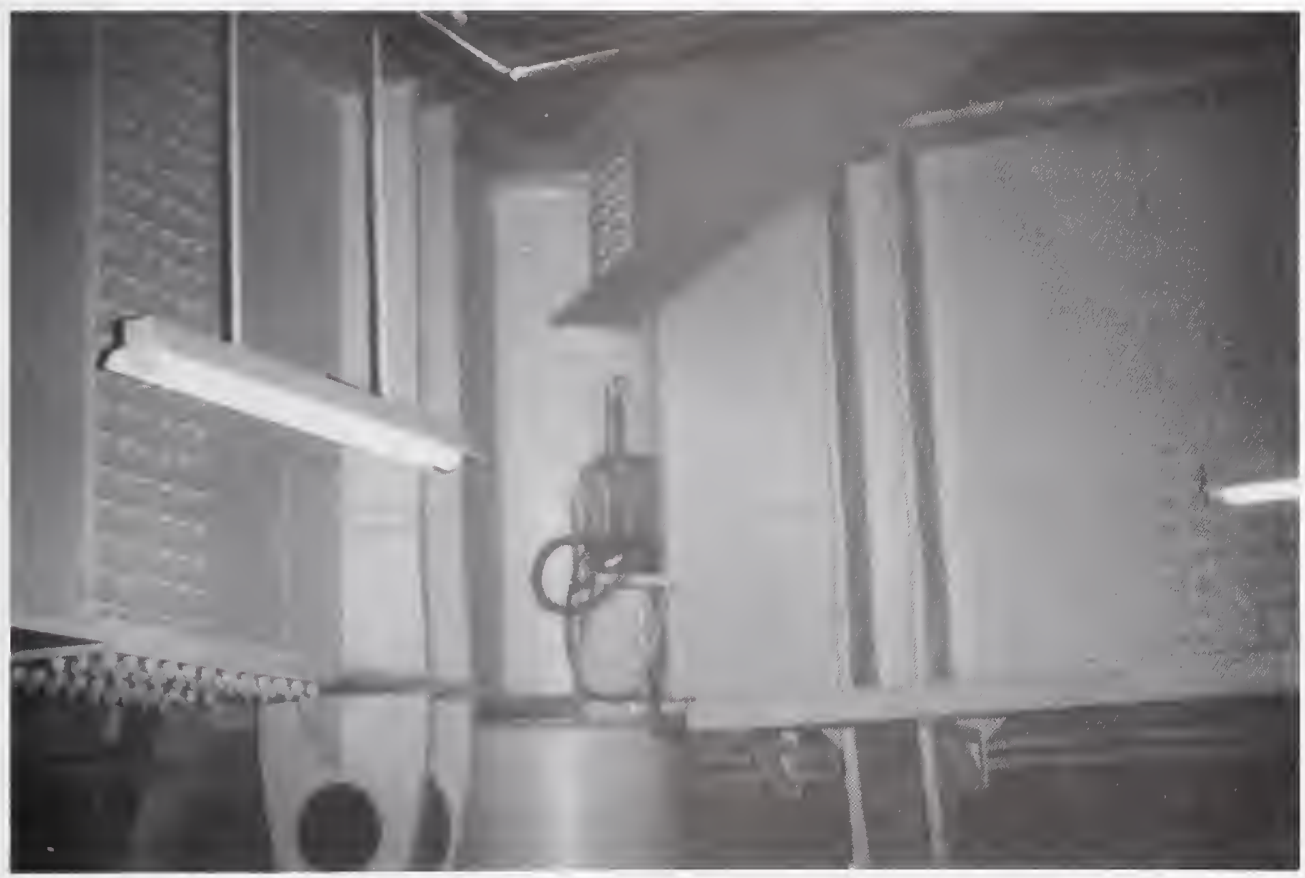

Figure 4.4.11 Deep girders of the rigid diaphragm above a column. 


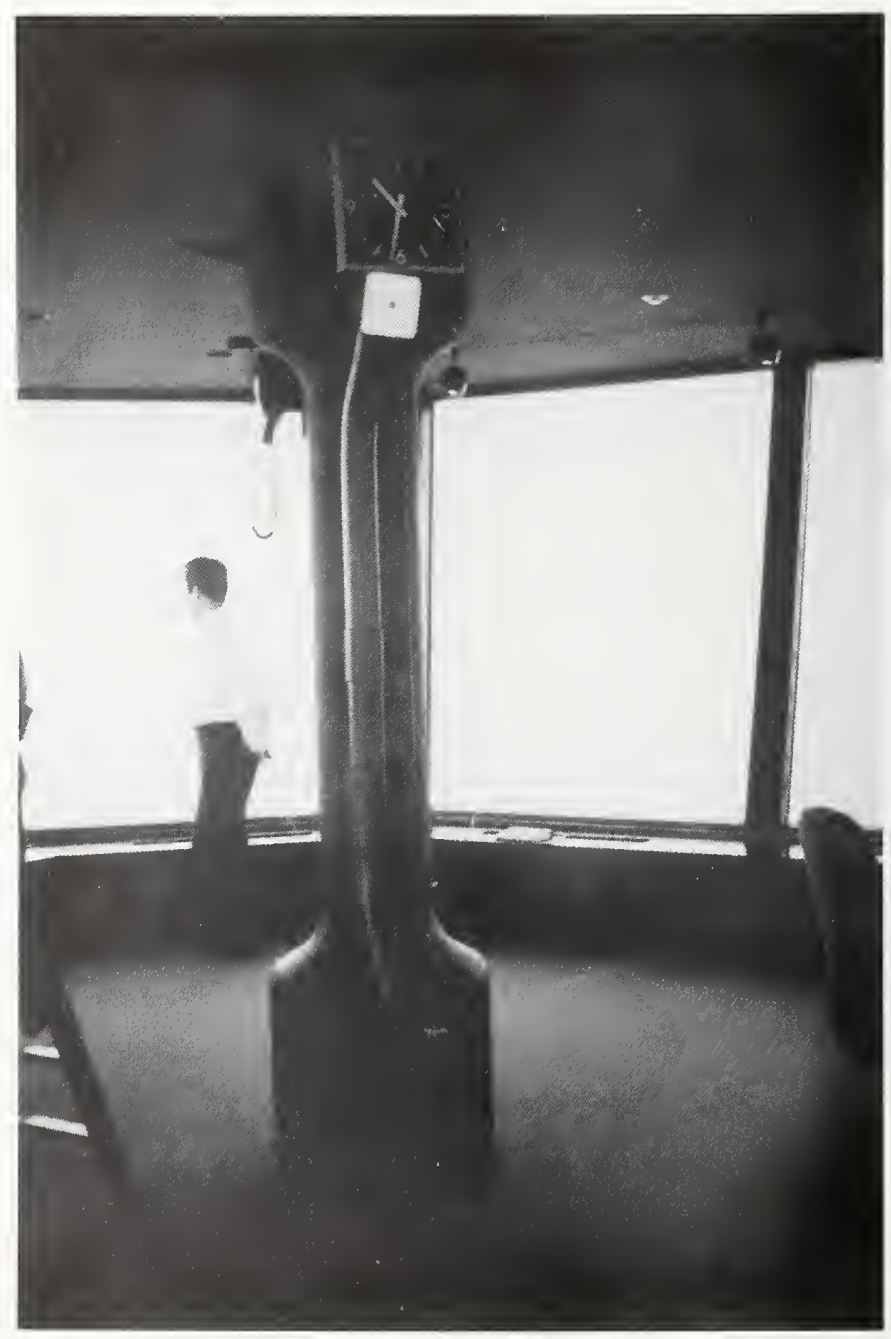

Figure 4.4.12 Column supporting the cab roof in Kansai Control Tower. 


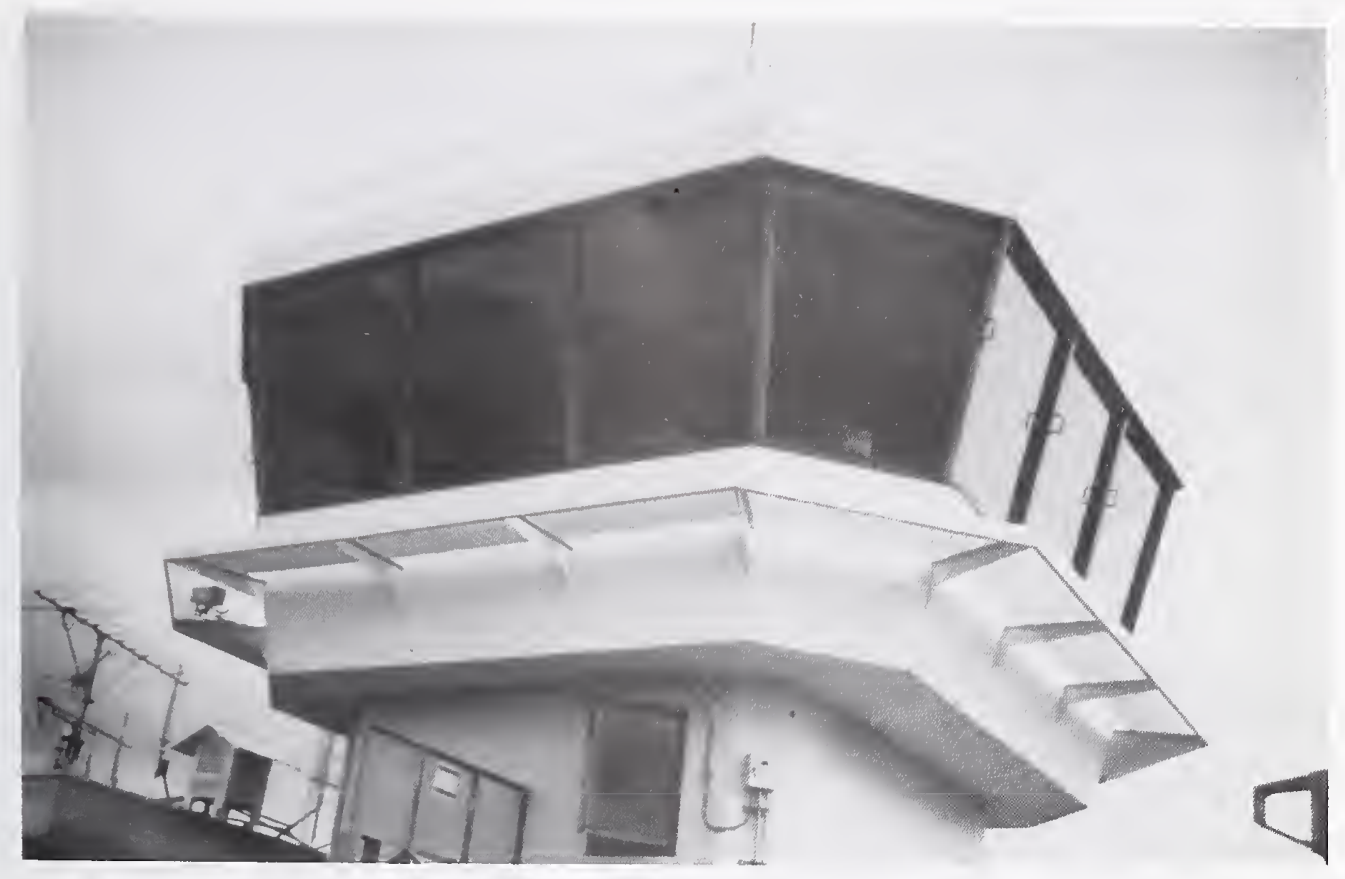

Figure 4.4.13 Cab of the Osaka Airport Control Tower.

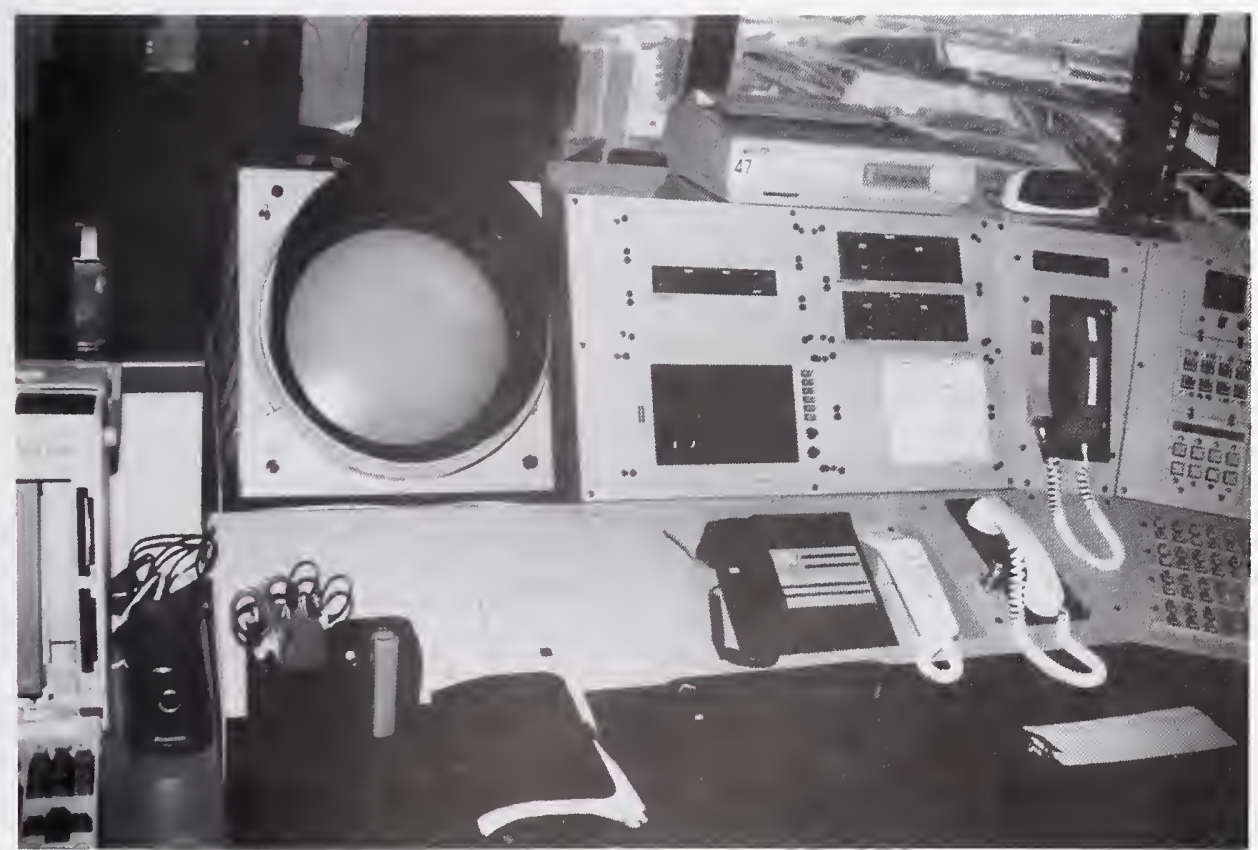

Figure 4.4.14 Supervisor control position located in center of control tower Cab. 


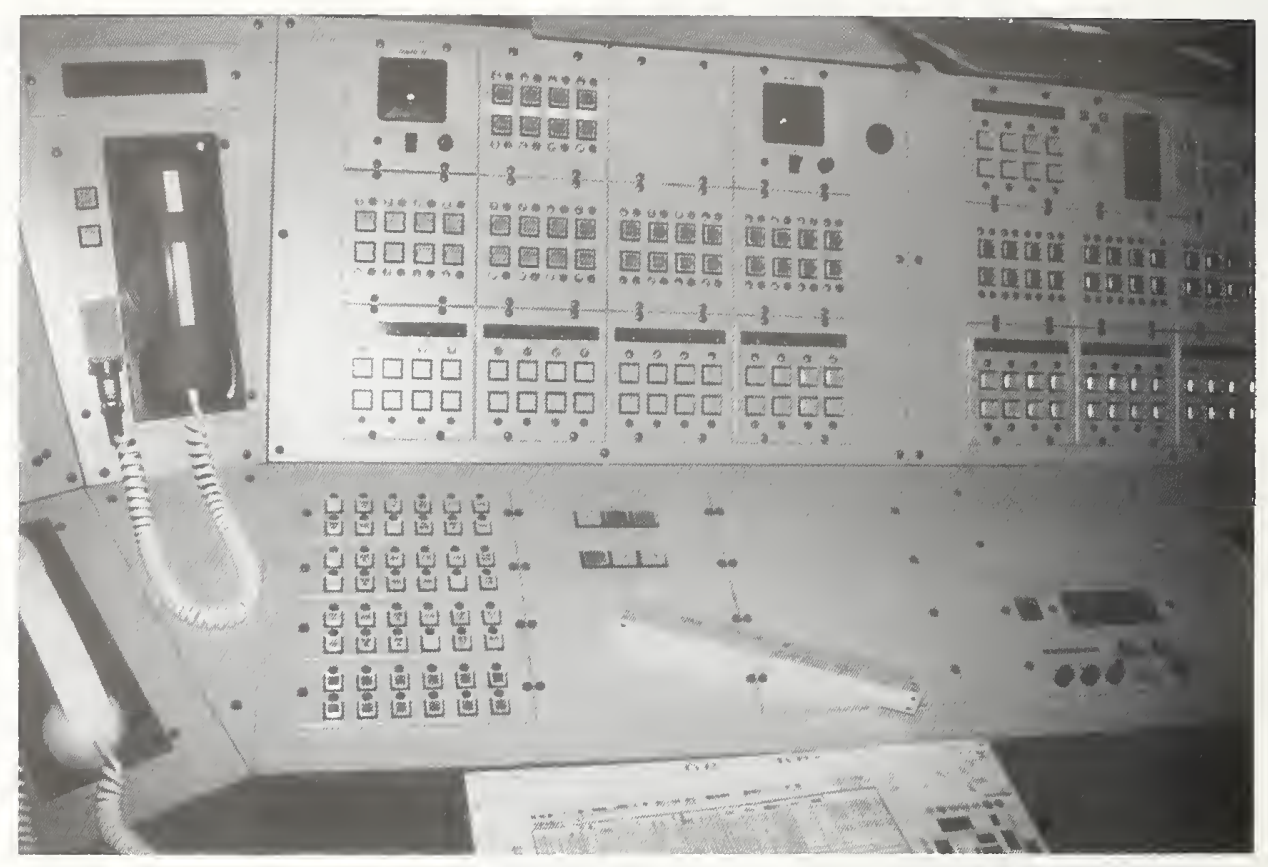

Figure 4.4.15 Supervisor control position communication council.

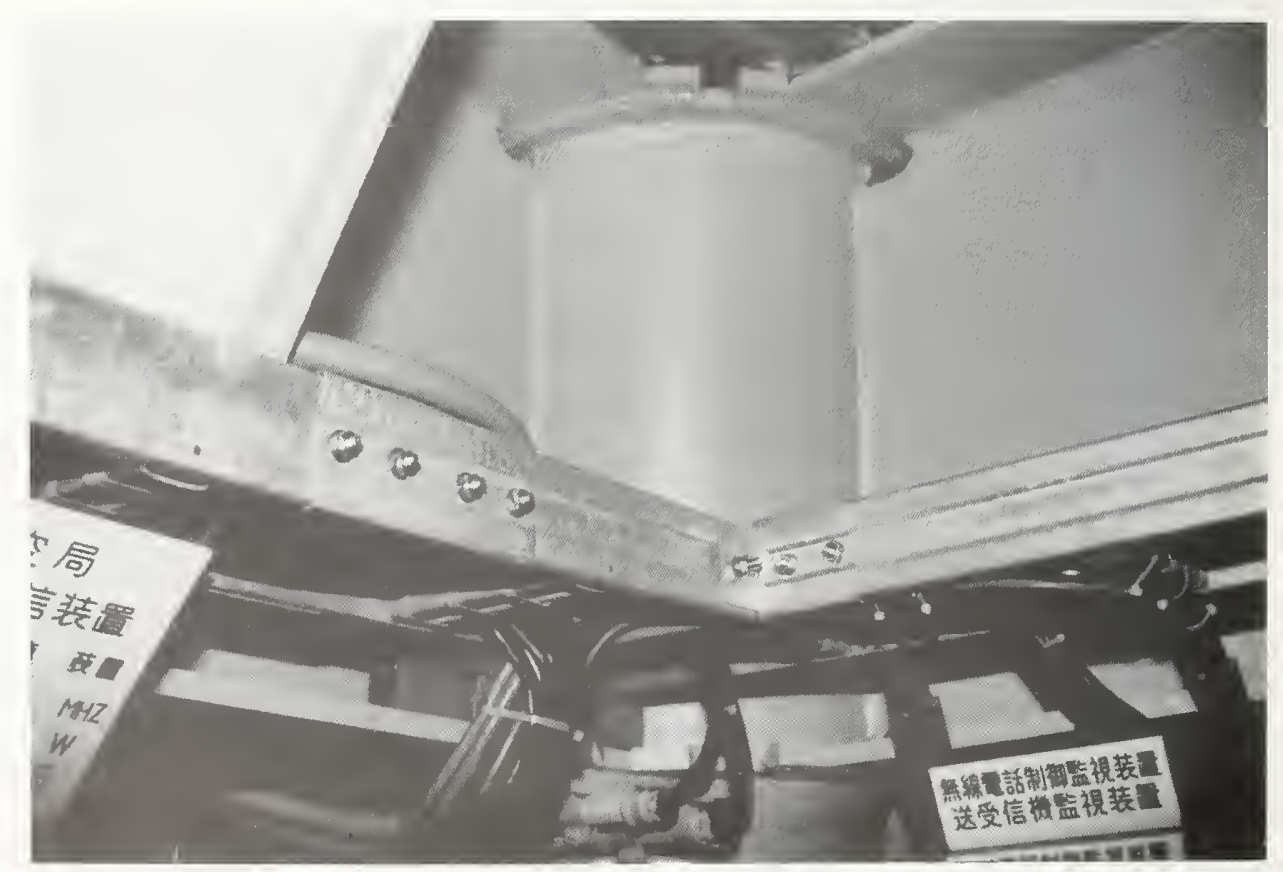

Figure 4.4.16 Communications cable tray with bolted connections above cab. 


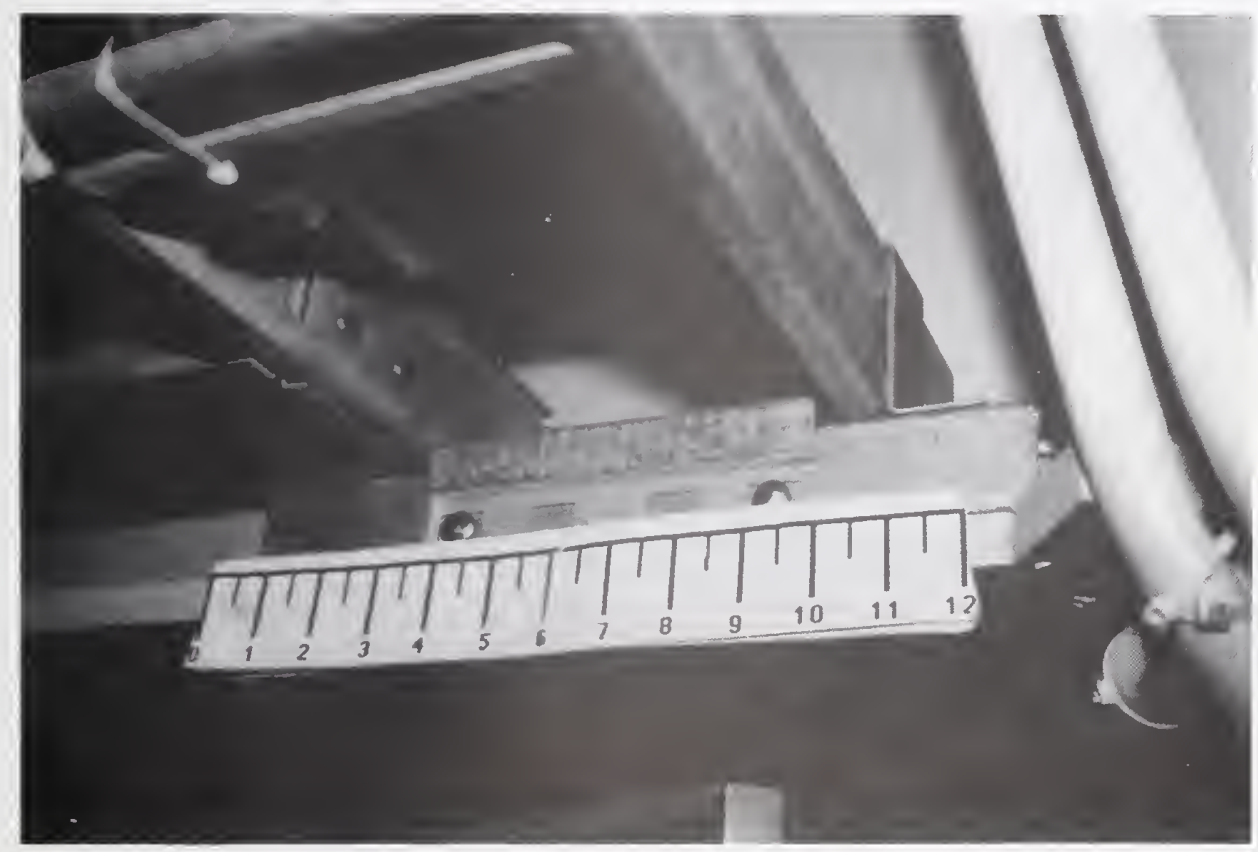

Figure 4.4.17 Communications cable tray secured with friction clips. 


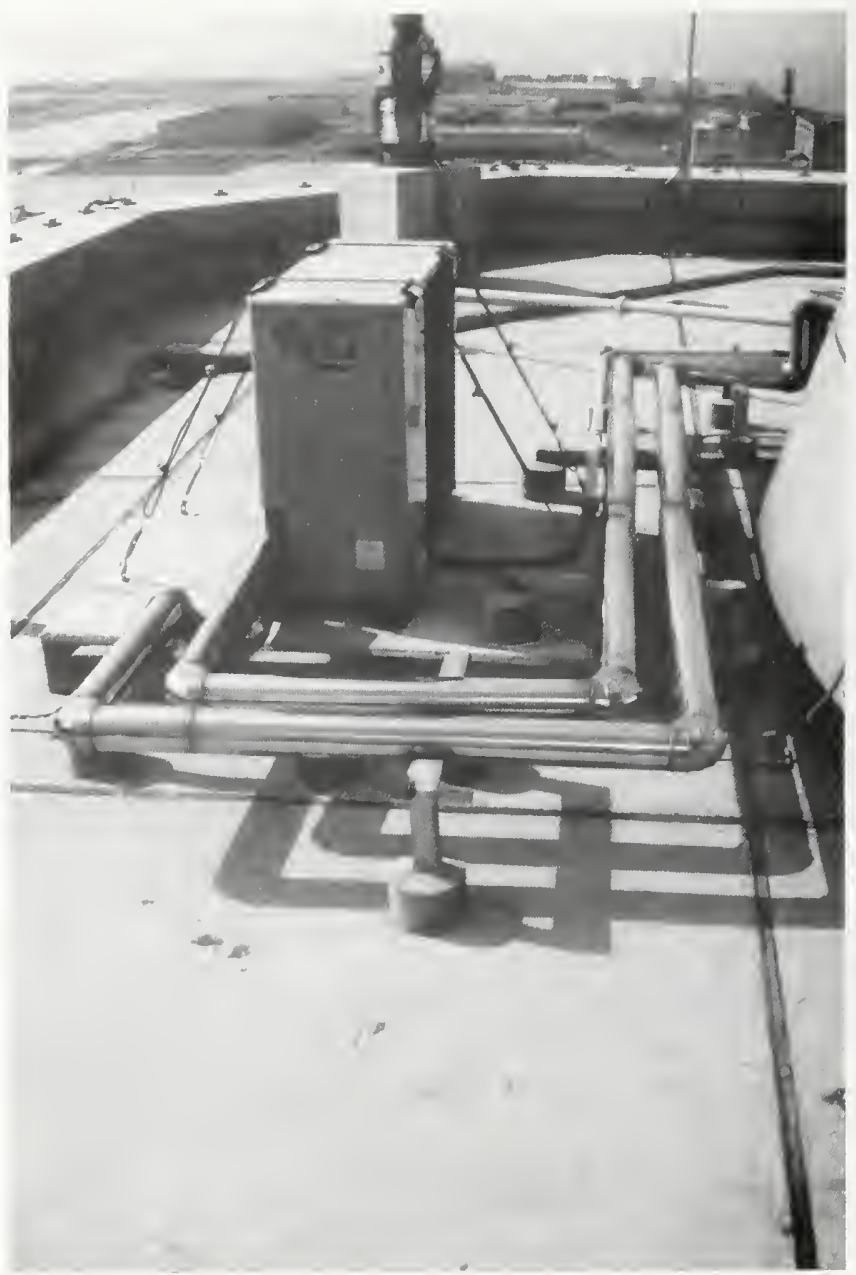

Figure 4.4.18 Roof-mounted heat exchanger braced with cables. 


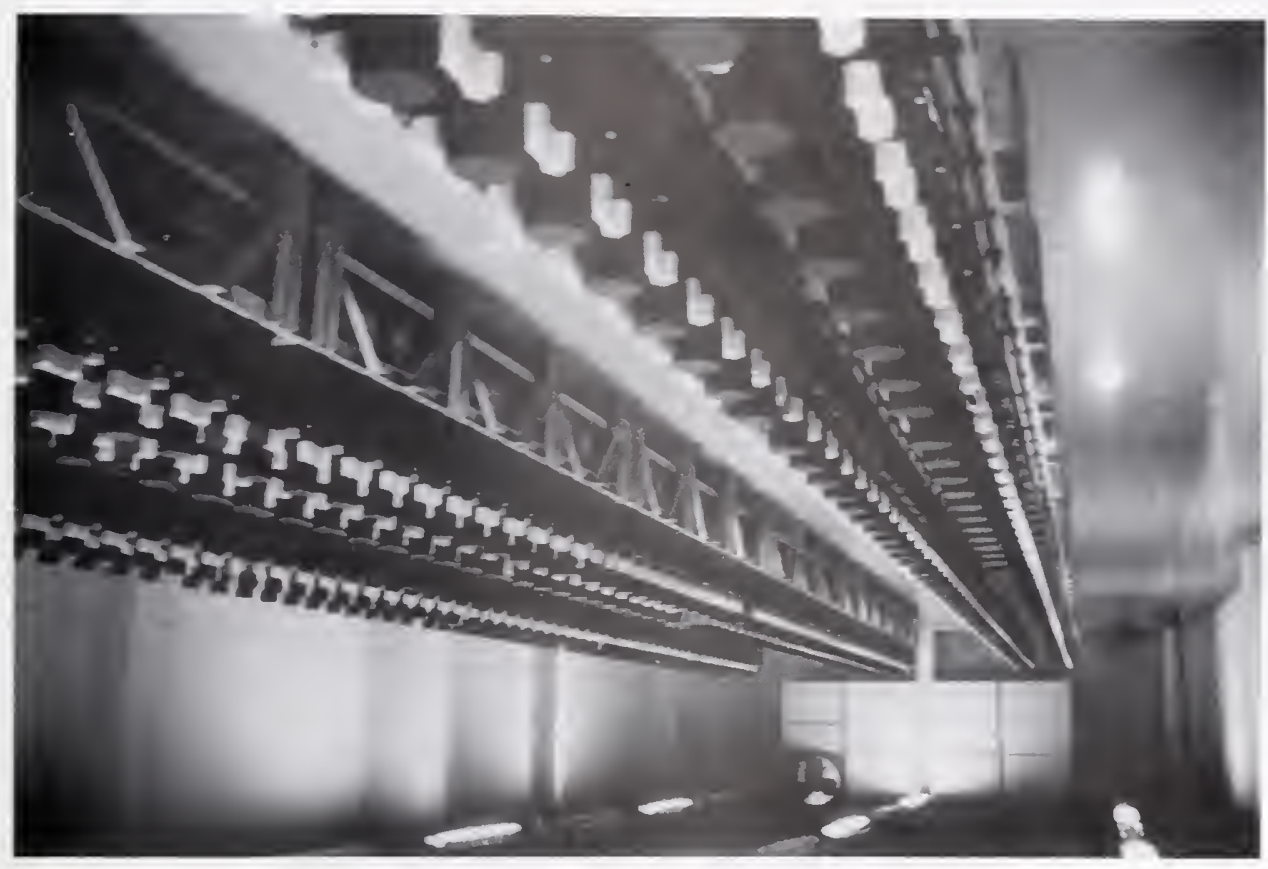

Figure 4.4.19 Very long battery string on low slung battery racks provides emergency power.

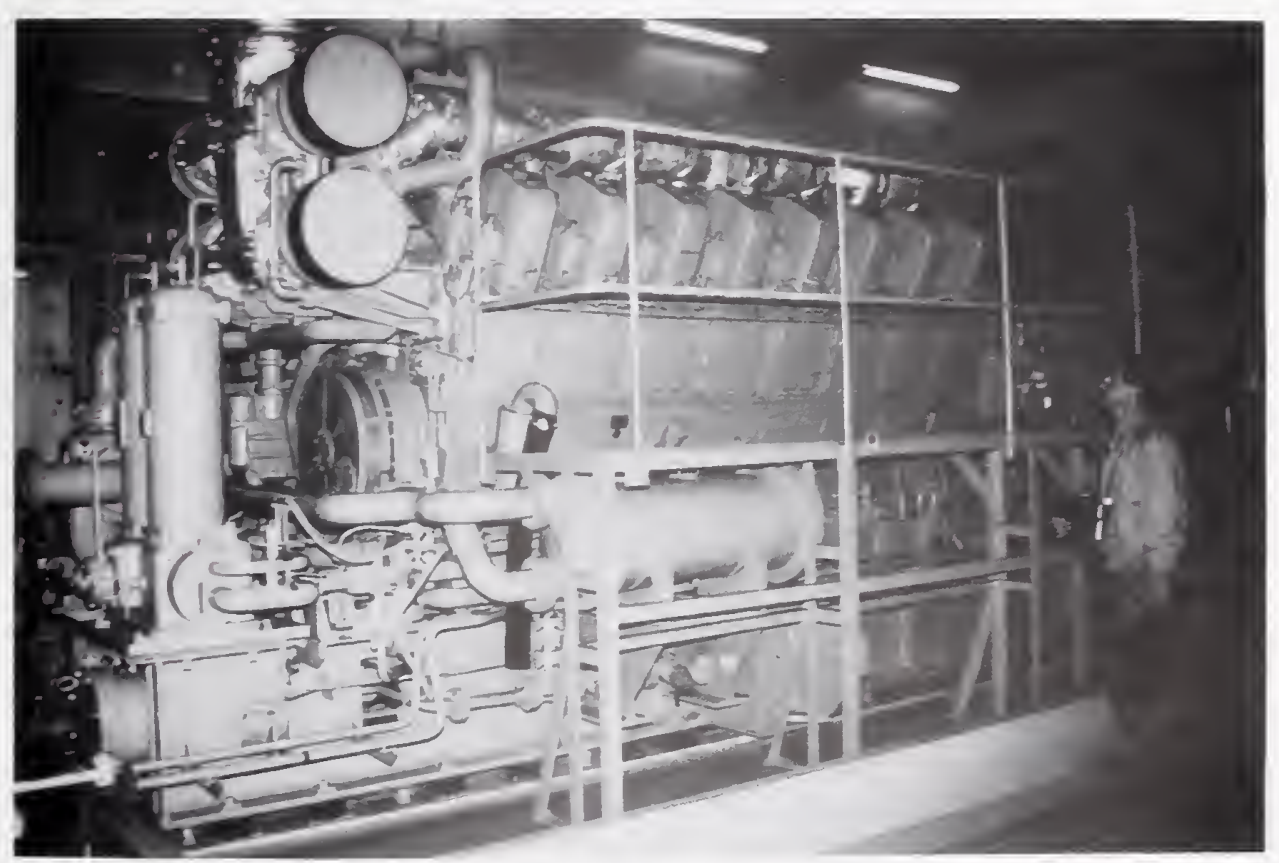

Figure 4.4.20 Large diesel engine-generator on vibration isolators typically found in Japan. 


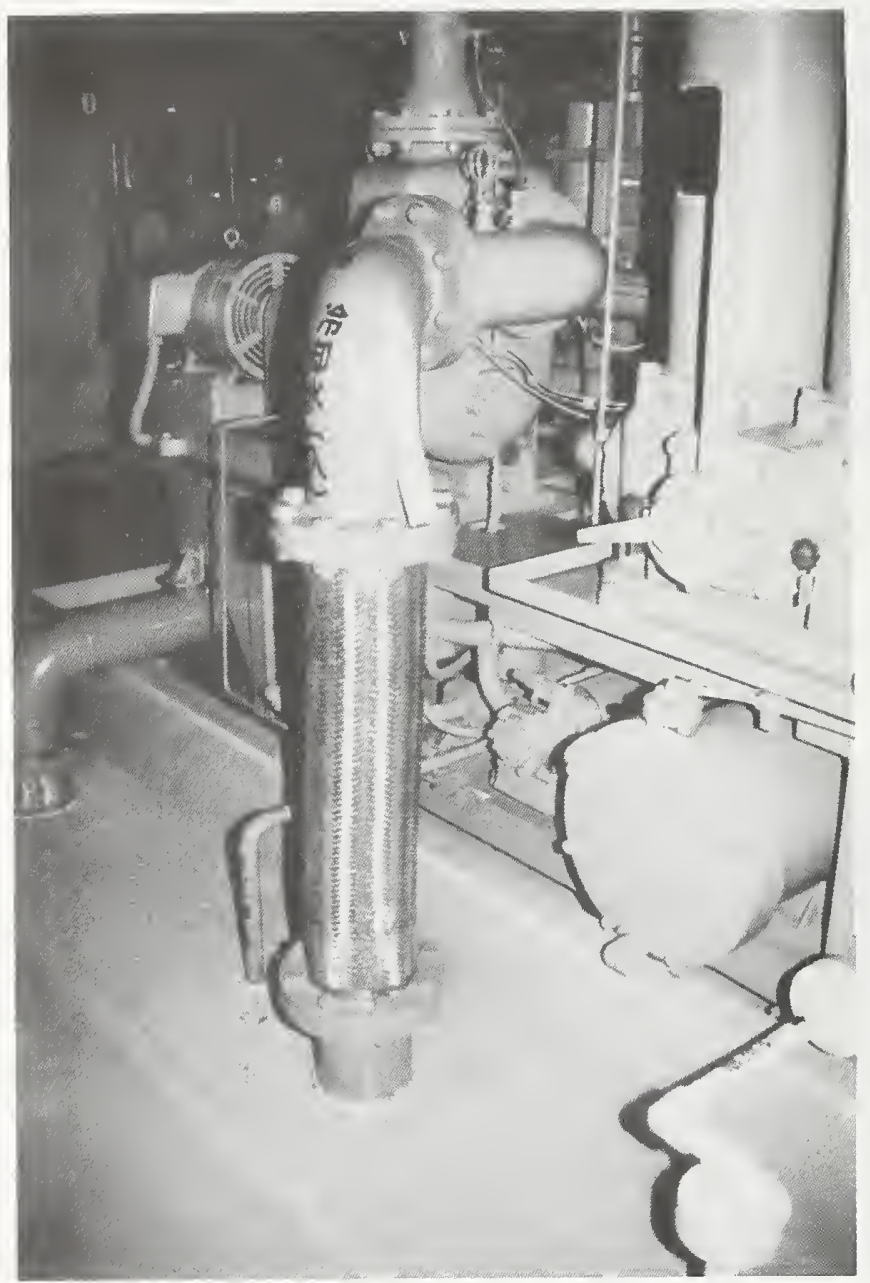

Figure 4.4.21 Flexible coupling in water cooling line to diesel engine-generator. 
Figure 4.4.22 Cooling tower and water tank for emergency engine-generator.

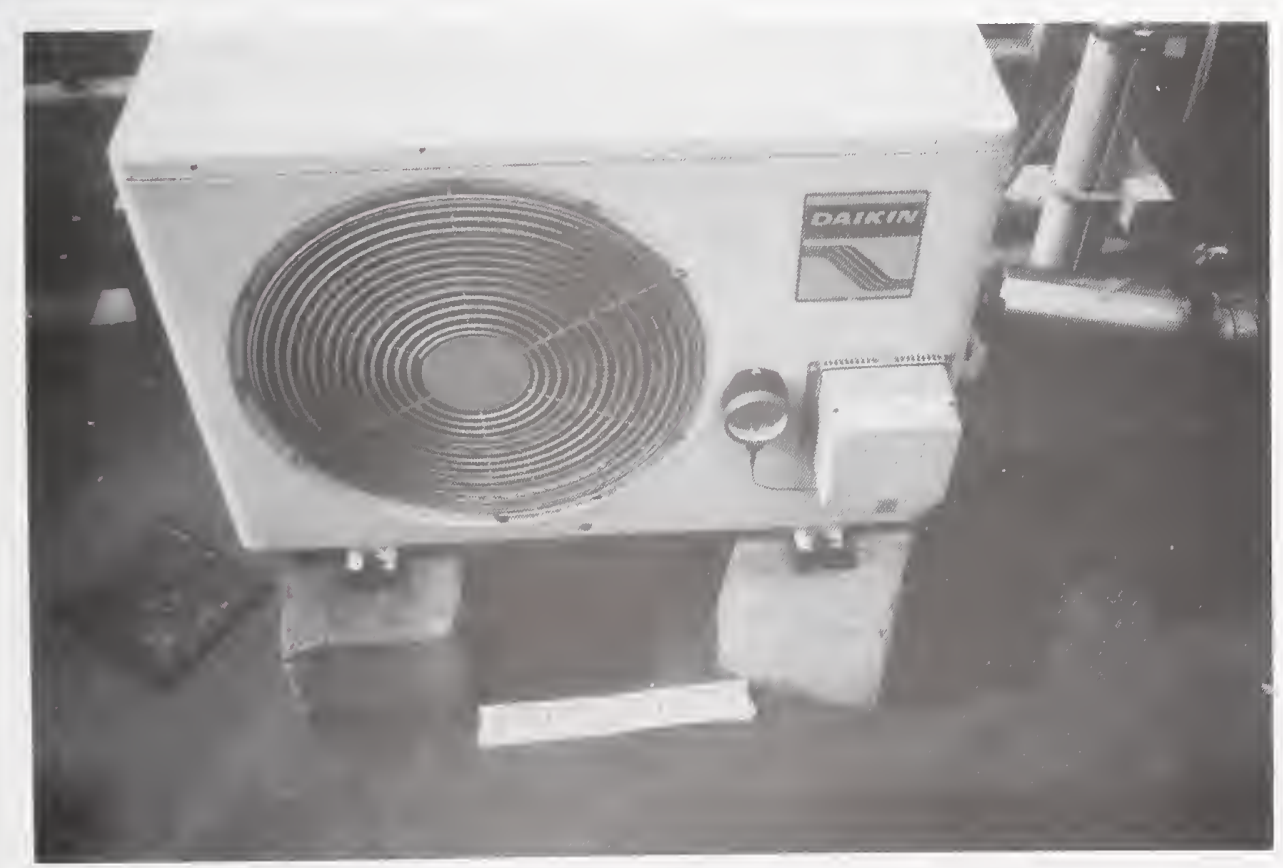

Figure 4.4.23 Heat exchanger on roof near control tower cab is rare example of poorly anchored equipment. 


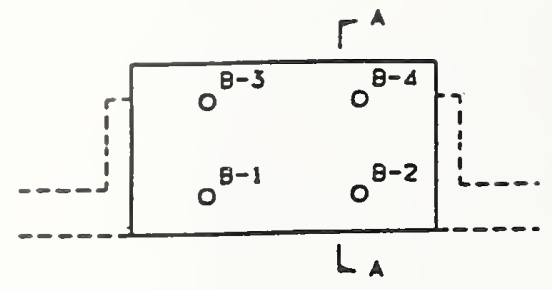

First Floor Plan View

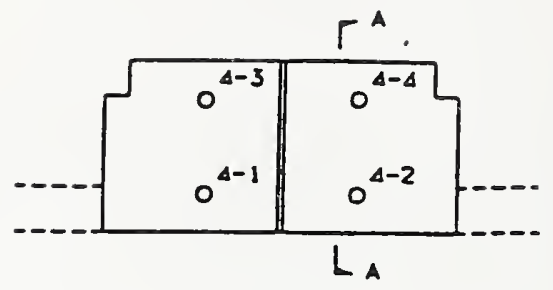

Fourth Floor Plan View

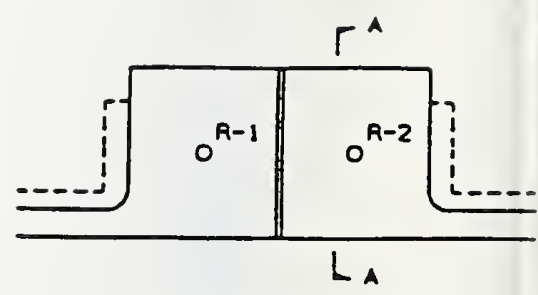

Roof Plan View

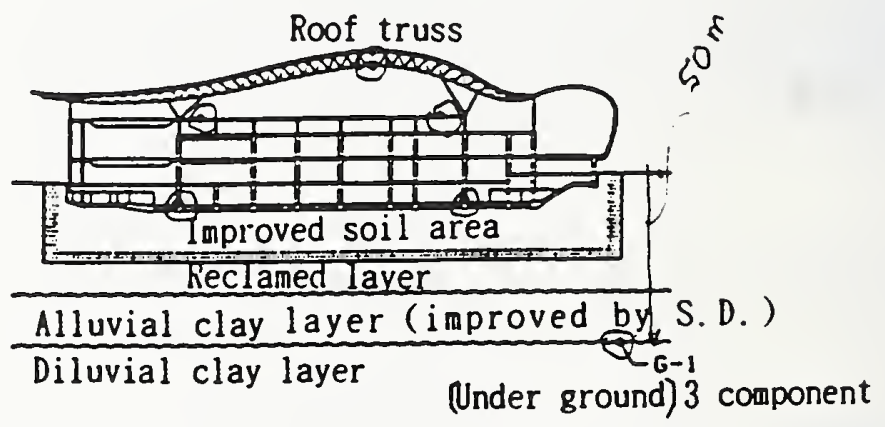

Profile of Terminal Building (Section A-A)

Airport Terminal Building

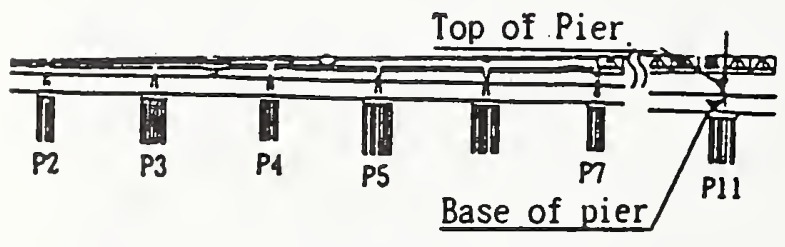

Access Bridge - Profile

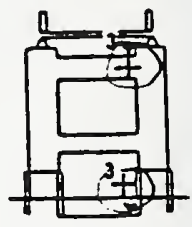

Detail Instrument Location

Access Bridge

Figure 4.4.24 Strong-motion instrument locations at Kansai Airport. 


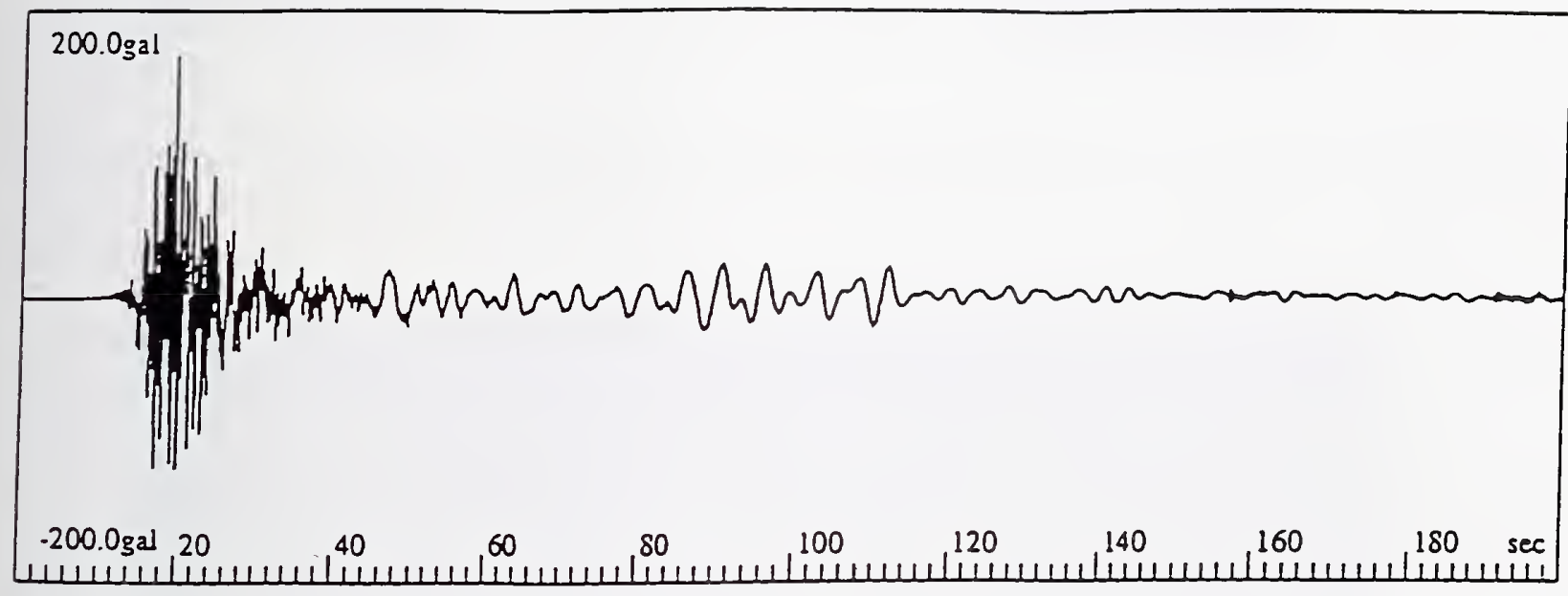

Figure 4.4.25 Strong-motion record from Kansai Airport runway - Position W. 


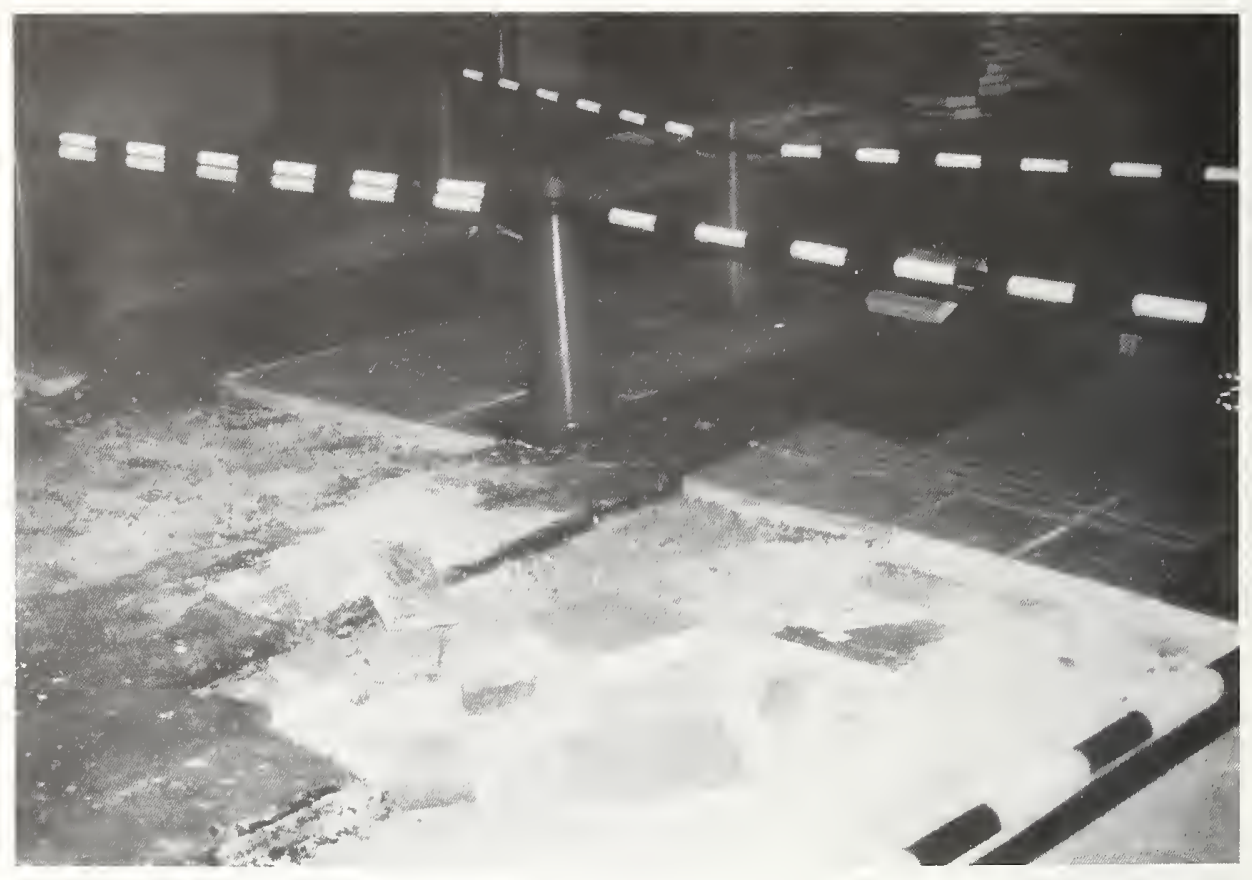

Figure 4.4.26 Subsidence in sidewalk and repaired sidewalk outside the Kansai Terminal Building.

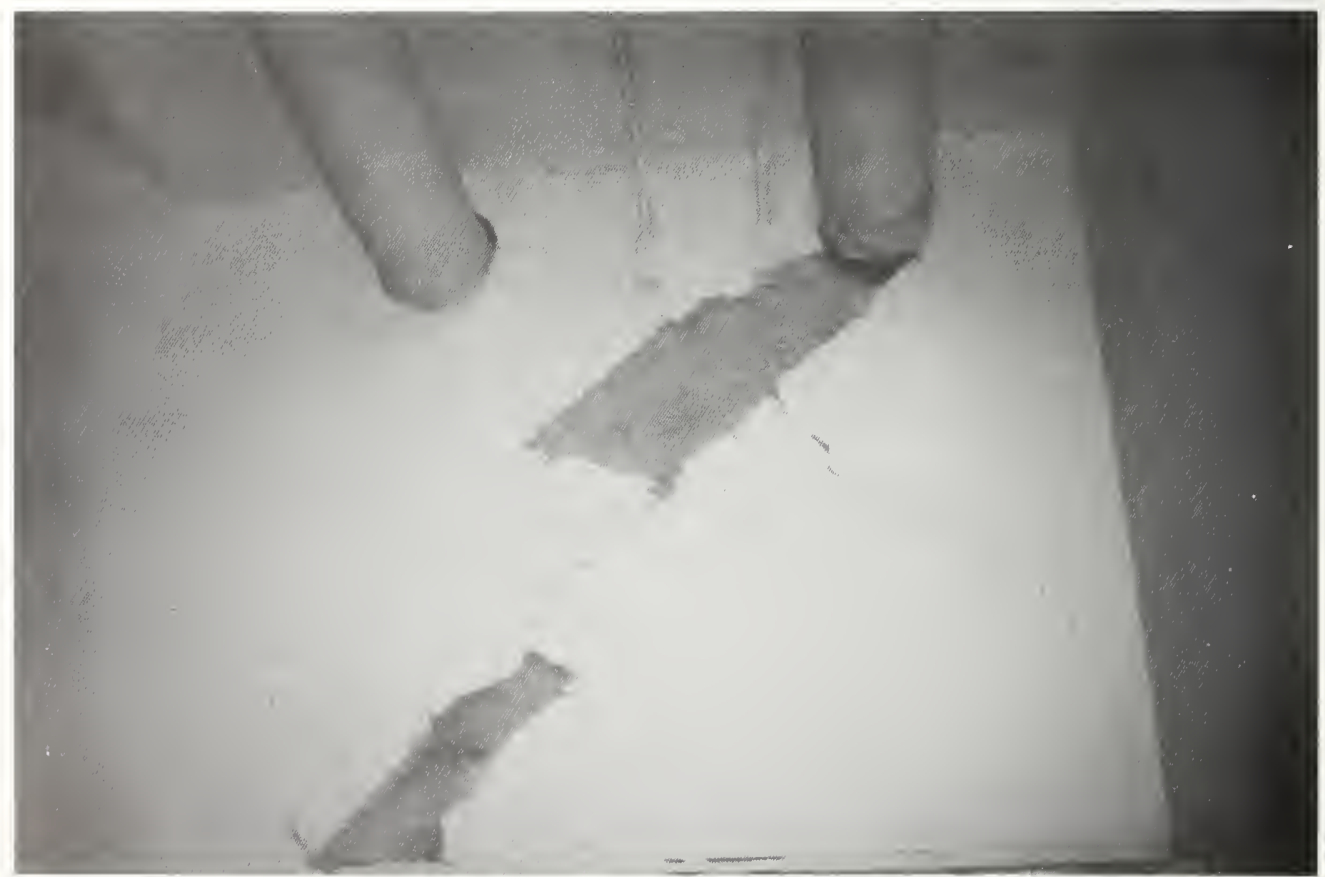

Figure 4.4.27 Cracks in the stair-well shear walls of the Osaka Airport Administration Building. 


\subsection{Ports and Harbors}

\subsubsection{Overview}

Kobe has been a prominent port city since the formal opening of its harbor to the West on January 1, 1868. It is the largest foreign trade port in Japan and the third busiest port in the world. It has also been one of the world's most expensive ports to construct. Two major manmade islands, Port and Rokko Islands, cost about $\$ 2$ billion dollars to create. The port contains 152 berths with an aggregate wharf length of $27 \mathrm{~km} \mathrm{[1].} \mathrm{The} \mathrm{Port} \mathrm{operates} 400$ dockside gantry cranes and derricks to load and unload cargo.

In addition to the port facilities on Port and Rokko Island, there is extensive commercial, recreational, and residential development, particularly in the central part of each island. Many high-rise buildings have been constructed.

The Kobe port facilities are built on ground reclaimed from Osaka Bay (Figure 4.5.1). The source of the fill is obtained from outcrops of the Kobe and Osaka Groups and weathered granite from the adjacent Rokko Mountains. The fill was excavated from several large scrapping areas east and west of Kobe. The first reclamation efforts filled 529 hectares along the Kobe City shoreline from 1953 to 1970 . Port and Rokko Island were created following these reclamation efforts. Reclamation of Port Island, which is west of Rokko Island, started first and was done in two phases. The first phase, which filled 436 ha, was from 1966 to 1980 . The second phase started in 1986, and increased the size of the island by 390 ha Rokko Island, which is 580 ha, was reclaimed from 1973 to 1992.
Construction of Port Island is described by Nakakita and Watanabe [2]. Silty sand fill was placed in standing water with an average water depth of $12 \mathrm{~m}$ and continues to an elevation of about $4 \mathrm{~m}$ above water level.

The upper and lower parts of the fill were placed using different techniques. The lower part of the fill to within $2 \mathrm{~m}$ of high water level was dumped into standing water from a trap-based barge with no compaction effort. The lower part of fill was created in $2-\mathrm{m}$ to 4-m-thick layers. The upper part of the fill was accomplished by scooping from barges that were moored to the quay wal', transporting to the interior of the island by a movable conveyor, and spreading with modest compaction by rolling. No significant effort was made during reclamation to compact the sandy fill to increase its liquefaction resistance.

Preearthquake field blow counts typically ranged from 5 to 10 .

The extensive damage to the port of Kobe highlights the seismic hazard to port facilities posed by sandy fills. Such materials have been widely used in both United States and worldwide to reclaim ground for port development and expansion.

A typical soil profile in the reclaimed area is shown in Figure 4.5.2. Immediately underlying the fill is an approximately $13-\mathrm{m}$ thick layer of marine clayey silt with water contents that ranged from 7 to 100 percent. In addition, soft compressible clays were encountered over a 20 -m interval beneath a depth of $50 \mathrm{~m}$. Intercalated between these two marine clays is a $30-\mathrm{m}$ thick sequence of alternating sand and clay. Consolidation of the naturally occurring soft clayey silt 
beneath the fill was a major geotechnical concern during the reclamation and post reclamation construction of wharf structures and buildings. Large settlements caused by the weight of the fill are documented.

Most of the quay walls forming the wharfs are sand-filled caisson structures, although a few consist of cellular steel sheet piles. A design drawing of the caisson-type construction is shown in Figure 4.5.3. The foundation for each caisson was prepared by excavating the natural silt layer on the sea floor and replacing it with sand fill. A gravel pad was placed on the fill and then the 10-m-tall concrete caisson was lowered into place and filled with local sandy material. The waterside crane rail rests on the caisson. Most of the gantry cranes have rail spans of $30.5 \mathrm{~m}$, but a few of the older cranes at Port Island and Maya Wharf have rail spans of $16 \mathrm{~m}$. The $30.5-\mathrm{m}$ rail girders are supported either by a concrete slab placed on engineered fill or a concrete pile supported wall and the $16-\mathrm{m}$ rail girders rest on a concrete pile supported wall.

\subsubsection{What happened}

Liquefaction was widespread along the shoreline and on the islands in the port area (Figure 4.5.4). Evidence for liquefaction included areally extensive blankets of ejected sand and water and ground cracking parallel to the shoreline. Most of the ejected materials consisted of silty sands. Locally, however, $10-\mathrm{cm}$ diameter granite fragments were ejected. Damage to quay walls in the harbor area from liquefaction and lateral spreading was extensive. For example, aerial photography and on-site inspection indicate that $11.5 \mathrm{~km}$ and $12.5 \mathrm{~km}$ of quay wall along Port and Rokko Island, respectively, were seriously damaged by permanent ground displacement. Laterally spreading typically displaced walls seaward about $1 \mathrm{~m}$ to $2 \mathrm{~m}$.
Downdropped blocks formed on the landward side within $20 \mathrm{~m}$ of the wall (Figure 4.5.5). The land surface of the downdropped block was commonly lowered as much as $3 \mathrm{~m}$. Ground cracking associated with the lateral spreading along the shoreline extended landward from quay walls for distances of about $100 \mathrm{~m}$.

\section{$A$ variety of ground improvement} techniques are available, but they are costly. The localization of lateral spreading near the quay walls suggests that only portions of the fill need to be improved. The development of such guidelines would facilitate remedial efforts at other ports with similar exposure.

Loading and unloading of cargo from ships was essentially brought to a standstill by damage to dockside gantry cranes associated with permanent ground displacements that damaged wharf areas and affected the crane rail systems that run along the quay walls. Differential horizontal displacements between the crane rails associated with lateral spreading distorted and damaged the steel moment frames of many cranes along the waterfront (Fig. 4.5.6). The primary damage to cranes was structural. There was little damage to the mechanical components. Despite the distortion of the framing of the cranes, most remained upright. Frames with weak portal beams, lacking ductile moment frames, incurred leg buckling above the portal beams. Cranes with strong portal beams and ductile moment frames were damaged less severely. 
The large lateral displacements of the quay walls undoubtedly were caused by the increase in lateral pressure on the wall from the liquefied soil mass retained behind the wall. Because of the large settlements of the caissons themselves, it is suspected that the sandy fill beneath the caissons liquefied as well. Figure 4.5.7 is a hypothetical cross section illustrating the interpretation of the failure mode of caisson-type quay walls. Note that the lateral spreading also displaced the landside pile-supported crane rail.

Permanent horizontal ground deformation from lateral spreading did not appear to extend inland more than about $100 \mathrm{~m}$ from the sea walls. Liquefaction settlements inland from the quay walls, however, were dramatic and areally extensive on both Port and Rokko Islands. Settlements ranged from $30 \mathrm{~cm}$ to $50 \mathrm{~cm}$ throughout the harbor area, but locally exceeded $100 \mathrm{~cm}$.

Most buildings and elevated transportation corridors on the islands are pile supported. Settlements were easy to detect because piles extend through the liquefied zone. Damage from settlements was primarily limited to underground utility connections to structures.

Damage from ground shaking was modest relative to damage caused by permanent ground deformation associated with liquefaction. For example, only a few straddle carriers, used to transport cargo containers, were toppled by the ground shaking. A recording of ground shaking on reclaimed ground in Kobe north of Port Island is shown in Figure 4.5.8. The station is located at the Port of Kobe Construction Office near the shoreline and is free field. No evidence of liquefaction was reported at this station. The peak horizontal acceleration was 502 gals $(0.51 \mathrm{~g})$.
Liquefaction reduced the strength of shaking at the land surface on Port Island. At a Port Island station which is $1860 \mathrm{~m}$ south of the Construction Office station, the peak horizontal acceleration at the land surface - was only 341 gals $(0.35 \mathrm{~g})$ despite a peak acceleration of 565 gals $(0.58 \mathrm{~g})$ at the base of the fill.

\subsubsection{Lessons for United States}

The extensive damage to the port of Kobe highlights the seismic risk to port facilities posed by loose sandy fills. Such materials have been widely used in both the United States and worldwide to reclaim ground for port development and expansion. The 1995 Hyogoken-Nanbu earthquake illustrates once again the potential for these fills to liquefy and generate large permanent ground displacements when shaken by earthquakes. The 1995 earthquake furthermore illustrates the ability of such liquefaction to totally disable a port.

Stabilization of loose sandy fills by ground improvement is generally a costly endeavor because of the volume of material that must be improved. For regions with low to modest earthquake hazard, the cost/benefit ratio may be too high to warrant ground improvement efforts. The localization of lateral spreading around the margin of the Port and Rokko Islands suggests that the hazard of permanent horizontal ground deformation can be substantially reduced by improving only the outer margins of these loose fills. While large vertical settlements may still occur, particularly in inland areas of unimproved ground, damage may be tolerable. Modern pile-supported structures on Port and Rokko Islands performed well in locations where they were subjected only to ground settlement. 
Another important engineering lesson from the Kobe port experience is the vulnerability from using one style of design for a key part of an important facility. Clearly liquefaction was not considered to be a significant possibility during the design of port quay walls. By repeatedly using quay wall designs that were vulnerable to lateral spreading, operation of the entire port was left vulnerable to this hazard.

\subsubsection{Research}

The extensive damage to the quay walls that disabled the port operations indicates that the failure mechanism of these structures needs to be understood from the perspective of being able to design against such failures. A variety of ground improvement techniques are available, but in general they are costly. The localization of lateral spreading near the quay walls suggests that only portions of the fill need to be improved. The development of such guidelines would facilitate remedial efforts at other ports with similar exposure.

The large vertical settlements observed in sandy fill during the earthquake also provide an excellent opportunity to develop a case history of ground deformation associated with liquefaction. There are very few well documented examples of post-liquefaction consolidation. The numerous pile-supported structures and bench marks provide an opportunity to systematically document the regional nature of the soil consolidation. The high level of ground shaking, approximately $0.5 \mathrm{~g}$, and the large volumetric strains, greater than $10 \%$, should permit rigorous evaluations of existing methods for predicting settlement.

\subsubsection{Summary}

Liquefaction during the 1995 HyogokenNanbu earthquake disabled the port of Kobe, the third largest port in the world. Permanent ground deformation caused failure of quay walls and differential displacements of crane rails causing crane operations to stop. Lateral spreading was restricted to the margins of the port facilities, usually extending less than $100 \mathrm{~m}$ from quay walls. Vertical settlements of $30 \mathrm{~cm}$ to $50 \mathrm{~cm}$ were widespread inland, but did not do great damage because of their uniform character. Port facilities were built on ground reclaimed from Osaka Bay. The land was reclaimed by loosely dumping silty sand into about $12 \mathrm{~m}$ of standing water. Liquefaction of the fill was not a geotechnical concern during construction. Because loose sandy fill is commonly used for ground reclamation in many ports, it is important that the failure mechanisms of the quay wall be studied in order to develop cost- effective remedial methods for these other ports.

\subsubsection{References}

1. Fairplay, World Ports Directory, Pairplay Information Systems, Ltd., Surrey, United Kingdom, pp.407-408, 1994

2. Nakakita, U., and Watanabe, Y., Soil stabilization by preloading in Kobe Port Island, in Proceedings of the 9th International Conference on Soil Mechanics and Foundation Engineering, Tokyo, Case History Volume, pp.611-622, 1977. 


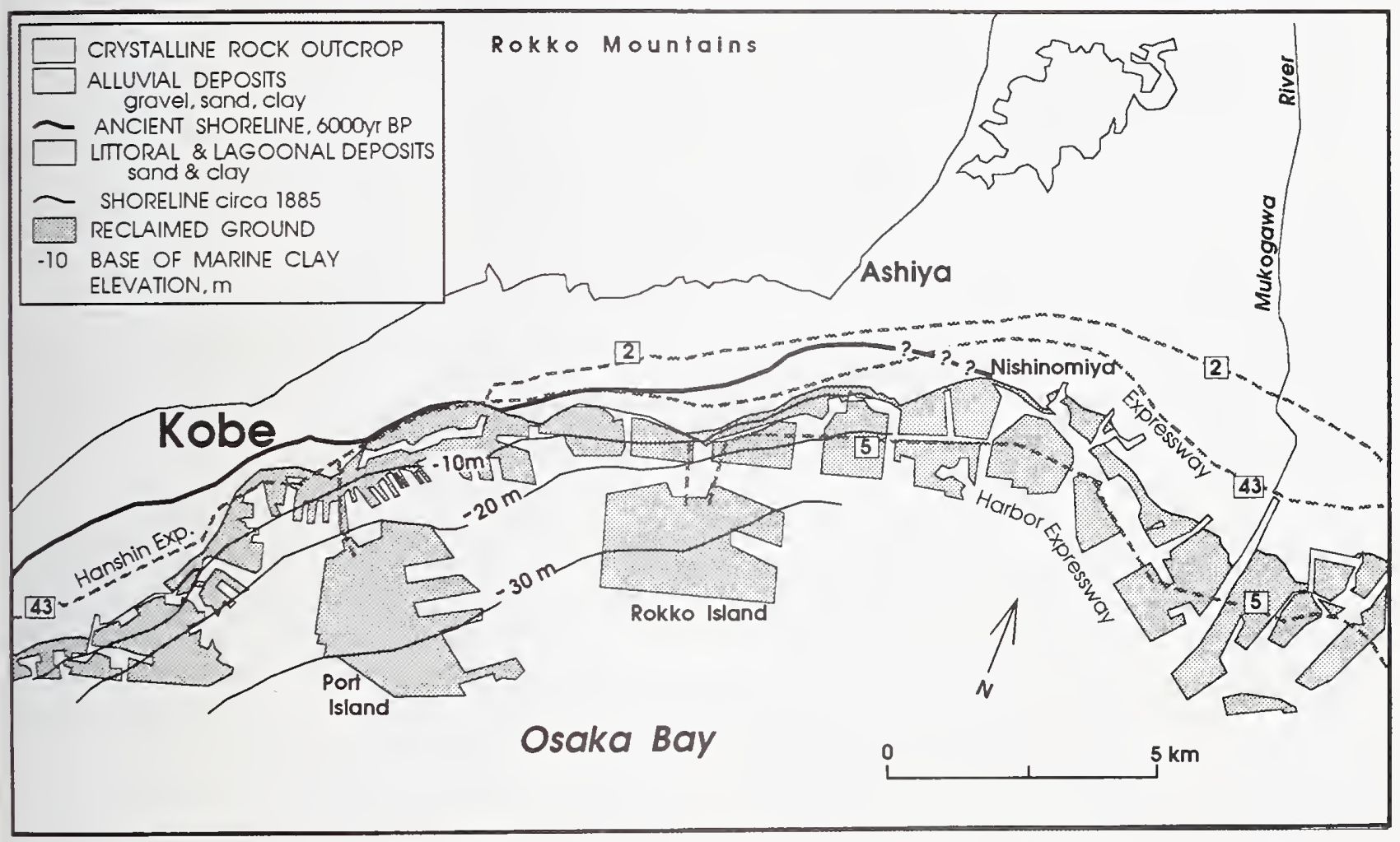

Figure 4.5.1 Map of Kobe area with reclaimed ground boundary. 


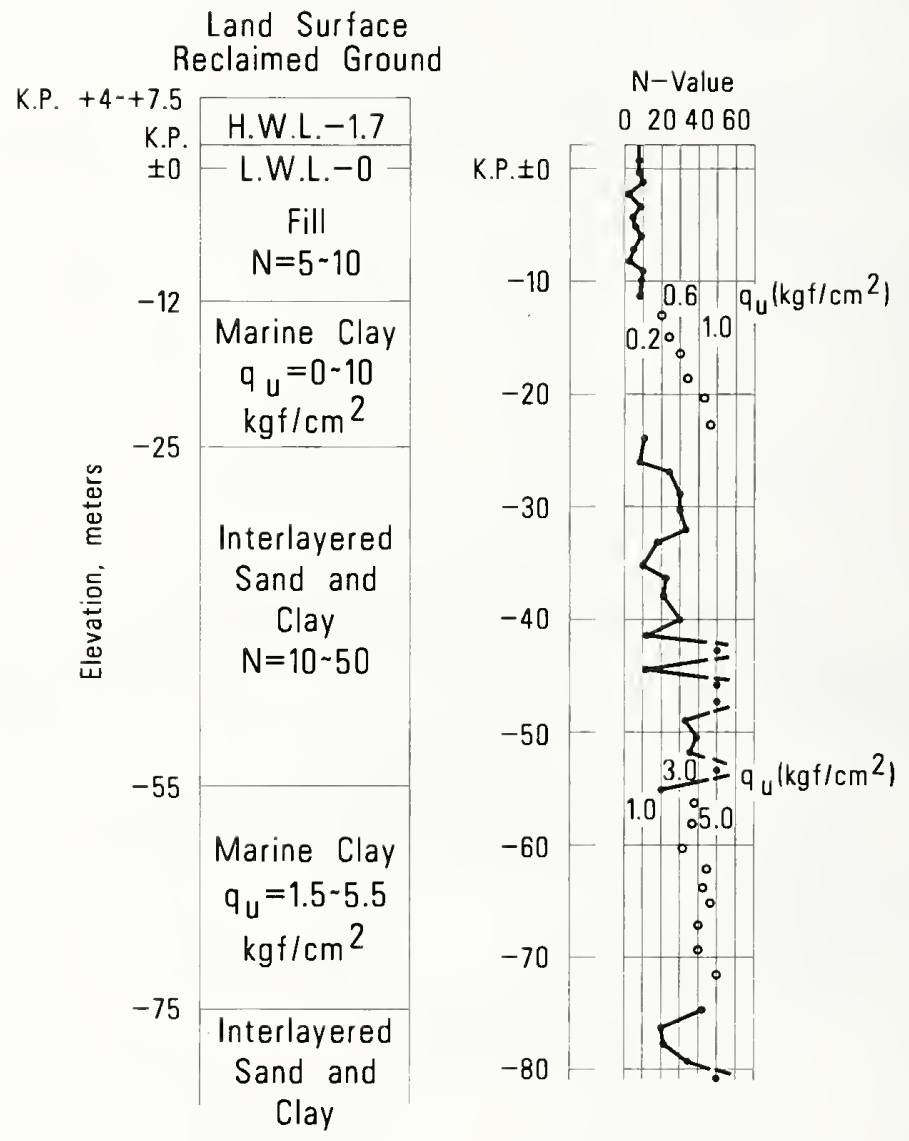

Figure 4.5.2 Typical soil profile at Port island (from Nakakita and Wantanabe, 1977). 


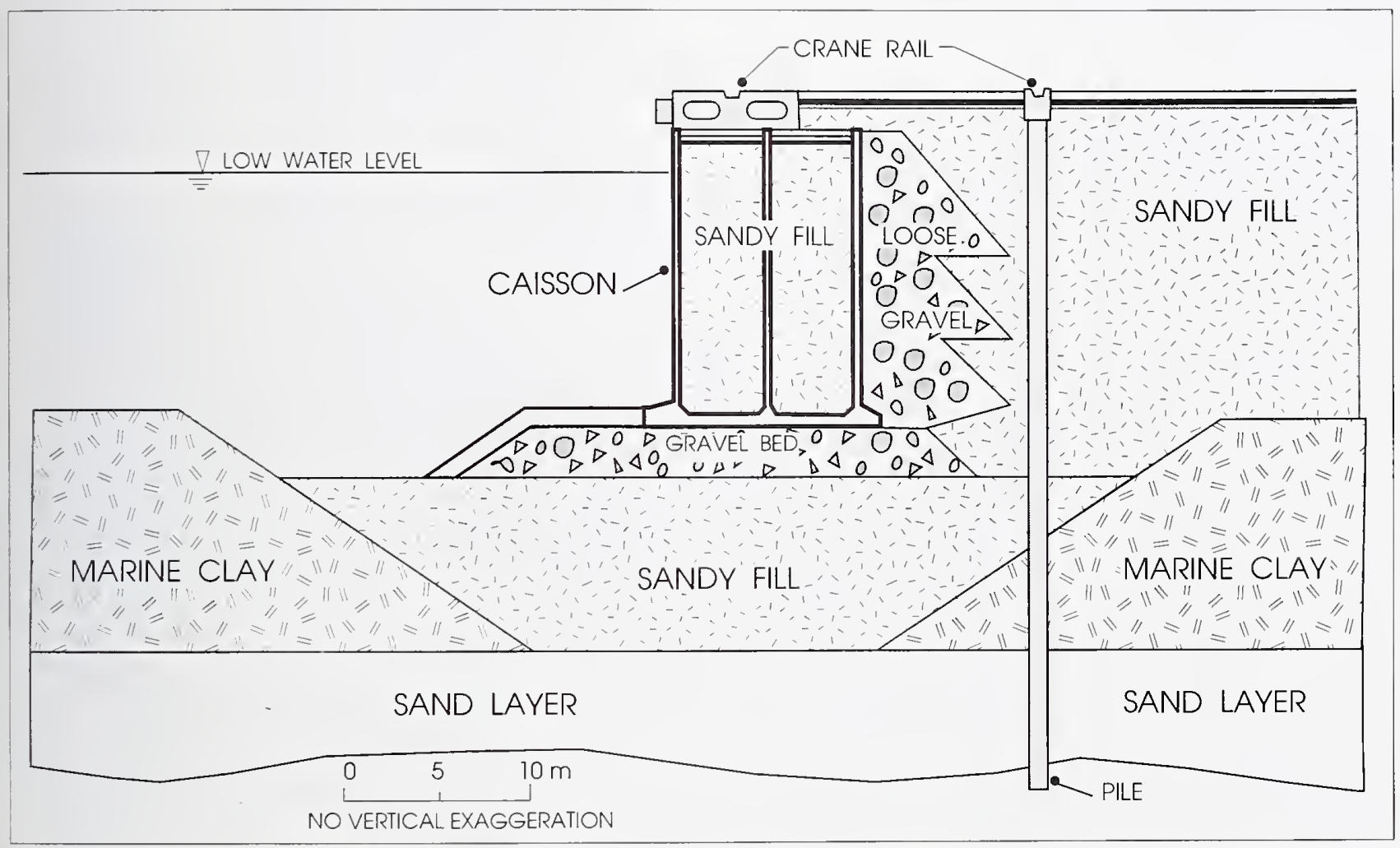

Figure 4.5.3 Construction drawing of wharf on Port Island (From Port and Harbor Research Institute). 


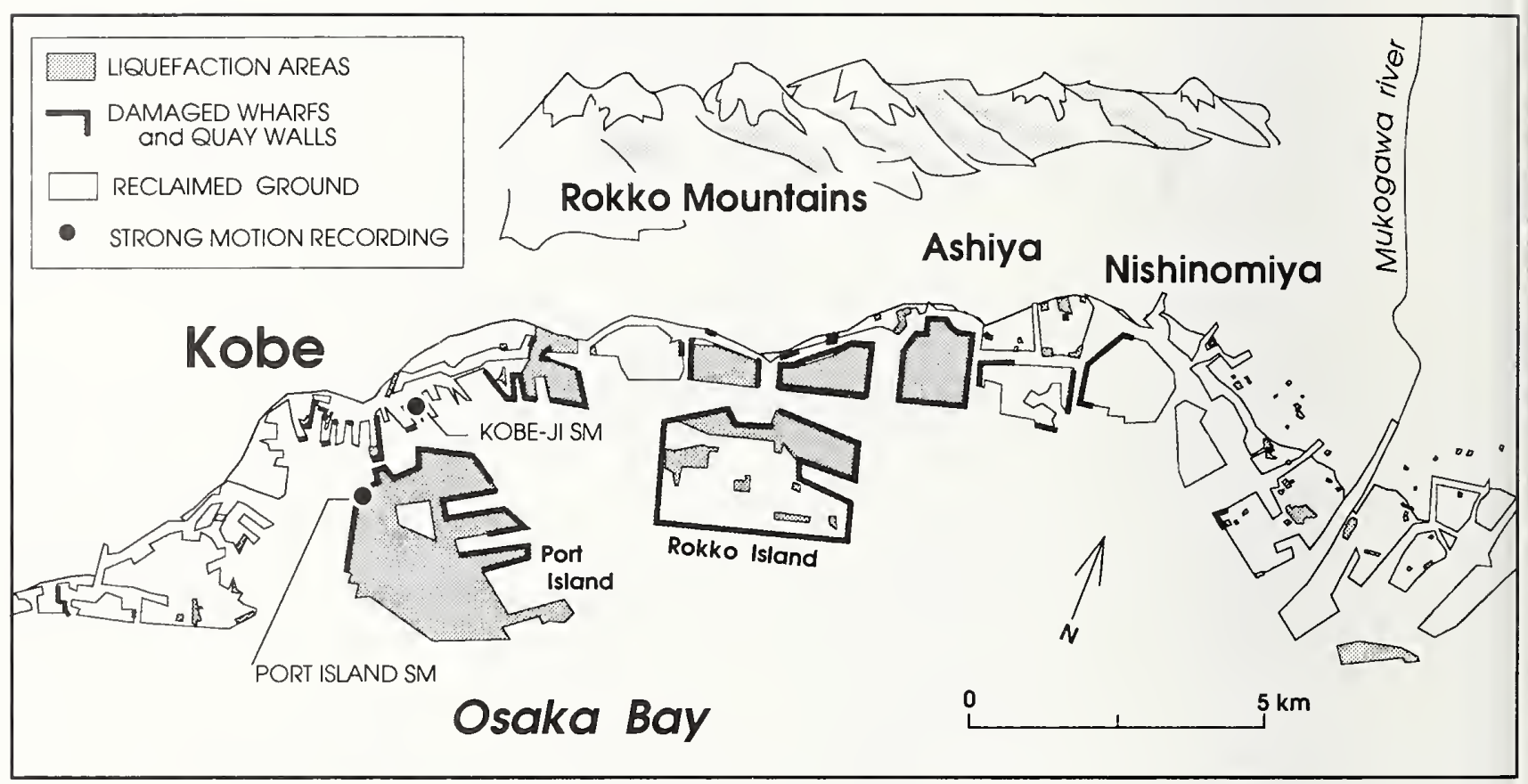

Figure 4.5.4 Areas of liquefaction and damaged quay walls in the Port of Kobe. Areas are generalized from aerial photography and unpublished maps by the Geographical Survey of Japan. 


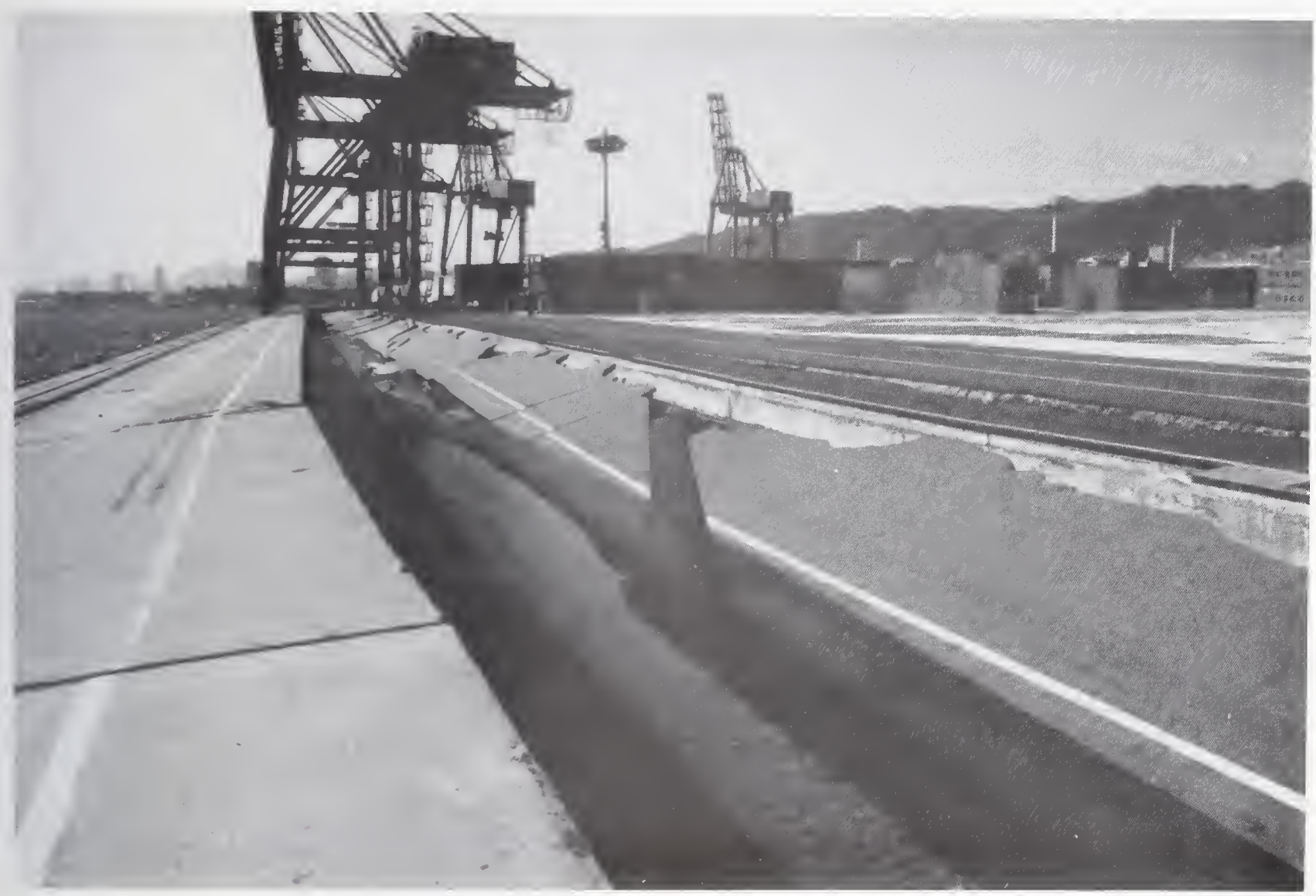

Figure 4.5.5 Damaged to Maya Wharf caused by liquefaction-induced lateral spreading. Downdropped block has formed behind quay wall where land has settled and moved outward. Landward side of block is the pile-supported rear crane rail. Photograph taken February 15, 1995. 


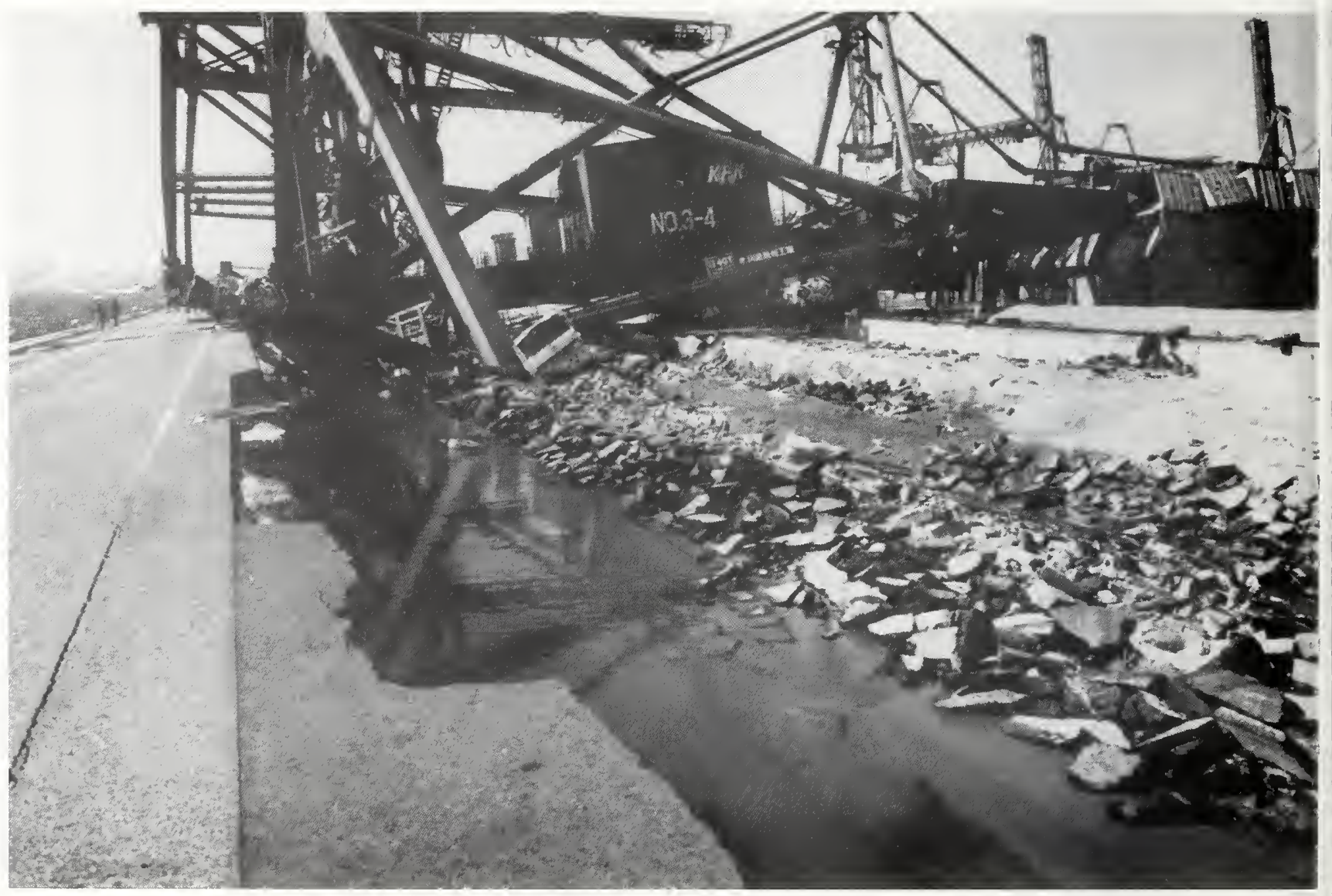

Figure 4.5.6 Collapsed crane caused by permanent differential horizontal displacement between crane rails on Rokko Island. Lateral spreading caused permanent seaward displacement of quay wall and crane rails to pull apart. This caused the legs of the crane to pull apart and crane to topple. Photograph taken February $15,1995$. 


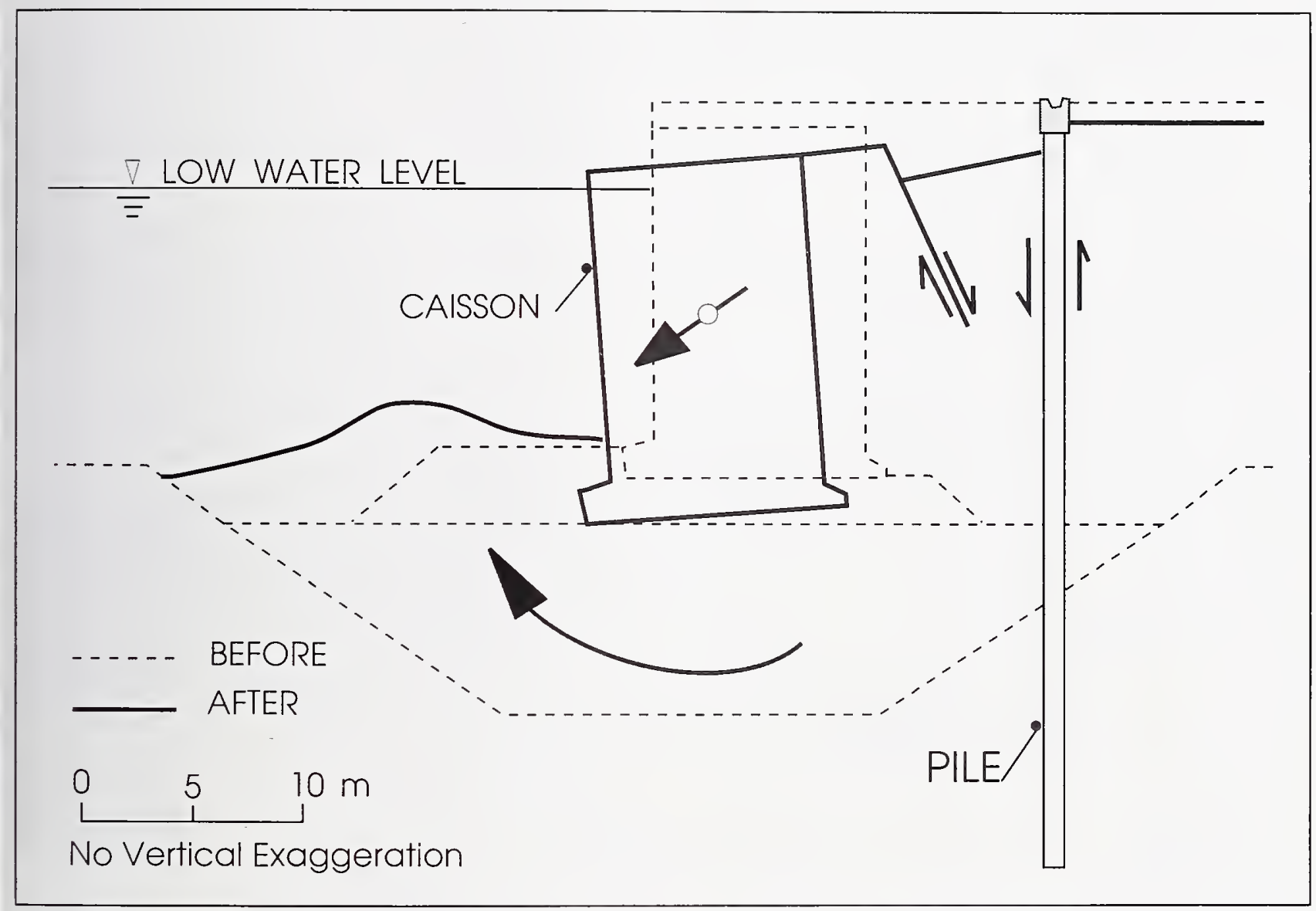

Figure 4.5.7 Hypothetical failure mechanism of caisson quay wall. 


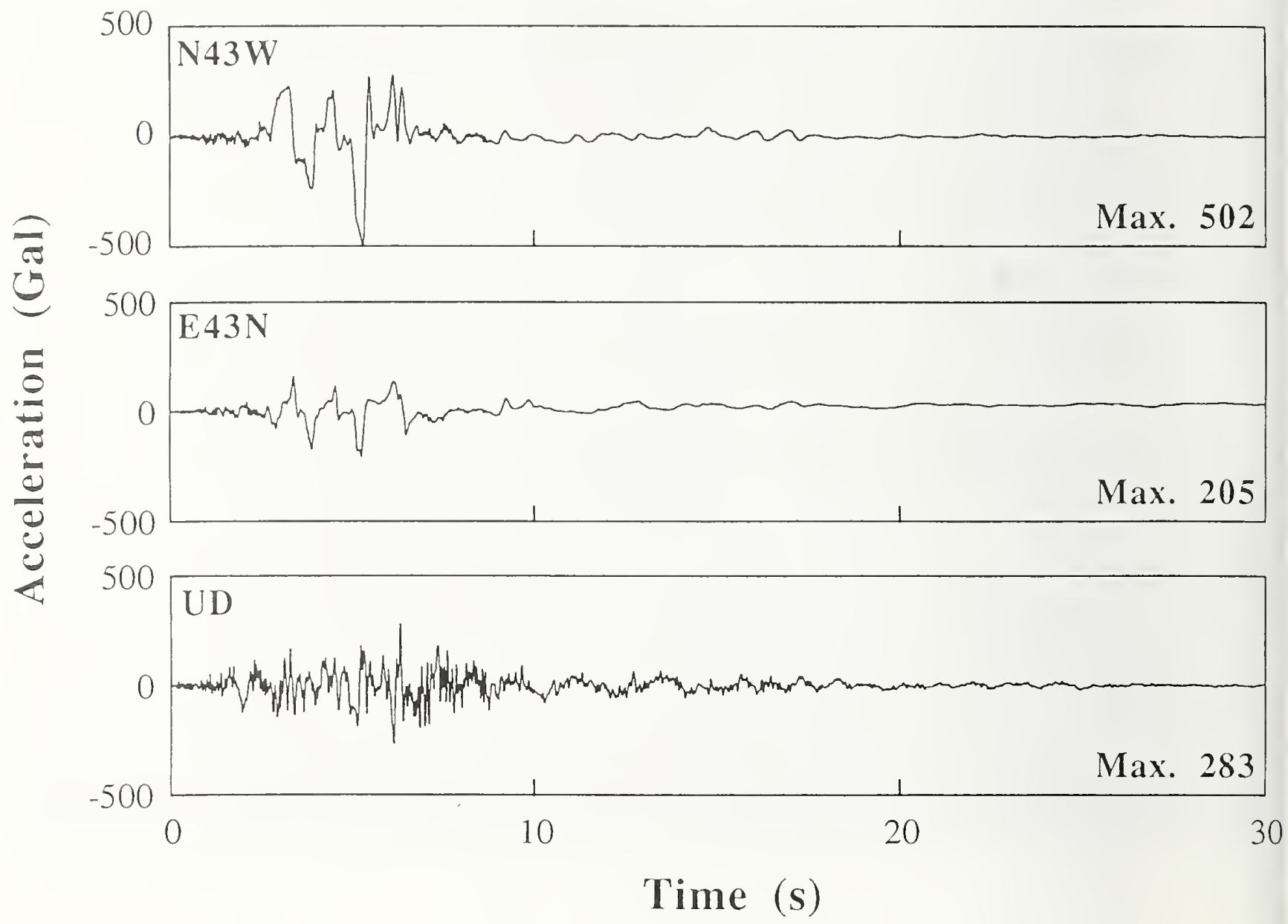

Figure 4.5.8 Kobe-ji strong ground motion record at Port of Kobe Construction Office from January 17, 1995, Hyogoken-Nanbu earthquake 


\section{CHAPTER 5}

\section{PERFORMANCE OF LIFELINE SYSTEMS}

\subsection{Introduction}

Lifelines are public works and utilities systems including telecommunications, electrical power, gas and liquid fuels, transportation, and water supply and sewage treatment. They are vulnerable to natural and man-made hazards such as earthquake, extreme wind, flood, accident, and terrorism. Proper performance of lifelines is important to assure public safety, vitality of economic activity, and quality of life. However, lifelines and their importance to our way of life generally are not recognized until their failure causes deaths and destruction, impedes emergency response following a major disaster, hinders post-disaster recovery, or paralyses a community. Disruption of regional lifeline systems as the result of a major natural disaster such as this earthquake in Kobe, can have a profound effect on the entire nation because of the economic interdependence of lifeline systems and the functions they support.
- The Kobe earthquake is expected to be the costliest natural disaster in recent human history and a significant portion of those losses is due to the loss of function of lifeline systems immediately after the earthquake, the cost of their repair and replacement, and the related near- and longterm indirect economic losses.

This chapter gives a brief overview of the performance of lifeline systems; water and wastewater systems, gas delivery systems, electric power, telecommunications, and hospitals. Observations of lifelines related to expressways, highway, railways and rapid transit systems, airports, and ports and harbors are given in Chapter 4. Postearthquake fires issues are presented in Chapter 6. 


\subsection{Water and Wastewater Systems}

This section describes the City of Kobe's water system, as well as the Hanshin Water Authority Water Purification Plant that is jointly owned and provides water to the cities of Kobe, Ashiya, Nishinomiya, and Amagasaki. Damage to the Kobe's wastewater system is also described.

No information has been gathered for the other cities east of Kobe. The City of Kyoto's water system had no pipeline damage, and suffered only minor window glass damage and damage to a small diameter buried pipeline at one of its purification plants.

\subsubsection{Overview of Water System}

\subsubsection{System General Overview}

The City of Kobe water system serves 608844 households including 1.5 million people. The system was started in 1900 as the 7 th modern water system in Japan. The Water Department began actively using computers in 1987, inputting water pipe drawings and boring log data for 4000 borings in 1988.

The city area is $547 \mathrm{~km}^{2}$ of which $251 \mathrm{~km}^{2}$ has water service. The balance of the city is underdeveloped, and has no water service. The Kobe Water Department has over 1000 employees. Its system includes the following inventory:

- $3963 \mathrm{~km}$ pipe

- 239 reservoirs at 119 sites

- 43 pump stations with 231 pumps

- $64 \mathrm{~km}$ transmission tunnels
Figure 5.2.1 shows a schematic of the system and Figure 5.2.2 shows a more detailed map of the system serving the urban area.

\section{The U.S. lifeline earthquake} community should learn from both the successes and failures observed in Kobe. Successes include the monitoring and control system, performance of water treatment plants (except geotechnical) and tankage, and possibly seismic joint pipe. Failures include lack of adequate water supply for fire suppression and inadequate focus on geotechnical failure.

The system is divided by Mt. Rokko into two service areas, Hokushin and Shigaichi. The Hokushin area is served by Sengari Reservoir located in the north. This mountainous area makes up less than $10 \%$ of the water demand, and has been developed primarily since the 1960's.

The Shigaichi area, the Kobe urban and western parts, is served by the Yodogawa River. The area is approximately $30 \mathrm{~km}$ long, east to west, and $1.5 \mathrm{~km}$ to $6 \mathrm{~km}$ wide, running between the shoreline and the mountains. Over $90 \%$ of the water demand is from this region. Water to this area is supplied from the east; it takes up to 12 hours for the water to traverse the distance from east to west.

Water is pumped to the water purification plants, and runs by gravity to the west at an elevation starting at $90 \mathrm{~m}$ above sea level through Kobe's tunnel system. The tunnel 
system operates in the open channel flow or low pressure regime. The first tunnel, 1.8-m diameter and built in the 1930's, is constructed in rock with an unreinforced concrete lining. The second tunnel, 2.5-m diameter, was built in the 1950's and lined with reinforced concrete. There is apparently no concern about water quality degradation in the tunnel even though it is open channel flow. Water used at an elevation above $90 \mathrm{~m}$ (apparently $15 \%$ of the demand) is pumped from the tunnel system. Refer to Figure 5.2.3 for a schematic of the system profile.

The Kobe water system is designed to provide both water for drinking and fire protection. There is no dedicated water system for fire suppression, although one was under consideration in 1993. Fire fighting is the responsibility of the fire department.

There are a number of cisterns (Photo 1) located throughout the City for use for fire suppression. The urban area is laid out on a $400 \mathrm{~m}$ by $400 \mathrm{~m}$ grid. Three quadrants of the grid each has a fire hydrant, and the four quadrant has a cistern. There is one special radio system for communication between the water and fire departments during emergency response situation.

\subsubsection{Supplies}

Nearly all of Kobe's water comes from surface water supplies. Nearly three quarters of Kobe's water comes from the east with primary sources including Lake Biwa and the Yodogawa River. Table 5.2.1 summaries these sources. Figure 5.2.1 shows where many of these sources are located.

\subsubsection{Water Treatment Plants}

All of Kobe's water is treated before it is distributed. There are eight water purification plants treating potable water for Kobe, and one treating water for industrial use The three largest plants are Uegahara, Hanshin (Kabutoyama), and Sengari. The Uegahara and Hanshin (Kabutoyama) plants are immediately adjacent to one another, and are located to the east of the City. The Sengari plant is located north-northeast of the City. Table 5.2.2 summarizes the water treatment plants information. Figures 5.2.4 and 5.2.5 show schematics of two of the purification plants that were damaged in the earthquake, Uegahara and Motoyama.

\subsubsection{Distribution}

Kobe has an aggressive pipeline replacement program that has resulted in $90 \%$ of their system being constructed of steel or ductile iron pipe. Their pipe inventory is summarized in Table 5.2.3.

Approximately $6 \%$ of that pipe employs special seismic joints as depicted in Figure 5.2.6 and Photo 2. These joints, Standard G113 and 114, Japan Water Works Association (JWWA), are specially designed to allow longitudinal extension and compression but are restrained before they separate. The ductile iron pipe with $S$ joints is manufactured by both Kubota and Kurimoto, and is estimated to cost $30 \%$ more than pipe without seismic joints. All new pipelines greater than $400 \mathrm{~mm}$ in diameter and all pipelines in reclaimed and landslide-prone areas are required to be constructed with this seismic resistant pipe. For example, all major pipelines on Rokko Island are constructed with this special seismic resistant joint. 
The steel pipe Kobe uses employs butt welded joints. Pipe larger than $600 \mathrm{~mm}$ diameter is welded from both interior and exterior, smaller diameter pipe only from the exterior.

Kobe Water uses polyethylene encasement, commonly referred to as baggies, for external corrosion control for their ductile iron pipe. They line larger diameter pipe with cement mortar, and smaller diameter pipe with epoxy. For new service connections, they use High Impact Vinyl Pipe, thought to be similar to PVC used in the United States.

Kobe has an aggressive pipeline replacement program which began in 1964. Tables 5.2.4 and 5.2.5 summarize this program covering both general renewal and earthquake specific upgrade.

The results of Kobe's aggressive pipeline replacement program were evident in a leakage survey of its system undertaken in 1990. The Kobe system had a $93.5 \%$ effective use of its water compared to Tokyo which had $87.8 \%$ and Osaka $92.7 \%$. Effective use is calculated by dividing the amount of water delivered to customers (through meters) divided by the amount of water taken from the source. Meter accuracy and system leakage are the two elements that can dramatically affect the results.

In addition to potable water pipelines, Kobe has an industrial water pipeline system. Water is treated at Uegahara Water Purification Plant in a separate treatment system delivering a lower grade water quality, and distributed to Rokko and Port Islands, and other industrial areas along the shoreline. That system includes the following pipelines: conveyance, $21 \mathrm{~km}$; transmission, $13 \mathrm{~km}$; and distribution, $62 \mathrm{~km}$.

\subsubsection{Distribution Reservoir and Pump Stations}

The Kobe Water Department has an inventory of 239 service reservoirs at 119 sites. These include cast-in-place concrete reservoirs (approximately 80\%), and precast concrete reservoirs and welded steel reservoirs (approximately 20\% combined), which range in capacity from $40 \mathrm{~m}^{3}$ to $20000 \mathrm{~m}^{3}$. Table 5.2 .6 summarizes the location of these reservoirs by elevation, and Table 5.2 .7 by area.

Nearly all of the reservoirs are constructed with two at each site. This provides redundancy for post-earthquake function and allows the removal of one from service for cleaning.

Kobe does not use pressure reducing valves between pressure zones as is commonly done in the United States. Rather, control tanks are used, with flow from the upper pressure zone into the tank controlled by an altitude valve.

Kobe Water has a program to advance the design of reservoirs to meet a wide range of requirements including general structural performance, earthquake performance, and corrosion resistance. At the Okuhirano Water Purification Plant, Kobe constructed two reservoirs at about the same time, one using welded steel and the other precast/post-tensioned (prestressed) concrete. The objective was to be able to evaluate the relative long-term performance of both designs. Figure 5.2.7 shows a section of the steel reservoir. It is specially designed to accommodate radial expansion during filling, similar to the U.S. precast/post-tensioned concrete tank design. Inherent in the design is damping of compressive earthquake loading on the steel shell. 


\subsubsection{Control System}

The Kobe Water Control Center, built in 1977 , is located at the Okuhirano Purification Plant. It is a Fujitsu $400 \mathrm{MHz}$ UHF-multi-directional multiplex broadcasting system. It monitors over 2000 sets of information including reservoir level; tunnel level; tunnel, transmission, and distribution flow; pump status; and access alarms. It controls 469 components including pump on/off, rate-of-flow controllers, valve controls, and control selection.

The Control Center communicates with distributed facilities through a repeater station on the International Trade Center Building. That repeater serves much of the urban area and the Uegahara Water Purification Plant directly and also transmits secondary repeaters at Mt. Rokko, which serves the northern service area and Sengari Water Purification Plant; and Mt. Takao which serves the western area. Figure 5.2.8 presents a schematic of the communication/repeater system.

\subsubsection{Earthquake Monitoring and Control}

Kobe Water has an earthquake monitoring and control system in place to isolate water from the system and to maintain it in selected reservoirs for drinking following an earthquake. Without this system in place, pipe damage in the system would result in a quick drainage of the service reservoirs. The system is also designed to maintain water for fire suppression. There is no capability however, to isolate major lines crossing vulnerable areas, such as lines to the reclaimed land areas.

The system consists of ground motion monitoring at the Okuhirano Control
Center, a control panel, telemetry (as described above), and reservoirs with earthquake isolation valves at 21 locations, with plans for a total of 29 locations. The earthquake valves are motor operated with backup batteries.

The seismograph at the Control Center measures ground motion and provides input into the earthquake control system. The earthquake control system allows both automated and manual control of isolation valves on service reservoirs. The decision logic is given below:

- Level 1: 40 gal--manual alarm

- Level 2: 80 gal--automatic shut down when combined with excessive rate of change of flow

- Level 3: 250 gal--automatic shut down

Figure 5.2.9 shows a schematic of the control system.

There are dual reservoirs at each of the 21 sites, one has an isolation valve to be controlled following an earthquake and the other does not. This concept allows shutdown of one reservoir while maintaining service should an inadvertent shutdown signal be received. If the system can keep up with system leakage, the isolated reservoir can be put back on line from the Control Center. If the system can not keep up with the demand, the reservoir remains isolated.

Emergency planners based the number of locations of isolated reservoirs on serving the population 3 liters per day for drinking for 7 days. They estimated that it would take up to 7 days to repair the system. Figure 5.2.10 shows the locations of the reservoirs within the system. Isolated tanks were selected so that each would serve an 
area approximately $4 \mathrm{~km}$ in diameter.

Figure 5.2.11 shows a schematic of the local post-earthquake water distribution system at each reservoir.

\subsubsection{What Happened to the Water System}

\subsubsection{Conditions Following the Earthquake}

Earthquake valves closed on 18 out of 21 service reservoirs following the earthquake storing $33800 \mathrm{~m}^{3}$ of water. Total storage before the earthquake (5:05 a.m., January 17) was $338455 \mathrm{~m}^{3}$. Minimum storage after the earthquake (6:01 a.m., January 18 ) was $94906 \mathrm{~m}^{3}$. The 86 distribution reservoirs serving the urban area without earthquake valves quickly emptied as shown in Figure 5.2.12. This resulted in inadequate water available for fire suppression.

Water carried by the Hanshin system dropped from $6000 \mathrm{~m}^{3} / \mathrm{hr}$ to $1000 \mathrm{~m}^{3} / \mathrm{hr}$ immediately following the earthquake. This was caused by loss of power to Yodogawa River Pump Stations for 15 hours following the earthquake as well as transmission main breaks.

Water restoration work began on January 18. Leaks were identified and repaired with the following priorities:

(a) damaged areas, medical facilities, areas with populations

(b) broken pipes, minor leakage areas (i.e., fix areas first that could be easily restored)

(c) broken pipes, major leakage areas

(d) shelters and areas in danger of landslides
Mutual aid was provided by estimated 1000 people from 37 agencies.

U.S. utility decision makers need to be thinking in terms of consequences similar in magnitude to the Kobe event. For example, what happens when you have no records because all utility buildings are destroyed? What happens...?

Emergency supply using water tank trucks was initiated on the evening of January 17. Later, water supply aid came from other cities and from the Self Defense Forces. Regular water supply points were established and increased in numbers as time went on. Figure 5.2.13 shows the status of emergency water supply in the days following the earthquake in terms of truck loads of water, distribution points, and relief workers working on water distribution. It is not clear what the correlation is between trucking in water and use of service reservoirs that had been isolated for local distribution for drinking. When service was resumed, the chlorine feed rate at the purification plant was increased but no boil water notice was issued. When leaks were repaired, lines were flushed, but not disinfected.

Figure 5.2.14 shows the percent of people receiving water after the earthquake. Figures 5.2.15 and 5.2.16 show the number of emergency response workers from other cities assisting in restoration of the distribution system and purification and pump station equipment, respectively. Based on the information provided by the Kobe Water Department in these figures, it appears that it took approximately one week to muster mutual aid. 
Figure 5.2.17 shows the status of water system restoration by ward, through

February 13. Based on the information in the figure, approximately three quarters of this system was initially without service. The western area of the system was the most severely impacted, while the northern part of the system had the least damage. Other parts of the system appear to be equally hard hit. Water was restored to $99 \%$ of customers by March 29. It took 35 days to restore water to Port Island.

\subsubsection{Damage to Water Facilities}

This section describes damage to specific system components.

Supply Reservoirs A cracked handrail along a walkway on the dike was noticed at the Nunobiki Reservoir. Also, at the same site, the service bridge required major repairs. At the Karasuhara Reservoir site, vertical cracks occurred at one location on the back of the dike.

Water Purification Plants Uegahara, Hanshin (Kabutoyama), and Motoyama water purification plants were damaged by the earthquake. The Sengari, Okuhirano, and Sumiyoshi water purification plants had little damage. Information is not available on the other two small plants, Arima and Mt. Rokko.

Uegahara Water Purification Plant The plant was rendered inoperable following the earthquake. On the west side of the plant, fill behind a retaining wall subsided when the retaining wall moved outward. This resulted in the separation of pipeline joints on three treated water lines, each $1.2 \mathrm{~m}$ diameter reinforced concrete. The lines were (a) Uegahara potable water, (b) Uegahara industrial water, and (c) Hanshin potable pipeline. The Hanshin line was operating as of February 11.

Some subsidence occurred under the sludge thickener building. The floor settled differentially. There was subsidence around the pile supported foundation of the sludge hoppers. Unanchored electrical equipment toppled in the sludge thickener building. The building and adjacent sludge hoppers were both pile-supported. The cross section of the slope, retaining wall, and fill is unclear.

This same subsidence also probably led to the following damage: muddy water and increased water volume in water passages (pipe galleries); clarifiers (damage to expansion joints, water leakage); process tanks (some leakage); sludge thickening equipment (extensive damage to piping and equipment); high rate filter piping (bent and disconnected); and other damage to pipe, mechanical, and electrical equipment. Steel baffles in the clarifiers were damaged from impulsive hydraulic forces.

\section{Hanshin Water Authority (Kabutoyama)} Water Purification Plant The plant was not damaged and was operating at $3000 \mathrm{~m}^{3} / \mathrm{hr}$ as of February 12. There was a major landslide in back (northeast) of the treatment plant, undercutting the wastewater treatment building which was pile supported, and taking out a tennis court and a sludge drying bed. The slide killed 36 people in a housing development below, and dammed the Nigawa River. The original slope was $18^{\circ}$, much less than the $30^{\circ}$ where the code requires mitigation. After the slide occurred, workers placed a plastic cover to cover the area above slide to keep rain off, installed slope monitoring instruments, and began to do borings to further investigate the slide. This was the largest slide in the urban area. Damage to buildings appeared to be light with occasional roof damage. 
Motoyama Water Purification Plant The Motoyama Plant had damage to two segments of pipelines and minor cracking in a process tank. Pipelines to and from the backwash water tank failed as a result of slope failure.

The retaining wall along the side of the Simiyoshi River moved, breaking the intake box overflow line. Water is fed to the intake box through a pipeline connected to a small diversion structure in the river bed. This facility is located upstream of the plant. There was a concern that the cast iron raw water line running from the intake box to the treatment plant may have been damaged as a result of the retaining wall movement, and should be checked before it is put into operation. The property owners living just above the suspect raw water line were uneasy because they did not want a break to undermine their houses.

Intake, Pump Stations, and Transmission Pipelines The intakes and pump stations near the Yodogawa River were not damaged. The two major lines from the Yodogawa River were broken at 10 locations. One ductile iron line had a split $30 \mathrm{~cm}$ long and $5 \mathrm{~cm}$ wide. One 100 meter section had to be replaced. One pipe failure had an opening $30 \mathrm{~cm}$ long by $4 \mathrm{~cm}$ to $5 \mathrm{~cm}$ wide. It took 12 days to repair the raw water lines serving the plant. Transmission pipe materials may have included both ductile iron and/or prestressed concrete.

The Mt. Rokko Tunnels, carrying water from the Uegahara and Hanshin plants west to be distributed, had not been inspected on the interior when information was collected for this report. However, no major leakage was occurring and only minor damage was expected.
Pumps in Karasuhara mine (spring) were destroyed and out of service. The spring only provides a minor supply to the Kobe water supply system. Other pump stations were undamaged. Damage to air rclease valves was reported.

Distribution Reservoirs (Tanks) Of the 119 reservoirs throughout the City, there was only minor damage to one pre-World War II cast-in-place partially buried concrete tank. At the Egeyama Reservoir, there was leakage in the pipe connecting the reservoir and the adjoining well, and a vertical crack in the expansion joint. A $500 \mathrm{~mm}$ diameter transmission main to Egeyama Reservoir, 10 $\mathrm{m}$ long, was replaced.

Distribution Pipes Distribution pipeline damage was reported as follows:

\begin{tabular}{|c|c|}
\hline $\begin{array}{l}\text { distribution pipes } \\
(75-300 \mathrm{~mm})\end{array}$ & 1,800 \\
\hline service lines $(<75 \mathrm{~mm})$ & $\underline{10,000}$ \\
\hline Total & 11,800 \\
\hline
\end{tabular}

An early survey of the 328 distribution pipe failures is shown below:

\begin{tabular}{|c|c|c|}
\hline & Failure & Percent \\
\hline Pipe breaks & 54 & 16 \\
\hline $\begin{array}{l}\text { Pipe joint } \\
\text { damage (ramming } \\
\text { and pull out) }\end{array}$ & 136 & 41 \\
\hline $\begin{array}{l}\text { Equipment } \\
\text { (fire hydrants, air } \\
\text { release valves, etc) }\end{array}$ & 69 & 21 \\
\hline Other & $\underline{70}$ & $\underline{21}$ \\
\hline Total & $\overline{328}$ & 100 \\
\hline
\end{tabular}

Table 5.2.8 shows Kobe Water pipeline damage data as of March 29 including the type of damage. Only 964 of the 1800 repairs identified at that time are shown in the table. Pipc material is not identified. 
Approximately $80 \%$ of the pipe in the system was ductile iron. Ductile iron pipe has performed well in previous earthquakes. It would make sense that the primary failure mode was pulled joints.

The three predominant types of service line failures were (a) house collapse, (b) joint separation, and (c) failure where the line passed below the concrete stormwater gutter. Service line repairs were accomplished at a rate of two per day with a crew of 5 to 6 .

It is estimated that indoor and outdoor supply pipe leakage sites will number 50000 , out of a total city water supply region of 650000 homes.

There was significant pipeline damage on Kobe's Port Island where Tyton-type and/or mechanical joints were deployed. In contrast, there was very little water pipeline damage on Rokko Island where the great majority of mains were ductile iron pipe with S-type joints.

Pipelines hung on the Kobe, Rokko, Mikage, and Fukae bridges were damaged, and in some cases disrupted service to these islands.

As the distribution system repair was nearing completion, water demand was more than $30 \%$ greater than pre-earthquake use. This raised concern that there were still many leaks that had not been identified.

There were two major issues identified that delayed system restoration: (a) no water pressure was available to check the repairs as the tunnels were drained, and (b) access was limited by collapsed buildings and traffic congestion. However, there were adequate repair materials.
Water Department Buildings The Water Department Main Office, including administration and enginee ring, was located on the 6th floor of the Old City Hall Building (City Hall Annex). The 6th floor of this eight story concrete frame building pancaked. Because of the early morning hour, only one employee was killed. Distribution system maps, facility drawings, etc., were not available during the initial restoration phase. Later in the restoration, some records were being pulled out of the collapsed floor.

The Water Department maintained a distribution and maintenance building in five areas throughout the City. The upper three floors of the eight story Water Department Eastern Center partially collapsed. The Western Center partially burned. The combined damage of these three facilities made emergency response and restoration very difficult. The Central, North, and Tarumi Centers were not damaged.

\section{Monitoring and Control System The} control system designed to isolate reservoirs for drinking worked in 18 out of 21 sites, and water was saved for drinking. Two of the failures were electrical or mechanical related, and one hydraulic. Three repeater stations and telemetry systems were undamaged.

\subsubsection{Wastewater System Overview and Damage}

This section describes the Kobe wastewater system. An overview of the system and associated damage will be described first. Second, damage to the Higashinada Wastewater Treatment Plant, where the most extensive damage took place, will be described. 


\subsubsection{System and Damage Overview}

The Kobe sewer system serves 1.46 million people. The collection area of $157 \mathrm{~km}^{2}$ is $97.4 \%$ sewered. Kobe has eight wastewater treatment plants, three of which were damaged by the earthquake, as shown in Table 5.2.9. The sludge is barged to Rokko Island where it is incinerated. The remaining 15 tons of ash are landfilled. There are 23 pump stations; 20 were damaged or inoperable from power loss, building damage, or caisson damage. Most were operable when power was restored.

Collection system pipe is $70 \%$ concrete, $20 \%$ PVC, and 10\% VCP. Kobe uses Fiber Reinforced Plastic for large diameter pipe and PVC for smaller diameter pipe in liquefaction areas. The length of sewers by sewage treatment plant service area is shown in Table 5.2.10. While we were informed that some of the sewers are combined sewers, it is unclear whether the storm sewers shown in Table 5.2.10 drain into the respective treatment plant.

In the future, Kobe is considering constructing a transmission line between the Higashinada and Tarumi WWTP to provide operational flexibility.

Three pipelines were relocated in the Daikai area where the subway station collapsed and as a result were heavily damaged. At the time of the team's visit, the crew was checking flows in manholes, and inspecting $60 \mathrm{~km}$ of sewers with 30 to 40 TV crews.

There was only one public health incident where sewerage was backed up. Photos 25 and 26 show a manhole that floated due to liquefaction near the Higashinada Plant. Photo 27 shows a sewer that was buoyed as a result of liquefaction on Port Island. The estimated cost of sewer repair is 12 billion yen ( $\$ 120$ million). Fifty people were involved in the planning and design of the restoration phase and an estimated 400 people were assisting in the restoration effort.

\subsubsection{Higashinada Wastewater Treatment Plant}

The Higashinada Wastewater Treatment Plant is the City of Kobe's largest plant providing one third of the city's treatment capacity. It is an activated sludge plant, located on Uozaki Hama Machi (island), immediately east of the bridge to Rokko Island as shown in Figure 5.2.18.

The plant has an average daily flow of $162000 \mathrm{~m}^{3}$ /day of which $23 \%$ is industrial.

Some sewage is from a combined sanitary/storm collection system. The plant capacity is $225000 \mathrm{~m}^{3} / \mathrm{day}$, and is being expanded to $350000 \mathrm{~m}^{3} /$ day. The oldest portion of the plant was constructed starting in 1962, shortly after placement of the fill for the island was completed.

The facility was heavily damaged when the seawall along the north side of the plant adjacent to the channel moved as much as $3 \mathrm{~m}$ towards the water as a result of liquefaction (Photos 29, 30). As a result, the entire site settled an average of one meter. Liquefaction-induced lateral spread and settlement were most severe within a distance of $100 \mathrm{~m}$ south of the seawall along the southern margin of the channel. Horizontal displacements of $3 \mathrm{~m}$ and settlements as large as $2 \mathrm{~m}$ were observed within the plant site. Figure 5.2.19 shows the plant layout and notes damage locations.

Lateral displacement and settlement ruptured the inverted siphon at the plant through which raw sewage was conveyed to the plant on the other side of the channel for treatment. Because of the loss of the 
siphon, sewage was being dumped directly into the channel.

Figure 5.2.20 presents a soil profile for the borings located in Figure 5.2.19. The soils consist of about $6 \mathrm{~m}$ to $8 \mathrm{~m}$ of artificial fill, primarily granitic sands and gravels, underlain by approximately $3 \mathrm{~m}$ to $5 \mathrm{~m}$ of alluvial sand. The fill and alluvial sands are loose, as evidenced by the low uncorrected blow counts between 5 and 15. The sands are underlain by soft to medium soft alluvial clay approximately $8 \mathrm{~m}$ thick, which overlie deep deposits of dense granular soils and still clays. The water table is about $2 \mathrm{~m}$ below ground surface.

Lateral deformation caused severe damage to underground structures and facilities founded on spread footings. The effluent channel separated in 4 places (Photo 31). The pipe rack distorted from foundation settlement (Photo 32).

Primary and secondary clarifiers and aeration basins were pile supported. The primary clarifiers were $8 \mathrm{~m}$ deep so the pile length subjected to liquefied sand was relatively small. Secondary clarifiers and aeration basins were only $4 \mathrm{~m}$ deep which subjected a longer pile length to liquefaction and lateral movement and resulted in some pile damage. Aeration tank joint separation is shown in Photos 33 and 34. Photo 35 shows scrapper chains which came off of sprockets. Concrete piles supporting digester tanks closest to the channel cracked at their tops. Photos 36 and 37 show broken sludge digester connecting piping.

Differential settlement and lateral spreading of approximately $600 \mathrm{~mm}$ occurred at the filter building, as shown in Photos 38 and 39 resulting in some pile damage. The control building and the sludge thickener room moved north $60 \mathrm{~cm}$ (Photos 40, 41). The return activated sludge pump and backup blower room flooded. Equipment and piping on mat foundations near the south edge of the channel was damaged due to ground movement (Photos 42-46).

It is expected to take 2 years to 3 years to repair the plant at a cost of 25 billion yen (\$250 million). This estimate seems low for the extensive damage observed.

\section{Recent earthquakes have shown that there is a low probability of maintaining a water system following an earthquake. Consideration should be given to identifying and developing alternate supplies.}

As of February 10 the Higashinada Plant was providing primary treatment with chlorination. This was accomplished by an innovative but necessary use of the channel between the mainland and island. The channel was blocked off at either end with a row of piles and covered with a filter membrane making a temporary sedimentation basin. Temporary baffles are placed in the sedimentation basin to keep solids away from the membrane filter, and to keep sewage from short circuiting to the filter membranes on each end. As raw sewagc enters the pump station, chlorine and a chemical coagulant are added. The sewage enters into the temporary sedimentation basin. The sewage solids settle to the bottom of the basin, and the liquid passes through the filter membrane. The solids area dredged from the bottom and pumped to a barge located outside the sedimentation basin where they are thickened. Solids are then dewatered and taken to a landfill. 


\subsubsection{Lessons for United States and Research Needs}

There do not appear to be any significant technical surprises from this earthquake which are applicable to the United States, but there are a number of reoccurrences of many situations that should help clarify earthquake planning and earthquake resistant design.

\subsubsection{Overwhelming Conditions}

We need to always be aware of the potential magnitude of earthquake consequences. This earthquake was the largest earthquake in recent years to directly impact an urban area in a country with facilities comparable to the United States. The results were overwhelming in terms of loss of life and property damage, as well as poor performance of utility systems.

From an emergency response perspective, there is always discussion about what might occur following a large earthquake located in a densely populated area. It is beyond comprehension for most people outside of California that such an event will happen, and therefore they do not truly consider the consequences. One of the biggest issues in the Kobe event was the loss of all transportation. Every major mass transportation route failed, and surface roads were blocked by fallen buildings. The resulting congestion made walking the fastest form of transportation. This caused emergency response to slow to a crawl.

The same situation was true for the response of utility personnel. For moderate earthquakes, there is an emergency response plan to enable effective data acquisition and response. However, utility decision makers need to be thinking in terms of consequences similar to the Kobe event.
For example, what happens when you have no records because all utility buildings are destroyed? What happens if the plan is to dispatch crew to isolate critical pipelines to save water or shut off natural gas, but the fastest way to get there is by walking?

\subsubsection{Fire Following}

We need to examine the issue of fire following earthquakes. While there was no fire storm, there were over 100 ignitions, and in many cases no water to suppress them. Water purveyors and fire departments should relook at the vulnerability of water supplies. Recent earthquakes have shown that there is a low probability of maintaining a water system following an earthquake. Consideration should be given to identifying and developing alternate supplics.

Similarly, the use of monitoring and control systems should be considered and/or reconsidered to enable the timely control of a water system following an earthquake to increase the probability of delivering water to suppress fires. Water purveyors and fire departments should use permanent ground deformation mapping to identify areas where pipclines will likely fail so that plans can be made to isolate damaged areas and/or use alternate water supplies.

\subsubsection{Geotechnical Issues}

We need to refocus on the potential consequences of geotechnical failures. Many lifeline system owners are lulled into an earthquake program that includes nonstructural upgrades, and minor building strengthening. Geotechnical hazards are often considered and potentially dramatic consequences identified; however, efforts to remediate these consequences are dropped when mitigation costs are developed. 
In Kobe, geotechnical failures governed the poor performance of the water system. Landslides, consolidation, and liquefaction or lateral spread stopped the flow of water from the source: damaged two major and one small water treatment plants; and tore the distribution system apart. In general, the structural aspects of the "steel" transmission pipelines matched current design used in the United States. The treatment plant structures performed reasonably well except that they were on soils that failed. An aggressive pipeline replacement program apparently only marginally helped mitigate geotechnical failure-related damage to the pipeline distribution system.

\subsubsection{Design}

In general, water treatment plants and service reservoirs performed well. The United States should study Japanese design approaches for these facilities. As discussed above, their tank designs are somewhat different from those used in the United States and apparently had no damage when subjected to high peak ground acceleration.

Pipelines were heavily damaged, except that preliminary information on performance of the $S$ joint pipe appears that it had no or few failures. If it is confirmed that it performed well in areas of significant permanent ground deformation, such as what was observed at Rokko Island, we should introduce it to the United States. If it did not perform well, we should find out why, and improve U.S. pipe design based on those findings.

An estimated $65 \%$ of the pipeline failures were pulled joints. As $80 \%$ of the pipe inventory in Kobe was ductile iron pipe with Tyton or mechanical joints without restraint, we should not become complacent with use of non-restrained joints in areas expecting significant permanent ground deformation.

\subsubsection{Recovery}

The three Kobe Water Department buildings storing records were destroyed. The probability of this occurring is very low. In the United States, we should make sure that our resources are distributed so that the loss of any one facility will not substantially impact our ability to respond to an earthquake.

\subsubsection{Summary}

The Hyogoken-Nanbu earthquake left one million households without water following the event, with only $70 \%$ restoration in three weeks. Water for fire suppression was substantially exhausted after six hours.

The two large diameter transmission lines carrying water from the Yodogawa River to the Uegahara and Hanshin (Kabutoyama) water purification plants failed in ten locations. This source constitutes nearly three quarters of Kobe's supply. The Uegahara and Hanshin (Kabutoyama) plants are Kobe's largest. In addition to their supplies being disrupted, soil failures at the plants resulted in failure of the major treated water lines, as well as moderate damage to the plants themselves. The tunnels carrying water from the plants west to Kobe remained intact.

Kobe Water had an aggressive earthquake design program for some of their service reservoirs. There were no tank failures reported for the 239 tanks located at 119 sites. There was some connecting piping failure at one tank. However, it should be noted that these tanks were in the hills surrounding the city and in areas of relatively low ground motion. 
Nearly $90 \%$ of Kobe's water distribution system was made of either welded steel or ductile iron pipe, both thought to be resistant to earthquakes. This unusually high percentage of earthquake-resistant pipe resulted from an aggressive pipeline replacement program initiated in the mid1960's. Even with this in place, an estimated 1800 pipeline failures occurred in distribution piping. It is speculated that much of this damage is associated with joint separation from liquefaction-induced lateral spread. This should be verified through followup studies.

Kobe had implemented a monitoring and control system designed to isolate reservoirs to be used for drinking following an earthquake. The system worked as designed. It should be determined whether this effort would have been better focused on water for fire suppression. In other words, was the water saved for drinking critical in meeting that demand, or was drinking water available from other sources? There was no system focused on postearthquake performance of the water system to provide water for fire suppression. There was no water available to put out many of the 100 plus ignitions.

The Higashinada Wastewater Treatment Plant provides one-third of Kobe's treatment capacity. Liquefaction or lateral spreading failures resulting in movement of a retaining wall $2 \mathrm{~m}$ to $3 \mathrm{~m}$ towards a waterway dropping the entire site an average of one meter. The result was devastating. A $2 \mathrm{~m} \mathrm{x}$ $2 \mathrm{~m}$ effluent channel separated in four places. The control and filter buildings moved, and equipment and piping settled as the soil moved away from under them. More attention should be paid to geotechnical failures.
The lifeline earthquake community in the United States should learn from both the successes and failures observed in Kobe. Successes include the monitoring and control system, performance of water treatment plants (except geotechnical) and tankage, and possibly seismic joint pipe. Failures include a lack of adequate water supply for fire suppression (including alternate supplies) and inadequate focus on geotechnical failure.

\subsubsection{Acknowledgments}

The authors would like to thank Professor Takada at Kobe University and Mr. Matsushita at the Kobe Water Department for providing information on the Kobe water system both before the earthquake (October 1993) and following the earthquake. Input and review is also gratefully acknowledged from Messrs John Eidinger and LeVal Lund who provided information gathered in a followup ASCE/TCLEE study trip to Kobe.

Dr. Ian Austin, Mr. Fumihiro Kujihara, and Mr. Ken Sasaki, all from Chiyoda-Dames \& Moore in Tokyo, made local arrangements, provided translation, and travelled with $\mathrm{Mr}$. Don Ballantyne in Kobe. Their assistance is greatly appreciated. 
Table 5.2.1

Kobe Water Supplies

\begin{tabular}{|l|c|c|}
\hline Source and Comments & $\begin{array}{c}\text { Percent of } \\
\text { Total Supply }\end{array}$ & $\begin{array}{c}\text { Supply in } \\
1000 \mathrm{~m}^{3} / \text { day }\end{array}$ \\
\hline $\begin{array}{l}\text { Lake Biwa/Yodogawa River - includes Hanshin Water Supply } \\
\text { Authority (Yodogawa River 30 km east of Kobe). }\end{array}$ & $73.9 \%$ & 606 \\
\hline Sengari Reservoir (constructed in 1919) & 13.8 & 113 \\
\hline Karasuhara Reservoir (constructed in 1905) & 4.4 & 36 \\
\hline Rivers in City - Sumiyoshi, Sanyo Shinkansen Tunnel & 3.8 & 31 \\
\hline \hline $\begin{array}{l}\text { Nunobiki Reservoir, 420,000 } \mathrm{m}^{3} \text { capacity constructed in } \\
\text { 1900; oldest gravity concrete dam in Japan) }\end{array}$ & 2.4 & 20 \\
\hline Dondo Dam & 1.7 & 14 \\
\hline Total & 100 & 820 \\
\hline
\end{tabular}


Table 5.2.2

Water Treatment Plants Serving Kobe

\begin{tabular}{|c|c|c|c|c|c|c|c|c|c|c|}
\hline \multirow{2}{*}{\multicolumn{2}{|c|}{ Filter Plant }} & \multirow{2}{*}{$\begin{array}{l}\text { Han- } \\
\text { shin } \\
\text { Water } \\
\text { Co. (1) }\end{array}$} & \multicolumn{5}{|c|}{ Urban Area } & \multicolumn{2}{|c|}{$\begin{array}{c}\text { Hokushin } \\
\text { District }\end{array}$} & \multirow{2}{*}{ 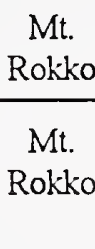 } \\
\hline & & & $\begin{array}{c}\text { Uegahara } \\
\text { (potable) } \\
\text { (2) }\end{array}$ & $\begin{array}{l}\text { Uegahara } \\
\text { (indus.) }\end{array}$ & $\begin{array}{l}\text { Okuhi- } \\
\text { rano (3) }\end{array}$ & $\begin{array}{l}\text { Moto- } \\
\text { yama }\end{array}$ & $\begin{array}{l}\text { Sumi- } \\
\text { yoshi }\end{array}$ & $\begin{array}{l}\text { Sen- } \\
\text { gari }\end{array}$ & $\begin{array}{l}\text { Ari- } \\
\text { ma }\end{array}$ & \\
\hline \multicolumn{2}{|c|}{ Date Constructed } & & 1917 & 1964 & 1900 & & & 1967 & & \\
\hline \multicolumn{2}{|l|}{ Source } & $\begin{array}{l}\text { Yodo- } \\
\text { gawa } \\
\text { River }\end{array}$ & $\begin{array}{l}\text { Sengari } \\
\text { Reserv. }\end{array}$ & $\begin{array}{l}\text { Yodo- } \\
\text { gawa } \\
\text { River }\end{array}$ & $\begin{array}{l}\text { Nonobiki, } \\
\text { Karasuhara } \\
\text { Reservoirs }\end{array}$ & $\begin{array}{l}\text { Sumi- } \\
\text { yoshi } \\
\text { River }\end{array}$ & & $\begin{array}{l}\text { Sen- } \\
\text { gari } \\
\text { Reser }\end{array}$ & & \\
\hline \multirow{2}{*}{$\begin{array}{l}\text { Number } \\
\text { of Filter } \\
\text { Basins }\end{array}$} & slow & & 8 & & - & - & - & - & 1 & - \\
\hline & rapid & & 8 & & 4 & 4 & 5 & $8(4)$ & - & 1 \\
\hline \multicolumn{2}{|c|}{$\begin{array}{l}\text { Capacity per day } \\
\left(1000 \mathrm{~m}^{3}\right)\end{array}$} & 144 & 128 & 150 & 60 & $8(5)$ & 6 & 108 & 0.3 & 1 \\
\hline
\end{tabular}

Note:

1. Municipal corporation including Kobe, Ashiya, Nishinomiya, and Amagasaki, and has three water treatment plants (a) Kabutoyama, (b) Inagawa, and (c) Amagasaki.

2. The Hanshin Water Authority Water Treatment Plant (Kabutoyama) is immediately adjacent to the Uegahara Water Purification Plant. Uegahara uses sodium hypochlorite for disinfection.

3. Control center adjacent to treatment plant.

4. Granular activated carbon media.

5. Usually runs at $6,000 \mathrm{~m}^{3}$, including $1,000 \mathrm{~m}^{3}$ to Sake plant in summer and 2,000 $\mathrm{m}^{3}$ in winter. 
Table 5.2.3

Pipe in Place as of April 1994

\begin{tabular}{|l|l|l|l|}
\hline Pipe Material & Joint Type & Length $(\mathrm{km})$ & Remarks \\
\hline \multirow{2}{*}{ Ductile Iron Pipe } & $\begin{array}{l}\text { Earthquake Resistant } \\
\text { Joint (S, SII) }\end{array}$ & $237.3(6.0 \%)$ & $\begin{array}{l}\text { All trunk mains }>400 \mathrm{~mm} \text { diameter; } \\
\Rightarrow 300 \mathrm{~mm} \text { for reclaimed land and } \\
\text { landslide areas. }\end{array}$ \\
\cline { 2 - 3 } & Mechanical Joint & $3,180.2(80.2 \%)$ & $300 \mathrm{~mm}$ (sub main) \\
\cline { 2 - 3 } & Tyton Joint & $75 \mathrm{~mm}-200 \mathrm{~mm}$ (distribution pipe) \\
\hline Steel Pipe & Welded Joint & $103.3(2.6 \%)$ & high pressure pipe (>100 psi) \\
\hline Cast Iron Pipe & Mechanical Joint & $308.9(7.7 \%)$ & Replacement in progress \\
\cline { 2 - 3 } & Leaded Joint & $7.0(0.2 \%)$ & \\
\hline Polyvinyl Chloride Pipe & Bell \& Spigot Joint & $126.4(3: 1 \%)$ & Replacement in progress \\
\hline Asbestos Cement Pipe & & 0 & Replacement completed in 1987 \\
\hline Total & & $3963.1(100 \%)$ & \\
\hline
\end{tabular}


Table 5.2.4

Rehabilitation and Renewal Project - 1978

\begin{tabular}{|l|c|c|c|}
\hline Year & Cost (million yen) & Diameter (mm) & Length Replaced $(\mathrm{km})$ \\
\hline $1982-86$ & 10,480 & $700-100$ & 139 \\
\hline $86-88$ & 4000 & $800-150$ & 20 \\
\hline $89-91$ & 4000 & $800-150$ & 27 \\
\hline
\end{tabular}

Table 5.2.5

Strengthening/Earthquake Proofing Pipelines - 1991

\begin{tabular}{|l|c|c|c|c|}
\hline & $\begin{array}{c}\text { Cast Iron } \\
\text { Pipe }\end{array}$ & $\begin{array}{c}\text { Polyvinyl } \\
\text { Chloride Pipe }\end{array}$ & $\begin{array}{c}\text { High-Pressure } \\
\text { Pipe Network }\end{array}$ & Total \\
\hline Length Replaced $(\mathrm{km})$ & 84 & 3 & 20 & 107 \\
\hline Cost (billion yen) & 9.1 & 0.2 & 2.2 & 11.5 \\
\hline
\end{tabular}


Table 5.2.6

Summary of Service Reservoirs by Elevation

\begin{tabular}{|l|c|c|c|l|}
\hline Layer & $\begin{array}{c}\text { Altitude above } \\
\text { Sea Level }\end{array}$ & Blocks & $\begin{array}{c}\text { Water } \\
\text { Consumption (\%) }\end{array}$ & Reservoir Sites \\
\hline 1 & $0-30 \mathrm{~m}$ & 10 & 53 & 10 \\
\hline 2 & $31-60 \mathrm{~m}$ & 10 & 20 & 13 \\
\hline 3 & $61-90 \mathrm{~m}$ & 14 & 13 & 19 \\
\hline 4 & $91-180 \mathrm{~m}$ & 31 & 11 & 77 (includes layers 5,6) \\
\hline 5 & $181-280$ & 8 & 3 & included in layer 4 \\
\hline 6 & Over 280 & 1 & $<1$ & included in layer 4 \\
\hline Total & & 74 & 100 & 119 \\
\hline
\end{tabular}

Table 5.2.7

Reservoir Distribution by Area

\begin{tabular}{|l|l|c|c|c|c|}
\hline \multicolumn{2}{|l|}{ Block Name } & Urban & Western & Northern & Total \\
\hline \multirow{2}{*}{ Distribution Reservoirs } & Sites & 71 & 8 & 30 & $109(1)$ \\
\cline { 2 - 6 } & Reservoirs & 147 & 14 & 54 & $215(1)$ \\
\hline \multirow{3}{*}{ Pumps } & Sites & 25 & 5 & 12 & 42 \\
\cline { 2 - 6 } & Pumps & 132 & 18 & 50 & 200 \\
\cline { 2 - 6 } & $\begin{array}{l}\text { Discharge } \\
\text { Lines }\end{array}$ & 50 & 9 & 17 & 76 \\
\hline Population (1,000's) & & 1117 & 103 & 174 & 1394 \\
\hline $\begin{array}{l}\text { Population Served } \\
(1,000)\end{array}$ & & 1116 & 86 & 174 & 1377 \\
\hline
\end{tabular}

1. Total numbers of distribution reservoirs differ from Table 6 . Information source is different and presumed to be from several years earlier. 
Table 5.2.8

Kobe Water Pipeline Damage

(As of March 29, 1995)

\begin{tabular}{|r|r|r|r|r|r|r||}
\hline $\begin{array}{r}\text { Diameter } \\
(\mathrm{mm})\end{array}$ & $\begin{array}{r}\text { Inventory } \\
(\mathrm{m})\end{array}$ & Repairs & $\begin{array}{r}\text { Repairs/ } \\
\mathrm{km}\end{array}$ & $\begin{array}{r}\text { Broken } \\
\text { Pipe }\end{array}$ & $\begin{array}{r}\text { Pulled } \\
\text { Joint }\end{array}$ & $\begin{array}{r}\text { Damaged } \\
\text { Fitting }\end{array}$ \\
\hline 50 & 63,143 & 15 & 0.24 & 6 & 9 & 0 \\
\hline 75 & 165,051 & 40 & 0.24 & 7 & 30 & 3 \\
\hline 100 & 790,329 & 197 & 0.25 & 43 & 127 & 27 \\
\hline 150 & $1,455,137$ & 301 & 0.21 & 55 & 206 & 40 \\
\hline 200 & 744,689 & 138 & 0.19 & 23 & 104 & 11 \\
\hline 250 & 39,706 & 6 & 0.15 & 3 & 3 & 0 \\
\hline 300 & 386,606 & 139 & 0.36 & 20 & 96 & 23 \\
\hline 350 & 18,195 & 5 & 0.27 & 0 & 4 & 1 \\
\hline 400 & 79,700 & 30 & 0.38 & 4 & 17 & 9 \\
\hline 450 & 3,082 & 0 & 0 & 0 & 0 & 0 \\
\hline 500 & 88,450 & 24 & 0.27 & 2 & 7 & 15 \\
\hline 600 & 45,224 & 13 & 0.29 & 2 & 3 & 8 \\
\hline 700 & 46,857 & 24 & 0.51 & 1 & 7 & 16 \\
\hline 800 & 10,264 & 9 & 0.88 & 3 & 5 & 1 \\
\hline 900 & 26,131 & 21 & 0.80 & 1 & 6 & 14 \\
\hline 1,000 & 498 & 2 & 4.02 & 0 & 0 & 2 \\
\hline Total & $3,963,062$ & 964 & 0.24 & 170 & 624 & 170 \\
\hline & & & & & & \\
\hline
\end{tabular}


Table 5.2.9

Kobe Wastewater Treatment Plants

\begin{tabular}{|l|r|l|l||}
\hline $\begin{array}{l}\text { Wastewater } \\
\text { Treatment Plant }\end{array}$ & $\begin{array}{l}\text { Capacity } \\
\left(1000 \mathrm{~m}^{3} / \mathrm{day}\right)\end{array}$ & Location & Post-Earthquake Status \\
\hline \hline Higashinada & 225.0 & Shoreline & $\begin{array}{l}\text { Heavily damaged; detailed damage description in } \\
\text { text. }\end{array}$ \\
\hline Seibu & 161.5 & Shoreline & $\begin{array}{l}\text { Secondary plant with 2 process trains. Concrete } \\
\text { yard piping was damaged; pump station settled } \\
\text { and flooded. Repaired within one week. }\end{array}$ \\
\hline Tarumi & 133.9 & Shoreline & No damage \\
\hline Chubu & 77.9 & Shoreline & $\begin{array}{l}\text { Plant suffered cracks in the sedimentation tank } \\
\text { and the dislodged chain drive. Operating within } \\
1 \text { day. }\end{array}$ \\
\hline Tamatsu & 75.0 & $1 \mathrm{~km}$ inland & No damage \\
\hline Suzurandi & 43.8 & $10 \mathrm{~km}$ inland & No damage \\
\hline Port Island & 20.3 & Port Island & No damage \\
\hline Myodani & 12.0 & $10 \mathrm{~km}$ inland & No damage \\
\hline \hline Total & 749.4 & & \\
\hline \hline Tobu Sludge Center & 150 tons/day & Rokko Island & Damaged \\
\hline
\end{tabular}


Table 5.2.10

Kobe Wastewater 'System Piping

\begin{tabular}{|l|r|r|}
\hline Treatment Plant Area & $\begin{array}{l}\text { Sanitary Sewer } \\
\text { Length }(\mathrm{km})\end{array}$ & $\begin{array}{l}\text { Storm Sewer } \\
\text { Length }(\mathrm{km})\end{array}$ \\
\hline Chubu + Seibu & 790 & 109 \\
\hline Higashinada & 719 & 76 \\
\hline Tarumi & 619 & 108 \\
\hline Tamatsu & 570 & 103 \\
\hline Inland Areas & 406 & 49 \\
\hline Suzurandi & 186 & 33 \\
\hline Port Island & 28 & 4 \\
\hline Total & 3318 & 482 \\
\hline
\end{tabular}




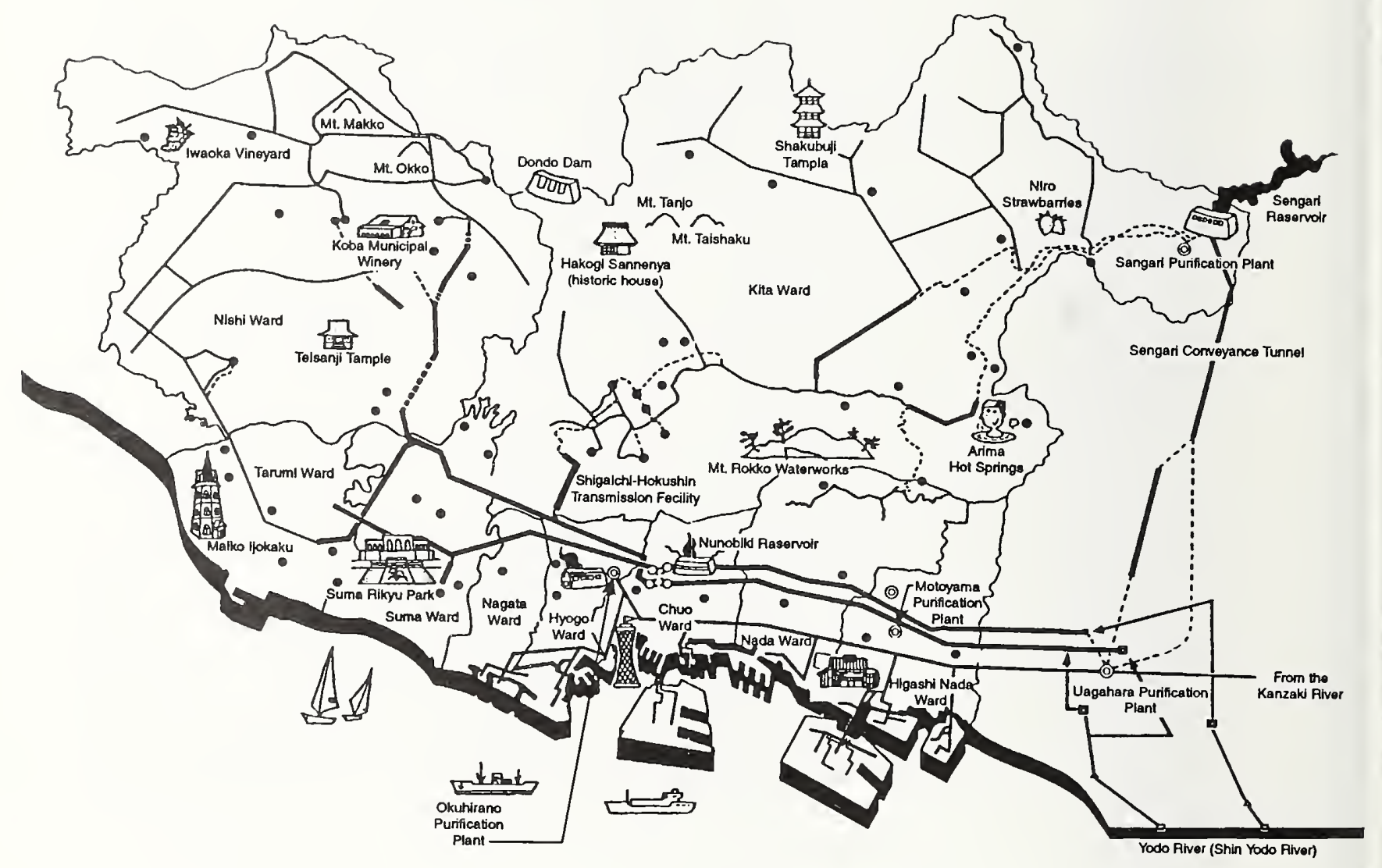

Figure 5.2.1 Kobe water system schematic. 


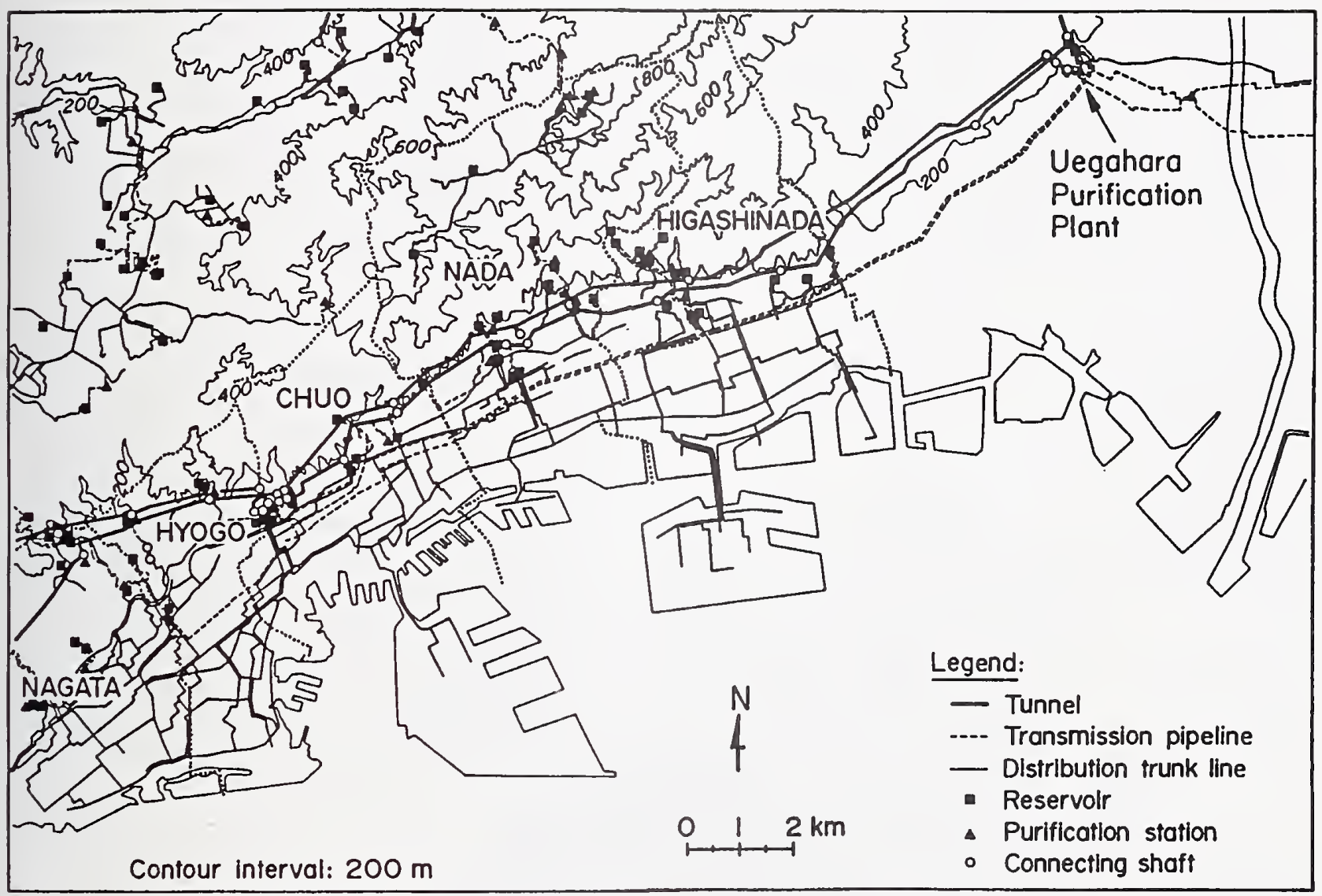

Figure 5.2.2

Kobe water system urban area. 


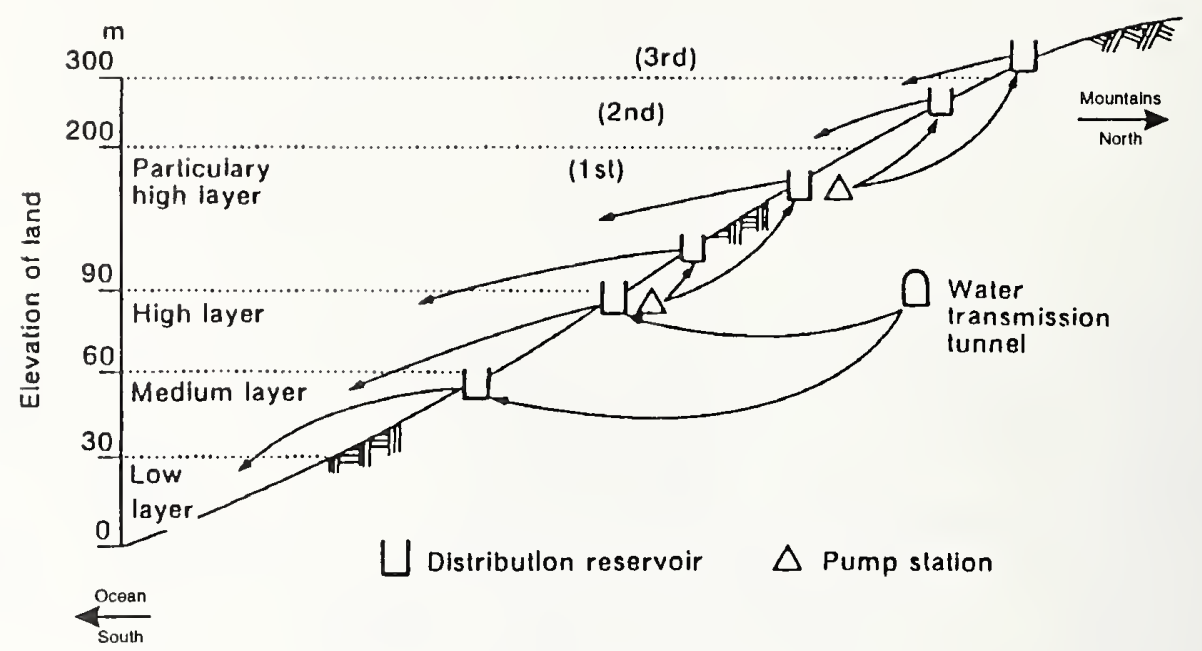

Figure 5.2.3

Schematic profile of Kobe water delivery system.

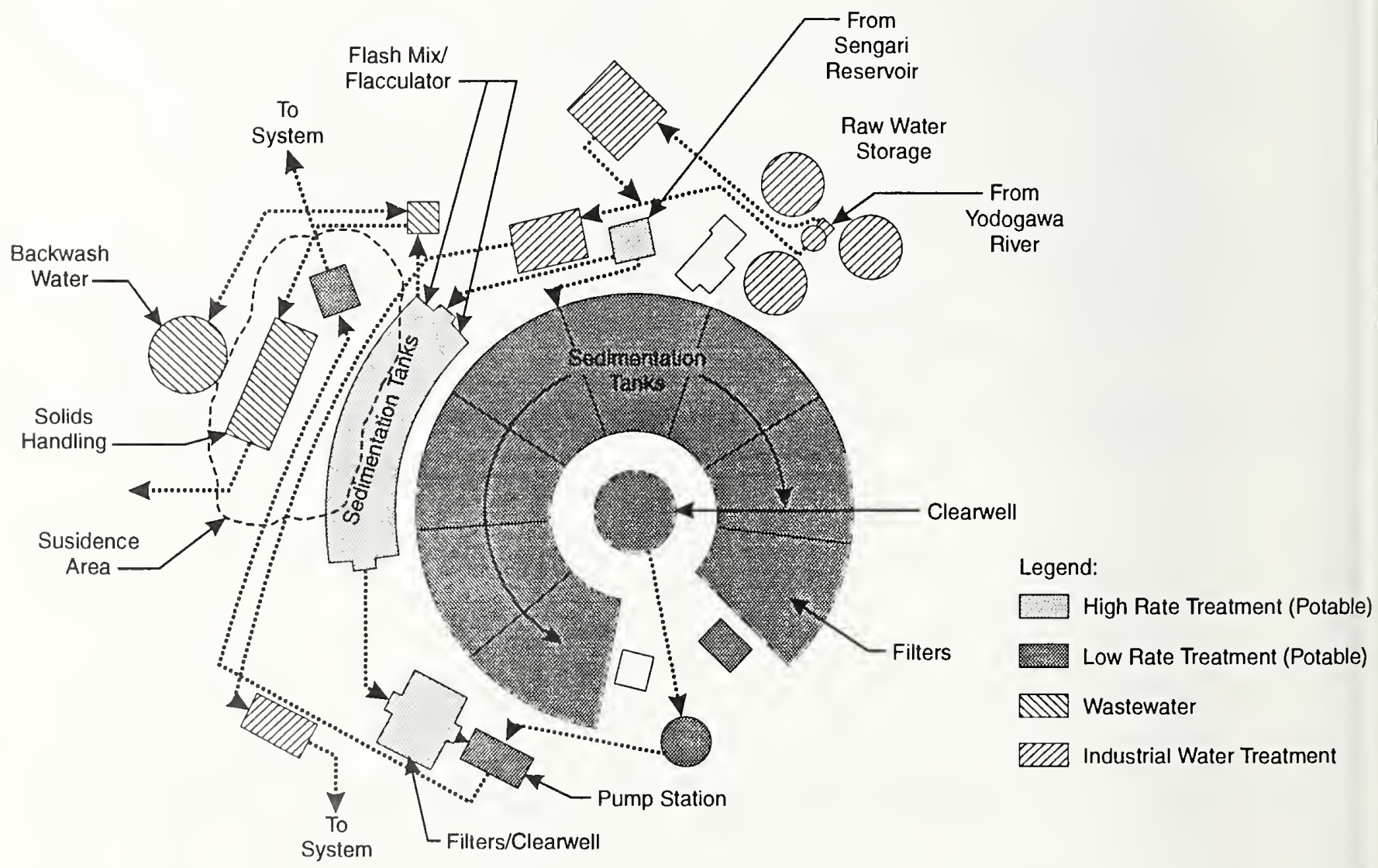

Figure 5.2.4

Uegahara Water Purification Plant schematic. 


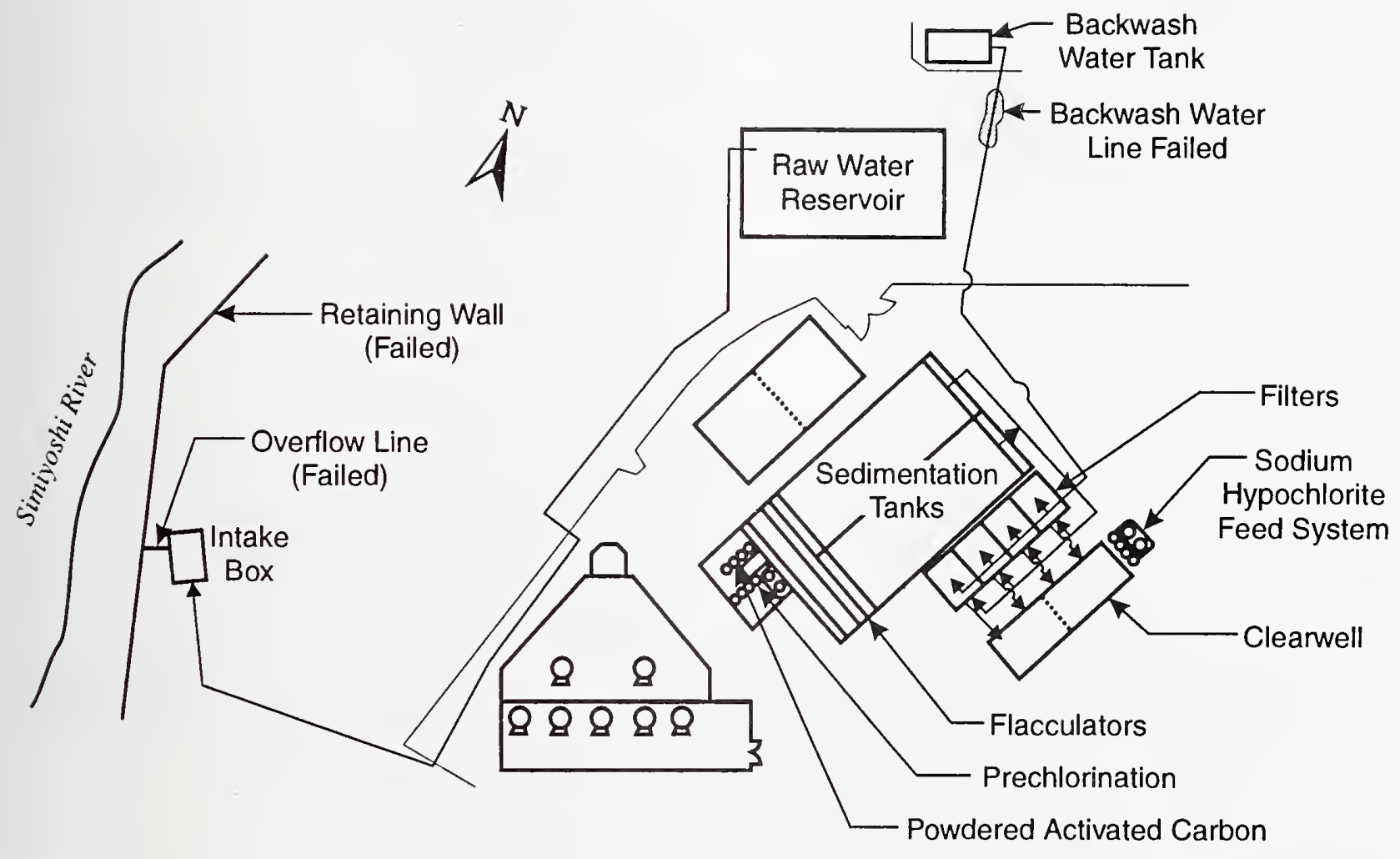

Figure 5.2.5

Motoyama Water Purification Plant schematic. 

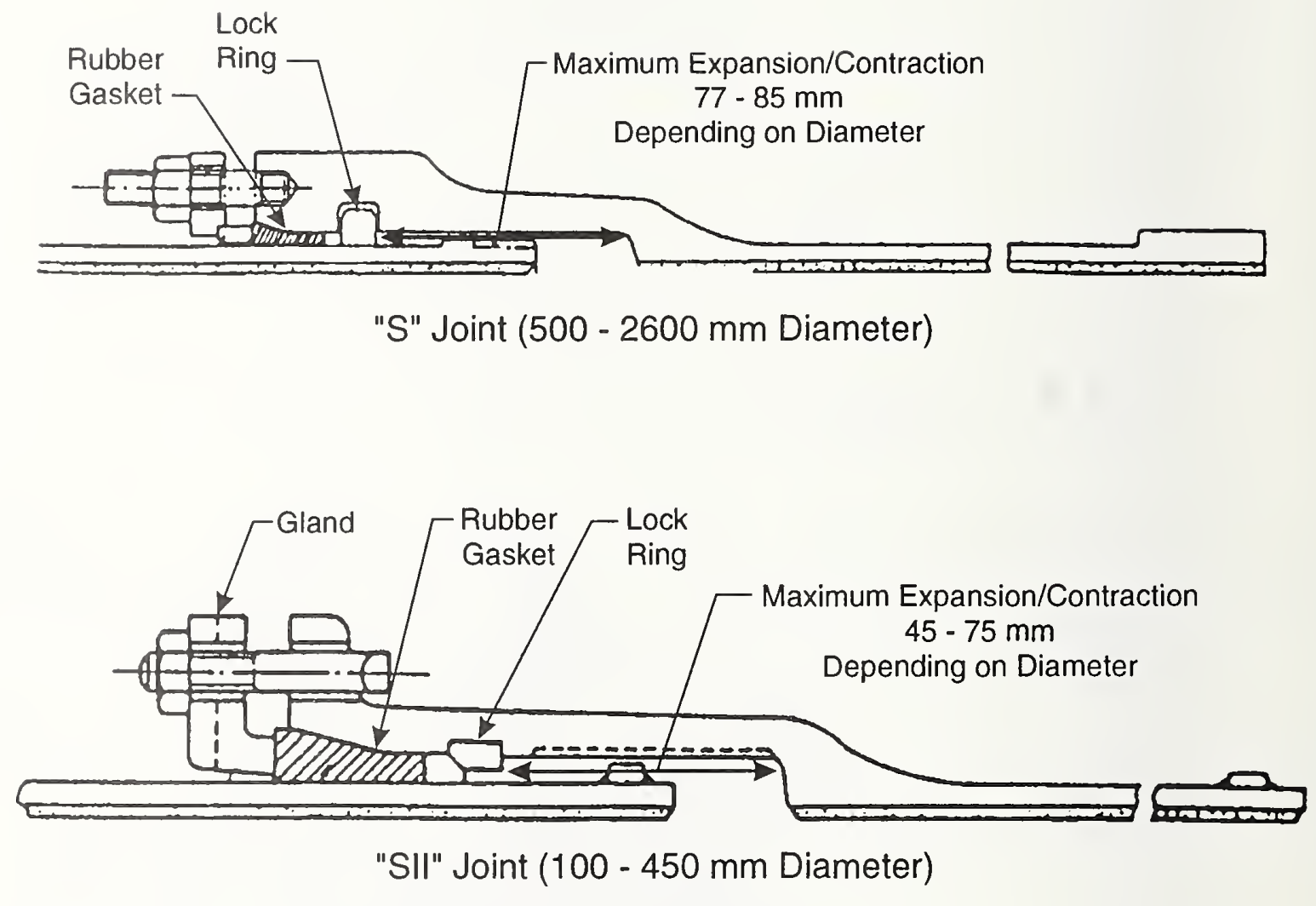

Figure 5.2.6 Seismic joints, S and SII. 


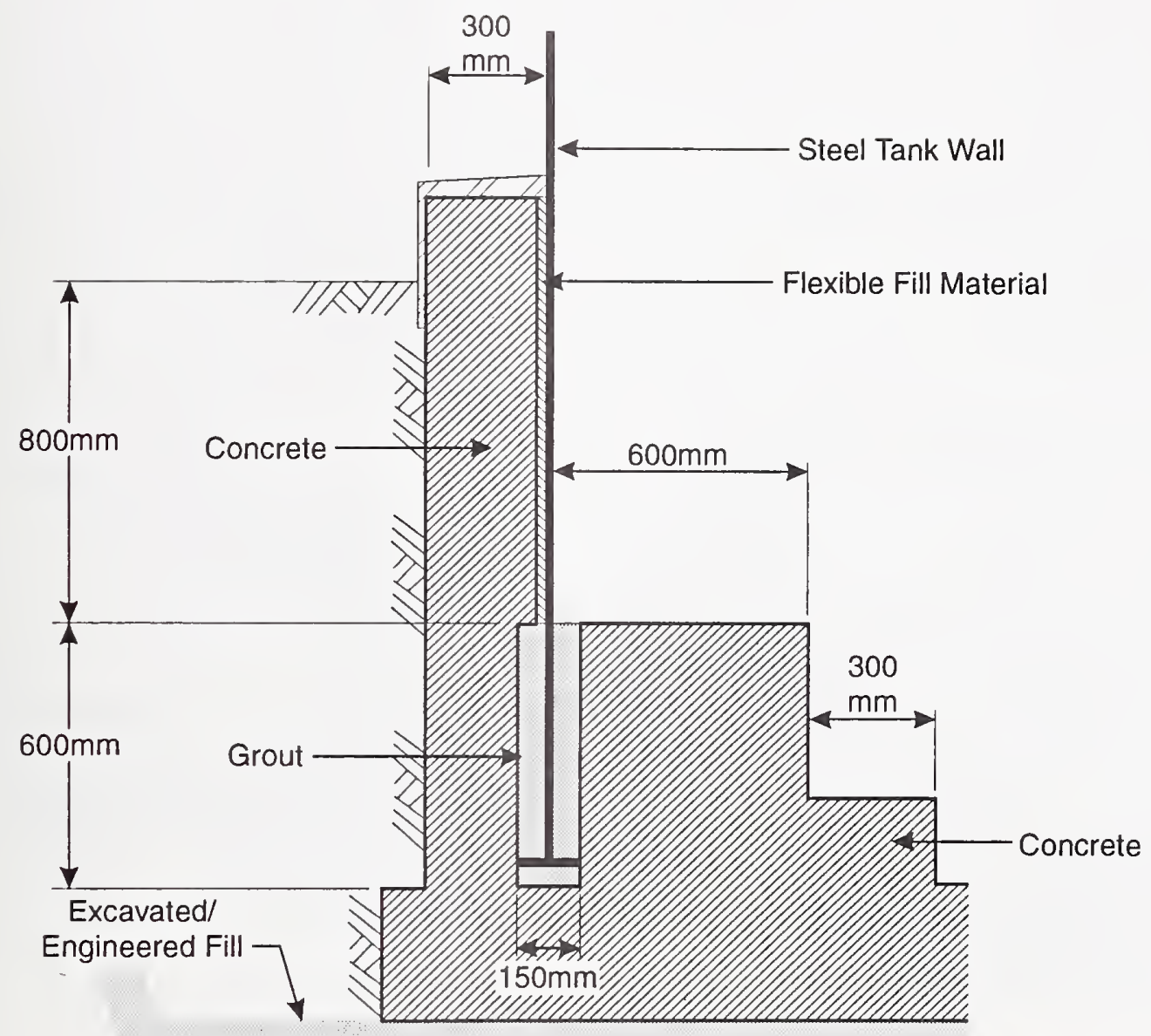

Figure 5.2.7

Tank section at Okuhirano Purification Plant. 


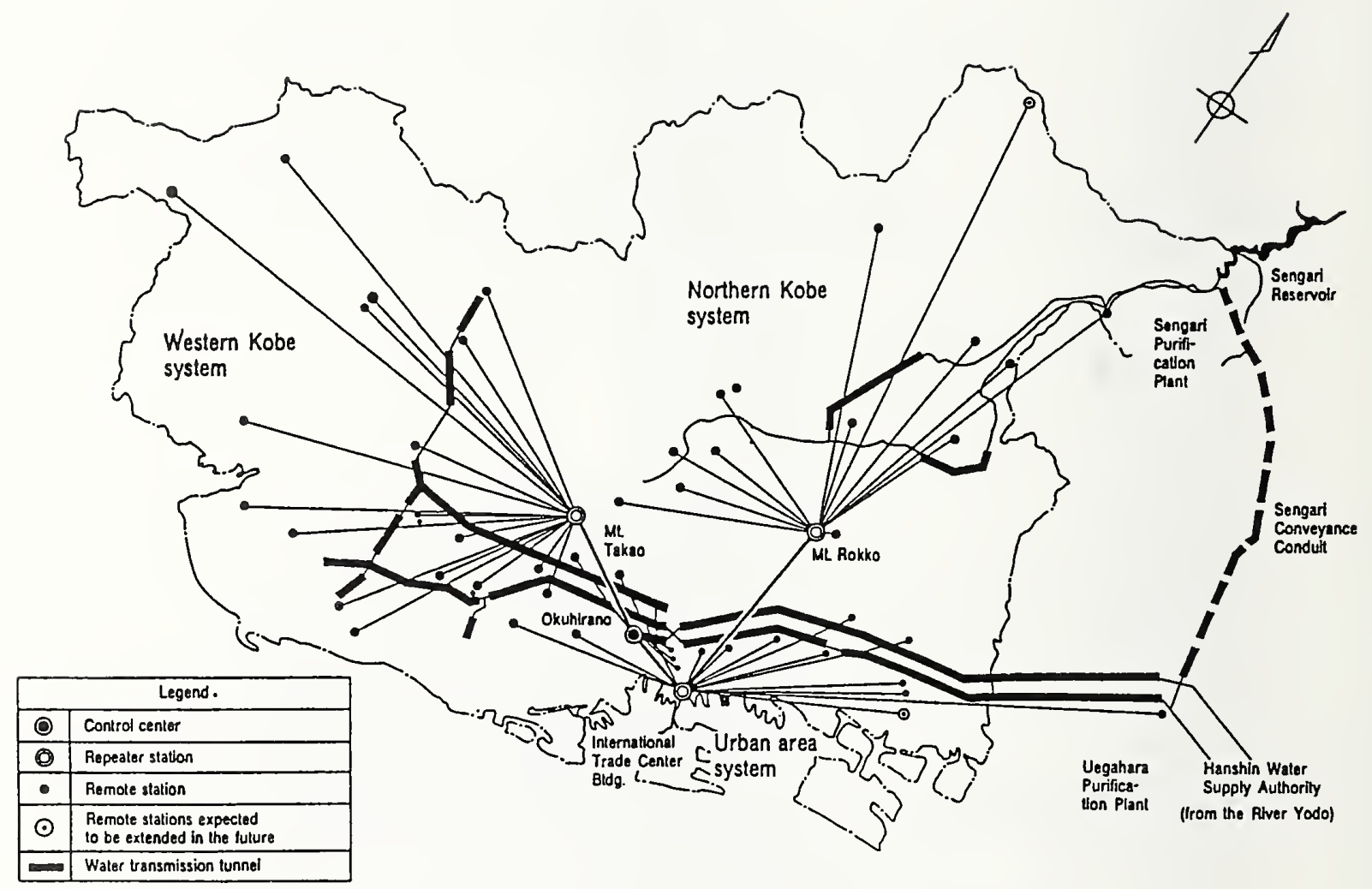




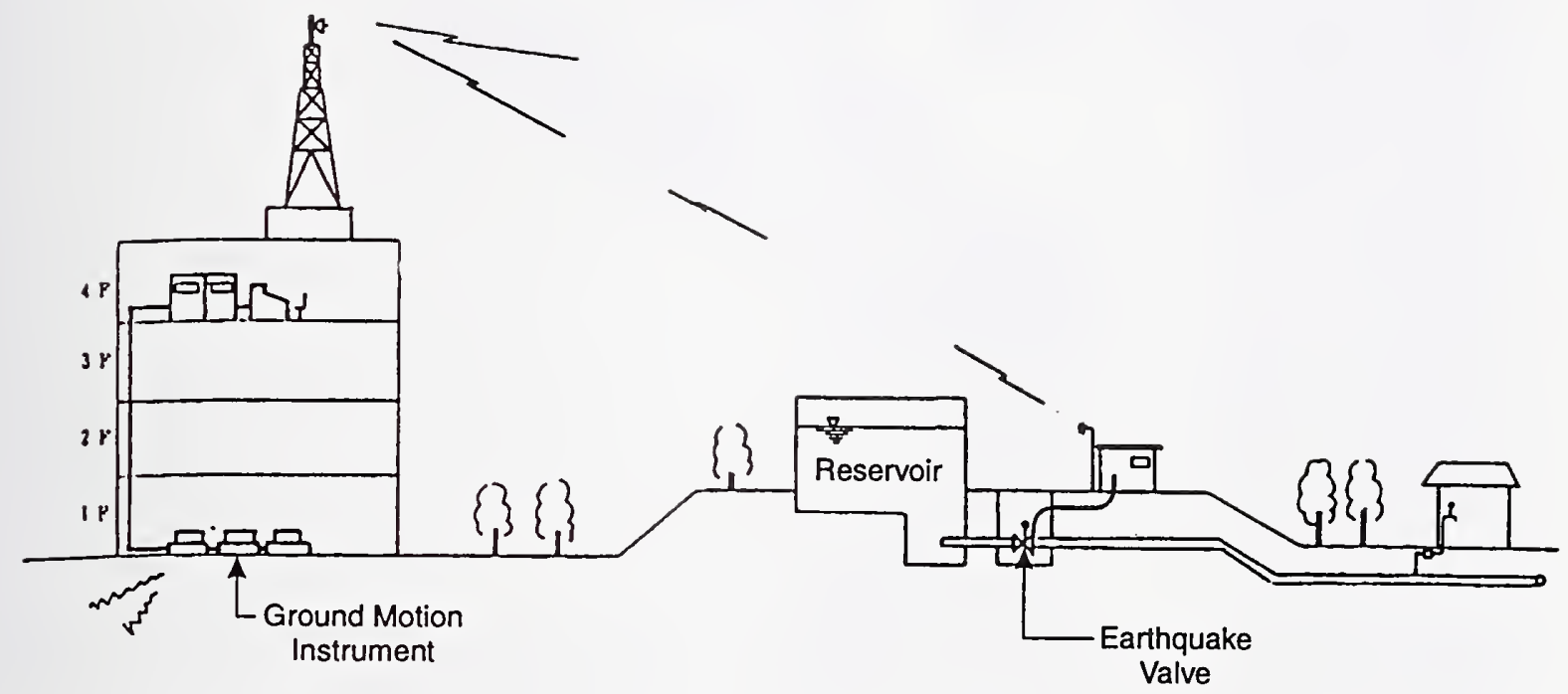

Figure 5.2.9 Schematic of typical communication from ground motion instrument, through radio communication, to the earthquake valve. 


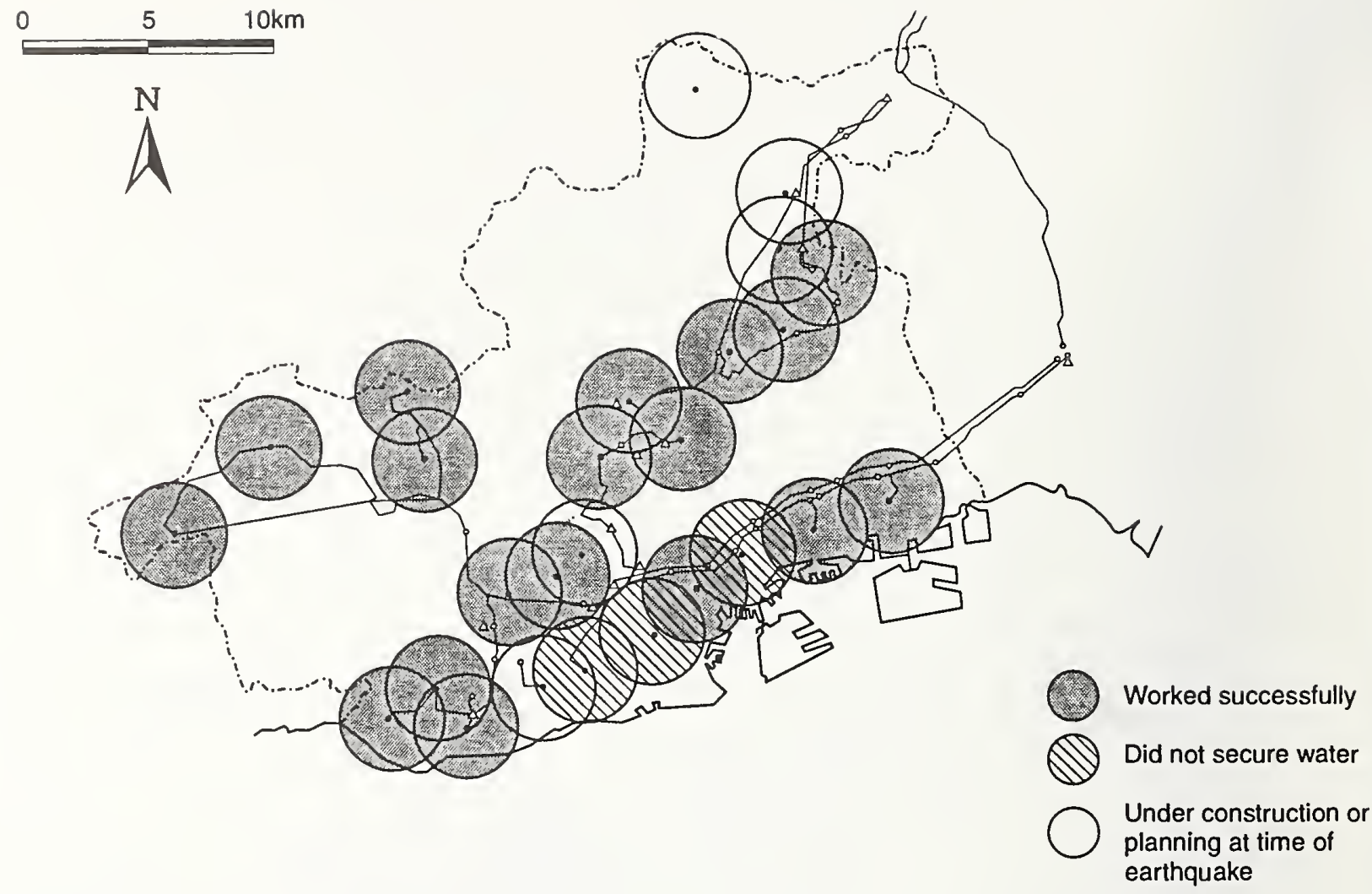

Figure 5.2.10 Map of Kobe water service area showing reservoirs with earthquake valves and their respective service area.

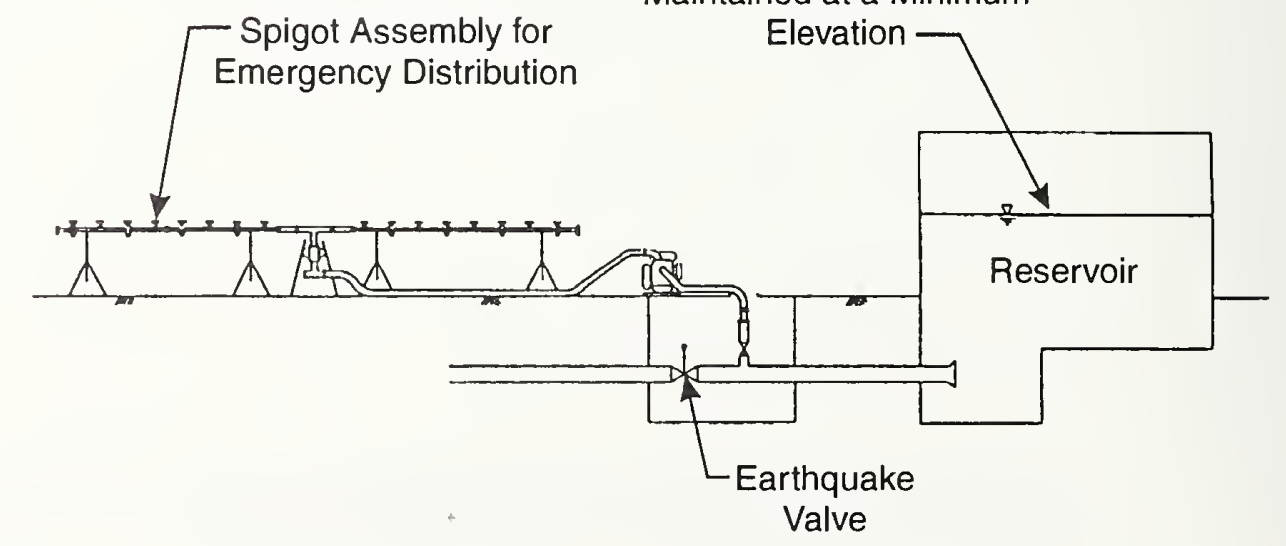

Figure 5.2.11 Schematic of water distribution from tank with earthquake valve. 


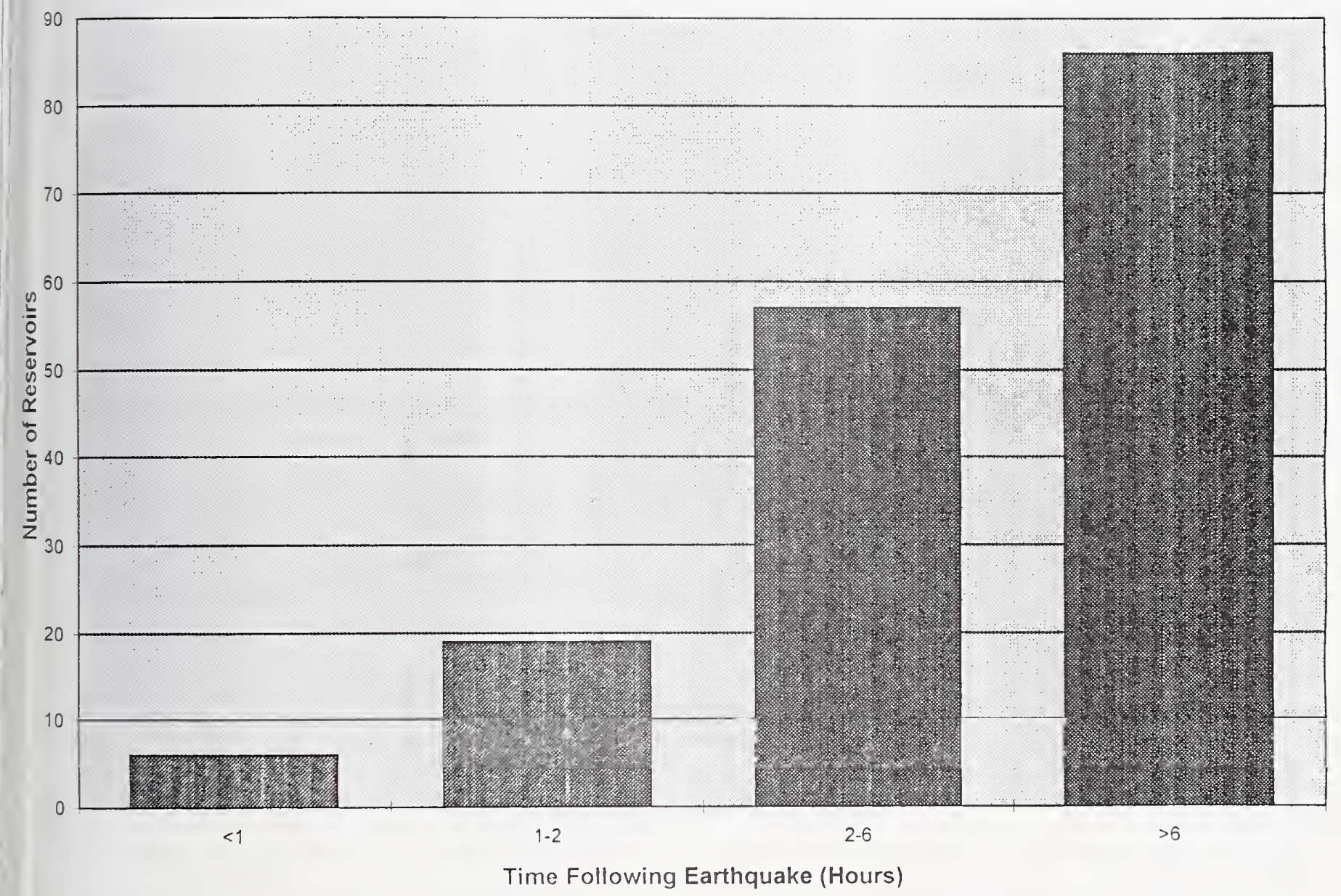

Figure 5.2.12 Water loss from reservoirs after Kobe earthquake. 


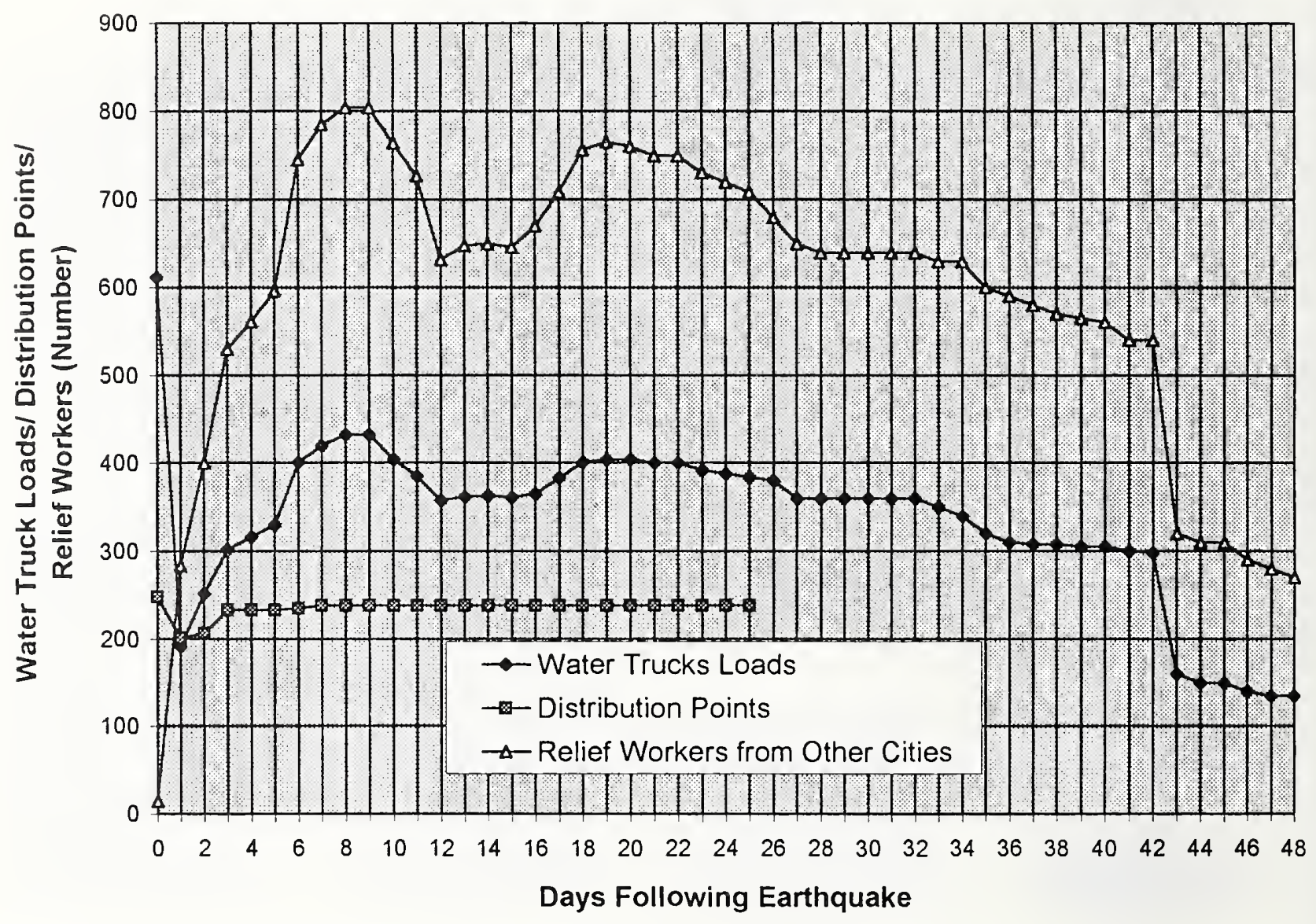

Figure 5.2.13 Status of emergency water supply. 


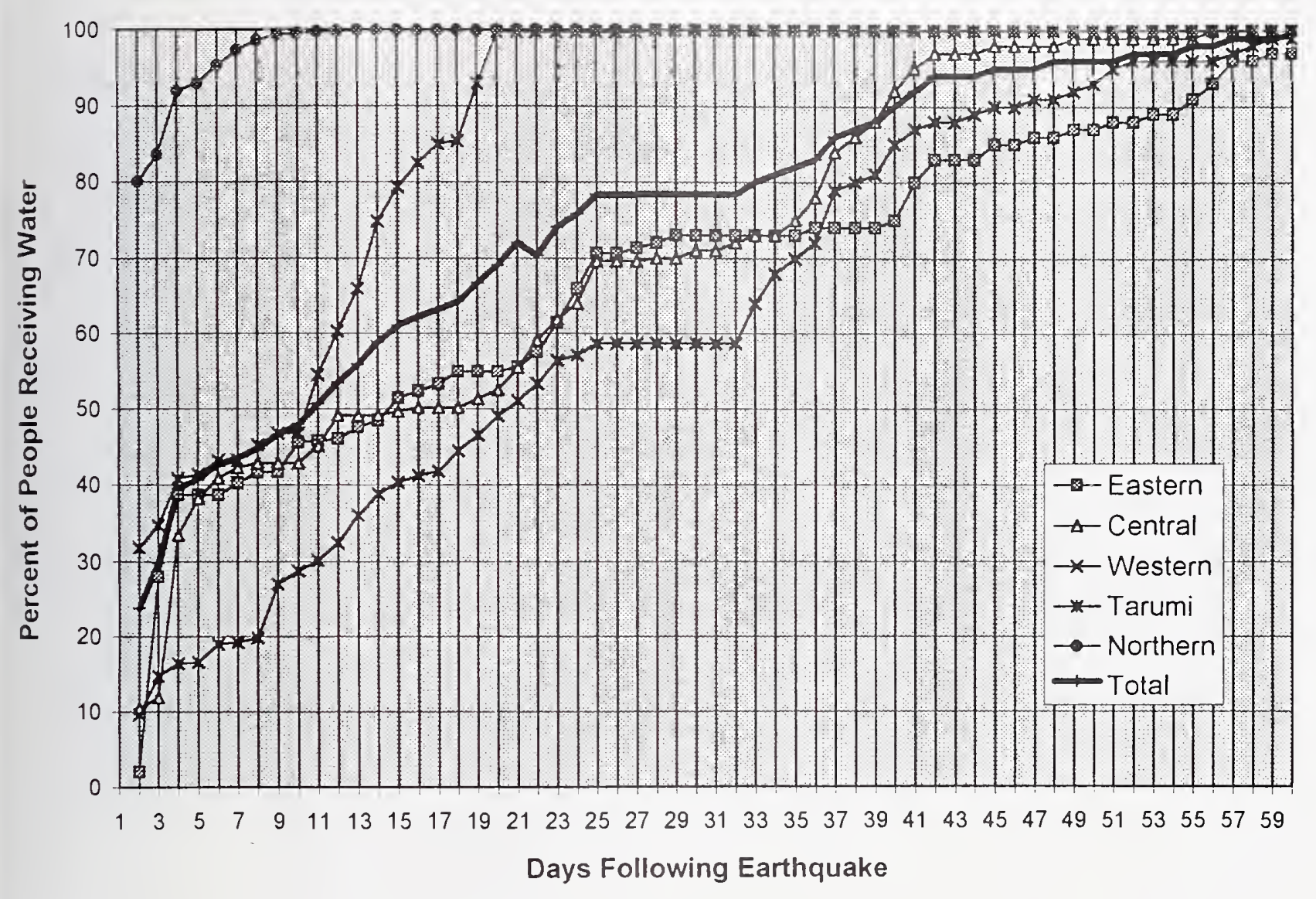

Figure 5.2.14 Percent of people in Kobe receiving water following earthquake. 


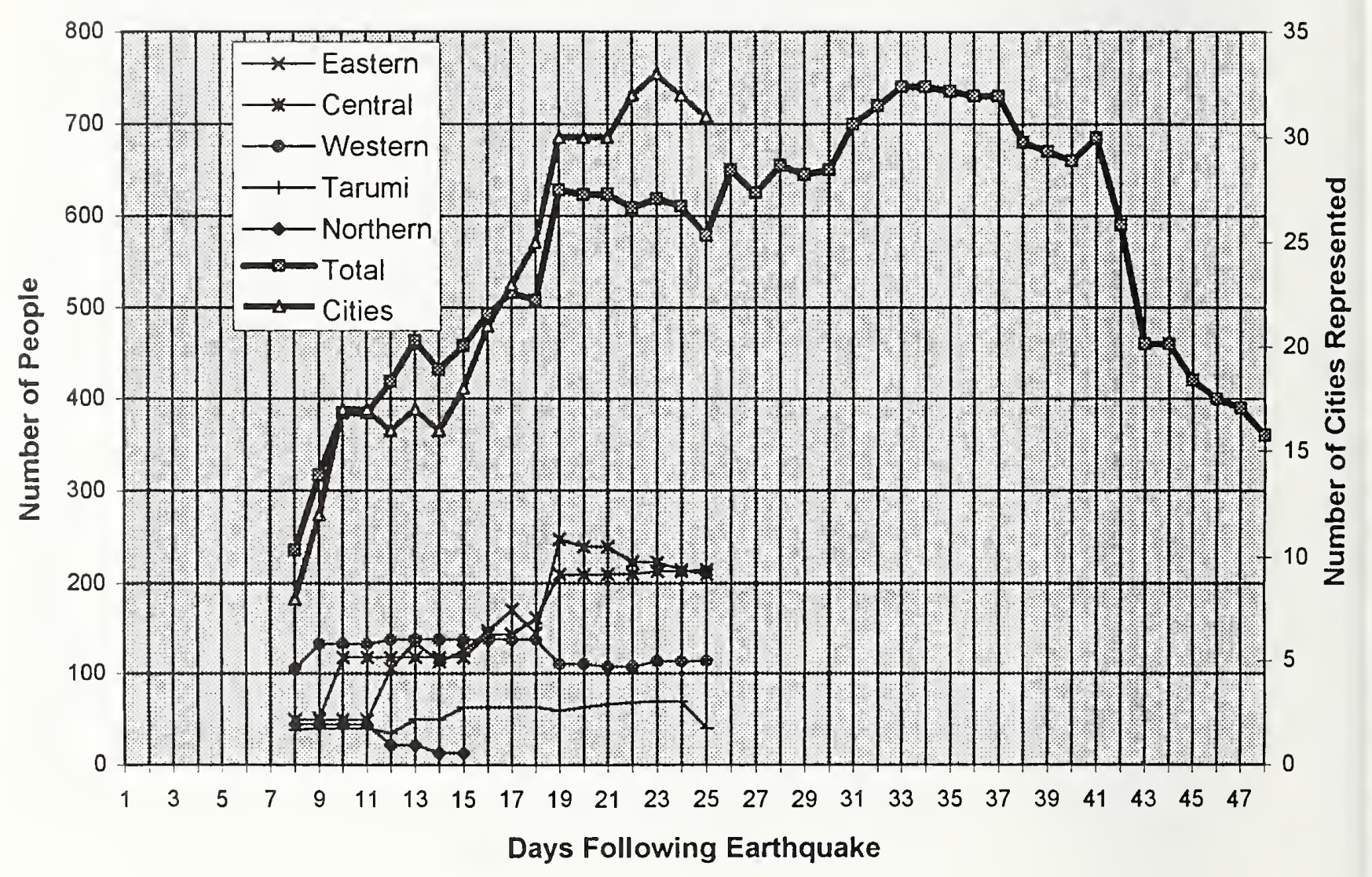

Figure 5.2.15 Mutual aid from other cities repairing the water distribution system. 


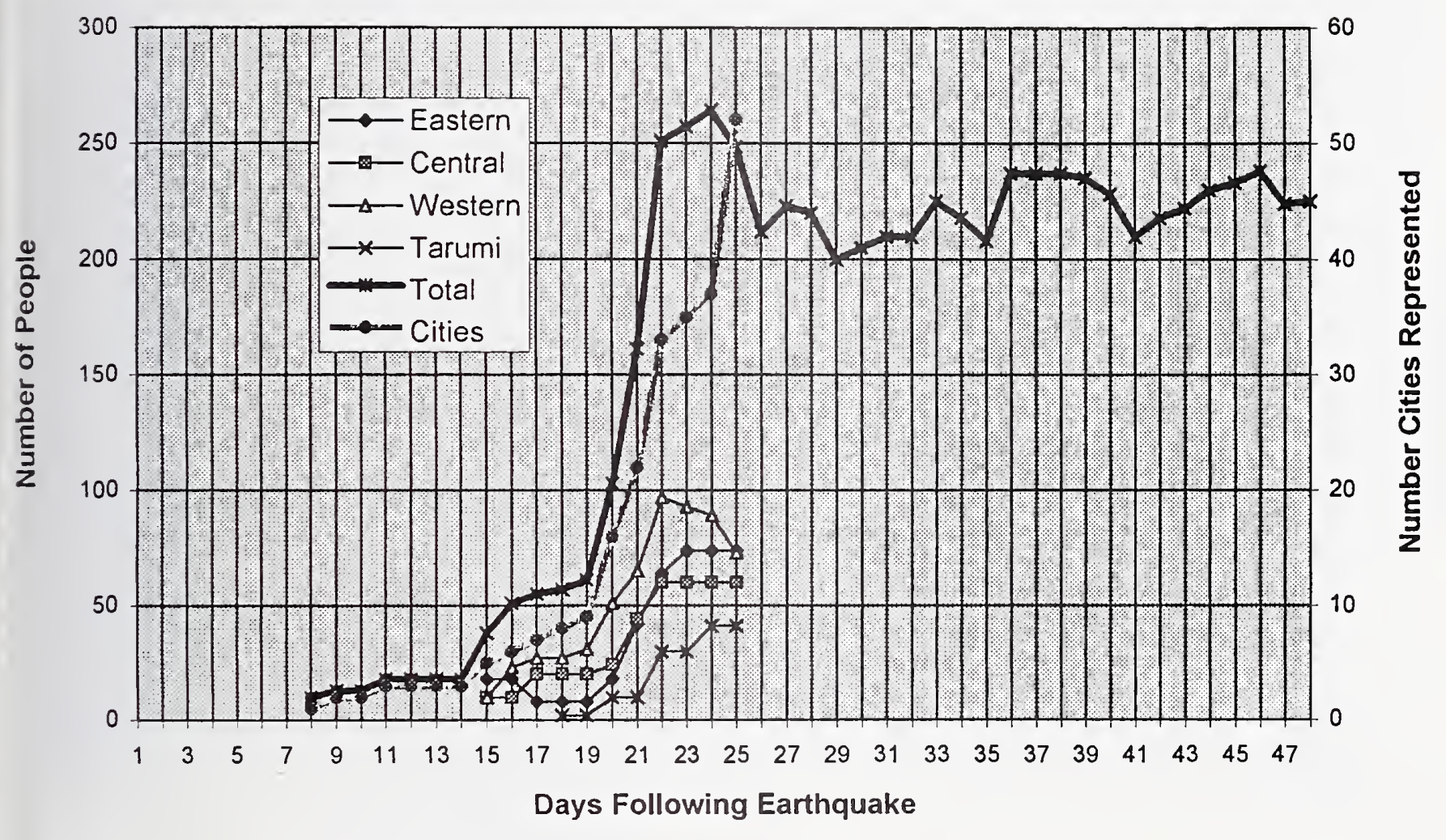

Figure 5.2.16 Mutual aid from other cities repairing the water supply system (purification plants, pump stations, and tanks). 


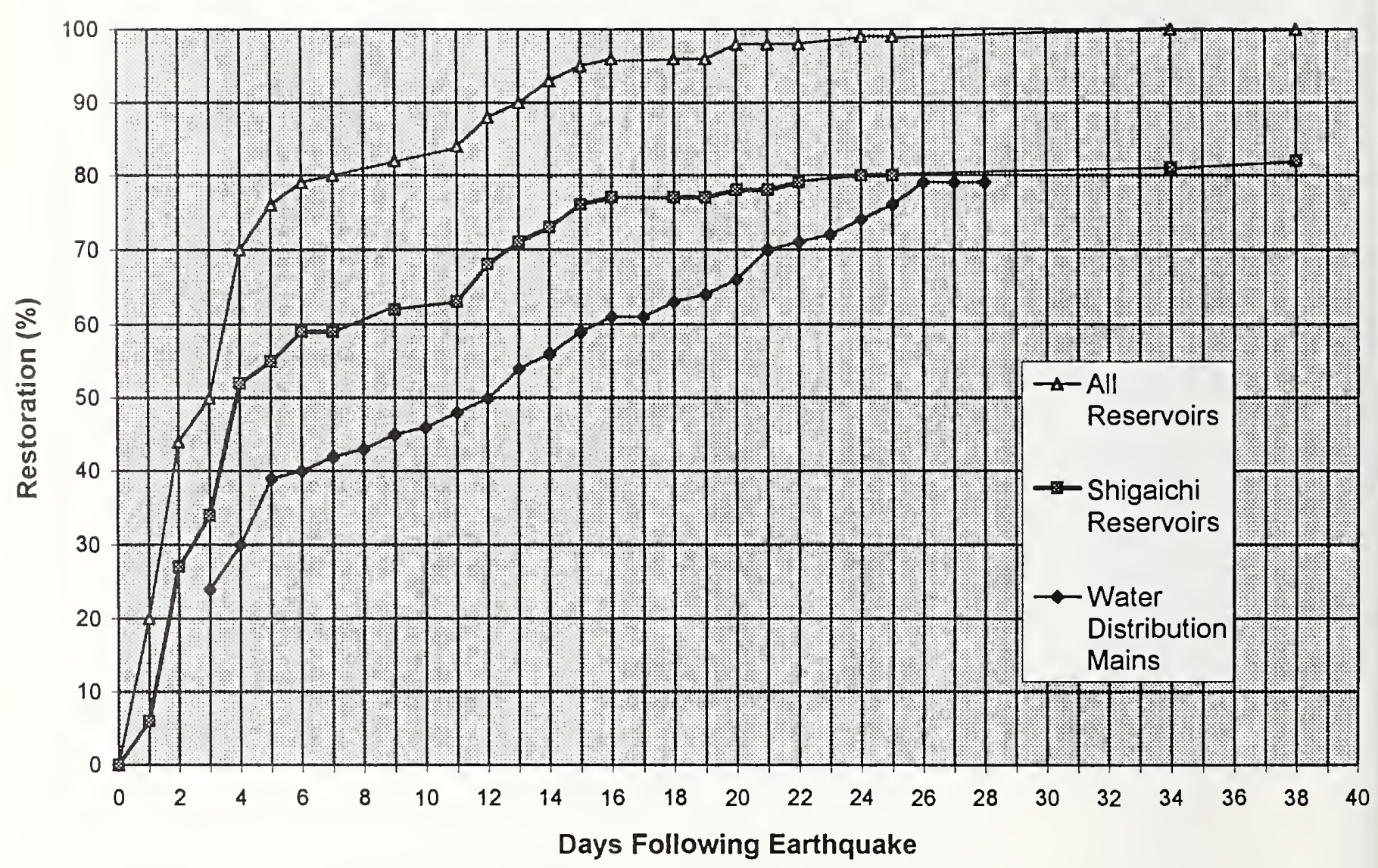

Figure 5.2.17 Restoration of distribution reservoirs and water mains. 


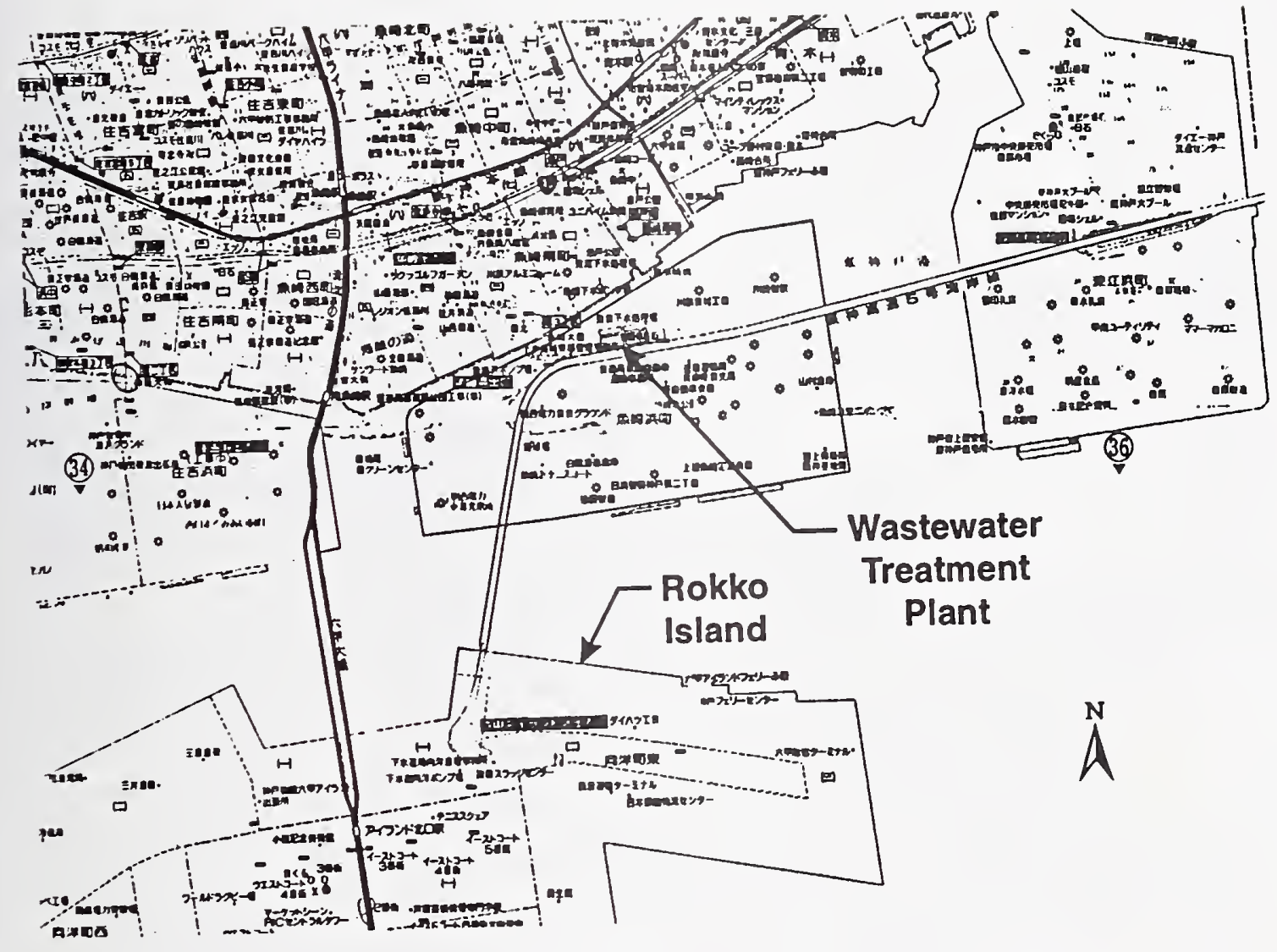

Figure 5.2.18

Location map for Higashinada Wastewater Treatment Plant. 


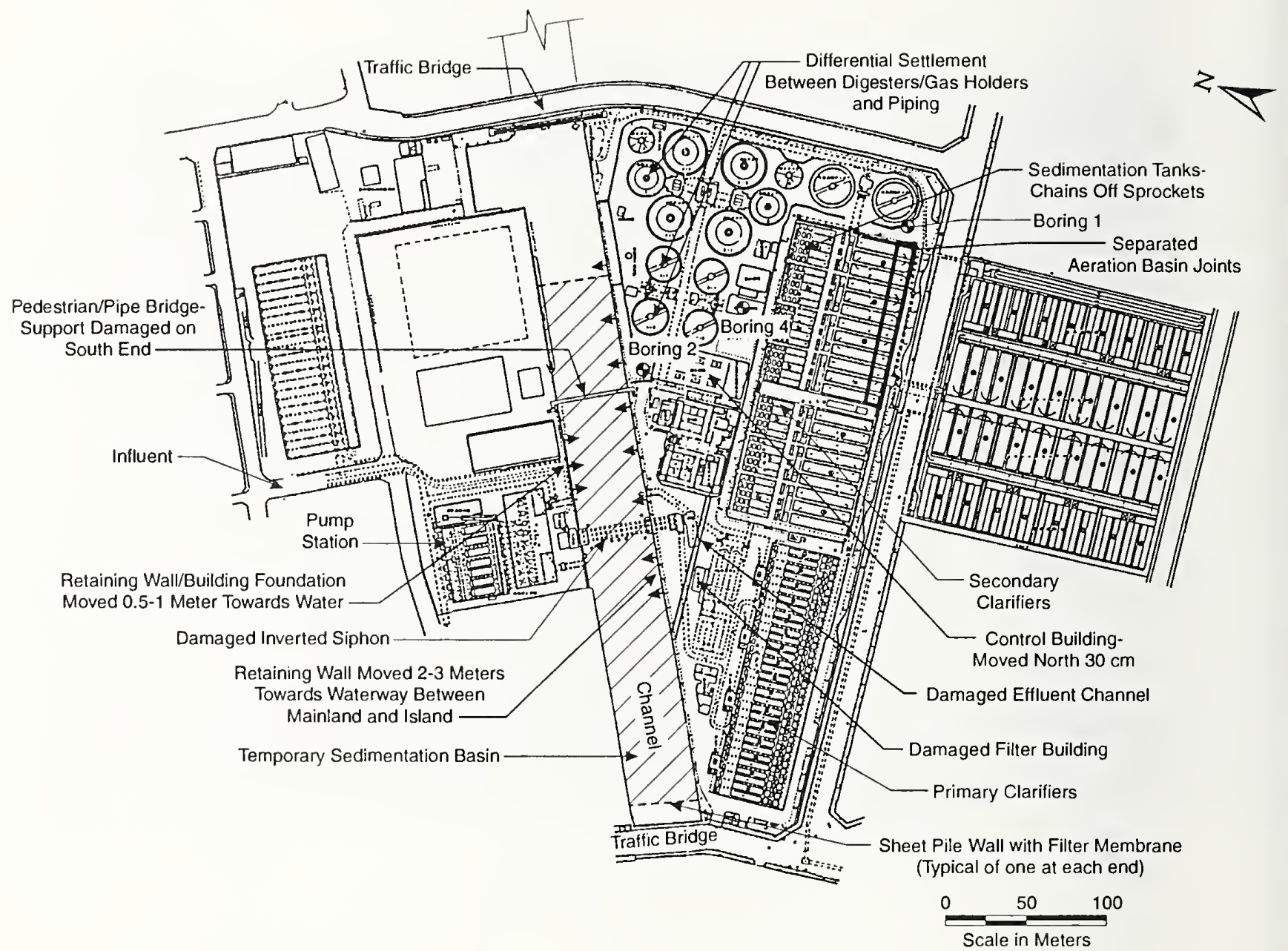

Figure 5.2.19 Higashinada Wastewater Treatment Plant site plan showing damage locations. 


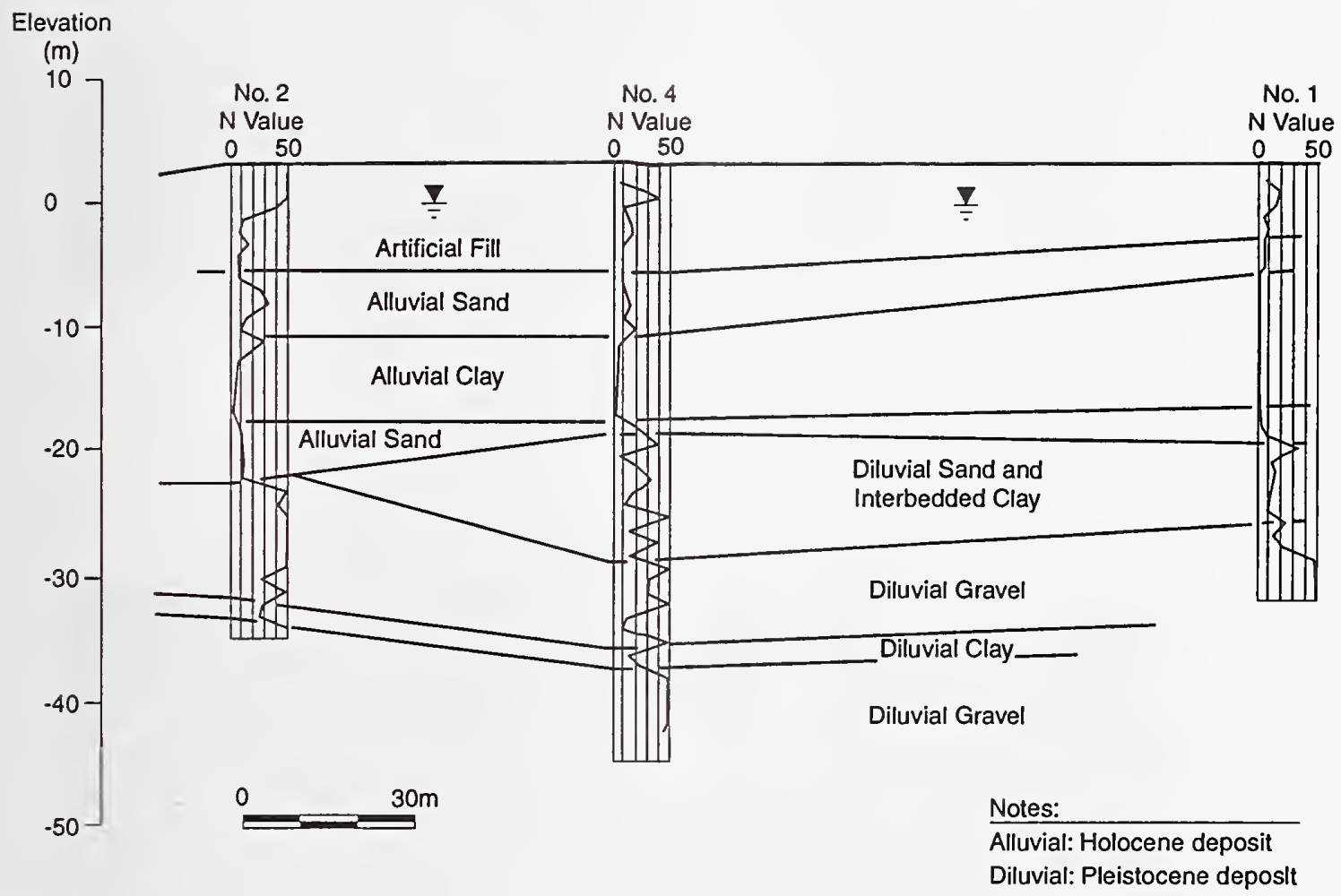

Figure 5.2.20

Soil profile at Higashinada Wastewater Treatment Plant. 


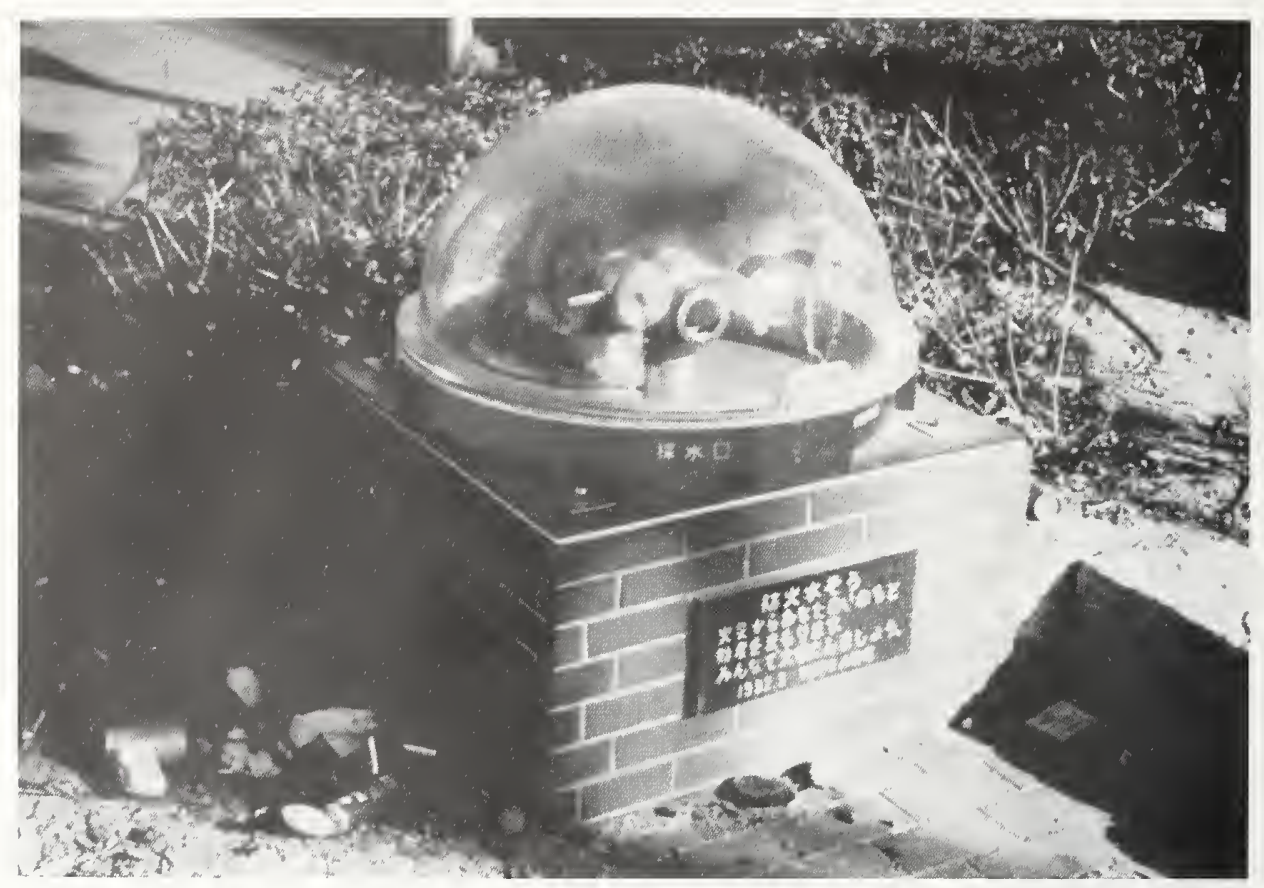

Photo 1 Cistern for water for fire protection in Kobe.

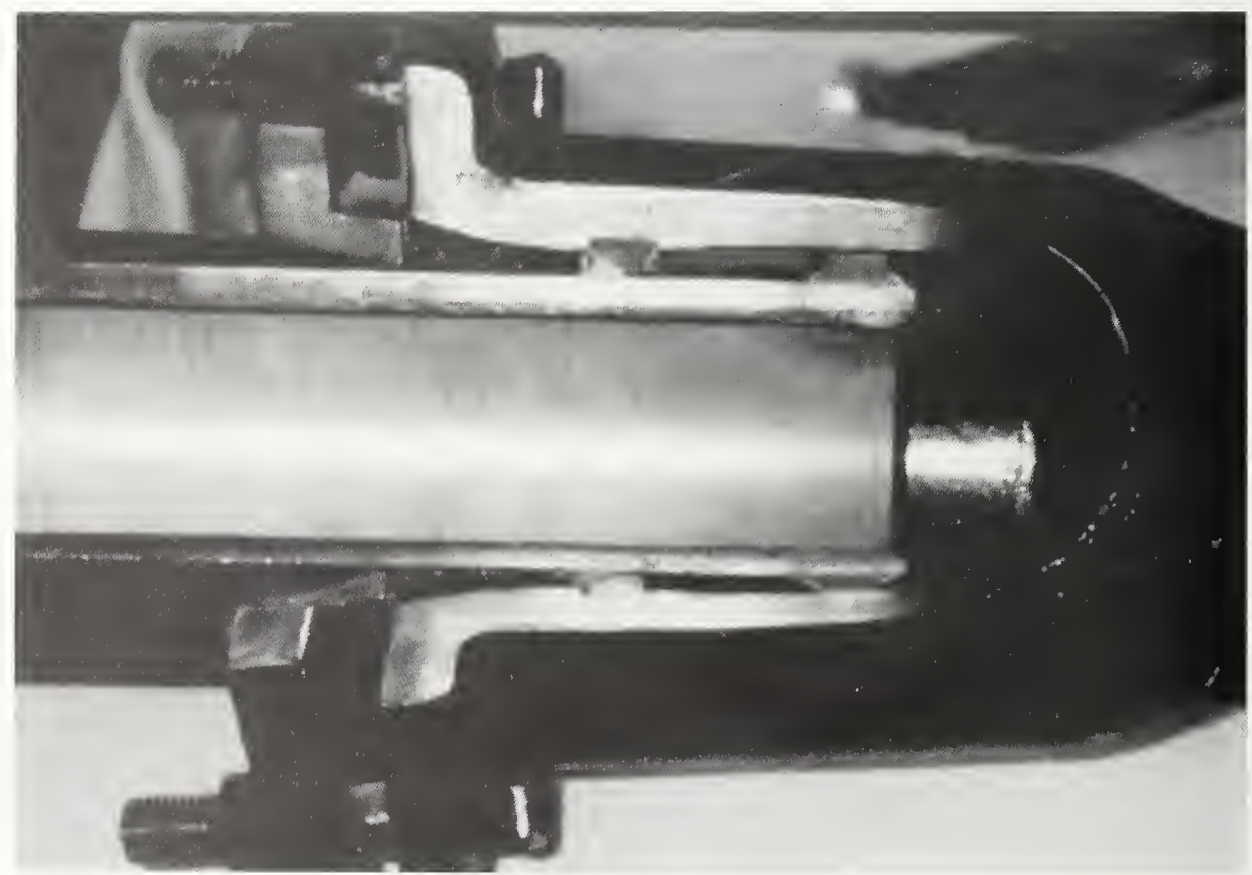

Photo 2 Type SII (seismic) joint. 


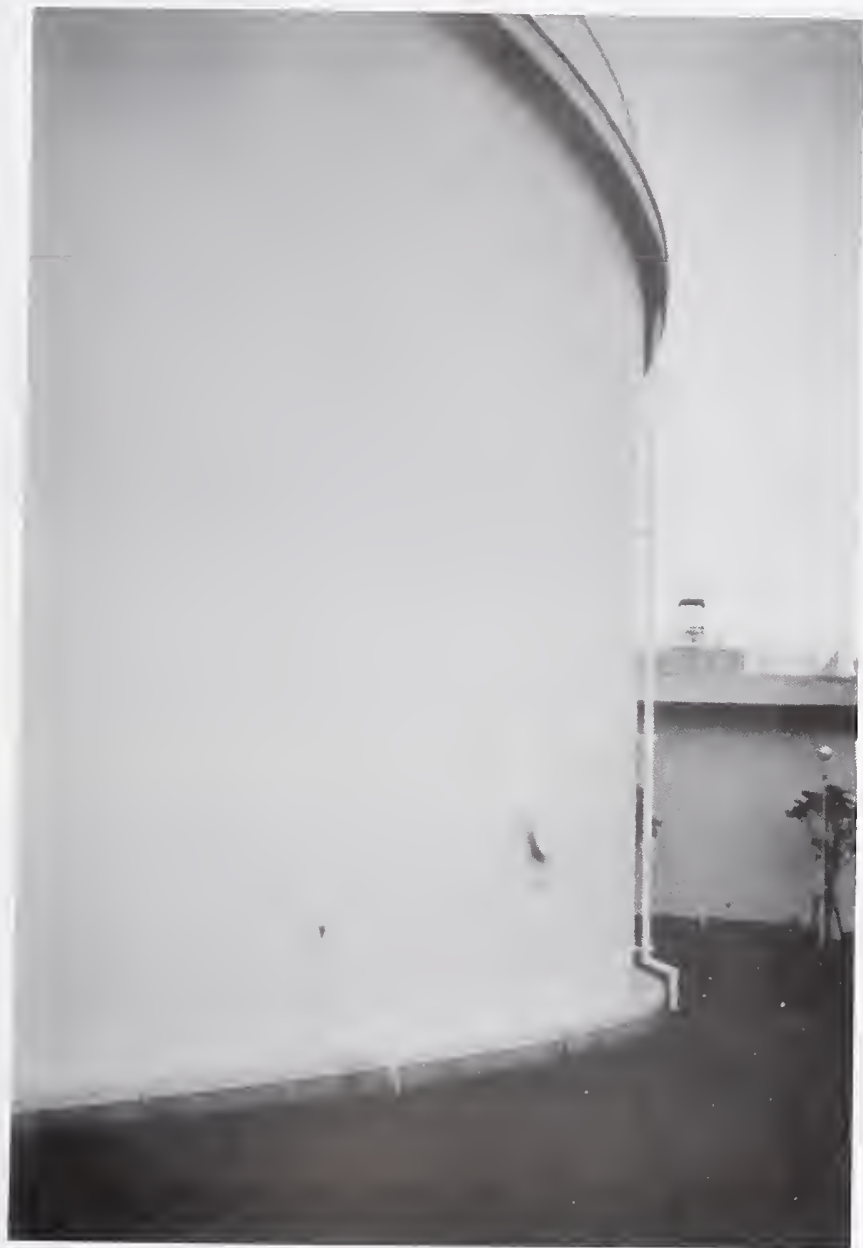

Photo 3 Steel water storage tank at Okuhirano Purification Plant, less than 7 years old. 


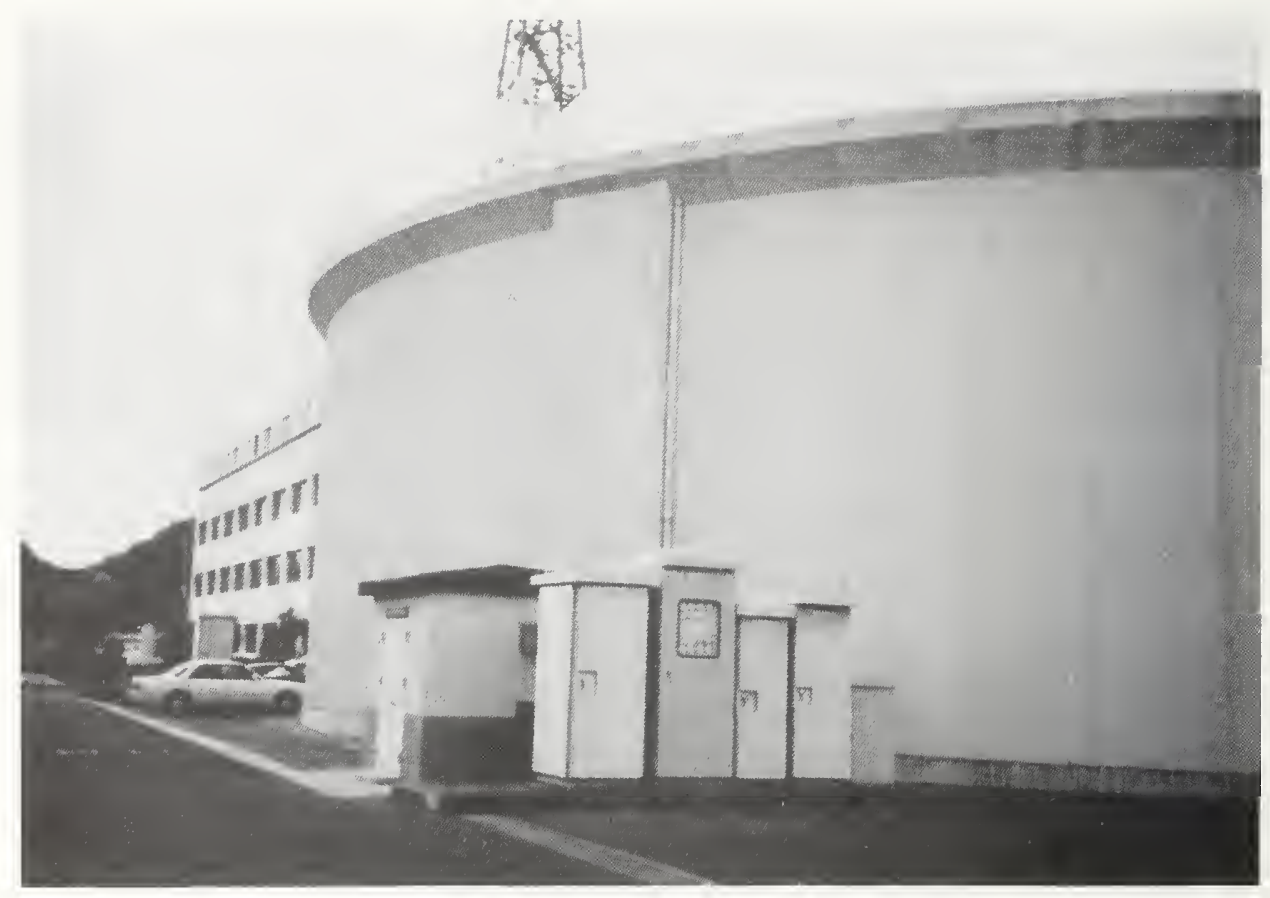

Photo 4 Concrete water storage tank at Okuhirano Purification Plant, less than 7 years old.

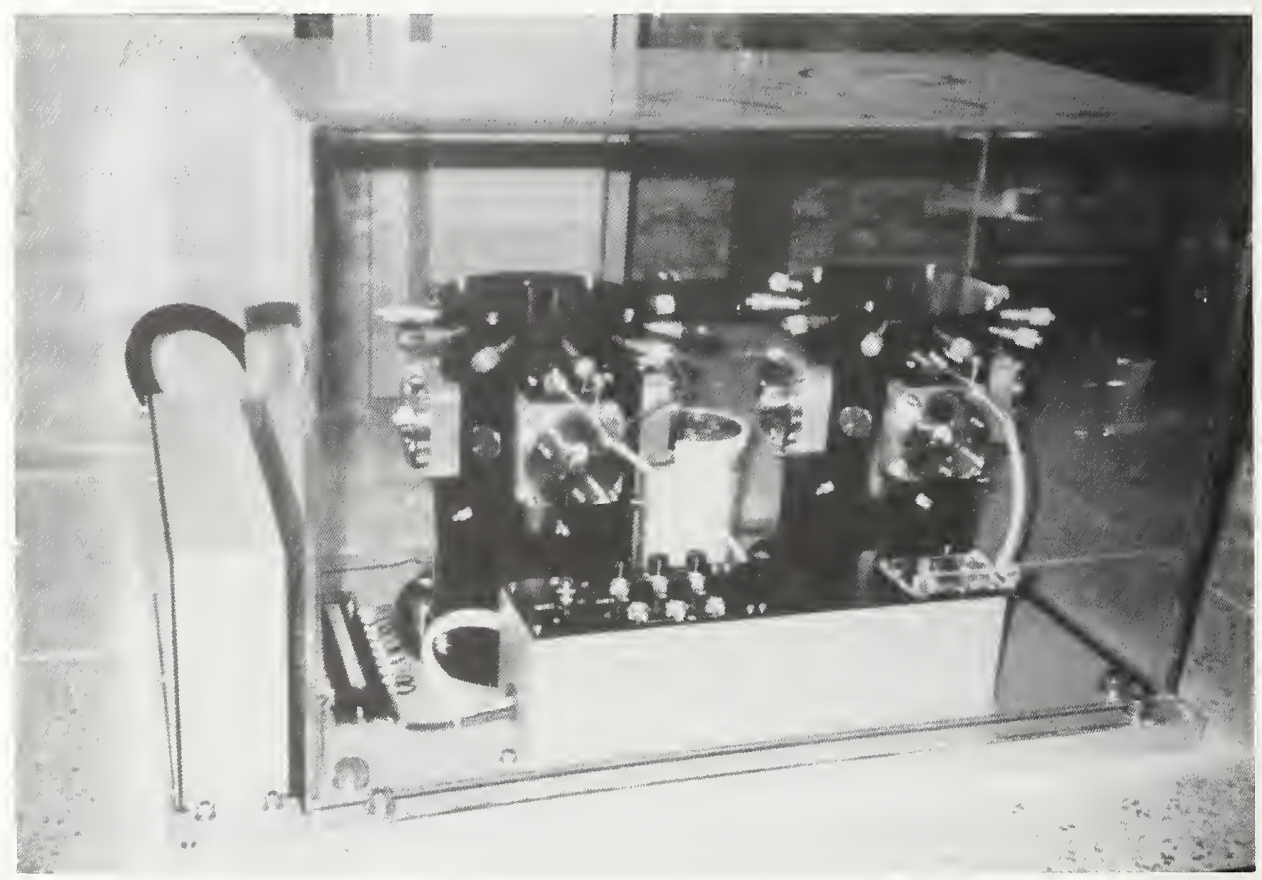

Photo 5 Seismograph at Okuhirano Control Center used for control of earthquake valves on reservoirs. 


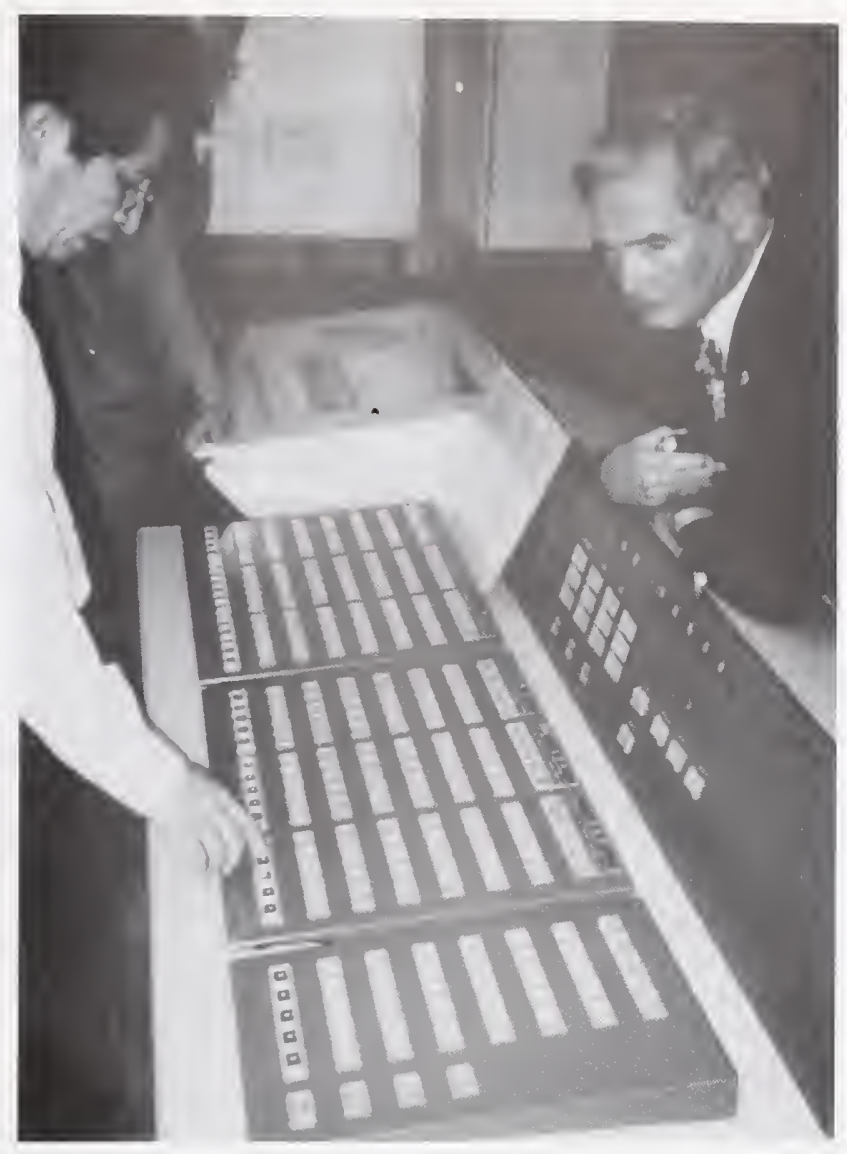

Photo 6 Control Panel for earthquake valves to provide flexibility to control automatically or by operations staff in Okuhirano Control Center.

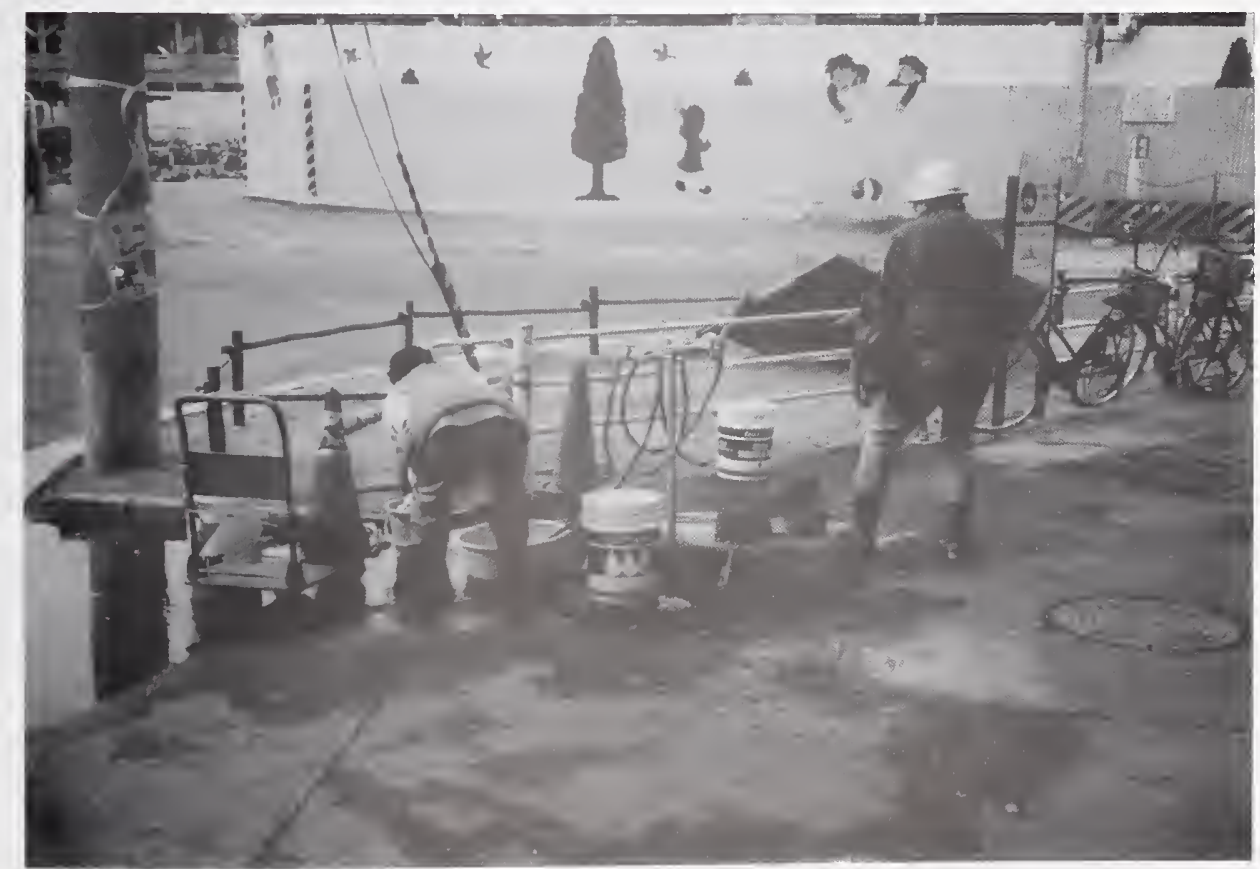

Photo 7 Person collecting water from central water distribution point near the collapsed Daikai Subway Station. 


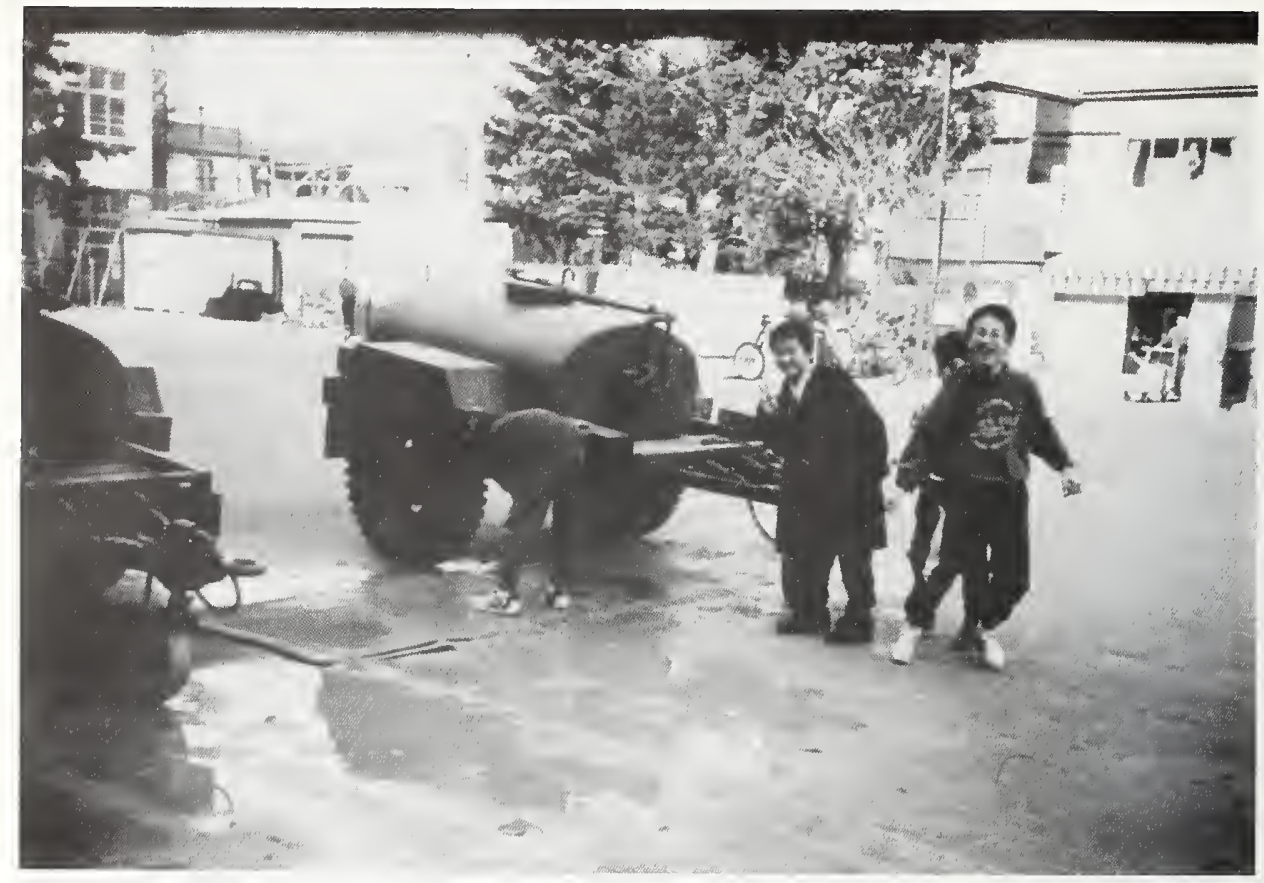

Photo $8 \quad$ Emergency water supply delivered in tank trailer.

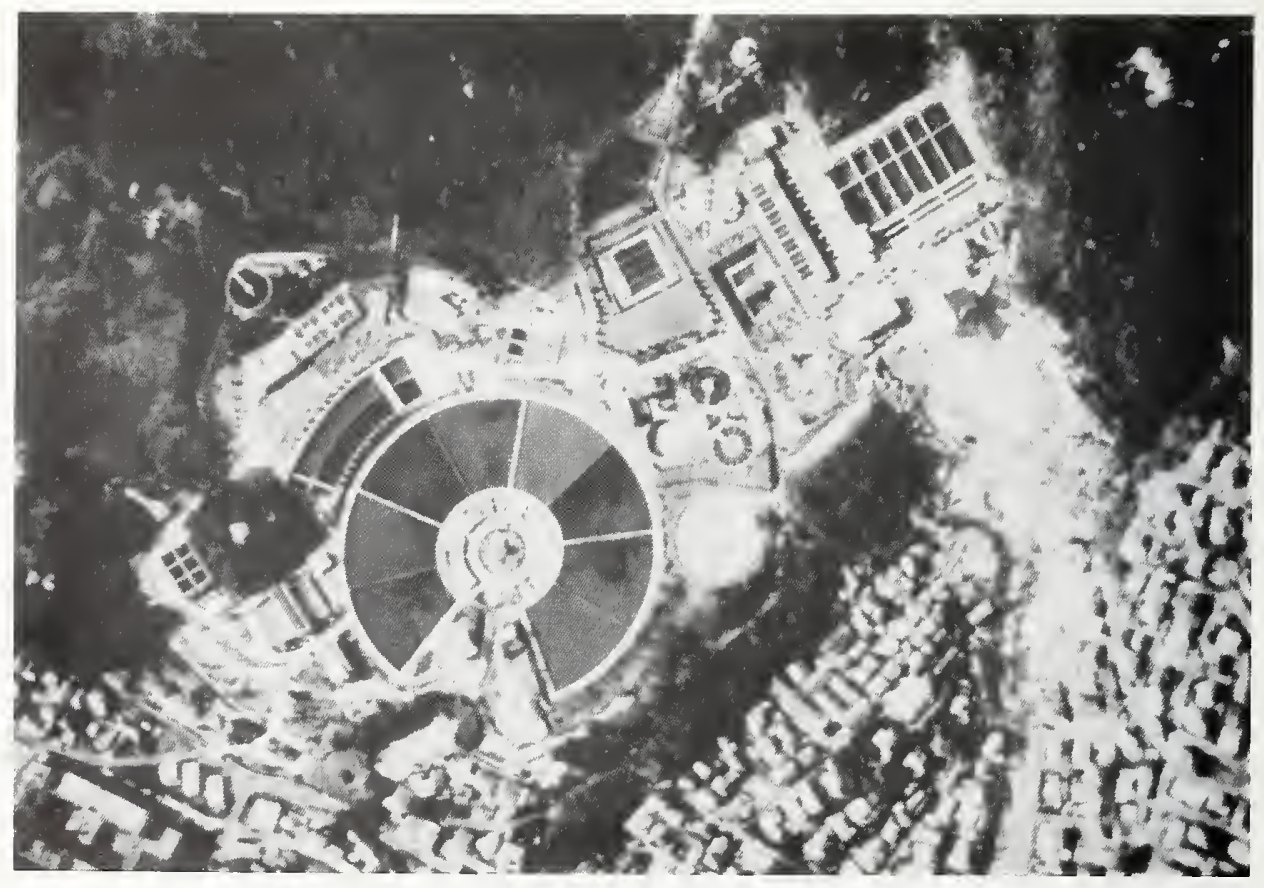

Photo 9 Aerial view of Kobe's Uegahara Water Purification Plant (lower left) with the Hanshin (Kabutoyama) Water Purification Plant immediately adjacent (upper right). The landslide that undercut the Hanshin (Kabutoyama) Plant's solids handling building is evident. The area at about 10:00 O'clock outside the circular basin settled approximately $30 \mathrm{~cm}$, separating joints on three $1.2 \mathrm{~m}$ diameter pipelines over a lengtl of approximately $100 \mathrm{~m}$, and damaging the solids handling building. 


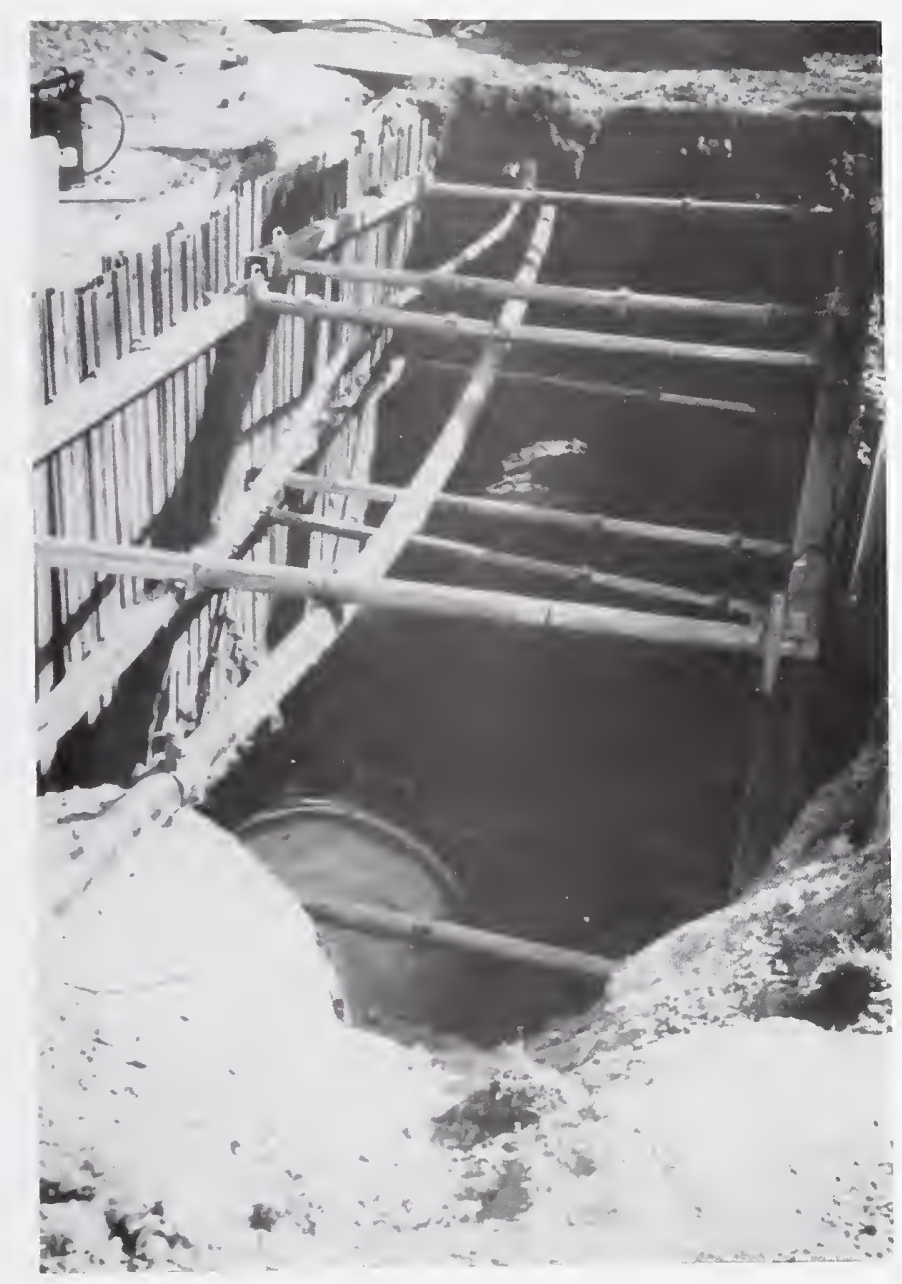

Photo $10 \quad$ Repair of one of the three $1.2 \mathrm{~m}$ treated water lines leaving the Uegahara/Hanshin Plants site. 


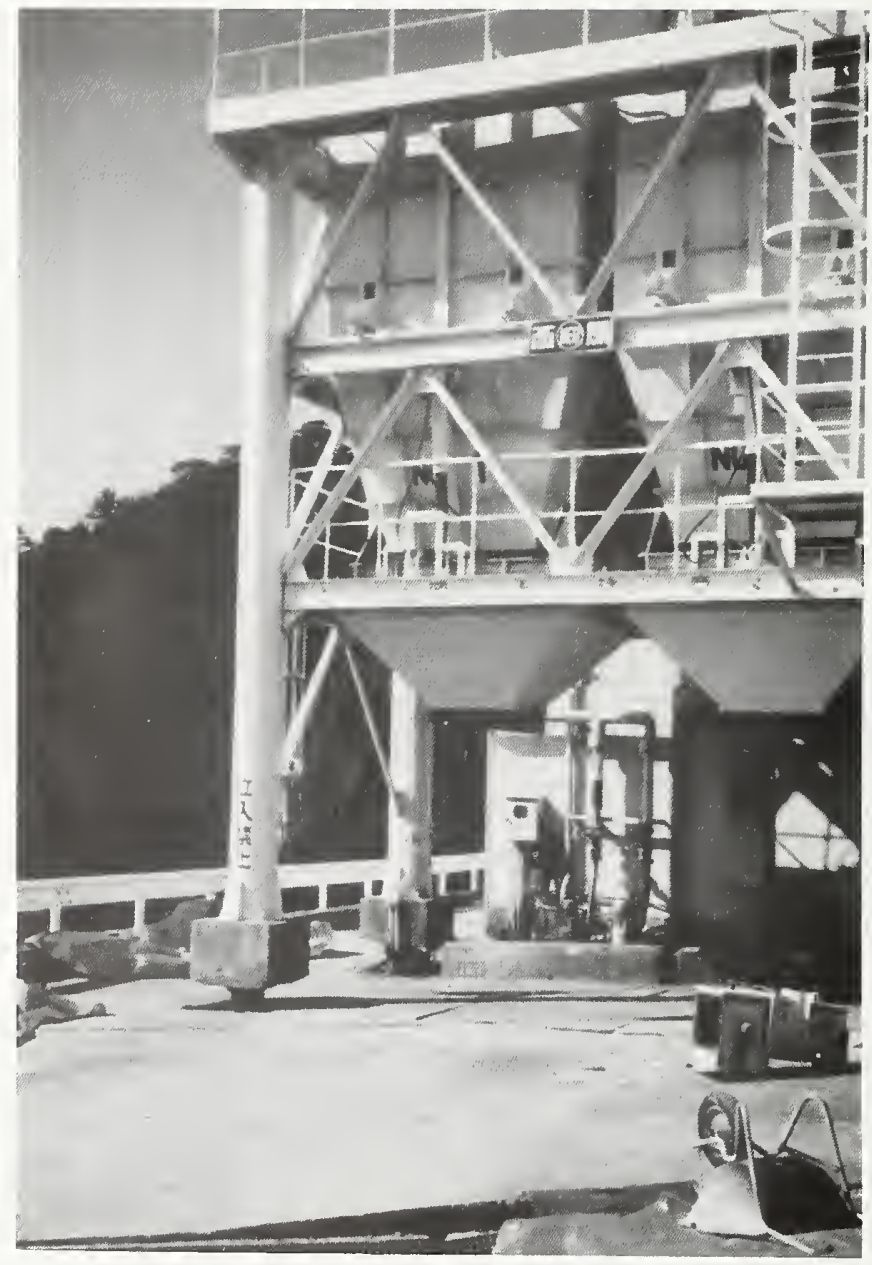

Photo 11 Subsidence (approximately $30 \mathrm{~cm}$ ) around pile-supported sludge hoppers at Uegahara Plant. 


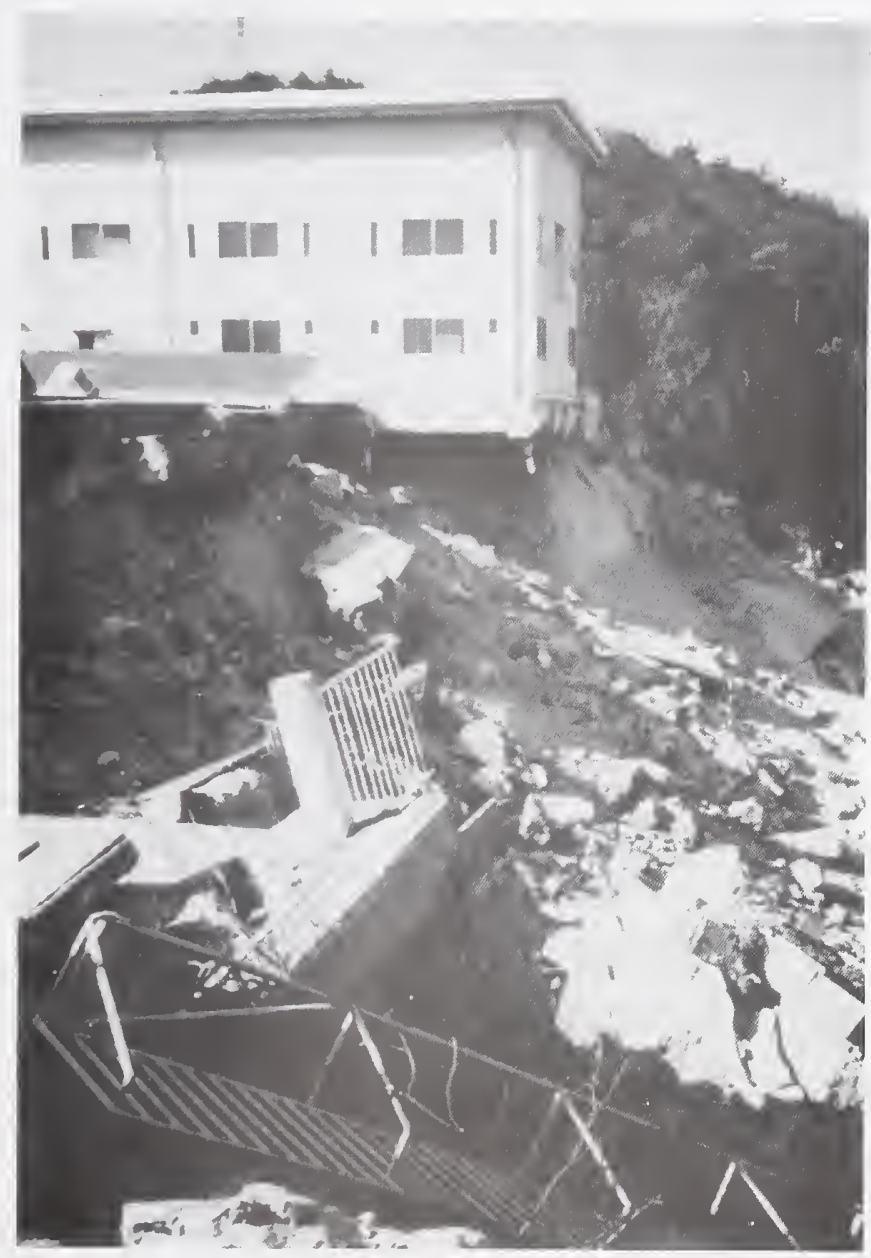

Photo 12 Landslide undermined solids handling building at the Hanshin (Kabutoyama) Plant. 


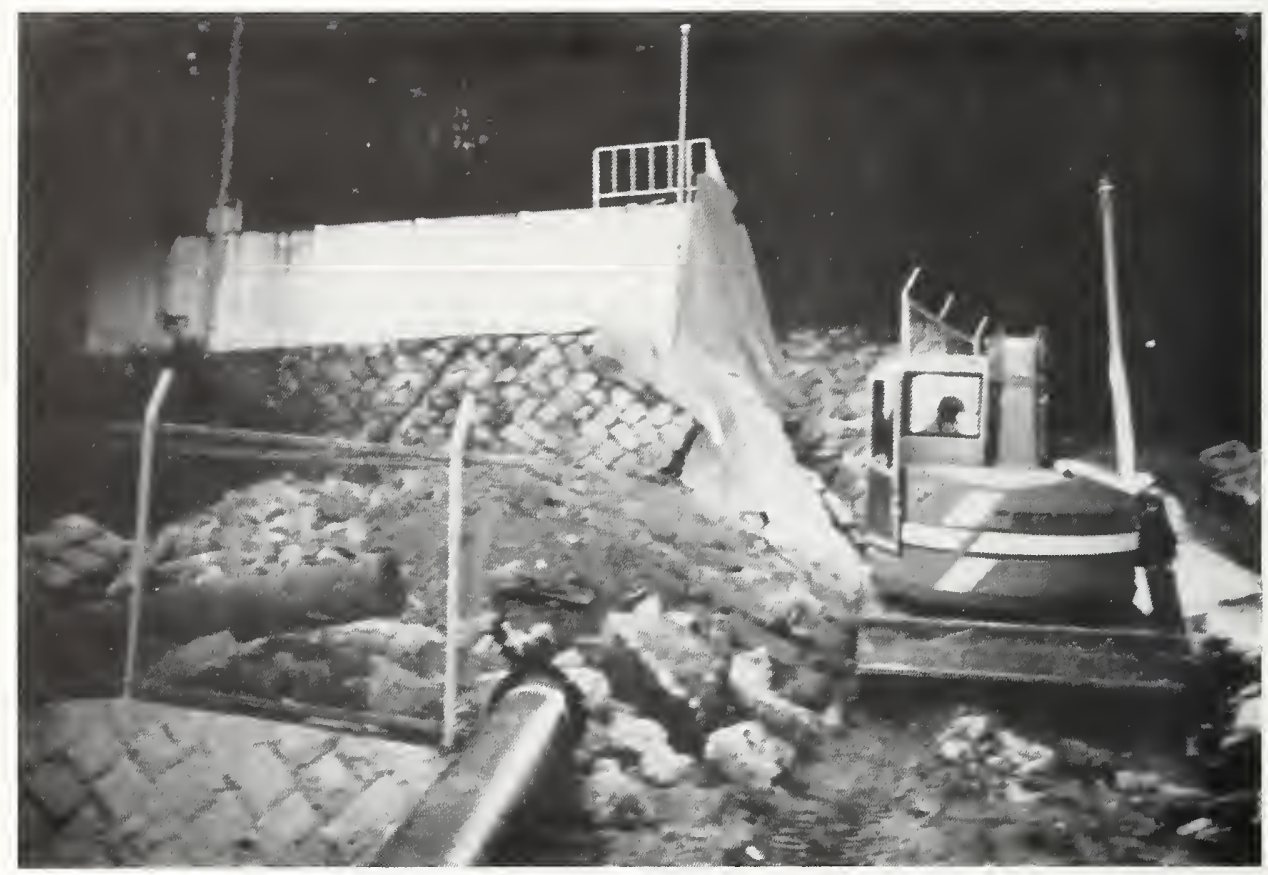

Photo 13 Broken lines to/from backwash tank at the Motoyama Water Purification Plant.

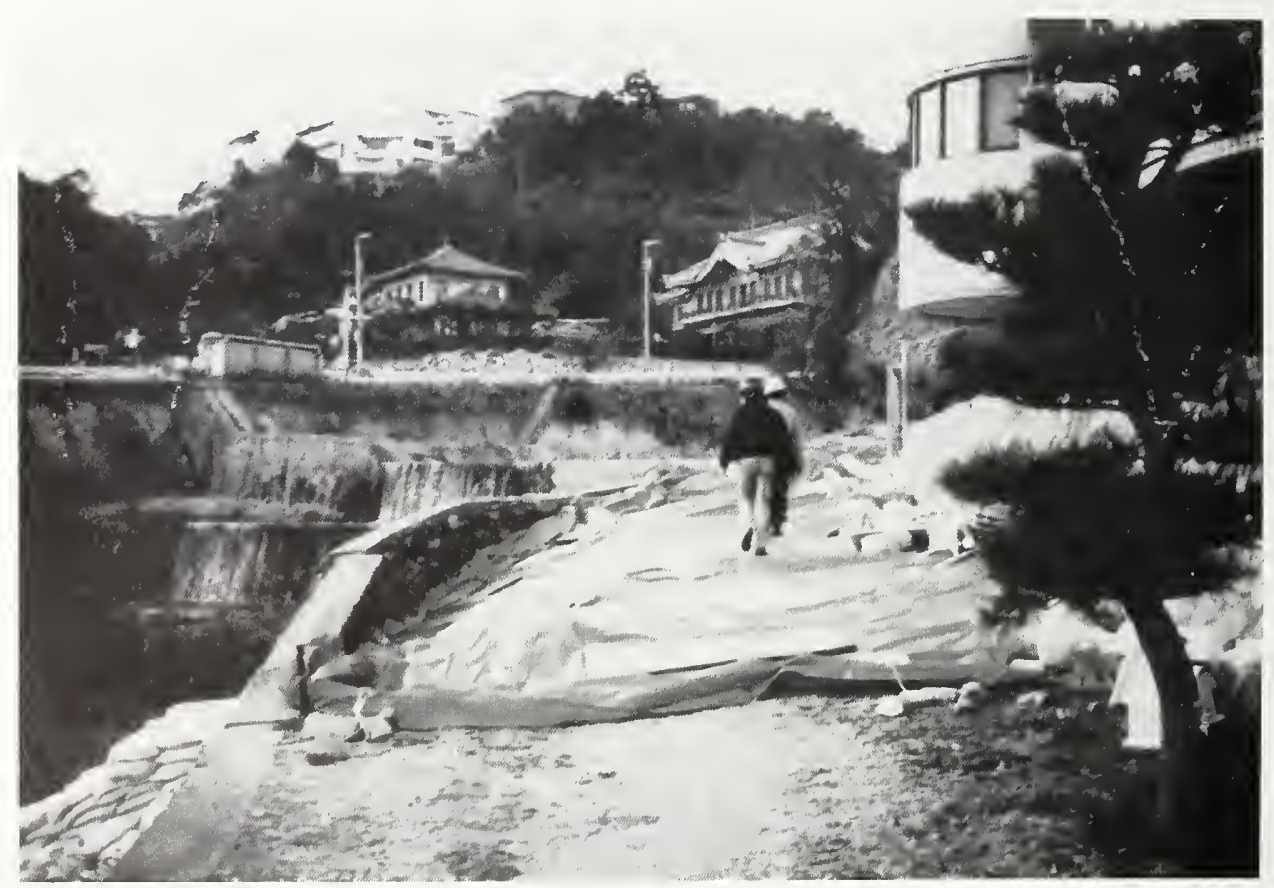

Photo 14 The retaining wall on the left cracked damaging the overflow line from the Motoyama Plant's intake box. 


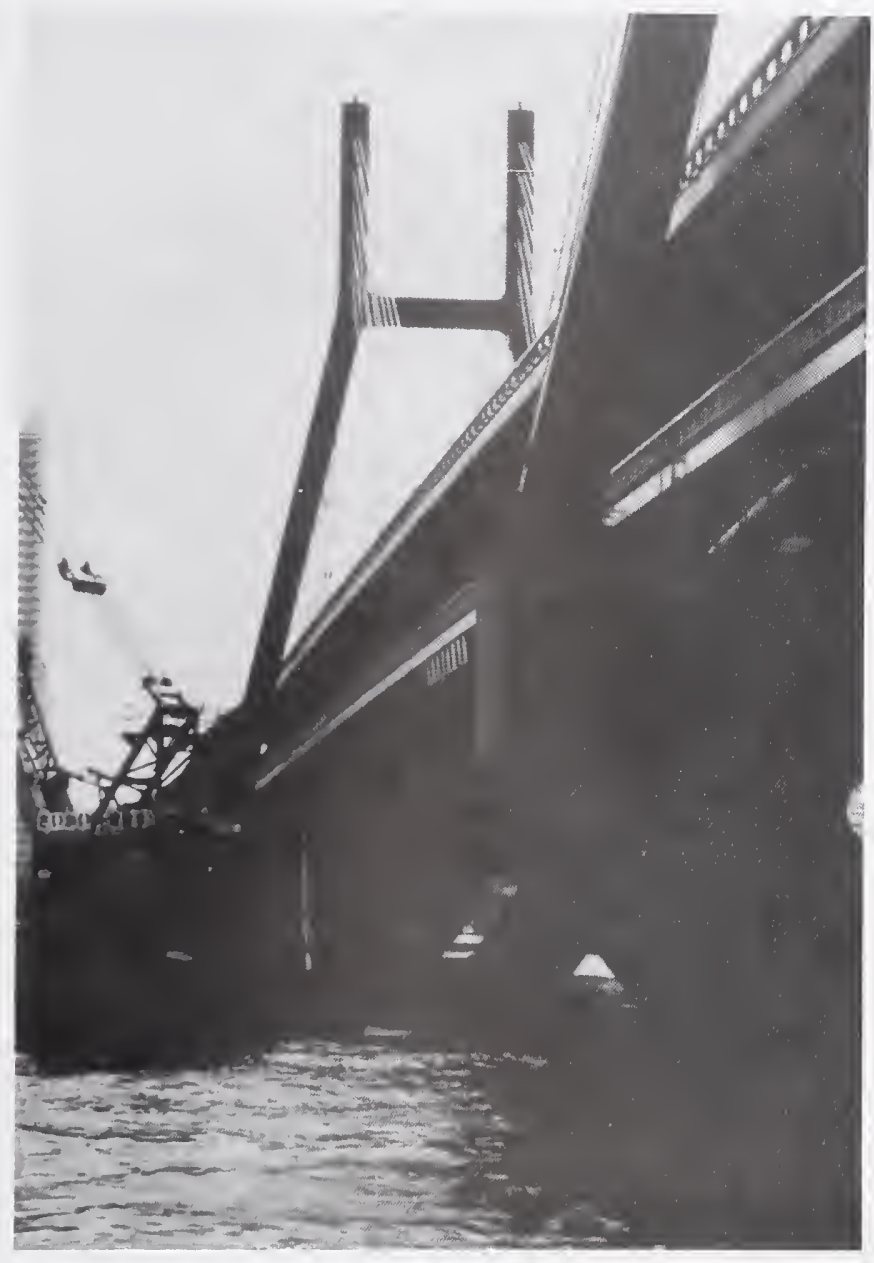

Photo 15 Pipe hanging from bridge to Rokko Island (just to the right of crane cab). 


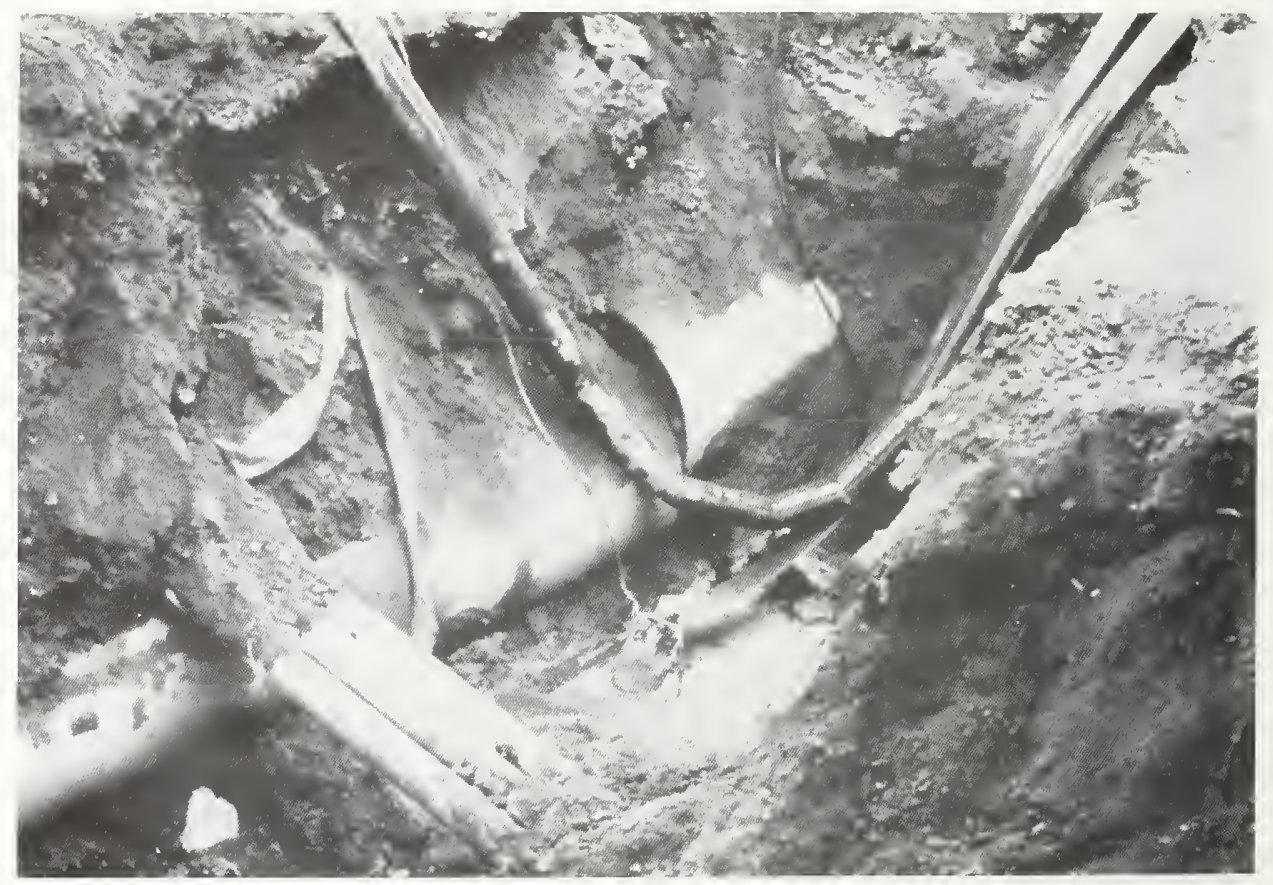

Photo 16 Repair of 700 -mm welded steel pipeline which ruptured at a weld on the north side of Port Island in an area affected by liquefaction induced lateral spread. This line carries the entire potable water supply for the island.

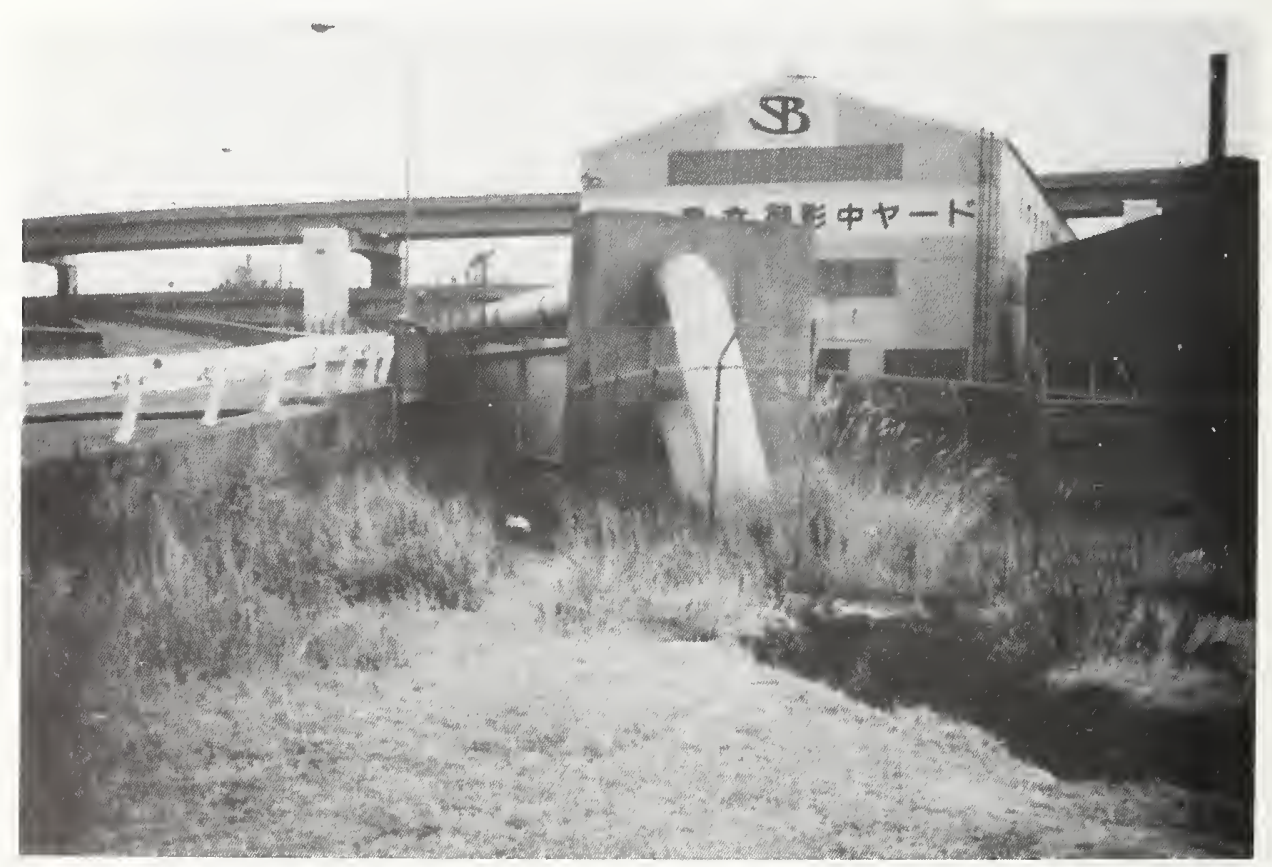

Photo 17 Ground cracking from lateral spread in fill area along a water way. Immediately behind the crack, a pipeline emerges out of the ground to be supported on the bridge. 


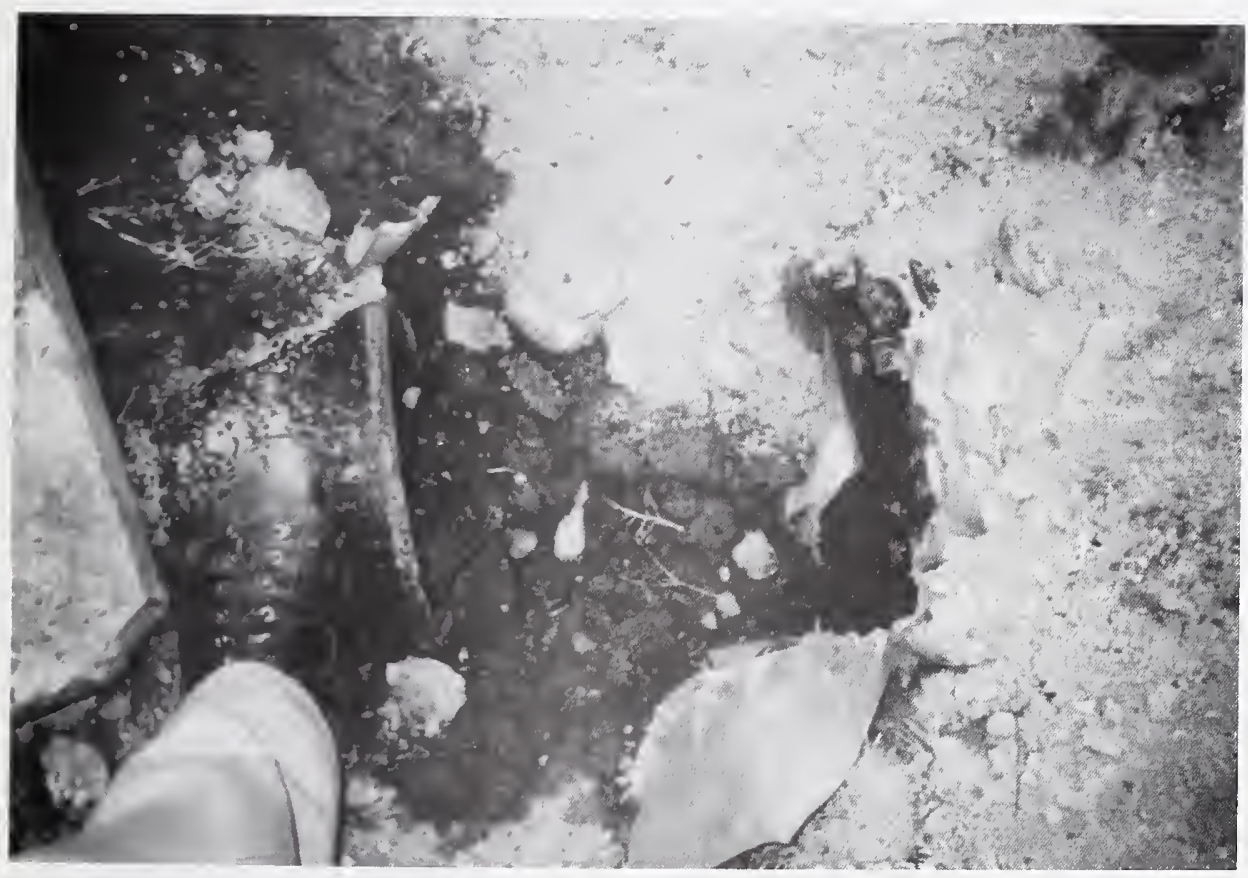

Photo 18 Shows a $300 \mathrm{~mm}$ diameter pipe joint in the bottom of the crack (Photo 17), where the bell (to the right) was separated from the spigot (under foot). 


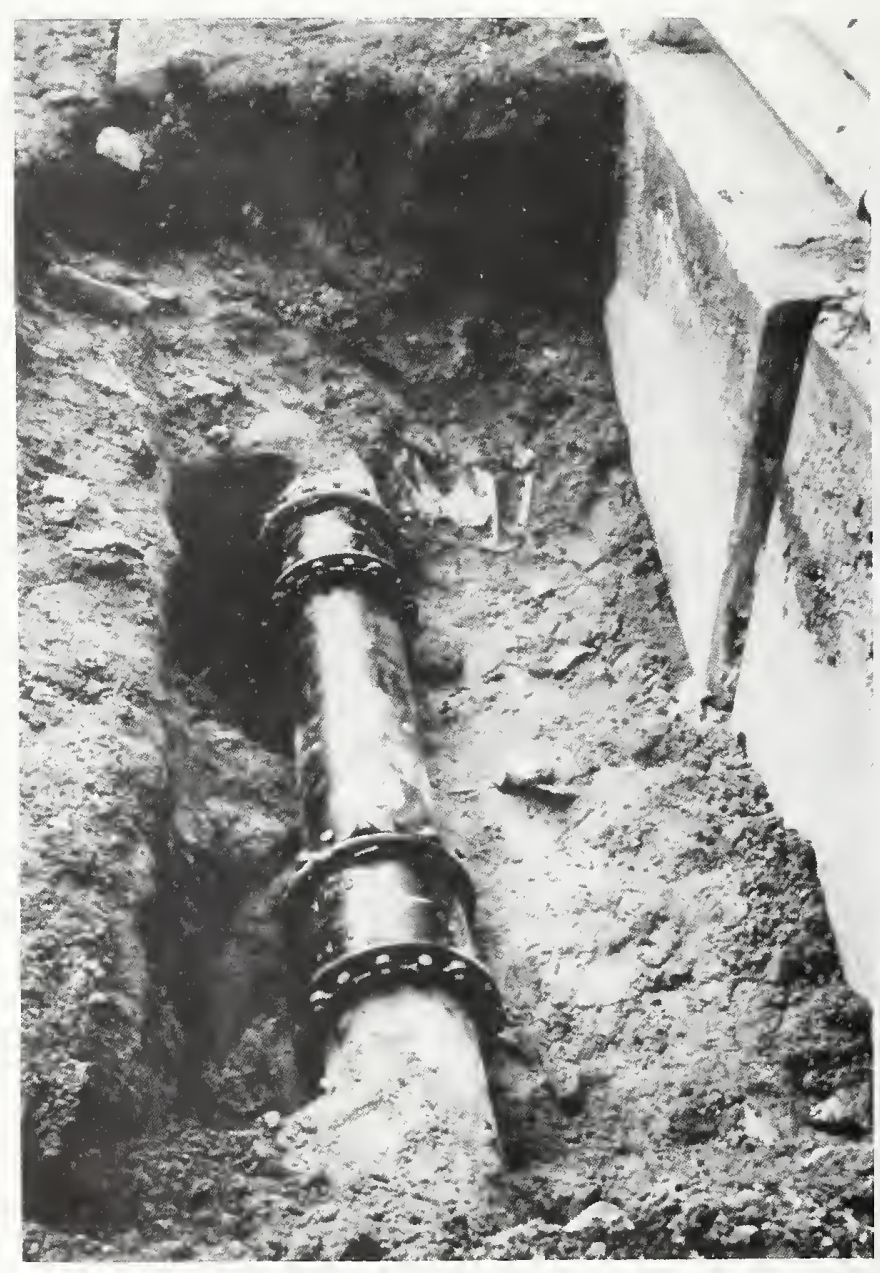

Photo 19 Pipe repair on approach to bridge to island where the wastewater plant was located. Settlement and slight lateral movement (see concrete wall on right) likely caused the pipe failure. 


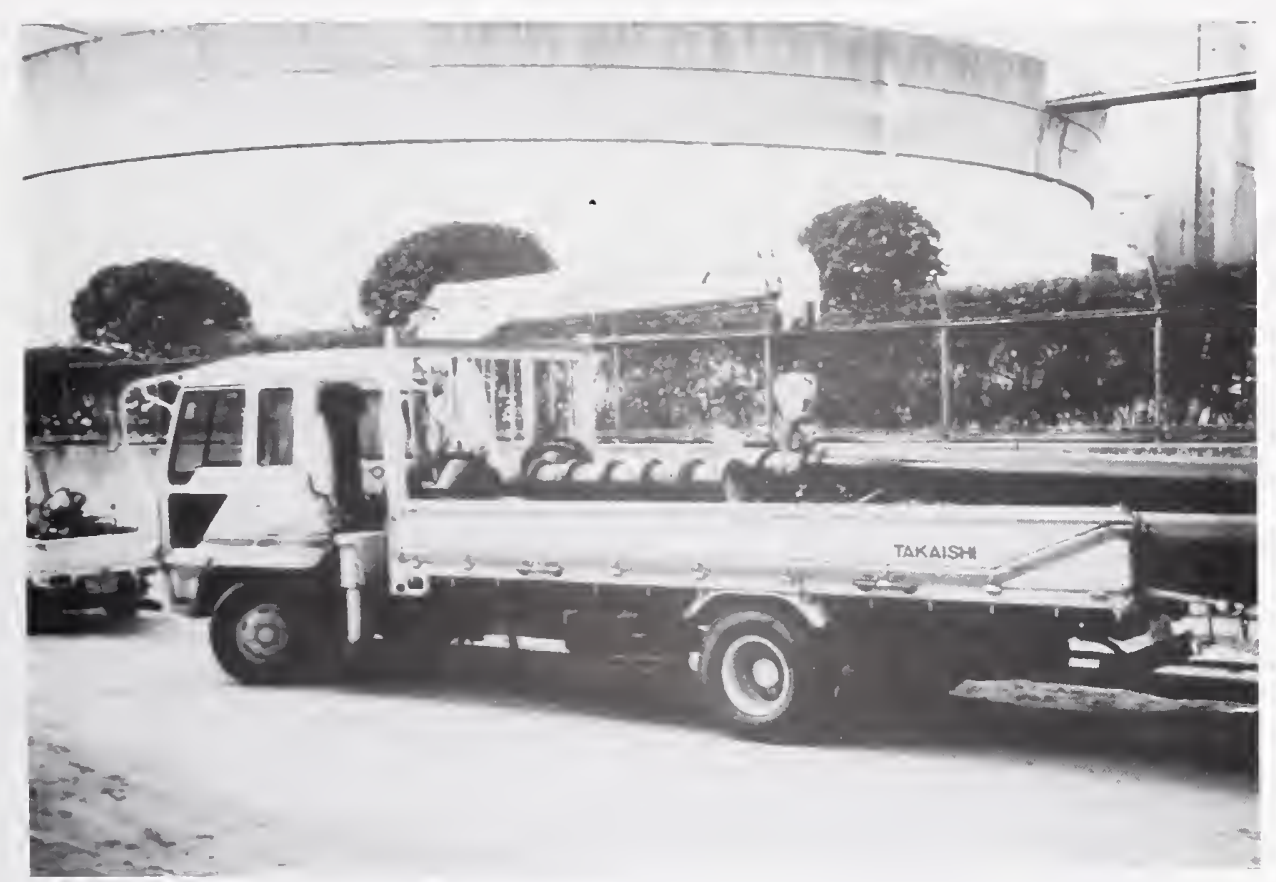

Photo $20 \quad$ Kyoto Water Department truck and crew was making repair shown in Photo 19. The crew was directed to make the repair as quickly as possible, even though the repair might be temporary. The crew also indicated that the materials they used in Kyoto were completely different from those used by Kobe Water.

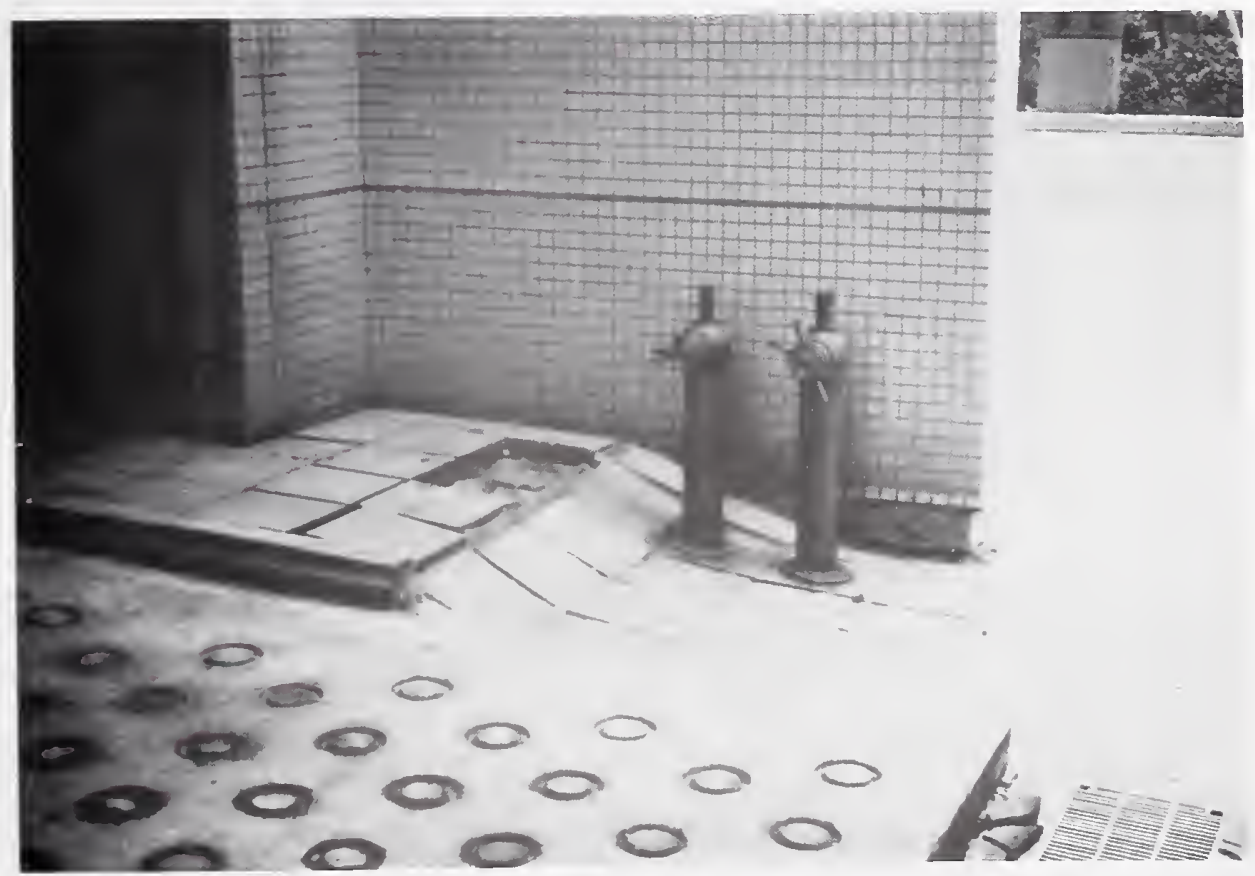

Photo 21 Differential settlement at building in mid-Rokko Island. Most modern buildings on the island were pile supported and were note damaged. Differential settlement required repair of utility connections as shown in Photo 22. 


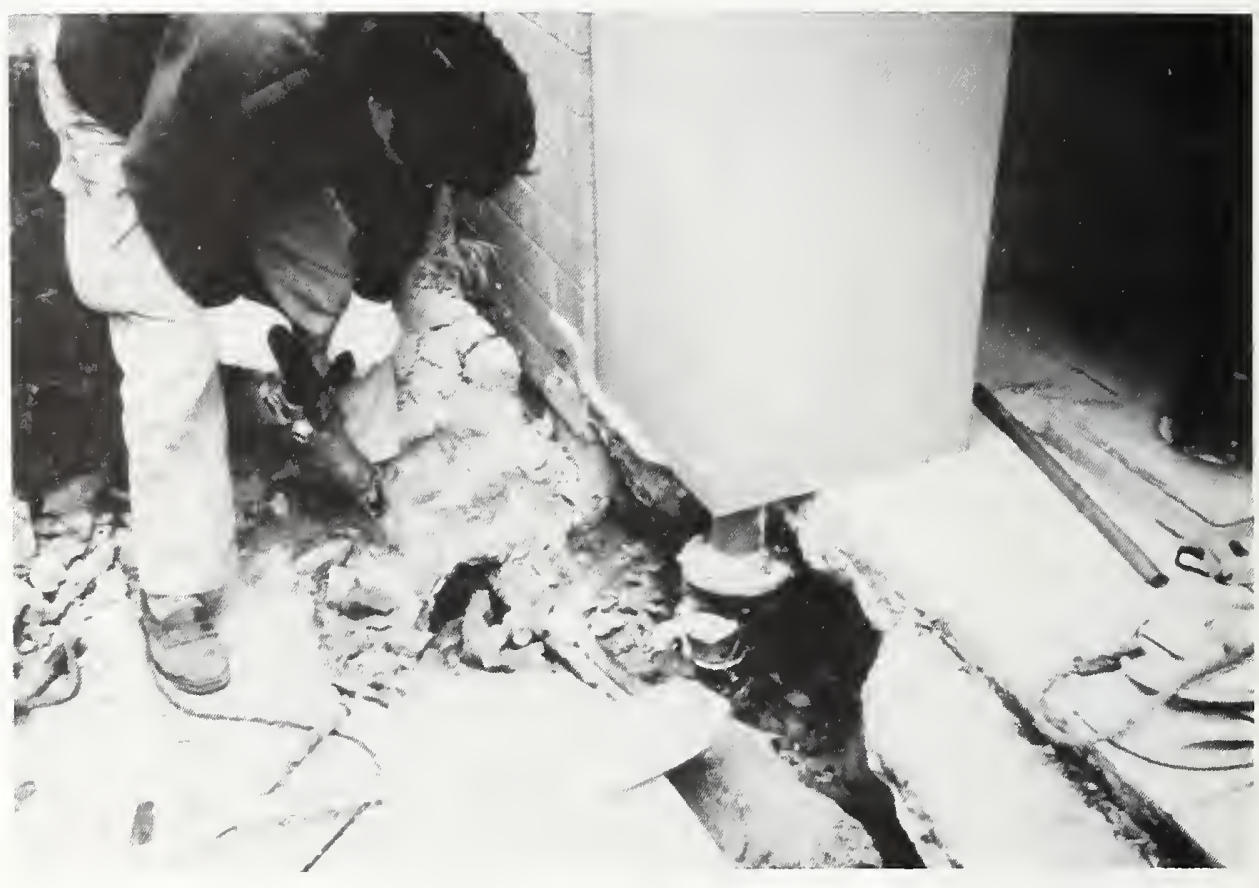

Photo 22 Repair of utility connections in mid-Rokko Island. 


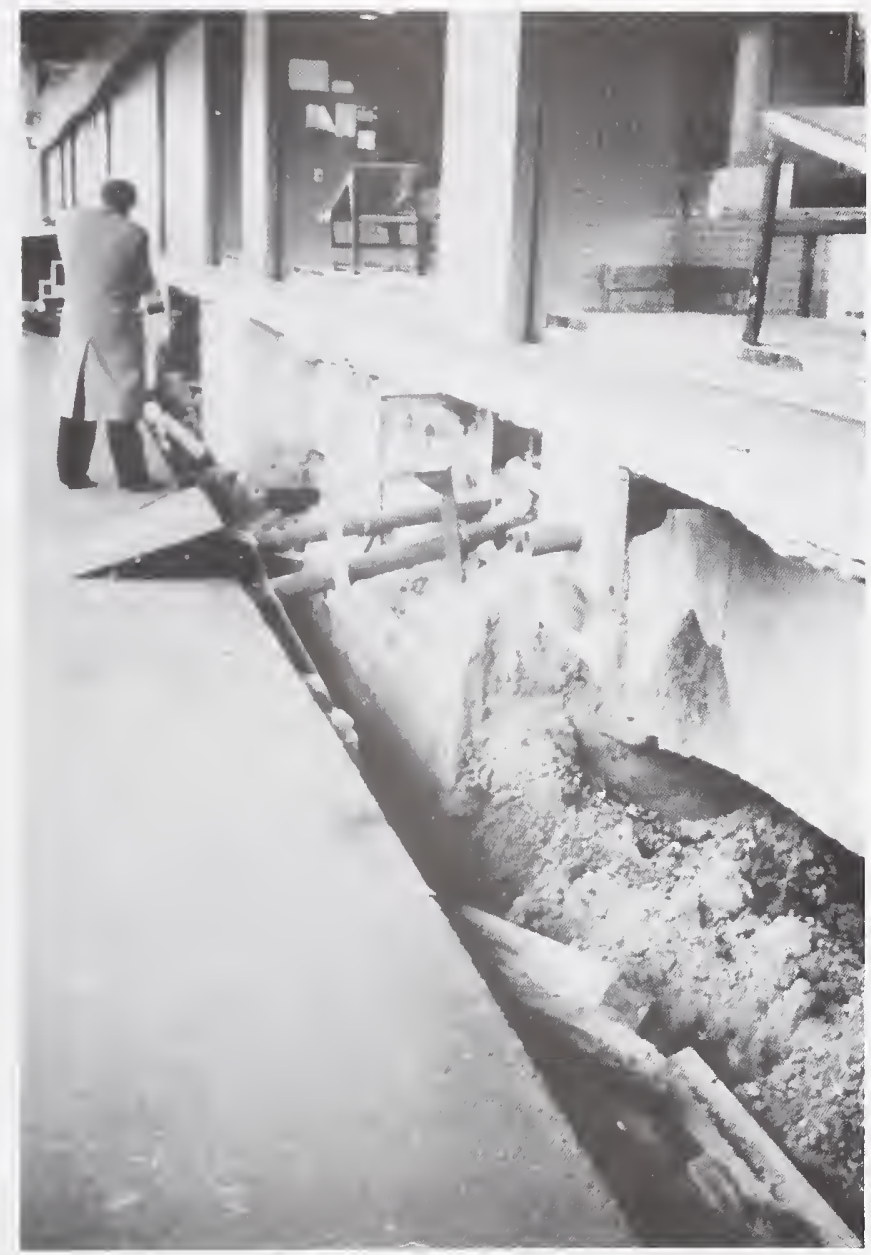

Photo 23 Differential settlement of approximately one meter along the front of pile supported ferry terminal on Port Island connecting Kobe to Kansai Airport. Utility connections were left hanging. 


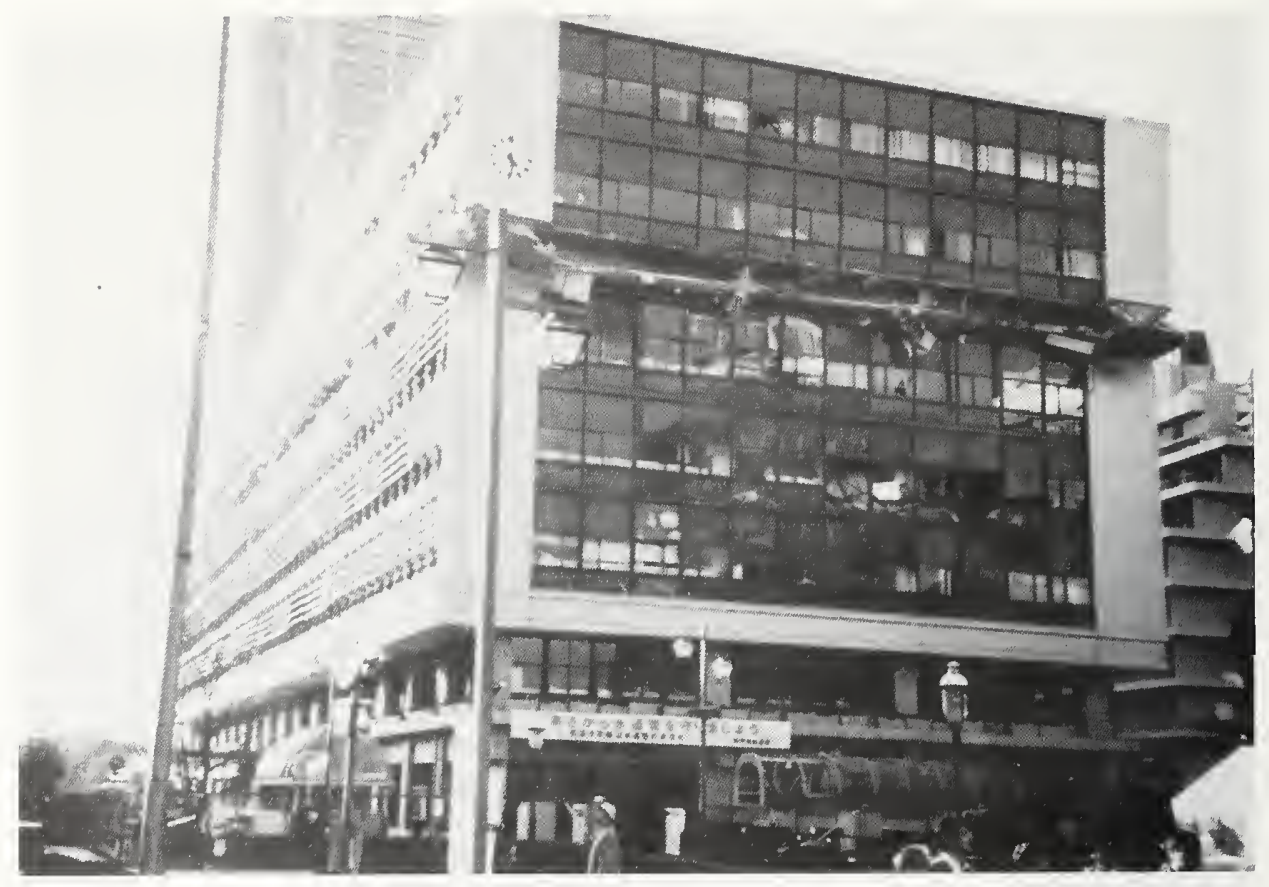

Photo 24 Pancaked sixth floor of City Hall Annex.

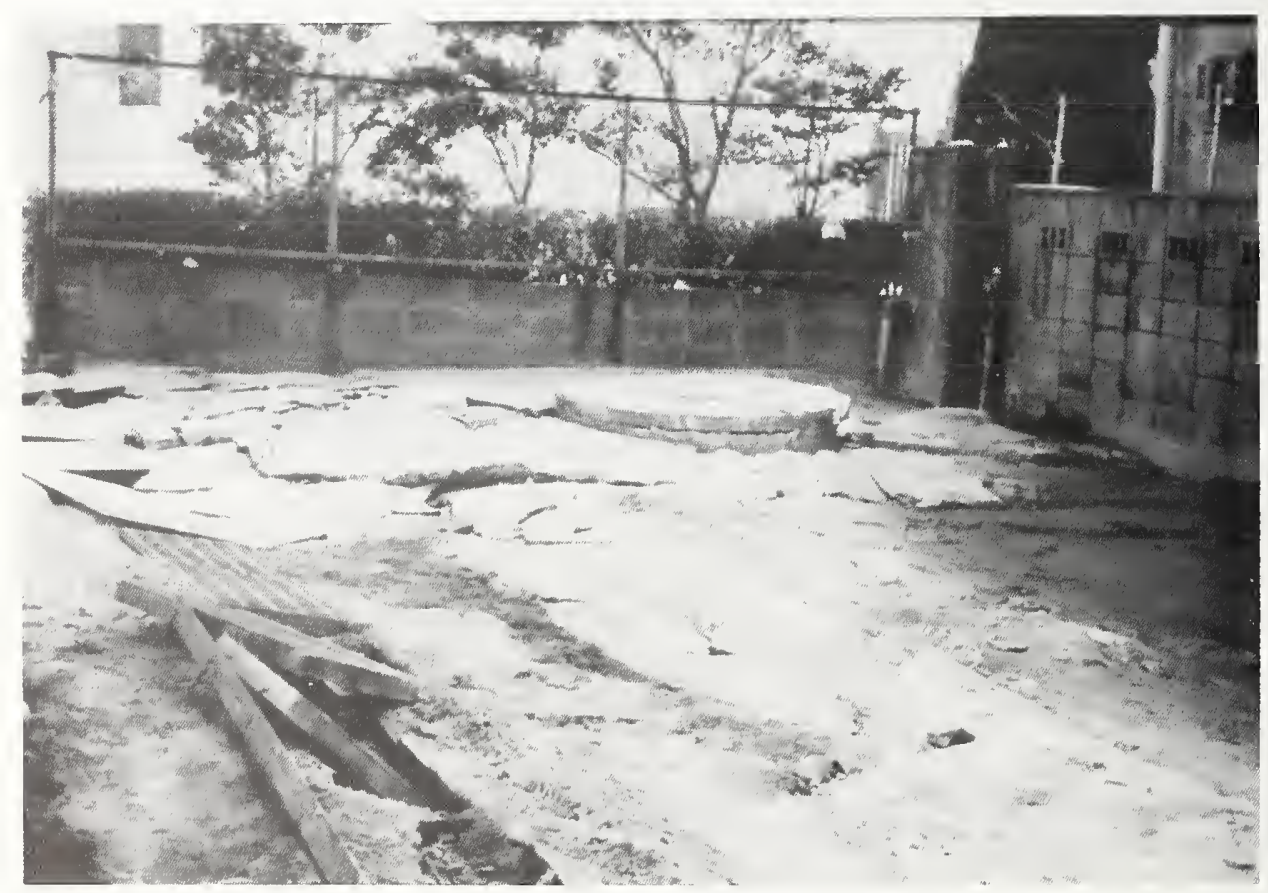

Photo 25 Manhole floated as a result of liquefaction near the wastewater treatment plant. 


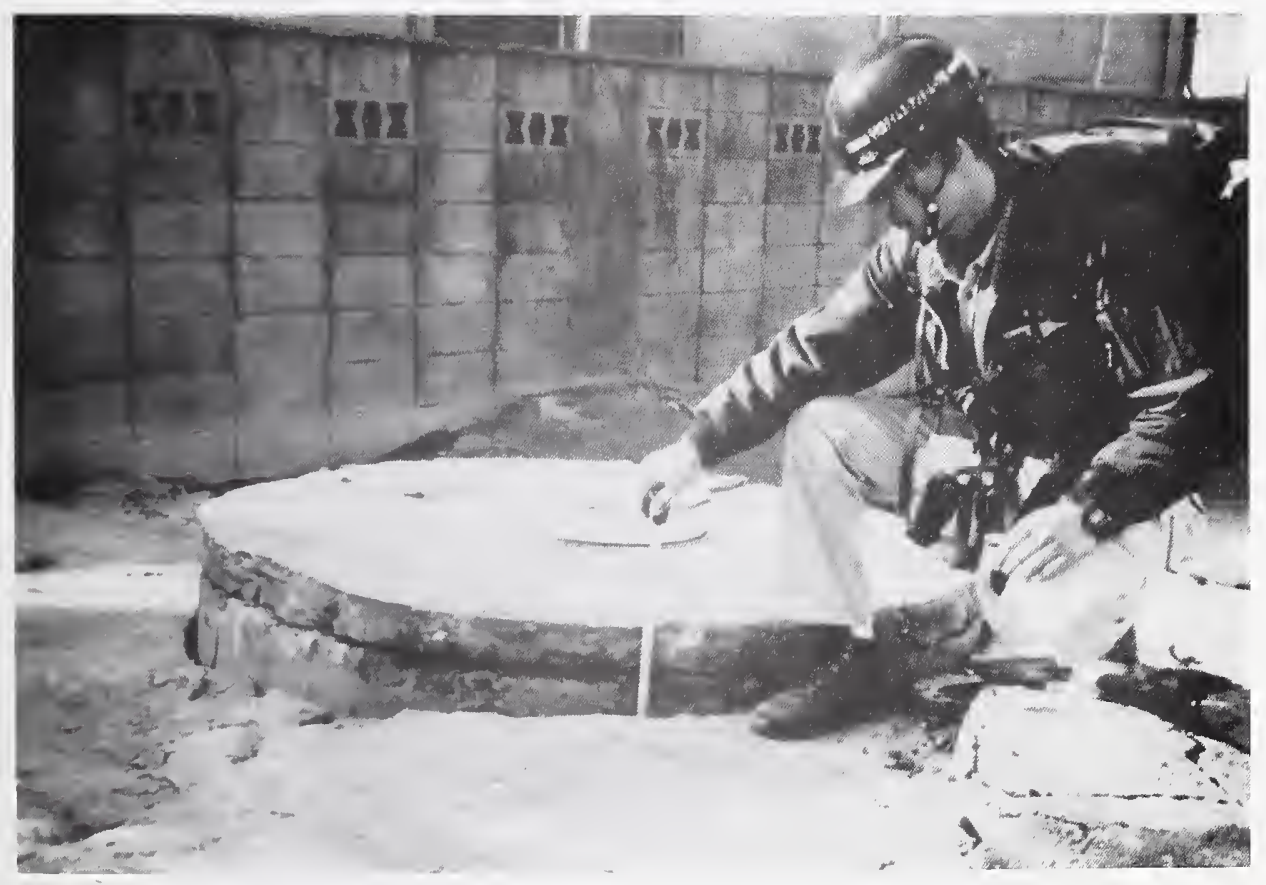

Photo $26 \quad$ Same as Photo 25. 


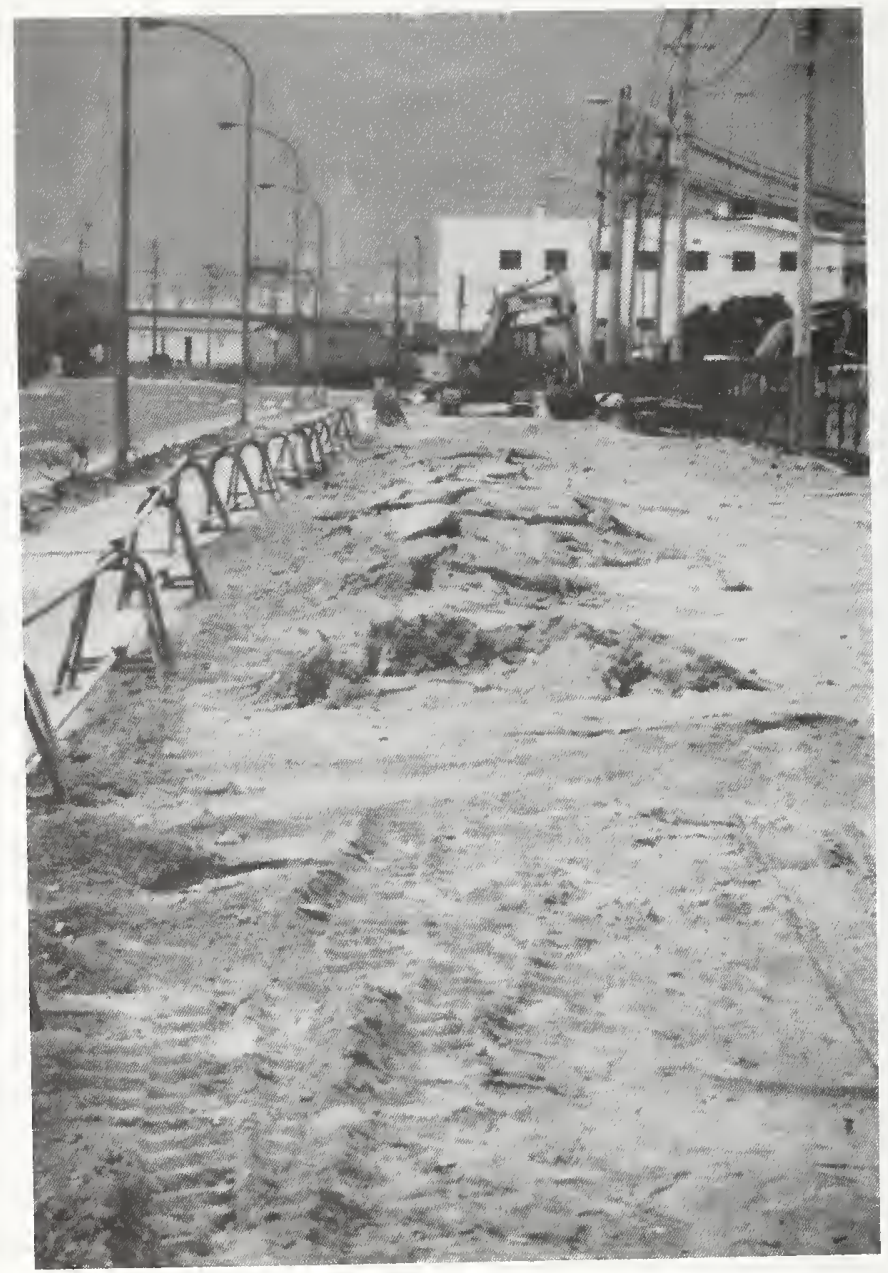

Photo 27 A $500 \mathrm{~mm}$ diameter sewer floated upward on Port Island, resulting in the upheaval of ground. 


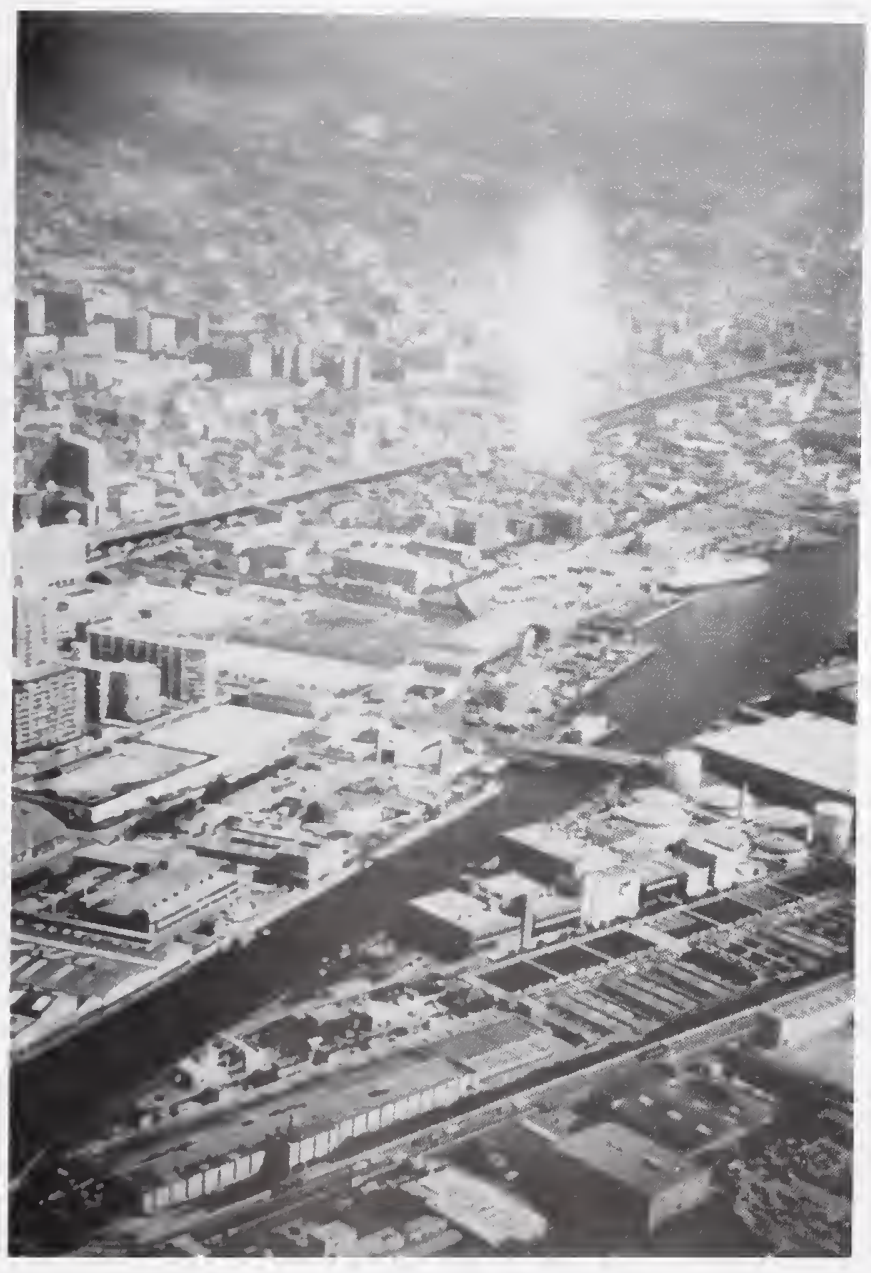

Photo 28 Aerial view of Higashinada Wastewater Treatment Plant. 


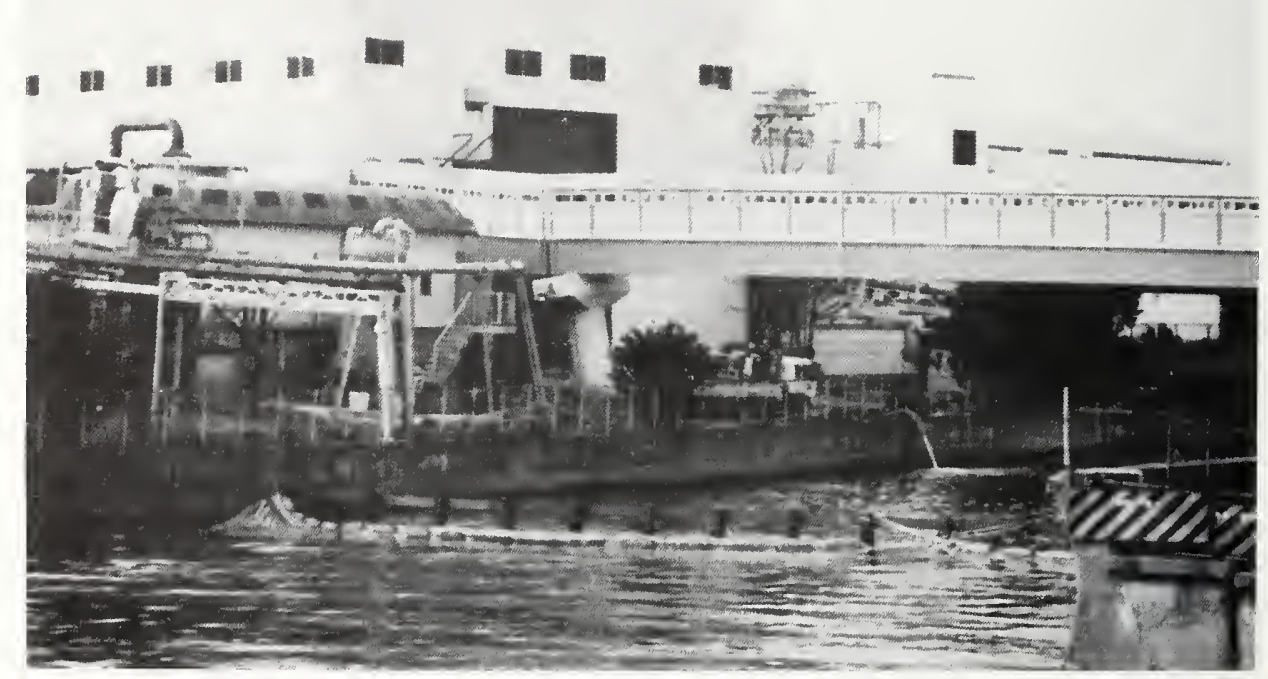

Photo 29 Retaining wall along the inlet between the island and mainland moved towards the water (north) 2 to 3 meters, resulting in the entire site subsiding an average of one meter.

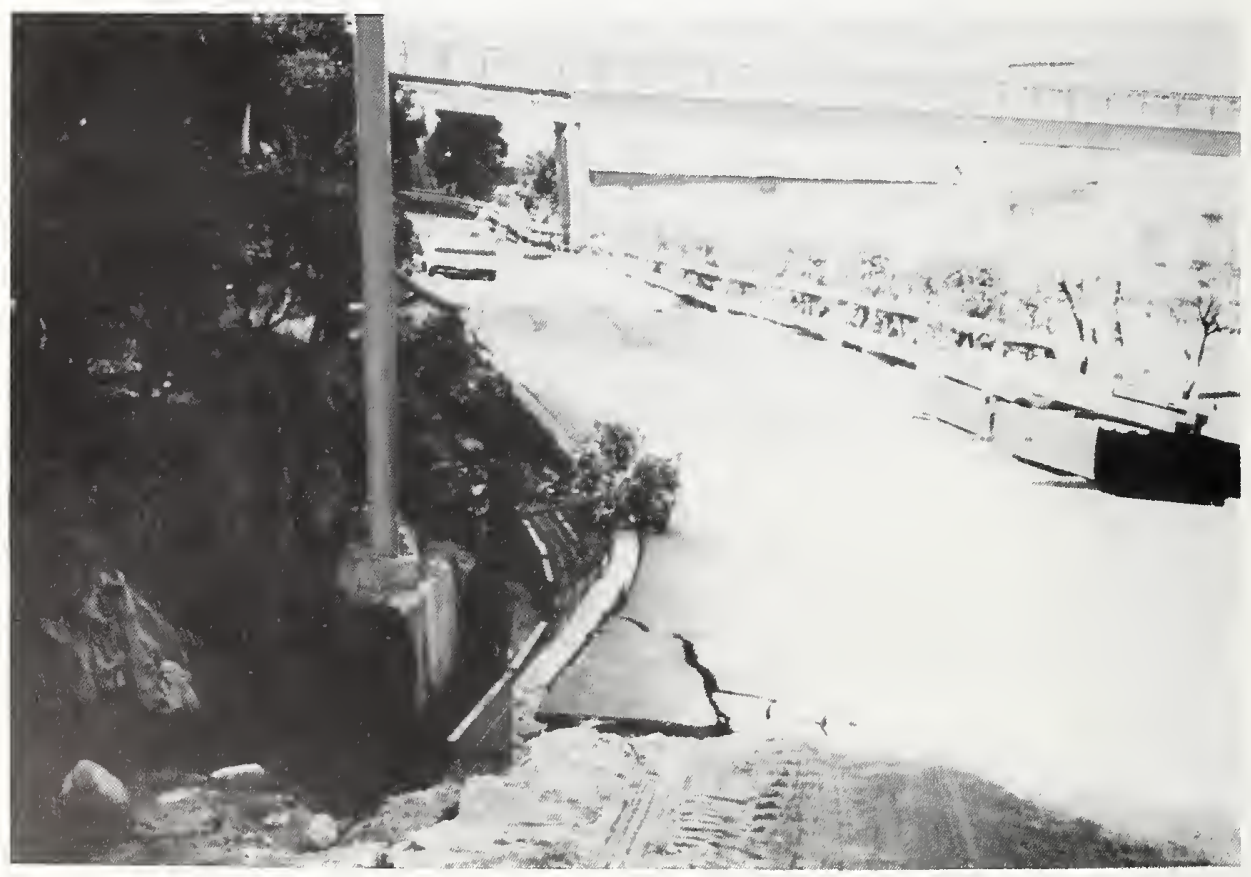

Photo 30 Ground cracking behind the retaining wall (which is off to the left). 


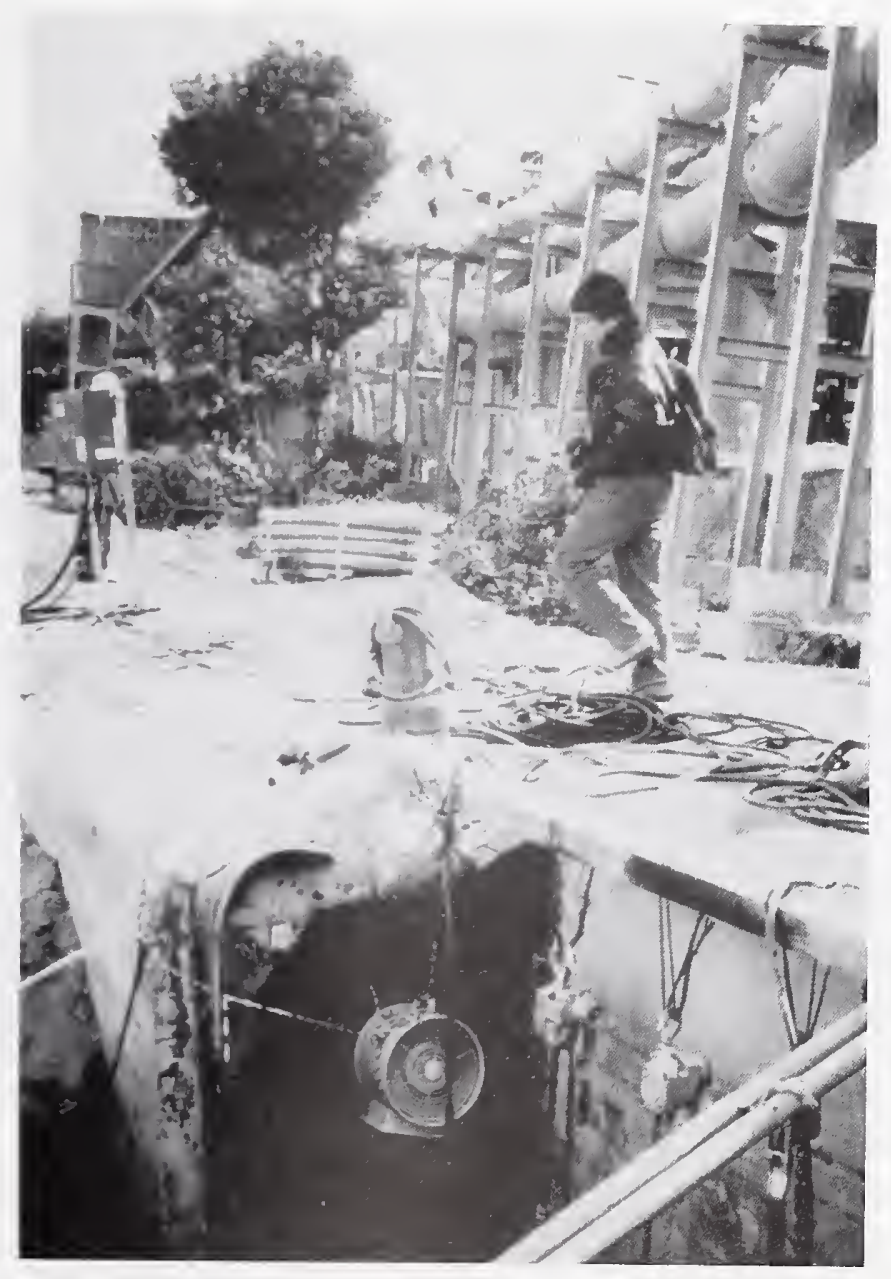

Photo 31 Effluent channel, approximately $2 \mathrm{~m}^{2}$, offset nearly one meter from lateral spreading. 


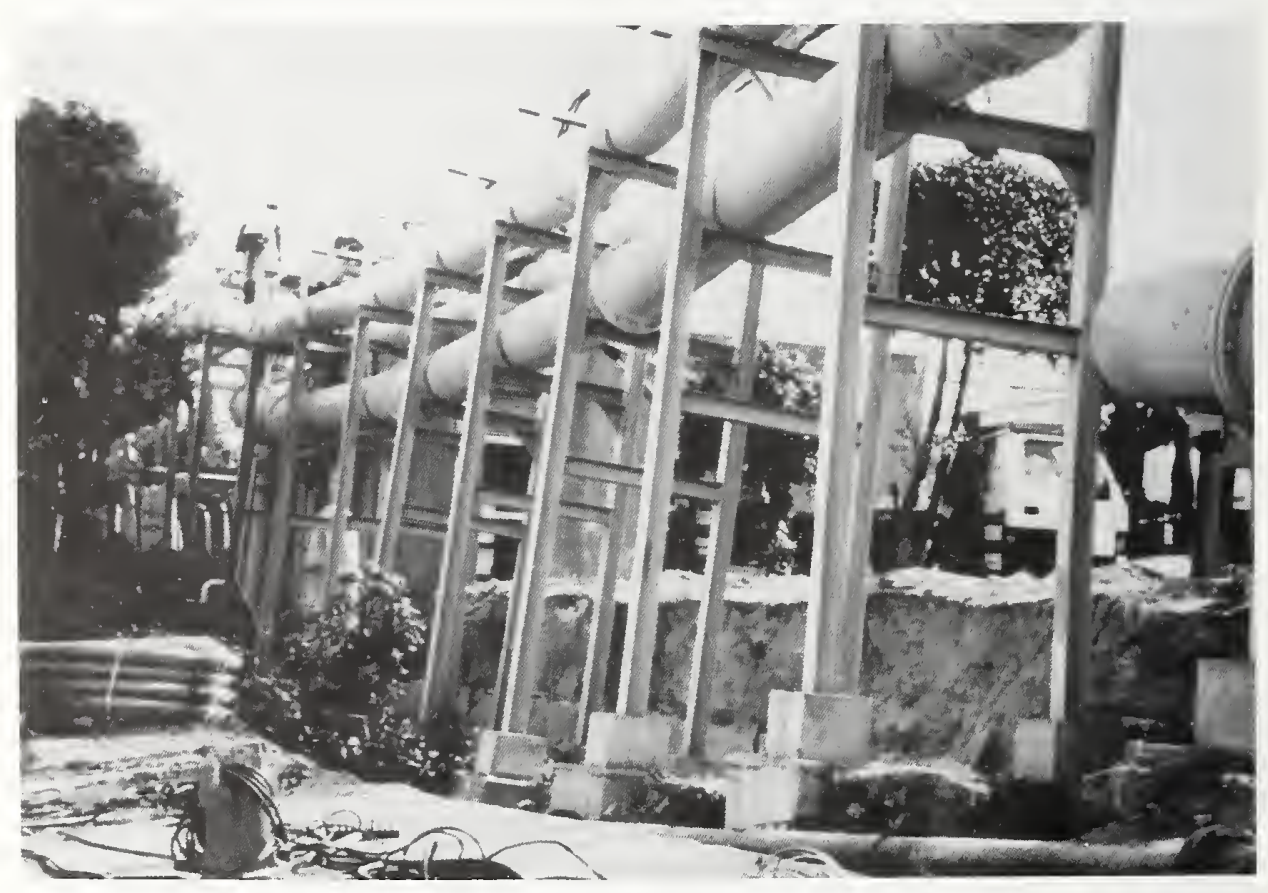

Photo 32 Pipe rack foundations adjacent to channel settled approximately one meter, distorting piping. 


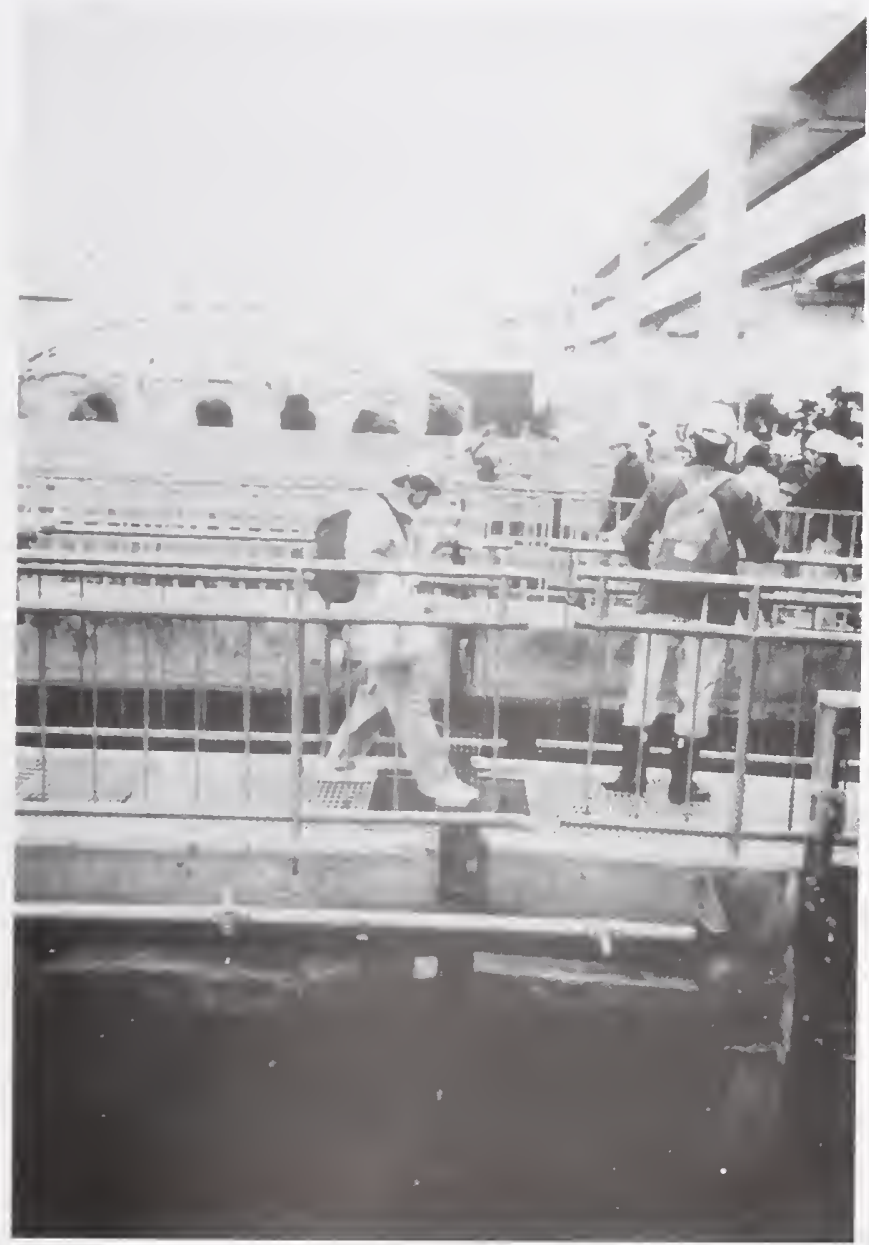

Photo 33 Aeration tanks construction joint separated down the entire bank of tankage as a result of settlement. 


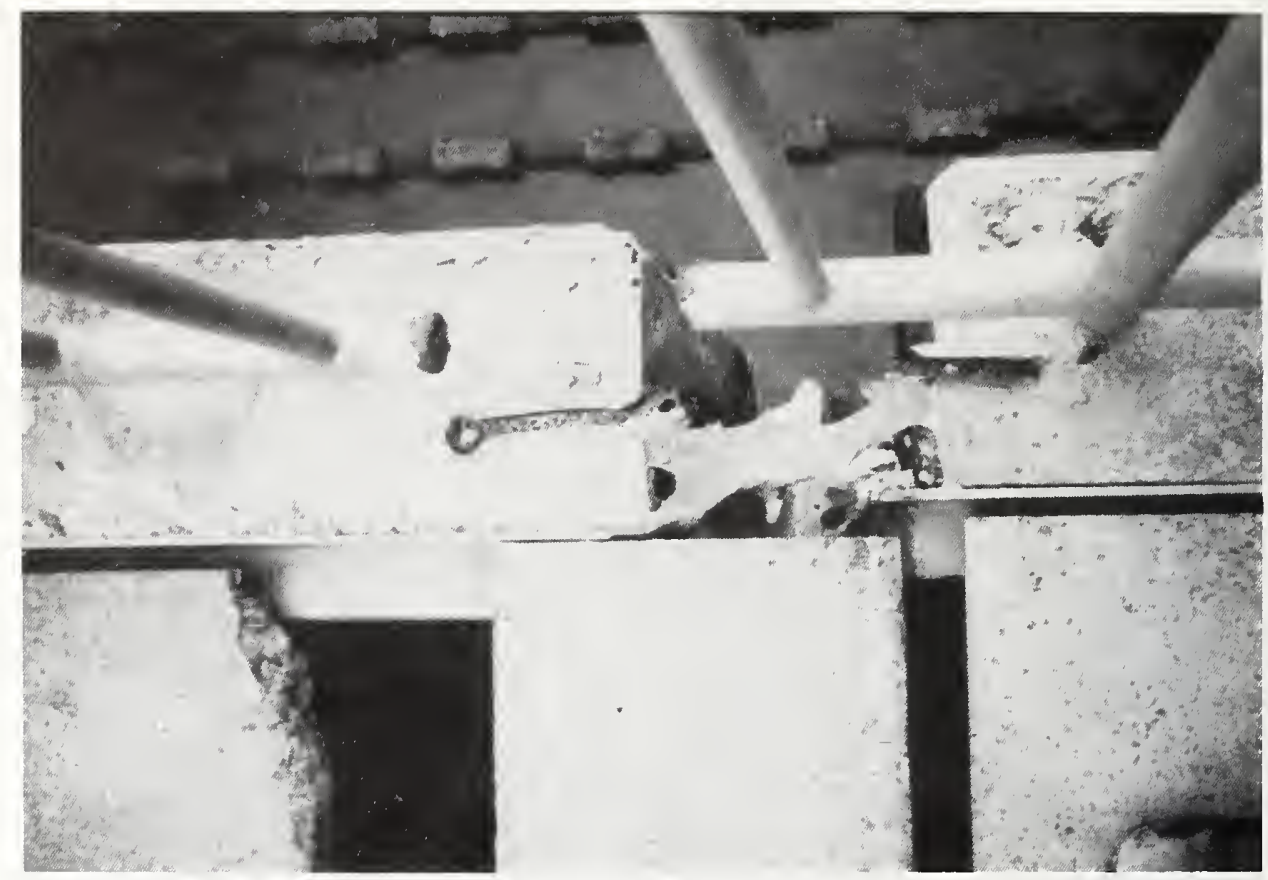

Photo 34 Close up of torn dumbbell rubber water stop in aeration tank.

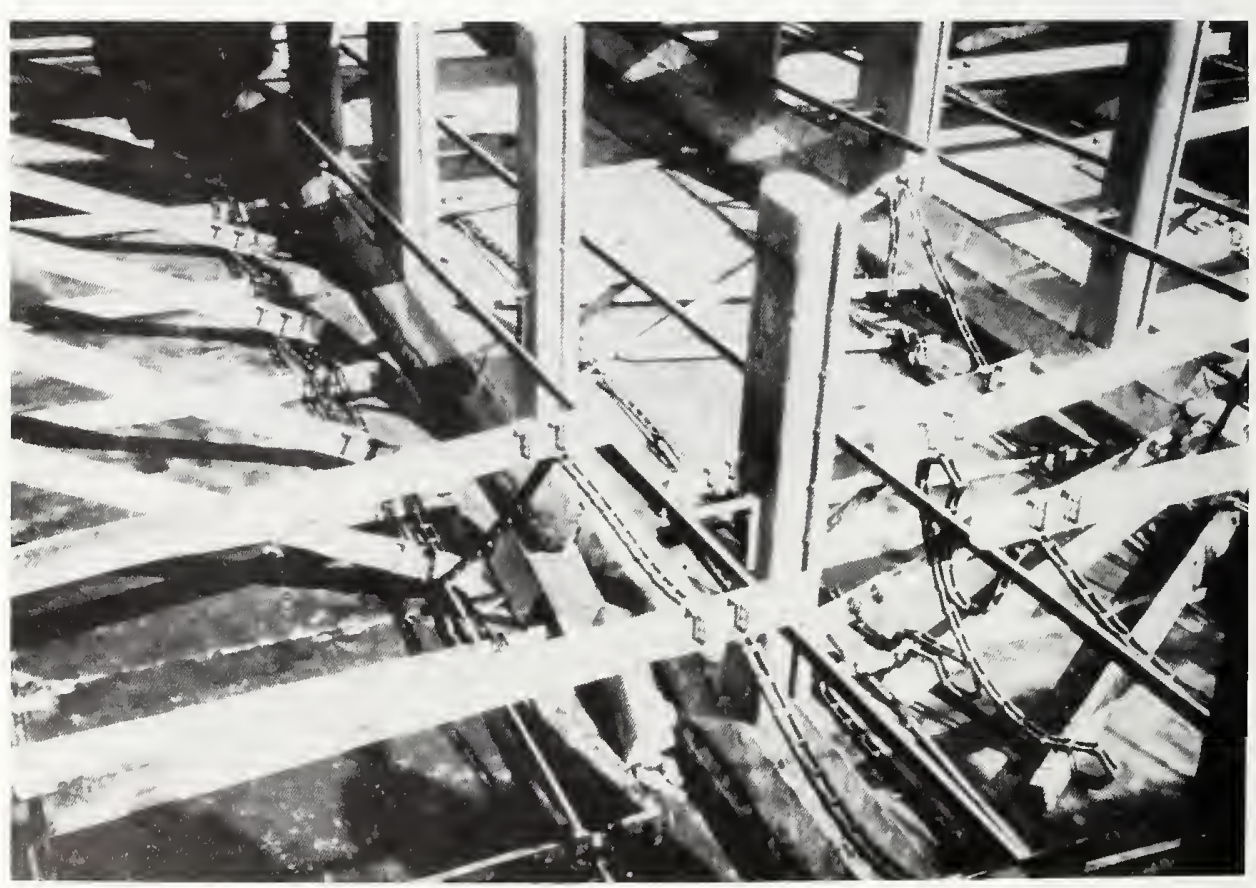

Photo 35 Sludge scraper chain came off sprockets in sedimentation tanks. 


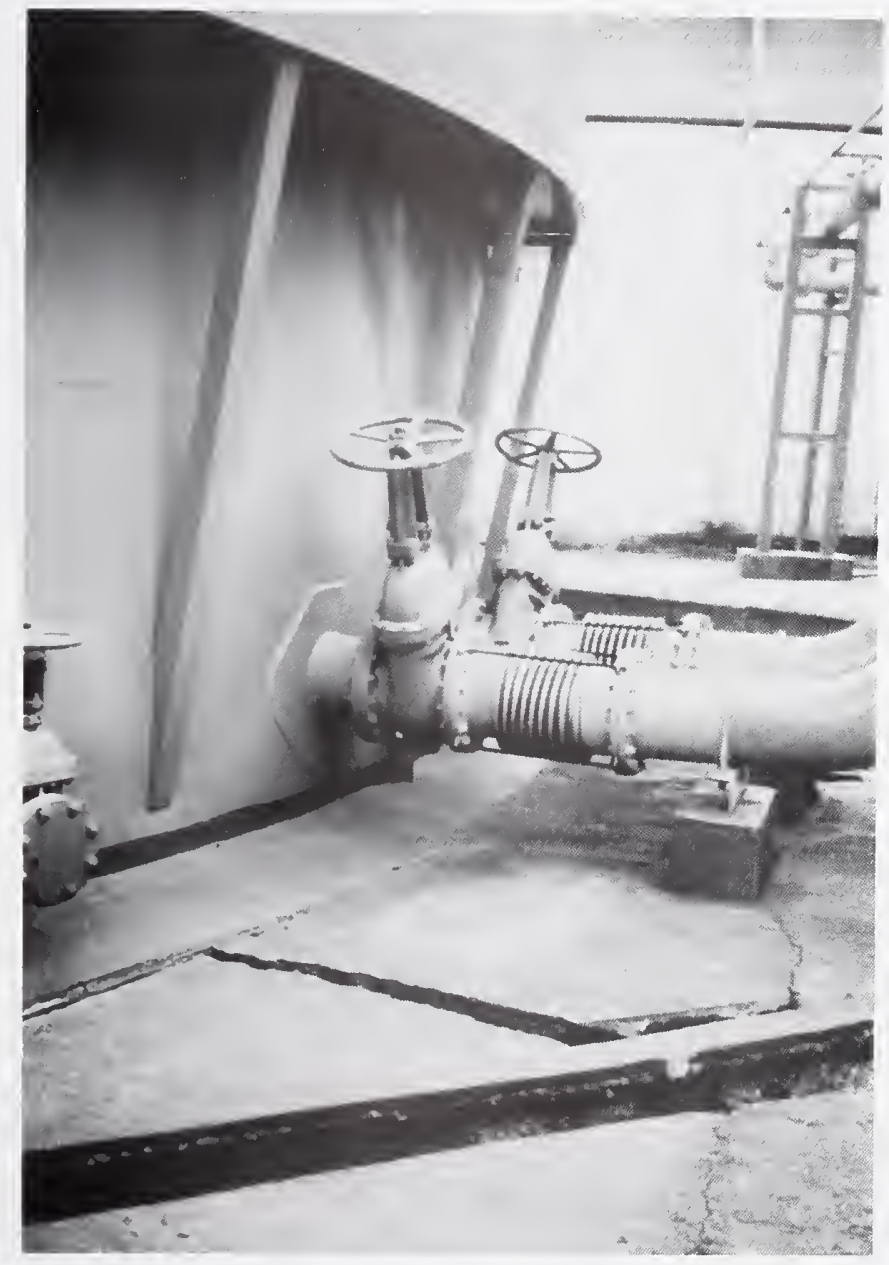

Photo 36 Differential movement from settlement between pile supported tanks and non-pile supported pipe caused flexible joint to distort. 


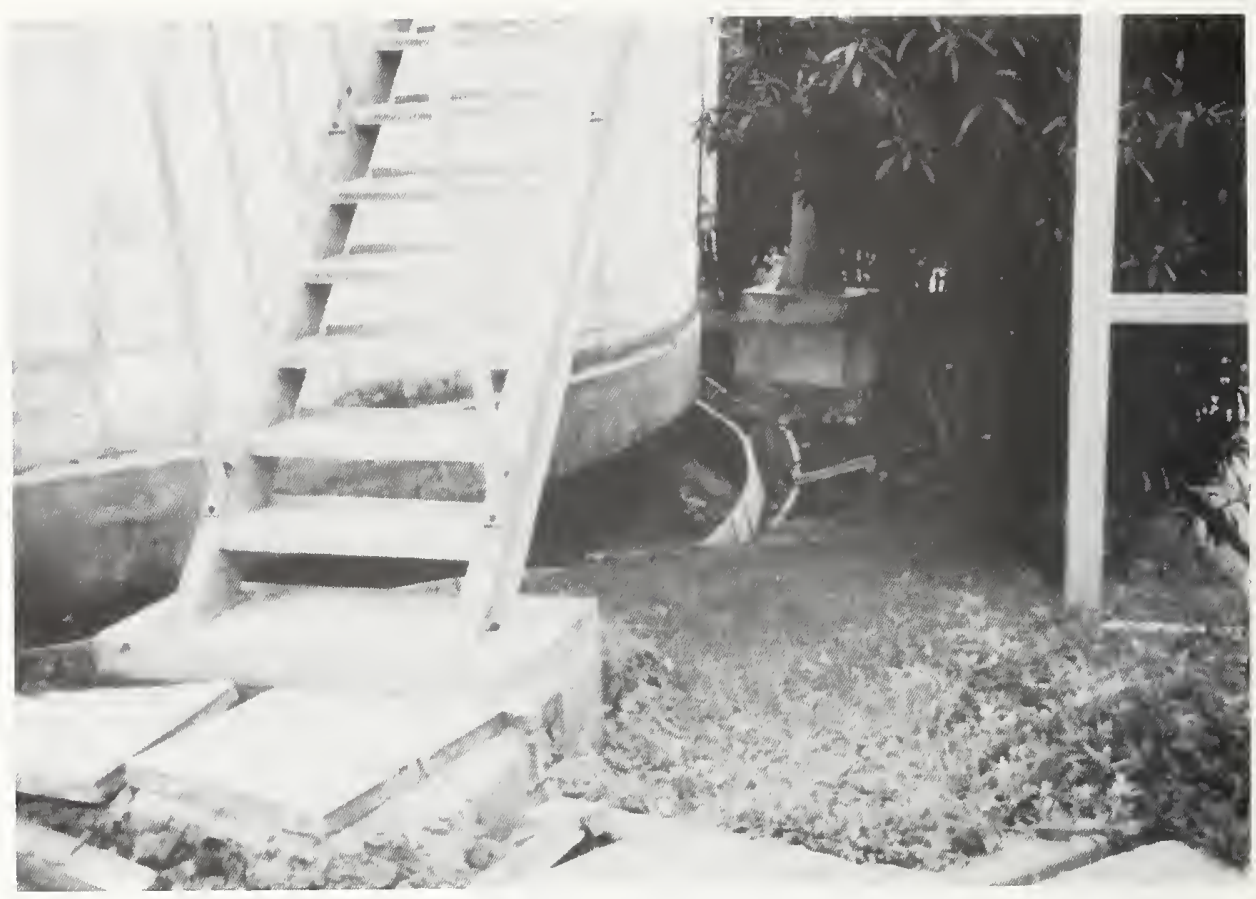

Photo 37 Differential settlement between pipe and non-pile supported structures damaged piping throughout the plant.

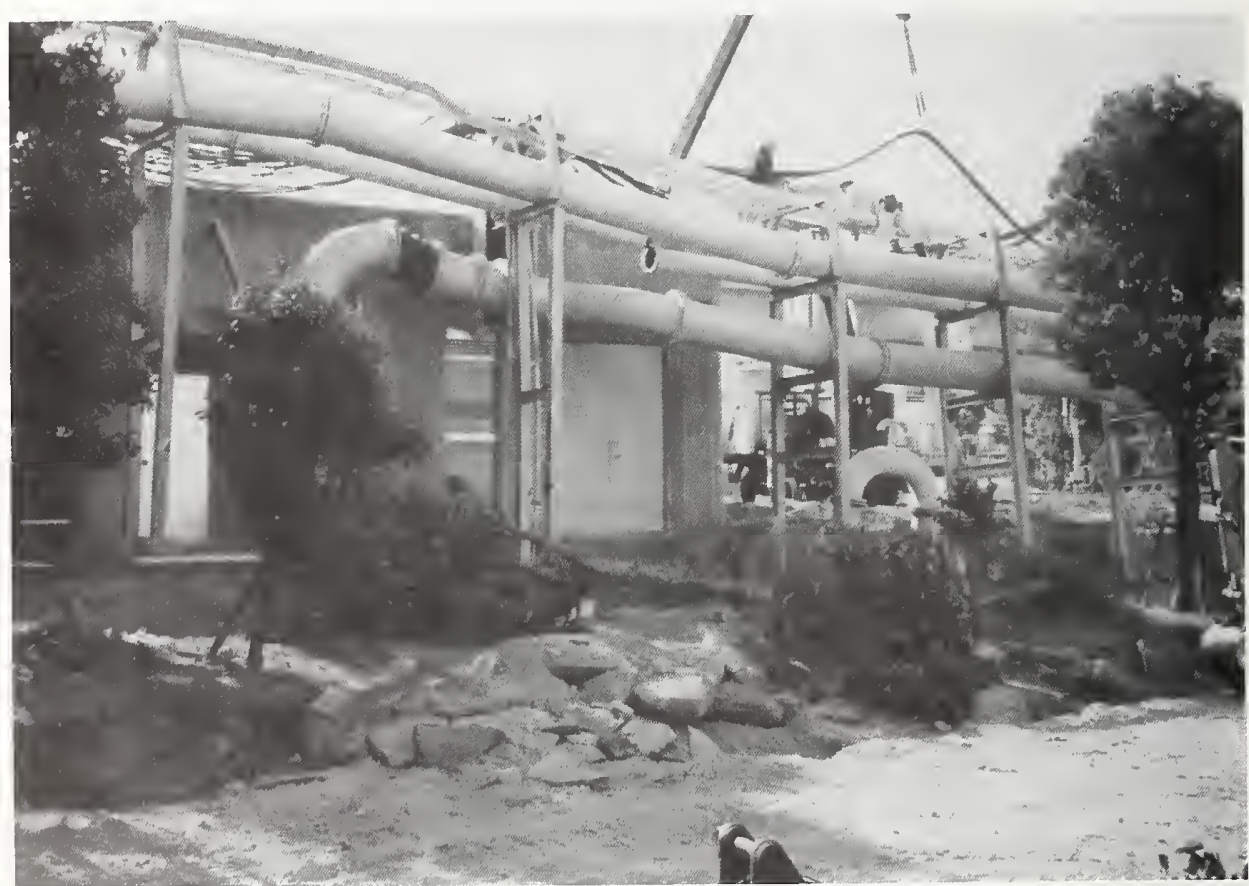

Photo $38 \quad$ Filter building support pipes failed allowing the building to move and settle differentially. 


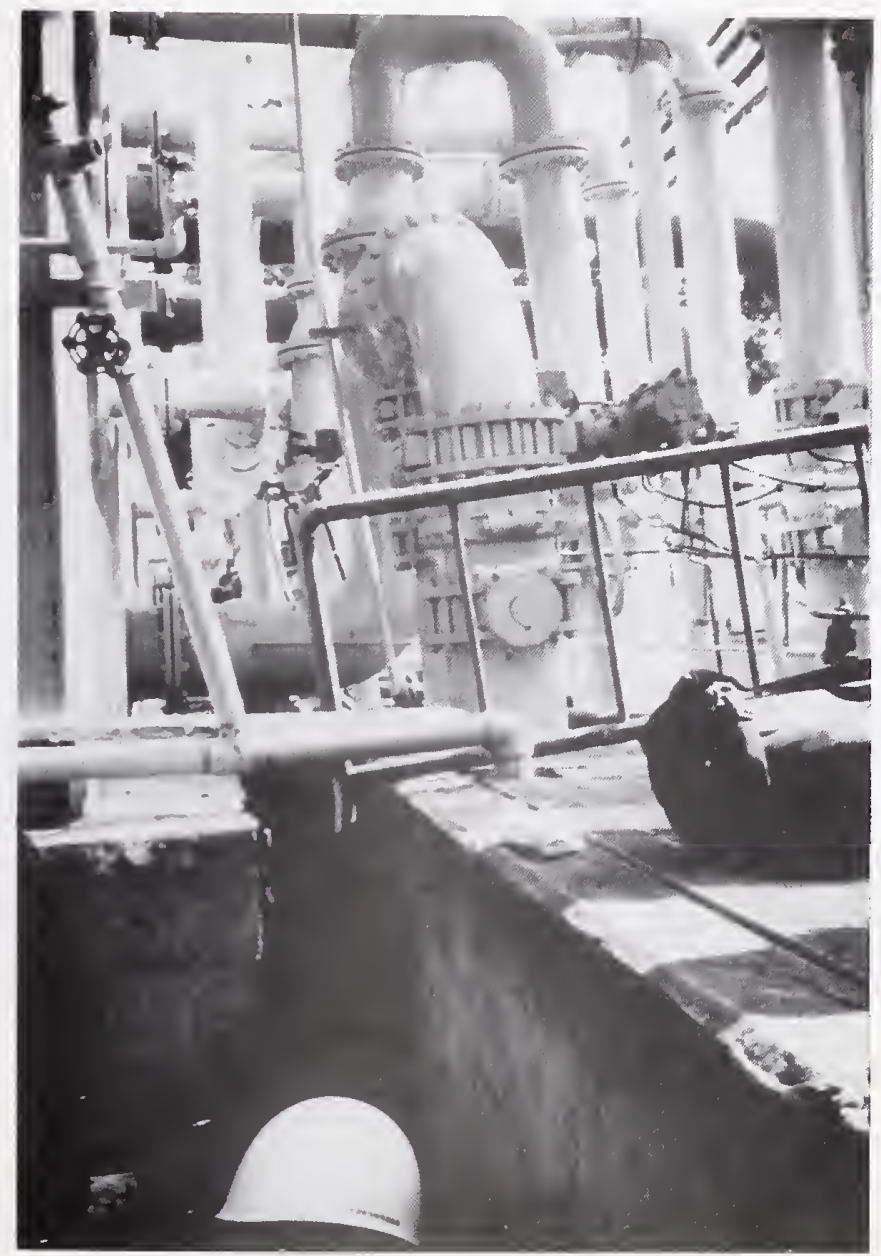

Photo 39 Piping distorted as a result of the building movement. 


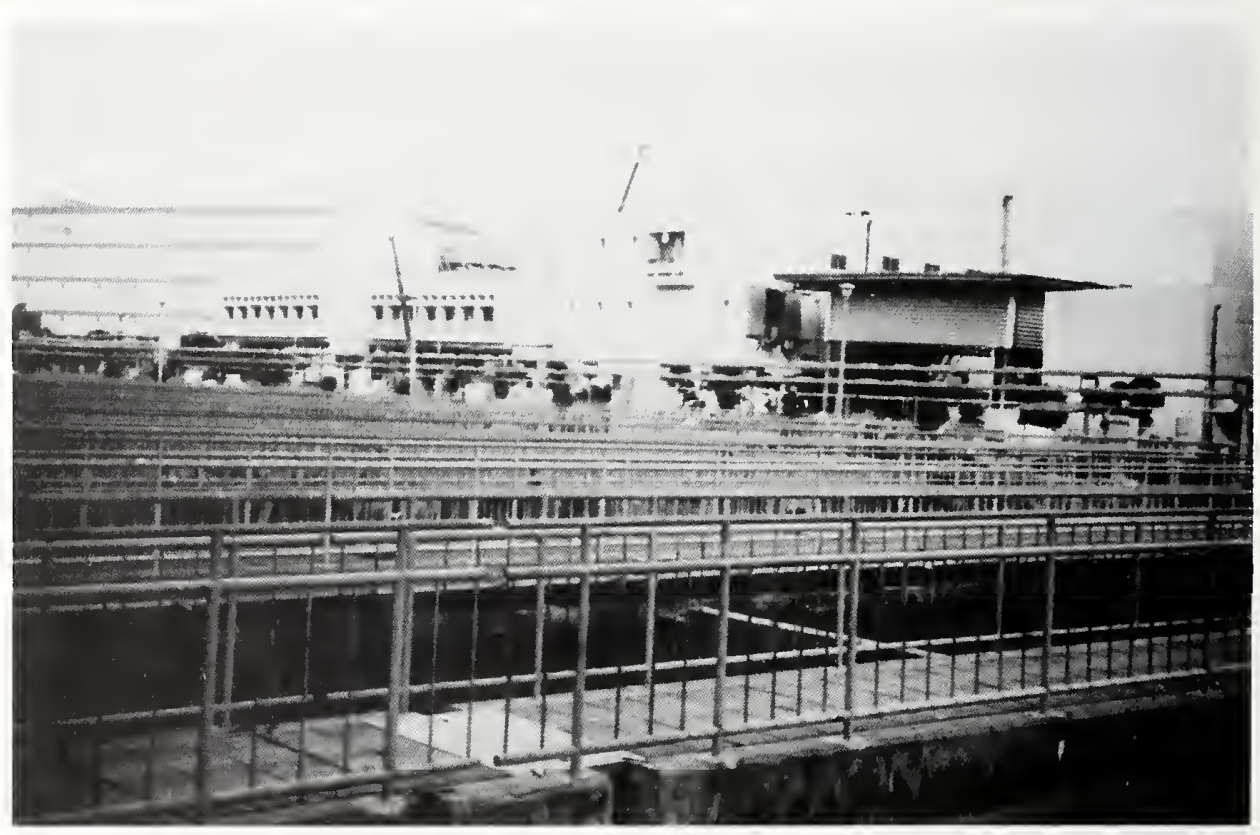

Photo 40 Control building (upper right), which is pile supported, moved towards inlet approximately $30 \mathrm{~cm}$, moving away from adjacent building which had a basement. 


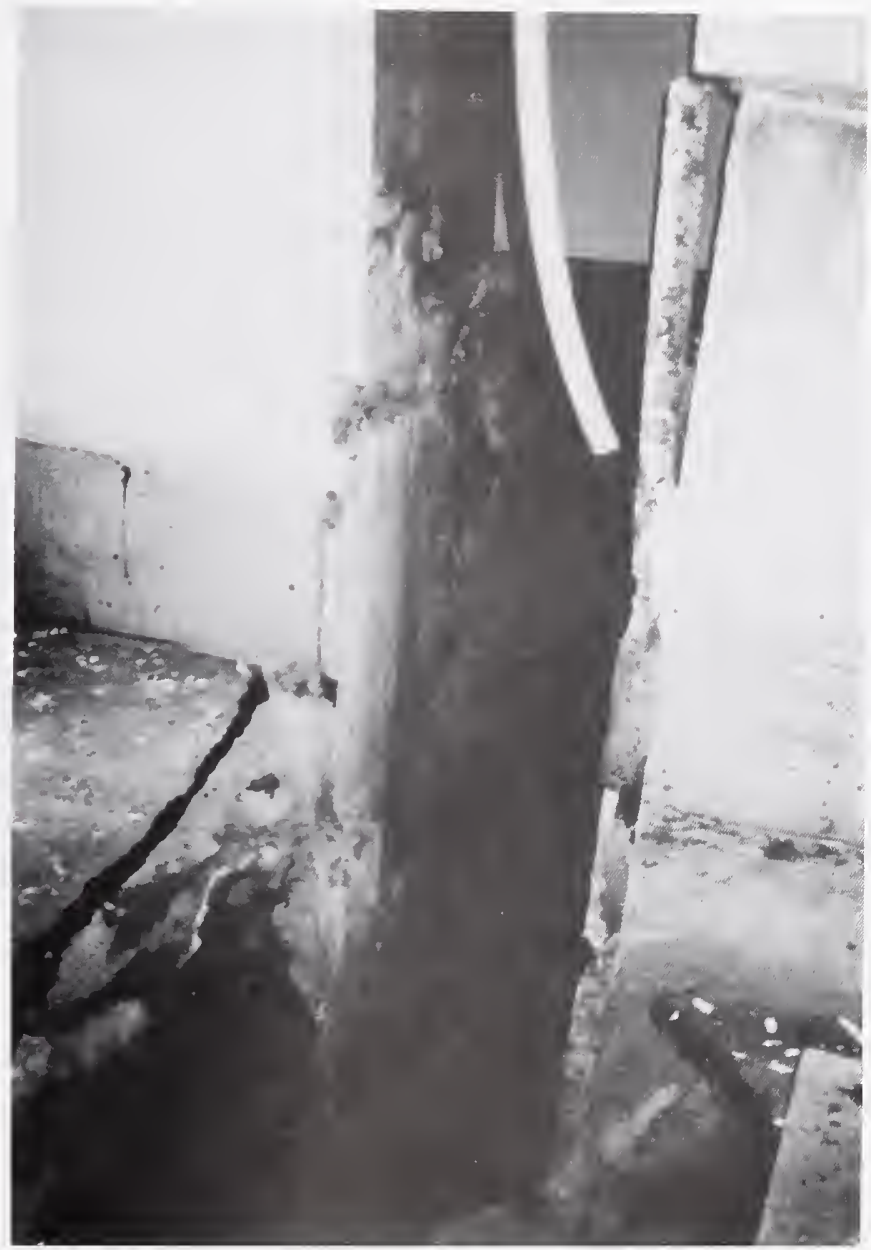

Photo 41 Shows the gap between the two buildings in Photo 40. 


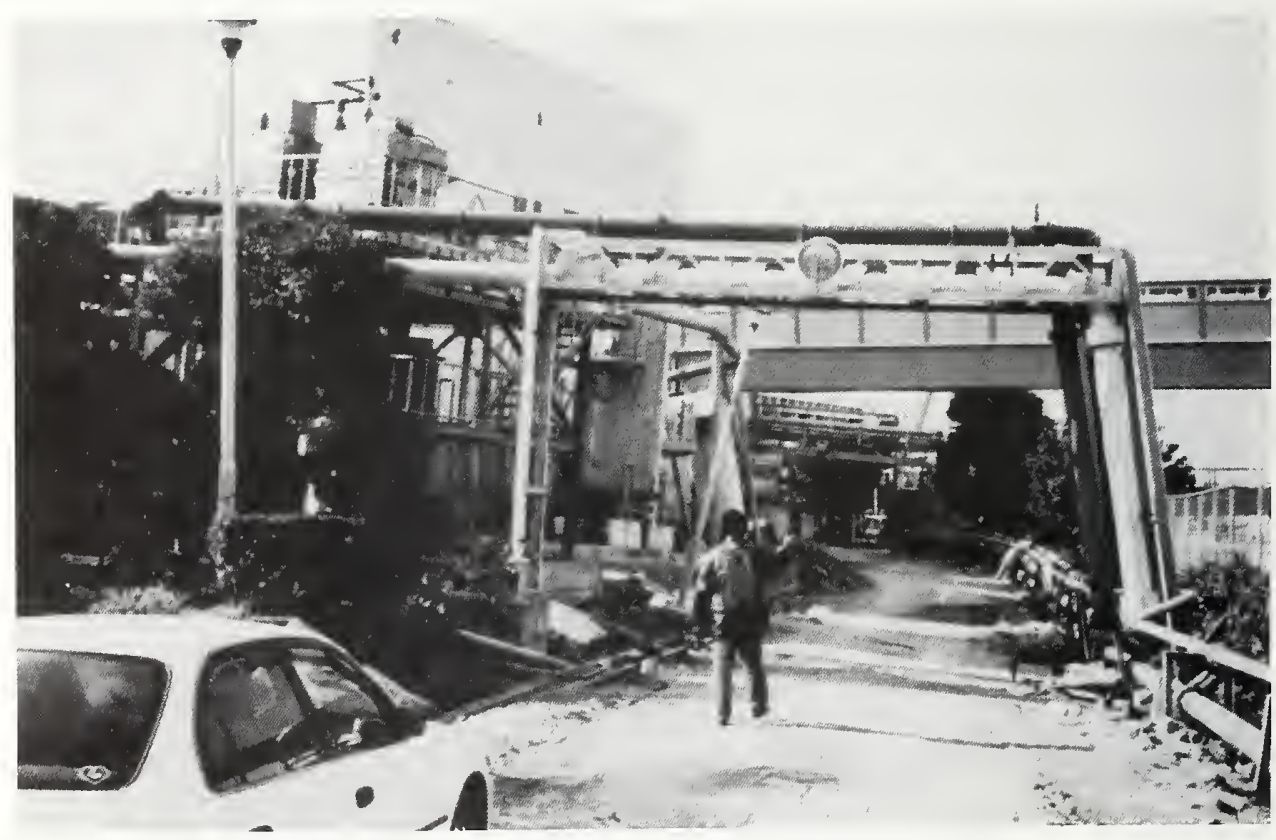

Photo 42 Piping distorted as a result of the movement. 


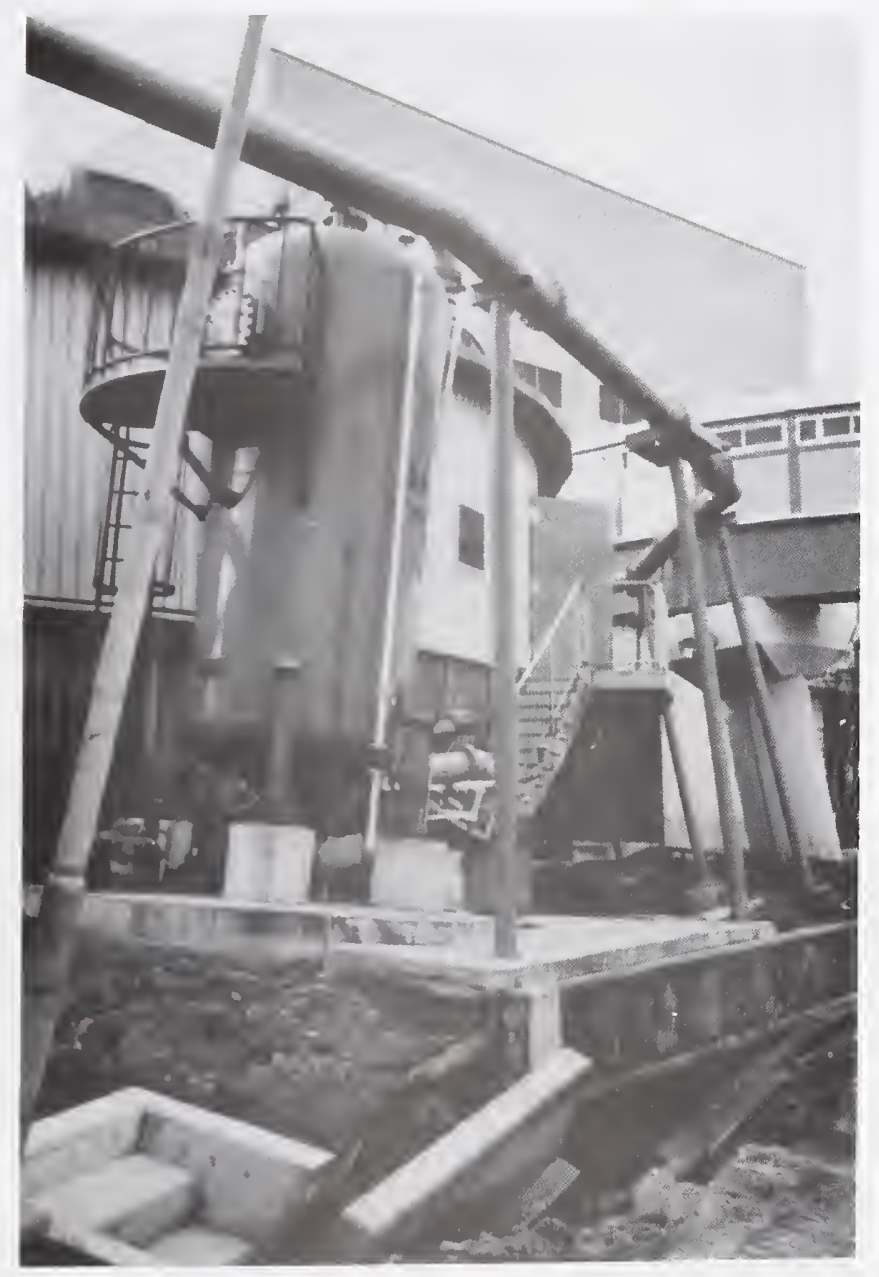

Photo 43 Piping and equipment distorted as a result of subsidence of the structures' foundation. 


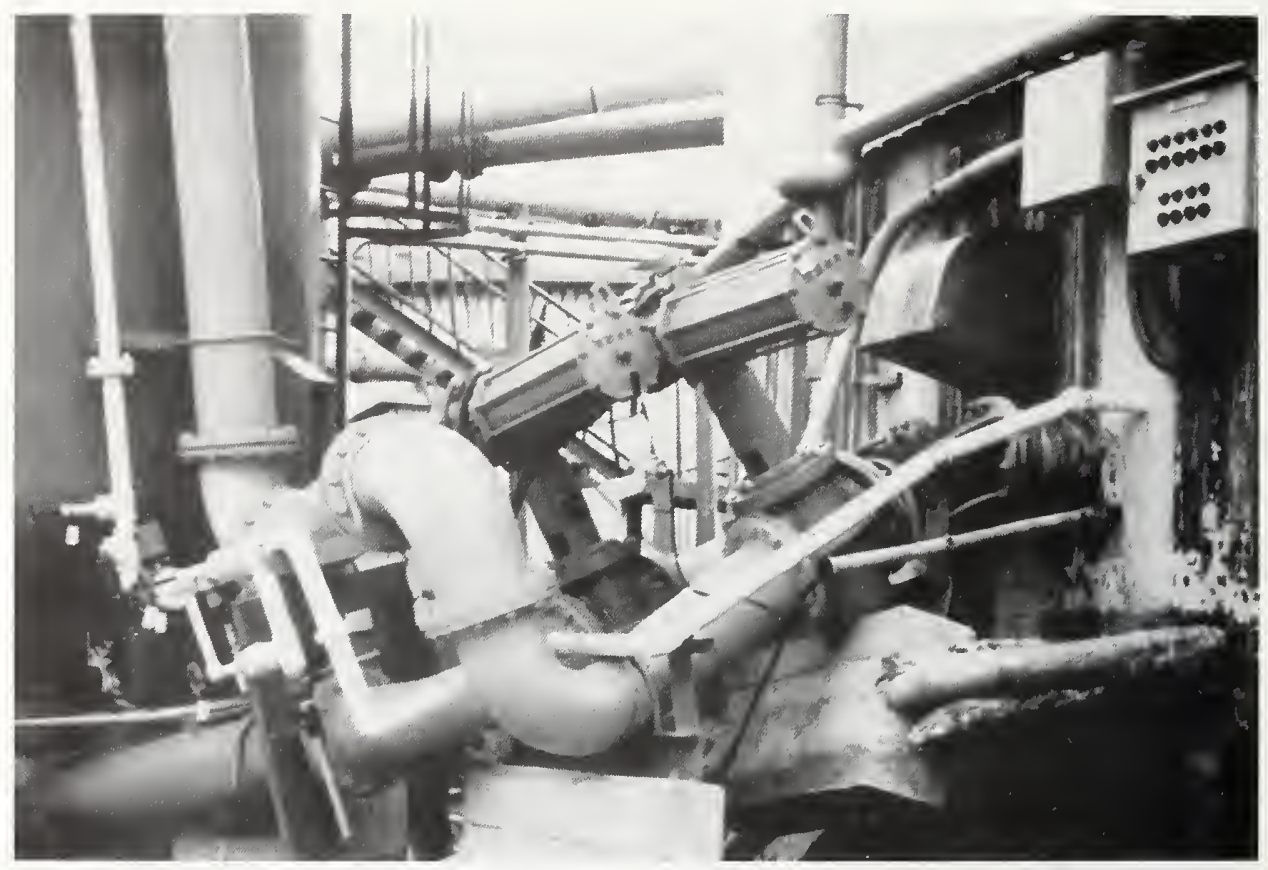

Photo $44 \quad$ Same as Photo 43.

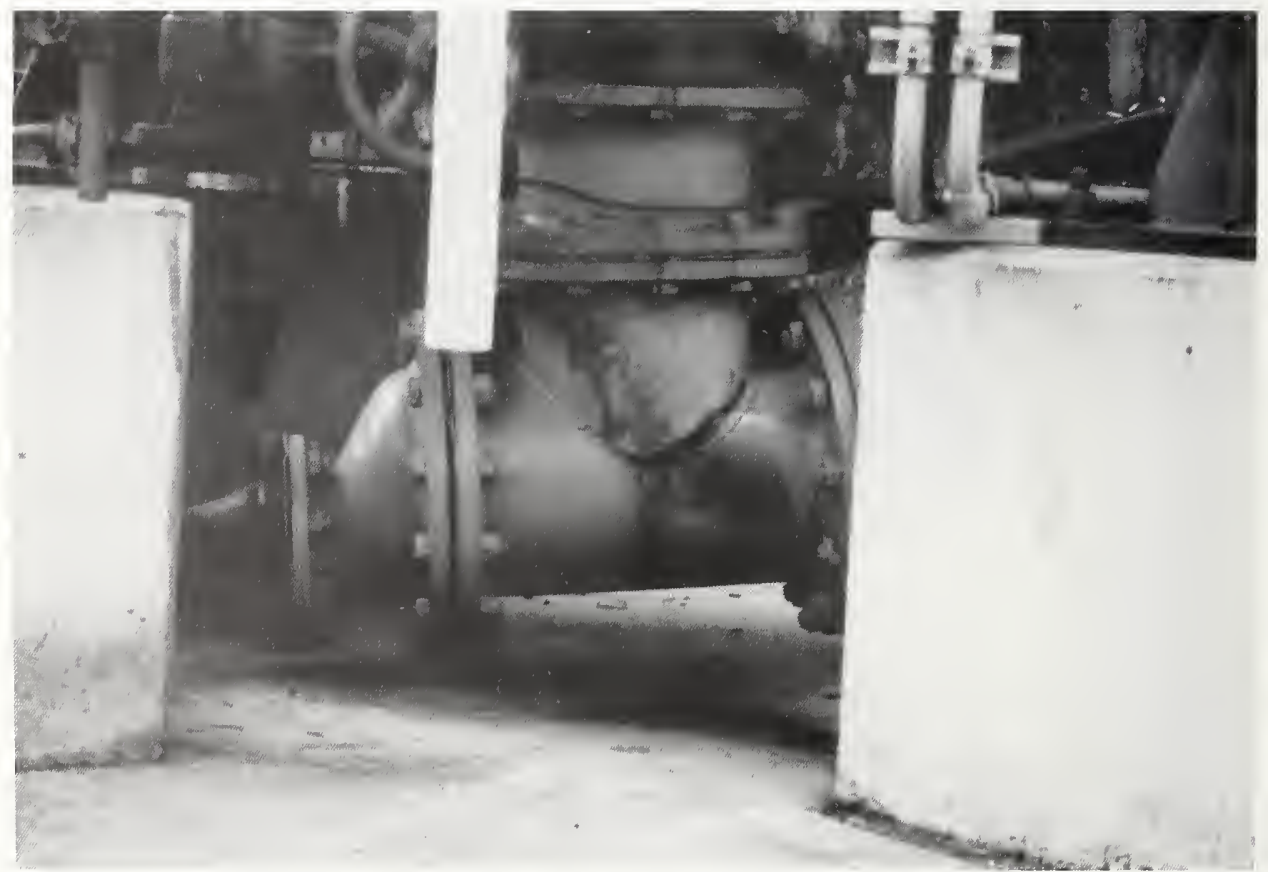

Photo $45 \quad$ Same as Photo 43. 


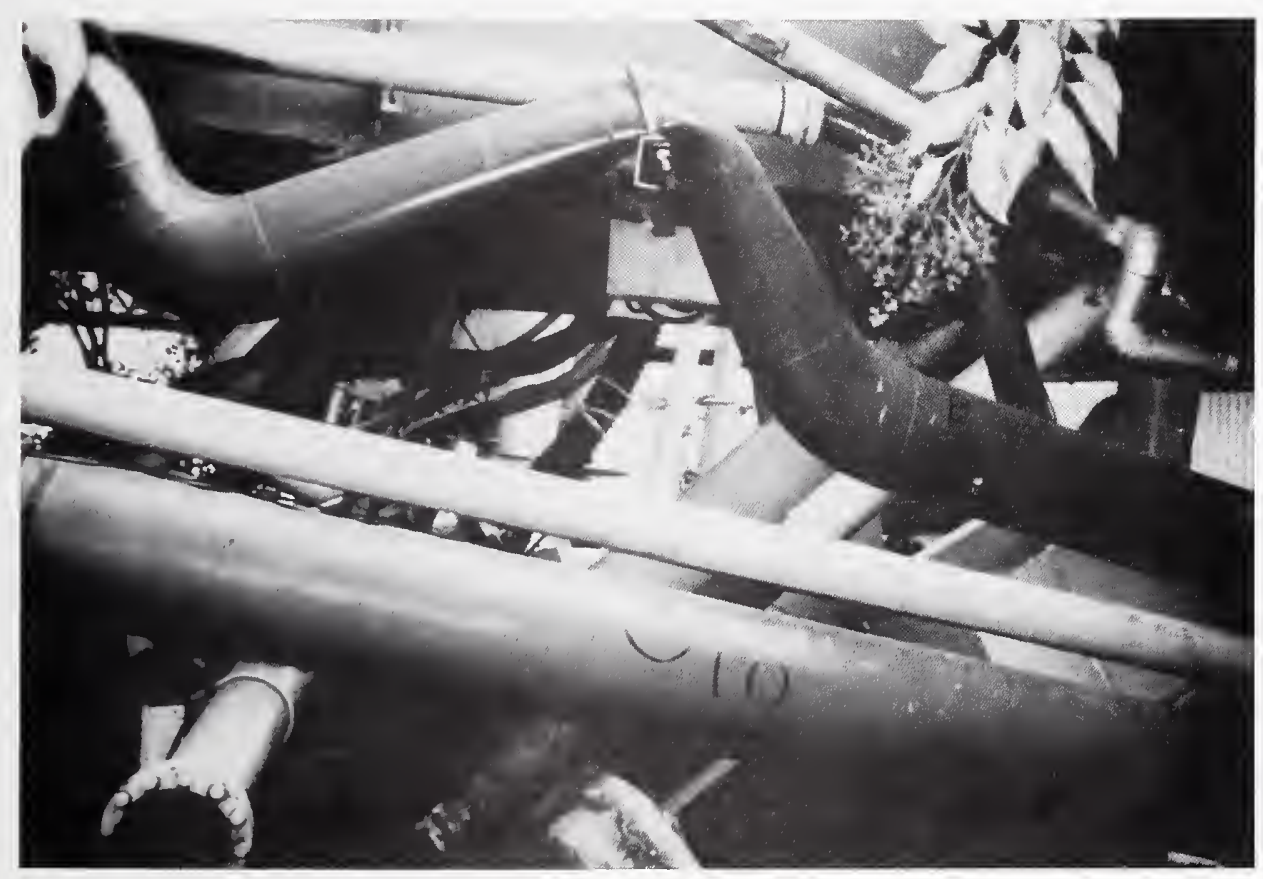

Photo 46 Welded steel pipe, approximately $200 \mathrm{~mm}$ in diameter folded when the foot/pipe bridge support was distorted from lateral spread. 


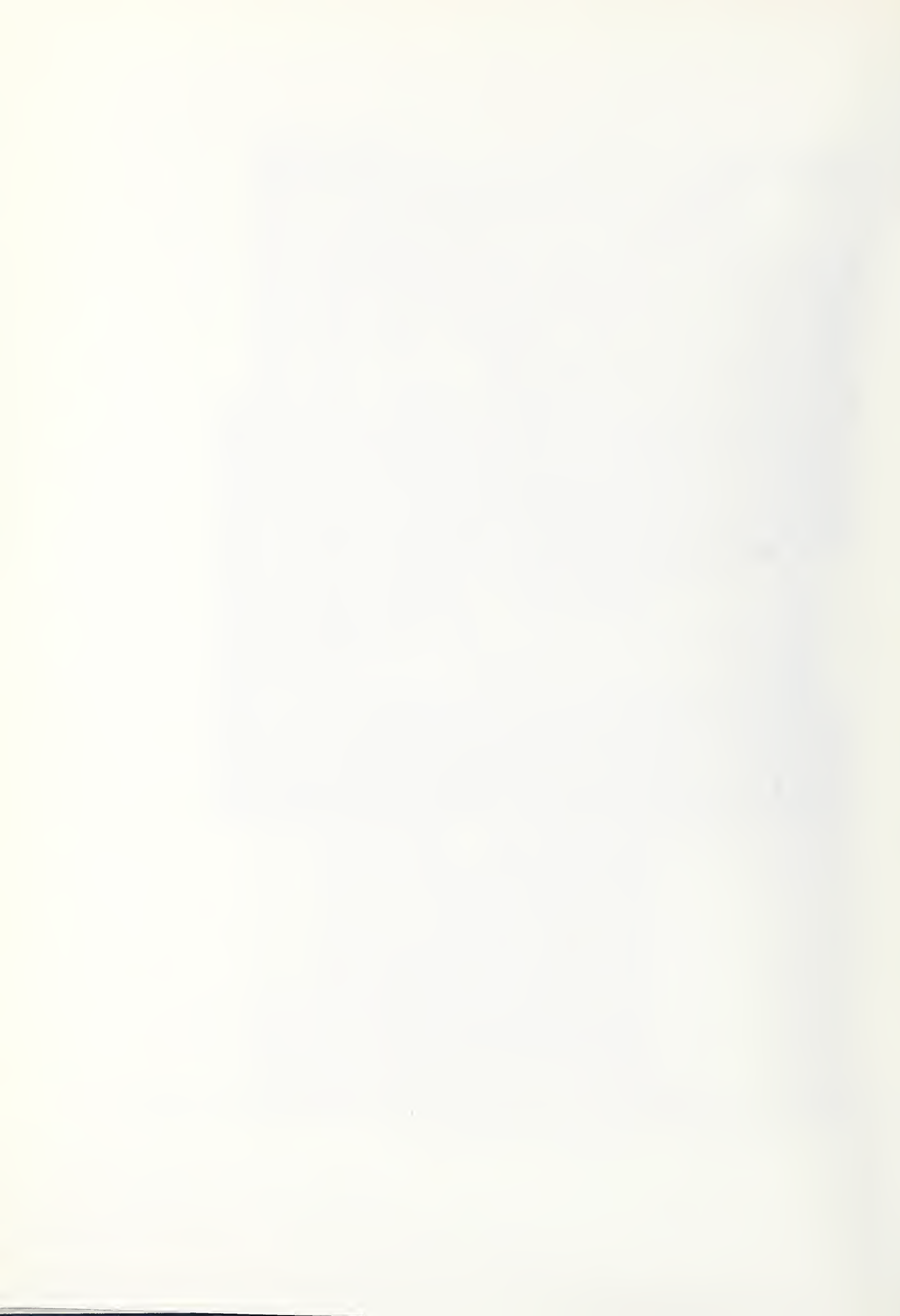




\subsection{Gas Delivery System}

\subsubsection{System Description}

Natural gas for the areas most severely affected by the earthquake, including Kobe City, Ashiya, Amagasaki, and Nishinomiya, is supplied by the Osaka Gas Company, Ltd. The company provides gas to more than 5.6 million metered customers, accounting for $30 \%$ of the total gas sales volume in Japan. Major trunk lines, pipelines, and distribution mains total $49430 \mathrm{~km}$. The Osaka Gas system is comparable in size to the gas delivery network operated by the Southern California Gas Company, which is the largest U.S. gas supplier with approximately 4.6 million metered customers and nearly $74000 \mathrm{~km}$ of transmission, distribution supply, and distribution pipelines. Liquefied natural gas (LNG) accounts for about $94 \%$ of the Osaka Gas system feedstock. Most of the supply is imported by means of tankers from Brunei, Australia, and Indonesia.

Residential gas operations accounted for nearly $40 \%$ of total volume sales in 1994 and about $95 \%$ of the customer base. Industrial gas sales accounted for nearly $42 \%$ of total volume in 1994, compared to only $30 \%$ in 1989. The rapid increase in industrial supply shows the increasing dependency of industrial heat energy demand on gas. At the time of the Hyogoken-Nanbu earthquake, about $41 \%$ of the industrial heat energy demand in the Osaka Bay region was being met with natural gas to fuel heating units, such as furnaces and boilers.

Figure 5.3.1 is a map of the main facilities and pipelines of the Osaka Gas system. Three LNG terminals provide the primary sources for distribution. The two Senboku terminals have a combined capacity of 25.6 million $\mathrm{m}^{3}$, and the Himeji terminal has a capacity of 8.1 million $\mathrm{m}^{3}$. Gas is conveyed regionally through a system of major trunk lines, which operate at internal pressures of $4 \mathrm{MPa}$. Transportation of gas also is accomplished through what is termed a "medium pressure" system of A lines, at internal pressures of $0.3 \mathrm{MPa}$ to $1.0 \mathrm{MPa}$, and $\mathrm{B}$ lines at internal pressures of $0.1 \mathrm{MPa}$ to $0.3 \mathrm{MPa}$. There are 19 gas distribution stations where 37 gas holders are located for a nominal overall capacity of 4.15 million $\mathrm{m}^{3}$. Only the major trunk lines, medium pressure A lines, and distribution stations in Kobe and Nishinomiya are shown on the map.

Emergency plans should be developed; and formal and specific communication procedures should be established between gas, electric power, water supply, and fire department personnel.

The Osaka Gas system is divided into what company personnel call "super blocks." The eight super blocks of the network are large areas which can be isolated through telemeter control by closing valves activated by compressed carbon dioxide. Closing valves with carbon dioxide allows for control independent of electric power supply. The system can be subdivided further into about 55 "middle blocks," each of which may provide service to hundreds of thousands of customers. The middle blocks must be isolated by means of manually operated valves. The low pressure pipeline system within the middle blocks can be subdivided again into sectors, each provides service to between 3000 and 4000 customers. 
From 1976 to 1991, Osaka Gas was involved in a conversion program in which artificial gas plants, producing methane from coal and petroleum sources, were decommissioned and replaced with supply from LNG terminals. As a consequence of these changes and other operational considerations, the distribution network was divided into the aforementioned sectors, each of which could be isolated and converted to natural gas. This partitioning of the system is typical of the way in which gas delivery systems are organized and can be used for system restoration in the event of major supply disruption.

\subsubsection{Observations}

\subsubsection{LNG Facilities and Trunk lines}

There was no significant damage reported at the Senboku and Himeji LNG terminals, and at the gas distribution stations. As shown in Figure 5.3.1, there were three distribution stations with gas holders at Kobe, Fukiai, and Nishinomiya. No significant damage was reported at these structures even though they were subjected to high levels of acceleration. Peak accelerations at the Fukiai and Nishinomiya stations of $0.85 \mathrm{~g}$ and $0.81 \mathrm{~g}$, respectively, were recorded.

At the time of the earthquake, there were $490 \mathrm{~km}$ of transmission or major trunk lines in the system. The trunk lines are composed of X-42 or X-52 steel pipe with full penetration, electric arc, girth welds. Typical wall thickness for a $600-\mathrm{mm}$ diameter pipe is $12 \mathrm{~mm}$. There was no damage reported in the trunk lines.

\subsubsection{Medium Pressure Lines}

The medium pressure $\mathrm{A}$ lines are composed principally of steel pipe with full penetration, electric arc, girth welds. The oldest pipelines in this system were constructed in 1952. The medium pressure $B$ lines were composed either of electric arc welded steel pipe or ductile iron pipe with restrained mechanical joints on $5 \mathrm{~m}$ spacings. The mechanical joints are similar to the S-type joints deployed in the water supply system. The joints are equipped with a locking mechanism, and are installed to allow $6 \mathrm{~cm}$ of extension and $2 \mathrm{~cm}$ of compression. There were $1245 \mathrm{~km}$ and $3800 \mathrm{~km}$ of $\mathrm{A}$ and $\mathrm{B}$ lines, respectively, at the time of the earthquake.

Restoration of gas can be especially critical in winter, as it was in Kobe. The situation in Kobe can be replayed if a major earthquake happens in central and eastern United States during the winter season.

Table 5.3.1 summarizes the number of repairs and principal types of damage sustained by the medium pressure pipelines, based on data reported by Oka [2]. There were a total of 35 and 61 repairs to medium pressure $\mathrm{A}$ and $\mathrm{B}$ lines, respectively. The damage was concentrated at Dresser couplings and bolted flange joints. The Dresser couplings were typically $600-\mathrm{mm}$ long sleeve joints with compression gaskets and restraining devices against pullout. Damage was predominantly in the form of leakage where compression gaskets had loosened. A total of 14 low grade girth welds were damaged on steel pipelines. The low grade welds were installed after 1962 and were characterized by poor root penetration of the welds. Steel pipelines installed after 1962 were constructed in 
accordance with modern welding practices and did sustain weld damage.

At several locations medium pressure steel pipelines were subjected to large permanent ground deformation. Even though the steel pipelines were deformed at these locations, no leakage was observed. For example, the collapse of the Daikai Station (see Section 4.3.2.6 on Underground Rapid Transit Systems) imposed $2.5 \mathrm{~m}$ of settlement over a length of about $25 \mathrm{~m}$ to $50 \mathrm{~m}$ on a $400-\mathrm{mm}$ diameter A-line. No leakage was reported at this location. Oka [2] cites other examples of substantial steel pipeline distortion with no gas leakage at a landslide site and a location of liquefaction-induced bridge abutment deformation. These pipelines, which were composed of X-grade steel with full penetration electric-arc, girth welds, provides field evidence for the high degree of ductility and resistance to rupture of this type of modern steel pipeline.

\subsubsection{Low Pressure Distribution System}

The low pressure distribution system operating at internal pressures equivalent to $150 \mathrm{~mm}$ to $210 \mathrm{~mm}$ of water column, or about $1.8 \mathrm{kPa}$, sustained the greatest damage. There were $43895 \mathrm{~km}$ of low pressure lines at the time of the earthquake. In Kobe and adjacent communities, the low pressure system is composed predominantly of steel pipe with threaded steel couplings, or screw joints. A small portion of the low pressure system, approximately $5 \%$, is composed of polyethylene mains and services. Some steel piping with restrained mechanical joints and polyethylene linings was deployed in areas of artificial fill as a seismic countermeasures.

Table 5.3.2 summarizes damage reported by Oka [2] in the low pressure distribution system. There was no observed failure in the bodies of steel pipe segments, and only 36 locations of ruptured cast iron pipe walls. The predominant type of damage was failure at the threaded, or screw, joints of steel piping and leakage and cracking at the joints of cast and ductile iron pipelines. There was a total of 5190 repairs to distribution mains and branches within city streets, compared with 10161 damaged service lines and 11108 locations of damage at piping attached to buildings. Over $80 \%$ of the low pressure system damage was sustained by services. There were no repairs in polyethylene piping.

\subsubsection{Seismic Monitoring and Control System}

The Osaka Gas Company operates a system of seismic sensors throughout its service area to provide rapid feedback about the likelihood of earthquake damage to pipelines and associated facilities. The theoretical aspects of seismic monitoring and control and the application of such measures to the gas system in the Osaka area have been described by Takada, et al., [4]. The monitoring system works by telemetering data from an array of seismic sensors, which are deployed throughout the service area, to the company control center in Osaka. Data from the sensors, which includes acceleration and velocity, provide information about the severity of ground motion. In combination with the appropriate algorithms, these data can be used to estimate levels of damage. With these preliminary damage assessments, field crews are directed to confirm or modify the estimates and proceed with emergency operations.

At the time of the earthquake, 34 sensors had been installed throughout the service area, and company plans had been implemented to install an additional 30 
sensors by the end of March 1995. Strong motion data were acquired from the seismic sensor array, and additional information was obtained through emergency calls from customers and reports from field personnel during the morning of January 17.

Figure 5.3.2 is a map showing the 8 super blocks and middle blocks of the Osaka Gas system. The gas supply was shut down in the 5 middle blocks shaded in the figure. Osaka gas personnel report that by 11:30 a.m. on January 17 , gas supply was suspended to 386000 customers in Blocks 2 and 3. Blocks 7 (102000 customers), 1 (221000 customers), and 4 (124000 customers) were shut down by 4:15 p.m., 5:10 p.m., and 9:00 p.m., respectively, suspending gas supply to a total of 836000 customers. By January 23, gas supply had been discontinued to 857400 customers, or $15 \%$ of the total in Osaka Gas' service area. Venting from gas pipelines was accomplished by radio-controlled venting regulators on major trunk lines and manually operated valves on medium pressure lines. In areas of the system outside the five shaded blocks in Figure 5.3.2, there were 24844 reports of gas leakage.

\subsubsection{Repair and Restoration}

Approximately 6000 employees of Osaka Gas and 2300 personnel from 86 other utility companies were engaged in the repair and restoration shortly after the earthquake. The outside work force from other utilities was increased to approximately 3700 by early March.

Restoration was performed on a sector-bysector basis. After a sector was isolated, each customer meter box was closed and air pressure tests were performed on mains and services. Leaks were repaired and additional air pressure tests were performed. After repairs to mains and services, leakage tests and repairs, if needed, were performed in each customer building. Restoration progress was hampered by the need to clean water and debris which had washed into broken gas lines from adjacent soil and ruptured water mains. Restoration also was restricted by blocked and damaged roads and traffic congestion. Full restoration of a single sector often required 4 to 5 days.

By February 13, all medium pressure $\mathrm{A}$ lines had been put back into service, and the $B$ lines were almost completely restored. By February 13 and 22, gas service had been restored to $32 \%$ and $46 \%$ of the customers, respectively. It was not until mid-April, however, that gas service had been restored throughout the system, excepting severely damaged structures. Figure 5.3.3 shows both the number of customers restored per day and the cumulative percentage of the damaged system that was restored as a function of time [2]. As of April 11, gas had been restored to 700000 customers. Because of structural collapse, fire, and associated damage, service could not be restored to roughly 160000 customers.

The total expense of restoration is estimated at 190 billion yen, or approximately $\$ 2.3$ billion. This cost covers network repair, replacement, administration, and related activities.

\subsubsection{Intelligent Meters}

Approximately $74 \%$ of customers were equipped with intelligent metcrs according to Osaka Gas personnel. The meter is equipped with a seismic sensor triggered by acceleration exceeding $0.2 \mathrm{~g}$, a pressure sensor, and a flow rate transducer. The pressure and flow rate sensors detect abnormal drops in pressure and increases in 
flow, respectively, which are indicative of broken and disengaged piping and gas appliances. A microcomputer monitors the incoming signals and shuts off flow, if required. A lithium battery is used as a power supply for the microcomputer and gas shut-off valve.

Gas company personnel report that the intelligent meters appear to have functioned as intended. Data were not available, however, at the time of writing this report from which to assemble statistics about meter performance or to assess the extent to which the meters reduced fire initiation.

\subsubsection{Lesions for the United States}

One of the most important lessons associated with gas system performance during the Hyogoken-Nanbu earthquake is the need to coordinate the restoration of electric power with an assessment of the state of gas system repair. In the first day after the earthquake, electric power was restored to $60 \%$ of customers at the same time that shutting down and venting of middle blocks were being performed and appraisals were being made of gas system damage. It appears that there was no prearranged coordination between gas and electric company personnel to restore electric service in concert with shutting off and venting gas in areas severely damaged by the earthquake. Although the consequences of restoring electricity in areas of gas leakage have not been fully evaluated, it appears that early restoration of electric power in some areas of Kobe with leaking gas may have contributed to additional fires.

Emergency plans should be drawn up and specific, formal communication procedures should be established between gas, electric power, water supply, and fire department personnel. Specific checking mechanisms should be embodied in emergency response and restoration procedures so that gas and electric power personnel cannot proceed beyond a certain recovery level until there has been formal confirmation by their counterparts that gas systems are secure.

The difficulty and substantial time required for restoration of gas service in Kobe is an important reminder of the complexities and resources required for the resumption of gas supply after large areal shutdowns.

Restoration of gas can be especially critical in winter, as it was in Kobe. It may be advantageous, therefore, to provide for remote control and other rapid means of isolation of smaller, more manageable areas of the gas system. Strategies of this type require microzonation techniques which are capable of identifying areas with the potential for locally severe site response and soil liquefaction. Hazard mapping and scenario earthquake planning can be especially valuable to identify and isolate troublesome areas.

Although the widespread damage to steel pipe with threaded steel couplings occurred at an unprecedented scale, the vulnerability of this type of piping has been long recognized and reported in the technical literature [1,3]. Threaded steel sections are not only vulnerable to earthquake effects because of reduced cross-sectional area, but because threaded sections tend to be locations of corrosion concentration. A threaded coupling provides for a rigid connection, and thus lacks the longitudinal flexibility inherent in a pipeline with mechanical couplings that maintain a seal with compression gaskets.

The extensive damage to vulnerable piping is a very important lesson and a sobering reminder of potential earthquake effects in weak systems. Although threaded steel 
piping is used rarely in U.S. gas systems, many U.S. systems do use cast iron mains for low pressure distribution. Several of these systems are located in midwestern, eastern, and west coast portions of the United States which are susceptible to serious earthquakes, albeit with various return intervals. Although cast iron pipelines have provided generally long and reliable service, they nonetheless are composed of brittle material that does not possess sufficient ductility to accommodate large ground deformation caused by liquefaction or locally high transient motion. Given the vulnerable nature of cast iron pipelines to large differential movement, it is especially important to identify portions of cast iron systems in liquefiable soils as the basis for network isolation, replacement, and special emergency response planning.

\subsubsection{Research Needs}

The performance of the gas system reinforces the need to understand better the interactions among different lifelines. Recent earthquakes, such as the 1989 Loma Prieta, 1994 Northridge, and 1995 Hyogoken-Nanbu earthquakes, provide excellent vehicles for exploring these interactions. Of special importance is the relationship between gas system disruption as a potential source of flammable substances and the damage to and restoration of electric power as a potential source of ignition. There is a need to evaluate and optimize the use of water and fire protection relative to gas and electric system vulnerabilities and operational characteristics.

The Hyogoken-Nanbu earthquake provides an excellent opportunity to study the seismic behavior of a particular class of pipelines, such as threaded steel piping, at locations of permanent ground deformation caused by liquefaction and at locations where transient ground deformation was the principal source of pipeline distortion. Comparison and contrast of pipeline performance for these two conditions will help quantify seismic risk and improve system planning, retrofitting and design. The earthquake also provides an opportunity to evaluate the response of several different types of pipelines to similar levels of seismic intensity so that appropriate levels of vulnerability can be established for risk assessment.

The performance of the intelligent gas meter should be investigated to provide a more complete database with respect to the earthquake operation and effectiveness of seismic gas shutoff valves. The HyogokenNanbu earthquake provides an opportunity to assemble statistics on triggering, fire initiation relative to locations of shutoff meters, and overall reliability and effectiveness of the devices.

\subsubsection{References}

1. Katayama, T. and R. Isoyama, "Damage to Buried Distribution Pipelines during the 1971 San Fernando Earthquake," Earthquake Behavior and Safety of Oil and Gas Storage Facilities, Buried Pipelines and Equipment, PVP.Vol. 77, American Society of Mechanical Engineers, pp. 124-132, 1983.

2. Oka, S., "Damages of Gas Facilities by Great Hanshin Earthquake and Restoration Process," Proceedings, 6th U.S.-Japan Workshop on Earthquake Disaster Prevention for Lifeline Systems, Osaka, Japan, Public Works Research Institute, Tsukuba, Japan, July 1995. 
3. O'Rourke, T.D., M.D. Grigoriu, and M.M. Khater, "Seismic Response of Buried Pipes," Pressure Vessel and Piping Technology - A Decade of Progress, C. Sundararajan, Ed., ASME, New York, NY, pp. 281-323, 1985.
4. Takada, S., T. Fuke, and J. Ueno, "Seismic Monitoring and System Control for Lifelines," Technical Memorandum No. 3198, Proceedings of the Fifth U.S.Japan Workshop on Earthquake Disaster Prevention for Lifeline Systems, Tsukuba Science City, Japan, pp. 481-502, October 1992. 
Table 5.3.1

Summary of Repairs of Medium-Pressure Gas Pipelines [Oka (2)]

\begin{tabular}{|c|c|c|c|c|c|c|c|c|c|c|c|c|}
\hline & \multicolumn{4}{|c|}{ Steel Pipe } & \multirow{3}{*}{$\begin{array}{l}\text { Pipe } \\
\text { Body }\end{array}$} & \multicolumn{3}{|c|}{ Ductile Iron Pipe } & \multirow{3}{*}{$\begin{array}{l}\text { Pipe } \\
\text { Body }\end{array}$} & \multirow{3}{*}{$\begin{array}{l}\text { Total } \\
\text { for } \\
\text { Joints }\end{array}$} & \multirow{3}{*}{$\begin{array}{c}\text { Total } \\
\text { for Pipe } \\
\text { Bodies }\end{array}$} & \multirow{3}{*}{$\begin{array}{l}\text { Grand } \\
\text { Total }\end{array}$} \\
\hline & \multirow{2}{*}{$\begin{array}{c}\text { Welded } \\
\text { Joint }\end{array}$} & \multirow{2}{*}{$\begin{array}{c}\text { Flange } \\
\text { Joint }\end{array}$} & \multirow{2}{*}{$\begin{array}{l}\text { Mechan- } \\
\text { ical Joint } \\
\text { (Dresser) }\end{array}$} & \multirow[t]{2}{*}{ Subtotal } & & \multicolumn{2}{|c|}{ Mechanical Joint } & \multirow[t]{2}{*}{ Subtotal } & & & & \\
\hline & & & & & & $\begin{array}{l}\text { GM } \\
\text { II }\end{array}$ & \begin{tabular}{|l} 
Bell-and- \\
Spigot \\
\end{tabular} & & & & & \\
\hline $\begin{array}{c}\text { Medium-A } \\
\text { pressure }\end{array}$ & 8 & 5 & 22 & 35 & 0 & NA & NA & NA & NA & 35 & 0 & 35 \\
\hline $\begin{array}{c}\text { Medium-B } \\
\text { pressure }\end{array}$ & 6 & 17 & 38 & $\overline{61}$ & 0 & 3 & 7 & 10 & 0 & 71 & 0 & 71 \\
\hline Total & 14 & 22 & 60 & 96 & 0 & 3 & 7 & 10 & 0 & 106 & 0 & 106 \\
\hline
\end{tabular}

NA - not applicable

GMII - gas mechanical joint with a compression gasket 
Table 5.3.2

Summary of Repairs of Low-Pressure Gas Distribution Pipelines [Oka (2)]

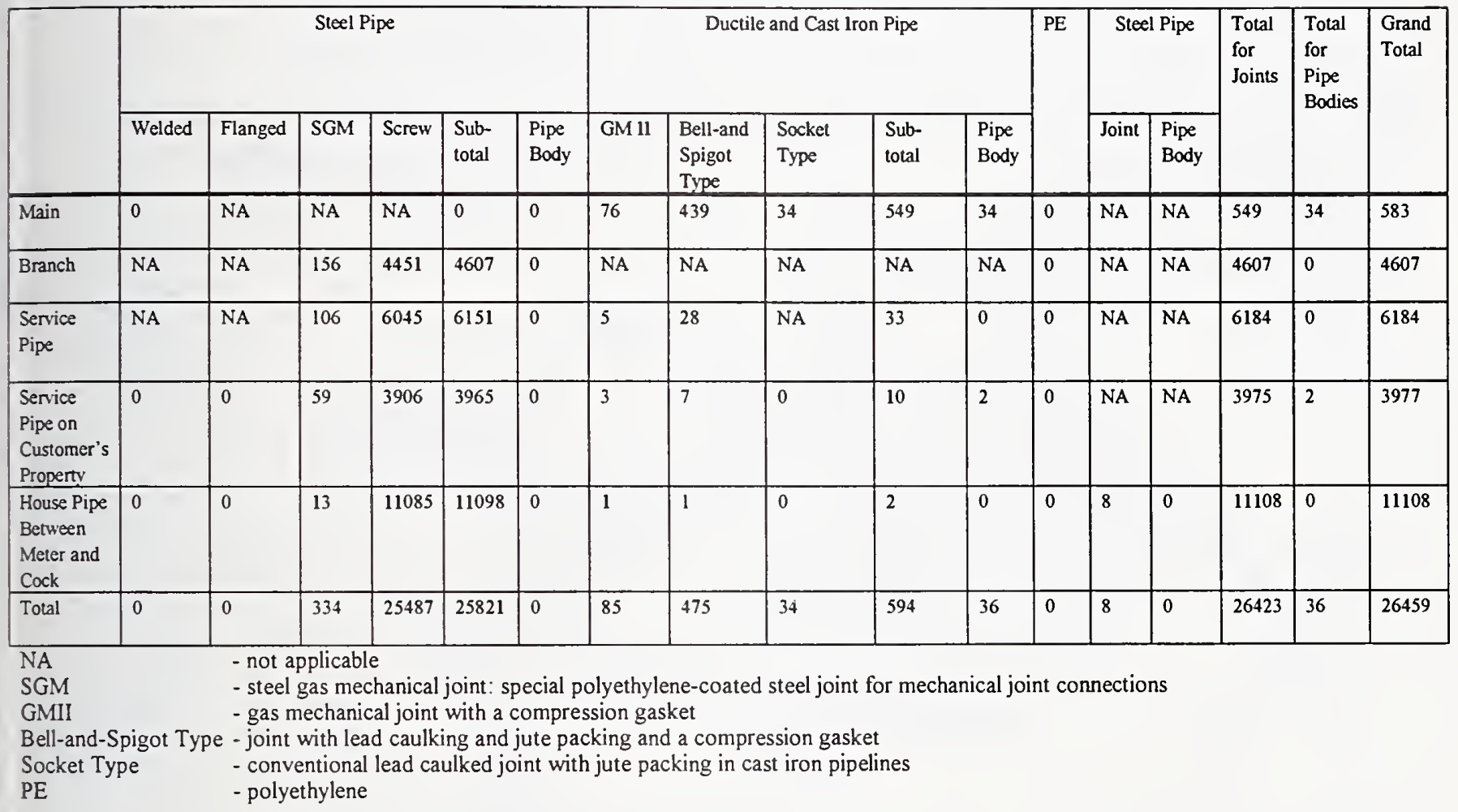




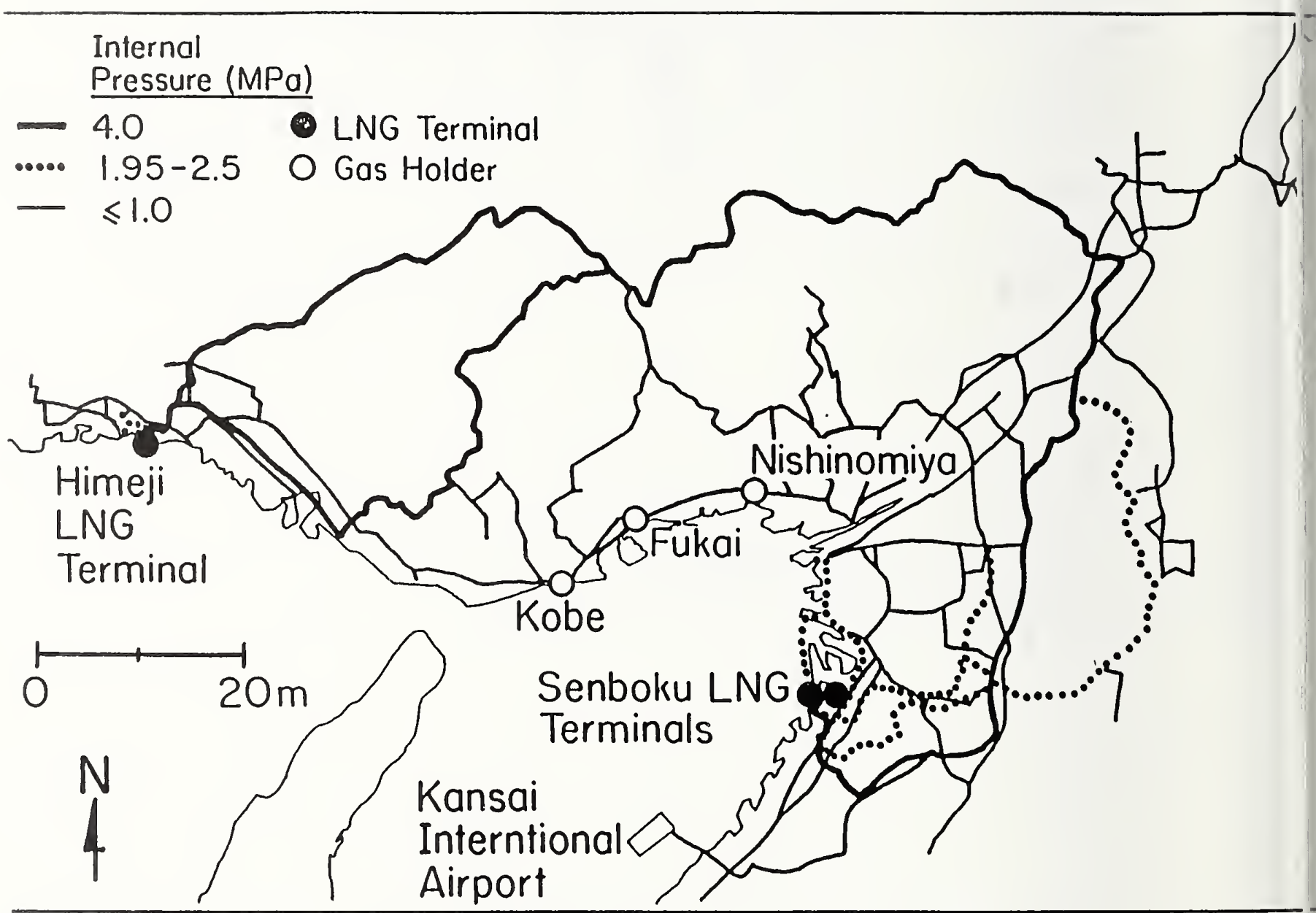

Figure 5.3.1 Map of principal facilities, trunk lines, and major pipelines operated by the Osaka Gas Company. 


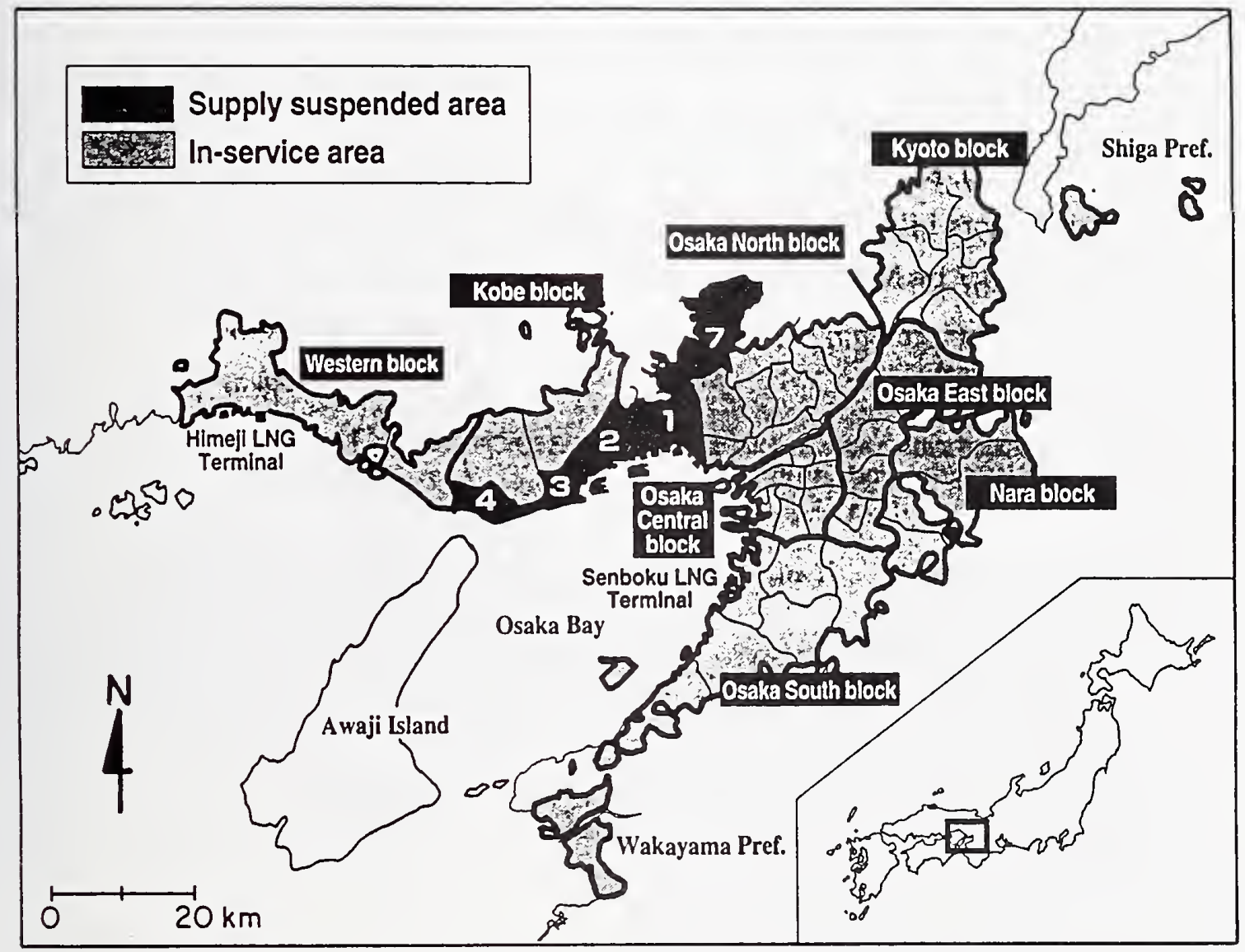

Figure 5.3.2 Map of super blocks and middle blocks in the Osaka Gas system showing areas where gas flow was shut off after the earthquake. 


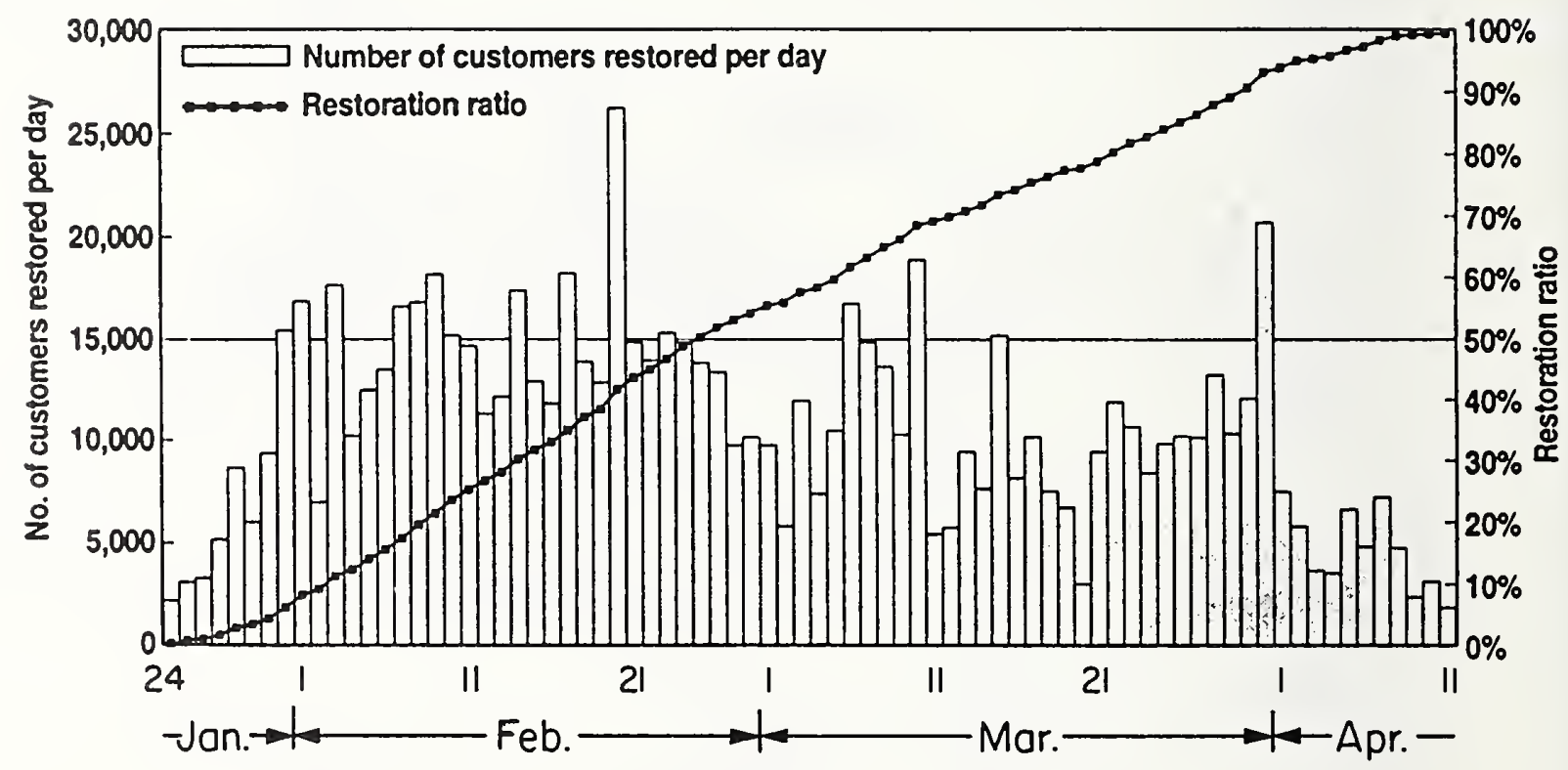

Figure 5.3.3 Graph showing rate of gas system restoration after the earthquake [Oka (2)]. 


\subsection{Electric Power}

\subsubsection{Overview}

\subsubsection{Kansai Electric Company}

The Kansai Electric Power Company is one of the nine major investor-owned electric utilities in Japan. It was established in 1951 as a result of a nationwide reorganization of the electric power industry. The service area of the company is located in the central part of the main island in the Japanese archipelago, and covers about $28500 \mathrm{~km}^{2}$, or about $8 \%$ of Japans total land area. The area has a population of about 20 million people and the company supplies about 12 million customers (meter connections). The Kansai area ranks second after the Tokyo metropolitan area in economic importance to Japan. The company serves four major cities: Osaka with 2.5 million, Kyoto with 1.39 million, Kobe with 1.47 million, and Nara with 0.35 million people [1]. A summary of vital statistics is given in Table 5.4.1.

While the Kansai District accounts for only $8 \%$ of the land, it consumes 18 percent of the nation's power. The break down of power sales is given in Table 5.4.2.

\subsubsection{System Description}

In the earthquake impacted area the transmission and sub-transmission voltages are $500 \mathrm{kV}, 275 \mathrm{kV}, 154 \mathrm{kV}$, and $77 \mathrm{kV}$. The $500 \mathrm{kV}$ system lies primarily to the north, northeast, and east of the earthquake impacted area. These lines carry power from major nuclear generating stations on the Japan Sea, and large pumped storage facilities. There are eight fossil-fuel generating facilities on Osaka Bay east of the epicenter with a total capacity of 5912 MW. The $500 \mathrm{kV}$ substations use gas-insulated circuit breakers and in some cases gas-insulated bus. Breaker-and-a-half bus configuration is used at most $500 \mathrm{kV}$ substations. Most $500 \mathrm{kV}$ substations in other parts of Japan use double bus-single breaker bus configurations. The lower voltage substations are configured as double bus-single breaker with a tie breaker between the busses. Figure 5.4.1 shows a simplified schematic diagram of the service area with major facilities and transmission lines. The primary distribution voltage is 6.6 $\mathrm{kV}$, although there are some $22 \mathrm{kV}$ and 33 $\mathrm{kV}$ distribution lines.

Aerial lines and towers are used for most high voltage lines, although there are more $275 \mathrm{kV}$ cables in urban areas than is typical for $230 \mathrm{kV}$ in California. Distribution is primarily aerial on concrete poles, with cables in steel conduit in central business areas like Kobe.

\subsubsection{Differences in Equipment, Facilities, and Practices Between Kobe and the United States}

There are notable differences between the facilities observed in the Kobe area and those found in California. It should be noted that these observations are based on visits to only three substations, two operating at $275 \mathrm{kV}$ and one at $77 \mathrm{kV}$. No $500 \mathrm{kV}$ facilities were visited.

The transmission towers tend to have heavier construction than in the United States, probably due to large wind loading associated with typhoons, and the fact that they typically carry more circuits than in the U.S. (Figure 5.4.2). The distribution system uses spun-concrete poles that were typically more heavily loaded than in the United States (Figure 5.4.3). 
The three substations that were visited, all in urban areas in which residential and light industrial areas were adjacent to the substation, had acoustical enclosures around all transformers. High voltage transformers often had a separate, smaller line reactor nearby, but outside the acoustical enclosure. The units resemble power transformers with a 10 MVA rating. Under light load these units are used to control system voltage. Transformers tended to be larger than in the United States, with weights of about 800000 pounds, not including radiators. All transformers were bolted to cast-in-place plates in foundation pads as compared to welding to embedments, which is common in the United States. Different reports were given on transformer bushings. One description was that porcelain is grouted into pockets in flanges, and the other indicated that they are the same as those used in the United States, that is, post-tension is used to hold the upper porcelain to the flange. Circuit breakers use post-tension connections of the porcelain to their flanges, as is common for transformers in the United States. The radiators on some $77 \mathrm{kV}$ transformers have substantial structural supports and piping connections to the transformer body included a flexible coupling (Figure 5.4.4). The transformers at a distribution substation operating between $77 \mathrm{kV}$ and $6.6 \mathrm{kV}$ were designed differently than those observed in the United States in that they had a large metal box supported on a large porcelain insulator on top of the transformer (Figure 5.4.5). Japan also uses a frail plate (busting plate) on top of transforms that can quickly release over pressures. In the United States, pressure release valves are used. The valves are self-closing but have a more limited tlow capacity and release pressure slower. On an earthquake investigation after the Off-Miyagi earthquake in 1978, thin (about $1-1 / 2 \mathrm{~cm}$ ) rubber pads under the transformers were thought to contribute to extensive bushing damage. None of these pads were observed in this earthquake.

Much of the equipment, such as potential transformers (Figure 5.4.6) and bulk-oil circuit breakers (Figure 5.4.7), appeared to be much larger than one would expect based on $230 \mathrm{kV}$ equipment found in the United States (Figure 5.4.8). All capacitors are enclosed in large tanks and have transformers installed on the isolated rack (Figure 5.4.9). A typical U.S. installation is shown in Figure 5.4.10. Flexible conductors were used to interconnect all equipment and in busses, however, liberal slack was not always provided. It was reported that Kansai Power uses flexible conductors, including their $500 \mathrm{kV}$ switchyards, with the exception of some operating at $77 \mathrm{kV}$. Some equipment installations were designed to conform to seismic design practices that were instituted in 1980, although most substation equipment observed was installed prior to this date. The support structures for some of these newer installations were very massive and stiff (Figure 5.4.11). Ground resistors are used, but they do not appear in this form in the U.S. Lightning arrester are frequently supported on short concrete pads just above the ground and surrounded by a railing to keep electrical clearances (Figure 5.4.12). Wave traps which are suspended from overhead bus supports (Figure 5.4.13), use a current-voltage transformer as a lower restraint rather than a separate insulator string that are attached to a structure or the ground as is done in the United States (Figure 5.4.14). The two high voltage sites had large water tanks to store water for cleaning salt deposits off of porcelain after typhoons. There were also water spray nozzles distributed in the high voltage switchyard that are activated under certain wind conditions to add water to the 
atmosphere to reduce the salt concentration as there is a concern with flash-over. Many bushings are covered with a thin, green colored silicone rubber to improve surface properties of the porcelain. The transformers that provided station power were much larger than those found in the United States, even at much larger substations. Their system uses a grounded neutral, as it is thought to reduce the chances of fire.

In general, Kansai Electric does not store any spare parts at substation. In the United States, some spares, such as bushings, post insulators, and lightning arresters are distributed throughout the system at major transmission substations. As in Japan, small parts, hardware, and electronic parts used in control rooms, such as protective relays, are stored at service centers.

\subsubsection{Seismic Design Criteria}

During the visit to Kansai Power, a copy of the "Guide for Seismic Design of Substation Equipment," developed by the Japan Electric Association [2] was provided (English translation) and represented the current practice for the seismic design of high voltage substations. It was developed after the Off-Miyagiken (Sendai) earthquake of 1978 and represents a consensus document of a committee representing the Ministry of International Trade and Industry (MITI), the Society of Electrical Cooperative Research, the Central Research Institute of Electric Power Industry (CRIEPI) (This is the Japanese counterpart to the Electric Power Research Institute in the U.S.), electric power companies and the equipment manufacturers. It was to serve as a "tentative substitute of Japanese standard..." Only the key points of this 42 page document are discussed here. The guide was to provide a design procedure to avoid serious problems in the supply of power resulting from earthquakes. It was limited to main circuit apparatuses and auxiliary equipment rated above $170 \mathrm{kV}$. Its criteria were to be used for new construction and when equipment had major renovation. There was no retrofit requirement.

The document, through a review of existing strong motion data in Japan (549 records including those from the Off-Miyagi earthquake of 1978) and a few U.S. records and past earthquake performance, sets forth a basic seismic design. Figure 5.4.15 reproduces a map of the expected distribution of horizontal accelerations with a 75 year return interval. Based on this plot, the maximum horizontal acceleration is set at $0.3 \mathrm{~g}$ to be applied at the ground surface. Vertical accelerations, typically only used for wall bushings, are to be one half horizontal values. Analysis and testing are to be done at resonant frequencies between $0.5 \mathrm{~Hz}$ and $10 \mathrm{~Hz}$. The provisions of the guide were to be applied uniformly throughout Japan, for sites that met a minimum requirement for soil properties. (The velocity of the secondary wave is higher than $150 \mathrm{~m} / \mathrm{s}$ or the blow count value of the soil is higher than 5 . It is not known if this test is consistent with those used in the United States) For sites that do not meet this requirement, special design should be applied to the equipment.

Additional requirements are to be applied to outdoor porcelain type apparatus and outdoor type transformers. For porcelain type apparatus, equipment shall be designed to withstand a quasi-resonant three cycle sinusoidal wave at its lowest support. For outdoor transformers, the tentative provisions call for bushings to be designed to withstand a quasi-resonant horizontal acceleration of a $0.5 \mathrm{~g}$ three cycle sinusoidal wave to be applied to the bottom of the bushing turret. The main body of the 
transformer is to be designed for a $0.5 \mathrm{~g}$ static acceleration. A provision is made that a user of the equipment can stipulate a 2 cycle sinusoidal, $0.3 \mathrm{~g}$ test or actual earthquake waves may be used. Provisions for indoor equipment are covered in the document, but will not be discussed here.

The design practice used prior to the issuing of the document was to be applied to most other equipment, based on its good earthquake performance. It is noted that the use of aluminum pipe busbars is under investigation and is to be covered in a supplemental report.

\subsubsection{What Happened}

\subsubsection{Seismic Environment at Power Facilities}

Figure 5.4.1 shows a rendering of a map provided by Kansai Electric showing the peak horizontal and vertical accelerations at 11 strong motion instruments located at power facilities. Instruments on the Japan Sea coast are located at a gas turbine and three nuclear generating stations and had peak horizontal accelerations between $13 \mathrm{gal}$ and $70 \mathrm{gal}$ and peak vertical accelerations ranging between $6 \mathrm{gal}$ and $56 \mathrm{gal}$. The accelerations of 547 gal horizontal and 478 gal vertical were recorded at the Shin-Kobe substation located about $24 \mathrm{~km}$ east-northeast of the epicenter. The Amagasaki-Higashi and the Nanko generating stations had 279 gal and 126 gal horizontal, and 331 gal and 199 gal vertical, respectively. The three sites with the largest accelerations had high vertical acceleration relative to their horizontal accelerations. It is noted that the record obtained at the Shin-Kobe substation and many others recorded in this earthquake significantly exceed the 1980 design guide criteria. Table 5.4.3 provides information about the characteristics of strong-motion instruments at Kansai Power facilities. Note that these are digital instruments with 16 bit resolution, sample rates between 100 to 1000 samples per second, a bandwidth from $1 \mathrm{hz}$ to between $30 \mathrm{hz}$ and $60 \mathrm{hz}$, and full scale ranging from 300 gal to 2000 gal. It is interesting to note that these bandwidths are comparable to instruments used in the United States. It has been reported that most Japanese instruments have an upper cutoff frequency of about $10 \mathrm{hz}$.

\subsubsection{Restoration of Service}

The overall performance of the power system, as measured by the restoration of power to substations and to areas that were not severely damaged, was very good. It should be noted that power could not be restored to some areas as this presented life-safety hazards until some damage could be cleared. Figure 5.4.16 shows the number of customers (meters - not individuals) without service as a function of time. The initial estimate of one million customers is very rough. It is interesting to note the slight increase in the number of customers without power during the 17 th, as was believed due to loss of service associated with the spread of fire. The disruption after the 18 th is primarily due to the slow process of restoring the massive damage to the distribution system. It should be noted that some of the restoration was of a temporary nature to get power to customers, and substantial rework was required. Figure 5.4.16 also shows the recovery of load following the earthquake.

Extensive mutual aid was provided, primarily to restore the distribution system. Work crews totaling 295 individuals, 46 high voltage generating vehicles $(6.6 \mathrm{kV})$ with a total capacity of $16 \mathrm{MW}, 74$ vehicles with materials to support the crews, water trucks, 
substation and transmission line hardware, and 2 earth station vehicles for communication were provided. Figure

5.4.17 shows the sources and types of mutual aid provided by utilities within Japan. The mobile generating units were distributed to critical facilities, such as hospitals. Table 5.4.4 shows the number and work assignment distribution of restoration personnel. The average length of stay of mutual aid personnel was about 10 days.

It is interesting to note that some pictures contained in picture books published by newspapers show massive destruction to the power distribution system but a working traffic light (Figure 5.4.18). To help control traffic, special power lines were set up for traffic signals. U.S. delegates who were attending a meeting in Osaka at the time of the earthquake observed special power distribution lines being strung to establish power outlets at residences. It is not known how widespread this practice was.

\subsubsection{Overview of Damage}

A summary of damage to power system facilities is given in Table 5.4.5. There were four $500 \mathrm{kV}$ substations just outside of the damage area. Figure 5.4.19 is a composite of several figures provided by Kansai Electric Co. This figure shows transmission lines and substations that were damaged, substations that were blacked out as a result of damage, the times that power was restored to major substation, and the approximate time that power was restored to various service areas. There are five $275 \mathrm{kV}$ substations that were de-energized as a result of damage at the substation, four that were damaged but did not lose power because of the damage, and two substations and one switching station that were undamaged. Six $154 \mathrm{kV}$ substations were damaged but did not lose power because of the damage and six were undamaged. Of the forty $77 \mathrm{kV}$ (and below) substations near the epicenter, four were de-energized as a result of damage, 28 were damaged, but did not lose power as a result of the damage, and eight were undamaged. It is interesting to note that the Awaji Island did not lose power (Figure 5.4.19). The disruption in a large part of the west end of the disrupted area was due to damage to one of the 275 $\mathrm{kV}$ substations. It was reported [3] that nearly all problems that caused disruption could be attributed to transformer bushings at five $275 \mathrm{kV}$ substations and one at 187 $\mathrm{kV}$ substation and four at $77 \mathrm{kV}$ substations.

As a result of the damage from this earthquake and the large amplitude of the recorded ground motions, the power industry is reviewing seismic design criteria. It is anticipated that this study will be competed in about 2 years.

The total cost of damage and some upgrading to the electrical system was reported by Kansai Electric as about $\$ 2.3$ billion. About $\$ 1$ billion was attributed to the distribution system and the remainder to transmission, generation and possibly the loss of the Kobe office building. In the review of damage to the distribution system, it was impossible to get a feeling of the losses, but as discussed below, extensive damage was done in the Kobe business district to buried conduit and surface facilities were damaged over a much broader area. Damaged generating facilities were not visited, but most were generally put back into service quickly. Three generating stations experienced soil subsidence and the Higashinada generating station (120 MW) was going to require substantial restoration time. 


\subsubsection{Itami Control Center and Substation}

The Itami substation was reported to be the most severely damaged substation. The substation is located approximately $39 \mathrm{~km}$ East-Northeast of the epicenter on what was wetlands adjacent to the Mukogawa river. The substation was originally built in 1941 and the $275 \mathrm{kV}$ switchyard was added in 1960. The age of specific banks or bus positions is not known, but much of the equipment in the switchyard is over 20 years old. The control house is 3 years old and it was built on a specially prepared foundation, but piles were not used. The $275 \mathrm{kV}$ switchyard has a double-bus single-breaker configuration with 11 positions. There are four $275 \mathrm{kV}$ lines supplying the bus, six transformer banks (three $275 \mathrm{kV}$ to $154 \mathrm{kV}$ and three $275 \mathrm{kV}$ to $77 \mathrm{kV}$ ), and one tie breaker. The $275 \mathrm{kV}$ and $154 \mathrm{kV}$ busses have bulk-oil circuit breakers. Figure 5.4.20 shows a modified schematic one-line diagram for the $275 \mathrm{kV}$ and $154 \mathrm{kV}$ switchyards that is approximately configured with the same physical layout at the site. Note that for a few items of equipment, individual phases are shown. The control house, two water tanks, transmission and microwave towers, and two large fissures in the ground are also shown.

The review of seismic response of the equipment at the facility will start where the high voltage lines enter the switchyard and work through to the lower voltage switchyards, the control house and its equipment, and then the transmission-line towers.

The four $275 \mathrm{kV}$ circuits enter the substation from drops from dead-end structures. Two phases of each circuit have wave traps (Figure 5.4.13). Note that there is relatively little slack between the wave trap and the adjacent disconnect switch. Several failures were observed. In two cases, one of the four cast iron legs on the lower flange of the current-voltage transformer failed. One unit was observed in the graveyard (Figure 5.4.21), and one unit was still in service with a cracked base support (Figure 5.4.22). One current-voltage transformer had a porcelain failure at the base just above its lower flange (Figure 5.4.23). Several other current-voltage transformers developed leaks at "O" rings used to seal the units, but these were repaired and put back into service. Two damaged wave traps were also observed in the graveyard. Notation on an operating diagram indicated that disconnect switches on each circuit were damaged, but the number of phases or type of damage is not known. These were the units adjacent to the wave traps and vibration of the wave trap could generate interaction loads.

In the United States, the lower wave trap restraint of suspended wave traps is typically configured like the phase without a current-voltage transformer (CVT) or wave trap. That is, the wave trap restraint is connected to a structure or to the ground with an insulator string. The CVT would have its own support adjacent to the wave trap restraint. In the configuration shown, the lower support is provided by the CVT, so that it must withstand its own inertial loads and the wave trap restraint loads. In the United States, CVTs and similar devices, such as potential transformers, have been very seismically vulnerable, even without interaction loads. As noted earlier, the CVTs appear to be large for their operating voltage as compared to the United States. In Japan, all of the CVTs were supported on lattice-types structures that were probably relatively stiff. In the United States most CVTs are supported on a tubular steel column that is probably relatively flexible. 
CVTs in the United States with stiffer supports appear to perform better.

One bulk-oil circuit breaker was used in each of the $275 \mathrm{kV}$ circuits that fed into the bus (Figure 5.4.24). Two of these units were marked as damaged and one had a slipped bushing (Figure 5.4.25). The damage patterns in the United States and Japan appear to be reversed. That is, in the U.S. transformer bushings tend to slip, with over 50 examples in the Northridge earthquake, and circuit breaker bushings do not. The opposite is true in Japan. There were two spare bushings at the site, an unusual occurrence since most spares are stored at service centers in Japan. Twelve bushings from two circuit breakers were removed to replace damaged units at other sites (Figure 5.4.26).

A double-bus single break configuration is used on the $275 \mathrm{kV}$ bus. The potential transformers on the bus were much larger that those typically found in the United States (Figure 5.4.6). These units were installed after 1980, when more stringent design standards were used and the support structure and anchorage details reflects this (Figure 5.4.27). These units were not damaged. Twelve of the thirty disconnect switches in or adjacent to the double bus were indicated as being damaged. A picture of one unit (Figure 5.4.28) shows that the post insulator failed at its base. Note that this is an isolated failure and that there is relatively little slack between the drop and the disconnect switch. In the Northridge earthquake several switches were damaged due to the dynamics of the switch and probably interaction loads associated with the insulator string used in the drop. However, in Northridge the metal supports below the post insulators of the switch were deformed, while in Japan the post insulators failed. Since the insulator string is relatively light weight, nonlinear effects due to the interaction of the string, slack in the connections, and vertical motions of the conductor support tower may cause larger than expected loads. The post insulators in the graveyard, which had solid cores, had an unusual failure mode, as they appeared to split in half longitudinally (Figure 5.4.29).

In the position shown in Figure 5.4.12, adjacent to the circuit breaker is a pot-head of a cable to Bank 6, a disconnect switch and a lightning arrester. The pothead design is different from that used in the United States in that there are standoffs between the bottom flange of the pot-head porcelain and its support structure, similar to lightning arresters. The disconnect switch is similar to the center break disconnect switches used in the United States, except arms are fabricated from copper rather than aluminum. The three lightning arresters in this position failed (Figure 5.4.30), and probably damaged the B-phase disconnect switch in the background. The lightning arrester is supported from a short concrete pedestal. This configuration avoids the expense of a support structure and the dynamic amplification that it contributes to the response of the lightning arrester. Note that there is a small fence around the lightning arrester to maintain adequate clearance. Under U.S. rules, a tall fence would probably be required to prevent access. The lightning arrester has a standoff that is the same diameter as the lighting arrester. This type of design is occasionally used in the United States, but small insulators are much more common. Seven of the fifteen lightning arresters failed in this elements, as indicated by items in the graveyard (Figure 5.4.31). The lightning arresters were also positioned much further from transformer bushings than in the United States. Many of the porcelain members were a bright green color, which 
was from a thin silicon rubber coating applied to the porcelain (Figure 5.4.32).

The site has six transformer banks, each bank consisting of a three-phase

transformer. Some units weighed about 800000 pounds and were anchored by eight $3.75 \mathrm{~cm}$ to $4.5 \mathrm{~cm}$ diameter bolts. All units were bolted to nuts or plates embedded in the transformer pad. Three of the banks had anchorage failures, with one unit moving about $45 \mathrm{~cm}$ (Figure 5.4.33). As a result of the displacement, flexible covers on tertiary bus were severely stressed (Figure 5.4.34), control cables that entered the transformer junction box through a hole in the concrete pad were almost sheared off (Figure 5.4.35), a low voltage bushing failed at its top due to interaction load with the adjacent item of equipment, and the case of the transformer hit and shorted out connections in a cabinet that contained tertiary circuits (Figure 5.4.36). A decision was made to replace some of these transformers and a soil investigation was underway to determine the requirements for the foundation of the new transformers. Because of the proximity of residential and light industry to the substation, transformers have acoustical enclosures. In one case the enclosure supports were damaged and the enclosure had shifted (Figure 5.4.37). A small line reactor, which looks like a transformer and controls line voltage under light loads, was connected to the main banks and also had damaged or failed anchorage. One units sheared its anchor bolts and slid about 25 $\mathrm{cm}$ in the opposite direction form that of the main transformer (Figure 5.4.38), aggravating the interaction problems with the transformer bushings.

\footnotetext{
Capacitor banks observed at several sites have a different form than those typically found in the United States. The capacitors are enclosed in relatively large tanks and
}

have small transformers located on the electrically isolated rack (Figure 5.4.9). Note that the post insulators that form diagonal braces are mounted so that they can take tensile and compressive loads.

Station batteries were secured to well-braced and anchored battery racks (Figure 5.4.39). A rack of a different design, positioned close to the floor, reduces the need for bracing (Figure 5.4.40). A common detail found at several Japanese facilities is the use of stiff rubber spacers between the cells and bctween the cells and their restraints (Figure 5.4.41). Cabinets associated with the batteries were well-anchored. Just outside of the battery room there was a relay cabinet that was unanchored at the time of the earthquake and it fell over and relays had to be replaced. The cabinet is now anchored at its base and brace at the top. The cable trays were similar to those used by the power industry in the United States, except that they have rungs rather than solid bottoms (Figure 5.4.42).

Several soil effects were observed at the site. As noted above, the site was constructed on wetlands adjacent to a river. Figure 5.4.20 shows two large cracks in the surface of the site. Figure 5.4.43 shows one of the large cracks that opened about $25 \mathrm{~cm}$ in the switchyard. Where these cracks crossed concrete cable trenches the trenches were fractured or deformed (Figure 5.4.44). The crack which crossed the site diagonally opened between $20 \mathrm{~cm}$ and $30 \mathrm{~cm}$. Because of the potential of control cable damage (Figure 5.4.45), all transformers were operated manually rather than by using the controls until the cables could be checked. None of the cables were damaged, but a pipe for a system of compressed air in one of the trenched failed. Bus support structures and equipment foundation pads were also disturbed. The footings on a bus 
support structure rotated and there was a crack in the soil about a foot deep (Figure 5.4.46). A lightning arrester support structure tipped over about 2-1/2 degrees (Figure 5.4.47), which probably contributed to the failure of the lightning arrester. The diagonal crack also passed though the six separate footings of a $275 \mathrm{kV}$ disconnect switch. This switch had been removed and a monolithic pad of reinforced concrete about 1-1/4 $\mathrm{m}$ thick was being installed (Figure 5.4.48). At the time of the visit, work was in progress to repair water pipes near the control house. This did not have any effect on equipment or technical operations, but it did make it difficult for operating personnel as sanitary facilities were not available.

Water stored in two 100000 liter tanks was used to clean porcelain after typhoons. These were old installations and their response was somewhat puzzling. Each tank was surrounded by a $10 \mathrm{~cm}$ thick concrete ring about $45 \mathrm{~cm}$ outside of the outer diameter of the tank. The annular ring between the tank and the concrete was covered with asphalt. It has been suggested that these rings were to retain the soil that was compacted below the tanks. Each tank was secured by about eight bolts on chairs. The details of the anchorage of the bolts is not known, but it was reported that they were not secured to the concrete ring. The bolts on the southern tank were stretched or pulled out, the asphalt strip between the tank and the concrete ring was broken and deformed, and some of the chairs were deformed indicating that there was a large force between the anchor bolt and the chair (Figure 5.4.49). On the north tank, the bolts appeared similar to those on the south tank, and some chairs were deformed, but there was no disturbance to the asphalt at the bottom of the tank or by the concrete ring. There was no indication that the tank had rocked, other than the bolt position. The good detailing in the flexiblc pipc connection provided to this old installation (Figure 5.4.50) is rarely seen in the United States. Other soil effects are discussed below relative to a transmission-line tower.

A transmission tower adjacent to the control house had the ground around the tower footings settled about $15 \mathrm{~cm}$ (Figure 5.4.51). Conduit attached to the tower by a " $U$ " bolt was pulled down with the soil about $8 \mathrm{~cm}$ (Figure 5.4.52), and there was damage to concrete cable trenches near the base of the tower. Relative movement of the soil and the tower could damage signal lines coming off of the tower, such as optical fibers, if adequate slack is not provided.

The transmission tower adjacent to the one shown above also carried two $275 \mathrm{kV}$ circuits and two $154 \mathrm{kV}$ circuits. These are dead-end types structures (Figure 5.4.53). That is, the insulator string is in the load path of the line to the tower, rather than the line being supported by a string hanging from the arm. Note that the lines on the lefit side of the tower are supported by post insulators below the tower arm. On those and several other transmission lines the post insulators failed at the sand ring and were hanging from the line. This did not put the line out of service, but did require repair. Some towers carry optical fiber communication cables in their transmission tower ground wire that are used for protective relay signaling. This provides a redundant path with the microwave system, but there are no plans to eliminate carrier signals and wave traps, as has been done by some utilities in the United States.

A microwave tower at the site had two members that were bent or had minor buckling (Figure 5.4.54), which did not effect operations. While this damage was minor, it is very unusual for earthquakes to damage 
communication towers. The foundation did not appear to be disturbed. Communication equipment and an engine-generator at the site were not visited because of a lack of time.

\subsubsection{Shin-Kobe Substation}

The Shin-Kobe substation is located about $30 \mathrm{~km}$ Northeast of the epicenter on a hillside on at least three man-made terraces. The back of each cut was faced with a concrete wall. While grading diagrams were not seen, it appears that the back part of the terraces were on cut and the front part were on fill. This appears to be born out by cracks and separation in a wall at one side of the site and subsidence and cracks at other locations. Circuit breakers were frequently located on the fill part of the terrace.

Damage to equipment at the site was similar to that at Itami. Lightning arresters failed and damaged disconnect switches when they fell (Figure 5.4.55). Bulk-oil circuit breaker bushings slipped on their lower flange (Figure 5.4.56), probably due to inertial rather than interaction loads because of the configuration of the conductors. Post insulators on disconnect switches failed (Figure 5.4.57). The failures could have been from combined effects of interaction and inertial loads. Insulators in general did not fail at the base of the insulator stack, but in the body of the porcelain, and in some cases fractured the porcelain longitudinally. The three insulators in the stack were graded, that is, successive segments from the bottom were thinner. The vast majority of post insulator failures in the United States are at the sand ring rather than in the body of the insulator.

There were several differences in the damage between this substation and Itami substation. Transformer anchorage did not fail. Post insulators supporting neutral resistors failed (Figure 5.4.58). Of particular interest, a $77 \mathrm{kV}$, three-phase, gas-insulated circuit breaker lost three bushings (Figure 5.4.59). In the United States, the failure of any equipment at this voltage is unusual, and a dead-tank circuit breaker has never failed. One possible cause of the failure was that the ground settled and the bus support structure did not because of its better foundation. If the vertical drop to the circuit breaker did not have slack, as is often the case, the relative displacement could have pulled the internal conductor from the bushing.

Another feature not observed in the United States was fresh water spray heads that were used during certain wind and atmospheric conditions to lower the concentration of salt in the air to reduce the potential for flash-over in the $275 \mathrm{kV}$ switchyard (Figure 5.4.60).

\subsubsection{Fukiai Control Center and Substation}

The Fukiai substation is a distribution substation operating between $77 \mathrm{kV}$ and 6.6 $\mathrm{kV}$, the primary distribution voltage of Kansai Power Co. The substation has three, three-phase transformer banks and the 77 $\mathrm{kV}$ switchyard is gas insulated. A control center is located in a building adjacent to the substation.

Transformer Bank 1 failed its anchorage, slid into an acoustical or fire wall, and caused it to lean (Figure 5.4.61). A pot head connected to one phase of the transformer primary failed (Figure 5.4.62), probably when the bushing hit the pot head. The radiators are supported by structural members at the top and bottom, and the piping connections at the top and bottom 
incorporate flexible couplings (Figure

5.4.63). This design feature would eliminate a common seismic problem in the United States of leaking radiator connections on transmission transformers. Relative motion between the control cable support structure and the radiators was sufficient to overcome the current $60 \mathrm{~cm}$ gap and cause the radiators the be crushed and leak (Figure 5.4.64).

The anchorage on transformer Bank 2 apparently failed, but some bolts were still in their holes, suggesting that the transformer may have rocked back and forth. Diagonal rods bracing the fire walls all failed, indicating that there had been significant motion of the wall. Conductors, supported from post insulators connected to the fire wall structure appear to have loaded the bushings and caused leaks. The design and damage to Bank 3 was similar to that on Bank 2. Three mobile transformers temporarily replaced the damaged units. Due to severe traffic congestion, the first transformer arrived from Osaka about 3 PM. The second unit arrived in the afternoon of the next day, the delay again due to very heavy traffic. Each unit has a 10 MVA rating.

The site had $77 \mathrm{kV}$ and $6.6 \mathrm{kV}$ gas insulated switchyards which were undamaged (Figure 5.4.65).

In a building adjacent to the switchyard there is a small control center. The earthquake caused computer monitors to fall to the floor, but there was little significant damage. Station batteries associated with the control center and substation were well-restrained in battery racks that were well-braced and anchored similar to those shown in Figure 5.4.39.

5.4.2.7 Performance of Generating

\section{Facilities}

Prior to the earthquake, 35 generating units were operating or in a startup process. However, of these 35 units, 12 units (8 units that were operating and 4 units that were in startup process) stopped due to excessive turbine shaft vibrations and other causes triggered by the earthquake. Among those units which automatically stopped, no damage was found to the facilities of 4 units, and these units were started up the same day. The remaining 8 units, however, had leakage at boiler tubes and other problems and temporary repairs were completed by January 27, 1995. Figure 5.4.66 shows the location of generating station in the earthquake impacted area. Table 5.4.6 summarizes damage reported to thermal power generating units that shut down as a result of the earthquake. Table 5.4.7 summarizes damage to generating units that continued to operate during and after the earthquake. No damaged generating station sites was visited. There were no leaks in fuel oil tanks at generating sites, but one tank was emptied as there was concern that it would leak due to a nearby soil failure. Soil deformation and liquefaction at generating stations, which were located adjacent to Osaka Bay, had the largest impact on generation facilities.

\subsubsection{Performance of High Voltage Transmission Lines}

Problems with transmission towers were discussed in the section on the Itami substation. The damage did not disrupt the operation of the lines and was of a character described above. It was reported (Electric Utility Week, 1995) that ten transmission lines suffered damage, three $154 \mathrm{kV}$ and seven $77 \mathrm{kV}$. In addition, two $275 \mathrm{kV}$ towers, one $154 \mathrm{kV}$ tower, sixteen $77 \mathrm{kV}$ towers, and one $22 \mathrm{kV}$ tower suffered slight 
damage, but did not affect service. Conductors opened on one $77 \mathrm{kV}$ line and two $22 \mathrm{kV}$ lines. There were broken insulators on thirteen $275 \mathrm{kV}$ towers, twenty six $154 \mathrm{kV}$ towers, and three $77 \mathrm{kV}$ towers. One tower had problems with its footings. All lines were temporarily restored within two days.

\subsubsection{Performance of the Distribution System}

Because of the pervasiveness of the distribution system, only an extremely limited assessment of the damage is possible. Summary statistics for the distribution system are given in Table 5.4.5 and are taken from a Kansai Electric report dated March 7, 1995. Based on pictures that appeared in publications (Figure 5.4.67 and 5.4.18), much of the damage to the aerial system had been cleared and many repairs had been made at the time of the site visit, almost one month after the earthquake. Several types of damage were observed from the visit and a review of pictures in publications. In the Kobe business district, where the distribution system is underground in steel conduits, relatively little had been done to the system, and major demolition activities were underway to remove damaged buildings, many in excess of eight stories. It was reported [3] that there were 446 circuits damaged along the Kobe district's 57614000 miles of distribution lines. Restoration required 900 poles and 300 transformers be replaced, although the data in (Kansai Electric Company, 1995) has much higher numbers.

The limited observations of the aerial system used outside of the central business district shows extensive damage to spun concrete utility poles. Clearly many poles were pushed over when nearby houses fell into the street (Figure 5.4.68). Other poles appeared to fail as a result of severe shaking, although some may have been pulled over by power lines connected to nearby poles that were knocked down by falling houses (Figure 5.4.69). Downed poles were also a serious impediment to foot traffic (Figure 5.4.70), as well as the passage of vehicles. There were many cases where poles settled when the ground liquefied (Figure 5.4.71). In this case, one of the most extreme examples, the stirrup protruding from the pole at a level just below the knee of the individual in the picture, was originally about $2 \mathrm{~m}$ above the ground, thus, this pole settled about $1.5 \mathrm{~m}$. To a casual observer, this damage is not obvious. It is not clear how extensive this type of damage is. There were many areas with liquefaction, particularly on Rokko and Port Islands.

The damage to underground facilities in the central Kobe business district is indicated by the distortion of some of the above ground transformers and disconnect switched (Figure 5.4.72), and the distortion in pavements. In the business district, steel conduit, rather than plastic, is used. To the extent that the system has been inspected, there appears to be very little damage to the electrical cables, not withstanding the deformations experienced by the conduit. In a few locations, rather unconventional temporary repairs were made to restore service (Figure 5.4.73). Here, a $6.6 \mathrm{kV}$ primary distribution line has been connected to a conduit below grade and strung on existing poles to a third floor window in a building across the street. The line is then brought to the units substation in the basement of the building so that power can be temporarily restored. 
5.4.3 Implications of Observations to the United States

(a) Leaks and porcelain failure of transformer and circuit breaker bushings has contributed to the poor seismic performance of high voltage substation equipment in the United States and Japan.

(b) The use of flexible couplings in piping connections of the transformer radiator to the transformer body may reduce problems with leaks observed in the United States.

(c) The performance of instrumentation transformers in Japan appears to be better than in the United States.

Some units acted as lower restraints to suspended wave traps, and still performed better than in the United States.

(d) At potentially liquefiable sites, the need for adequate slack was demonstrated.

(e) The use of concrete poles appears to increase the vulnerability of the aerial distribution system. In the 1992 Cape Mendocino earthquake over 600 wooden poles were about to be replaced because they were weakened due to dry rot, and none of these failed.

\subsubsection{Research Needs}

(a) The performance of transformers and circuit breaker bushings in the United States and Japan is just the opposite of each other. That is, in Japan circuit breaker bushings failed due to slipping and transformer bushings did not. Why is the performance in the two countries so different? (b) Several bolted transformers moved even though they appeared to have substantial anchorage. While new transformers are typically welded to embedments in the United States, bolts are often used for retrofits. What were the design and actual loads on the equipment that failed and what was the cause of the anchorage failures?

(c) It would be useful to evaluate the performance of seismic design practices that were formulated in 1980 in Japan. Only two high voltage substations were visited and it appeared that most of the equipment predated the new criteria. There may have been other substation with equipment that met the new criteria and the evaluation of the relative performance of the new and old criteria may be possible.

(d) It would be interesting to explore the reasons for the relatively good performance of instrumentation transformers (PTs, CVTs, CCPD, etc.) in Japan as compared to that in the United States. While these components appear to be larger in Japan, they also appear to be supported on more rigid structures. The differences in design and installation should be explored.

(e) There have been failures of equipment adjacent to line drops. The drops, which use insulator strings to restrain the lower end of the line, have very little weight associated with them but there appears to be interaction problems. The nature of these problems should be explored.

(f) At least one substation and one power station that suffered damage had strong motion instruments that recorded the earthquake. It would 
be very beneficial to review the performance of equipment at these sites using the response spectra for the site and more detailed information that could be derived from site conditions.

(g) There is a need to weigh the advantages, disadvantages and the risks associated with rigid and flexible bus and evaluate their performance in the United States and Japan.

(h) The relative performance of spun concrete and wooden poles should be evaluated. When a house falls on a pole, it can be expected to fail, but there appeared to be many concrete pole failures that are not observed in the United States with wooden poles. It would be useful to evaluate the relative performance of the systems, their advantages and disadvantages and if the use of the poles is different in the two countries.

(i) The large differences in the design of capacitors in the United States and Japan from a seismic performance point of view should be explored.

\subsubsection{Summary}

The overall performance of power systems, as measured by the extent and duration of disruption, was very good. The seismic performance of high voltage equipment was different than that observed in the United States. In Japan, dead-tank circuit breakers were damaged and transformers failed their anchorage which contributed to bushing damage. In the United States, more damage appears to be associated with transformer bushings, the failure of current-voltage transformers, potential transformers, and disconnect switches. If sites are subject to liquefaction, it is important that flexible bus be used with liberal, but manageable slack.
Transformer anchorage frequently failed. There was relatively little damage to high voltage substations as compared to what was observed in the Loma Prieta and Northridge earthquakes. The subsidence at substations appears to have contributed to the failure of bushings connected to vertical conductor drops, as little slack is typically provided. There was uniformly high quality use of good design and installation details in station batteries. The bushing performance of transformer and circuit breaker bushings in the United States and Japan are very different and unexplained. Discounting the direct damage to poles from falling houses, there appeared to be very high damage to the aerial system resulting from the failure of concrete poles.

\subsubsection{Acknowledgments}

The help of Mr. O. Usuda and Mr. K. Matsuno in visiting Itami substation is gratefully acknowledged as well as the assistance of many other Kansai Electric Power Co. personnel who provided information on the earthquake response of their facilities. The help provided by Jim Stoner, Duke Power, in interpreting one-line drawings is also acknowledged.

\subsubsection{References}

1. Current Information on Kansai Electric Company, March 1994.

2. "Guide for Seismic Design of Substation Equipment," Japan Electric Association Guide: JEAG 5003-1980, 1980.

3. Electric Utility Week, January 30, 1995. 
Table 5.4.1

Summary of Vital Statistic of the Kansai Electric Company (as of March 31, 1994 )

$\begin{array}{llr}\text { Installed Generation } & \text { MW } & 35,035 \\ \text { Nuclear } & \text { MW } & 9,768 \\ \text { Fossil Fuel } & \text { MW } & 18,581 \\ \text { Hydro } & \text { MW } & 6686 \\ \text { Energy Sáles } & \text { Millions of KWH } & 123,300 \\ \text { Number of customers } & \text { Thousands } & 11,730 \\ \text { System Peak Demand } & \text { MW } & 28,411 \\ \text { Electric Operating Revenues } & \text { Millions of Yen } & 2,371,828 \\ \text { Assets } & \text { Millions of Yen } & 6,204,016 \\ \text { Number of Employees } & & 26,205\end{array}$

Table 5.4.2

Breakdown of Kansai Power Electricity Sales

Lighting (mostly residential)

Light and Power (office buildings, and hospitals)

$28.4 \%$

Small Power (small- and medium-sized factories, shops)

19.7

Steel Industry

13.6

Chemical Industry

7.8

Machinery Manufacturing

3.9

Cement, Glass, and Ceramics

5.9

Textile Industry

2.4

1.0

Other Manufacturers

8.5

Transportation, Communications Electrical, Gas, Water Construction businesses etc.

Others (water heaters, etc.) 
Table 5.4.3

Specification of Kansai Power Strong-Motion Instruments

\begin{tabular}{|l|c|c|c|c|c|c|}
\hline \multicolumn{1}{|c|}{ Location } & Year & $\begin{array}{c}\text { Sensitivity } \\
\text { Gal }\end{array}$ & $\begin{array}{c}\text { Frequency } \\
\text { Range, Hz }\end{array}$ & $\begin{array}{c}\text { Number } \\
\text { of Bits }\end{array}$ & $\begin{array}{c}\text { Sample } \\
\text { Rate }\end{array}$ & Components \\
\hline Mihama PS & 1976 & $0.1-600$ & $0.1-30$ & 16 & 100 & 3 \\
\hline Takasago PS & 1983 & $0.2-2000$ & $0.1-40$ & 16 & 400 & 3 \\
\hline Ohi PS & 1991 & $0.03-1000$ & $0.1-30$ & 16 & 100 & 3 \\
\hline Miyazu PS & 1989 & $0.1-500$ & $0.1-50$ & 16 & 500 & Vertical \\
\hline Yamazaki & 1986 & $0.1-1000$ & $0.1-50$ & 16 & 200 & 3 \\
\hline Nishikyoto SS & 1987 & $0.1-1000$ & $0.1-50$ & 12 & 400 & Vertical \\
\hline Kobe SS & 1988 & $0.1-1000$ & $0.1-30$ & - & 1000 & 3 \\
\hline Takasago PS & $1987^{\circ}$ & $.03-300$ & $0.1-30$ & 12 & 400 & 3 \\
\hline Akaho PS & 1987 & $0.1-1000$ & $0.1-60$ & 12 & 200 & Vertical \\
\hline Research Center & 1988 & $0.3-300$ & $0.1-30$ & 12 & 400 & 3 \\
\hline Ahagasaki No 3 & 1987 & $0.1-1000$ & $0.1-70$ & 12 & 200 & Vertical \\
\hline Nanko PS & $?$ & $0.1-1000$ & $0.1-20$ & 16 & 100 & Vertical \\
\hline Yao SS & $?$ & $.0021-69 k i n e$ & & & & \\
\hline Shigi SS & 1987 & $1-320$ & $0.3-30$ & 12 & 400 & 3 \\
\hline Minami-Osaka SS & $?$ & $.0021-69$ kine & $0.25-70$ & 16 & 100 & 3 \\
\hline Kainanko SS & 1981 & $0.03-300$ & $0.1-30$ & 12 & 400 & 3 \\
\hline Gobo PS & 1984 & $0.1-1000$ & $0.1-60$ & 12 & 200 & Vertical \\
\hline Tuzaki SS & $?$ & $.0012-40$ kine & $0.025-70$ & 16 & 100 & 3 \\
\hline
\end{tabular}

Table 5.4.4

Distribution of Workers During Restoration

\begin{tabular}{|c|c|c|c|c|c|c|c|c|}
\hline & Day & 17 & 18 & 19 & 20 & 22 & 23 & 24 \\
\hline \multirow{4}{*}{$\begin{array}{c}\text { Distribution } \\
\text { System }\end{array}$} & KEPCO & 371 & 657 & 788 & 765 & 794 & 794 & 709 \\
\cline { 2 - 9 } & Other Utilities & 0 & 260 & 284 & 287 & 291 & 283 & 219 \\
\cline { 2 - 9 } & Contractors & 639 & 2,070 & 2,895 & 2,963 & 3,616 & 3,616 & 3,032 \\
\cline { 2 - 9 } & Total & 1,101 & 2,987 & 3,967 & 4,015 & 4,701 & 4,693 & 3,960 \\
\hline \hline \multirow{4}{*}{$\begin{array}{c}\text { Transmission } \\
\text { Communications }\end{array}$} & KEPCO & 1,169 & 947 & 722 & 657 & 334 & 290 & 464 \\
\cline { 2 - 8 } & Contractors & 1,168 & 1,582 & 1,448 & 1,467 & 1,113 & 743 & 1,316 \\
\cline { 2 - 8 } & Total & 2,336 & 2,529 & 2,170 & 2,124 & 1,447 & 1,033 & 1,780 \\
\hline \hline & Grand Total & 3,346 & 5,516 & 6,137 & 6,139 & 6,148 & 5,726 & 5,740 \\
\hline
\end{tabular}


Table 5.4.5

\section{Summary of Damage to Power Facilities}

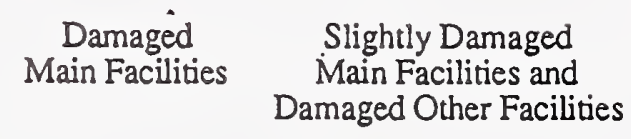

Total

Fossil Power Stations

Boiler, Gas Turbine

5

4

$12 \quad 20$

9

Substations

Transformers

17

30

29

Circuit Breakers

Power Capacitors

Shunt Reactors

Disconnect Switches

23
9

1

47

4

5

Lightning Arresters

Busses

Buildings

Neutral Grounding Devices, etc.

41

$15 \quad 15$

7 points 7

12 points 12

Overhead Transmission Lines

Wire

Supporting Structures

Insulator Assemblies

Grounds, etc.

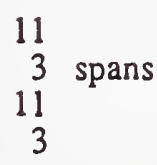

32

32

Underground Transmission Lines

Cables

Ducts

12

**23

9

36

1

52

10

5

2

Bridge Section of Line Support for Cable Termination

Oil Feeding Equipment

3

20

92

*384

*183

*257

*14

*4

$* 2$

11

1 span

1

11

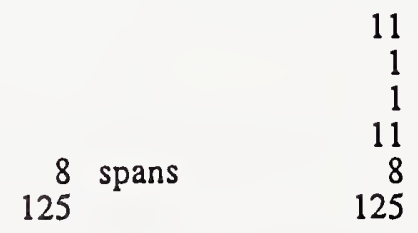

649

649

Distribution Lines $(6.6 \mathrm{kV})$

Overhead - Wire

Supporting Structures

Transformers

Underground - Cables

Underground - Ducts

Underground - Manholes

$* 6,188$ spans

6,188

$* 7,869$

7,869

185

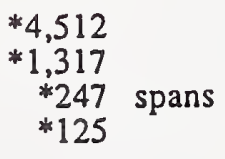

4,512

1,322

247

125

Communication Circuits

76

76 Cable

171 spans

171

* Verified before February 24

** 112 lines were damaged - 6 lines consist of overhead lines and underground lines. 
Table 5.4.6

\section{Power Stations Sustaining Damage to Main Facilities and Experiencing Trouble in Power Generation}

\begin{tabular}{|c|c|c|c|}
\hline Power Station & Unit No. & $\begin{array}{c}\text { Restoration } \\
\text { Date }\end{array}$ & Equipment Damage \\
\hline $\begin{array}{l}\text { Higashi Nada } \\
\text { gas turbine }\end{array}$ & 1,2 & June 1996 & $\begin{array}{l}\text { o Land subsidence spread across the entire } \\
\text { yard (fissures and liquefaction occurred) } \\
\text { o Uneven settling of buildings and } \\
\text { equipment foundations (gas turbine } \\
\text { foundations and the like) } \\
\text { o Exposed fuel tan foundation piles (fuel } \\
\text { tank does not appear to be leaning) } \\
\text { o Cracked, leaning time embankments }\end{array}$ \\
\hline $\begin{array}{c}\text { Amagasaki } \\
\text { Higashi }\end{array}$ & 1,2 & Jan. 19,18 & $\begin{array}{l}\text { o Land subsidence and fissures (areas } \\
\text { surrounding the main building, on-site roads, } \\
\text { and the like) } \\
\text { Distilled water tank leaning, purified water } \\
\text { tank has settled, drainage gutter damage, and } \\
\text { partial cracking of oil retention embankment) } \\
\text { o Steel frame damage to turbine building } \\
\text { (braced portions and the like) } \\
\text { - Pipe support damage (main steam pipes, } \\
\text { high temperature reheating steam pipes, and } \\
\text { the like) }\end{array}$ \\
\hline Osaka PS & $1,2,4$ & $\begin{array}{c}\text { Jan. } \\
22,27,23\end{array}$ & $\begin{array}{l}\text { - Boiler tube damage (cooling spacer tubes } \\
\text { bent and fractured; wall tubes partially } \\
\text { deformed from impacts) }\end{array}$ \\
\hline Sakaiko PS & 2 & Jan. 20 & $\begin{array}{l}\text { o Boiler tubes bent (bending of cooling spacer } \\
\text { tubes) } \\
\text { - Economizer header drain tube nozzle } \\
\text { fractured }\end{array}$ \\
\hline Sanpo PS & 1 & Jan. 23 & $\begin{array}{l}\text { - Economizer element damage (cracks } \\
\text { developed on welded portions of attached } \\
\text { metal fixture) }\end{array}$ \\
\hline $\begin{array}{l}\text { Himeji No. } 2 \\
\text { Takasago } \\
\text { Himeji LNG } \\
\text { Terminal, etc. }\end{array}$ & 2 & Jan. 18 & $\begin{array}{l}\text { - Thermal insulation dropped off (high } \\
\text { temperature reheating steam pipes and the } \\
\text { like) } \\
\text { o Building structure damage (cracks developed } \\
\text { on the main building and service building) } \\
\text { o Partial cave-in of soil bank } \\
\end{array}$ \\
\hline & & & Legend: - Repaired \\
\hline
\end{tabular}

Unit numbers in bold face type automatically stopped. The following units stopped, but were not damaged and were re-started - Himeji No. $2(1,3,5)$, Takasago (2). 


\section{Table 5.4.7}

Power Stations Sustaining Damage to Facilities

\begin{tabular}{|c|c|c|l|}
\hline Power Station & Unit No. & $\begin{array}{c}\text { Restoration } \\
\text { Date }\end{array}$ & \multicolumn{1}{|c|}{ Equipment Damage } \\
\hline Amagasaki No 3 & $1-3$ & Summer '95 & $\begin{array}{l}\text { Damage to boiler seismic-tie } \\
\text { Deformed boiler frame }\end{array}$ \\
\hline Kasugade & 1,2 & Summer '95 & $\begin{array}{l}\text { o Superheater and reheater spacers became } \\
\text { detached from boiler }\end{array}$ \\
\hline Nanko & 1 & February 2 & - Boiler tubes bent (cooling spacer tubes bent) \\
\hline Osaka & 2 & February 3 & Bent boiler tube \\
\hline Sakaiko & 1 & April 26 & Bent boiler tube \\
& 4 & May 11 & \\
\hline Takaigo & - & End Sept. & Cracked road on premises \\
\hline
\end{tabular}




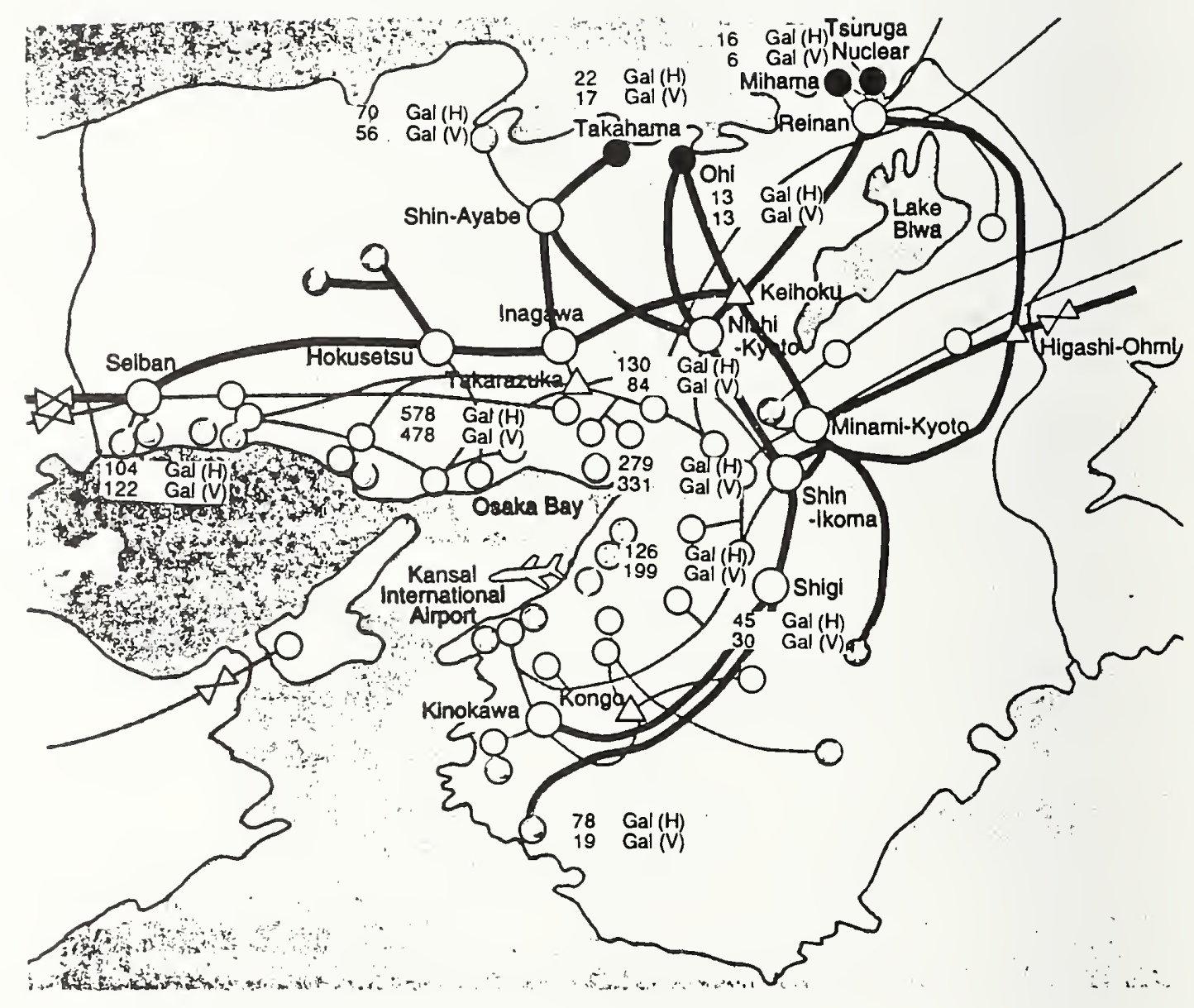

Figure 5.4.1

Schematic diagram of Kansai service area and peak acceleration at utility instruments. 


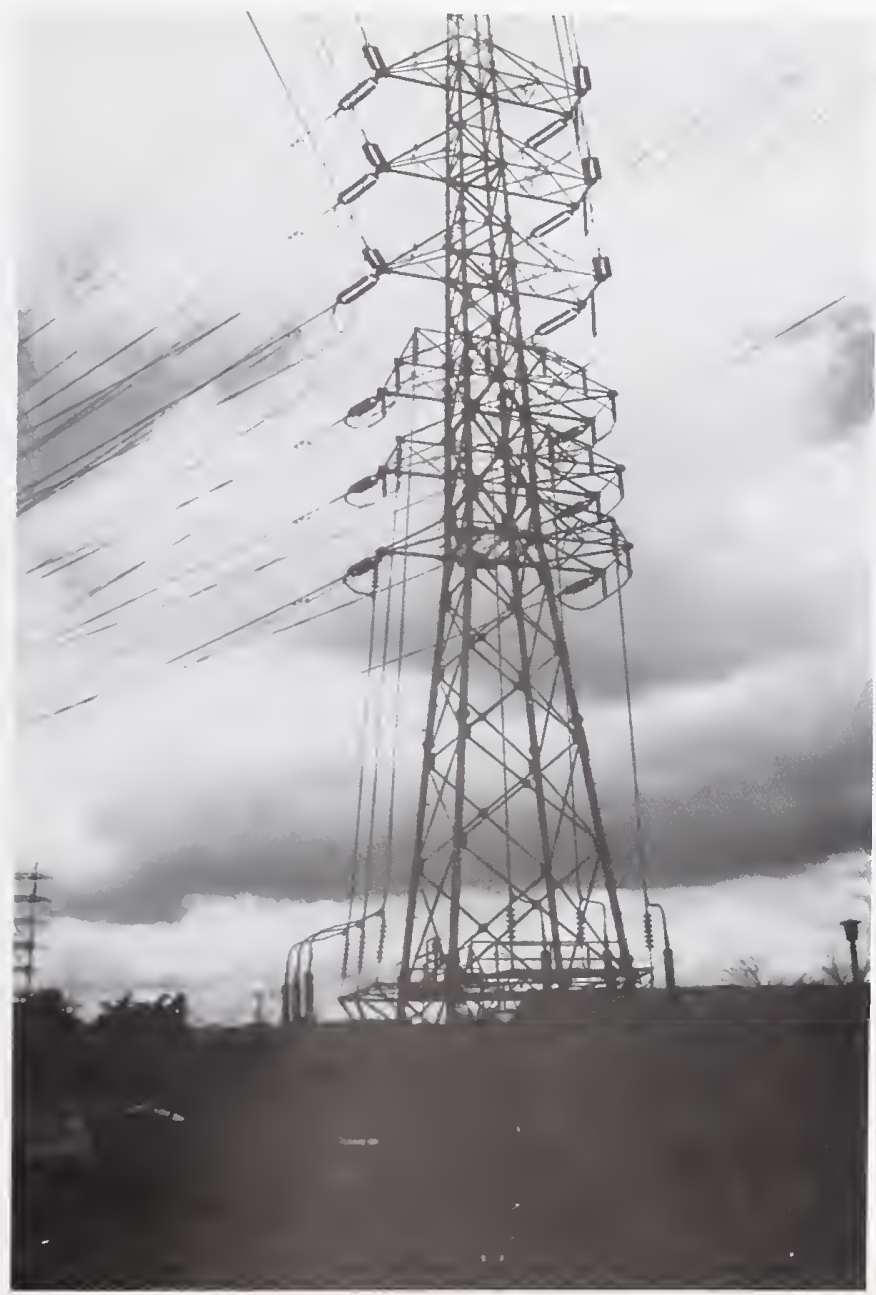

Figure 5.4.2 Transmission tower carrying two $275 \mathrm{kV}$ and two $154 \mathrm{kV}$ circuits. 


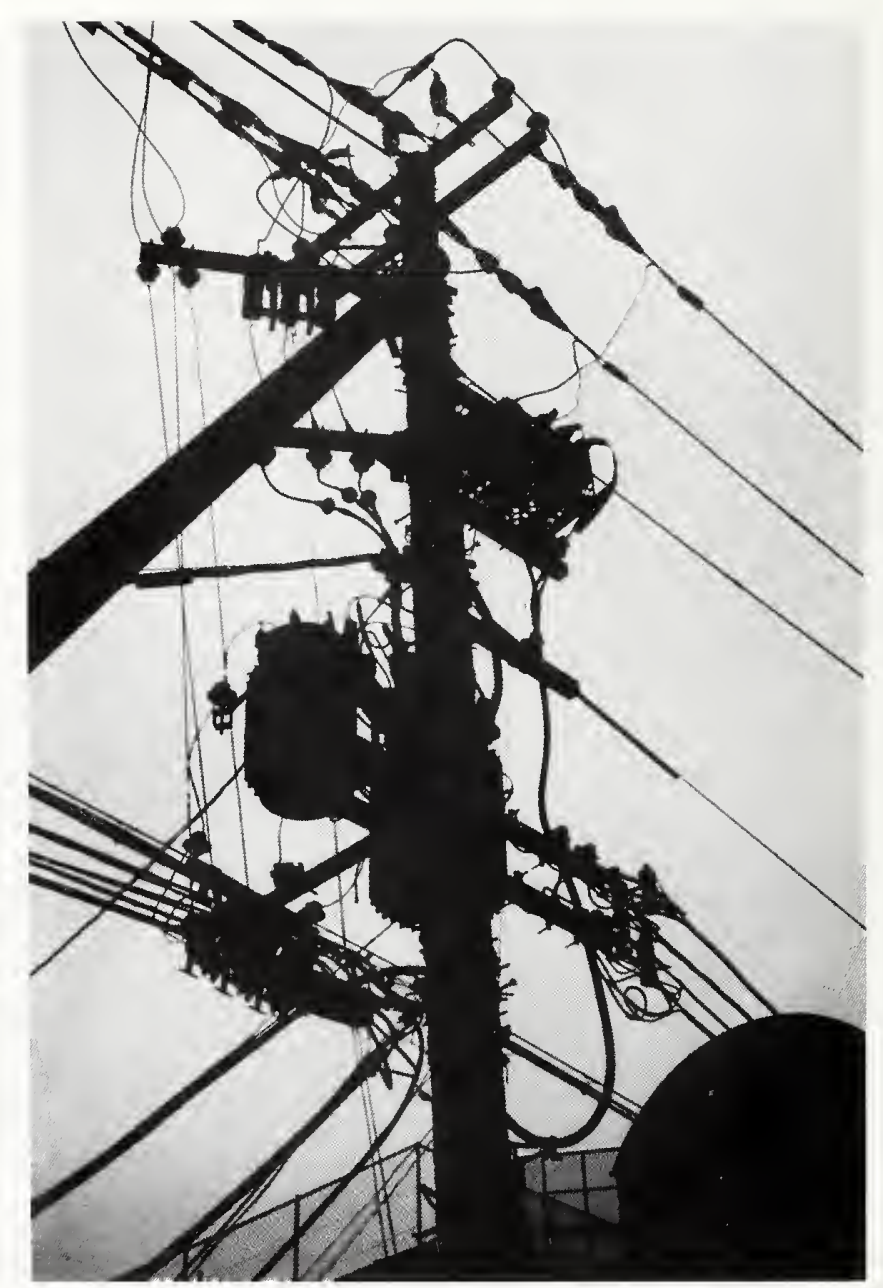

Figure 5.4.3

Spun-concrete distribution pole used in Kobe. 


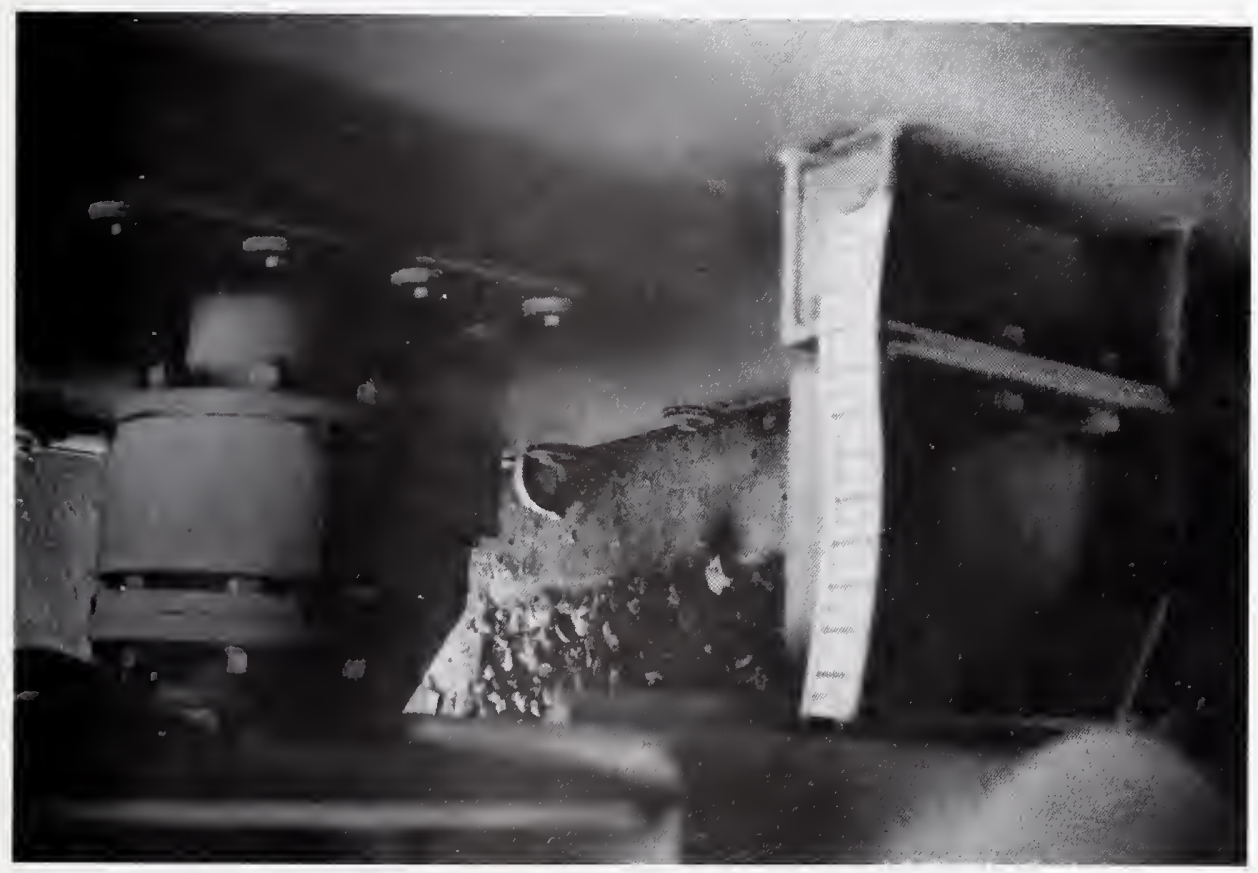

Figure 5.4.4 Distribution transformer $(77 \mathrm{kV}$ to $6.6 \mathrm{kV})$ have radiators with structural supports independent of the piping system and flexible couplings in connections. 


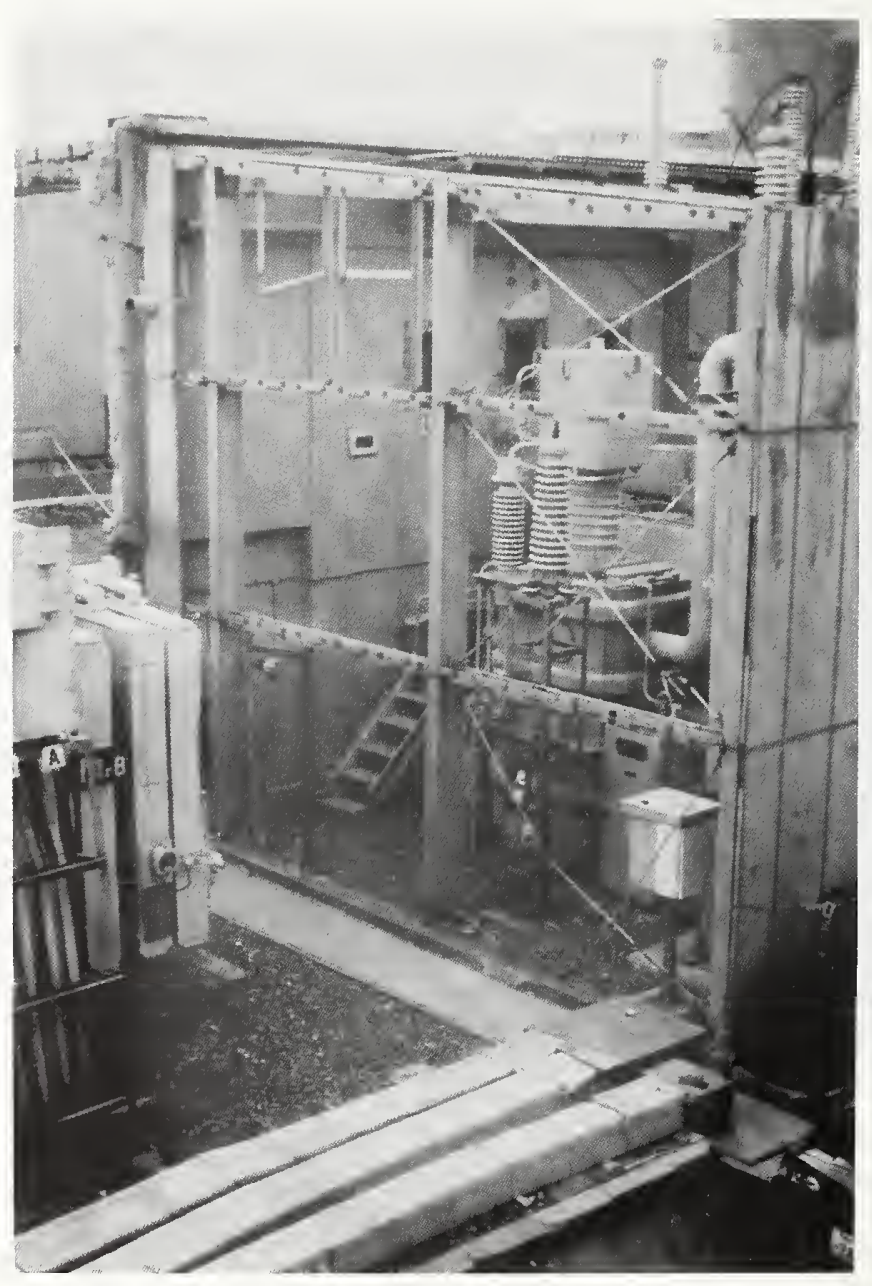

Figure 5.4.5

The box with porcelain support is a design feature on a distribution transformer not seen in the U.S. 


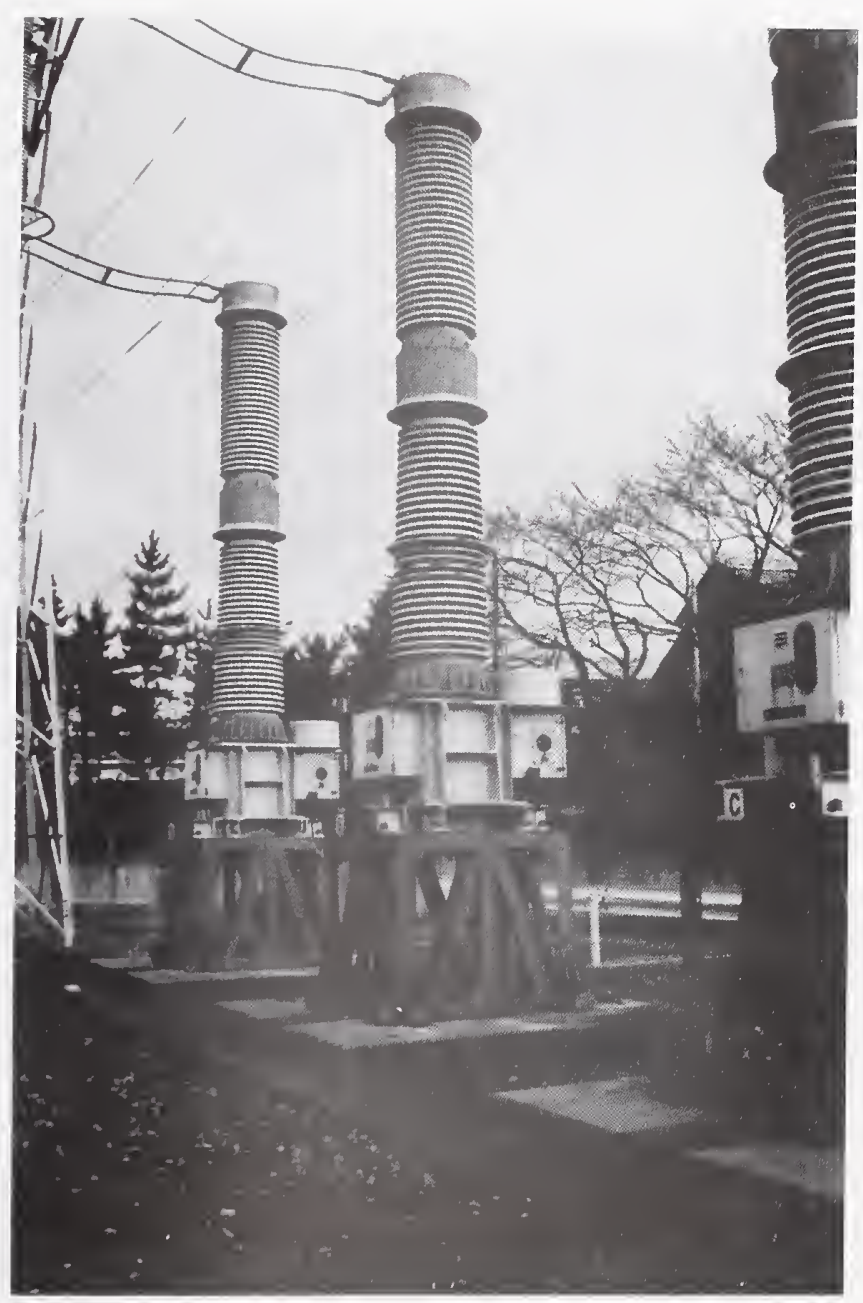

Figure 5.4.6 The $275 \mathrm{kV}$ potential transformers are much larger than their counter part in the U.S. 


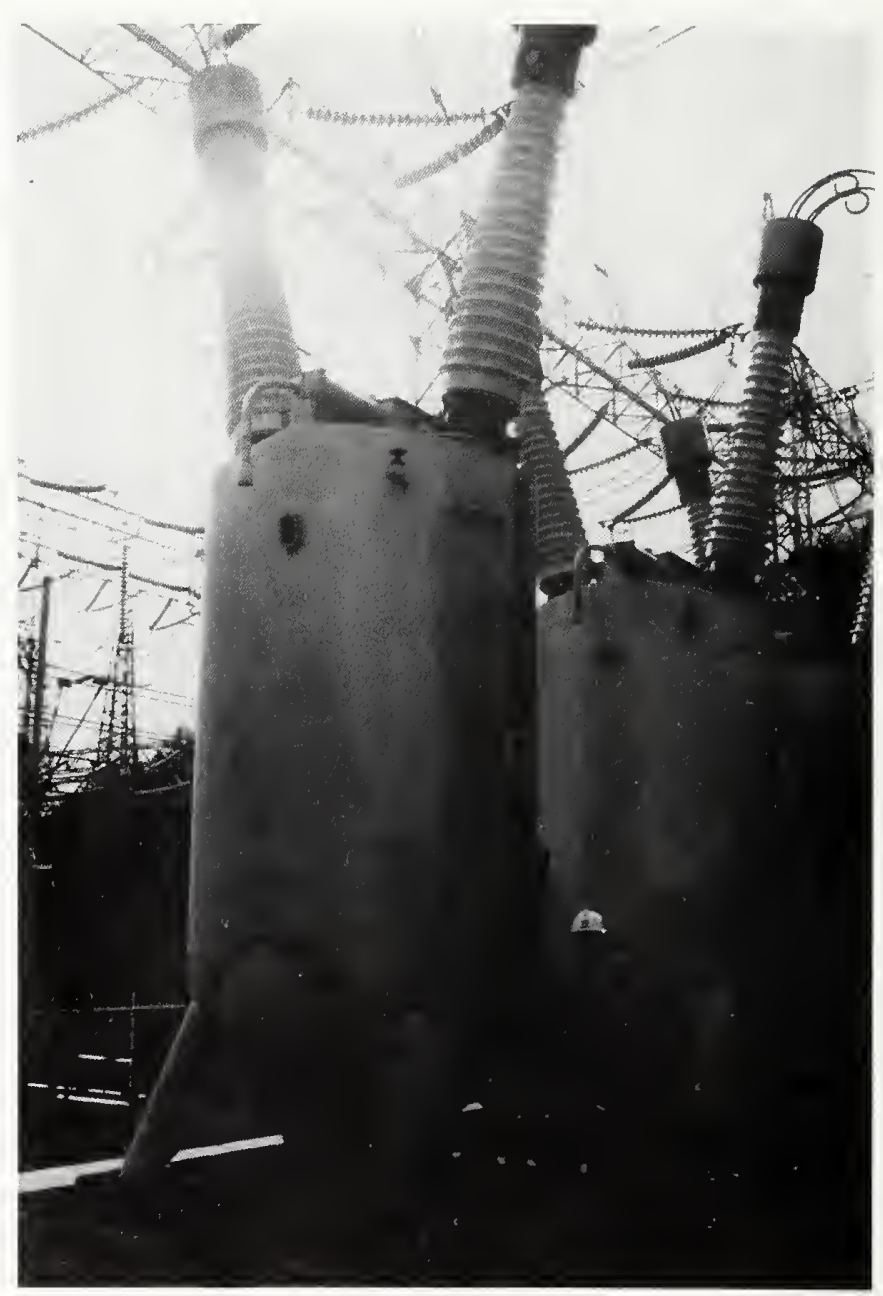

Figure 5.4.7

A $275 \mathrm{kV}$ bulk-oil circuit breaks which is very large compared to $230 \mathrm{kV}$ units in the U.S. 


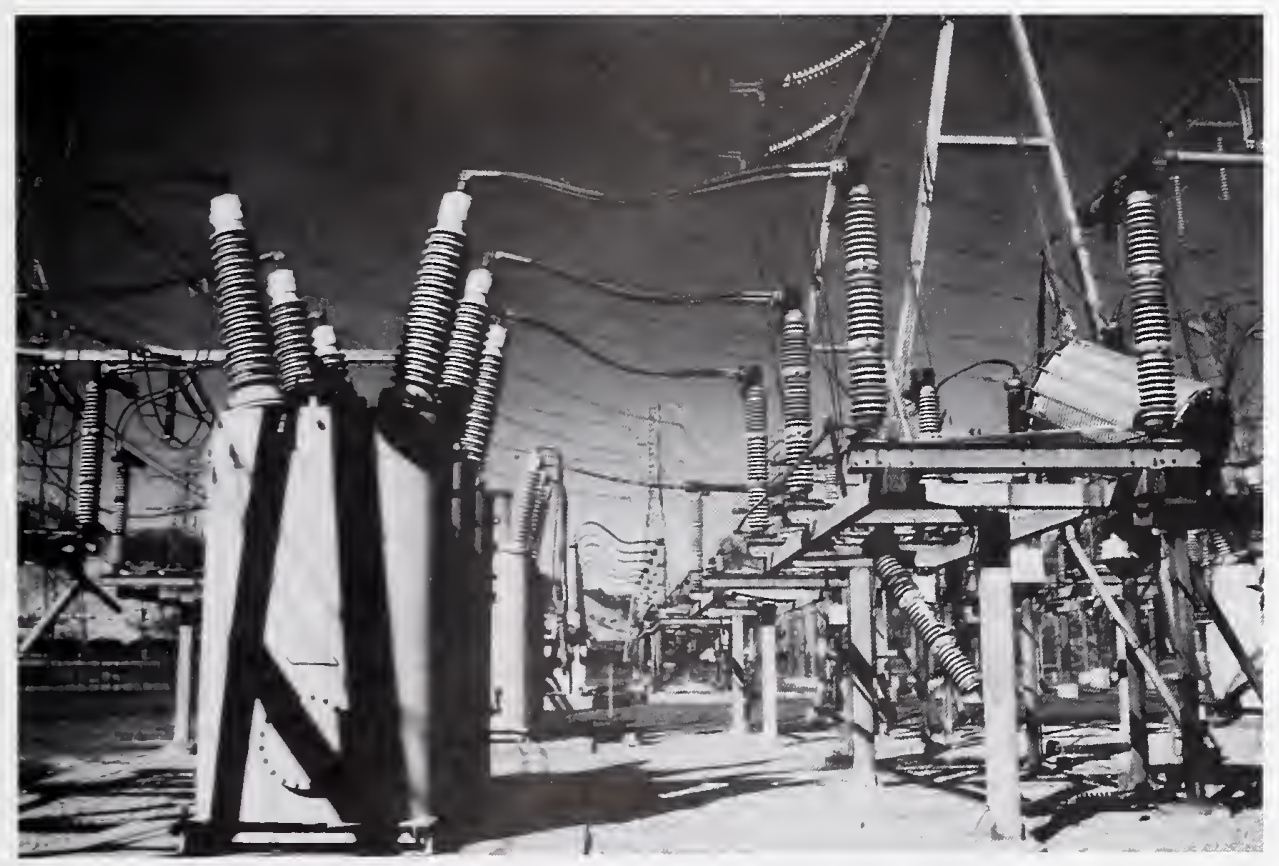

Figure 5.4.8 Typical $230 \mathrm{kV}$ bulk-oil circuit breaker in the U.S. 


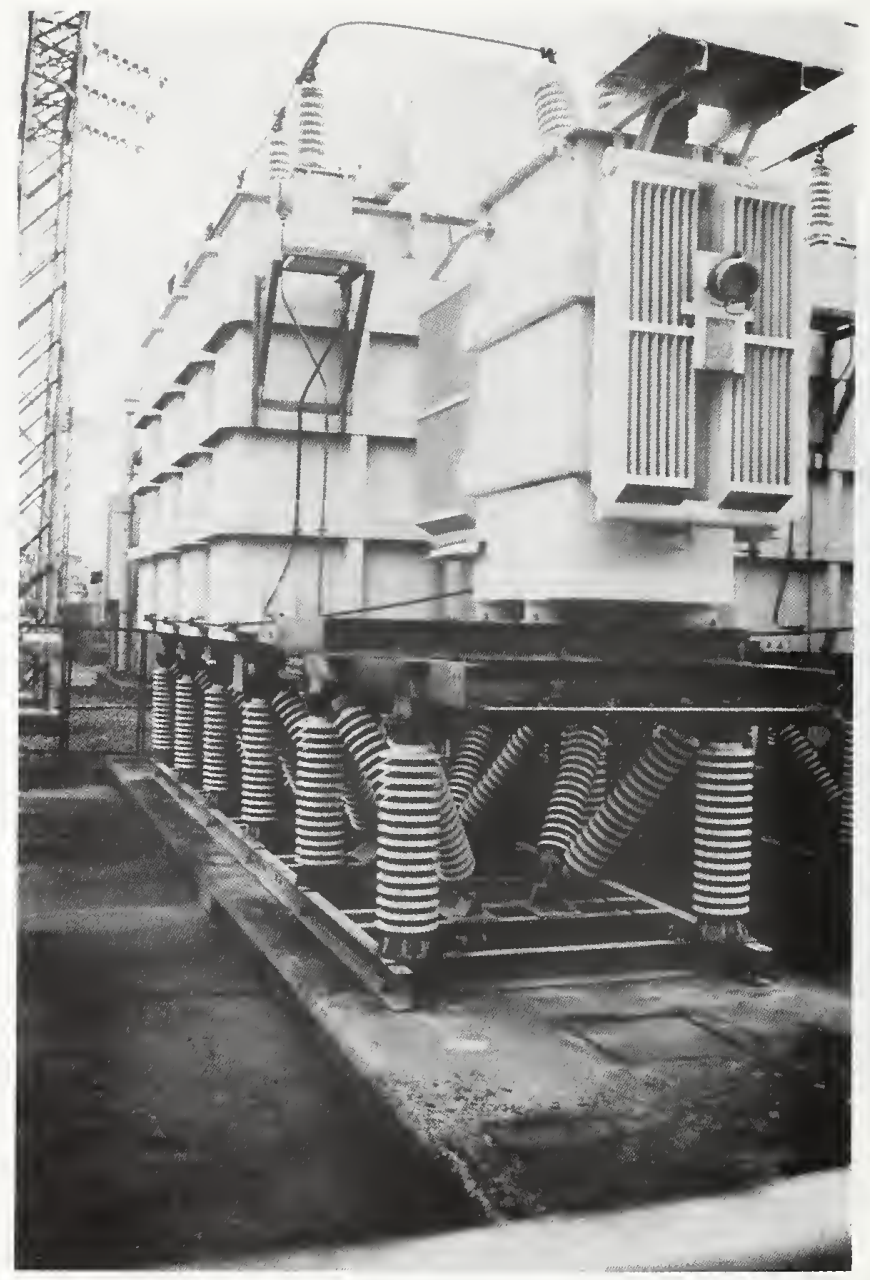

Figure 5.4.9

Capacitors observed in Japan are in large tanks and have small transformers on isolated rack, a different configuration than in the U.S. 


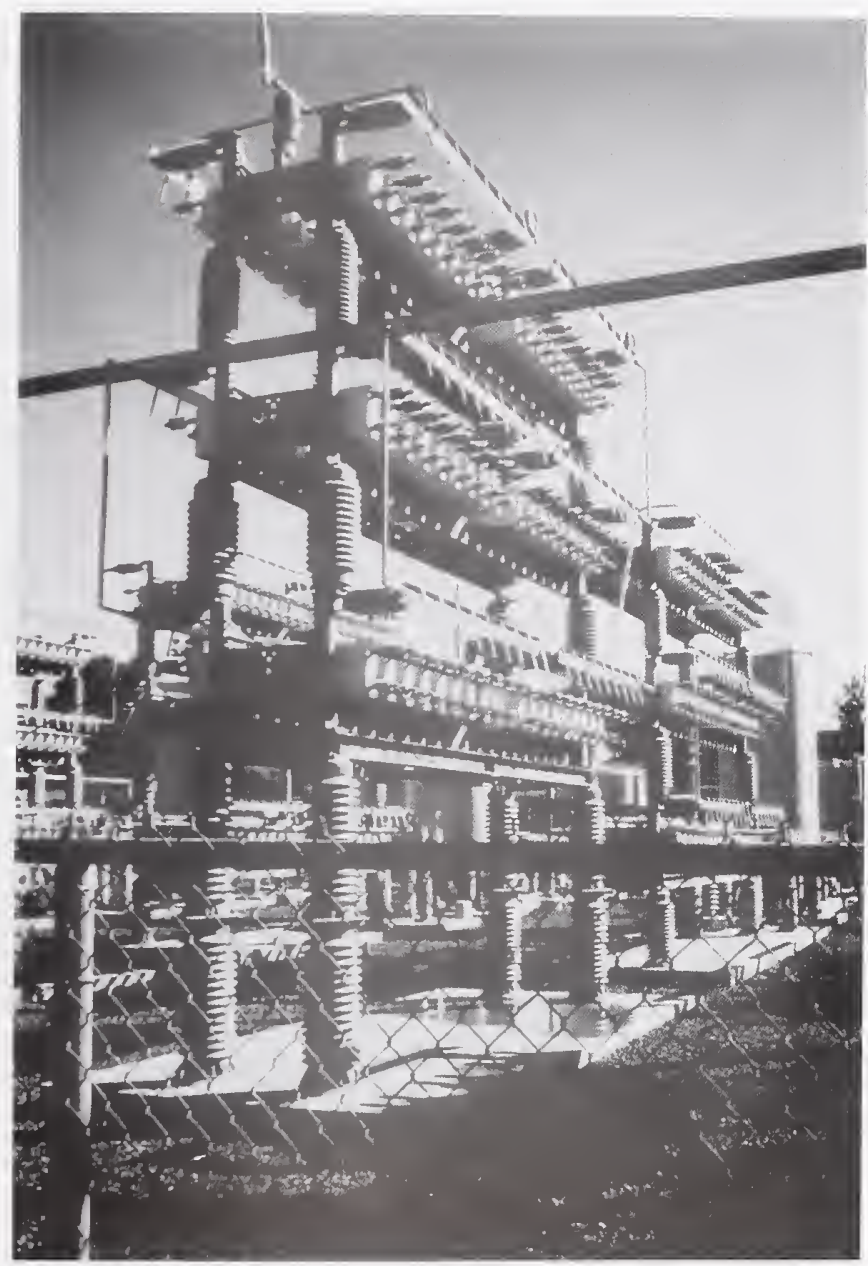

Figure 5.4.10 Typical capacitor rack in the U.S. 


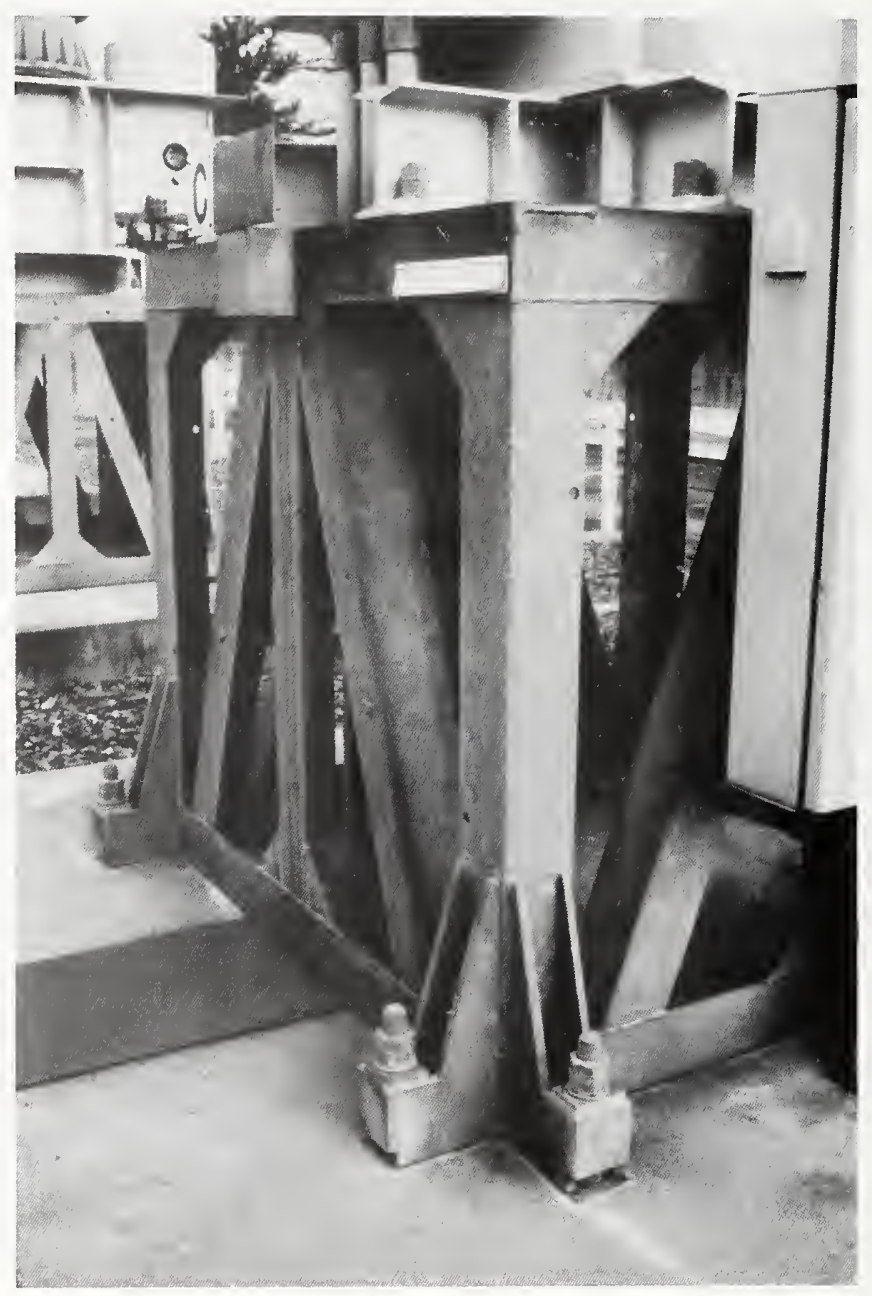

Figure 5.4.11 Very stiff support structure for a potential transformer installed after the more stringent seismic design practices were adopted in 1980. 


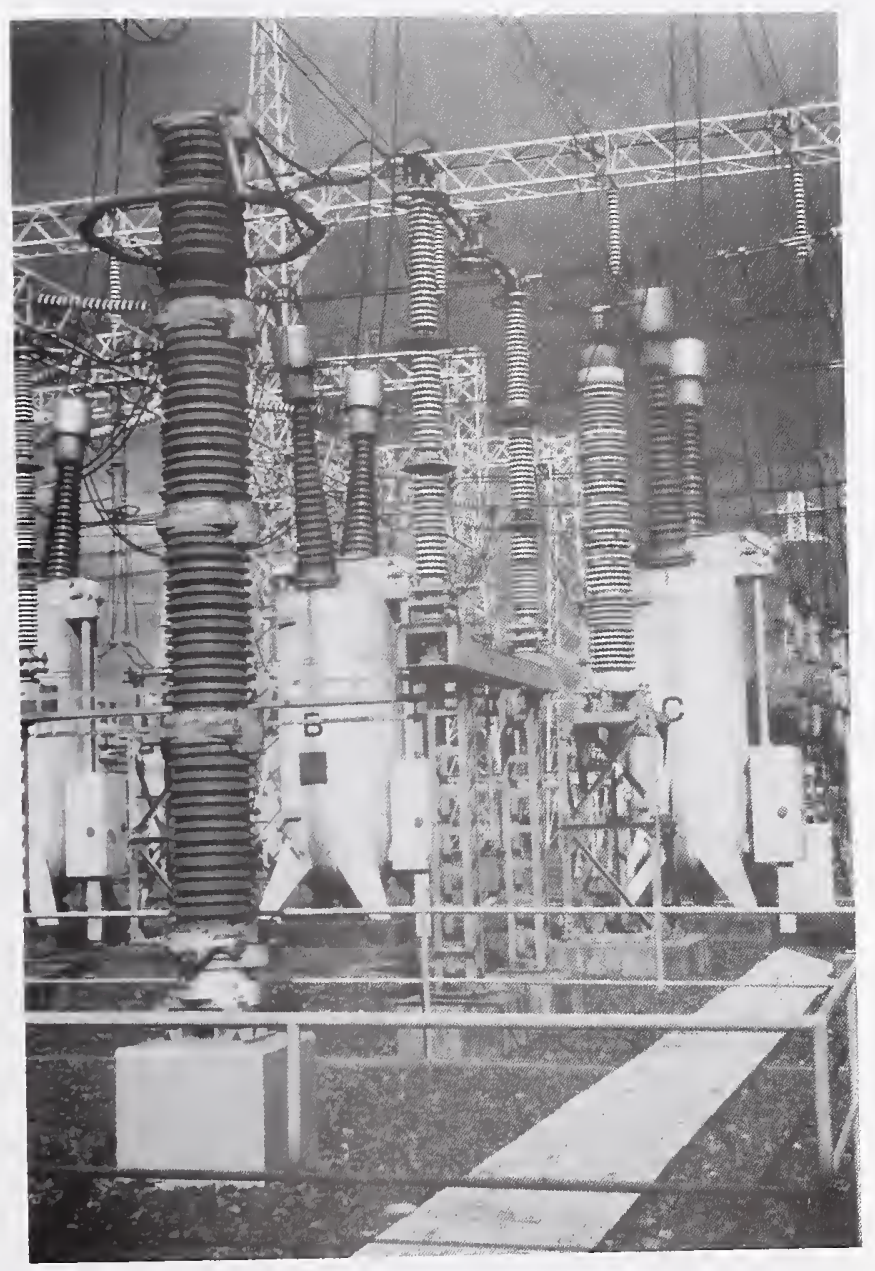

Figure 5.4.12 A $275 \mathrm{kV}$ circuit breaker, disconnect switch, pot head and lightning arrester. Lightning arrester installed on short pedestal reduces cost and amplification of a taller support structure. 


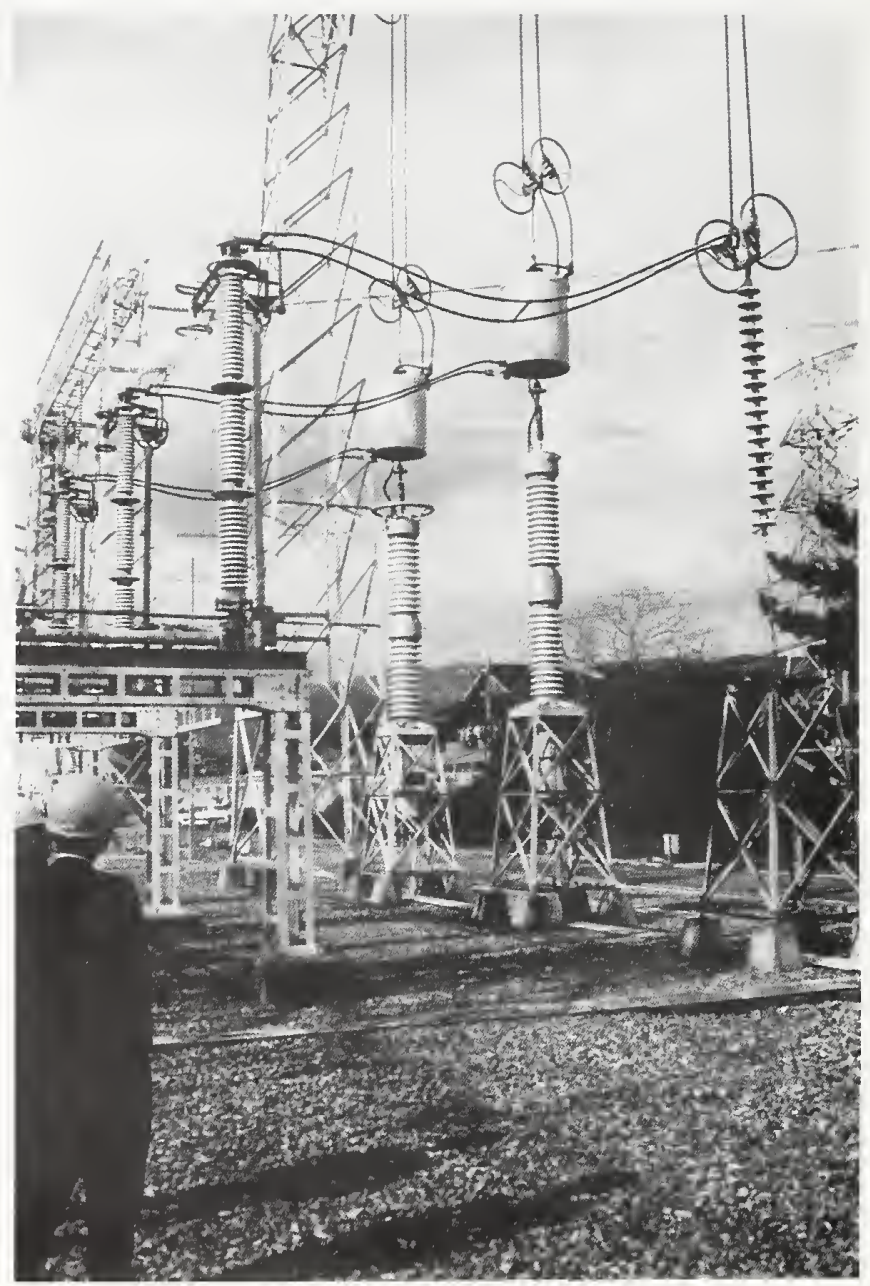

Figure 5.4.13

A current-voltage transformer are used as the lower restraint for a suspended wave trap. 


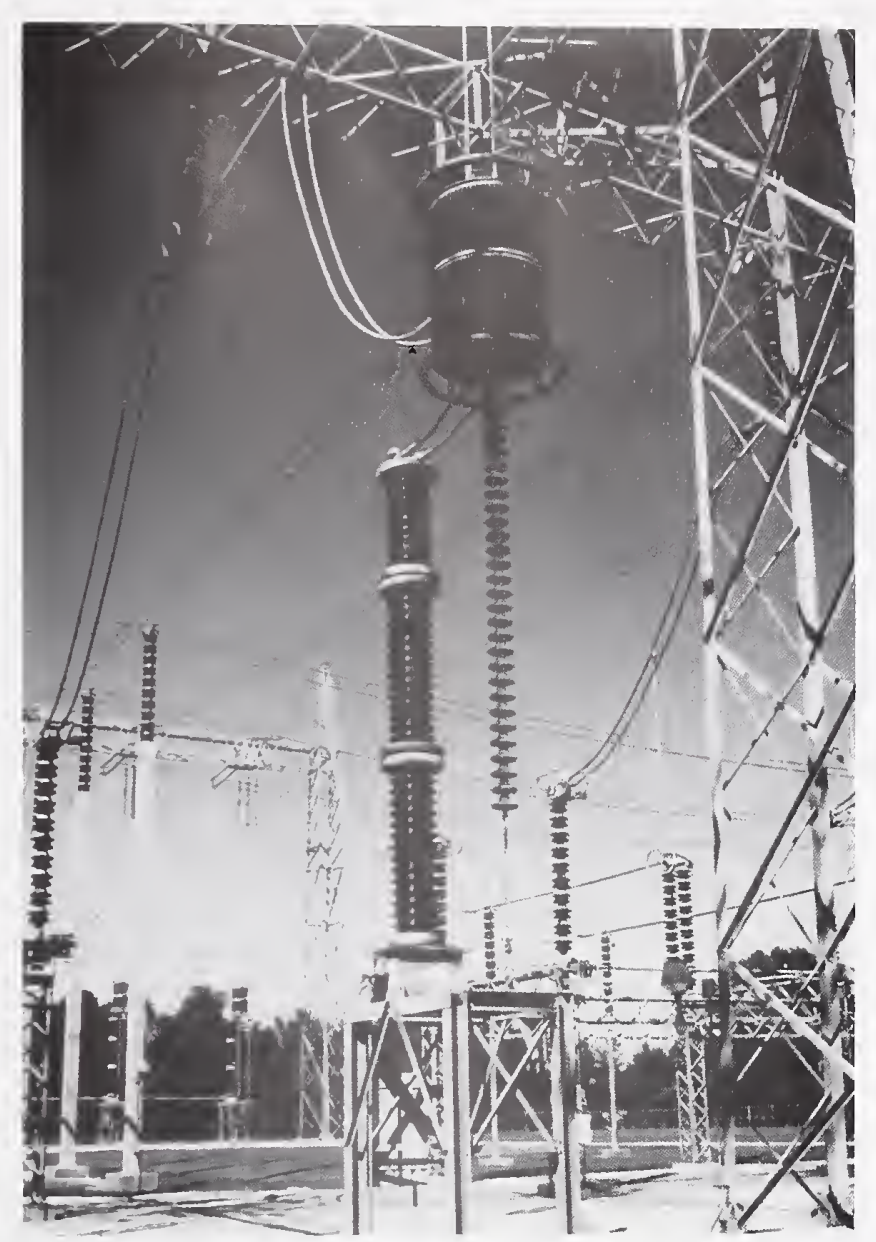

Figure 5.4.14 In the U.S. suspended wave traps usually have independent lower restraints

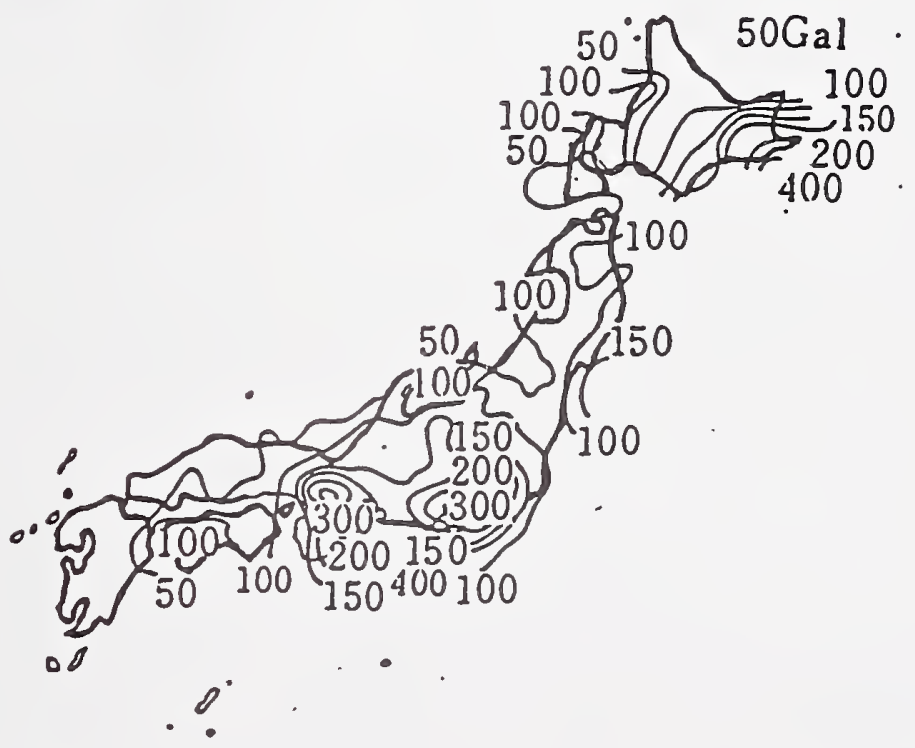

Figure 5.4.15 The Kawasumi map showing the distribution of horizontal accelerations on the ground surface expected one at the interval of 75 years. (From Ref. 2). 


\section{Number of Customers Without Power}

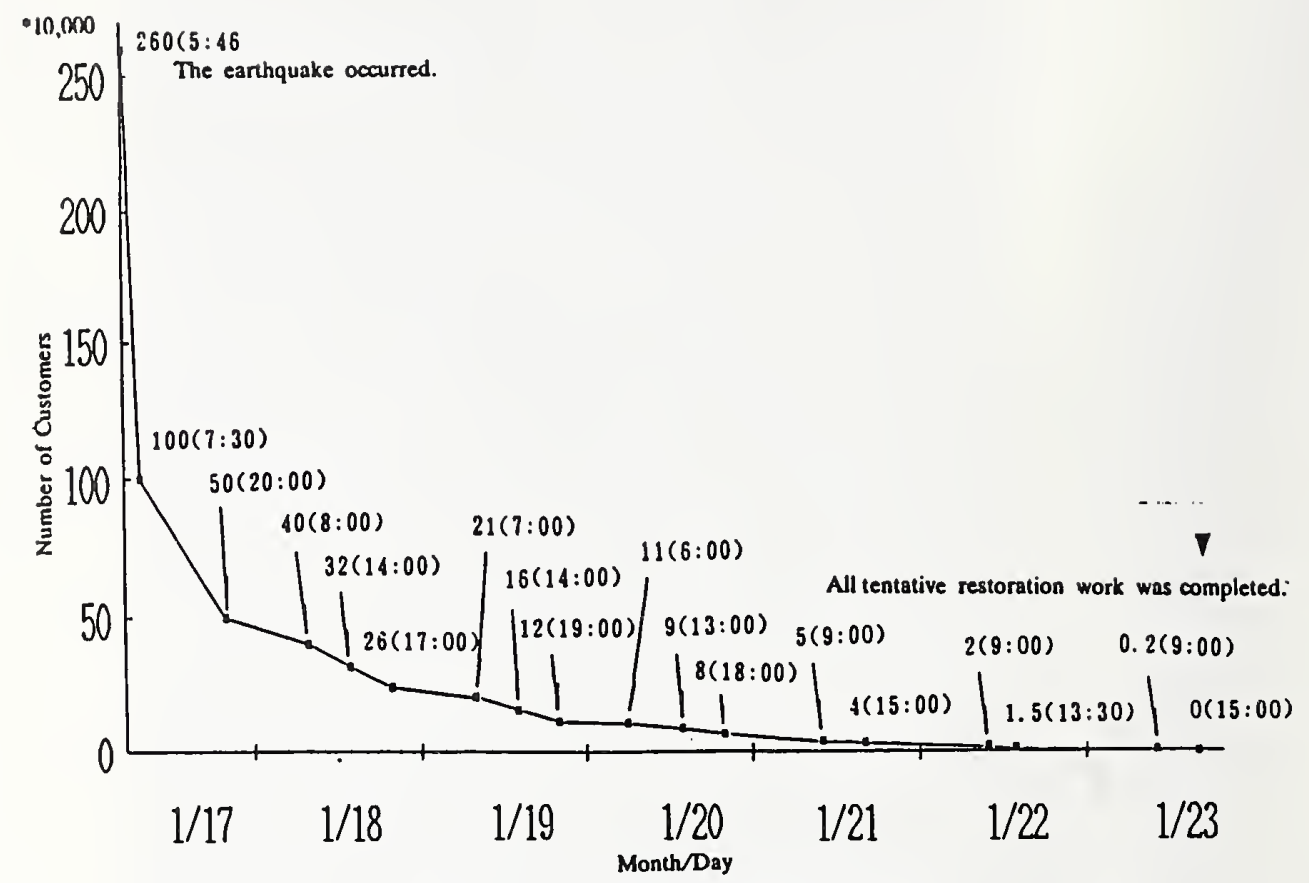

Load Losses Following the Earthquake

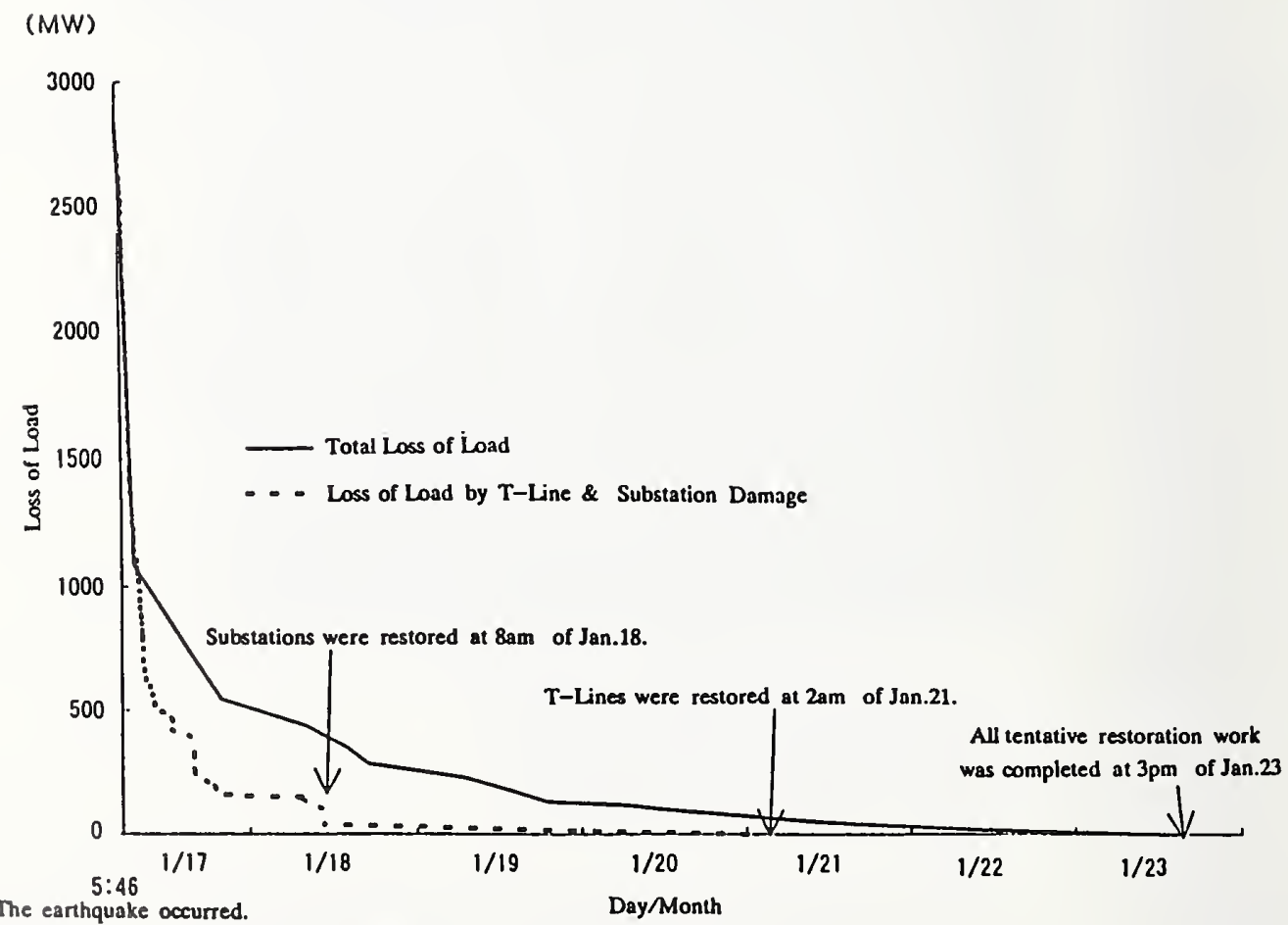




\section{Aid of Other Electric Utilities}

TOTAL

Distribution

319 Workers, 52 High Voltage Power Generating Vehicles $(17,890 \mathrm{kVA})$

77 Vehicles, Commodities of living, Water Wagons, etc.

Substation and $\mathrm{T}$-Line

Disconnecting Switches, Hardware for Insulator Assembly, etc.

Communication

2 Earth Stations on Vehicles

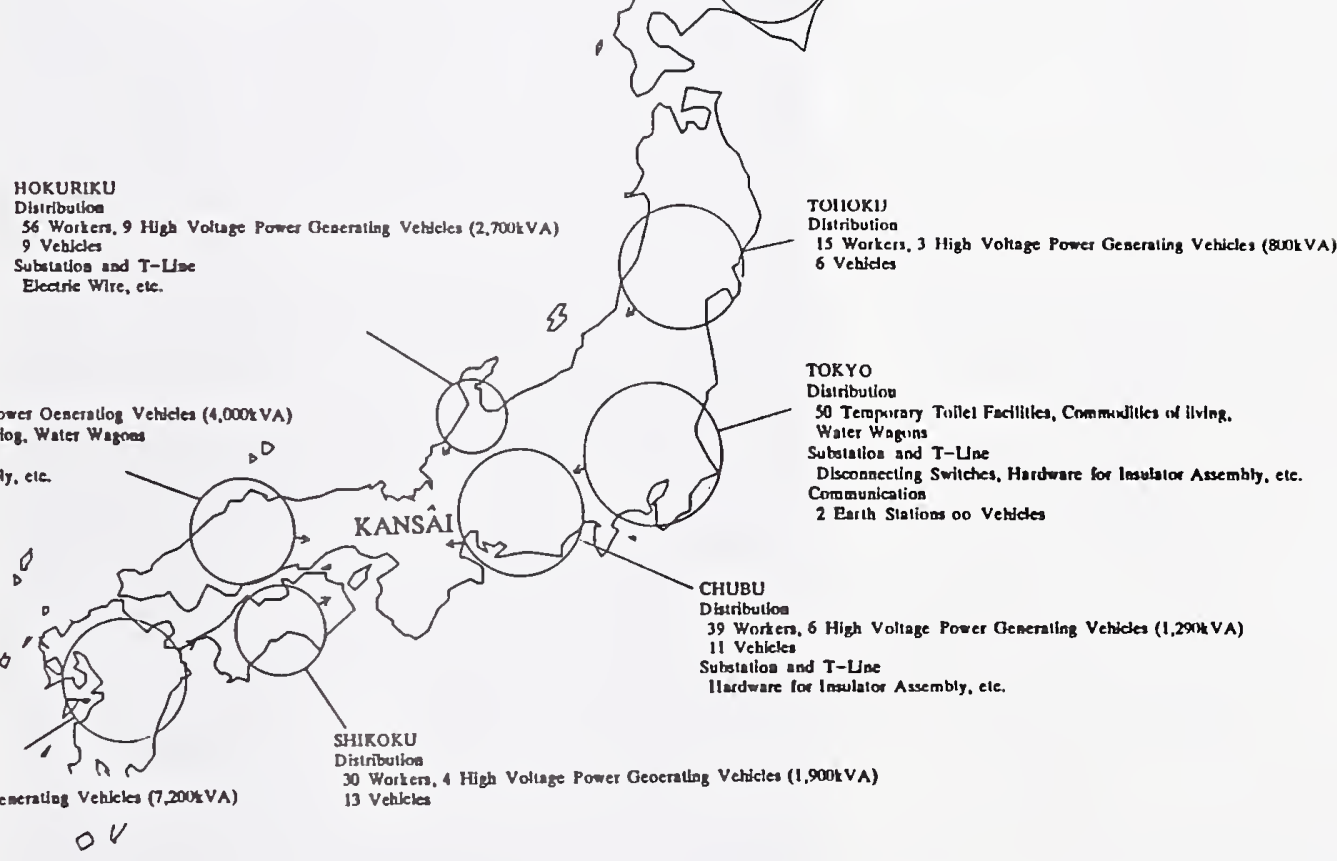

Distributic

102 Worker

24 Velicke:

Subration and T-Line

0

\section{CHugoxu}

71 Worten, 6 High Vohage Power Oeneration Velwetes $(4,000 \mathrm{rVA})$

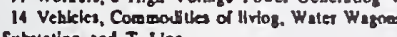

Suberation and T-LDe

Herdware for lesolator Amembly, elc

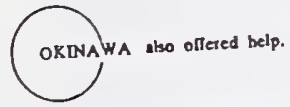

PLPCTRIC POWER DEVELOPMENT COMPANY aiso offered help. Fossll power produetion sections of otber eledric atilities abo offered thelp.

Figure 5.4.17

Sources and types of mutual aid from other utilities. 


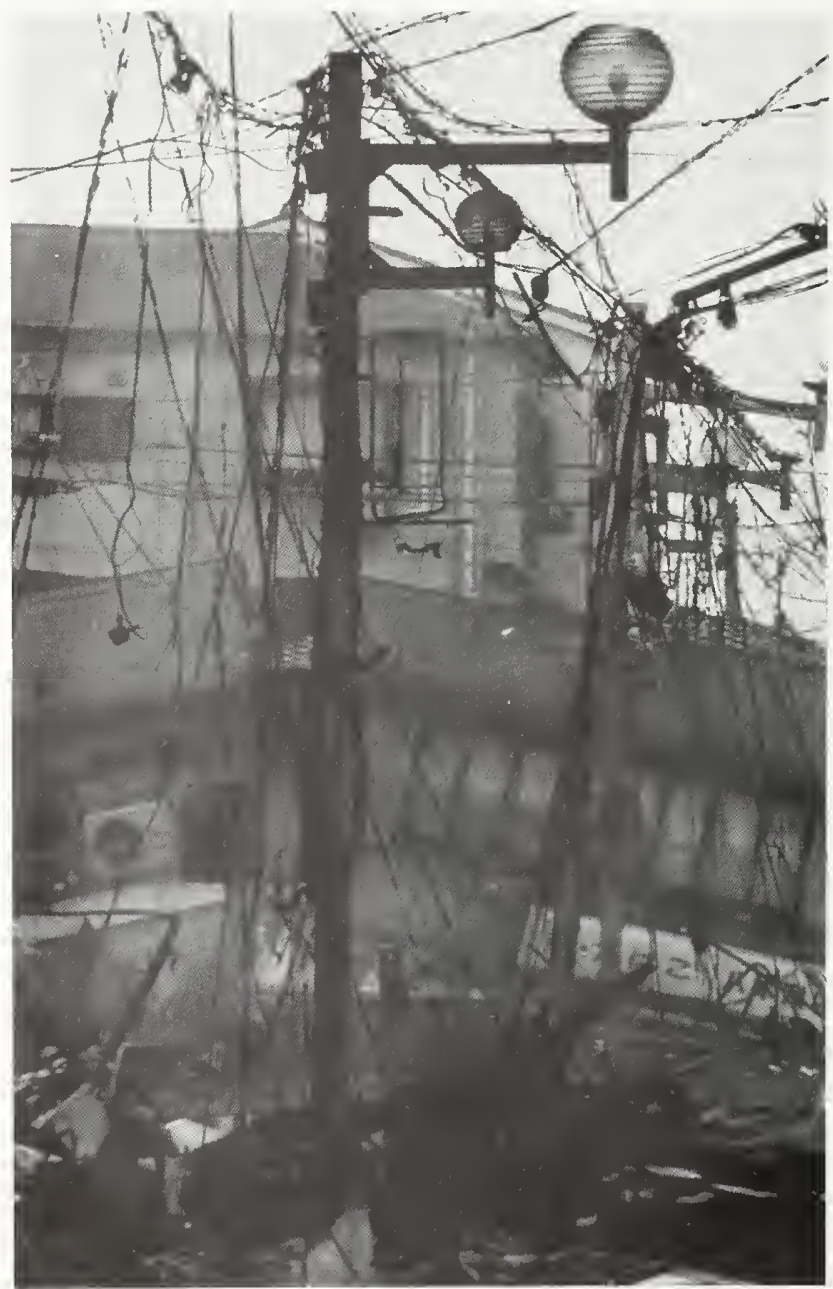

Figure 5.4.18

Damage to the distribution system was massive, but a traffic light in the background is the result of special restoration of the traffic control system. 


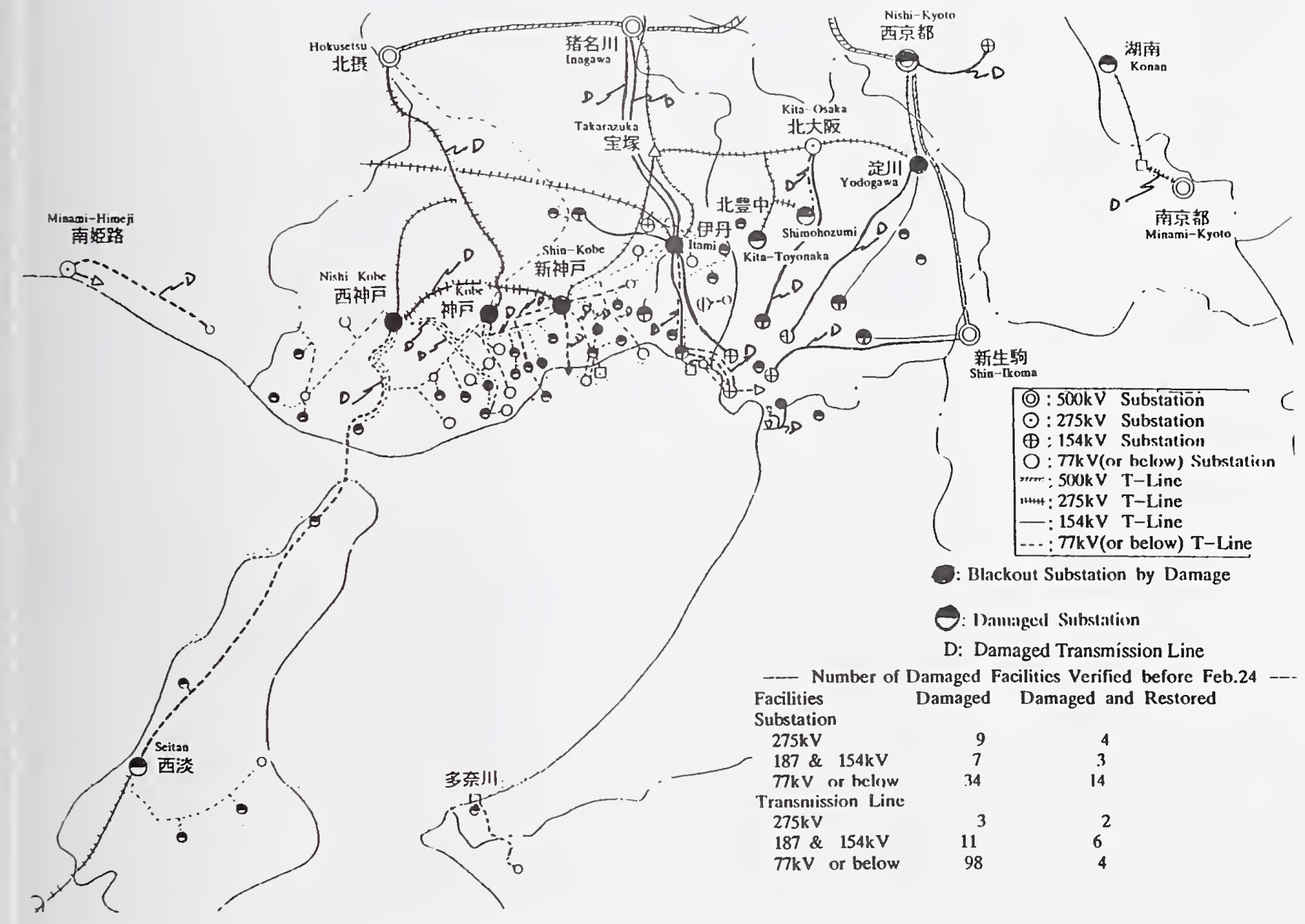

Figure 5.4.19

Schematic diagram showing the damage to substations and transmission lines. 


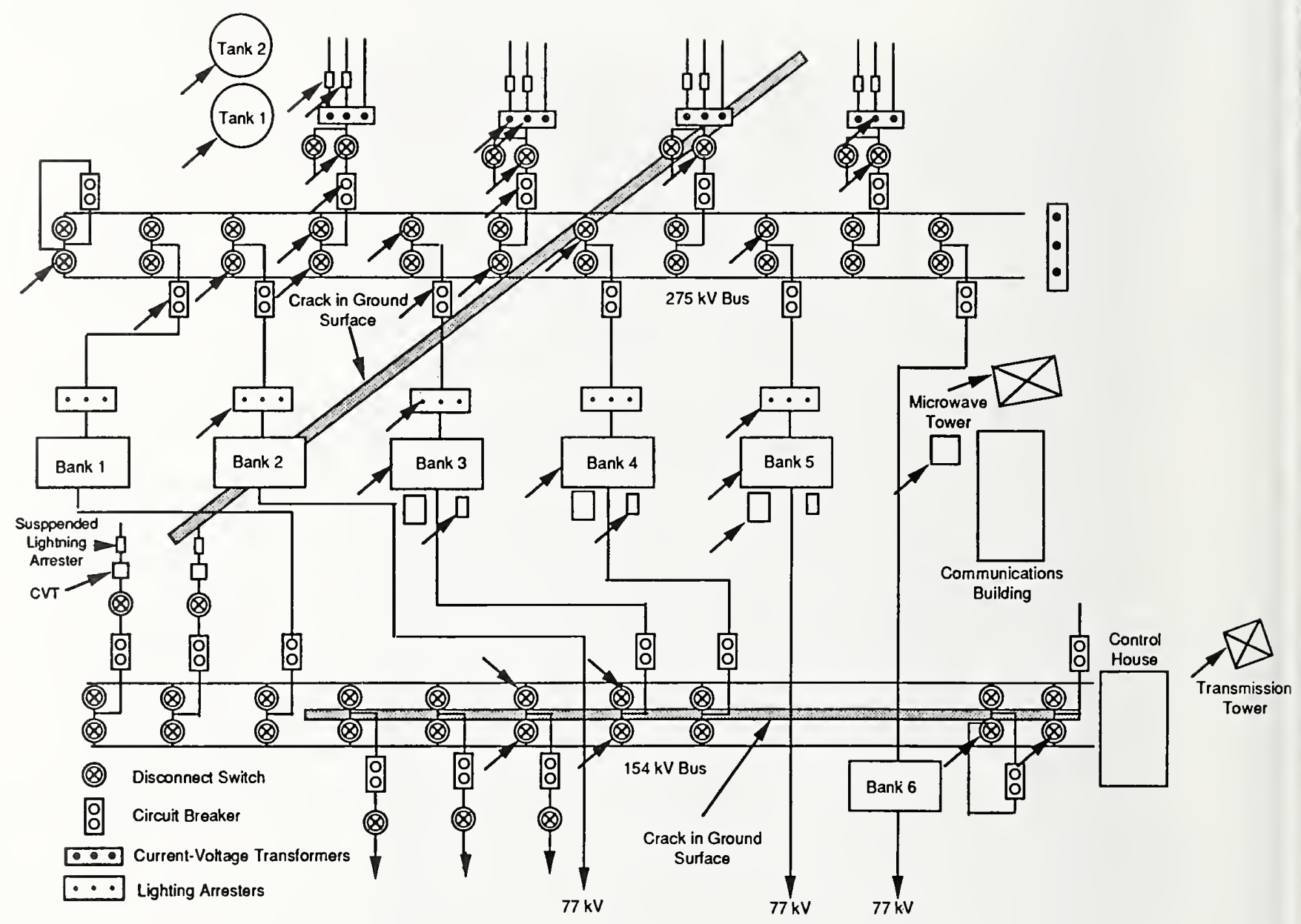

Figure 5.4.20

A modified one-line diagram for the $275 \mathrm{kV}$ and $154 \mathrm{kV}$ switchyard. 


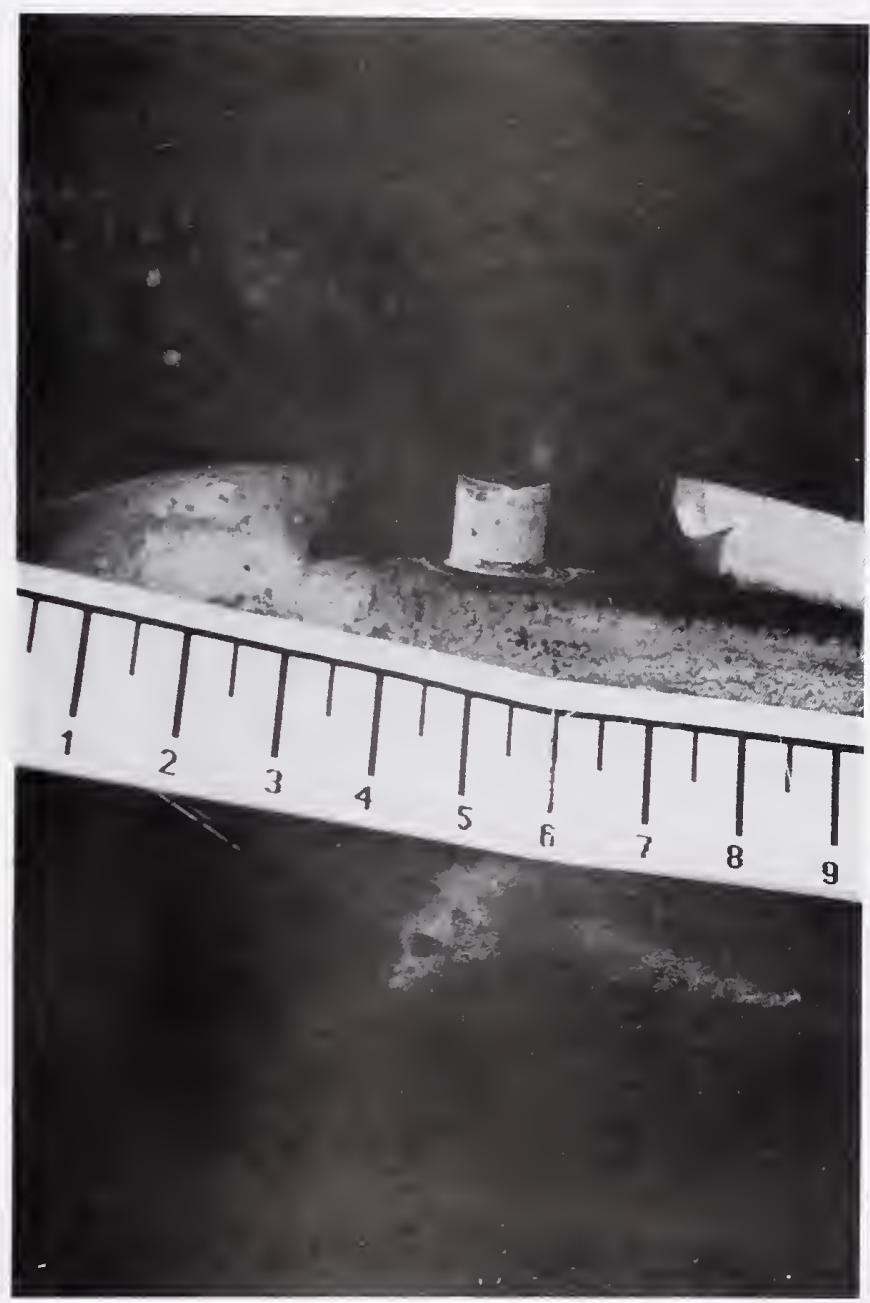

Figure 5.4.21 Failure of a current-voltage transformer base flange. 


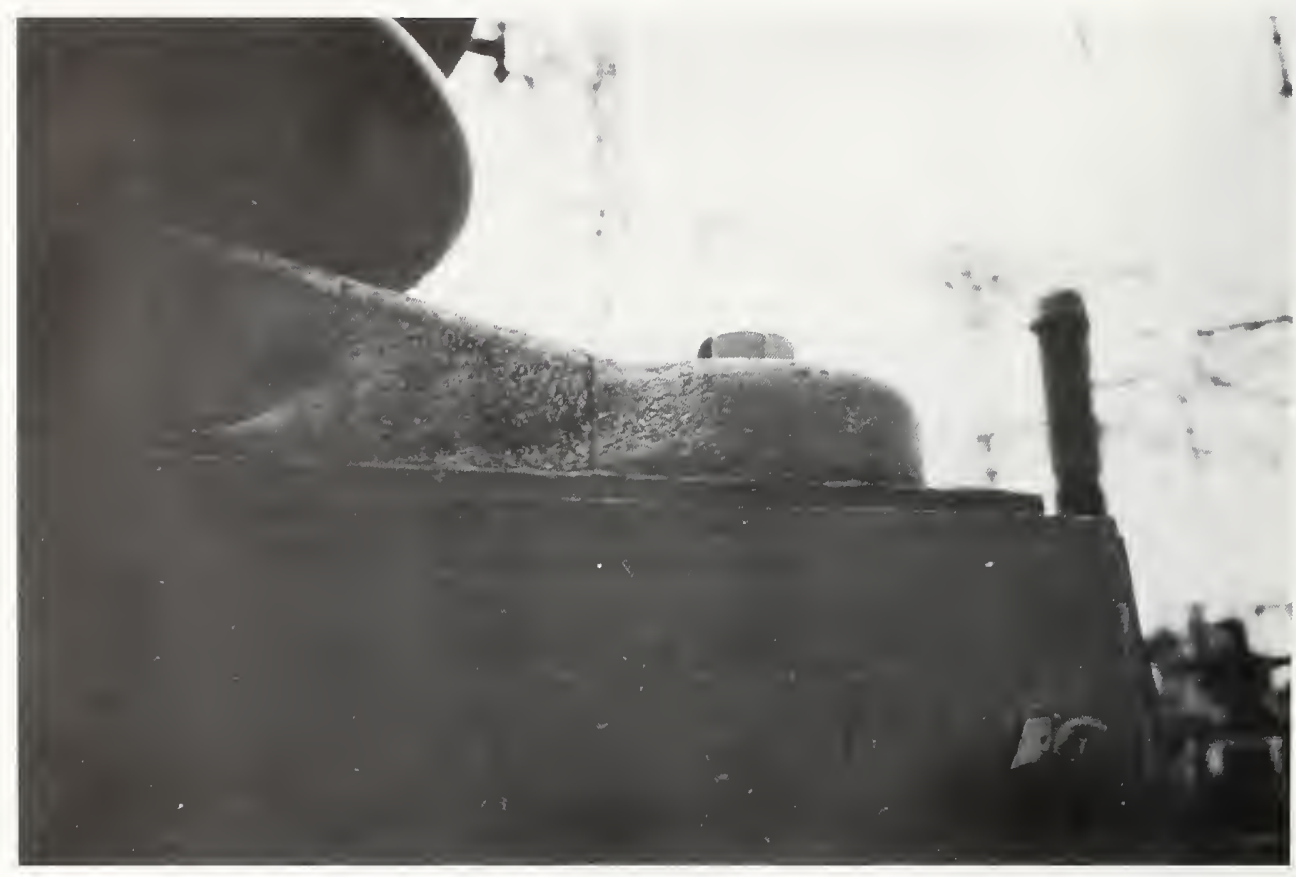

Figure 5.4.22

A cracked cast iron anchor tab on a current-voltage transformer remained in service.

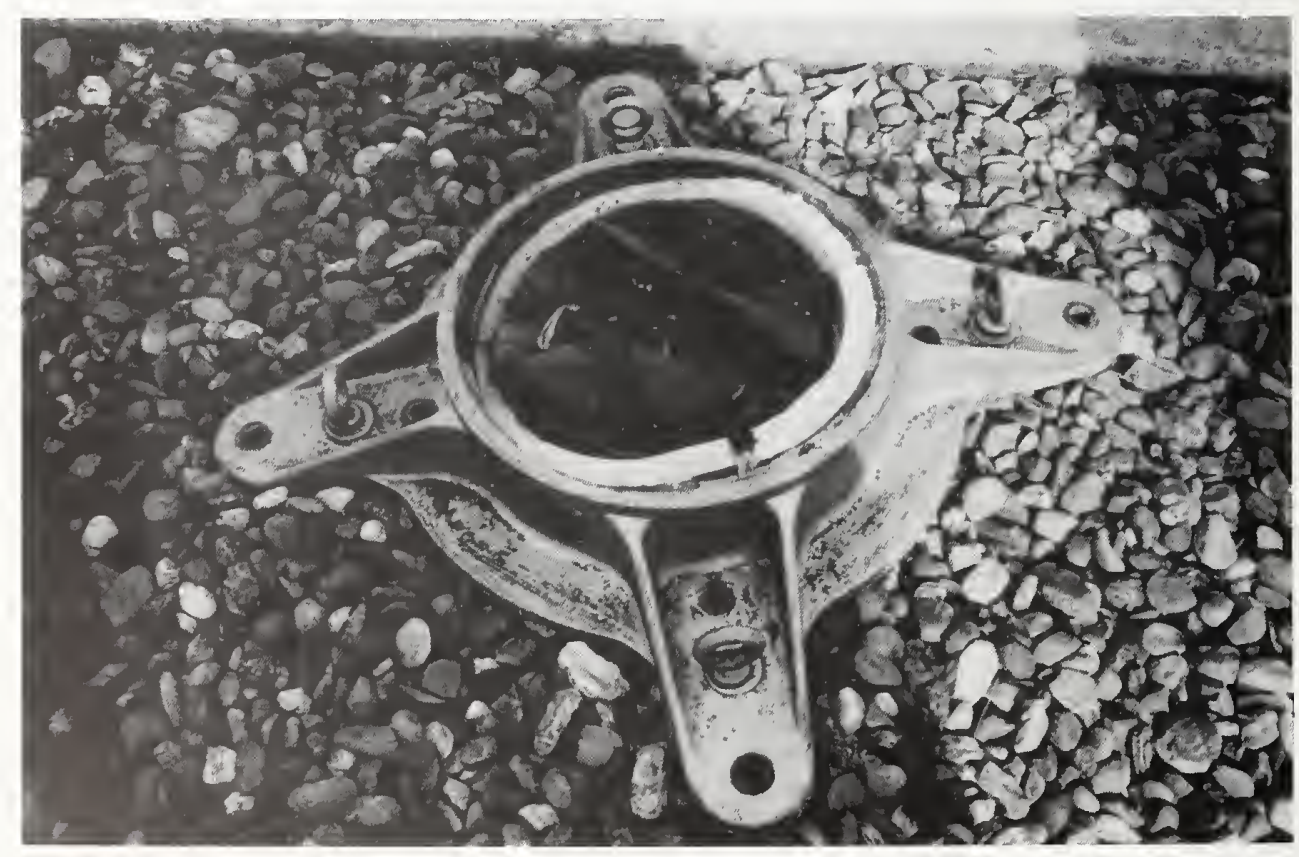

Figure 5.4.23 Porcelain failed at the base plate of this current-voltage transformer. 


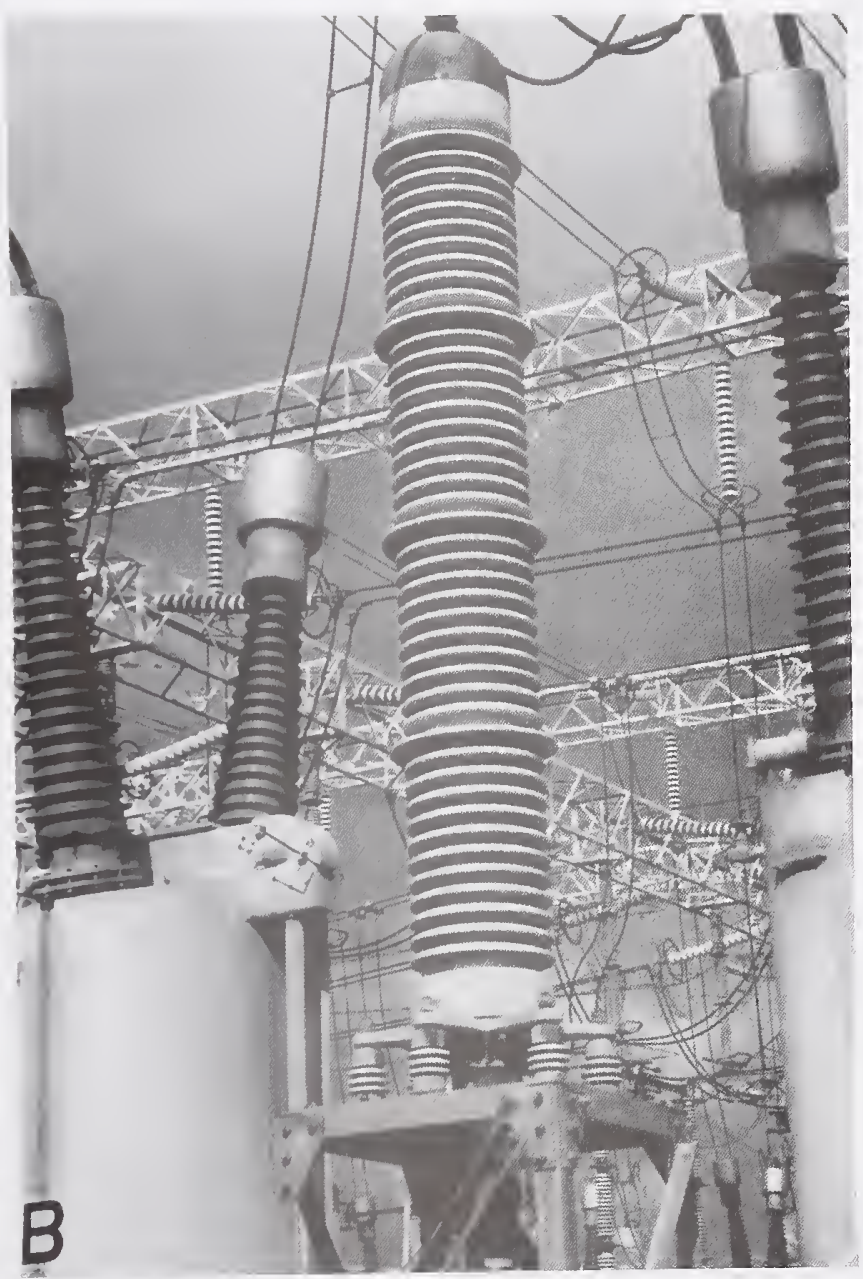

Figure 5.4.24

Bulk-oil circuit breaker and pot head on a $275 \mathrm{kV}$ circuit. 


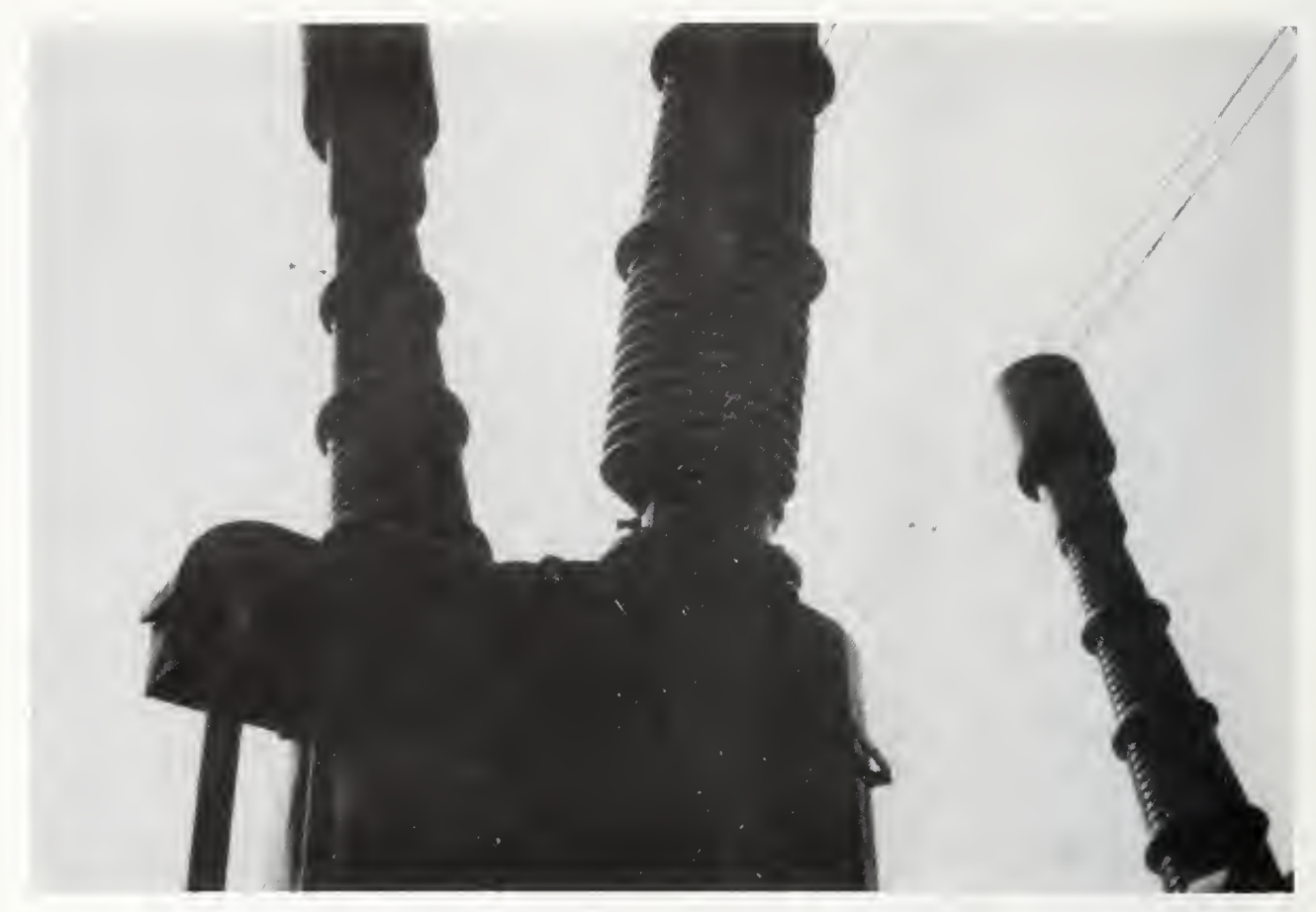

Figure 5.4.25 The porcelain slipped on its lower flange on a $275 \mathrm{kV}$ bulk-oil Circuit breaker.

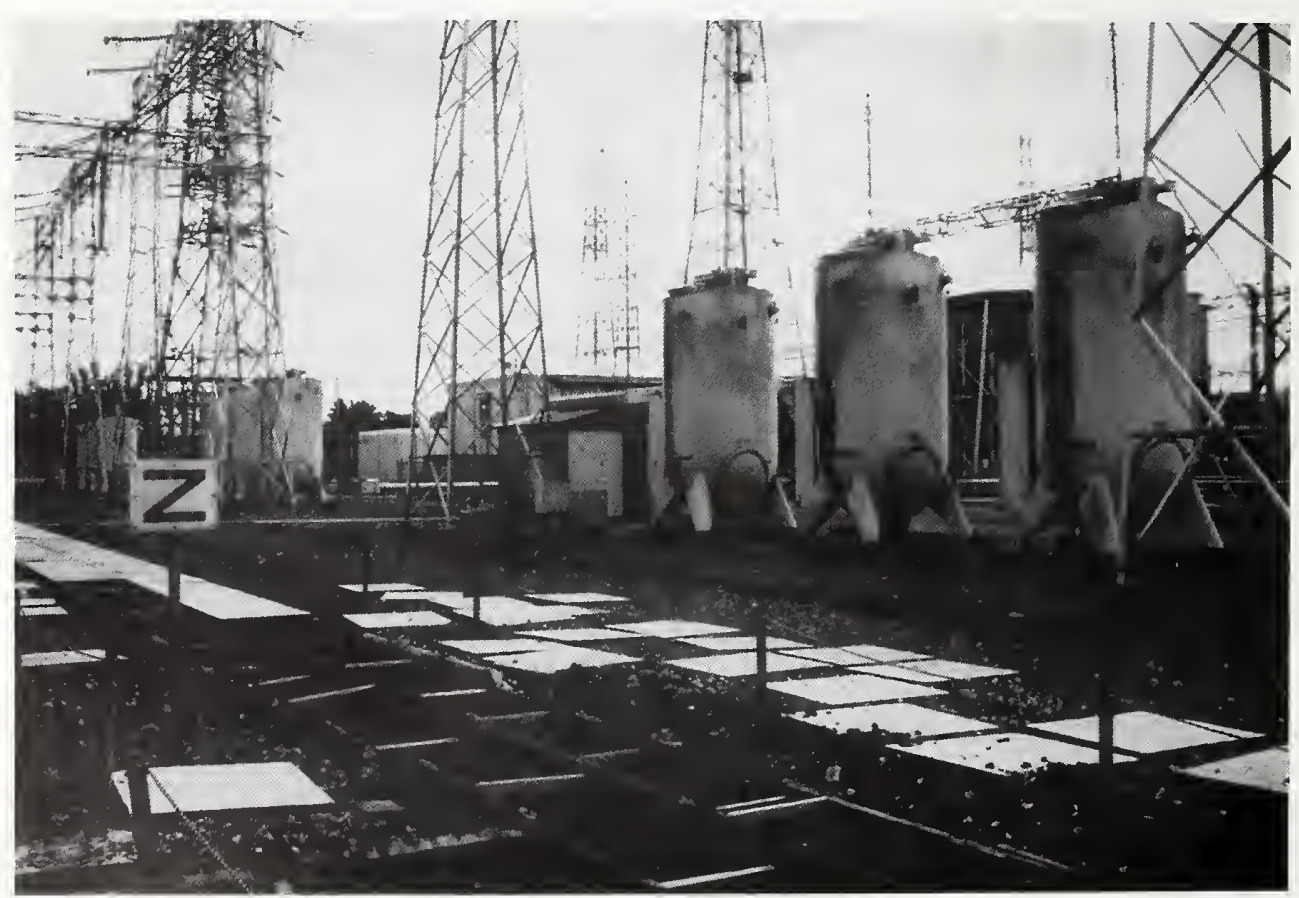

Figure 5.4.26

Bulk-oil circuit breakers with the bushings removed to replace damaged units at other sites. 


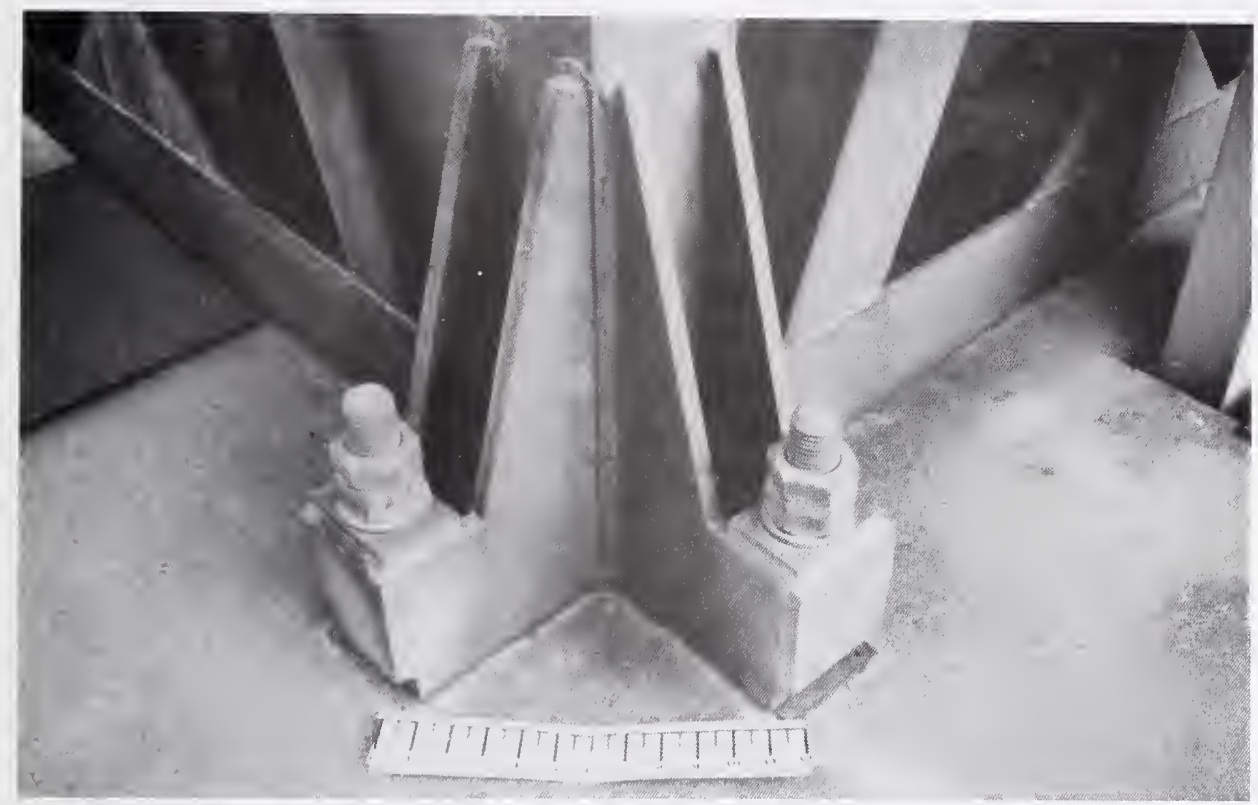

Figure 5.4.27

Very strong and stiff anchorage detailed used on a large potential transformer to meet more stringent 1980 seismic design criteria. 


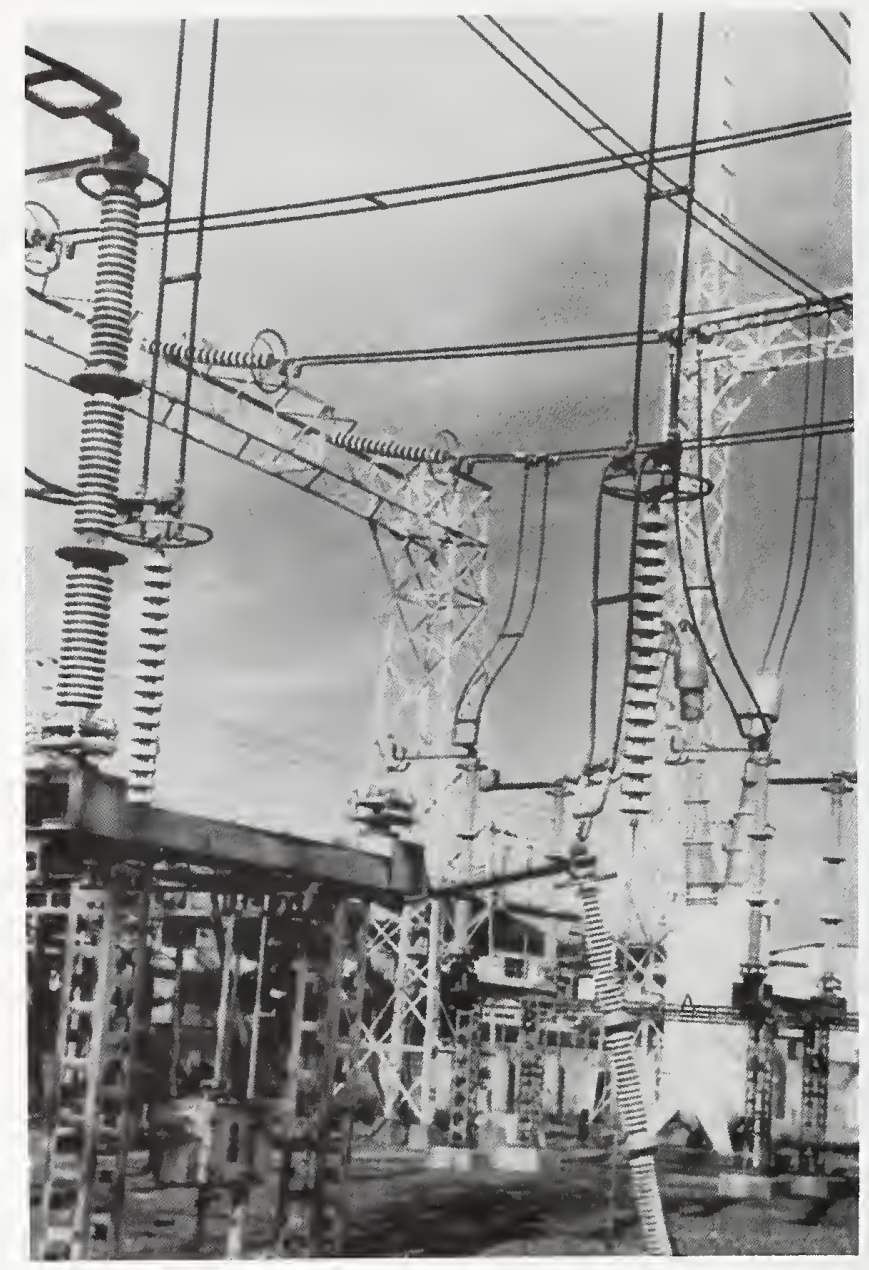

Figure 5.4.28

Isolated failure of disconnect switch may be due to interaction with the bus drop and insulator string. 


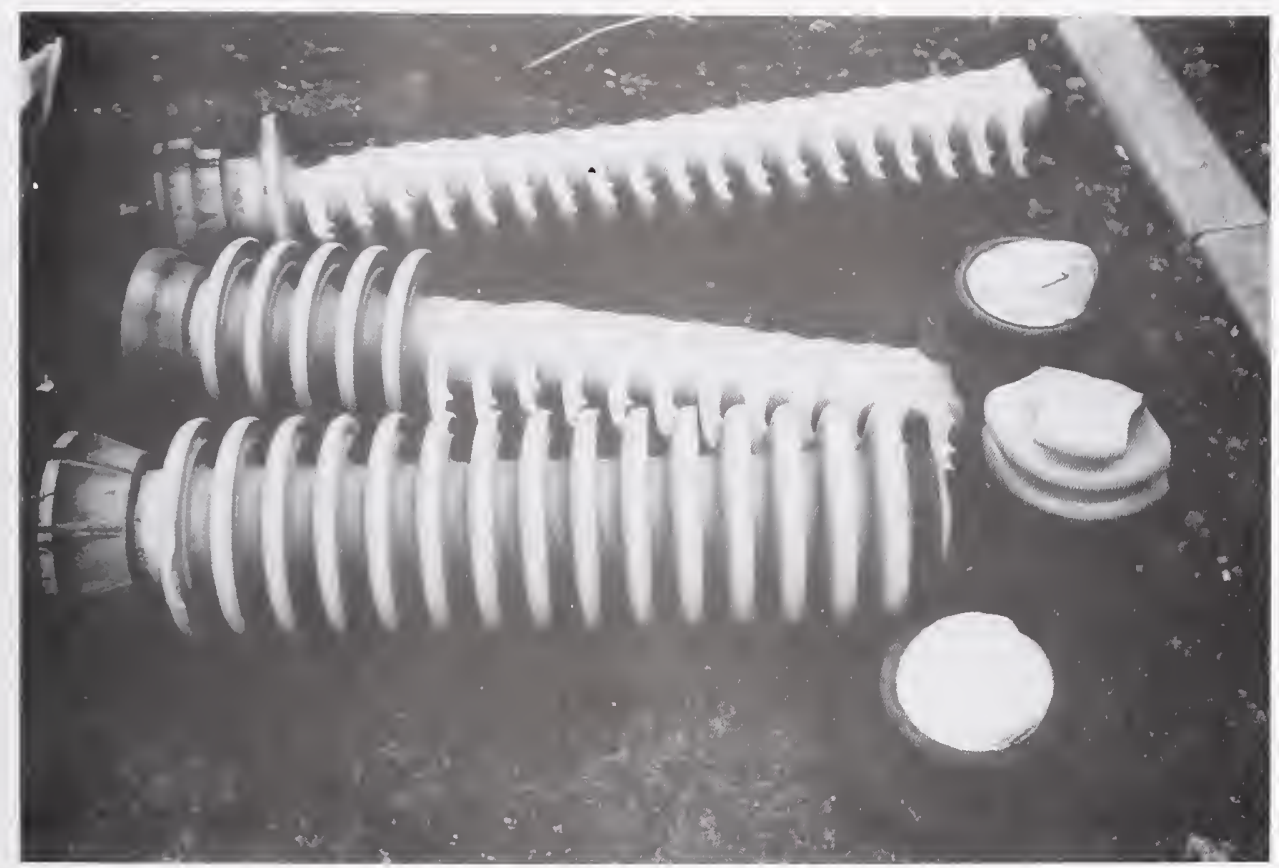

Figure 5.4.29

Damaged post insulators in the grave yard exhibit unusual longitudinal cracks.

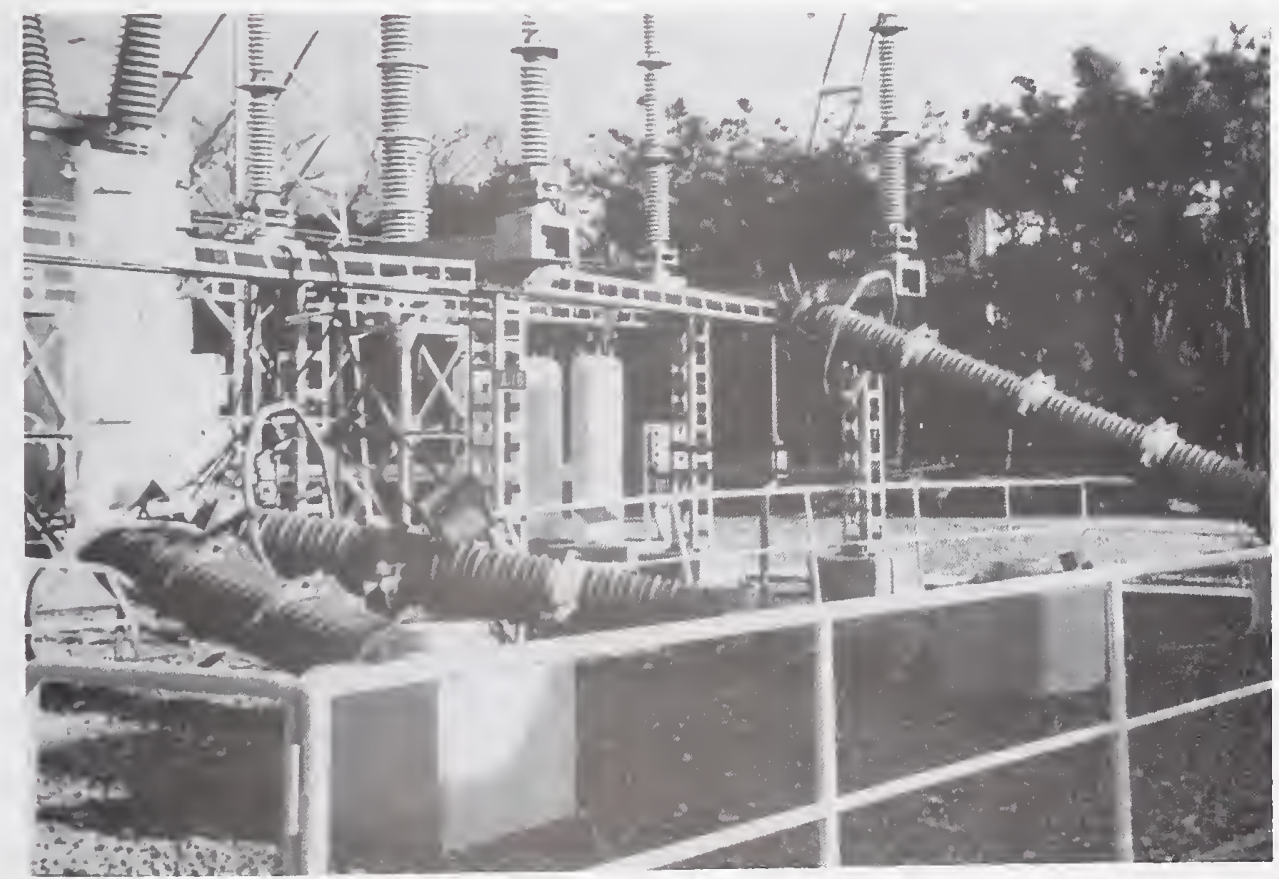

Figure 5.4.30

The standoff incorporated into the design of the base of the lightning arrester failed. 


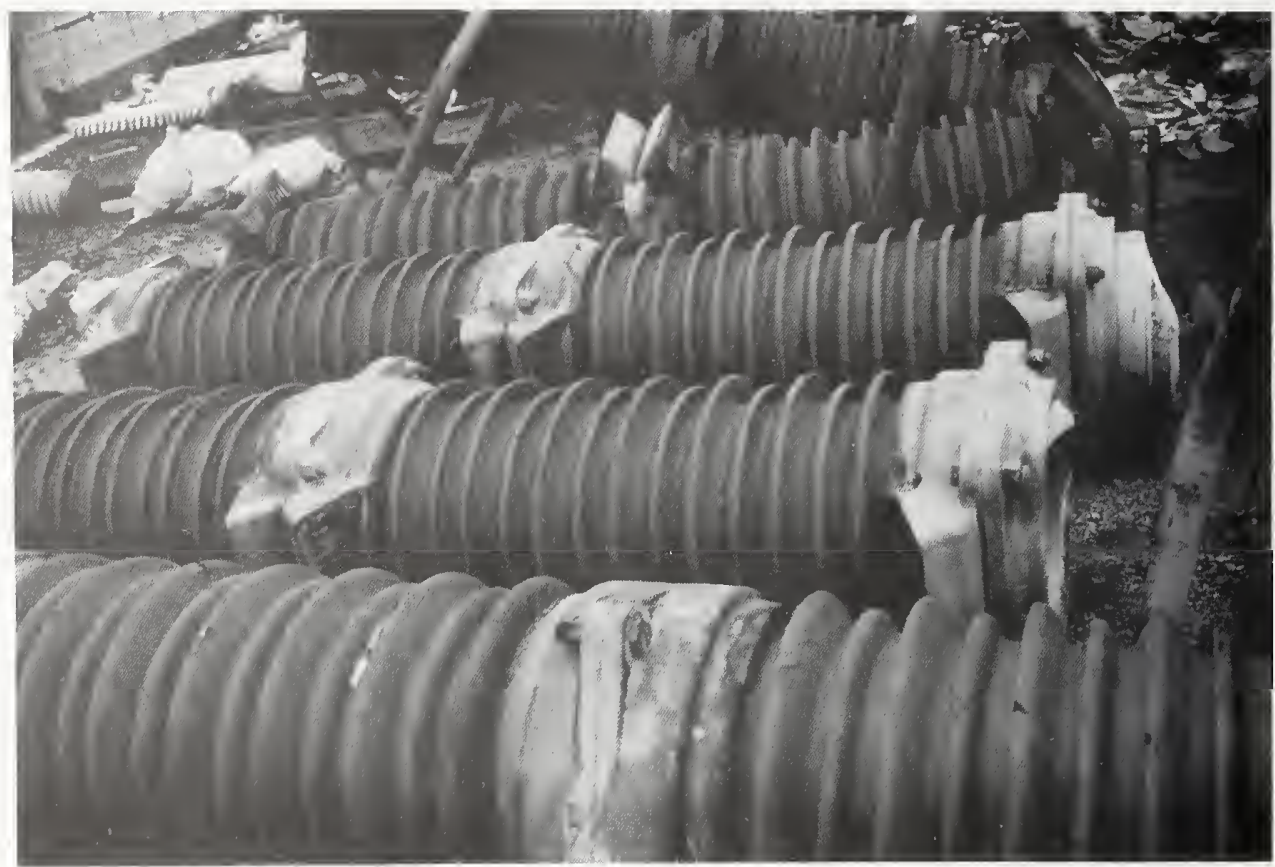

Figure 5.4.31

Damaged $275 \mathrm{kV}$ lightning arrester in the grave yard.

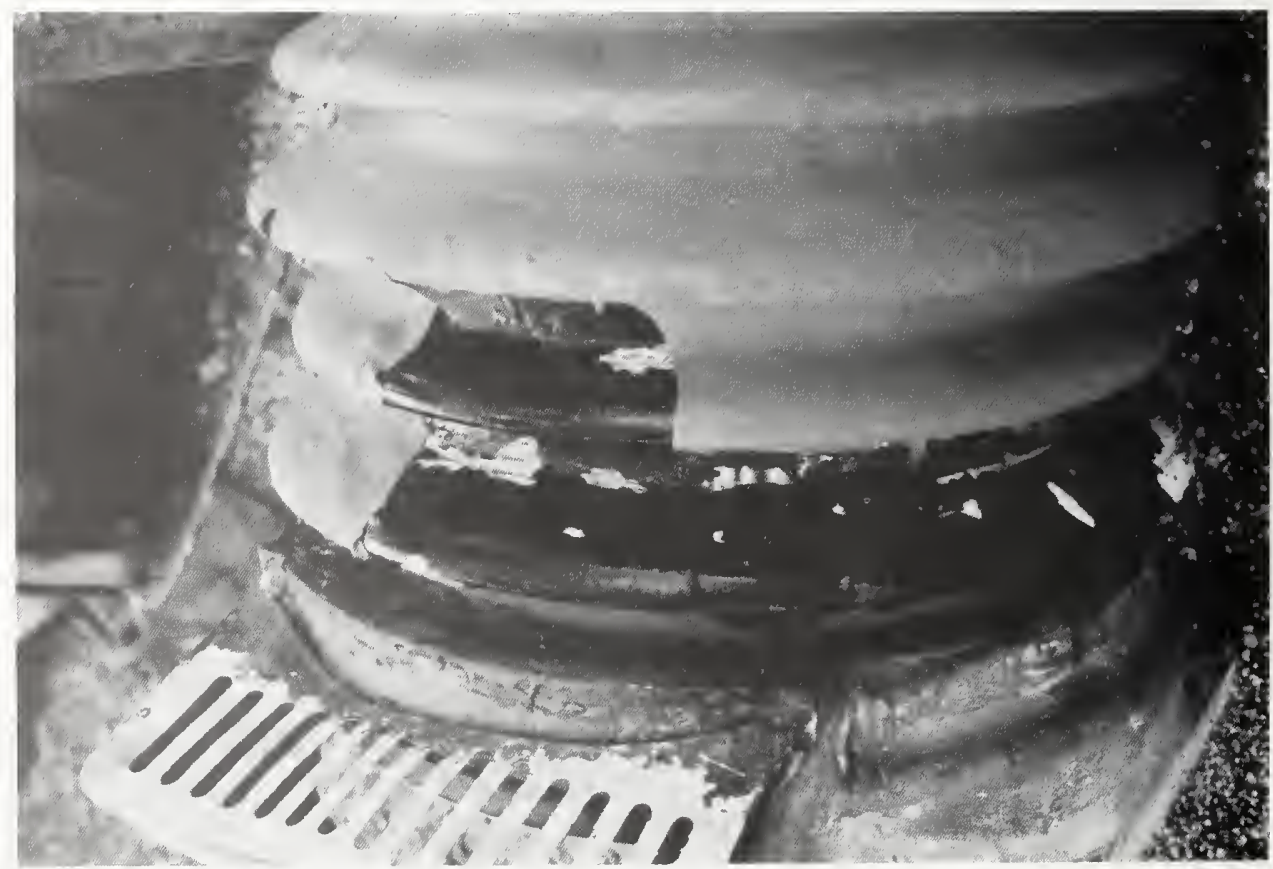

Figure 5.4.32

Silicon rubber used to improve contamination problems has peels from this damaged equipment in the grave yard. 
Figure 5.4.33

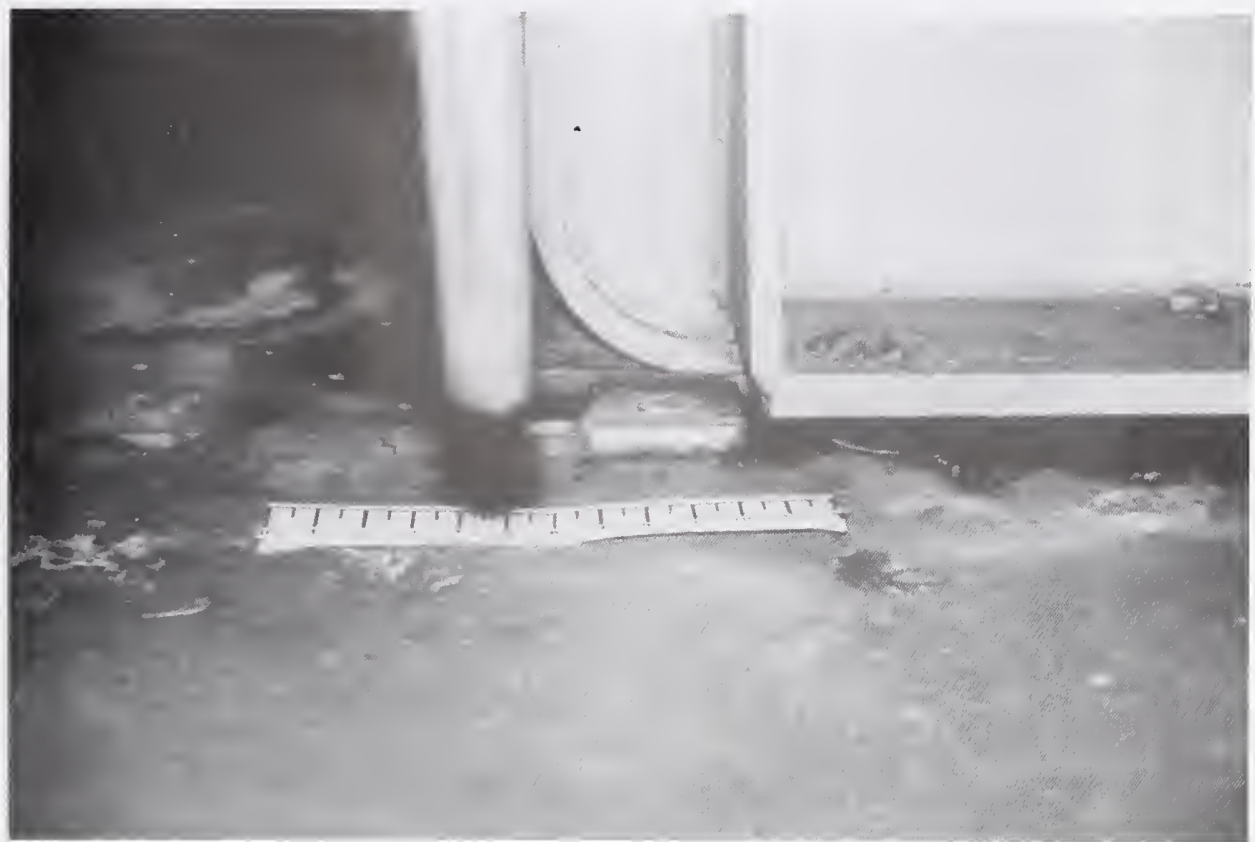

Bolts anchoring a transformer failed allowing the unit to slide $45 \mathrm{~cm}$ and causing damage to bushings.

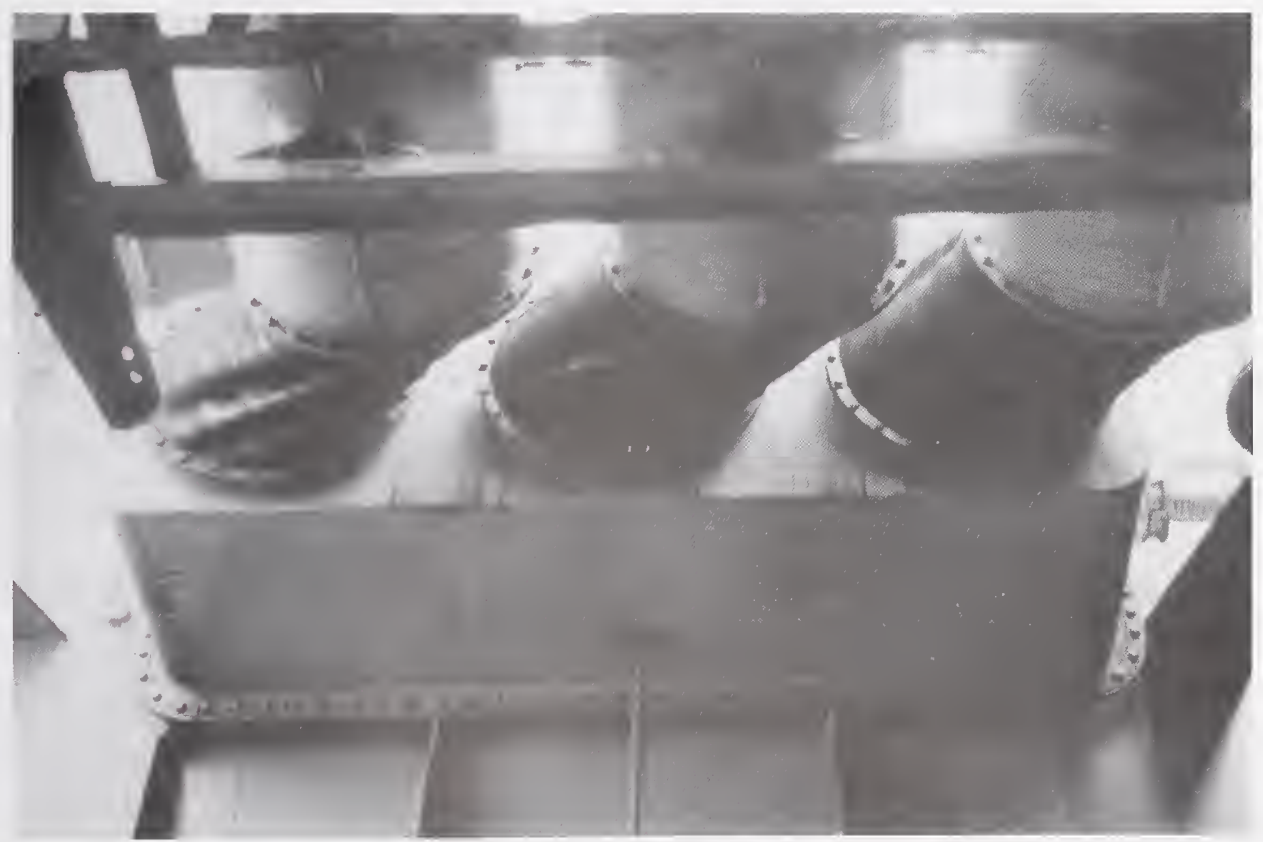

Figure 5.4.34

Offset in bus covers caused by the failure of transformer anchorage and its movement. 


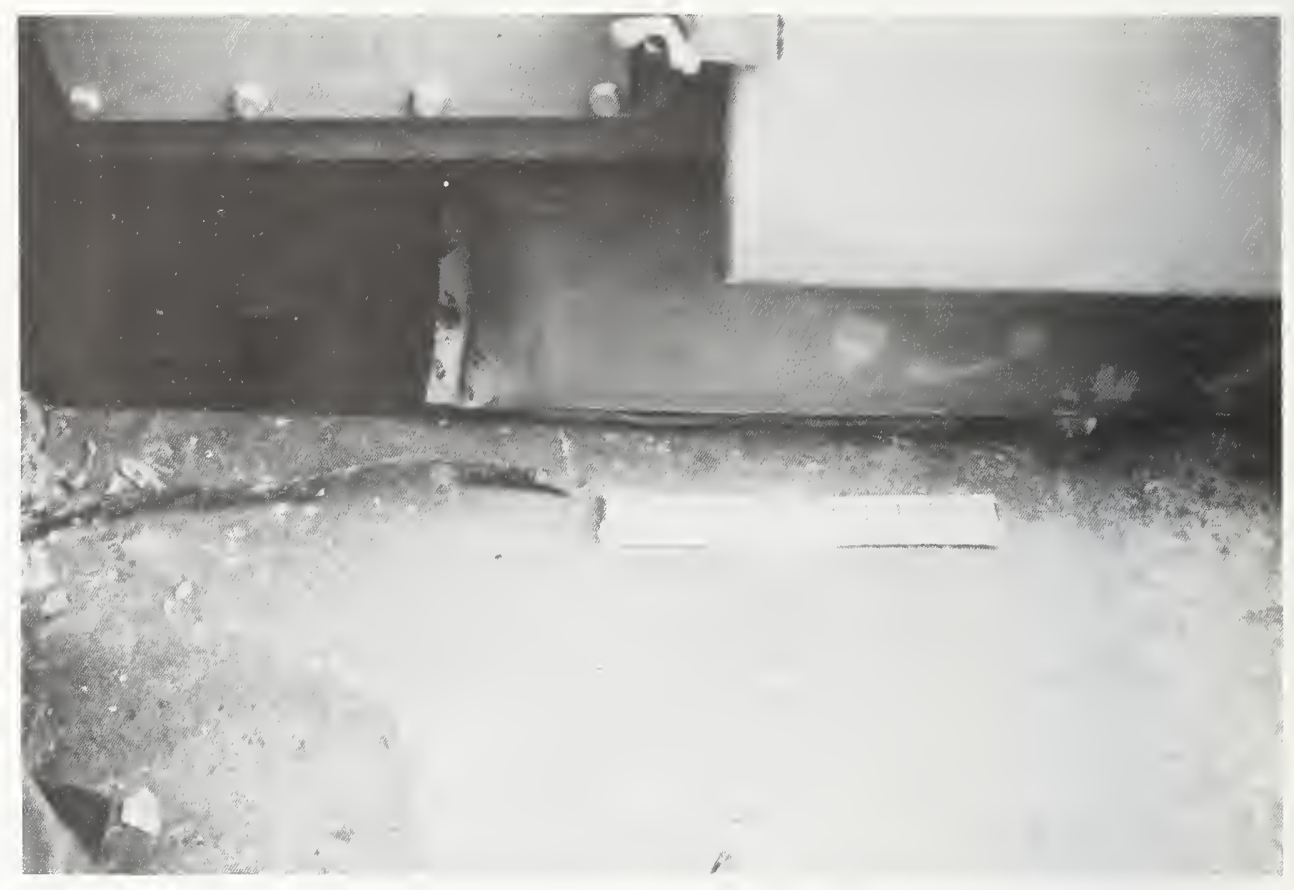

Figure 5.4.35

Transformer control cables were almost sheared off due to movement of the transformer.

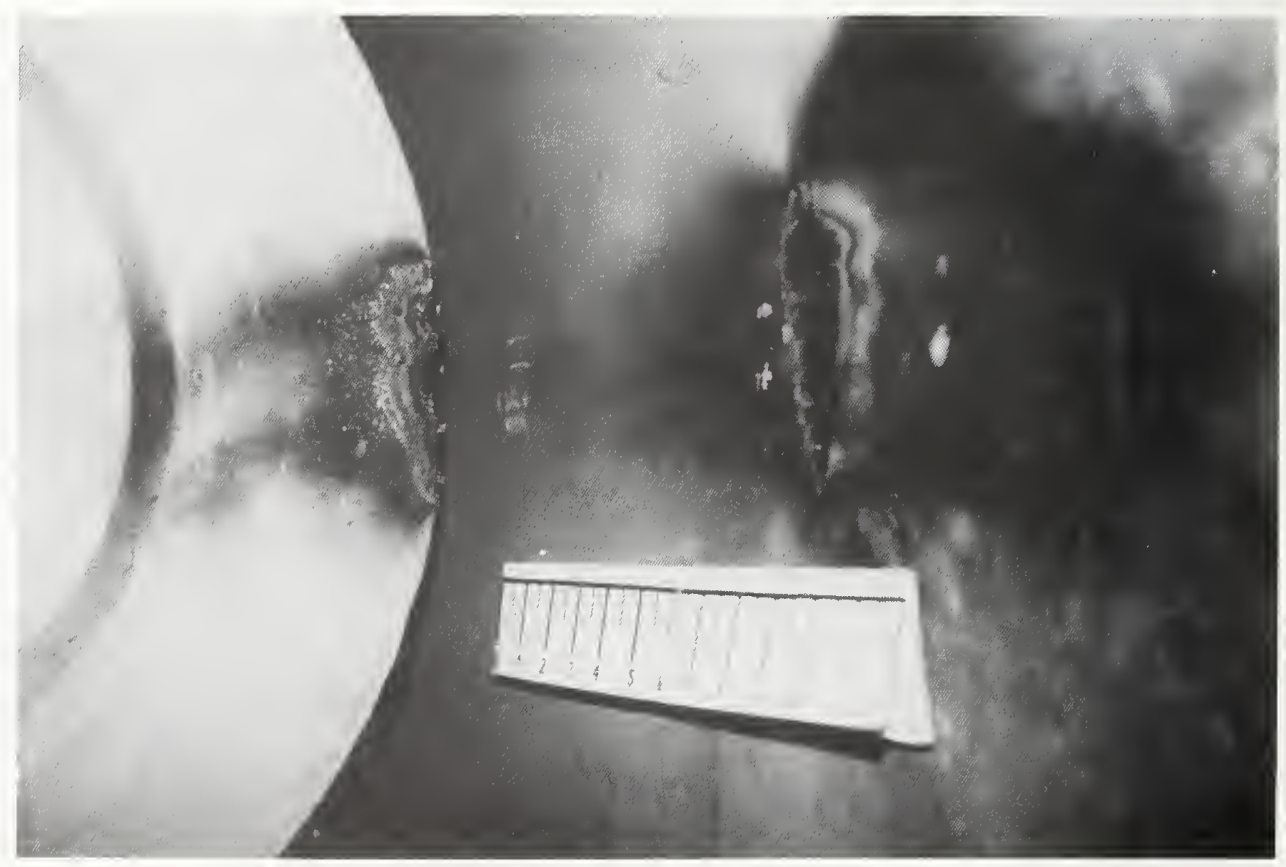

Figure 5.4.36

Movement of transformer damaged cabinet and shorted transformer case the tertiary output. 


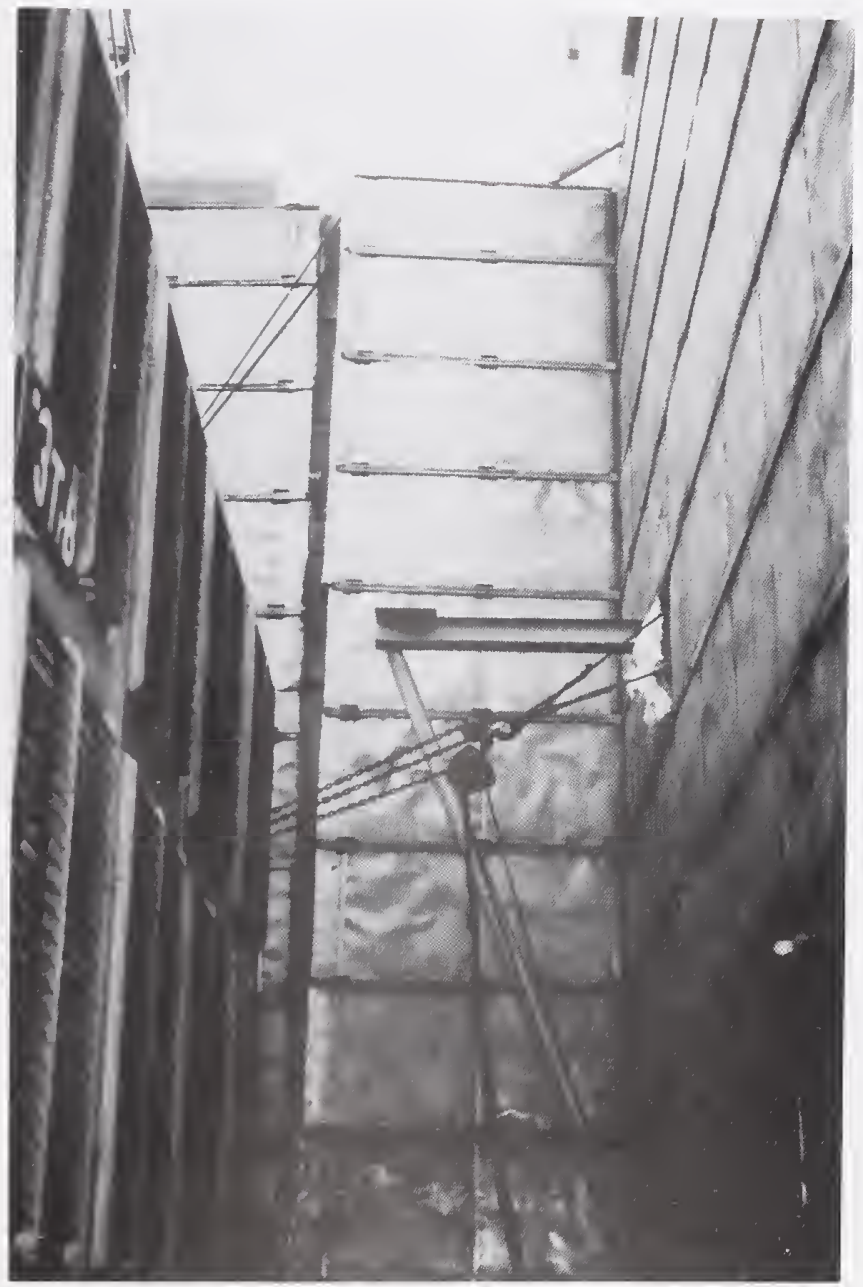

Figure 5.4.37 Transformer acoustical enclosure support was damaged and the enclosure shifted. 


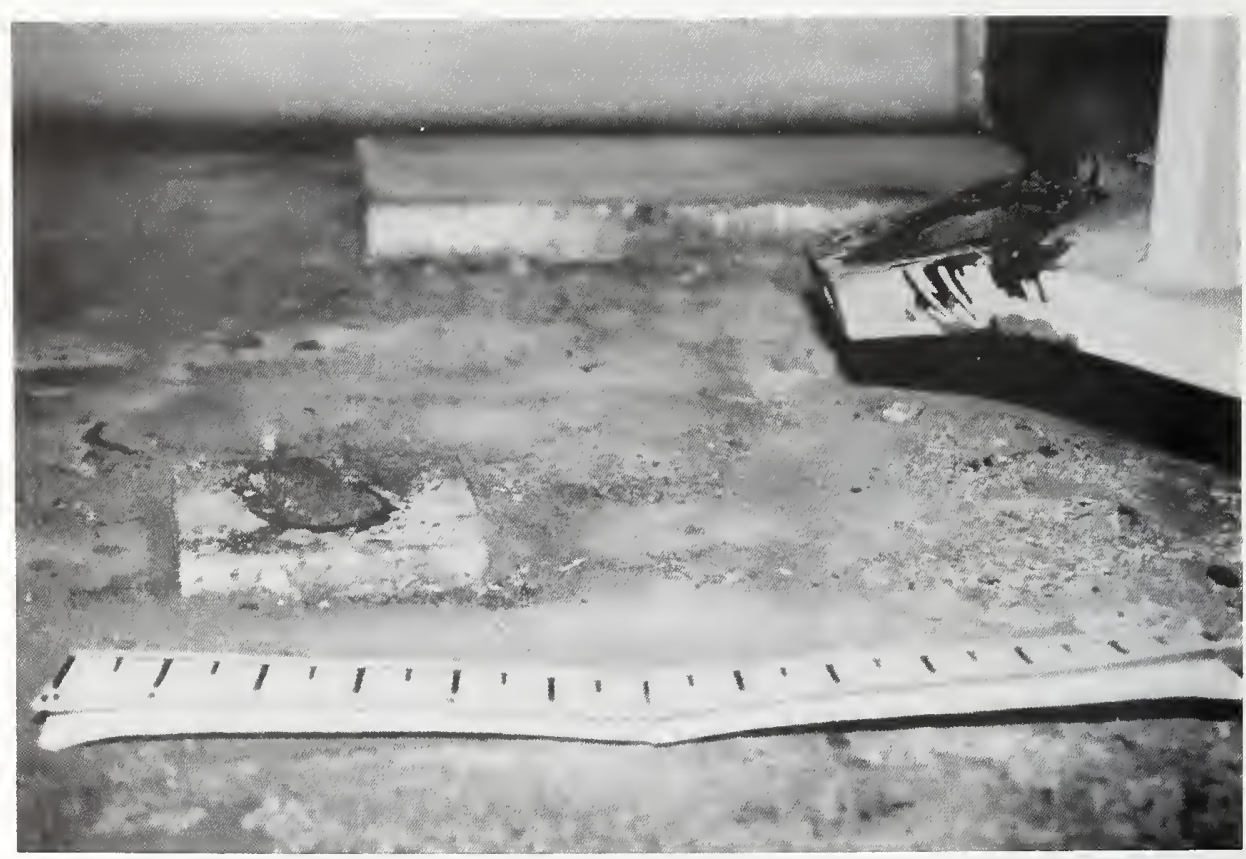

Figure 5.4.38

Small transformer sheared its anchor bolts and moved $25 \mathrm{~cm}$ increasing the load on bushings. 


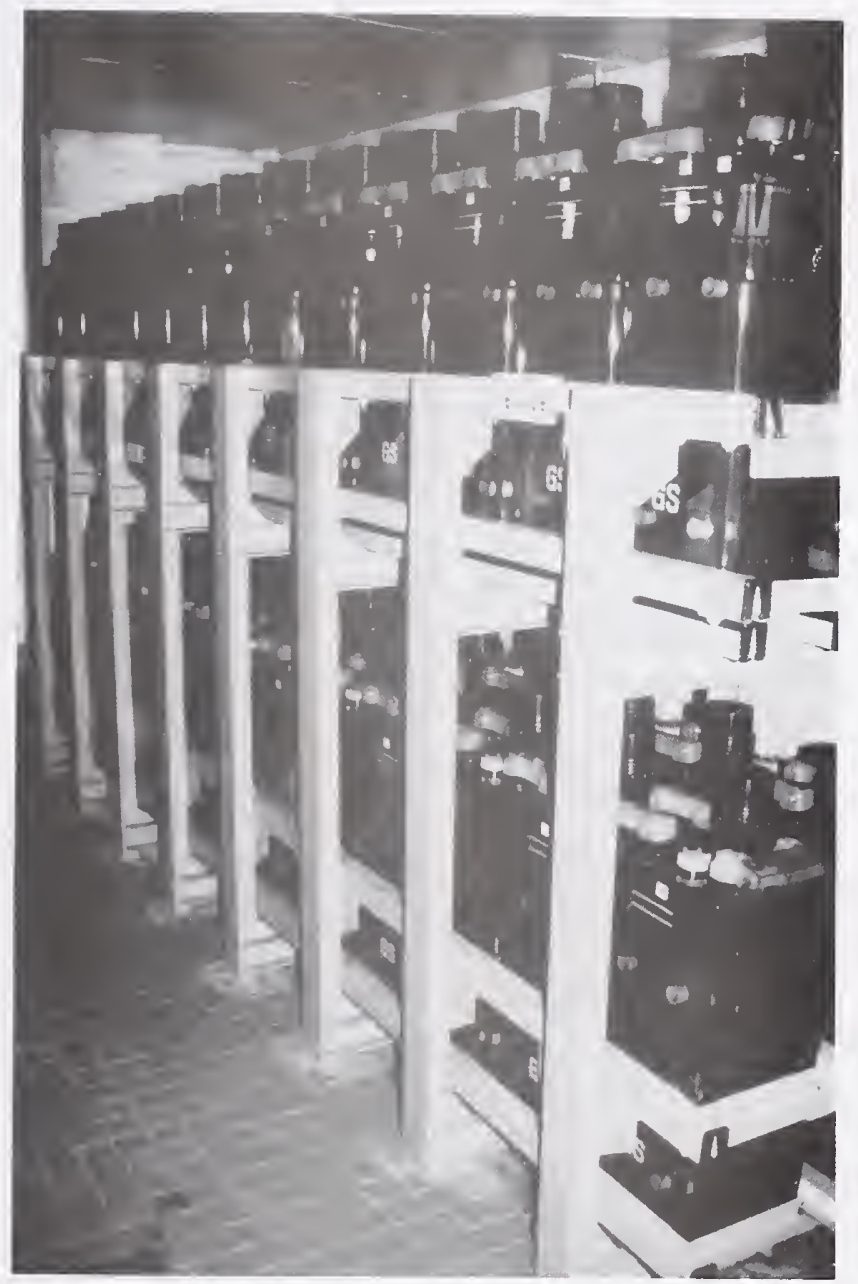

Figure 5.4.39 Batteries are secured to a well braced and anchored battery rack. 


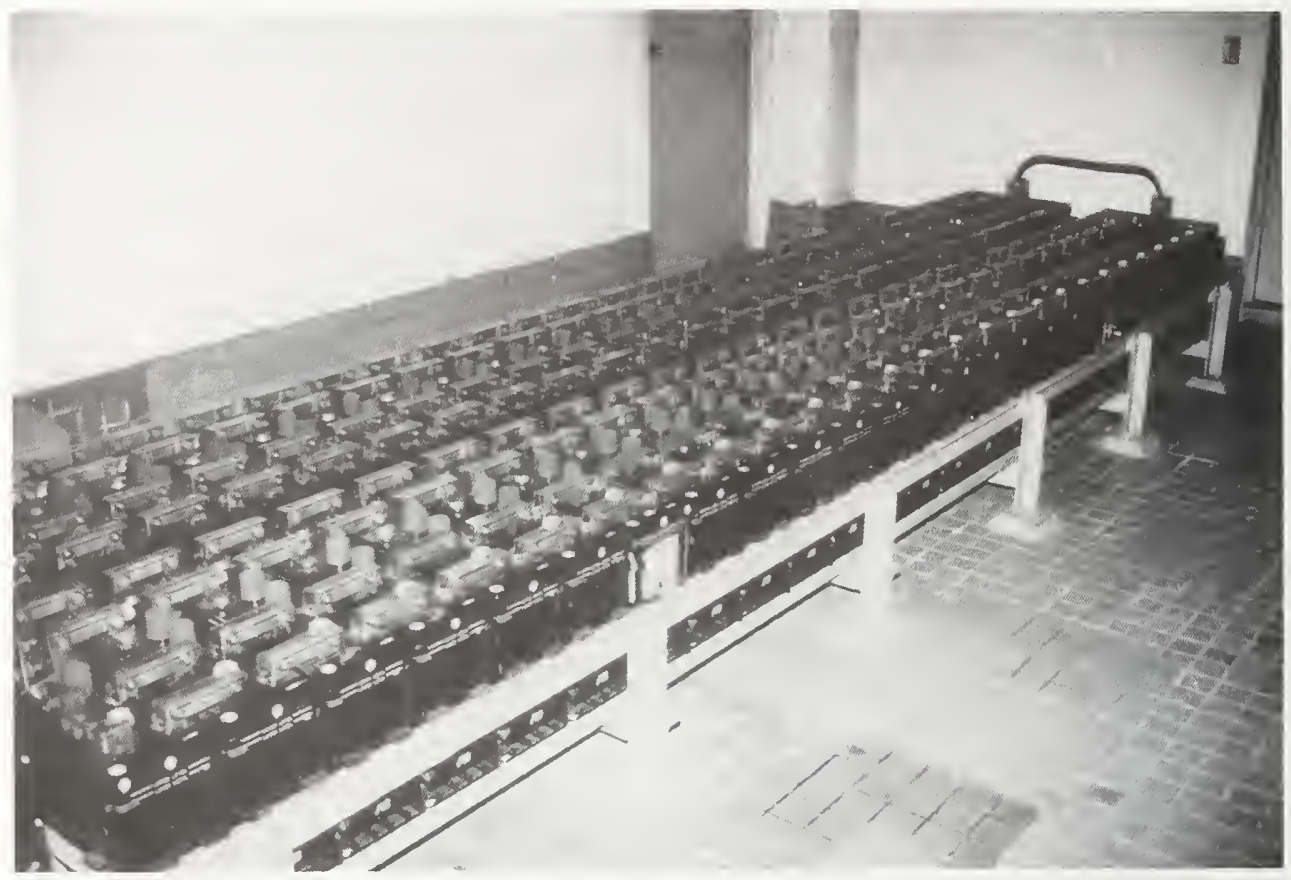

Figure 5.4.40

A low slung battery rack configuration not found in the U.S. reduces bracing requirements of the rack.

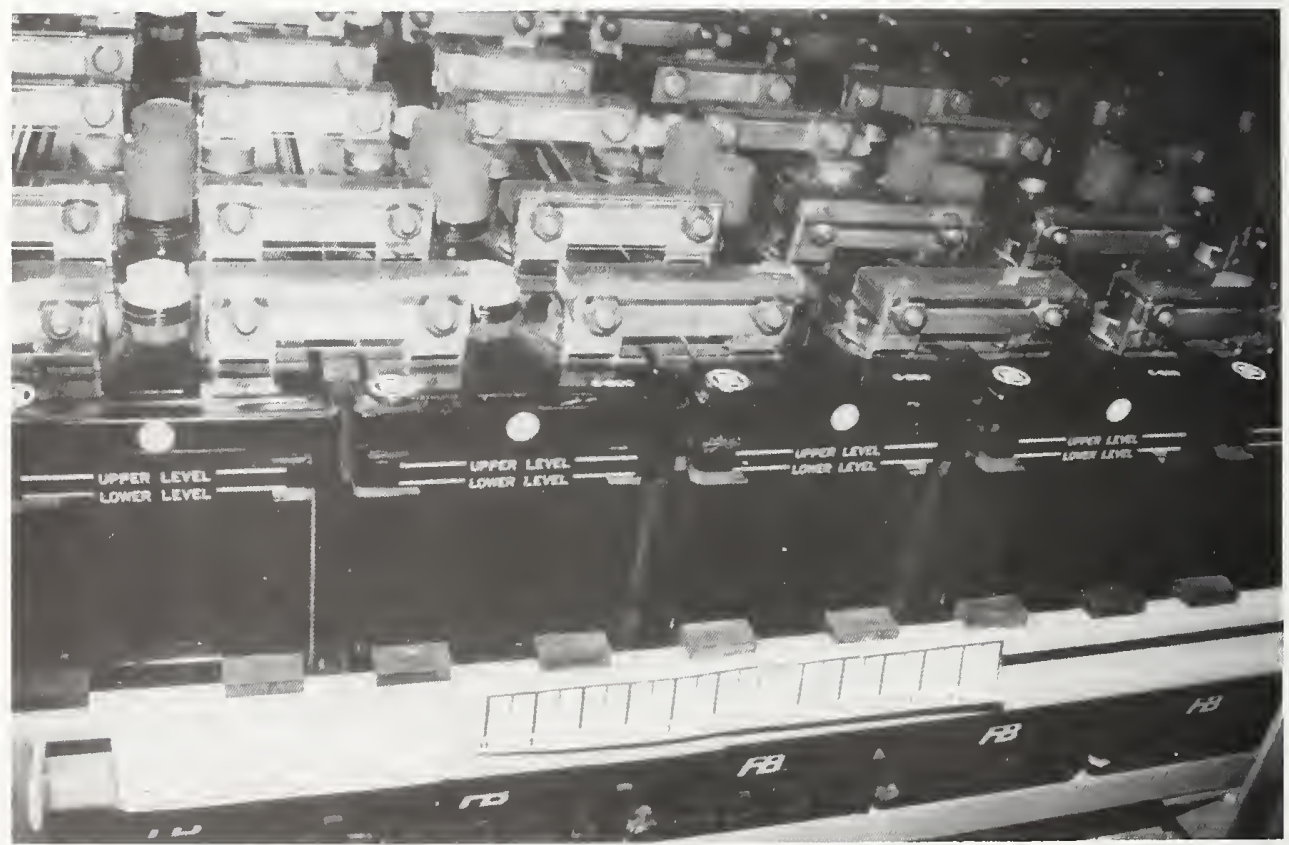

Figure 5.4.41

A different approach using rubber spacers in Japan to restraining cells to battery racks. 


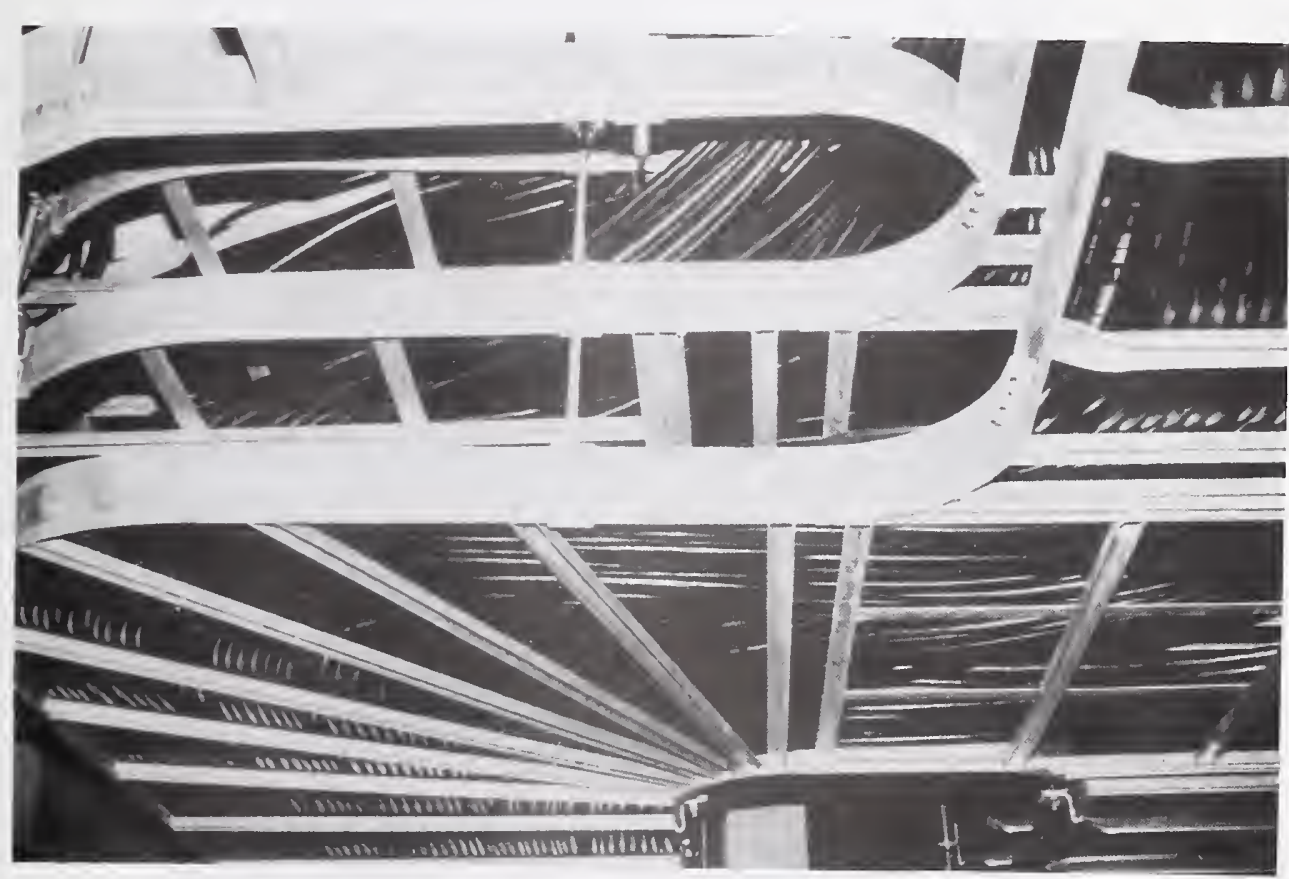

Figure 5.4.42 Cable tray sections are bolted together and cables restrained with ties to the tray. 


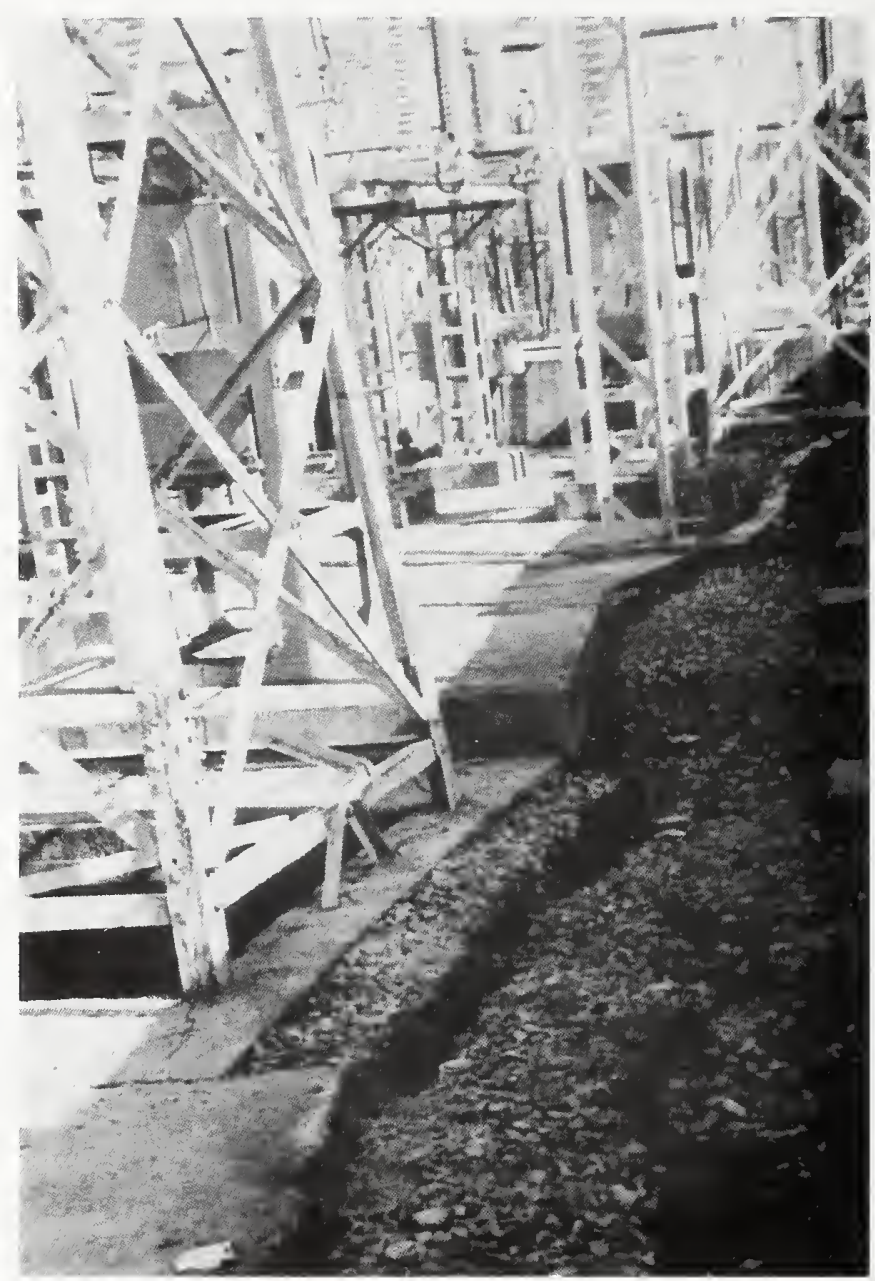

Figure 5.4.43

A long crack in the ground surface opened about $25 \mathrm{~cm}$ and damaged cable trenches. 


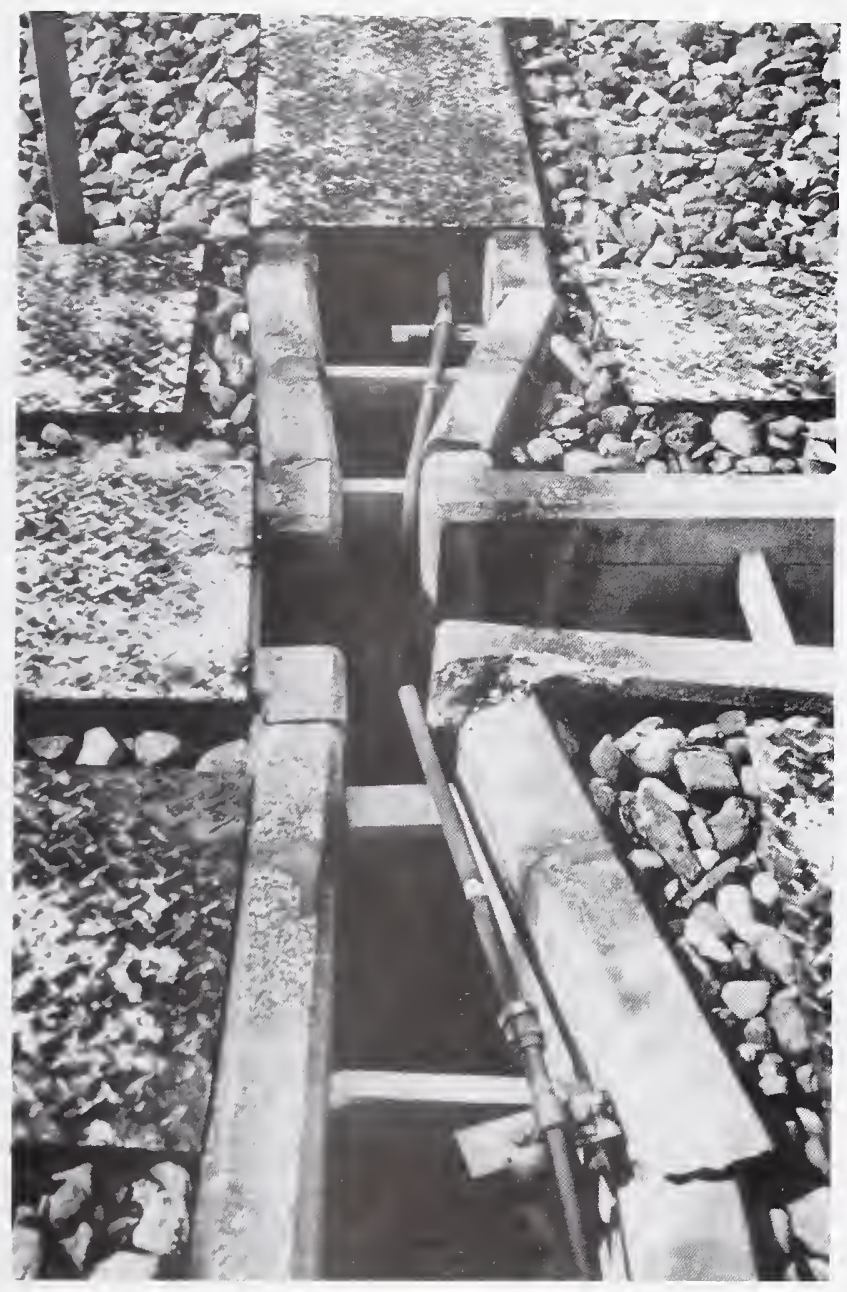

Figure 5.4.44 Cable trenches were deformed with the ground fracturing an air line be leaving control cables undamaged. 


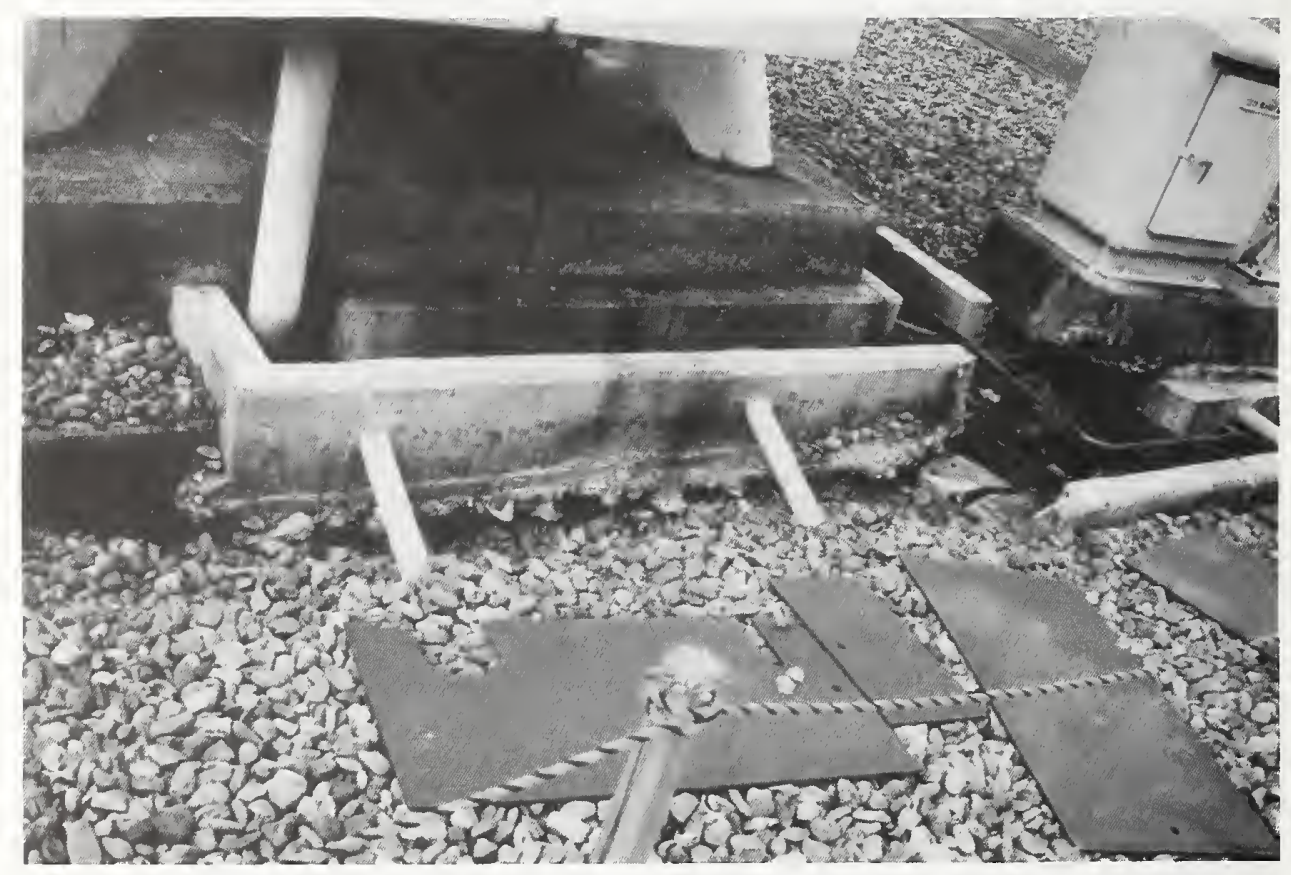

Figure 5.4.45 Large soil deformations at equipment and pedestal foundations did not damage control cables. 


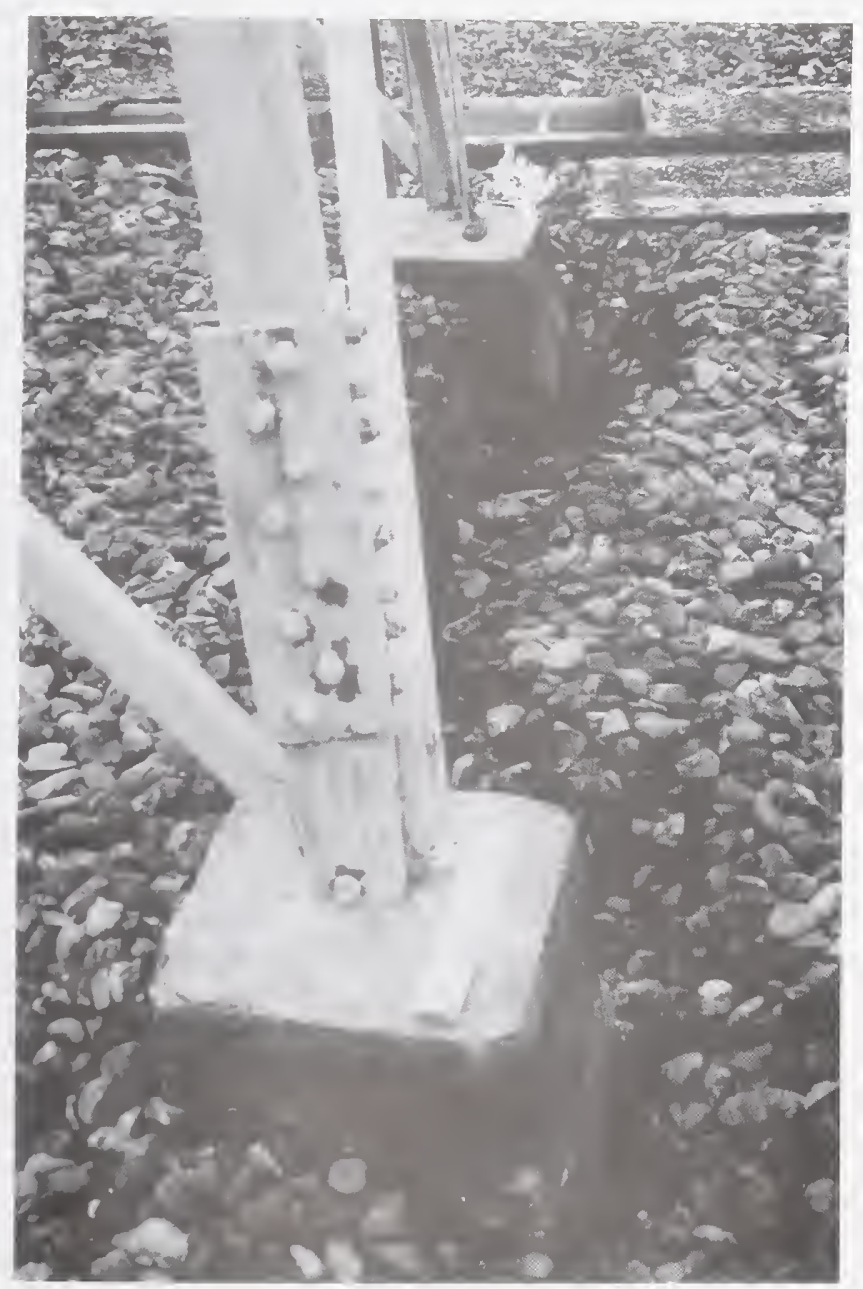

Figure 5.4.46

Foundations of conductor support structures were disturbed and individual footings rotated as much as 25 degrees. 


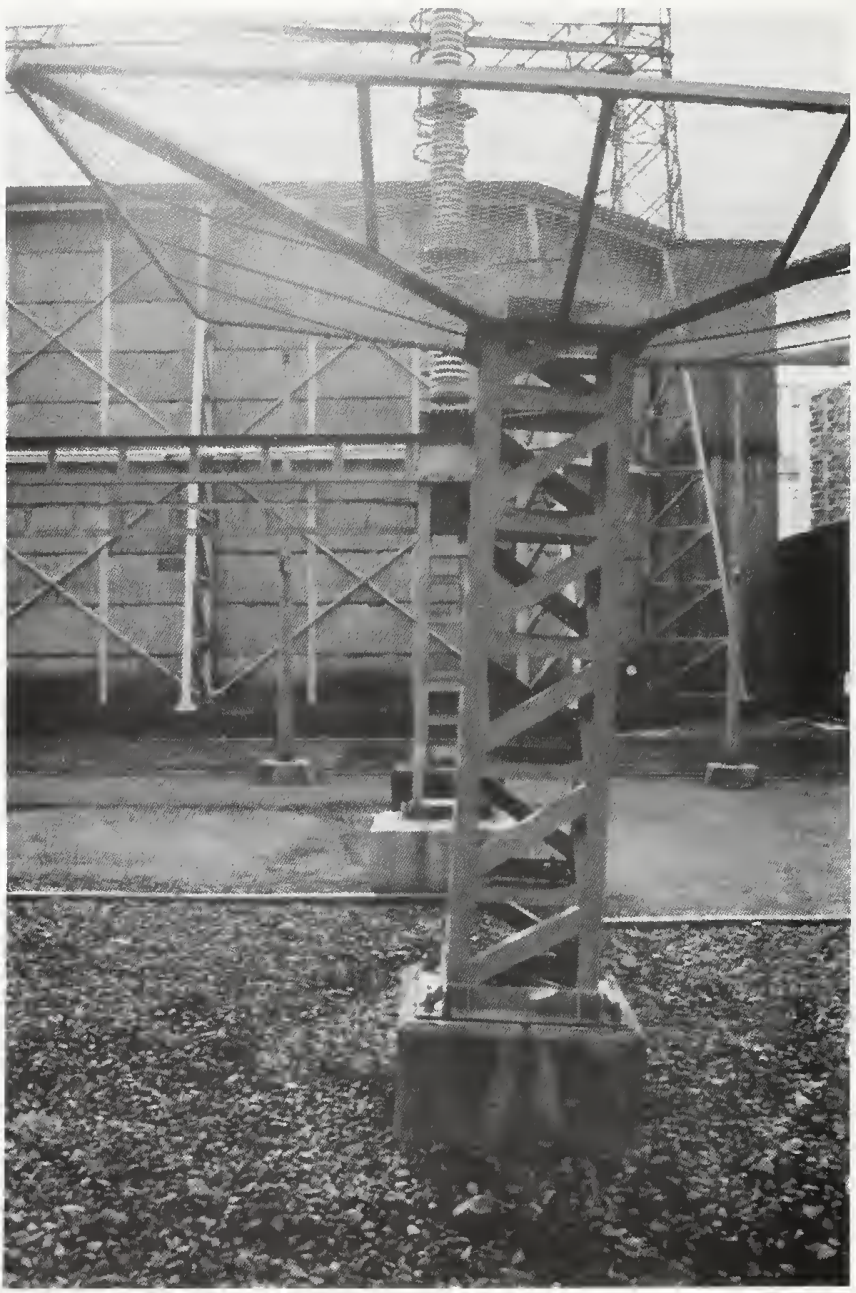

Figure 5.4.47

A lightning arrester support structure tipped about 2-1/2 degrees and probably contributed to the failure of the lighting arrester. 


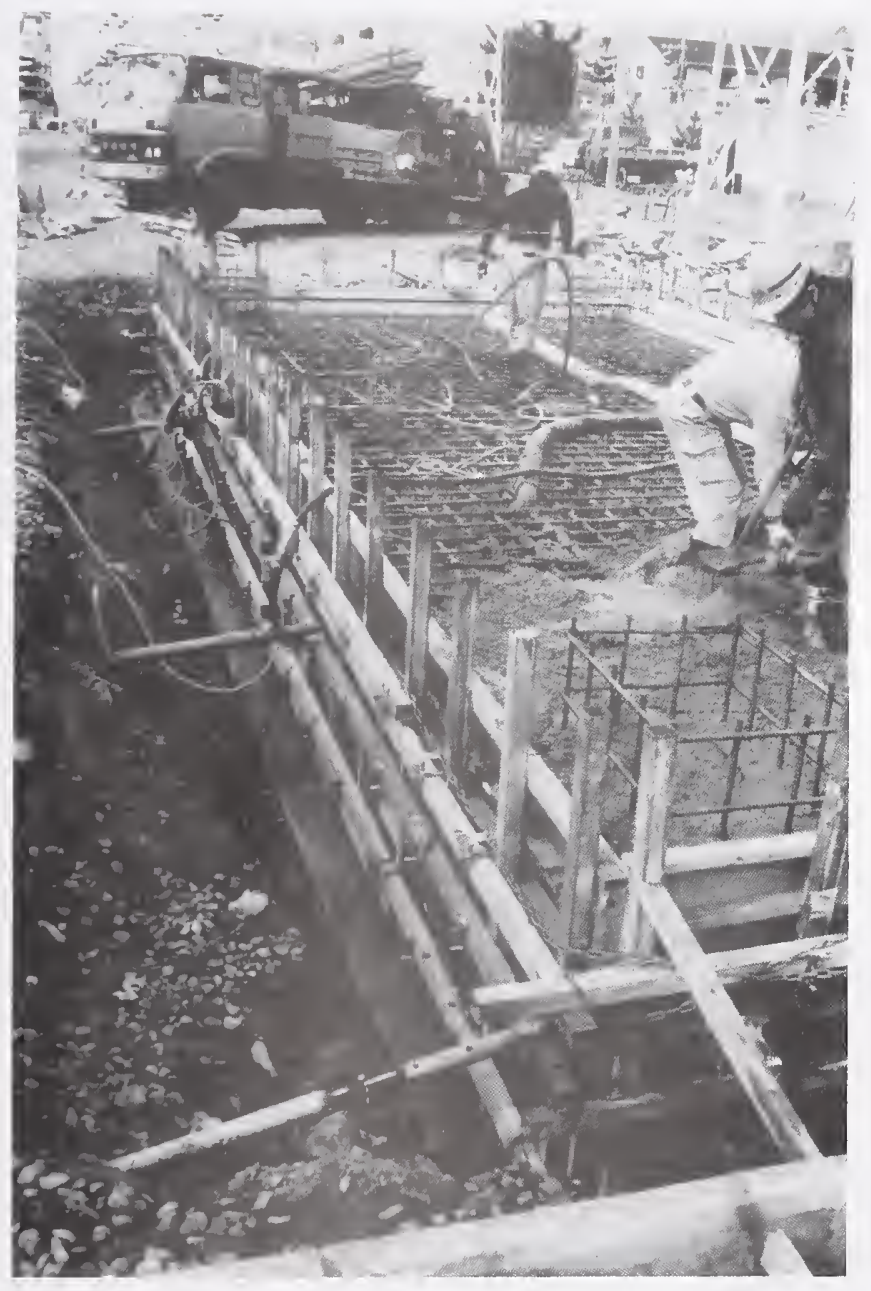

Figure 5.4.48

A new monolithic disconnect switch pad replaced individual footings that were disturbed by a surface crack in the soil. 


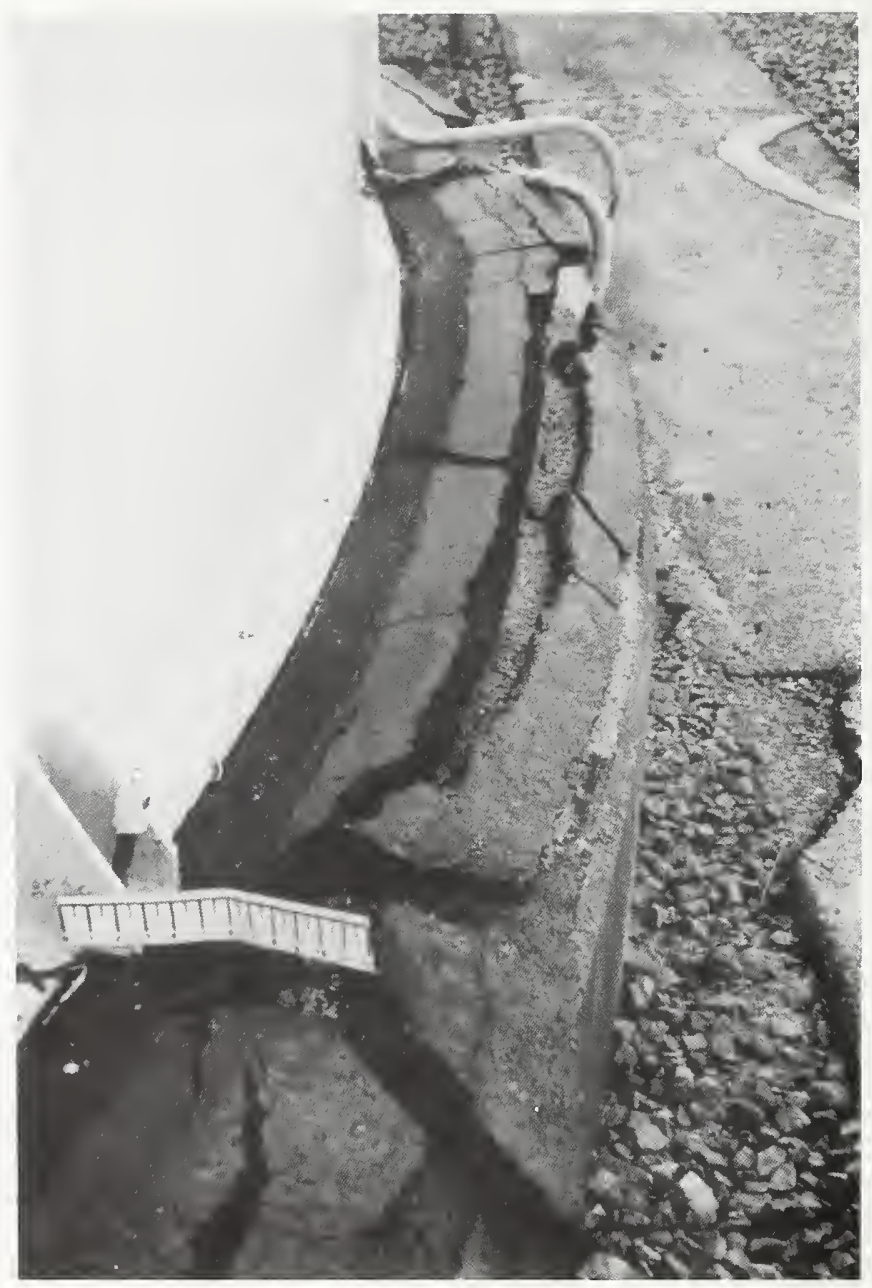

Figure 5.4.49

The asphalt surface between the tank and the concrete ring was broken and the bolts stretched or were pulled out due to rocking of the tank. 


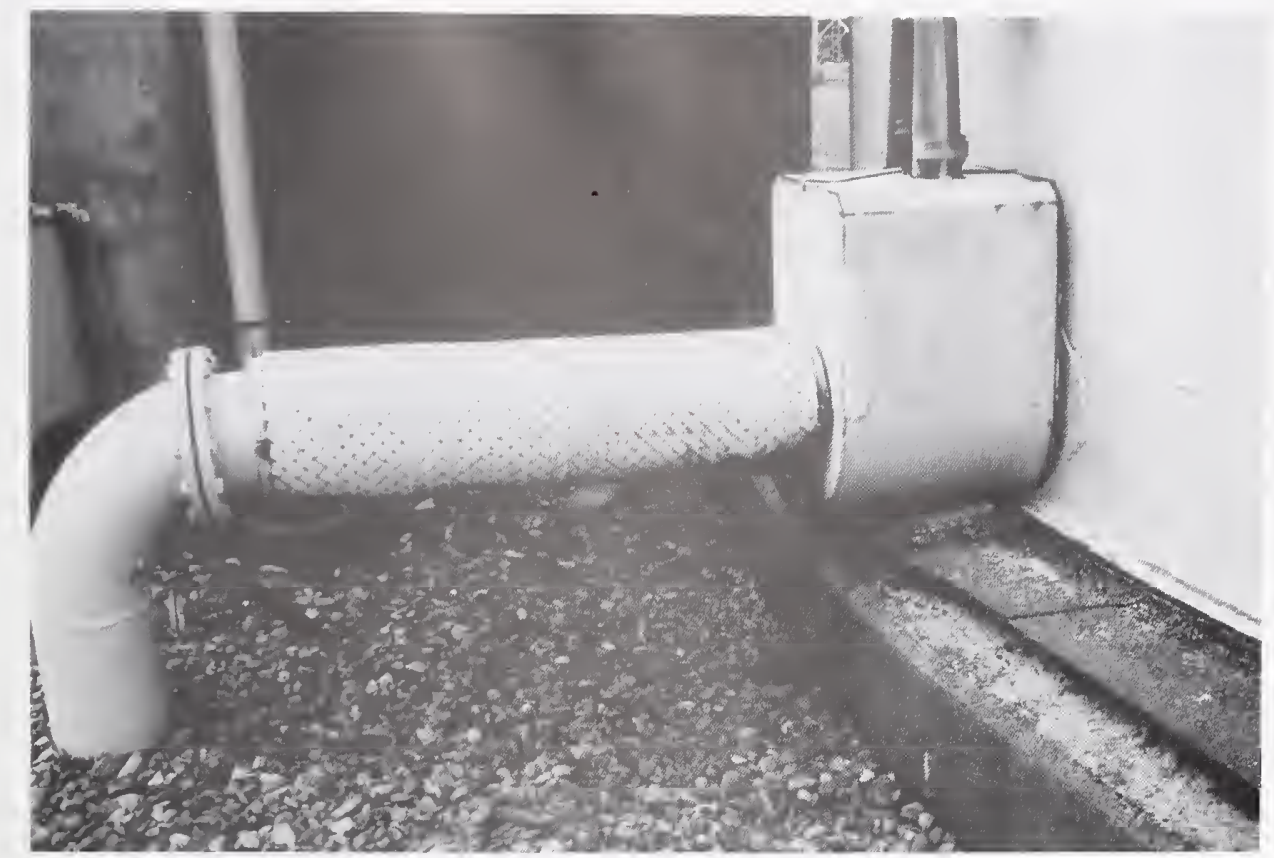

Figure 5.4.50

While these were old installations, the tanks were provided with flexible coupling at pipe connections.

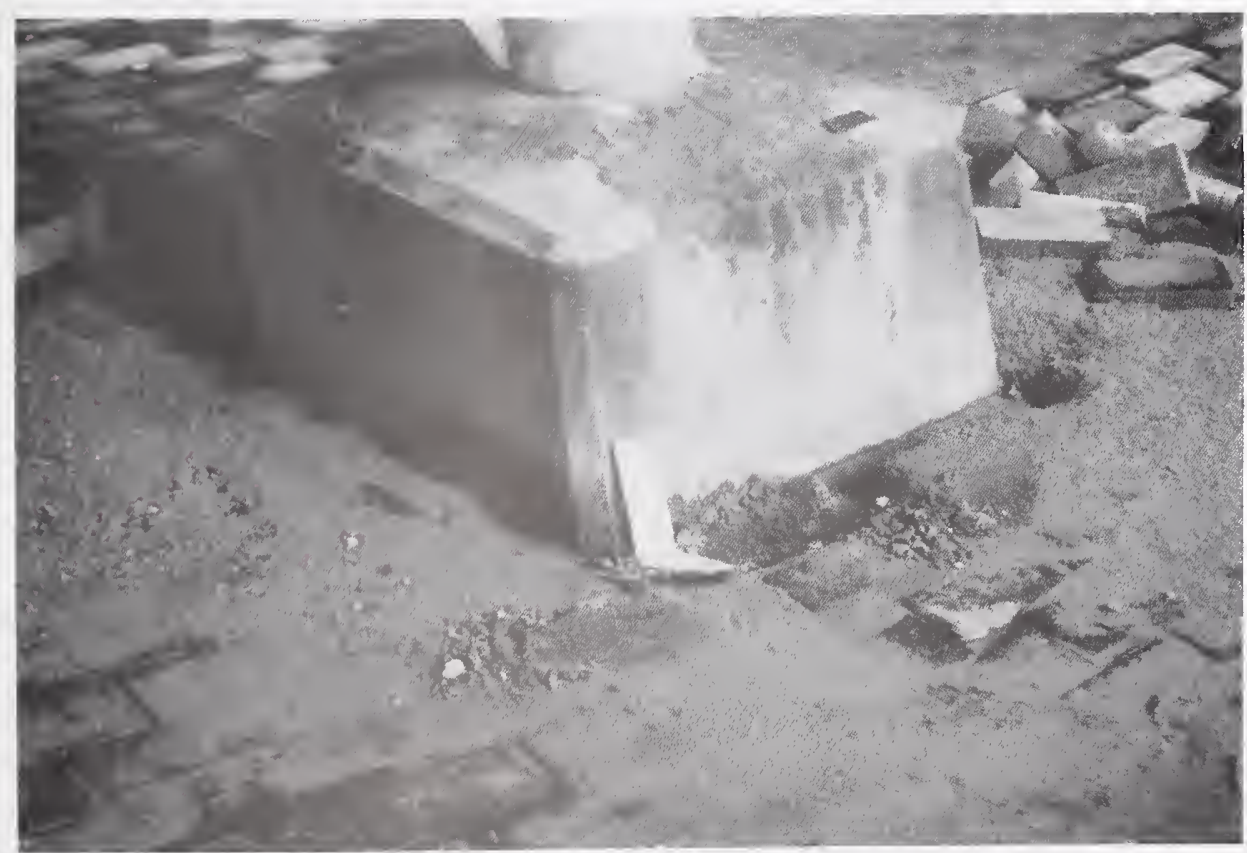




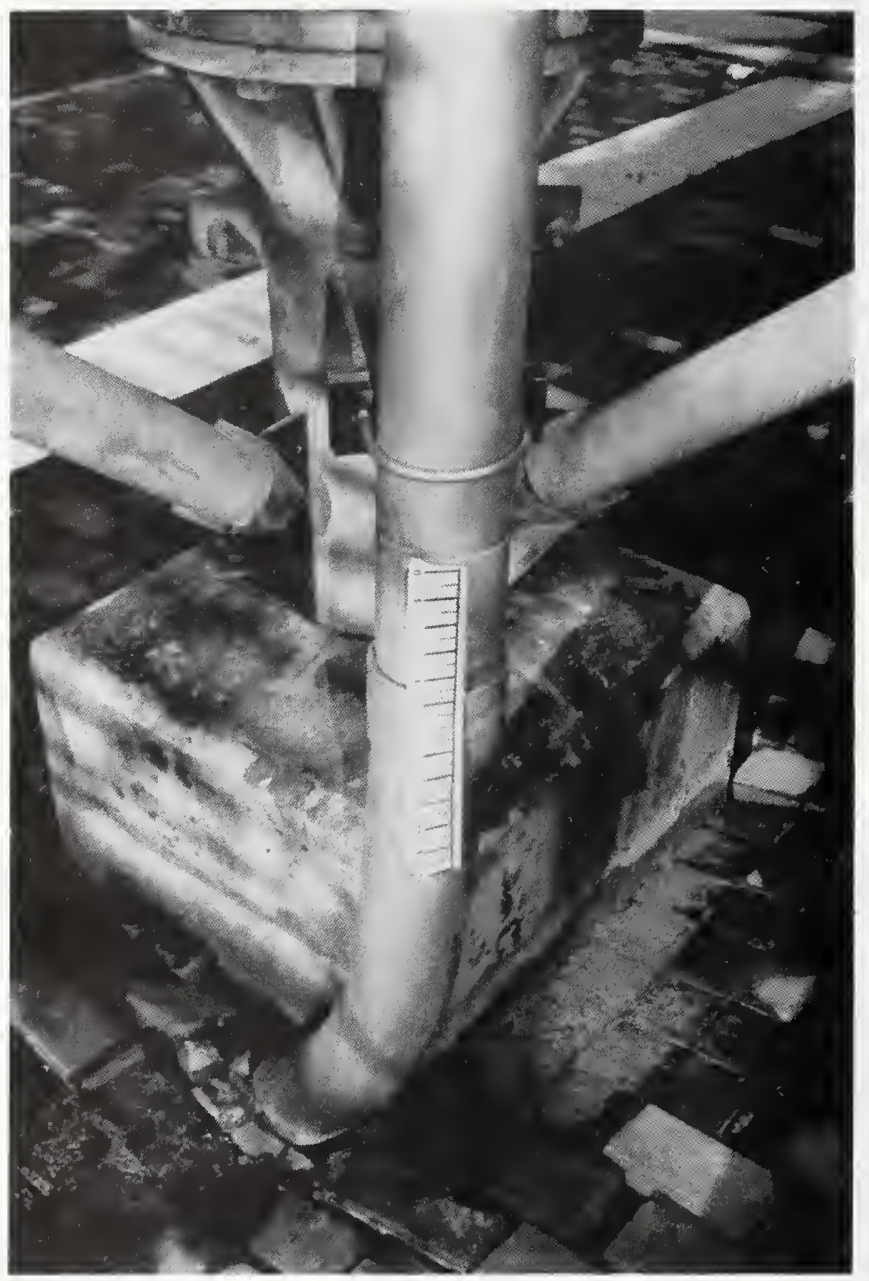

Figure 5.4.52

Conduit attached to the tower and buried in the ground was displaced about $8 \mathrm{~cm}$ and has the potential of damaging internal signal cables is they are not provided with adequate slack. 


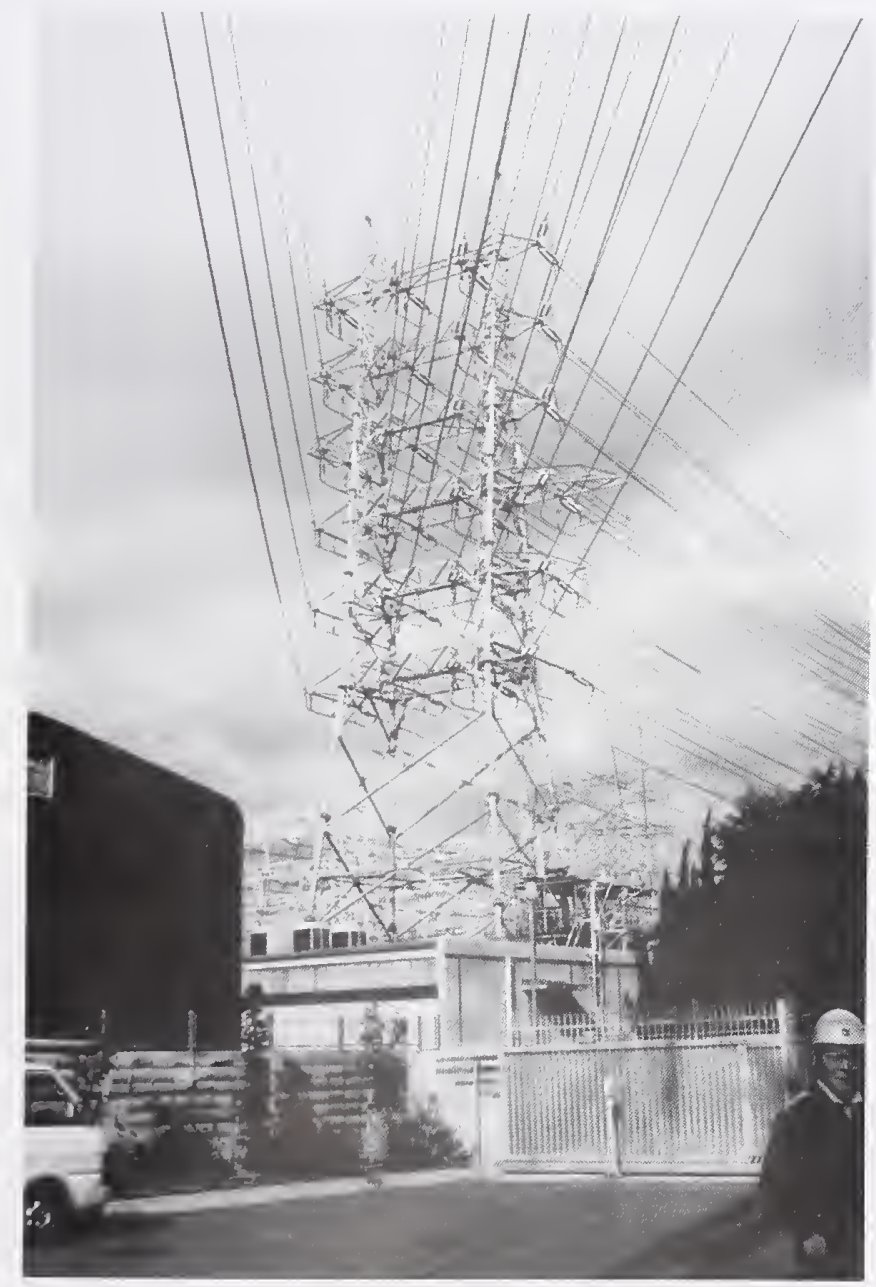

Figure 5.4.53 Post insulators that restrain the lines as they pass under the support arm failed on several towers, but did not cause disruption. 


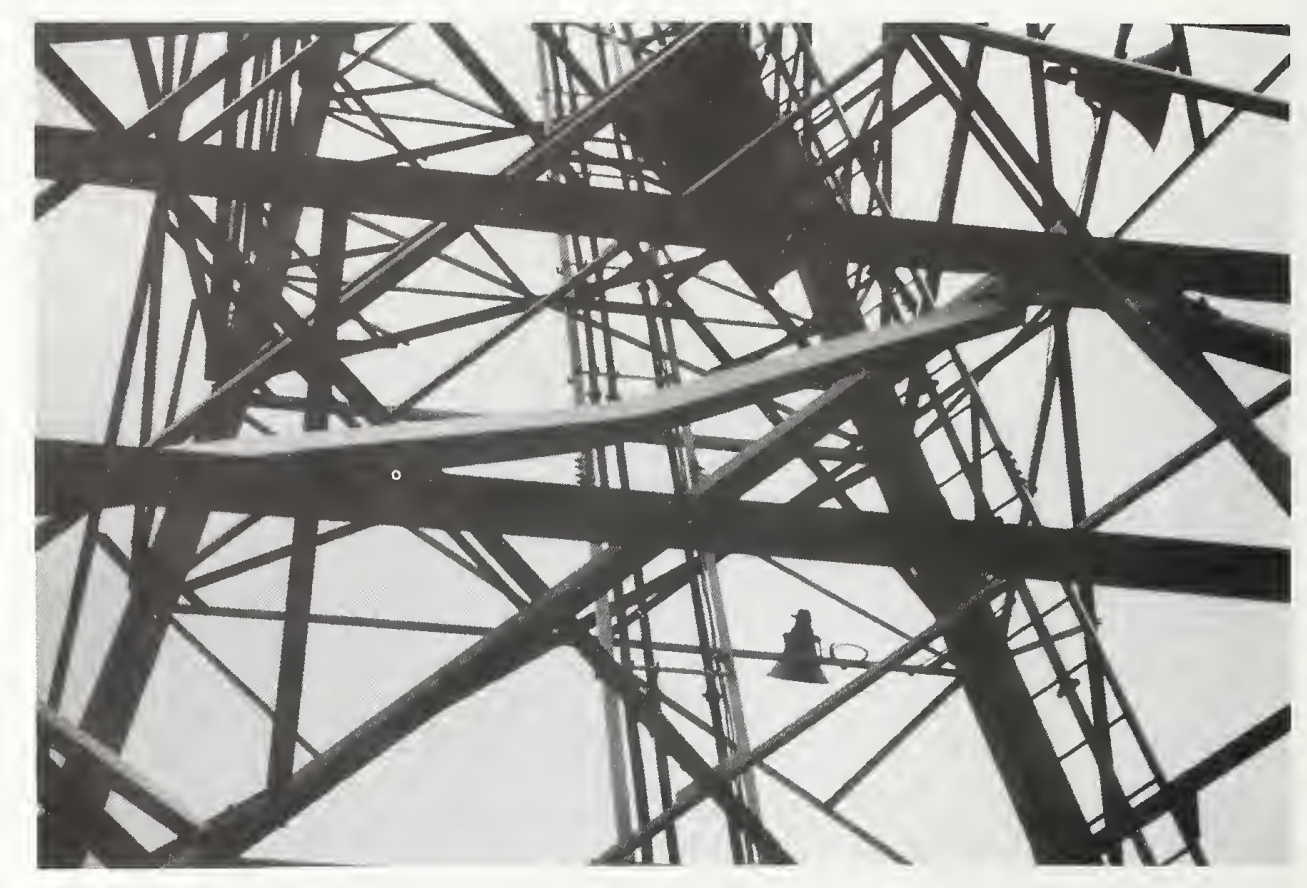

Figure 5.4.54

The bent member in a microwave tower is very unusual, but it did not effect operations.

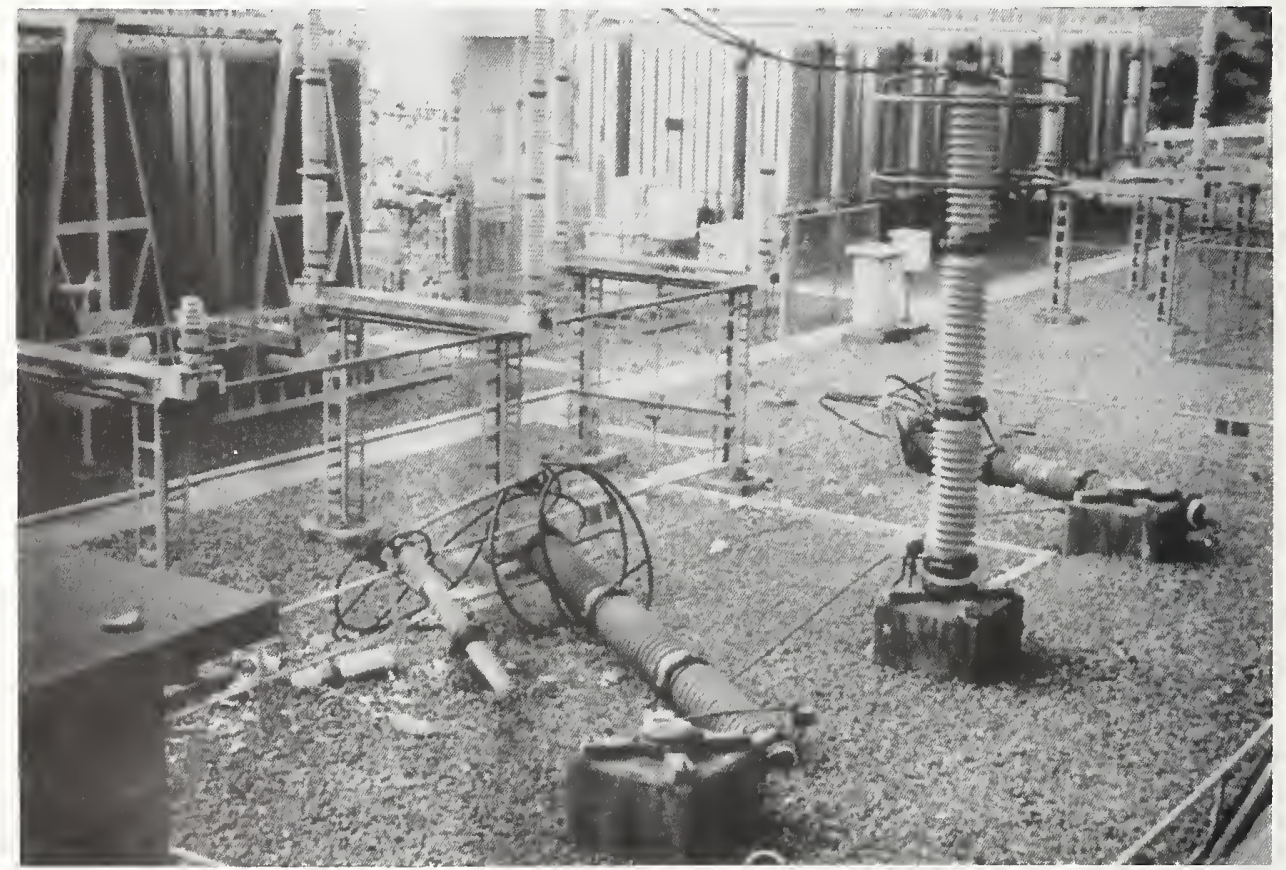

Figure 5.4.55

Lightning arresters failed and probably pulled down adjacent disconnect switched. 


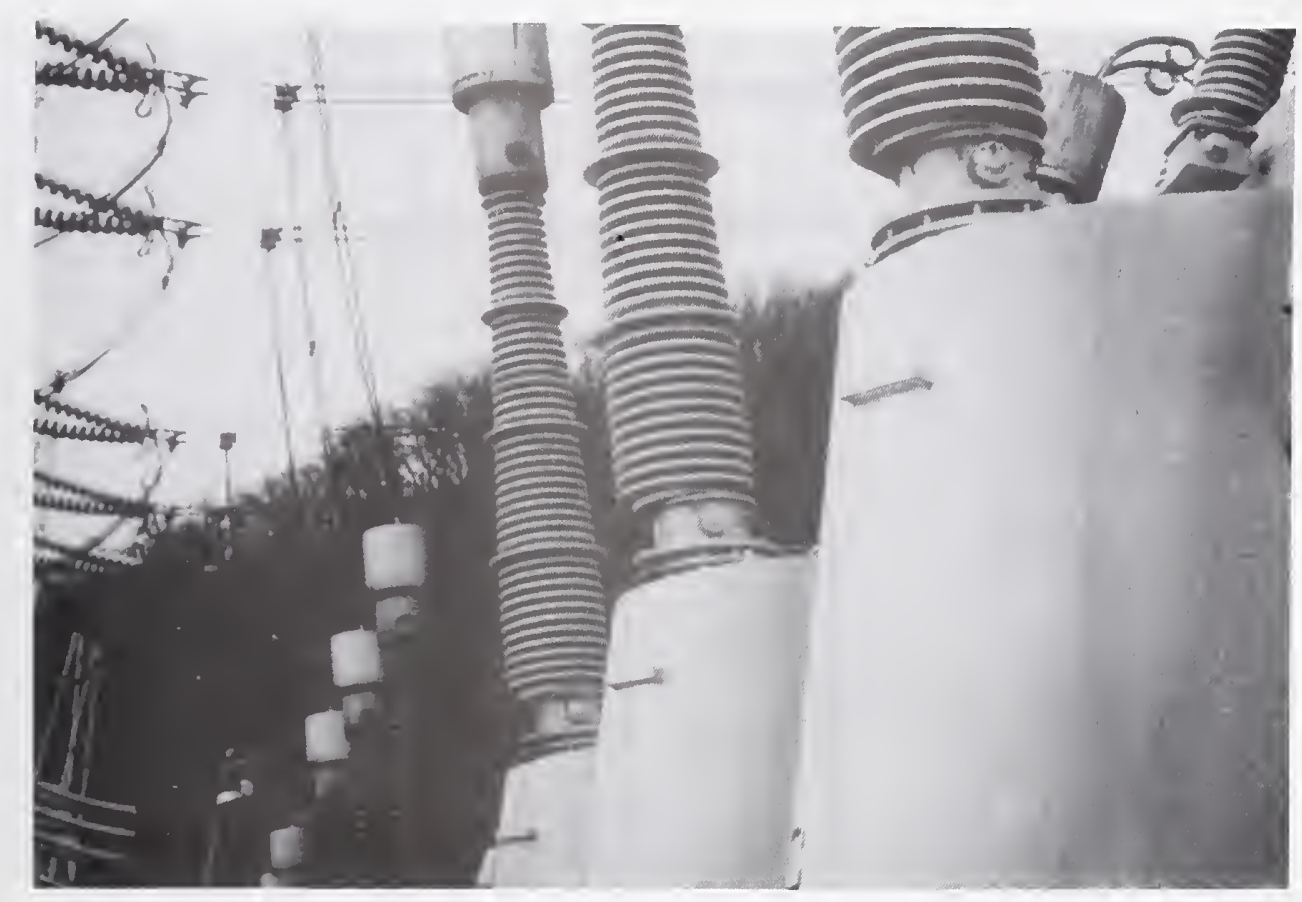

Figure 5.4.56

All three bushings shifted on this $275 \mathrm{kV}$ bulk-oil circuit breaker.

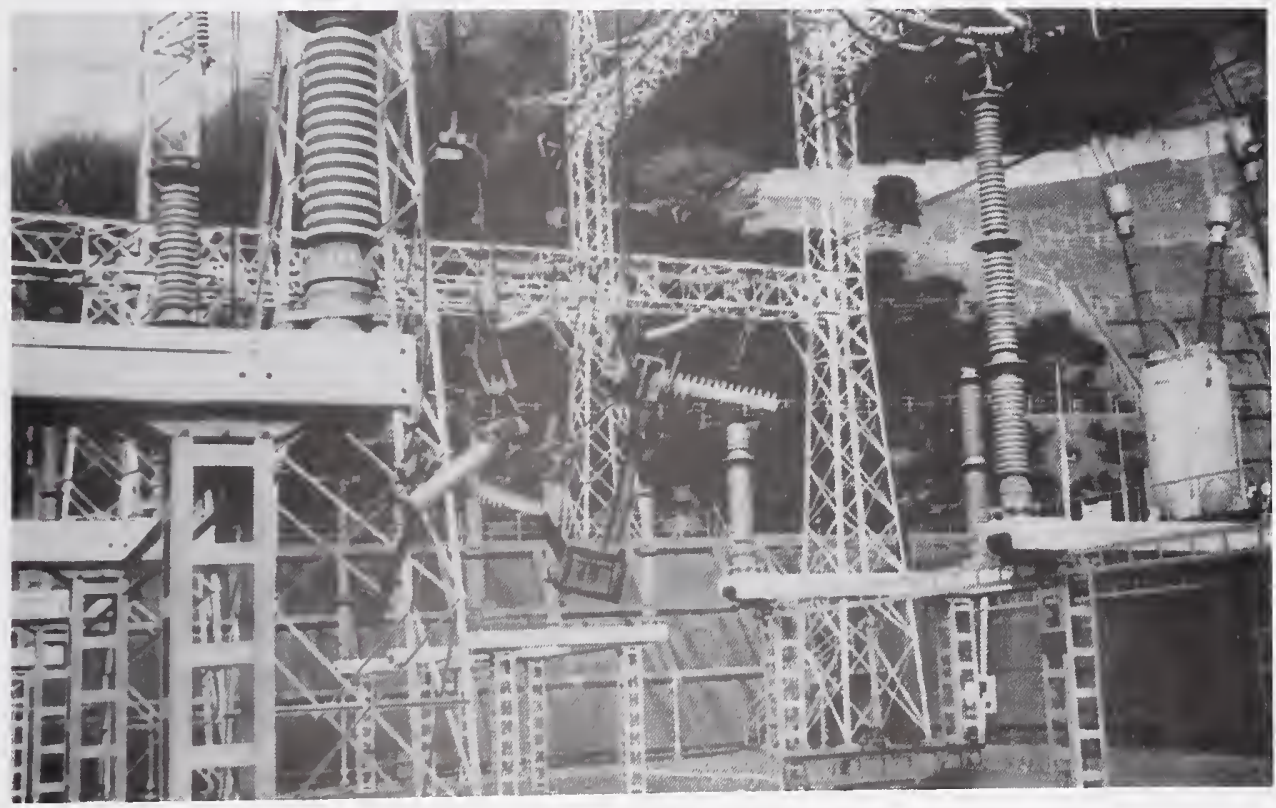

Figure 5.4.57

The failure pattern of splits in the post insulators of these disconnect switches is unusual. 


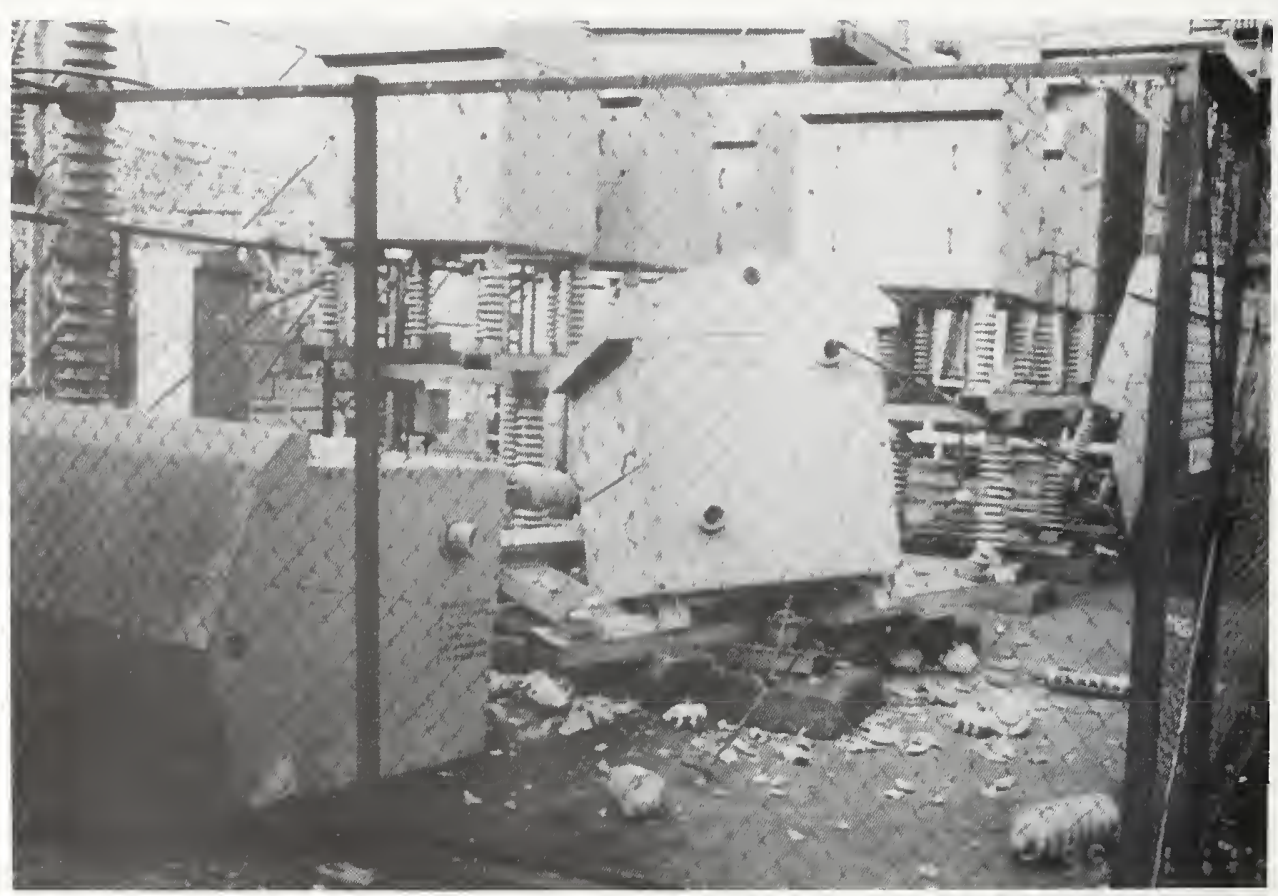

Figure 5.4.58

Neutral resistors failed, a device not used in this configuration in the U.S.

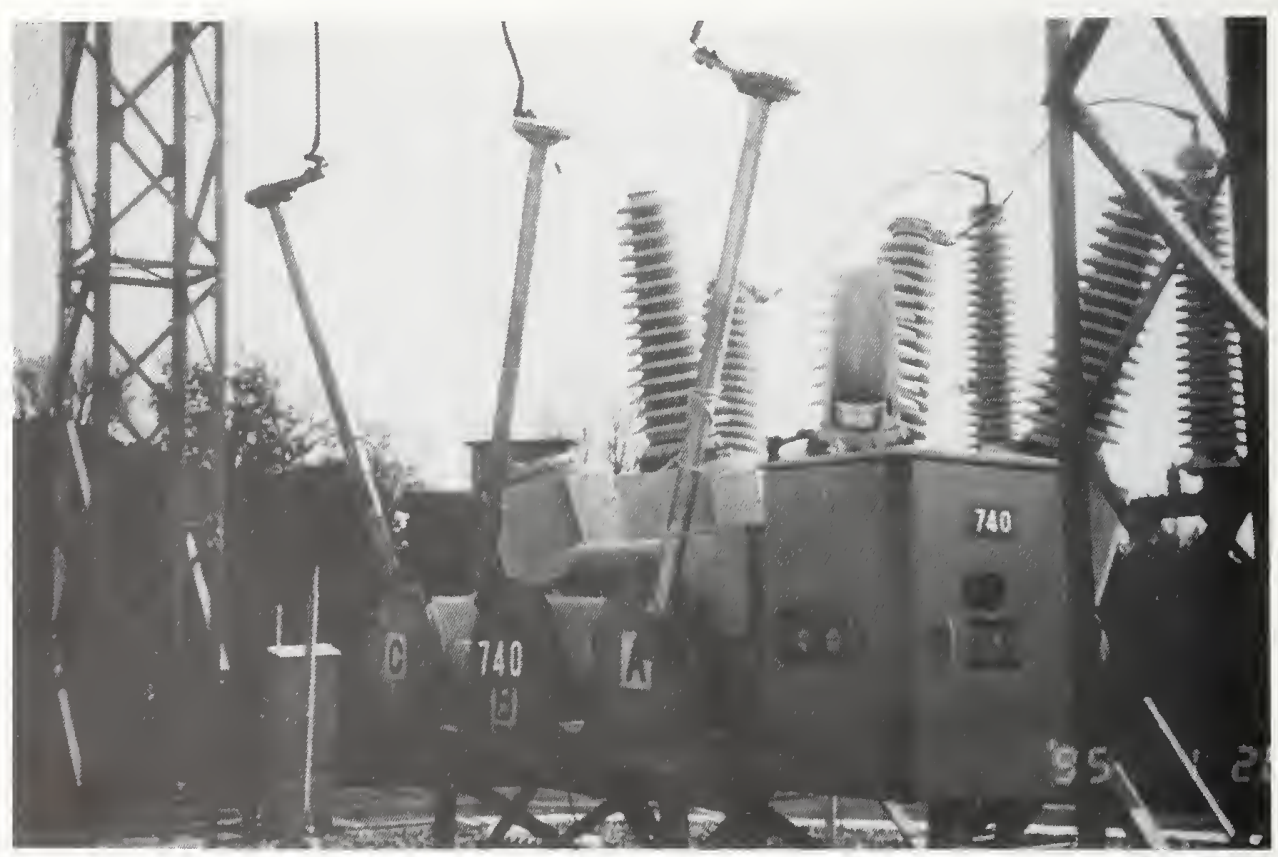

Figure 5.4.59

A $77 \mathrm{kV}$ three-phase, dead-tank gas insulated circuit breaker failed it bushings, probably due to inadequate slack to accommodate soil settlement at the site. 


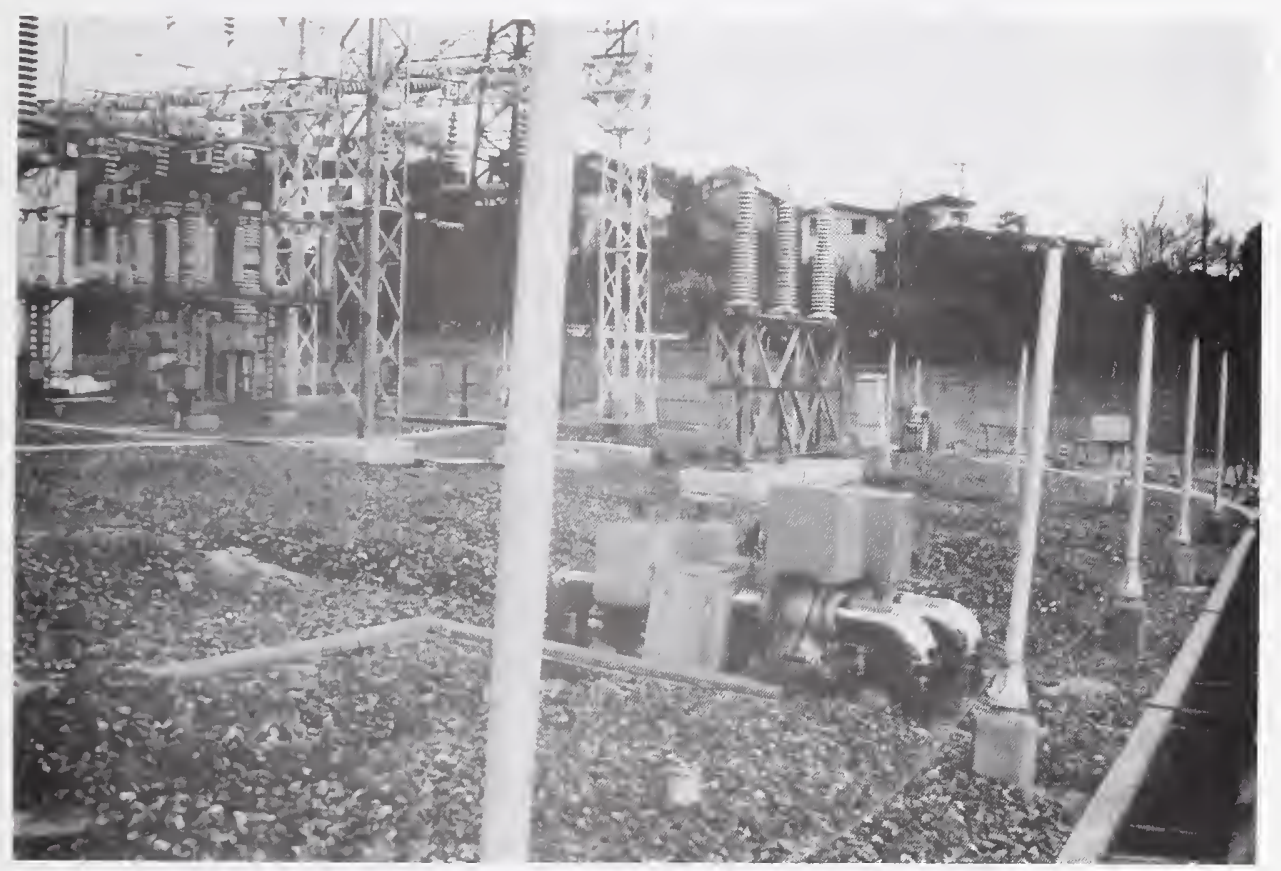

Figure 5.4.60 The water spray heads near the fence are used to reduce salt concentration and the potential of flash-over under certain atmospheric conditions. 


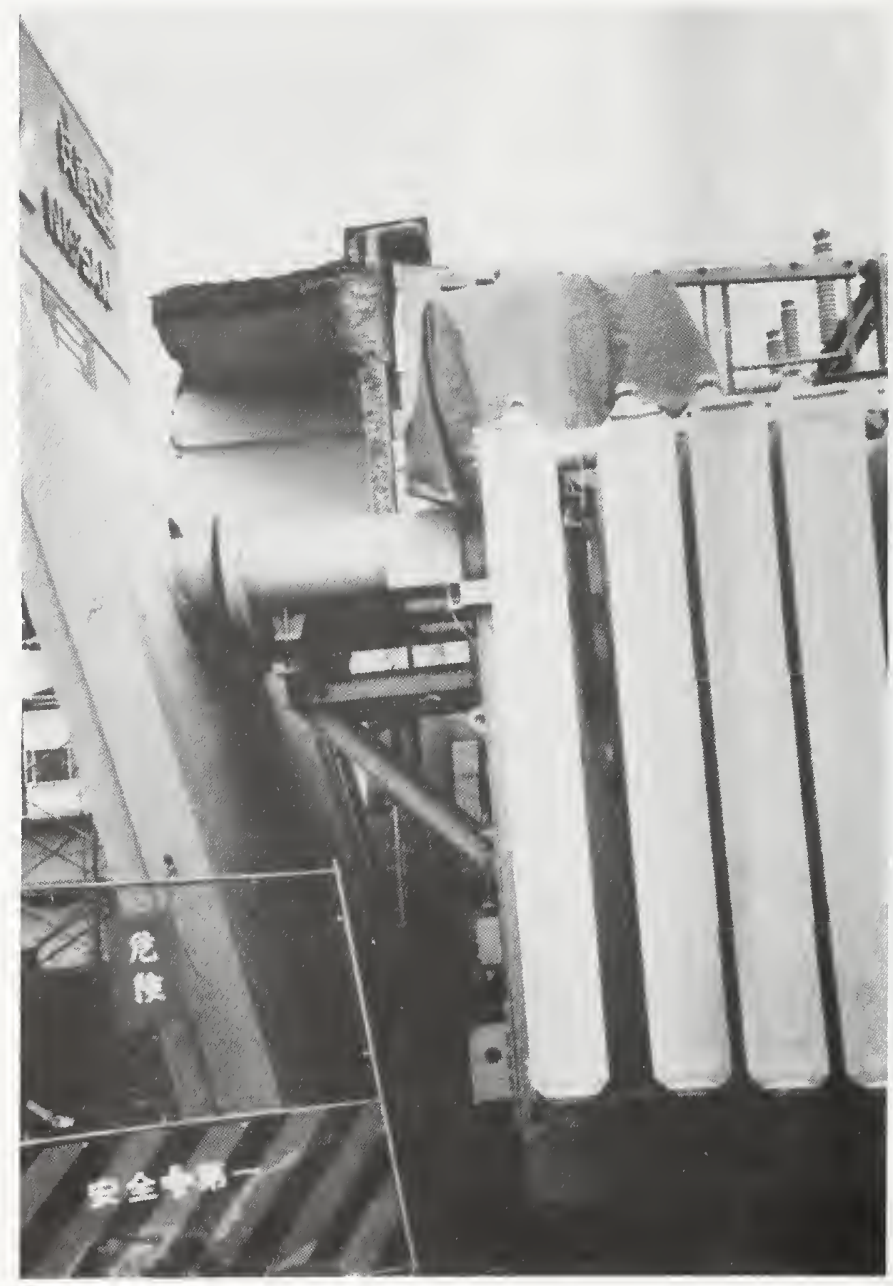

Figure 5.4.61 A transformer pushed over the fire wall after it failed its anchorage. 


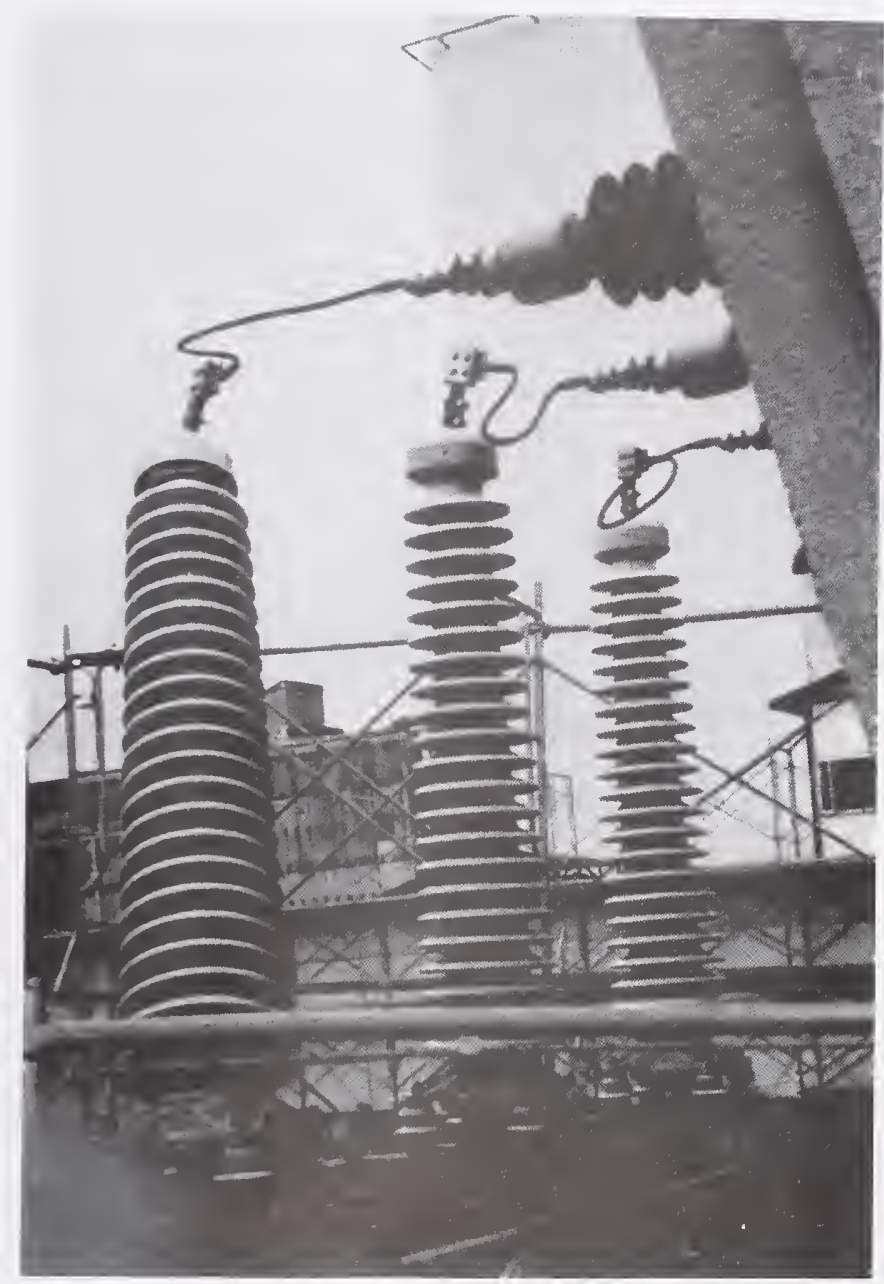

Figure 5.4.62

A pot head connected to the bushing failed, probably when it was hit by the bushing. 


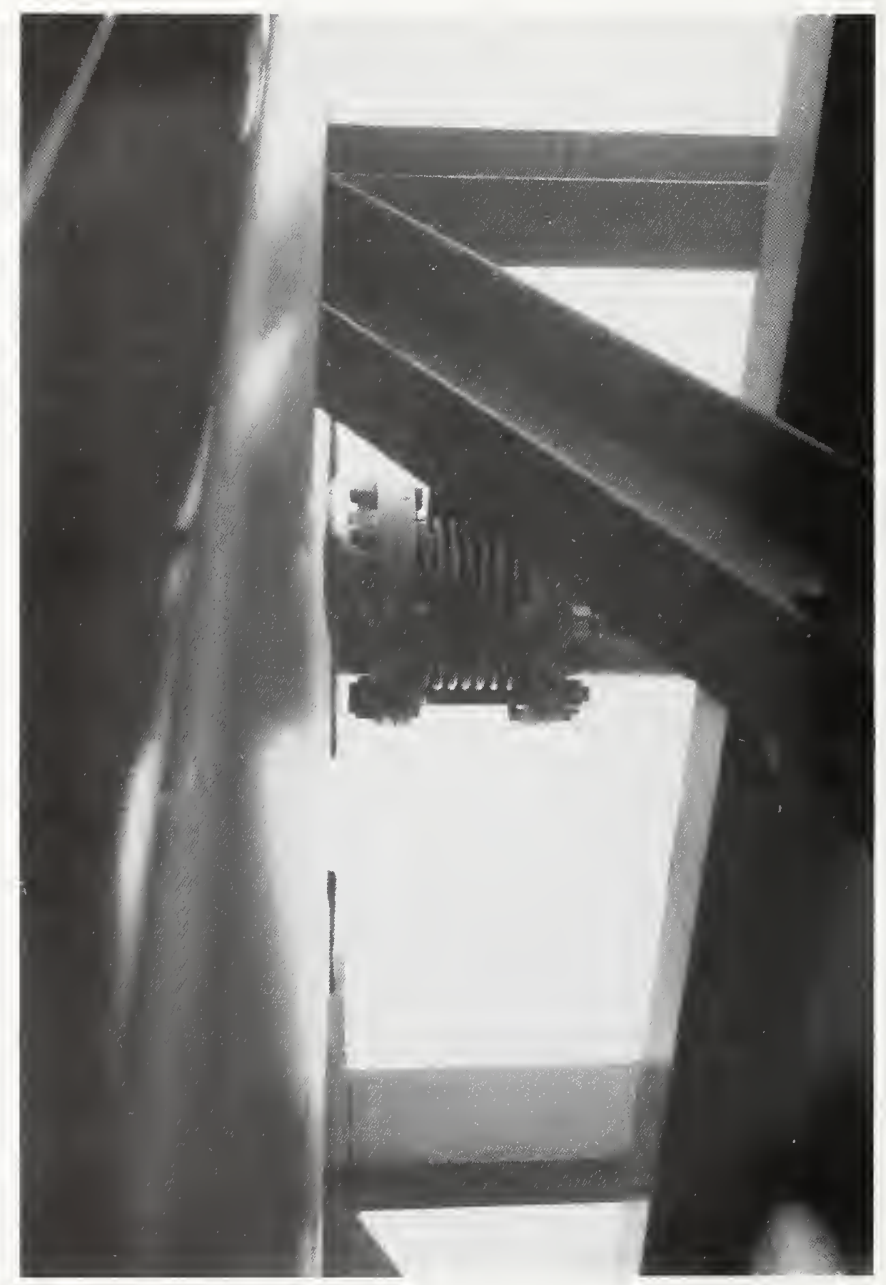

Figure 5.4.63

The radiator on this distribution transformer has a structural support and the piping connections have flexible couplings. 


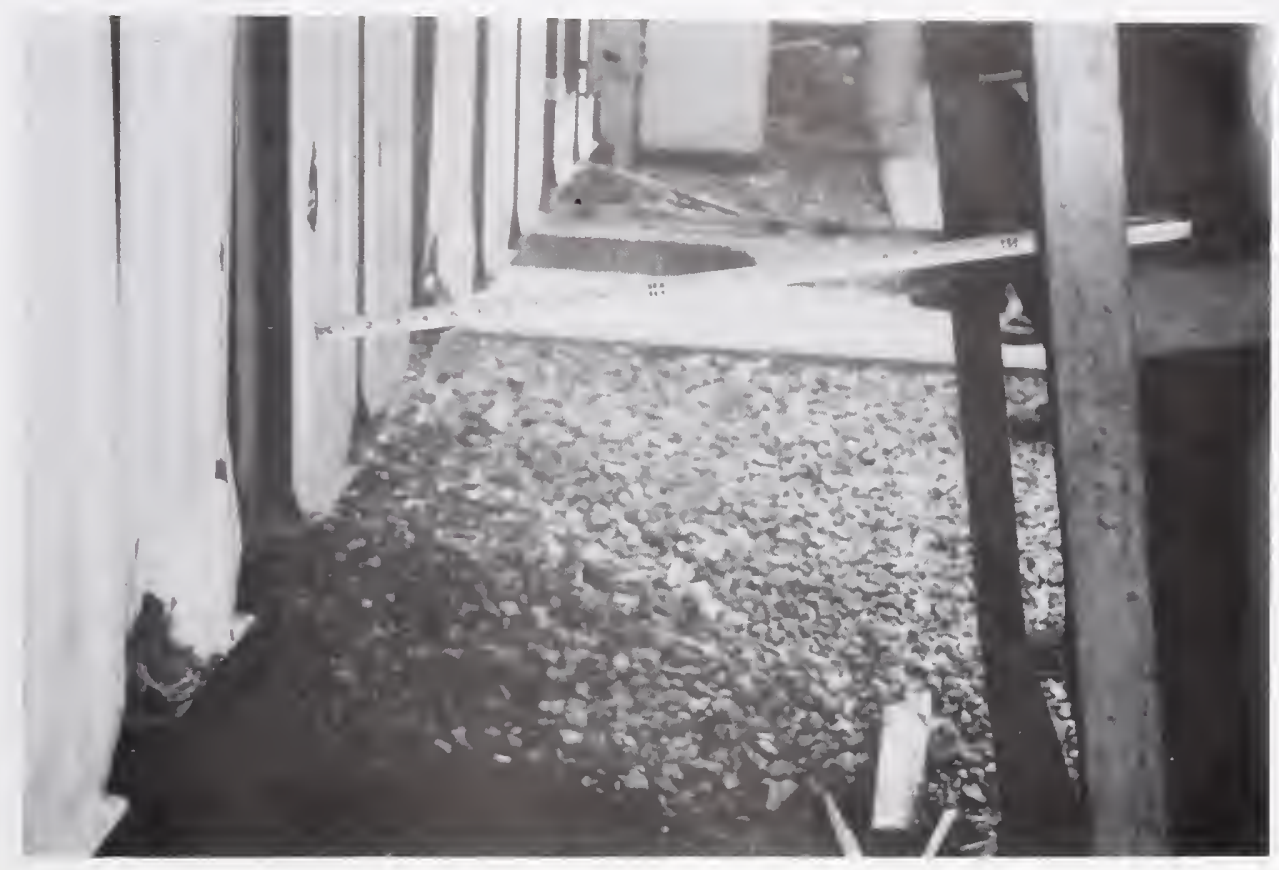

Figure 5.4.64

Movement of the transformer after its anchorage failed allowed the radiators to hit a nearby structural support causing a leak.

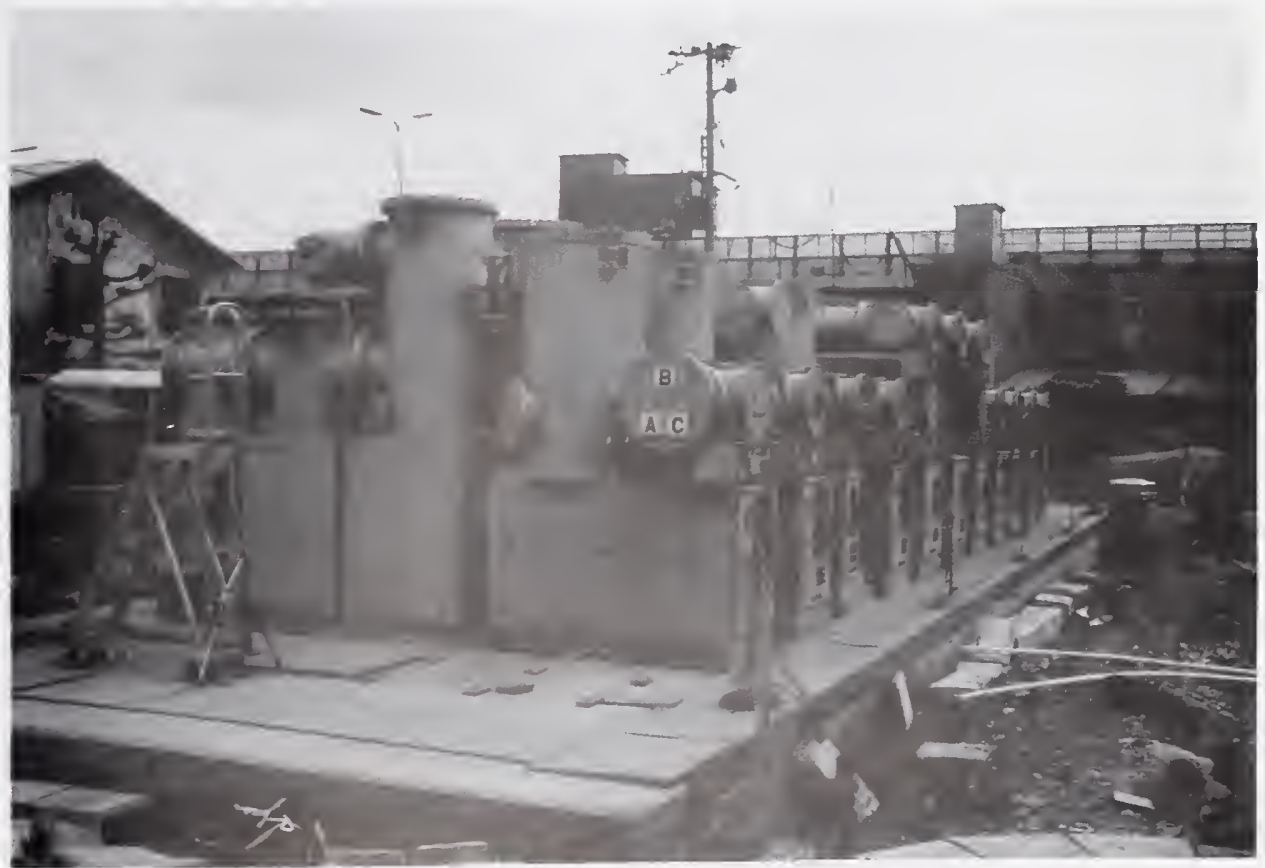

Figure 5.4.65

A $77 \mathrm{kV}$ and $6.6 \mathrm{kV}$ gas insulate distribution substation. 


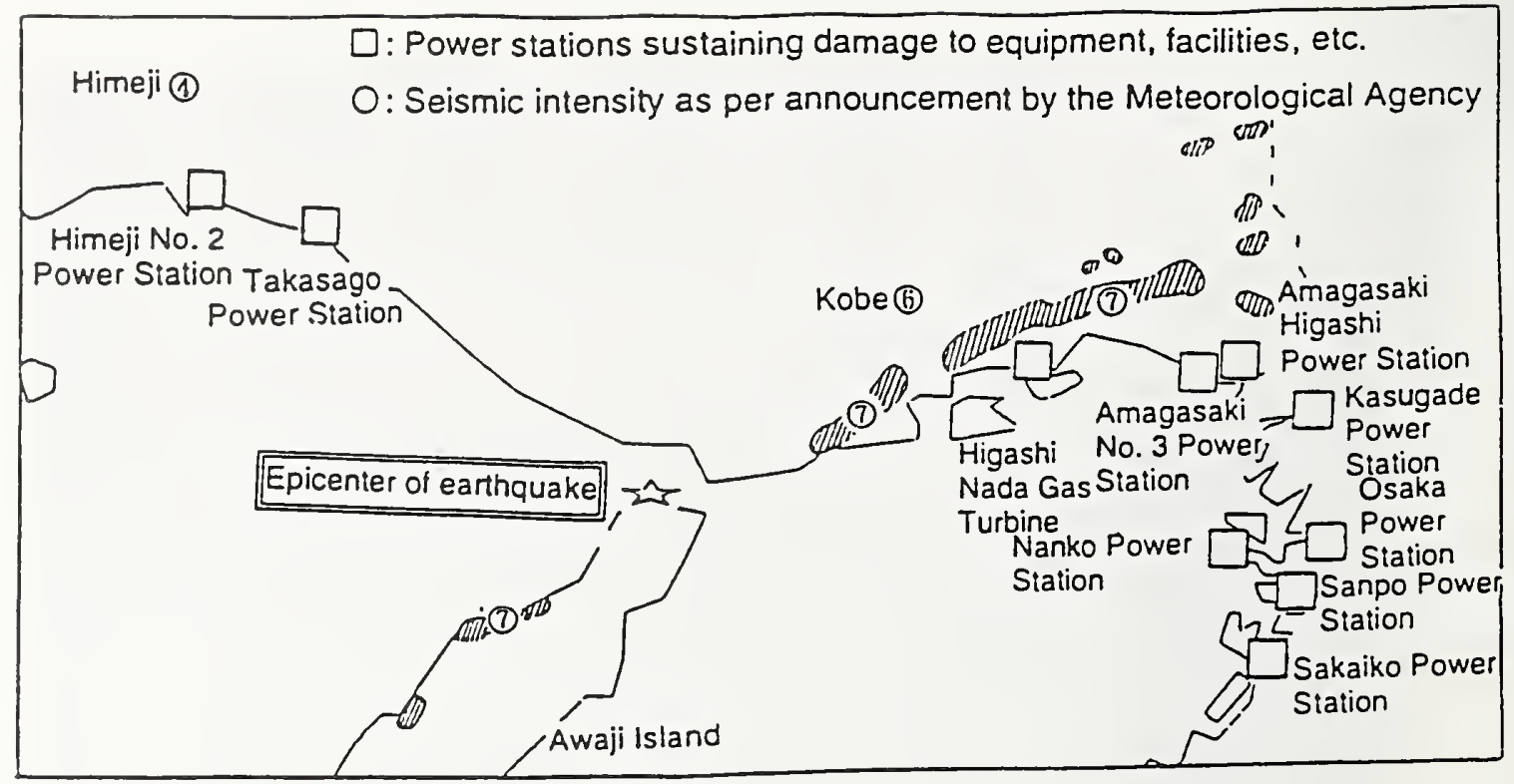

Figure 5.4.66

Location of Generating Stations in the Earthquake Impacted Area.

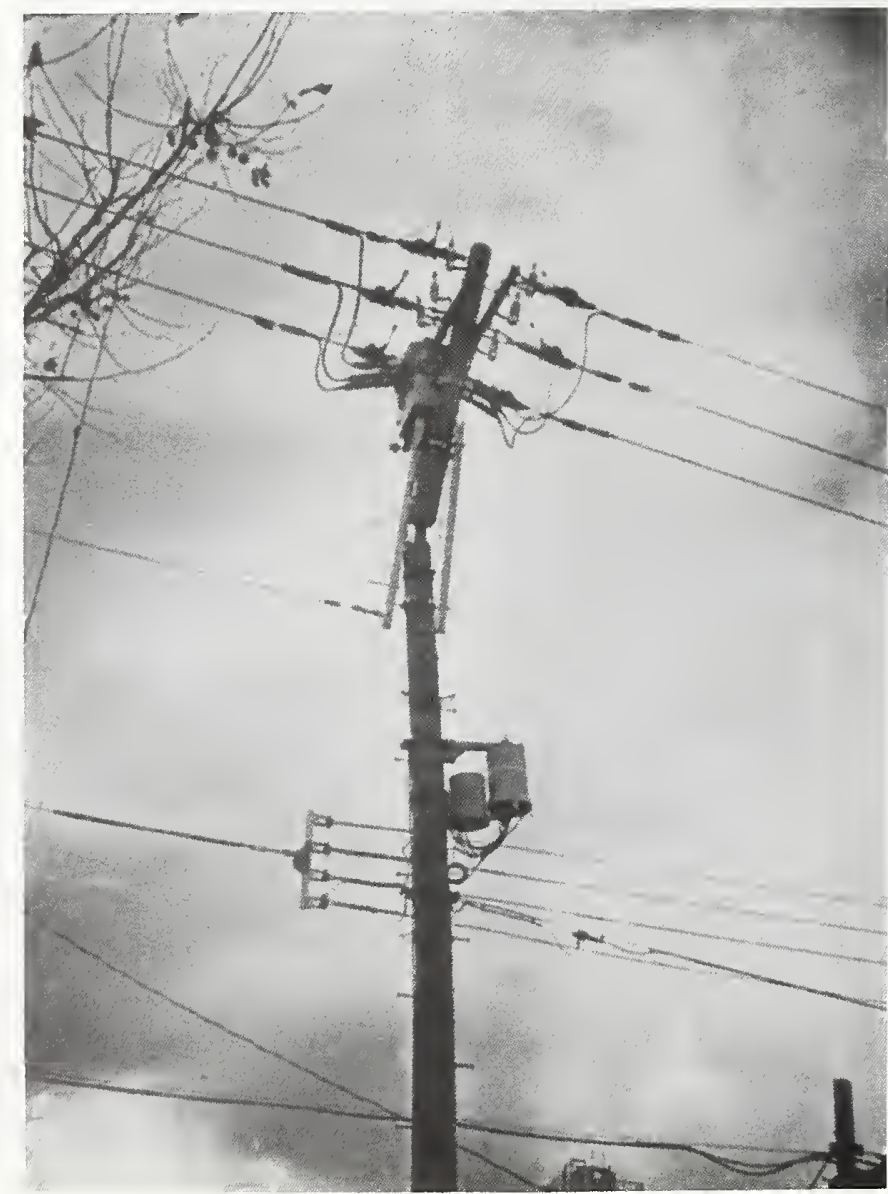

Damage to the aerial distribution system was severe in many regions. 


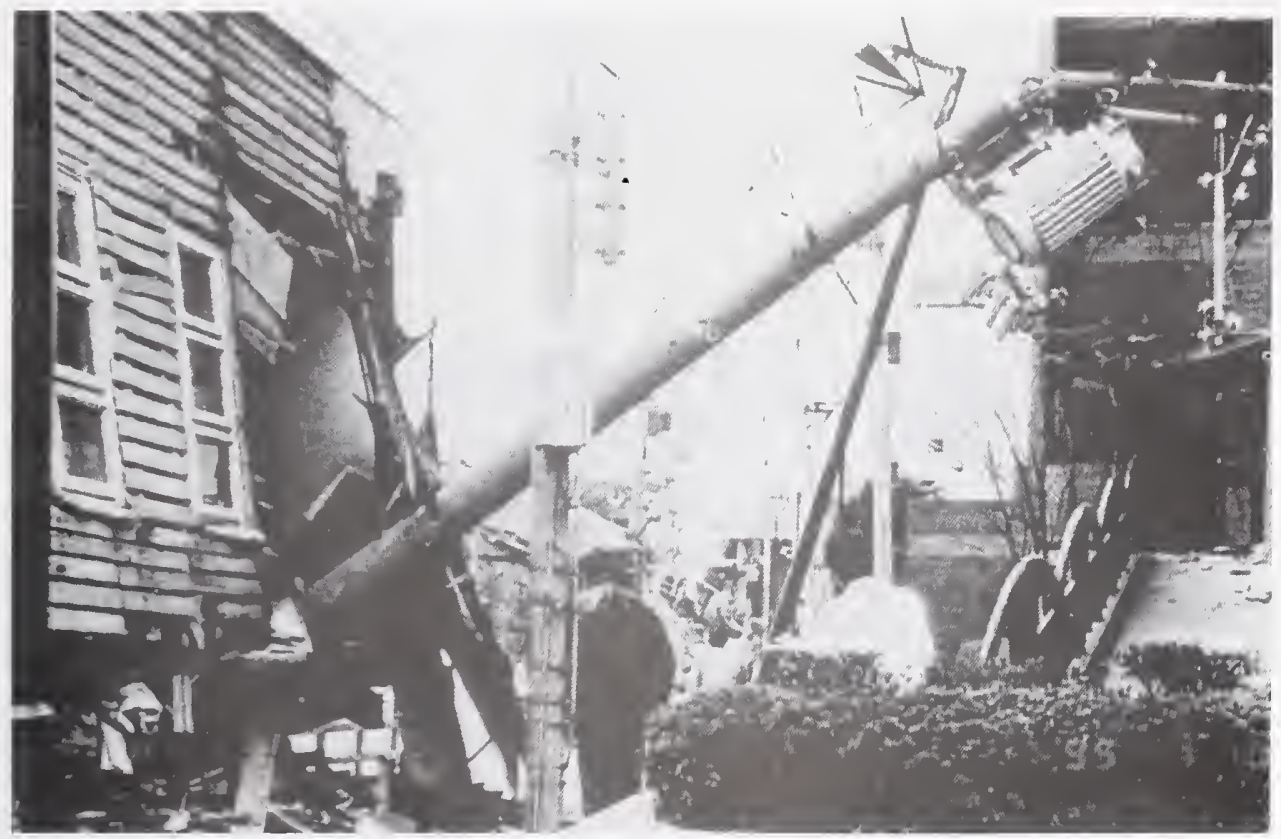

Figure 5.4.68 Fallen housed pushed over some distribution poles.

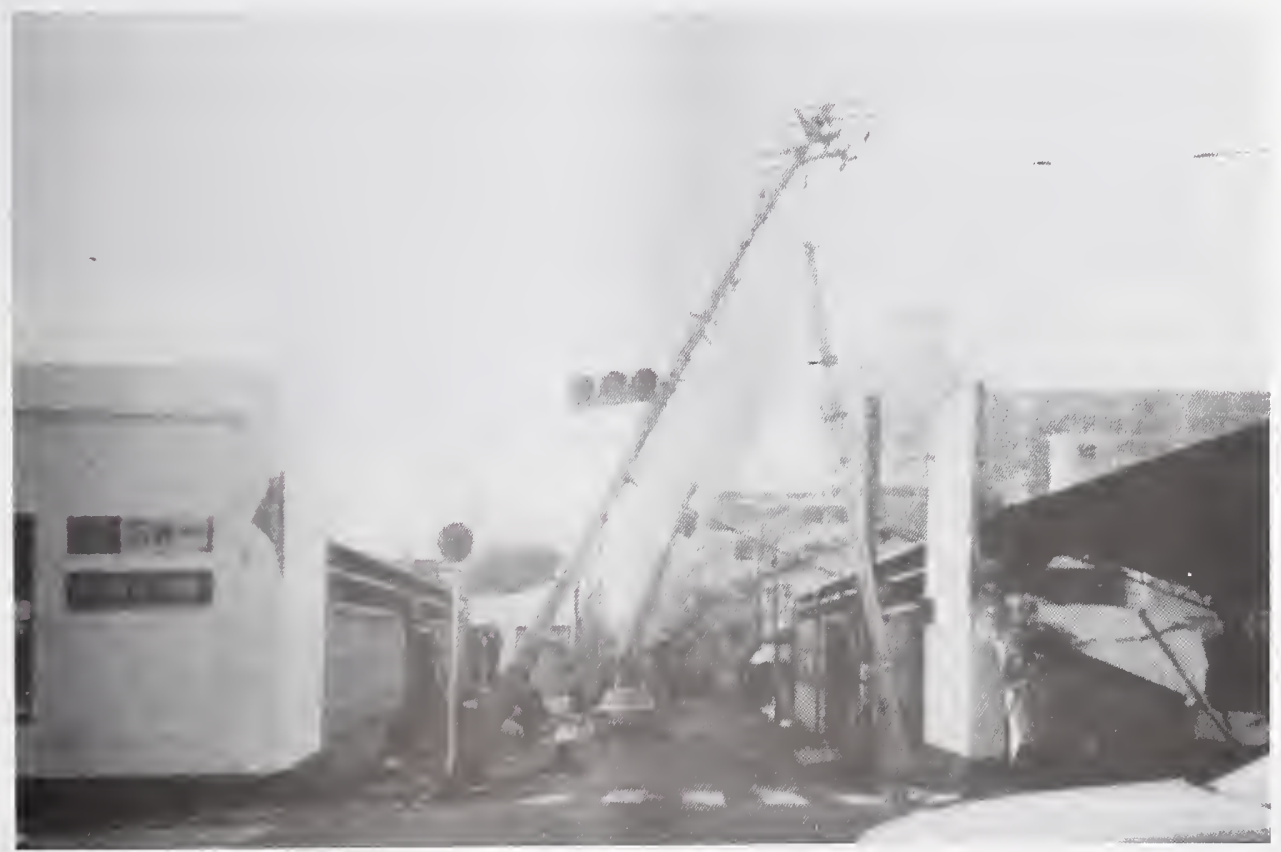

Figure 5.4.69

Some poles failed due to inertial loads or were pulled down by other fallen poles. 


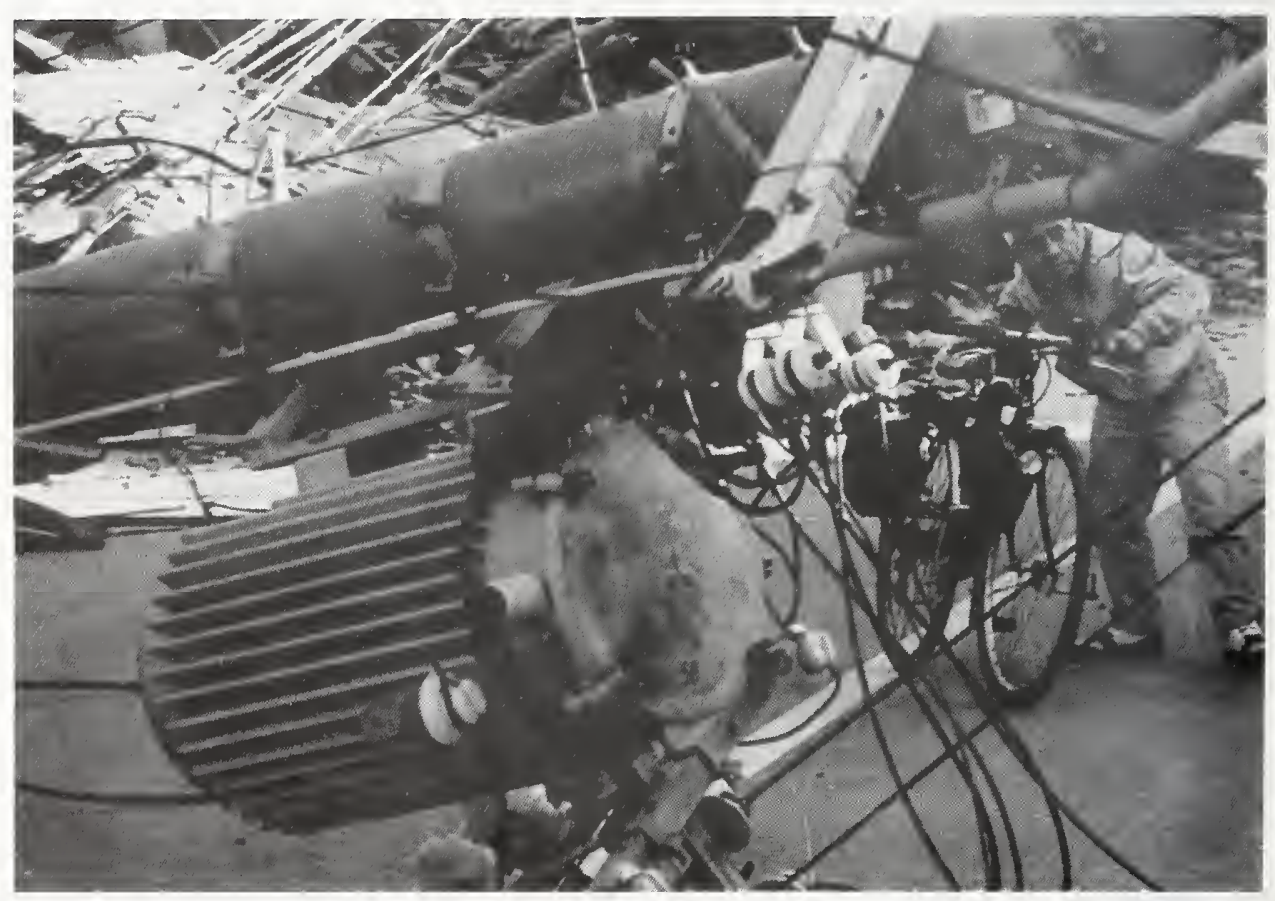

Figure 5.4.70 Fallen poles contributed to the disruption of traffic. 


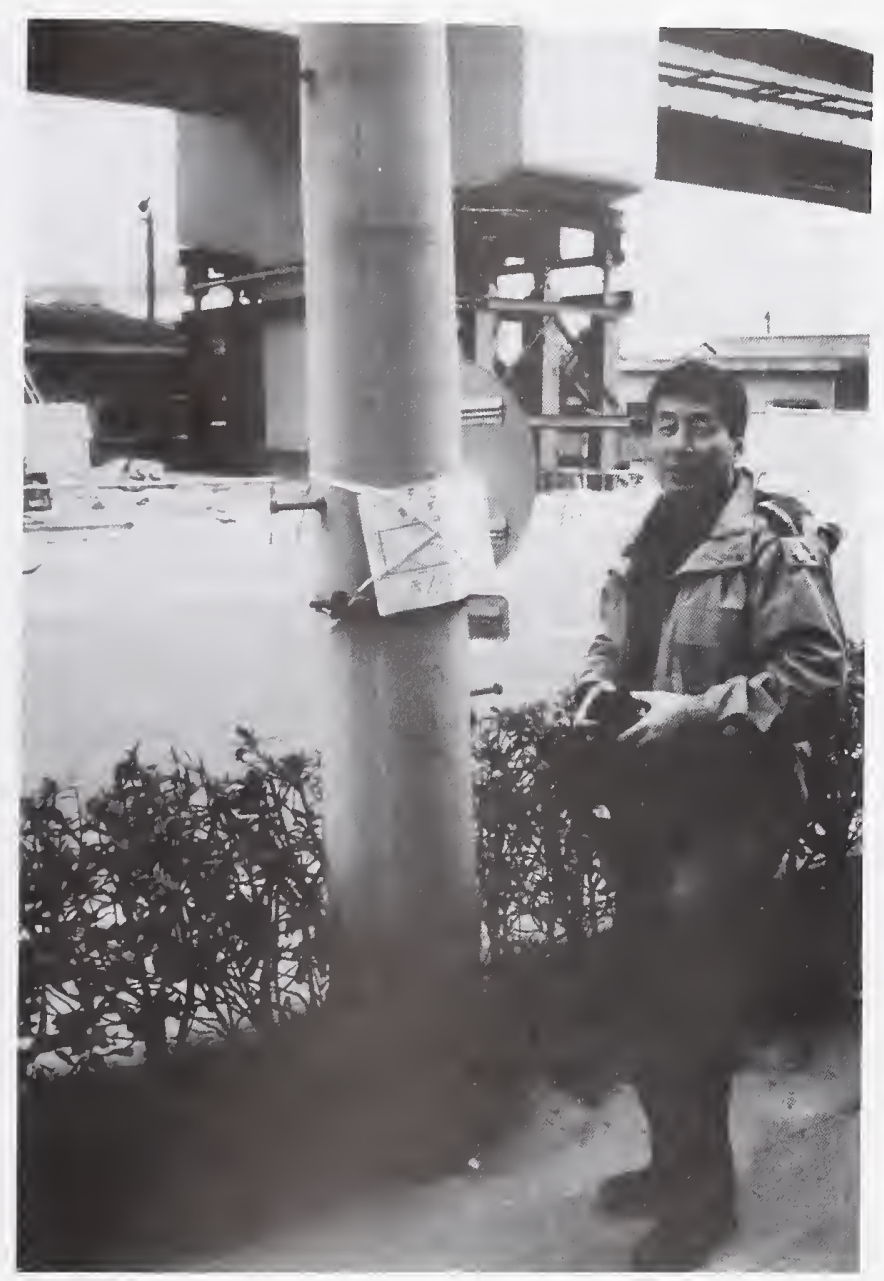

Figure 5.4.71 This pole settled about 1-1/2 $\mathrm{m}$ due to liquefaction at the site. 


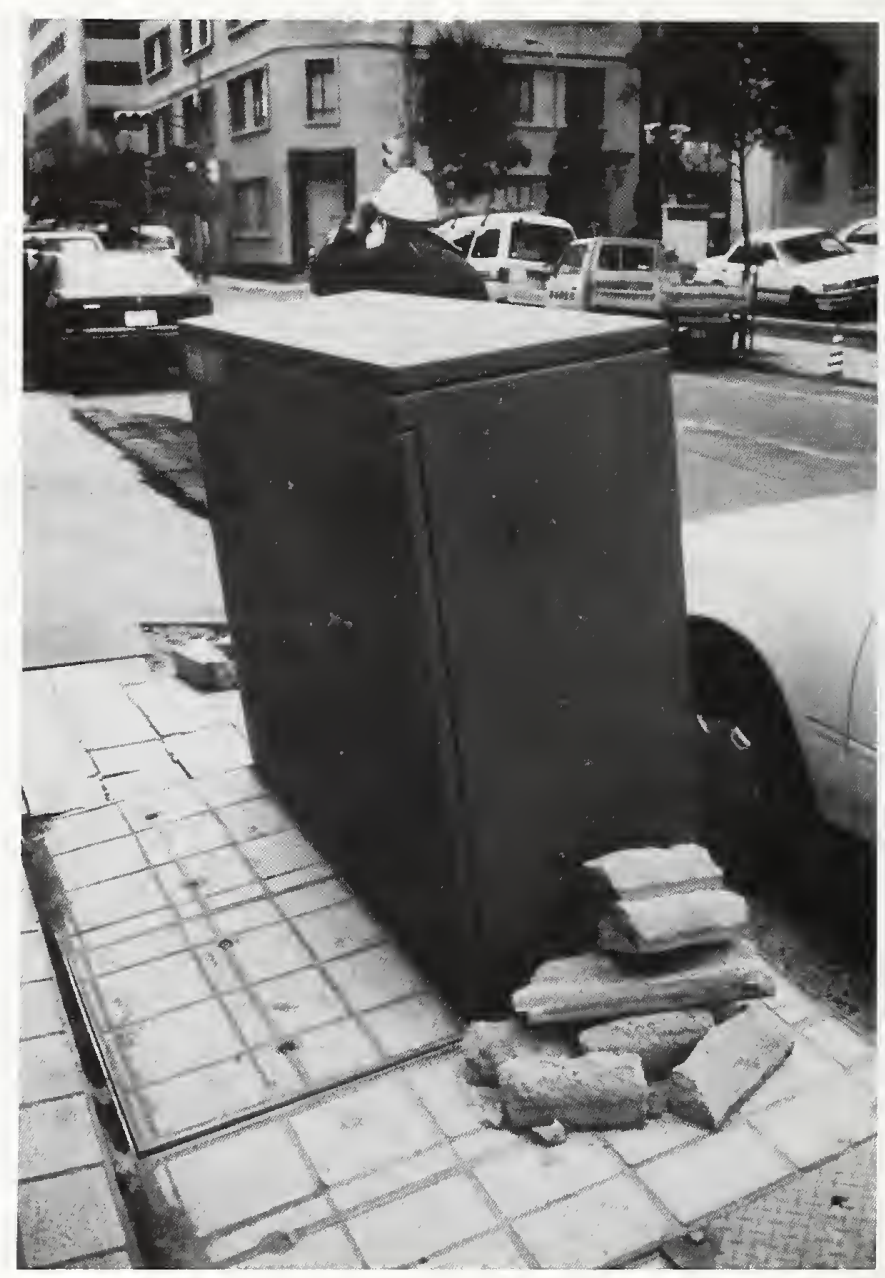

Figure 5.4.72

The conduit and the foundation pad under this transformer pad was disrupted in down town Kobe due to soil liquefaction. 


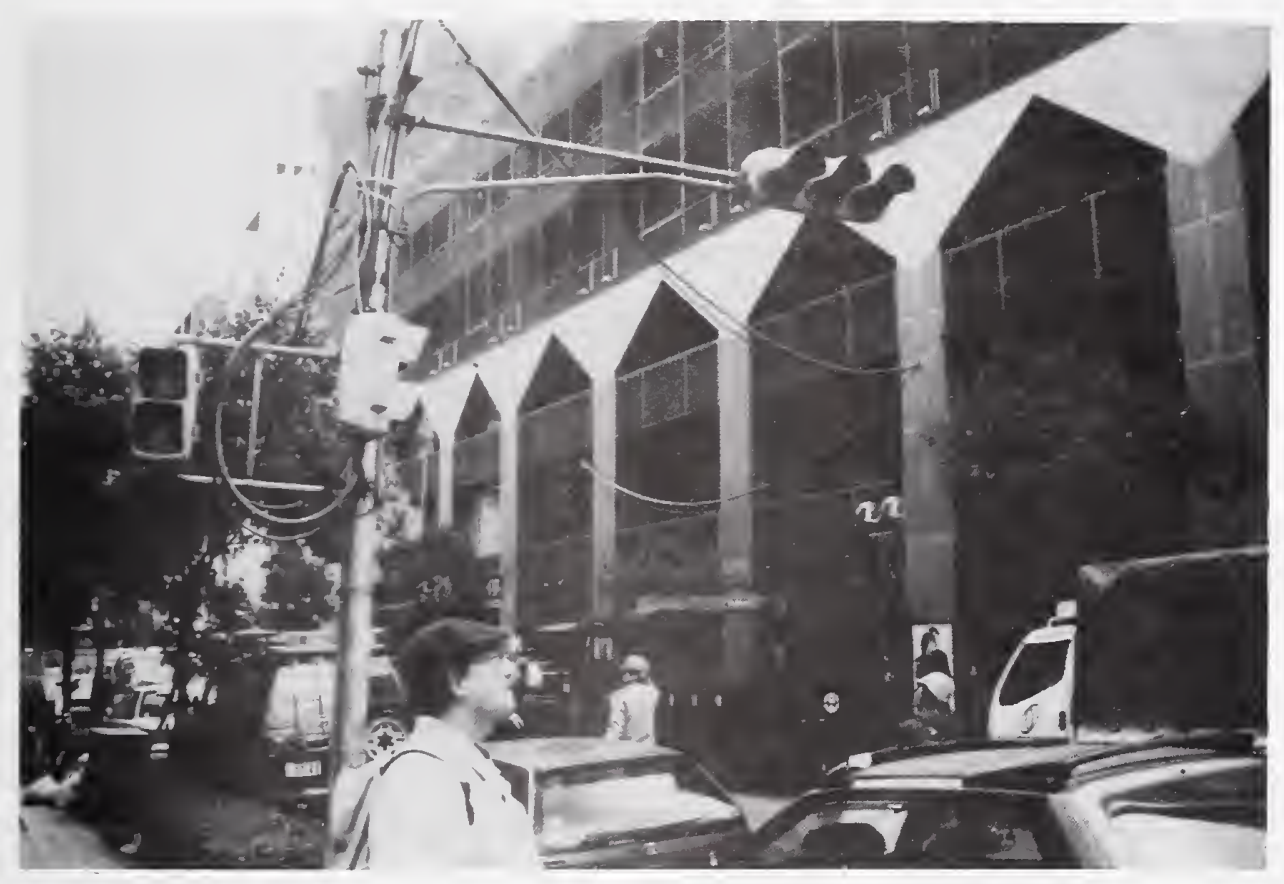

Figure 5.4.73 A primary distribution line of $6.6 \mathrm{kV}$ was temporarily installed to restore power to a building. 


\subsection{Telecommunications}

\subsubsection{Nippon Telegraph and Telephone (NTT) Corporation}

The telephone communication system is dominated by NTT, although independent companies are now providing long-distance services. The large metropolitan areas of Tokyo, Nagoya, and Osaka have diverse communication routing systems installed [1]. The Osaka regional center has connections to five district centers, and there is a loop connecting the district centers providing multiple redundant transmission routes. There are also priority service line in Japan that are available to customers at additional charges that connect the customer to two central offices, although diverse routes from the customer may not be used. It appears that this option is available at lower cost in Japan than in the United States as it is used more frequently. In addition, special provisions have been made to new conduit installations to improve their earthquake resistance.

Table 5.5.1 shows current measures used to improve the earthquake resistance of conduit joints. It was reported that welded steel conduit is exclusively used. This is in contrast to the United States, where plastic conduit is used. Central offices are connected by optical fiber, copper cable and microwave trunks. Tunnels are used to carry communication trunk lines. NTT has two types of tunnels: bored or shielded tunnels make up $60 \%$ of the tunnel system, and cut-and-cover tunnels make up the other $40 \%$. The shield tunnels are from $7 \mathrm{~m}$ to $20 \mathrm{~m}$ deep and are about $4.5 \mathrm{~m}$ in diameter. The cut and cover tunnels are from $2 \mathrm{~m}$ to $4 \mathrm{~m}$ deep, and their cross sections are $2 \mathrm{~m}$ to $3 \mathrm{~m}$ square. In addition, there are joint utility tunnels made by the government that have separate sections for communication, power, and gas lines that are paid for by a utility tax. These tunnels tend to be very costly, but are encouraged by the government because they reduce the impact of surface transportation cause by the installation of tunnels or repair of buried lines. Tunnels have sumps or pumps to remove water that leaks into the tunnel.

The loss of water to communication facilities and its effect on emergency power in this earthquake further substantiates this vulnerability to U.S. facilities.

The annual capital expenditures of NTT are about $\$ 200$ billion; annual revenues are about $\$ 400$ billion.

\subsubsection{What Happened}

A briefing was held at an NTT facility at which system damage was described and pictures of damage were distributed. An NTT news release was also distributed [2]. The earthquake reconnaissance team of the Technical Council on Lifeline Earthquake Engineering (TCLEE), ASCE, also provided information on system response. No damaged central offices were visited in Kobe. The total loss was estimated by NTT to be $¥ 300$ billion (over $\$ 3.6$ billion). It is understood that NTT is not insured for earthquake damage to network facilities. It is unknown whether this cost will be recovered through rates.

\subsubsection{Central Offices}

Three central office buildings sustained damage, but the damage had no effect on operations except for one office. The three 
damaged central offices at Kobe, Kobe Sai, and Saiku were restored by January 29.

Three building-mounted towers were damaged. One, which was removed later, is shown in Figure 5.5.1. A buckled member can be seen on the inner cord on the right leg. Because of the concern that the tower may collapse, the building was evacuated until the tower was removed. The tower on the Daikai-building was back to normal on January 21 and the one on the Kobe-Port-building was back to normal by January 24. They both have been reinforced.

There was a loss of commercial power in most of the earthquake impacted area (see Section 5.4). Of the 1440000 lines in the Kobe area, 285000 had problems related to power failures. By noon on January 18 , electrical problems were solved by the restoration of commercial power or the use of mobile emergency generators. As in the United States, central offices have large battery power plants that can provide power for several hours and there is an engine-generator to recharge the batteries to provide long-term emergency power. There was no battery damage. It was reported that at one central office, the engine-generator would not operate because there was a loss of municipal water needed for cooling. The central offices do not appear to have provisions for a quick electrical hookup when a generator fails, as are now being added by some California utilities. It is not clear why only one central office was impacted by water disruption, as most of the area was without water. It was also not clear why the loss of air conditioning, which also requires water, did not impact operations, as switches usually require cooling, even in winter.

\subsubsection{Outside Plant}

There was extensive damage to conduit at manholes and at locations where it entered central offices. The information received at the briefing indicated that there were no failures to optical fiber trucks and only a few to copper trunks. Reliable, independent sources indicate that there was damage to optical fiber trunks. The news release (NTT, 1990) notes that the earthquake caused damage to 193000 lines, and approximately 100000 were restored by January 31 . The remaining lines that were out of service were due to collapsed or fire destroyed buildings. There was also damage to 3170 special service lines, and approximately 2730 were restored by January 31 . There were 440 of these lines that could not be restored and temporary lines were laid.

There were varying degrees of damage to tunnels. A superimposed seismic intensity map on the NTT tunnel network indicated that about $6 \mathrm{~km}$ were in JMA 7+ zone, 2 $\mathrm{km}$ in JMA 6 zone, and $4 \mathrm{~km}$ in JMA 5 zone. After the earthquake, 10 sump pumps were used to remove water that collected in the tunnels due to leaks and seepage. They had to be operated using mobile generators due to the loss of commercial power. These generators were obtained through contract. It was noted that waterproofing specialists were in short supply after the earthquake to make tunnel repairs, and were thus critical in terms of making timely repairs.

The shield tunnels had no damage. There were problems with some of the cut and cover tunnels. A manager and three supervisors checked out the $12 \mathrm{~km}$ of buried tunnel in the Kobe area, and the damage was repaired by March 26. At the Mindato Central Office, which is located about $200 \mathrm{~m}$ from Kobe Bay just north of Highway 43, 
the tunnel settled about $7 \mathrm{~cm}$ relative to the building and shifted about $7 \mathrm{~cm}$ laterally; however, there was no damage to trunk lines. Figure 5.5.2 shows a schematic diagram of the tunnel-building connection and a post-earthquake repair used to stop water leaks. This detail was used throughout Japan. There was minor damage to the Joint Utility Tunnels, primarily slight movement at construction joints resulting in leaks (Figure 5.5.3). Communication cables in the Joint Utility Tunnel had fire resistant covers near entrances and staircases, but were generally unprotected (Figure 5.5.4).

At many manholes, the conduits were pushed into the manhole boxes by up to 30 $\mathrm{cm}$. This can exceed the available cable slack and cause a cable failure (Figure 5.5.5). The relative motion also can damage the manhole-conduit seal, and water seepage can also damage the cables. In older conduits, cable slack was $2 \mathrm{~cm}$ at the manholes, and some of these broke. At new conduits, cable slack was up to $15 \mathrm{~cm}$, and these did not break. It appears that there can be large variations in slack provided to cables at manholes. In an earlier visit to Tsukuba City, an NTT Outside Plant research group proposed service loops of about $8 \mathrm{~cm}$ diameter before each splice joint. However, a tie-wrap to secure the loop to a tray or shelf was also recommended, so that the deployment of the slack may be impeded. Liquefaction and soil movement also moved junction boxes (Figure 5.5.6). Figu re 5.5.7 shows a schematic diagram of a $4 \mathrm{~cm}$ offset of plates used to form the manhole entry. Subsidence of soil around manholes also caused conduit failures (Figure 5.5.8). Conduit carried on bridges were also damaged due to motion of the bridge deck (Figure 5.5.9). Subsidence in roadways caused extensive damage (Figures 5.5.10 and 5.5.11). Telephone booths were also severely damaged by soil failures (Figure 5.5.12).

At a stream crossing the telephone conduits were supported on their own bridge. The slope on one side slumped into the water, imposing large deformations on the bridge and conduits, and causing the failure of the conduits. Visually, the displaced conduits appeared to have moved up to $1 \mathrm{~m}$. At another location, the walls of a canal moved towards each other causing conduit spanning the canal to buckle (Figure 5.5.13).

The extensive damage to concrete poles used to carry aerial lines is discussed in Section 5.4.2. In addition to the failure of poles due to liquefaction, inertial loads, interaction with fallen houses and other poles, some lines were damaged due to fire (Figure 5.5.14).

\subsubsection{Network Operations}

There were significant problems with congestion, that is, attempts to place more calls than the system can accommodate, a situation common in the United States from even minor earthquakes. On January 17, call volume from other parts of Japan to Kobe increased by a factor of 50 over normal traffic. This dropped to 20 times normal traffic on January 18 . There were reports that it would typically take ten attempts to complete a call. At the same time, it may only take three attempts to complete a call using the cellular system. During a visit of an ASCE/TCLEE reconnaissance teams at the end of March, some areas required as many as five attempts to complete a call using a pay telephone.

To prevent switch saturation, line control was implemented. Restrictions on calling were removed on January 22, when call volume was about twice normal levels. Due 
to load control efforts by NTT, some areas away from the earthquake, for example in area code 0742 south of Osaka, could not call other parts of 07 areas, even though those areas had no telephone system damage. About 50000 extra lines were installed to the Hyogo area by using mobile switching units and mobile satellite transmission units. Telephones were connected directly to mobile switching units.

\subsubsection{Restoration}

Initially 7000 NTT personnel, many from other parts of Japan, were working on restoration. During the ASCE/TCLEE visit at the end of March, there were still 3000 personnel working on locating damage and restoring outside plant.

Six mobile satellite units were used after the earthquake to provide transmission capacity due to damaged towers. In addition, 11 diesel-generators were used to provide power where commercial power was disrupted and emergency power was not provided or had failed.

On Port Island, television inspection of a 7.5 $\mathrm{cm}$ steel conduit had just been started at the time of the visit. Two out of five steel conduits that had been inspected failed due to differential settlement, but the cables were not damaged.

It was reported (NTT, 1990) that NTT will examine the current disaster management program based on Japanese intensity 6 by organizing a Large Scale Disaster Management Committee to review the impact of the earthquake and submit a report with recommendations by July, 1995.

\subsubsection{Special Post-Earthquake Services}

NTT provided free telephone service, including long distance, with 2700 phone sets, including 350 fax machines at 760 locations in the disaster area.

Telegram service was provided for the people who evacuated Kobe. E-mail providers also established a database of the displaced, injured and diseased persons so that relatives could obtain information quickly.

\subsubsection{Lessons for the United States}

Three building-mounted microwave towers were damaged, one of which was removed. One of the striking features about communications towers in Japan, where there are large wind loads associated with typhoons, is their massive construction as compared to those found in the United States. The damage to Japanese towers suggests that those in the United States may also be vulnerable, particularly where central offices are built on poor soil.

The loss of water to communication facilities and its effect on emergency power further substantiates this vulnerability to U.S. facilities.

\subsubsection{Research Needs}

There is a need to get a better understanding of practices used for outside plant in Japan and to review in detail, their earthquake performance. The collection and analysis of this data on outside plant damage can provide insight into the outside plant in the United States, particularly in the Midwest where liquefaction is expected to be a serious problem. 


\subsubsection{Summary}

There was relatively little service-disrupting damage to central offices. Emergency power was disrupted due to the loss of water at central offices, which caused the loss of service to 285000 lines. There was extensive damage to outside plant. A massive restoration effort was required to restore service and the restoration of conduit and other facilities continues, two months after the earthquake. Total cost of damage from the earthquake is estimated by NTT at $\$ 3$ billion. NTT has established a committee to review the impacts of the earthquake and will make recommendations for changes.

\subsubsection{Acknowledgments}

The translation of the news release (NTT, 1995) by Alex Tang, Nortcl, and Satoshi Tanaka, Princeton University, is gratefully acknowledged.

\subsubsection{References}

1. "Disaster Prevention Mcasures of NTT for Telecommunications Network Systcms," IEEE Communications Magazine, pp. 18-24, Junc 1990.

2. A news release in Japancse, dated February 1, 1995, "Damage and Restoration of Hyogo-Nanbu Earthquake," was distributed at the NTT briefing, 1995. 
Table 5.5.1

Current Measures Used to Improve Earthquake Resistance of Conduit Joints

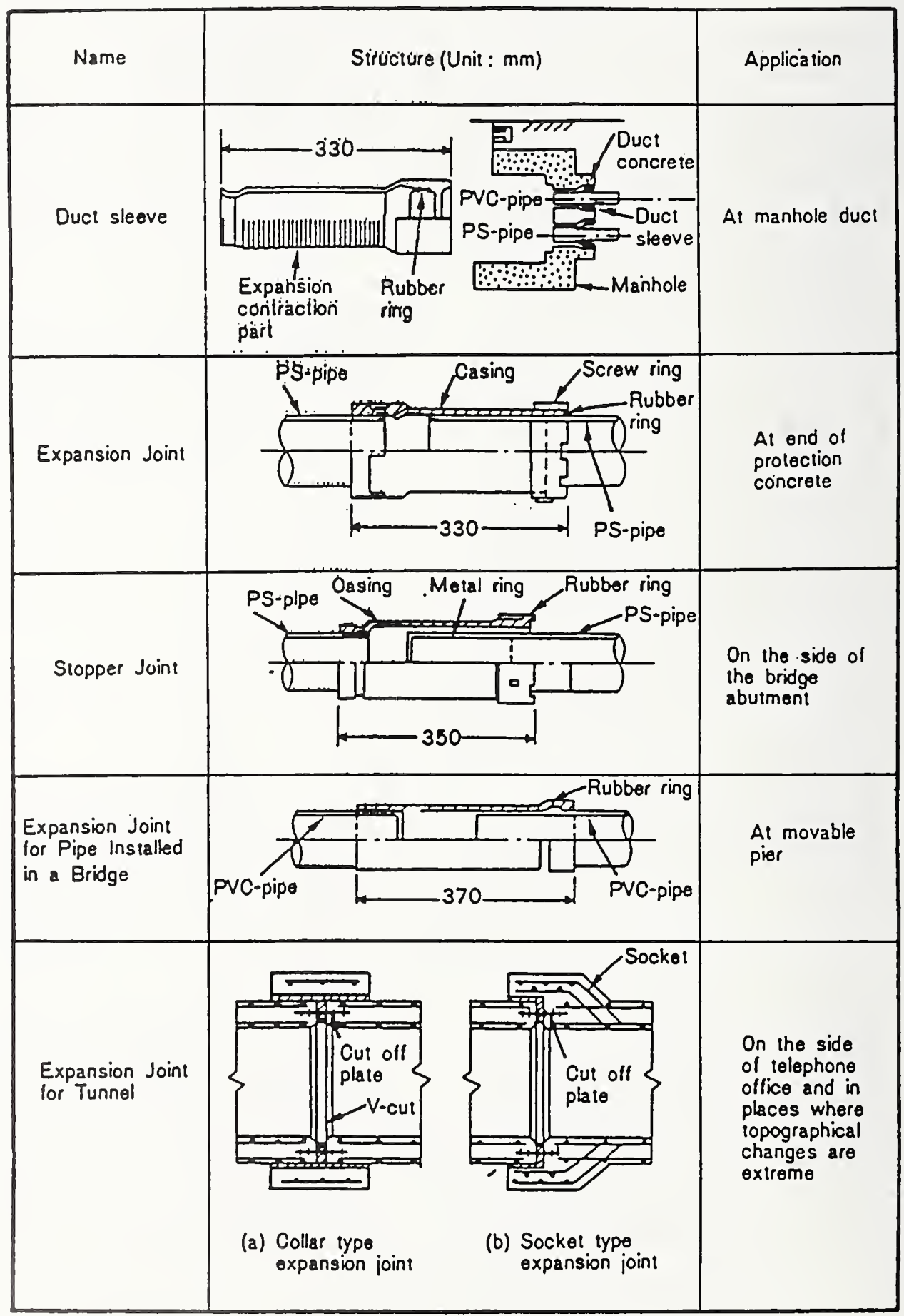




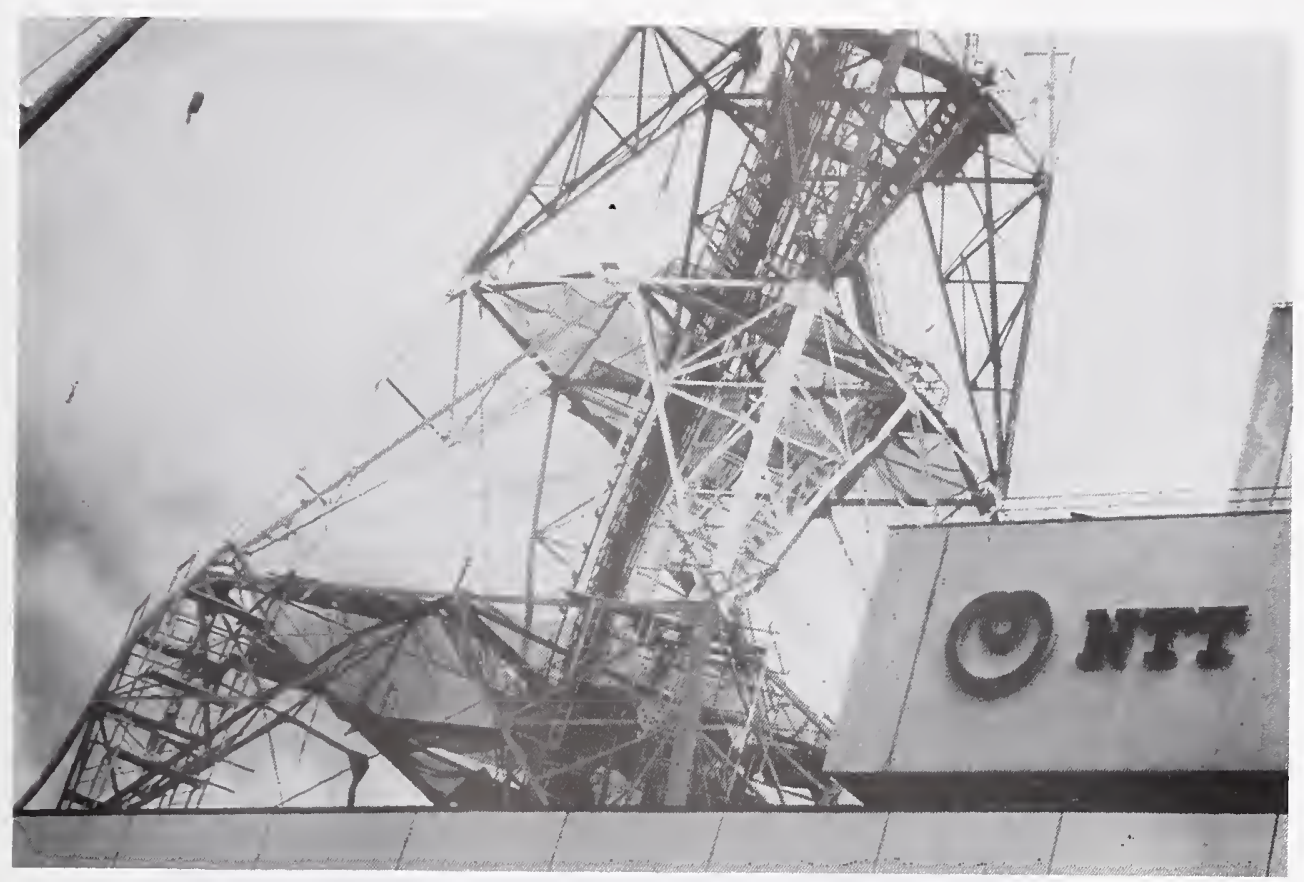

Figure 5.5.1

Microwave tower on top of a central office which was damaged and later removed.

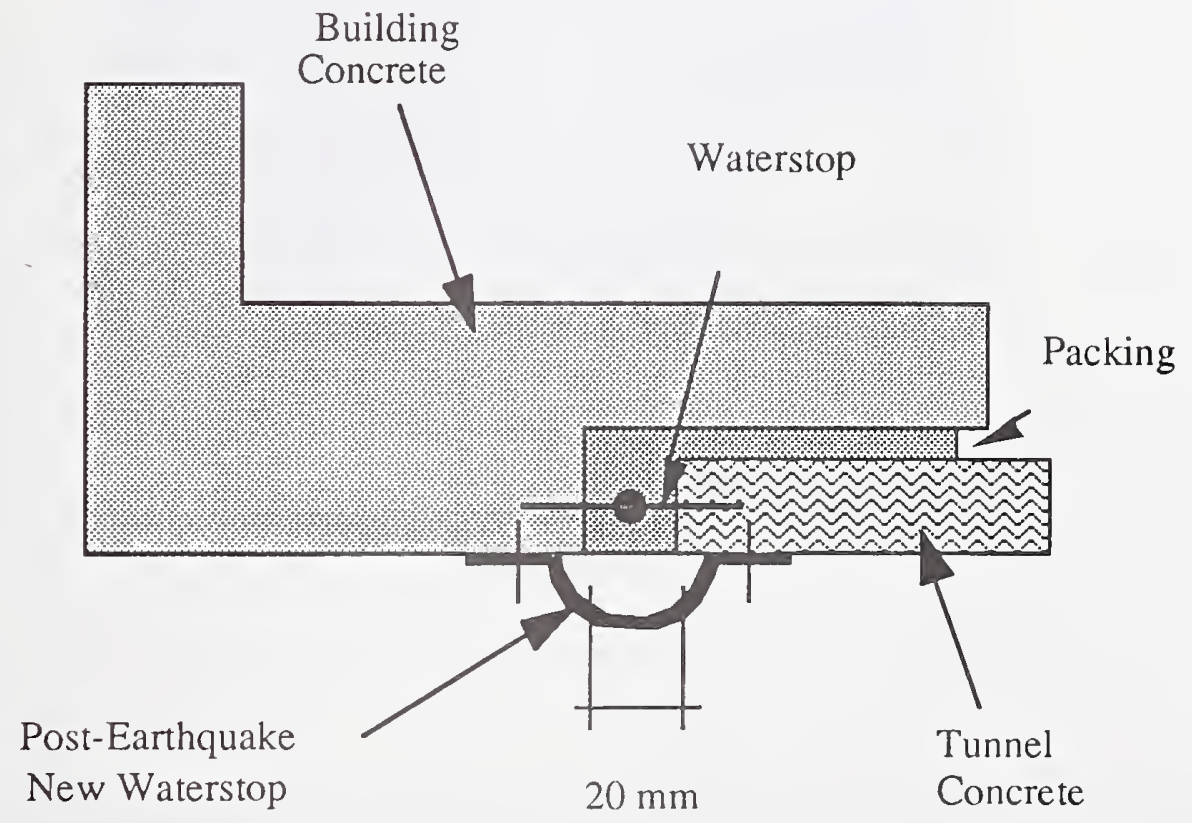

Figure 5.5.2

Schematic diagram of tunnel-building connection detail and post-earthquake repair. 


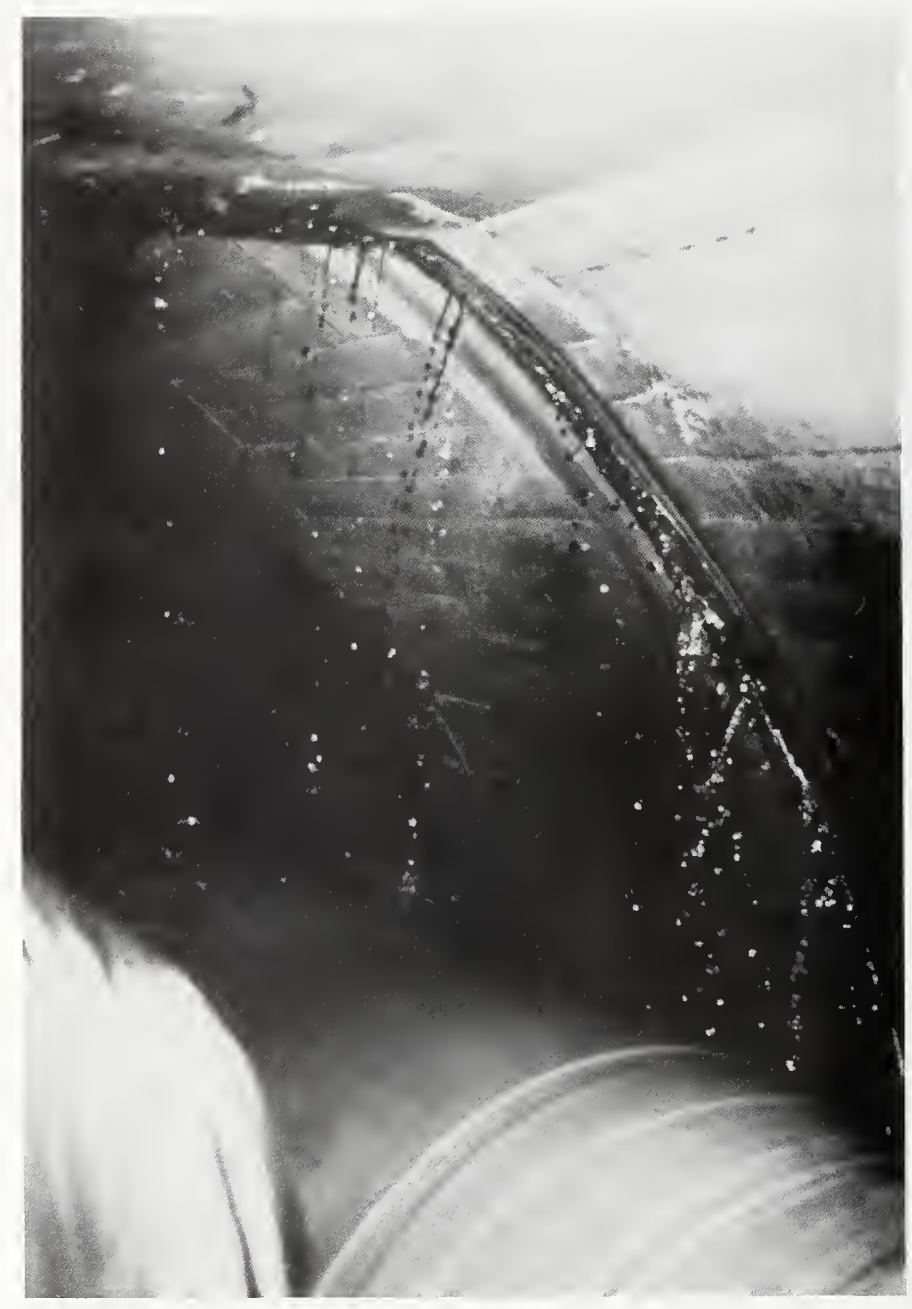

Figure 5.5.3

Slight movement at a construction joint caused a small water leak in a joint utility tunnel. 


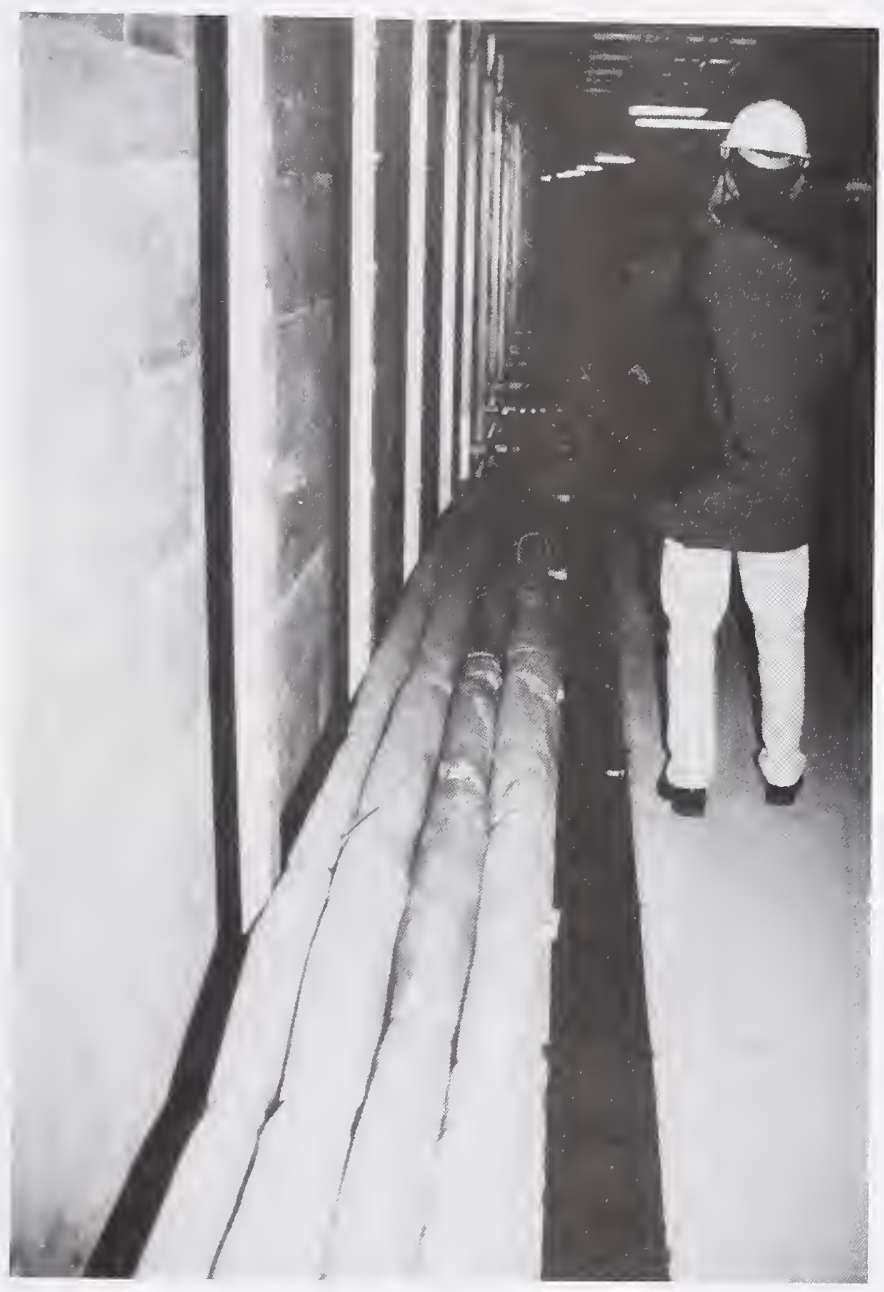

Figure 5.5.4

Trunk lines in the joint utility tunnel had fire retardant covers near entrances and stairways. 


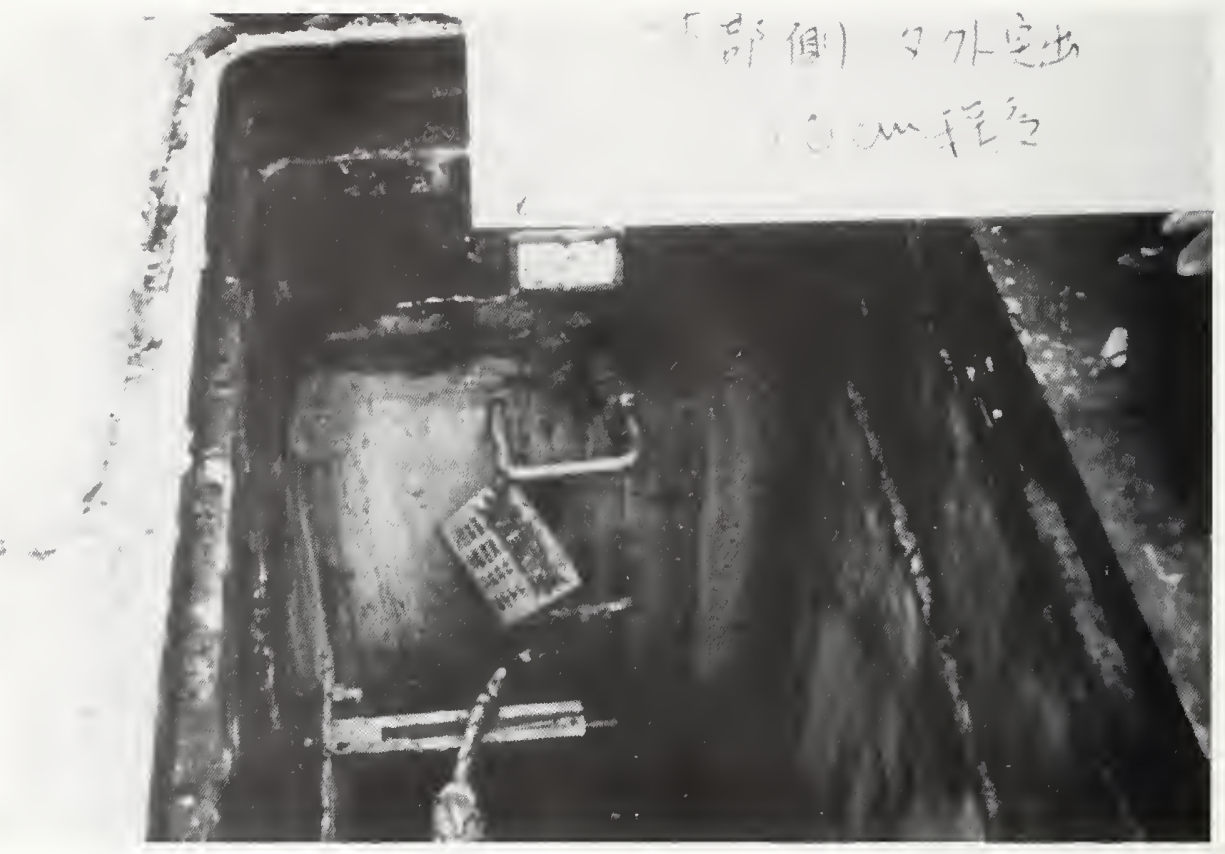

Figure 5.5.5

Cables were pushed into manhole boxed breaking water seals and in some cases damaging cables.

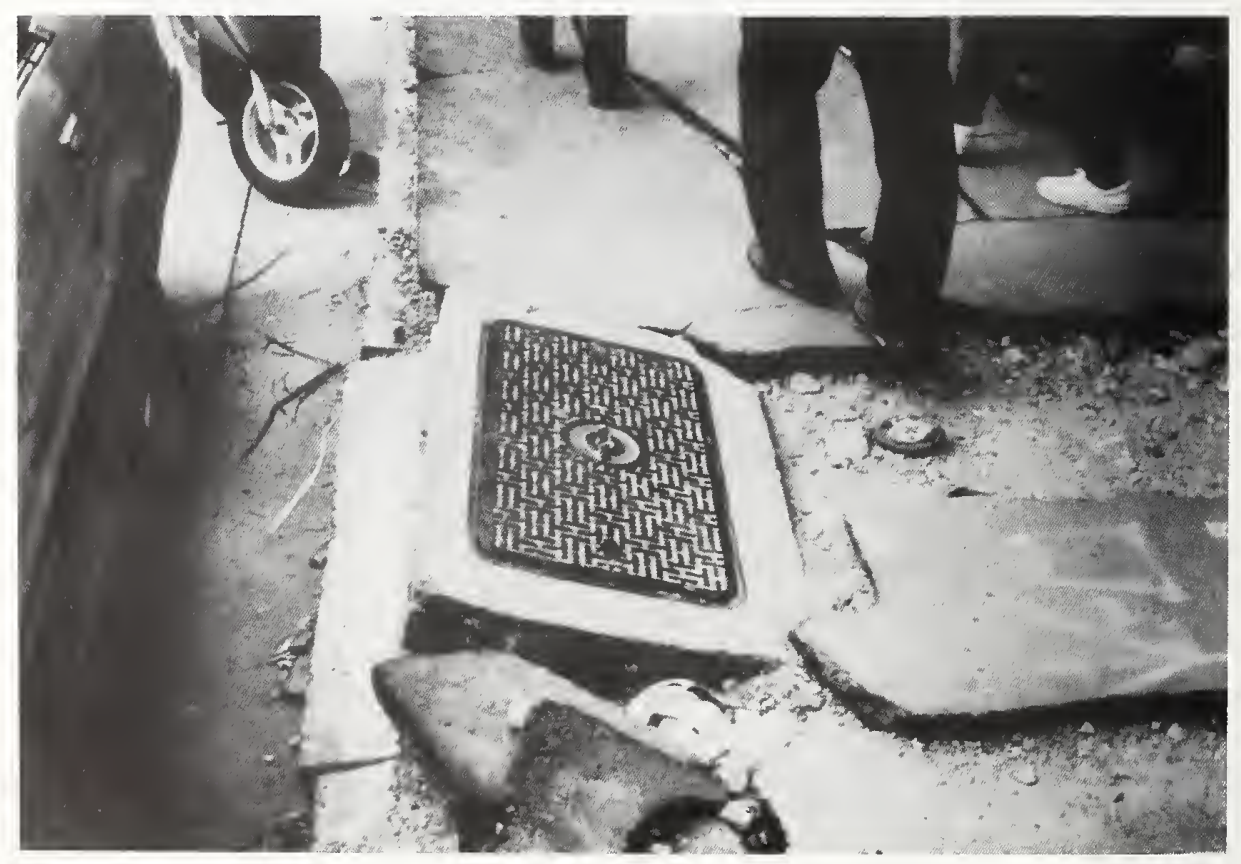

Figure 5.5.6

Movement of manhole box can damage conduits and trunk lines. 


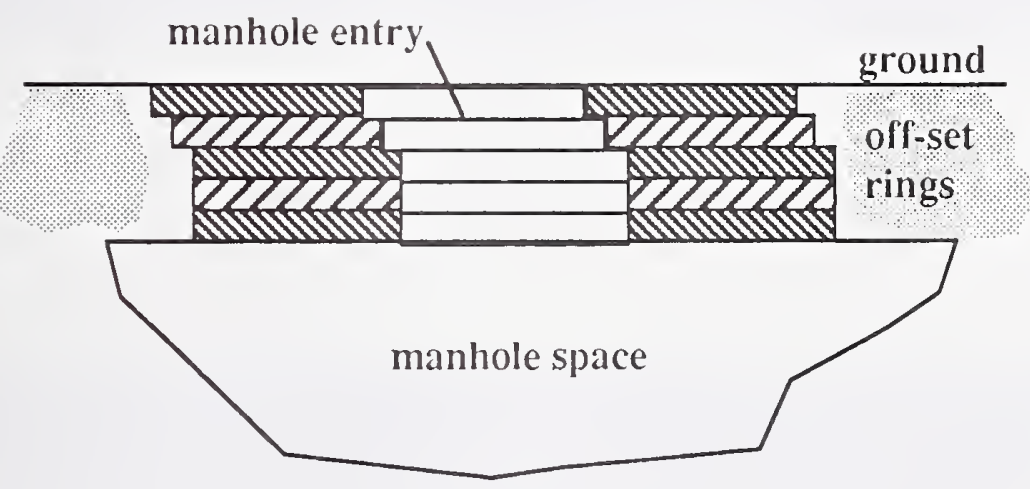

Figure 5.5.7

The entry of a manhole built by stacking rings were offset by $4 \mathrm{~cm}$ due to soil failure. 


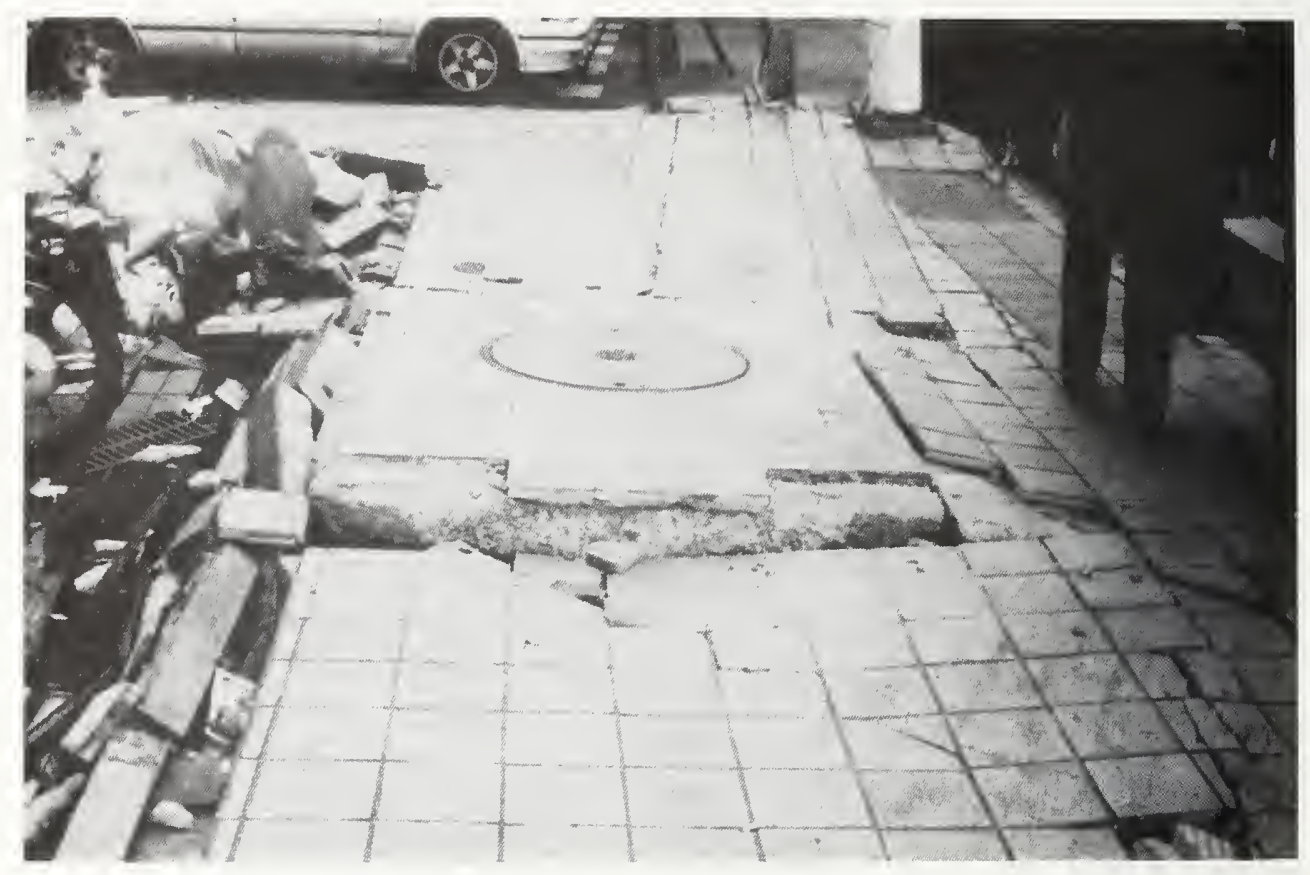

Figure 5.5.8 Subsidence around manhole can damage conduit and trunk lines.

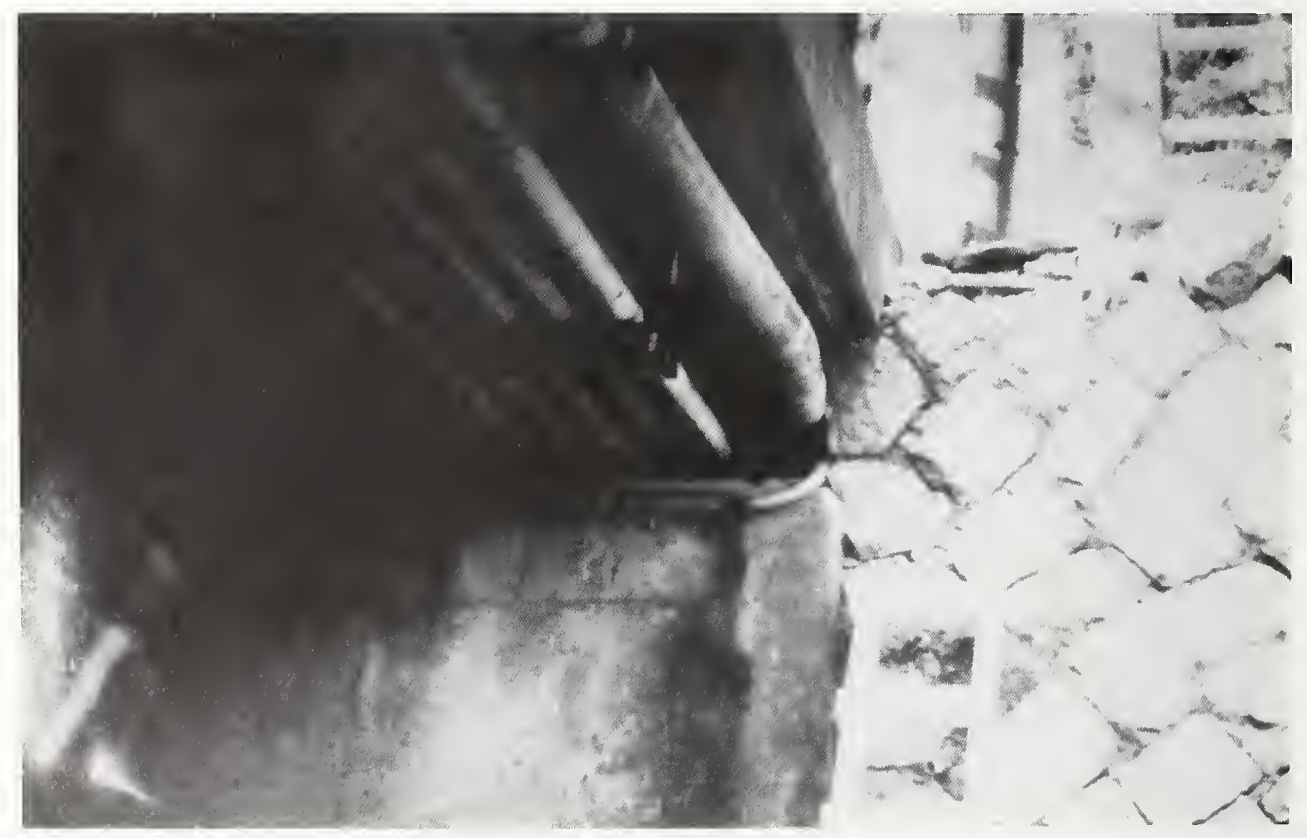

Figure 5.5.9 Conduits carried on bridges were damaged when bridge deck moved. 


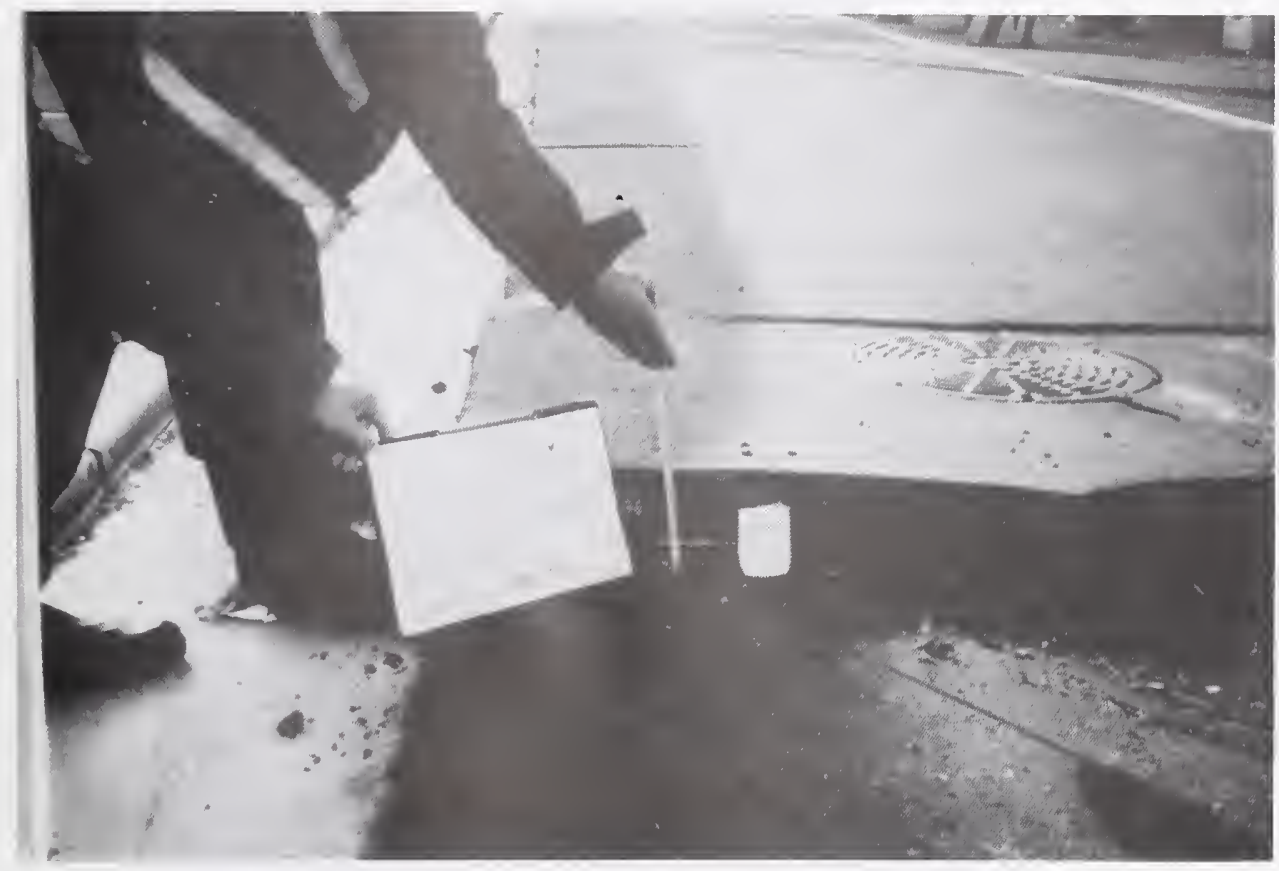

Figure 5.5.10

Large differential settlements in roadways can damage conduit and trunk lines.

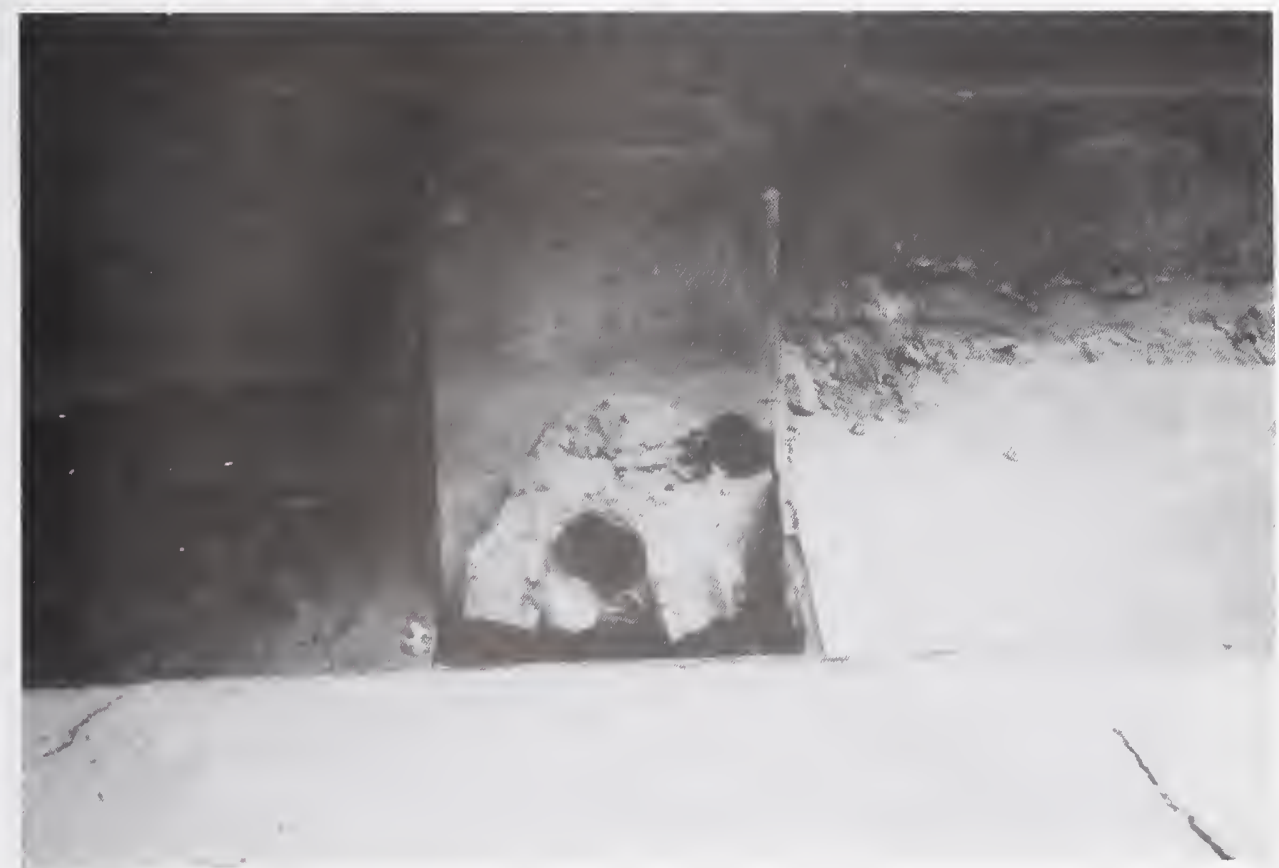

Figure 5.5.11

Settlement of a walkway adjacent to a building shears conduit and cables. 


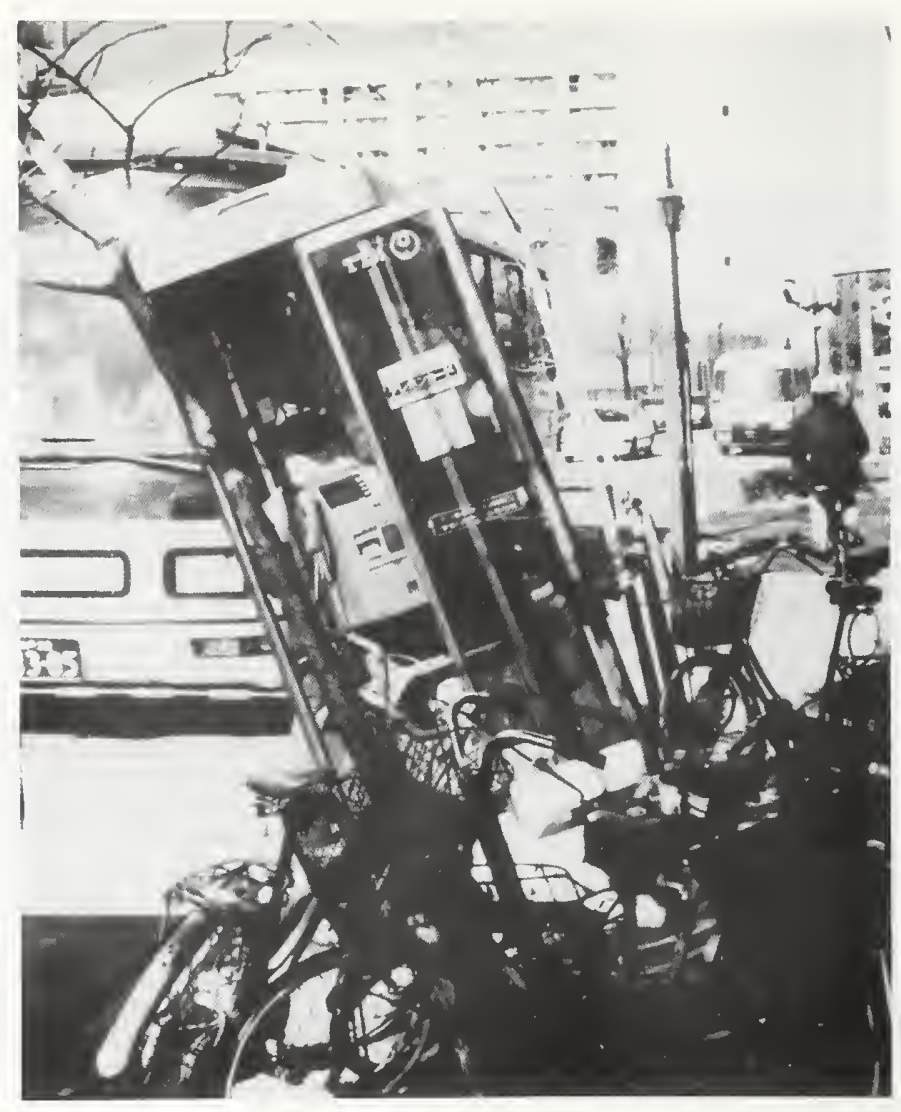

Figure 5.5.12

Soil instability damaged telephone booths.

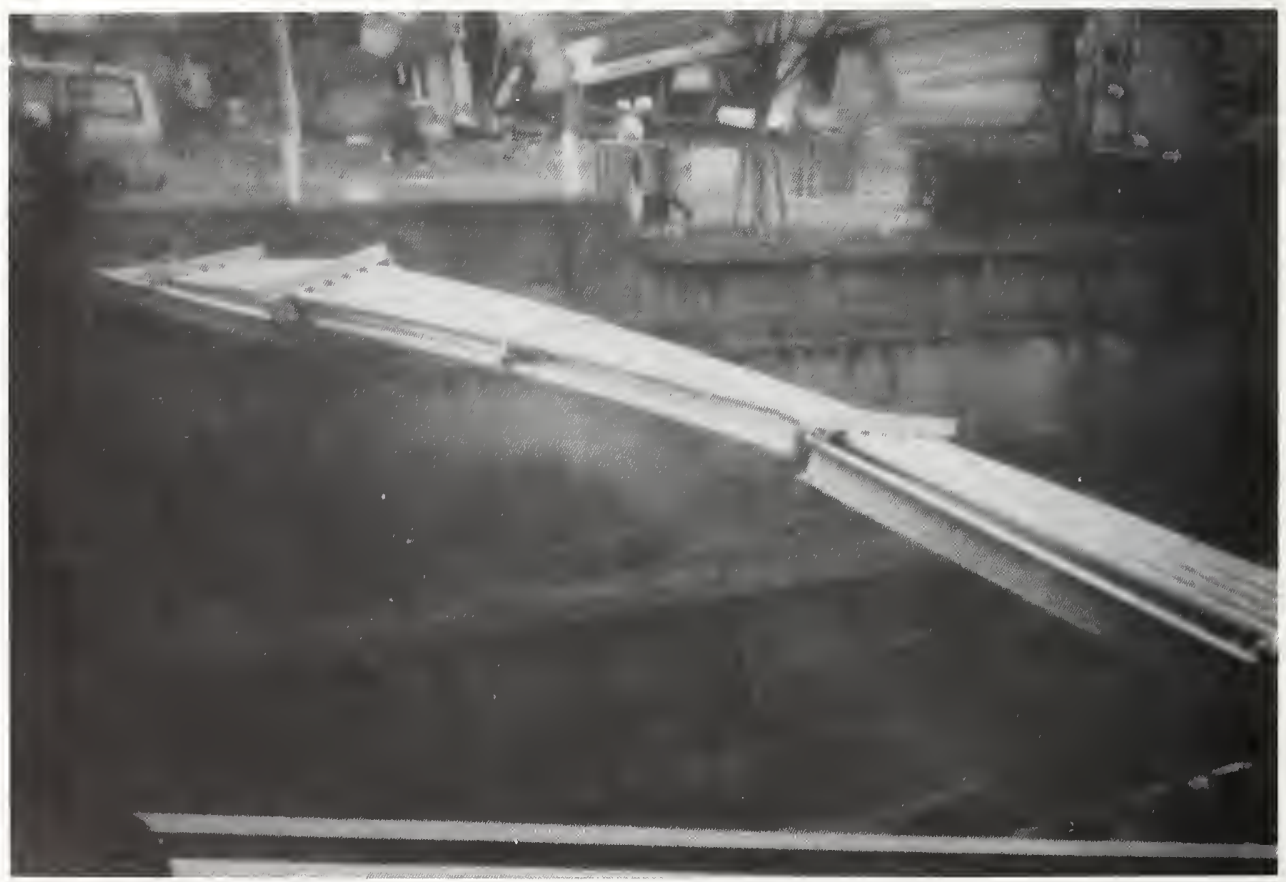

Figure 5.5.13

Walls of a canal moved causing conduit bridge and conduit to buckle. 


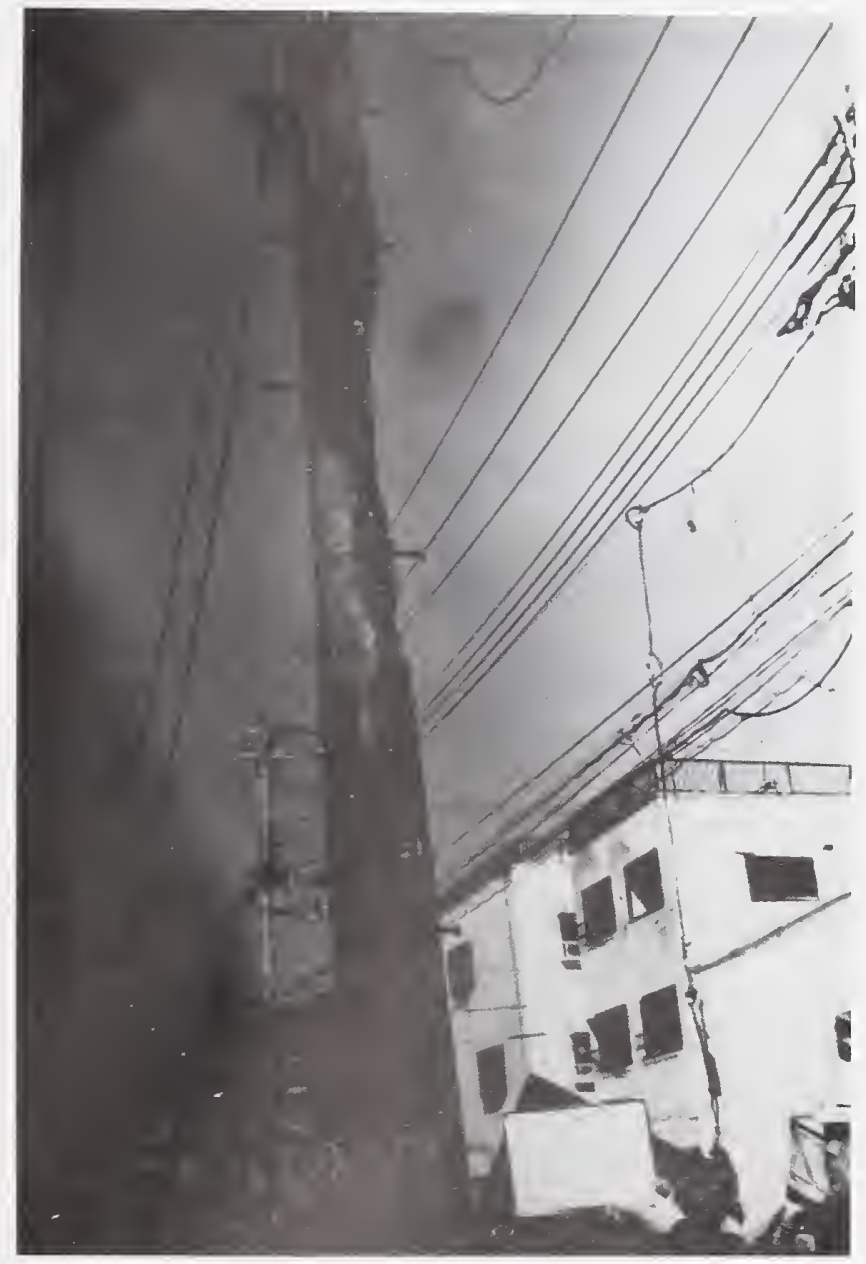

Figure 5.5.14

Fire damaged aerial lines and cables along the pole. 


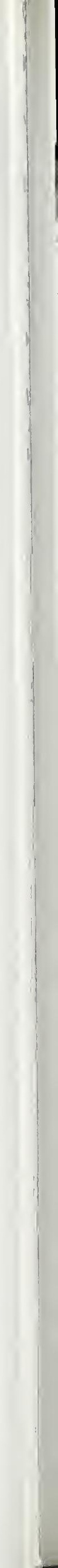




\subsection{Hospitals}

\subsubsection{Overview}

\subsubsection{Scope of Investigations}

The investigations of hospitals focused on the impact of lifeline disruption on hospital operations. Some additional information was gathered, but issues related to the medical response and patient treatment were not investigated. The Kobe Medical College of the University of Kobe was visited [1]. A limited amount of information about the Hyogo Medical Center was also obtained through a brief interview [2].

\subsubsection{Kobe Medical College of the University of Kobe}

The Kobe Medical College is located about $10 \mathrm{~km}$ east-northeast of the epicenter. It is about $1 \mathrm{~km}$ north of the Japan Railroad Kobe station and up a slight hill from the shore. Thus, the buildings on the campus are not on reclaimed land adjacent to the Osaka Bay. There are several buildings associated with the college including a new hospital building, built about 1985, an old hospital building, built about 1967 and at least one large classroom and laboratory building. The two hospital buildings are about 10 stories high. They were joined by a narrow section that contained corridors connecting the two buildings. The old hospital building did have cracks in a first floor wall between windows that was being repaired with injected epoxy (Figure 5.6.1). This damage indicates that there was significant ground motion at the site.

The hospital appears to be similar in some respects to teaching hospitals in the United Sttes. It is a critical care facility and obtains its patients primarily by reference of physicians of patients that have special needs. The earthquake did not have a significant impact on admissions to the pediatric section of the hospital.

\section{We need to review lifeline needs in critical facilities, such as hospitals, and establish guidelines for minimum levels of service for each lifeline.}

\subsubsection{What Happened}

\subsubsection{Kobe Medical College of the University of Kobe}

There appeared to be relatively little structural damage to the hospital, except as noted above. In the new wing of the hospital a section of a wall that joins the new and old wings had severe local damage due to interaction of the two buildings where the corridor connects the two buildings (Figure 5.6.2). There was some spalling of concrete adjacent to at least one seismic joint observed during the short visit to the hospital.

There were reports that equipment in a ward on the tenth floor moved and some items fell from work tables to the floor. There apparently was some damage to the oxygen distribution system causing a drop in pressure in the system. The hospital has a centralized oxygen source that distributes oxygen throughout the hospital. One patient in the pediatric ward, who was dependent on oxygen, was transferred to another hospital. The cause of the problem could not be explored because of a lack of time.

The hospital has two emergency generators, one each in the old and new wings of the 
hospital. The unit in the new wing, which is assumed to be 10 years old - the same age as the wing - is a large diesel generator. It is designed to start automatically when there is a loss of commercial power and provides emergency power to the hospital complex. It is installed on elastomer vibration mounts (Figure 5.6.3). This type of mount was observed on all emergency generators in Japan, including some units that were about 30 years old (Figure 5.6.4). This type of engine mount has not been observed in the United States, although it would appear to have some advantages over mounts used in the United States. The elastomer has good damping characteristics and the mount does not need a snubber to limit motion. This is an advantage because when vibration-isolated equipment hits snubbers, large accelerations can result. All utility connections to the engine-generator were provided with flexible couplings. The engine-generator, like many large units, uses compressed air to start the generator. The air tanks and compressor were well anchored (Figure 5.6.5). The day tank was supported on a well-braced and anchored structure (Figure 5.6.6). There was a 3000 liter water storage tank used for engine cooling water that was well anchored and provided with flexible couplings. The cooling system for the diesel engine uses a single pass system. That is, water from the water tank passes through and cools the engine, and then is dumped into the sewer system. Water to refill the tank is provided from the municipal water supply.

The engine-generator in the old wing of the hospital was a smaller unit and was a quality installation similar to the unit in the new wing (Figure 5.6.7). This unit is started manually and serves as a back up to the new unit. This engine has a closed loop cooling system that includes a cooling tower on the roof of the hospital. This type of system makes much better use of the available water, but still requires that evaporative losses, which take place in the cooling tower, be made up. The make up water for the engine cooling system comes from the building water supply, which will be discussed below.

The engine in the new wing started when commercial power was lost. However, due to the loss of the municipal water supply, when the small tank near the engine was empty, there was a loss of cooling water and the unit shut down due to overheating. The old generator, with the closed loop water cooling system, was switched manually to pick up the load in the new wing, and this appeared to meet the emergency needs of the hospital.

There were no provisions to connect an external generator to the facility should both generators have failed to operate.

Commercial power was restored to the hospital at 8:40 am on January 17 , and the generator was shut off 2 hours later after commercial power continued without interruption.

Three large buildings in the hospital complex have an integrated water system depicted in Figure 5.6.8. The system consists of a tank on top of each building and a common large water storage tank with a capacity of 400 tons (400000 liters). It should be noted that very few hospitals in the United States have the water storage capacity of the Kobe facility. This tank, which is supplied with water by the municipal water supply, has four pumps associated with it. Three of the four pumps supply the tanks on the roof of each of the buildings. A fourth pump supplies water to the fire suppression system in the three buildings. This pump also supplies water to 
two of the building tanks. There was a pipe failure in the line connecting the fire suppression system to the tank in the old hospital, Building No. 1. This system also supplied make up water to the emergency engine in the old hospital wing.

There was a break in the pipe connecting the fire suppression system to the tank in Building 1. The pump that feeds this tank and the fire suppression system were shut off after the danger of fire had passed. It is not known if Building 1 lost all of its water supply. The extent of flooding that may have occurred due to the pipe failure is also unknown. The water contained in the roof tanks and the main storage tank lasted 6 hours. Provision was made for a tanker truck to deliver water to the hospital - 20 tons every 2 hours. However, there was no simple way of getting the water from the tanker truck into the hospital system. Initially, this water was carried to the top of the building manually, as none of the elevators were operating. By the second day one of the elevators was operating; but other than the elevator ride to the roof, it was a manual operation. This operation continued until the municipal supply was restored after 4 or 5 days.

The telephone system within the hospital consisted of a main distribution frame (Figure 5.6.9), Private Branch Exchange (PBX), an uninterruptable power supply (UPS), cable trays, and a remote switch. The Private Branch Exchange was connected to Nippon Telephone and Telegraph (NTT) trunks through the main distribution frame. The uninterruptable power supply (batteries) was charged by commercial power or the emergency generator in the complex, if commercial power was lost. In addition, there were a few telephones connected to NTT through the main distribution frame without going through the Private Branch
Exchange (Figure 5.6.10). These were to provide communications in the event that there was a failure in the Private Branch Exchange. The communication equipment was well anchored to a regular building floor (raised floors were not used in the communications room). The batteries for the uninterruptable power supply were mounted in a cabinet, and restrained by brackets attached to the shelves (Figure 5.6.11). The restraints were not snug at the ends and they were made of relatively lightweight metal. It is interesting to note that the cells and bus straps connecting the cells are constructed so that the top edges of the cells butt against each other, thus, there is no need for spacers between the cells. The battery cabinet was well anchored. The communication cable tray sections were bolted together (Figure 5.6.12), so that they formed a structural system. The communication cable trays typically used in the US are fabricated with friction clips, so that units cannot withstand tensile loads (Figure 5.6.13). The trays were bolted to structural walls (Figure 5.6.14). This is a more reliable method of anchoring the cable trays than the $\mathrm{J}$ bolts that are often used in the United States (Figure 5.6.15). The main distribution frame was bolted to the cable tray to provide bracing at the top of the frame to limit the motion of the frame (Figure 5.6.16). There were no problems with the main communication facilities. The remote system had unspecified problems, however, there was insufficient time to explore the difficulties. The impact of congestion on the NTT telephone system on hospital operations is not known.

The loss of the gas supply also had a large impact on hospital operations, as gas was used for preparing patient food. It might be interesting to briefly compare some of the lifclines at Kobe Medical College with a university teaching hospital in 
California, namely Stanford University Hospital (SUH). It should be noted that no comparison is made between the relative size or special roles that the respective institutions may have in their unique environments. Water is supplied to SUH from the municipal system. There are no storage facilities for raw water, however, a well at the university can also be connected to supply the hospital. There are three tanks (23000 1, 6000 l, and 2300 1) that store water treated by reverse osmosis that can be interconnected. The water used for dialysis is treated by a special processing units and there is no storage capability. There is a 23000-liter liquid oxygen tank that supplies the hospital's needs and a distribution system. There are also many small portable units that can meet the needs of individual patients. The main oxygen distribution system has many sectionalizing valves, but it would be very time consuming to isolate sections to find a leak, as all patients would have to be transferred to portable tanks before a section could be isolated. The reduction in overall flow would have to be compared with the use in the isolated section to determine if there was a leak. There are shut off valves for gas within the hospital. Research labs and the kitchens use gas. The kitchens also have electric stoves. Emergency power for the main hospital complex is provided by a large co-generating unit located on campus. It is interesting to note that if there is a loss of the municipal water supply, the co-generating plant will have to shut down.

\subsubsection{Hyogo Medical Center}

As a result of the earthquake, a water tank on the roof of the hospital collapsed, flooding part of the hospital. As was true in many parts of Kobe, there was a loss of water and power. Because of the loss of water, the emergency generator would not operate so that the hospital lost all power and it had to be evacuated. The water to the hospital was disrupted for about two weeks.

\subsubsection{Lessons for the United States}

The loss of water supply at Kobe Medical College indicates that hospitals need to establish an emergency water use policy. Normal water use is well beyond what one could expect in resupply after a major earthquake. There is also a need to facilitate the delivery of water into the hospital water system. This requires that there be appropriate water hookups and pumps. The hookups do exist for fire service on some facilities. That is, there is an external access to a stand pipe that is fitted with a valve or check valve so that an external source can be attached to the system when the system is pressurized. As in the Loma Prieta and Northridge earthquakes, it appears that some critical facilities, such as hospitals, should have a method for quickly hooking up an external generator should the emergency power fail. The impact of the loss of gas on food preparation was also significant, as many patients requires special meal. As in the United States, the loss of elevators in a hospital is a common problem.

\subsubsection{Research Needs}

There is a need to review lifeline needs at critical facilities, such as hospitals, and establish guidelines for minimum levels of service for each lifeline. Alternative facilities and equipment that can mitigate the effect of the loss of lifeline service should be evaluated and guidance provided to facility designers. There is a need for guidelines for the distribution of special lifelines within hospitals, such as oxygen. 
There is a need to review different classes of water needs in hospitals and establish guidelines for technical and administrative procedures for controlling and reducing water use in emergency situations.

\subsubsection{Summary}

The quality of lifeline facilities and their installation, from an earthquake engineering perspective, observed in the hospital visited was very high as compared to U.S. installations. Few U.S. hospital would have a large emergency water supply as existed at Kobe Medical College. The loss of water still had a large impact on hospital operations. The loss of water disabled one generator at the hospital and also caused the loss of all emergency power at another medical facility. The 400 ton capacity water storage tank lasted only 6 hours which implies that almost 70000 tons were used per hour immediately after the earthquake. Some of this usage may have been due to a water line break shown in Figure 5.6.8. The resupply by tanker truck was at a rate of 10000 tons an hour, so that water consumption had to be significantly reduced. The dependence on gas for food preparation - was disruptive to hospital operations. The distribution of lifelines within a hospital needs review. Special services, such as the distribution of oxygen, can be disrupted, particularly when lines pass through seismic joints.

\subsubsection{Acknowledgments}

The authors wish to thank Dr. David Stevenson, Department of Pediatrics, Stanford University Hospital; Dr. Nakamura, Head Pediatrics, Medical College of University of Kobe; and Dr. Tanaka, Department of Pediatrics, for their assistance in arranging interviews with hospital personnel during the course of this study. 


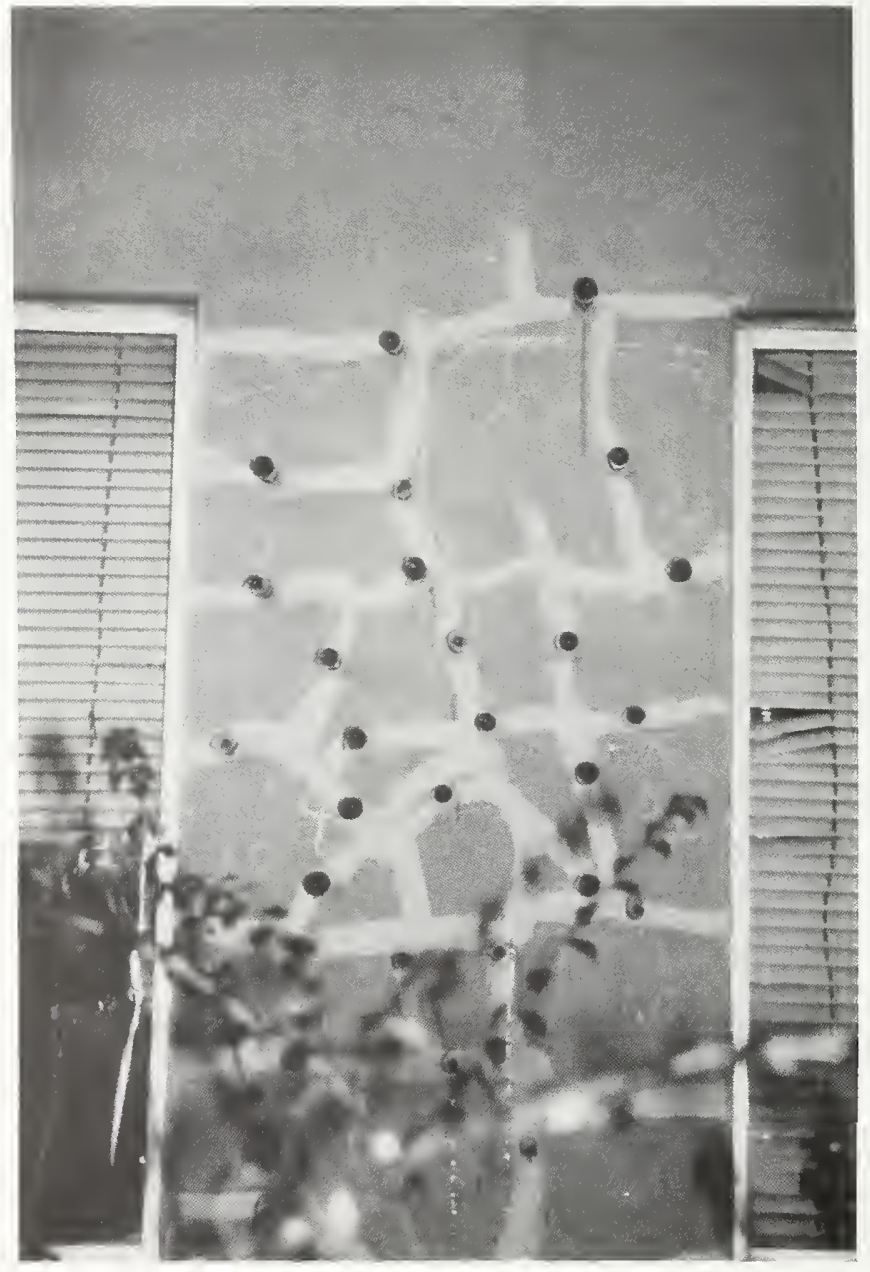

Figure 5.6.1

Column on the first floor of the old hospital being repaired with epoxy injection. 
Figure 5.6.2

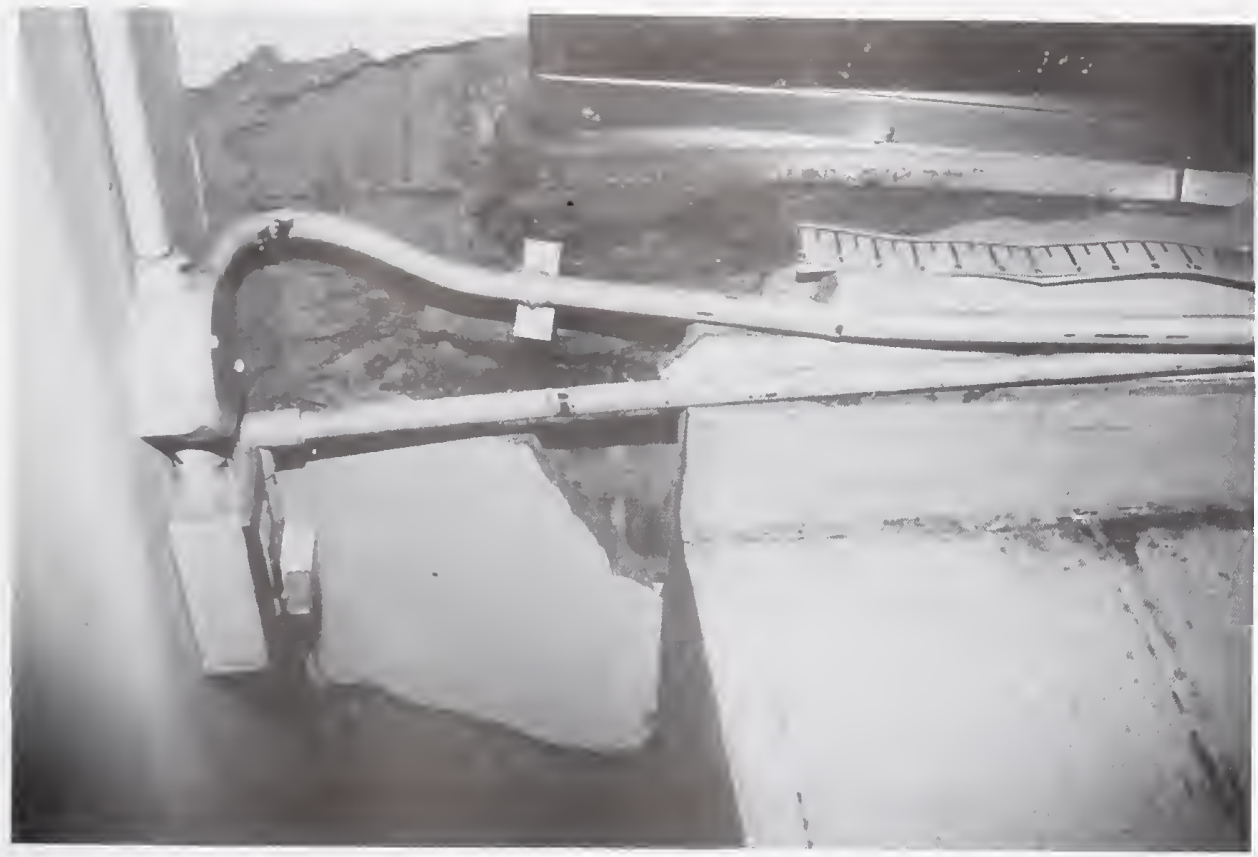

Beam shattered due to interaction between the two wings of the hospital at cross walks connecting the buildings.

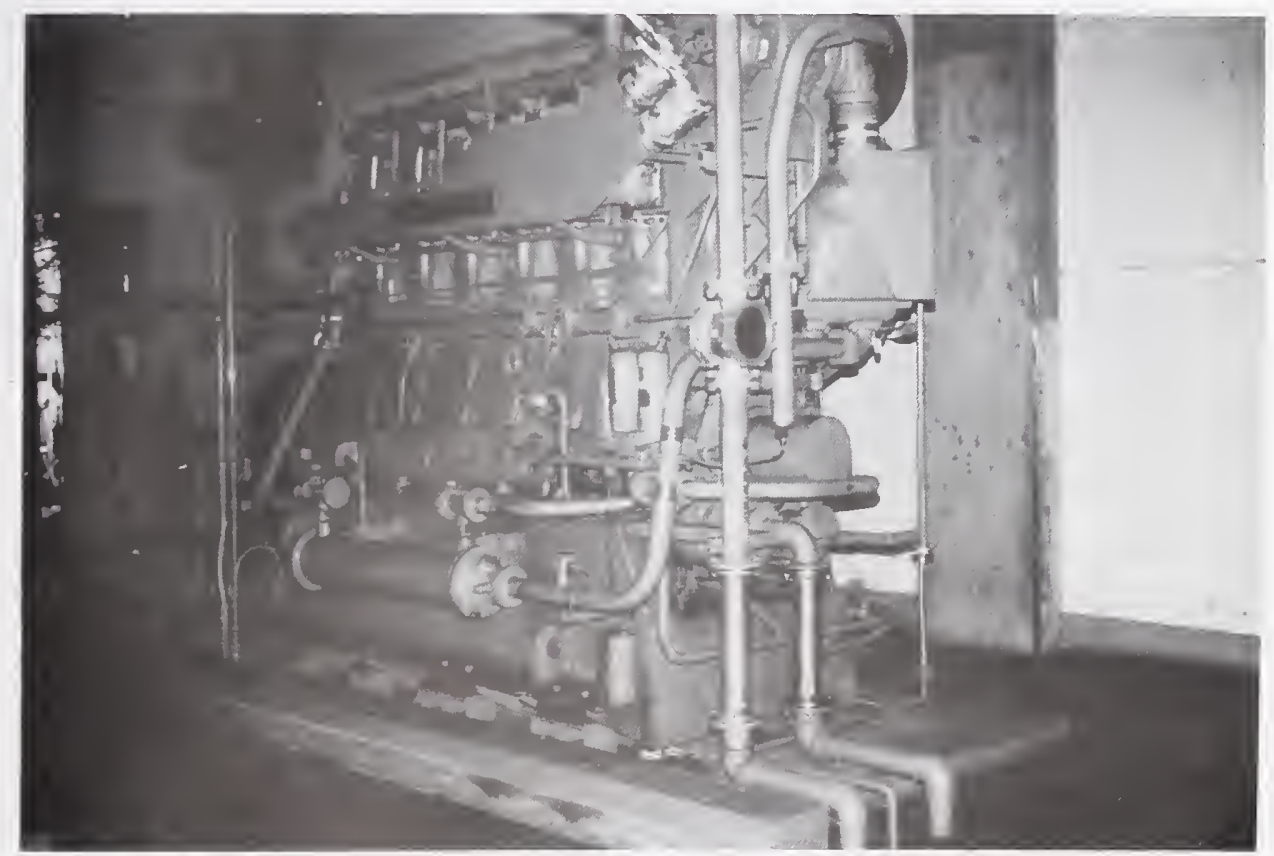

Figure 5.6.3

Engine-Generator in the new hospital wing, which has vibration isolators and flexible connections on utilities. 


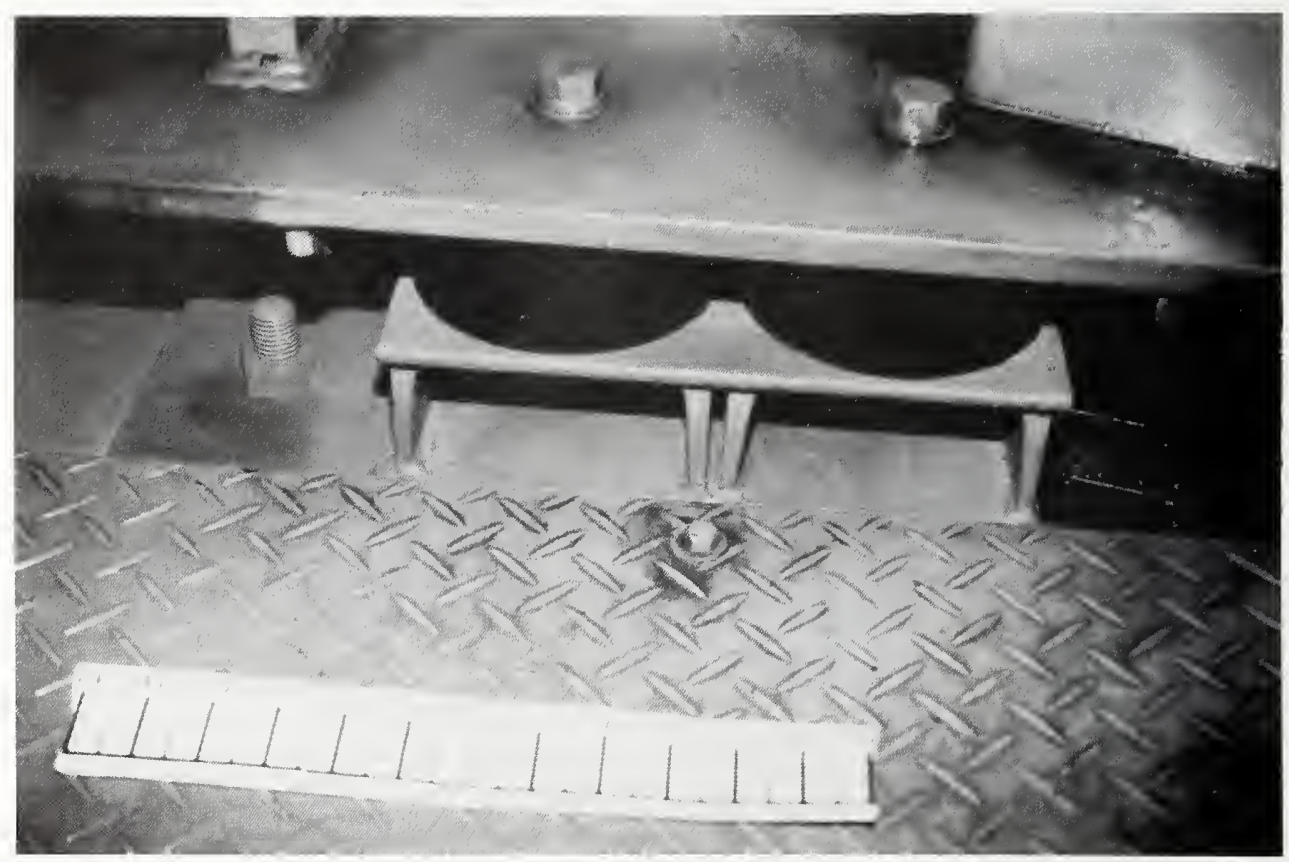

Figure 5.6.4

Detailed view of vibration isolators used on emergency power engines. 


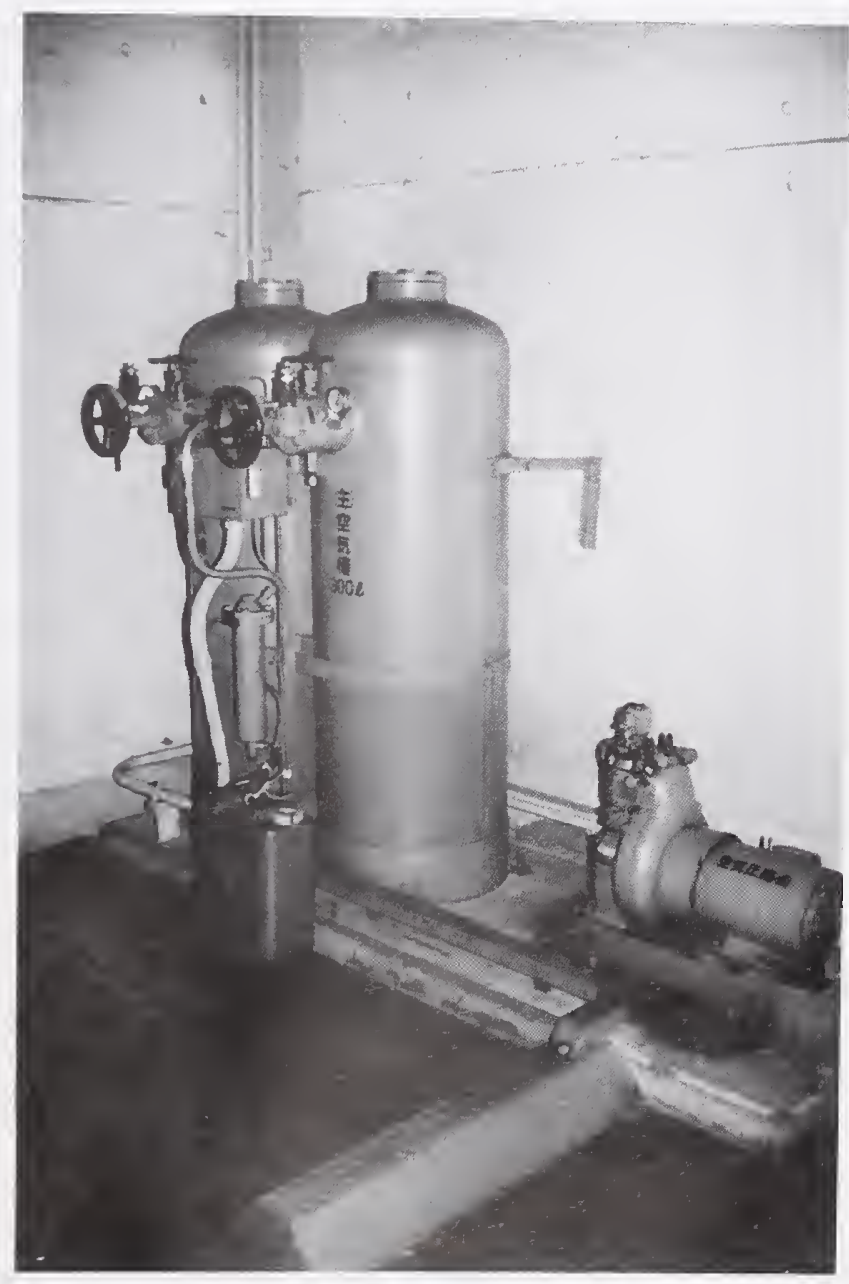

Figure 5.6.5

Compressor and air storage tanks used to start the diesel engine. 


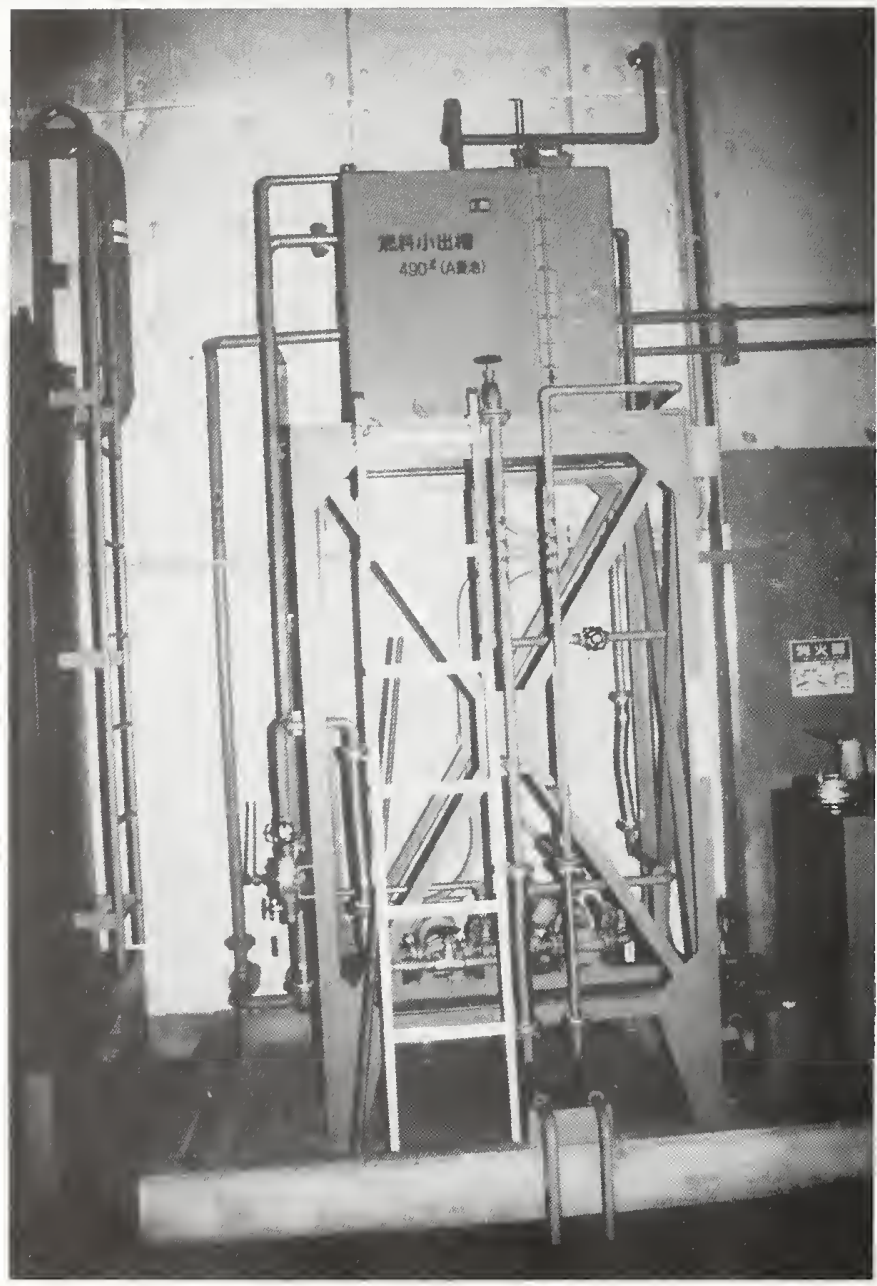

Figure 5.6.6

Day tank and pump for the fuel supply to the diesel engine. 


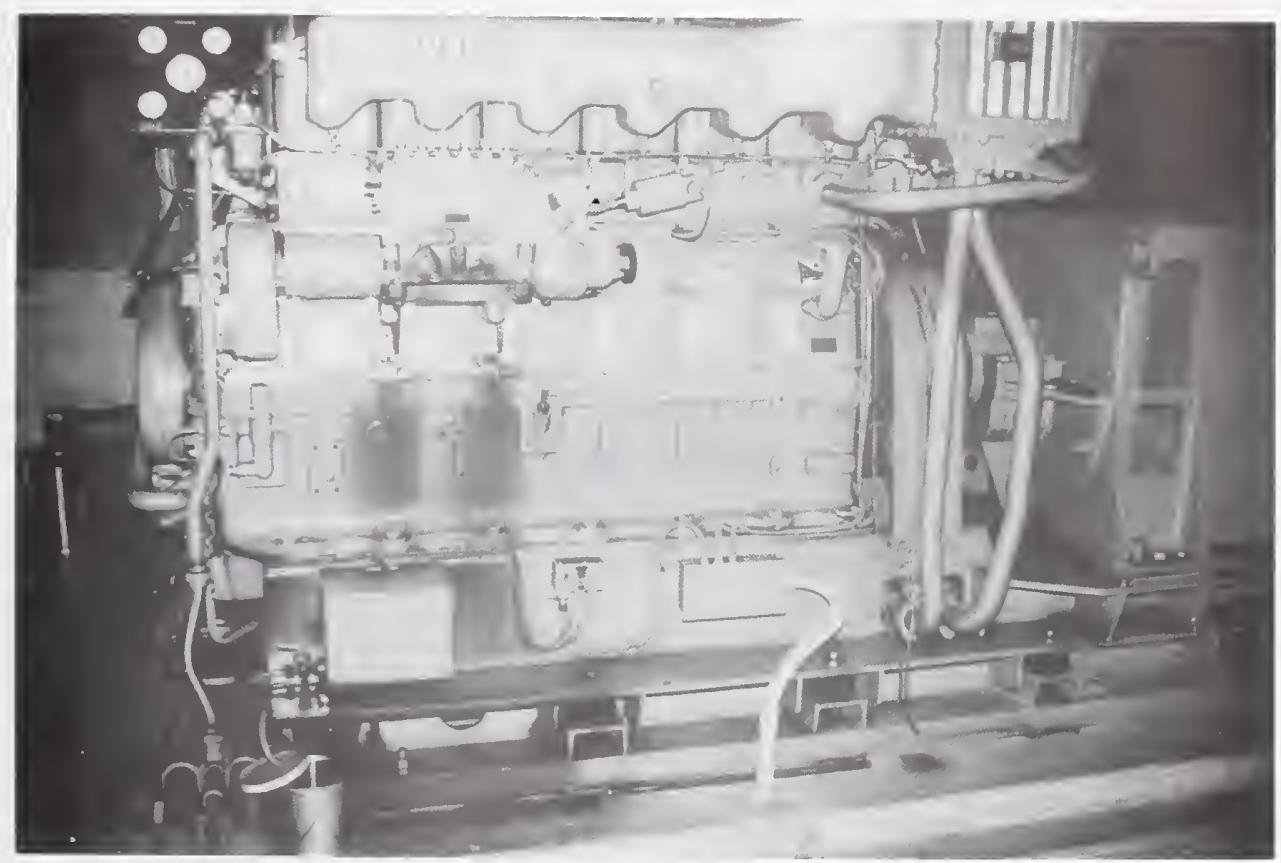

Figure 5.6.7

Diesel engine used for emergency power in the old wing of the hospital.

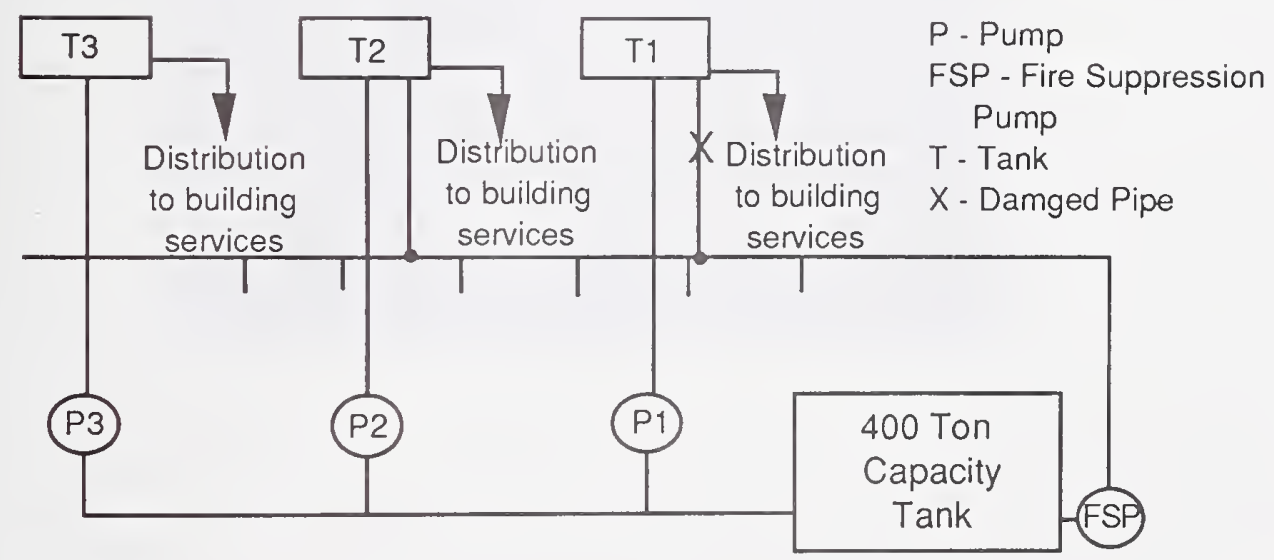

Figure 5.6.8

Schematic diagram for the Kobe Medical College water system. 


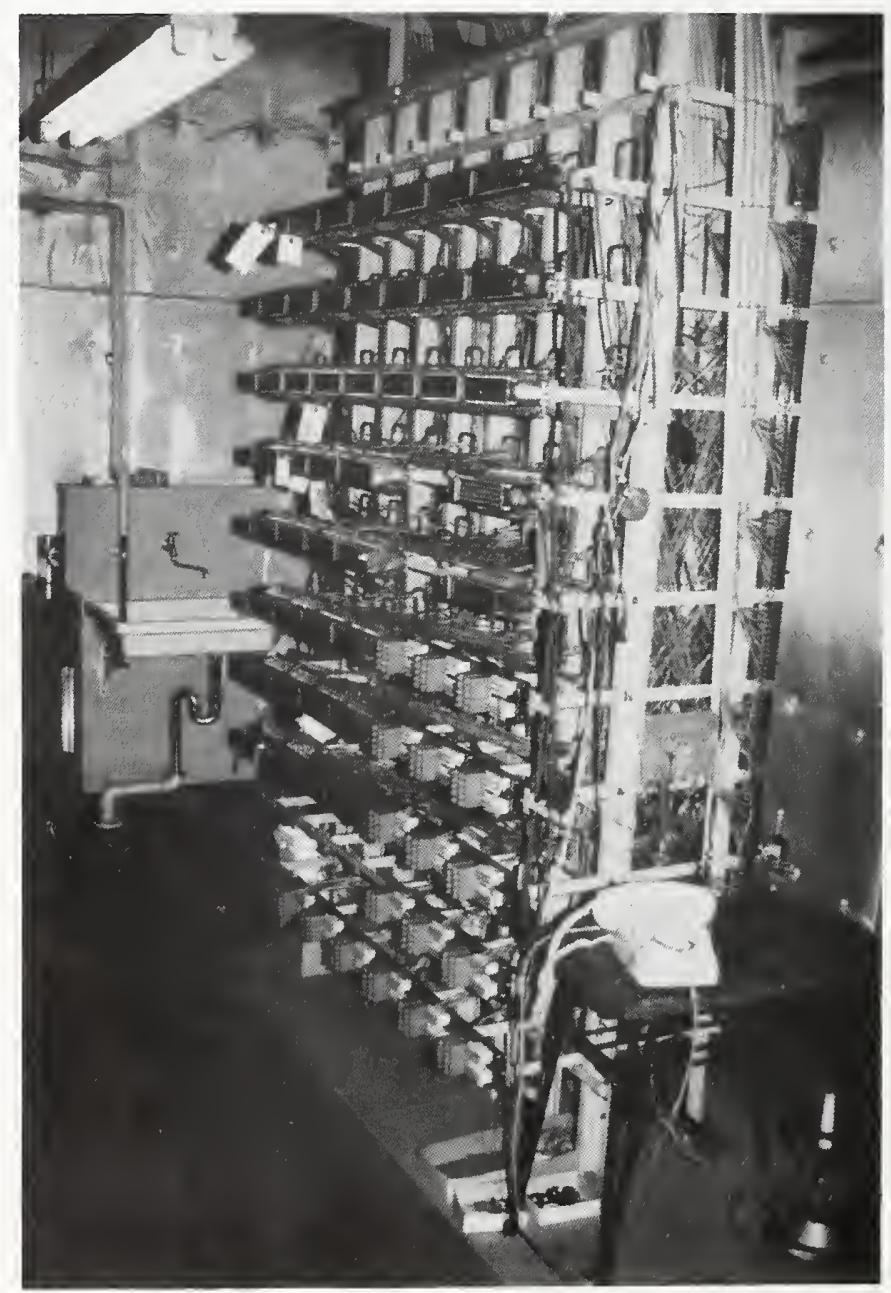

Figure 5.6.9

Main distribution frame for the hospital communication system. 


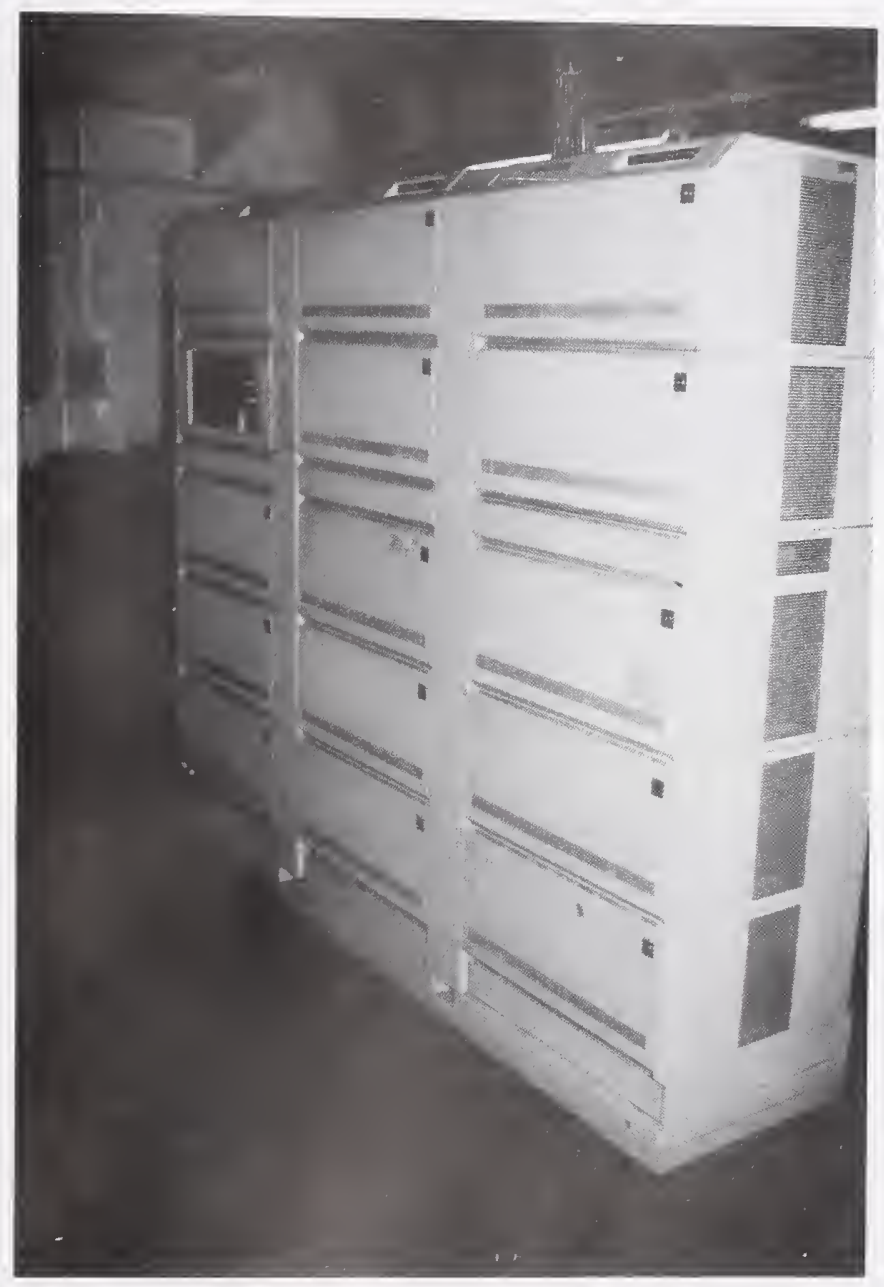

Figure 5.6.10

Part of the Private Branch Exchange (PBX)switch used by the hospital. 


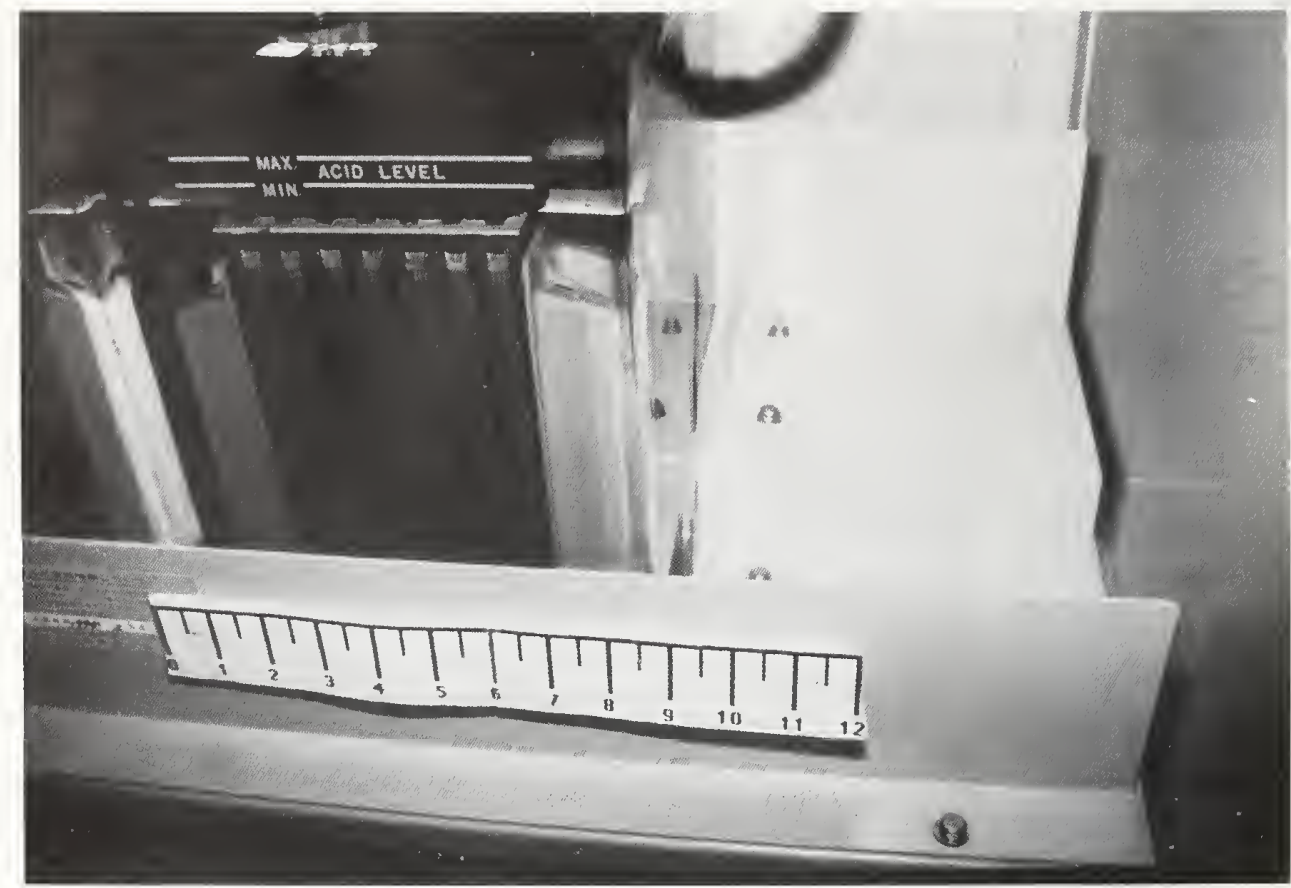

Figure 5.6.11

Battery within UPS used by the PBX. Note that cells fit snugly together, that there is a gap between the end restraint and the cell, and that the end restrain is light weight.

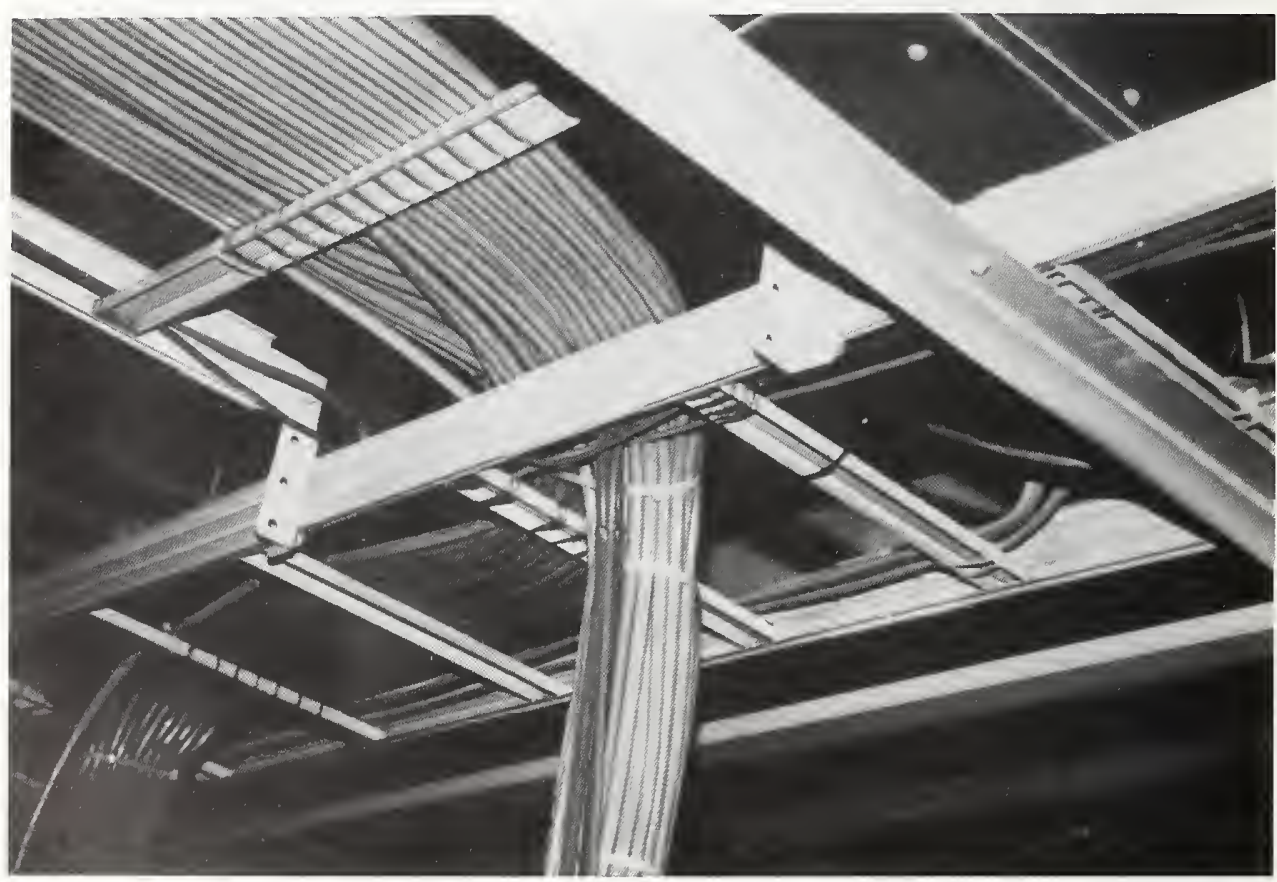

Figure 5.6.12

Cable trays used by the telecommunication system use bolted connections. 
Figure 5.6.13

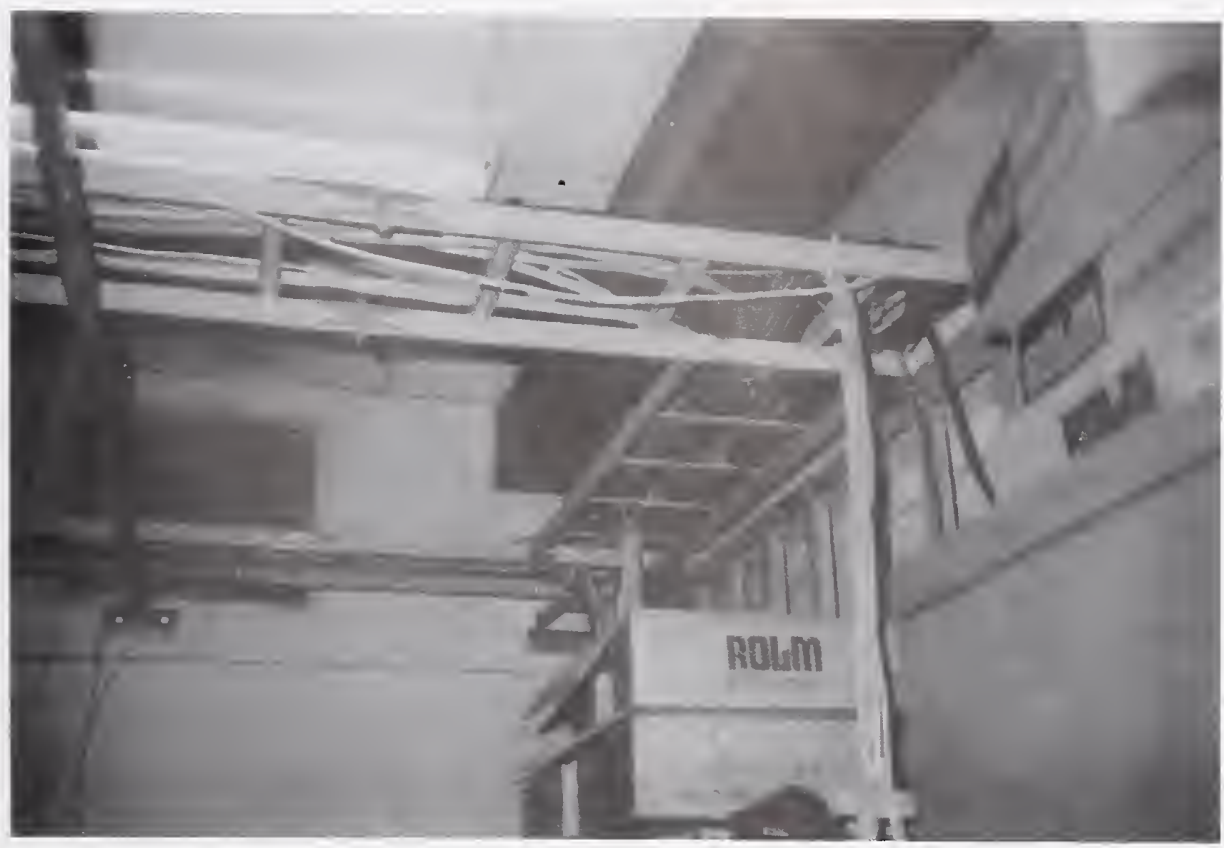

Typical, low tensile strength, friction-clip type communication cable tray hardware used to join tray sections in the U.S.

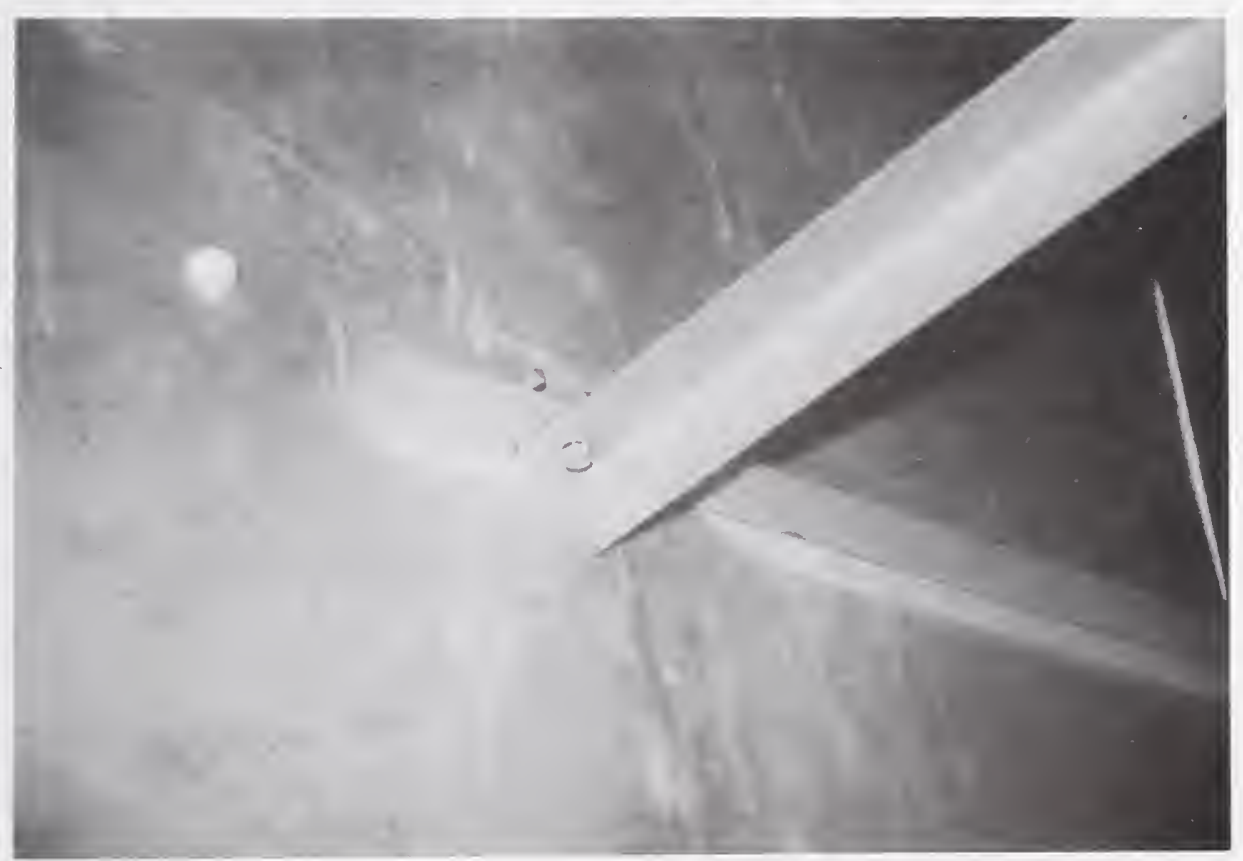

Figure 5.6.14

Bolted connections are used to anchor cable trays to structural walls. 


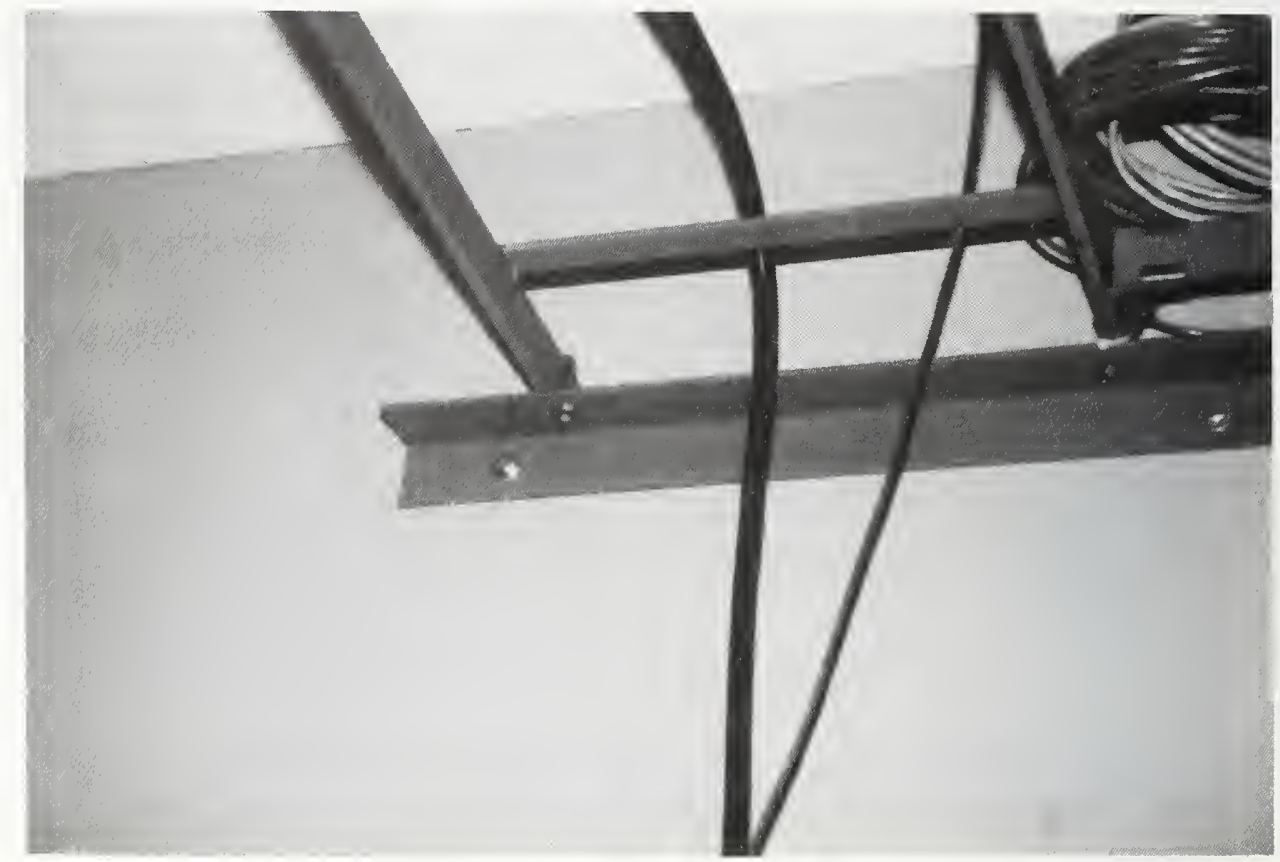

Figure 5.6.15 $\mathrm{J}$ bolts are often used to secure cable trays to walls. These type of connections have not been reliable.

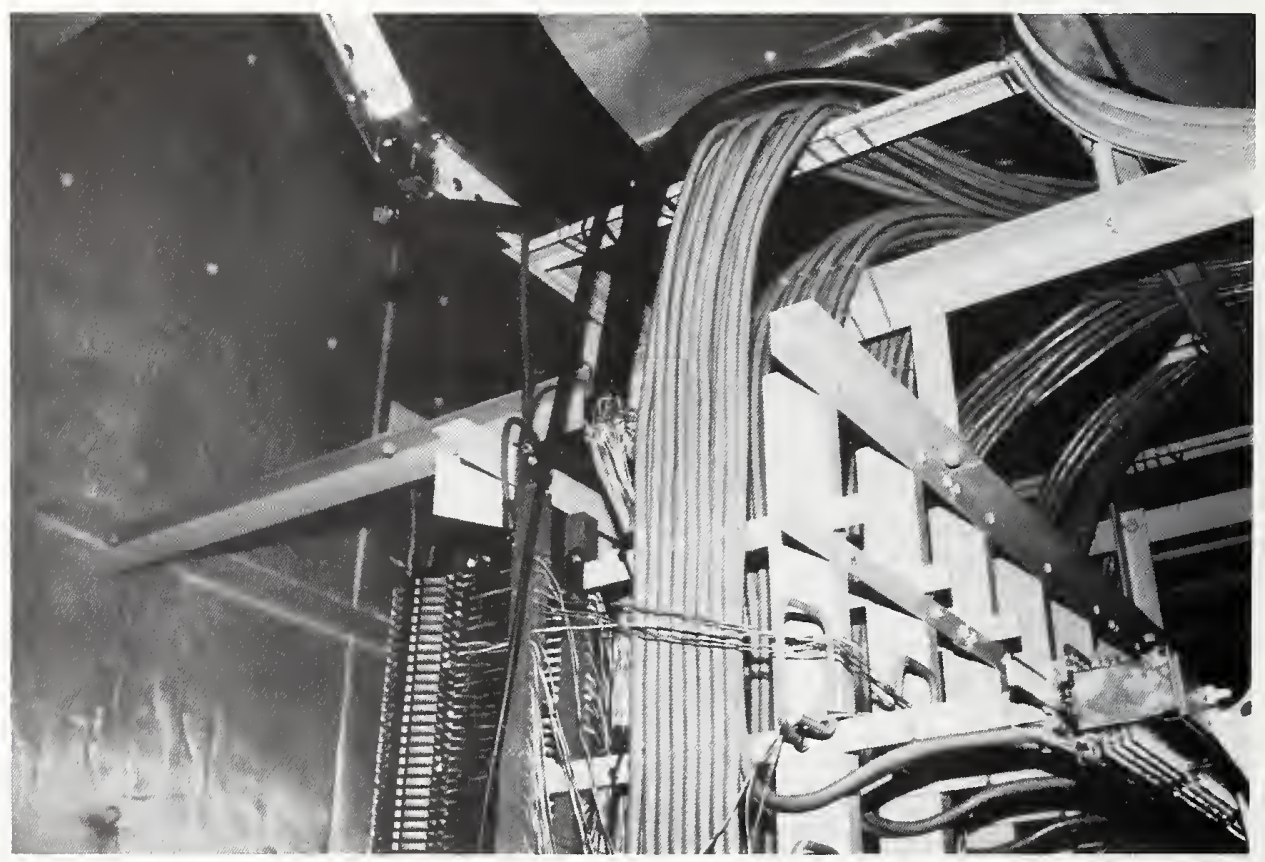

Figure 5.6.16

The main distribution frame is bolted to the cable tray to provide bracing at the top of the frame. 


\section{CHAPTER 6}

\section{POST EARTHQUAKE FIRES}

\subsection{Introduction}

As a result of the 1995 Hyogoken-Nanbu earthquake, 148 fires [1] occurred in the Kobe city area, between January 17 and 20 . Approximately $660000 \mathrm{~m}^{2}$, occupied by more than 6900 buildings, were damaged by fire. Due to the large number of simultaneous fires, disrupted water supplies and blocked roads, fire fighting efforts were largely ineffective. The fire spread was limited primarily by wide roads, open spaces, noncombustible walls, fire resistive building construction and favorable weather conditions.

This chapter examines the fire events, factors contributing to the cause and spread of the fires, the performance of fire protection systems including the response of the fire department, lessons to be learned from this disaster, and research needs. The information in this chapter is based on observations, news media coverage, and preliminary reports from the Building Research Institute of Japan [1] and the Fire Research Institute of Japan [2].

\subsection{Fire Events Following the}

\section{Earthquake}

The earthquake occurred at 5:46 am on January 17, 1995. Based on the "119" (fire department) calls for January 17, 53 separate fires were reported between the time of the earthquake, 5:46 am, and 7 a.m. Between 7 a.m. and 9 a.m. 13 additional fires were reported, bringing the total to 66. Before midnight, 42 more fires had been reported. An additional 40 fires were reported during the next 3 days, bringing the total number fires attributed to the earthquake to 148 [3]. To provide a point of reference, the Kobe City fire department responded to 812 reported fires in 1992 [4]. Therefore over a typical four day period, the Kobe City Fire Department would expect to respond to nine reported fires or approximately two per day.

Alternative water delivery systems need to be developed and utilized in large urban areas for fire suppression after an earthquake.

Typically a reported fire involves a single building or building complex. However, following the earthquake, many of the reported fires involved a large contiguous group of buildings. Figure 6.2.1 shows the number of fires reported during the 10 days after the earthquake. Only the fires from the first four days have been considered as direct results from the earthquake by the Japanese research organizations investigating the fires. The 148 fires reported over that four day period occurred in 6 of Kobe City's 9 wards (Suma, Nagata, Hyogo, Chuo, Nada and Higashinada) and in Ashiya City, Nishinomiya City, and Amagasaki City (Figure 6.2.2). Preliminary reports [1,2] indicate that approximately $660000 \mathrm{~m}^{2}$, and more than 6900 buildings, were damaged by fire. Approximately 500 deaths were caused by fire. Figure 6.2 .3 is a photograph representative of post earthquake fire damage in Kobe. 
The area which received the heaviest damage from fire was the Nagata Ward on west side of Kobe City. The fire area in Nagata accounted for almost $50 \%$ of the total area damaged by fire. Buildings in the Nagata Ward were predominantly 2 story wooden structures approximately 50 years old. The buildings were of wooden post and beam construction with wooden lathe, a thin veneer of exterior stucco and thin wood interior panels. The structures had heavy tile roofs seated on a layer of dirt. This roof design was used to resist damage by typhoons. The heavy roof along with insufficient lateral support allowed the buildings to collapse easily, resulting in a debris pile that included thin dry wood with a large exposed surface area. In addition, the Nagata area had residential, commercial, and industrial facilities, frequently intermixed in the same building. Many of the industrial occupancies were synthetic shoe factories which had highly flammable solvents and plastics. The Nagata Ward is also the most densely populated ward in Kobe City having 10985 people per square kilometer [2].

As addressed in Chapter 5, disruptions of water, gas, and electrical service proved disastrous. No water was available from the fire hydrants for fire fighting due to a severely damaged water system. Damage to the natural gas lines and damaged but energized electric lines provided fuel and ignition sources, respectively, for the fires. Kobe City's transportation network was also severely damaged by the earthquake. Many roads were damaged or blocked by debris from collapsed buildings.

Given the multiple simultaneous fires that occurred, lack of a reliable source of fire fighting water, and the difficultly in accessing the fire areas, many of the fires burned unabated until they reached a fire barrier.
Most of the Study Team's investigation focused on the perimeters of the fire areas, examining the conditions that halted the progress of the fires.

The fire investigation involved a preliminary visit, during the week of January 23, to one of the larger fire sites south of Shin Nagata Station and three smaller sites (less than one block in size) north east of Shin Nagata Station. A detailed investigation of eight of the largest fire sites took place during the week of February 13 (Table 6.2.1).

\subsubsection{Fire Causes}

Based on our observations there were several combinations of fuels and ignition sources which most likely caused the fires. Broken natural gas pipes (Figure 6.2.4) were evident at many of the fire sites. Kerosene heaters were present in the ruins of most of the buildings (Figures 6.2.5 and 6.2.6). The temperature in Kobe was $3{ }^{\circ} \mathrm{C}$ the morning of the earthquake, so it is likely that early risers had turned on the heaters to warm their homes. Customarily heaters would not be used during the night while people are sleeping. Electric power lines were

\section{Locations where the fire spread stopped were clear demonstrations of the effectiveness of passive fire protection systems.}

knocked down by the earthquake or torn from collapsed buildings creating potential arcing situations. Some electric lines were still connected to partially collapsed buildings (Figure 6.2.7). These lines may have stretched, creating a reduced cross sectional area of the wire, which could cause 
ignition of a fire due to overheating. Insulation may have pulled away from the wires making short circuits or ground faults more likely. The majority of the fire damage occurred in areas of predominantly wooden construction which provided fuels to sustain and spread fires which ignited.

Of the 148 fires, 88 fires were reported more than 3 hours after the earthquake occurred. Although there may have been some slow growing fires that initially were not reported, a significant number of fires started well after the initial shock. These may have been fires associated with aftershocks, fires resulting from restoration of electrical power, fires associated with recovery activities, and the spread of the initial fires to create additional separate fïres. Fire spread will be covered in more detail in the next section, however it should be noted that fire spread was slow due to favorable weather conditions. According to Dr. Murosaki of Kobe University, ignitions due to power restoration were prevalent [5]. Many damaged homes had a serviceable electric power connection following the earthquake. When electric power was restored, damaged appliances, wiring, and light fixtures ignited combustibles. This is supported in part by data from the Kansai Electric Power Company [6]. The power company had reduced the number of customers without electricity from 1 million just after the earthquake to 420000 by the evening of the 17th (Figure 6.2.8). Then there was an increase in the number of customers without electric power from 420000 to 500000 during the evening of the 17 th. The rate at which the customers' service was restored occurred at a much reduced rate until most of the fires were out on the 18 th. The reason for the increase in the number of customers without power has been attributed to the fires that developed during the evening of the 17 th. Dr.
Murosaki and his students had examined 69 of the 148 fire sites at the time of our investigation. At that time, Dr. Murosaki indicated that about $25 \%$ of those fires were caused by restoration of electricity.

Other potential sources of the fires which occurred later in the day on the 17 th and during the 18th and 19th could have been candles used in search and rescue efforts or in shrines to commemorate people who had been lost to the earthquake; fires for warming displaced survivors, which had gotten out of control; and suspected arson.

Table 6.2.2 provides a breakdown of the number and the size of the fire sites for the day of the earthquake [3]. The number of fires shown in the table is the total number of fires in a given size range from the time of the earthquake until the time shown in the upper column. Note that the majority of the fires that occurred after 7 a.m. were relatively small fires. In other words, fires no larger than the size of a small apartment building.

\subsubsection{Fire Spread}

Three primary means of fire spread in conflagrations are (a) flame spread over a continuous fuel surface or array, i.e., direct flame impingement on the fuel, (b) ignition of adjacent fuel by thermal radiation from flames and (c) spot ignitions started down wind of the main fire by burning brands and embers. In this disaster, the primary mechanism of fire spread was direct flame impingement.

For fire to spread by flame impingement, the flames must be in contact with unburned fuel, i.e, the fire can only spread along a continuous fuel chain. In the earthquake damaged areas continuous fuel chains were prevalent. Rubblized structures are a good 
example (Figure 6.2.9). The structures collapsed leaving combustible debris next to adjacent structures. In some cases the structures collapsed across streets providing a path for the fire spread from one block to another (Figure 6.2.10). In several of the fire areas, markings and residue could be seen across streets where the fire had spread from one side to another.

Wire glass exterior windows appeared to be effective in reducing the fire spread. These windows with small gauge wire are common in Japan but are rare in the United States.

For fire to spread solely due to thermal radiation, the "source fire" must be intense enough to heat the target fuel, which is remote from the fire, to its spontaneous ignition temperature. The spontaneous ignition temperature for many organic materials is approximateiy $600{ }^{\circ} \mathrm{C}$ [7]. In laboratory tests with arrays of wooden sticks, it has been demonstrated that reducing the open area between sticks can reduce the heat release rate significantly [8]. Similarly due to under-ventilated conditions, the heat release rate of a collapsed wooden structure is less than that of the structure prior to collapse due to under ventilated conditions. The reduced "source fire" intensities of the collapsed structures minimized the flame spread by radiation and by fire brands.

For fire to spread due to burning brands or embers, brands must be lofted into the air by the fire, blown by the wind, and land on unburned fuel. If the brands or embers are hot enough when they land on the fuel to provide ignition, the fire spreads. The average wind velocity during the 3 days following the earthquake was low; $2.6 \mathrm{~m} / \mathrm{s}$ on the $17 \mathrm{th}, 3.6 \mathrm{~m} / \mathrm{s}$ on the 18 th and $3 \mathrm{~m} / \mathrm{s}$ on the 19th $[3,9]$. Experience and predictions of fire conflagrations indicate that at wind speeds above $9 \mathrm{~m} / \mathrm{s}$ the fire spread and associated loss will increase dramatically [10]. This is due primarily to flame extension, increased burning rate, and wind aided transport of burning brands. The temperature ranged from a low of $0^{\circ} \mathrm{C}$ to a high of $8{ }^{\circ} \mathrm{C}$ over the 3 day period. The relative humidity stayed between $45 \%$ and $70 \%$ between the 17 th and the 19 th. The calm, cool and relatively moist conditions are not as conducive to fire spread as windy, hot and dry conditions.

Automobiles were identified by Murosaki [5] as a mechanism for fire spread. Burnt automobiles were seen in narrow alleys between burnt structures. The automobiles, serving as a source of fuel, spread fire from one building to the other. Parking areas with burnt cars were also observed (Figure 6.2.11). Without the fuel provided by the autos, the parking areas would have acted as fire breaks (Figure 6.2.12).

In summary, the intensity of the fires was reduced since a large number of the combustible buildings in the fire area were collapsed and the flame spread was not wind driven due to favorable weather conditions. Since direct flame impingement was the primary source of flame spread, with minor contributions from the other flame spread mechanisms, the spread of the fires was relatively slow.

\subsubsection{Performance of Fire Protection Systems}

There are two basic categories of fire protection systems for buildings; active and passive. Examples of active systems are automatic sprinkler systems and hose 
stations. Passive systems are features of the design of the building, such as fire resistive or noncombustible construction, compartmentation, and protection of openings.

Fire departments could be thought of as an active fire protection system for a city. Wide roadways and city blocks with only noncombustible construction acting as fire breaks could be thought of as a macro-scale passive fire protection system.

\subsubsection{Active Systems}

Active building systems were not a factor in mitigating the fires during this disaster. No active systems were present in the residential fire areas and only hose stations and stand pipes were observed in the burned out industrial/commercial areas. A few hose station systems had self contained water supplies, however the majority of suppression systems were rendered useless by a lack of water due to the broken supply piping. Even if the fire department could have supplied water to the standpipe systems of a building, many standpipe connections which had broken free of the building system were observed (Figure 6.2.12).

\subsubsection{Passive Systems}

Most of the structures involved in the postearthquake fires were old (greater than 50 years), 2-story, wooden framed, structures with a mortar exterior similar to stucco. The mortar was held in place by thin brads and the brads were widely spaced. This construction style is known as Ohkabe. While the exterior mortar covering is noncombustible, very little of it stayed in place after the earthquake. As a result, Ohkabe buildings, which did not collapse, had their wooden structure exposed (Figures 6.2.13 and 5.2.14). Solid wooden walls are difficult to ignite, however, the wood lattice and bamboo construction of these walls provided an optimized burning configuration. The exposed wood construction was well ventilated, with extensive surface area, and layered to allow re-radiation.

Some passive systems were effective in stopping the fire's spread or limiting fire damage to the exterior of the building. Gasoline stations, electric power sub stations and schools survived the earthquake and the ensuing fires quite well. The buildings all used a combination of passive fire protection systems.

Gasoline stations are required to have concrete block perimeter walls, approximately $2 \mathrm{~m}$ tall. In addition, noncombustible shielding is installed on top of the block walls. These walls are intended to protect adjacent structures from a fire at the gasoline station. In this disaster, the walls protected the gasoline stations from the adjacent buildings which were on fire. In one case, an entire city block was destroyed with the exception of the corner gasoline station (Figures 6.2.15 and 6.2.16).

Electric power substations also had perimeter walls which served to prevent fire from encroaching on the building. Typically the walls were $2 \mathrm{~m}$ or less in height. In some cases, there was very little space $(1 \mathrm{~m}$ or less) between the walls and the buildings and the fire impinged on the side of the building burning the paint. However, the buildings' exterior walls were made of concrete and had no windows, so even though flame impinged on the exterior walls, the buildings did not ignite (Figure 6.2.17).

School buildings also had perimeter walls. But unlike the "bunker style" construction of the power stations, the schools had many unprotected openings, such as large windows 
and doorways. The schools, however, had open spaces around the buildings serving as playgrounds, soccer fields, etc. These spaces in conjunction with the perimeter walls served to prevent fire spread.

Many buildings with non-combustible exteriors were destroyed by fire because they were surrounded by burning buildings and the flames penetrated openings such as windows (Figure 6.2.18). Other buildings with noncombustible exteriors had burn patterns from flame impingement on them but the buildings were saved because they had windows that remained in place (Figures 6.2.19 and 6.2.20). The difference was wired glass in the windows. The wired glass would crack from the heat of the flame but the wire would keep the glass in place and not allow the flame to penetrate to the inside of the building. Steel shutters were another example of successful window and door protection which was observed.

On a larger scale, clusters or groups of fire resistive buildings, with noncombustible exteriors, served to prevent the spread of fire. If the fire resistive buildings were surrounded by combustible structures, a fire starting in the combustible structures would burn around and in some cases through the fire resistive building. In areas where there were adjacent fire resistive buildings, only those buildings next to the burning combustible structures were effected. Fire spread from one fire resistive building to another was not evident.

\subsubsection{Fire Service}

The Kobe City Fire Bureau has 27 stations with approximately 1300 personnel. The department is well equipped with more than 200 vehicles, including pumper/rescue trucks, aerial ladder trucks, lighting trucks, rescue trucks, ambulances, fire boats and helicopters. The department also has a volunteer corp with approximately 4000 members [4]. Kobe City had made significant preparation for a loss of their fire hydrant system by constructing 971 water cisterns across Kobe City for fire fighting use, of which 628 of the cisterns were reinforced to withstand earthquakes. The cisterns ranged in size from 10000 to 40000 liters. A photograph of a modern, conspicuous, seismically reinforced fire fighting water cistern connection is shown in Figure 6.2.21.

The damage caused by the earthquake alone would have overwhelmed the rescue capacity of any modern, well equipped and well trained fire department. The outbreak of fires across the city compounded this problem. As a result, the fire service had very limited success in containing or suppressing the fires. The difficulties the Kobe Fire City Fire Bureau faced were: (a) multiple fires at one time, (b) limited water supply, (c) limited access to fire sites, (d) priority on rescue efforts and (e) earthquake damage affecting the fire stations and fire fighters.

Immediately following the earthquake, 53 fires were reported. On average this was almost two fires per fire station.

Unfortunately, the fires were not uniformly distributed across the city. The fires were concentrated on the east and west sides of Kobe City. Many of these initial fires were fed by natural gas and they grew quickly. No fire department is prepared to immediately handle that number of major fire incidents simultaneously.

After arriving at the fire scene, fire fighters found the pressure from many of the fire hydrants to be inadequate. In some cases, the fire fighting cisterns were utilized. In the older sections of town, where the fire 
damage was the most severe, most of the cisterns were of the old design (unreinforced masonry) and were not designed to withstand an earthquake (Figure 6.2.22). For example, of the 92 fire fighting water cisterns in the Nagata Ward only 23 were seismically reinforced. Given the extent of the ground motion, it is likely that many of the older cisterns were damaged and lost their water.

Many fire fighters had difficulty reaching the fire sites due to collapsed buildings and debris blocking the roadways (Figure 6.2.23 to 6.2.25). With the main highways through Kobe City heavily damaged, traffic jammed the remaining roads and pedestrians looking for refuge or searching for relatives added to the congested streets. Given that many of the fire hydrant connections and cisterns are accessed via metal plates in the streets (Figure 6.2.26) and sidewalks it is likely that many of the cisterns were inaccessible due to collapsed structures and debris. The city is divided into north and south portions by the JR rail line. Several of the train line overpasses collapsed, thus limiting movement north and south (Figure 6.2.24).

The fire apparatus in Japan are small in order to navigate the narrow streets. This limits the amount of water the trucks can carry. Based on conversations with fire fighters, the pumpers only carry approximately 8001 of water. Since Kobe City had no water tankers, pumpers had to be used to transport water. Given the congestion and debris on the roads this was an extremely slow and difficult process. Scawthorn [11] indicates that during a fly over of the fire areas, on the 17 th at approximately 5 p.m., "No fire streams were observed, and all the fires were burning freely..."

With many people trapped in buildings, rescue had priority over fire suppression efforts. Experience has shown that the chances of surviving are highest during the first 24 hours (Figure 6.2.27) [12]. Many of the collapsed building which were occupied at the time of the earthquake were two story wood frame homes with heavy tile roofs. Rescues from this type of structure did not require the use of specialized tools or extrication equipment to reach many of the people trapped in their homes. These types of buildings are often the most "survivable" type since they have a large number of void spaces where victims can be trapped, yet still be viable. These are rescue situations where the general public could be effective in providing rescues since heavy equipment is not required. While some rescues were performed by untrained residents, some level of information and training could make rescues by the general public more effective and wide spread.

The Kobe City Fire Bureau was affected by the earthquake, as was everyone within the impacted area. At one of the fire stations we observed that the building had been damaged by the earthquake and that the metal doors for the two apparatus bays were cut out with a welding torch (Figure 6.2.28). It is not known to what extent this affected that station's response but there was clearly a delay. Fire service personnel who were not at the stations at the time of the earthquake may have suffered losses at their homes and disruptions in public transportation which may have prevented them from responding to the emergency. Researchers have developed models $[13,14]$ which can be used to optimize post earthquake fire fighting efforts. The models predict simultaneous ignitions and the rate at which the fires are spreading and compare them with fire department response times and suppression effectiveness. These models are beneficial for pre-planning 
exercises. They were not applicable to this incident, because they assume that the fire department can access the fire site and that water for fire fighting will be available. In Kobe, accessibility and water were the exception.

\subsubsection{Resident Self-help}

Disasters of the magnitude of a major earthquake followed by large fires overwhelm the capabilities of fire departments and public service rescue organizations. In cases such as these resident self-help needs to be part of the disaster response. After the earthquake, there were many cases where residents were quite effective in stopping the spread of fire. The residents formed bucket brigades bringing water from rivers and school swimming pools. In one incident, residents protected a kerosene storage facility in their neighborhood by removing debris which fell next to the kerosene warehouse and holding a fire line with buckets of water.

In another instance, a father and son protected their house while the collapsed structure next to their home burned to the ground. The fire in their neighborhood started mid afternoon on the day of the earthquake. The fire continued to burn for the next 3 days damaging several city blocks. The house which was saved had a perimeter wall, but it was less than $1 \mathrm{~m}$ from the house on the side exposed to the fire. The father and son kept dumping water, from buckets filled in the river two blocks away, on the fire side of the wall to keep the fire from spreading to their home. It appeared the fire would overrun the families efforts, when flame impinged on the second story of the home cracking the wired glass windows and burning the plastic eave troughs and down spouts. Fortunately, the wind shifted the fire away from the house allowing the residents to apply more water to the boundary area near the house and save their home from destruction.

\section{Information necessary for residents to prepare for post-earthquake fires needs to be developed and disseminated to the public.}

While these efforts were heroic and effective, they appeared to have little overall impact on the fires. They were only possible since the flame spread occurred at a relatively slow rate due to light winds. If the wind speed was $9 \mathrm{~m} / \mathrm{s}$ or higher, fighting the fires with buckets of water would not have been effective.

\subsection{Lessons for the United States}

Locations where the fire spread stopped were clear demonstrations of the effectiveness of passive fire protection systems. For maximum effect, the systems need to be designed on a city wide basis. A network of wide roadways would serve as fire breaks and provide ample egress and emergency access. Consideration must be given to buildings which border the egress routes and the components of the egress routes, such as bridges. The buildings should be designed to withstand earthquake forces and should be built of noncombustible materials. This concept can be thought of as creating fire resistive egress corridors for cities, with performance goals similar to those desired for means of egress in buildings.

Wired glass exterior windows appeared to be effective in reducing the fire spread. These windows with small gauge wire are common 
in Japan but are rare in the United States.

Alternative water delivery systems need to be developed and utilized. One such system might consist of caches of high volume, diesel powered (or other independent power supply), portable pumps located near natural sources of water around the city. From the pumps, networks of large diameter hose line could distribute water to portable drafting tanks or to pumpers.

Fire fighting with aircraft dropping water or Class A foam should be examined. For areas near bodies of water where scooper aircraft or helicopter buckets can be used, fast turn around time would make this option attractive. Although aircraft dropped water cannot attack interior fires it may be effective on fires in rubblized buildings. Fire fighting from the air may be a method of overcoming the problem of accessing the fires due to blocked roads.

Information necessary for residents to prepare for post-earthquake fires needs to be further developed and disseminated to the general public. Technologies to assist residents in protecting themselves and their property need to be developed and evaluated.

\subsection{Research Needs}

The following have been identified as areas for possible improvement in reducing the loss of post-earthquake fires.

(a) Limit Ignitions--Re-energization of an earthquake damaged area needs to be coordinated between the different utilities and the emergency rescue and recovery services. Work needs to be conducted on the impact of earthquakes on gas service to buildings and appliances. Prior to restoration of electrical service, techniques or instrumentation needs to be developed to assure that electricity is not restored to damaged structures or areas with natural gas leaks.

(b) Passive Fire Protection Systems-Examine current construction requirements for fire resistive buildings, especially the protection of openings such as windows and doorways. Special efforts should be taken toward materials or systems which could be retrofit to existing structures. The concepts of fire resistive egress corridors for cities should continue to be investigated.

(c) Alternative Water Supplies and Delivery Systems--Wildland fire agencies utilize a wide variety of methods to move water to the fire location. Their methods should be examined for applicability to an urban conflagration.

(d) Predictions of post-earthquake fire losses--Case studies of the fire propagation and the fire suppression activities from this earthquake could provide a basis for further post earthquake fire model development.

\subsection{Summary}

The 1995 Hyogoken-Nanbu Earthquake demonstrated the potential for significant fire damage following an earthquake even though favorable weather conditions kept fire intensities relatively low and helped to limit fire spread. New fire ignitions and spread continued for days after the 
earthquake as a result of electric power restoration and the need for open fires by earthquake survivors. The large number of simultaneous fires, disrupted water supply, rescue operations, and limited access to fire sites rendered the fire suppression activities by the fire department ineffective. City and building design, zoning, home owner selfhelp and alternative water delivery systems need to be reevaluated in areas prone to earthquakes.

\subsection{Acknowledements}

Many Japanese researchers provided us with the logistical support and guidance that enabled us to conduct this investigation. For their efforts, appreciation is extended to Dr. Hiroaki Suzuki and Mr. Ichiro Nakaya of the Building Research Institute in Tsukuba, Mr. Masatomo Yoshida of the Japan Building Laboratory in Osaka, Dr. Koichi Yokoyama and Dr. Hiroshi Sata of the Public Works Research Institute in Tsukuba and Professor Murosaki of Kobe University. We would also like to thank Dr. Takashi Kashiwagi of the Building and Fire Research Laboratory at NIST and Mr. Takashio Noto a guest researcher at NIST for their assistance in interpreting the preliminary data received from Japan.

\subsection{References}

1. Heisei 7 Hyogoken-Nanbu Earthquake Disaster Investigation Report (Preliminary Report). Ministry of Construction, Building Research Institute (Japan), February 1995

2. Urban Area Fire Investigation Report of Kobe City as a Result of the Hyogo Ken Nambu Earthquake
(Draft Report). Fire Defense Agency, Fire Research Institute (Japan), March 1995.

3. Urban Area Fire Investigation Report of Kobe City as a Result of the Hyogo Ken Nambu Earthquake (Draft Report), Appendix 7 Kobe City Fire Department Official Report. Fire Defense Agency, Fire Research Institute (Japan), March 1995.

4. Statistical Data of the Kobe City Fire Bureau. Kobe City Fire Bureau, Kobe, Japan, April 1993.

5. Personal Communication with Dr. Suzuki of FRI and Dr. Murosaki of Kobe University, 1995.

6. Earthquake Impact on Electric Facilities of the Kansai Electric Power Co., Inc. The Kansai Electric Power Co., Inc., February 2, 1995.

7. Drysdale, D.D., An Introduction to Fire Dynamics, John Wiley and Sons, New York, 1985.

8. Bryner, N.P. and Mulholland, G.W. Smoke Enissions and Burning Rates for Urban Structures. Atmospheric Environment Vol 25A, No 11. Pergamon Press, Great Britian. pp2553-2562, 1991.

9. Kobe Weather Data for January 17 and 18, 1995. Meteorological Research Institute (Japan), January, 1995.

10. "1994 Northridge Earthquake, Performance of Structures, Lifelines, and Fire Protection Systems." National Institute of Standards \& 
Technology, NIST SP862,

Gaithersburg, MD, May, 1994.

11. The Hyogoken-Nanbu Earthquake, Preliminary Reconnaissance Report, Earthquake Engineering Research Institute, February 1995.

12. Risk Factors for Injuries Due to the 1990 Earthquake in Luzon,

Philippines. Bulletin of the World Health Organization, Vol 70, 1992.
13. Sekizawa, A., Sagae, K., and Sasaki, H. A Systematic Approach for the Optimum Firefighting Operation against Multiple Fire Following a Big Earthquake. Fire Safety Science Proceeding of the Second International Symposium, pp 423432.

14. Eidinger, J.M., Dong, W., Fire Following Earthquake in Development of a Standardized Earthquake Loss Estimation Methodology, prepared for National Institute of Building Sciences by RMS Inc., February 1995. 
Table 6.2.1

Fire Sites Investigated by the UJNR Fire Team

Site

No.

1

2

3

4

5

6

7

8
City

Location

Sugawara Market Area

Kobe, Nagata Ward

Kobe, Nagata Ward

Kobe, Nagata/Suma Wards

Kobe, Suma Ward

Kobe, Nagata Ward

Kobe, Nada Ward

Kobe, Nada Ward

Kobe, Nada Ward

Shin Nagata Station, South

Mizukasa West Park

Chitose Small Park

Shikanashita, Block 3

Rkko, Block 1\&2
Burned

Area

$\left(\mathbf{m}^{2}\right)$

74,043

39,570

106,241

1164

15,542

179

Takahashi Hospital Area

68,850

825

Oishiminami, Block $2 \& 3$

2,456

24

2,398

41

19,940

221 
Table 6.2 .2

Number and Size of Fires on the Day of the Earthquake.

Fire Area

Less than $1,000 \mathrm{~m}^{2}$

Greater than $1,000 \mathrm{~m}^{2}$,

Less than $10,000 \mathrm{~m}^{2}$

Greater than $10,000 \mathrm{~m}^{2}$
January 17 th, 7 am

23

20

10
January 17 th, midnight

60

31

14 


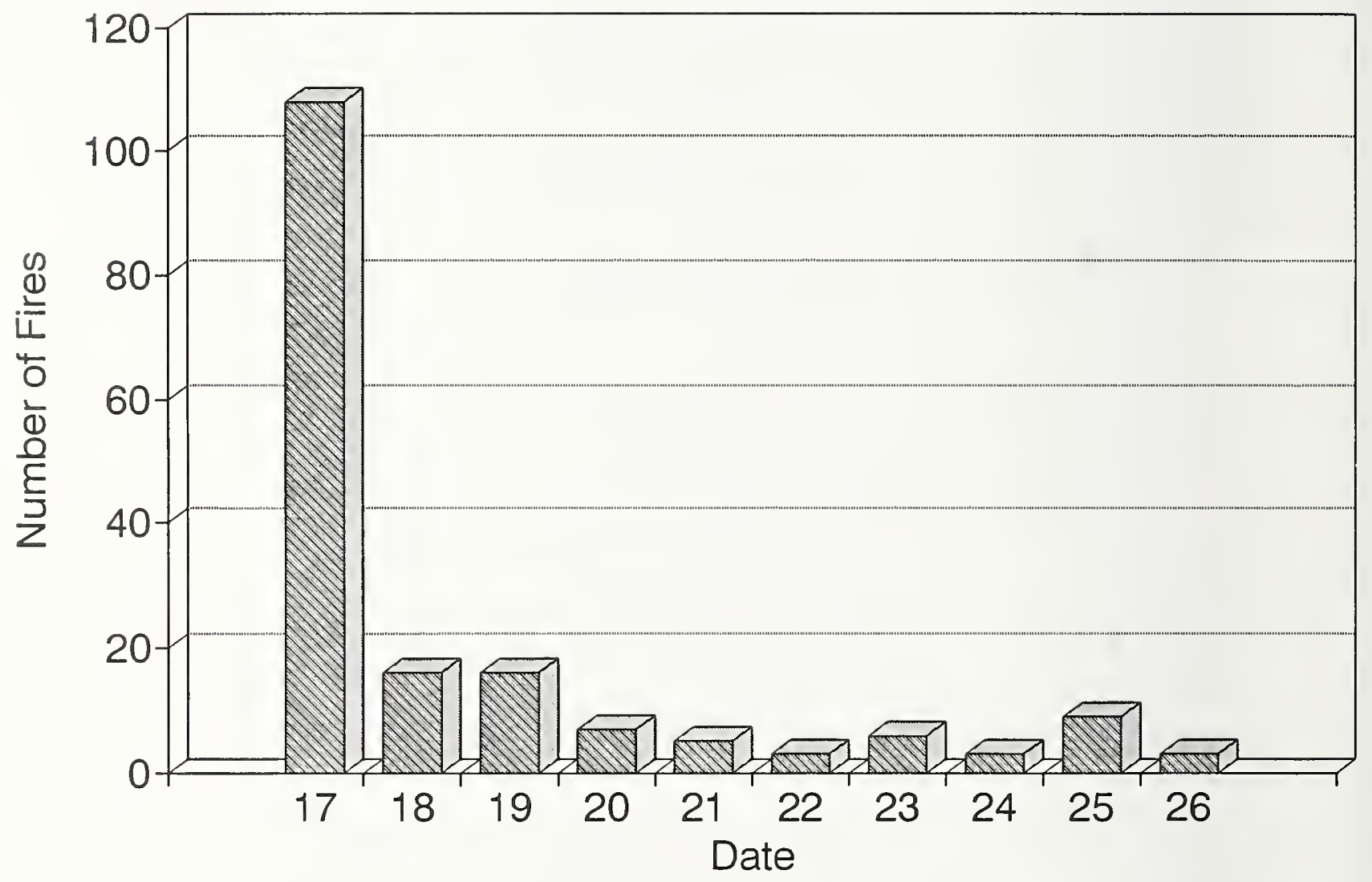

Figure 6.2.1 Post-earthquake fire occurrences

(January 17 through January 26, 1995). 


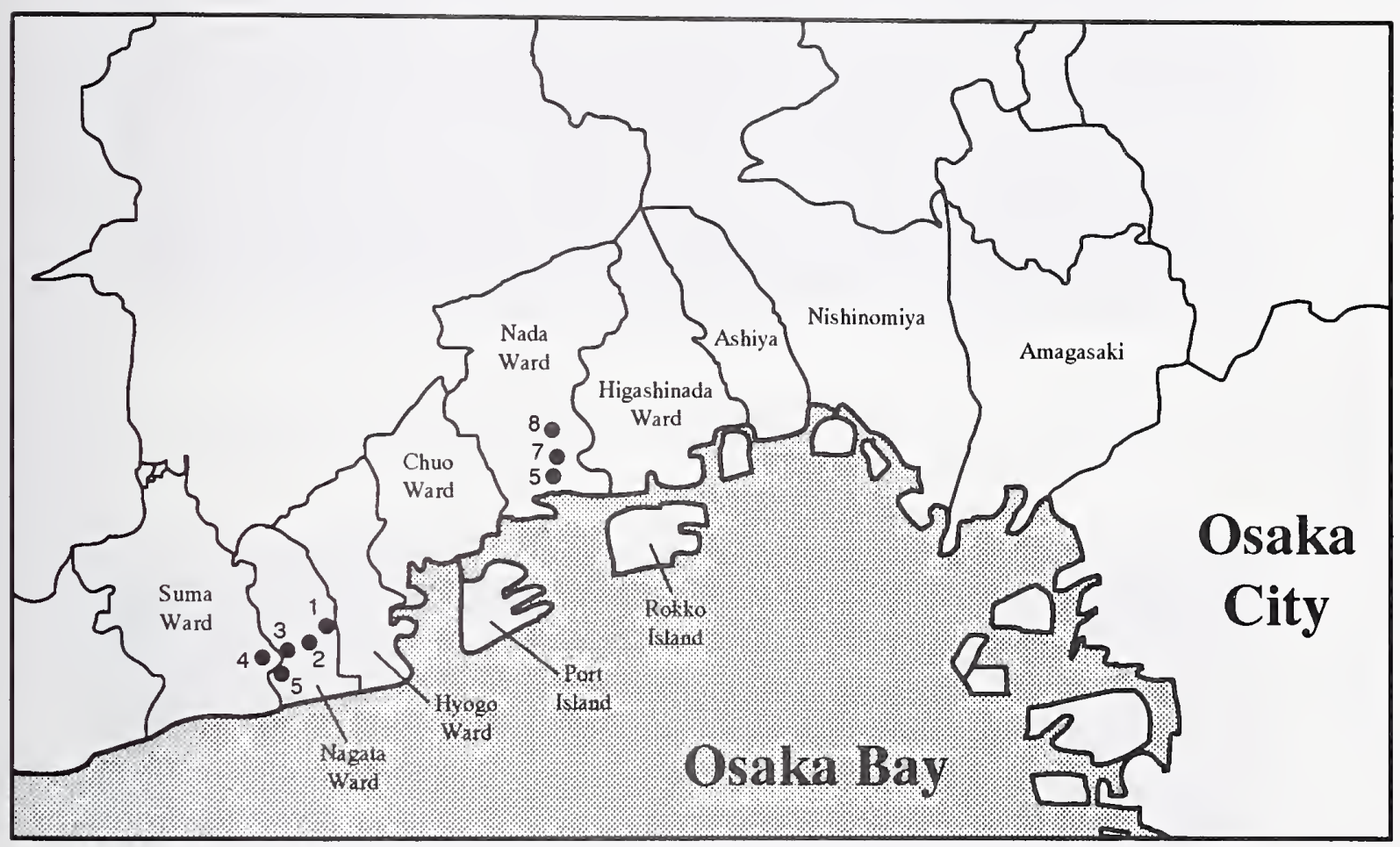

Figure 6.2.2 Kobe City map showing UJNR fire investigation sites. 


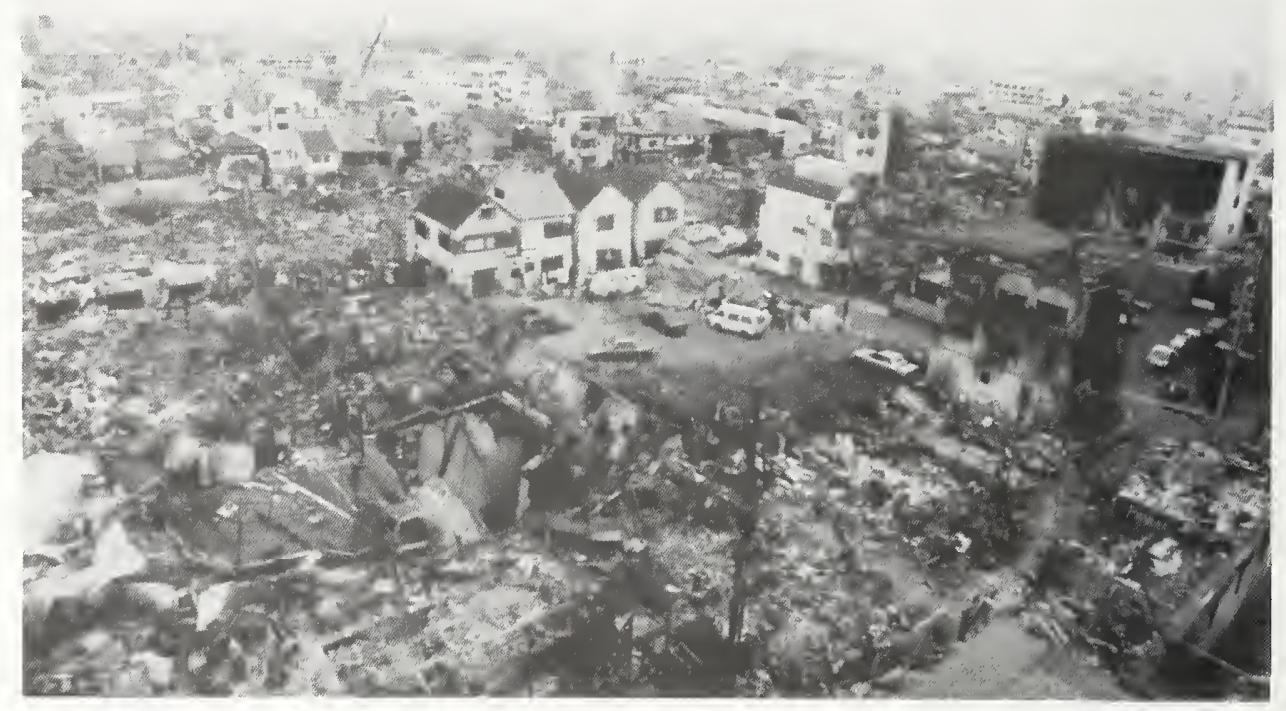

Figure 6.2.3 View of post earthquake fire damage in Nada Ward, Kobe (Site No. 8).

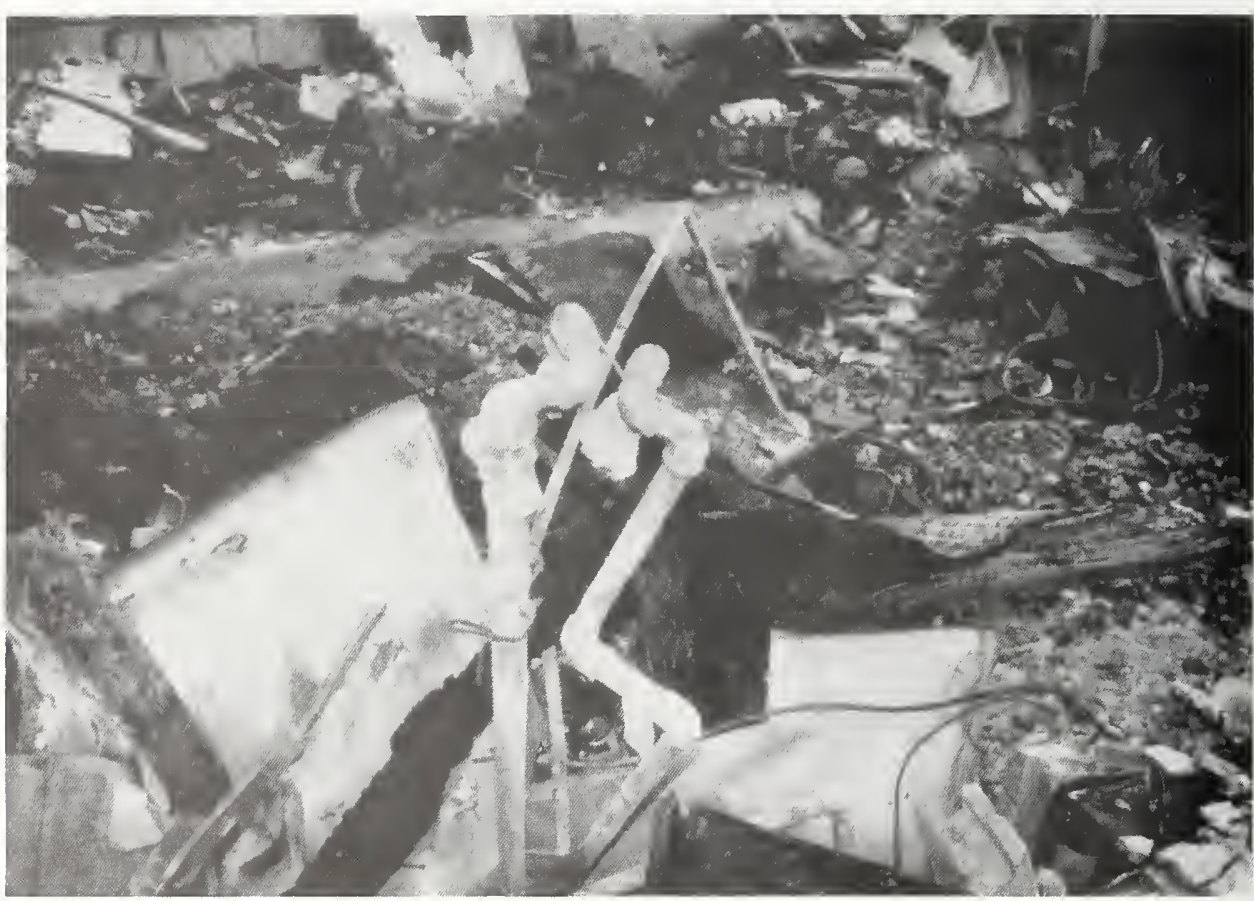

Figure 6.2.4 Broken gas meter connection. 


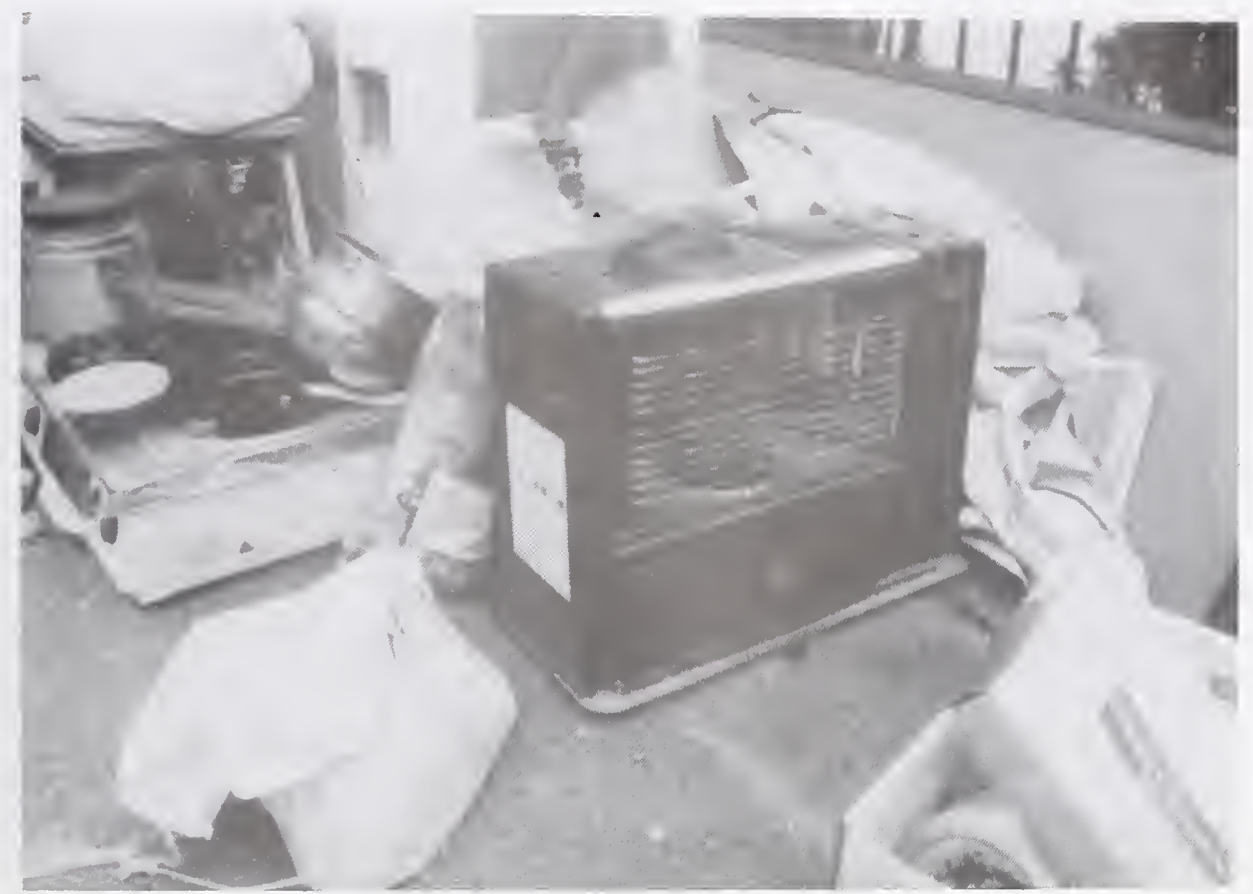

Figure 6.2.5 Kerosene heater representative of those found in and around many of the businesses and residences.

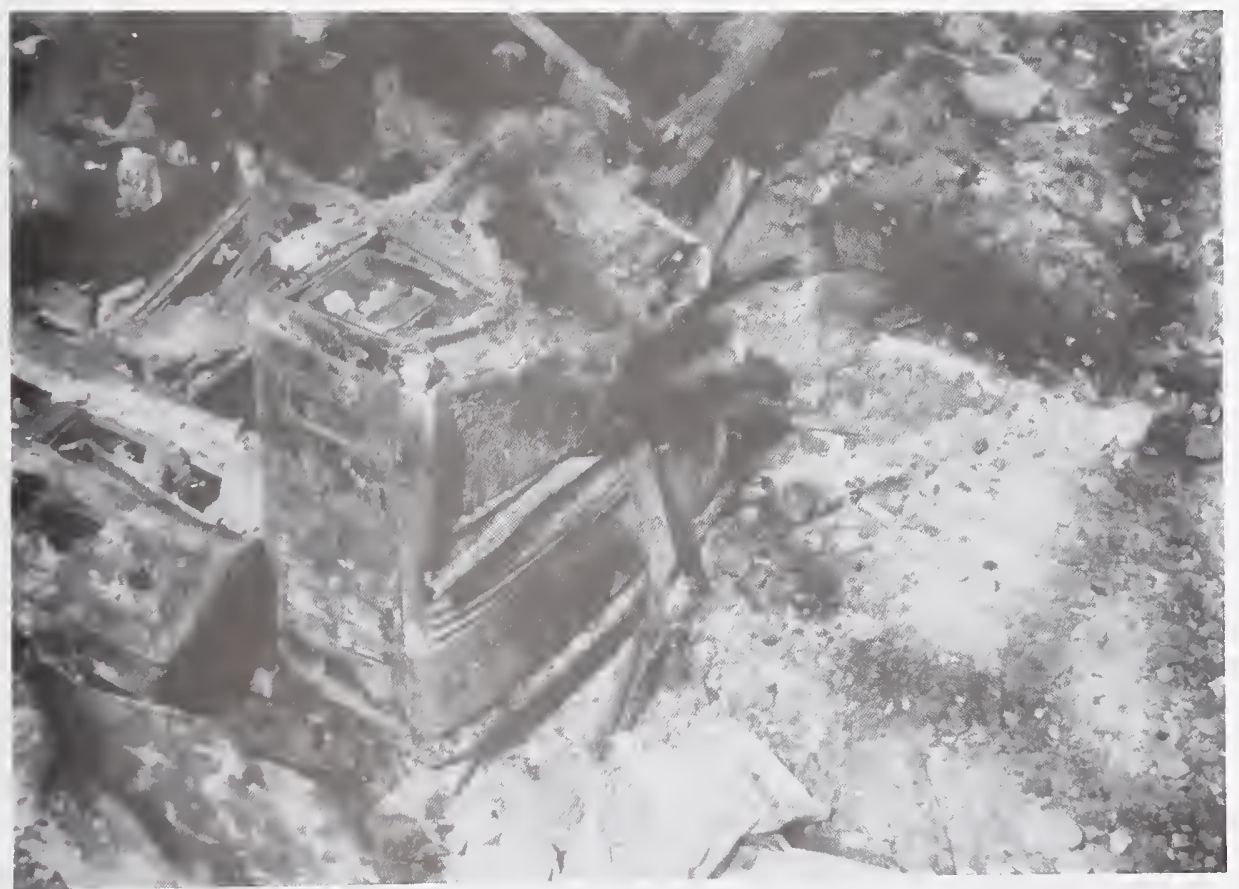

Figure 6.2.6 Kerosene heater representative of those found at many of the fire sites. 


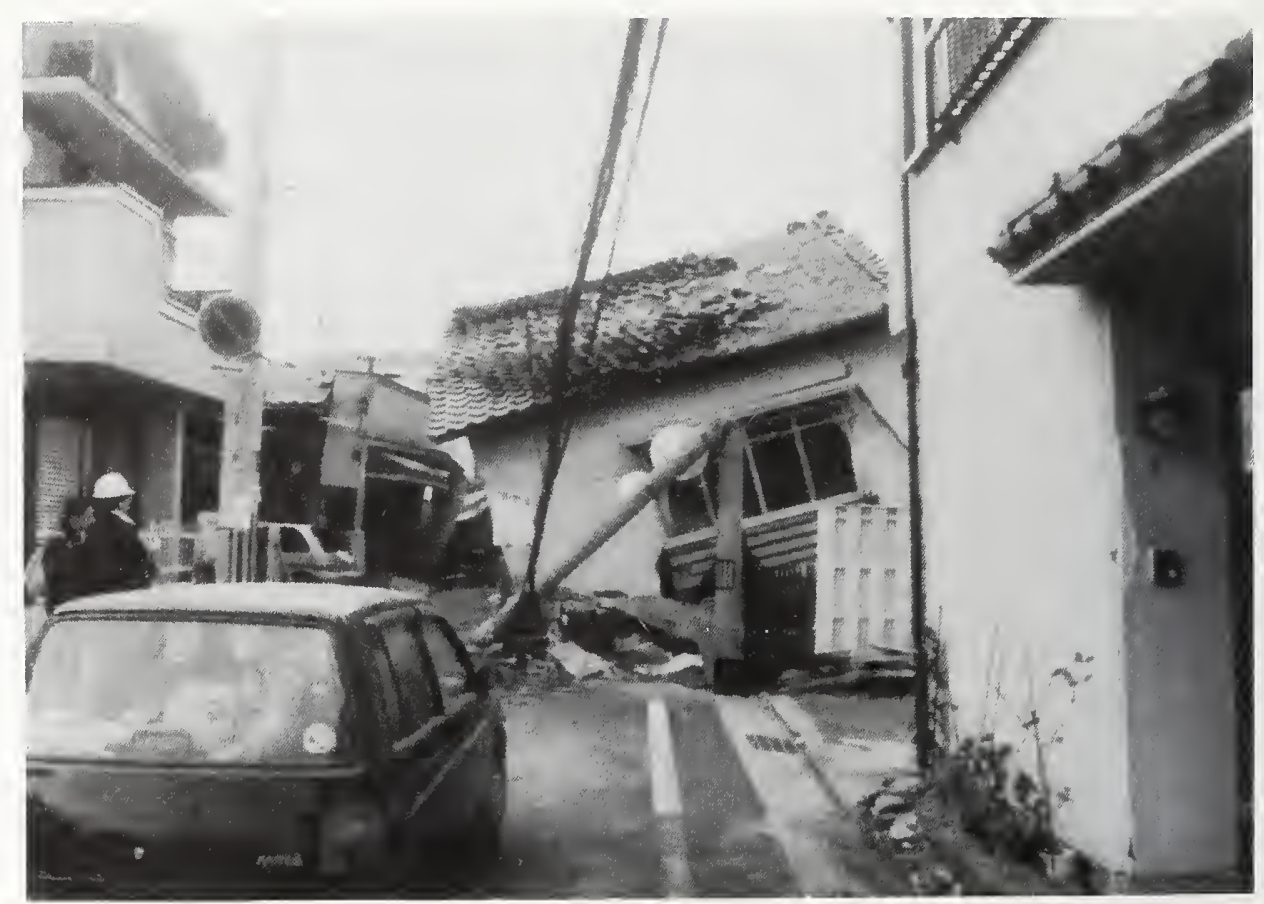

Figure 6.2.7 Example of electric power lines connected to a damaged house.

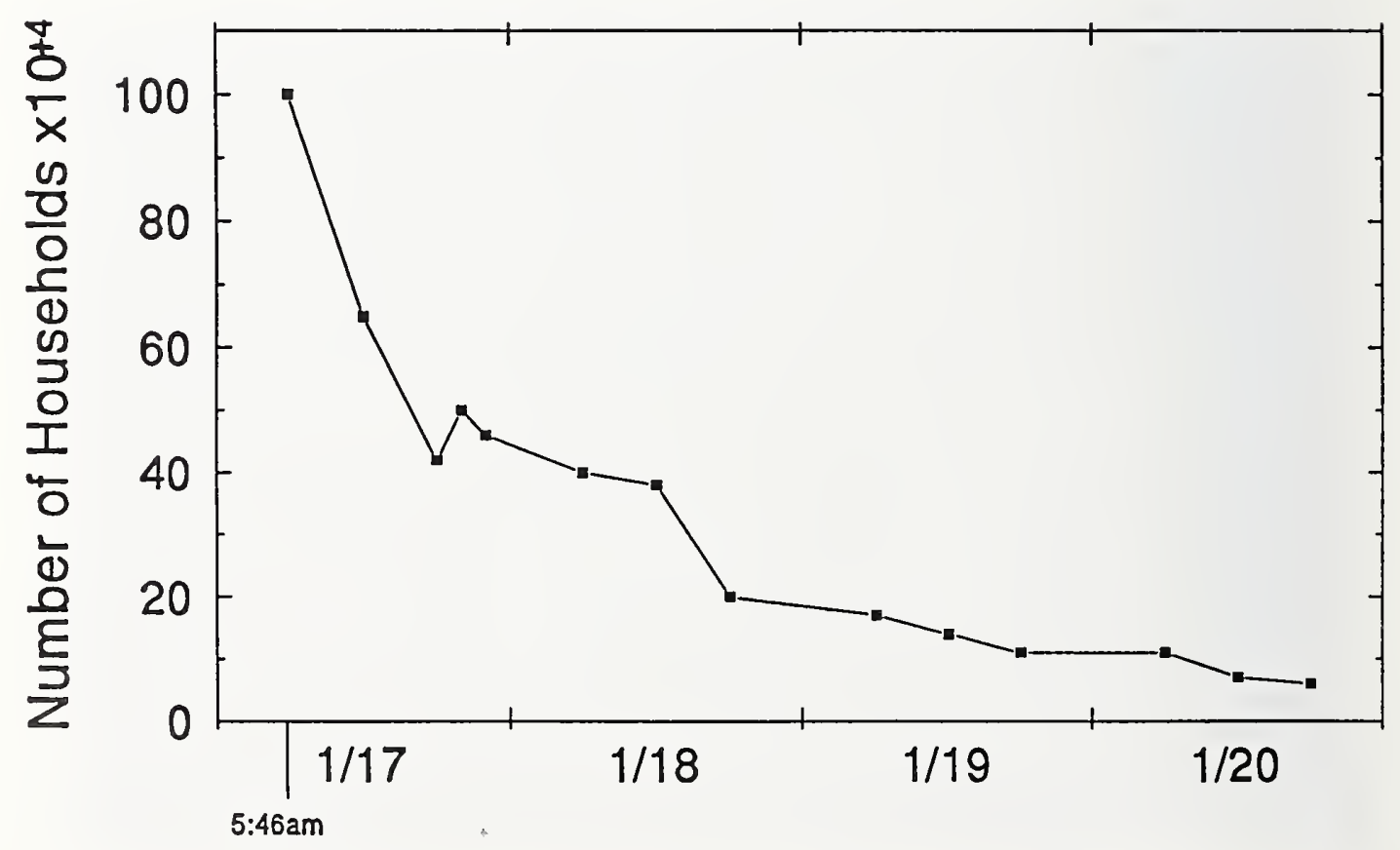

Figure 6.2.8 Number of households without electric service. 


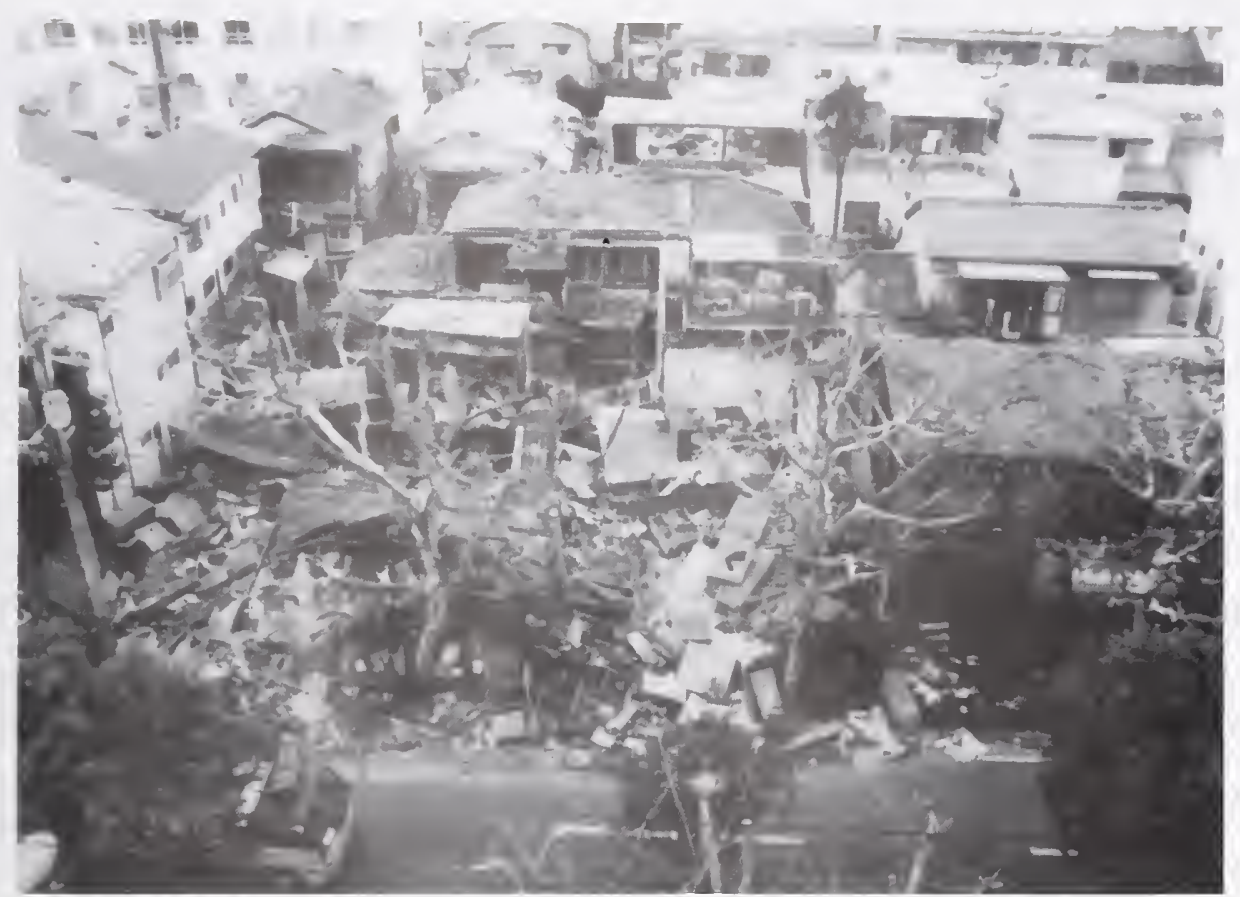

Figure 6.2.9 Collapsed houses. Notice that the pile of debris is in contact with the adjacent houses, forming a continuous fuel chain.

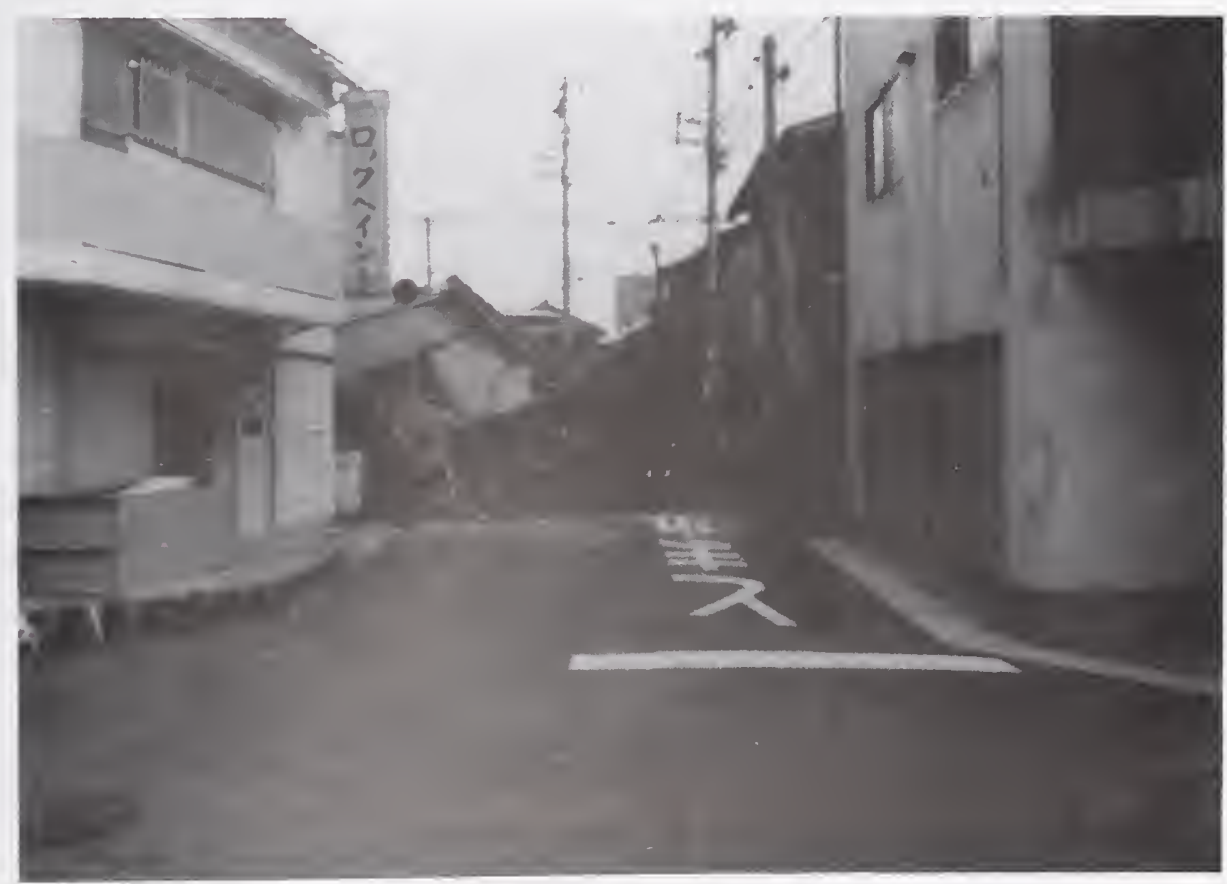

Figure 6.2.10 Collapsed structure across street. 


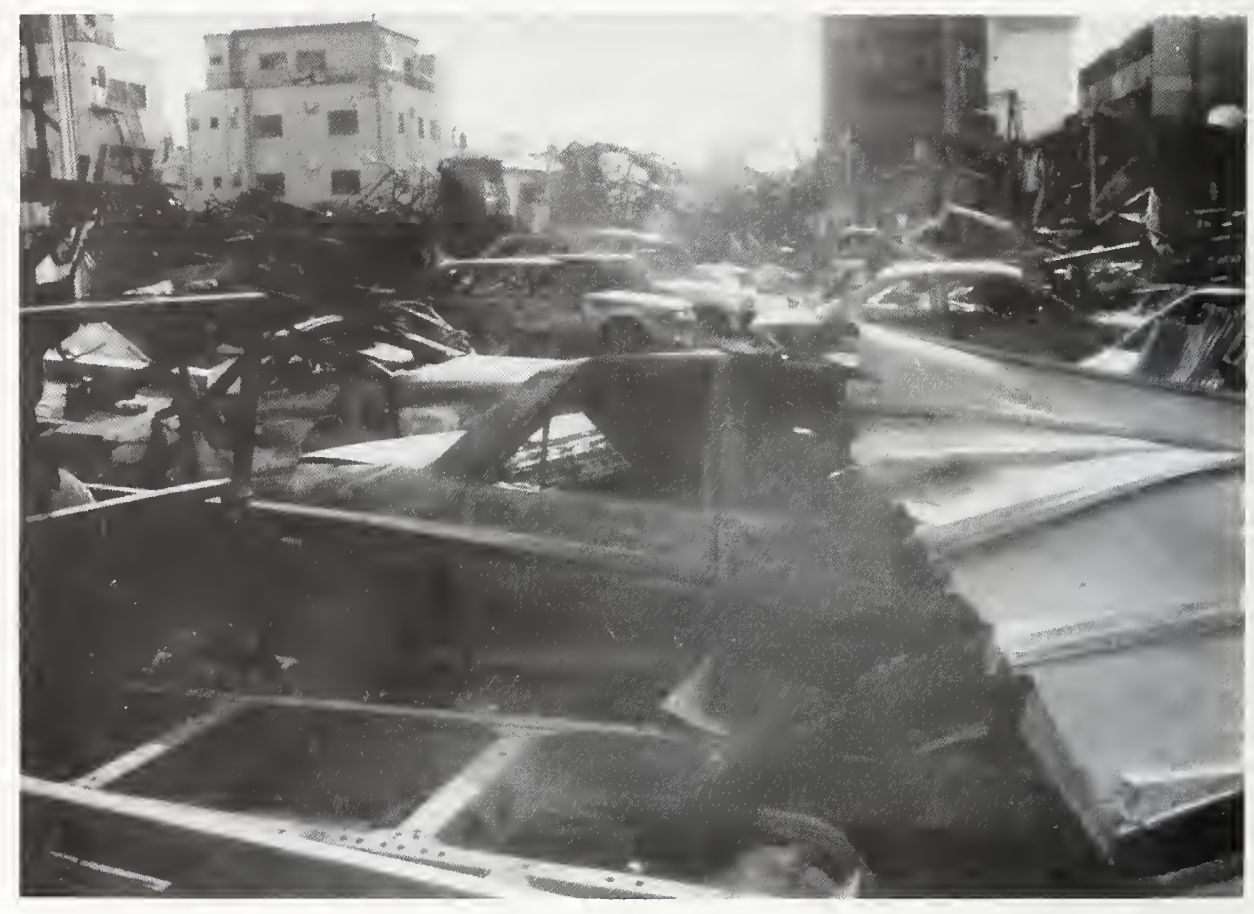

Figure 6.2.11 Parking area where automobiles contributed to fire spread between buildings.

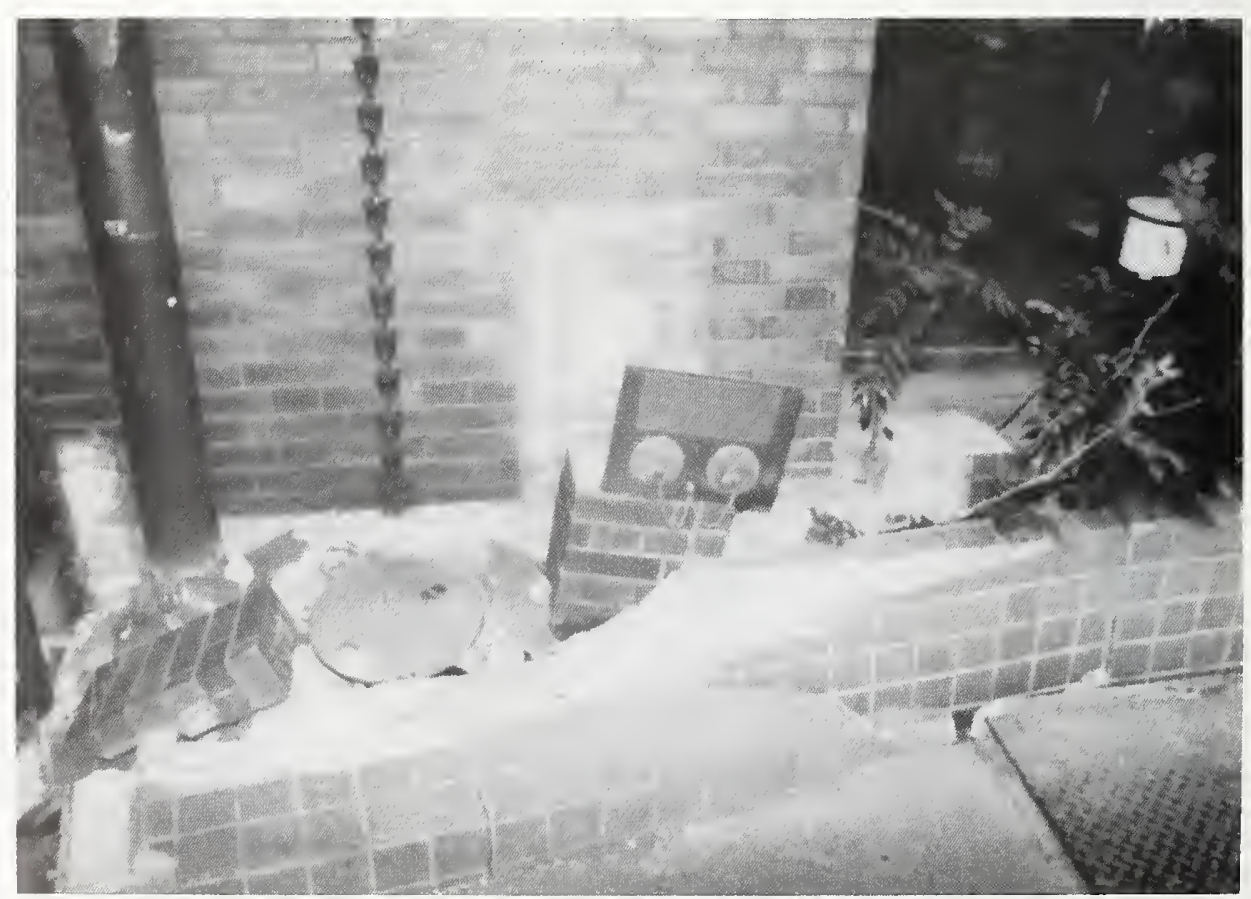

Figure 6.2.12 Standpipe connection severed at street level. 


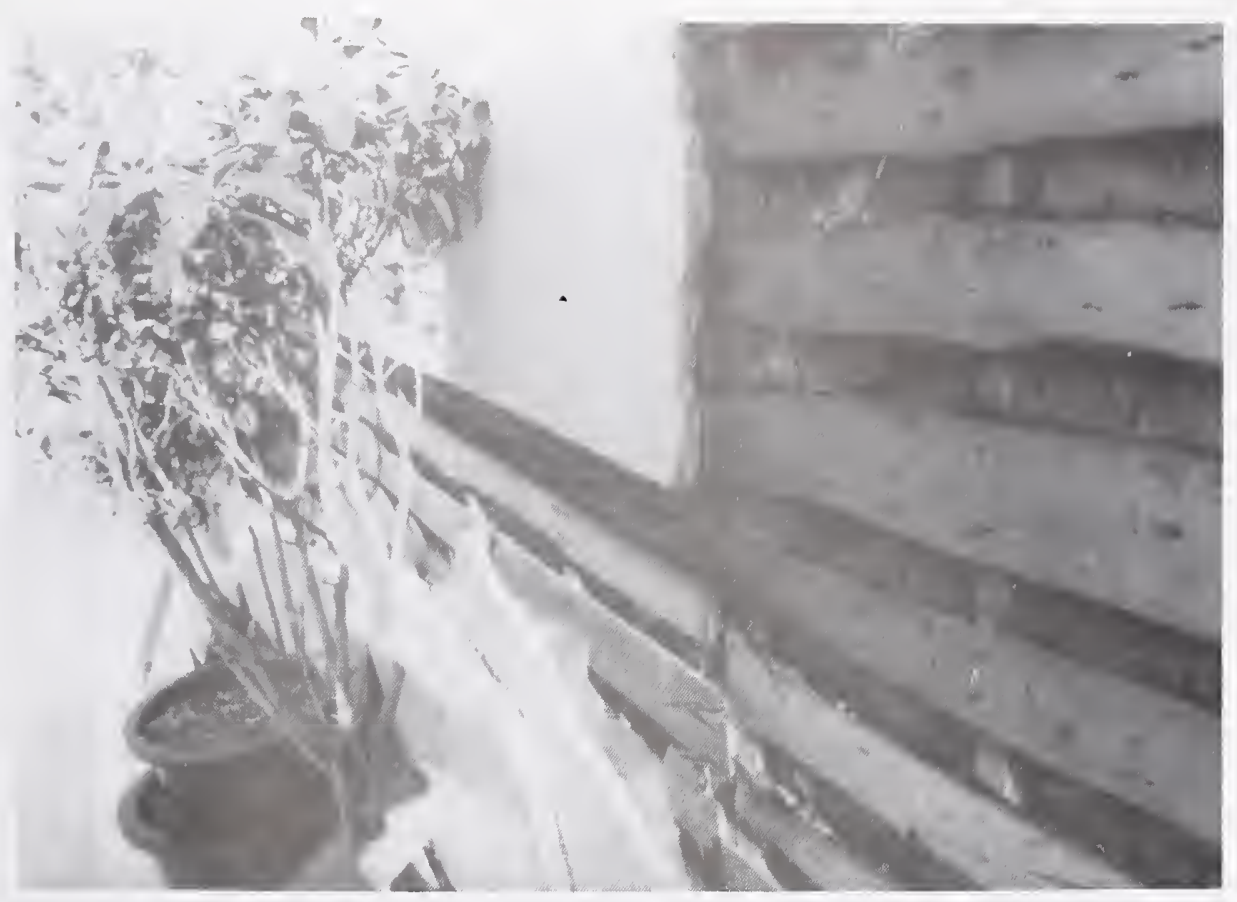

Figure 6.2.13 Example of okabe construction with portions of the fire resistive mortar displaced by the earthquake.

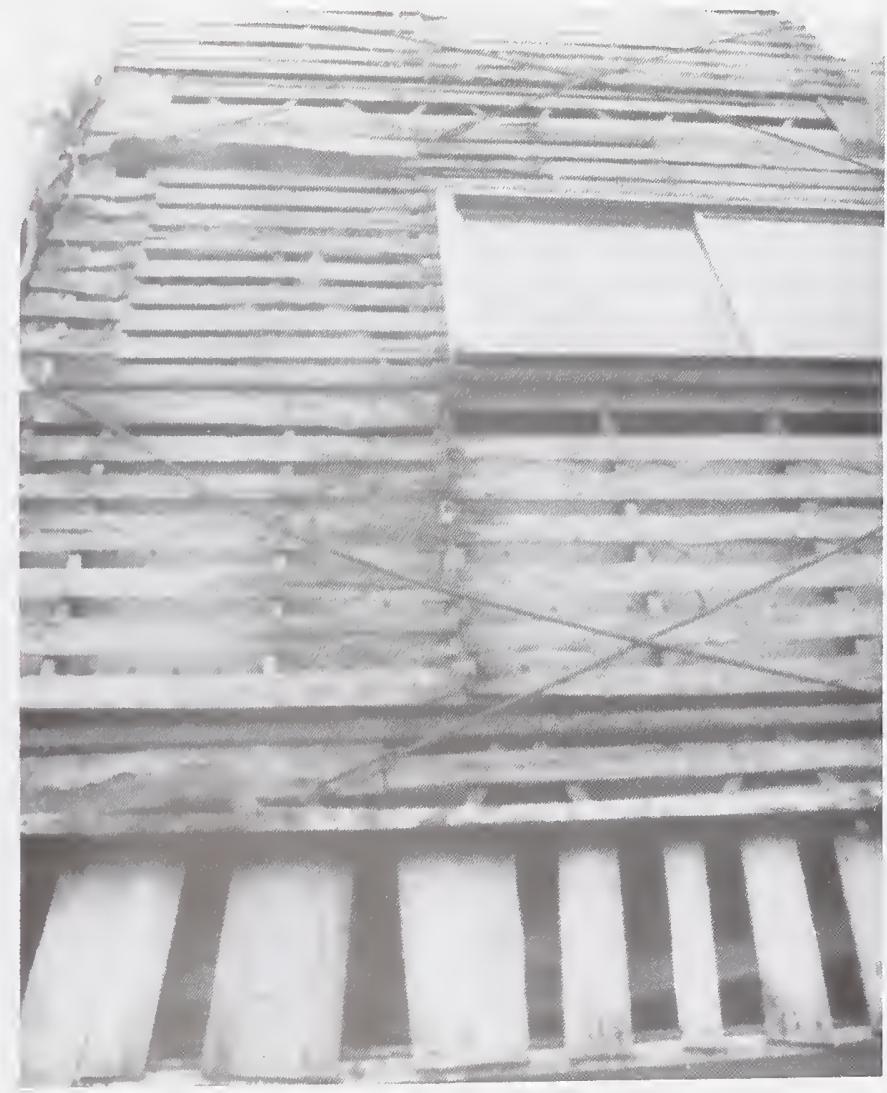

Figure 6.2.14 Example of a structure with mortar exterior after earthquake. 


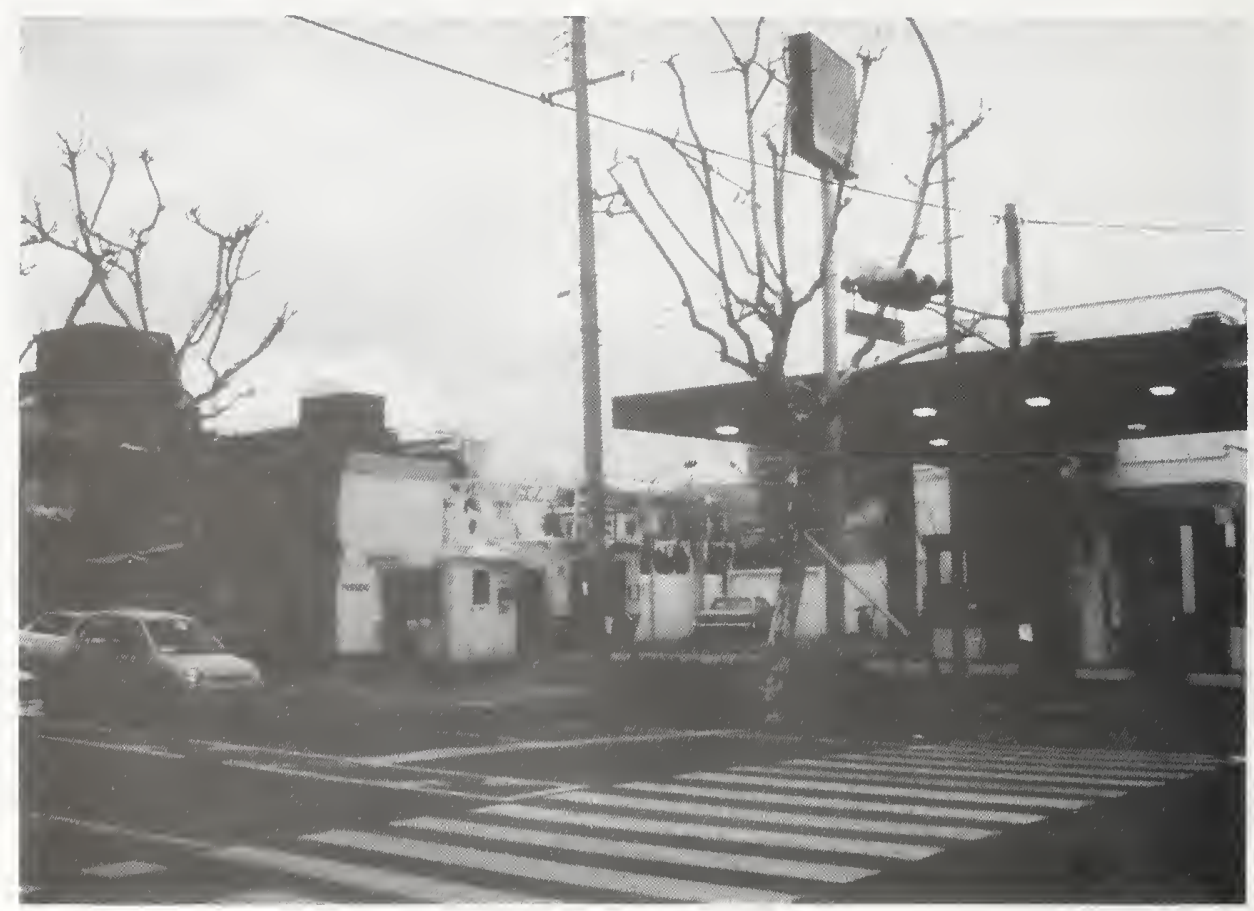

Figure 6.2.15 Gasoline Filling Station on the SW corner of the Sugawara Market Fire Area (Site No. 1).

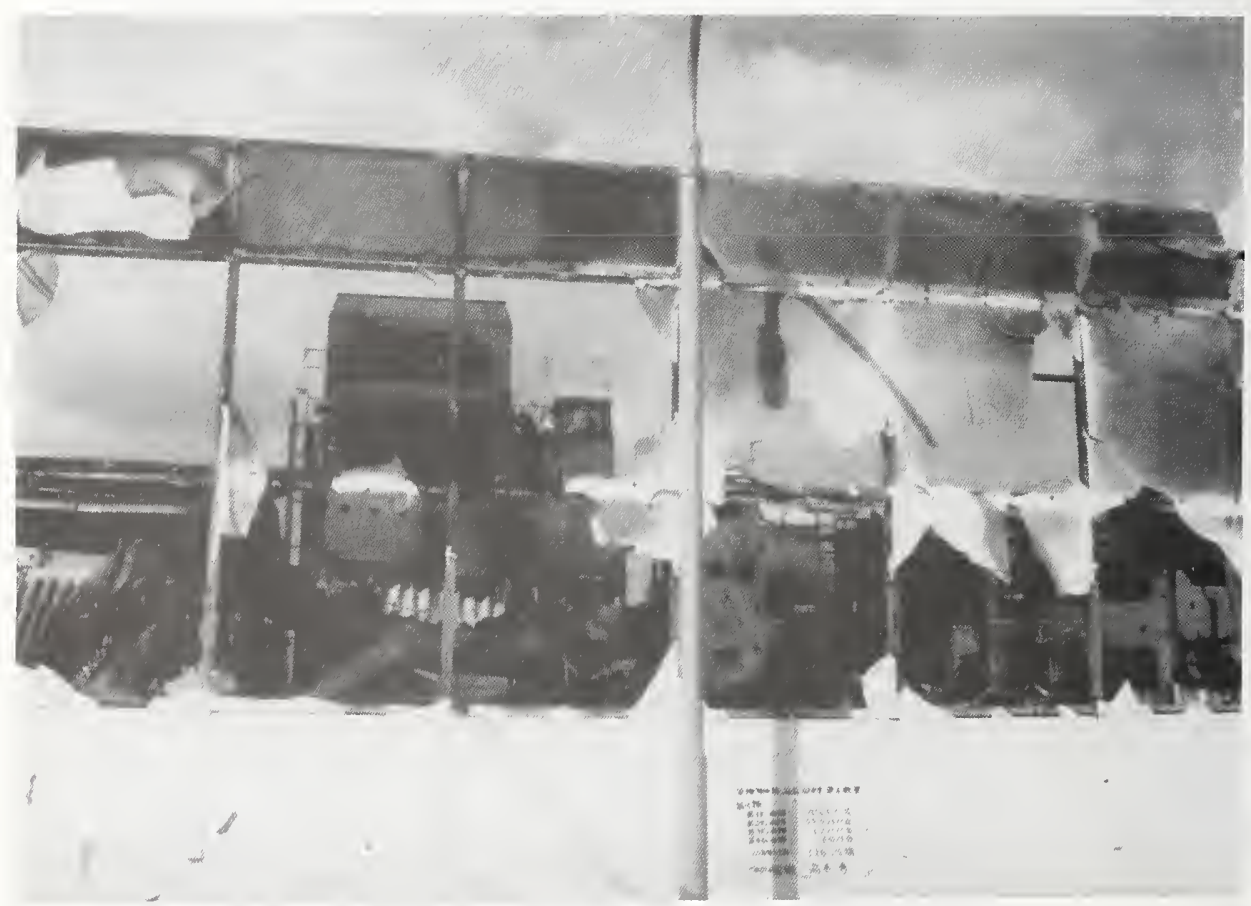

Figure 6.2.16 Gasoline Filling Station Perimeter Wall and Non-Combustible Shielding. 


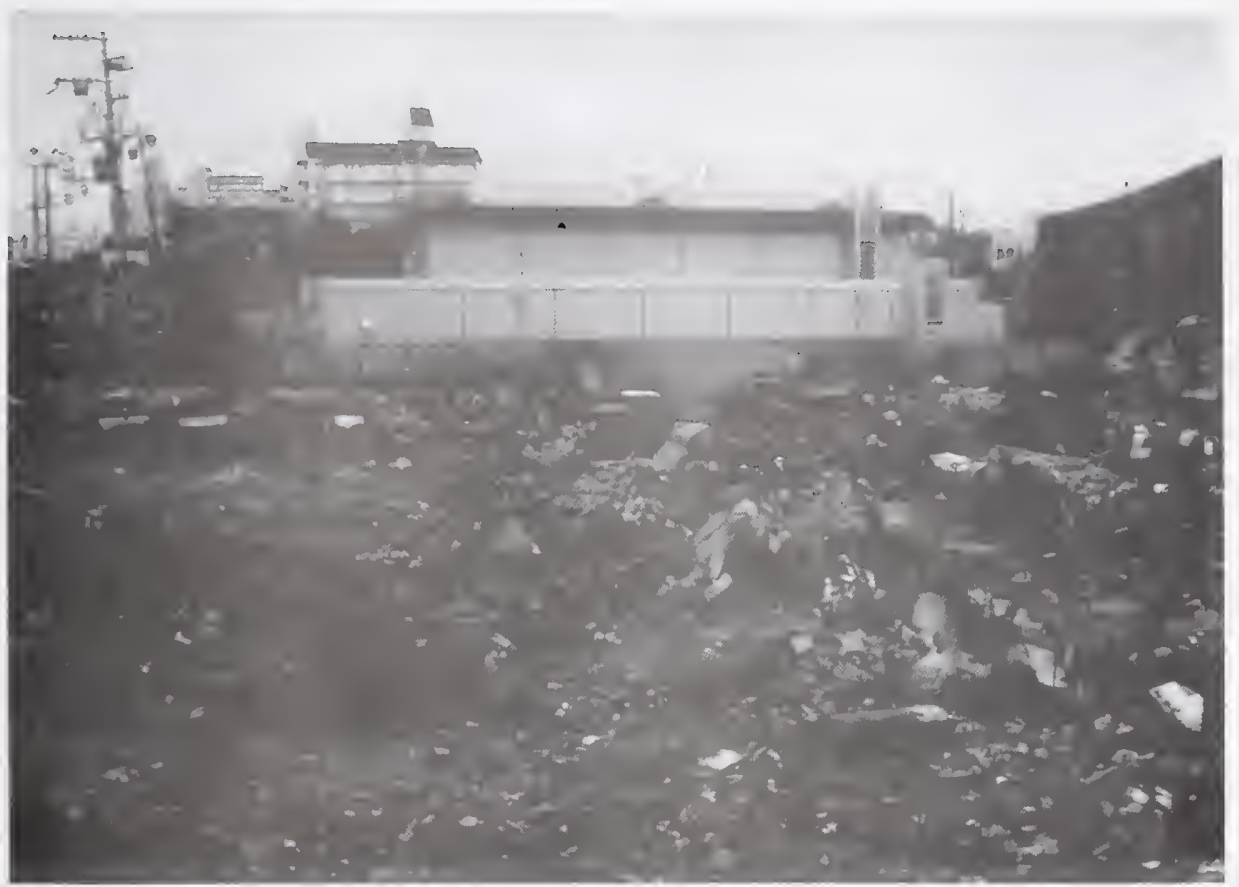

Figure 6.2.17 Electric Power Sub-Station.

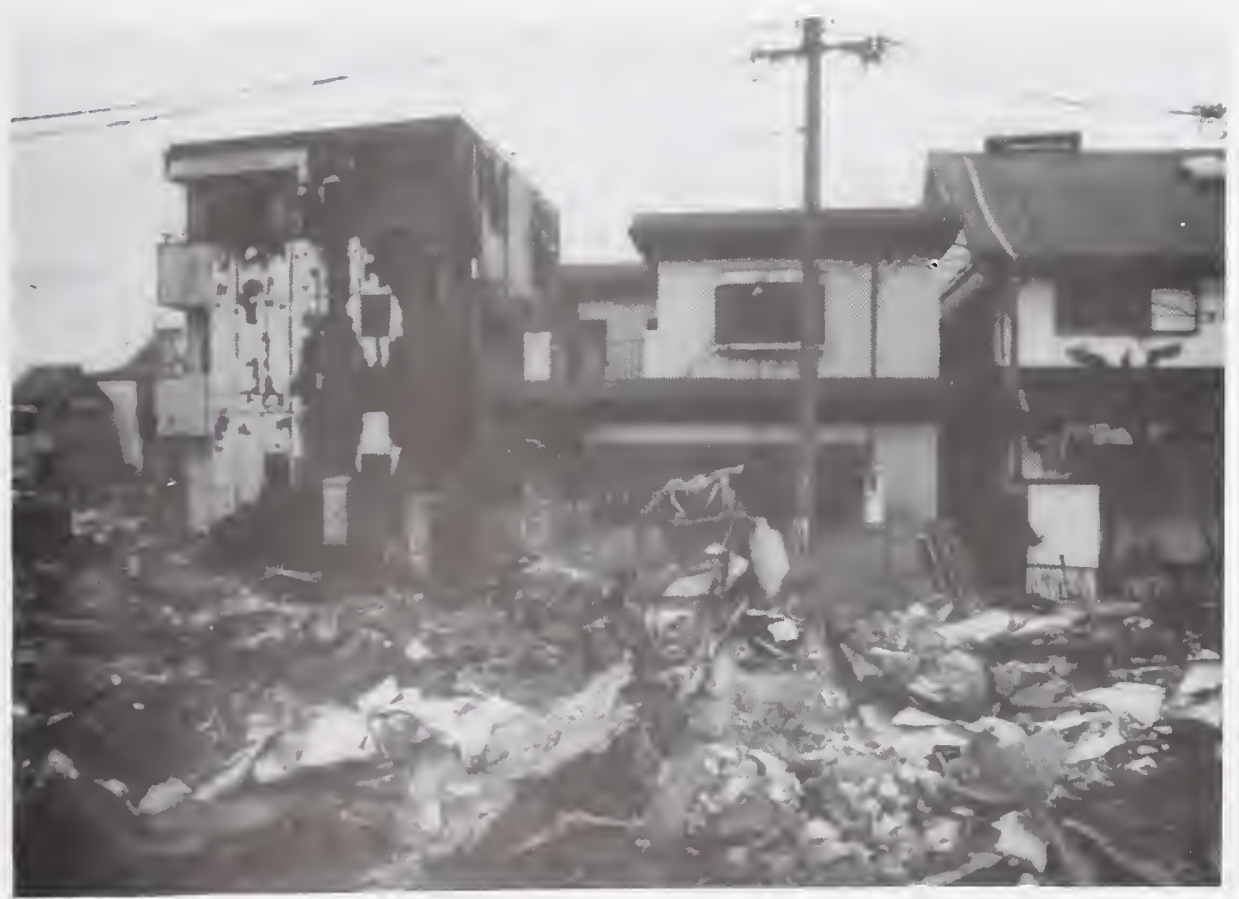

Figure 6.2.18 Burned out structure constructed from fire resistive materials. 


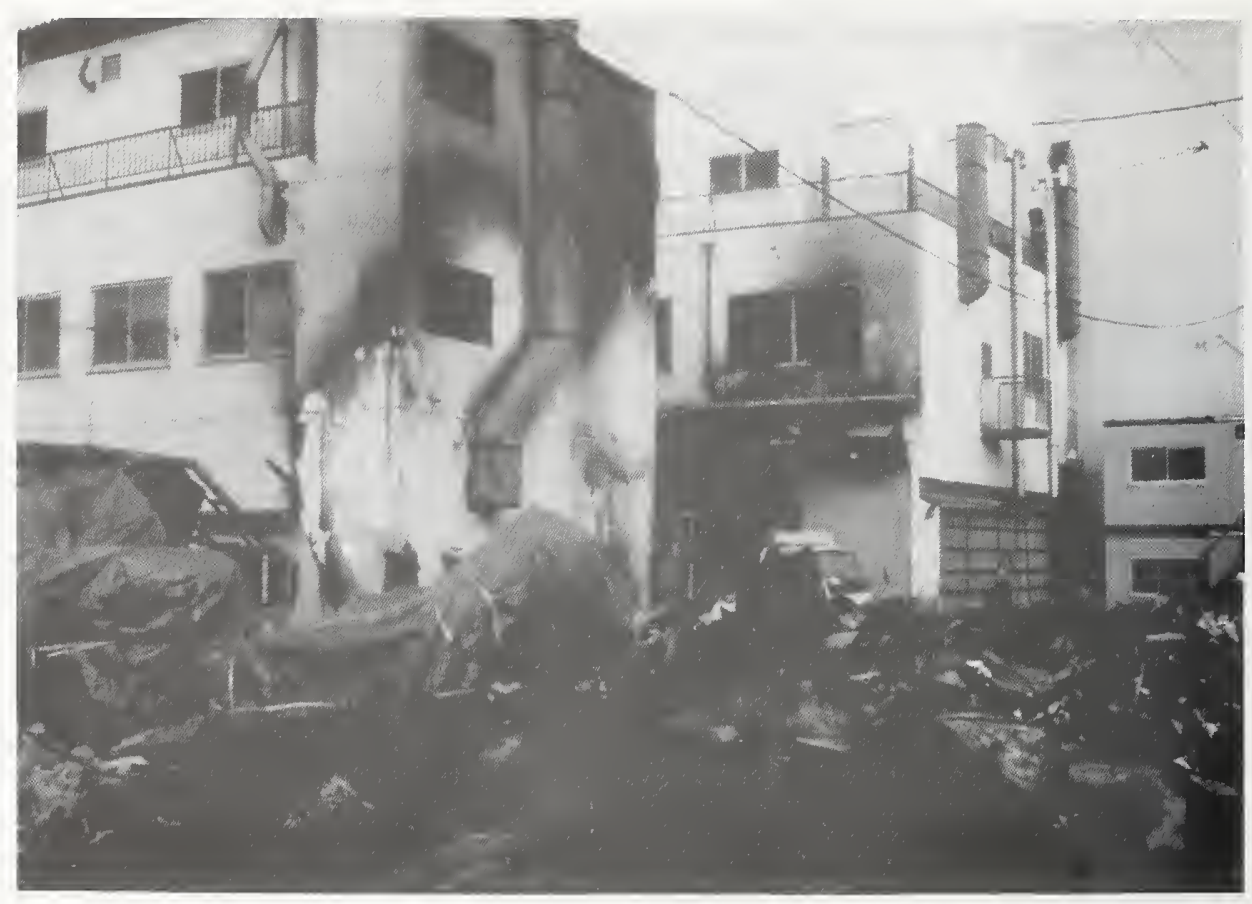

Figure 6.2.19 Buildings with fire resistive exteriors and wired glass windows.

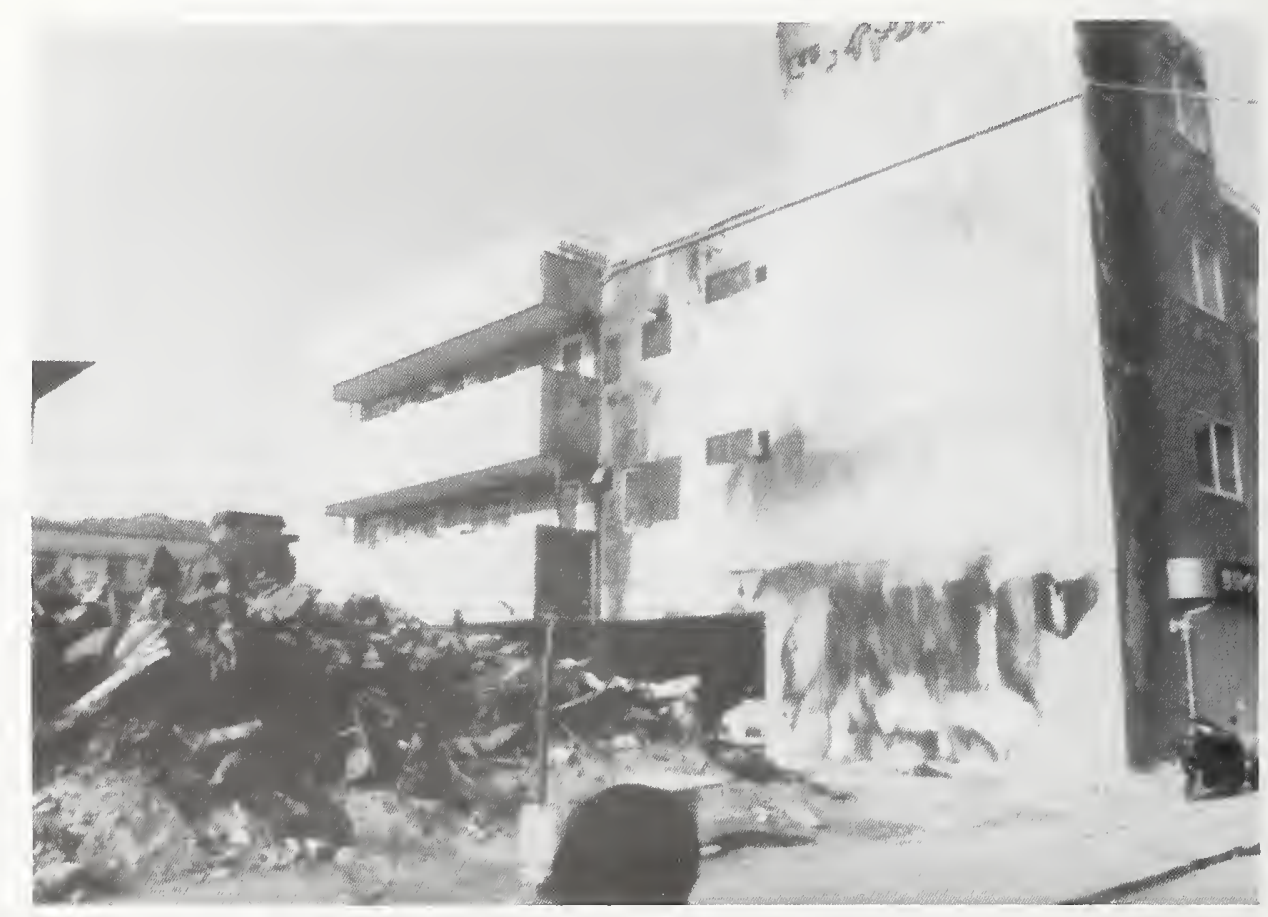

Figure 6.2.20 A building with a fire resistive exterior and wired glass windows. 


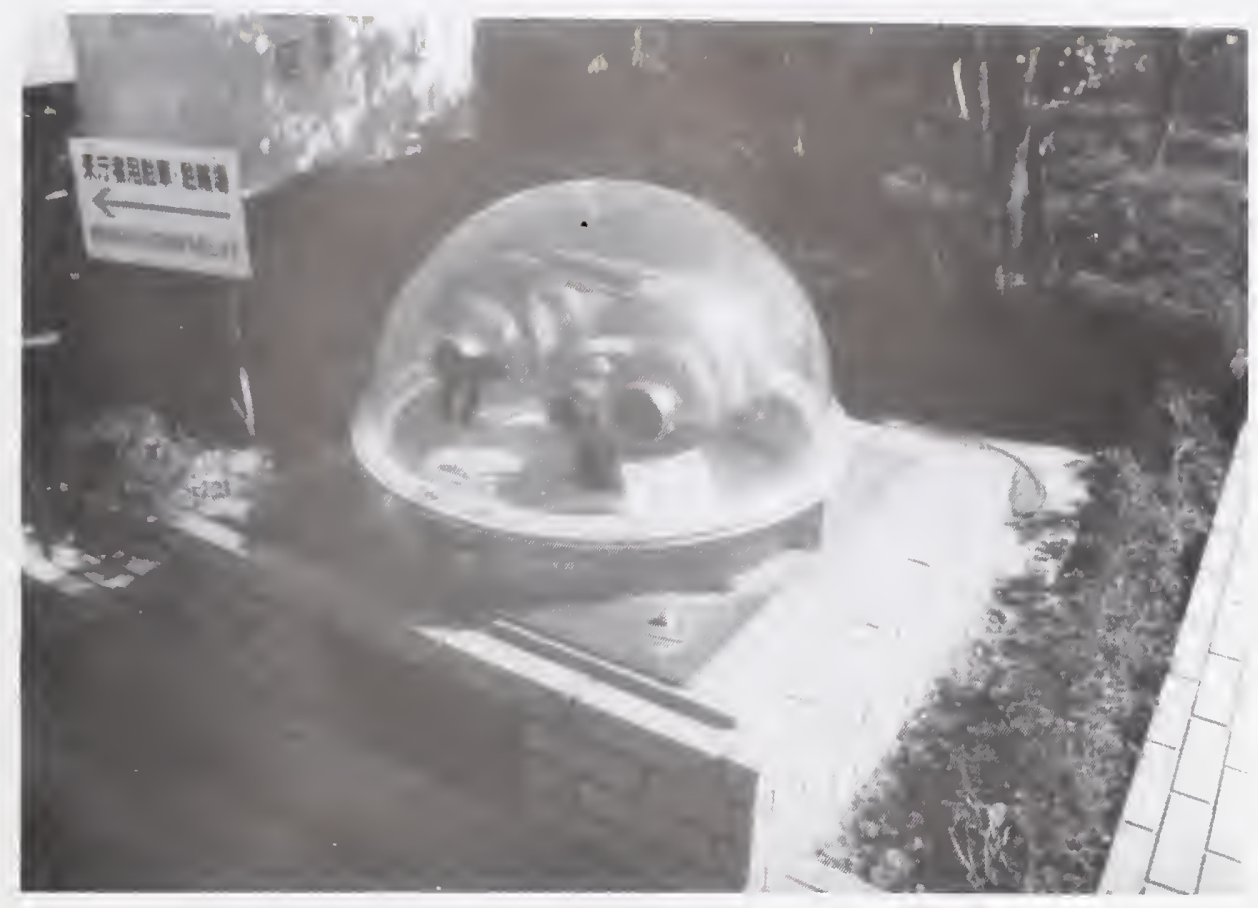

Figure 6.2.21 Seismically reinforced fire fighting water cistern.

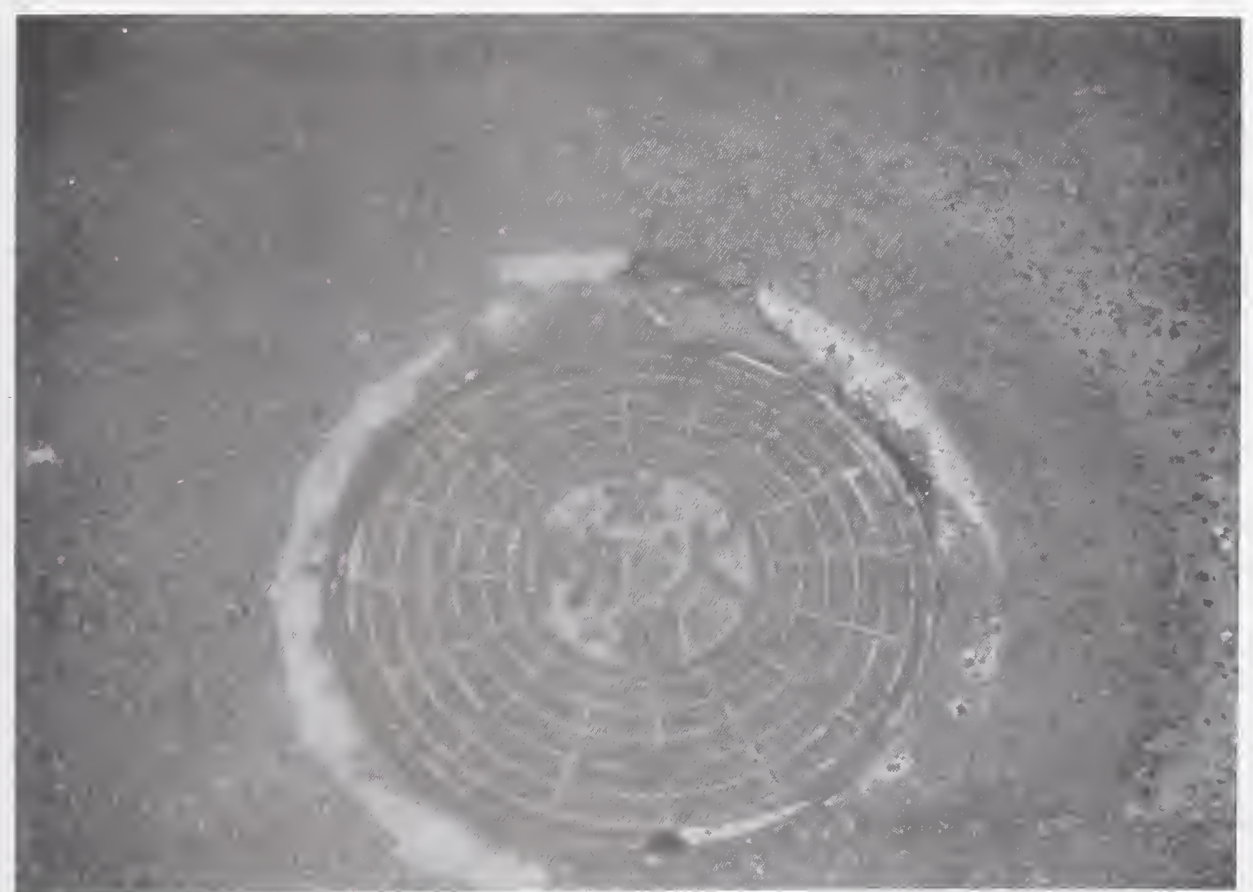

Figure 6.2.22 Access cover to unreinforced fire fighting water cistern. 


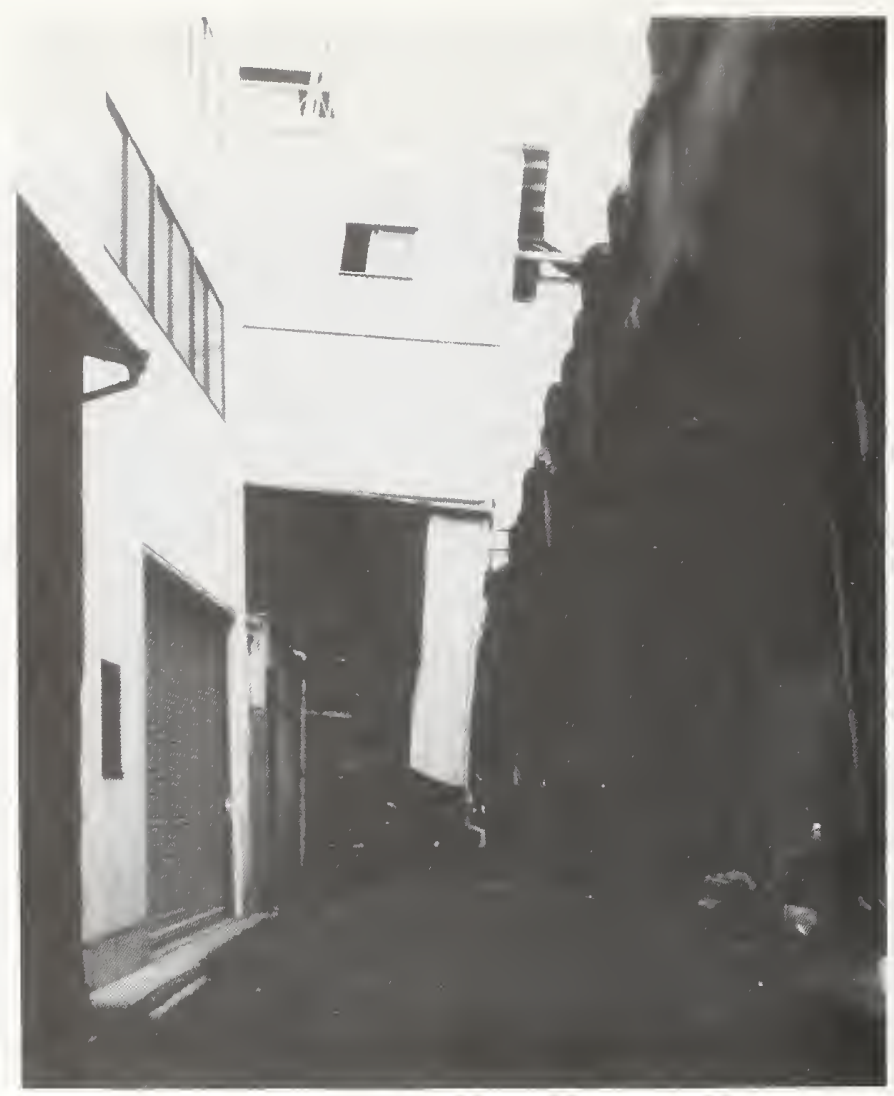

Figure 6.2.23 Road blocked by three story building.

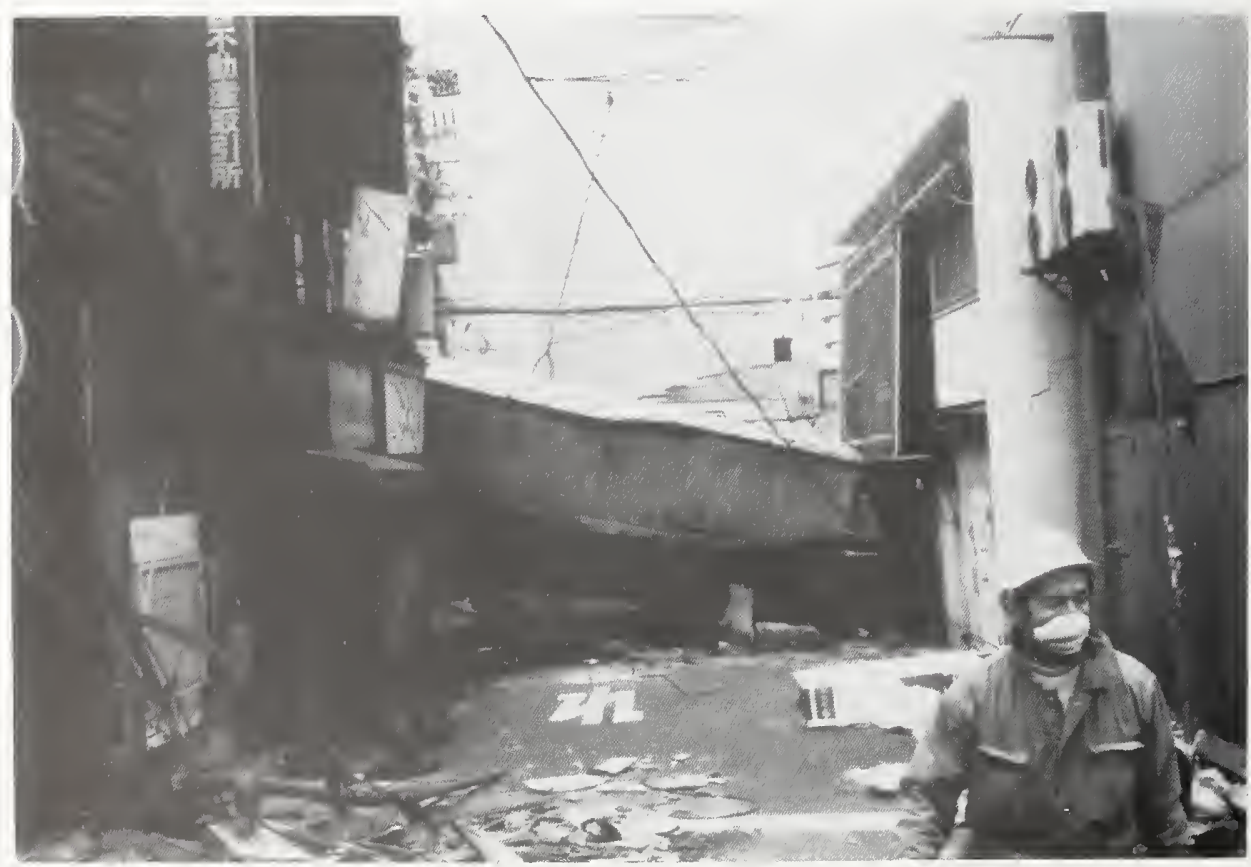

Figure 6.2.24 Road blocked by collapsed structure. 


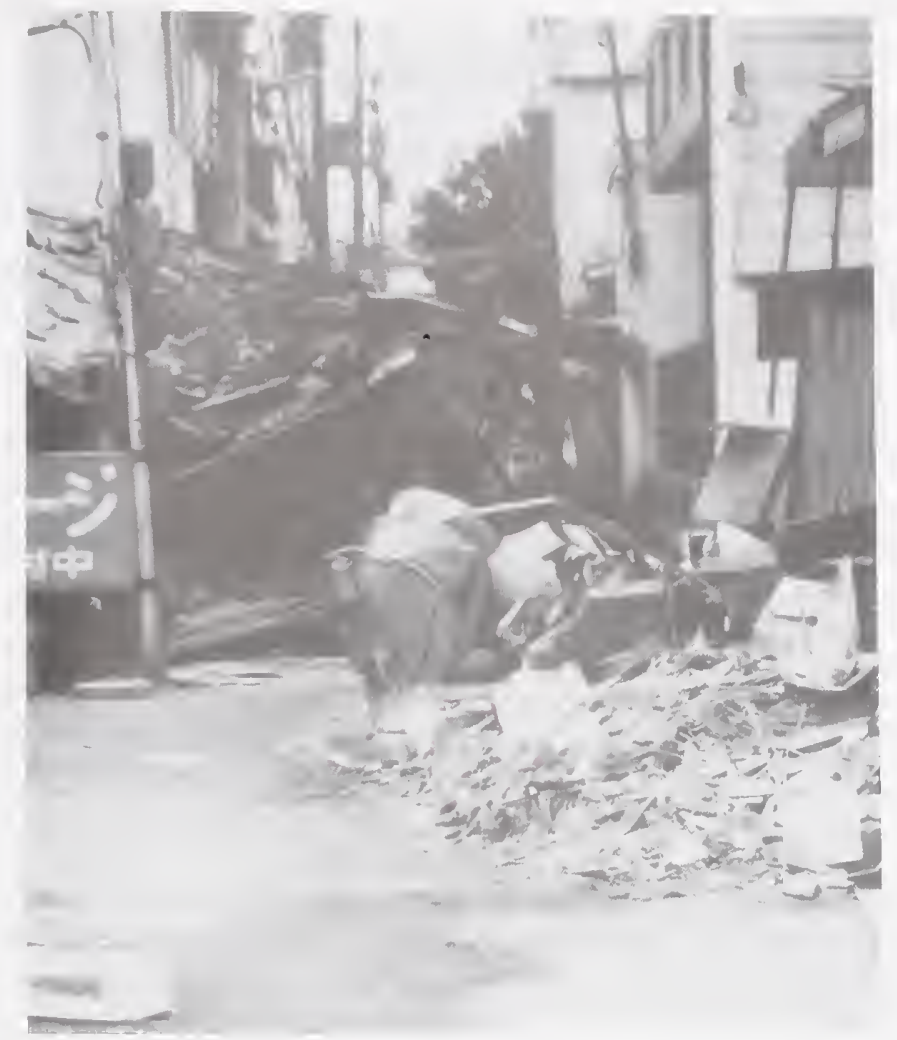

Figure 6.2.25 Road blocked by collapsed structure.

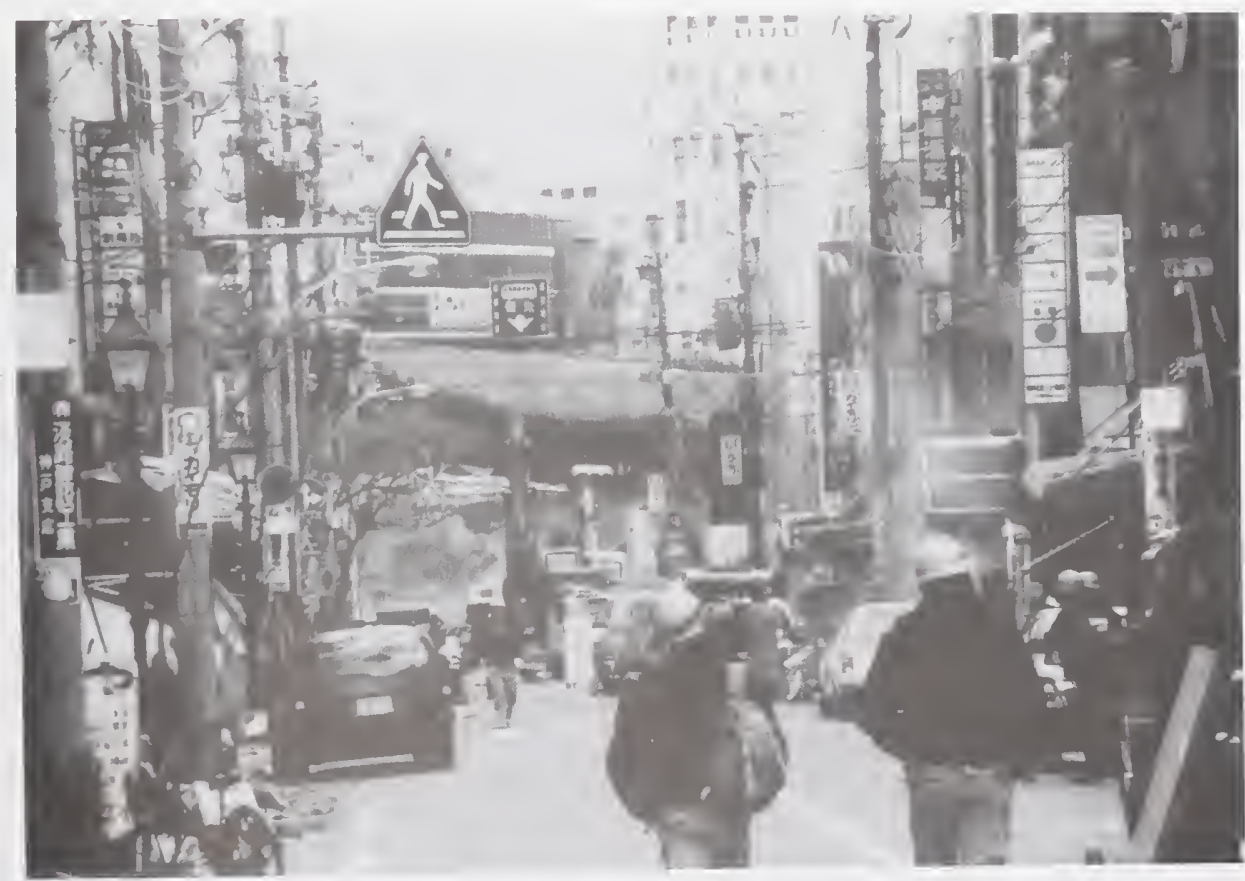

Figure 6.2.26 Collapsed train overpasses such as this one divided Kobe north and south. 
Rescues vs. Time

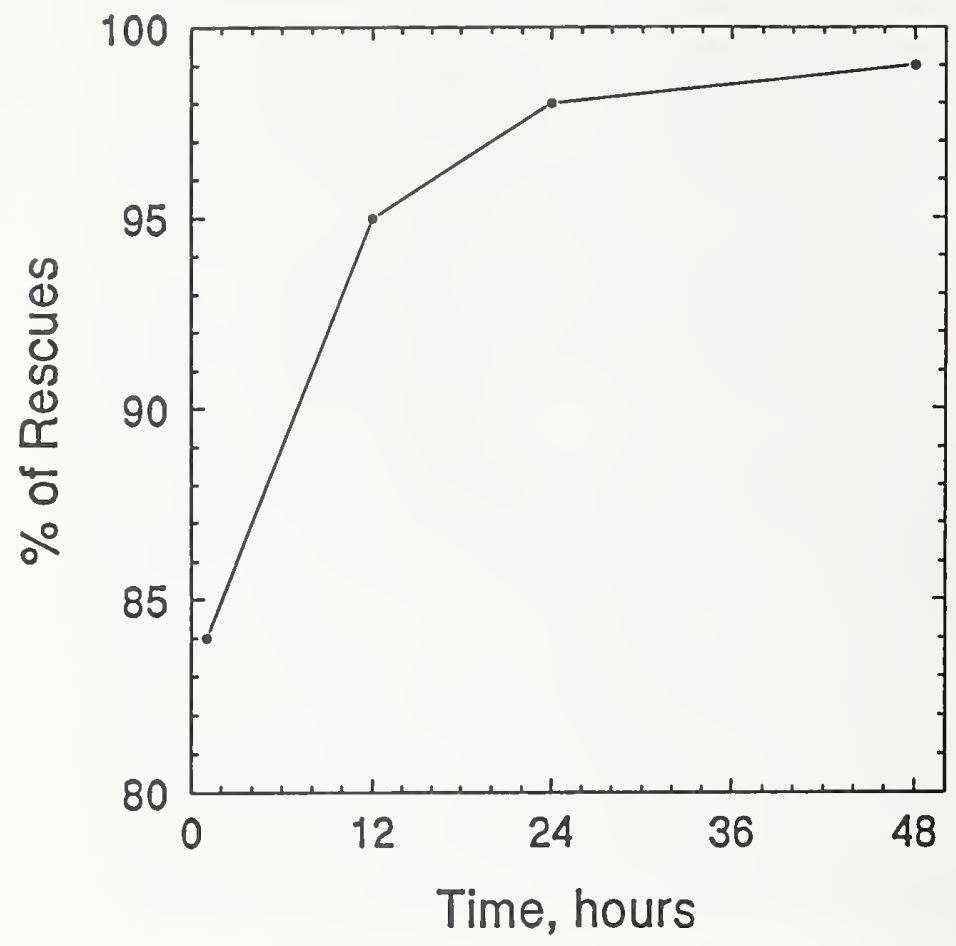

Figure 6.2.27 Time history of rescues made after the 1990 earthquake in Luzon, Philippines.

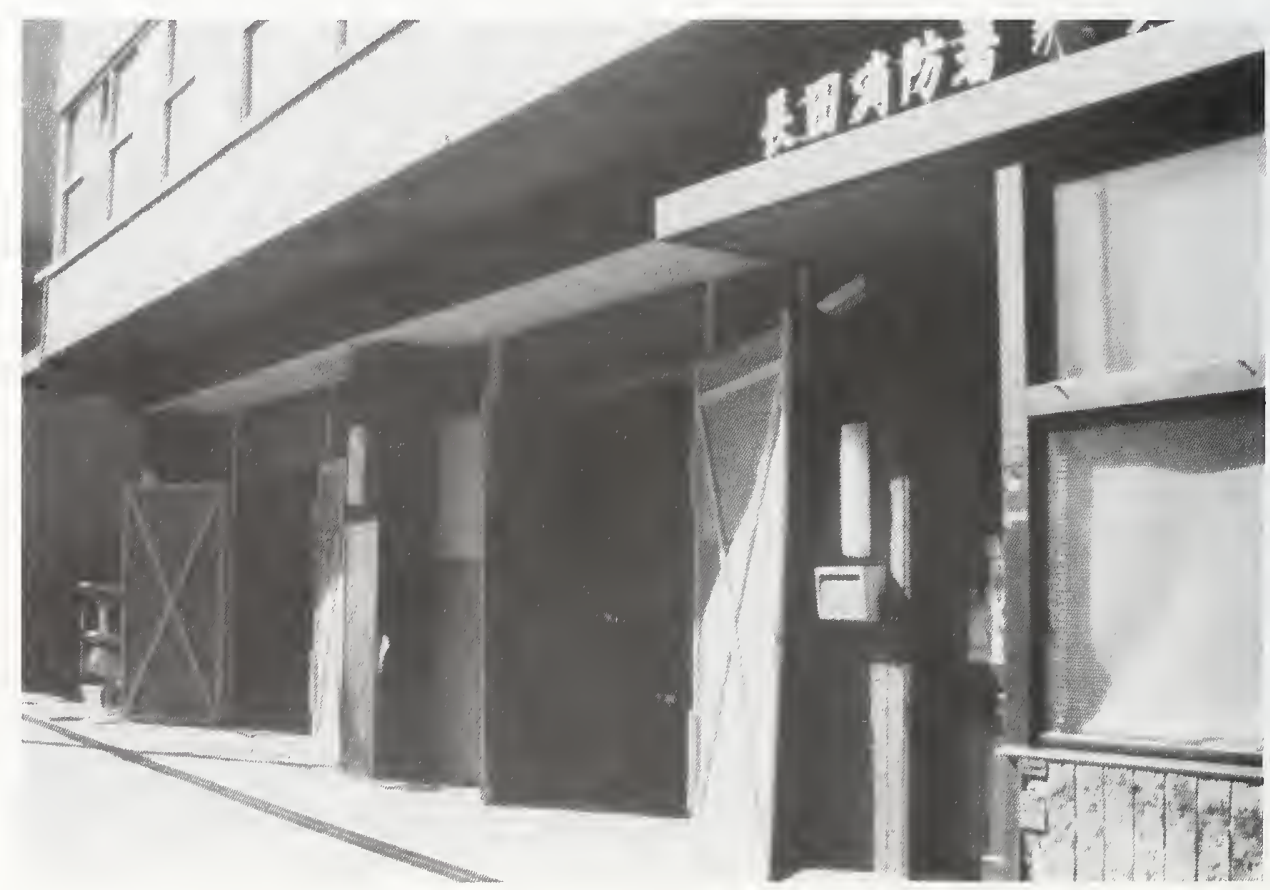

Figure 6.2.28 Fire station damaged by the earthquake. 


\section{OBSERVATIONS, CONCLUSIONS, AND RECOMMENDATIONS FOR RESEARCH}

\subsection{Introduction}

The January 17, 1995 Hyogoken-Nanbu (Kobe) earthquake was the first earthquake in recent history that had a direct hit on a modern urban region and resulted in unprecedented damage and economic loss. Many U.S. cities have similar geographic settings as the City of Kobe, i.e., narrow strip of coastal land, soft soils along the shore, and congested urban buildup and transportation systems. Examples of these cities include Seattle, Washington, and Long Beach and San Diego, California along the west coast; New York City, Boston, Charleston, South Carolina, and Memphis, Tennessee, all located in the eastern and central regions. In many respects, the nature of devastation of Kobe by this earthquake is most relevant to the cities in the eastern and central United States.

Urban areas in eastern and central United States are much older than the region in Japan where this earthquake hit--Kobe was rebuilt after World War II. However, many of the Japanese buildings were constructed without the benefit of modern seismic design, likewise their lifeline systems. The Kobe earthquake therefore provided an unprecedented opportunity to learn many valuable lessons that can help prepare us to reduce the devastating effect from future earthquakes.

\subsection{Observations and Conclusions}

Some key observations and conclusions which resulted from the visits of the team members are summarized below.

\subsubsection{Seismology, Geology, and Geotechnology}

The earthquake reemphasized that moderate to large earthquakes directly beneath densely urbanized areas can cause catastrophic loss of life and property.

1. Proximity to the earthquake crustalrupture zone Strong-motion recordings show that peak acceleration values attenuated from valucs greater than $0.8 \mathrm{~g}$ near the source zone to values less than $0.25 \mathrm{~g}$ at some sites at distances near $20 \mathrm{~km}$ on firm soils. This rapid attenuation of strong shaking appears to have been an important factor influencing the confinement of damage primarily to the Awaji Island, Kobe City and Nishnomiya areas.

\section{Amplification effects of soft-soil deposits} The amplification effects of Holocene soil deposits appear to have contributed to increased peak amplitudes and duration of strong shaking at many sites. The increased levels of shaking contributed to direct structural failures and liquefaction induced ground failures. The amplification effects of the Holocene soil deposits are consistent with those inferred empirically from the Loma Prieta earthquake.

\section{Liquefaction susceptibilities of reclaimed land and soft soil deposits}

From the geotechnical viewpoint, the liquefaction of about $17 \mathrm{~km}^{2}$ of land underlain by artificial fill highlights the seismic hazard of loose sandy soils. The experience during the 1995 earthquake reaffirmed the proclivity of areas built on these fills for large permanent ground 
deformations when they are strongly shaken. Many artificial fills in coastal and river areas of the United States are similar to the loose sandy fills in Kobe, which performed so poorly. Much artificial land has been created in the United States by dredging or dumping sand into open water without compaction. These older fill areas in ports and harbors, both in seismically active areas and areas of low seismicity, are vulnerable to earthquakes. As the 1995 earthquake demonstrated, this vulnerability can extract a steep price when these areas are strongly shaken.

\subsubsection{Buildings}

With the exception of the unique SRC construction type, the construction and detailing practices of Japanese buildings have generally evolved in a manner that closely parallels U.S. practice. Code improvements, while not identical, have occurred at the same general pace in both countries. This tragic earthquake therefore offers an excellent opportunity to reflect on several general issues.

\section{Poor performance of traditional wood}

houses The majority of the casualties in this earthquake were caused by the collapse of old Shinkabe and Ohkabe houses made of wood. They were built primarily to support gravity loads. In more recent Ohkabe design, lightweight cross braces were introduced to provide better lateral resistance. There were no indications of plywood or particle-board shearwalls being used in these constructions, as is common practice in the United States. Many severely damaged houses had heavy ceramic roof tiles set on soil as bedding, which contributed a great deal to their collapse.

2. Damages to older reinforced concrete buildings Many older reinforced concrete
(RC) moment frame buildings experienced full or partial floor collapses. The damaged low to mid-rise $\mathrm{RC}$ buildings that were observed could easily have been U.S. buildings that were constructed in the 1950's and 1960 's, particularly in zones of low to moderate seismicity. The large amount of damage that occurred in Kobe points out the high vulnerability of these older, poorly detailed structures. This problem is not only one of concern for the zones of higher seismicity in the western United States, but it is also a concern for the lower seismicity zones in the central and eastern United States, where detailing practices in many cases have not kept pace with Western U.S. practice. These older and less ductile RC structures will require significant rehabilitation to be made less vulnerable.

\section{Good performance in new $\mathrm{RC}$ buildings}

No evidence of collapse in any of the newer (post-1981) engineered RC structures was evident. The 1981 Japanese code improvements, which added the second phase of seismic design that addresses ultimate capacity, is quite similar to the intent of current U.S. building codes that focus on life safety, or collapse prevention, in the one-time severe seismic event. In this light, this earthquake is a vindication of the current code philosophies in both countries and the technical changes that have occurred in those codes as a result of the $\mathrm{RC}$ research that has been carried out since the early 1970's in both the United States and Japan.

\section{Performance-based design philosophy $A$} somewhat more subtle issue regarding new construction is whether there should be standards that provide better building envelope integrity than the basic one-event life safety standard that we have today. It was clear from the external envelope surveys that racking had caused many windows in newer structures to crack or pop out of their 
frames. Also, facade cracking and other minor damages were present. These less severe damages represent costs to the building owners, and in many circumstances can also pose life safety dangers from falling debris. The event should fuel further debate in both the United States and Japan about weighing initial construction costs against potential future earthquake losses.

\section{Avoiding stiffness or mass irregularities} The earthquake again pointed out the need for avoiding the use of "soft" stories and stiffness or mass irregularities either in plan or elevation. Many of the older building collapses could be at least partially attributed to the presence of such weak links.

\section{Eliminating pounding between buildings} The need to eliminate pounding of adjacent buildings was evident. Building separation is the obvious solution. When it is not provided, the interactions of adjoining buildings must be considered.

7. Performance of steel frame structures The performance of steel frame structures was generally encouraging. Although there was extensive damage in many of these structures, particularly low- to mid-rise apartments and offices, few collapsed and egress means were maintained. The nature of the damage also indicates that extensive monetary damage can be inflicted on a structure in the form of cladding failures. The extensive base metal and weld failures observed at the AHST complex in Ashiya City echo problems first observed in steel structures in the United States following the January 17, 1994 Northridge earthquake.

\subsubsection{Highways and Bridges}

1. Lessons for bridge design in central and eastern United States To bridge engineers and owners in the central and eastern United States, this earthquake is perhaps of greater significance than recent earthquakes in California. One reason is that the predominant type of bridge in Japan is the steel girder superstructure supported by bearings on concrete columns and foundations. This class of bridge is also found throughout the central and eastern United States. Bridges in California tend to be concrete box girders with monolithic bents and integral abutments especially in shorter bridges. The performance of Japanese bridges is thus of particular relevance to states east of the Sierra Nevada "Snowy Range."

A second reason is that the difference between the maximum credible earthquake and the design earthquake is clearly very large for this region of Japan, which is a situation that is also considered to exist in the United States, but to a greater degree in the eastern and central United States than in the west.

(a) The closure of arterial highways and bridges affects emergency relief and business recovery and can have a major economic impact on a region and its ability to survive such a disaster.

(b) Large damaging earthquakes can occur in areas that are considered to have, on average, only a moderate exposure to seismic hazards.

(c) Capacity design procedures, ductile details and generous seat widths are necessary to prevent catastrophic collapse during large earthquakes.

(d) Minimum connection forces need to be enforced for all seismic zones unless such connections can be shown to be fully protected by acceptable yielding of the substructures. Redundancy in 
connection detailing is particularly important for essential structures.

(e) Critically important structures must be designed to a higher level of performance than that provided by current specifications, if full service is to be maintained after a large earthquake. Multi-level performance criteria and corresponding design strategies are necessary for important bridges.

(f) Retrofit measures reduce damage but inappropriate use and/or installation can defeat their purpose and perhaps even trigger collapse.

(g) Lateral spreading due to liquefaction can lead to span collapse even in modern structures with massive foundations (caissons) and well-engineered fills.

(h) Premature failure of some bearings appear to have reduced the seismic loads in their supporting substructures by uncoupling the superstructure from its supports.

(i) Skewed bridges are susceptible to in-plane rotation leading to large displacements at their supports and possible unseating of girders in the acute corners.

\subsubsection{Railways and Rapid Transit System}

\section{Damage to elevated structure sections}

Rail services suffered more damage along the elevated structure sections than along the elevated embankment sections. Most damage to the elevated structures occurred at columns either at the bottom of superstructures or at a joint region. Although shear reinforcement spacing at both ends of the column were reduced by about one-half, the old non-ductile details were vulnerable to high ductility demands.
The damage was similar to unretrofitted column damage observed in past California earthquakes.

\section{Better performance of Port and Rokko}

Liners Both the Port Liner and the Rokko Liner were built with modern codes. Columns along the Port Liner are mostly reinforced concrete whereas columns along the Rokko Liner were built with steel. It is difficult to conclude which type of substructure performed better without detailed structural information. In general, steel columns suffered minor yielding and local buckling while concrete columns either yielded or failed in shear.

\section{Need for a systematic retrofit technique} for RC structures Although damage to the reinforced concrete structures was extensive, the major cause of collapsed structures was the nonductile detailing of the steel reinforcement. Structures designed by current specifications performed well with minor damage. With the vast amount of elevated structures in need of repair and retrofit, a systematic retrofit technique is needed.

\section{Collapse at the Daikai Station The} failure of the Daikai Station is highly significant because it is the first instance of catastrophic earthquake damage to a modern cut-and-cover subway station. The failure appears to have resulted from earthquake-induced transverse shear distortion in combination with loads enhanced by vertical accelerations. Shear distortion promotes plastic hinge formation which, in combination with enhanced vertical loads, can result in a collapse mechanism. Shear distortion and vertical accelerations apparently led to collapse of the center reinforced concrete columns at the Daikai Station. 
Current design practices, which account for transient shear deformation and vertical accelerations, are consistent with the failure mechanisms inferred from observations of damaged sections of the Kobe underground rapid transit systems. Failure of the central columns at Daikai Station emphasize the importance of designing to prevent plastic hinge formation leading to a collapse mechanism. The lack of significant confining steel at failed reinforced concrete columns suggests that attention to confinement and ductility can play an important role in strengthening underground structures against earthquake effects.

Attention also needs to be focused on the density and stiffness of backfill adjacent to structures built by cut-and-cover methods.

\subsubsection{Airports}

1. Good performance of airport facilities at Kaisai Airport The braced frame structural system in the recently completed Kansai control tower appears to have an effective seismic design; but it has not yet been put in a severe test. The leveling system provided in the basement of this building is an innovative approach to provide for the possible uneven ground settlement that may be caused by liquefaction or consolidation. The use of interior columns to support the roof of the cab in the Kansai control tower did not appear to be a significant visual impediment. Its use in the United States should be explored to reduce earthquake window damage frequently observed in this country.

\subsubsection{Ports and Harbors}

1. Severity of damage The extensive damage to the port of Kobe highlights the seismic hazard to port facilities posed by loose sandy fills. Such materials have been widely used in both the United States and worldwide to reclaim ground for port development and cxpansion. The earthquake illustrates once again the potential for these fills to liquefy and generate large permanent ground displaccments when shaken by carthquakes. It further illustrates the ability of such liquefaction to totally disable a port.

2. Ground improvement of loose sandy fills Stabilization of loose sandy fills by ground improvement is generally cost prohibitive because of the volume of material that must be improved. The localization of lateral spreading around the margin of the Port and Rokko Islands suggests that the hazard of permanent horizontal ground deformation can be substantially reduced by improving only the outer margins of these loose fills. Modern pile-supported structures on Port and Rokko Islands performed well in locations where they were subjected only to ground settlement.

\section{Consideration of multi-style of design} Another important engineering lesson from the Kobe port experience is the vulnerability from using one style of design for a key part of an important facility. Possibly liquefaction was not considered to be a significant possibility during the design of port quay walls. By repeatedly using quay wall designs that were vulnerable to lateral spreading, operation of the entire port was left vulnerable to this hazard.

\subsubsection{Water and Wastewater Systems}

There are reoccurrences of many situations that should help clarify earthquake planning and earthquake resistant design.

\section{Overwhelming Conditions From an} emergency response perspective, there is always discussion about what might occur following a large earthquake located in a 
densely populated area. One of the biggest issues in the Kobe event was the loss of all transportation. Every major mass transportation route failed, and surface roads were blocked by fallen buildings. The resulting congestion made walking the fastest form of transportation. This caused emergency response to slow to a crawl.

Utility decision makers need to be thinking in terms of consequences similar to the Kobe event. For example, what happens when you have no records because all utility buildings are destroyed or become inaccessible? What happens if the plan is to dispatch crew to isolate critical pipelines to save water or shut off natural gas, but the fastest way to get there is by walking?

2. Fire Following Recent earthquakes have shown that there is a low probability of maintaining a water system following an earthquake. Consideration should be given to identifying and developing alternate supplies.

Similarly, the use of monitoring and control systems should be considered to enable the timely control of a water system following an earthquake to increase the probability of delivering water to suppress fires. Water purveyors and fire departments should use permanent ground deformation mapping to identify areas where pipelines will likely fail so that plans can be made to isolate damaged areas and/or use alternate water supplies.

3. Geotechnical Issues In Kobe, geotechnical failures governed the poor performance of the water system. Landslides, consolidation, and liquefaction or lateral spread stopped the flow of water from the source; damaged two major and one small water treatment plants; and tore the distribution system apart. In general, the structural aspects of the "steel" transmission pipelines matched current design used in the United States. The treatment plant structures performed reasonably well except that they were on soils that failed. An aggressive pipeline replacement program apparently only marginally helped mitigate geotechnical failure-related damage to the pipeline distribution system.

\section{Recovery The three Kobe Water}

Department buildings storing records were destroyed. The probability of this occurring is very low. In the United States, we should make sure that our resources are distributed so that the loss of any one facility will not substantially impact our ability to respond to an earthquake.

\subsubsection{Gas Delivery System}

\section{Coordination in restoration process $A$} most important lesson associated with gas system performance during the earthquake is the need to coordinate the restoration of electric power with an assessment of the state of gas system repair. In Kobe, it appears that there was no pre-arranged coordination between gas and electric company personnel to restore electric service in concert with shutting off and venting gas in areas severely damaged by the earthquake. It appears that early restoration of electric power in some areas of Kobe with leaking gas may have contributed to additional fires.

Emergency plans should be developed and specific, formal communication procedures should be established between gas, electric power, water supply, and fire department personnel. Specific checking mechanisms should be embodied in emergency response and restoration procedures so that gas and electric power personnel cannot proceed 
beyond a certain recovery level until there has been formal confirmation by their counterparts that gas systems are secure.

2. Gas Service restoration can be a timeconsuming process The difficulty and substantial time required for restoration of gas service in Kobe is an important reminder of the complexities and resources required for the resumption of gas supply after large areal shutdowns. Restoration of gas can be especially critical in winter, as it was in Kobe. It may be advantageous, therefore, to provide for remote control and other rapid means of isolation of smaller, more manageable areas of the gas system. Strategies of this type require microzonation techniques which are capable of identifying areas with the potential for locally severe site response and soil liquefaction. Hazard mapping and scenario earthquake planning can be especially valuable to identify and isolate troublesome areas.

3. Poor performance of steel pipe with threaded steel couplings Widespread damage to steel pipe with threaded steel couplings occurred at an unprecedented scale. Threaded steel sections are not only vulnerable to earthquake effects because of reduced cross-sectional area, but because threaded sections tend to be locations of corrosion concentration. Further, a threaded coupling provides for a rigid connection, and thus lacks the longitudinal flexibility inherent in a pipeline with mechanical couplings that maintains a seal with compression gaskets.

Although threaded steel piping is used rarely in U.S. gas systems, many U.S. systems do use cast iron mains for low pressure distribution. Several of these systems are located in midwestern, eastern, and west coast portions of the United States which are susceptible to serious earthquakes, albeit with various return intervals. Although cast iron pipelines have provided generally long and reliable service, they nonetheless are composed of brittle material that does not possess sufficient ductility to accommodate large ground deformations caused by liquefaction. Given the vulnerable nature of cast iron pipelines to large differential movement, it is especially important to identify portions of cast iron systems in liquefiable soils as the basis for network isolation, replacement, and special emergency response planning.

\subsubsection{Electric Power}

\section{Poor performance of high voltage} bushings Leaks and porcelain failure of transformer and circuit breaker bushings has contributed to the poor seismic performance of high voltage substation equipment in the United States.

\section{Flexible couplings for transformer} radiators The use of flexible couplings in piping connections of the transformer radiator to the transformer body may reduce problems with leaks observed in the United States.

\section{Better performance of instrumentation transformers The performance of instrumentation transformers in Japan appears to be better than in the United States. Some units acted as lower restraints to suspended wave traps, and still performed better than those in the United States.}

4. Need for adequate slack At potentially liquefiable sites, the need for adequate slack was demonstrated. Slack needs to be provided in vertical drops at sites that are vulnerable to subsidence.

5. Performance of concrete poles The use of concrete poles appear to increase the 
vulnerability of the aerial distribution system. In the 1992 Cape Mendocino earthquake over 600 wooden poles were about to be replaced because they were weakened due to dry rot, and none of these failed.

\subsubsection{Telecommunications}

1. Performance of microwave towers Three building-mounted microwave towers were damaged, one of which was removed. One of the striking features about communications towers in Japan, where there are large wind loads associated with typhoons, is their massive construction as compared to those found in the United States. The damage to Japanese towers suggests that those in the United States may also be vulnerable, particularly where central offices are built on poor soil.

2. Effect of loss of water The loss of water to communication facilities and its effect on emergency power further substantiates this vulnerability of U.S. facilities.

\subsubsection{Hospitals}

1. Need for emergency water supply The loss of water supply at Kobe Medical College indicates that hospitals need to establish an emergency water use policy and normal water use in hospitals is well beyond what one could expect in resupply after a major earthquake. There is also a need to facilitate getting delivered water into the hospital water system.

\subsubsection{Post Earthquake Fires}

1. Effectiveness of passive fire protection Locations where the fire spread stopped were clear demonstrations of the effectiveness of passive fire protection systems. The systems need to be designed on a city wide basis. A network of wide roadways would serve as fire breaks and provide ample egress and emergency access. Consideration must be given to buildings which border the egress routes and the components of the egress routes, such as bridges. The buildings should be designed to withstand earthquake forces and should be built of noncombustible materials. This concept can be thought of as creating fire resistive egress corridors for cities, with performance goals similar to those desired for means of egress in buildings.

\section{Effectiveness in using wire glass exterior} windows Wired glass exterior windows appeared to be effective in reducing the fire spread. These windows with small gauge wire are common in Japan but are rare in the United States.

\section{Alternative water delivery systems}

Alternative water delivery systems need to be developed and utilized. One such system might consist of caches of high volume, diesel powered (or other independent power supply), portable pumps located near natural sources of water around the city. From the pumps, networks of large diameter hose line could distribute water to portable drafting tanks or to pumpers.

\section{Fire fighting with aircraft Fire fighting} with aircraft dropping water or Class $\mathrm{A}$ foam should be examined. For areas near bodies of water where scooper aircraft or helicopter buckets can be used, fast turn around time would make this option attractive. Although aircraft ciropped water cannot attack interior fires it may be effective on fires in rubblized buildings. Fire fighting from the air may be a method of overcoming the problem of accessing the fires due to blocked roads.

\section{Information regarding preparation for post earthquake fires Information necessary}


for residents to prepare for post-earthquake fires needs to be further developed and disseminated to the general public.

Technologies to assist residents in protecting themselves and their property need to be developed and evaluated.

\subsection{Recommendations for Research}

Research needs in each of the technical areas covered during the team's reconnaissance visits are summarized in the following:

\subsubsection{Seismology, Geology, and Geotechnology}

1. Availability of strong-motion data set in soft-soil deposits The large set of recordings on Holocene soil deposits within $5 \mathrm{~km}$ to $20 \mathrm{~km}$ of the crustal rupture provides a unique set of in-situ measurements of the response of soft-soil deposits at high input ground motion levels. These data provide a potentially important data set for research on: (a) the location and nature of the crustal-rupture process as it can be inferred from augmentations to the seismological and strong-motion data sets, (b) compilation, analyses, and distribution of the strong-motion recordings obtained by all contributing agencies, (c) compilation of detailed seismic and geotechnical logs at as many of the strong-motion stations as resources permit, (d) thorough analyses of surface and borehole strong motion recordings to develop an improved understanding of the response of soft-soil deposits at high input ground motion levels, and (e) interpret improved estimates of the response of soft-soil deposits for purposes of code revisions and site-specific design analyses.
The extensive lateral spreading around the margins of the artificial fills placed in Osaka Bay provides an opportunity to clarify the mechanism of horizontal ground displacements associated with soil liquefaction. The widespread damage to engincered works should permit documentation of details of deformation fields associated with lateral spreading. This understanding should improve the design of countermeasures to minimizc the impact of liquefaction on engineered works. Areas of ground improvement need to be documented. Evaluation of the performance of these areas should increase confidence in our ability to reduce the hazard from liquefaction of sandy soils.

\subsubsection{Buildings}

\section{Improvement of performance of existing} $\mathrm{RC}$ buildings The most urgent research need for RC buildings is the extensive research on seismic vulnerability assessment, rehabilitation, and retrofit for older, nonductile RC moment frame and shear wall buildings in the three to ten story range. These buildings are numerous both in Japan and the United States, so they represent a substantial area of risk and potential damage cost. More accurate models of existing nonductile structures are needed,

necessitating research on older member and system capacities. Rehabilitation techniques need to be cost effective and nonintrusive for building owners and users. Continued focus on improving the deformation capacities of columns, girders, and joints in moment frames is needed. Beyond this, continued research into less traditional techniques for rehabilitation, such as supplemental energy dissipation and the use of newer structural composites, should be conducted. 
2. Difference in design philosophies

Current Japanese design techniques result in stiffer but less ductile RC structures than in the United States. A study of these two differing approaches would seem to be appropriate.

\section{Study of Steel-Reinforced Concrete} (SRC) buildings The distinctive Japanese practice of SRC construction should be studied. Disregarding the apparent problems that existed with discontinuities in these systems, it is important to examine whether the use of such composite construction does enhance ductility in RC beyond that provided by current U.S. RC detailing techniques, and if so, to determine its cost-effectiveness with respect to current detailing techniques.

4. Steel frame structures The behavior of heavy steel frame highrise structures under strong low cycle lateral loading should be examined. Given the wealth of data concerning the design procedures, weldment details, and material specifications for the AHST complex in Ashiya City, research should be conducted into the behavior of built-up steel column sections and truss weldments under very low cycle fatigue. This would augment research programs already underway in the United States following the Northridge earthquake.

\subsubsection{Highways and Bridges}

\section{Study of bridges with strong-motion} records Conduct correlation studies on those bridges with strong motion records to calibrate theoretical models against actual behavior. Valuable insight into the performance of these two important types of bridges would be derived from such studies.

\section{Case studies of steel bearings and earthquake couplers Develop a detailed}

database on the performance of steel bearings and earthquake couplers (restrainers) followed by case studies on selected bridges in which these devices failed. Results from such a study would help determine the need for a review of current U.S. design criteria for connection forces and restrainers.

\section{Study of superstructure-foundation} interaction Analyze structural response due to large foundation movements during liquefaction and lateral spreading and the development of optimum mitigation measures to minimize structural impacts.

\section{Performance of retrofitted bridges}

Perform case studies on those bridges that had been retrofitted before the earthquake to determine the effectiveness of the retrofit measures. Known measures for which performance could be evaluated include earthquake couplers, steel jackets and viscous dampers.

\section{Development of performance-based} design approach Develop multiple-level performance criteria which define expected damage and serviceability states for various earthquake scenarios and the corresponding design strategies/structural options necessary to satisfy these criteria. Involvement of social scientists (planners, economists and experts in public policy) should be encouraged in this study.

\section{Study failure mechanisms in large} concrete columns under combined axial and shear loads Concretc columns in single or multi-column bents in Japanese bridges have very large cross sections and fall outside the range of U.S. test data. Although it is unlikely that U.S. practice will adopt similar sized members for short- and medium-span bridges in the near future, columns of this size and with these reinforcement ratios are 
encountered in some long span structures. Correlation of assessment methods and limit states with field data from this earthquake could give valuable insight into the lateral load capacity of large concrete members. It is noted that such field data are rare and this opportunity is probably unique.

7. Study of bridges with steel substructures The relatively large number of damaged steel substructures provides an opportunity to calibrate proposed new methods for the seismic design of steel bridge columns. In particular, their capacity for ductile actions and the identification of their limit states should be investigated with the objective of refining the R-factors in the U.S. bridge codes for these components.

\subsubsection{Railways and Rapid Transit System}

1. Ductility study between RC, Steel, and SRC columns Because of the low redundancy of single column structures, the structural layout and substructure performance becomes more important for those structures than for structures with multiple column bents. Research is needed to compare the ductility between reinforced concrete, steel and steel reinforced concrete composite columns. A damage index should be developed to assess the repairability of columns after an earthquake. Force levels encountered at collapse sites should be compared to current U.S. design forces to validate current designs.

2. Study of transient shear distortion It would be advantageous to investigate the levels of transient shear distortion which can occur in soil profiles near a seismic source, particularly when strong motion is characterized by relatively long pulses of substantial acceleration, leading to high velocities and displacements. The severity of racking in underground structures resulting from strong motion with high amplitude and relatively long periods needs to be understood better, and the combined effects of racking and high vertical accelerations needs additional clarification.

\section{Study of differential lateral movements Site response needs to be investigated in terms of differential lateral movements which occur during earthquake loading at sites with thick deposits of soft to medium clay and loose sand. The effects of depth and soil liquefaction on soil shear distortion and structural racking also need further research.}

\subsubsection{Airports}

\section{Development of methods for improving} the performance of control towers The earthquake performance of control tower windows in the United States has been poor and similar performance was observed at Osaka Airport. The loss of these windows can be very disruptive to operations so improved performance is desirable. The Kansai Airport control tower incorporated columns in their design that did not appear to significantly adversely effect the functionality of the tower. Practical methods are needed to upgrade these towers in a way that will not interfere with the function of the towers.

\subsubsection{Ports and Harbors}

\section{Better design and construction of quay} walls The extensive damage to the quay walls that disabled the port operations indicates that the failure mechanism of these structures needs to be understood from the perspective of being able to design against such failures. A variety of ground improvement techniques are available, but in general they are costly. The localization of lateral spreading near the quay walls 
suggests that only portions of the fill need to be improved. The development of such guidelines would facilitate remedial efforts at other ports with similar exposure.

\section{Study of ground deformation due to} liquefaction The large vertical settlements observed in sandy fill during the earthquake also provide an excellent opportunity to develop a case history of ground deformation associated with liquefaction. The numerous pile-supported structures and bench marks provide an opportunity to systematically document the regional nature of the soil consolidation.

\subsubsection{Water and Wastewater Systems}

1. Study of water treatment plant design In general, water treatment plants and service reservoirs performed well. We should study Japanese design approaches for these facilities. Their tank designs are somewhat different from those used in the United States and apparently had no damage when subject to high peak ground acceleration.

\section{Study of the performance of S-joint pipe}

Pipelines were heavily damaged, except that preliminary information on performance of the $S$ joint pipe indicates that it had no or few failures. If it is confirmed that it performed well in areas of significant permanent ground deformation, such as what was observed at Rokko Island where such pipe was placed, we should introduce it to the United States. If it did not perform well, we should find out why, and improve U.S. pipe design based on those findings.

\subsubsection{Gas Delivery System}

1. Study of interaction among lifelines The performance of the gas system reinforces the need to understand better the interactions among different lifelines. Recent earthquakes provide excellent vehicles for exploring these interactions. Of special importance is the relationship between gas system disruption as a potential source of flammable substances and the damage to and restoration of electric power as a potential source of ignition. There is a need to evaluate and optimize the use of water and fire protection relative to gas and electric system vulnerabilities and operational characteristics.

\section{Study of seismic performance of several} types of pipelines The earthquake provides an excellent opportunity to study the seismic behavior of a particular class of pipelines, such as threaded steel piping, at locations of permanent ground deformation caused by liquefaction and at locations where transient ground deformation was the principal source of pipeline distortion. Comparison and contrast of pipeline performance for these two conditions will help quantify seismic risk and improve system planning, retrofitting and design. The earthquake also provides an opportunity to evaluate the response of several different types of pipelines to similar levels of seismic intensity so that appropriate levels of vulnerability can be established for risk assessment.

\section{Performance of intelligent gas meter}

The performance of the intelligent gas meter should be investigated to provide a more complete database with respect to the earthquake operation and effectiveness of seismic gas shutoff valves. The earthquake provides an opportunity to assemble statistics on triggering, fire initiation relative to locations of shutoff meters, and overall reliability and effectiveness of the devices. 


\subsubsection{Electric Power}

1. Study of the performance of transformers and circuit breaker bushings The performance of transformers and circuit breaker bushings in the United States and Japan is just the opposite of each other. That is, in Japan circuit breaker bushings failed due to slipping and transformer bushings did not. Study should be conducted to find out whether there is a difference in design and installation procedures in the two countries.

2. Study of failure mechanism of bolted transformers Several bolted transformers moved, even though they appeared to have substantial anchorage. While new transformers are typically welded to embedments in the United States, bolts are often used for retrofits. The design and actual loads on the equipment that failed and the cause of the anchorage failures should be evaluated.

\section{Study of the performance of} instrumentation transformers It would be interesting to explore the reasons for the relatively good performance of instrumentation transformers (PTs, CVTs, CCPD, etc.) in Japan as compared to those in the United States. While these components appear to be larger in Japan, they also appear to be supported on more rigid structures. The differences in design and installation should be explored.

\section{Study of equipment failure next to line} drops There have been failures of equipment adjacent to line drops. The drops, which use insulator strings to restrain the lower end of the line, have very little weight associated with them but there appears to be interaction problems. The nature of these problems should be explored.
5. Study of substation performance with respect to strong-motion records At lcast one substation and one power station that did suffer damage had strong motion instruments that recorded the earthquake. It would be very beneficial to review the performance of equipment at these sites using the response spectra for the site and more detailed information that could be derived from site conditions.

\section{Study of the relative performance of} spun concrete and wooden poles When a house falls on a pole, it can be expected to fail, but there appeared to be many concrete pole failures that are not observed in the United States with wooden poles. It would be useful to evaluate the relative performance of the systems, their advantages and disadvantages and if the use of the poles is different in the two counties.

\subsubsection{Telecommunications}

\section{Study of the performance of outside} plant There is a need to get a better understanding of practices used for outside plant in Japan and to review in detail, their earthquake performance. The collection and analysis of this data on outside plant damage can provide insight into the outside plant in the United States, particularly in the Midwest where liquefaction is expected to be a serious problem.

\subsubsection{Hospitals}

\section{Review to establish guidelines for} minimum levels of service for each lifeline There is a need to review lifeline needs at critical facilities, such as hospitals, and establish guidelines for minimum levels of service for each lifeline. Alternative facilities and equipment that can mitigate the effect of the loss of lifeline service should be evaluated and guidance provided 
to facility designers. There is a need for guidelines for the distribution of special lifelines within hospitals, such as oxygen.

2. Need for different classes of water supply There is a need to review different classes of water needs in hospitals and establish guidelines for technical and administrative procedures for controlling and reducing water use in emergency situations.

\subsubsection{Post Earthquake Fires}

1. Limit ignitions Re-energization of an earthquake damaged area needs to be coordinated between the different utilities and the emergency rescue and recovery services. Work needs to be conducted on the impact of earthquakes on gas scrvice to buildings and appliances. Prior to restoration of electrical service, techniques or instrumentation needs to be devcloped to assure that electricity is not restored to damaged structures or areas with natural gas leaks.
2. Passive fire protection systems There is a need to examine current construction requirements for fire resistive buildings, especially the protection of openings such as windows and doorways. Special efforts should be taken toward materials or systems which could be retrofit to cxisting structures. The concepts of fire resistive egress corridors for cities should continue to be investigated.

3. Alternative water supplies and delivery systems Wildland fire agencies utilize a wide variety of methods to move water to the fire location. Their methods should be examined for applicability to an urban conflagration.

4. Predictions of post-earthquake fire losses Case studies of the fire propagation and the fire suppression activities from this earthquake could provide a basis for further post earthquake fire model development. 

.

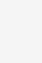
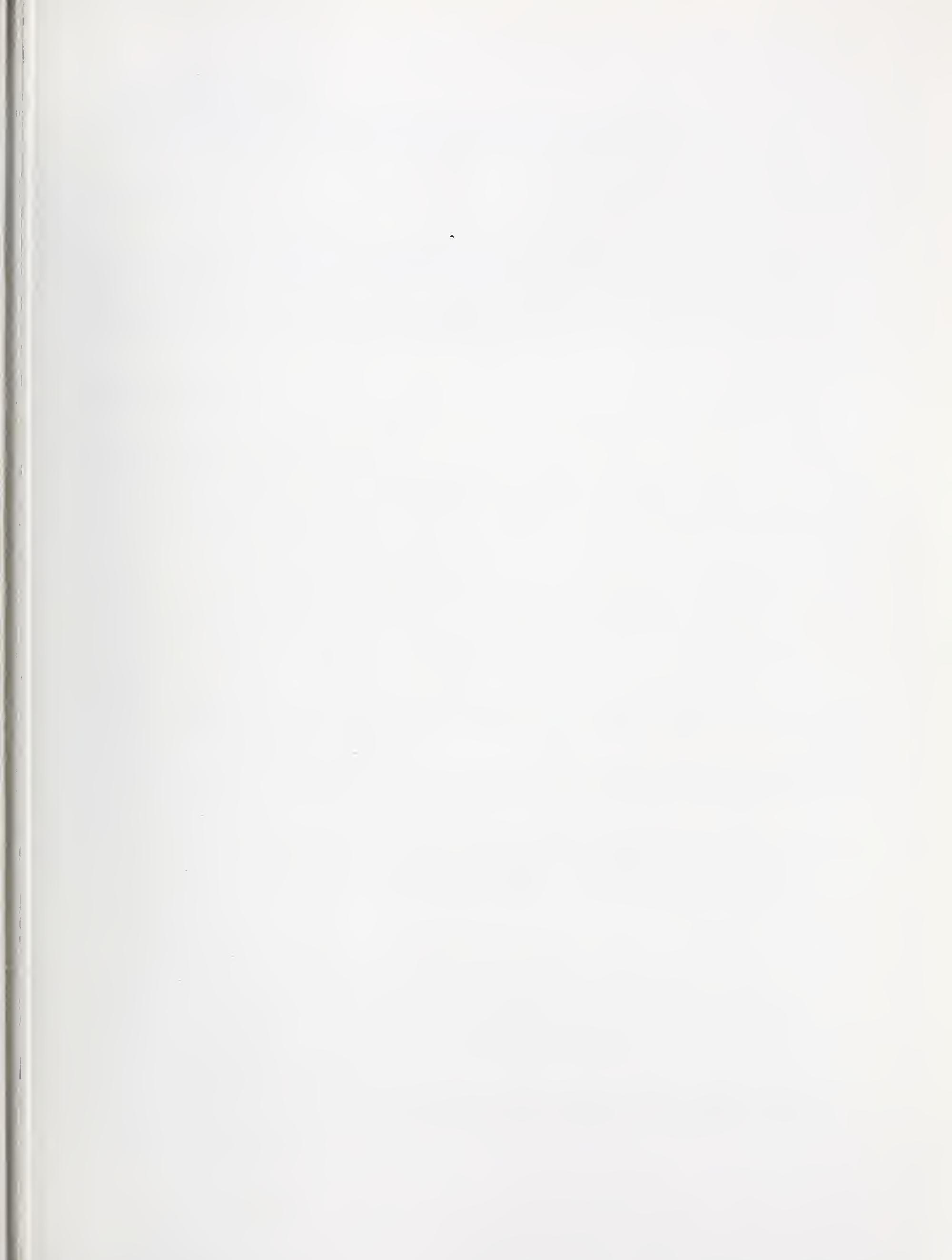


\section{NTST Technical Publications}

\section{Periodical}

Journal of Research of the National Institute of Standards and Technology-Reports NIST research and development in those disciplines of the physical and engineering sciences in which the Institute is active. These include physics, chemistry, engineering, mathematics, and computer sciences. Papers cover a broad range of subjects, with major emphasis on measurement methodology and the basic technology underlying standardization. Also included from time to time are survey articles on topics closely related to the Institute's technical and scientific programs. Issued six times a year.

\section{Nonperiodicals}

Monographs-Major contributions to the technical literature on various subjects related to the Institute's scientific and technical activities.

Handbooks-Recommended codes of engineering and industrial practice (including safety codes) developed in cooperation with interested industries, professional organizations, and regulatory bodies.

Special Publications - Include proceedings of conferences sponsored by NIST, NIST annual reports, and other special publications appropriate to this grouping such as wall charts, pocket cards, and bibliographies.

National Standard Reference Data Series-Provides quantitative data on the physical and chemical properties of materials, compiled from the world's literature and critically evaluated. Developed under a worldwide program coordinated by NIST under the authority of the National Standard Data Act (Public Law 90-396). NOTE: The Journal of Physical and Chemical Reference Data (JPCRD) is published bimonthly for NIST by the American Chemical Society (ACS) and the American Institute of Physics (AIP). Subscriptions, reprints, and supplements are available from ACS, 1155 Sixteenth St., NW, Washington, DC 20056.

Building Science Series-Disseminates technical information developed at the Institute on building materials, components, systems, and whole structures. The series presents research results, test methods, and performance criteria related to the structural and environmental functions and the durability and safety characteristics of building elements and systems.

Technical Notes-Studies or reports which are complete in themselves but restrictive in their treatment of a subject. Analogous to monographs but not so comprehensive in scope or definitive in treatment of the subject area. Often serve as a vehicle for final reports of work performed at NIST under the sponsorship of other government agencies.

Voluntary Product Standards-Developed under procedures published by the Department of Commerce in Part 10, Title 15, of the Code of Federal Regulations. The standards establish nationally recognized requirements for products, and provide all concerned interests with a basis for common understanding of the characteristics of the products. NIST administers this program in support of the efforts of private-sector standardizing organizations.

Order the following NIST publications-FIPS and NISTIRs - from the National Technical Information Service, Springfield, VA 22161.

Federal Information Processing Standards Publications (FIPS PUB)-Publications in this series collectively constitute the Federal Information Processing Standards Register. The Register serves as the official source of information in the Federal Government regarding standards issued by NIST pursuant to the Federal Property and Administrative Services Act of 1949 as amended, Public Law 89-306 (79 Stat. 1127), and as implemented by Executive Order 11717 (38 FR 12315, dated May 11, 1973) and Part 6 of Title 15 CFR (Code of Federal Regulations).

NIST Interagency Reports (NISTIR) - A special series of interim or final reports on work performed by NIST for outside sponsors (both government and nongovernment). In general, initial distribution is handled by the sponsor; public distribution is by the National Technical Information Service, Springfield, VA 22161, in paper copy or microîiche form. 


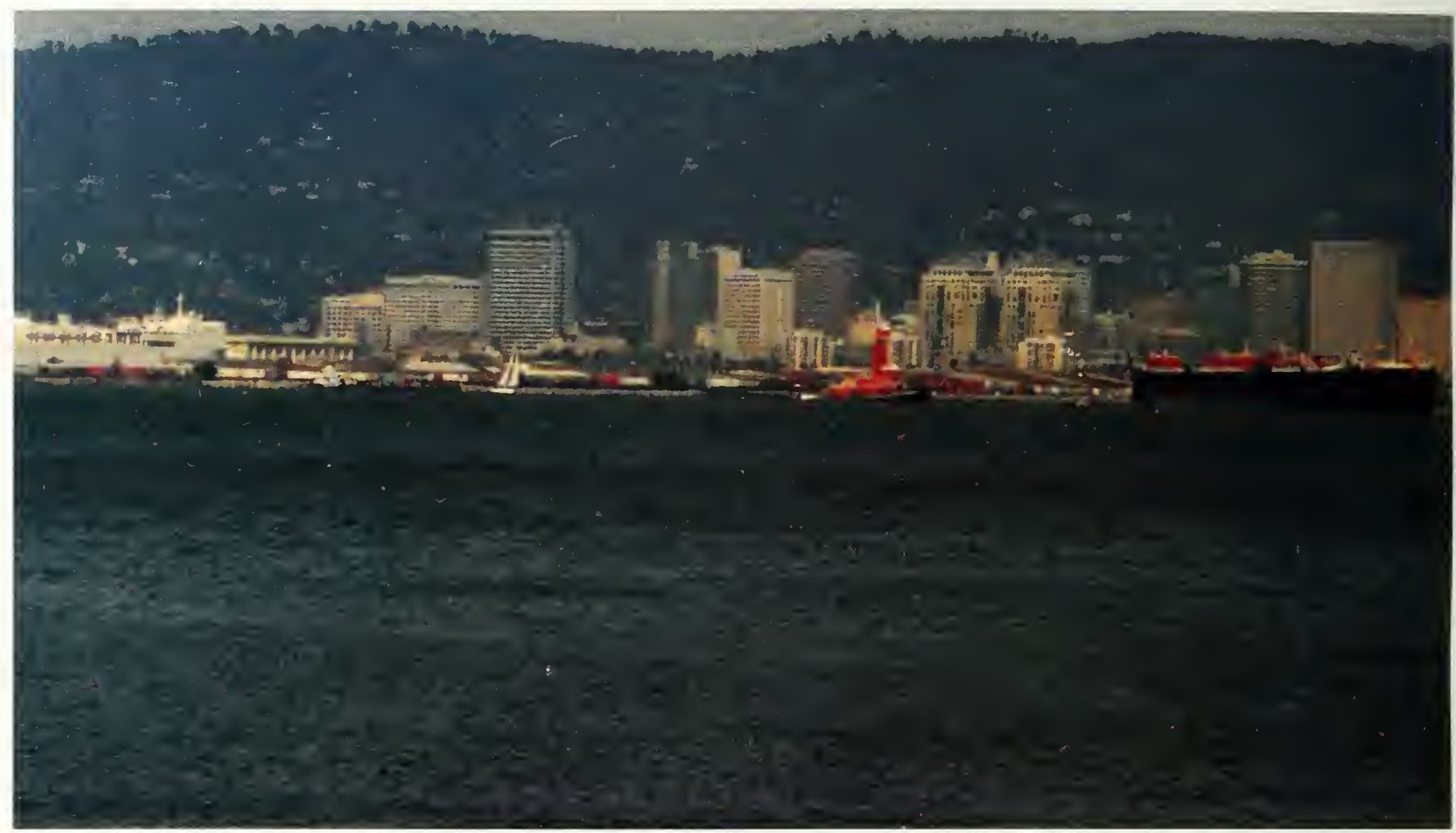

Hayward Fault, Oakland, San Francisco Bay, California, U. S. A.

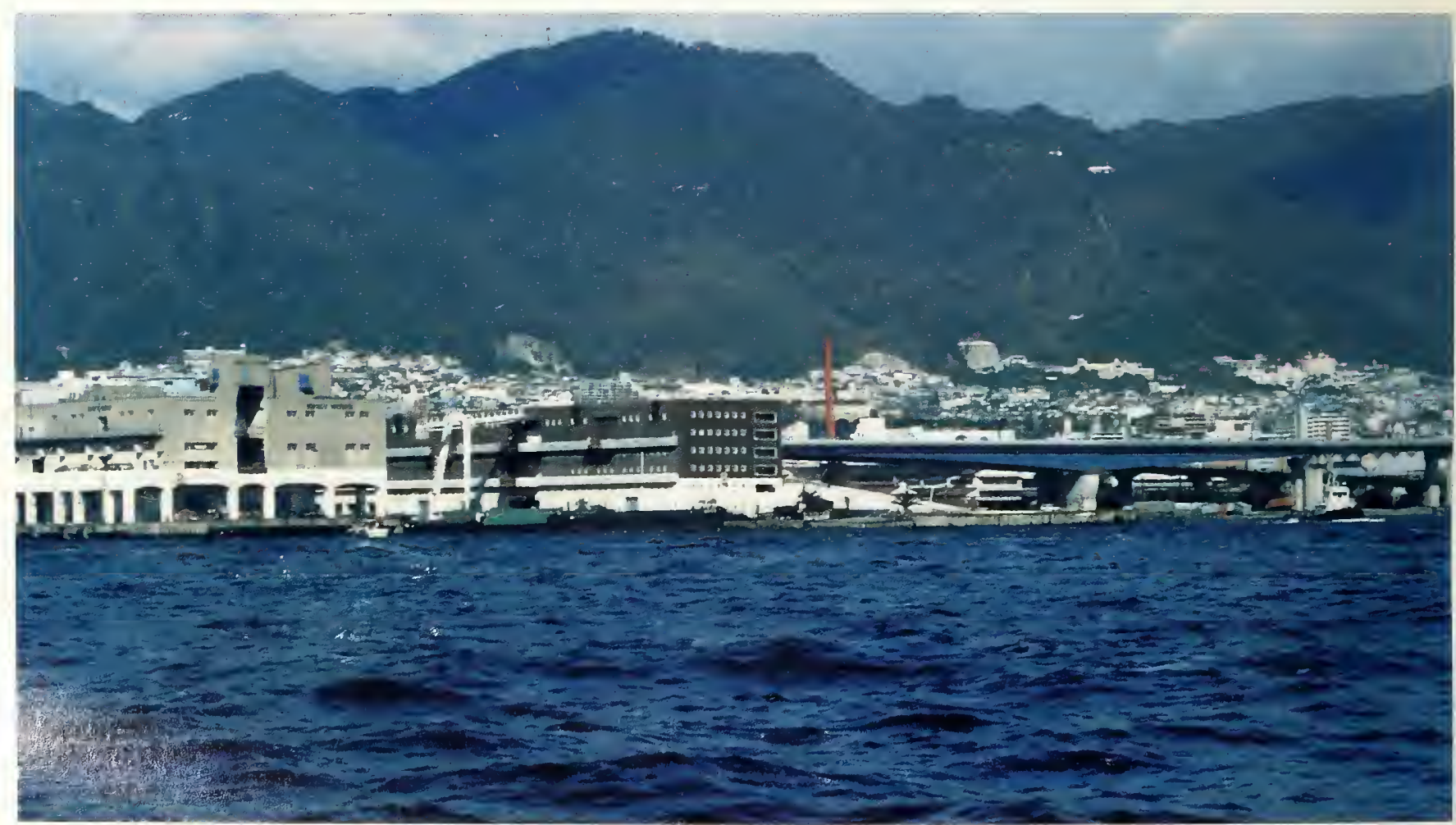

Rokko Mountain, Kobe, Osaka Bay, Japan 